NUCLEAR FUEL CYCLE TECHNOLOGY AND POLICY PROGRAM

Nuclear Energy Research I nitiative (NERI)

Project 06-040

\title{
Flexible Conversion Ratio Fast Reactor Systems Evaluation Final Report
}

Project DE-FC07-06I D14733

Principal I nvestigators: Neil E. Todreas Pavel Hejzlar

MI T-NFC-PR-101

J une 2008

OTHER CONTRI BUTORS:

Chris J. Fong

Anna Nikiforova

Robert Petroski

Eugene Shwageraus

J oshua Whitman 
Project No 06-040: Flexible Conversion Ratio Fast Reactor Systems Evaluation

\section{Abstract}

This is the final report under award DE-FC07-06ID14733, Project No. 06-040. Conceptual designs of lead-cooled and liquid salt-cooled fast flexible conversion ratio reactors were developed. Both concepts have cores rated at $2400 \mathrm{MWt}$ placed in a largepool-type vessel with dual-free level, which also contains four intermediate heat exchangers (IHXs) coupling a primary coolant to a compact and efficient supercritical $\mathrm{CO}_{2}$ Brayton cycle power conversion system. Decay heat is removed passively using an enhanced Reactor Vessel Auxiliary Cooling System (RVACS) and a Passive Secondary Auxiliary Cooling System (PSACS). The most important findings were that (1) it is feasible to design the lead-cooled and salt-cooled reactor with the flexible conversion ratio $(\mathrm{CR})$ in the range of $\mathrm{CR}=0$ and $\mathrm{CR}=1$ in a manner that achieves inherent reactor shutdown in unprotected accidents, (2) the salt-cooled reactor requires Lithium thermal Expansion Modules (LEM) to overcome the inherent salt coolant's large positive coolant temperature reactivity coefficient, (3) the preferable salt for fast spectrum high power density cores is $\mathrm{NaCl}-\mathrm{KCl}-\mathrm{MgCl}_{2}$ as opposed to fluoride salts due to its better thermalhydraulic and neutronic characteristics, and (4) both reactor concepts achieve about 30\% higher power density than the gas-cooled fast reactor, but attain power density 3 times smaller than that of the sodium-cooled reactor.

\section{Acknowledgement}

"This material is based upon work supported by the Department of Energy under Award Number DE-FC07-06ID14733." The principal and collaborating investigators acknowledge the contributions of Anne Boogaerts, M. A. Pope, Jeongik Lee, and A.R. Ludington.

\section{Disclaimer}

"This report was prepared as an account of work sponsored by an agency of the United States Government. Neither the United States Government nor any agency thereof, nor any of their employees, makes any warranty, express or implied, or assumes any legal liability or responsibility for the accuracy, completeness, or usefulness of any information, apparatus, product, or process disclosed, or represents that its use would not infringe privately owned rights. Reference herein to any specific commercial product, process, or service by trade name, trademark, manufacturer, or otherwise does not necessarily constitute or imply its endorsement, recommendation, or favoring by the United States Government or any agency thereof. The views and opinions of authors expressed herein do not necessarily state or reflect those of the United States Government or any agency thereof." 


\section{Executive Summary}

The goal of this project is to develop the conceptual designs of fast flexible conversion ratio reactors using lead and liquid salt coolants and to compare the results with a gascooled fast reactor developed in an MIT NERI project and a sodium-cooled reactor under development at ANL. To maintain the scope of the study manageable within the 2-year time frame and funding constraints, core designs that fit in the same reactor plant were executed for two limiting conversion ratios: (1) near zero, to transmute legacy waste and (2) near unity, to operate in a sustainable closed cycle. To reap the benefits of economy of scale, a large power rating of $2400 \mathrm{MWt}$ was set as the target thermal power for both reactor designs. In addition, the achievement of inherent reactor shutdown in unprotected accidents (without scram) was set as a desirable goal.

\section{Plant design}

Vessel and plant designs are such that either $\mathrm{CR}=1$ or $\mathrm{CR}=0$ cores can be accommodated without any changes except for plugging penetrations in the vessel head that are not used after transition from the $\mathrm{CR}=0$ to the $\mathrm{CR}=1$ core. The key features adopted for plant design are as follows:

- Use of forced circulation of coolant for normal operation with centrifugal pumps,

- Use of a large reactor vessel and placement of intermediate heat exchangers (IHX) inside the reactor vessel,

- Use of the efficient and compact supercritical $\mathrm{CO}_{2}\left(\mathrm{~S}-\mathrm{CO}_{2}\right)$ power conversion system as the balance of the plant,

- Use of natural circulation for decay heat transfer to the reactor vessel and of an enhanced reactor vessel auxiliary cooling system (RVACS) complemented by a passive secondary auxiliary cooling system (PSACS) for ultimate decay heat removal to the air.

One of the key questions for the 2400MWt rating is the feasibility of fitting four IHXs, $600 \mathrm{MWt}$ each, into the annular space between the core barrel and the vessel. In addition to the constraint of the limited space within the reactor vessel, temperature constraints and pressure drop constraints on the $\mathrm{S}-\mathrm{CO}_{2}$ side to maintain high efficiency of the Brayton cycle, as well as pumping power and velocity limits on the primary side, have to be considered. A shell-and-tube heat exchanger configuration with supercritical carbon dioxide on the tube side and lead or salt on the shell side was employed. The $\mathrm{CO}_{2}$ side employs helical ribbed tubes (on the inside) for heat transfer enhancement. Overall, the feasibility of fitting four IHXs and four pumps within the reactor vessel for the guard vessel outer diameter of $10.2 \mathrm{~m}$ was confirmed, based on thermal hydraulic analyses. 
However, further feasibility study, such as roof mechanics, in-service inspection, seismic analyses, refueling system design, are necessary to confirm this conclusion.

Because supercritical $\mathrm{CO}_{2}$ is at the high pressure of $20 \mathrm{MPa}$ inside the IHX, while the lead coolant is at atmospheric pressure, the design of the vessel and flow paths needs to ensure that ingress of $\mathrm{CO}_{2}$ into the core is prevented in case of an IHX tube rupture. This is accomplished through a dual-free-level vessel design first proposed by Russian scientists for the BREST reactor and adopted later by the MIT/INL team for a lead-cooled actinide burner of a lower power rating.

Heat is removed through IHXs to a supercritical $\mathrm{CO}_{2}$ power conversion system (PCS) to drive turbomachinery and a generator. The PCS is a recompression $\mathrm{S}-\mathrm{CO}_{2}$ cycle developed at MIT under other NERI and direct Generation IV funding via Sandia National Laboratory. A four-loop design has been adopted where each IHX rated at $600 \mathrm{MWt}$ supplies $\mathrm{CO}_{2}$ to PCS loops generating about $265 \mathrm{MWe}$, thereby providing a reactor electric power rating of $1060 \mathrm{MWe}$. The advantage of the $\mathrm{S}-\mathrm{CO}_{2}$ power cycle is its high efficiency, high power density, and simplicity, which is expected to reduce plant overnight cost.

Achievement of passive decay heat removal from a 2400MWt core is one of the major challenges because of the reactor power being 2.4 times larger than that of S-PRISM. The approach adopted is the use of an enhanced RVACS plus a supplementary Passive Secondary Auxiliary Cooling System (PSACS). RVACS enhancements adopted as most promising are a combination of a liquid metal bond in the gap between the reactor vessel and guard vessel, use of a perforated plate in the air gap, and a dimpled guard vessel wall. The achievable decay heat removal rates were found to be between 15 and $17 \mathrm{MWt}$ depending on heat transfer correlations for air flow along a dimpled surface. Because this is still insufficient to keep the peak cladding temperatures below the $725^{\circ} \mathrm{C}$ limit, the PSACS is employed to assist RVACS in the early stage of the accident when decay power is high. The PSACS consists of four independent, 50\% capacity, safety-grade cooling loops, each connecting the IHX $\mathrm{CO}_{2}$ outlet header to a passive auxiliary heat exchanger (PAHX) submerged in a water storage tank. The system is isolated under normal conditions by inlet and outlet isolation valves which fail-open upon loss of $\mathrm{A} / \mathrm{C}$ power. This creates a flow path where pressurized $\mathrm{CO}_{2}$ flows from the IHX to the elevated PAHX thereby rejecting heat into the water. After the water tanks are evaporated, RVACS alone can remove decay heat.

It was also found that the PCS has a large capacity for decay heat removal since it is selfpowered, as the decay heat drives the turbine, which in turn drives the compressors that deliver a significant flow rate through the IHX. However, the PCS is not a safety-grade system to avoid a substantial increase of PCS cost due to the special treatment requirements imposed on safety related systems, structures, and components by $10 \mathrm{CFR}$ 50. Therefore, the PCS trains cannot be given credit in safety analyses in Chapter 15 of the Final Safety Analysis Report, despite their utility as a first line of defense in most accident events. RVACS and PSACS are the ultimate safety grade decay heat removal systems. They were confirmed to be effective even in an unprotected station blackout. 
Since most accident scenarios lead to turbine trip and generator disconnection from the grid, one of the key challenges for the PCS is to prevent shaft overspeed. This can be accomplished through several possible bypass lines equipped with fast acting valves: turbine bypass, IHX bypass, and PCS bypass. All three options were found to be effective in maintaining the shaft speed below the $120 \%$ speed limit. The turbine bypass was found to be preferable, and a strategy was devised to use a proportional-integral (PI) controller to control bypass valve stem position to maintain (after shaft overspeed is avoided) a turbine speed that allows natural circulation to remove reactor power through the PCS in a self-sustaining operation.

\section{Lead-cooled reactor}

Reactor physics analyses have confirmed the feasibility of both the $C R=0$ and the $C R=1$ cores from a neutronics viewpoint. The lead-cooled 2400MWt core contains 349 canned fuel assemblies, each containing $21 \times 21$ pin positions in a square lattice. In the $\mathrm{CR}=0$ core, each fuel assembly has control rods with 25 rodlets inserted into guide tubes in the central $5 \times 5$ positions of the assembly. All control rods are of double-entry design to minimize reactivity changes during seismic events and to flatten the axial power profile. The $\mathrm{CR}=1$ core requires significantly fewer control rods due to its smaller reactivity swing. Hence, only one-third of the assemblies are equipped with control rods. During the transition from the $\mathrm{CR}=0$ to the $\mathrm{CR}=1$ core, excess control rods can be removed and head penetrations plugged.

The $\mathrm{CR}=1$ core is a 1-batch 3-region core using metallic U-TRU-Zr fuel, where the composition of transuranics corresponds to that of discharged LWR fuel with $50 \mathrm{MWd} / \mathrm{kg}$ burnup. To maintain low power peaking during core life, variation in heavy metal loading between different core regions through $\mathrm{Zr}$ content adjustment is used rather than TRU enrichment grading. Therefore, the core contains 3 regions, each with different $\mathrm{Zr}$ weight fraction $(10,15$ and $19 \mathrm{wt} \%)$ and thus different uranium $(75,70.83$ and $67.5 \mathrm{wt} \%)$ and TRU $(15,14.17$ and $13.5 \mathrm{wt} \%)$ weight fractions, while the TRU to heavy metal ratio remains fixed. The maximum radial peaking is 1.21 at middle of life. Core average discharge burnup is $77 \mathrm{MWd} / \mathrm{kgHM}$. The corresponding cycle length for a single-batch core reload is 1800 EFPD (about 5.5 years at 90\% capacity factor) and is limited by cladding peak fluence. The core does not have any blankets and achieves a conversion ratio of 1.0 .

The $\mathrm{CR}=0$ core was designed as a 3-batch core with $\mathrm{TRU}-\mathrm{Zr}$ metallic fuel to accommodate a large reactivity swing. The initial fuel composition has $34 \mathrm{wt} \% \mathrm{TRU}$ and a $66 \mathrm{wt} \% \mathrm{Zr}$ matrix. This composition allows the achievement of about a 550 EFPD (1.7 yrs at $90 \%$ capacity factor) cycle length and a discharge burnup of $320 \mathrm{MWd} / \mathrm{kgHM}$. This high burnup is achieved because of a small heavy metal weight fraction in the pins and is not expected to pose a problem, because the number of fissions during the pin lifetime is comparable to that of a $\mathrm{CR}=1$ core, and more $\mathrm{Zr}$ diluent in the pins provides more volume for the swelling of the HM. Any $\mathrm{CR}=0$ core needs to cope with compensation of a large reactivity swing. The reactivity swing is $38 \$$, which is comparable to PWR values. However, unlike in PWRs, fast spectrum reactors cannot use 
soluble boron or burnable poisons to compensate for excess reactivity during the cycle. Therefore, a large number of double-entry control rods are employed. Although this control rod drive (CRD) design requires a longer vessel to accommodate space for bottom entry, it overcomes the problems posed by CRD movements relative to the core in seismic events with associated large reactivity insertions, minimizes the CRD driveline expansion effect, and reduces axial peaking. The $\mathrm{CR}=0$ core has a higher radial power peaking than the $\mathrm{CR}=1$ core, but the proposed fuel management strategy shown in Figure E-7 makes it possible to maintain the highest radial power peaking below 1.35. Therefore, the maximum achievable power density is limited by the $\mathrm{CR}=0$ core. TRU consumption rate is $1282 \mathrm{~kg} / \mathrm{yr}$, or $0.32 \mathrm{kgTRU} / \mathrm{yr} / \mathrm{MWt}$. This exceeds the TRU destruction rate of accelerator driven systems, such as ATW, which reported the value of $0.262 \mathrm{kgTRU} / \mathrm{yr} / \mathrm{MWt}$, and it is due to the higher capacity factor of a critical reactor.

The coolant temperature reactivity coefficient (CTC) for the $\mathrm{CR}=1$ core is positive, but less than that of the sodium-cooled IFR because lead coolant exhibits a smaller coolant density change with temperature than sodium and moderates less. For the $\mathrm{CR}=0$ core, the CTC is practically zero at BOC and slightly negative at EOC because of higher leakage of the more neutronically transparent $\mathrm{CR}=0$ core. Thermal expansion reactivity feedbacks (core radial expansion, fuel thermal expansion) are negative and their values are within the expected range. The Doppler coefficient is negative and for the $\mathrm{CR}=1$ core slightly larger than for IFR metallic fuel. For the $\mathrm{CR}=0$ core, Doppler feedback is significantly smaller than that of the $\mathrm{CR}=1$ core due to the absence of fertile U238. The main challenge for the $\mathrm{CR}=0$ core is related to the inadvertent Control Rod Withdrawal accident, which necessitates the use of CRDs in every fuel assembly to reduce the reactivity worth of any individual control rod. Interestingly, the $\mathrm{CR}=0$ core exhibits more favorable reactivity coefficient ratios for self-controllability than the $\mathrm{CR}=1$ core due to smaller CTC and Doppler effect. Overall, reactivity coefficient ratios for both cores fall within the range satisfying the self-controllability criteria. Transient analyses of unprotected accidents confirmed that the core can achieve inherent shutdown from reactivity feedbacks without exceeding temperature limits.

Decay heat curves generated for the $\mathrm{CR}=1$ and $\mathrm{CR}=0$ cores differ substantially from the ANS 2005 curves for LWRs. For the $\mathrm{CR}=1$ core, decay power becomes, after 100 seconds, larger than that of the LWR and the difference increases with time and reaches as much as $25 \%$ at 60 hours, which corresponds to the time when the demand on DHR systems is largest. For the $\mathrm{CR}=0$ core, the LWR decay power remains higher than the LWR curve for about the first 20 hours. Because of the smaller decay power and smaller $\mathrm{CTC}$ of the $\mathrm{CR}=0$ core compared to that of the $\mathrm{CR}=1$ core, the transient response of the $\mathrm{CR}=1$ core is more challenging than for $\mathrm{CR}=0$ core, even though power peaking of the $\mathrm{CR}=0$ core is slightly larger. Therefore, the thermal hydraulic analyses limits are met for the $\mathrm{CR}=1$ core; they are also met by the $\mathrm{CR}=0$ core. The implication for the FCR design is that the plant needs to be designed to accommodate $\mathrm{CR}=1$ transients even if it is started with a $\mathrm{CR}=0$ core.

Transient analysis of both reactor cores was performed for three accidents: Unprotected Station Blackout (SBO), Unprotected Loss of Flow, and Unprotected Overpower. The 
protected SBO was also analyzed to confirm existence of a margin to freezing. The SBO event posed the largest challenge because of the need to balance the PSACS design to prevent cladding overheating in the unlikely unprotected SBO while avoiding coolant freezing in the SBO with scram under various combinations of PSACS trains in operation. A solution to this problem was found by identifying a suitable PSACS design with a small PSACS heat exchanger and a large water tank. This design prevented the peak cladding temperature (PCT) from crossing the cladding temperature limit while maintaining the coolant temperature above freezing for all combinations of accident conditions (protected vs. unprotected) and number of operating trains (two, three, or four) The simulation of the accident with different conditions showed that surviving the SBO for both cores for up to 72 hours without exceeding the limits is possible. Transient analyses have confirmed that both $\mathrm{CR}=1$ and $\mathrm{CR}=0$ cores perform satisfactorily within the limits in all three unprotected transients and the protected SBO. It has also been shown that the $\mathrm{S}-\mathrm{CO}_{2}$ PCS can be effectively used as a heat sink in loss of flow accidents (LOFA) and Unprotected Transient Over Power (UTOP) accidents, since decay heat provides energy to heat up $\mathrm{CO}_{2}$ through the IHX. The $\mathrm{CO}_{2}$ then drives the turbine and compresssors on the same shaft to provide $\mathrm{CO}_{2}$ flow between the IHX and the precooler.

\section{Liquid Salt-cooled Reactor}

The salt of choice for the liquid salt reactor design is the ternary chloride salt NaCl-KCl$\mathrm{MgCl}_{2}$ (30-20-50). This salt was chosen over more familiar fluoride salts because of its superior thermal hydraulic and neutronic properties: in particular, a much lower viscosity and coefficient of thermal expansion.

The major neutronic design challenge of liquid salt-cooled reactor cores, for both fluoride and chloride salts, is the large positive Coolant Temperature Coefficient (CTC), primarily due to salt's large thermal expansion coefficient. The large magnitude of the CTC leads to considerable difficulty in achieving the core self-controllability criteria. A wide range of design strategies, such as tight lattice, axial blankets, streaming assemblies, and zirconium hydride control rods, were explored to reduce the CTC. However, these resulted in only marginal improvements, which were found to be insufficient to achieve self-controllability of the core.

Moreover, these strategies to overcome large positive CTC seriously limited thermal hydraulic performance. Specifically, all of these strategies reduced the achievable power density. The tight lattice $(\mathrm{P} / \mathrm{D} \sim 1.09)$ resulted in a higher core pressure drop and a larger coolant temperature rise, while the latter three measures increased the effective hot-spot peaking factor. Taken together, these factors reduced the maximum power density for the salt reactor to below $70 \mathrm{~kW} / 1$, even for a high core pressure drop of over $1.0 \mathrm{MPa}$. This power density was significantly below the target value of $100 \mathrm{~kW} / \mathrm{l}$ and the power densities of other liquid-cooled reactors.

Therefore, a reactivity control device known as the Lithium thermal Expansion Module (LEM) was employed to meet the core self-controllability criteria. The introduction of LEMs allowed the improvement of the salt-cooled core design in several aspects: 
Project No 06-040: Flexible Conversion Ratio Fast Reactor Systems Evaluation

- Near zero or even slightly negative CTC can be achieved through variation in the number of LEMs or the LEM's geometry. CTC values assure the selfcontrollability of the core, with ample safety margin.

- The core design can be significantly simplified because the use of axial blankets and streaming assemblies are no longer required to reduce CTC. As a result, the average pin linear power can be increased, leading to much higher achievable core power density.

- Utilization of LEMs allows a partial opening of the lattice and thus as much as a $30 \%$ increase in the core power density.

- The possibility of increasing the coolant volume fraction and, thus, the core cooling capabilities can be traded off for an increase of the system thermal margin or reduction in pressure losses across the core instead of (or in combination with) achieving higher power density.

Two conceptual $\mathrm{CR}=1$ core designs with LEMs that satisfy the core self-controllability criteria were developed. The first core design features the target $100 \mathrm{~kW} / 1$ power density and tight fuel pin pitch $(\mathrm{P} / \mathrm{D}=1.08)$. The second core has a $\mathrm{P} / \mathrm{D}$ value of about 1.19 , which allowed an increase of the core average power density to $130 \mathrm{~kW} / 1$ for the same core pressure drop and thermal margin as in the first $100 \mathrm{~kW} / 1$ core design. Both cores can be designed to have a reasonable radial power distribution, with peaking factors below 1.3 throughout the fuel cycle. Similar to the lead-cooled core, the $\mathrm{CR}=1$ liquid $\mathrm{NaCl}-\mathrm{KCl}-$ $\mathrm{MgCl}_{2}$ salt-cooled cores have three radial zones of different $\mathrm{Zr}$ to $\mathrm{HM}$ ratio in order to tailor the power peaking and maintain a nearly steady power profile during irradiation. Both core design options investigated achieve a conversion ratio slightly higher than unity with respect to the overall TRU amount. As in the lead-cooled core, net breeding of $\mathrm{Pu}$, coincident with net destruction of MA, was observed. Both cores have hexagonal lattices and a larger heavy metal loading than the lead-cooled core. The $130 \mathrm{~kW} / 1$ core is preferable because it provides more space in the vessel for pumps and IHX placement and achieves higher specific power ( 35 versus $23 \mathrm{~kW} / \mathrm{kgHM}$ ), and thus lower fuel cycle cost. Therefore, further neutronic and thermal hydraulic analyses were performed for the higher power density core.

As in the lead-cooled reactor case, the fuel cycle is limited by the peak cladding fluence rather than the core reactivity. The cycle length is about 1900 EFPD for the $130 \mathrm{~kW} / 1$ core, assuming a $4 \times 10^{23} \mathrm{n} / \mathrm{cm}^{2}$ fast fluence limit. The peak cladding fluence is reached first in the innermost fuel zone because it has the lowest HM density and a somewhat higher power peak. In the outermost radial fuel zone, however, the cladding fluence is only about half that of the inner zone at the end of the cycle. Therefore, the fuel from the outer zone can, in principle, be reshuffled within the core and be used for another cycle, providing a significant saving in fuel cycle cost. Three successive TRU recycling stages were modeled, in which all TRUs at the end of each cycle were assumed to be reprocessed after 7 years of decay and re-fabricated into the new fuel with the addition of natural uranium only. The results of the simulations indicate that the cycle length and other core performance parameters can be maintained in a sustainable manner from one TRU recycling stage to another. 
The design of the $\mathrm{CR}=0$ salt-cooled core is based on the tight lattice core $(\mathrm{P} / \mathrm{D}=1.19)$ with $130 \mathrm{~W} / \mathrm{cc}$ power density. As in the lead-cooled case, three batch fuel management is adopted for the salt-cooled core. Each fuel assembly included 12 LEMs and 19 control rod locations. The initial TRU loading that provides the cycle length limited by the peak clad fluence $\left(4 \times 10^{23} \mathrm{n} / \mathrm{cm}^{2}\right)$ was determined to be $30 \mathrm{wt} . \%$, which is somewhat lower than the $34 \mathrm{wt} . \%$ in the $\mathrm{CR}=0$ lead-cooled core case. The resulting fuel cycle length is about 540 EFPD. The fuel loading pattern was developed to provide reasonable radial power peaking factors. In the current design, the maximum radial power peaking factors are below 1.35, which is comparable to the lead-cooled core. The achievable discharge fuel burnup is $340 \mathrm{MWd} / \mathrm{kg}$, which corresponds to about $36 \%$ TRU burnup fraction.

Both the $\mathrm{CR}=1$ and $\mathrm{CR}=0$ cores with LEMs satisfy the self controllability criteria. Because of the more positive CTC and more negative Doppler feedback of the $\mathrm{CR}=1$ core, the $\mathrm{CR}=1$ core needs double the amount of LEMs than the $\mathrm{CR}=0$ core ( 24 versus 12). LEMs are designed such that during normal operation about $25 \%$ of their lithium is inserted at the top of the core. This is necessary because the worth at the top of the core is small. Also, to compensate for positive CTC (which is linear with core temperature) at the beginning of the transient, the lithium surface needs to be located close to the higher worth region. This way, a LEM design was identified such that the net effect of CTC is about zero through the desirable coolant temperature range. The reactivity penalty from partial lithium insertion is very small (about $0.25 \$$ ) and can be reduced by bottlenecking the top part of the LEM capillary. The LEM performance and its effect on reactivity were confirmed through a detailed RELAP5 model of LEMs.

Steady state thermal hydraulic analysis has benefited significantly from the use of LEMs allowing a larger P/D of 1.19 and larger coolant volume fraction by over $50 \%$ in comparison with very tight lattice LEM-free assemblies. The small number of LEMs needed ( 24 and 12 per 397 pin assembly for the $C R=1$ and $C R=0$ cores, respectively) has a much smaller impact on the hot-spot heat flux than the axial blankets, streaming assemblies, and hydride control rods investigated prior to introduction of LEMs. Nevertheless, the impact on thermal hydraulics is substantial: the LEM reference design achieves significantly higher power density (129 vs. $68 \mathrm{~kW} / \mathrm{l})$, lower core pressure drop (0.7 vs. $1.07 \mathrm{MPa})$, and lower maximum cladding temperature $\left(642\right.$ vs. $\left.650^{\circ} \mathrm{C}\right)$.

Similarl to the lead core and previous salt core designs, a conservative subchannel model was used to calculate the thermal hydraulic performance of the reference salt design. The results confirmed that both cladding and fuel temperature limits can be met with margin for both the $\mathrm{CR}=1$ and $\mathrm{CR}=0$ cores. The results from the subchannel core model were also used to produce an equivalent core model in RELAP5-3D for transient analyses. This RELAP model agrees well with the subchannel model; for the same coolant flow rate, core pressure drop agrees within $0.3 \%$, and maximum cladding temperature within $1{ }^{\circ} \mathrm{C}$, both well within modeling uncertainties.

The salt/S- $\mathrm{CO}_{2} \mathrm{IHX}$ is of the shell-and-tube type with ribbed tubes on the $\mathrm{CO}_{2}$ side to enhance heat transfer, similar to that of the lead-cooled design. Four kidney shaped IHXs 
were used to maximize the use of space in the downcomer. The thickness of the heat exchanger tubes and plena were chosen so that material stresses would not exceed the limits set by the updated ASME code for T91 steel at the operating temperatures to achieve a lifetime of 30 years. However, because salt has an almost 5 times smaller density than lead, the requirements for minimization of pressure drop on the shell side are more demanding than those of lead. This is because the pressure loss through the IHX determines the maximum allowed separation distance between the two free levels in the vessel. The low pressure drop requirement and inferior heat transfer properties of salt versus lead result in more tubes of larger length than those of the lead-cooled concept. The larger IHXs required bottlenecking of the core barrel, but all 4 IHXs could be fitted into the $10.2 \mathrm{~m}$ OD vessel.

As for the lead-cooled concept, three transient analyses were performed - unprotected SBO using RVACS/PSACS, unprotected LOFA using the PCS for decay heat removal and unprotected overpower. Since salts operate at a low Reynolds number, all transients exhibit a transition to laminar flow. During SBO, the peak cladding temperature was found to exceed, in the early stage, the $725^{\circ} \mathrm{C}$ limit for $\sim 120 \mathrm{~s}$. This is because pump coastdown is faster than reactivity-feedback driven shutdown for a short period of time and because salt has a significantly larger film temperature than lead coolant. Although several options to reduce peak cladding temperature (PCT), such as reduced core inlet temperature or reduced power density to $100 \mathrm{~kW} / 1$, were evaluated and found to be successful in keeping PCT below the limit, the design was not modified. This is because these measures would result in an economic penalty, and several literature sources suggest that such short duration of PCT above the $725^{\circ} \mathrm{C}$ limit is acceptable without any appreciable cladding thinning from plutonium-iron eutectic penetration. More R\&D into this issue is necessary and in case of negative results, the backup solution is the use of a metal foil barrier between fuel and cladding to prevent eutectic formation. In the longer term, reactivity feedbacks, including that due to LEMs, cause the reactor to shut down. However, past this initial shutdown, cooling by the PSACS and RVACS causes reactivity to rise again, resulting in a reactor restart into a low-power $(\sim 6 \%)$ steady state if three or four PSACS trains with large $100 \%$ tanks are operating. This operation is sustained until about 36 hours after the transient begins, after which the PSACS tanks are depleted and all cooling occurs through the RVACS. At 36 hours, the decay heat is low enough that the RVACS is sufficient to keep the core peak cladding temperature below its $725^{\circ} \mathrm{C}$ limit.

Design of the Liquid Salt Fast Reactor (LSFR) against freezing in protected SBO turned out to be particularly difficult, not only because of the small salt margin to freezing, but also because this reactor has the largest CTC coefficient. LEMs can be designed to compensate for the salt $\mathrm{CTC}$ in a limited temperature range, primarily for reactivity increase upon coolant heating. During core cooling below the nominal temperature, LEMs are out of the core and the large positive CTC yields strong power reduction during cool down, speeding up reactor shutdown and thus increasing the core cooling rate. SBO analyses have shown that for the $\mathrm{CR}=1$ core and the originally sized PSACS (tank diameter/height $=6 \mathrm{~m} / 12 \mathrm{~m}$ and 350-tube, $4 \mathrm{~m}$-long heat exchanger) the salt can freeze in about 20 hours, if the reactor is scrammed and 4 PSACS trains are operating, and in 
Project No 06-040: Flexible Conversion Ratio Fast Reactor Systems Evaluation

$\sim 10$ hours for $\mathrm{CR}=0$, which has lower decay heat. The best solution to this problem turned out to be the use of smaller PSACS tanks and heat exchangers. It was shown that sizing the PSACS heat exchangers to transfer $40 \%$ less power (250-tubes, 2.4-long heat exchanger) than the original design and using $25 \%$ smaller PSACS tanks $(\mathrm{D} / \mathrm{H}=6 \mathrm{~m} / 9 \mathrm{~m})$ can accommodate both the unprotected SBO with peak cladding temperatures below the $725^{\circ} \mathrm{C}$ limit and the protected SBO without salt freezing. An alternative solution for future investigation is the use of PSACS-air heat exchangers, which require larger film $\Delta \mathrm{T}$.

Similar to the lead-cooled design, the salt-cooled $\mathrm{CR}=1$ and $\mathrm{CR}=0$ cores can accommodate unprotected LOFA through PCS self-sustained operation. The core never experiences a shutdown; instead it settles smoothly into a new steady state at a naturally circulated reactor power of approximately $87 \mathrm{MW}$, matching the heat removed by the RVACS and power conversion system. This desirable behavior is possible because of the use of a proportional integral controller, which is able to decrease the heat removal capacity of the power conversion system in a similar fashion to the decrease in reactor power. The turbine speed setpoint of $25 \mathrm{rad} / \mathrm{s}$ corresponds to the PCS power that in combination with RVACS power removal matches the natural circulation capability of lead coolant through the primary system with peak cladding temperature below the limit and core inlet temperature well above freezing point. Unprotected overpower resulted in only $13 \%$ and $27 \%$ power increases for the $C R=1$ and $C R=0$ cores, respectively, with peak cladding and fuel temperatures well below their limits.

Overall, it can be stated that a liquid salt-cooled reactor with safety characteristics similar to those of the IFR can be designed, but it needs LEMs or similar devices to mitigate its large positive CTC. However, R\&D is needed to address the significant uncertainties in salt properties and heat transfer correlations in a wire-wrap geometry. Also, LEM performance will require testing.

\section{Cross Comparison of Various Designs}

The LFR and LSFR 2400MWt FCR reactors were compared against two other reactor candidates: a gas-cooled fast reactor (GFR) with $\mathrm{CR}=1$ developed at MIT under a different NERI project, and (2) a sodium-cooled actinide burning reactor, designated SFR in this report, under development at ANL. Because the GFR was designed only for $\mathrm{CR}=1$, the $\mathrm{CR}=1$ designs were selected for comparison. Because the ANL design is of the modular type with a significantly smaller power rating of $1000 \mathrm{MWt}$ than the other three designs, the 1000 MWt SFR core was enlarged to a $2400 \mathrm{MWt}$ core: a consistent power rating with the other designs. The power increase was achieved by adding more fuel assemblies, while keeping assembly and pin dimensions the same as that of the ANL design. However, zirconium grading that keeps TRU/U ratio constant, as for the LFR and LSFR reactors, was used instead of TRU enrichment zoning to maintain power peaking low throughout the cycle. Reactor physics analysis for the new core was performed to confirm neutronic feasibility. 
The cross comparison among individual concepts was performed in view of Generation IV goals. Because all reactors can achieve a conversion ratio of unity without blankets and do not use separated plutonium $(\mathrm{Pu})$, all concepts have similar intrinsic proliferation resistance characteristics in terms of $\mathrm{Pu}$ isotopics, and the differences will stem from protective measures implemented throughout the entire fuel cycle. All $\mathrm{CR}=1$ concepts also offer high uranium resource utilization, as well as excellent management of not only their nuclear waste but also reduction of the long-term stewardship burden by depleting legacy TRU from spent LWR fuel. Although this may be surprising, both the $C R=0$ and $\mathrm{CR}=1$ cores can reduce the stockpile of spent LWR fuel over about the same period in growing nuclear energy demand scenarios, because the first $\mathrm{CR}=1$ core requires large TRU loadings. The main difference between the $\mathrm{CR}=0$ and $\mathrm{CR}=1$ cores is that a much larger $\mathrm{CR}=1$ reactor fleet would be needed than for $\mathrm{CR}=0$ cores. But in either case, a relatively large number of fast reactors need to be deployed; the cost of fast reactors will have to be reduced to become competitive with LWRs to make such deployment successful. Therefore, in terms of the sustainability goal, it was concluded that it can be achieved by all four concepts equally.

Because of the paramount importance of improved economics of fast reactors, significant effort was applied to utilization of the designs of the LFR and LSFR to achieve cost reduction. The approaches included (1) large power rating units $(2400 \mathrm{MWt})$ to benefit from economy of scale, (2) maximizing plant efficiency through (i) the use of advanced cladding material to maximize the cladding temperature limit, (ii) maximizing coreaverage outlet temperature through orificing and low power peaking design, (iii) removal of intermediate loop to maximize turbine inlet temperature, and (iv) use of a highly efficient power conversion system, (3) the minimization of the plant footprint to reduce the amount of steel and concrete material, and (4) the achievement of high specific power to reduce the fuel cycle cost. Although a SFR plant design was not carried out, it was noted that the SFR could benefit from a similar plant design if a double-wall IHX with helium gap for leak detection is used and the intermediate loop is eliminated. Thus, pending confirmation of feasibility of this approach for the SFR, it was concluded that both liquid metal and salt-cooled reactors could potentially achieve similar cost reduction. The GFR has the largest vessel among the four fast reactor concepts and employs $4 \times 50 \%$ large emergency cooling systems plus a robust containment that needs to be designed for higher pressures than the other contenders. On the other hand, it does not require IHXs, which are heavy and costly components and achieves $4 \%$ higher efficiency due to its highest turbine inlet temperature. Such a high efficiency is expected to compensate for the higher containment and vessel cost. However, the GFR relies on ODS cladding, which will take a much longer time to develop and qualify than the T-91 cladding for the other 3 reactors.

The sodium-cooled core has an almost 3 times higher power density $(290 \mathrm{~kW} / 1)$ than the lead and salt-cooled cores, which results in significantly smaller core dimensions. On the other end of the spectrum is the GFR with its power density of only $85 \mathrm{~kW} / 1$. High power density allows the reduction of vessel size, although this may not be the case for passive decay heat removal systems, which use the vessel as a heat transfer surface and thus favor large vessel size. 
The SFR also achieves the largest specific power of $65 \mathrm{~kW} / \mathrm{kgHM}$, followed by the LFR with $45 \mathrm{~kW} / \mathrm{kgHM}$ and LSFR with $35 \mathrm{~kW} / \mathrm{kgHM}$. Cores with low specific power have longer cycle length. For instance, the GFR has a cycle length of 18 years and the SFR only 3.1 years. Cycle length is limited by the peak cladding fluence, which also determines achievable core-average discharge burnups. These are in the range of 70 to 80 $\mathrm{MWd} / \mathrm{kgHM}$ for metallic fueled cores - relatively low values for fast reactors, signifying the importance of the development of advanced cladding materials. The GFR has a notably higher burnup of $140 \mathrm{MWd} / \mathrm{kgHM}$, partially due to its softer spectrum, partially due to the use of ODS cladding which is expected to have higher fast fluence limit, but most importantly due to lower neutron flux because of much larger heavy metal and TRU loadings and thus a higher number density of fissile isotopes.

It is also interesting to note that, although different coolants have different moderating power, the neutron spectra among the four cores have only small differences. This is because each core design required a different geometry or, in case of the GFR, a different fuel to achieve target power density and reactivity feedback ratios supporting reactor selfcontrollability. The GFR has the softest spectrum because it employs $\mathrm{BeO}$ diluent in $\mathrm{UO}_{2}$ fuel. On the other hand, the salt-cooled core unexpectedly has a harder spectrum than the lead-cooled reactor because it required a very tight lattice to minimize the coolant temperature reactivity coefficient.

The comparison study also shows that it is possible to design each reactor concept to achieve self-controllability. However, different measures are needed to attain this goal for each coolant. The lead-cooled reactor has the smallest positive coolant temperature reactivity coefficient (CTC) and does not need additional devices to satisfy selfcontrollability criteria. On the other hand, the LSFR has the largest CTC, primarily due to its largest thermal expansion coefficient, and reducing it to acceptable levels without resorting to drastic and uneconomic core design changes requires the introduction of lithium expansion modules, which allow achievement of negative reactivity feedback from coolant salt heat up. The achievement of self-controllability in a SFR core without blankets is more challenging than that of the lead-cooled core, but is deemed possible with sufficient optimization of the core. The attainment of self-controllability in the GFR is the most challenging among all the investigated concepts. This is because the GFR can undergo rapid depressurization in a large-break loss of coolant accident (LOCA), which requires negative coolant void worth - a very difficult task in fast reactors in general and in gas-cooled reactors even more so since the strategy of reducing leakage is not very effective in the relatively neutronically transparent gas. Nevertheless, this goal was successfully achieved in the $\mathrm{S}-\mathrm{CO}_{2}$ cooled GFR through the use of $\mathrm{BeO}$ diluent in $\mathrm{UO}_{2}$ fuel and $\mathrm{S}-\mathrm{CO}_{2}$ reflector assemblies.

An important feature of self-controllable designs is the capability to remove sufficient heat during shutdown passively as well as decay heat during the long term. This is especially challenging for the reactors with a large power rating since the driving forces for natural phenomena are small and typically require large decay heat removal systems, negatively affecting capital cost. The $2400 \mathrm{MWt}$ lead and salt-cooled FCR reactors have 
been designed with two safety systems - a passive reactor vessel auxiliary cooling system (RVACS) and a passive secondary auxiliary cooling system (PSACS). However, there were differences in performance between the lead and salt-cooled concepts. While the LSFR can accommodate the unprotected station blackout accident (SBO) without exceeding the peak cladding temperature limit for any number of operating PSACS trains with relatively small PSACS tanks, the lead-cooled reactor requires significantly larger tanks to keep the peak cladding temperatures below the limit. This difference stems from the different CTCs of each reactor that lead to differences in primary system temperatures and reactor power in the long term restart. Because larger tanks may not be economically attractive, one could also employ smaller tanks and scram the reactor manually or restore power. The operator has $\sim 24$ hours to initiate scram, which is ample time for such action. The LSFR does not need to scram and can maintain peak cladding temperature within limits for 72 hours with smaller PSACS tanks, independent of the number of operating PSACS trains, as long as 2-out-of-4 trains are in operation. However, it is more difficult to overcome the freezing challenge because of the smaller salt margin to freezing. A solution was found that can accommodate both the unprotected SBO with peak cladding temperatures below the $725^{\circ} \mathrm{C}$ limit and the protected SBO without salt freezing for 72 hours. It is based on sizing the PSACS tanks and heat exchangers to prevent reactor restart in the unprotected SBO with 2 PSACS trains operating and preventing PSACS tank evaporation in less than 36 hours in the protected SBO with 4 trains in operation.

The SFR has the largest margin to freezing, making it less of an issue for the limiting case of all PSACS trains operating in a protected SBO event. The GFR decay heat removal principle is very different from that of liquid metal cooled reactors. It employs cooling loops that connect its low $\Delta \mathrm{p}$ core with elevated gas/water heat exchangers, all enclosed in a guard containment designed for a pressure of about $0.8 \mathrm{MPa}$. In case of a LOCA, the primary system and PCS depressurize into the containment, increasing the containment pressure to an equilibrium of about $0.7 \mathrm{MPa}$. However, the GFR suffers from potential bypasses (e.g. through the double-ended break of coaxial pipes or through a PCS train) that can lead to a significant reduction of core flow. For this and other reasons, fully passive decay heat removal (DHR) was abandoned in the MIT GFR design, and battery or fuel cell powered blowers are used with passive natural circulation as a backup.

Overall, comparing the four concepts, it can be stated that all can be designed to passively accommodate the unprotected limiting accidents, but it does not seem to be a preferable option in the GFR, where the active safety or semi-passive approach will likely result in more economic and more reliable plants. 


\section{$\underline{\text { Table of Contents }}$}

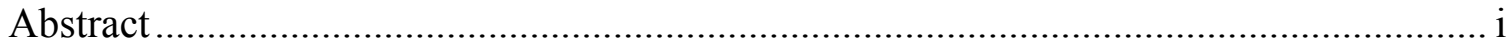

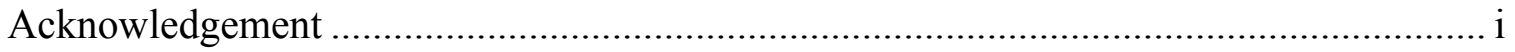

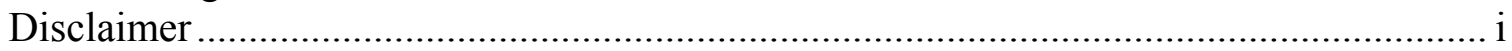

Executive Summary ................................................................................................ ii

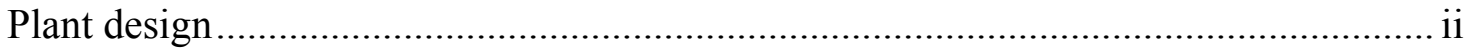

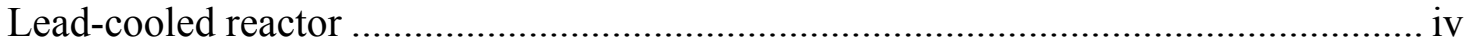

Liquid Salt-cooled Reactor ........................................................................... vi

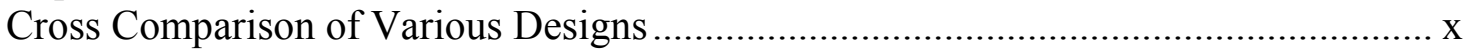

Table of Contents ................................................................................................... 1

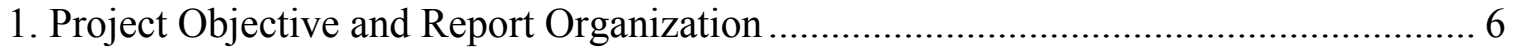

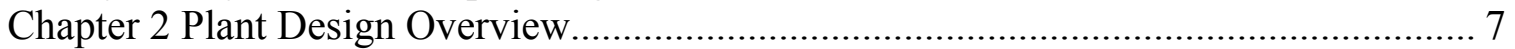

2.1 Design Choices and Constraints ....................................................................... 7

2.1.1 Choice of Conversion Ratio ...................................................................... 7

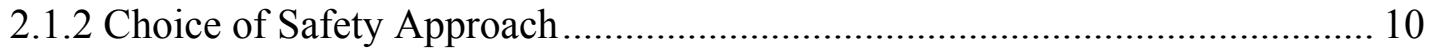

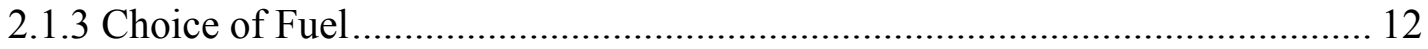

2.1.4 Service Limits and Choice of Vessel and In-Core Materials............................ 12

2.1.5 Operating Temperature and Power Cycle Selection......................................... 18

2.2 Overall Reactor and Plant Design.................................................................... 20

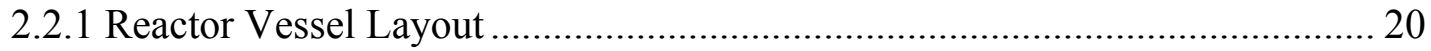

2.2.2 Power Conversion System Design............................................................ 24

2.2.3 Passive Decay Heat Removal Systems and Strategies for Managing Accidents

2.3.1 Decay Heat Removal from the Reactor Vessel using RVACS

2.2.3.2 Passive Secondary Auxiliary Cooling System (PSACS) .......................... 30

2.2.3.3 DHR through Power Conversion System ............................................... 34

2.2.3.4 Approaches for Managing Turbine Overspeed...................................... 36

2.2.3.5 Comprehensive Strategy for Managing Transients................................ 46

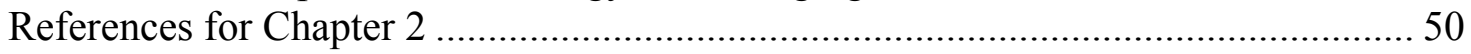

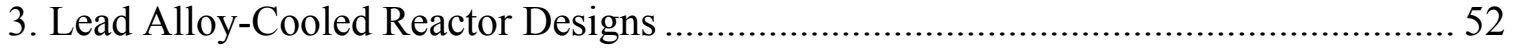

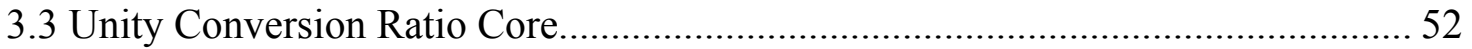

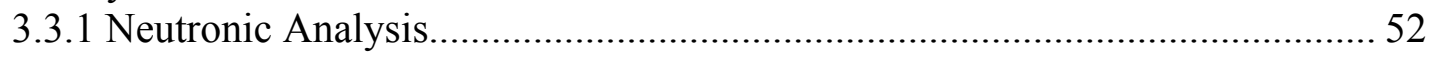

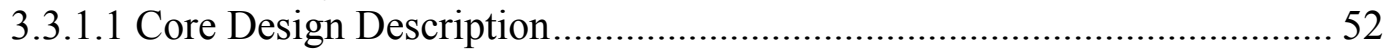

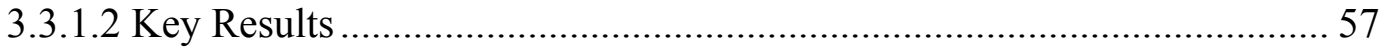

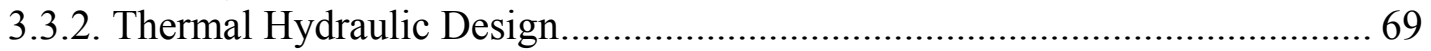

3.3.2.1 Steady State Thermal Hydraulic Design ............................................. 70

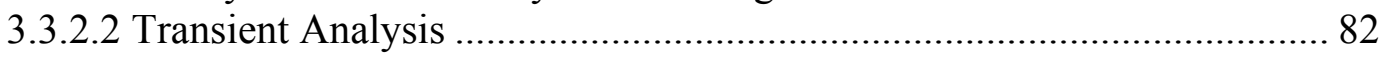

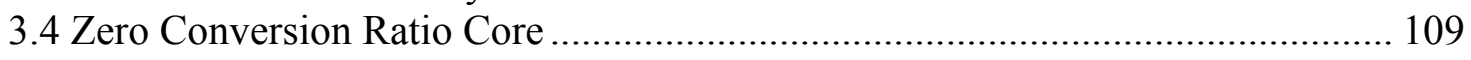

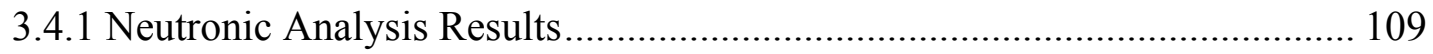

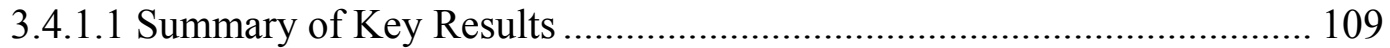

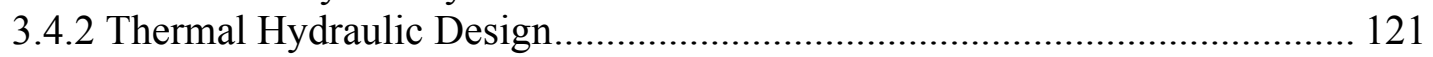

3.4.2.1 Steady State Thermal Hydraulic Design............................................. 121

3.4.2.2 Transient Analysis ........................................................................... 124

3.5 Conclusions of Lead-cooled Reactor Studies ................................................ 131 
Project No 06-040: Flexible Conversion Ratio Fast Reactor Systems Evaluation

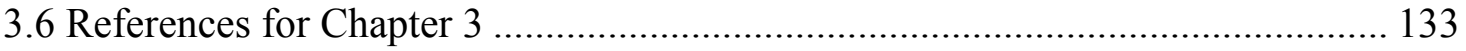

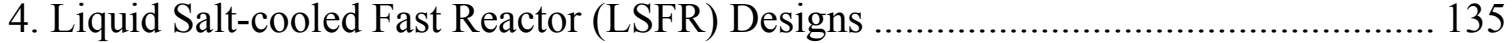

4.1 Selection of the Most Promising Salt Candidate ................................................. 135

4.1.1 Properties of the Most Promising Salt Candidate ........................................ 137

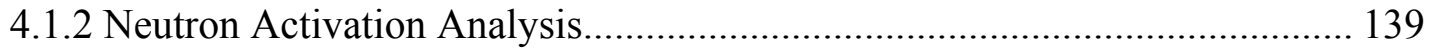

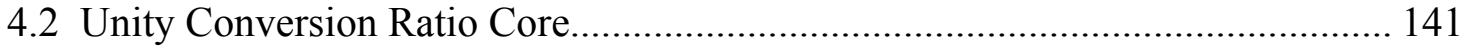

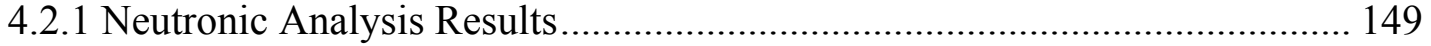

4.2.2 Thermal Hydraulic Analysis Results ...................................................... 172

4.2.2.1 Steady State Design ..................................................................... 172

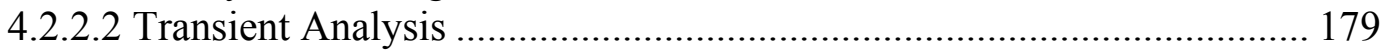

4.3 Zero Conversion Ratio Core ............................................................................... 204

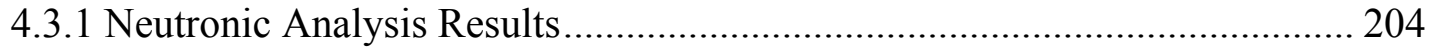

4.3.2 Thermal Hydraulic Analysis Results .......................................................... 217

4.3.2.1 Steady state design.................................................................. 217

4.3.2.2 Transient performance ................................................................ 219

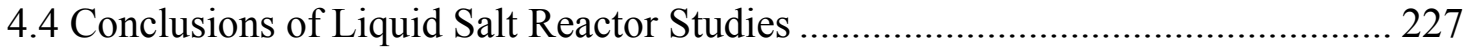

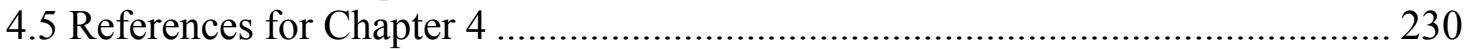

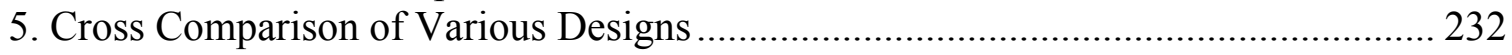

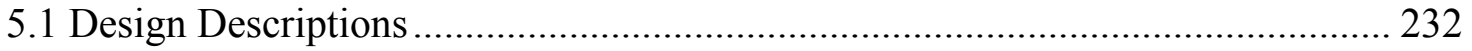

5.1.1 Selection of Representative Designs for Comparison .............................. 232

5.1.2 Gas-Cooled Fast Reactor Brief Description ........................................... 233

5.1.3 Sodium-Cooled Fast Reactor Brief Description ........................................ 237

5.2 Comparison Goals and Overall Results ....................................................... 238

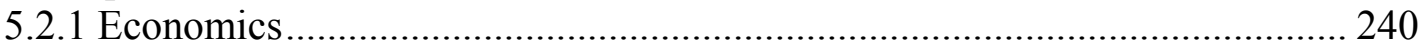

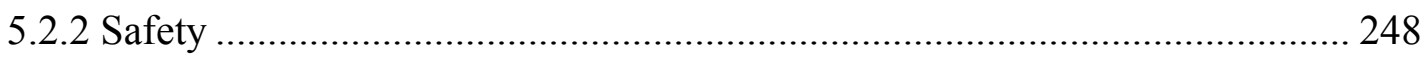

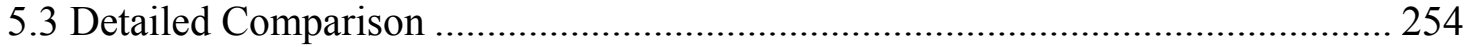

5.3.1 Neutronic Performance Comparison........................................................... 254

5.3.2 Coolant Comparison .............................................................................. 264

5.3.2.1 Thermophysical Properties ........................................................... 264

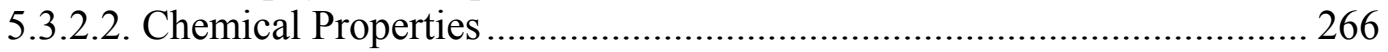

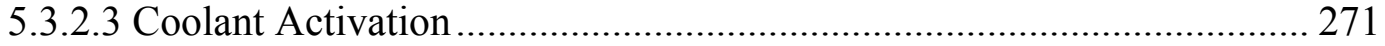

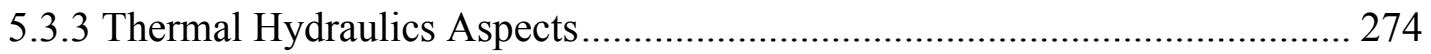

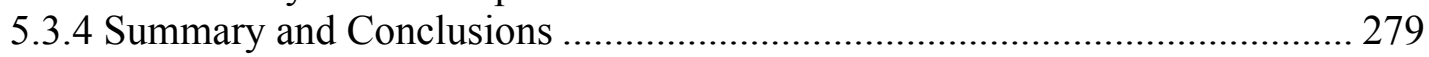

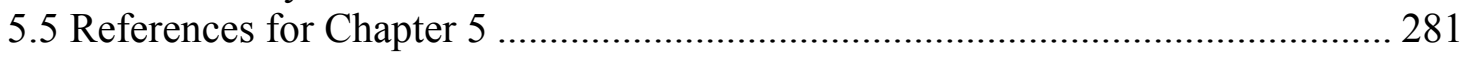

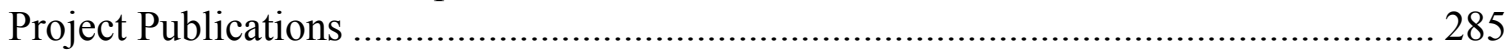

Appendix 2A The S-CO $\mathrm{CO}_{2}$ Power Conversion Unit for a 2400MWt Fast Reactor ......... 286

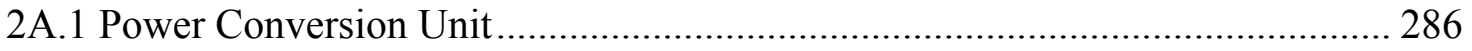

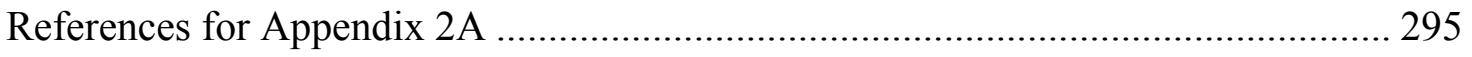

Appendix 2B RVACS Decay Heat Removal Options and Analysis Model................. 296

2B.1 Option of Finned Guard Vessel - Problem Formulation .................................. 296

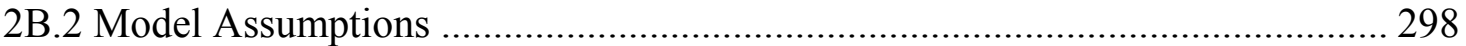

2B.3 Energy Balances ................................................................................... 299

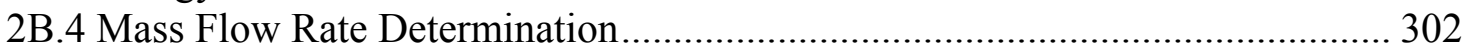

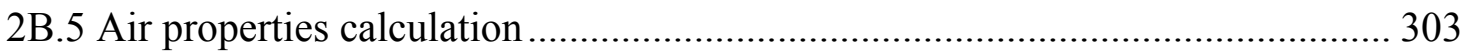

2B.6 Pressure drop and change in temperature calculations................................. 304

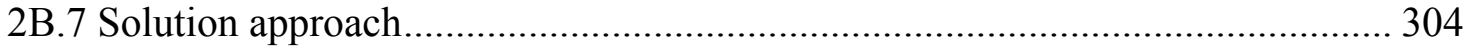


2B.8 Modification for Perforated Plate Heat Transfer Calculation: ......................... 306

2B.9 Modification for Dimpled Wall Heat Transfer Approximation ........................ 310

2B.9.1 Dimpled Wall Performance Estimates Based on Experimental Results ..... 310

2B.9.2 Dimpled Wall Numerical Evaluations ....................................................... 312

2B.10 Option of Multiple-Stage RVACS ............................................................... 316

2B.11 Pseudo-Steady State Transient Analysis ...................................................... 317

2B.12 Enhancement of Gap Heat Transfer and Guard Vessel Stress Intensity

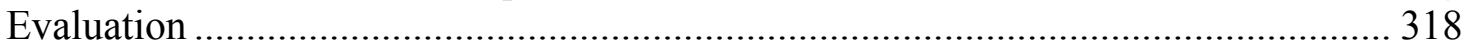

2B.13 Cases Evaluated and Numerical Results ................................................... 320

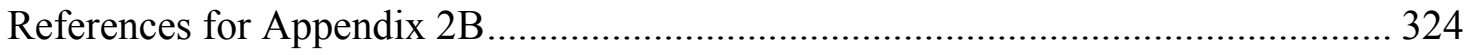

Appendix 2C Supplementary Decay Heat Removal Options ..................................... 326

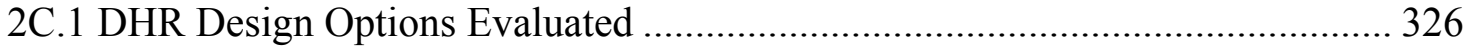

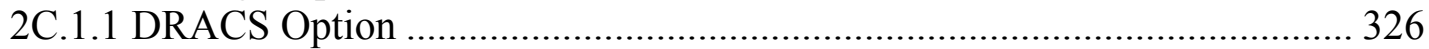

2C.1.1 PSACS Options ............................................................................... 328

2C.2 Selection of PSACS Design for Further Studies .......................................... 332

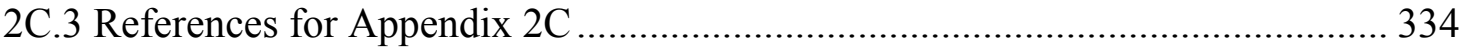

Appendix 2D Analysis of Supplementary Decay Heat Removal Options .................... 335

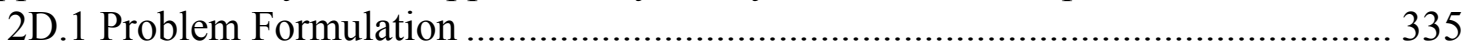

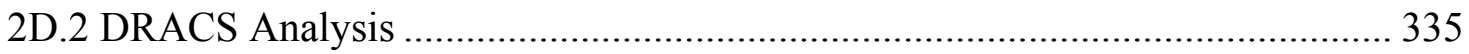

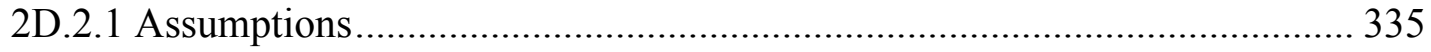

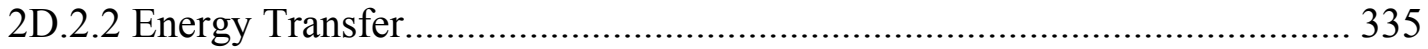

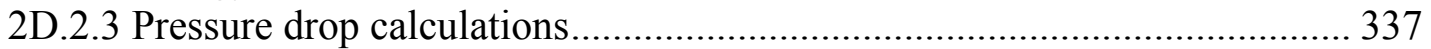

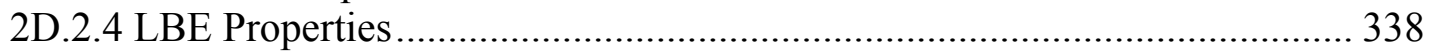

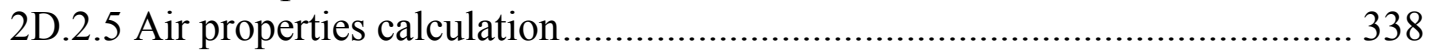

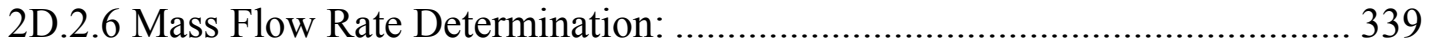

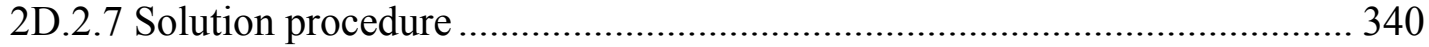

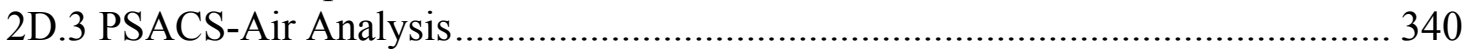

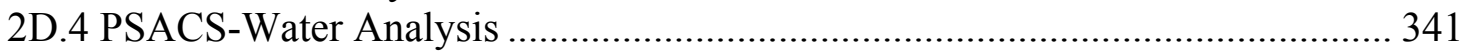

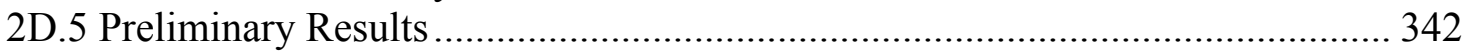

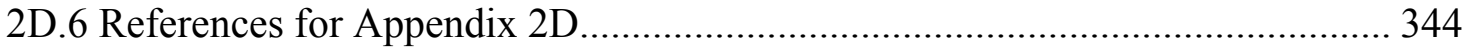

Appendix 3A Reactor Physics Analysis Tools and Methods …................................ 345

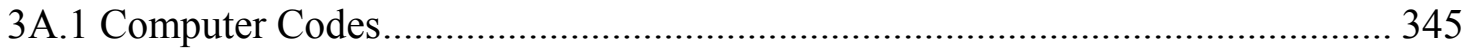

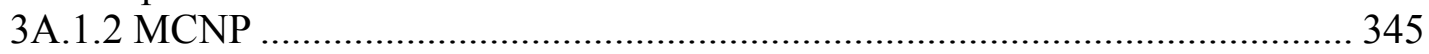

3A.1.3 MCODE …................................................................................. 348

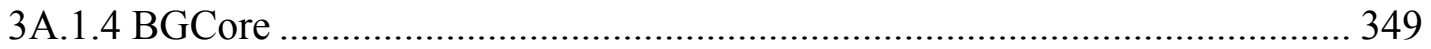

3A.1.5 ANL Suite of Diffusion Codes.............................................................. 351

3A.2 REBUS-3 Analysis for Lead-cooled Core and Comparison with MCODE Results

3A.2.1 Computational Model of Lead-Cooled Core for DIF3D8 and REBUS-3

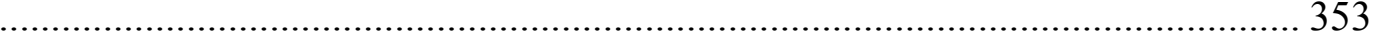

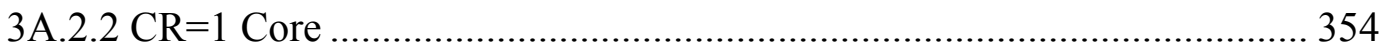

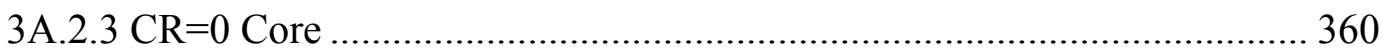

3A.2.4 Conclusion .................................................................................. 362

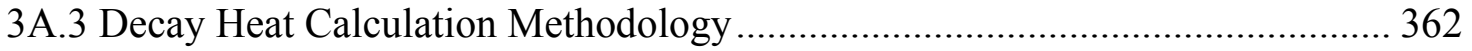

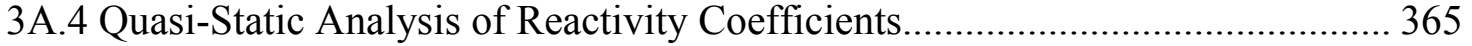

3A.4 Analysis of Lithium Expansion Modules................................................. 370 


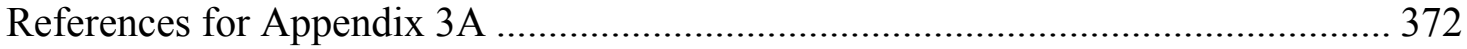

Appendix 3B Thermal Hydraulics Analysis Tools and Methods ............................... 374

3B.1 SUBCHAN - A Simplified Model for Thermal Hydraulic Analysis of Lead-

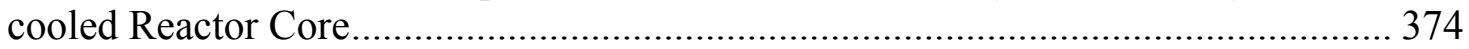

3B.1.1 Flow Distribution among Parallel Non-communicating Channels ............. 376

Energy Balance and Cladding and Fuel Temperature Profiles............................ 378

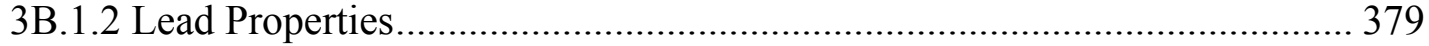

3B.1.3 Model Verification .................................................................................. 381

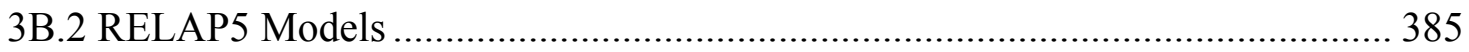

3B.2.1 Overall RELAP5-3D Model Nodalization .......................................... 385

3B.2.2 Details of RELAP5-3D Core Model .................................................. 387

3B.2.3 Details of RELAP5-3D Model of Intermediate Heat Exchanger............ 388

3B.2.4 Details of RELAP5-3D Model of RVACS .......................................... 392

3B.2.4 Details of RELAP5-3D Model of PSACS ............................................ 393

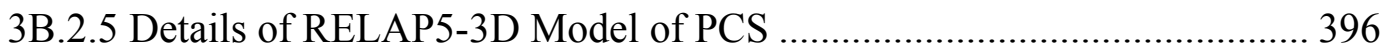

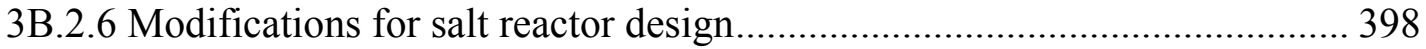

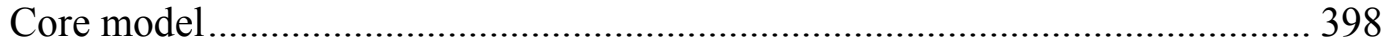

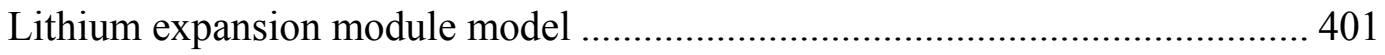

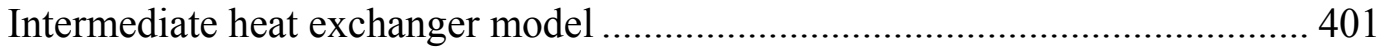

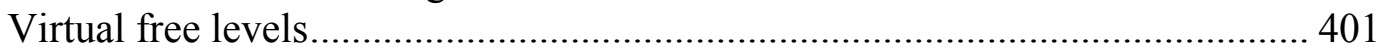

Incorporation of chloride salt properties into RELAP5-3D ............................. 406

3B.2.7 RELAP5-3D Model of Reactivity Coefficients ......................................... 408

Implementation in Lead-cooled Cores........................................................... 408

Salt reactor reactivity feedback implementation.......................................... 411

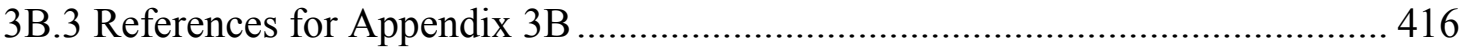

Appendix 3C Intermediate Heat Exchanger Model.................................................... 417

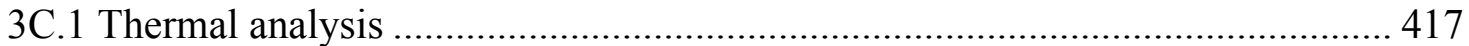

3C.2 Pressure Drop on the Tube Side ..................................................................... 419

3C.3 Lead heat transfer coefficient and friction factor ........................................ 419

3C.4 Pressure Drop on the Shell Side ............................................................... 420

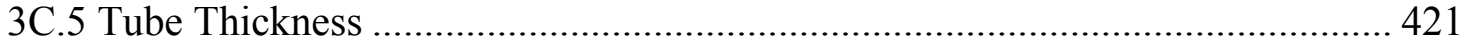

$3 \mathrm{C} .6 \mathrm{CO}_{2}$ heat transfer coefficient and friction factor .......................................... 421

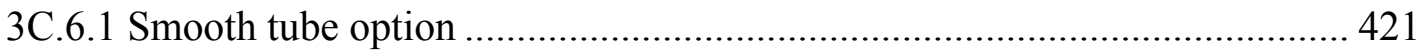

3C.6.2 Enhanced Heat Transfer Option ....................................................... 421

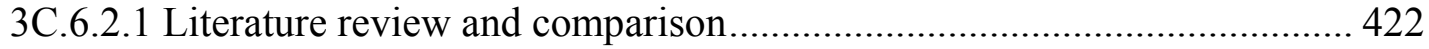

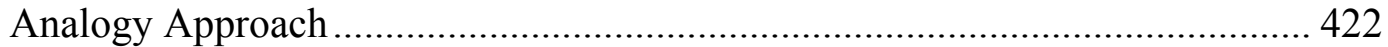

Statistical Approach ............................................................................... 423

3C.6.2.2 Selected Correlations................................................................. 423

3C.6.2.3 Heat exchanger with ribbed tubes design......................................... 423

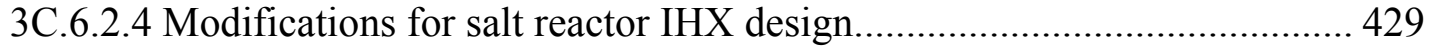

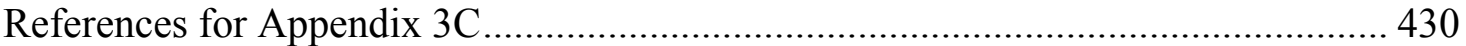

Appendix 4A Overview of Potential Salt Candidates............................................. 432

4A.1 Database of Initial Liquid Salt Candidates ..................................................... 432

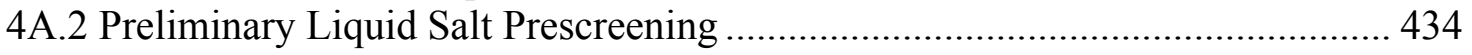

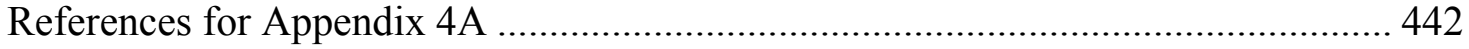


Project No 06-040: Flexible Conversion Ratio Fast Reactor Systems Evaluation

Appendix 4B Alternative Strategies to Reduce the Coolant Temperature Reactivity

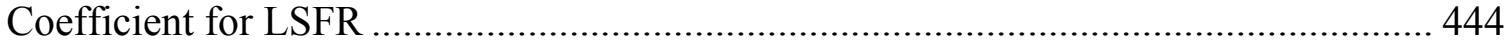

4B.1 Investigation of CTC reduction strategies for $\mathrm{NaF}-\mathrm{KF}-\mathrm{ZrF}_{4}$ cooled core ........ 444

4B.2 Determination of Target CTC Values .......................................................... 449

4B.3 Investigation of CTC reduction strategies for chloride salts cooled core ......... 454

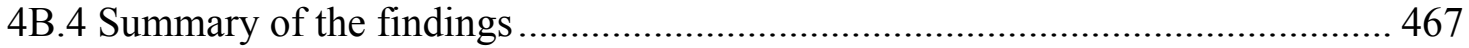

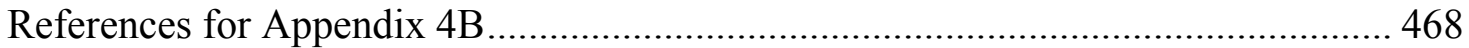

Appendix 5A Core Conceptual Design of a 2400MWt Sodium-cooled Reactor ........... 469

5A.1 Description of 1000MWt ABR Core ..................................................... 469

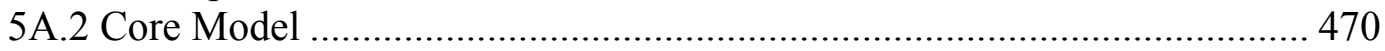

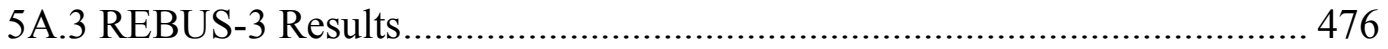

5A.4 Sodium-cooled $\mathrm{CR}=1$ core modeling with MCNP ..................................... 484

Sodium-Cooled Reactor Reactivity Coefficients........................................... 486

References for Appendix 5A ............................................................................ 489 


\section{Project Objective and Report Organization}

\section{Project Objective}

The overall objective of this NERI project is to develop a feasible design for a flexible conversion ratio fast reactor system for time-dependent management of both fissile inventories and higher actinides. The focus of the design effort is on reactor core designs having two conversion ratios: (1) near zero, to transmute legacy waste and (2) near unity, to operate in a sustainable closed cycle. Furthermore, two liquid reactor coolant core candidates, lead and liquid salt (the term liquid salt is adopted to distinguish pure salt from molten salt containing molten fuel), are to be designed. Finally, these lead and salt designs will be cross-compared with gas and sodium fast reactor designs. The gas coolant core results are obtained from an already ongoing MIT NERI project and sodium results are obtained from work at Argonne National Laboratory.

\section{Report Organization}

The project is organized into 3 tasks: (1) Lead Alloy-Cooled Reactor Design, (2) Liquid Salt-Cooled Reactor Design, and (3) Cross-Comparison of Various Designs. This final report summarizes accomplishments achieved under each task during this project. It is organized into 5 chapters. Following this chapter, Chapter 2 describes design choices, adopted constraints and gives a plant design overview including the strategy for decay heat removal and turbine overspeed protection, which is common to both the lead and liquid salt-cooled reactors. The lead-cooled reactor core conceptual design is described in Chapter 3. The results of liquid salt-cooled design work are summarized in Chapter 4. Finally, Chapter 5 compares these designs with those using gas and sodium coolants. Each chapter focuses on main results and performance characteristics of each design; analysis details are given in Appendices. 
Project No 06-040: Flexible Conversion Ratio Fast Reactor Systems Evaluation

\section{Chapter 2 Plant Design Overview}

The goal of this study is to design a plant which can accommodate flexible conversion ratio cores. Moreover, because we have selected very similar core inlet and outlet temperatures for both lead and liquid salt coolants and because material limits for both coolants are similar, both the lead and liquid salt-cooled concepts are designed to have the same reactor vessel, balance of plant as well as decay heat removal approach. This chapter describes the overall reactor and plant design approach, which is common to both reactor coolants and independent of conversion ratio. Design choices made are discussed in Section 2.1, followed by the description of the overall plant design in Section 2.2. Section 2.3 describes the passive decay heat removal system and strategies for accident management.

\subsection{Design Choices and Constraints}

\subsubsection{Choice of Conversion Ratio}

Most of the fast reactor designs to date have been performed for a fixed conversion ratio. In the 60ties and 70ties, a high conversion ratio was pursued to maximize breeding while more recently the focus has shifted to low conversion ratio reactors to burn actinides that are continuously accumulating in the spent LWR fuel. While such designs accomplish the task of breeding or burning, they cannot dynamically respond to changing strategies and demands in the fuel cycle. It is well known that the anticipated need for breeders that were developed in the sixties and seventies did not materialize, since low-cost uranium resources were abundant due to slow nuclear power generation growth, while concerns grew over accumulated long-lived actinides in spent LWR fuel and associated permanent waste repository issues. This stimulated the recent development of transuranic (TRU) burners. However, long-term fuel cycle simulation studies performed at MIT [Aquien et al, 2006a] have shown that fertile-free burners (conversion ratio of zero) impose significant constraints on the fuel cycle since their construction is limited by the availability of TRUs. Therefore, there is a need for a flexible conversion fast reactor that can effectively respond to the dynamically changing needs/priorities of the nuclear industry as well as those of society, by managing TRUs in such a way that resources are used effectively and the waste burden is minimized while maintaining high safety, proliferation resistance, and attractive economics. This project addresses such needs by developing a reactor with a flexible conversion ratio.

Given the project duration and funding constraints, it is not possible to perform detailed designs for the full spectrum of conversion ratios between zero and the largest conversion ratio (CR) for maximized breeding. Therefore, two target reactor designs will be considered: one with $\mathrm{CR}=0$ aiming at the reduction of the existing TRU stockpile (if not possible, the minimum $\mathrm{CR}$ achievable will be identified), the second with $\mathrm{CR} \sim 1.0$ to 
achieve a TRU sustainable fuel cycle. The former CR target is selected to confirm feasibility of the most challenging design in terms of reactivity feedbacks and reactor control. The latter option of $\mathrm{CR}=1.0$ is selected because conversion ratios greater than unity typically require blankets where high grade plutonium can be generated, compromising the proliferation resistance goal. Moreover, MIT fuel cycle simulation studies have shown that fuel cycles with such reactors can easily deplete legacy TRUs [Aquien et al., 2006b]. The $\mathrm{CR}=1.0$ core is loaded with LWR-grade TRU as a fissile component for the first core. Subsequent cores are fueled with recycled TRU with the addition of natural or depleted uranium. Fertile blanket regions are not included, thus increasing proliferation resistance.

In summary, the goal of this project is to confirm the feasibility of these two limiting cases of $\mathrm{CR}=0$ and $\mathrm{CR}=1$ cores for lead and liquid salt-cooled reactors and to compare the results with other coolants.

Each CR design has its own challenges. Both the lead-cooled and liquid salt-cooled versions of these designs have the following key challenges:

1. Large positive coolant void worth. A major contribution to positive coolant void worth comes from the spectral component (the others being leakage and coolant absorption) of reactivity response to coolant density reduction. In Pu-driven fast reactor cores, a harder neutron spectrum from coolant voiding leads to reduced fission and capture rates in major $\mathrm{Pu}$ fissile isotopes with a prevailing decrease of the capture rate, resulting in a net reactivity increase due to the smaller capture-tofission ratio. Two key minor actinides (MAs) such as Np237 and Am241 exhibit an increase of fission rate upon spectrum hardening, as more neutrons appear above their fast fission threshold - similar to the fertile isotope U238. However, because their fast fission cross section is higher than that of U238 and the energy at which the fast fission cross section increases is lower, the effect of fast threshold fissions is more pronounced than for U238. It is also to be noted that, contrary to most odd A nuclides, which exhibit a decreasing trend of fission cross section with increasing energy, the cross sections of both Np237 and Am241 increase for $\mathrm{E}>0.1 \mathrm{MeV}$ by two orders of magnitude.

Since boiling of lead or liquid salt is not realistically possible, reactivity increase from coolant temperature rise is the major coolant reactivity feedback to be managed. The liquid salt coolants are significantly more challenging than lead because of their (1) much higher thermal expansion coefficient (and thus correspondingly large coolant density and neutron spectrum changes) and (2) low mass nuclides which provide more moderation. Various design approaches to minimize the reactivity coolant temperature coefficient, such as a tight lattice to minimize coolant fraction, pancake and parfait cores, and consideration of streaming fuel assemblies will be explored. The goal will be to strive not necessarily for a negative coolant temperature coefficient (since it may not be achievable in large cores without significant economic penalties), but for a combination of all reactivity feedbacks such that one can achieve a passive reactor 
shutdown in unprotected (without scram) accidents - an approach similar to that of the ANL Integral Fast Reactor (IFR).

2. Small effective delayed neutron fraction. This fraction is small since the highmass number isotopes, which fission, have a small delayed neutron yield. Moreover, delayed neutrons are emitted at lower energies than prompt neutrons and are thus more likely to be parasitically absorbed in control rods and structural materials. This reduces the effective delayed neutron fraction and raises concerns regarding the controllability of critical reactors. The $\mathrm{CR}=0$ core is expected to have a lower $\beta_{\text {eff }}$ because the significant degree of $\mathrm{U} 238$ fission in the $\mathrm{CR}=1$ core will increase $\beta_{\text {eff. }}$

3. Small fuel temperature coefficient. The hard spectrum of the lead alloy or liquid salt-cooled cores leads to a decrease of absorption rate in resonances. This results in a significant drop in the Doppler effect. For the $\mathrm{CR}=0$ core, the amount of fertile isotopes is very small, further reducing the fuel temperature coefficient. Hence, other measures to attain a reasonable value of negative fuel temperature feedback may need to be employed. Reactivity changes from thermal expansion of the fuel are also prompt. Hence, if an appreciable negative reactivity insertion from fuel thermal expansion is realized, the required magnitude of the negative Doppler coefficient may be reduced.

In addition, a fertile-free design with $\mathrm{CR}=0.0$ will exhibit a large reactivity swing in the absence of fertile isotopes. This is a significant challenge because there is no efficient burnable poison for fast spectrum reactors except for relatively large loadings of Np237 or Am241, which are transmuted to fissile isotopes. However, this option was rejected because the TRU vector is fixed to that of spent LWR fuel.Also complicating this option were the issues of large positive coolant temperature coefficient for highly Np237 and Am241 loaded cores and fuel cycle implications". One possible approach to reduce reactivity swing is to significantly decrease cycle length. This approach was rejected because it leads to a very short cycle length of less than 6 months, which is economically unattractive for utilities. The effective way to accommodate the significant reactivity swing in a fertile-free burner without large penalty on cycle length is through a large number of double-entry control rods [Hejzlar et al., 2004]. The same approach will be used for all cores in this project.

Finally, flexible conversion ratio implies the need for the exchangeability of fuel assemblies to allow the gradual transition between $\mathrm{CR}=0$ and $\mathrm{CR}=1$ designs. This requirement puts two additional constraints on the core design:

- The major issue is the need for a large number of control rods for the $\mathrm{CR}=0$ core to accommodate the large reactivity swing. Moreover, the CRDs have to be double-entry rods to avoid super-prompt criticality during seismic events. This requires available space for these rods below the core. Hence, the $\mathrm{CR}=1$ core will

\footnotetext{
* Separating of Np237 and Am241 from plutonium is undesirable because the separated plutonium stream is a proliferation concern.
} 
have to use similar rods, even though these would not be necessary for the $\mathrm{CR}=1$ core.

- Control rod penetrations through the vessel head have to be at the same position for both cores. However, it is possible to plug selected positions, if these are no longer needed after transition from the $\mathrm{CR}=0$ to the $\mathrm{CR}=1$ core.

\subsubsection{Choice of Safety Approach}

As discussed above, a positive coolant temperature coefficient is expected for both leadand liquid salt-cooled designs. The self-controllability goal that was set for the reactor safety assessment is based on methodology developed at ANL in the framework of the IFR design [Wade and Hill, 1997].

A self-controllable reactor, such as the IFR, needs (1) to be capable of dissipating decay heat with reliance on natural phenomena and (2) to exhibit a combination of reactivity feedbacks that lead to an inherent reactor shutdown without reliance on reactor scram. The former requirement is satisfied through reliance on the heat storage capacity of a large pool to absorb the initial decay power peak, and design measures to promote natural circulation through the core, thus effectively transporting decay heat to the ultimate heat sink ${ }^{*}$.

Self-controllability requires that, in a quasi-static reactivity balance sense, the reactor is inherently shut down to a safe state under the most restricting anticipated transients without scram. There are three external paths through which the core can be compromised: (1) coolant flow rate, (2) coolant core inlet temperature, and (3) externally induced reactivity changes, either due to control rod motion or seismically-induced core geometry changes. These all-encompassing paths are embodied in three generic anticipated transients without scram [Wade and Fujita, 1989]: Unprotected Loss of Flow (ULOF), Unprotected Loss of Heat Sink (ULOHS) and Unprotected Transient Overpower (UTOP). Wade and Hill, [1997] showed that for sufficiently large margins between the operating point and safety limits, one can design a sodium-cooled core with reactivity feedback ratios that assure passive self-regulation if the following ranges for the reactivity coefficients expressed in terms of measurable integral reactivity parameters are met [Wade and Hill, 1997]:

S1: $\mathrm{A} / \mathrm{B} \leq 1$, where $\mathrm{A}$ is the net power reactivity coefficient in cents and $\mathrm{B}$ represents the power/flow coefficient of reactivity in cents $/ 100 \%$ power/flow, which controls the asymptotic temperature rise in an unprotected loss of flow transient. In the case of natural circulation at full power, this criterion can be relaxed.

\footnotetext{
* Various heat sinks were explored. Passive decay heat removal from the 2400MWt core is especially challenging because of the large decay power that needs to be removed. The approach selected uses an enhanced Reactor Vessel Auxiliary Cooling System (RVACS) supplemented by a Passive Secondary Auxiliary Cooling System. The details of decay heat removal strategy will be discussed in Section 2.2.
} 
S2: $1 \leq \frac{C \Delta T_{c}}{B} \leq 2$, where $\mathrm{C}$ characterizes the inlet temperature coefficient of reactivity in cents $/{ }^{\circ} \mathrm{C}$ and $\Delta T_{c}$ is full-power, steady-state coolant temperature rise. This term ensures inherent balanced response to an unprotected loss of heat sink transient and coolant inlet freezing.

S3: $\frac{\Delta \rho_{T O P}}{|B|} \leq 1$, where $\Delta \rho_{T O P}$ is the reactivity vested in a single control rod. This term controls the asymptotic temperature rise in unprotected overpower transients.

Hejzlar [MacDonald and Buongiorno, 2002] derived similar criteria for the lead-cooled reactor coupled to the $\mathrm{S}-\mathrm{CO}_{2}$ power cycle. These are summarized in Table 2.1-1. The last column of Table 2.1-1 was derived in this project for the liquid salt of choice, NaCl-KCl$\mathrm{MgCl}_{2}$. The S-criteria in the last three rows of Table 2.1-1 will be used in this project for the design of self-controllable lead and liquid salt-cooled reactor cores, respectively.

The first guidance for acceptable coolant temperature coefficient will be taken to be the value for the sodium-cooled IFR coefficient, albeit a full self-controllability analysis will determine the final value. A more detailed description of the quasi-static approach to reactor safety used in this study is presented in Section 4 of Appendix 3A

Table 2.1-1 Comparison of S-criteria for various coolants (from MacDonald and Buongiorno, 2002)

\begin{tabular}{|l|l|l|l|}
\hline & $\begin{array}{l}\text { IFR } \\
\text { Na-cooled }\end{array}$ & $\begin{array}{l}\text { ABR } \\
\text { Lead-cooled }\end{array}$ & $\begin{array}{l}\text { ABR } \\
\text { NaCl-KCl-MgCl } \text {-cooled }^{-}\end{array}$ \\
\hline Coolant inlet temperature $\left({ }^{\circ} \mathrm{C}\right)$ & 350 & 461 & 496 \\
\hline $\begin{array}{l}\text { Core coolant temperature rise, } \\
\Delta \mathrm{T}_{\mathrm{c}}\left({ }^{\circ} \mathrm{C}\right)\end{array}$ & 150 & 92 & 84 \\
\hline Coolant freezing point $\left({ }^{\circ} \mathrm{C}\right)$ & 97.8 & 327 & 396 \\
\hline $\begin{array}{l}\text { Temperature limit to cladding } \\
\text { structural damage }\end{array}$ & $725^{\circ} \mathrm{C}$ & $725^{\circ} \mathrm{C}$ & $725^{\circ} \mathrm{C}$ \\
\hline $\begin{array}{l}\text { Conservative margin to } \\
\text { freezing }\end{array}$ & $\Delta \mathrm{T}_{\mathrm{c}}$ & $\Delta \mathrm{T}_{\mathrm{c}}$ & $\sim 1.2 \Delta \mathrm{T}_{\mathrm{c}}$ \\
\hline $\begin{array}{l}\text { Conservative margin to } \\
\text { cladding damage }\end{array}$ & $\Delta \mathrm{T}_{\mathrm{c}}$ & $1.25 \Delta \mathrm{T}_{\mathrm{c}}$ & $1.7 \Delta \mathrm{T}_{\mathrm{c}}$ \\
\hline S1 criterion criterion & $\frac{A}{B} \leq 1$ & $\frac{A}{B} \leq 1.25$ & $\frac{A}{B} \leq 1.15$ \\
\hline S2 criterion & $1 \leq \frac{C \Delta T_{c}}{B} \leq 2$ & $1 \leq \frac{C \Delta T_{c}}{B} \leq 2.7$ & $1 \leq \frac{C \Delta T_{c}}{B} \leq 2.36$ \\
\hline S3 & $\frac{\Delta \rho_{T O P}}{|B|}$ & $\frac{\Delta \rho_{T O P}}{B} \leq 1.25$ & $\frac{\Delta \rho_{T O P}}{B} \leq 1.15$ \\
\hline
\end{tabular}




\subsubsection{Choice of Fuel}

The primary choice for the fuel is metallic U-TRU-Zr $(10 \% \mathrm{Zr})$ alloy for the $\mathrm{CR}=1$ core and metallic TRU-Zr alloy for the low CR core. The metallic fuel form has a number of advantages. Metallic fuel has a high thermal conductivity and thus low fuel temperatures - key features making possible the achievement of the self-controllability goals discussed above. This is because fuel temperature changes between normal operation and shutdown conditions are small, and hence the positive fuel temperature feedback in unprotected loss of flow or loss of heat sink accidents is favorably small and can be compensated by negative reactivity feedback from coolant temperature rise. In addition, a high heavy metal density provides favorable neutronic performance, especially in case of the $\mathrm{CR}=1$ core without blankets.

The burnup limit is set at $150 \mathrm{MWd} / \mathrm{kgHM}$ (average) and $200 \mathrm{MWd} / \mathrm{kgHM}$ (peak) for UTRU-Zr $(10 \% \mathrm{Zr})$ fuel. This is based on irradiation experience with ternary (U-Pu-Zr) metal alloy pins in HT-9 ferritic cladding, which have achieved a $200 \mathrm{MWd} / \mathrm{kg}$ peak discharge burnup and were qualified and demonstrated for a $150 \mathrm{MWd} / \mathrm{kg}$ peak discharge burnup and a $100 \mathrm{MWd} / \mathrm{kg}$ average burnup [Hill et al., 1999]. These numerical constraints on the burnup can be relaxed for the actinide-burner design, where fertile material is absent and the major fraction of the fuel is the zirconium matrix $(\sim 75 \% \mathrm{Zr}$ in comparison to $10 \% \mathrm{Zr}$ for the ternary metallic fuel). Therefore, for given energy produced in the fuel (and thus for a given amount of fission gases released to the fission plenum) the attainable burnup is much higher. Also, with such a large fraction of zirconium, these fuels might be able to withstand even higher burnups. However, research and experimental demonstration of fuel that can withstand these burnups will be required. Therefore, for TRU-Zr fuels of $\mathrm{CR}=0$ cores, burnup values to give the same burnup per fuel volume as the above values will be adopted as limits. A smear density of $75 \%$ will be taken as the target, since it was proven to achieve high burnups without pellet-cladding interactions [Pahl et al., 1990].

The limiting fuel temperature for U-Pu-Zr alloy with $10 \mathrm{wt} \% \mathrm{Zr}$ is $1000^{\circ} \mathrm{C}$. The same temperature limit will be adopted for U-TRU-Zr fuel for the $\mathrm{CR}=1.0$ core, albeit more research is needed to confirm the effect of small amounts of minor actinides on the fuel alloy melting point. This assumption should be reasonably accurate because the minor actinides constitute only a small fraction of the fuel and have chemical properties that are similar to plutonium. The fuel for the $\mathrm{CR}=0$ core contains significantly larger zirconium content, which will result in a higher melting point. Hejzlar et al. [2004] suggest that a limit of $1200^{\circ} \mathrm{C}$ should be a conservative limit for fertile-free zirconium-based fuel. The same limit will be used for fertile-free fuel in this project.

\subsubsection{Service Limits and Choice of Vessel and In-Core Materials}

Temperature limits adopted for the cladding and vessel of the lead and liquid salt-cooled reactors are summarized in Table 2.1-2. The selection of cladding material poses a challenge since the cladding is exposed to corrosive coolants, high temperatures, stresses from fission gas build-up, and high fast fluence. High fast neutron flux excludes 
austenitic steels because of their high nickel content, which promotes extensive swelling due to helium generation from the $(\mathrm{n}, \alpha)$ reaction of nickel isotopes $\mathrm{Ni}^{58}$ and $\mathrm{Ni}^{60}$ Therefore, ferritic-martensitic stainless steels were chosen as the candidate materials. Three material categories are considered according to their time availability:

1. Currently available materials that do not require development (designated "Now")

2. Materials achievable on a relatively short time scale (designated "Achievable"), and

3. Materials that require significant $R \& D$ and will require a significant development time before they could be adopted (designated "Stretch")

Each of these categories is listed in a separate column in Table 2.1-2. Table 2.1-2 gives two limits for each material. The first limit is for long term steady state operation and is determined by two factors: (1) chemical compatibility with coolant, e.g. corrosion limits and (2) mechanical performance, which is characterized by material strength and resistance to creep under stress. The second limit is for transients that significantly challenge the material and that are very rare or may not even occur during the reactor lifetime (for example unprotected, i.e. without scram, accidents) when the material can be exposed to high temperatures for shorter time periods. In these cases, the material must maintain its integrity, but would not be reusable after such an occurrence. This limit is determined either by the transformation temperature from ferrite to austenite or by the incipience of fuel to cladding interaction, which can occur in metallic fuels. For cladding materials a non-reusable limit is given since cladding can be replaced. For the vessel, lower limits that allow reuse are specified since the vessel cannot be replaced during the plant lifetime.

\section{Cladding}

The reference cladding material for the "Now" category is ferritic-martensitic stainless steel HT-9 (Fe-12Cr-1Mo) Pb-Bi-Sn eutectic-bonded with the fuel. This steel exhibits very good resistance to irradiation-induced swelling with no swelling up to 3.3$4.0 \times 10^{23} \mathrm{n} / \mathrm{cm}^{2} \quad(\mathrm{E}>0.1 \mathrm{MeV})$ or $150-200 \mathrm{dpa}$ [Dubberley, 2000]. The drawback for operation in lead alloy-cooled reactors is its high corrosion rate for temperatures above $550^{\circ} \mathrm{C}$, which is well below the temperatures allowable by mechanical performance. Therefore, the limit of $550^{\circ} \mathrm{C}$ is used as the maximum temperature for long term operation. The key question is what cladding temperature limit to adopt for the liquid salt of choice, $\mathrm{NaCl}-\mathrm{KCl}-\mathrm{MgCl}_{2}$. Data for corrosion rates for this salt are not available, but it is expected that the corrosion rate will be smaller than that of lead coolant. Thus, the same temperature as for lead $-550^{\circ} \mathrm{C}$ - was selected as the maximum temperature limit for the liquid salt-cooled concept. This choice of maximum temperature will have to be confirmed with corrosion tests.

The transient temperature limit for cladding of both the lead and salt-cooled cores was selected to be $725^{\circ} \mathrm{C}$ because this is the temperature below which no fuel/cladding chemical interaction has been observed. Beyond this temperature, significant diffusion of actinides into the cladding from the fuel can create low-melting-point regions, resulting in thinning and subsequent failure of the cladding [Pahl et al., 1990]. Furthermore, it is 
important to keep the cladding material temperature below the transformation from ferrite to austenite because this transition results in significant property as well as volume changes. This transformation depends on material composition and for $12 \mathrm{Cr}-\mathrm{MoVNb}$ steels ranges between $760^{\circ} \mathrm{C}$ to $850^{\circ} \mathrm{C}$ [Klueh and Harris, 2001]. This is slightly higher than the limit from fuel/cladding chemical interaction, hence the former limit is applied.

The drawback of the HT-9 steel for lead-cooled reactor application is its chemical compatibility temperature limit, which is lower than the mechanical performance limit. This significantly reduces the design space available to maximize plant efficiency and thus improve economy. Therefore, under development at MIT are advanced ferriticmartensitic steels with a new alloy cladding surface that will raise the corrosion-limited temperature to the mechanical performance limit. The new material will use a high chrome boiler tube material T-91 similar in composition to that of HT-9 as a base, with a corrosion resistant alloy cladding surface. The T-91 (9Cr-1MoVNb) steel is ASME code approved to $649^{\circ} \mathrm{C}$ for Section III, Class 2 and 3 components and was also very recently approved for Subsection NH for Class 1 applications. There are limits to code applicability involving time and temperature plus other limits, such as $1 \%$ strain on cladding. Since the fuel of the $\mathrm{CR}=1$ core has a longer residence time than the $\mathrm{CR}=0$ core (6.5 years versus 5 years) and because creep limited lifetime affects temperature limits, the range between $625^{\circ} \mathrm{C}$ and $650^{\circ} \mathrm{C}$ was adopted for the Achievable case. This provides more margin to work with for the $\mathrm{CR}=0$ core, which has higher radial power peaking. Of course, the pins and cladding have to be designed to satisfy the $1 \%$ strain limit and creep limited lifetime at these temperatures. The transient temperature limit is the same $\left(725^{\circ} \mathrm{C}\right)$ as for HT-9 for the same reasons as discussed above. Also, it is important to note that these materials are quenched and tempered and $725^{\circ} \mathrm{C}$ is above the tempering temperature (typically in the $550-600^{\circ} \mathrm{C}$ range). Hence, neither HT-9 nor T-91 can be reused if this temperature is achieved. The same limits were adopted for liquid saltcooled cores.

Finally, ODS steel is considered as the candidate for the Stretch case category for both the lead and liquid salt-cooled concepts. Oxide dispersion strengthened (ODS) ferritic/martensitic steels have been developed for application as fuel cladding material for fast breeder reactors. The major advantages of these alloys are (1) their strength and creep resistance at high temperatures $\left(\sim 700^{\circ} \mathrm{C}\right.$ for steady state, $725^{\circ} \mathrm{C}$ for transient $)$ which are typically better and degrade more slowly with temperature than niobium $(\mathrm{Nb})$ and molybdenum (Mo) refractory alloys; (2) they are relatively lightweight and less expensive than refractory alloys; (3) their low swelling and embrittlement with exposure to high-energy neutrons $(>0.1 \mathrm{MeV})$ up to high fluences; and (4) their high resistance to oxidation and nitration at high temperatures which simplifies handling and assembly. However, the manufacturing of long pins, whole assemblies and welding of ODS steel is not an easy task and will require development. Moreover, while extensive R\&D effort has been spent on developing these materials, actual manufacturing experience has been insignificant. In fact, the major suppliers of these materials, Special Metals (Huntington, West Virginia) and one or two European/Asian sources, have essentially ceased production of these materials as a commercial product. Therefore, these steels were put into the Stretch category. The temperature limit adopted for long term steady state 
operation is $700^{\circ} \mathrm{C}$. The transient limit selected is $725^{\circ} \mathrm{C}$ as for HT-9 because the composition is similar and the issue of significant diffusion of actinides into the cladding applies as well.

Finally, it needs to be noted that there are two issues that will require more R\&D to be able to confirm these limits:

1. For $\mathrm{CR}=0$ designs, the content of plutonium is relatively high; because plutonium migrates to the fuel periphery, it may form a eutectic at temperatures lower than the adopted limit of $650^{\circ} \mathrm{C}$ for the achievable case. Currently there are no data available for fertile-free fuels. Hence, experiments will be needed to confirm the adopted temperature limit on cladding. If eutectic formation begins to occur at lower temperatures, addition of a barrier, such as zirconium liner or multilayer metal foil [Taylor, 1994], should be used to keep the limit at $650^{\circ} \mathrm{C}$. Otherwise, the core outlet temperature would have to be lowered, resulting in reduced plant efficiency negatively impacting economics.

2. The bond material $\mathrm{Pb}-\mathrm{Bi}-\mathrm{Sn}$ has been proposed as a bond for $\mathrm{UO}_{2}$ fuel and Zircaloy-4 cladding for LWRs, but there is no experience with this bond for metallic fuel and steel cladding. Therefore, an R\&D program would be required to confirm compatibility of this bond with metallic fuel and T-91 steel under irradiation.

In addition to the temperature limits, surfaces exposed to flowing lead alloys have to satisfy velocity limits. The cladding materials of lead-bismuth cooled reactors used in Russian submarines required that the velocity not exceed a $2 \mathrm{~m} / \mathrm{s}$ limit. This is because these steels rely on Fe-oxide protection, and oxide can become unstable at higher velocities. The newer materials with $\mathrm{Si}$ or $\mathrm{Al}$ oxide based films for protection under development at MIT should allow higher velocity limits. Thus, the limit of $3 \mathrm{~m} / \mathrm{s}$ was adopted for ferritic-martensitic steels with the new alloy cladding surface, with the expectation that further development can raise this limit to $4 \mathrm{~m} / \mathrm{s}$ or higher. No such limit is needed for the salt-cooled design. However, because liquid salts have high viscosities and tend to have high pressure drop, we adopted the core pressure drop limit of $1 \mathrm{MPa}$ for the liquid salt-cooled concept. These limits are also included in Table 2.1-3.

\section{Vessel}

For the vessel, two materials are considered. The currently available A533 or A508 plate and forging steels are listed in Section II for Class I service with an upper continuous operating temperature limit of $347^{\circ} \mathrm{C}$. For transients, the physical upper temperature limit is determined by the tempering temperature of the material during fabrication. To remain below the tempering temperature these steels should not be heated above $550^{\circ} \mathrm{C}$, which was taken as the transient limit. However, it needs to be noted that although the long term operation temperature limit is relatively low, A533 or A508 compatibility with lead coolant may be an issue because of the relatively high nickel content in these steels. The solubility of nickel in liquid lead can be as high as $20 \mathrm{wt} \%$. Thus, a liner resistant to corrosion in lead alloys would be needed. Moreover, the upper temperature limit of $347^{\circ} \mathrm{C}$ is too close to the melting point of lead of $327^{\circ} \mathrm{C}$, making it difficult to design a reactor where the desirable core inlet temperature is above $400^{\circ} \mathrm{C}$ and where passive 
decay heat removal is through the vessel. This is even more challenging for our preferred salt coolant, which has a melting point of $396^{\circ} \mathrm{C}$, well above the material limit of $347^{\circ} \mathrm{C}$.

The high-chromium ferritic/martensitic steel $9 \mathrm{Cr}-1 \mathrm{Mo}$ steel is a candidate in the achievable category. For this steel there are data from the U.S. and Japanese fast reactor development programs for temperatures up to $500^{\circ} \mathrm{C}$. Therefore, this temperature limit was adopted for steady state operation. The transient limit for the $9 \mathrm{Cr}-1 \mathrm{Mo}$ steel is the same as for the A533 class steel $\left(550^{\circ} \mathrm{C}\right)$ since it is determined by the tempering temperature. Note that there is a difference in transient limits between the cladding and the vessel, since the cladding limit is a non-reusable limit, i.e., cladding cannot be re-used after exposure to these temperatures, while the vessel can be reused after reaching the $550^{\circ} \mathrm{C}$ limit. Several notes on $9 \mathrm{Cr}-1 \mathrm{Mo}$ steel are in order:

1. In the Japanese designs, the life of components was limited to 10 years.

2. Fabrication is an order of magnitude harder than for A533/A508 steels.

3. Welding is difficult, requiring careful post-weld heat treatment.

4. This steel is susceptible to thermal aging, which causes a decrease in strength.

5. The code case needs to be developed. The current ASME Code, Subsection NH limits time dependent deformation (creep) to "insignificant" amounts. For high temperature operation a considerable effort must be spent (and some work is in progress related to NGNP/GNEP) to rationalize/modify the ASME code to allow "significant" time dependent deformation. The ramifications for NDE and inspections and monitoring of the vessel during life will also be very significant.

Therefore, more R\&D and testing to overcome the above issues plus ASME code development will be needed before $9 \mathrm{Cr}-1 \mathrm{Mo}$ steel can be used.

However, the $550^{\circ} \mathrm{C}$ transient temperature limit of the $9 \mathrm{Cr}-1 \mathrm{Mo}$ vessel wall steel may still be too low to dissipate decay heat from the vessel. Therefore, stainless steel 316 (SS316) was also included in the table as a potential candidate, even though it is significantly more expensive than other candidates. The advantage is that the code for this steel exists, hence the steel is in the Available Now category. The ASME Code, Subsection $\mathrm{NH}$, which regulates the design of pressure retaining components, shows that it has higher allowable stress than other materials for the design of Class 1 components for elevated temperature service (SS304, Alloy $800 \mathrm{H}$ and $2.5 \mathrm{Cr}-1 \mathrm{Mo}$ ). This steel was also used for the S-PRISM design. Buongiorno has shown that for a guard vessel of thickness greater than $15 \mathrm{~cm}$ and diameter of $6 \mathrm{~m}$, the temperature limit for transients of lower frequency (Level C Service Loadings), is about $750^{\circ} \mathrm{C}$ [Buongiorno, 2001]. Because of the larger vessel in our design, we adopted the limit of $700^{\circ} \mathrm{C}$, which will have to be confirmed by analysis. The steady state operation limit is $430^{\circ} \mathrm{C}$ if the lifetime of the vessel is to be more than 34 years. 
Project No 06-040: Flexible Conversion Ratio Fast Reactor Systems Evaluation

Table 2.1-2 Service Limits for Lead- and Salt-cooled Reactors

\begin{tabular}{|c|c|c|c|c|}
\hline \multirow{2}{*}{ Cladding } & & Now & Achievable & \begin{tabular}{|l|} 
Stretch \\
\end{tabular} \\
\hline & Material & \begin{tabular}{|l|}
$\mathrm{HT}-9$ \\
$12 \mathrm{Cr}-1 \mathrm{Mo}^{1}$
\end{tabular} & $\begin{array}{l}\mathrm{T}-91 \\
9 \mathrm{Cr}-1 \mathrm{MoVNb}^{2}\end{array}$ & $\mathrm{ODS}^{3}$ \\
\hline & $\begin{array}{l}\text { Date of material } \\
\text { availability }\end{array}$ & Now & $2010^{4}$ & $2015^{5}$ \\
\hline & $\begin{array}{l}\text { MAX Temperature } \\
\text { Steady State }\end{array}$ & $550^{\circ} \mathrm{C}$ & $625-650^{\circ} \mathrm{C}$ & $700^{\circ} \mathrm{C}$ \\
\hline & $\begin{array}{l}\text { Transients } \\
\text { (not reusable) }\end{array}$ & $725^{\circ} \mathrm{C}$ & $725^{\circ} \mathrm{C}$ & $725^{\circ} \mathrm{C}$ \\
\hline & Velocity (SS) ${ }^{8}$ & $2 \mathrm{~m} / \mathrm{s}$ & $3 \mathrm{~m} / \mathrm{s}$ & $3 \mathrm{~m} / \mathrm{s}$ \\
\hline Vessel & Material & $\begin{array}{l}\text { A533 or A508 } \\
(\text { SS 316) }\end{array}$ & $9 \mathrm{Cr}-1 \mathrm{Mo}$ Steel $^{6}$ & \\
\hline & Date in hand & $\begin{array}{l}\text { Now } \\
\text { (Now) }\end{array}$ & $2012^{4}$ & \\
\hline & $\begin{array}{l}\text { Max Temp } \\
\text { Steady State }\end{array}$ & $\begin{array}{l}347^{\circ} \mathrm{C} \\
\left(430^{\circ} \mathrm{C}\right)\end{array}$ & $500^{\circ} \mathrm{C}$ & \\
\hline & $\begin{array}{l}\text { Transient } \\
\text { (reusable) }\end{array}$ & $\begin{array}{l}550^{\circ} \mathrm{C} \\
\left(700^{\circ} \mathrm{C}\right)\end{array}$ & $550^{\circ} \mathrm{C}$ & \\
\hline
\end{tabular}

${ }^{1}$ Typical composition $\mathrm{Cr}(11.95 \%)-\mathrm{Mo}(1 \%)-\mathrm{Ni}(0.6 \%)-\mathrm{Mn}(0.6 \%)-\mathrm{W}(0.52 \%)-\mathrm{Si}(0.38 \%)-$ $\mathrm{V}(0.3 \%)-\mathrm{C}(0.2 \%)$

$29 \mathrm{Cr}-1 \mathrm{MoVNb}$ class used extensively for boiler applications and similar in composition to HT9

${ }^{3}$ Oxide dispersion strengthened ferritic steel, similar composition as HT-9 plus yttria dispersion

${ }^{4}$ Long term testing and qualification still needed

${ }^{5}$ Can be made reliably for clad service at an earlier date but fabrication and welding is difficult and requires development. Long term testing and qualification still needed.

${ }^{6}$ Fabrication is an order of magnitude harder than A533/A508

${ }^{7}$ For lead-cooled reactor, thin liner material that is corrosion resistant and prevents liquidmetal embrittlement of the vessel is needed

${ }^{8}$ Only for lead-cooled reactor 
Table 2.1-3 Summary of design constraints for lead- and salt-cooled reactors (Achievable case)

\begin{tabular}{|c|c|c|}
\hline \multirow{4}{*}{ Cladding limits } & Steady state membrane temperature: & $650^{\circ} \mathrm{C}^{1}$ \\
\hline & Transient inner temperature: & $725^{\circ} \mathrm{C}$ \\
\hline & Fluence $(\mathrm{E}>0.1 \mathrm{MeV})$ : & $3.3-4.0 \times 10^{23} \mathrm{n} / \mathrm{cm}^{2}$ \\
\hline & Irradiation damage: & $150-200 \mathrm{dpa}$ \\
\hline \multirow[t]{2}{*}{ Fuel limits } & Maximum temperature $(\mathrm{CR}=0 / \mathrm{CR}=1)$ & $1200 / 1000^{\circ} \mathrm{C}$ \\
\hline & Peak burnup ${ }^{2}(\mathrm{CR}=0 / \mathrm{CR}=1)$ & $\begin{array}{l}\text { Heavy metal loading } \\
\text { dependent } / 150 \mathrm{MWd} / \mathrm{kg}\end{array}$ \\
\hline \multirow[t]{3}{*}{ Vessel limits } & Steady state maximum membrane temperature: & $430^{\circ} \mathrm{C}$ \\
\hline & Transient maximum membrane temperature: & $750^{\circ} \mathrm{C}$ \\
\hline & Fluence (above $1 \mathrm{MeV}$ ) & $5 \mathrm{E}+19 \mathrm{n} / \mathrm{cm}^{2}$ \\
\hline \multicolumn{2}{|c|}{ Maximum coolant velocity } & $3 \mathrm{~m} / \mathrm{s}$ \\
\hline \multirow{5}{*}{ Neutronic constraints } & $\mathrm{Pu}$ isotopic composition & $\begin{array}{l}\text { Same or dirtier than } \\
\text { LWR spent fuel }\end{array}$ \\
\hline & & \\
\hline & Reactivity & $\mathrm{L}^{4}: \leq 1.25 \quad \mathrm{~S}^{4}: \leq 1.62$ \\
\hline & coefficients & $\mathrm{L}: \geq 1 ; \leq 2.2 \mathrm{~S}: \geq 1 ; \leq 2.7$ \\
\hline & $\Delta \rho_{T O P} / \mathrm{B}^{3}$ & $\mathrm{~L}: \leq 1.25 \quad \mathrm{~S}: \leq 1.62$ \\
\hline \multirow[t]{2}{*}{ Vessel size $^{5}$} & Outer vessel diameter: & $9.2 \mathrm{~m}-10 \mathrm{~m}$ \\
\hline & $\begin{array}{l}\text { Vessel height: } \\
\text { : }\end{array}$ & $19.5 \mathrm{~m}$ \\
\hline \multicolumn{3}{|c|}{$\begin{array}{l}{ }^{1} \text { For the } \mathrm{CR}=0 \text { core, which has a content of Pu larger than } 20 \mathrm{wt} \% \text {, a smaller limit than } 650^{\circ} \mathrm{C} \\
\text { may be required, driven by fuel/cladding chemical interaction (FCCI) issues since Pu may form } \\
\text { a eutectic with iron resulting in cladding thinning. A large amount of } \mathrm{Zr} \text { in the fertile-free fuel } \\
\text { will mitigate FCCI and the exact limit is currently uncertain. Also, a zirconium liner can be } \\
\text { developed to prevent this eutectic formation. The } 650^{\circ} \mathrm{C} \text { limit is consistent with the achievable } \\
\text { category of materials, which were selected for the analyses in the project and assume successful } \\
\text { completion of ongoing R\&D on materials development. }\end{array}$} \\
\hline \multicolumn{3}{|c|}{$\begin{array}{l}\text { Alloy-type fuel, taking into account cladding stress for given cladding dimensions and } \\
\text { temperature limits, based on earlier analyses }\end{array}$} \\
\hline \multicolumn{3}{|c|}{$\begin{array}{l}\text { Reactivity coefficient ratios. These limits are preliminary and will have to be revisited } \\
\text { depending on core temperatures }\end{array}$} \\
\hline \multicolumn{3}{|c|}{${ }^{4} \mathrm{~L}$ stands for lead-cooled core, $\mathrm{S}$ for salt-cooled core } \\
\hline \multicolumn{3}{|c|}{5 S-PRISM (a non-pressurized vessel) dimensions take } \\
\hline
\end{tabular}

\subsubsection{Operating Temperature and Power Cycle Selection}

The reactor is intended to be coupled with the supercritical $\mathrm{CO}_{2}\left(\mathrm{~S}-\mathrm{CO}_{2}\right)$ power conversion cycle [Dostal et al, 2006] due to the high efficiency and simplicity of this power cycle. Temperature selection is derived from the cladding limit, achievable power peaking, and reactor vessel wall limit. Given the $650^{\circ} \mathrm{C}$ cladding temperature limit, the advanced $\mathrm{S}-\mathrm{CO}_{2}$ design at turbine inlet temperature of $650^{\circ} \mathrm{C}$, can be excluded a priori. Rather, the basic $\mathrm{S}-\mathrm{CO}_{2}$ design at $550^{\circ} \mathrm{C}$ (or $530^{\circ} \mathrm{C}$ ) turbine inlet temperature is the first 
choice, assuming that very small radial core peaking can be achieved and that IHXs are designed with small temperature differences. Another advantage of this cycle is that multiple stress calculations for cladding temperatures compatible with the $\mathrm{S}-\mathrm{CO}_{2}$ cycle at $530^{\circ} \mathrm{C}$ are available from the earlier INL/MIT lead-alloy cooled reactor project [Hejzlar et al., 2004], so it has been established that metallic clad is feasible from the stress point of view. Finally, allowable stresses fall precipitously at $650^{\circ} \mathrm{C}$, and design of an IHX to accommodate a $20 \mathrm{MPa} / 0.1 \mathrm{MPa}$ pressure difference and achieve reasonable creep-limited life is extremely difficult with current materials. Hence, the basic $\mathrm{S}_{-} \mathrm{CO}_{2}$ cycle design with a turbine inlet temperature of $530^{\circ} \mathrm{C}$ was selected. This selection dictates the core outlet coolant temperature to be about $550^{\circ} \mathrm{C}$, i.e., $20^{\circ} \mathrm{C}$ hot-cold temperature difference between lead and $\mathrm{CO}_{2}$ flows.

Core inlet temperature must be well above coolant melting points $\left(327^{\circ} \mathrm{C}\right.$ for lead and $396^{\circ} \mathrm{C}$ for the liquid salt), and compatible with an optimized $\mathrm{S}-\mathrm{CO}_{2}$ cycle. Thus, an inlet temperature $100^{\circ} \mathrm{C}$ above the melting point, i.e., $496^{\circ} \mathrm{C}$ was selected. This temperature also goes well with the temperature rise of the optimized $\mathrm{CO}_{2}$ in the IHX. 
Project No 06-040: Flexible Conversion Ratio Fast Reactor Systems Evaluation

\subsection{Overall Reactor and Plant Design}

Vessel and plant design of both the lead and salt-cooled reactors are such that either $\mathrm{CR}=1$ or $\mathrm{CR}=0$ cores can be accommodated without any changes except for plugging penetrations in the vessel head that are not used after transition from the $\mathrm{CR}=0$ to the $\mathrm{CR}=1$ core. The key features adopted for plant design are as follows:

- Use of forced circulation of coolant for normal operation with centrifugal pumps. The choice of forced circulation over natural circulation was necessitated by the relatively high power density target of $100 \mathrm{~kW} / 1$ adopted for these concepts. Moreover, it allows more compact and thus more economical core design, as well as lower fuel cycle cost due to higher specific power.

- Use of a large reactor vessel and placement of intermediate heat exchangers (IHX) inside the reactor vessel. The pool type concept was selected over the loop type layout because (1) it eliminates the loss of coolant accident and is more compact than the loop type design, (2) it provides large thermal storage of the sodium pool that is beneficial in accident response, and (3) it makes possible the placement of IHXs inside the vessel. Inertness of both lead and liquid salt with respect to the secondary fluid $\left(\mathrm{CO}_{2}\right)$, makes it possible to place IHXs inside the vessel. This arrangement simplifies the primary system layout and reduces the containment volume. Even though it is a challenging task to fit IHXs of a 2400MWt system inside the vessel, the decision was made to explore the feasibility of this potentially economically attractive option.

- Use of the efficient and compact supercritical $\mathrm{CO}_{2}$ power conversion system (PCS) as the balance of the plant. This choice was motivated by the high efficiency and significant compactness of the $\mathrm{S}-\mathrm{CO}_{2} \mathrm{PCS}$, which are expected to reduce capital cost per installed $\mathrm{kWe}$ and electricity generation cost.

- $\quad$ Use of natural circulation for decay heat transfer to the reactor vessel and of an enhanced reactor vessel auxiliary cooling system (RVACS) complemented by a passive secondary auxiliary cooling system (PSACS) for ultimate decay heat removal to air. Achievement of passive decay heat removal from the $2400 \mathrm{MWt}$ reactor was a major challenge in the development of this concept and various options that were explored will be discussed in separate report sections.

This section describes these features which are common to both the $\mathrm{CR}=0$ and $\mathrm{CR}=1$ core designs, as well as to both coolants.

\subsubsection{Reactor Vessel Layout}

Placement of IHXs in the vessel raises the important challenge of preventing ingress of $\mathrm{CO}_{2}$ from the secondary side of the IHX into the core in case of tube rupture. This is because $\mathrm{CO}_{2}$ is at the high pressure of $20 \mathrm{MPa}$, and if the tube rupture occurs near the IHX bottom and if the opening of the break is directed downward, the momentum of the $\mathrm{CO}_{2}$ jet could possibly force some $\mathrm{CO}_{2}$ into the core, leading to undesirable reactivity 
insertion. To eliminate this concern, the dual-free-level vessel design, shown in Figure 2.2.1-1, was adopted. This approach is the same as used in the development of a leadcooled actinide burner of smaller power rating [Hejzlar et al., 2004] and originally proposed for the Russian BREST design [Adamov et al., 2004].

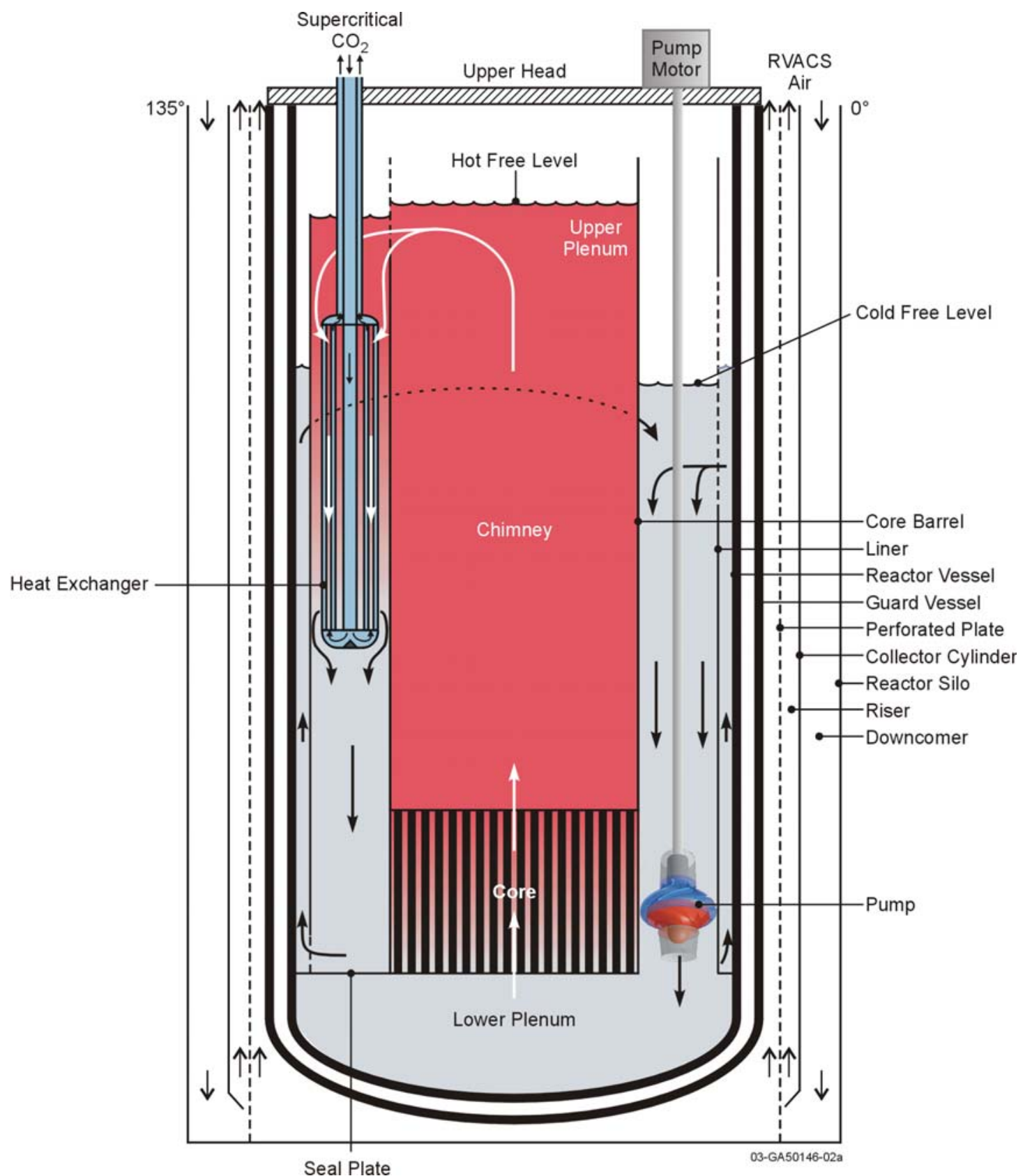

Figure 2.2.1-1 Schematic of reactor vessel with dual-free-level [from Hejzlar et al., 2004]

The upper core barrel contains many large holes that direct the coolant into portions of the annulus between the core barrel and the reactor vessel liner. The upper plenum, defined as the region above the first level of holes in the core barrel, below the upper head, and inside the vessel liner, contains the free level of the hot pool. An inert cover 
gas fills the space between the hot free level and the upper head. The lead alloy coolant flows downward through portions of the annulus between the core barrel and reactor vessel liner where four counter-flow heat exchangers are located. The lead alloy flows down on the shell side of the heat exchangers. After exiting the bottom of the heat exchangers, the coolant flows down through a downcomer region until reaching holes in the reactor vessel liner located near the elevation of the seal plate. These holes direct the coolant into the annular gap between the liner and the reactor vessel, which is called the vessel riser. The coolant flows upward through the riser until reaching holes located in the upper liner, which directs the fluid into annular regions containing four primary coolant pumps. The coolant flows down through these annular regions, which are referred to as the pump downcomer, until flowing through the coolant pumps and seal plate into the lower plenum.

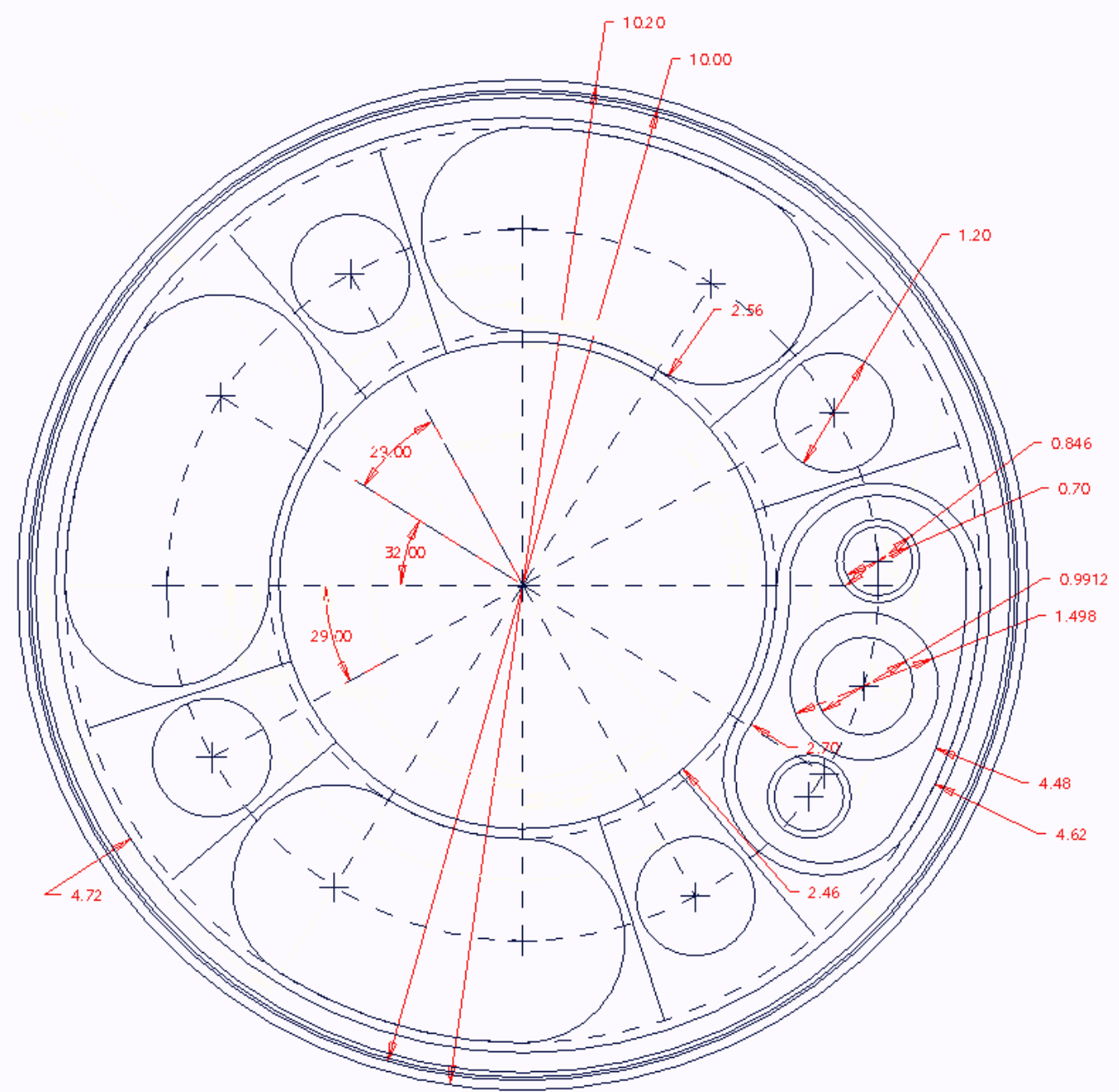

Figure 2.2.1-2 Vessel layout with IHXs and pumps with key dimensions (meters)

Four centrifugal pumps and four kidney-shape shell-and-tube IHXs are placed in the vessel. Four pumps are preferable because they are of smaller size and provide a better match to the $\mathrm{S}-\mathrm{CO}_{2}$ power conversion system (PCS) units, since if one PCS fails, 
operation of three PCSs with 3 pumps is possible. The heat exchangers are placed in the annulus between the chimney and the vessel liner. The lead leaving the chimney enters the heat exchangers through a number of openings in the shell. To avoid flow predisposition towards the inner wall of the shell, baffles, which also support the tubes to prevent flow-induced tube vibration, are employed. The $\mathrm{CO}_{2}$ enters the heat exchanger from the top through the main central tube and flows down to the bottom distribution plenum where it is redistributed into the array of tubes that form the heat transfer surface. To enhance heat transfer on the $\mathrm{CO}_{2}$ side, the tubes employ helical ribs. Heated $\mathrm{CO}_{2}$ then mixes in the upper mixing plenum and leaves the heat exchanger through two outer outlet tubes. Figure 2.2.1-2 depicts the vessel layout with four IHX units and Table 2.2.1-1 gives key dimensions for both the lead and salt-cooled designs.

The thermal hydraulic analyses, discussed in Sections 3.3.2 and 3.4.2 in this report, have shown that it is feasible to place the core and major in-vessel components including four IHXs in the guard vessel diameter of $10.2 \mathrm{~m}$. However, further feasibility studies, such as roof mechanics, in-service inspection, seismic analyses, refueling system design, are necessary to confirm this conclusion.

Table 2.2.1-1 Reactor Vessel and IHX Main Parameters

\begin{tabular}{|c|c|c|c|c|}
\hline \multicolumn{3}{|c|}{ Reactor coolant } & Lead & Liquid Salt \\
\hline \multicolumn{3}{|c|}{ Number of IHXs } & 4 & 4 \\
\hline \multicolumn{3}{|c|}{ Number of centrifugal pumps } & 4 & 4 \\
\hline \multicolumn{3}{|c|}{ Power per IHX (MWt) } & 600 & 600 \\
\hline \multirow{9}{*}{$\begin{array}{l}\text { Reactor } \\
\text { vessel } \\
\text { geometry }\end{array}$} & \multirow[t]{3}{*}{ Guard vessel } & Outer diameter $(\mathrm{m})$ & 10.2 & 10.2 \\
\hline & & Inner diameter $(\mathrm{m})$ & 10.0 & 10.0 \\
\hline & & Wall thickness (m) & 0.10 & 0.10 \\
\hline & \multirow[t]{3}{*}{ Reactor vessel } & Outer diameter $(\mathrm{m})$ & 9.94 & 9.94 \\
\hline & & Inner diameter $(\mathrm{m})$ & 9.84 & 9.84 \\
\hline & & Wall thickness (m) & 0.05 & 0.05 \\
\hline & \multirow[t]{2}{*}{ Liner } & Liner-to-vessel gap (m) & 0.19 & 0.19 \\
\hline & & Wall thickness (m) & 0.01 & 0.01 \\
\hline & \multicolumn{2}{|c|}{ Vessel Height $(\mathrm{m})$} & $\sim 19 \mathrm{~m}$ & $\sim 18.7 \mathrm{~m}$ \\
\hline \multirow{11}{*}{$\begin{array}{l}\text { Intermediate } \\
\text { Heat } \\
\text { exchanger }\end{array}$} & \multicolumn{2}{|l|}{ Type } & Tube-and-shell & Tube-and-shell \\
\hline & \multicolumn{2}{|l|}{ Material } & $\begin{array}{l}\text { T-91 (9Cr- } \\
1 \mathrm{Mo}-\mathrm{V}-\mathrm{Nb})\end{array}$ & $\begin{array}{c}\text { T-91 (9Cr- } \\
1 \mathrm{Mo}-\mathrm{V}-\mathrm{Nb})\end{array}$ \\
\hline & \multirow[t]{6}{*}{ Geometry } & Number of heat exchangers & 4 & 4 \\
\hline & & Number of tubes (per IHX) & 19173 & 21989 \\
\hline & & Outer tube diameter $(\mathrm{m})$ & $14.0 \mathrm{E}-03$ & $13.0 \mathrm{E}-03$ \\
\hline & & Tube wall thickness (m) & $2.22 \mathrm{E}-03$ & $2.02 \mathrm{E}-03$ \\
\hline & & Tube pitch to diameter ratio & 1.23 & 1.23 \\
\hline & & Tube length (m) & 5.70 & 6.90 \\
\hline & \multirow{3}{*}{$\begin{array}{l}\mathrm{CO}_{2} \text { side rib } \\
\text { geometry }\end{array}$} & Rib height (m) & $3.50 \mathrm{E}-04$ & $3.50 \mathrm{E}-04$ \\
\hline & & Number of starters & 5 & 5 \\
\hline & & Helix angle (degrees) & 27 & 27 \\
\hline
\end{tabular}


Project No 06-040: Flexible Conversion Ratio Fast Reactor Systems Evaluation

\subsubsection{Power Conversion System Design}

The Power Conversion System (PCS) selected for both the lead and salt-cooled reactors is a recompression $\mathrm{S}-\mathrm{CO}_{2}$ cycle developed at MIT under other NERI and direct Generation IV funding via Sandia National Laboratory. The benefits of the $\mathrm{S}-\mathrm{CO}_{2}$ cycle versus the classical Rankine cycle are the simplicity and significant compactness of the $\mathrm{S}-\mathrm{CO}_{2}$ cycle and its higher efficiency, which are expected to lead to lower electricity generation cost. Figure 2.2.2-1 shows one $265 \mathrm{MWe}(600 \mathrm{MWt})$ train of the $\mathrm{S}-\mathrm{CO}_{2} \mathrm{PCS}$ to be connected to one IHX and Figure 2.2.2-2 shows the schematic flow path of the recompression $\mathrm{S}-\mathrm{CO}_{2}$ cycle.

In the main compressor (MC) (points $1-2$ in Figure 2.2.2-2), a fraction of the fluid flow is compressed to high pressure. It is preheated in the low temperature recuperator (LTR) (points 2-3) and proceeds to the recompressing compressor (RC) outlet where it is merged with the rest of the fluid flow from the recompressing compressor. The total fluid flow is now preheated in the high temperature recuperator to the IHX inlet temperature (points $4-5$ ). The heat addition into the cycle takes place in the IHX (points 5-6) and enters the turbine at the highest temperature, where it undergoes expansion (points 6-7). After leaving the turbine, the high temperature fluid exchanges heat in the high (points 7 -8 ) and low (points $8-9$ ) temperature recuperators. Before entering the precooler (PRE) the fluid flow is split (streams 10 and 11). One fraction of the fluid is recompressed to high pressure (points $11-12$ ), the other is cooled in the precooler (points $10-1$ ) to the main compressor inlet temperature.

The power conversion system was optimized for the IHX outlet $\mathrm{CO}_{2}$ temperature (turbine inlet) of $546^{\circ} \mathrm{C}$ and the total volume of recuperators and precooler of $120 \mathrm{~m}^{3}$. Figure 2.2.2-3 illustrates the cycle diagram of the optimized PCS with state points and main data of interest related to efficiency. The cycle operates between pressures of 7.7 MPa and $20 \mathrm{MPa}$, and the cycle low temperature is $32^{\circ} \mathrm{C}$, which is just above the critical point of $\mathrm{CO}_{2}$. The cycle achieves an attractive net electrical efficiency of $44 \%$, accounting for all losses including water pumping power and switchyard losses. All cycle heat exchangers (except for the IHX) are HEATRIC ${ }^{\mathrm{TM}}$ printed circuit heat exchangers (PCHEs). All the heat exchangers are assumed to have straight semi-circular channels for the purpose of this study. The actual designs of recuperators will have zig-zag semi-circular channels, which will reduce the total volume of the heat exchangers from $120 \mathrm{~m}^{3}$ to $65 \mathrm{~m}^{3}$. Straight semi-circular channels were used due to lack of knowledge about accurate heat transfer and pressure drop correlations in zig-zag channels.

Detailed information for the optimized $\mathrm{S}-\mathrm{CO}_{2} \mathrm{PCS}$ for the lead-cooled reactor, including the dimensions and heat exchanger designs, is given in Appendix 2A. The IHXs for the salt and lead-cooled reactors were designed such that the interfacing $\mathrm{S}-\mathrm{CO}_{2}$ cycle parameters (turbine inlet temperature, $\mathrm{IHX} \mathrm{CO}$ inlet temperature, $\mathrm{CO}_{2}$-side IHX pressure drop and flow rate) are the same so that identical PCS can be used for both plants. 
Project No 06-040: Flexible Conversion Ratio Fast Reactor Systems Evaluation

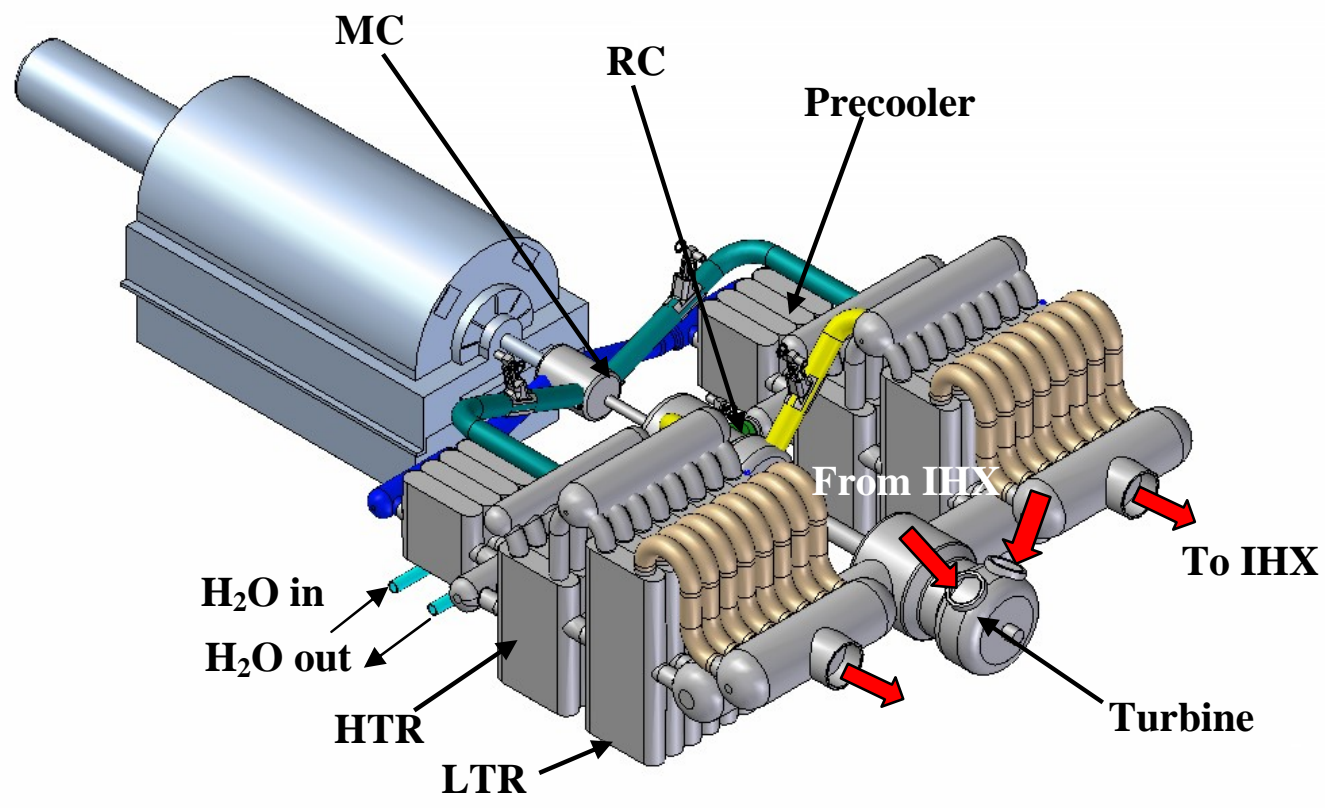

Figure 2.2.2-1 A $265 \mathrm{MWe}$ train of the $\mathrm{S}-\mathrm{CO}_{2}$ power conversion system

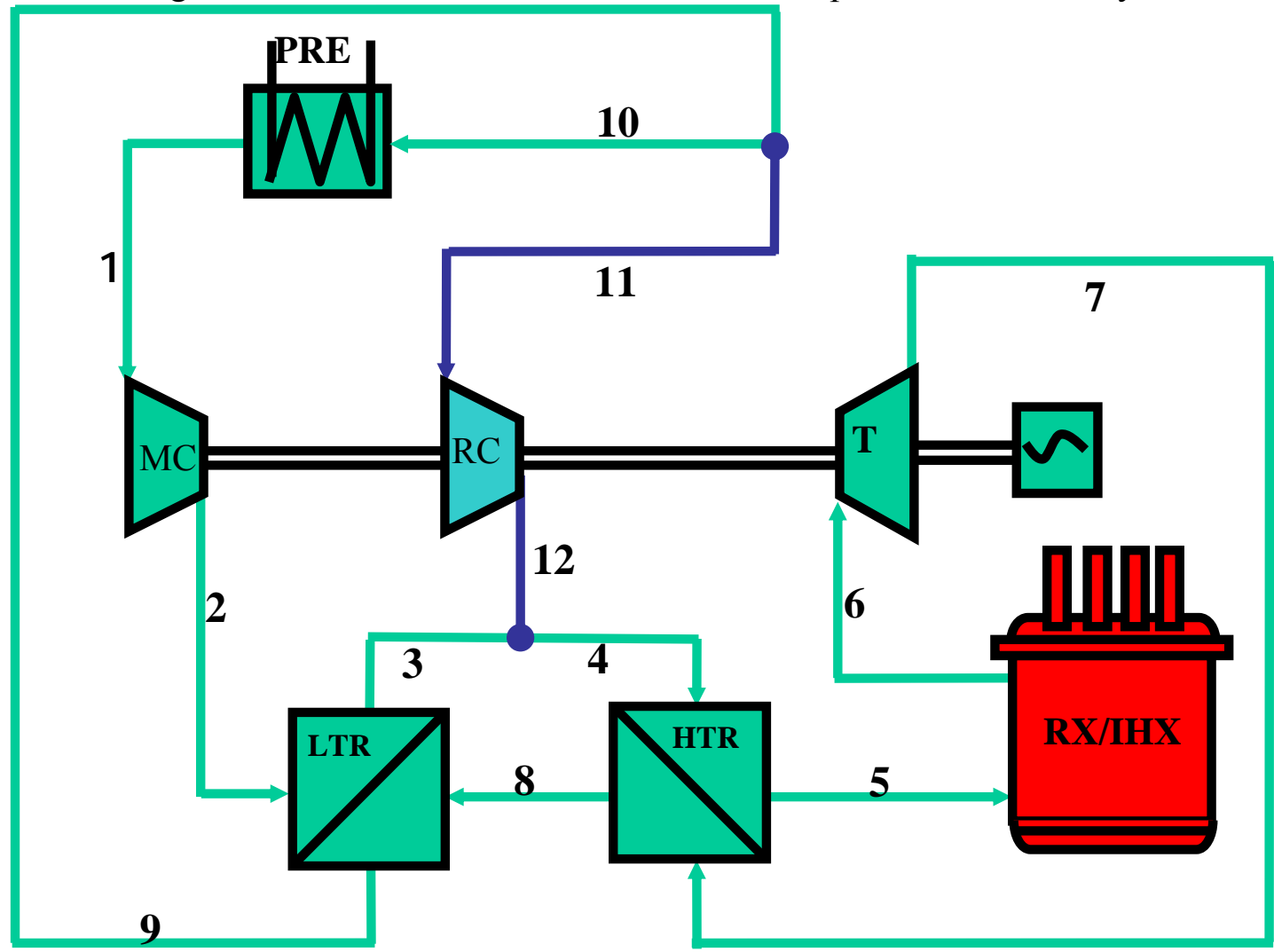

Figure 2.2.2-2 Schematic of recompression $\mathrm{CO}_{2}$ cycle with flow paths 
Project No 06-040: Flexible Conversion Ratio Fast Reactor Systems Evaluation

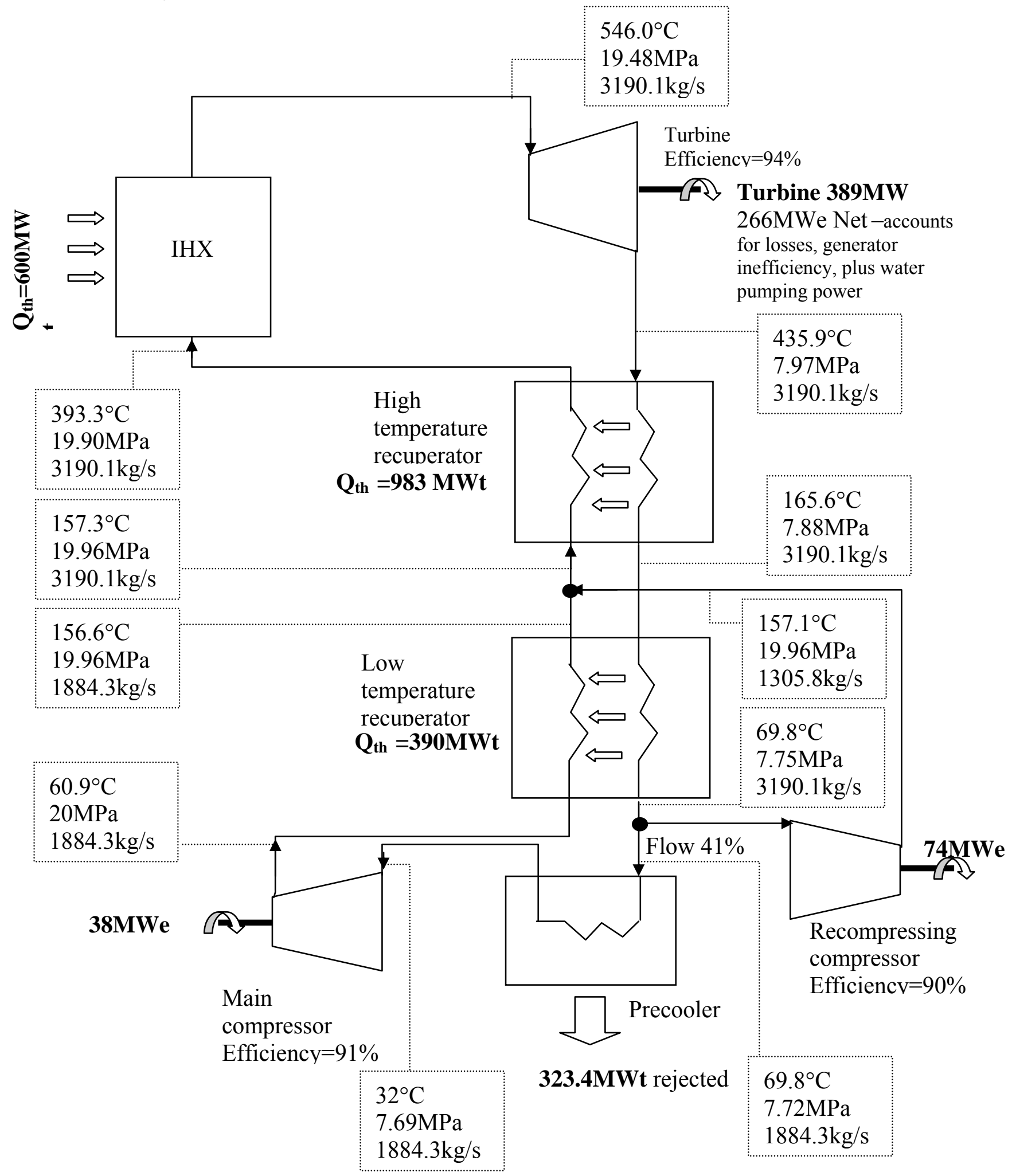

Figure 2.2.2-3 Cycle Diagram for New PCS model 


\subsubsection{Passive Decay Heat Removal Systems and Strategies for Managing Accidents}

One of the objectives for the development of a flexible conversion ratio reactor was the achievement of its inherent shutdown and passive decay heat removal in unprotected accidents. Use of passive means for decay heat removal poses one of the major challenges for the large power rating of 2400MWt, which is 2.4 times higher than that of the GE sodium-cooled reactor S-PRISM. This section describes the decay heat removal (DHR) approaches explored and the selected DHR system that achieves satisfactory performance. In addition, approaches for managing unprotected transients and turbine overspeed are discussed.

\subsubsection{Decay Heat Removal from the Reactor Vessel using RVACS}

The first approach to remove decay heat from the core by passive means was the use of an enhanced Reactor Vessel Auxiliary Cooling System (RVACS) similar to GE's SPRISM design. A number of different enhancements were evaluated using simplified analyses described in Appendix 2B. The peak coolant temperature during the simulated unprotected loss of the heat sink transient was assessed using an approximated transient analysis (see Section 2B.11 in Appendix 2B), with the results shown in Table 2.2.3-1.

These enhancements include:

- the addition of liquid metal into the gap between the reactor and guard vessels,

- the addition of vertical fins welded to the exterior of the guard vessel

- the addition of a perforated plate to the air riser to provide an additional surface for the guard vessel to radiate energy to, and two additional surfaces from which the heat can be convectively removed

- the addition of dimples to the exterior of the guard vessel and/or the separator plate

- $\quad$ use of a multiple-stage RVACS, where air would be introduced at two or three points vertically along the guard vessel

The first major change from the S-PRISM RVACS concept was the addition of liquid metal into the gap between the reactor and guard vessels. In comparison with an argonfilled gap where radiation is the primary mode of heat transfer, a lead-bismuth gap with its high thermal conductivity substantially reduces the temperature drop across the gap, which allows a significant increase of the guard vessel wall temperature and thus of the heat transfer to the air flow. On the other hand, the guard vessel thickness must be increased in order to bear the weight of the lead-bismuth gap material and the reactor vessel, since the reactor vessel is essentially "floated" by the gap fill in the guard vessel. Seismic analyses (see Appendix 2B) have shown that keeping the guard vessel thickness of $22 \mathrm{~cm}$ would be necessary, which would significantly increase wall resistance and heat transfer capability. Therefore, a seismic isolation system, similar to that employed for SPRISM, is used. This system makes it possible to meet allowable stress in a seismic event at a guard vessel thickness of $10 \mathrm{~cm}$ and to achieve a high heat transfer rate though the gap and two vessel walls. 
Table 2.2.3-1Summary of Decay Heat Removal Results

\begin{tabular}{|c|c|c|c|c|c|c|}
\hline $\begin{array}{l}\text { RVACS } \\
\text { Type }\end{array}$ & $\begin{array}{l}\text { Optimal } \\
\text { Riser } \\
\text { Width }\end{array}$ & $\begin{array}{l}\text { Mass } \\
\text { Flow } \\
\text { Rate at } \\
460{ }^{\circ} \mathrm{C}^{1}\end{array}$ & $\begin{array}{l}\text { Heat Removal } \\
\text { Rate at } \\
460^{\circ} \mathrm{C}\end{array}$ & $\begin{array}{l}\text { Mass Flow } \\
\text { Rate at } \\
600^{\circ} \mathrm{C}\end{array}$ & $\begin{array}{l}\text { Heat Removal } \\
\text { Rate at } \\
600^{\circ} \mathrm{C}\end{array}$ & $\begin{array}{l}\text { Maximum Coolant } \\
\text { Temperature } \\
\text { During Passive } \\
\text { Shutdown }\end{array}$ \\
\hline $\begin{array}{l}\text { Bare 1- } \\
\text { stage }^{2,3}\end{array}$ & $0.29 \mathrm{~m}$ & $131 \mathrm{~kg} / \mathrm{s}$ & $7.8 \mathrm{MW}$ & $145 \mathrm{~kg} / \mathrm{s}$ & $11.3 \mathrm{MW}$ & $775^{\circ} \mathrm{C}$ \\
\hline Bare 2-stage ${ }^{4}$ & $0.19 \mathrm{~m}$ & $171 \mathrm{~kg} / \mathrm{s}^{5}$ & $8.5 \mathrm{MW}$ & $190 \mathrm{~kg} / \mathrm{s}$ & $12.0 \mathrm{MW}$ & $761^{\circ} \mathrm{C}$ \\
\hline $\begin{array}{l}200 \text { Fins } \\
\text {-Stage }\end{array}$ & $0.40 \mathrm{~m}$ & $141 \mathrm{~kg} / \mathrm{s}$ & $9.3 \mathrm{MW}$ & $153 \mathrm{~kg} / \mathrm{s}$ & $12.5 \mathrm{MW}$ & $753{ }^{\circ} \mathrm{C}$ \\
\hline $\begin{array}{l}\text { 200 Fins } \\
\text { 2-Stage }\end{array}$ & $0.28 \mathrm{~m}$ & $184 \mathrm{~kg} / \mathrm{s}$ & $9.9 \mathrm{MW}$ & $200 \mathrm{~kg} / \mathrm{s}$ & 13.4 MW & $737^{\circ} \mathrm{C}$ \\
\hline $\begin{array}{l}\text { Conservative } \\
\text { Dimples 1- } \\
\text { Stage }\end{array}$ & $0.41 \mathrm{~m}$ & $140 \mathrm{~kg} / \mathrm{s}$ & 9.7 MW & $153 \mathrm{~kg} / \mathrm{s}$ & $13.8 \mathrm{MW}$ & $730^{\circ} \mathrm{C}$ \\
\hline $\begin{array}{l}\text { Conservative } \\
\text { Dimples 2- } \\
\text { Stage }\end{array}$ & $0.27 \mathrm{~m}$ & $186 \mathrm{~kg} / \mathrm{s}$ & $10.5 \mathrm{MW}$ & $203 \mathrm{~kg} / \mathrm{s}$ & 14.7 MW & $717^{\circ} \mathrm{C}$ \\
\hline $\begin{array}{l}\text { Optimistic } \\
\text { Dimples 1- } \\
\text { Stage }\end{array}$ & $0.35 \mathrm{~m}$ & $158 \mathrm{~kg} / \mathrm{s}$ & $11.5 \mathrm{MW}$ & $172 \mathrm{~kg} / \mathrm{s}$ & 16.0 MW & $700{ }^{\circ} \mathrm{C}$ \\
\hline $\begin{array}{l}\text { Optimistic } \\
\text { Dimples 2- } \\
\text { Stage } \\
\text { Perforated } \\
\text { Plate }^{6} 1- \\
\text { Stage, } \\
\text { extrapolated }\end{array}$ & $0.23 \mathrm{~m}$ & $208 \mathrm{~kg} / \mathrm{s}$ & $\begin{array}{l}12.3 \mathrm{MW} \\
\sim 9 \mathrm{MW}\end{array}$ & $227 \mathrm{~kg} / \mathrm{s}$ & $\begin{array}{l}17.0 \mathrm{MW} \\
\sim 13 \mathrm{MW}\end{array}$ & $\begin{array}{l}688{ }^{\circ} \mathrm{C} \\
\sim 740^{\circ} \mathrm{C}\end{array}$ \\
\hline \multicolumn{7}{|c|}{$\begin{array}{l}1 \text { Temperatures in heading are temperatures of primary lead coolant within reactor vessel } \\
2 \text { Bare refers to no air-side heat transfer enhancements (bare wall) } \\
3 \text { 1-Stage refers to the normal air-side RVACS, as shown in Fig. 2B-15 in Appendix 2B } \\
4 \text { 2-Stage refers to the split level RVACS in Figure 2B-15 in Appendix 2B } \\
5 \text { For 2-Stage designs, mass flow rate refers to the total rate (the sum from the two levels) } \\
6 \text { Perforated plate data extrapolated from S-PRISM and ALMR data }\end{array}$} \\
\hline
\end{tabular}

The finned guard vessel option makes possible an appreciable increase in decay power removal. Fins also add significant heat transfer area to the vessel and could potentially add some stiffness and rigidity to the guard vessel, thus improving performance in a seismic event. However, attaching the fins would be very difficult. Additionally, the stress imparted on the vessel by the welds would need to be considered and could lead to quality assurance problems if conducted in the field rather than assembled in a factory. For these reasons, guard vessel fins were discarded from further consideration.

The dual-level riser option where air is introduced at two levels vertically along the guard vessel (see Appendix 2B.10 for the layout) increases the heat transfer by increasing the temperature difference between the hot guard vessel and the bulk air temperature. However, the gain is relatively modest, because lower air temperature reduces the buoyancy driving force and consequently the air flow rate and heat transfer coefficient. It was determined that such a modest gain in performance is not worthwhile considering the increased complexity and cost. 
The perforated plate introduced by GE for S-PRISM is an appealing enhancement which achieves an appreciable increase of removable heat rate while not contacting the guard vessel, thereby eliminating the possibility of compromising the integrity of the vessel during construction and assembly. Therefore, this option was retained for the current RVACS design.

The best performing enhancement option is the incorporation of dimples on the exterior of the guard vessel. Dimples have been studied in recent years, with very promising results showing large heat transfer enhancement with a relatively small friction factor increase. The heat transfer enhancement is due to a combination of increased surface area and boundary layer separation. Because this option allowed the largest gain in removable power, it was selected in combination with the perforated plate as the primary candidate for enhanced RVACS design. Evaluation of RVACS performance with a dimpled guard vessel wall is based on experimental data by Burgess et al. [2003] - see Appendix 2B. Because experimental data were not available for the same geometry as the RVACS gap, the Computational Fluid Dynamics (CFD) code FLUENT was also used in an effort to reduce the uncertainty of dimple heat transfer enhancement for RVACS. However, the results of benchmark calculations against laboratory experiment data (see Section 2B.9.2 in Appendix 2B) showed that FLUENT had difficulties in accurate prediction of heat transfer coefficients and friction factors along dimpled surfaces. Therefore, the results based on experimental data in smaller geometries, which are used in the analyses of this report, carry uncertainty on the geometry effect that needs to be resolved in the future.

Nevertheless, more accurate system analyses of the unprotected station blackout using a RELAP5 model (see Section 1.1.1.2 of the $5^{\text {th }}$ Quarterly report) showed that an enhanced RVACS with dimples alone would not be sufficient to remove the required decay heat. Moreover, the decay heat rate specific to our FCR core materials was found to be appreciably higher than the decay power curve for $\mathrm{UO}_{2}$ fuel from the latest ANS 2005 Standard which was used for preliminary scoping studies in Appendix 2B.11, making it even more difficult for the RVACS with dimpled surface and perforated plate to assure adequate performance. Therefore, it was decided to no longer pursue a reduction of heat transfer uncertainties from dimpled surfaces, in favor of researching additional DHR options, which would aid RVACS. These options are described in the next section. 
Project No 06-040: Flexible Conversion Ratio Fast Reactor Systems Evaluation

\subsubsection{Passive Secondary Auxiliary Cooling System (PSACS)}

Because enhanced RVACS alone was not sufficient to remove decay power from the 2400MWt core without exceeding the peak cladding temperature limit, it was necessary to provide a supplementary decay heat removal system. Various passive DHR systems were considered and evaluated as described in Appendix 2C. They included:

- $\quad$ A Direct Reactor Auxiliary Cooling System (DRACS) consisting of an In-Vessel Heat Exchanger connected by a lead-bismuth eutectic loop to the air cooled Passive Auxiliary Heat Exchanger (PAHX) located in the chimney of the RVACS riser

- $\quad$ A Passive Secondary Auxiliary Cooling System (PSACS), which removes decay heat via the IHX and standby loop filled with secondary $\mathrm{S}-\mathrm{CO}_{2}$ that transports heat by natural circulation from the IHX to (1) $\mathrm{CO}_{2}$ /air (PSACS-Air) or (2) $\mathrm{CO}_{2}$ /water heat exchangers (PSACS-Water).

These three DHR options were first sized using a simple analysis described in Appendix $2 \mathrm{D}$ and were then examined and compared using engineering, cost, and safety criteria. Eleven qualitative metrics were determined for the comparison of the designs, and two of the three - PSACS-Air and PSACS-Water - were selected for a more detailed evaluation. The final selection between these two candidates was then made using the Analytic Deliberative Process (ADP), as described in Appendix 2C. PSACS-Water, further designated as PSACS, was identified as the most promising decay heat removal system that would aid RVACS.

A schematic of the PSACS is shown in Figure 2.2.3-1. The PSACS uses the IHXs, which are rated for $600 \mathrm{MWt}$ each and can therefore easily transfer the decay power at low natural circulation flows. Thus, no additional in-vessel heat exchangers are needed. The decay heat is transferred from the primary system into the secondary system via IHXs and then into an ultimate heat sink using a $\mathrm{CO}_{2}$ natural circulation loop. Note that the IHX needs to be made and classified as a safety-grade component. Because the IHXs form a pressure boundary between high pressure secondary $\mathrm{CO}_{2}$ and low pressure primary sodium and are placed in the reactor vessel, they are already classified as Safety Related per USNRC regulations, and their use for the PSACS function does not require reclassification and associated cost increase [Eide et al., 1990].

The PSACS is isolated under normal operating conditions (see Figure 2.2.3-1). During an SBO event, the main turbine will be tripped and isolated and the PSACS isolation valves will open, allowing $\mathrm{CO}_{2}$ natural circulation flow into the Passive Auxiliary Heat Exchanger (PAHX). This can be accomplished with a high degree of reliability and without operator action by using a series configuration of fail-closed and parallel configuration of fail-open valves common in industry today. Upon loss of normal power, the turbine isolation and PSACS valves will swap positions thereby placing the PSACS in service. $\mathrm{S}-\mathrm{CO}_{2}$ flow will leave the $\mathrm{IHX}$ and flow into tubes passing through the 
PAHX, which is located higher than the IHXs. The PAHX is a vertically oriented bank of tubes submerged in an in-containment water storage tank. The $\mathrm{S}-\mathrm{CO}_{2}$ will flow through parallel banks of tubes and transfer heat into the water via convection. No external driving force will be required as the PAHX will be located at a suitable elevation so as to establish natural circulation via thermal head. The amount of water in the tank is established to provide a heat sink sufficient for the period of about 25 hours, i.e., until all decay power can be removed solely by the RVACS.

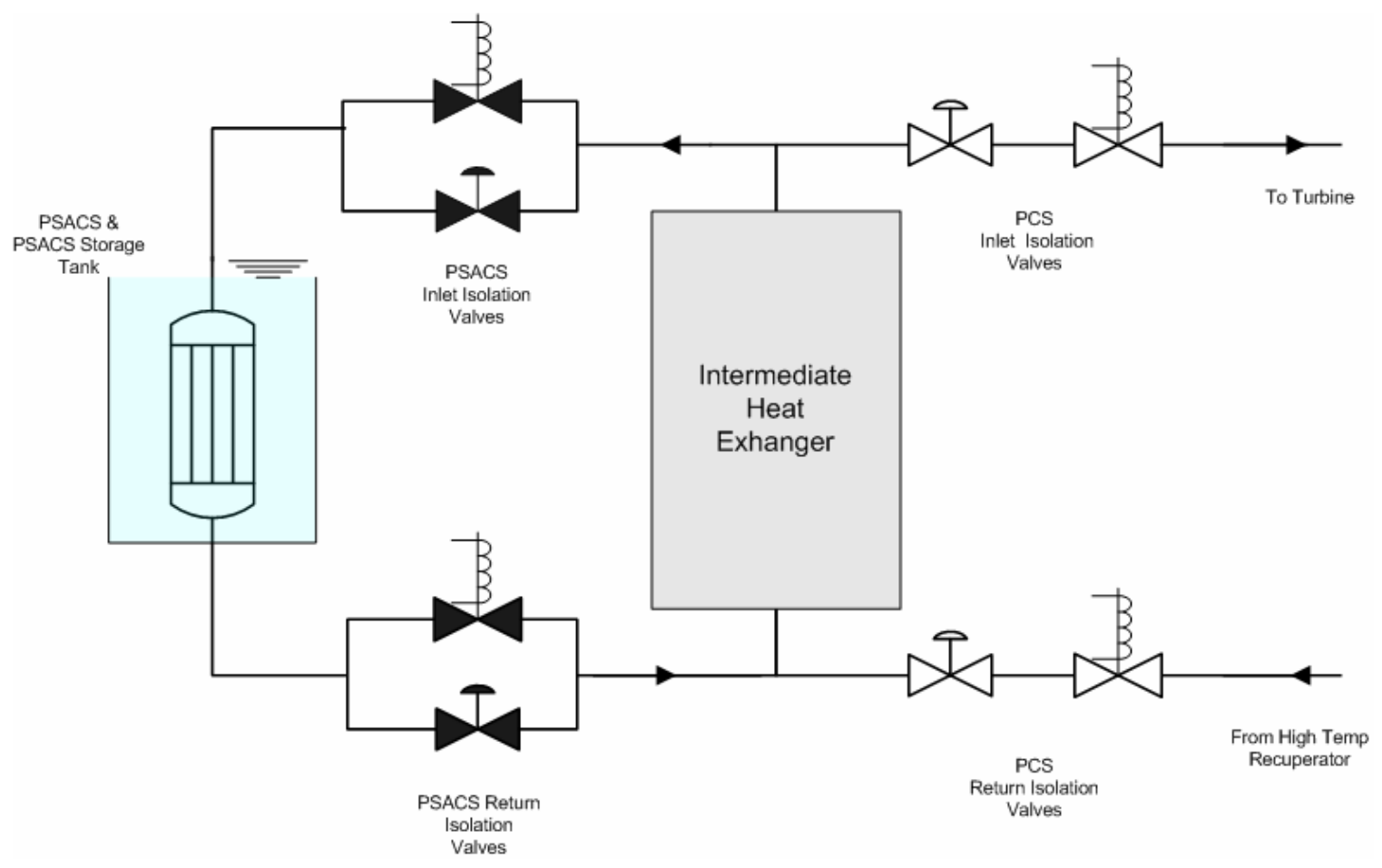

Figure 2.2.3-1 - PCS Loop and PSACS Train

The PSACS relies on a density differential between its hot and cold legs (i.e. thermal head) and elevation difference (PSACS is located 2.0 meters above the in-vessel IHXs) to provide cooling based on natural circulation. Because no external energy sources (e.g. pumps, blowers) are used, the PSACS is classified as a passive safety system. Unlike the RVACS, the PSACS must be isolated during normal operation. This prevents boiling of the PSACS Storage Tank water and improves economics by limiting heat loss from the power conversion system (PCS). PSACS main design parameters are summarized in Table 2.2.3-2.

The PCS must be isolated during a transient such as an SBO. Failure to isolate a PCS train creates a flow bypass around the corresponding PSACS train. $\mathrm{Hot}_{\mathrm{CO}_{2}}$ exiting the IHX could instead flow through the PCS rather than the PSACS. Furthermore, PCS piping is non-safety related and therefore less robust than the PSACS piping. Without isolation, a rupture or leak in the PCS could depressurize the PSACS, thereby challenging its effectiveness. 
Table 2.2.3-2 Passive Secondary Auxiliary Cooling System Data

\begin{tabular}{|l|l|l|r|r|}
\hline Reactor & & Lead & Salt $^{*}$ \\
\hline Passive & Water Tank & Height $(\mathrm{m})$ & 14.0 & $\sim 9.0\left(12^{\dagger}\right)$ \\
\cline { 3 - 5 } $\begin{array}{l}\text { Secondary } \\
\text { Auxiliary }\end{array}$ & & Diameter $(\mathrm{m})$ & 6.0 & $\sim 6.0$ \\
\cline { 2 - 5 } $\begin{array}{l}\text { Cooling } \\
\text { System }\end{array}$ & Passive & Number of tubes & 350 & $\sim 350$ \\
\cline { 2 - 5 } & Auxiliary Heat & Tube length $(\mathrm{m})$ & 4.0 & $\sim 2.4\left(4^{\dagger}\right)$ \\
\cline { 2 - 5 } & Exchanger & Inner diameter $-\mathrm{CO}_{2}$ side $(\mathrm{m})$ & $8.00 \mathrm{E}-03$ & $8.00 \mathrm{E}-03$ \\
\cline { 3 - 5 } & (PAHX) & Tube thickness $(\mathrm{m})$ & $2.80 \mathrm{E}-03$ & $2.80 \mathrm{E}-03$ \\
\cline { 3 - 5 } & & Outer diameter - water side $(\mathrm{m})$ & $1.36 \mathrm{E}-02$ & $1.36 \mathrm{E}-02$ \\
\cline { 3 - 5 } & & P/D ratio & 3 & 3 \\
\hline
\end{tabular}

*Salt PSACS values are approximate because the salt PSACS was not explicitly designed; instead it was modeled by adjusting the lead PSACS model. These values correspond to the final reference PSACS design ( $60 \%$ power, $75 \%$ tank size).

'Original size of the PSACS tank and PAHX, referred to as $100 \%$ throughout Chapter 4 on salt design. Final tank height that achieves the best performance is $9 \mathrm{~m}$ and PAHX tubes length is $2.4 \mathrm{~m}$ length (referred to as $60 \%$ PSACS).

An early design goal was to ensure that the probability of component-based system failure was negligible. Valve reliability data for large $\mathrm{S}-\mathrm{CO}_{2}$ isolation valves could not be located, so information for similar valve types with other working fluids was used [Eide et al., 1990]. These data are presented in Table 2.2.3-3.

Table 2.2.3-3 - Valve Reliability Data from Nuclear Computerized Library for Assessing Air Operated Valves:

Reactor Reliability [Eide et al., 1990]

\begin{tabular}{|l|l|l|}
\hline Working Fluid & Point Estimate & Pr[fail to open/close] \\
\hline \multirow{3}{*}{ Water/Steam } & Mean & $1 \times 10^{-3}$ \\
\cline { 2 - 3 } & $95^{\text {th }}$ percentile & $4 \times 10^{-2}$ \\
\hline \multirow{3}{*}{ Sodium } & Mean & $3 \times 10^{-3}$ \\
\cline { 2 - 3 } & $95^{\text {th }}$ percentile & $1 \times 10^{-2}$ \\
\hline \multirow{2}{*}{ Helium } & Mean & $1 \times 10^{-4}$ \\
\cline { 2 - 3 } & $95^{\text {th }}$ percentile & $4 \times 10^{-4}$ \\
\hline
\end{tabular}

Solenoid Operated Valves:

\begin{tabular}{|l|l|l|}
\hline Working Fluid & Point Estimate & Pr[fail to open/close] \\
\hline \multirow{3}{*}{ Water/Steam } & Mean & $5 \times 10^{-4}$ \\
\cline { 2 - 3 } & $95^{\text {th }}$ percentile & $2 \times 10^{-3}$ \\
\hline \multirow{3}{*}{ Sodium } & Mean & $3 \times 10^{-3}$ \\
\cline { 2 - 3 } & $95^{\text {th }}$ percentile & $1 \times 10^{-2}$ \\
\hline \multirow{2}{*}{ Helium } & Mean & $3 \times 10^{-4}$ \\
\cline { 2 - 3 } & $95^{\text {th }}$ percentile & $1 \times 10^{-3}$ \\
\hline
\end{tabular}

Valve reliability in a sodium environment was selected as the bounding case, and the reliability values shown above were used to model the PSACS and PCS cases. To improve system reliability the isolation valves for the PCS were placed in series and the isolation valves for the PSACS were placed in parallel. This configuration ensures that a single valve failure will not disable a PSACS train or a PCS loop. A fault tree displaying the configuration is shown in Figure 2.2.3-2. 


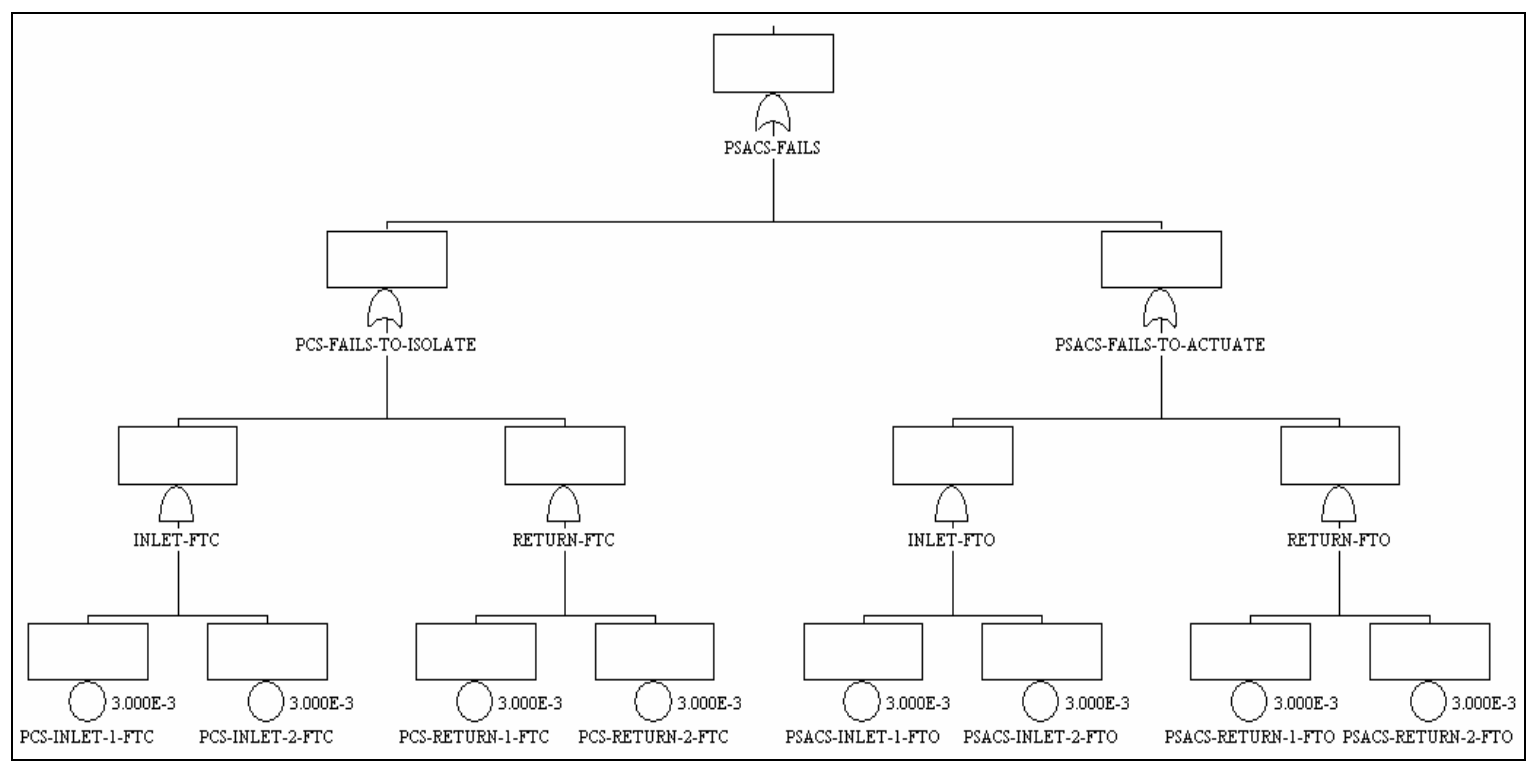

Figure 2.2.3-2 - PSACS Fault Tree

Four combinations of valve failures i.e. minimum cutsets can be identified:

1. Failure of both PSACS inlet valves

2. Failure of both PSACS return valves

3. Failure of both PCS inlet valves

4. Failure of both PCS return valves

Using the valve reliability from Table $2.2 .3-3$, the failure probability for one train of PSACS is approximately $3.6 \times 10^{-5}$.

Because the PSACS is a 2/4 system (its function requires operation of 2 of the installed 4 trains), the probability of system failure is substantially less than that of one train failing. The conservative Beta-Factor model was applied at the train level to assess the consequences of common cause failure. Assuming that $10 \%$ of train failures are due to common cause failure $(\beta=0.10)$, the failure probability for a 2 -out-of- 4 system can be expressed as [Rausand and Hoyland, 2004]:

$\operatorname{Pr}[$ failure $]=4 q^{3}-3 q^{4}+\beta q$,

where $\mathrm{q}$ is the probability of train failure.

Inserting the values for the PSACS, we observe that the probability of independent failure is dominated by the probability of common cause failure:

$\operatorname{Pr}[$ failure $]=1.9 \times 10^{-13}-5 \times 10^{-18}+(0.10)\left(3.6 \times 10^{-5}\right) \approx 3.5 \times 10^{-6}$

We can therefore conclude that the probability that the PSACS will fail to complete its mission due to valve related failures is extremely low due to redundant and diverse 
Project No 06-040: Flexible Conversion Ratio Fast Reactor Systems Evaluation

design features such as multiple isolation valves and actuators. The $2 / 4$ logic of the PSACS and the fact that the RVACS has no moving parts and is always operational combine to provide a robust and reliable defense against a variety of transients including SBO.

\subsubsection{DHR through Power Conversion System}

The supercritical $\mathrm{CO}_{2}$ power conversion system offers the unique opportunity to remove the decay heat by driving the turbomachinery. In this case, the gas is circulated through the turbine which is mounted on the same shaft as the compressors. The decay heat is removed from the core through the IHXs and then further rejected through the precoolers. Similarly to the PSACS, the PCS can also serve as a heat sink in case of an accident. However, this would require that the entire PCS would have to be classified as Safety Related. Within the current regulatory framework, Safety Related components must be seismically qualified to withstand the Safe Shutdown Earthquake, also known as the Design Basis Earthquake (CFR 100, Appendix A (Seismic Requirements)). In addition, the Quality Assurance rules of 10 CFR 50, Appendix B (Quality Assurance Requirements for Nuclear Power Plants) would have to apply to the whole balance of the plant. The reclassification of nearly the entire PCS as Safety Related would lead to a substantial increase in construction, maintenance, and procurement costs. Moreover, it would likely pose operational challenges. Because of the considerable increase in cost associated with upgrading the PCS to a Safety Grade system for decay heat removal, the PSACS rather than the PCS was designed as Safety Related for this reactor. However, the PCS can still be used to remove the decay heat in case of an accident provided that the safety-grade PSACS is always available to perform. This section describes the approach of decay heat removal using the PCS.

When the station blackout accident is initiated, the generators are disconnected from the power grid. However, the turbomachinery does not immediately stop. Moreover, since turbine energy can no longer be transferred into the grid, any additional energy input into the turbine is converted into kinetic energy, driving the shaft and the compressors, which deliver significant $\mathrm{CO}_{2}$ flow through the IHXs. It is assumed that all four PCS loops are in operation and that some cooling water flow can be maintained through the precoolers either by natural circulation or by pumps in the case of a loss of primary flow scenario when electricity to the precooler pumps is available.

When the generator is disconnected from the grid during the SBO accident, imbalance in shaft torque leads to a rapid increase in shaft speed. To protect against shaft overspeed, the overspeed protection system, described in Section 2.2.3.5, is invoked first using the turbine bypass valve. After the speed of the turbine is reduced to safe values, the turbine bypass valve can also be used to control turbine speed in such a manner that the turbine provides enough power to drive compressors on the same shaft so that a sufficient flow rate through IHXs to remove decay heat is achieved. This can be accomplished using a shaft speed signal controller that acts on the bypass valve. A proportional-integral controller (PI controller) was selected for this purpose. The PI controller uses the error 
between the actual (measured) shaft speed and the desired speed value to adjust the bypass valve position. The following procedure was used in modeling the PI controller:

1. The desired shaft speed value (setpoint) is determined;

2. The actual shaft speed (aka process variable) is measured;

3. The error between set and actual shaft speeds, $\mathrm{V}_{1}$, is calculated;

4. The proportional value, $\mathrm{P}$, determines the reaction to the current error;

5. The integral value, I, measures the reaction based on the sum of past errors;

6. The weighted sum of $\mathrm{P}$ and I parameters is further used to adjust the control variable, i.e. speed.

The diagram of a PI controller is depicted in Figure 2.2.3-3. The very first estimate of the variable (output from the controller) is the proportional reaction of the controller used to obtain a rough estimate. The integral controller is further used for fine tuning until the setpoint is reached. Once tuned, the controller relies mostly on the integral response.

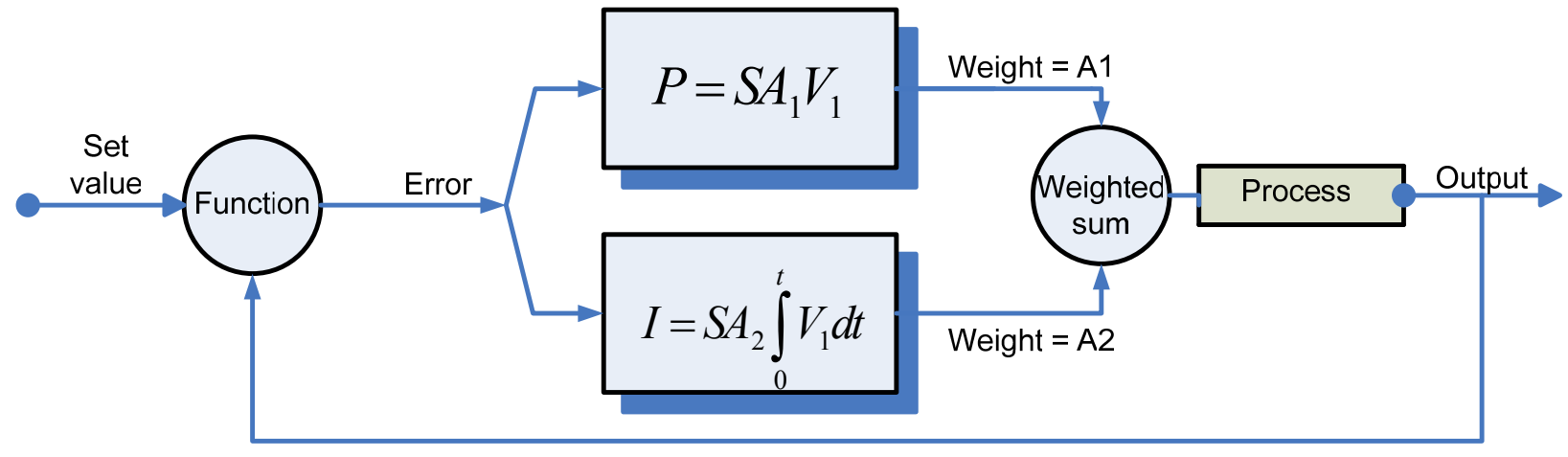

Figure 2.2.3-3 PI controller diagram.

Ideally, the turbine speed is held nearly constant, so the decay heat can be removed for as long as possible through the PCS. In this case, the mass flow rate through the turbine must be adjusted in such a way that the speed of the shaft remains constant. This can be done through control of the turbine bypass valve open area or can also be extended to other valve configurations. The list below represents the values that are either assumed or calculated following the algorithm specific for tuning the turbine shaft speed:

- Desired turbine speed

- Measured turbine speed

- The error between them is an input to the function

- Estimated factor $\mathrm{S}$

- Estimated weights A1 and A2

- The obtained correction is fed into the valve stem function

- The valve area is itself a function of valve stem (non-linear)

- The flow rate responds to the change in the valve area

- The shaft reacts to the flow rate $->$ new value is measured 
Table 2.2.3-4 summarizes the PI controller factors and values used for the model. The PI controller was used in the loss of flow accident analysis, which is discussed in Chapter 3.

Table 2.2.3-4 PI controller factors used in loss of flow accident simulation

\begin{tabular}{|l|c|}
\hline Factor & Value \\
\hline Setpoint & $50 \mathrm{rad} / \mathrm{sec}$ \\
\hline Estimated factor $\mathrm{S}$ & 0.04 \\
\hline Proportional weight $\mathrm{A}_{1}$ & 2.50 \\
\hline Integral weight $\mathrm{A}_{2}$ & 0.01 \\
\hline
\end{tabular}

After turbine overspeed is prevented by fast opening of the bypass valve. The turbine bypass valve controls the shaft speed by adjusting the position of the stem valve, based on shaft speed signal. Opening the bypass valve reduces turbine flow and partial closure leads to turbine flow increase. When the difference between the setpoint of the turbine velocity and the initial turbine speed, $368 \mathrm{rad} / \mathrm{sec}$, is small, the PI controller iteration converges to the setpoint very quickly. Because the PCS and IHX have large heat removal capacity, relatively low shaft speed is sufficient to remove reactor power. The setpoint for shaft-speed is selected such that the heat removed by the PCS in a selfsustaining operation matches the natural circulation capability of the reactor.

The value of the proportional weight was iterated: (1) if the value was taken too large, system instabilities were observed; (2) for small values (given a large error), the controller was not sensitive enough. The integral term accounts for both magnitude of the error as well as the duration. Integral weight accelerates the conversion of the variable to the setpoint. However, in the case of a station blackout accident, the decay heat curve decreases in a relatively slow fashion. Therefore, a small integral weight should be applied to ensure that the turbine velocity (and the amount of decay heat removed through the IHX) has a smoothly decreasing behavior comparable to the decay heat curve.

Analyses in Chapter 3 show that the shaft speed control using a well tuned PI controller is very effective in removing decay heat from the primary system through the PCS after the generators are disconnected from the grid. The PI controller parameters can be tuned to take into account the dependence on the difference between the decay heat and the amount of heat removed by RVACS.

\subsubsection{Approaches for Managing Turbine Overspeed}

When the generator is disconnected from the grid during the SBO accident, imbalance in torque leads to a rapid increase in shaft speed. The speed and acceleration of the turbine shaft are primarily determined by the torques of the turbine and compressors and the shaft moment of inertia [Pope, 2006]. It is imperative that the rotational speed of the turbine remains below the overspeed limit to prevent potential damage of the equipment. Exact overspeed limit is uncertain at this stage of gas turbine development, but it is expected that the turbine should be able to withstand $130 \%$ overspeed due to its small size. In this analysis, a conservative value of $120 \%$ for the turbine overspeed limit was adopted. 
To protect against excessive turbine overspeed and evaluate the effectiveness of various options to limit the overspeed to allowable levels, a number of possible bypass paths were investigated. The bypasses include fast acting valves that are closed during normal operation and are actuated when the turbine rotational speed increases. To prevent turbine overspeed requires very fast-acting valves. This is because in case of generator trip, the rate of the shaft speed increase is high. The initial rotational speed of the turbine is $376.99 \mathrm{rad} / \mathrm{sec}$, and the $120 \%(452.4 \mathrm{rad} / \mathrm{sec})$ overspeed limit is exceeded in less than 0.5 seconds. The valve opening time must be on the order of 0.5 seconds or faster as can be seen in Figure 2.2.3-4. However, such rates of valve opening are consistent with fast acting valves for steam turbines and should not pose significant challenges for valve design. The performance of three types of bypass options was evaluated:

- Turbine bypass;

- Intermediate heat exchanger bypass (IHX bypass);

- Power cycle bypass (PC bypass);

Table 2.2.3-5. Turbine bypass valve position.

$\begin{array}{cc}\text { Normalized stem position } & \text { Normalized valve area } \\ 0.00 & 0.00 \\ 0.33 & 0.00 \\ 0.75 & 0.95 \\ 1.00 & 1.00\end{array}$

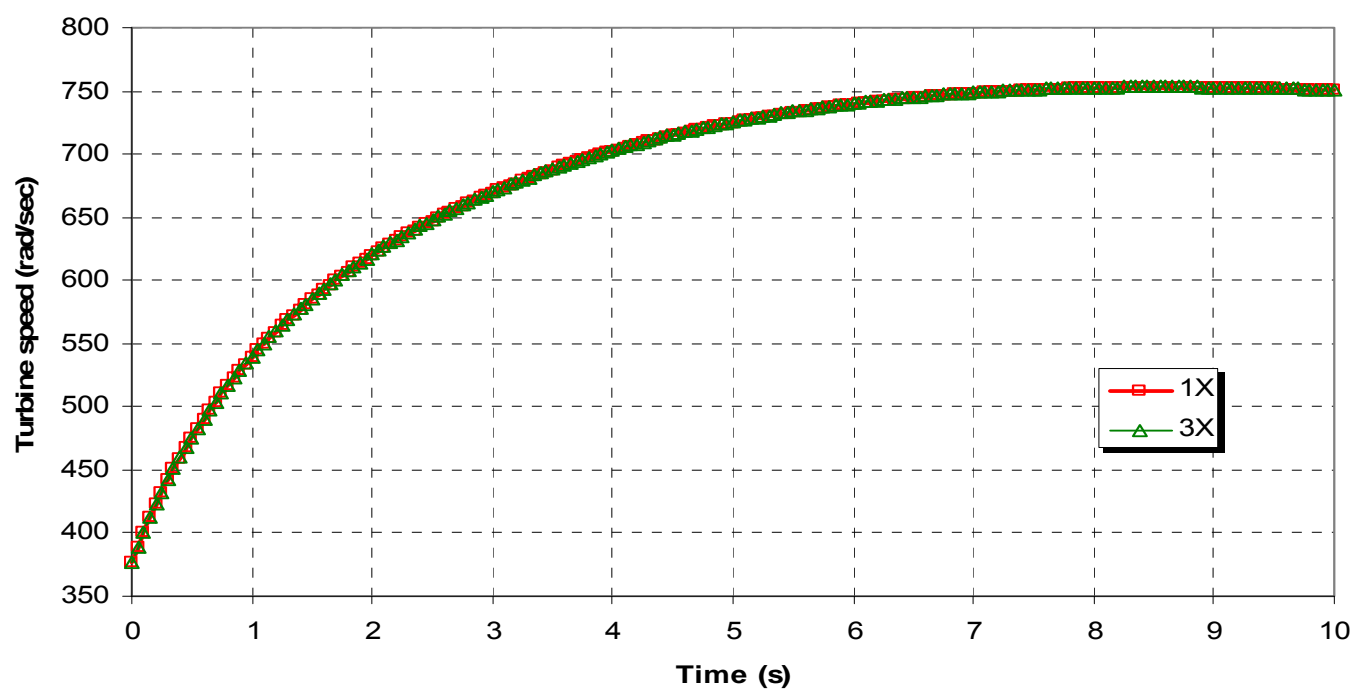

Figure 2.2.3-4 Turbine rotational speed after the generators are decoupled from the grid -Case of no bypass ( $1 \mathrm{x}$ and $3 \mathrm{x}$ show response of 1 and 3 lumped PCS trains).

All bypass options were modeled in RELAP5-3D, and the models are discussed in more detail in Appendix 3B.2. The valve components were modeled in RELAP5-3D as motor valves. That allowed simulation of a valve that is driven open or closed at a given rate following a trip command. There are two ways to model the valve's response: linear, where the rate of area change is specified by a constant, and non-linear, where the 
normalized valve flow area is correlated with the stem position. Table 2.2.3-5 shows the non-linear case.

In this model, it is assumed that the valves are actuated at the instant the accident starts. Because real valves cannot respond to an event immediately, the second option with delay in valve opening is more realistic. Normalized stem position is then correlated to the rate of opening the valve. By manipulating the rate of opening, the turbine overspeed can be managed to obtain the desired value. The dependence of the turbine speed on the rate of valve opening is presented in Figures 2.2.3-5 and 2.2.3-6. The first case (labeled as "rate $=1$ ") assumed a constant change in stem position with a rate of $1.0 \mathrm{~Hz}$. Thus, the valve is fully open in 1 second. The second case (labeled as "rate=2") is twice as fast as the first one with rate of $2.0 \mathrm{~Hz}$.

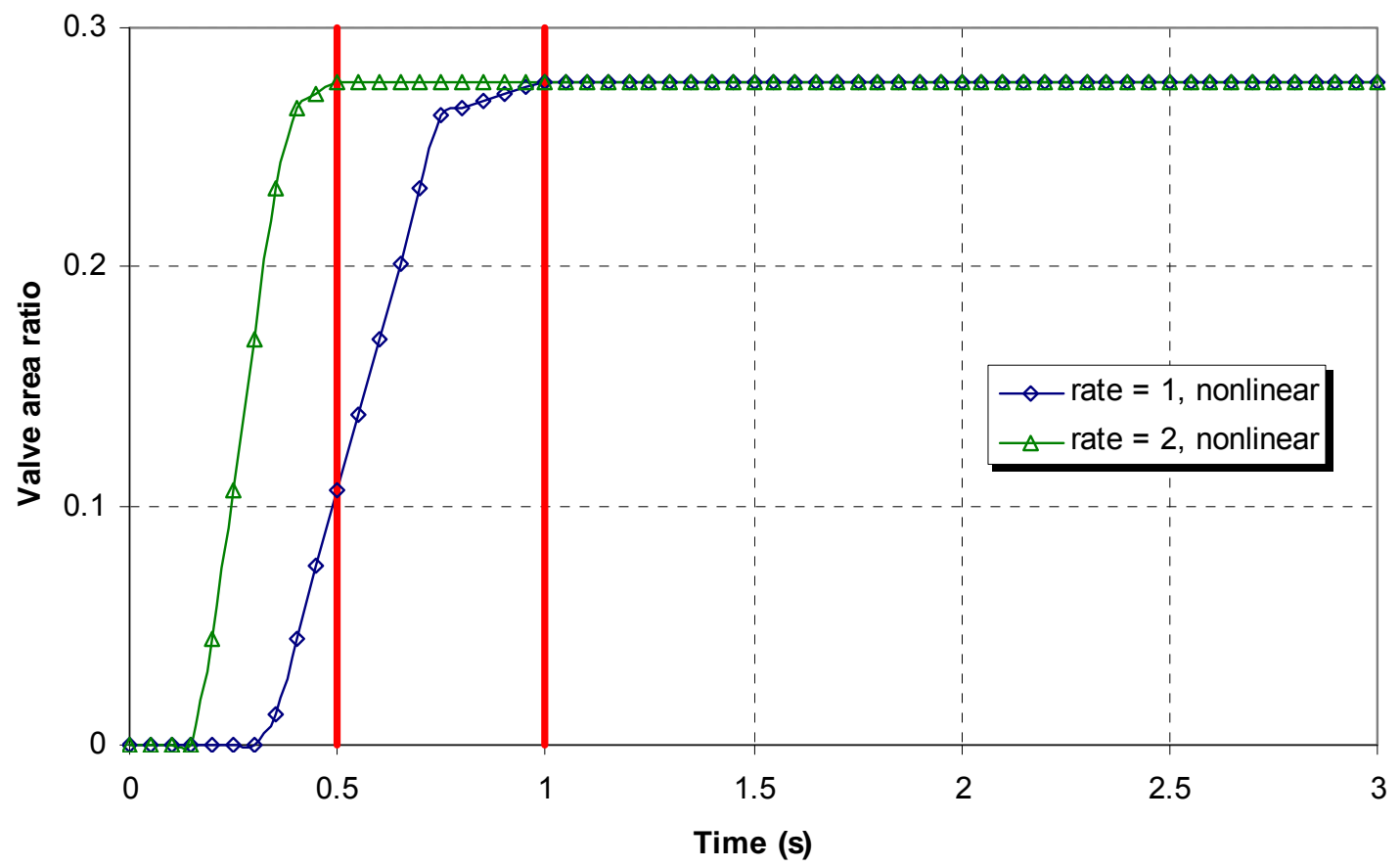

Figure 2.2.3-5 Normalized valve area during first 3 seconds of the accident.

Figure 2.2.3-5 shows normalized valve area during the first 3 seconds into the accident. Because Case 2 valve movement is twice as fast as that of Case 1, it takes half of the time to turn fully open. As can be seen in Figure 2.2.3-5, at a rate of $2 \mathrm{~Hz}$, the turbine overspeed is below $120 \%$. This shows that such fast acting valves can hold the turbine overspeed to the peak value of only $18 \%$ which occurs at 0.7 seconds into the accident. Therefore, the rate of change of stem position of $2 \mathrm{~Hz}$, which is equivalent to change of normalized valve area from 0 to 1 in 0.5 seconds, was selected and used in all transients throughout this report. 
Project No 06-040: Flexible Conversion Ratio Fast Reactor Systems Evaluation

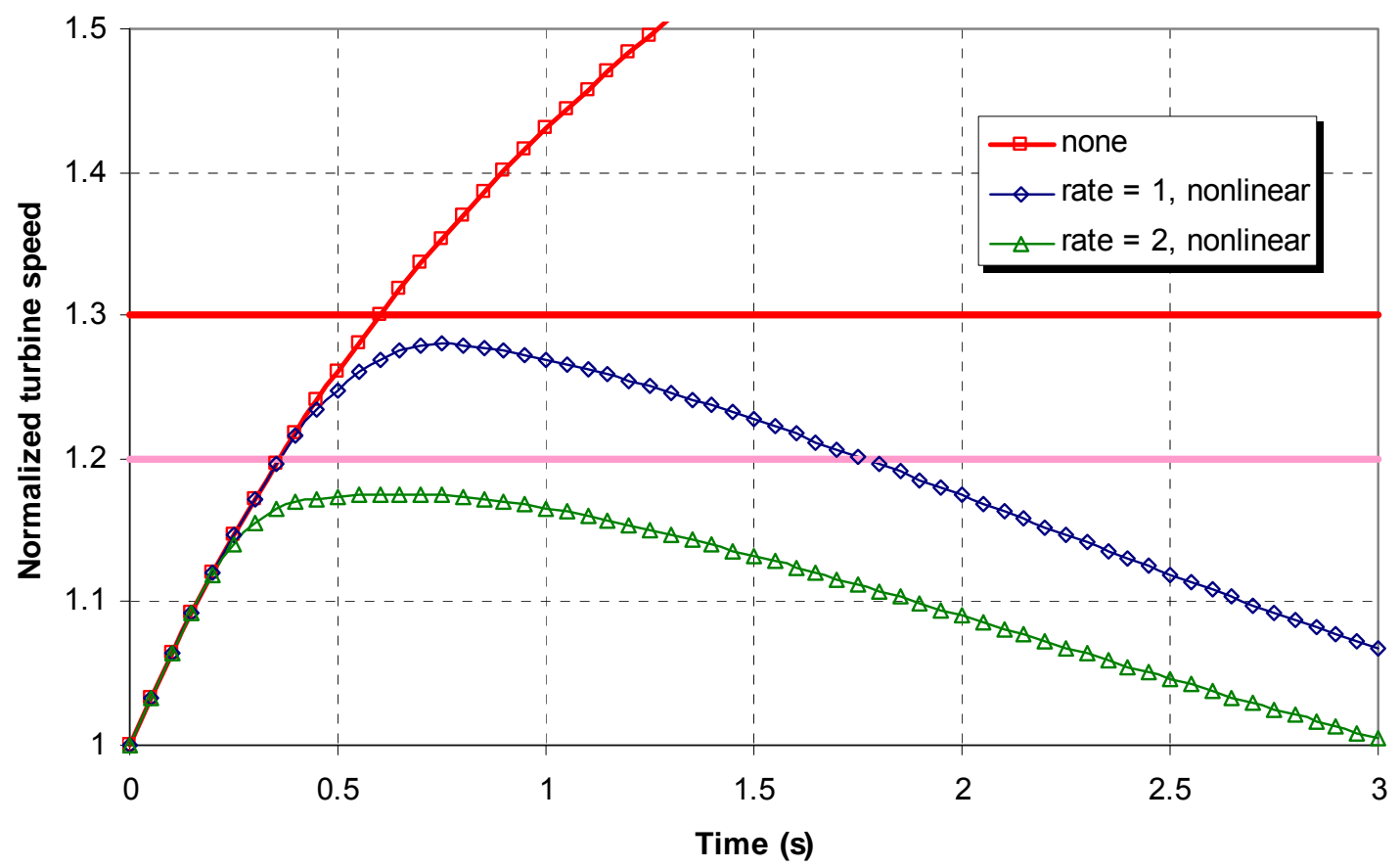

Figure 2.2.3-6 Normalized turbine speed during first 3 seconds of the accident.

\subsection{Turbine Bypass Placement Considerations}

In the turbine bypass arrangement used in the above study, the fluid from the IHX outlet (turbine inlet) is diverted around the turbine and rejoins the stream before entering the high temperature recuperator (HTR.) The schematic of the bypass is shown in Figure 2.2.3-7. The resulting reduction in flow rate through the turbine and increase in pressure at the turbine exit help to prevent the shaft rotational overspeed. However, since part of the flow does not pass through the turbine, the temperature of the fluid entering the high temperature recuperator is higher than during normal operation which increases thermal stresses in the HTR. In addition, the turbine bypass is generally undesirable because the valves are exposed to high-temperature gas from the outlet of the IHX. Figure 2.2.3-8 shows HTR gas inlet temperature (in ${ }^{\circ} \mathrm{C}$ ). Nominally, the temperature is around $436^{\circ} \mathrm{C}$, but during the transient with the turbine bypass, the temperature increases to almost $480^{\circ} \mathrm{C}$. The increase in temperature is nearly $40^{\circ} \mathrm{C}$ which is significantly smaller than in helium Brayton cycles, but not negligible in terms of thermal stress increase. Because it is of high interest to minimize thermal stress in the HTR, other bypass locations were explored. 


\section{Intermediate Heat Exchanger Bypass}

The IHX bypass location is shown in Figure 2.2.3-9. The IHX valve which is closed during normal operation opens due to de-energized actuators. The bypass pipe connects the high pressure HTR cold side outlet (at 19.8 MPa) with the turbine outlet which is at the significantly lower pressure of $7.97 \mathrm{MPa}$. The difference in pressures drives the flow to the low pressure line through the bypass which causes reduction in the flow through the turbine. As in the case of the turbine bypass, the IHX bypass keeps the shaft overspeed under the limit of $120 \%$. This bypass location is generally preferred over the turbine bypass since it does not lead to an increase of HTR inlet temperature. However, as can be seen from Figure 2.2.3-10, there is still a significant temperature transient on the HTR inlet, albeit in the direction of reduced temperatures. Hence the potential for thermal shock is not avoided using the IHX bypass.

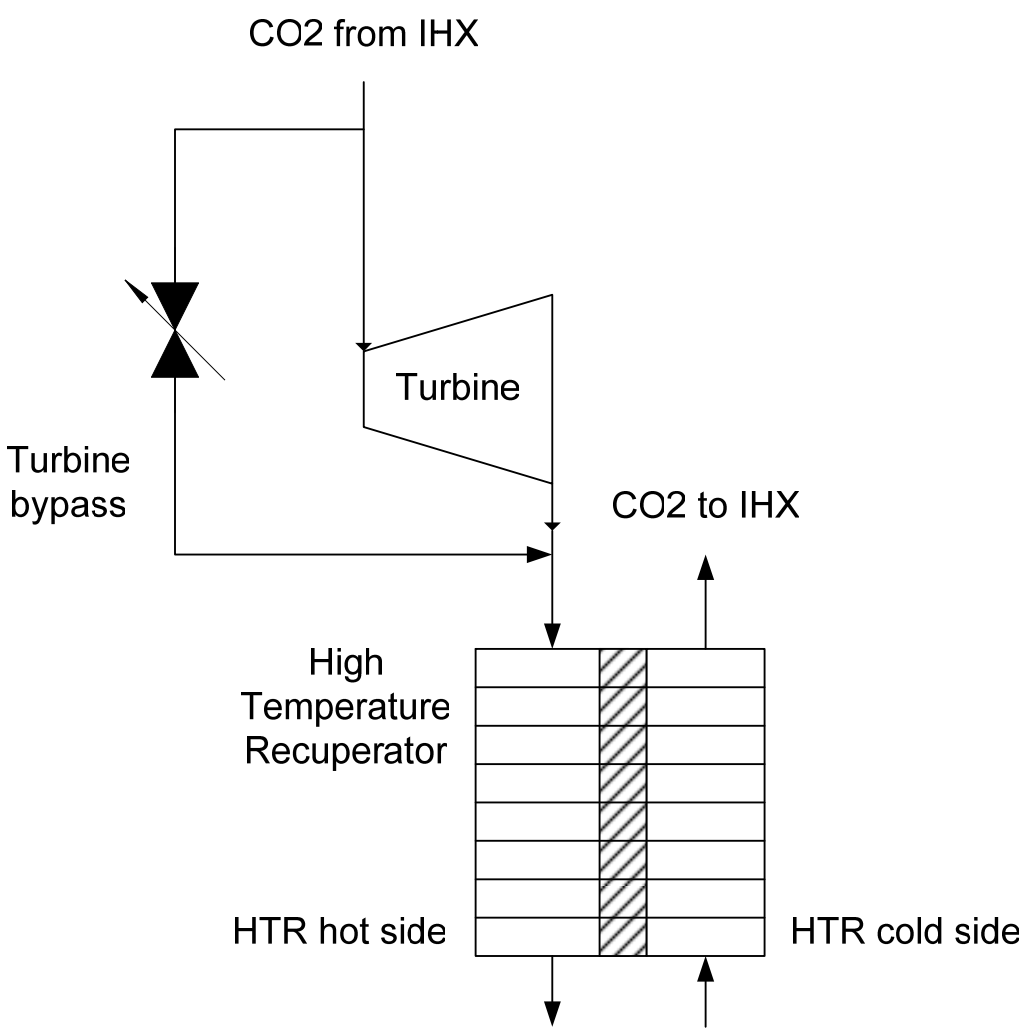

Figure 2.2.3-7 Schematic of the turbine bypass location. 
Project No 06-040: Flexible Conversion Ratio Fast Reactor Systems Evaluation

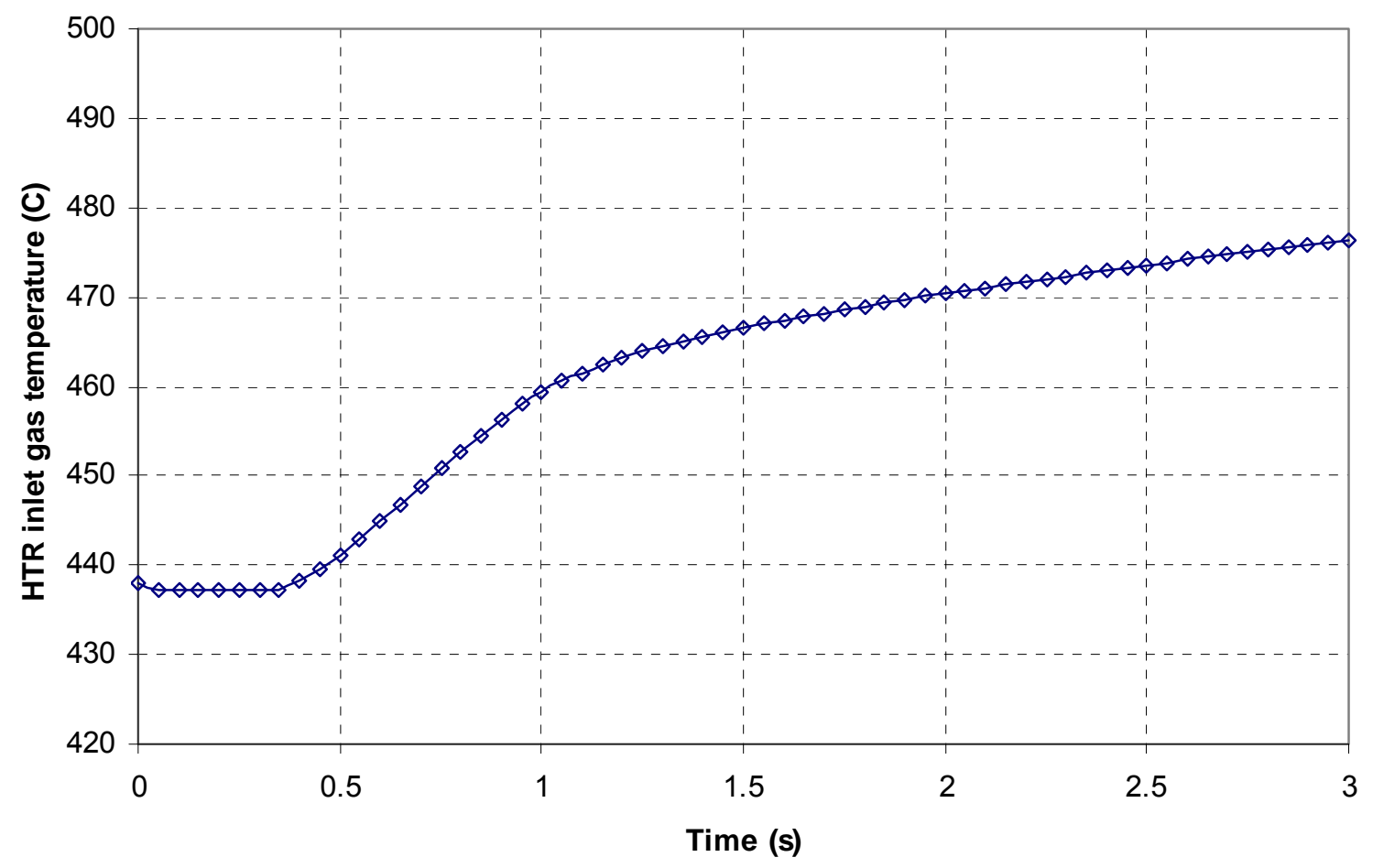

Figure 2.2.3-8 HTR gas inlet temperature $\left({ }^{\circ} \mathrm{C}\right)$ for turbine bypass valve case.

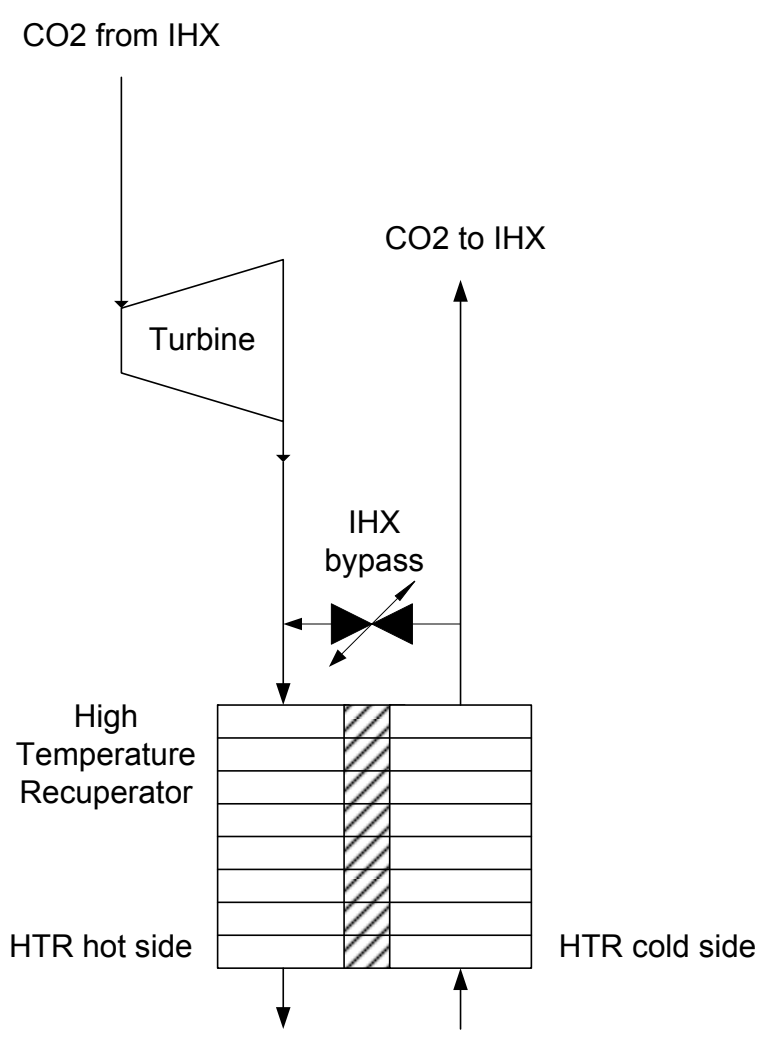

Figure 2.2.3-9 Schematic of the IHX bypass location. 
Project No 06-040: Flexible Conversion Ratio Fast Reactor Systems Evaluation

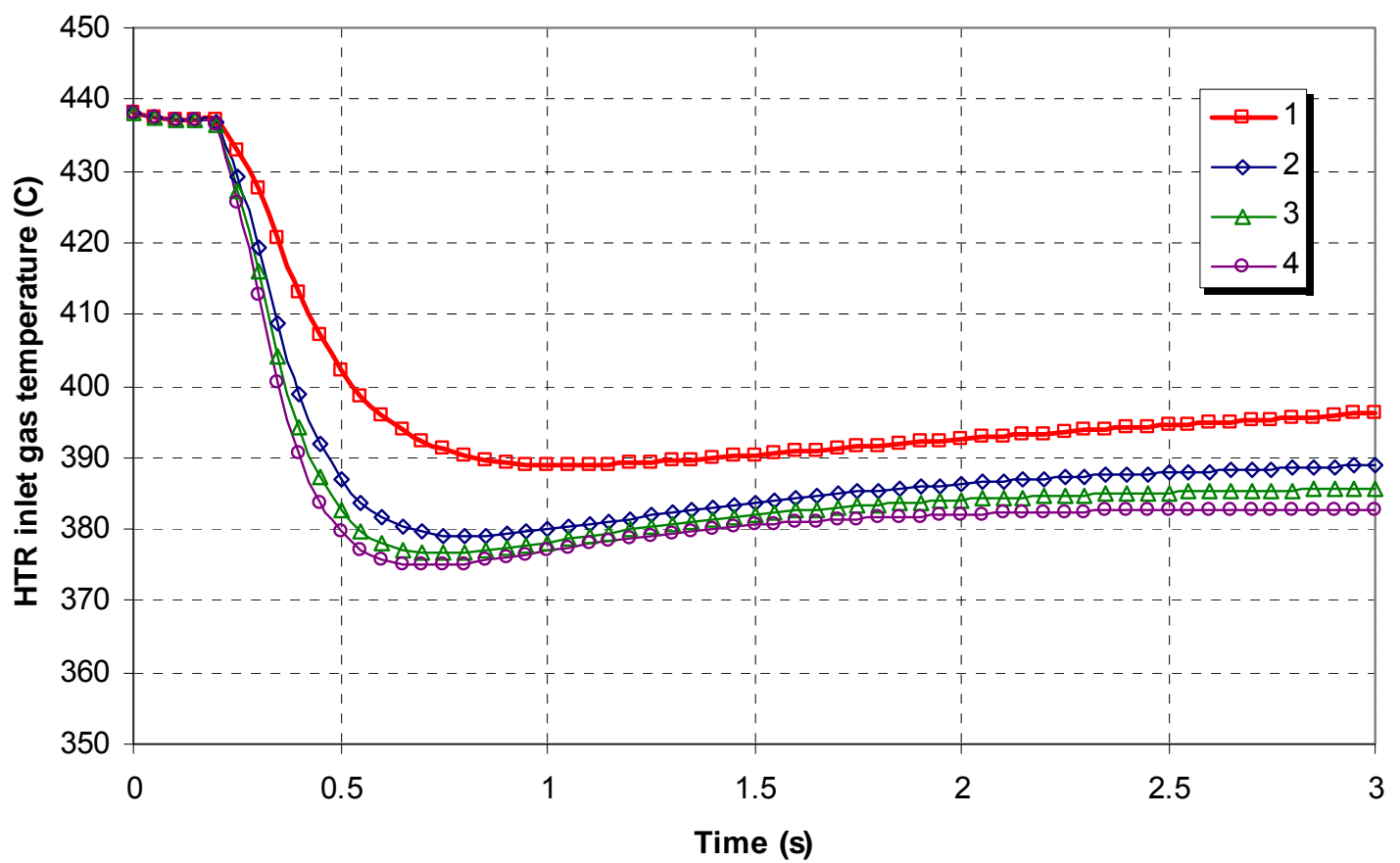

Figure 2.2.3-10 HTR gas inlet temperature $\left({ }^{\circ} \mathrm{C}\right)$ for IHX bypass valve case.

All cases considered for IHX bypass are for non-linear valves identical to the ones considered for turbine bypass. The rate of change in stem position was $2 \mathrm{~Hz}$, but different valve areas, indicated by numbers 1-4 on the legend of Figure 2.2.3-10 were explored. Figure 2.2.3-11 shows the valve area ratios for these cases, where the valve area ratio is defined as the ratio of the valve area to the area of the adjacent piping. The actual area of the valve (in $\mathrm{m}^{2}$ ) is given for every case in parentheses. Figure 2.2.3-12 shows normalized turbine speeds for different cases. The limit for the turbine rotational speed of $120 \%$ adopted earlier requires the area of the valve to be $0.6 \mathrm{~m}^{2}$ or more. Thus, Case 4 was used for further comparison with the other bypass options.

\section{$\underline{\text { Power Cycle Bypass (PCB) }}$}

The PCB bypass location is shown in Figure 2.2.3-13. Similarly to previous cases, the bypass valve which is closed during normal operation opens due to de-energized actuators. The bypass pipe connects the outlet of the main compressor which is at the high pressure of $19.98 \mathrm{MPa}$ with the precooler inlet which is at a significantly lower pressure of $7.69 \mathrm{MPa}$. Thus, this case is similar to the IHX bypass, but the temperature difference between the main compressor outlet and the precooler inlet is small, which was expected to yield a small thermal shock at the precooler inlet. 
Project No 06-040: Flexible Conversion Ratio Fast Reactor Systems Evaluation

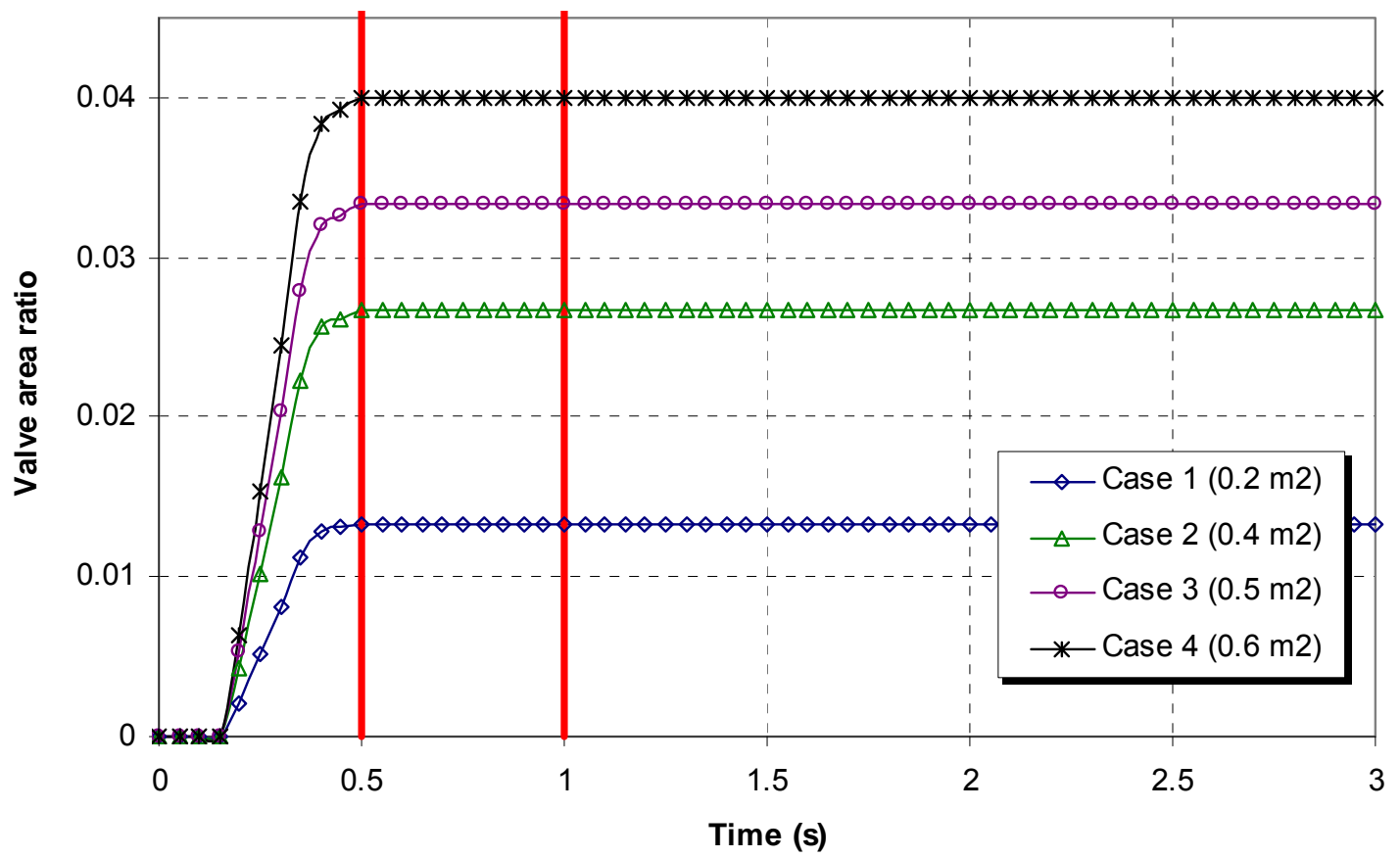

Figure 2.2.3-11 Normalized valve area during first 3 seconds of the accident.

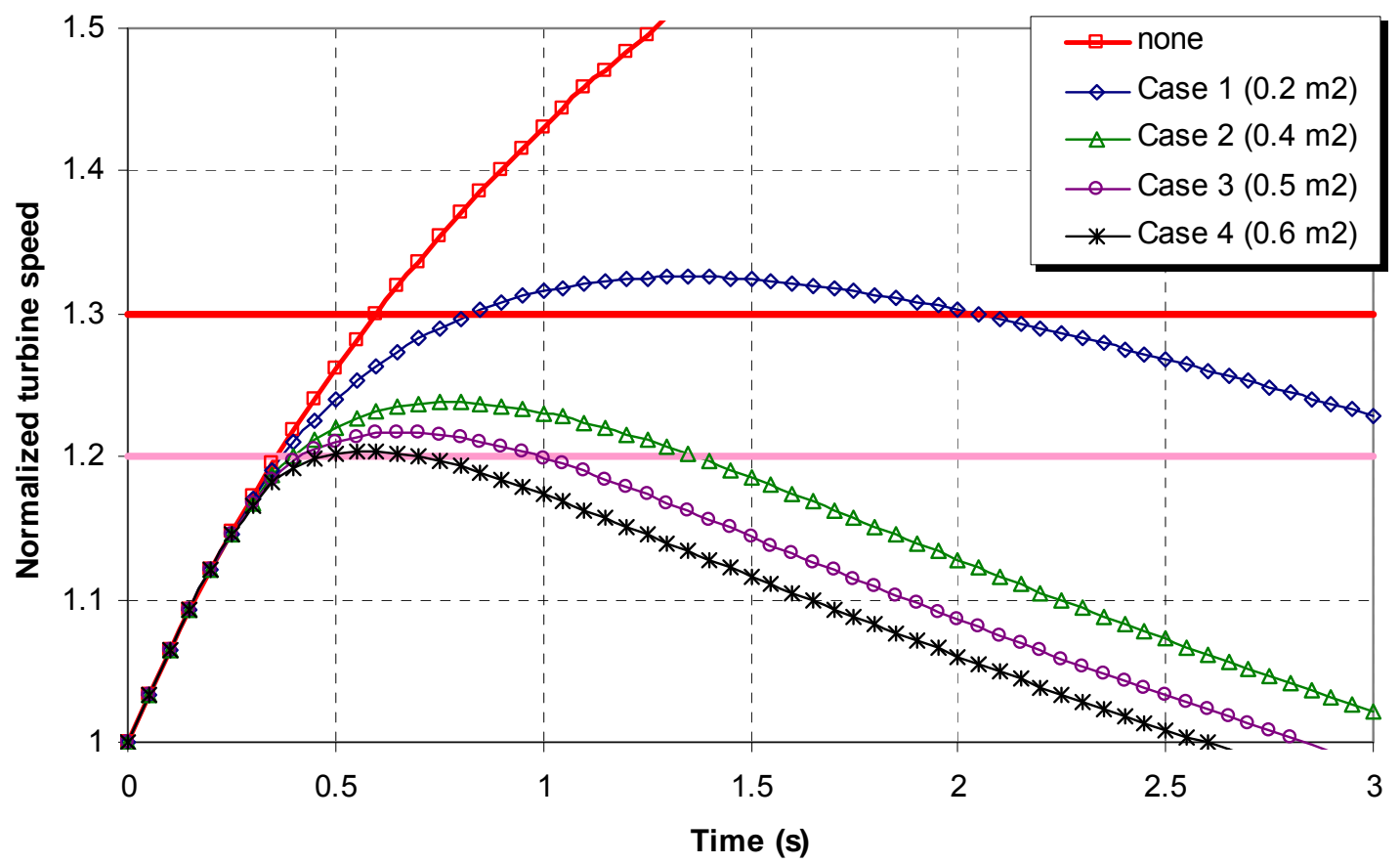

Figure 2.2.3-12 Normalized turbine speed during first 3 seconds of the accident. 
As can be seen from Figure 2.2.3-14, the PCB can maintain the shaft overspeed under the limit of $120 \%$ for Case 4 . However, an appreciable temperature transient on the inlet of the precooler is still observed and the potential for thermal shock is not eliminated. This is because the high pressure $\mathrm{CO}_{2}$ from the main compressor outlet undergoes substantial cooling during expansion through the bypass valve resulting in cooling of the precooler inlet stream. The magnitude of the temperature difference between nominal value and the minimum shown in Figure 2.2.3-15 is even higher than that of the other bypass cases.

Normalized gas inlet temperatures for all three bypass locations are compared in Figure 2.2.3-16. As can be observed, the PCB creates the largest relative temperature difference. The most favorable case in terms of relative temperature stress on components appears to be turbine bypass. Therefore, this bypass location was selected as preferable and was used for all of the studies in this report. It is also noted that turbine bypass provides the most rapid response of turbine speed reduction since it bypasses only the turbine and has the smallest stored mass between the inlet and outlet of the bypass line.

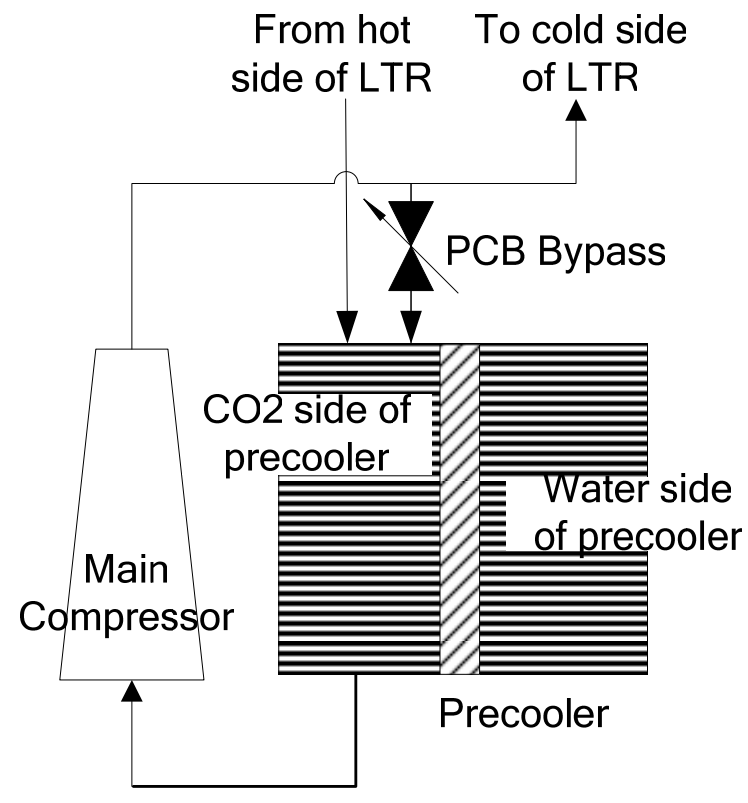

Figure 2.2.3-13 Schematic of the power cycle bypass location. 
Project No 06-040: Flexible Conversion Ratio Fast Reactor Systems Evaluation

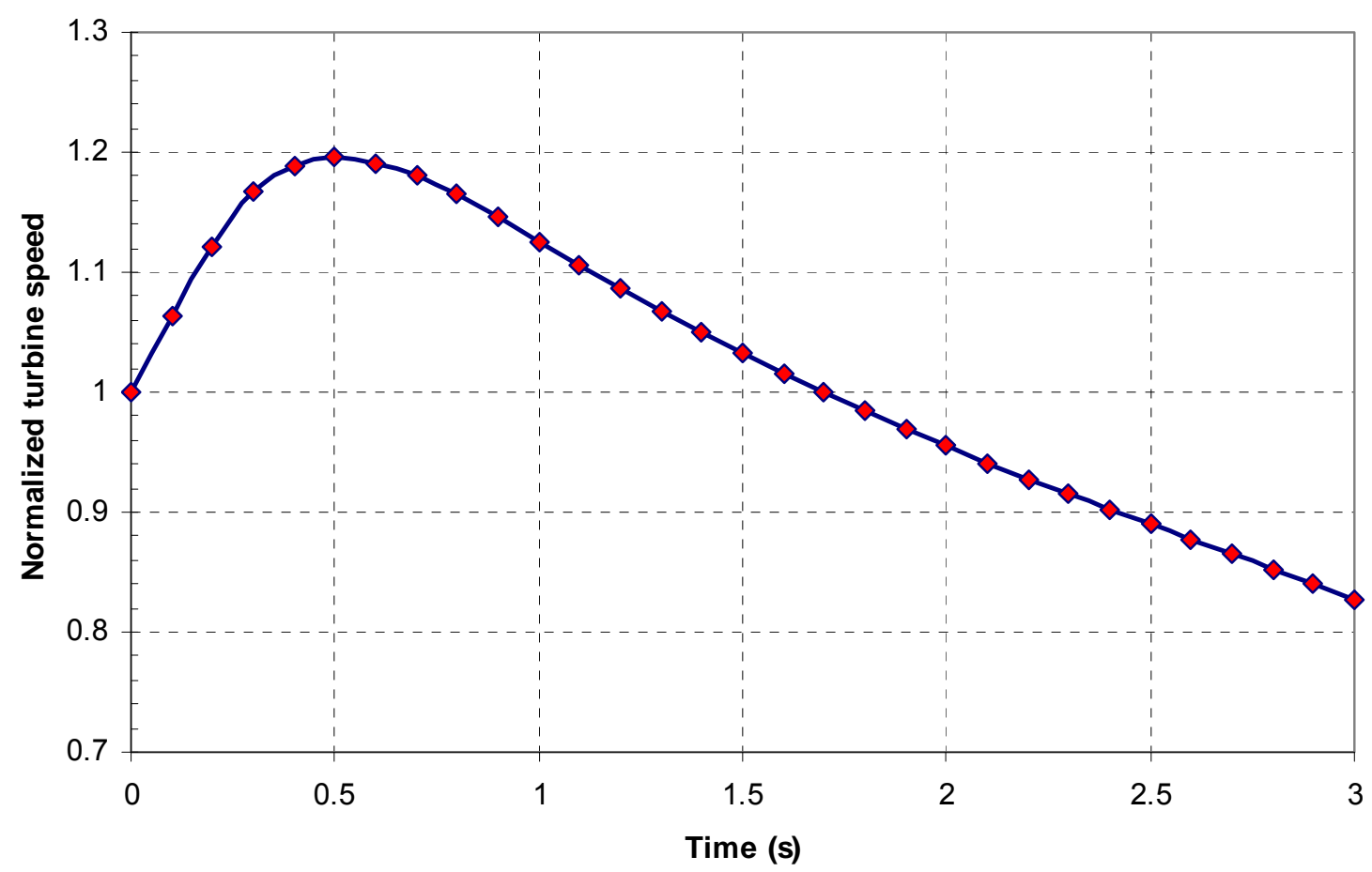

Figure 2.2.3-14 Normalized turbine speed during first 3 seconds of the accident (Case 4).

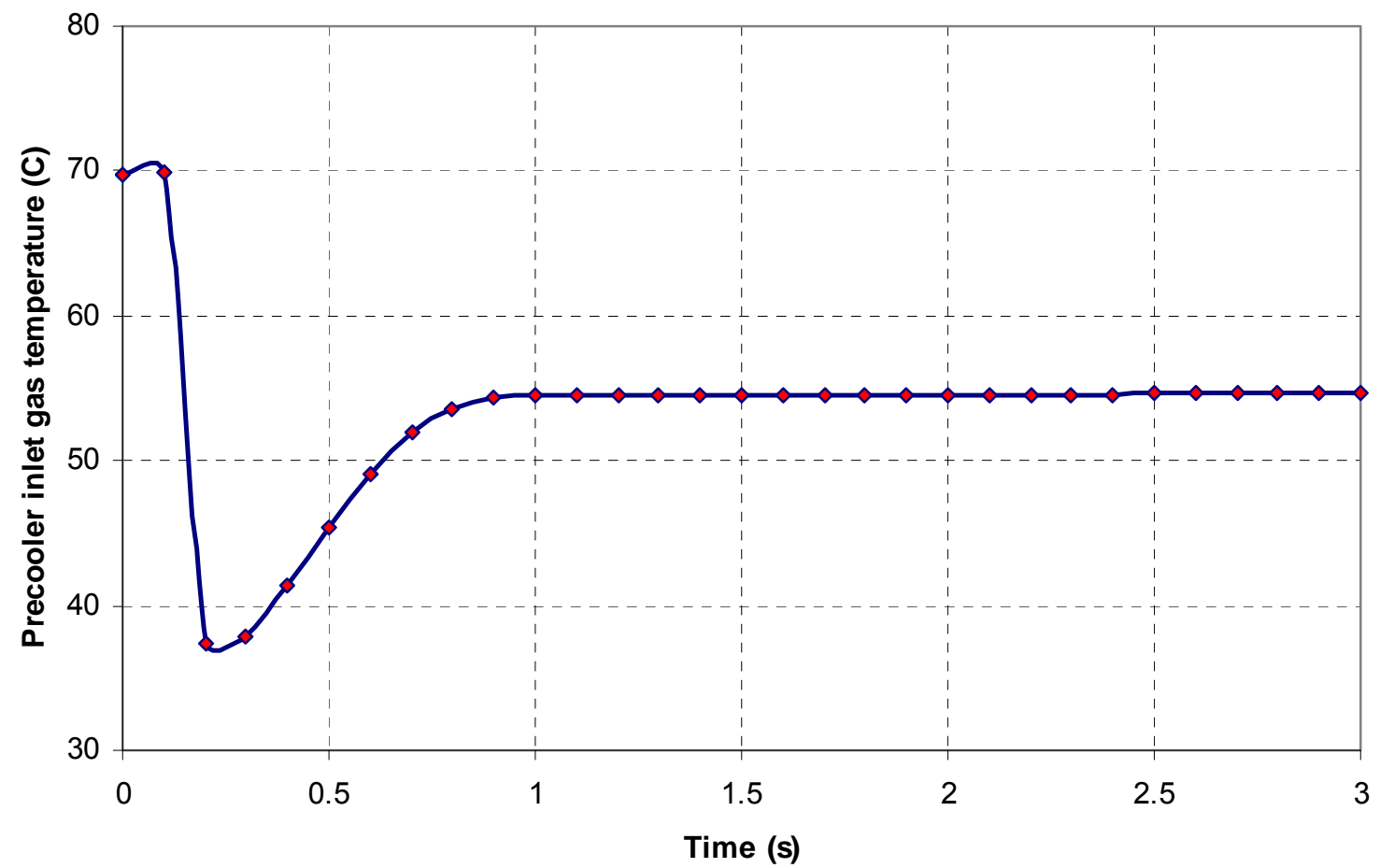

Figure 2.2.3-15 Precooler gas inlet temperature $\left({ }^{\circ} \mathrm{C}\right)$ for PCB valve case. 
Project No 06-040: Flexible Conversion Ratio Fast Reactor Systems Evaluation

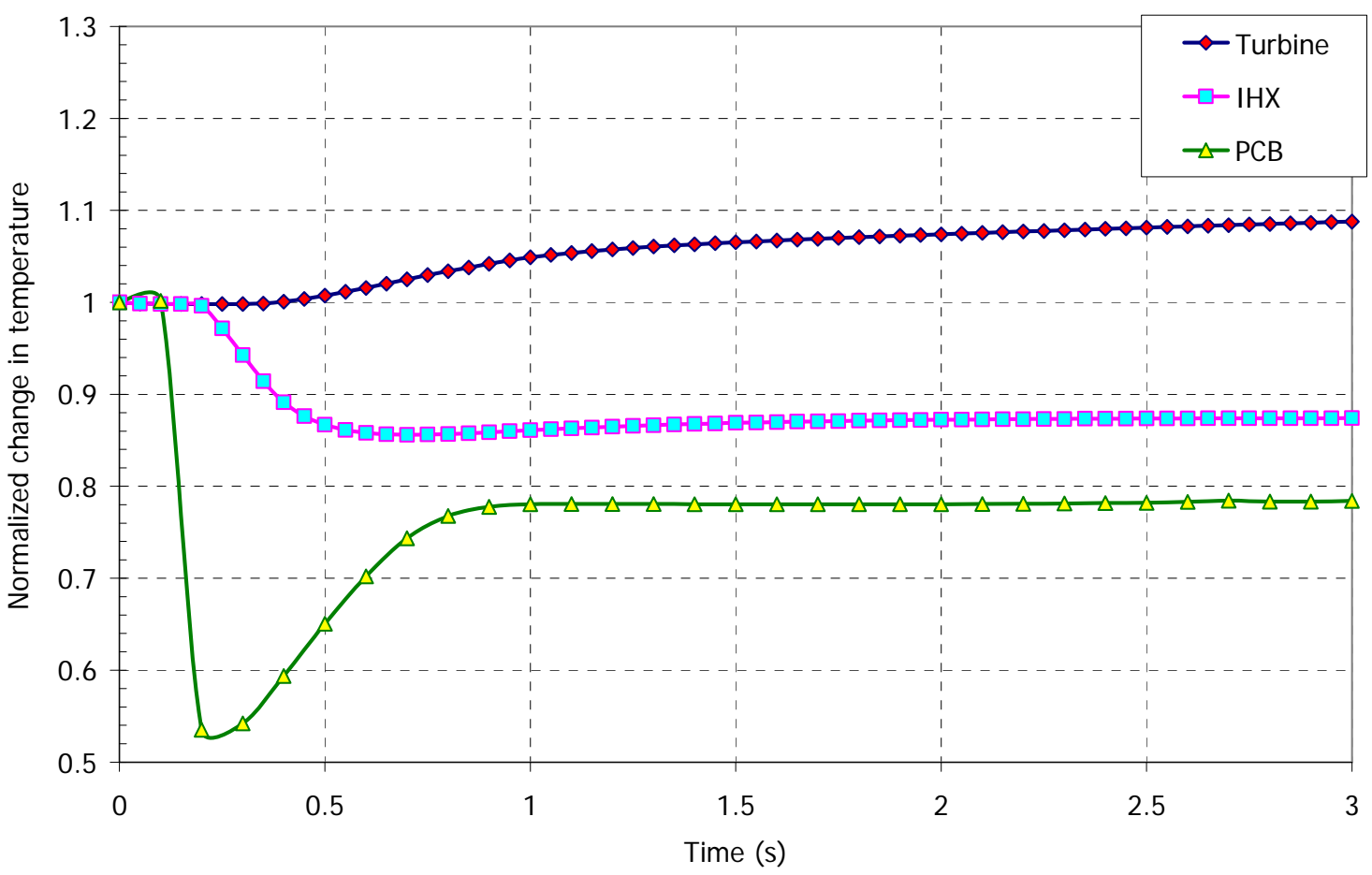

Figure 2.2.3-16 Comparison of normalized gas inlet temperature for three cases.

\subsubsection{Comprehensive Strategy for Managing Transients}

One of the objectives for the FCR concept was to achieve self-controllability and reactor shutdown without exceeding structural temperature limits even in case of failure to SCRAM. The most challenging accident without SCRAM is an unprotected station blackout, since the unprotected loss of flow and unprotected control rod withdrawal can be accommodated through the self-sustained operation of the $\mathrm{S}-\mathrm{CO}_{2} \mathrm{PCS}$. Therefore, the discussion will focus on SBO, but also applies to other accidents in case the PCS is not available.

Transient simulations indicated that during an SBO coincident with a failure to SCRAM and operation of PSACS trains can be accommodated with peak cladding temperatures within the $725^{\circ} \mathrm{C}$ temperature limit, independent of the number of operating PSACS trains. This is because the reactor power self-adjusts to RVACS+PSACS heat removal capacity. However, because unprotected accidents have an extremely low probability, it is more important to assure safe reactor performance under protected accidents. Although this is typically easier to do than for unprotected accidents, lead and salt-cooled reactors pose a challenge in this respect because of the potential of freezing of coolants that have a high melting point. Therefore, one needs not only to guarantee sufficient DHR not to exceed maximum cladding temperature, but also to avoid excessive cooling to remain above coolant melting point. This is not an easy task for multiple DHR trains, since it is not known a priori how many of the $4 \times 50 \%$ trains will be operating. The DHR strategy 
must ensure that the peak cladding temperatures are not exceeded and the coolant does not freeze under both unprotected and protected accidents.

The six plausible PSACS configurations during an SBO are listed in Table 2.2.3-6. The first letter of the Configuration ID indicates the state of the reactor protection system: $\mathrm{P}=$ protected/SCRAMMED, $\mathrm{U}=$ unprotected/UNSCRAMMED. The number following this letter indicates the number of PSACS trains initially available during the event. P1 and U1 are not considered in this analysis since they are extremely unlikely. STATUS columns indicate the cases which were analyzed in this project to confirm acceptable performance and cases that were not analyzed. The latter cases are expected to exhibit acceptable response since these are bounded by the analyzed cases.

The challenge with mitigating an SBO is that design changes that improve the PSACS with respect to one configuration may degrade PSACS performance in another configuration. For example, a larger heat exchanger would help U2 but would hurt P4. Therefore, a comprehensive design strategy is needed. Unprotected SBOs are beyond design basis and are extremely unlikely. They assume a loss of two independent offsite power sources, two independent onsite power sources, and two independent SCRAM trains. We therefore chose to focus on design basis events, P4, P3, and P2. Our design philosophy was that design changes should not be made that adversely affect PSACS performance in these configurations even if it improves performance for $\mathrm{U} 4, \mathrm{U} 3$, and $\mathrm{U} 2$.

Table 2.2.3-6- PSACS Configuration Table

\begin{tabular}{|c|c|c|c|c|}
\hline $\begin{array}{l}\text { Configuration } \\
\text { ID }\end{array}$ & Comments & Concern & Status - LFR & Status -LSFR \\
\hline $\mathrm{P} 4$ & Most likely & Freezing & $\mathrm{OK}$ & Analyzed, OK. \\
\hline P3 & $\begin{array}{l}\text { Expected to occur } \\
\text { during plant life (e.g. } \\
\text { one train out for } \\
\text { maintenance) }\end{array}$ & Freezing & $\begin{array}{l}\text { Not analyzed - } \\
\text { bounded by P4 } \\
\text { or P2, }\end{array}$ & $\begin{array}{l}\text { Not analyzed - } \\
\text { bounded by P4 } \\
\text { or P2. }\end{array}$ \\
\hline P2 & $\begin{array}{l}\text { Unlikely, but within } \\
\text { design basis }\end{array}$ & $\begin{array}{l}\text { Clad } \\
\text { Damage }\end{array}$ & Analyzed, OK & Analyzed, OK. \\
\hline U4 & Beyond design basis & $\begin{array}{l}\text { Clad } \\
\text { Damage }\end{array}$ & $\begin{array}{l}\text { Not analyzed - } \\
\text { bounded by P4. }\end{array}$ & Analyzed, OK \\
\hline U3 & Beyond design basis & $\begin{array}{l}\text { Clad } \\
\text { Damage }\end{array}$ & $\begin{array}{l}\text { Not analyzed - } \\
\text { bounded by } \\
\text { U2. }\end{array}$ & $\begin{array}{l}\text { Not analyzed - } \\
\text { bounded by U2 }\end{array}$ \\
\hline $\mathrm{U} 2$ & Beyond design basis & $\begin{array}{l}\text { Clad } \\
\text { Damage }\end{array}$ & Analyzed, OK & Analyzed, OK \\
\hline
\end{tabular}




\section{Design Strategy}

The initial concern was that the most likely PSACS configuration, P4, would result in coolant freezing. The solution to this approach was to reduce the decay heat removal during P4 to an acceptable level without introducing additional failure modes or increasing system complexity.

Initially, changing the PSACS isolation valves to a battery operated design was considered. This approach would allow manual or automatic isolation of one or more PSACS trains to prevent over-cooling. The downside to this change is that several new failure modes are introduced. First, each PSACS train has two isolation valves in a parallel configuration. Therefore, to isolate a train, both valves must fully close and there is a possibility that this will not be successful. Furthermore, the current PSACS isolation valves are of a highly reliable fail-safe design that fails open upon loss of AC. Changing this valve design to one that can open and close reduces their reliability and increases the probability that a PSACS train will fail to actuate when needed or fail spuriously during a transient.

With these considerations in mind, a more passively safe design was selected. Rather than altering the PSACS valves, the size of the PSACS heat exchanger and water tank can be adjusted to accommodate both $\mathrm{P} 4$ and $\mathrm{P} 2$. The final design removes enough heat during U2 to prevent clad damage but does not overcool and freeze the primary during P4. The PSACS HX and tank sizing to achieve acceptable performance differ between the LFR and LSFR concepts and will be presented in Chapters 3 and 4. Figures 2.2.3-17 and 2.2.3-18 show examples of the peak cladding temperature response of LFR for both $\mathrm{CR}=1$ and $\mathrm{CR}=0$ to station blackout. It can be observed that LFR with optimized PSACS can accommodate both protected and unprotected SBOs with an acceptable margin to coolant freezing and without exceeding the cladding temperature limit.

This design modification maintains the passive philosophy of the PSACS and ensures that the appropriate level of decay heat removal is provided under all credible SBO scenarios. The PSACS provides a robust SBO mitigation capability with two, three, or four operational trains and does not under- or over-cool the primary system. In the extremely unlikely event of a SBO coincident with a failure to SCRAM, the PSACS provides a long term mitigation capability. To accommodate the unprotected worst case for LFR requires a relatively large PSACS tank. Alternatively, a smaller tank could be used together with additional compensatory actions, such as manual scram or recovery of $\mathrm{AC}$ power, before the reactor restarts. This is possible since there is ample time for these actions: 24 hours for a $\mathrm{CR}=1$ core or 11 hours for a $\mathrm{CR}=0$ core. 
Project No 06-040: Flexible Conversion Ratio Fast Reactor Systems Evaluation

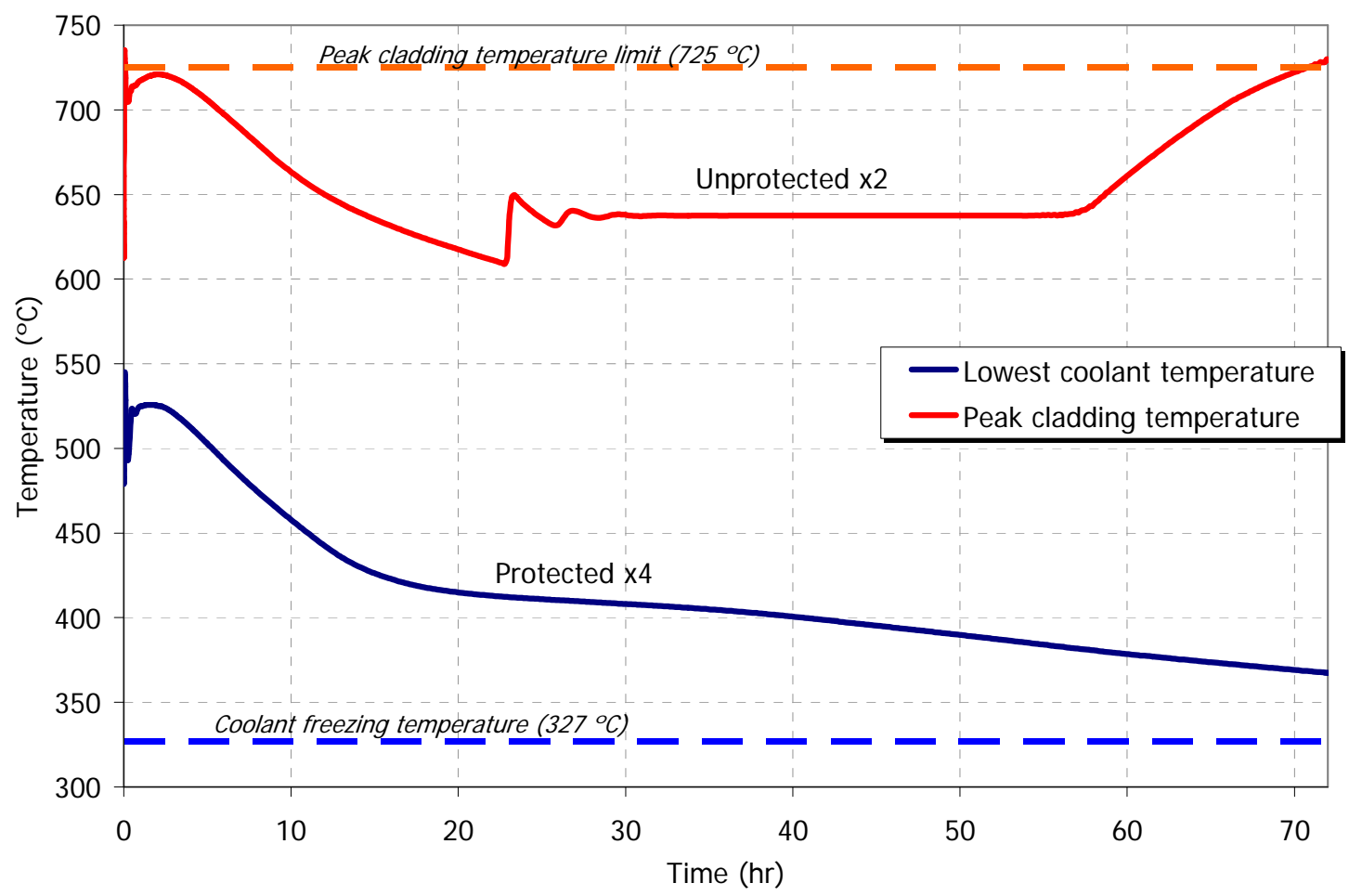

Figure 2.2.3-17 SBO bounding cases for $\mathrm{CR}=1$

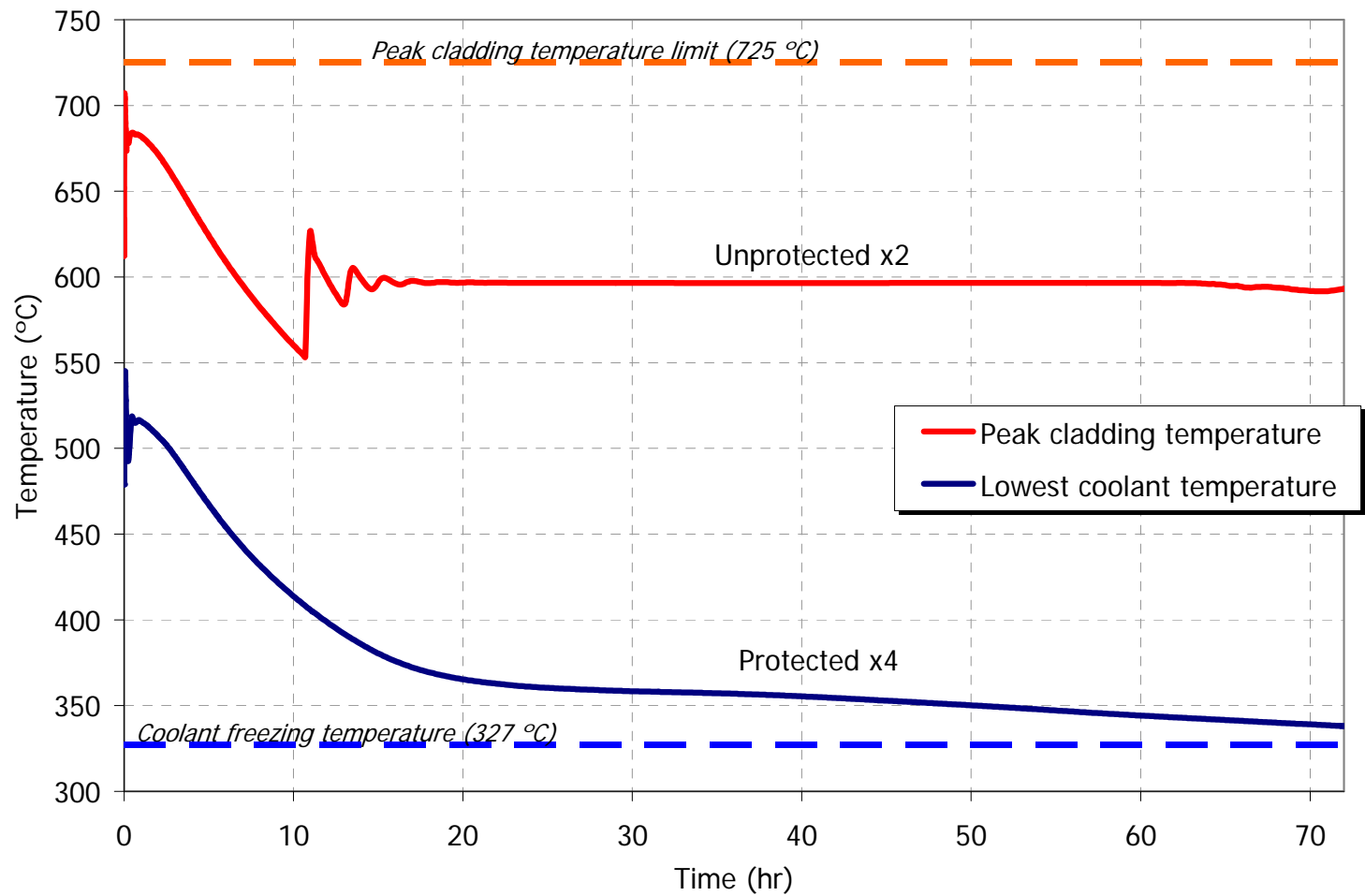

Figure 2.2.3-18 SBO bounding cases for $\mathrm{CR}=0$ 


\section{References for Chapter 2}

E. Adamov et al., "Conceptual Design of BREST-300 Lead-Cooled Fast Reactor", Proc. of the ARS'94 Int. Topical Mtg. on Adv. Reactor Safety, Pittsburgh, PA, Apr. 17-21 (1994)

Aquien A., Kazimi M.S., and Hejzlar P., "Fuel Cycle Options for Optimized Recycling of Nuclear Fuel”, Report MIT-NFC-TR-086, Center for Advanced Nuclear Energy Systems, June 2006a.

Aquien A., Kazimi M. S., and Hejzlar P., "Transuranics Recycling in Various Reactor/Fuel Cycle Systems", Transactions of the American Nuclear Society, Vol. 95, Albequerque NM, USA, November 12-16, $2006 \mathrm{~b}$.

J. Buongiorno, "Temperature Limits for Heavy-Liquid-Metal Reactor Vessels", Proc. of the 2001 ANS Winter Meeting, Reno, NV, Nov. 11-15 (2001).

Dostal V., Driscoll M. J. and Hejzlar P., “ A Supercritical Carbon Dioxide Cycle for Next Generation Nuclear Reactors”, MIT-ANP-TR-100, March 2004.

Dubberley A. E., Boardman C. E., Yoshida K., and Wu T., "SuperPRISM Oxide and Metal Fuel Core Designs", ICONE-8002, Proc. of ICONE-8, $8^{\text {th }}$ Int. Conf. on Nucl. Eng., Baltimore, MD, Apr. 2-6, 2000.

Eide S., Chmielewski V., and Swantz T., "Generic Component Failure Data for Light Water and Liquid Sodium Reactor PRAs," Idaho National Engineering Laboratory, 1990.

Hejzlar P., Buongiorno J., MacDonald P. E., Todreas N. E., "Design Strategy and Constraints for Medium-Power Lead-Alloy-Cooled Actinide Burners," Nuclear Technology, 147, 3, pp. 321-343, 2004.

Hill R. N., J. E. Cahalan, H. S. Khalil, and D. C. Wade, "Development of Small, Fast Reactor Core Design Using Lead-Based Coolant," Proc. of the Global 1999 Int. Conf., Jackson Hole, WY, Aug. 1999.

Klueh R.L. and Harries D.R., "High-Chromium Ferritic and Martensitic Steels for Nuclear Applications", American Society for Testing and Materials", West Conshocken, 2001.

Pahl R. G., Porter D. L., Lahm C. E., and Hofman G. L., "Experimental Studies of U-PuZr Fast Reactor Fuel Pins in the Experimental Breeder Reactor-II", Metallurgical Trans. A, 21A, 1863-1870, 1990. 
Project No 06-040: Flexible Conversion Ratio Fast Reactor Systems Evaluation

Pope M.A., Hejzlar P., and Driscoll M.J." "Thermal Hydraulics of a $2400 \mathrm{MWt}$ Supercritical $\mathrm{CO}_{2}$-Direct Cycle GFR", MIT-ANP-TR-107, Center for Advanced Nuclear Energy Systems, Massachusetts Institute of Technology, 2006.

Rausand M., and Hoyland A., System Reliability Theory Models, Statistical Methods, and Applications, $2^{\text {nd }}$ ed, Wiley Publishing, Hoboken, NJ, 2004.

Wade, D.C., Chang, Y.I., "The Integral Fast Reactor Concept: Physics of Operation and Safety”, Nuclear Science and Engineering, 100, pp. 507-524, 1988.

Wade D. C. and Hill R. N., "The Design Rationale of the IFR," Prog.in Nucl Energy, 31 (1), pp.13-42, Jan. 1997.

Wade D.C. and Fujita E.K., "Trends Versus Reactor Size of Passive Reactivity Shutdown and Control Performance," Nuclear Science and Engineering, Vol. 103, pp. 182-195, 1989. 


\section{Lead Alloy-Cooled Reactor Designs}

\subsection{Unity Conversion Ratio Core}

\subsubsection{Neutronic Analysis}

This section describes the design of the lead-cooled fast spectrum reactor with a unity conversion ratio. The main objective of the design is to achieve a self sustainable fuel cycle, which generates and burns TRU at about the same rate. Such a fuel cycle would require natural uranium feed only, whereas TRUs would be continuously recycled. At the same time, if necessary, it should be possible to replace the core with one that has a close to zero conversion ratio without any major modifications in the design.

The goal of achieving a unity conversion ratio should be achieved while meeting a number of design constraints:

- The unity conversion ratio should be achieved without using fertile blankets to assure proliferation resistance of the fuel cycle.

- The core average power density should be at least $100 \mathrm{~W} / \mathrm{cm}^{3}$ (which is typical of current generation LWRs) in order to provide economic competitiveness. Specific power and fuel cycle length should also have reasonably high values for the same reason.

- The core reactivity feedback coefficients should be such that the core materials safety limits are not compromised under most limiting accident scenarios.

- Burnup, fluence, temperature and other limits imposed on the core materials and discussed in Section 2.1 should be satisfied.

The analysis reported in this section was primarily performed with the Monte Carlo Nparticle transport code MCNP-4C [Briesmeister, 2000]. The cross-section data used in the calculations were based on the JEFF-3.1 evaluated data file. The fuel burnup calculations were performed with MCODE [Xu et al., 2002] which couples MCNP with ORIGEN-2.2 [Croff, 1983]. Detailed description of the tools used in this analysis is presented in Appendix 3A.

\subsubsection{Core Design Description}

The $\mathrm{CR}=1$ core is a 1-batch 3-region core using metallic fuel, where the composition of transuranics corresponds to that of discharged LWR fuel with $50 \mathrm{MWd} / \mathrm{kg}$ burnup. The reference fuel form used in the analysis is metallic U-TRU-Zr alloy with at least $10 \mathrm{wt} . \%$ of $\mathrm{Zr}$. The metallic fuel has a number of favorable properties such as high thermal conductivity and a high heavy metal density. A significant advantage of metallic fuel with respect to self-controllability is a small negative Doppler feedback, which results in a small reactivity addition in unprotected loss of flow and loss of heat sink accidents. Smear density of $70 \%$ was assumed in this analysis, which for the selected fuel pin design corresponds to $93.5 \%$ of theoretical fuel density. 
The fuel composition of the $\mathrm{CR}=1$ core was selected so that the desired $\mathrm{CR}$ could be maintained in a sustainable manner. That is, the actinides discharged from the core can be recycled into the next core and maintain comparable cycle length and CR without requiring any external feed of TRU. In addition, the content of $\mathrm{Zr}$ in the fuel is varied to maintain acceptable radial core power distribution throughout the fuel cycle. The ratio of TRU to natural uranium is kept constant in all three radial fuel zones and equal to 1:5.

The fuel pins used in the current design are $390 \mathrm{~cm}$ long and have four axial zones. The lower $30 \mathrm{~cm}$ zone includes boron carbide shielding that protects the core support structures, which are difficult to replace, from radiation damage. The shield is followed by the $1 \mathrm{~m}$ long metallic $\mathrm{Zr}$ reflector. An all-lead bottom reflector, inside and outside the fuel pin, would have superior neutronic performance to $\mathrm{Zr}$. However, the question of active fuel support with liquid lead underneath remains open. Therefore, metallic Zr was chosen as a more practical option. The $130 \mathrm{~cm}$ active core includes the metallic TRU-U$\mathrm{Zr}$ fuel lead-bonded with T-91 stainless steel cladding. Finally, the remaining $130 \mathrm{~cm}$ space above the active fuel length is the plenum, designed to accommodate the fission gases released during core operation.

The fuel assemblies are enclosed by stainless steel cans to control coolant flow through the assembly and mitigate the consequences of some severe accidents. However, the presence of the cans reduces the core reactivity due to parasitic absorption and additional neutron leakage. On the other hand, "open" fuel bundles are planned to be used in the lead-cooled BREST reactor currently under development in Russia [Adamov et al., 1994]. In addition to a higher core multiplication factor and, as a result, lower TRU loading requirements and higher conversion ratio, the uncanned fuel assemblies provide a number of additional advantages, such as some coolant mixing between the adjacent bundles and less severe consequences in case of a channel flow blockage event. This makes it worthwhile, therefore, to evaluate a lead-cooled core with uncanned fuel assemblies. Such analysis is beyond the scope of this project and could be performed in the future.

Double-entry control rods were used to provide additional safety features during seismic and large temperature change accidents as well as flatten the core axial power distribution [Hejzlar et al., 2004]. In about one-half of the fuel assemblies, the control rods are inserted from the top, and in the rest, from the bottom. The top-entry control rods have tungsten weights attached at the bottom to overcome the buoyancy force in case of a control rod drive failure.

The schematic axial core cross section view, as modeled in the neutronic analysis, is presented in Figure 3.3.1-1. An assembly picture to scale is shown in Figure 3.3.1-2.

The core and fuel assembly designs of the $\mathrm{CR}=1$ core are summarized in Tables 3.3.1-1 and 3.3.1-2 respectively. 
Project No 06-040: Flexible Conversion Ratio Fast Reactor Systems Evaluation

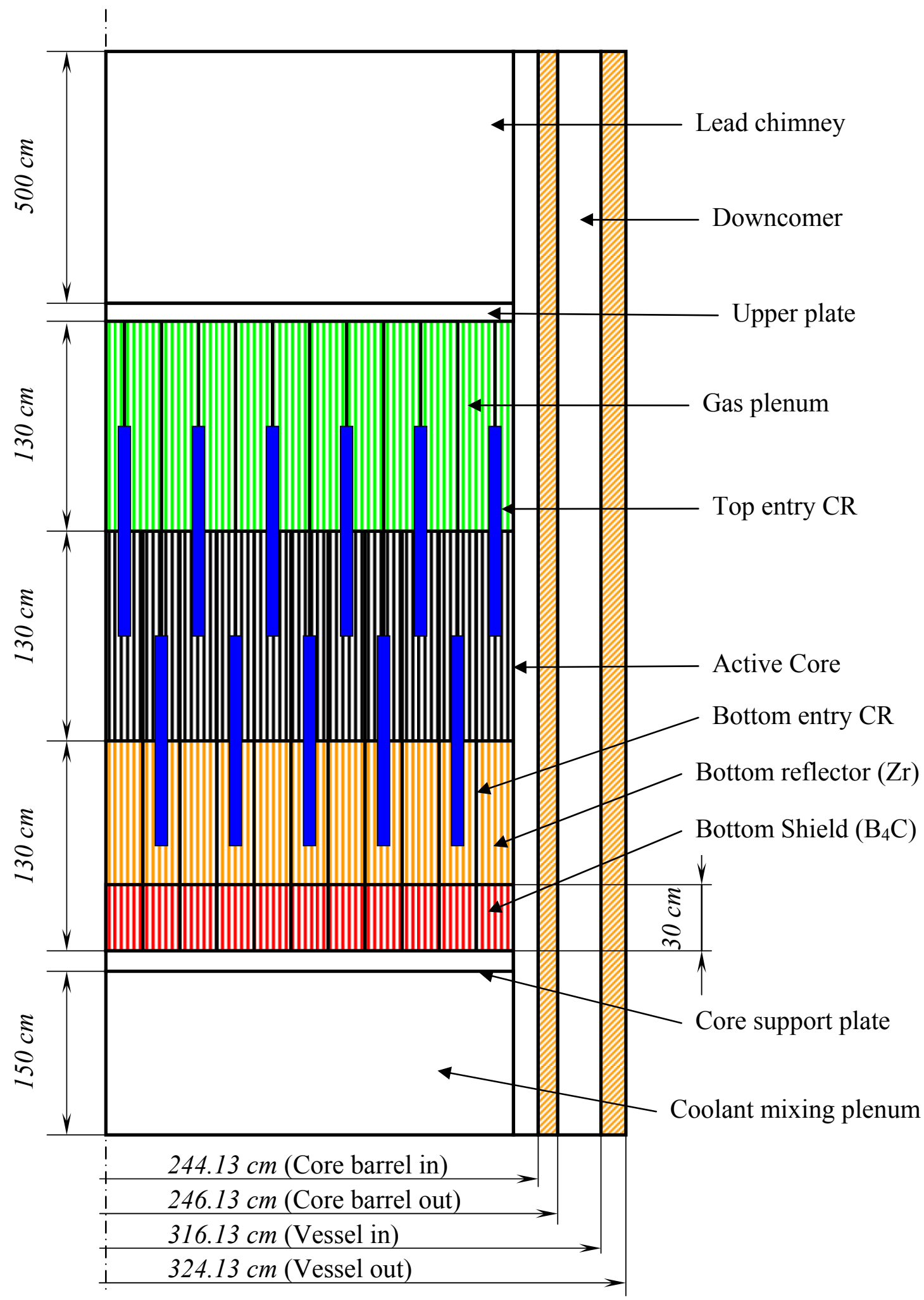

Figure 3.3.1-1 Schematic core layout 
Project No 06-040: Flexible Conversion Ratio Fast Reactor Systems Evaluation

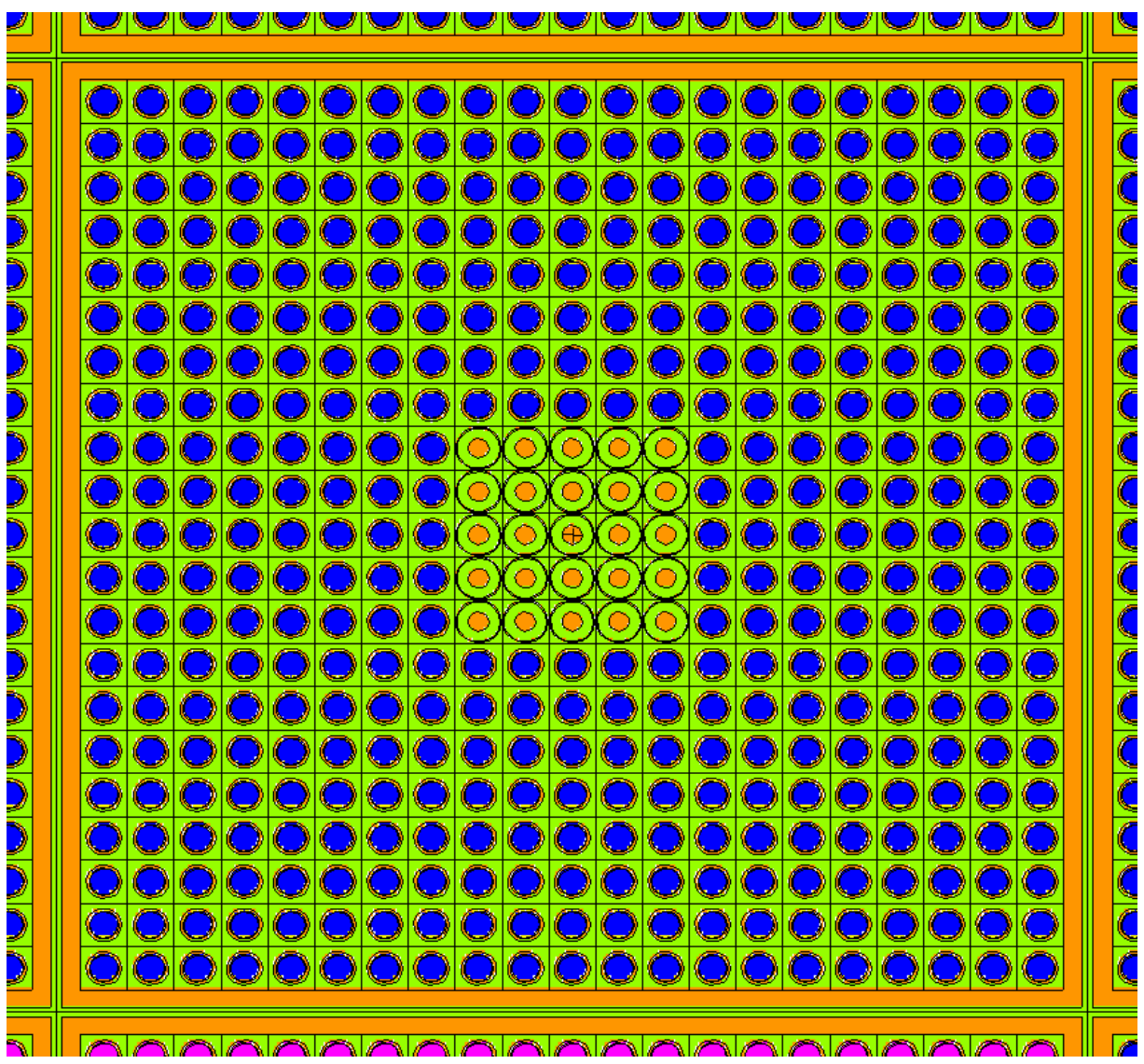

Figure 3.3.1-2 Assembly with cans to scale (blue are fuel rods, green and orange are guide tubes with control rods)

The radial cross-section of the core is schematically shown in Figure 3.3.1-3. In order to flatten the radial power distribution, the core was divided into three radial zones with different fuel compositions. Preliminary analysis as well as previous studies showed that tailoring the TRU loading to achieve a favorable power distribution is relatively ineffective because, with burnup, the power distribution gradually returns to the fundamental mode flux shape. It was shown that a much more effective strategy is to vary the concentration of diluent material in the fuel (here, $\mathrm{Zr}$ weight \%) keeping the uranium to TRU ratio the same [Handwerk et al. 2006]. In this case, the power shape remains relatively constant through the fuel cycle. 
Table 3.3.1-1 Unity conversion ratio core model description

\begin{tabular}{|l|r|}
\hline Parameters & Value \\
\hline Bottom coolant mixing plenum height, cm & 150.000 \\
\hline Core support plate thickness, cm & 4.500 \\
\hline Core support height (shield + bottom reflector), cm & 130.000 \\
\hline Active core height, cm & 130.000 \\
\hline Gas plenum height, cm & 130.000 \\
\hline Upper plate thickness, cm & 1.000 \\
\hline Lead chimney height, cm & 500.000 \\
\hline Core barrel inner radius, cm & 244.131 \\
\hline Core barrel outer radius, cm & 246.131 \\
\hline Reactor vessel inner radius, cm & 316.131 \\
\hline Reactor vessel outer radius, cm & 324.131 \\
\hline Number of assemblies & 349 \\
\hline Core cross sectional area, $\mathrm{cm}{ }^{2}$ & $165,080.6$ \\
\hline Equivalent core radius, $\mathrm{cm}$ & 229.2 \\
\hline Core volume, $\mathrm{cm}^{3}$ & $21,460,477$ \\
\hline Core average power density, W/cm ${ }^{3}$ & 111.8 \\
\hline Initial core fuel inventory, $\mathrm{kgHM}$ & 53,631 \\
\hline Core specific power, W/gHM & 44.75 \\
\hline
\end{tabular}

Table 3.3.1-2 Unity conversion ratio core: Fuel assembly model description

\begin{tabular}{|l|r|}
\hline Parameters & Value \\
\hline Pin outer diameter, cm & 0.752 \\
\hline Pin Pitch to Diameter Ratio, cm & 1.300 \\
\hline Pin pitch, cm & 0.978 \\
\hline Fuel diameter, cm & 0.542 \\
\hline Gap thickness, cm & 0.042 \\
\hline Fuel-cladding bond & lead \\
\hline Cladding thickness, cm & 0.063 \\
\hline Cladding material & $\mathrm{T}-91$ \\
\hline Fuel assembly pitch, cm & 21.7488 \\
\hline Fuel assembly can thickness, cm & 0.394 \\
\hline Fuel assembly can material & $\mathrm{T}-91$ \\
\hline Inter assembly gap (hot), cm & 0.2229 \\
\hline CR guide tube outer radius, cm & 0.480 \\
\hline CR guide tube thickness, cm & 0.028 \\
\hline CR outer radius, cm & 0.432 \\
\hline CR active material & $\mathrm{B}_{4} \mathrm{C}\left(50 \%{ }^{10} \mathrm{~B}\right)$ \\
\hline
\end{tabular}




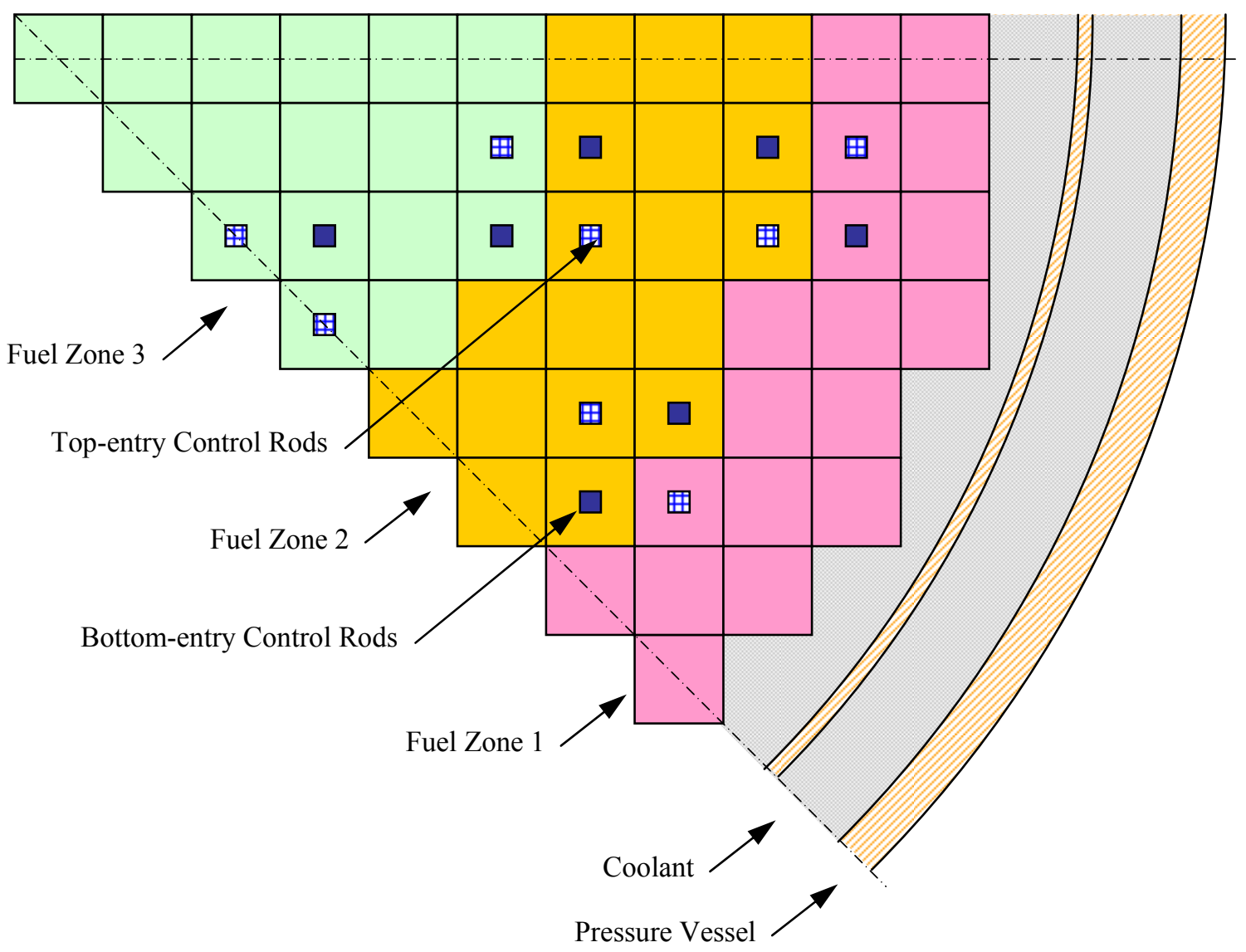

Figure 3.3.1-3 Radial core zoning.

\subsubsection{Key Results}

The fuel cycle length of approximately 1800 days is restricted by the peak cladding fluence limit of $4.0 \times 10^{23}(\mathrm{E}>0.1 \mathrm{MeV}) / \mathrm{cm}^{2}$, as shown in Figure 3.3.1-4. In the first cycle, with the initial actinide isotopic vector originating from typical LWR legacy waste, the conversion ratio is very close to unity, with small breeding of $\mathrm{Pu}$ but with the net destruction of MAs. The initial and discharge fuel composition in each radial fuel zone is summarized in Table 3.3.1-3.

The radial power distribution maps at three time points - Beginning (BOC), Middle (MOC), and End (EOC) of the fuel cycle - are presented in Figures 3.3.1-5 through 3.3.17 respectively. The radial power distribution can be maintained relatively flat over the entire cycle through the tailoring of $\mathrm{Zr}$ content in the fuel. The maximum radial power peak of 1.21 appears at MOC. A detailed, pin by pin power distribution in the "hot" assembly at MOC is presented in Figure 3.3.1-8. The peaking factors range from 0.98 to 1.02 as a result of the very flat flux profile typical of fast reactors. 
Project No 06-040: Flexible Conversion Ratio Fast Reactor Systems Evaluation

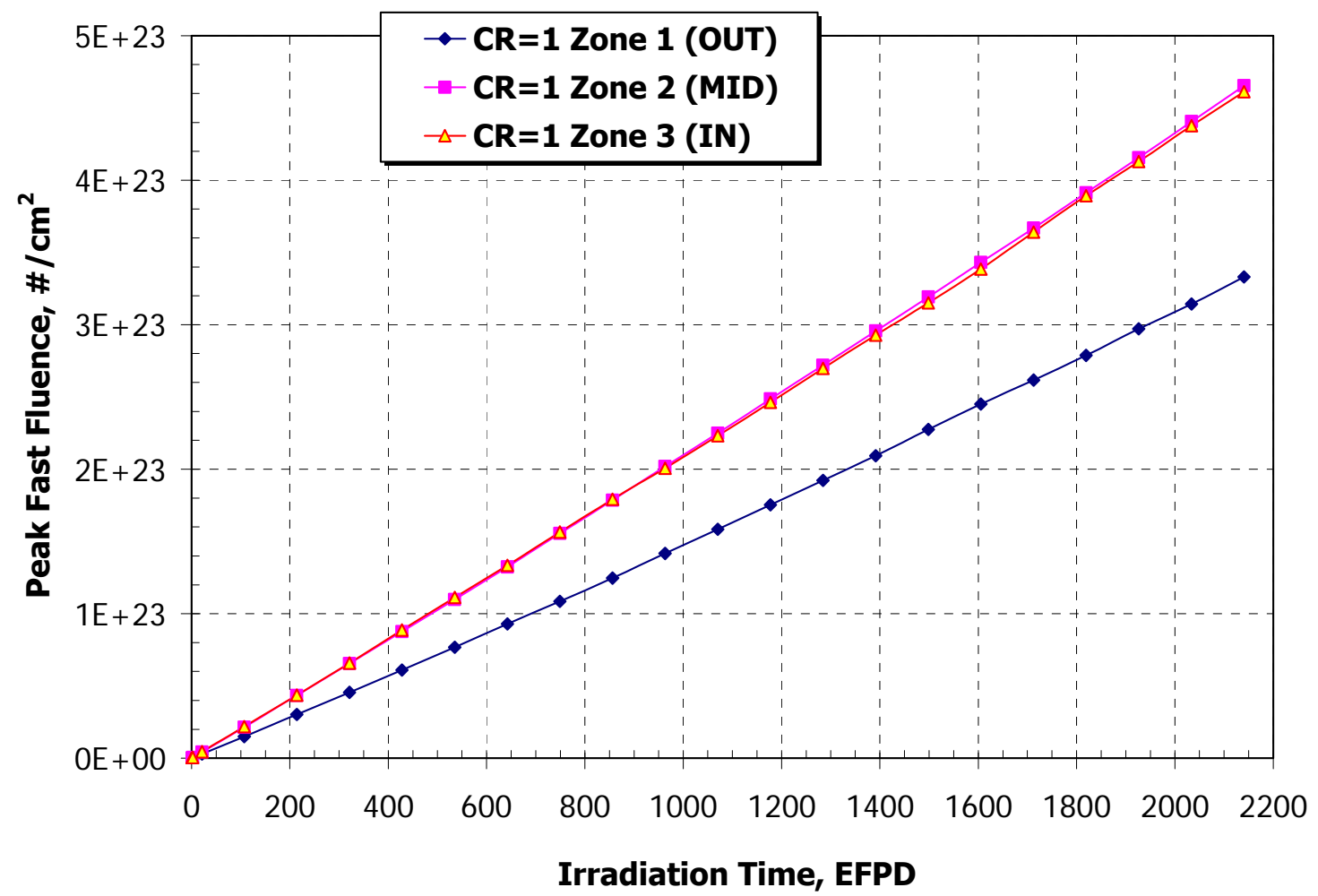

Figure 3.3.1-4 Peak cladding fast fluence

Two additional $\mathrm{CR}=1$ lead-cooled cores were simulated with TRUs recycled for the second and third time in order to evaluate the effect of changing TRU isotopic composition on fuel cycle length and conversion ratio. The TRU discharged from the first core with a decay period of 7 years was assumed to be mixed with natural uranium and reloaded to a subsequent core. The results of this TRU recycling process are presented in Figures 3.3.1-9 and 3.3.1-10.

Figure 3.3.1-9 presents the evolution of core criticality as a function of irradiation time. Figure 3.3.1-10 presents the core Pu content as a function of burnup. Tables 3.3.1-3 and 3.3.1-4 present the balance of materials in the three modeled consecutive cycles and evolution of TRU isotopic vector, respectively. 
Project No 06-040: Flexible Conversion Ratio Fast Reactor Systems Evaluation

Table 3.3.1-3 Summary of $\mathrm{CR}=1$ fuel cycle parameters

\begin{tabular}{|l|r|r|r|r|}
\hline \multicolumn{1}{|c|}{ Parameters } & \multicolumn{1}{c|}{ Zone 1 } & \multicolumn{1}{c|}{ Zone 2} & \multicolumn{1}{c|}{ Zone 3 } & \multicolumn{1}{c|}{ Core } \\
\hline Zr content, wt. \% & 10.0 & 15.0 & 19.0 & - \\
\hline Fuel density (g/cc) & 15.38 & 14.28 & 13.50 & - \\
\hline Smear density (g/cc) & 11.53 & 10.70 & 10.12 & - \\
\hline TRU content, wt. \% & 15.00 & 14.17 & 13.50 & 96 \\
\hline Natural Uranium content, wt. \% & 75.00 & 70.83 & 67.50 & 253 \\
\hline Number of FA with CRDs & 24 & 56 & 16 & 86,472 \\
\hline Number of FA without CRDs & 104 & 68 & 81 & 8,131 \\
\hline Initial HM loading, kg & 23,215 & 19,494 & 13,764 & 47,086 \\
\hline Pu & 3,342 & 2,807 & 1,982 & 1,255 \\
\hline NU (Natural Uranium) & 19,356 & 16,254 & 11,476 & 51,878 \\
\hline MA & 516 & 433 & 306 & 8,268 \\
\hline Discharge HM, kg & 21,732 & 17,733 & 12,413 & 42,657 \\
\hline Pu & 3,375 & 2,849 & 2,044 & 953 \\
\hline NU & 17,935 & 14,568 & 10,154 & 77 \\
\hline MA & 423 & 316 & 214 & 1800 \\
\hline Discharge burnup, MWd/kg & 60 & 86 & 93 & \\
\hline Cycle length, EFPD & - & - & - & \\
\hline
\end{tabular}

\begin{tabular}{|c|c|c|c|c|c|c|c|c|c|c|}
\hline 0 & 1 & 2 & 3 & 4 & 5 & 6 & 7 & 8 & 9 & 10 \\
\hline 1.08 & 1.08 & 1.06 & 1.05 & 1.04 & 1.03 & 1.14 & 1.11 & 1.01 & 0.98 & 0.76 \\
\hline 1 & 1.07 & 1.05 & 1.05 & 1.04 & 0.95 & 1.07 & 1.10 & 0.94 & 0.90 & 0.75 \\
\hline 2 & & 0.96 & 0.97 & 1.04 & 0.98 & 1.06 & 1.10 & 0.92 & 0.89 & 0.72 \\
\hline 3 & & & 0.96 & 1.06 & 1.19 & 1.17 & 1.11 & 1.13 & 0.92 & 0.69 \\
\hline 4 & & & & 1.20 & 1.19 & 1.15 & 1.08 & 1.08 & 0.85 & \\
\hline 5 & & & & & 1.07 & 1.02 & 1.14 & 0.96 & 0.74 & \\
\hline 6 & & & & & & 1.06 & 0.99 & 0.81 & & \\
\hline 7 & & & & & & & 0.82 & & & \\
\hline
\end{tabular}

Figure 3.3.1-5 CR=1 Core, Radial Power Distribution Map at BOC (0 MWd/kg) 
Project No 06-040: Flexible Conversion Ratio Fast Reactor Systems Evaluation

\begin{tabular}{|c|c|c|c|c|c|c|c|c|c|c|}
\hline 0 & 1 & 2 & 3 & 4 & 5 & 6 & 7 & 8 & 9 & 10 \\
\hline 1.17 & 1.17 & 1.15 & 1.12 & 1.09 & 1.06 & 1.15 & 1.10 & 0.99 & 0.94 & 0.72 \\
\hline 1 & 1.16 & 1.13 & 1.11 & 1.09 & 0.98 & 1.07 & 1.09 & 0.92 & 0.87 & 0.71 \\
\hline 2 & & 1.02 & 1.01 & 1.08 & 1.00 & 1.06 & 1.09 & 0.90 & 0.86 & 0.69 \\
\hline 3 & & & 1.00 & 1.09 & 1.20 & 1.16 & 1.09 & 1.11 & 0.89 & 0.66 \\
\hline 4 & & & & 1.21 & 1.19 & 1.14 & 1.05 & 1.05 & 0.82 & \\
\hline 5 & & & & & 1.06 & 1.00 & 1.11 & 0.92 & 0.71 & \\
\hline 6 & & & & & & 1.03 & 0.95 & 0.77 & & \\
\hline 7 & & & & & & & 0.78 & & & \\
\hline
\end{tabular}

Figure 3.3.1-6 CR=1 Core, Radial Power Distribution Map at MOC (40 MWd/kg)

\begin{tabular}{|c|c|c|c|c|c|c|c|c|c|c|c|}
\hline & 0 & 1 & 2 & 3 & 4 & 5 & 6 & 7 & 8 & 9 & 10 \\
\hline 0 & 1.15 & 1.14 & 1.12 & 1.09 & 1.07 & 1.04 & 1.14 & 1.10 & 0.99 & 0.96 & 0.78 \\
\hline 1 & & 1.13 & 1.10 & 1.08 & 1.07 & 0.97 & 1.05 & 1.08 & 0.92 & 0.89 & 0.77 \\
\hline 2 & & & 0.99 & 0.99 & 1.07 & 0.99 & 1.05 & 1.07 & 0.90 & 0.88 & 0.74 \\
\hline 3 & & & & 0.98 & 1.07 & 1.18 & 1.14 & 1.07 & 1.12 & 0.91 & 0.69 \\
\hline 4 & & & & & 1.20 & 1.18 & 1.14 & 1.06 & 1.06 & 0.84 & \\
\hline 5 & & & & & & 1.06 & 1.02 & 1.15 & 0.95 & 0.74 & \\
\hline 6 & & & & & & & 1.07 & 0.99 & 0.81 & & \\
\hline 7 & & & & & & & & 0.82 & & & \\
\hline
\end{tabular}

Figure 3.3.1-7 CR=1 Core, Radial Power Distribution Map at EOC (80 MWd/kg)

As can be observed from Figures 3.3.1-9 through 3.3.1-10 the reactivity limited burnup gradually increases with the number of TRU recycles despite the fact that the total TRU inventory is decreasing. This is because the $\mathrm{Pu}$ content slightly increases with the recycling of TRU, while the MA inventory is decreasing. The core reactivity changes very slightly (about $2 \% \Delta \rho$ ) over the lifetime of the core. The Pu isotopic vector remains practically constant, with a slight reduction in the amount of the Pu241 isotope. All MA isotopes exhibit net reduction in their amounts except for the two $\mathrm{Cm}$ isotopes, $\mathrm{Cm} 245$ and $\mathrm{Cm} 246$. The $\mathrm{Cm}$ isotope macroscopic cross-section error is relatively large because of their small quantity and therefore relatively poor reaction rate statistics. Therefore, more accurate analysis should be performed in order to verify the $\mathrm{Cm}$ isotope buildup results. 
Project No 06-040: Flexible Conversion Ratio Fast Reactor Systems Evaluation

\begin{tabular}{|l|l|l|l|l|l|l|l|l|l|l|l|l|l|l|l|l|l|l|l|l|}
\hline 0.99 & 1.00 & 1.00 & 0.99 & 0.99 & 1.00 & 1.02 & 1.02 & 1.01 & 1.00 & 1.00 & 1.00 & 0.99 & 1.01 & 1.00 & 0.99 & 1.00 & 1.01 & 1.00 & 0.99 & 0.99 \\
\hline
\end{tabular}

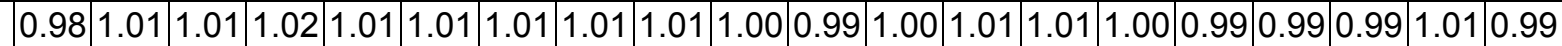
\begin{tabular}{ll|l|l|l|l|l|l|l|l|l|l|l|l|l|l|l|l|l|l|}
0.99 & 1.00 & 1.00 & 1.02 & 1.00 & 1.01 & 0.99 & 1.00 & 1.01 & 1.00 & 1.02 & 1.01 & 1.01 & 1.00 & 0.99 & 0.99 & 0.99 & 1.01 & 1.01 \\
\hline
\end{tabular}

\begin{tabular}{|l|l|l|l|l|l|l|l|l|l|l|l|l|l|l|l|l|l|}
1.01 & 1.00 & 1.01 & 1.00 & 1.01 & 1.01 & 0.99 & 1.01 & 1.02 & 1.00 & 1.01 & 1.00 & 1.00 & 1.01 & 1.00 & 0.99 & 1.01 & 0.99 \\
\hline
\end{tabular} \begin{tabular}{ll|l|l|l|l|l|l|l|l|l|l|l|l|l|l|l|l|}
1.01 & 1.01 & 1.01 & 1.00 & 1.01 & 1.01 & 1.01 & 1.01 & 1.00 & 1.00 & 1.00 & 1.00 & 1.01 & 1.00 & 1.01 & 0.99 & 1.00 \\
\hline
\end{tabular} \begin{tabular}{l|l|l|l|l|l|l|l|l|l|l|l|l|l|l|l|}
0.99 & 1.00 & 1.01 & 1.00 & 1.00 & 1.00 & 1.00 & 1.00 & 1.02 & 1.00 & 1.00 & 1.00 & 1.01 & 1.01 & 0.99 & 0.99 \\
\hline
\end{tabular} \begin{tabular}{l|l|l|l|l|l|l|l|l|l|l|l|l|l|l|l|}
0.98 & 1.01 & 1.01 & 1.01 & 1.01 & 1.00 & 1.01 & 1.00 & 1.00 & 1.00 & 0.99 & 0.99 & 1.00 & 0.99 & 1.00 \\
\hline
\end{tabular}

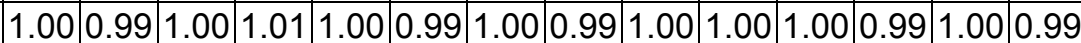
\begin{tabular}{|l|l|l|l|l|l|l|l|l|l|l|l|l|}
0.99 & 1.00 & 1.01 & 1.01 & 1.00 & 1.00 & 1.00 & 1.01 & 1.01 & 1.01 & 1.00 & 1.02 & 0.99 \\
\hline
\end{tabular} \begin{tabular}{ll|l|l|l|l|l|l|l|l|l|l|l|l|}
1.01 & 1.01 & 1.00 & 1.00 & 1.00 & 1.00 & 1.01 & 0.99 & 1.00 & 1.00 & 1.00 & 0.99 \\
\hline
\end{tabular} \begin{tabular}{|lll|l|l|l|l|l|l|l|l|l|}
1.01 & 1.02 & 1.00 & 1.00 & 1.01 & 1.01 & 1.02 & 0.99 & 0.99 & 0.99 & 0.99 \\
\hline
\end{tabular} \begin{tabular}{|l|l|l|l|l|l|l|l|l|l|}
1.01 & 1.02 & 1.01 & 1.00 & 1.01 & 1.01 & 1.01 & 1.00 & 1.01 & 0.98 \\
\hline
\end{tabular} \begin{tabular}{|l|l|l|l|l|l|l|l|l|}
0.98 & 0.99 & 1.00 & 1.00 & 1.01 & 1.00 & 1.02 & 1.00 & 1.00 \\
\hline
\end{tabular} \begin{tabular}{ll|l|l|l|l|l|l|l|}
1.00 & 0.99 & 1.01 & 0.99 & 1.01 & 1.00 & 1.00 & 0.99 \\
\hline
\end{tabular} \begin{tabular}{ll|l|l|l|l|l|l|l}
0.99 & 1.00 & 1.00 & 1.01 & 0.99 & 1.01 & 1.00 \\
\hline
\end{tabular} \begin{tabular}{ll|l|l|l|l|l|l|l|l|l|l|l|}
1.00 & 0.99 & 0.99 & 0.98 & 0.99 & 0.98 \\
\hline
\end{tabular} \begin{tabular}{l|l|l|l|l|l|l|l|l}
0.98 & 1.00 & 0.99 & 1.00 & 0.99 \\
\hline
\end{tabular} \begin{tabular}{ll|l|l|l|l|l|l|l|l|}
0.99 & 0.98 & 0.98 & 0.98 \\
\hline
\end{tabular} \begin{tabular}{ll|l|l|l|l|}
0.97 & 0.98 & 0.97 \\
\hline
\end{tabular} 0.970 .98

Figure 3.3.1-8. Pin power profile for the $\mathrm{CR}=1$ core in the "hot" assembly $[4,4]$ - see Figure 3.3.1-5

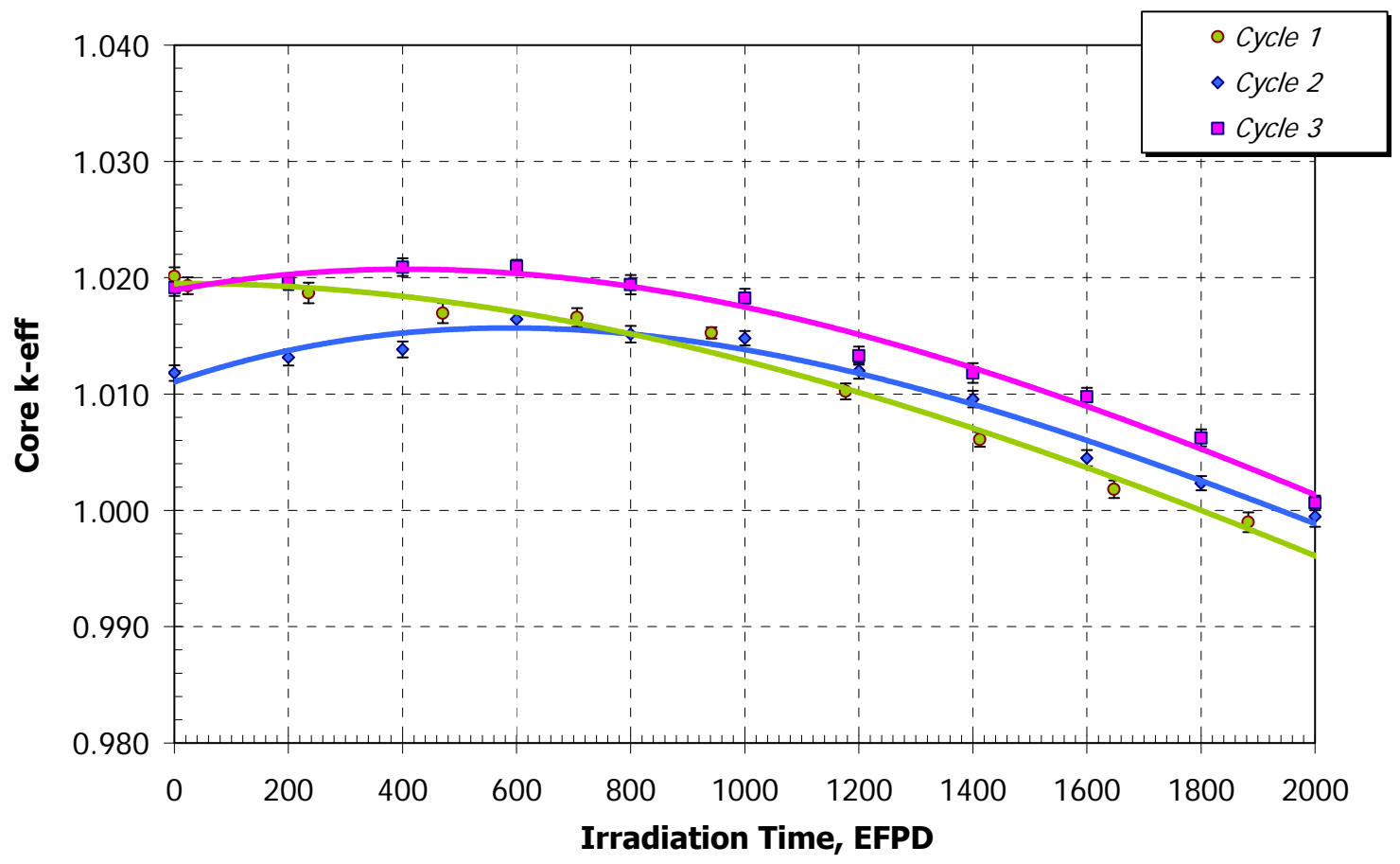

Figure 3.3.1-9. $\mathrm{CR}=1$ Core k-eff vs. irradiation time. 
Project No 06-040: Flexible Conversion Ratio Fast Reactor Systems Evaluation

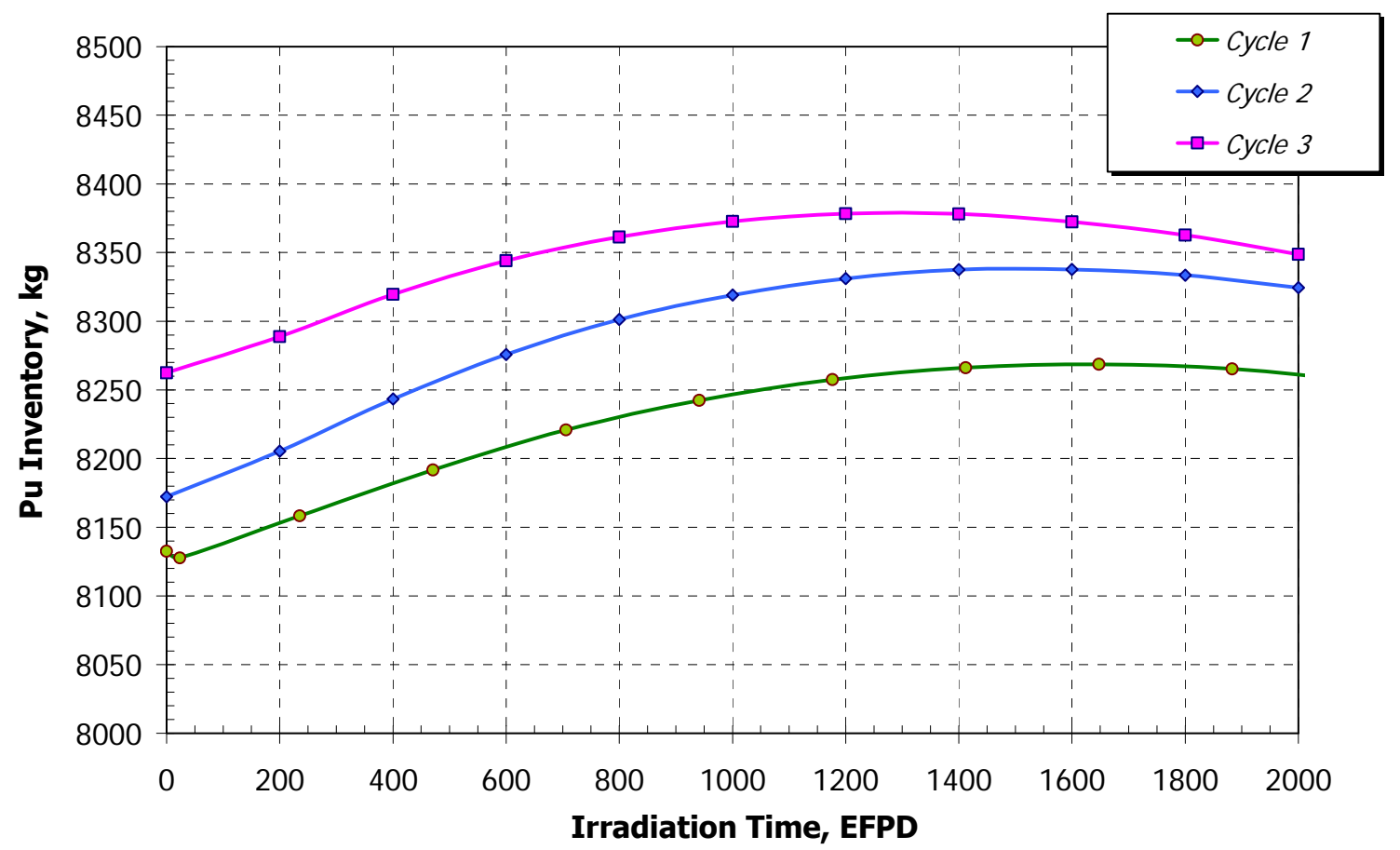

Figure 3.3.1-10 $\mathrm{CR}=1$ Core $\mathrm{Pu}$ inventory vs. Core irradiation time

Table 3.3.1-4 CR=1 Core materials balance

\begin{tabular}{|l|r|r|r|r|r|r|r|r|r|}
\hline & \multicolumn{3}{|c|}{ Cycle-1 TRU } & \multicolumn{3}{c|}{ Cycle-2 TRU } & \multicolumn{2}{c|}{ Cycle-3 TRU } & After 7y, \\
& Load, kg & Disch., kg & $\begin{array}{c}\text { After 7y, } \\
\mathrm{kg}\end{array}$ & Load, kg & Disch, kg & $\begin{array}{c}\text { Load, kg } \\
\text { Disch, kg }\end{array}$ & $\begin{array}{c}\text { After 7y, } \\
\mathrm{kg}\end{array}$ \\
\hline Core Total & 56,472 & 51,878 & - & 56,531 & 51,652 & - & 56,549 & 51,667 & - \\
\hline Pu & 8,131 & 8,268 & 8,171 & 8,171 & 8,327 & 8,261 & 8,261 & 8,352 & 8,293 \\
\hline U & 47,086 & 42,657 & - & 47,335 & 42,572 & - & 47,493 & 42,712 & - \\
\hline MA & 1,255 & 953 & 1,026 & 1,026 & 754 & 796 & 796 & 604 & 649 \\
\hline Pu+MA & 9,386 & 9,221 & 9,197 & 9,197 & 9,080 & 9,057 & 9,057 & 8,956 & 8,941 \\
\hline
\end{tabular}


Project No 06-040: Flexible Conversion Ratio Fast Reactor Systems Evaluation

Table 3.3.1-5 CR=1 Core TRU isotopic vector, wt \%

\begin{tabular}{|r|r|r|r|r|r|r|r|}
\hline & \multicolumn{3}{|c|}{ Cycle-1 } & \multicolumn{2}{c|}{ Cycle-2 } & \multicolumn{2}{c|}{ Cycle-3 } \\
\hline $\begin{array}{r}\text { Isotope ID } \\
\text { (ZZAAA) }\end{array}$ & (initial) & (disch.) & (after 7y) & (disch.) & (after 7y) & (disch.) & (after 7y) \\
\hline 93237 & 6.64 & 4.07 & 4.12 & 2.47 & 2.52 & 1.57 & 1.61 \\
\hline 94238 & 2.75 & 4.12 & 4.06 & 4.08 & 4.01 & 3.48 & 3.41 \\
\hline 94239 & 48.65 & 52.66 & 52.79 & 55.11 & 55.25 & 56.71 & 56.81 \\
\hline 94240 & 22.98 & 23.84 & 24.07 & 24.98 & 25.23 & 26.08 & 26.31 \\
\hline 94241 & 6.93 & 4.02 & 2.88 & 2.87 & 2.05 & 2.74 & 1.96 \\
\hline 94242 & 5.03 & 5.03 & 5.04 & 4.65 & 4.67 & 4.25 & 4.26 \\
\hline 95241 & 4.65 & 3.45 & 4.57 & 2.89 & 3.68 & 2.36 & 3.12 \\
\hline $95242 \mathrm{~m}$ & 1.47 & 0.25 & 0.25 & 0.30 & 0.29 & 0.26 & 0.26 \\
\hline 95243 & 0.02 & 1.45 & 1.45 & 1.41 & 1.41 & 1.34 & 1.34 \\
\hline 96242 & 0.0000 & 0.1567 & 0.0000 & 0.1334 & 0.0000 & 0.0689 & 0.0000 \\
\hline 96243 & 0.0050 & 0.0132 & 0.0112 & 0.0140 & 0.0118 & 0.0113 & 0.0095 \\
\hline 96244 & 0.4960 & 0.8070 & 0.6190 & 0.8773 & 0.6729 & 0.8838 & 0.6771 \\
\hline 96245 & 0.0380 & 0.1245 & 0.1247 & 0.1716 & 0.1719 & 0.1913 & 0.1915 \\
\hline 96246 & 0.0060 & 0.0173 & 0.0174 & 0.0367 & 0.0367 & 0.0566 & 0.0566 \\
\hline
\end{tabular}

\section{Reactivity Coefficients and Self Controllability Criteria}

A simplified core safety analysis was performed based on the quasi-static methodology approach outlined in Section 2.1.2. A more detailed description of this methodology is presented in Appendix 3A. The core operating conditions used in the analysis are summarized in Table 3.3.1-7. Reactivity coefficients and the coefficient ratios required for the reactor safety assessment are presented in Table 3.3.1-8. For comparison, Table 3.3.1-8 also shows the reactivity coefficients of the sodium-cooled Integral Fast Reactor (IFR) [Wade and Fujita, 1989].

The data used for the calculation of Doppler and Coolant Temperature Coefficients is presented graphically in Figures 3.3.1-11 and 3.3.1-12 respectively. The core reactivity dependence on the fuel and coolant temperatures obtained in this part of the study is used later for detailed core transient analysis with the RELAP code. The reactivity coefficients were calculated only at BOL because the fuel composition changes only slightly as new fissile actinides are being continuously generated at about the same rate as the original ones are being burnt. Moreover, the core power distribution also remains fairly constant during the cycle. As a result, the $\mathrm{CR}=1$ core reactivity coefficients are expected to be about the same throughout the fuel irradiation.

Comparing the reactivity coefficients with IFR values, one can observe that the Doppler coefficients are comparable since both reactors have similar metallic fuel although the lead core has a somewhat harder spectrum. The thermal expansion reactivity coefficient is also comparable to that of the IFR. In contrast, the core radial expansion coefficient is 
smaller than that of the IFR due to the larger size of the $\mathrm{CR}=1$ core. The coolant temperature coefficient is positive, but smaller than that of the IFR. This is a consequence of lead coolant, which exhibits a smaller reactivity insertion with density reduction and a larger increase of leakage due to the larger scattering cross section of lead.

Table 3.3.1-7. Lead-cooled core operating conditions

\begin{tabular}{|l|c|}
\hline Parameter & Value \\
\hline Coolant Inlet Temperature, ${ }^{\circ} \mathrm{C}$ & 479 \\
\hline Coolant Outlet temperature, ${ }^{\circ} \mathrm{C}$ & 574 \\
\hline Core Coolant Temperature Rise, $\Delta \mathrm{T}_{\mathrm{c}},{ }^{\circ} \mathrm{C}$ & 95 \\
\hline Coolant Freezing Point, ${ }^{\circ} \mathrm{C}$ & 327 \\
\hline Margin to Freezing, ${ }^{\circ} \mathrm{C}$ & 152 \\
\hline Cladding Failure Limit, ${ }^{\circ} \mathrm{C}$ & 725 \\
\hline Margin to Cladding Failure, ${ }^{\circ} \mathrm{C}$ & 151 \\
\hline
\end{tabular}

Table 3.3.1-8. Summary of reactivity feedback parameters

\begin{tabular}{|c|c|c|c|c|}
\hline & Units & BOL value & Error & IFR $^{*}, \mathrm{BOL}$ \\
\hline$\beta$ & & 0.0036 & \pm 0.0001 & 0.0035 \\
\hline$\alpha_{\mathrm{DC}}$ & $\phi / \mathrm{K}$ & -0.111 & \pm 0.030 & -0.120 \\
\hline$\alpha_{e}$ & $\phi / K$ & -0.117 & \pm 0.026 & -0.090 \\
\hline$\alpha_{\mathrm{Co}}$ & $\phi / \mathrm{K}$ & +0.131 & \pm 0.052 & +0.180 \\
\hline$\alpha_{\mathrm{RD}}$ & $\phi / \mathrm{K}$ & $\sim 0$ & $\mathrm{~N} / \mathrm{A}$ & $\sim 0$ \\
\hline$\alpha_{R}$ & $\phi / \mathrm{K}$ & -0.135 & \pm 0.013 & -0.220 \\
\hline A & $\phi$ & -22.92 & \pm 3.99 & -31 \\
\hline B & $\phi$ & -17.43 & \pm 2.43 & -35 \\
\hline $\mathrm{C}$ & $\phi / K$ & -0.23 & \pm 0.05 & -0.25 \\
\hline $\mathrm{A} / \mathrm{B}$ & & 1.31 & \pm 0.29 & 0.88 \\
\hline $\mathrm{C} \Delta \mathrm{Tc} / \mathrm{B}$ & & 1.27 & \pm 0.31 & 1.1 \\
\hline$\Delta \rho_{\mathrm{TOP}} / \mathrm{B}$ & & 0.33 & \pm 0.05 & - \\
\hline A/B limits & & \multicolumn{2}{|c|}{$x<1.06\left(1.59^{* *}\right)$} & $x<1.0$ \\
\hline $\mathrm{C} \Delta \mathrm{T}_{\mathrm{c}} / \mathrm{B}$ limits & & \multicolumn{2}{|c|}{$1<x<1.99(2.39)$} & $1<x<2$ \\
\hline$\Delta \rho_{\mathrm{TOP}} / \mathrm{B}$ limits & & \multicolumn{2}{|c|}{$x<1.06(1.59)$} & $x<1.0$ \\
\hline
\end{tabular}

* Typical IFR values for 1800 MWt core [Wade and Fujita, 1989].

${ }^{* *}$ Values in parentheses pertain to margin factor $\gamma=1$ (Eq. 1 in Section 4 of Appendix 3A).

Overall, the results indicate that the safety limits are satisfied within the uncertainty of the Monte Carlo calculations, except for the A/B criterion, which is above the conservative limit of 1.06 (See Appendix 3A for the derivation of self-controllability 
criteria). This is, to some extent, a consequence of the smaller core radial thermal expansion coefficient. Moreover, the A/B criterion is not satisfied, also due to the significantly smaller core temperature rise $\left(94^{\circ} \mathrm{C}\right.$ versus $150^{\circ} \mathrm{C}$ for IFR) of the leadcooled core, which makes the $\mathrm{B}$ coefficient smaller and the $\mathrm{A} / \mathrm{B}$ ratio larger. Although the A/B self-controllability criterion is above the conservative limit, it satisfies the limit for a uniform core radial power distribution. Because the radial power peaking is significantly smaller than 1.5 , it is expected that the transient analyses of unprotected accidents will yield acceptable performance.

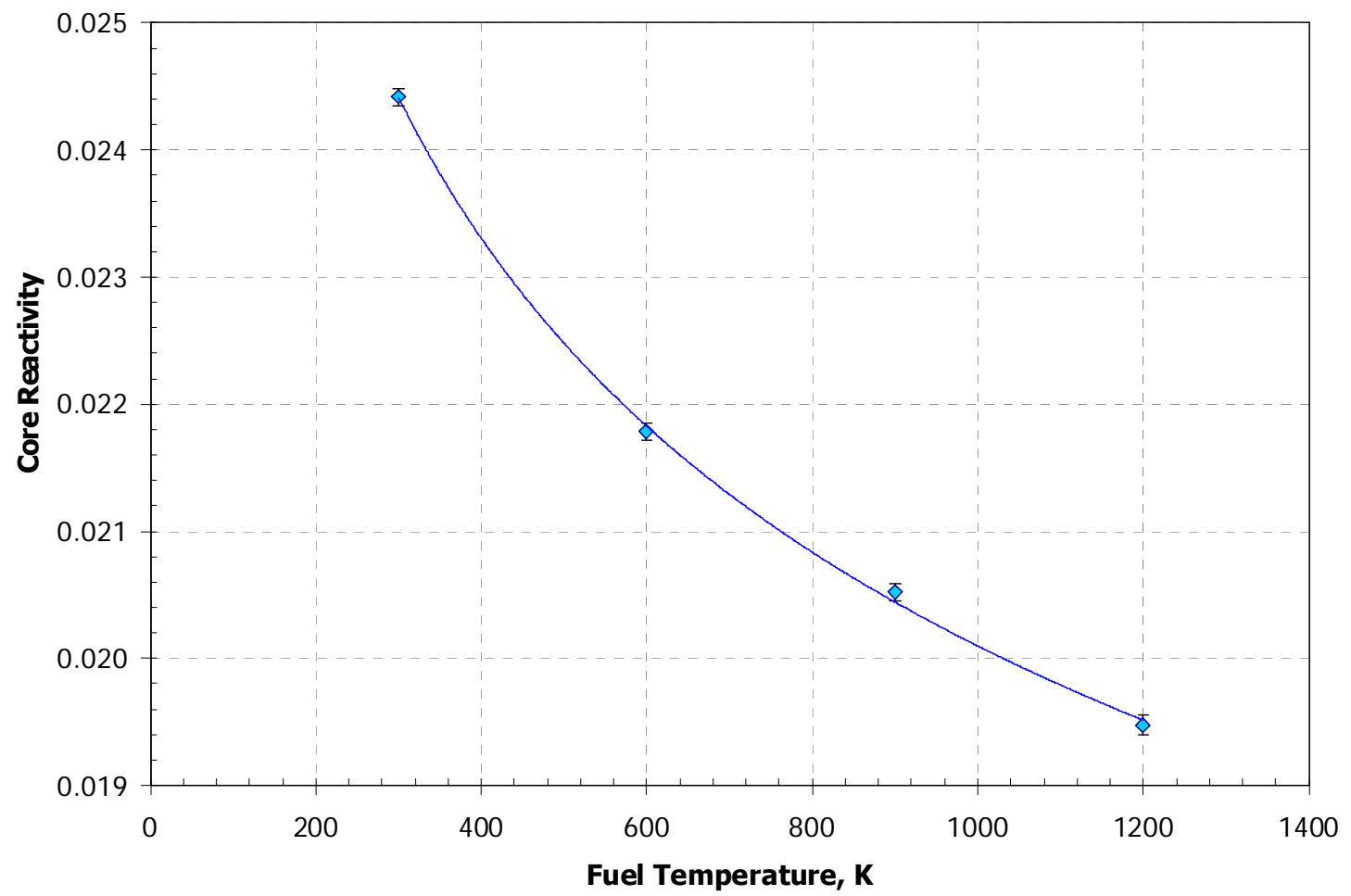

Figure 3.3.1-11 CR=1 Core reactivity vs. average fuel temperature

\section{Reactor vessel fluence}

The reactor vessel lifetime is primarily limited by the accumulated fast fluence. The adopted value for the fluence limit to the vessel structural material (SS316) was $5 \times 10^{19}$ (neutrons above $1 \mathrm{MeV}$ ) $/ \mathrm{cm}^{2}$. Energy dependent neutron fluence was calculated with the MCNP code at two critical core locations:

- the reactor vessel at the core mid plane axial location, where maximum neutron flux is expected

- the core support plate as the next closest-to-the-core structural component, which is also difficult to replace.

The results of the fast fluence calculations are reported in Table 3.3.1-9. Only the values for neutron fluence above $0.1 \mathrm{MeV}$ are reported because of the poor Monte Carlo statistics at higher energy bins. Nevertheless, even for the fluence above $0.1 \mathrm{MeV}$, the obtained results indicate that, over the target reactor lifetime of 40 years, the fast fluence is well below the adopted limit. This is a consequence of two major factors: the 
exceptionally good properties of the lead coolant as neutron reflector and a relatively large distance from the core to the vessel and support plate.

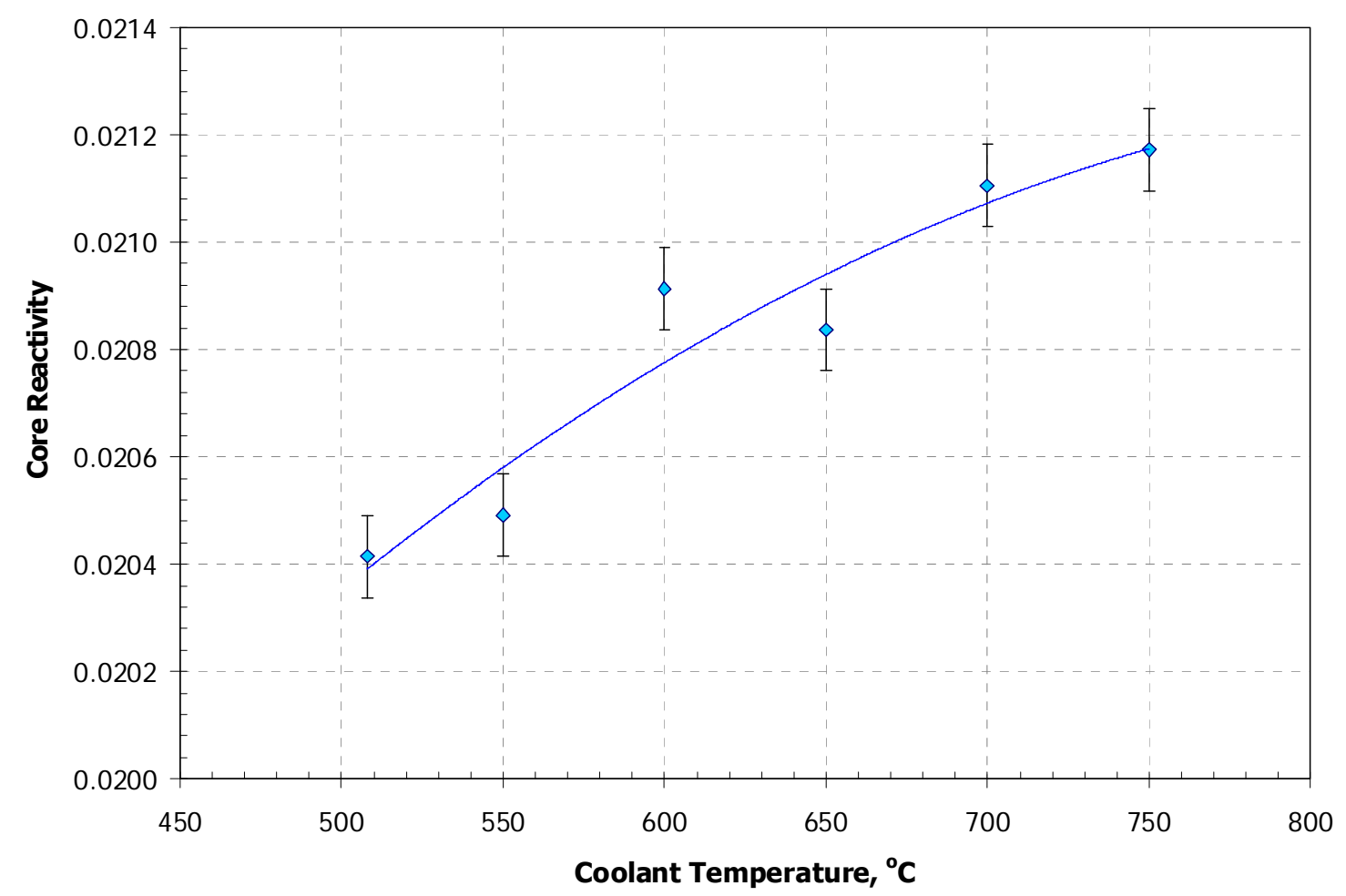

Figure 3.3.1-12 $\mathrm{CR}=1$ Core reactivity vs. average coolant temperature

Table 3.3.1-9. Fast fluence accumulated over 40 years lifetime in $\mathrm{CR}=1$ core components

\begin{tabular}{|l|c|}
\hline Parameter & Value \\
\hline Vessel above $(0.1 \mathrm{MeV}), \# / \mathrm{cm}^{2}$ & $(6.4 \pm 0.4) \mathrm{E}+18$ \\
\hline Core support plate above $(0.1 \mathrm{MeV}), \# / \mathrm{cm}^{2}$ & $(3.4 \pm 0.2) \mathrm{E}+19$ \\
\hline
\end{tabular}

\section{Decay Heat Curves}

An additional safety related quantity calculated in this analysis was the fuel decay heat after reactor shutdown. Typically, a standard decay heat curve is used in transient analysis. This standard decay heat data is generally derived from LWR systems with conventional $\mathrm{UO}_{2}$ fuel. In fast reactors however, the decay power is expected to be different because of the different neutron spectrum and fuel composition.

In order to account for these differences, a detailed burnup calculation of the $\mathrm{CR}=1$ leadcooled core was performed with the BGCore [Fridman et al., 2008] computer code. Over 1700 nuclides were tracked explicitly in coupled Monte Carlo and burnup/decay calculations using the most recent (JEFF 3.1) nuclear data for fission yields, decay constants and decay reaction Q-values. The capability of BGCore to predict the decay 
heat after shutdown was verified through comparison of BGCore results for a typical PWR $\mathrm{UO}_{2}$ fuel case with those obtained from the ANS-2005 [ANS, 2005] standard methodology. The BGCore code and decay heat calculation approach are described in detail in Appendix 3A.

The decay heat calculated for the $\mathrm{CR}=1$ lead-cooled core is compared with that of a standard PWR $\mathrm{UO}_{2}$ fuel in Figure 3.3.1-12 up to $10^{6}$ seconds after reactor shutdown, which is approximately the range over which the core cooling capabilities must be assured. Figure 3.3.1-13 shows the relative deviation of $\mathrm{CR}=1$ core decay heat from that of the PWR $\mathrm{UO}_{2}$.

As can be observed from the figures, the $\mathrm{CR}=1$ lead-cooled core has slightly lower decay power than in the PWR case up to about 100 seconds after shutdown. After 100 seconds, the $\mathrm{CR}=1$ decay power becomes larger than that of the LWR, and the difference increases with time and reaches as much as $30 \%$ at $10^{6}$ seconds ( $\sim 300$ hours). As a result of such notable deviation from the standard $\mathrm{UO}_{2}$ decay heat values, the transient analysis of the cores designed in this project with the RELAP5 code was performed using more accurate decay heat curves generated with the BGCore code for each case considered.

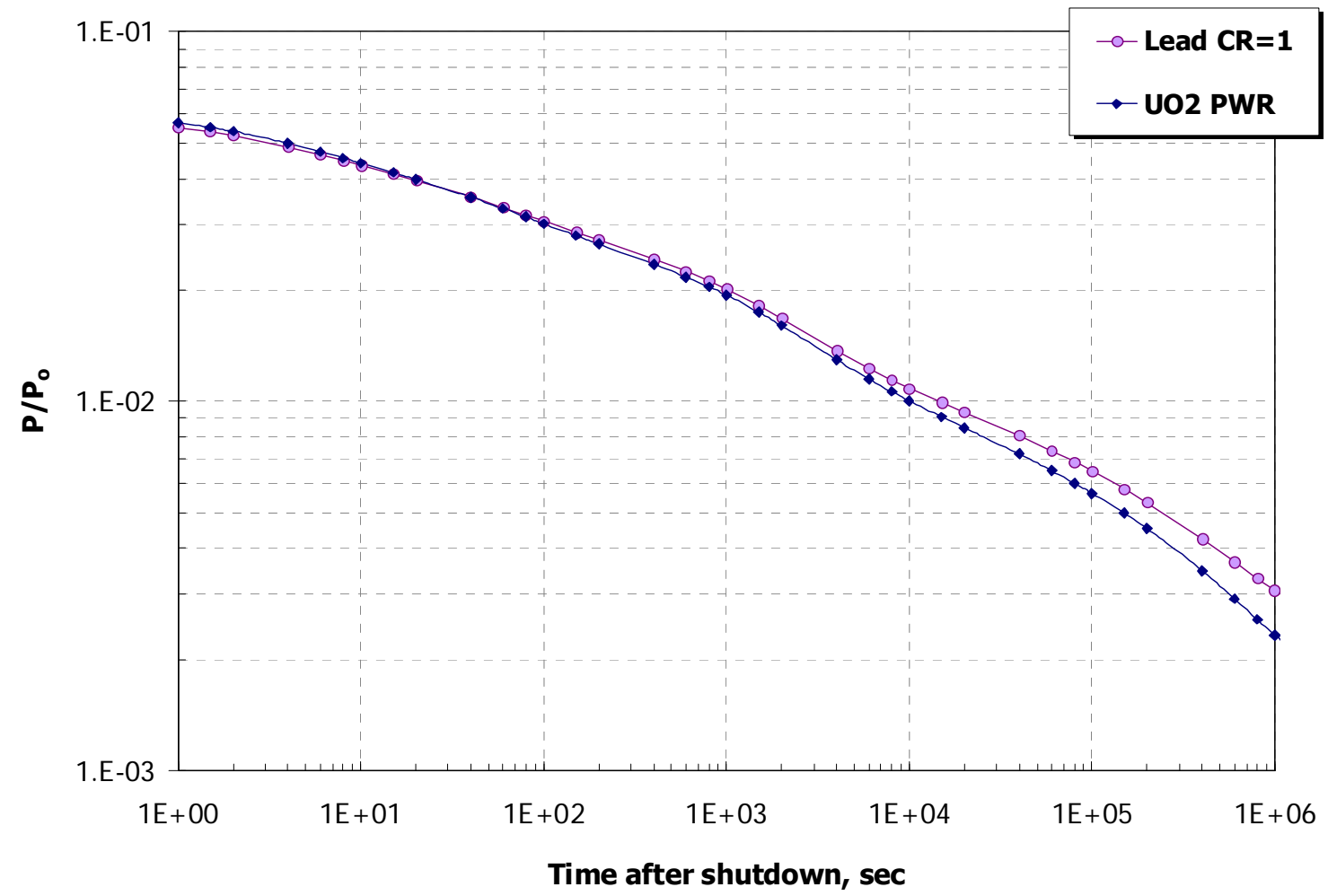

Figure 3.3.1-12 Comparison of $\mathrm{CR}=1$ core decay heat with typical PWR 
Project No 06-040: Flexible Conversion Ratio Fast Reactor Systems Evaluation

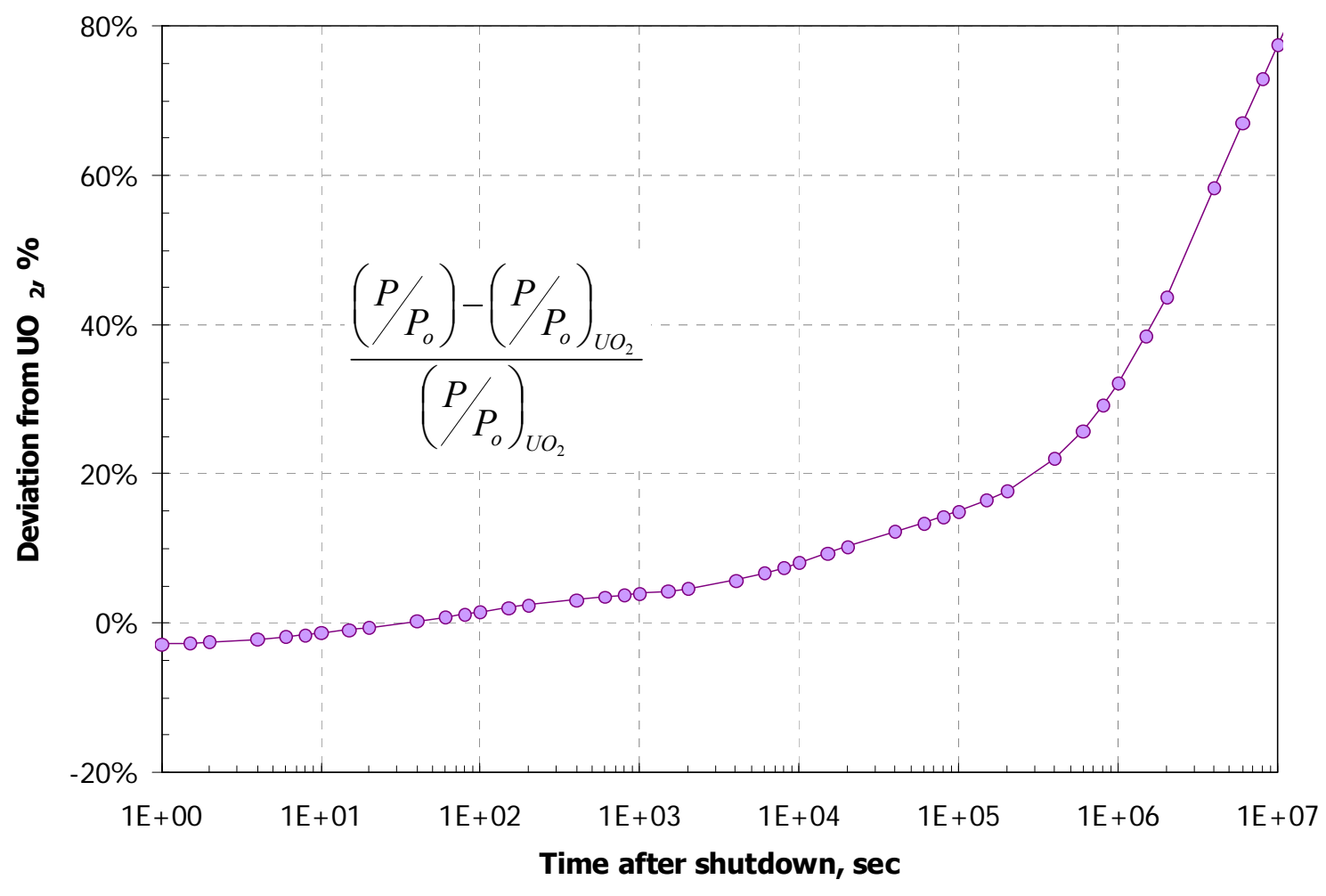

Figure 3.3.1-13 Relative deviation of $\mathrm{CR}=1$ core decay heat from typical PWR 
Project No 06-040: Flexible Conversion Ratio Fast Reactor Systems Evaluation

\subsubsection{Thermal Hydraulic Design}

The main objective and the unique challenge of the Flexible Conversion Ratio reactor thermal hydraulic design is the requirement that the reactor systems be able to accept cores with different fuel loadings. Two limiting cases of core configurations with zero and unity conversion ratios are considered. Due to significant variation of the fuel composition, the unity and zero conversion ratio cores have different numbers of control rods, power peaking maps, coolant velocities, decay heat curves, and reactivity coefficients. All of the differences must be accounted for in the thermal hydraulic design in order to assure that the inlet and outlet temperatures are the same for both cores. The same inlet and outlet temperature condition is necessary because both core designs are intended for the same Power Conversion System. TRU fuel and lead coolant impose temperature limits on the fuel cladding. Therefore, both cores must be designed within the limits while maximizing the core outlet temperature for better plant efficiency.

Another major challenge of the thermal hydraulic design is the achievement of a large power rating in a small footprint plant. A pool-type reactor plant with $2400 \mathrm{MWt}$ power output and Intermediate Heat Exchangers (IHX) inside the pool has the advantages of small footprint, elimination of intermediate loop, and benefit of economy of scale. Pool design also eliminates certain types of accidents, such as Loss of Coolant Accident from primary coolant pipe break. However, such a large power rating raises challenges related to the tight space within the vessel, where a core, primary coolant pumps, and four IHXs must be placed inside the vessel. While placement of the IHX inside the vessel eliminates additional loops, there is a possibility of ingress of the secondary coolant, supercritical carbon dioxide, at high pressure, in the core. Ingress of the gas results in coolant voiding which can lead to reactivity increase and the development of hot spots on the cladding. Therefore, the core must be protected against such incidents. IHX design is important for the overall plant performance. Iterative design and analysis of the IHX is necessary since its performance directly impacts the efficiency of the secondary side as well as the primary coolant pumping requirements.

Excellent reactor safety is a key goal for the plant design. A self-controllable reactor needs to demonstrate a combination of reactivity feedbacks that lead to an inherent reactor shutdown without reliance on reactor scram. The core is designed in such a manner that the reactivity coefficients satisfy the self-controllability criteria, as was discussed in Section 2.1.2. This provides a challenge since power generation from feedback shutdown is, for a period of time, larger than decay heat only, as would be the case with scram. This in combination with large power rating and the goal of dissipating the decay heat without reliance on the active system makes the design especially challenging.

Preliminary thermal hydraulic analysis of the system is performed using an in-house code SUBCHAN. Detailed description of the code organization and capabilities is provided in Appendix 3B.1. A separate design of the intermediate heat exchanger is performed using 
MS Spreadsheet. A detailed reactor system model including the primary system, IHXs, RVACS, and the power conversion system was built and analyzed in RELAP5-3D [RELAP, 2005]. The RELAP5-3D code has been developed for steady-state and transient simulation of reactor system behavior. The code allows for modeling control systems, pumps, turbines and other equipment crucial for the analysis during unprotected transients. The description of the models built in RELAP5-3D is provided in Appendix 3B.2.

\subsubsection{Steady State Thermal Hydraulic Design}

The steady state thermal hydraulic design of the reactor core and the intermediate heat exchangers (IHXs) follows from the design goals and constraints. The coolant temperature rise through the core is determined by the peak cladding temperature limit, margin to freezing point, and the balance-of-plant working temperatures. Similarly, the design and configuration of the IHXs is related to the secondary cycle temperatures and pressure drop constraint and the space availability within the reactor vessel. Thus, for a successful design it is necessary to achieve good balance between the design goals, limits discussed in Section 2.1, and economic practicability.

\subsection{Core Design}

Detailed description of the neutronic core design was provided in Section 3.3.1. The assembly peaking factors were adopted to calculate the core axial and radial temperature and coolant velocity distribution. Subchannel analysis of the core was conducted to determine the preliminary temperature and velocity distribution, and the pressure drop across the core. The objective of the present subchannel analysis was twofold: to determine whether the core design constraints are satisfied and to maximize the core average outlet temperature with sufficient margin to temperature and velocity limits through orificing. The in-house subchannel code SUBCHAN was used to calculate reactor operating parameters. The impact of three-zone core orificing on core outlet temperature distribution was also investigated. The analysis was completed using the power peaking maps from reactor physics analysis. The results of the subchannel analysis were further used as an input for RELAP5-3D

\section{Strategies to Maximize Core Average Outlet Temperature}

The fuel assembly of the unity conversion ratio core consists of 441 fuel pins or 416 fuel pins and 25 control rods per assembly (96 assemblies in the core have control rods). In the current investigation, three types of channels are considered: fuel channel ("hot") with further division into inner, corner and edge subchannels, control rod channel ("cold"), and inter-assembly channel ("cold"). Gamma heating is assumed for both types of cold channels (5\% of the average pin heat flux.) The schematic of the assembly layout and different channel classification is depicted in Figure 3.3.2-1.

Reactor physics analysis determined the core power map and intra-assembly pin peaking, as shown in Section 3.3.1. In the thermal hydraulic model, each channel represented 
either one assembly or several assemblies depending on the peaking factor. This involved the collapse of 349 assemblies into 41 groups, which were modeled in the SUBCHAN code. Each group represents assemblies with a unique peaking factor. The core temperature map was plotted. Such an approach allows applying the orificing coefficients to every individual assembly rather than using core-average values. Threezone orificing used in this analysis was manipulated until the desired core temperature distribution was obtained. In this analysis, a fixed orificing configuration was applied.

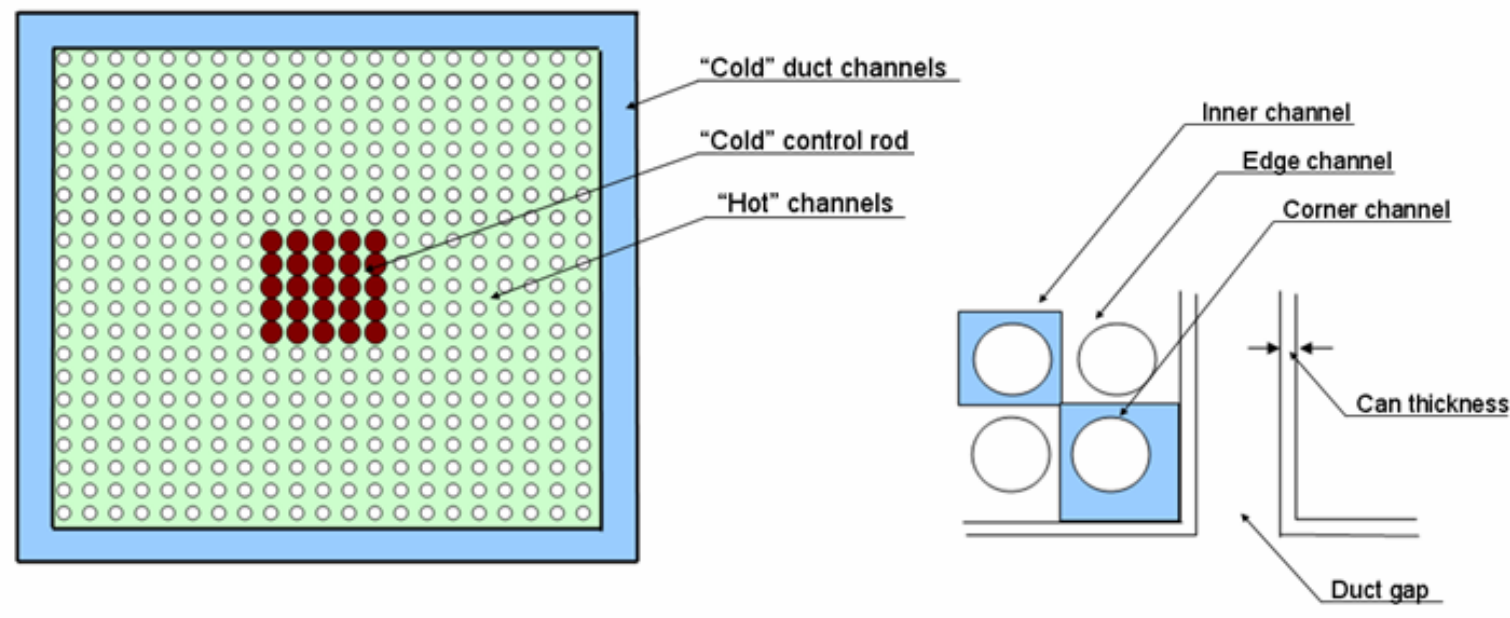

Figure 3.3.2-1 Fuel assembly layout and channel classification.

Benefits of the aforementioned three-zone orificing technique were explored by considering every assembly individually. First, non-orificed core cladding and outlet temperature distributions were analyzed. Figure 3.3.2-2 depicts the core peak cladding and outlet temperature maps of $1 / 8^{\text {th }}$ of the core without any orificing applied. The peak cladding temperatures range from $556.5^{\circ} \mathrm{C}$ to $622.6^{\circ} \mathrm{C}$. The outlet temperatures range from $594.6^{\circ} \mathrm{C}$ to $541.2^{\circ} \mathrm{C}$. Based on the core outlet temperature distribution, hotter assemblies were left non-orificed, while two-zone orificing was applied to the rest of the assemblies. Generally, orificing is used to maximize core average outlet temperature within the peak cladding temperature constraint. However, because transient analyses suggested that a margin to steady-state cladding limit is needed to remain below a relatively low transient peak cladding temperature limit of $725^{\circ} \mathrm{C}$, the approach to maximize the margin to clad temperature limit was chosen in this orificing study.

Three-zone orificing was found to be sufficient to significantly flatten the peak cladding and outlet coolant temperature distribution. The highest assembly peak cladding temperature was reduced from $622.6^{\circ} \mathrm{C}$ to $609.9^{\circ} \mathrm{C}$. The highest assembly outlet temperature was reduced from $594.6^{\circ} \mathrm{C}$ to $581.8^{\circ} \mathrm{C}$. The peak cladding (top) and outlet (bottom) temperature maps of the orificed core are given in Figure 3.3.2-3. Table 3.3.2-1 summarizes peak velocity and cladding temperature before and after orificing. A considerable margin exists between the cladding temperature limit of $625-650^{\circ} \mathrm{C}$ and the calculated value of the orificed core. The maximum velocity in the core is in the hottest assembly. Core orificing resulted in increased velocity through the channels with reduced flow resistance. 
Project No 06-040: Flexible Conversion Ratio Fast Reactor Systems Evaluation
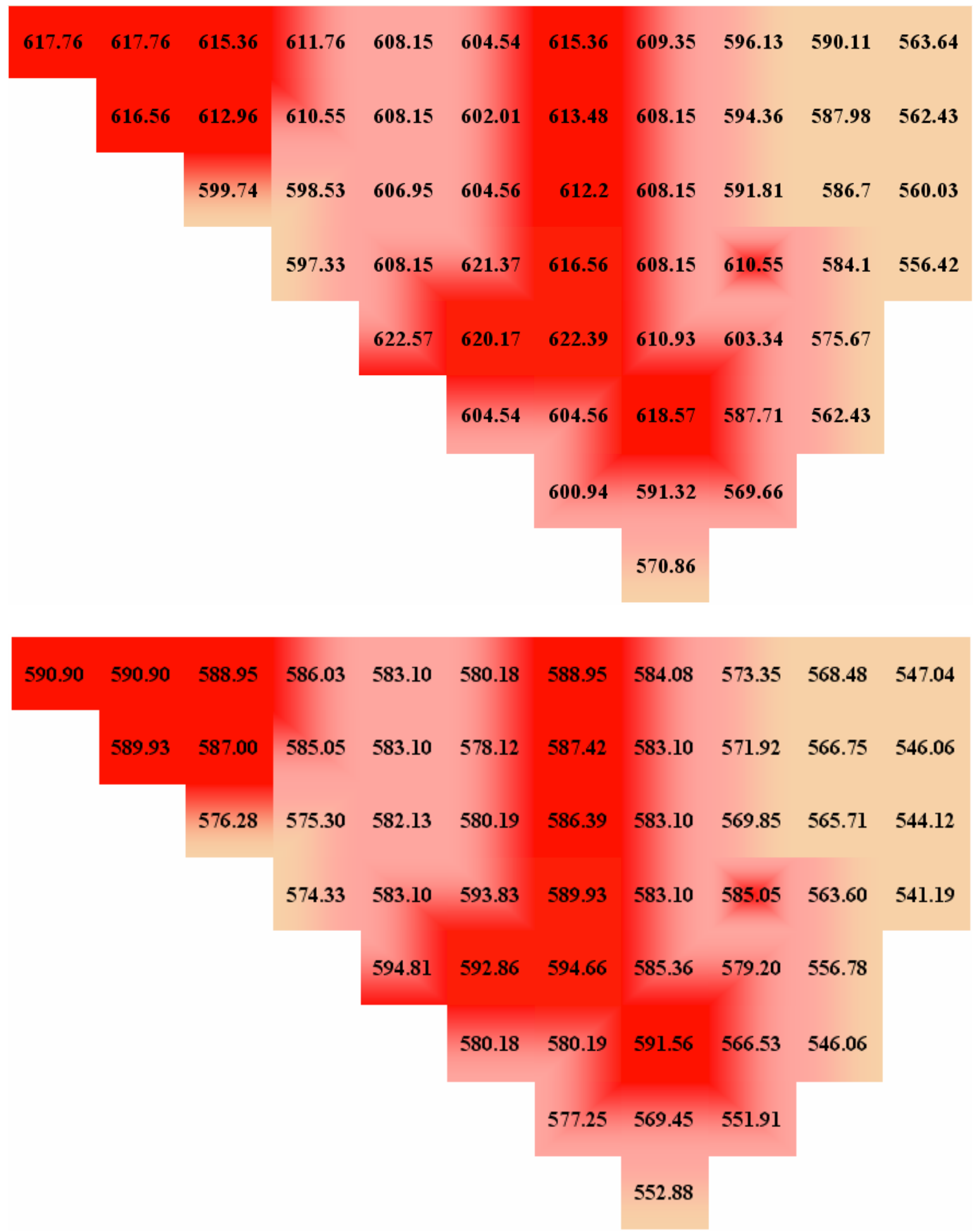

Figure 3.3.2-2 Assembly-average peak cladding (top) temperature $\left({ }^{\circ} \mathrm{C}\right)$ and outlet (bottom) temperature map for un-orificed core. 
Project No 06-040: Flexible Conversion Ratio Fast Reactor Systems Evaluation

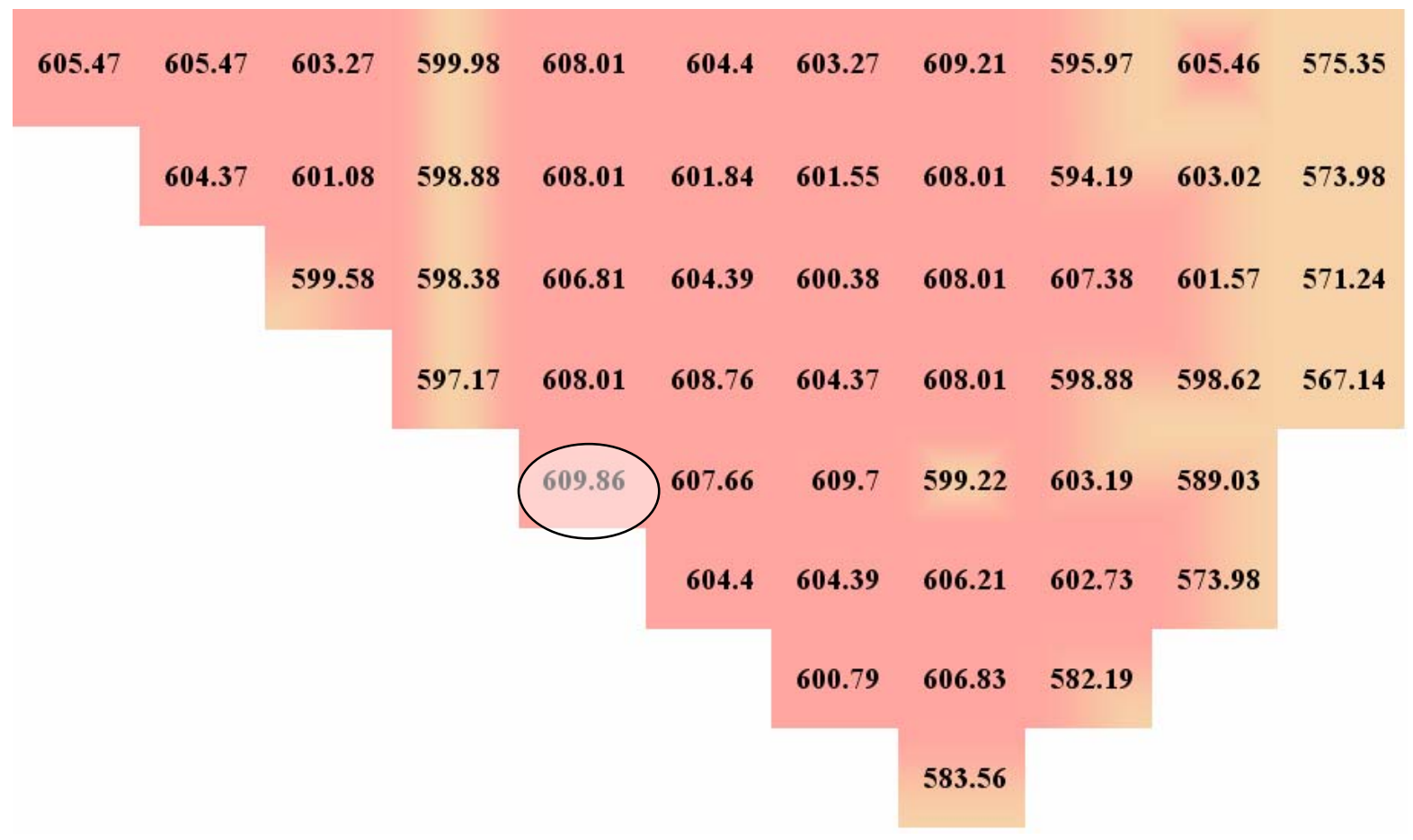

$\begin{array}{lllllllllll}578.28 & 578.28 & 576.54 & 573.94 & 582.95 & 580.03 & 576.54 & 583.93 & 573.19 & 584.05 & 558.91\end{array}$

$\begin{array}{llllllllll}\mathbf{5} 77.41 & 574.81 & 573.07 & 582.95 & 577.95 & 575.18 & 582.95 & \mathbf{5 7 1 . 7 4} & \mathbf{5 8 2 . 0 0} & \mathbf{5 5 7 . 7 6}\end{array}$

$\begin{array}{lllllllll}\mathbf{5} 76.12 & 575.14 & 581.98 & 580.02 & 574.26 & 582.95 & 585.64 & 580.79 & 555.48\end{array}$

$\begin{array}{llllllll}\mathbf{5 7 4 . 1 7} & \mathbf{5 8 2 . 9 5} & \mathbf{5 8 0 . 8 8} & \mathbf{5 7 7 . 4 1} & \mathbf{5 8 2 . 9 5} & \mathbf{5 7 3 . 0 7} & \mathbf{5 7 8 . 3 3} & \mathbf{5 5 2 . 0 6}\end{array}$

$\begin{array}{llllll}581.75 & 580.01 & 581.62 & 573.34 & 579.05 & 570.32\end{array}$

$\begin{array}{lllll}580.03 & 580.02 & 578.86 & 581.76 & 557.76\end{array}$

$\begin{array}{lll}577.10 & 585.19 & 564.61\end{array}$

565.76

Figure 3.3.2-3 Assembly-average peak cladding (top) and outlet (bottom) temperature

$\left({ }^{\circ} \mathrm{C}\right)$ map for orificed core. 
Project No 06-040: Flexible Conversion Ratio Fast Reactor Systems Evaluation

Table 3.3.2-1 Summary of peak assembly-average temperatures and velocity before and after orificing.

\begin{tabular}{|l|c|c|}
\hline & Un-orificed core & Orificed core \\
\hline $\begin{array}{l}\text { Orificing coefficients } \\
\text { (zone1/zone2/zone3) }\end{array}$ & N/A & $0.4 / 4.96 / 13.24$ \\
\hline Peak cladding temperature $\left({ }^{\circ} \mathrm{C}\right)$ & 622.6 & 609.9 \\
\hline Velocity $(\mathrm{m} / \mathrm{s})$ & 2.05 & 2.30 \\
\hline
\end{tabular}

Table 2.3.2-2 Summary of Main Parameters of Unity Conversion Ratio Lead Core

\begin{tabular}{|c|c|c|}
\hline \multicolumn{2}{|c|}{ Core thermal power (MWt) } & 2400 \\
\hline \multicolumn{2}{|c|}{ Maximum radial power peaking coefficient } & 1.21 \\
\hline \multirow[t]{7}{*}{ Assembly Geometry } & Assembly pitch (m) & $2.175 \mathrm{E}-01$ \\
\hline & Assembly can thickness (m) & $3.940 \mathrm{E}-03$ \\
\hline & Inter assembly gap (hot) (m) & $2.229 \mathrm{E}-03$ \\
\hline & Total number of fuel assemblies & 349 \\
\hline & Number of FA with CRDs & 96 \\
\hline & Number of fuel pins per assembly & 441 \\
\hline & Number of CRD per assembly & 25 \\
\hline \multirow{9}{*}{ Fuel pin geometry } & Pin outer diameter $(\mathrm{m})$ & $7.520 \mathrm{E}-03$ \\
\hline & Cladding thickness (m) & $6.300 \mathrm{E}-04$ \\
\hline & Gap thickness (m) & 4.200E-04 \\
\hline & Fuel heated length (m) & 1.3 \\
\hline & Fuel pin pitch $(\mathrm{cm})$ & 0.9776 \\
\hline & Pitch-to-diameter ratio & 1.3 \\
\hline & Plenum height $(\mathrm{m})$ top/bottom & $1.3 / 1.3$ \\
\hline & Cladding material & T-91 (9Cr-1Mo-V-Nb) \\
\hline & Gap bond & Lead \\
\hline \multirow[t]{3}{*}{ Fuel type } & Zone 1 (U/TRU/Zr), (wt. \%) & $75.00 / 15.00 / 10.00$ \\
\hline & Zone 2 (U/TRU/Zr), (wt. \%) & $70.83 / 14.17 / 15.00$ \\
\hline & Zone 3 (U/TRU/Zr), (wt. \%) & $67.50 / 13.50 / 19.00$ \\
\hline \multirow[t]{3}{*}{ Core average } & Coolant mass flow rate $(\mathrm{kg} / \mathrm{s})$ & 173600 \\
\hline & Inlet temperature $\left({ }^{\circ} \mathrm{C}\right)$ & 479.0 \\
\hline & Outlet temperature $\left({ }^{\circ} \mathrm{C}\right)$ & 573.3 \\
\hline \multirow[t]{6}{*}{ Hot subchannel } & Cladding temperature limit $\left({ }^{\circ} \mathrm{C}\right)$ & $625-650$ \\
\hline & Peak Cladding Temperature $\left({ }^{\circ} \mathrm{C}\right)$ & 610 \\
\hline & Temperature margin $\left({ }^{\circ} \mathrm{C}\right)$ & $15-40$ \\
\hline & Coolant velocity limit $(\mathrm{m} / \mathrm{s})$ & 3.00 \\
\hline & Velocity $(\mathrm{m} / \mathrm{s})$ & 2.40 \\
\hline & Velocity margin $(\mathrm{m} / \mathrm{s})$ & 0.60 \\
\hline \multirow[t]{3}{*}{ Orificing coefficients } & Zone 1 & 0.40 \\
\hline & Zone 2 & 4.96 \\
\hline & Zone 3 & 13.24 \\
\hline
\end{tabular}

\section{Summary of Key Performance Parameters}

Table 3.3.2-2 summarizes the main parameters of the unity conversion ratio reactor core. The steady state performance of the core is satisfactory for the imposed coolant velocity 
and peak cladding temperature limits. Orificing applied to the core inlet resulted in reduced cladding temperatures throughout the core. In this case, the purpose of the orificing was not to maximize the core coolant outlet temperature, but rather, to maximize the margin between the peak cladding temperature (PCT) and the PCT limits. Increasing the margin to the PCT limit accounts for uncertainties associated with the steady-state and transients analyses. The pressure drop through the entire core (active+fission gas plenum) is below $0.6 \mathrm{MPa}$, which results in relatively high requirements for the pumping power. The pumping power comparison for various coolants is presented in Chapter 5.

\section{Benchmark with RELAP Model}

Figure 3.3.2-4 compares hot subchannel cladding temperature as evaluated using SUBCHAN and RELAP5-3D. These calculation methods are in good agreement. Minor discrepancies are due to numerical and calculation uncertainties. Another source of difference comes from the fact that RELAP5-3D uses lead-bismuth alloy as a coolant while pure lead was used for SUBCHAN calculations.

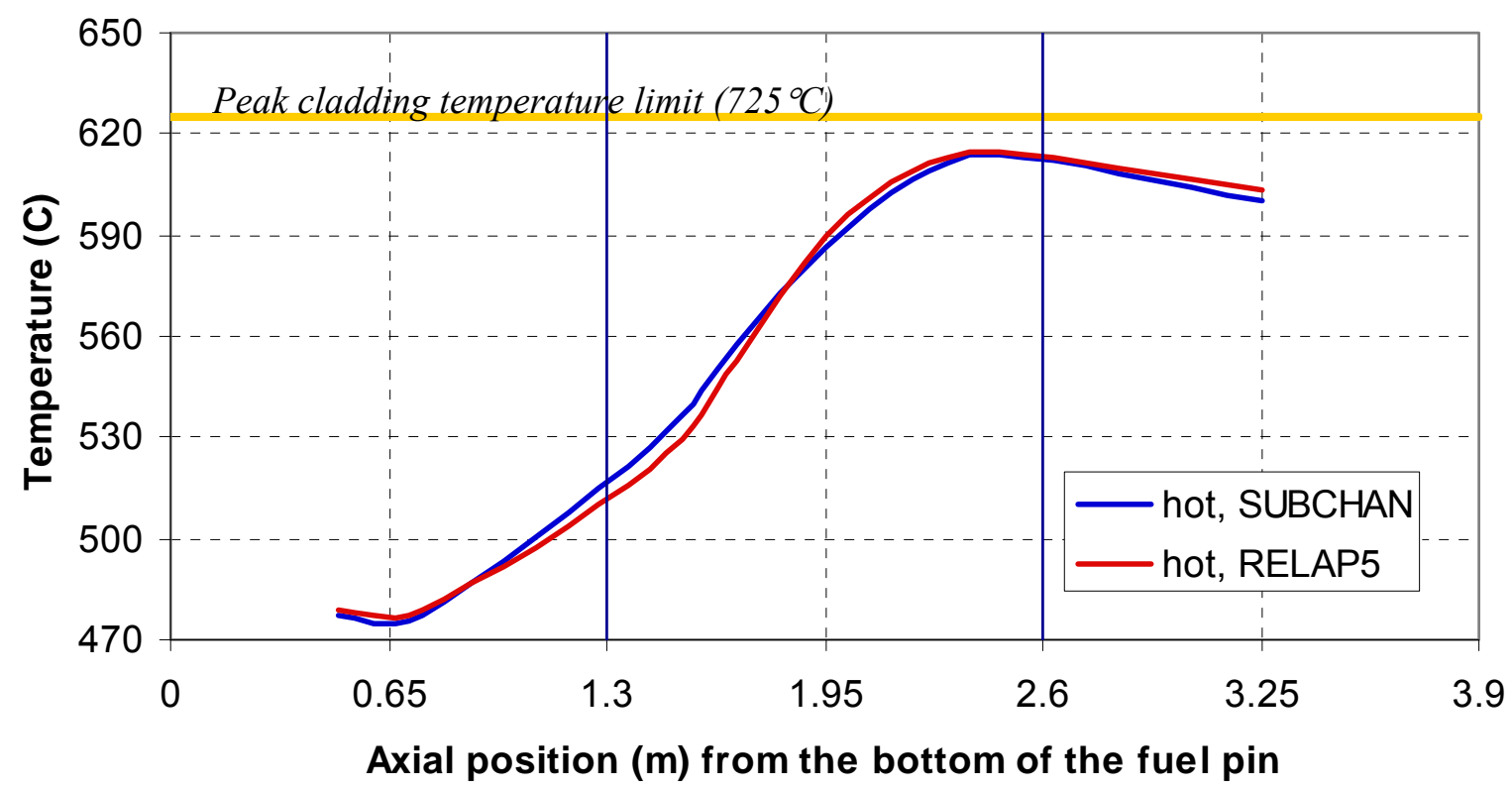

Figure 3.3.2-4 Comparison of hot subchannel temperature produced by SUBCHAN and RELAP

\subsubsection{IHX Design}

The Intermediate Heat Exchanger (IHX) is one of the key components of the plant system. IHX performance is defined by its heat removal capabilities and has an effect on the overall plant efficiency. The main IHX challenge is that the heat exchangers must be 
placed within the reactor vessel in a constrained space. The constraints are defined by the size of the core and by the maximum allowable diameter of the guard vessel. The diameter of the vessel is limited by manufacturer capabilities and by seismic analysis. In the present analysis, the maximum vessel diameter of $10.2 \mathrm{~m}$ is assumed - about $1 \mathrm{~m}$ larger than the vessel of the S-PRISM reactor [Boardman et al., 2000]. Pool design eliminates coolant loops on the primary side, leading to plant compactness and simplicity in design. Certain types of accidents involving a primary coolant pipe break are also eliminated. Placement of IHXs inside the vessel also eliminates intermediate loops. However, the constraint on the vessel size imposes a limit on the size of the heat exchanger. Additional challenges exacerbating the problems are:

- High pressure on the $\mathrm{CO}_{2}$ side $(19.7 \mathrm{MPa})$, which requires thicker tubes and gas plena walls,

- High temperature $\left(573^{\circ} \mathrm{C}\right)$, which reduces allowable stress of IHX material

- Desirable small temperature difference between lead coolant and $\mathrm{CO}_{2}$ to maximize plant efficiency

- Pressure drop constraints

- on the $\mathrm{S}-\mathrm{CO}_{2}$ side to maintain high (45\%) efficiency of the PCS,

- on the primary side to retain reasonable pumping power and velocity limits

- Large difference in the heat transfer coefficient between lead and $\mathrm{CO}_{2}$

The design and analysis of the intermediate heat exchangers (IHXs) have been a challenge due to high operating pressures and temperatures. The high pressure on the $\mathrm{CO}_{2}$ side required stress analysis to determine the appropriate tube thickness. Furthermore, the large difference in heat transfer coefficients between the lead coolant and supercritical carbon dioxide stimulated investigation into enhanced heat transfer on the $\mathrm{CO}_{2}$ side. Finally, the pressure drop constraint on the $\mathrm{S}-\mathrm{CO}_{2}$ side is directly related to the power conversion system efficiency; thus, the minimum achievable pressure drop was pursued. The above challenges are closely linked to material choice.

\section{Materials for IHX}

T-91 alloy (with functionally gradient surface treatment on the lead side) was investigated for use in heat exchangers since $316 \mathrm{SS}$ alloy is not compatible with the corrosive environment of lead at temperatures above $550^{\circ} \mathrm{C}$. A comprehensive overview of T-91 composition and associated corrosion issues in a lead-coolant environment are discussed in Chapter 5. Prior to the ASME Code 2007 Edition, T-91 alloy was ASME Code approved for temperatures up to $649^{\circ} \mathrm{C}$ only for Section III, Classes 2 and 3 components. Therefore, its use was limited to the applications outside the pressure boundary of the reactor systems, and its properties (e.g. allowable stress intensity which is crucial for the IHX design) as a function of service time were not available. The 2007 ASME Boiler and Pressure Vessel code included T-91 alloy as an acceptable material for Sec. III, Division 1, Subsection NB/NH for Class 1 components. Figure 3.3.2-5 depicts allowable 
stress intensity for T-91 alloy for a service lifetime of 20 years for the heat exchanger components.

Another important parameter that affects heat exchanger performance is the thermal conductivity of the structural material. The ASME code provides thermal conductivities for a great variety of materials. Figure 3.3.2-6 compares thermal conductivity of T-91 alloy versus $316 \mathrm{SS}$. At the temperature of interest, $577{ }^{\circ} \mathrm{C}$ and lower, the thermal conductivity of T-91 significantly exceeds the conductivity of $316 \mathrm{SS}$. The temperature of $470^{\circ} \mathrm{C}$ shown in Figure 3.3.2-6 corresponds to the heat exchanger temperature averaged for both lead and $\mathrm{CO}_{2}$ coolants. At this temperature, the thermal conductivity of T-91 is $33 \%$ higher than $316 \mathrm{SS}$, which results in better heat transfer and thus smaller IHXs.

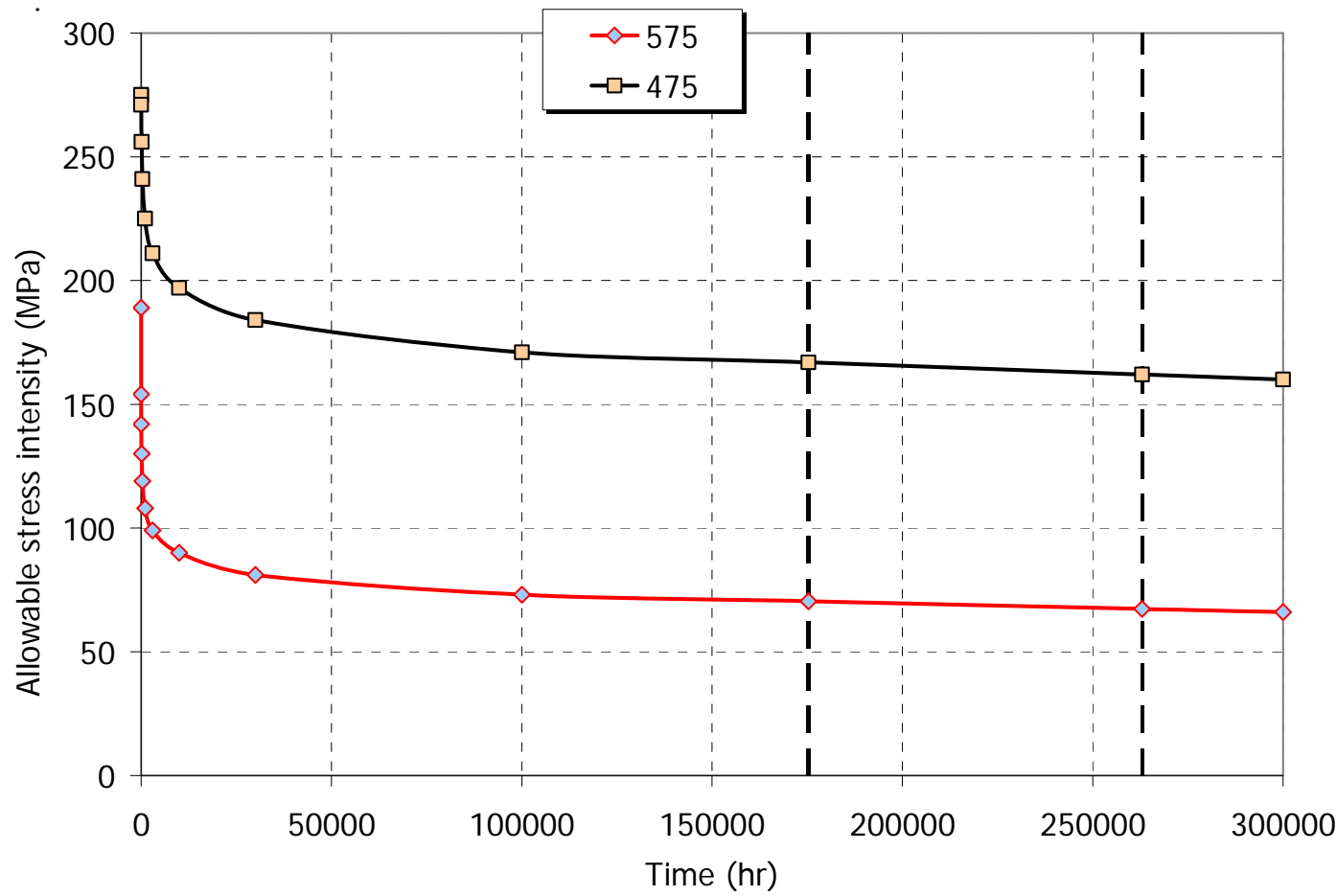

Figure 3.3.2-5 Allowable stress intensity $(\mathrm{MPa})$ as a function of time and temperature (in ${ }^{\circ} \mathrm{C}$ ) for T-91 alloy (ASME code, Division 1, Section III, Class 1 components.) 


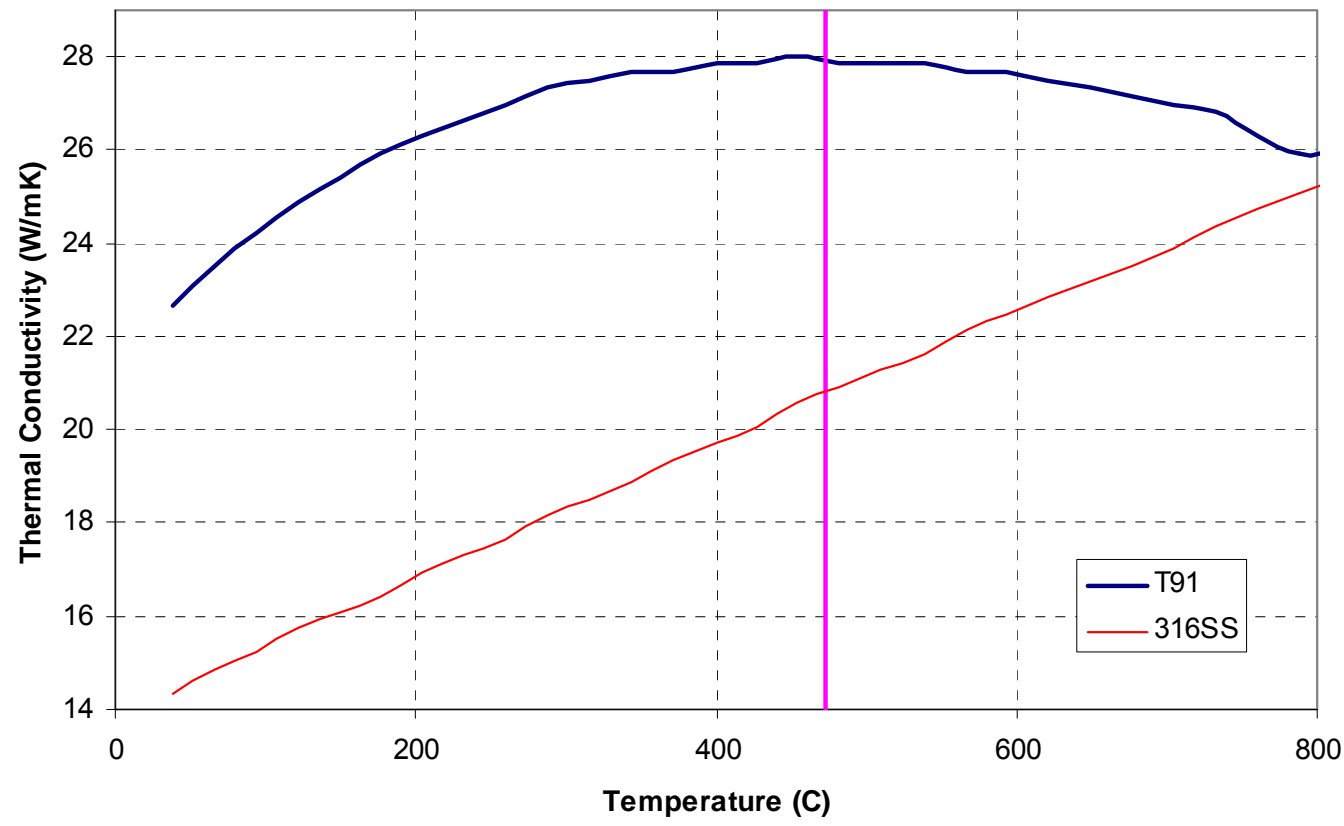

Figure 3.3.2-6 Thermal conductivity vs. temperature. The pink vertical line indicates the average temperature of both lead and $\mathrm{CO}_{2}$ within the heat exchanger.

\section{Overview of the IHX Design}

The design of the kidney-shaped heat exchanger is shown on Figures 3.3.2-7a and 3.3.27b. The gas enters the heat exchanger through the large inlet pipe and proceeds downward to the lower plenum, where it is distributed into small-diameter tubes. After the heat exchange with lead coolant which is on the outside of the tubes (shell side of the IHX), the gas is collected in the upper plenum. The $\mathrm{CO}_{2}$ outlet is split into two outlet pipes of smaller size. Concentric pipe design could not be applied to the heat exchanger due to the large size of the main inlet pipe

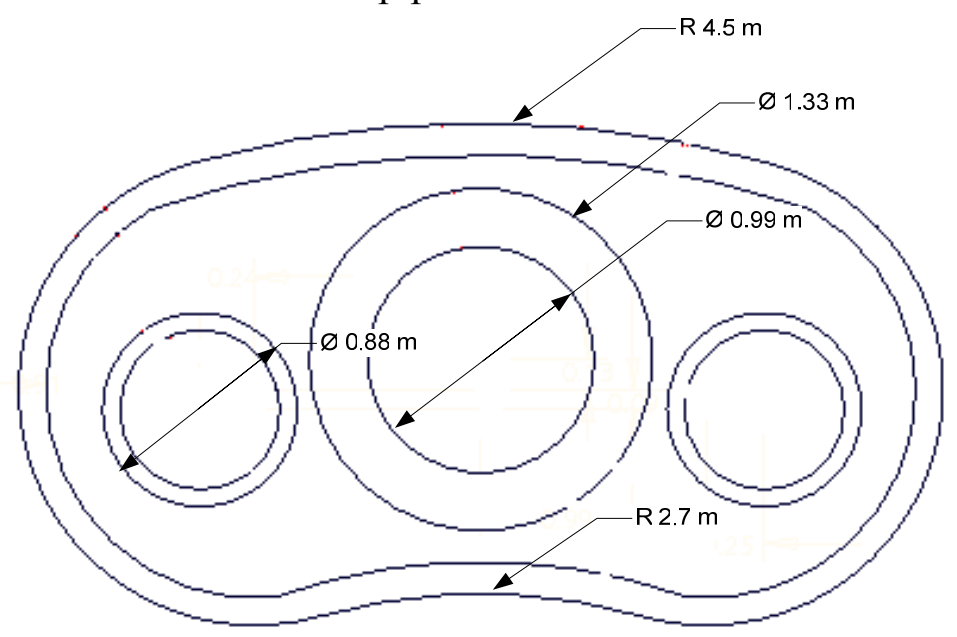

Figure 3.3.2-7 Kidney-shaped heat exchanger - top view 
Project No 06-040: Flexible Conversion Ratio Fast Reactor Systems Evaluation

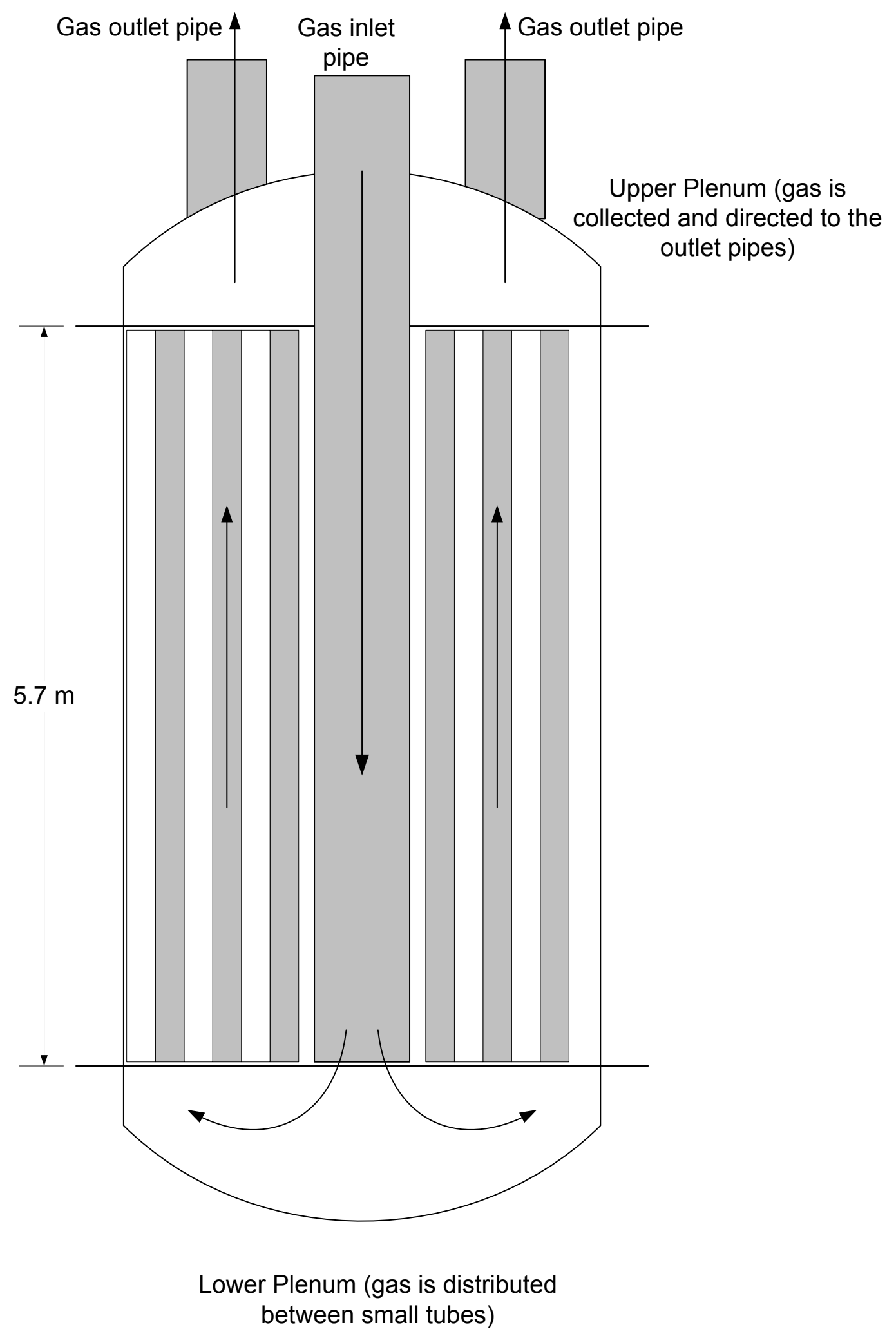

Figure 3.3.2-7b Kidney-shaped heat exchanger - vertical cross section 
The FCR reactor intermediate heat exchanger design is constrained by the size as well as performance and efficiency related to IHX lead inlet and outlet temperatures and $\mathrm{CO}_{2}$ pressure drop. The radial dimensions are limited by the core and vessel size, while its height is dictated by the vessel height. Azimuthal dimensions are influenced by the need for pump and other equipment space. The above challenges and space constraints within the reactor vessel motivated the exploration of the enhancement of heat transfer capabilities to reduce IHX dimensions. Heat transfer augmentation was considered for the $\mathrm{CO}_{2}$ side because it exhibited a heat transfer coefficient 3-5 times lower than that of the lead side. One of the possible methods to increase the heat transfer coefficient is through tube roughening on the inside tube surface. Repeated helical ribs were introduced on the inner tube side, which increases the $\mathrm{CO}_{2}$ heat transfer through disturbance of the surface sublayer [Ravigururajan, 1999]. The applicable correlations for predicting friction factor and Nusselt number developed by Bergles and Ravigururajan [Bergles and Ravigururajan, 1996] were selected for the heat exchanger design due to their generality and relevance to a wide range of applicable conditions. Such tube augmentation allowed an increase of heat transfer coefficient on the $\mathrm{CO}_{2}$ side by $20 \%$ and reduction of the tube length by over $1 \mathrm{~m}$.

The following requirements and assumptions were followed in the design:

Requirements:

- Pressure drop on $\mathrm{CO}_{2}$ side is around $500 \mathrm{kPa}$ (does not exceed $700 \mathrm{kPa}$ )

- Pitch is large enough to allow sufficiently low pressure drop on the lead side so that free level separation is not excessive

Assumptions:

- Steady state operation

- Homogeneous material

- No contact resistance between helical ribs and tube (extruded ribs)

- Constant heat transfer coefficient of the rib to the gas flow over the entire surface of the tube

The design approach and correlations comparison for enhanced heat transfer through internally ribbed tubes are described in Appendix C. Augmented tubes allow for a more compact heat exchanger without significant increase in the pressure drop. Comparison of enhanced and smooth tube heat exchanger performance is presented in Table 3.3.2-3. Reduction in tube length causes a decrease in pressure drop in both fluids, which can be seen for the lead case, but the presence of ribs on the $\mathrm{CO}_{2}$ side offsets that effect. Main characteristics of the final heat exchanger design are summarized in Table 3.3.2-4.

Table 3.3.2-3 Smooth vs. enhanced tube IHX performance for the same power output.

\begin{tabular}{lcc}
\hline & Smooth & Enhanced \\
\hline Tube length $(\mathrm{m})$ & 6.76 & 5.64 \\
\hline $\mathrm{S}-\mathrm{CO}_{2}$ pressure drop $(\mathrm{kPa})$ & 216 & 226 \\
\hline Lead pressure drop $(\mathrm{kPa})$ & 379 & 323 \\
\hline Total heat transfer coefficient $\left(\mathrm{W} / \mathrm{m}^{2} \mathrm{~K}\right)$ & 3290 & 3950 \\
\hline Lead heat transfer coefficient $\left(\mathrm{W} / \mathrm{m}^{2} \mathrm{~K}\right)$ & 22500 & 22500 \\
\hline $\mathrm{S}-\mathrm{CO}_{2}$ heat transfer coefficient $\left(\mathrm{W} / \mathrm{m}^{2} \mathrm{~K}\right)$ & 5000 & 6812 \\
\hline
\end{tabular}


Table 3.3.2-3 Main heat exchanger parameters.

\begin{tabular}{|c|c|}
\hline \multicolumn{2}{|l|}{ INPUT } \\
\hline Core power $(\mathrm{MWt})$ & 2400 \\
\hline Lead mass flow rate $(\mathrm{kg} / \mathrm{s})$ & 173600 \\
\hline $\mathrm{S}-\mathrm{CO}_{2}$ mass flow rate $(\mathrm{kg} / \mathrm{s})$ & 12757 \\
\hline Number of heat exchangers & 4 \\
\hline Target power transmitted in the IHX (per IHX) (MWt) & 600 \\
\hline Lead inlet temperature $\left({ }^{\circ} \mathrm{C}\right)$ & 573.3 \\
\hline Lead outlet temperature $\left({ }^{\circ} \mathrm{C}\right)$ & 477.0 \\
\hline $\mathrm{S}-\mathrm{CO}_{2}$ inlet temperature $\left({ }^{\circ} \mathrm{C}\right)$ & 396.5 \\
\hline S-CO $\mathrm{CO}_{2}$ target outlet temperature $\left({ }^{\circ} \mathrm{C}\right)$ & 549.3 \\
\hline $\mathrm{S}-\mathrm{CO}_{2}$ pressure $(\mathrm{MPa})$ & 19.7 \\
\hline \multicolumn{2}{|l|}{ IHX GEOMETRY } \\
\hline Lattice & Triangular \\
\hline Number of tubes (per IHX) & 19173 \\
\hline Outer tube diameter (mm) & 14 \\
\hline Tube wall thickness (mm) & $2.22 *$ \\
\hline Pitch to diameter ratio & 1.23 \\
\hline Inner IHX radius $\left(\mathrm{r}_{\mathrm{i}}\right)^{1}(\mathrm{~m})$ & 2.687 \\
\hline Outer IHX radius $\left(r_{o}\right)(m)$ & 4.496 \\
\hline \multicolumn{2}{|l|}{ TUBE GEOMETRY } \\
\hline Rib height (mm) & 0.35 \\
\hline Number of starters & 5 \\
\hline Helix angle $\left({ }^{\circ}\right)$ & 27 \\
\hline \multicolumn{2}{|l|}{ OUTPUT } \\
\hline Calculated power (MWt) & 598.7 \\
\hline Logarithmic temperature difference $\left({ }^{\circ} \mathrm{C}\right)$ & 46.7 \\
\hline $\mathrm{S}-\mathrm{CO}_{2}$ pressure drop $(\mathrm{kPa})$ & 226 \\
\hline Lead pressure drop $(\mathrm{kPa})$ & 323 \\
\hline $\mathrm{S}-\mathrm{CO}_{2}$ velocity $(\mathrm{m} / \mathrm{s})$ & 16.8 \\
\hline Lead velocity $(\mathrm{m} / \mathrm{s})$ & 2.17 \\
\hline Tube length (m) & 5.7 \\
\hline Total heat transfer coefficient $\left(\mathrm{W} / \mathrm{m}^{2} \mathrm{~K}\right)$ & 3950 \\
\hline Lead heat transfer coefficient $\left(\mathrm{W} / \mathrm{m}^{2} \mathrm{~K}\right)$ & 22500 \\
\hline $\mathrm{S}-\mathrm{CO}_{2}$ heat transfer coefficient $\left(\mathrm{W} / \mathrm{m}^{2} \mathrm{~K}\right)$ & 6812 \\
\hline
\end{tabular}


Project No 06-040: Flexible Conversion Ratio Fast Reactor Systems Evaluation

\subsubsection{Transient Analysis}

The analysis of the reactor behavior during transients is an important part of the design. The reactor must demonstrate acceptable performance during a range of potential initiating events. Currently there are no regulatory requirements for the initiating events for fast reactors analogous to those for light water reactors. However, lead-cooled reactors are still vulnerable to a number of events similar to those common in the LWR. Such events include loss of offsite power, withdrawal of control rods, and failure of primary pumps. Because an aggressive safety goal of accommodating unprotected accidents in a self-controllable manner, as for the IFR design [Wade, 1997], was set for this project, the transients will be modeled with an assumption of failure to scram. However, because of the high melting point of lead coolant, protected station blackout accidents were also modeled to ensure that the reactor is capable of safe shutdown without freezing the primary coolant. A comprehensive strategy for SBO transient management for both the unprotected and protected accidents was given in Section 2.2.3.5.

First, three unprotected accidents were analyzed: station blackout, unprotected primary coolant pump trip, and unprotected inadvertent reactivity insertion (unprotected overpower). The analysis of the reactor performance during transients allowed for determining whether the passive safety features of the reactor are adequate to ensure the core safety. The models used in the transient simulation are described in detail in Appendix 3B.2. In all models, four IHX/PCS loops were lumped into 2x2 loops to reduce the computational time. The decay heat calculated in Session 3.3.1 to account for the specifics of TRU fuel decay heat was used in the RELAP5-3D model. Also, the reactivity coefficients discussed in Section 3.3.1 were incorporated into the model.

During a station blackout accident, the main decay heat removal system is the RVACS. As described in Chapter 2, an additional Passive Secondary Auxiliary Cooling System (PSACS), which assists RVACS, is needed to keep the peak cladding temperature below limits. In addition, the heat removal capabilities of the power conversion system for an unprotected loss of coolant accident were analyzed, and the turbine overspeed protection options were modeled. The overspeed protection options are discussed in Section 2.2.3. Table 3.3.2-4 summarizes the initial conditions of the reactor at rated power. This section summarizes the main results and conclusions from the transient analysis.

\subsection{Unprotected Station Blackout Accident}

The safety approach of the FCR reactor is based on the defense-in-depth philosophy which includes multiple barriers to a radiation release during an accident. In addition, the reactor systems are designed not to exceed structural limits using passive means for reactor shutdown and cooling even during unprotected accidents such as LOFA or UTOP. The unprotected SBO accident is considered to be the limiting event in terms of its severity because it is characterized by the following:

- Loss of forced circulation as reactor coolant pumps trip due to loss of AC; 
- Loss of AC causes loss of precooler pumps;

- Generators are isolated from the grid due to loss of load;

- The reactor fails to scram and therefore must shut down due to negative reactivity feedback.

Table 3.3.2-4 Initial conditions at full power

$\begin{array}{lr}\text { Primary coolant system } & \\ \text { Core power }(\mathrm{MWt}) & 2400 \\ \text { Mass flow rate }(\mathrm{kg} / \mathrm{s}) & 173600 \\ \text { Core inlet temperature }\left({ }^{\circ} \mathrm{C}\right) & 479 \\ \text { Core outlet temperature }\left({ }^{\circ} \mathrm{C}\right) & 574 \\ \text { Maximum cladding temperature }\left({ }^{\circ} \mathrm{C}\right)(\mathrm{CR}=1 / \mathrm{CR}=0) & 610 / 624 \\ \text { Maximum fuel temperature }\left({ }^{\circ} \mathrm{C}\right) & 725 \\ \text { Secondary system } & \\ \text { Pressure }(\mathrm{MPa}) & 19.96 \\ \text { Mass flow rate }(\mathrm{kg} / \mathrm{s}) & 12848 \\ \text { Inlet temperature } & 397 \\ \text { Outlet temperature }\left({ }^{\circ} \mathrm{C}\right) & 548 \\ \text { RVACS } & \\ \text { Power removed }(\mathrm{MW}) & 6.8 \\ \text { Air flow rate }(\mathrm{kg} / \mathrm{s}) & 79.1 \\ \text { Air inlet temperature }\left({ }^{\circ} \mathrm{C}\right) & 37.8 \\ \text { Air exit temperature }\left({ }^{\circ} \mathrm{C}\right) & 122.1 \\ \text { Maximum guard vessel temperature }\left({ }^{\circ} \mathrm{C}\right) & 434.0\end{array}$

The accident was initiated at 0.0 seconds. During an SBO, the PSACS isolation valves fail open and the PCS isolation valves fail closed. The purpose of the turbomachinery isolation is twofold: the gas must be directed through the PSACS equipment to remove as much heat as possible and to prevent the turbine rotational overspeed that would result in turbine and compressor blade damage. In this case, when the power conversion system is isolated, the IHX bypass valves open to prevent flow stagnation in the loop. In the RELAP5-3D model described in Appendix 3B.2 the PCS was isolated at the beginning of the accident. Thus, in order to simplify the model and to reduce computational time, the PCS was modeled as time-dependent boundary conditions. Because the PCS is not part of the SBO accident sequence, such simplification does not have any effect on the results of this transient.

The PSACS and PCS valves are not operational during an SBO; their actuators are held closed (PSACS) or open (PCS) during normal operations by solenoid or instrument air. An SBO causes a complete loss of the onsite and offsite AC, causing the valves to deenergize and fail to their appropriate positions via stored potential energy. The PSACS design and function was described in Section 2.2.3.2 and will not be repeated here. Current regulations (10 CFR 50.63) require a SBO mitigation strategy of up to 8 hours. Future reactor designs such as AP1000 and ESBWR have 72 hour SBO mitigation strategies allowing for the elimination of safety-related emergency diesel generators. 
Seventy-two hours is typically a time considered for sufficient recovery of onsite or offsite AC power and was therefore adopted for our analysis.

The PSACS-Water version consists of four trains $(4 \times 50 \%)$, each for one intermediate heat exchanger as shown in Figure 3.3.2-8. Operation of only two trains should be sufficient for satisfactory performance during the station blackout accident. This fact was taken into account when the design parameters were calculated. Figure 3.3.2-9 shows the integrated layout of the primary and secondary (PCS and PSACS) reactor coolant systems and RVACS.

In the initial analysis, the ANS-79 standard decay heat curve available in RELAP5-3D had been used before the decay heat curves specific for FCR core designs were developed. The ANS-79 decay heat curve includes only four fissionable nuclides: U-235, U238, Pu239, and Pu241. However, as shown in Section 3.3.1, the FCR reactor cores contain TRU fuel with a variety of actinides $(\mathrm{Pu}, \mathrm{Am}, \mathrm{Cm}, \mathrm{Np})$ that uniquely determine the amount and variety of the fission products generated, resulting in significant differences in decay heat, as shown in Figure 3.3.1-13. Figure 3.3.2-10 compares the decay heat generated by the $\mathrm{CR}=1$ and $\mathrm{CR}=0$ TRU cores with the ANS-79 standard. As can be observed, the $\mathrm{CR}=1$ core is the limiting case due to its higher decay heat generation rate. Moreover, it has inferior reactivity feedback coefficients in comparison with the $\mathrm{CR}=0$ core. On the other hand, the $\mathrm{CR}=0$ case is more vulnerable to coolant freezing if all PSACS trains operate during a protected SBO.

The response of the FCR $\mathrm{CR}=1$ reactor to the station blackout accident with the ANS-79 decay heat curve standard and with the BGCORE-generated decay heat curve is presented in Figure 3.3.2-11. The considerable increase in the amount of the decay heat generated necessitated a redesign of the PSACS. First, the increase in the net amount of the decay heat generated required additional water in the PSACS water tank. Second, the PSACS heat exchanger size was adjusted to obtain the desired heat removal rate. Figure 3.3.2-12 depicts peak cladding temperature for both cores. Two peaks can be observed: the early peak around 2-3 hours and the delayed peak around 50 hours after the accident was initiated. The first peak is controlled by the rate at which the PSACS removes heat from the primary system. The second peak is the equilibrium point between the heat generated by the core and the heat removed by the RVACS. However, the second peak depends also on the amount of water in the PSACS tank. Note that the minimum in peak cladding temperature corresponds to the time of isolation of the PSACS or complete evaporation of water. The final design parameters, calculated after the actual decay heat curve was implemented and the PSACS was redesigned, are presented in Table 3.3.2-5. The RELAP5-3D model of the PSACS is described in detail in Appendix 3B.2. 
Project No 06-040: Flexible Conversion Ratio Fast Reactor Systems Evaluation

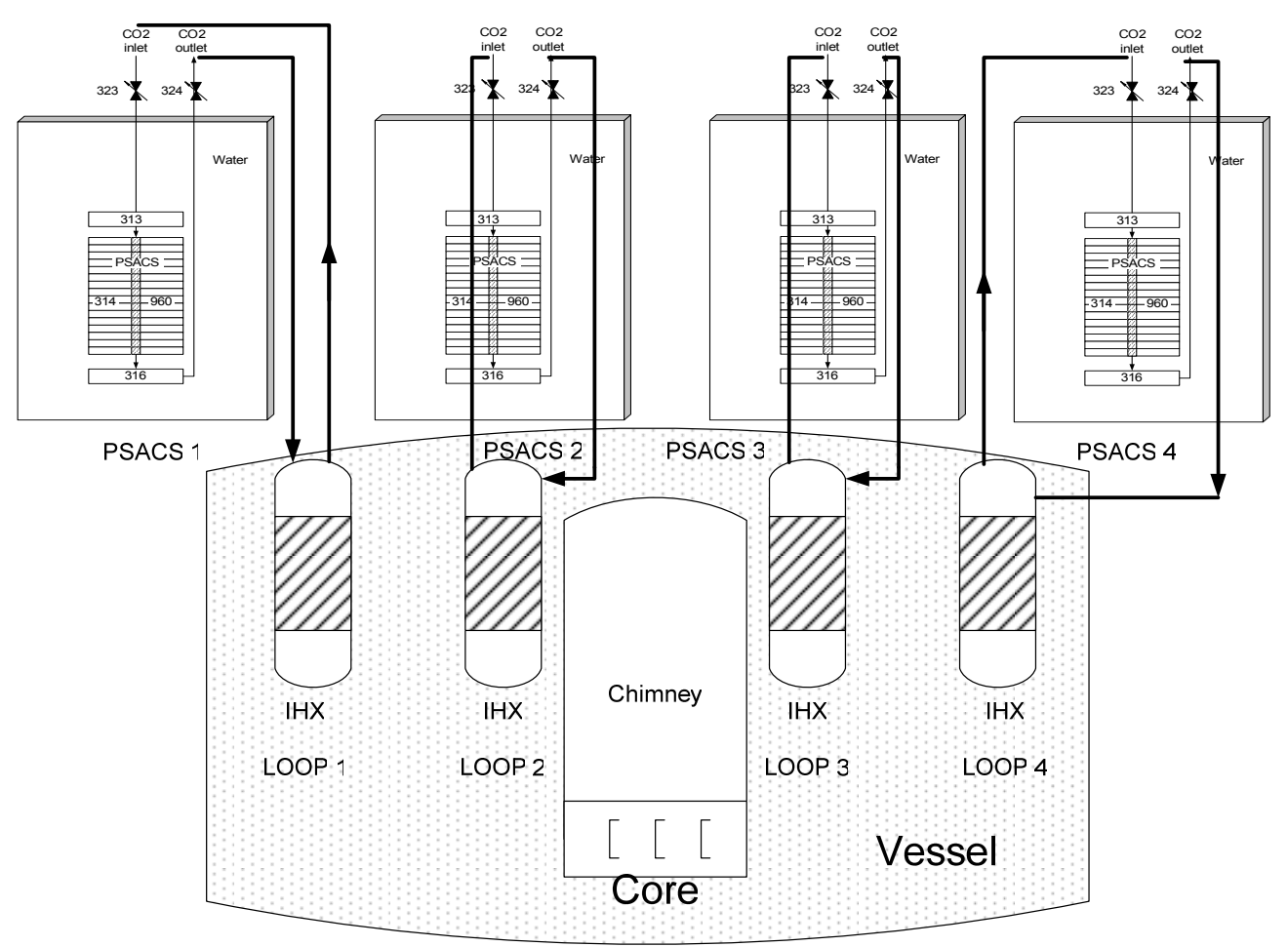

Figure 3.3.2-8 Relative layout of the reactor and PSACSs. 
Project No 06-040: Flexible Conversion Ratio Fast Reactor Systems Evaluation

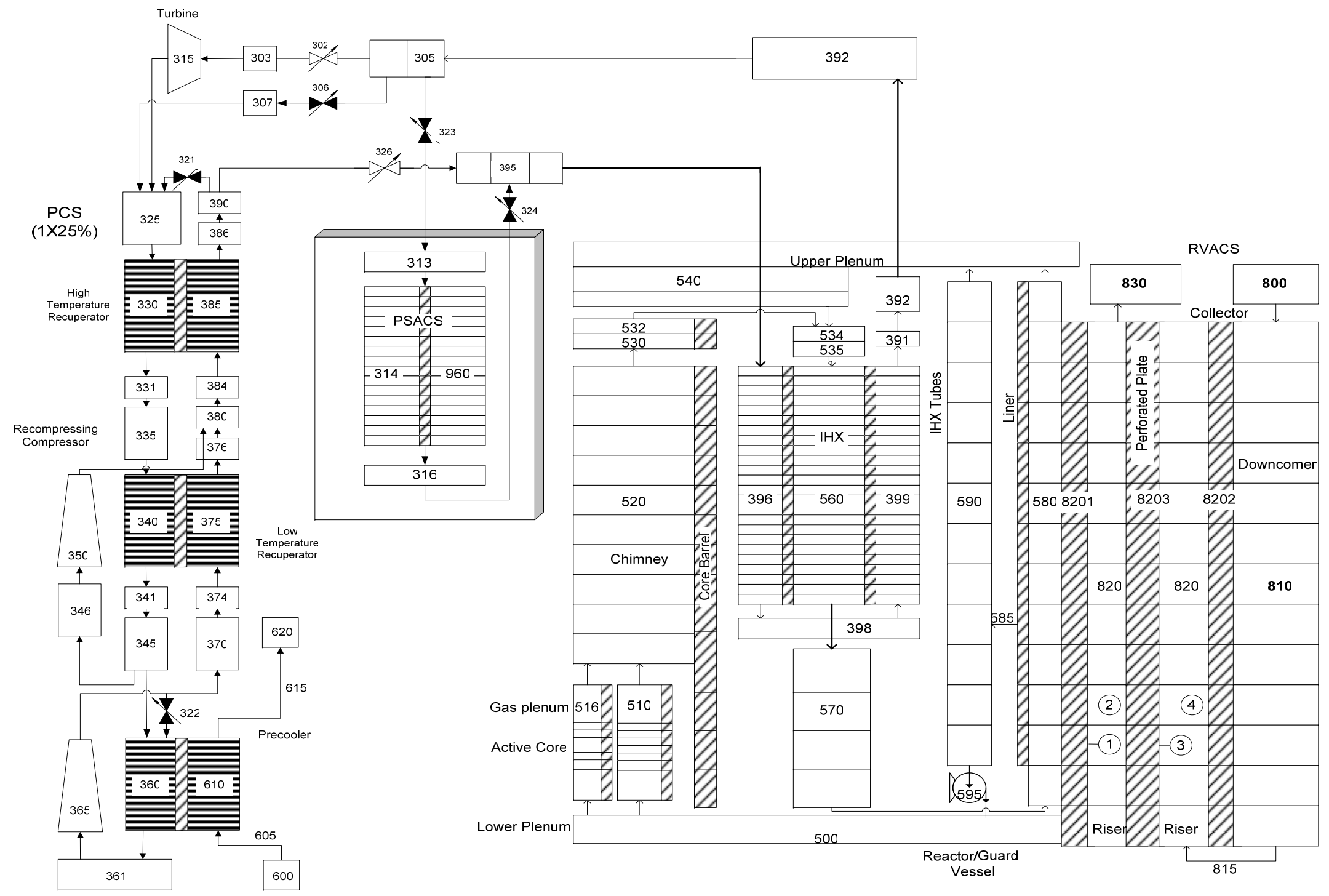

Figure 3.3.2-9 Integrated layout of the primary and secondary (PCS and PSACS) reactor coolant systems and RVACS. 
Project No 06-040: Flexible Conversion Ratio Fast Reactor Systems Evaluation

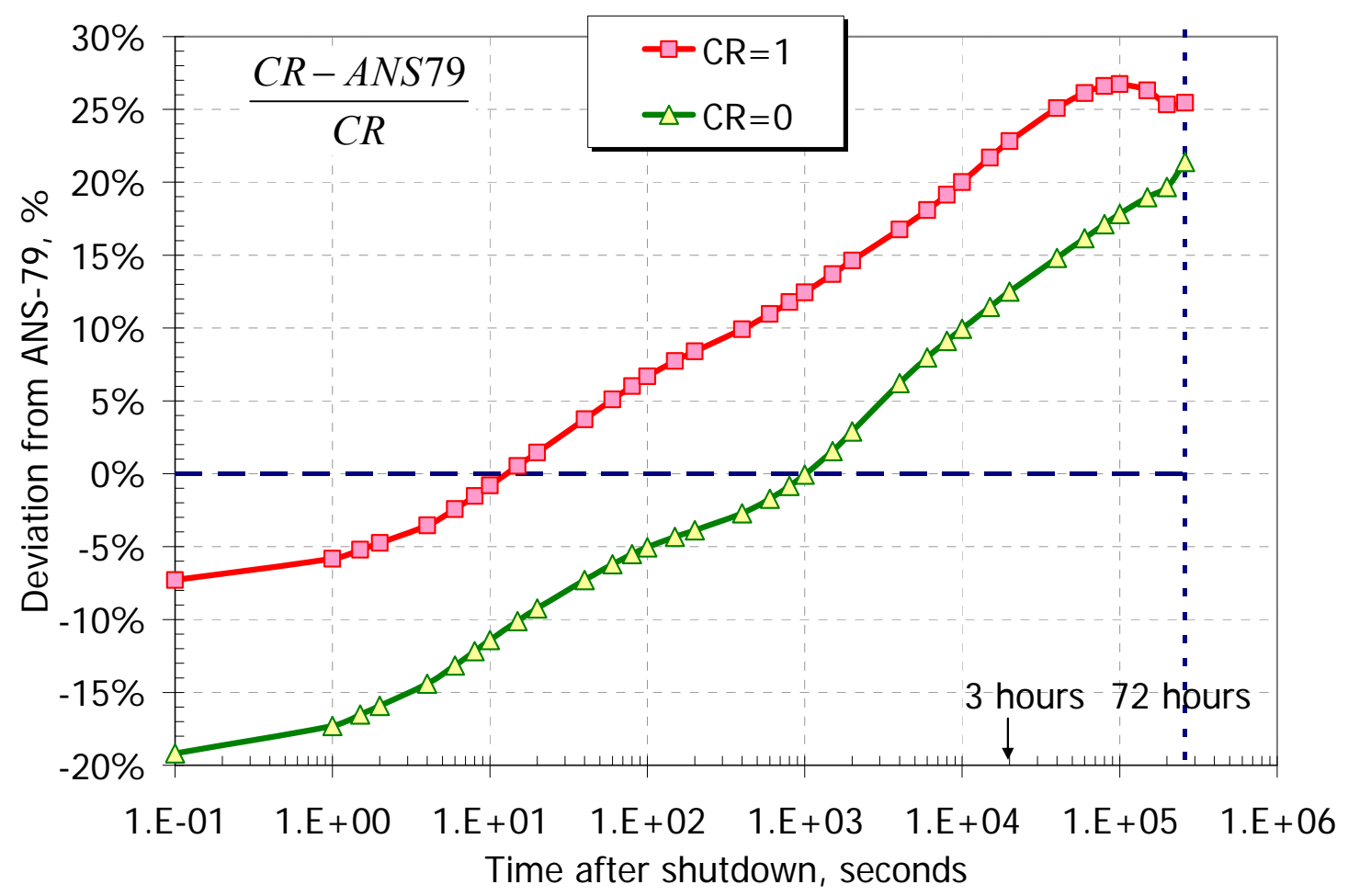

Figure 3.3.2-10 Decay heat generation rate deviation (\%) from ANS-79 decay heat curve

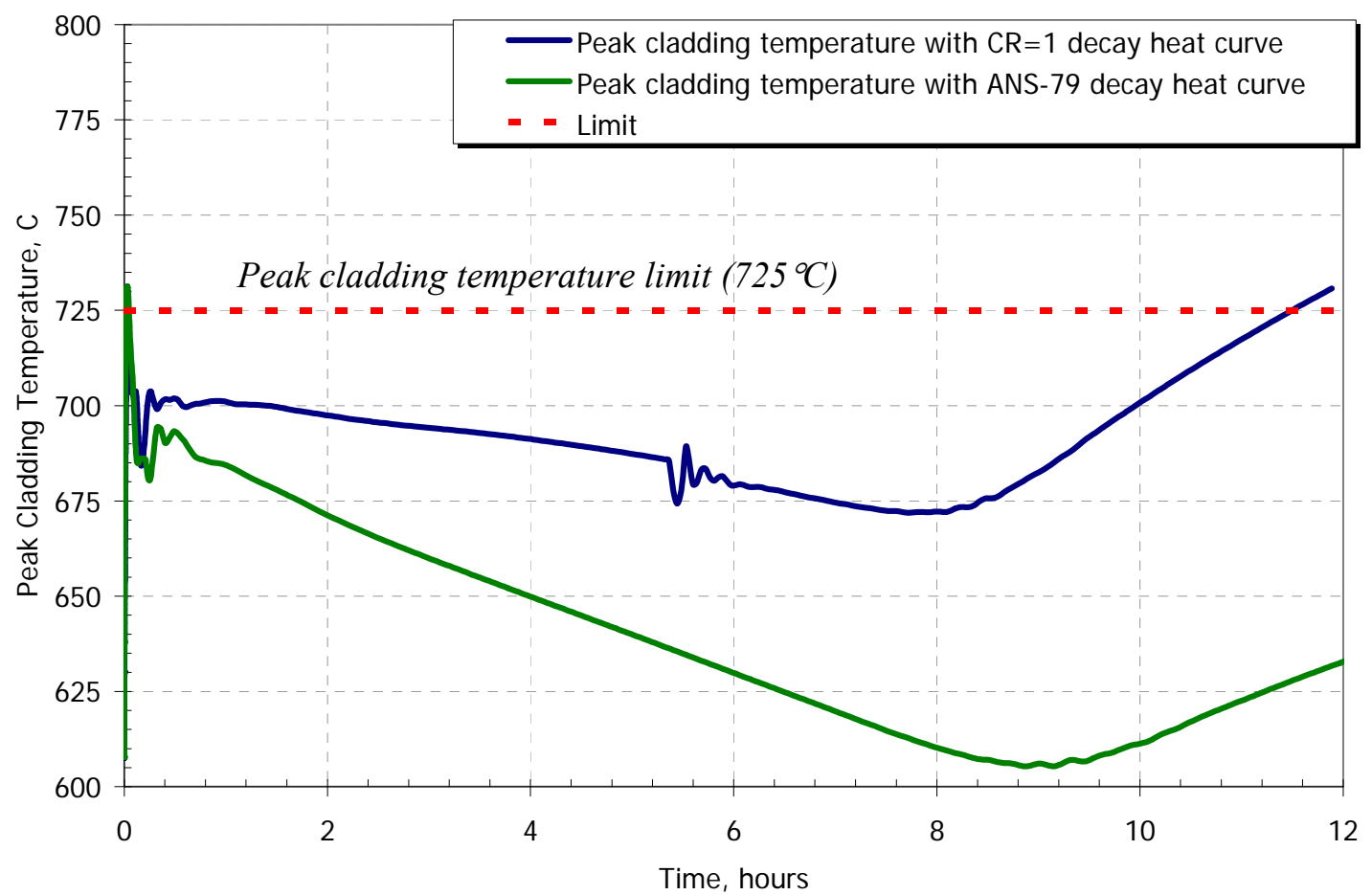

Figure 3.3.2-11 Comparison of peak cladding temperature for $\mathrm{CR}=1$ core with different decay heat curves. 
Project No 06-040: Flexible Conversion Ratio Fast Reactor Systems Evaluation

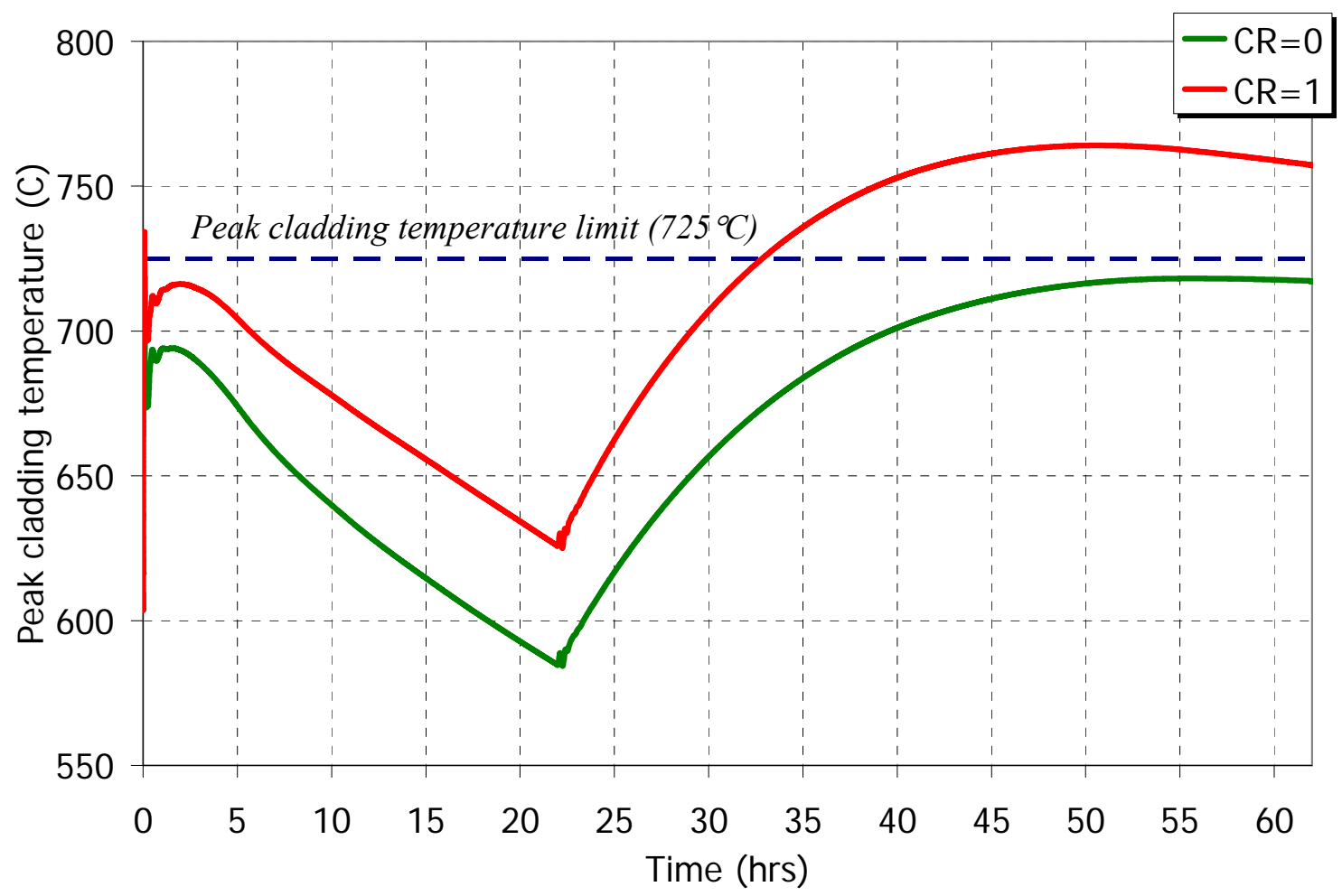

Figure 3.3.2-12 Peak cladding temperature during an unprotected SBO accident

Table 3.3.2-5 Design parameters for PSACS after the actual DHC was implemented.

\begin{tabular}{|c|c|c|}
\hline Parameter & Initial Value & Comments/Remarks \\
\hline \multicolumn{3}{|l|}{$\mathrm{CO}_{2}$ inlet initial conditions } \\
\hline $\mathrm{CO}_{2}$ inlet temperature $\left({ }^{\circ} \mathrm{C}\right)$ & 548 & $\mathrm{CO}_{2}$ outlet of IHX \\
\hline $\mathrm{CO}_{2}$ inlet pressure $(\mathrm{MPa})$ & 19.5 & \\
\hline $\mathrm{CO}_{2}$ flow rate $(\mathrm{kg} / \mathrm{s})$ & 32.1 & $\begin{array}{l}\text { Assumed for optimization purpose as } \\
1 \% \text { of the initial flow rate. Will be } \\
\text { determined by natural circulation. }\end{array}$ \\
\hline \multicolumn{3}{|l|}{ Water Tank $-\mathrm{H}_{2} \mathrm{O}$ initial conditions } \\
\hline $\mathrm{H}_{2} \mathrm{O}$ temperature $\left({ }^{\circ} \mathrm{C}\right)$ & 25 & Room pressure and temperature \\
\hline Tank diameter $(\mathrm{m})$ & 8.0 & \multirow{2}{*}{$\begin{array}{l}\text { The volume of the water was estimated } \\
\text { based on water properties and possible } \\
\text { duration of the accident. }\end{array}$} \\
\hline Tank height (m) & 14.0 & \\
\hline \multicolumn{3}{|c|}{ Passive Auxiliary Heat Exchanger (PAHX) } \\
\hline Number of tubes & 350 & \\
\hline Tube length (m) & 4.0 & \\
\hline Inner diameter $-\mathrm{CO}_{2}$ side $(\mathrm{m})$ & $8.00 \mathrm{E}-03$ & \\
\hline Tube thickness (m) & $2.80 \mathrm{E}-03$ & \\
\hline Outer diameter - water side $(\mathrm{m})$ & $1.36 \mathrm{E}-02$ & \\
\hline $\mathrm{P} / \mathrm{D}$ ratio & 3 & \\
\hline
\end{tabular}

One of the design goals of the FCR reactor is its ability to undergo inherent shutdown due to reactivity feedbacks. However, if the temperatures of the fuel, coolant and structures become 
low enough to result in zero or positive reactivity, the reactor restarts itself, causing a temporary power increase and an associated temperature rise, which leads to a new equilibrium after minor oscillations. Therefore, the PSACS heat exchanger would ideally have to be designed such that the peak cladding transient limit temperature is not exceeded and at the same time its heat removal rate is sufficiently low to avoid achievement of low temperatures at which the reactivity becomes positive. For the zero conversion ratio reactor, the PSACS size that ensured smooth reactor shutdown without restart and PCT temperature below the limit of $725^{\circ} \mathrm{C}$ was identified.

However, it turned out to be difficult to size the PSACS heat exchanger for the $\mathrm{CR}=1$ concept. A low heat removal rate leads to early peak cladding temperatures above the limit, since the high decay heat generation rate at the beginning of the transient cannot be accommodated. On the other hand, if the heat exchanger size is too large, the PCT will rapidly decrease leading to reactor restart. Figure 3.3.2-13 illustrates the case when the PSACS heat exchanger is too large. The decay heat is rapidly removed from the primary system, causing the coolant and fuel temperatures to drop below the point at which the reactivity becomes positive. Once the temperature of the primary system becomes too low, reactivity increases, resulting in power rise and low power oscillations. But even if one could find the right size of the PSACS to accommodate both conversion ratio cores, it would be difficult to size the PSACS HX for different numbers of operating loops (note that there are 4x50\% PSACS loops) and avoid reactor restart. This is because there is a priori no guarantee of how many PSACS loops will be operating $(2 \times 50 \%, 3 \times 50 \%$ or $4 \times 50 \%)$. Note from the Figure 3.3.2-13 that there is much additional power to be removed in case the reactor restarts. The additional power will result in faster evaporation of water from the PSACS tanks. On the other hand, the strategy discussed in Section 2.2.3.5 identified a major concern with coolant freezing in case of a reactor scram. In fact, since the unprotected accidents are beyond design basis, the coolant freezing in case of three or four operating PSACS trains in SBO with scram poses a significant challenge to the PSACS design. The PSACS can be designed such that cladding damage can be avoided in unprotected accidents by adding enough water in the PSACS water tank, but such a design can be counterproductive in much more likely accidents with scram. Thus, there are four PSACS design constraints:

(1) PCT during the first peak, which depends on the PSACS heat exchanger size, needs to remain below the PCT limit,

(2) PCT during the second peak, which depends on the RVACS performance, but also on the amount of water in the tank, needs to remain below the PCT limit,

(3) Primary system temperatures should not decrease below a limiting value at which reactivity becomes positive resulting in reactor restart for unprotected accidents (this temperature is also affected by PSACS heat exchanger size), and

(4) Coolant freezing, which can be a result of primary system overcooling during protected accidents when more than two PSACS trains are operating, should be prevented.

To satisfy all four constraints is not an easy task. Several configurations of the PSACS were considered. However, due to the complexity of the problem, no satisfactory results were obtained. The operating "window" for the PCT is slightly over $100^{\circ} \mathrm{C}$ (the PCT is constrained by a $725^{\circ} \mathrm{C}$ upper limit and a $\sim 605^{\circ} \mathrm{C}$ lower limit to prevent reactor restart) which is not enough to handle this type of accident. Protected accidents are easier to handle since they do not result in reactor restart, and the operating temperature window is between $725^{\circ} \mathrm{C}$ for peak cladding and $327^{\circ} \mathrm{C}$ for minimum coolant. However, because of a lower amount of heat generated, the 
cooling with the PSACS occurs at a higher rate than in unprotected accidents. Considering the additional issue of accommodating operation of different number of PSACS trains, a new strategy for the unprotected station blackout accident, described in Section 2.2.3.5, was devised.

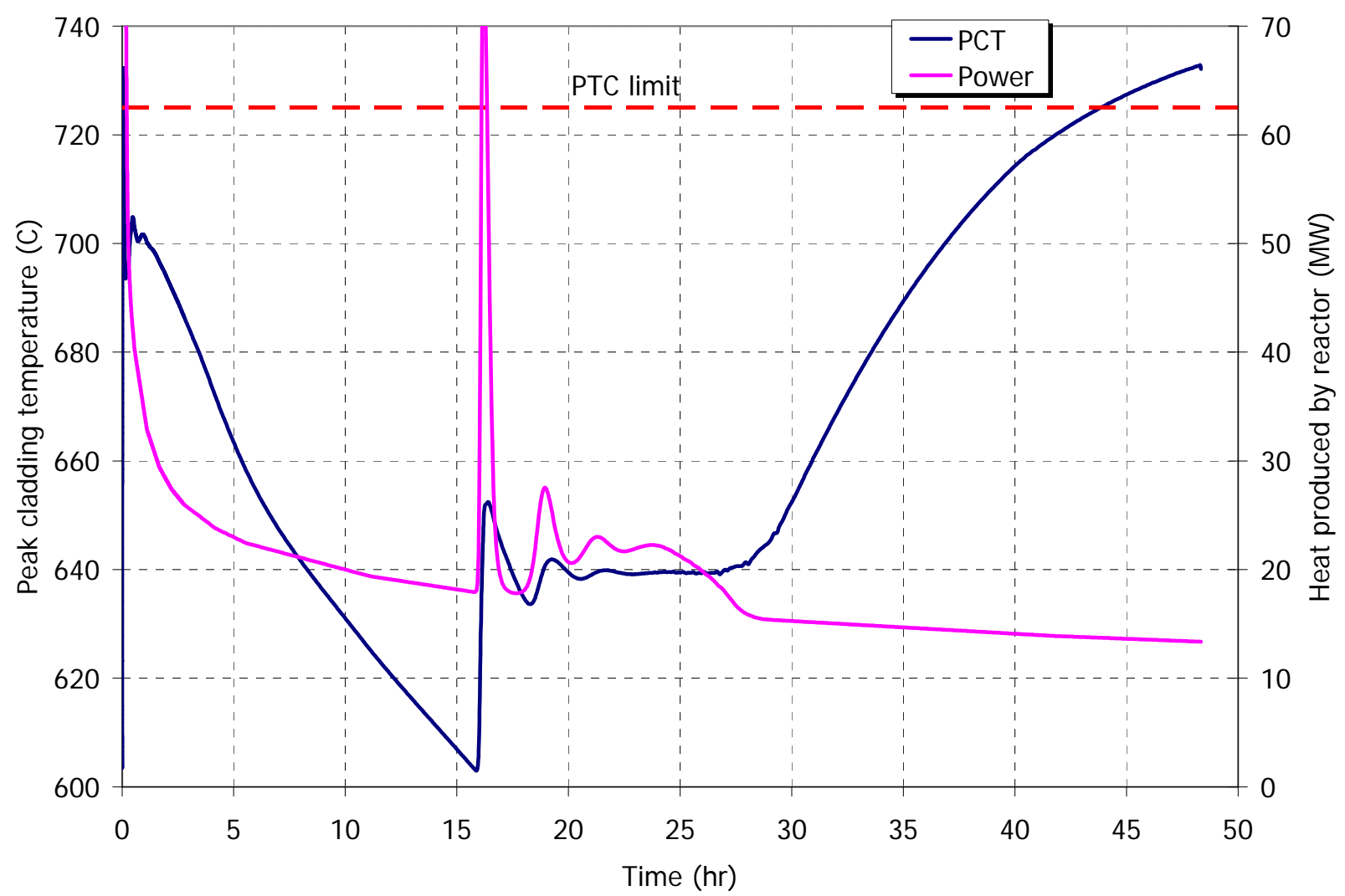

Figure 3.3.2-13 PCT response for a case of large size of PSACS heat exchanger.

\section{Results for Unprotected Station Blackout}

The unprotected station blackout exhibits first an overall primary system temperature increase since the heat generation exceeds the heat removal by RVACS and PSACS. The amount of heat that can be removed through PSACS depends on two parameters: the size of the gas-to-water heat exchanger and the amount of water in the PSACS tank. After reactivity feedbacks from increased core temperatures shut down the reactor, RVACS plus PSACS heat removal exceeds decay power, which results in reactor cooling until the reactivity reaches zero and the reactor restarts at low power. Once the reactor restarts, core power settles at a level equal to the heat rate that the PSACS plus RVACS can remove together. This causes increased water evaporation from the PSACS tank and faster tank depletion. Figure 3.3.2-14 plots the peak cladding temperature for the case of $2 \times 50 \%$ PSACS trains and $4 \times 50 \%$ PSACS trains operating. For both cases, the PSACS water tank was increased to $16 \mathrm{~m}$ in height and $8 \mathrm{~m}$ in diameter in order to accommodate the additional heat generated from reactor low-power restart. The heat exchanger has 350 four-meter-long tubes. 
Project No 06-040: Flexible Conversion Ratio Fast Reactor Systems Evaluation

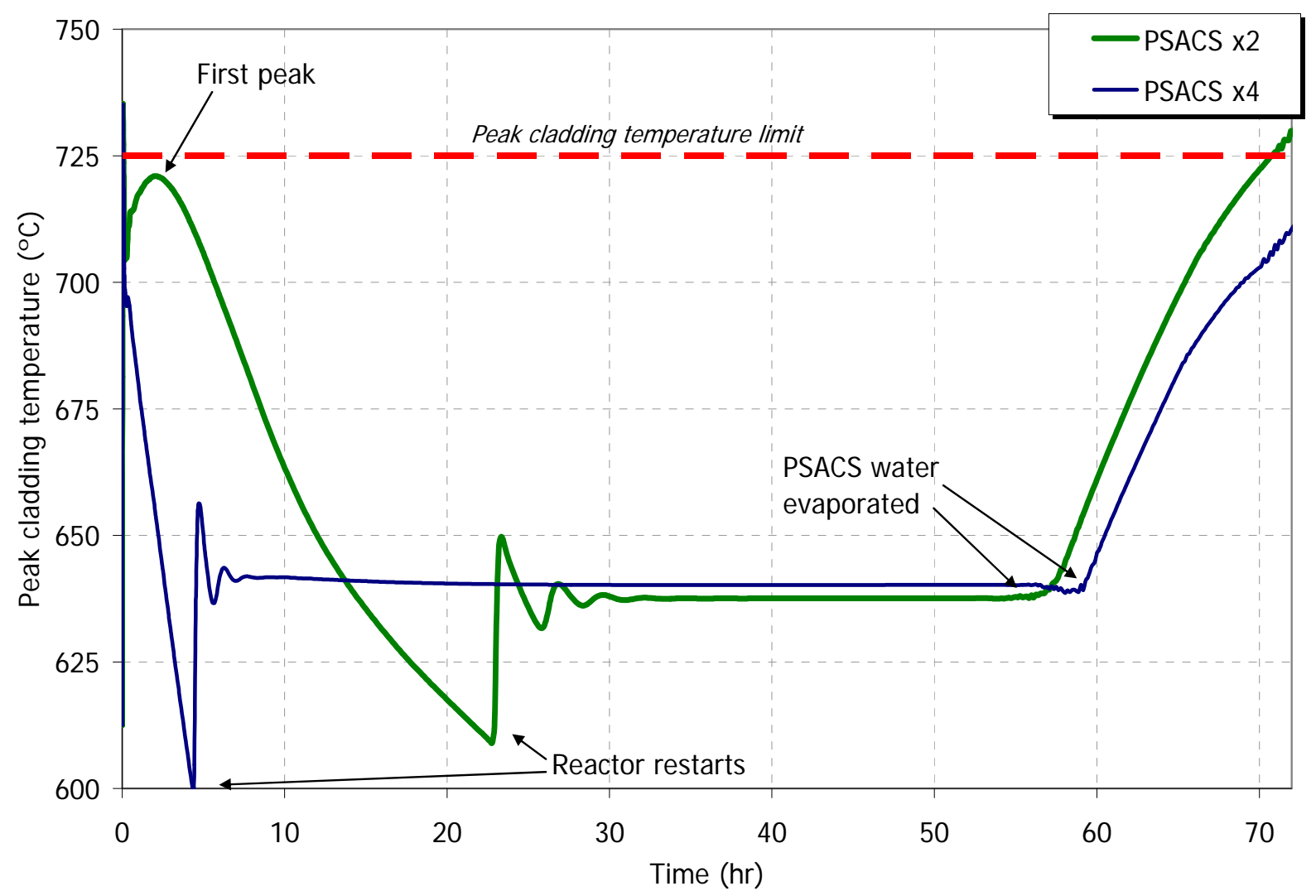

Figure 3.3.2-14 Comparison of PCT for PSACSx2 and PSACSx4 cases

This example illustrates the effect of the number of PSACS trains operating on the peak cladding temperature. The decay heat can be handled by only two trains, but PCT results for four operating trains is similar because of extra heat generated due to reactor restart. Both cases show complete PSACS water evaporation at 55-60 hours. The heat exchanger size was decreased to the smallest size for which the first PTC peak does not exceed the $725^{\circ} \mathrm{C}$ temperature limit. The small size of the heat exchanger allows for a slow cooldown of the system, while the large size PSACS water tank increases the time to evaporate the PSACS tank water. Slow cooldown is favorable because of delayed reactor restart and is necessary for the protected accidents because of the possibility of coolant freezing discussed later in this section.

The first peak occurs at $\sim 3$ hours into the accident. The restart for the PSACS $x 2$ case happens at $\sim 22$ hours, while the restart for the PSACS $\times 4$ case happens much earlier at $\sim 4.5$ hours. This difference arises from a faster primary system cooldown of the $\mathrm{x} 4$ case causing earlier reactor restart. The reactivity for both cases is illustrated in Figure 3.3.2-15. It can be observed that the reactivity becomes positive at $\sim 2.7$ hours for the PSACS $x 4$ case and at $\sim 14.6$ hours for the PSACS $x 2$ case. This is because of the decrease of core temperatures which inserts reactivity due to net negative reactivity feedback. Comparison of Figure 3.3.2-15 with Figure 3.3.2-16 shows that there is a significant delay between the time when reactivity exceeds zero and the reactor restarts. This is because the model did not consider the neutron source from spontaneous fissions; fission reactor power exhibited an extremely small value after prolonged reactor shutdown, resulting in a negligible fission power increase in comparison to decay heat until positive reactivity increased sufficiently to cause visible fission power increase. 
Project No 06-040: Flexible Conversion Ratio Fast Reactor Systems Evaluation

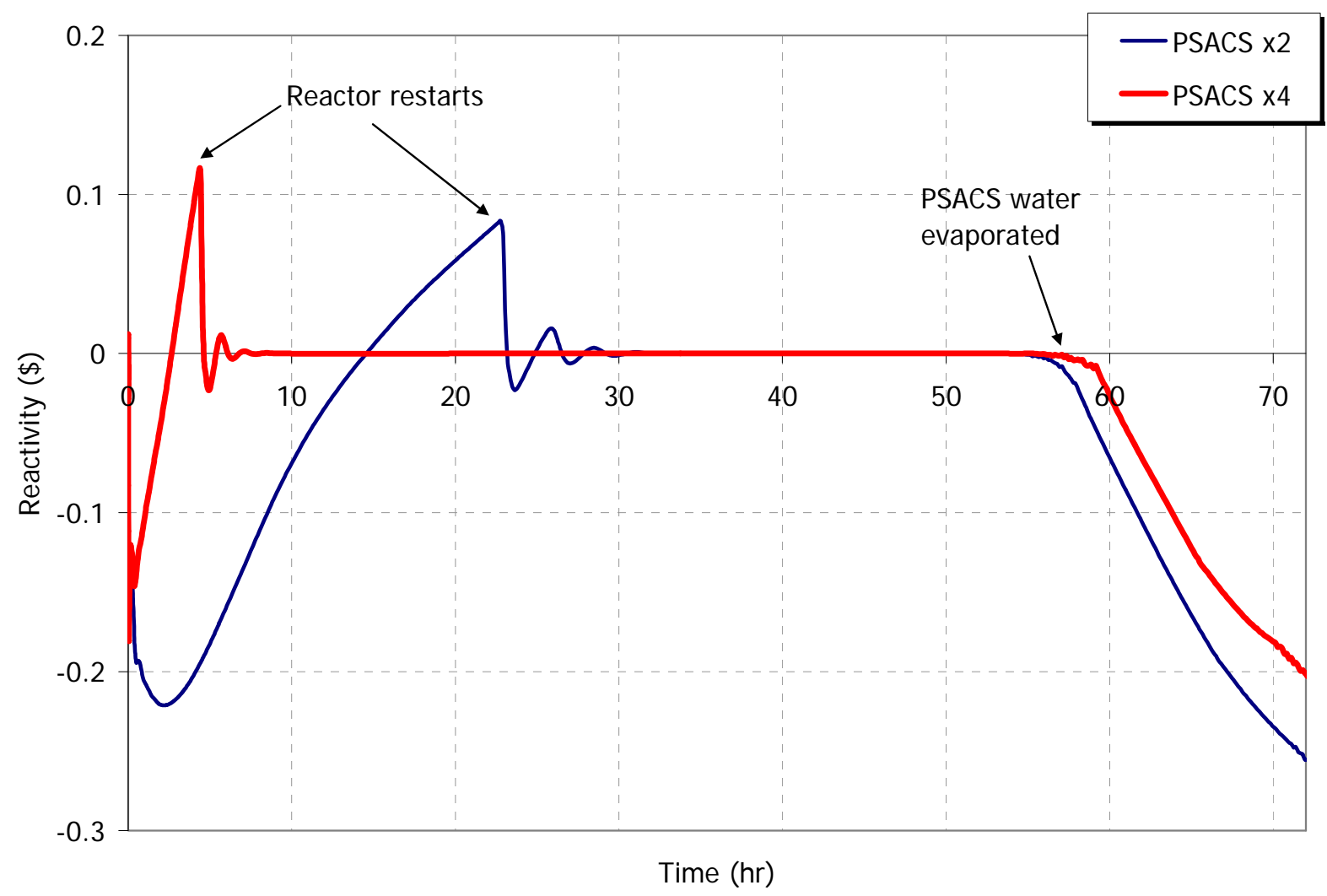

Figure 3.3.2-15 Reactivity during unprotected SBO for two and four trains of operating PSACS

Figures 3.3.2-16 and 3.3.2-17 illustrate the heat added to or removed from the primary system for the case with two and four operating PSACS trains, respectively. Both figures are consistent with observations from Figure 3.3.2-14. While the case with $4 \times 50 \%$ trains has twice the water mass in the PSACS tanks than the 2-train case, the restart results in a significantly higher peak and equilibrium power to be removed from the primary system. While the power for the PSACS $\mathrm{x} 2$ case settled at $\sim 19 \mathrm{MWt}$, the $\mathrm{x} 4$ case reached equilibrium at $30 \mathrm{MWt}$. This difference is a consequence of the different power from which initial restart occurs and of different primary system temperatures prior to restart. It can be observed that the cores of the $\mathrm{x} 2$ and $\mathrm{x} 4$ cases restarted from power of $\sim 16$ and $\sim 24 \mathrm{MWt}$, respectively. Lower temperature at the time of restart results in larger power peak because of more negative net reactivity feedback (and thus larger positive reactivity insertion on cooldown.)

Figure 3.3.2-18 shows the net difference between the core power and heat removed through PSACS (x2 and $\mathrm{x} 4$ ) and RVACS during the unprotected SBO. The equilibrium discussed earlier corresponds to the balance between heat generated by the core and removed by PSACS and RVACS together. The net heat balance drives the PCT response observed in Figure 3.3.2-14. It is also noted that the heat balance and PCT trend suggest that the PCT would exceed the $725^{\circ} \mathrm{C}$ limit after 72 hours. Because 72 hours is the sufficient time window for restoring AC power or initiating other corrective action, an overshoot beyond 72 hours is not of concern. 
Project No 06-040: Flexible Conversion Ratio Fast Reactor Systems Evaluation

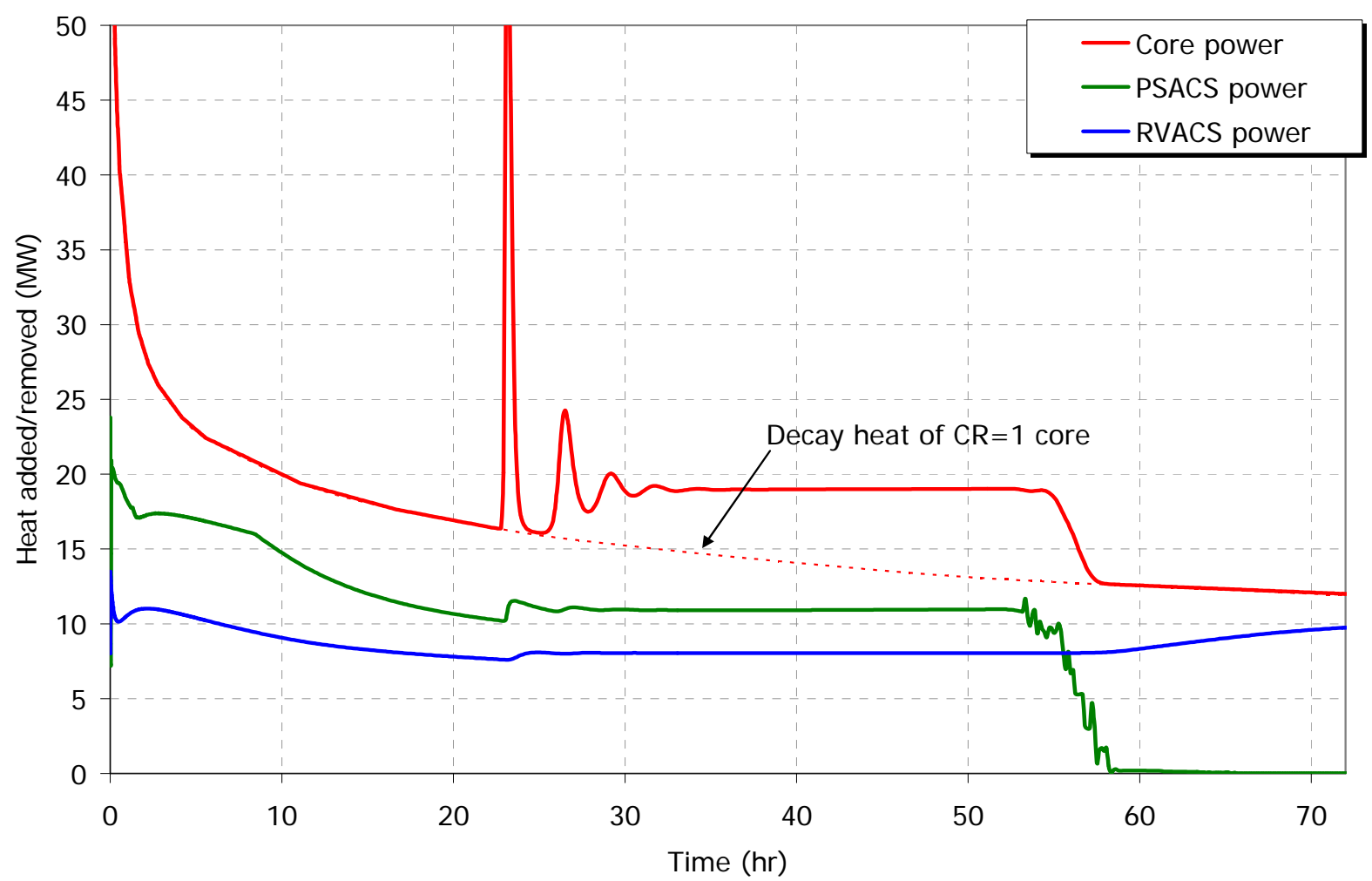

Figure 3.3.2-16 Heat added/removed during SBO with two operating PSACS trains

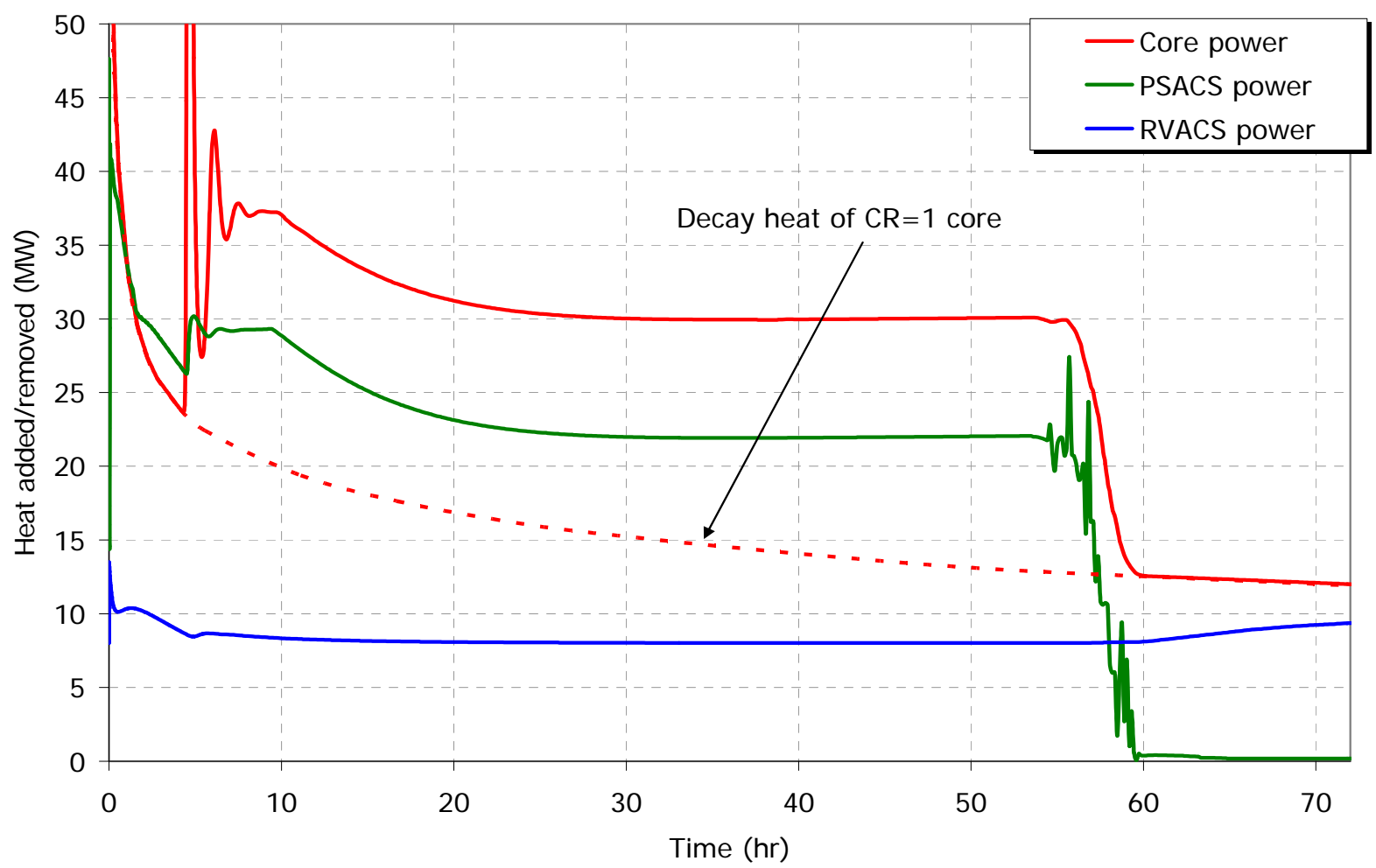

Figure 3.3.2-17 Heat added/removed during SBO with four operating PSACS trains 
Project No 06-040: Flexible Conversion Ratio Fast Reactor Systems Evaluation

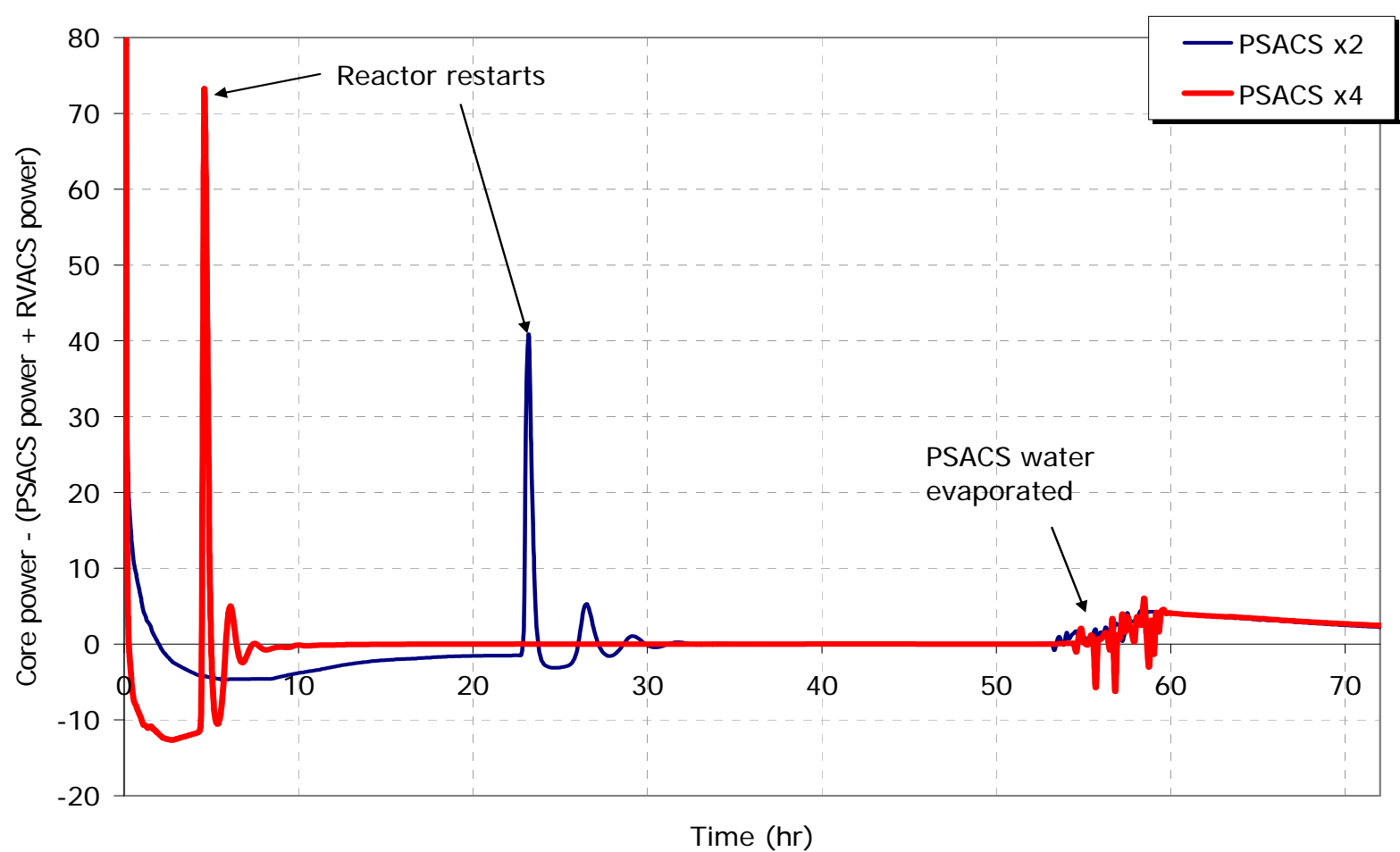

Figure 3.3.2-18 Difference between the core power and heat removed through PSACS (x2 and $\mathrm{x} 4$ ) and RVACS during unprotected SBO

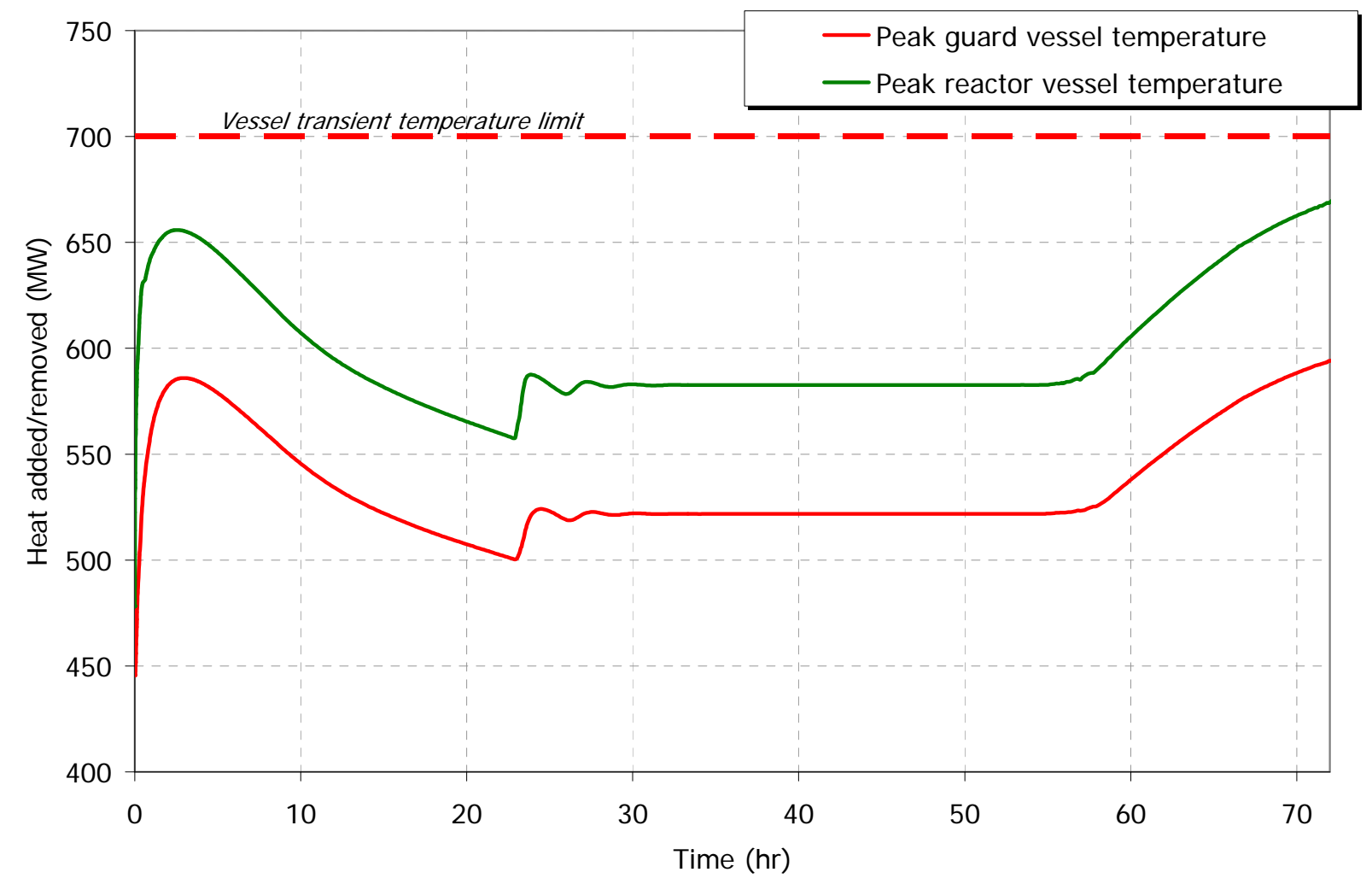

Figure3.3.2-19 Peak vessel membrane temperature for unprotected SBO with two trains 
Project No 06-040: Flexible Conversion Ratio Fast Reactor Systems Evaluation

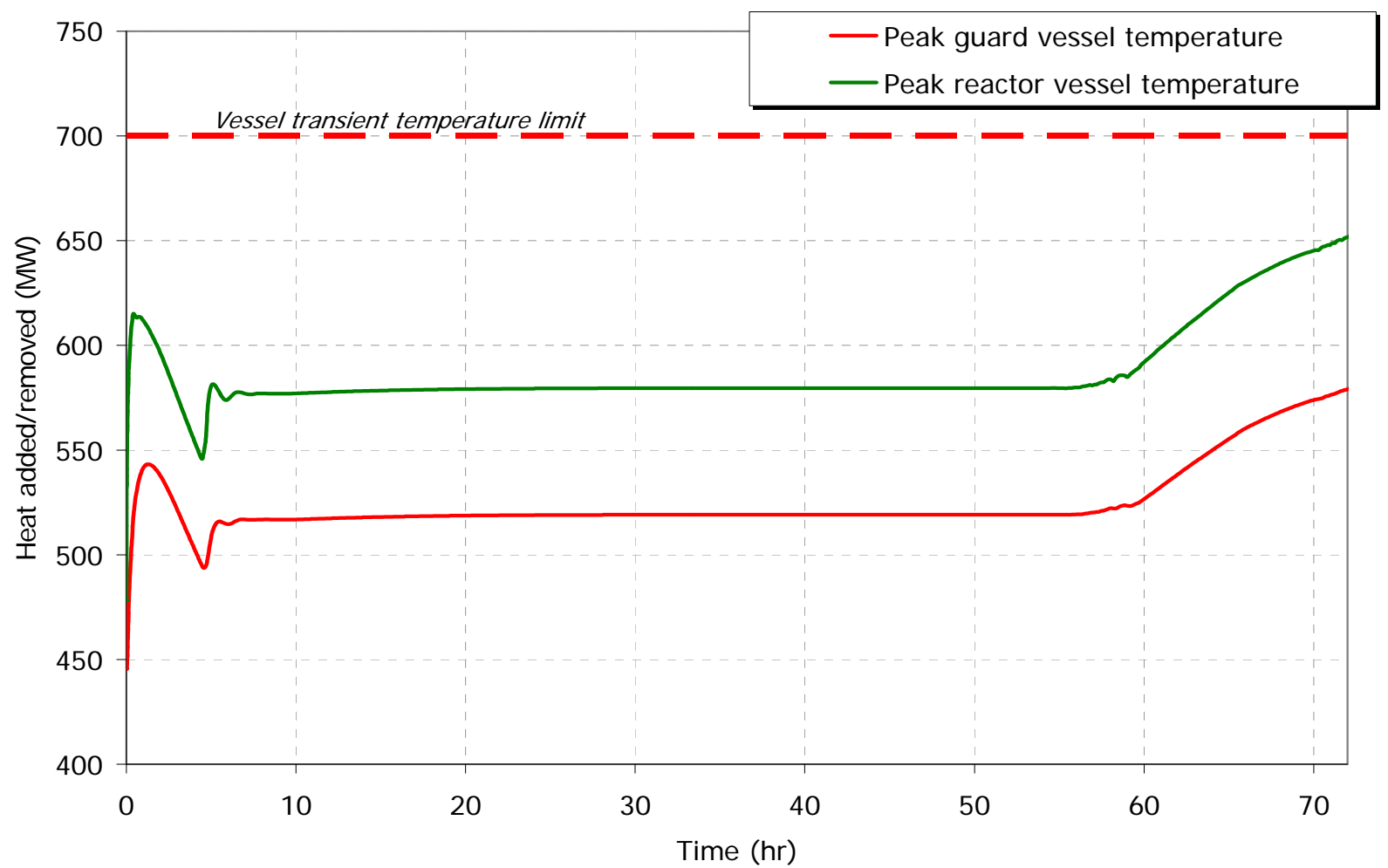

Figure 3.3.2-20 Peak vessel membrane temperature for unprotected SBO with four trains

Figure 3.3.2-19 plots peak reactor and guard vessel temperatures. The limit for peak vessel membrane temperature during a transient is $700^{\circ} \mathrm{C}$. For the case of two PSACS trains operating, the first peak reactor vessel temperature is $656^{\circ} \mathrm{C}$ occurring at around 2.5 hours. The maximum peak vessel temperature of $670^{\circ} \mathrm{C}$ occurs at 72 hours and would be increasing further if the transient was not terminated. The case with four operating PSACS trains, illustrated in Figure 3.3.2-20, is not limiting, with the first peak reactor vessel temperature of $615^{\circ} \mathrm{C}$ taking place at around 0.4 hours.

\section{Results for Protected Station Blackout}

As discussed in Section 2.2.3.5, the protected station blackout accident poses the concern of coolant freezing in case of system overcooling. Since any number of PSACS trains between 2 and 4 can be operating, the PSACS design must ensure that freezing is avoided regardless of the number of PSACS trains operating. Therefore, the PSACS water tank size has to be sufficiently large to assure enough water to keep PCT below its $725^{\circ} \mathrm{C}$ limit, but not too large to avoid coolant freezing. In addition, PSACS heat exchangers need to be selected not only to keep the PCT below the limit during the first peak of unprotected SBO, but also to minimize the cooling rate after reactor shutdown. The peak cladding temperature case is bounded by two operating trains during the unprotected SBO case. On the other hand, the case of concern of coolant freezing is a likely event with all PSACS trains operating during an SBO with a scram.

Figure 3.3.2-21 shows the peak cladding temperature for the case of 4 operating PSACS trains. Because the reactor was scrammed, the PCT during the first peak is not a concern. Figure 3.3.2- 
21 also shows the minimum coolant temperature which remains above freezing for the entire duration of the accident. Because coolant freezing is prevented with all four trains operating, it can be concluded that freezing will not occur in case of two or three operating PSACS trains. This is because heat removed from the core is smaller for 2 or 3 trains operating than for the bounding case of 4 trains.

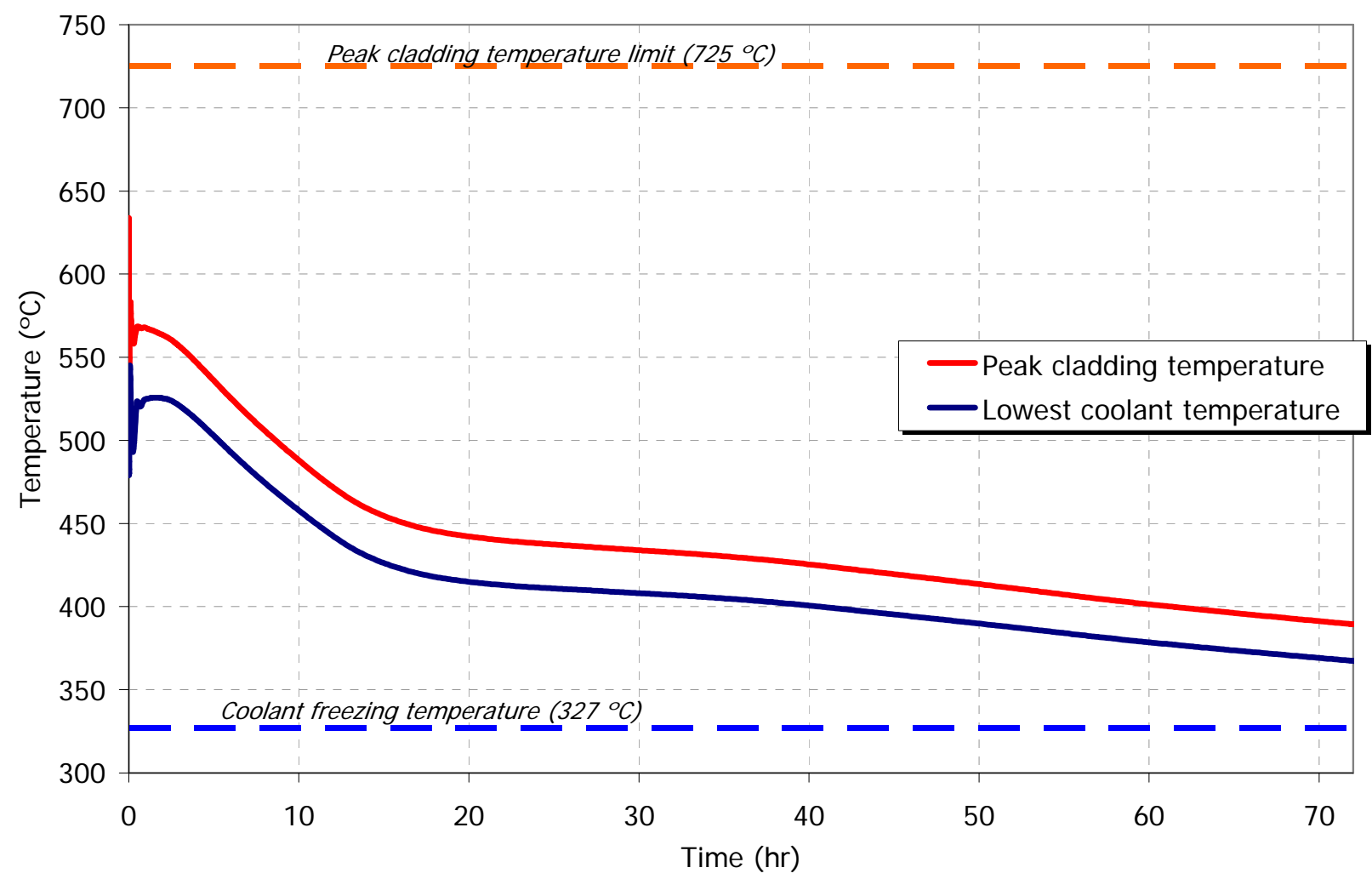

Figure 3.3.2-21 Peak cladding temperature and lowest coolant temperature for protected SBO with four operating PSACS trains

The heat generated (decay heat) and heat removed from the primary system through the PSACS and RVACS is shown in Figure 3.3.2-22. A more illustrative figure of merit showing the difference between core power and total heat removed through PSACS and RVACS is depicted in Figure 3.3.2-23. The difference between heat produced by the core and heat removed by the safety systems (MWt) explains the behavior of the primary system temperature. When the difference is positive, the temperature increases and vice versa. The difference becomes negative around 0.8 hours ( 2900 seconds) causing the temperature to peak. The difference remains negative throughout the rest of the transient, which is reflected in consistently decreasing temperature. Figure 3.3.2-24 shows the peak reactor and guard vessel temperature for the protected SBO with four trains. The reactor vessel temperature is always below the limit of $700^{\circ} \mathrm{C}$. 
Project No 06-040: Flexible Conversion Ratio Fast Reactor Systems Evaluation

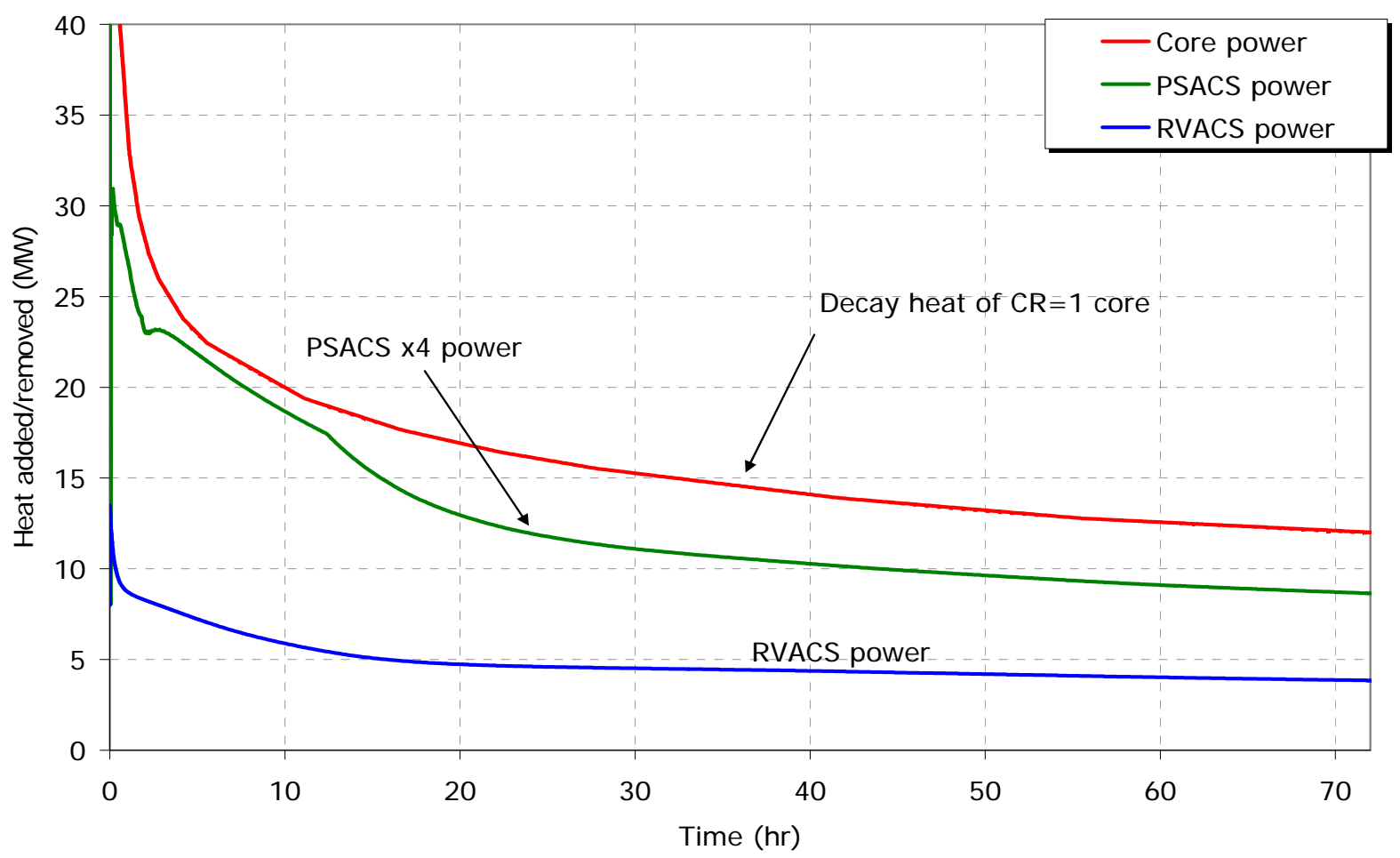

Figure 3.3.2-22 Heat added/removed for protected SBO with four operating trains

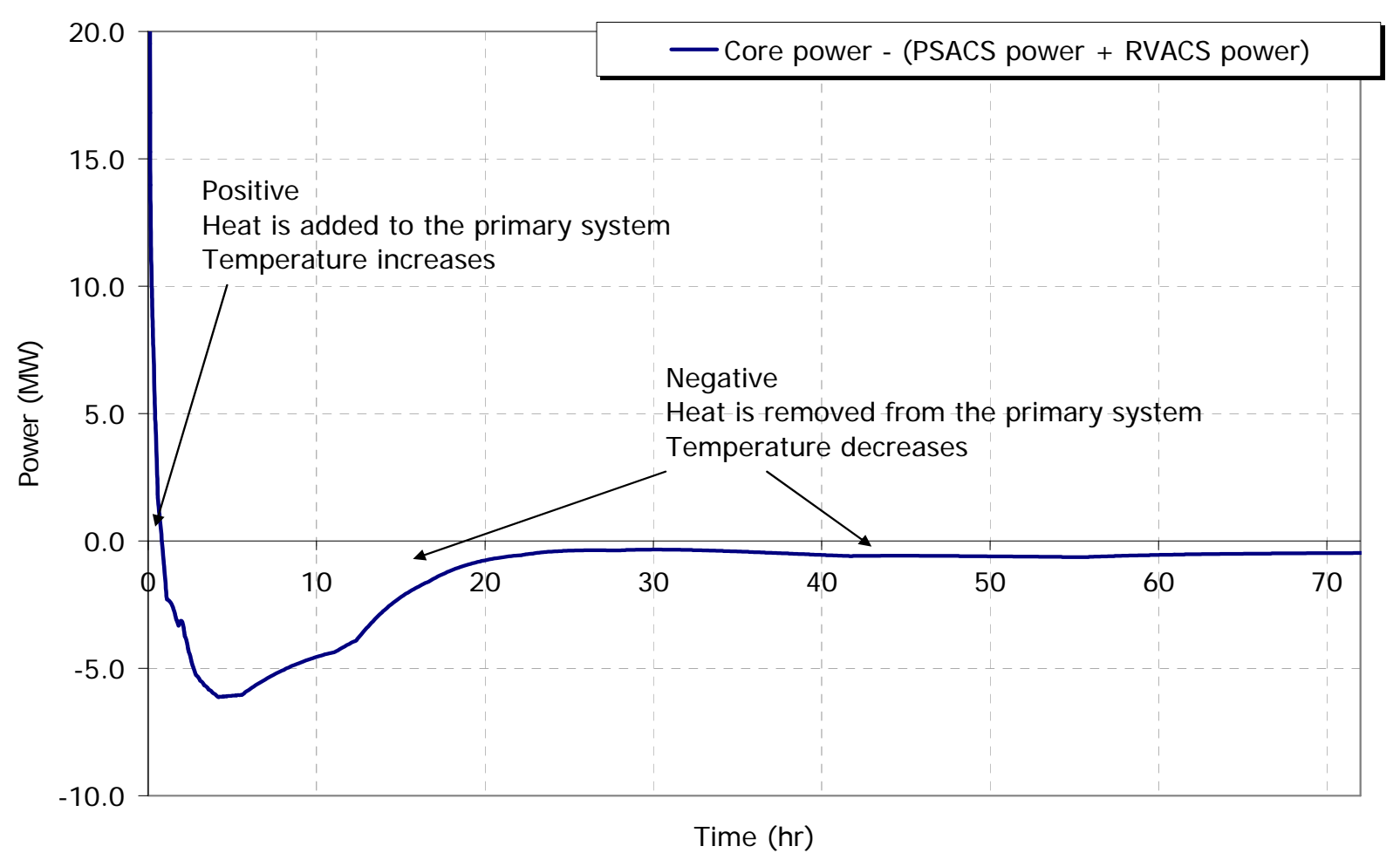

Figure 3.3.2-23 Difference between heat produced by the core and heat removed by the safety systems (MW) 
Project No 06-040: Flexible Conversion Ratio Fast Reactor Systems Evaluation

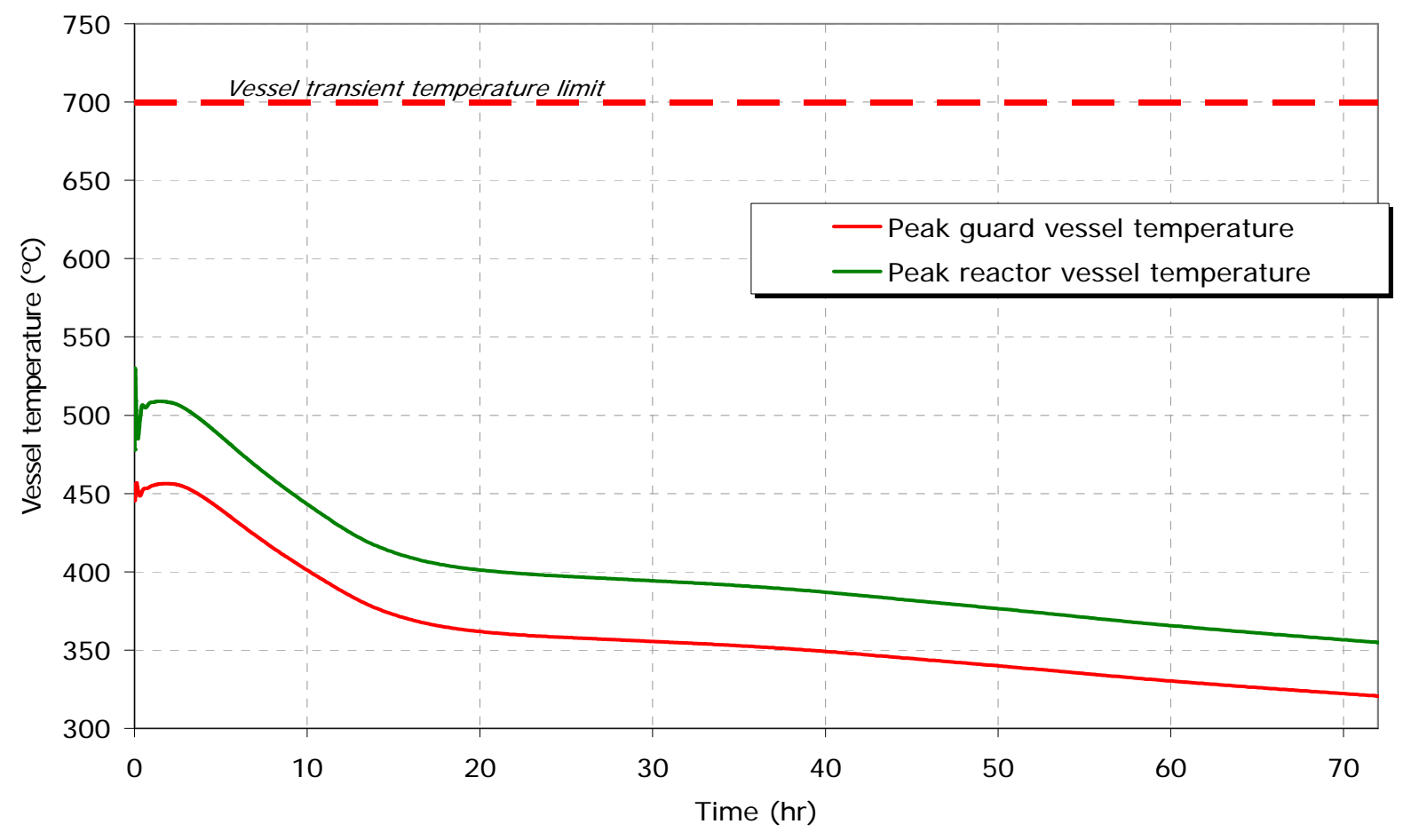

Figure 3.3.2-24 Reactor and guard vessel peak membrane temperature during protected SBO with 4 operating loops

\subsection{Unprotected Loss of Flow Accident}

The unprotected Loss of Flow Accident (LOFA) is caused by the complete loss of the electric power to the primary coolant pumps. This leads to generator trip, lost of heat sink and initiation of PSACS in the same manner as was analyzed in the SBO scenario. Therefore, the SBO results are applicable for unprotected LOFA as well. However, because the Brayton $\mathrm{S}-\mathrm{CO}_{2} \mathrm{PCS}_{\text {has }}$ significant capability for self-sustained operation using heat from the IHX to drive the turbine and compressor and because electricity to precooler pumps is available, it is of high interest to investigate plant response to unprotected LOFA using the PCS. Therefore, the RELAP5-3D model described in the previous section was used to evaluate this scenario using the power conversion system. Thus, the power conversion system is assumed connected to the IHX throughout the duration of the accident, and the precooler pumps are assumed to be active and controllable. The PSACS trains remain inoperative during this sequence. The following actions/assumptions were taken during this transient:

- Turbine bypass was used to protect against shaft overspeed after the generator is disconnected from the grid (see Section 2.2.3.4.5 for more details on turbine bypass)

- Turbine speed demand for the PID controller that controls turbine bypass valve opening after turbine speed is avoided was set to $50 \mathrm{rad} / \mathrm{sec}$. This speed was selected to achieve power removed through the PCS to match the natural circulation capability of the primary system within desirable core outlet/inlet temperatures.

- Precooler mass flow rate (water) was reduced to $5 \%$ of the original flow $(460 \mathrm{~kg} / \mathrm{sec})$ 
The initial conditions are the same as for the SBO and are presented in Table 3.3.2-4. In the case of pump trip accident with the PCS acting as the main heat removal system, the main concern is to avoid primary system undercooling and consequent reactor restart, since the PCS has a large capacity to remove heat. Therefore, a search had to be performed through preliminary runs and PID controller tuneups to identify the target shaft speed that can circulate a heat rate matching natural circulation-supported reactor power within a desirable temperature range. The temperature range is established such that the core outlet temperature remains sufficiently low to keep peak cladding temperature below the limit of $725^{\circ} \mathrm{C}$ with margin and the core inlet temperature remains well above the lead freezing point. Moreover, the average core temperature needs to be above the nominal operating temperature to support reactor power reduction through reactivity feedbacks to a value that can be removed by natural circulation of lead. The shaft speed of $50 \mathrm{rad} / \mathrm{sec}$ was found to provide this balance. More details on PI controller parameters are discussed in Section 2.2.3.4.

The results of the unprotected LOFA transient with shaft demand set to $50 \mathrm{rad} / \mathrm{s}$ are presented in Figures 3.3.2-25 through 3.3.2-33. To reduce the length of the report and compare more easily the differences between the two conversion ratio designs, both $\mathrm{CR}=1$ and $\mathrm{CR}=0$ are presented in each figure. As shown in Figure 3.3.2-25, immediately after the primary coolant pumps trip, primary system temperatures begin to rise. Peak cladding temperature shown in Figure 3.3.2-26 follows the trend of the core outlet temperature. The core power starts to decrease due the negative reactivity feedback associated with higher fuel and coolant temperatures. However, since there is a significant amount of heat removed through the IHXs, the reactor approaches a new steady state with natural circulation and power level of $154 \mathrm{MWt}$ for $\mathrm{CR}=1$ and $148 \mathrm{MWt}$ for $\mathrm{CR}=0$ cores, as depicted in Figure 3.3.2-27 ( $\sim 6.4 \%$ of the full power level). Figure 3.3.2-28 illustrates the normalized core power and core mass flow rate during the accident. The new steady state conditions are achieved approximately one hour after the start of the accident sequence. The natural circulation core mass flow rate is established at $7.2 \%$ of its initial value. Turbine speed and the gas mass flow rate through the turbine are shown in Figure 3.3.2-30. Note that the turbine speed converges to the preset value of $50 \mathrm{rad} / \mathrm{sec}$. The rate of convergence is defined by the settings of the PI controller.

Figure 3.3.2-31 compares the reactivity of both unity and zero conversion ratio cores. It can be seen that the $\mathrm{CR}=0$ core exhibits more negative reactivity than the unity conversion ratio core during the first 100 seconds into the accident. This is due to the significantly smaller coolant temperature reactivity coefficient of the zero conversion ratio core. Interestingly, the reactivity feedback effect is such that the PCT peak during that time is lower for $\mathrm{CR}=0$ than for $\mathrm{CR}=1$. (Recall that the steady state value of the PCT for $\mathrm{CR}=0$ is higher by $12^{\circ} \mathrm{C}$.) This is explained by the lower values of reactivity coefficients.

Figures 3.3.2-32 through 3.3.2-33 compare the behavior of the zero conversion ratio core as a function of the settings of the PI controller. Ideally, the turbine speed should be held nearly constant, so the decay heat can be removed for as long as possible through the PCS. In this case, the mass flow rate through the turbine must be adjusted in such a way that the speed of the shaft remains constant. This can be done through control of the turbine bypass valve open area or can also be extended to other valve configurations. In this example, the turbine bypass was used with the proportional weight held constant and integral weight varied. The integral weight accelerates the conversion of the turbine speed to the setpoint value which was set to $50 \mathrm{rad} / \mathrm{sec}$ to match primary and PCS heat rate, as discussed earlier. It was determined that a relatively 
small integral weight should be applied to ensure that the turbine velocity has a smoothly decreasing behavior comparable to the decay heat curve. However, if the integral weight is too small, the turbine speed decreases very slowly (integral weight of 0.0025 in Figure 3.3.2-31). This causes a higher heat removal rate through the turbine which leads to a higher core power (Figure 3.3.2-32). Therefore, the integral weight value must be chosen such that the peak cladding temperature is kept below the transient limit of $725^{\circ} \mathrm{C}$. Figure 3.3.2-33 summarizes the PCT for the three cases discussed. Note from the figure that the value of integral weight of 0.011 assures that the PCT is below the limit. Thus, the analysis described above used this integral weight. Peak fuel temperature remains well below its limit for both the $\mathrm{CR}=1$ and $\mathrm{CR}=0$ cores, and is not shown.

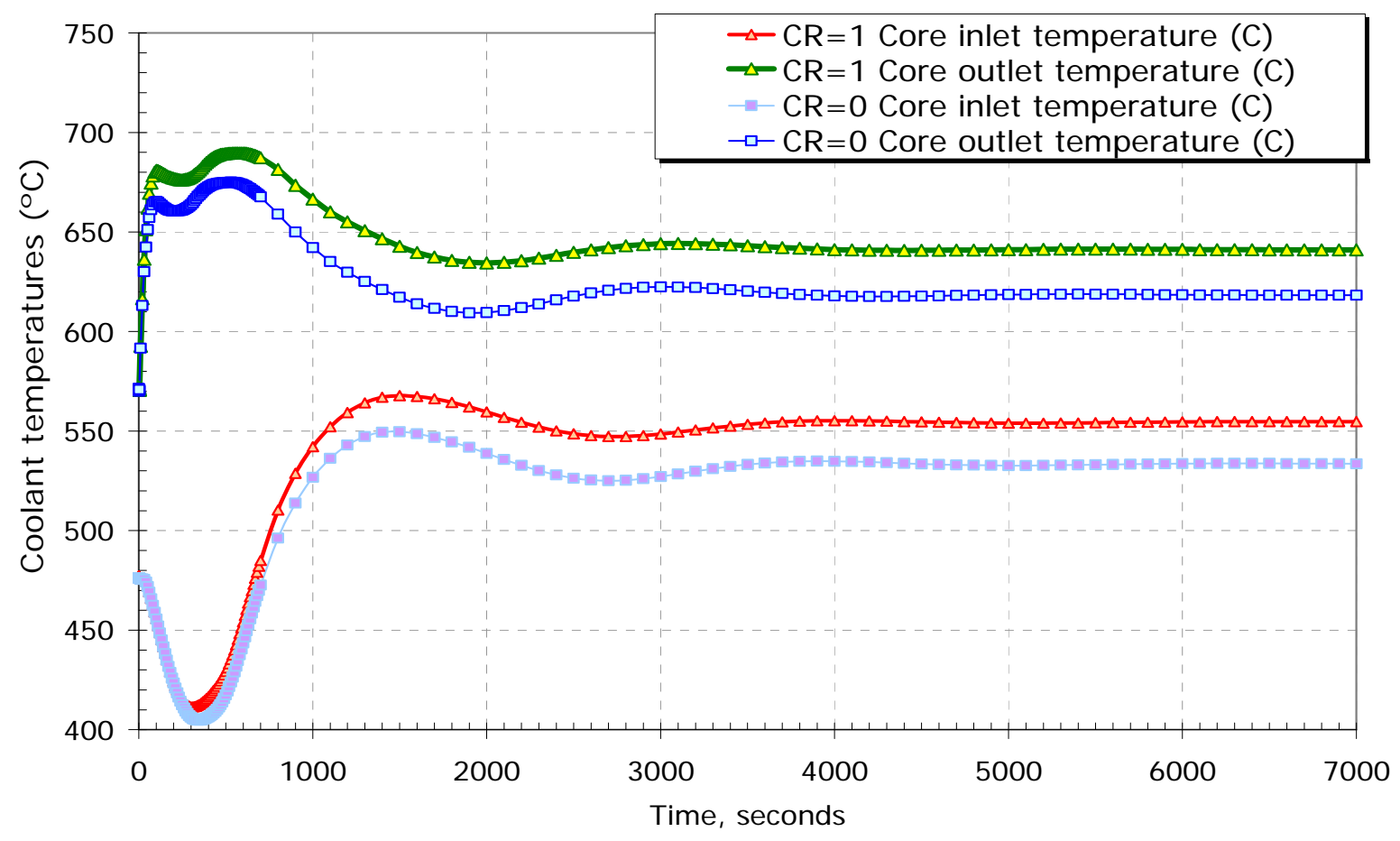

Figure 3.3.2-25 Core coolant temperatures during LOFA 
Project No 06-040: Flexible Conversion Ratio Fast Reactor Systems Evaluation

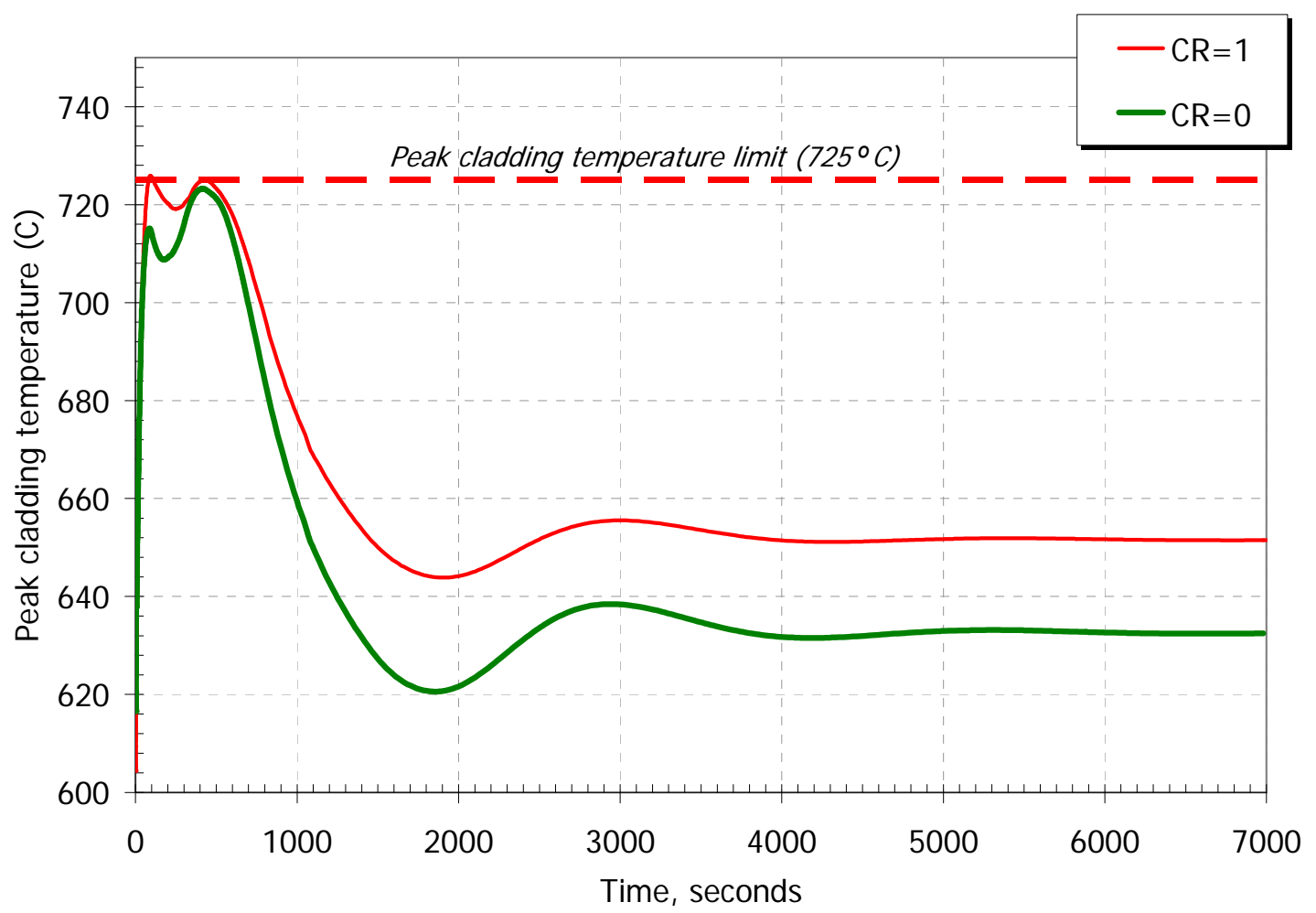

Figure 3.3.2-26 Peak cladding temperature during LOFA

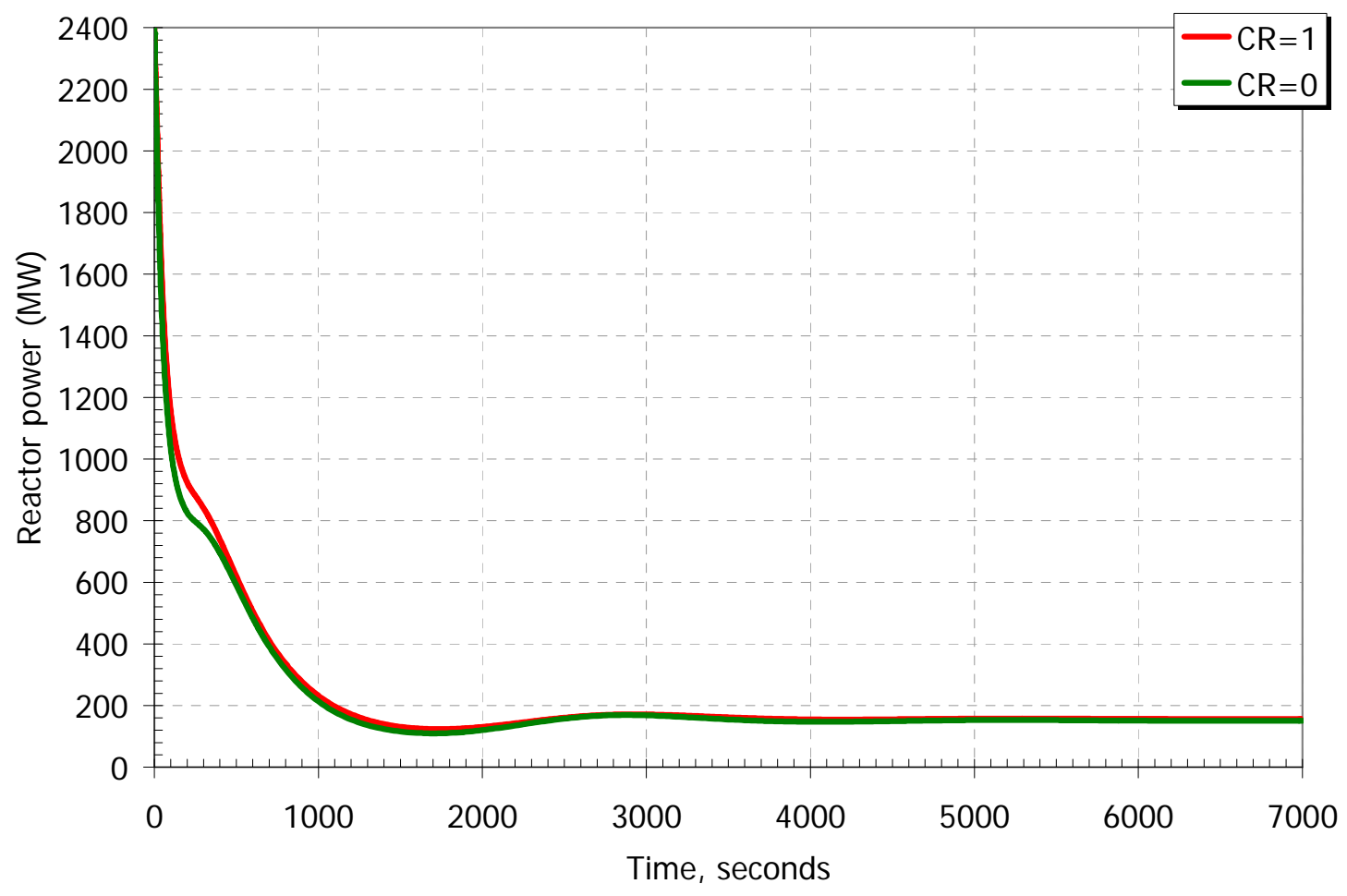

Figure 3.3.2-27 Reactor core power during LOFA 
Project No 06-040: Flexible Conversion Ratio Fast Reactor Systems Evaluation

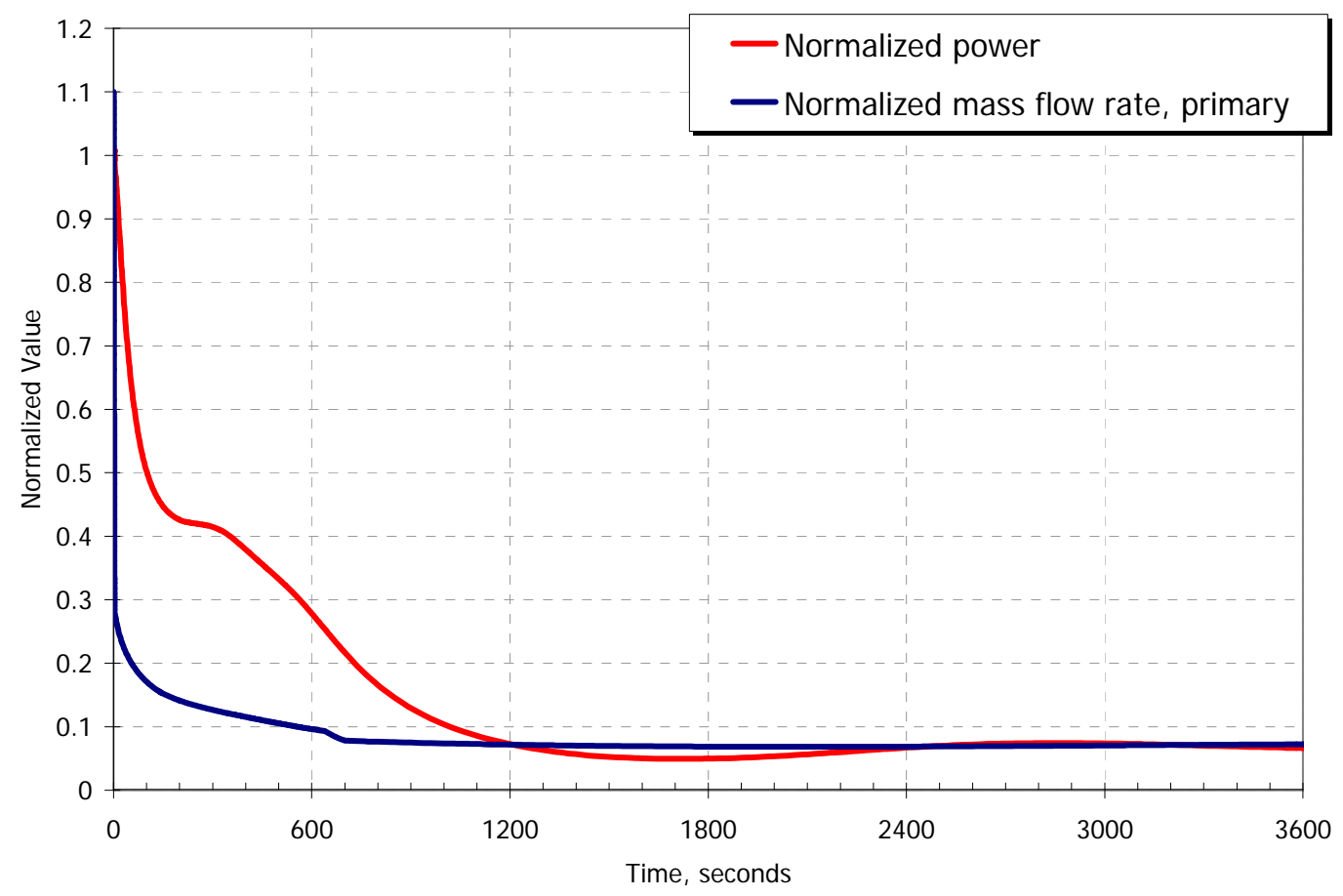

Figure 3.3.2-28 Normalized reactor power and primary coolant mass flow rate during LOFA $(\mathrm{CR}=1$ and $\mathrm{CR}=0$ behave very similarly)

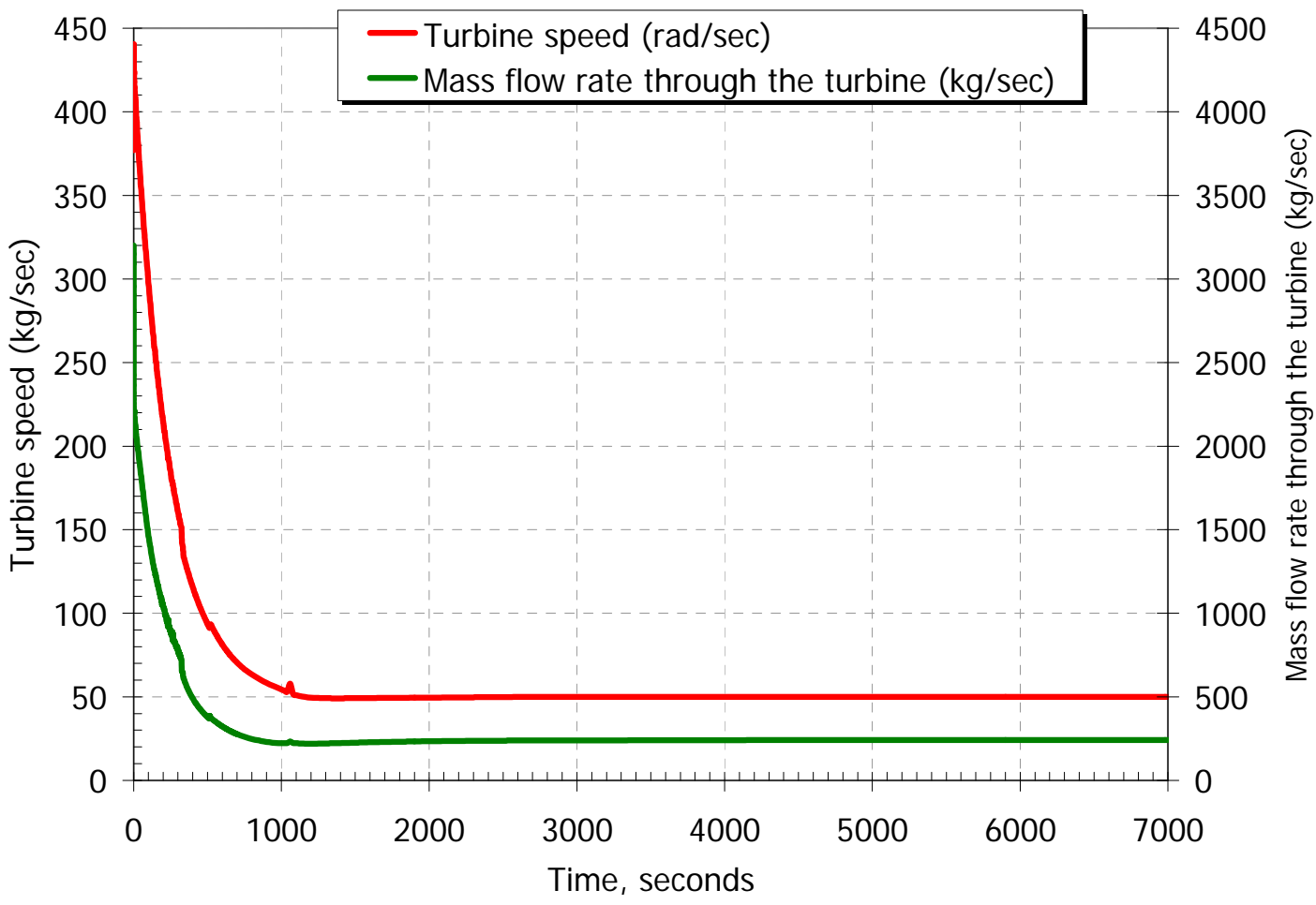

Figure 3.3.2-29 Turbine speed and $\mathrm{CO}_{2}$ mass flow rate during LOFA $(\mathrm{CR}=1$ and $\mathrm{CR}=0$ behave very similarly) 
Project No 06-040: Flexible Conversion Ratio Fast Reactor Systems Evaluation

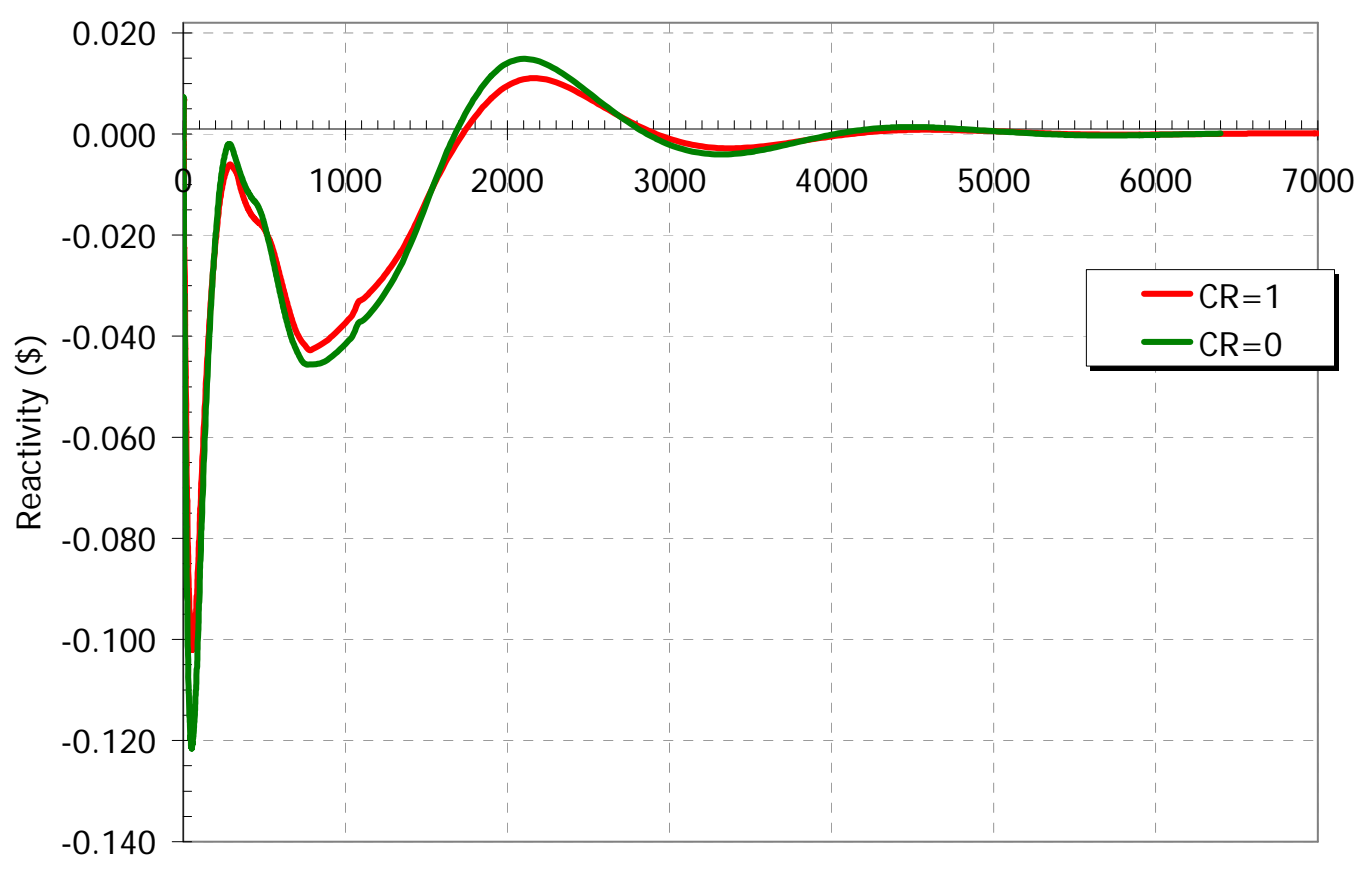

Time, seconds

Figure3.3.2-30 Reactivity dynamics during LOFA

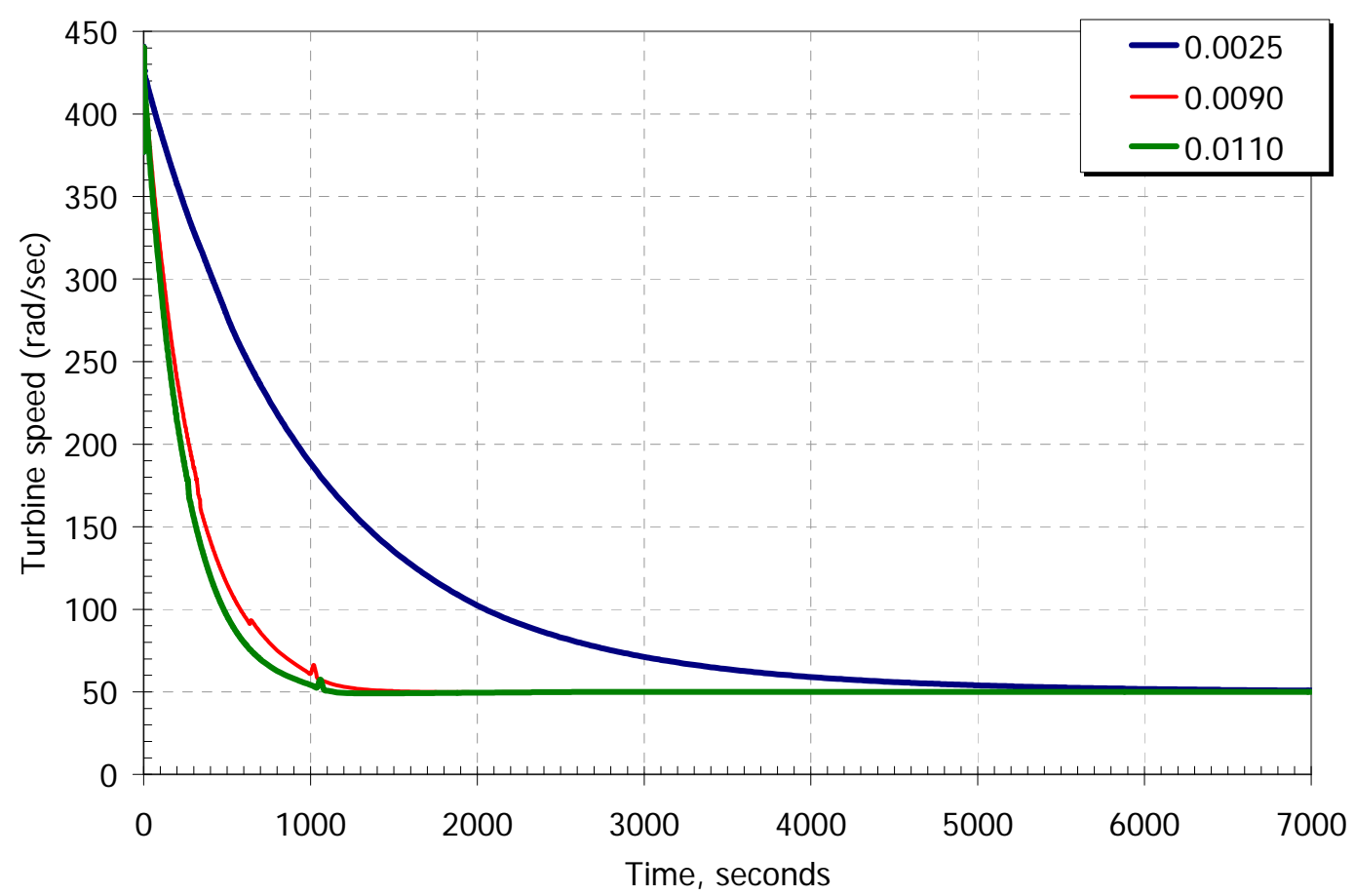

Figure 3.3.2-31 Effect of PI controller integral weight on the reactor $(\mathrm{CR}=0$ core) 
Project No 06-040: Flexible Conversion Ratio Fast Reactor Systems Evaluation

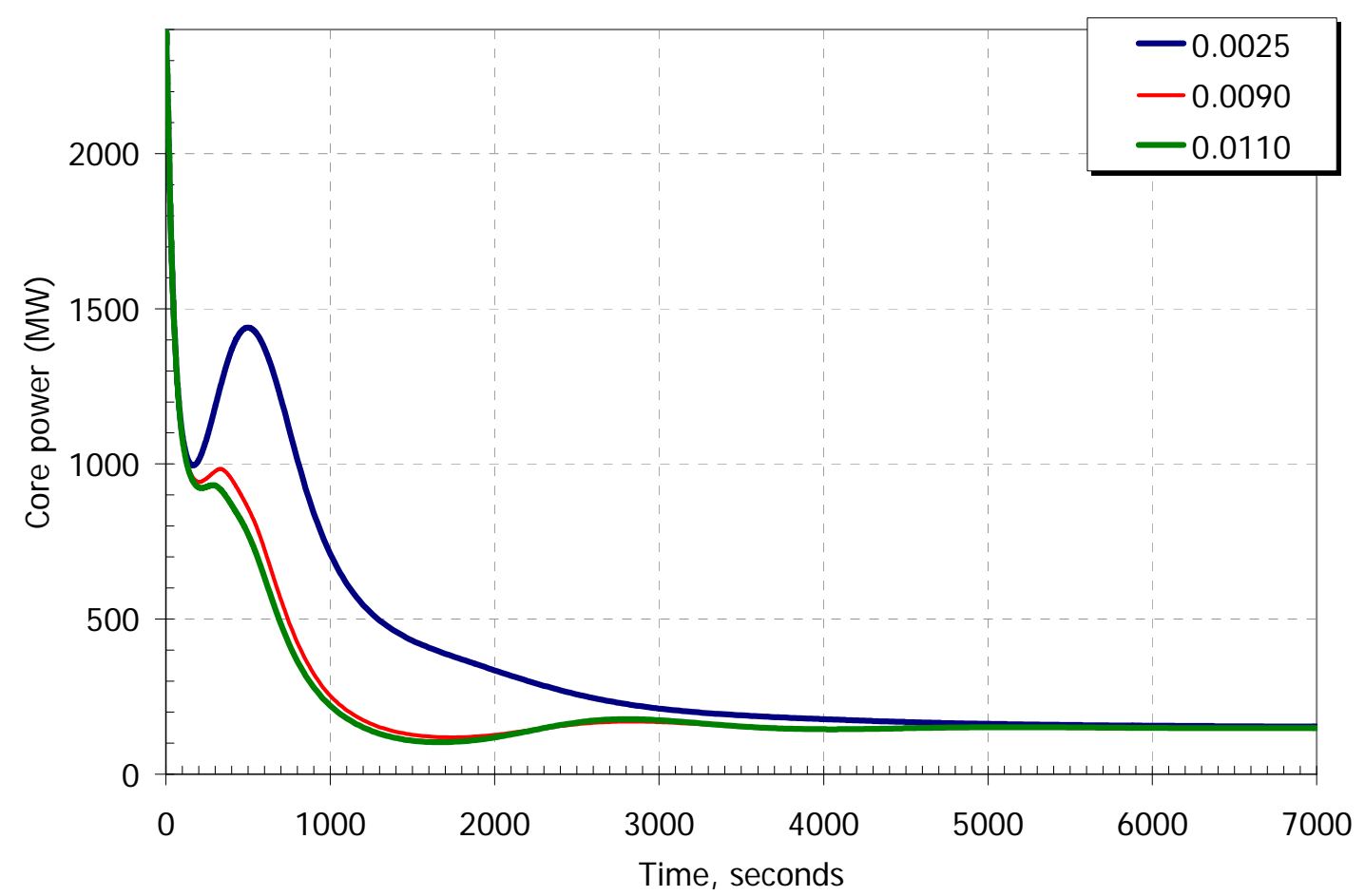

Figure 3.3.2-32 Effect of PI controller integral weight on the reactor ( $\mathrm{CR}=0$ core)

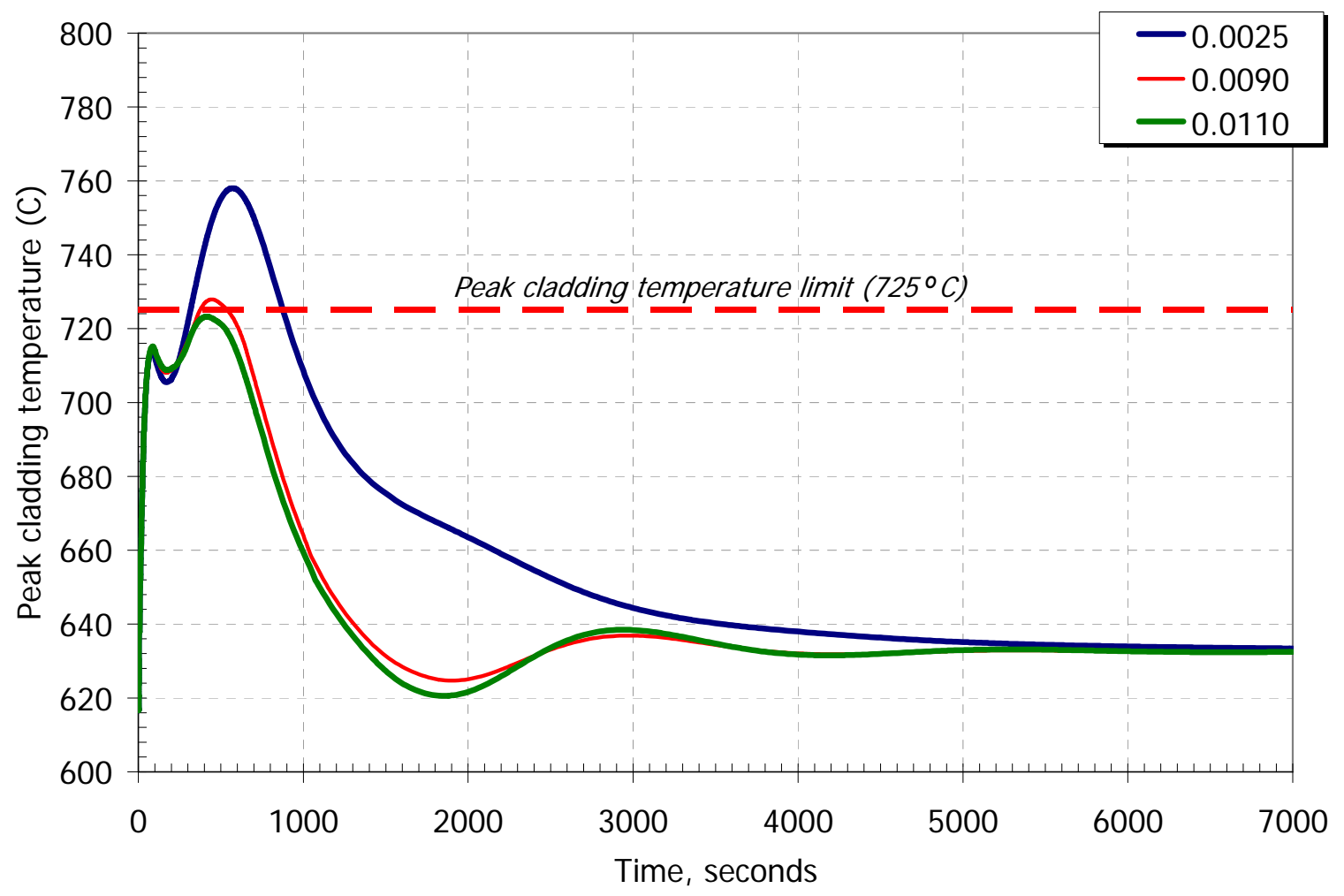

Figure 3.3.2-33 Effect of PI controller integral weight on the reactor ( $\mathrm{CR}=0$ core) 


\subsection{Unprotected Overpower Accident}

The Unprotected Transient Overpower (UTOP) accident assumes rapid withdrawal of the highest worth control assembly. The control assembly removal speed was assumed to be similar to one used in IFR safety analysis which was limited by the physical drive speed. Failure to scram was assumed in this analysis. However, the primary coolant pumps remained in use, and the PCS was allowed to passively respond to the accident in a load-follow fashion. Thus, the generators were assumed to remain coupled to the grid, and the precooler mass flow rate was kept at the nominal value.

Because it is instructive to compare performance of the $\mathrm{CR}=1$ and $\mathrm{CR}=0$ cores, both cores will be discussed in this section rather than in a separate section on the $\mathrm{CR}=0$ core. Table 3.3.2-7 summarizes the parameters used to calculate maximum rod worth. In the FCR core, the control rods (CR) are assembled into clusters of 25 rods residing in the middle of an assembly. Thus, in this analysis, the term "assembly" refers to the cluster of 25 rods. The maximum assembly worth is determined by excess reactivity of the core at BOL and the reactivity feedback caused by the Hot Full Power conditions. The value for the assembly withdrawal rate for $\mathrm{CR}=1$ was adopted from IFR safety studies [Wade, 1997.] However, one of two assumptions must be made for the $\mathrm{CR}=0$ core: the rate of withdrawal will be equivalent to that of the $\mathrm{CR}=1$ core in terms of withdrawal speed or in terms of $\$ / \mathrm{sec}$. The former assumption, which means that it would take the same amount of time for both $\mathrm{CR}=1$ and $\mathrm{CR}=0$ control assemblies to be fully withdrawn from the core, was used in the current analysis.

Table 3.3.2-7 Maximum rod worth parameters.

\begin{tabular}{|l|c|c|}
\hline Parameter & $\mathrm{CR}=1$ & $\mathrm{CR}=0$ \\
\hline k-effective (max) & 1.02 & 1.155 \\
\hline Excess reactivity (\$) & 5.4466 & 45.9586 \\
\hline CZP to HFP (\$) & 0.9190 & 1.1483 \\
\hline total (\$) & 6.3656 & 47.1069 \\
\hline \# of CR clusters & 96 & 349 \\
\hline \$/cluster (x25 rods) & 0.0663 & 0.1350 \\
\hline Maximum peaking factor & 1.21 & 1.34 \\
\hline Maximum assembly worth $(\$)$ & 0.0971 & 0.2424 \\
\hline Assembly withdrawal rate $(\$ / \mathrm{sec})$ & $+0.0050^{*}$ & $+0.0125^{* *}$ \\
\hline
\end{tabular}

* Value used in safety studies of the IFR [Wade, 1997]

**Value calculated assuming the same speed of assembly withdrawal as for $\mathrm{CR}=1$ core.

Table 3.3.2-8 contains the summary of main results for the UTOP accident. As the control assembly starts the runout, the core power follows the increase in reactivity as shown in Figure 3.3.2-34. Immediately, higher core temperatures (PCT is shown in Figure 3.3.2-35a and fuel centerline temperature is shown in Figure 3.3.2-35b) trigger negative reactivity feedback. Since the coolant temperature reactivity coefficient of the $\mathrm{CR}=1$ core is more positive than that of the $\mathrm{CR}=0$ core, the reactivity of the $\mathrm{CR}=0$ core returns back to negative values faster. Also, due to appreciably higher coolant and fuel temperatures of the $\mathrm{CR}=0$ core, the negative feedback of the $\mathrm{CR}=0$ core is more noticeable. The reactivity dynamics for both cores are shown in Figure 3.3.236. 
Table 3.3.2-8 Main results for UTOP.

\begin{tabular}{|l|c|c|}
\hline Parameter & $\mathrm{CR}=1$ & $\mathrm{CR}=0$ \\
\hline Peak cladding temperature $\left({ }^{\circ} \mathrm{C}\right)$ & 652 & 705 \\
\hline Peak power, $\mathrm{P} / \mathrm{P}_{0}{ }^{*}$ & 1.22 & 1.53 \\
\hline New equilibrium temperature $\left({ }^{\circ} \mathrm{C}\right)$ & 650 & 692 \\
\hline New equilibrium power, $\mathrm{P} / \mathrm{P}_{0}{ }^{*}$ & 1.06 & 1.11 \\
\hline
\end{tabular}

$* \mathrm{P}_{0}$ is the nominal steady state power of $2400 \mathrm{MWt}$

Since the $\mathrm{CR}=0$ core has a much larger maximum rod worth, its PCT during UTOP is higher when compared to the $\mathrm{CR}=1$ core. Consequently, due to the larger reactivity insertion, the $\mathrm{CR}=0$ core relative power increases by $\sim 50 \%$ of its original power. Once the control assembly motion ceases, the reactor reaches a new equilibrium at higher power and temperature conditions. A new equilibrium was established at around 500 seconds after the beginning of the accident. Overall, both conversion ratio cores can easily accommodate the unprotected overpower transient, as both the PCT and peak fuel temperature remain below their limits with an appreciable margin.

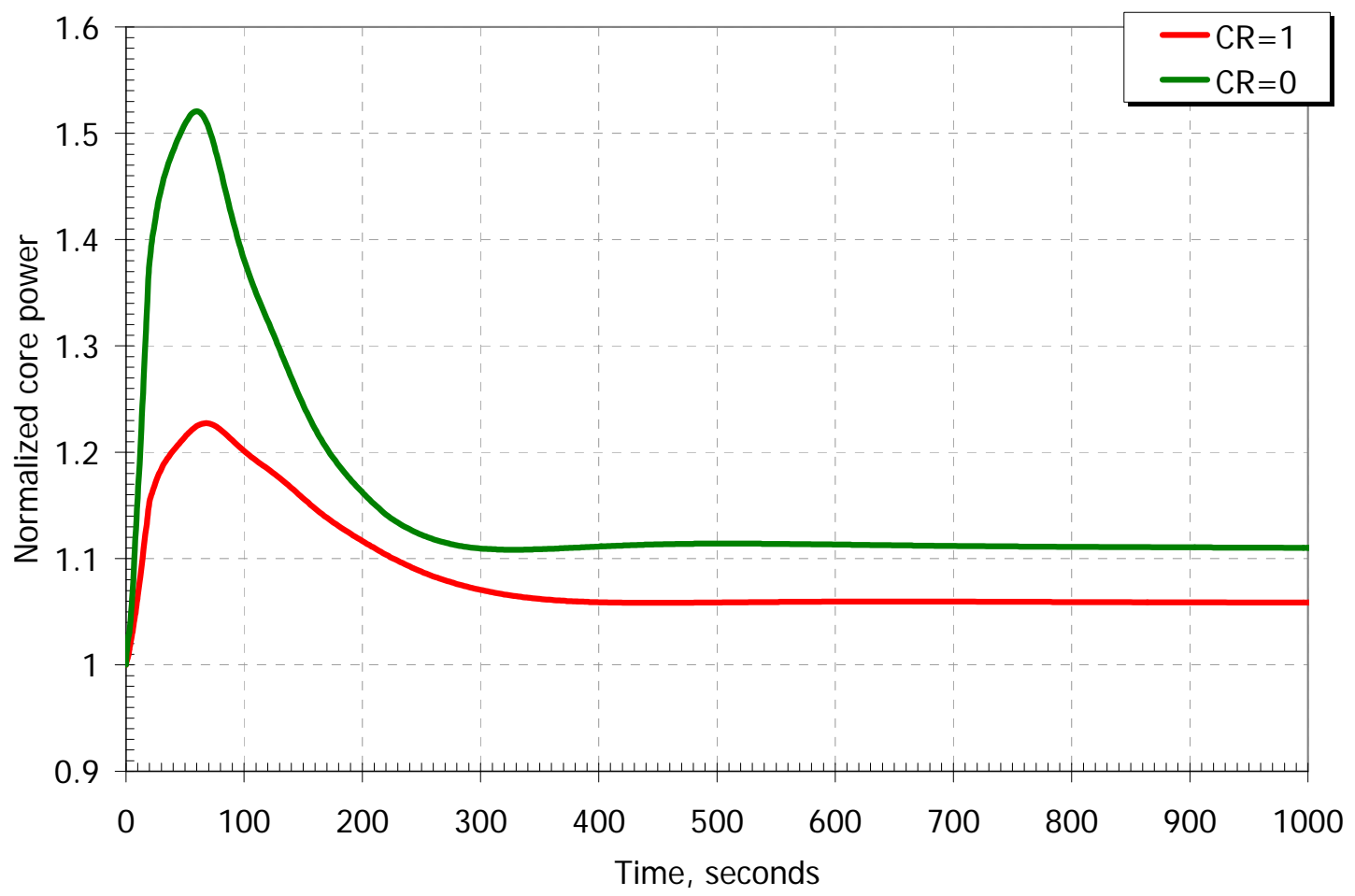

Figure 3.3.2-34 Normalized core power during UTOP 
Project No 06-040: Flexible Conversion Ratio Fast Reactor Systems Evaluation

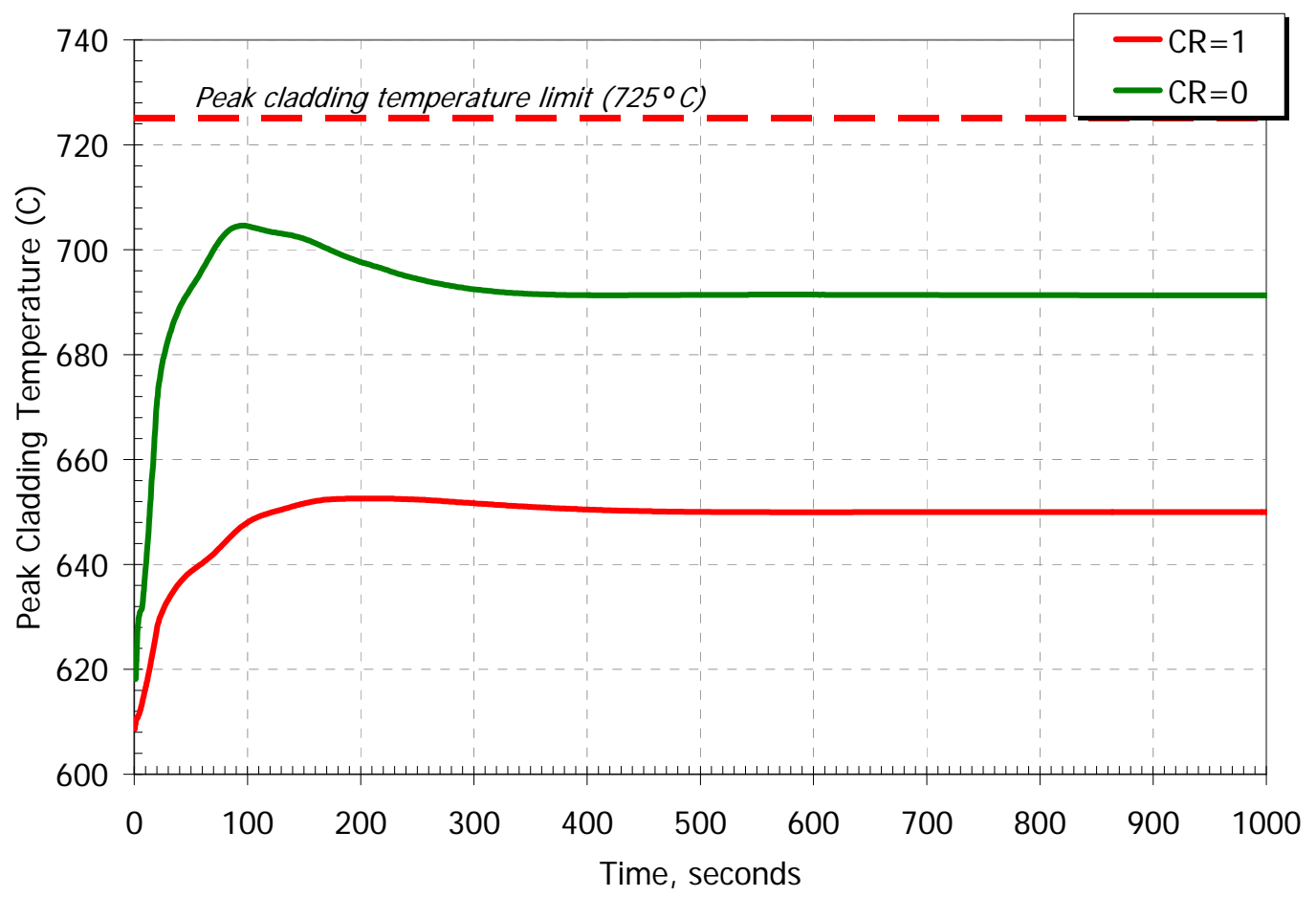

Figure 3.3.2-35a Peak cladding temperature during UTOP

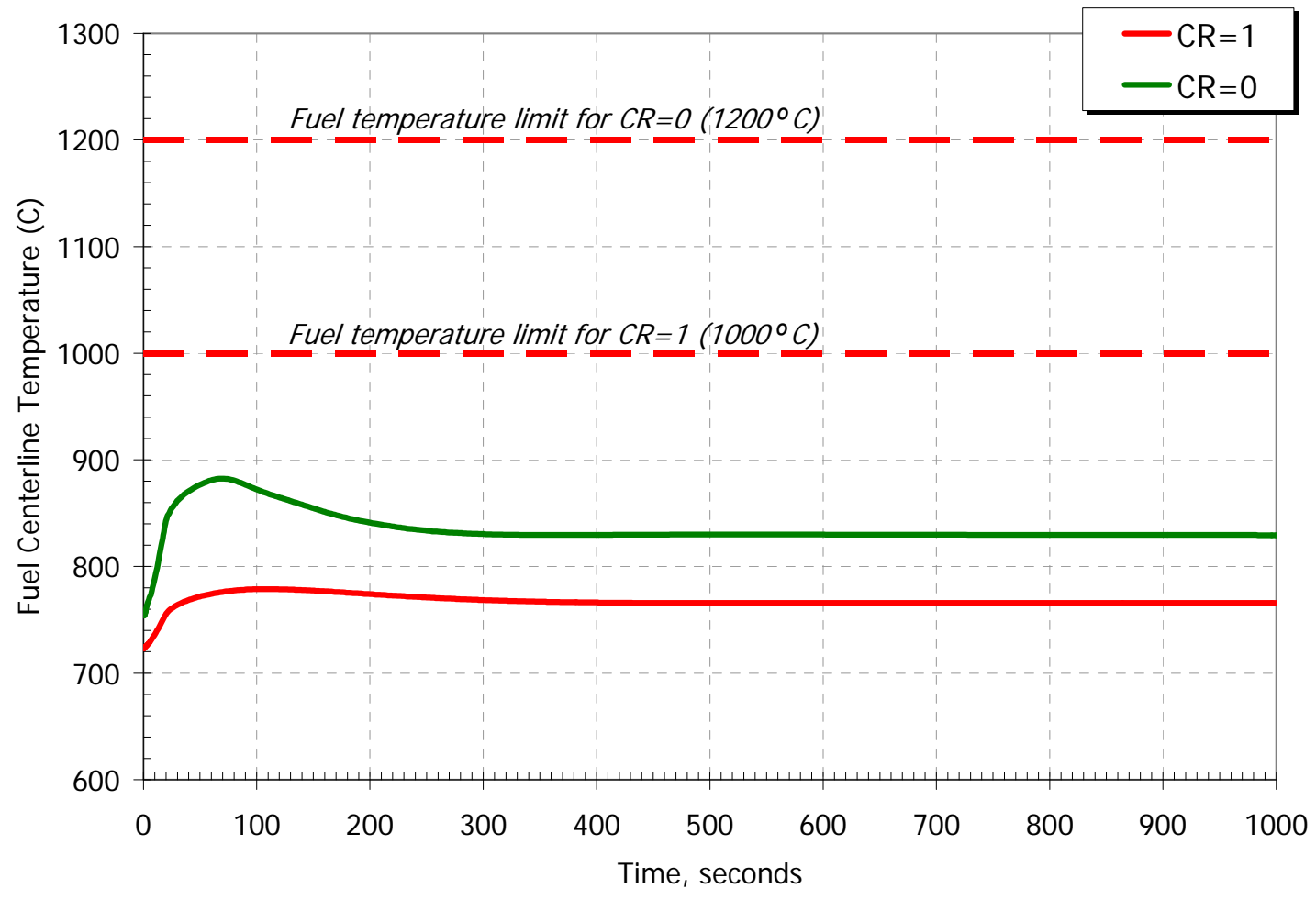

Figure 3.3.2-35b Fuel centerline temperature during UTOP 
Project No 06-040: Flexible Conversion Ratio Fast Reactor Systems Evaluation

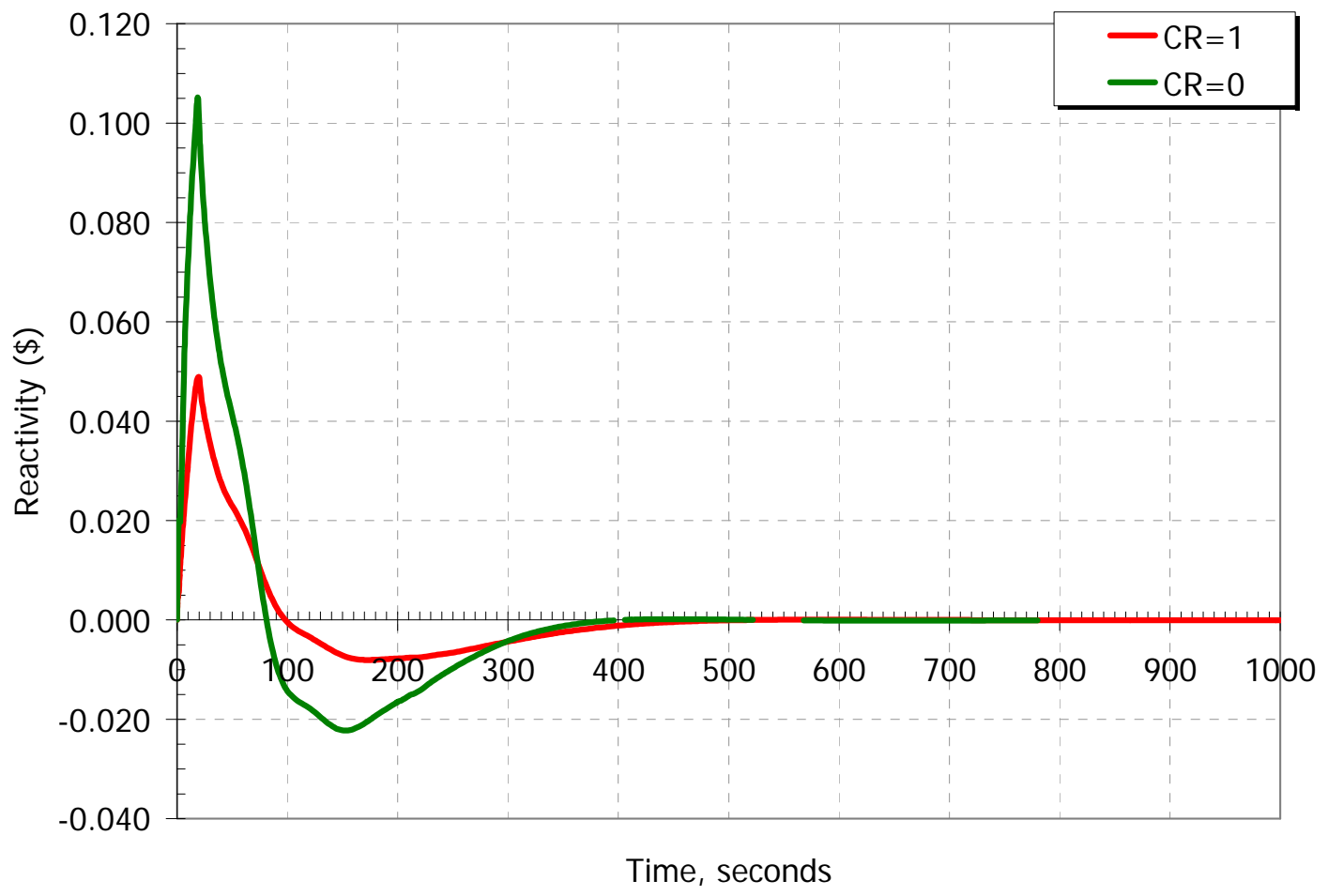

Figure3.3.2-36 Reactivity dynamics during UTOP (note different rates (\$/sec) of rod withdrawal.) 


\subsection{Zero Conversion Ratio Core}

\subsubsection{Neutronic Analysis Results}

The purpose of the zero conversion ratio core is to burn down accumulated transuranic waste with maximum efficiency. For that reason, the amount of fertile U238 in the fuel should be minimal or zero. Apart from that, the same design considerations outlined earlier for the unity conversion ratio core also hold for the zero conversion ratio core. The present analysis was also based on the previous studies of the fertile-free lead-cooled medium power reactor reported in Romano et al. [2004] and extended to a 2400MWt core.

\subsubsection{Summary of Key Results}

This section summarizes the neutronic design and performance parameters of the lead-cooled $\mathrm{CR}=0$ core based on the analysis performed in this project.

In contrast to the single-batch $\mathrm{CR}=1$ core, a 3-batch refueling scheme was adopted for the $\mathrm{CR}=0$ core. Such a refueling strategy enables a deeper burnup of the initial TRU and reduces the core reactivity swing, which is one of the major factors limiting the fuel cycle length of the $\mathrm{CR}=0$ core.

The fuel burnup analysis was performed assuming homogeneously smeared fuel assembly materials in order to speed up the burnup calculations. The control rods were assumed to be fully withdrawn from the core. This approach slightly underestimates the core criticality (by up to 1\%) because boron in the control rods is mixed with the materials in the upper and the lower plena. Otherwise, the homogeneous representation of fuel assemblies reproduces the core axial and radial power distribution with reasonable accuracy of better than $2 \%$. This was confirmed by a series of preliminary MCNP calculations which compared the results of homogeneous versus detailed heterogeneous fuel assembly geometry representations.

In order to simulate the equilibrium core in the MCNP model, the following procedure was adopted. The core was divided into roughly equal radial zones with 109, 120, 120 fuel assemblies in the inner, median, and outer zones respectively. First, fresh fuel was loaded into all three zones and the MCODE burnup calculation was performed until the core ran out of reactivity. The fuel composition as a function of burnup was calculated separately in each of the zones.

Next, an initial guess was made regarding the burnup distribution among the partially burned batches in the core based on the linear reactivity model. These estimates were subsequently used for extracting the fuel composition for the next cycle's partially burned batches. The procedure was repeated until equilibrium startup core conditions were established, i.e. the initial burnup of each burned batch is roughly equal to the EOC burnup of the previous batch. Two or three of such iterations were typically sufficient to achieve the equilibrium conditions.

The $\mathrm{CR}=0$ core loading map is presented in Figure 3.4.1-1. 
In contrast to the $\mathrm{CR}=1$ core, each fuel assembly in the $\mathrm{CR}=0$ core contains control rods for a number of reasons:

- Reactivity swing over the cycle is considerably larger for the $\mathrm{CR}=0$ core. Therefore, reactivity control is much more challenging. The reactivity letdown curve as a function of time is presented in Figure 3.4.1-2.

- Power peaking factors are typically higher for the $\mathrm{CR}=0$ core as illustrated below. Therefore, a large number of control rods is essential for managing the radial power distribution.

- Passive core shutdown safety requirements impose a limit on the maximum reactivity worth of individual control rods in the case of one inadvertent control rod withdrawal accident. Therefore, it is desirable to distribute the compensation of high excess reactivity of the $\mathrm{CR}=0$ core over the largest possible number of control rods in order to minimize their individual worth.

Initially, the burnup calculations were performed for three separate core zones each loaded with fresh, once, and twice burnt fuel batches. The basic problem with this approach is that the isotopic composition is averaged out for all the assemblies within the same batch at each burnup step. The inaccuracy in the prediction of local isotopic composition and, as a result, in local power is typically small. This is because the power of the assemblies within the batch deviates from the batch average power only slightly. However, in the current core loading pattern, some of the fresh fuel assemblies are located in the core central region and interspersed with twice burnt fuel assemblies (Figure 3.4.1-1) in order to minimize power peaking. As a result, the fresh fuel assemblies that are located in the central region are exposed to much higher neutron flux and subsequently deplete more rapidly than those located in the periphery. This, in turn, leads to some over-prediction of power density in the fresh fuel assemblies in the center and underprediction of power density for those on the periphery.

In order to reduce the error introduced by this approach, the burnup of the $\mathrm{CR}=0$ core was calculated using two separate burnup regions (central and peripheral) for the fresh fuel batch. A single burnup region was assumed for each of the once and twice burnt fuel batches.

The resulting core radial power distribution is shown in Figures 3.4.1-3 through 3.4.1-5 for the $\mathrm{BOC}, \mathrm{MOC}$, and EOC, respectively. The maximum radial power peaking factor is about 1.34 , which is larger than in the $\mathrm{CR}=1$ core case but still appears to be manageable for the thermal design, as discussed in the thermal hydraulic design section.

Pin power distribution was also calculated for the hot assembly and the results are presented in Figure 3.4.1-6. Similar to the $\mathrm{CR}=1$ core case, a very flat power profile was observed. The pin power peaking factors range from 0.98 to 1.02 .

The main fuel cycle parameters are summarized in Table 3.4.1-1. The initial fuel composition is $34 \mathrm{wt} . \%$ TRU and the rest, 66 wt. \%, is $\mathrm{Zr}$ matrix. As in the $\mathrm{CR}=1$ case, the fuel smear density was assumed to be $70 \%$ of theoretical, which corresponds to $93.5 \%$ real fuel density. The initial and discharge TRU isotopic vectors of the $\mathrm{CR}=0$ core are presented in Table 3.4.1-2. Such an initial TRU loading results in a fuel cycle of about 550 EFPD. 
Project No 06-040: Flexible Conversion Ratio Fast Reactor Systems Evaluation

Table 3.4.1-1 "CR=0" Core fuel cycle parameter summary".

\begin{tabular}{|l|r|r|r|}
\hline & \multicolumn{1}{|c|}{ Fresh } & \multicolumn{1}{c|}{ Once } & \multicolumn{1}{c|}{ Twice } \\
\hline Initial HM, kg & 3,884 & 3,409 & 2,665 \\
\hline Final HM, kg & 3,403 & 2,943 & 2,330 \\
\hline Number of assemblies & 120 & 120 & 109 \\
\hline BOC Burnup, MWd/kg & 0 & 120 & 241 \\
\hline EOC Burnup, MWd/kg & 122 & 238 & 323 \\
\hline Cycle Burnup, MWd/kg & 122 & 118 & 85 \\
\hline
\end{tabular}

* The results are for the first cycle (startup core). The equilibrium cycle with recycling of discharged TRU will require slightly higher heavy metal loadings to compensate for the less reactive TRU composition of recycled fuel.

Table 3.4.1-2 " $\mathrm{CR}=0$ ” Initial and discharge fuel composition summary.

\begin{tabular}{|c|c|c|c|}
\hline \multicolumn{2}{|c|}{ TRU Isotope ID } & Initial,wt \% & Discharge, wt \% \\
\hline 93 & 237 & 5.60 & 5.23 \\
\hline 94 & 238 & 2.50 & 6.20 \\
\hline 94 & 239 & 46.50 & 32.88 \\
\hline 94 & 240 & 23.00 & 32.46 \\
\hline 94 & 241 & 8.20 & 6.22 \\
\hline 94 & 242 & 6.70 & 7.44 \\
\hline 95 & 241 & 5.40 & 4.74 \\
\hline 95 & 243 & 1.60 & 2.15 \\
\hline 95 & $242 m$ & 0.0001 & 0.66 \\
\hline 96 & 242 & 0.0038 & 0.328 \\
\hline 96 & 243 & 0.4293 & 0.022 \\
\hline 96 & 244 & 0.0430 & 1.240 \\
\hline 96 & 245 & 0.0055 & 0.224 \\
\hline 96 & 246 & 0.0001 & 0.023 \\
\hline
\end{tabular}


Project No 06-040: Flexible Conversion Ratio Fast Reactor Systems Evaluation

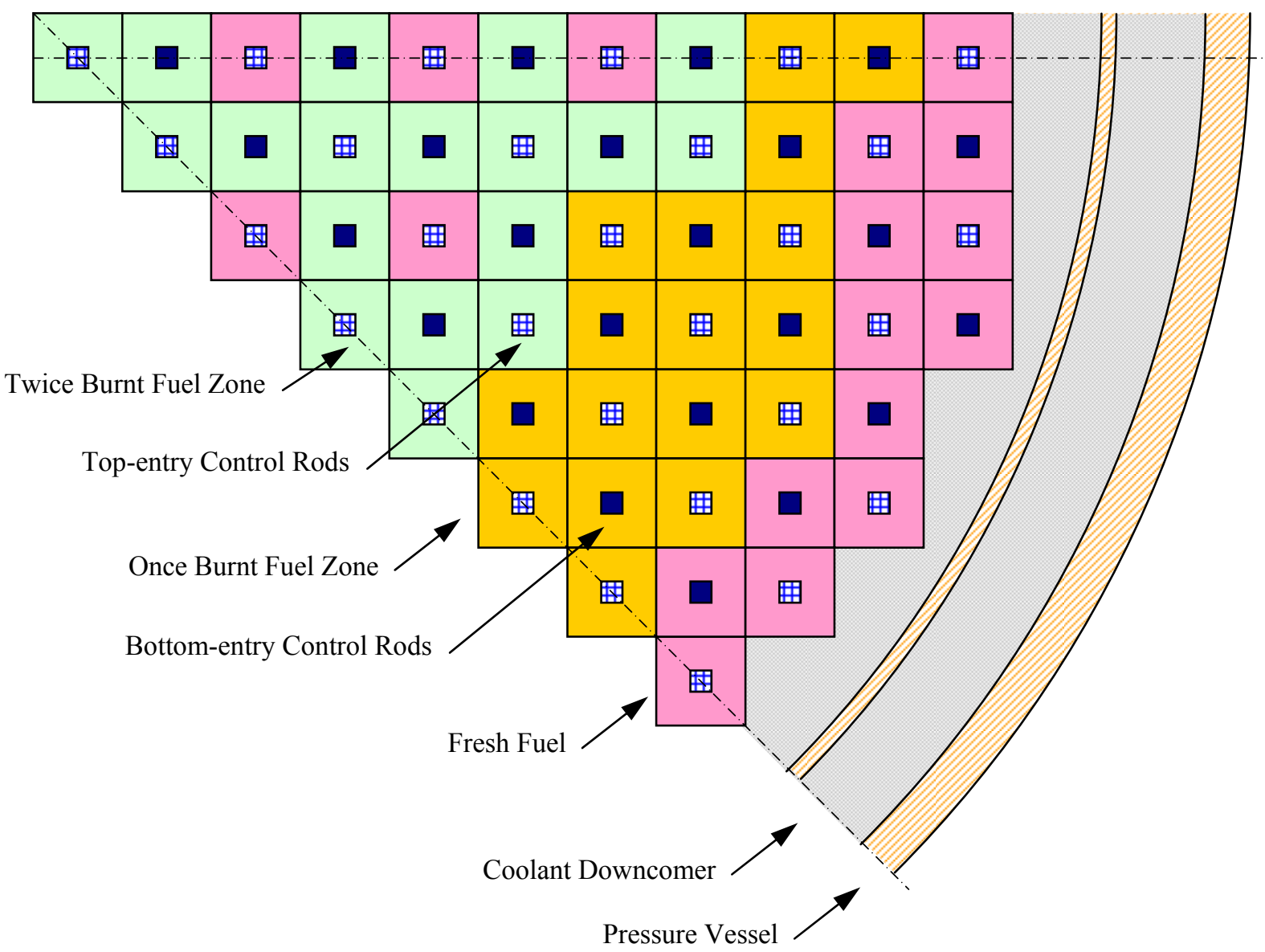

Figure 3.4.1-1. " $\mathrm{CR}=0$ ” core loading map.

As can be observed from Table 3.4.1-1, the startup core is capable of burning 35 to $40 \%$ of transuranic waste per pass through the $\mathrm{CR}=0$ core. It is noted that for an equilibrium core, the unburned TRU from the last batch will have to be reprocessed by separating fission products, and mixed together with fresh TRU from spent LWR fuel. Since the composition of reprocessed TRU from the $C R=0$ core is less reactive than fresh TRU from spent LWR fuel, slightly larger TRU loadings of the fresh batch will be needed to maintain the same cycle length.

The accumulated peak fluence in the cladding is shown in Figure 3.4.1-7. For the 3 consecutive cycles of 550 EFPD, the peak cladding fluence above $0.1 \mathrm{MeV}$ is on the order of $4 \times 10^{23} \mathrm{n} / \mathrm{cm}^{2}$, which is expected to be within the limits of T-91 stainless steel.

In summary, although power peaking factors for the $\mathrm{CR}=0$ core are generally larger than those of the $\mathrm{CR}=1$ core, they still appear to be manageable with respect to thermal hydraulic performance. 
Project No 06-040: Flexible Conversion Ratio Fast Reactor Systems Evaluation

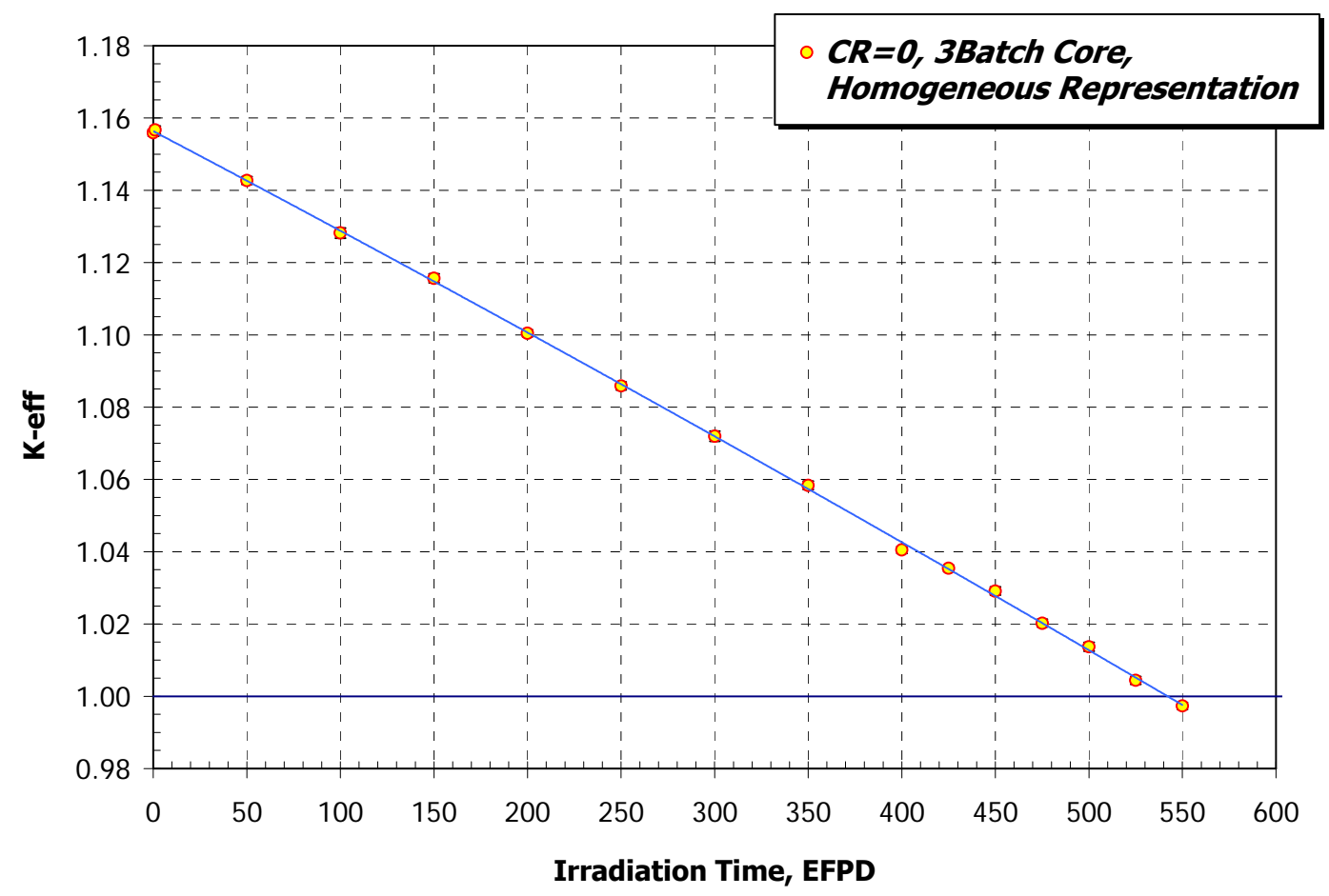

Figure 3.4.1-2. "CR=0" core k-eff as a function of time

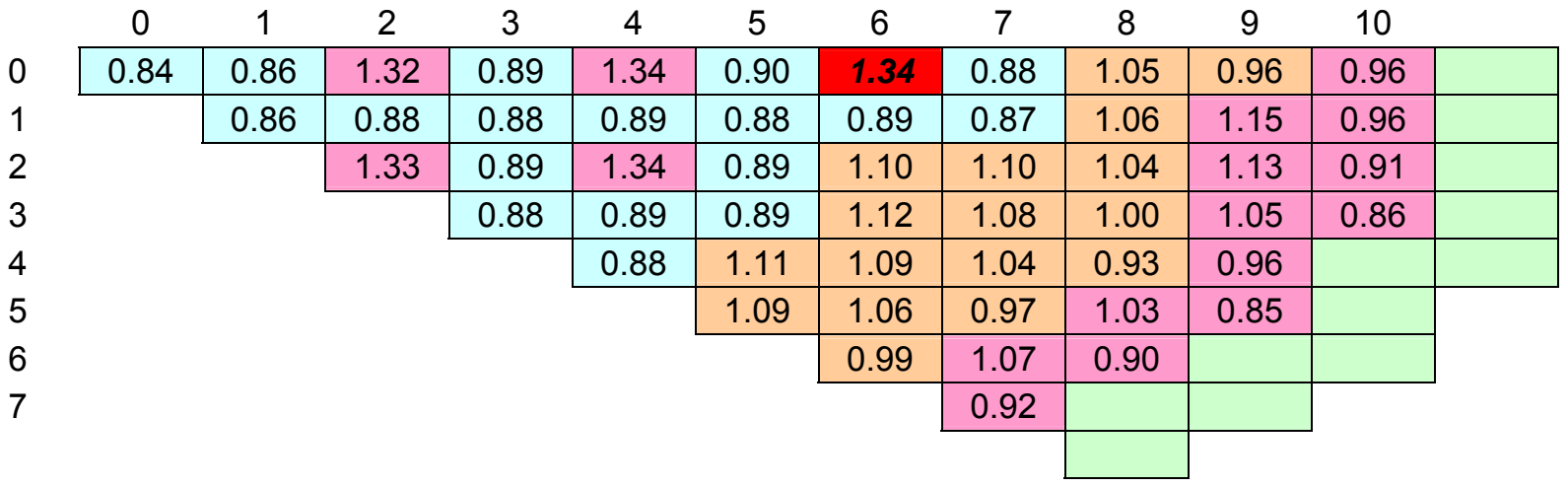

Fig. 3.4.1-4. " $\mathrm{CR}=0$ " Core, Radial Power Distribution Map at BOL (0 days)

\begin{tabular}{|c|c|c|c|c|c|c|c|c|c|c|}
\hline 0 & 1 & 2 & 3 & 4 & 5 & 6 & 7 & 8 & 9 & 10 \\
\hline 0.84 & 0.85 & 1.28 & 0.86 & 1.29 & 0.87 & 1.31 & 0.88 & 1.05 & 0.97 & 0.99 \\
\hline 1 & 0.85 & 0.86 & 0.86 & 0.87 & 0.86 & 0.88 & 0.87 & 1.05 & 1.20 & 0.98 \\
\hline 2 & & 1.28 & 0.86 & 1.29 & 0.87 & 1.09 & 1.09 & 1.05 & 1.17 & 0.94 \\
\hline 3 & & & 0.86 & 0.86 & 0.87 & 1.10 & 1.07 & 1.01 & 1.09 & 0.88 \\
\hline 4 & & & & 0.86 & 1.09 & 1.09 & 1.05 & 0.95 & 0.99 & \\
\hline 5 & & & & & 1.09 & 1.06 & 0.99 & 1.06 & 0.88 & \\
\hline 6 & & & & & & 1.00 & 1.11 & 0.94 & & \\
\hline 7 & & & & & & & 0.96 & & & \\
\hline
\end{tabular}

Fig. 3.4.1-5. "CR=0” Core, Radial Power Distribution Map at MOL (250 days) 
Project No 06-040: Flexible Conversion Ratio Fast Reactor Systems Evaluation

\begin{tabular}{|c|c|c|c|c|c|c|c|c|c|c|c|}
\hline & 0 & 1 & 2 & 3 & 4 & 5 & 6 & 7 & 8 & 9 & 10 \\
\hline 0 & 0.74 & 0.76 & 1.15 & 0.80 & 1.21 & 0.84 & 1.26 & 0.86 & 1.06 & 0.99 & 1.04 \\
\hline 1 & & 0.77 & 0.79 & 0.80 & 0.83 & 0.84 & 0.86 & 0.87 & 1.06 & 1.24 & 1.03 \\
\hline 2 & & & 1.18 & 0.83 & 1.25 & 0.86 & 1.08 & 1.09 & 1.06 & 1.21 & 0.99 \\
\hline 3 & & & & 0.83 & 0.85 & 0.88 & 1.11 & 1.09 & 1.03 & 1.14 & 0.92 \\
\hline 4 & & & & & 0.87 & 1.10 & 1.10 & 1.06 & 0.96 & 1.03 & \\
\hline 5 & & & & & & 1.11 & 1.08 & 1.00 & 1.10 & 0.92 & \\
\hline 6 & & & & & & & 1.01 & 1.14 & 0.98 & & \\
\hline 7 & & & & & & & & 1.00 & & & \\
\hline
\end{tabular}

Fig. 3.4.1-6. " $\mathrm{CR}=0$ " Core, Radial Power Distribution Map at EOL (525 days)

\begin{tabular}{|l|l|l|l|l|l|l|l|l|l|l|l|l|l|l|l|l|l|l|l|l|}
\hline 1.00 & 1.01 & 1.00 & 1.01 & 0.98 & 1.01 & 0.99 & 0.99 & 0.00 & 0.00 & 0.00 & 0.00 & 0.00 & 0.98 & 1.02 & 1.01 & 0.99 & 1.00 & 0.99 & 1.00 & 1.00 \\
\hline 1.02 & 1.01 & 0.99 & 1.00 & 1.01 & 1.00 & 1.00 & 0.98 & 0.00 & 0.00 & 0.00 & 0.00 & 0.00 & 0.99 & 0.99 & 0.99 & 1.00 & 1.00 & 1.00 & 1.00 & 1.00 \\
\hline 1.01 & 1.00 & 1.01 & 1.00 & 1.00 & 1.01 & 1.00 & 1.00 & 0.00 & 0.00 & 0.00 & 0.00 & 0.00 & 0.99 & 0.99 & 1.00 & 1.00 & 1.00 & 1.01 & 1.00 & 1.00 \\
\hline 1.01 & 1.01 & 1.02 & 1.00 & 0.99 & 0.99 & 1.00 & 0.99 & 0.98 & 0.99 & 0.98 & 0.99 & 0.99 & 0.99 & 0.99 & 1.01 & 0.99 & 1.00 & 0.99 & 1.00 & 1.01 \\
\hline 1.00 & 0.99 & 1.01 & 1.01 & 1.00 & 1.00 & 1.01 & 0.99 & 0.99 & 1.00 & 0.99 & 1.00 & 0.99 & 1.00 & 1.00 & 0.99 & 0.99 & 1.00 & 1.00 & 1.00 & 1.01 \\
\hline 1.00 & 1.00 & 1.01 & 1.00 & 1.00 & 1.00 & 1.00 & 1.00 & 0.98 & 1.00 & 1.00 & 1.00 & 1.00 & 0.99 & 1.01 & 1.00 & 1.01 & 1.01 & 1.00 & 0.99 & 1.00 \\
\hline 1.00 & 1.01 & 1.01 & 1.00 & 1.00 & 1.01 & 1.00 & 1.00 & 1.00 & 1.01 & 1.00 & 1.01 & 1.00 & 1.00 & 1.00 & 1.01 & 1.01 & 1.01 & 0.99 & 0.99 & 1.01 \\
\hline 1.02 & 1.00 & 1.00 & 1.01 & 1.00 & 1.00 & 1.00 & 1.01 & 0.99 & 1.00 & 1.00 & 1.01 & 1.01 & 1.00 & 1.00 & 1.01 & 1.00 & 1.00 & 1.00 & 0.99 & 1.00 \\
\hline 1.00 & 1.01 & 1.00 & 1.00 & 1.01 & 1.00 & 1.00 & 0.99 & 1.01 & 1.01 & 1.00 & 1.01 & 1.00 & 1.00 & 1.01 & 1.02 & 1.00 & 0.99 & 0.99 & 1.00 & 1.00 \\
\hline 1.00 & 1.01 & 1.01 & 1.00 & 1.00 & 1.00 & 1.01 & 1.01 & 1.00 & 1.00 & 1.00 & 1.00 & 1.01 & 1.01 & 1.00 & 1.01 & 1.01 & 1.00 & 0.99 & 1.00 & 0.99 \\
\hline 1.02 & 1.01 & 1.00 & 1.00 & 1.00 & 1.00 & 1.00 & 0.99 & 1.00 & 1.00 & 1.00 & 0.99 & 1.01 & 0.99 & 0.99 & 1.00 & 1.00 & 1.00 & 1.00 & 0.99 & 1.00 \\
\hline
\end{tabular}

Fig. 3.4.1-7. Pin power profile in "hot" assembly [6,0] (see Fig. 3.4.1-4). 
Project No 06-040: Flexible Conversion Ratio Fast Reactor Systems Evaluation

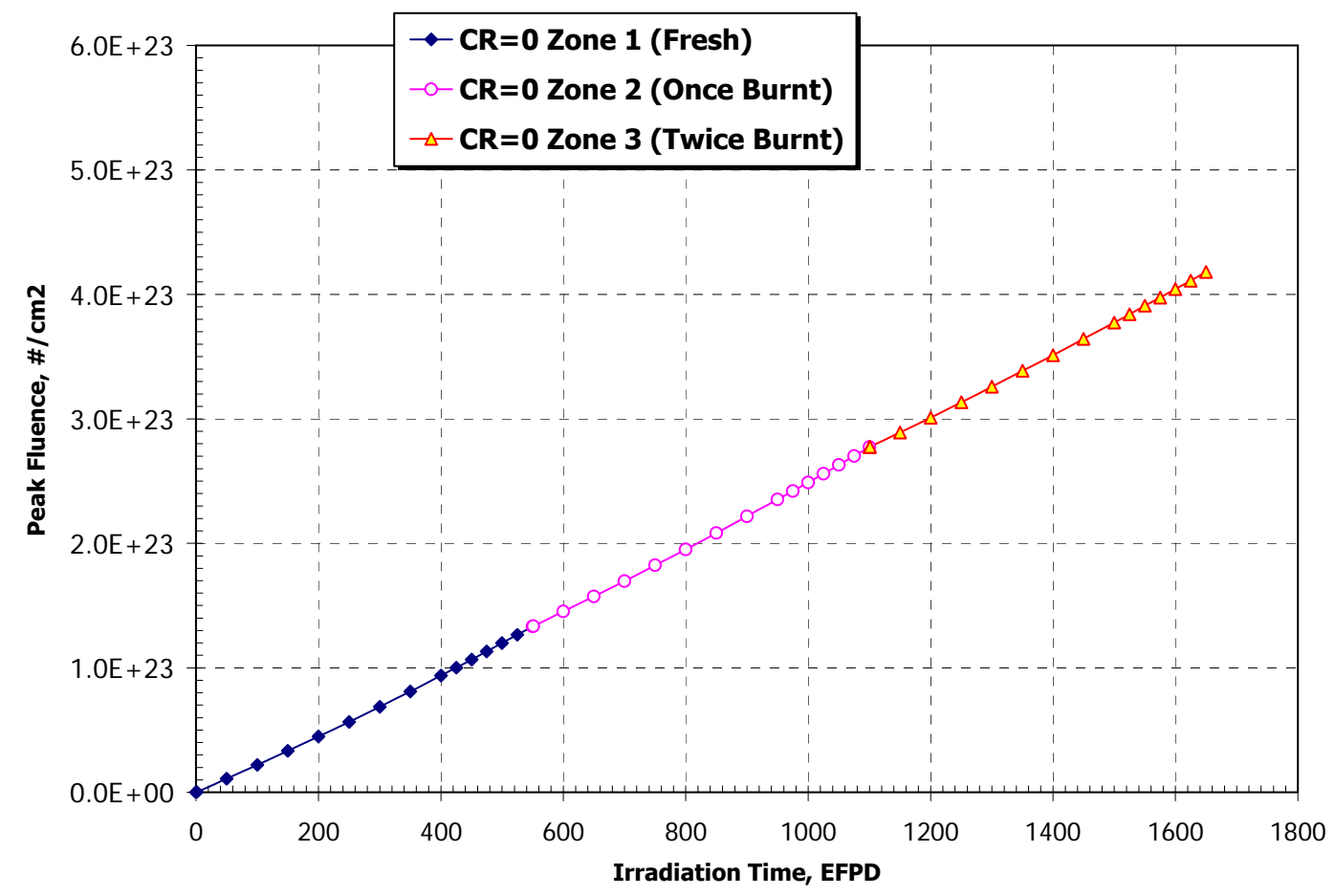

Figure 3.4.1-7 Accumulated peak fluence in the cladding as a function of time

\section{Reactivity Coefficients and Self-Controllability Criteria}

The same quasi-static approach to evaluation of reactor safety as described previously was applied also to the $\mathrm{CR}=0$ core case. Since the $\mathrm{CR}=1$ and $\mathrm{CR}=0$ cores are interchangeable, the operating and limiting conditions for both cores are identical and have been presented in Table 3.3.1-7.

The summary of reactivity feedback parameters for the $\mathrm{CR}=0$ core is presented in Table 3.4.1-3 and compared to values of an earlier fertile-free ABR design [Romano et al., 2004].

The reactivity coefficients were calculated at $\mathrm{BOC}$ and $\mathrm{EOC}$ because, in contrast to the $\mathrm{CR}=1$ core, the values of reactivity coefficients for the $\mathrm{CR}=0$ core change quite substantially over the irradiation time because of the changing fuel composition and the core power distribution.

The Doppler and Coolant Temperature Coefficients were calculated by performing a series of core criticality calculations at different fuel and coolant temperatures. The results of these calculations are presented in Figures 3.4.1-8 through 4.3.1-11. These data were subsequently used in a detailed transient analysis of the $\mathrm{CR}=0$ core with the RELAP5 computer code. 
Table 3.4.1-3 Summary of reactivity feedback parameters

\begin{tabular}{|c|c|c|c|c|c|c|}
\hline & \multirow[b]{2}{*}{ Units } & \multicolumn{4}{|c|}{$\mathrm{CR}=0$ Lead } & \multirow{2}{*}{$\begin{array}{c}\mathrm{ABR}^{*} \\
\mathrm{BOL}\end{array}$} \\
\hline & & BOC value & $\pm \sigma$ & EOC value & $\pm \sigma$ & \\
\hline$\beta$ & & 0.0029 & 0.0001 & 0.0028 & 0.0001 & 0.0028 \\
\hline$\alpha_{\mathrm{DC}}$ & $\phi / \mathrm{K}$ & -0.016 & 0.030 & -0.041 & 0.030 & -0.040 \\
\hline$\alpha_{\mathrm{e}}$ & $\phi / \mathrm{K}$ & -0.198 & 0.034 & -0.267 & 0.043 & -0.120 \\
\hline$\alpha_{\mathrm{Co}}$ & $\phi / \mathrm{K}$ & -0.006 & 0.044 & -0.030 & 0.038 & -0.030 \\
\hline$\alpha_{\mathrm{RD}}$ & $\phi / \mathrm{K}$ & $\sim 0$ & $\mathrm{~N} / \mathrm{A}$ & $\sim 0$ & $\mathrm{~N} / \mathrm{A}$ & $\sim 0$ \\
\hline$\alpha_{R}$ & $\phi / \mathrm{K}$ & -0.161 & 0.032 & -0.248 & 0.043 & -0.250 \\
\hline A & $\phi$ & -21.57 & 4.54 & -30.95 & 5.24 & -16.0 \\
\hline $\mathrm{B}$ & $\phi$ & -25.79 & 2.75 & -39.60 & 5.08 & -35.0 \\
\hline $\mathrm{C}$ & $\phi / \mathrm{K}$ & -0.38 & 0.05 & -0.59 & 0.06 & -0.44 \\
\hline $\mathrm{A} / \mathrm{B}$ & & 0.84 & 0.20 & 0.78 & 0.17 & 0.46 \\
\hline $\mathrm{C} \triangleq \mathrm{T} \mathrm{Tc} / \mathrm{B}$ & & 1.41 & 0.24 & 1.41 & 0.23 & 1.14 \\
\hline$\Delta \rho_{\mathrm{TOP}} / \mathrm{B}$ & & 0.98 & 0.10 & 0.18 & 0.02 & 1.43 \\
\hline A/B limits & & \multicolumn{2}{|c|}{$x<1.06(1.59)$} & \multicolumn{2}{|c|}{$x<1.06(1.59)$} & \\
\hline $\mathrm{C} \Delta \mathrm{T}_{\mathrm{c}} / \mathrm{B}$ limits & & \multicolumn{2}{|c|}{$1<x<1.99(2.39)$} & \multicolumn{2}{|c|}{$1<x<1.99(2.39)$} & \\
\hline$\Delta \rho_{\mathrm{TOP}} / \mathrm{B}$ limits & & \multicolumn{2}{|c|}{$x<1.06(1.59)$} & \multicolumn{2}{|c|}{$x<1.06(1.59)$} & \\
\hline
\end{tabular}

*700MWt ABR values from Romano et al., [2004].

${ }^{* *}$ Values in parentheses pertain to margin factor $\gamma=1$ (See Eq. 1 in Section 4 of Appendix 3A).

The Coolant Temperature Coefficient is practically zero at BOC and becomes even slightly negative towards the end of the cycle. This is a result of higher leakage contribution to the overall reactivity balance in comparison with the $\mathrm{CR}=1$ core, which is much less neutron transparent. The value of Coolant Temperature Coefficient at BOC reported in Romano et al. [2004] is even more negative, most probably due to the presence of neutron streaming channels in the ABR design as well as significantly smaller core dimensions, both resulting in even larger leakage.

Smaller ABR core dimensions result in a somewhat larger core radial expansion coefficient of the $\mathrm{ABR}$ core as compared with the studied $\mathrm{CR}=0$ core. The same trend was also observed in the analysis of the $\mathrm{CR}=1$ design.

In contrast to the $\mathrm{CR}=1$ core, the $\mathrm{CR}=0$ core has a small negative Doppler effect, and the $\mathrm{A} / \mathrm{B}$ criterion is easily satisfied. The small magnitude of the Doppler coefficient is typical for metallic-fueled cores, such as the IFR, where, for plutonium burning, Hill et al., [1995] reported a value of the Doppler coefficient of $\sim-0.05 \notin / \mathrm{K}$.

The most restrictive criterion for the $\mathrm{CR}=0$ core appears to be the one related to the inadvertent Control Rod Withdrawal accident, which necessitates the use of CRDs in every fuel assembly to reduce the reactivity worth of any individual control rod. The third self-controllability criterion is satisfied with a somewhat lower margin than typically assumed in conservative calculations 
given the statistical uncertainty. However, it is expected that the transient analysis of UTOP will yield acceptable performance because the actual power peak obtained in this analysis is smaller than the 1.5 assumed for conservatism. This expectation was based on an earlier analysis of an ABR core [Romano et al., 2004] where the third criterion exceeded the conservative limit and transient analysis yielded peak cladding temperatures, which were below the cladding temperature limit.

Detailed simulation of the UTOP accident with RELAP5 code is presented and discussed in the following section of this report.

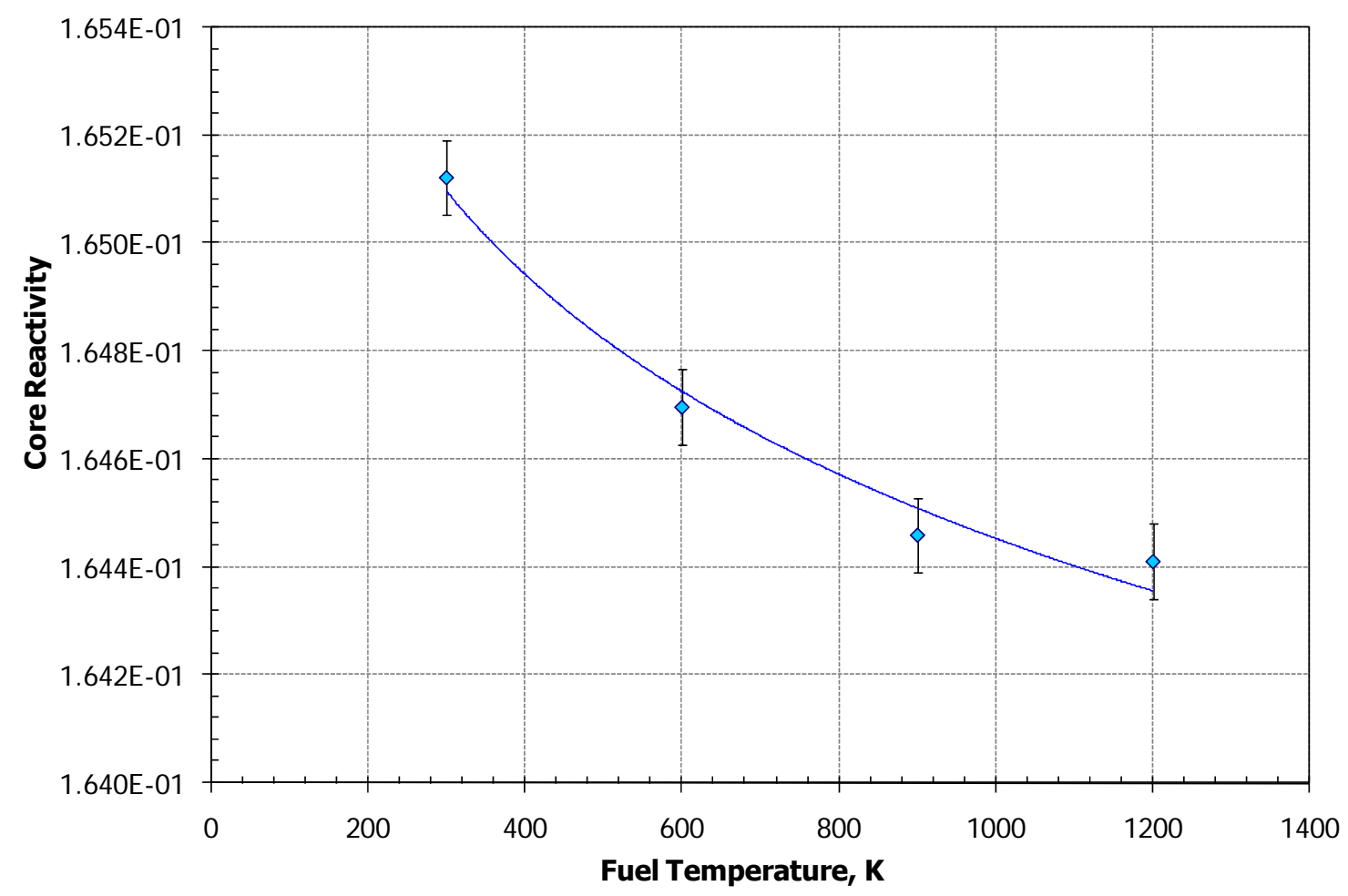

Figure 3.4.1-8 $\mathrm{CR}=0$ core reactivity as a function of fuel temperature at $\mathrm{BOC}$

\section{Reactor Vessel Fluence}

Similar to the analysis of the $\mathrm{CR}=1$ core, the fast neutron fluence to the reactor vessel and the core support plate were also calculated for the $\mathrm{CR}=0$ core design using the MCNP code. The vessel fluence was calculated at axial elevation corresponding to the core midplane where maximum neutron flux is expected.

The results of the calculations are summarized in Table 3.4.1-4 for both the $\mathrm{CR}=1$ and $\mathrm{CR}=0$ core designs. The values of neutron fluence are slightly larger in the $\mathrm{CR}=0$ case because of the more neutron transparent core and higher neutron leakage. Nevertheless, in both cases, the fast fluence is well below the adopted limit of $5 \times 10^{19}$ (neutrons above $\left.1 \mathrm{MeV}\right) / \mathrm{cm}^{2}$. The values presented in Table 3.4.1-4 are for fluence above $0.1 \mathrm{MeV}$ because of the poor statistics of calculations at higher energy bins. 
Project No 06-040: Flexible Conversion Ratio Fast Reactor Systems Evaluation

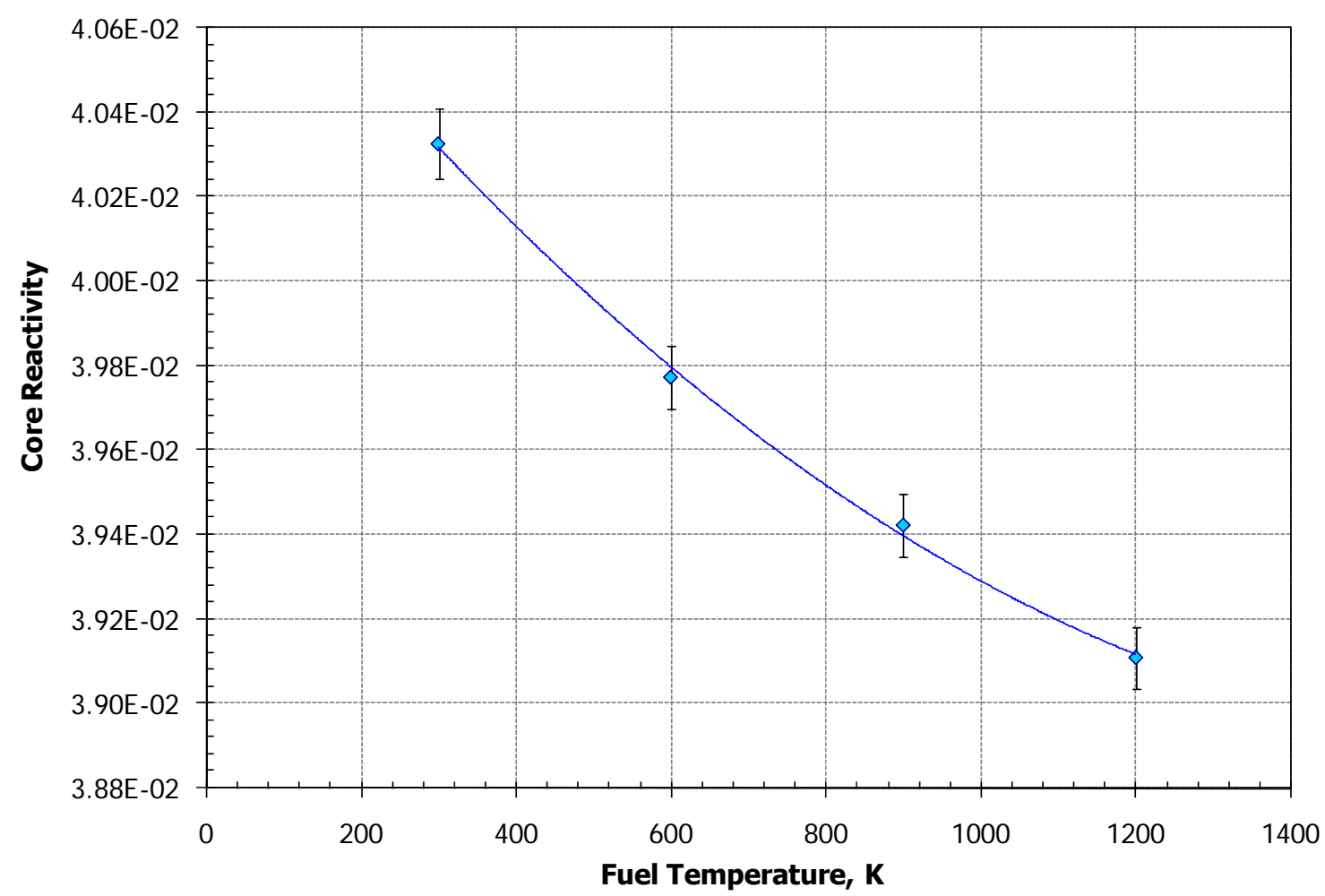

Figure 3.4.1-9 $\mathrm{CR}=0$ core reactivity as a function of fuel temperature at $\mathrm{EOC}$

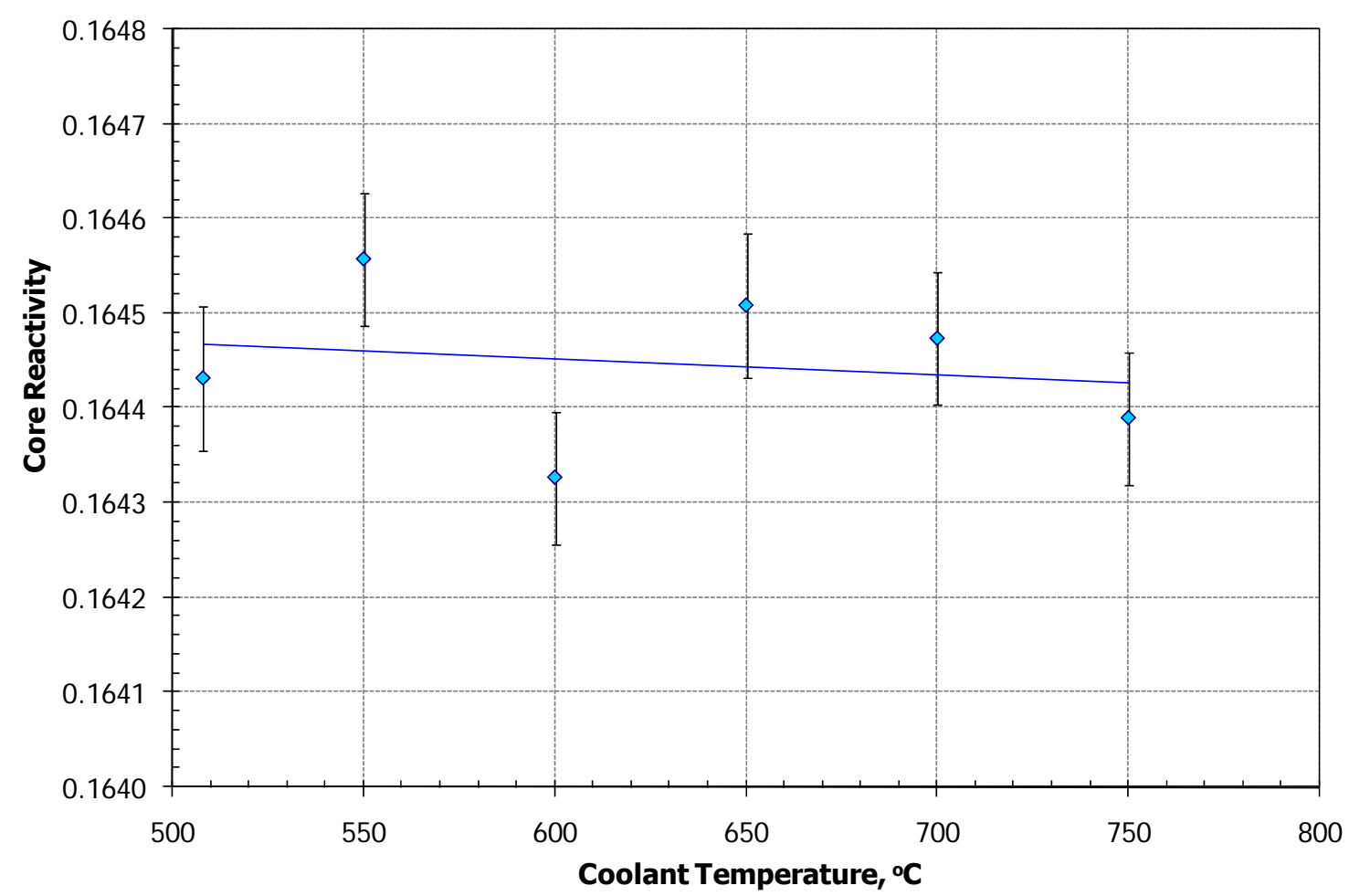

Figure 3.4.1-10 $\mathrm{CR}=0$ core reactivity as a function of coolant temperature at $\mathrm{BOC}$ 
Project No 06-040: Flexible Conversion Ratio Fast Reactor Systems Evaluation

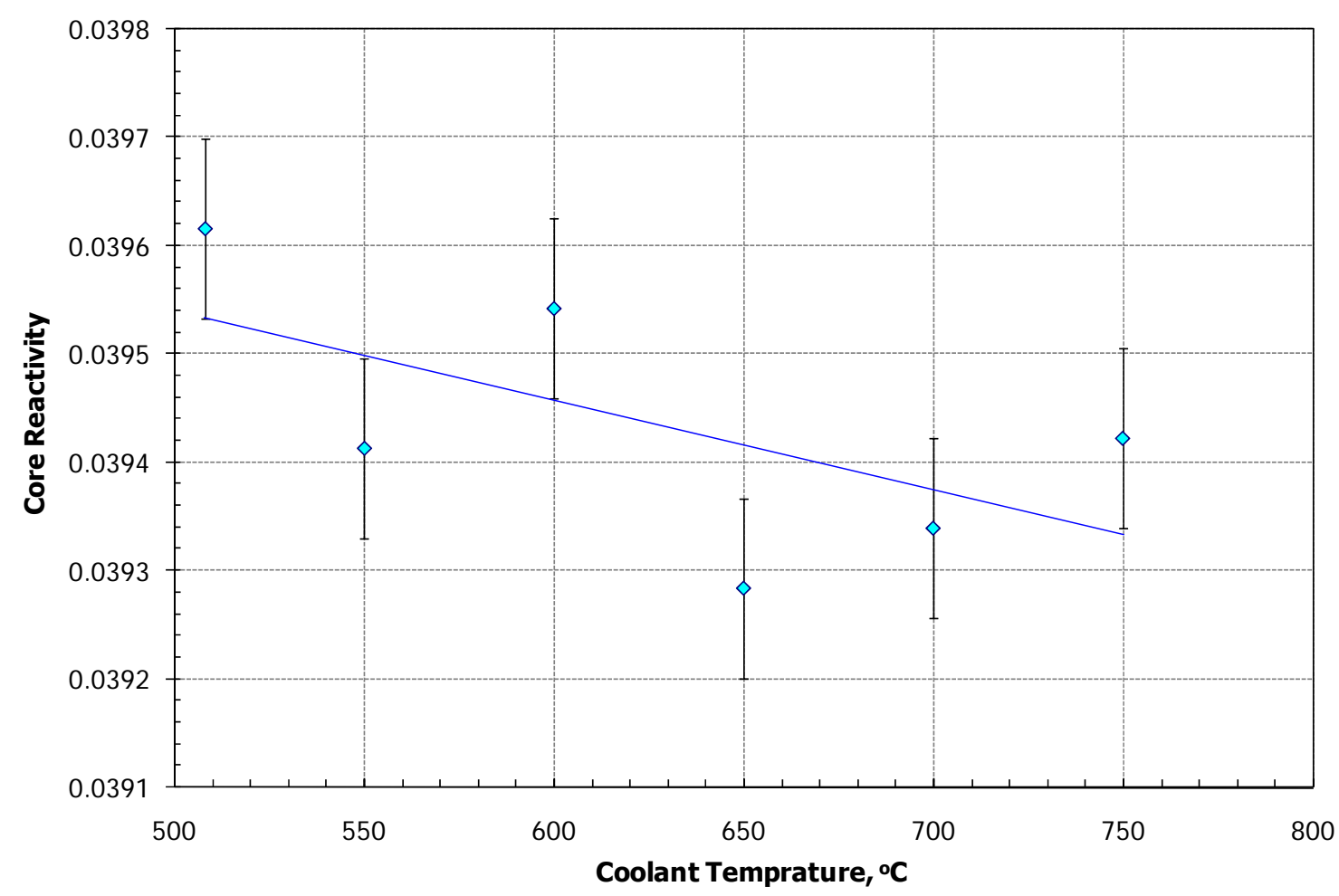

Figure 3.4.1-11 $\mathrm{CR}=0$ core reactivity as a function of coolant temperature at EOC

Table 3.4.1-4. Fast fluence accumulated during 40 years lifetime in $\mathrm{CR}=0$ core components

\begin{tabular}{|l|c|c|}
\hline Parameter & CR=0 & CR=1 \\
\hline Vessel above $(0.1 \mathrm{MeV}), \# / \mathrm{cm}^{2}$ & $(9.3 \pm 0.5) \times 10^{18}$ & $(6.4 \pm 0.4) \times 10^{18}$ \\
\hline Core support plate above $(0.1 \mathrm{MeV}), \# / \mathrm{cm}^{2}$ & $(4.3 \pm 0.2) \times 10^{19}$ & $(3.4 \pm 0.2) \times 10^{19}$ \\
\hline
\end{tabular}

\section{Decay Heat Curves}

Next, as for the $\mathrm{CR}=1$ core design, the depletion and decay calculations were performed for the lead-cooled $\mathrm{CR}=0$ core and the obtained decay heat data were compared with those of conventional PWR fuel. The results of the calculations are summarized in Figures 3.4.1-12 and 3.4.1-13. Figure 3.4.1-12 compares the normalized decay heat of the $\mathrm{UO}_{2} \mathrm{PWR}$ core with those of the lead-cooled $\mathrm{CR}=1$ and $\mathrm{CR}=0$ cores on a $\log -\log$ scale. Figure 3.4.1-13 shows the percent difference in the normalized decay heat between the two lead-cooled cores and the PWR core.

In the case of $\mathrm{CR}=0$, the LWR decay power remains higher for about 20 hours. However, from that point on, the LWR heat decreases with time at a much faster rate than that of the $\mathrm{CR}=0$ case, leading to about $50 \%$ higher power for the $C R=0$ case at $\sim 300$ hours. For the first 140 hours after shutdown, the $C R=0$ core decay heat is generally smaller than that of the $C R=1$ core by up to $10 \%$.

The calculations performed clearly demonstrate the importance of using decay heat data derived from an appropriate reactor model, which takes into account fuel composition and neutron spectrum. Therefore, the results of the decay heat calculations for the $\mathrm{CR}=1$ and $\mathrm{CR}=0$ lead- 
Project No 06-040: Flexible Conversion Ratio Fast Reactor Systems Evaluation cooled reactor cores will be used as input data for safety analysis of the respective reactors with the RELAP code.

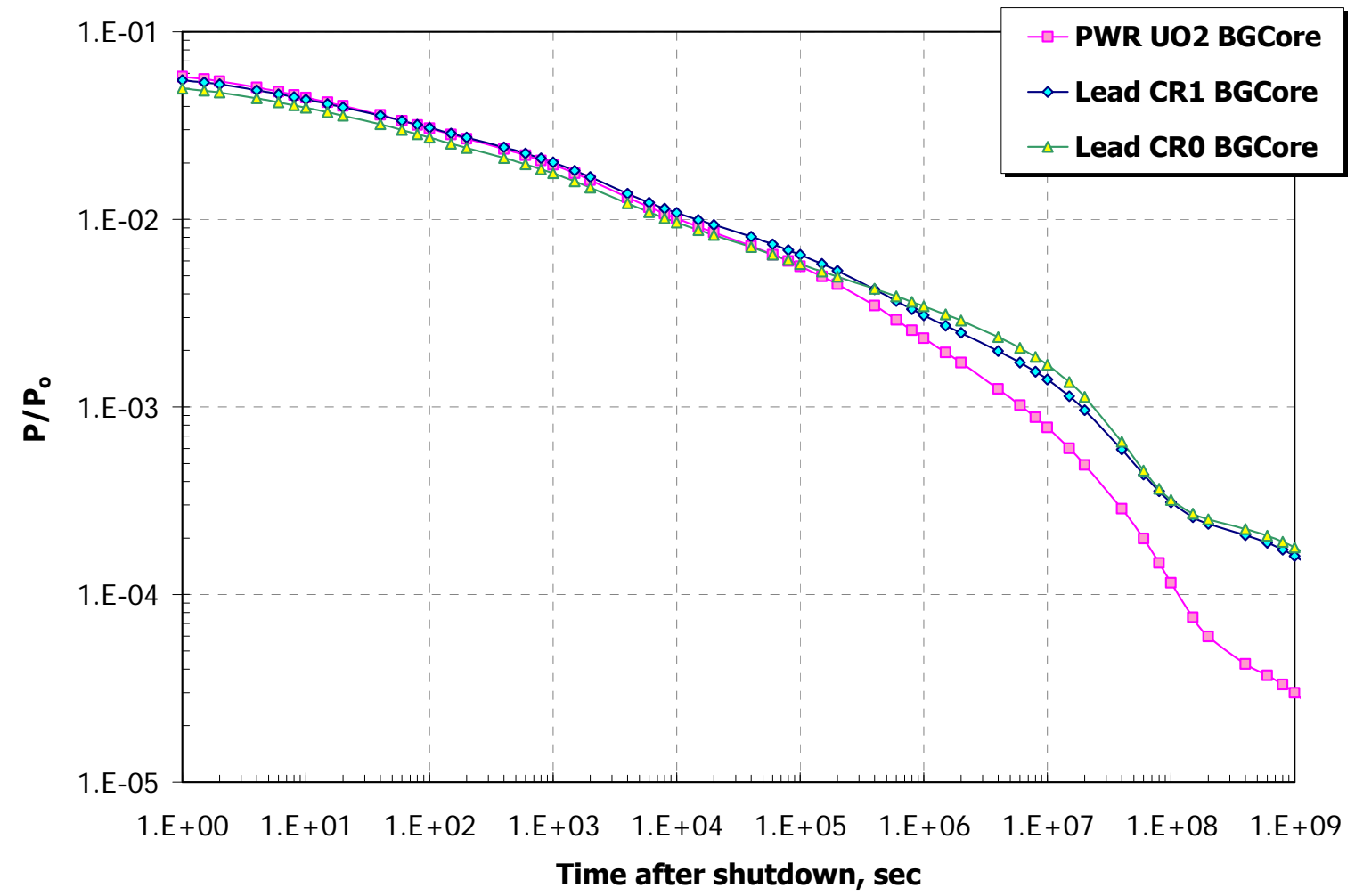

Figure 3.4.1-12. Decay heat power for $\mathrm{UO}_{2} \mathrm{LWR}$ and lead-cooled CR1 cores.

(Log-Log scale)

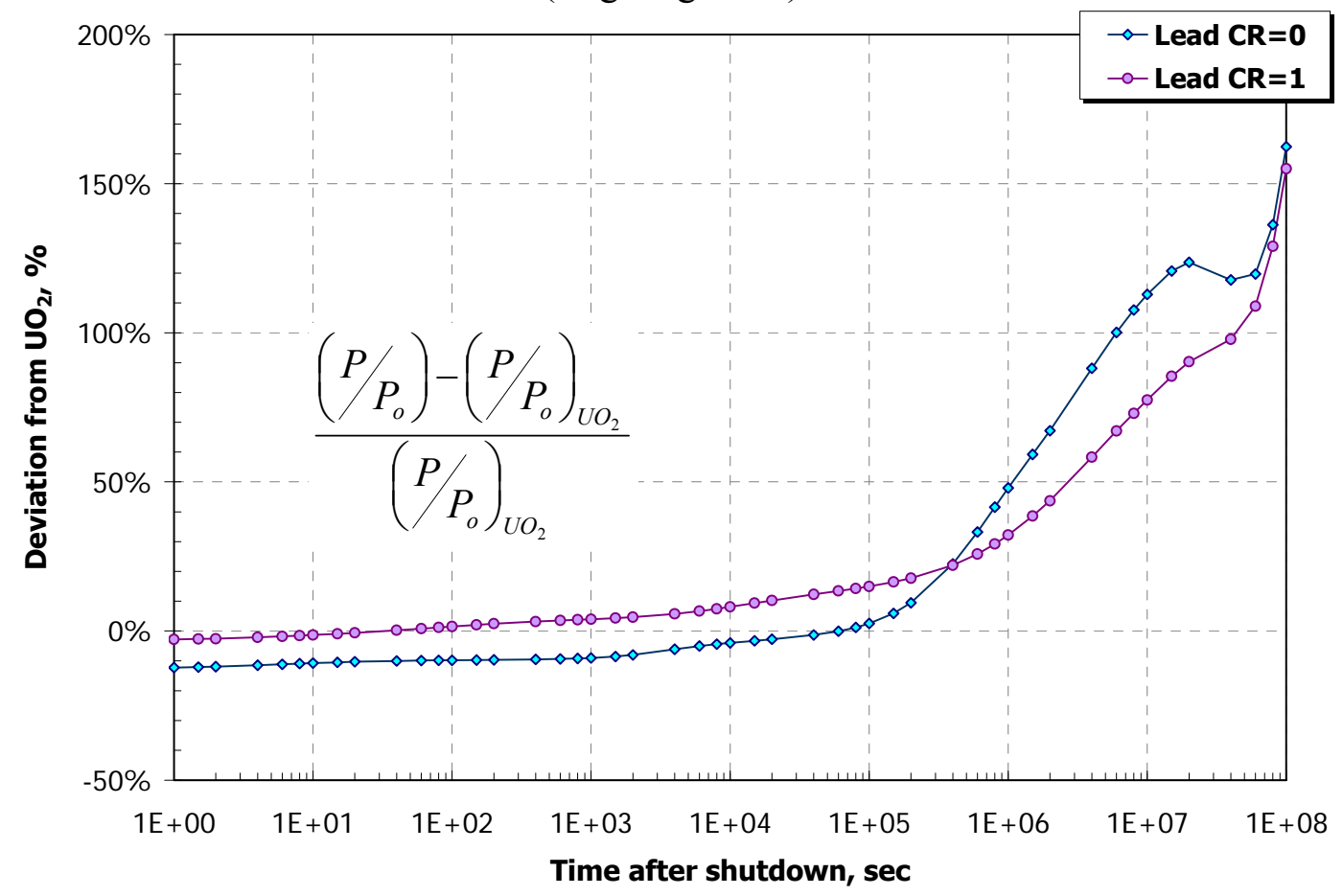

Figure 3.4.1-13. Difference between $\mathrm{P} / \mathrm{P}_{\mathrm{o}}$ values for $\mathrm{UO}_{2} \mathrm{LWR}$ and lead-cooled cores 
Project No 06-040: Flexible Conversion Ratio Fast Reactor Systems Evaluation

\subsubsection{Thermal Hydraulic Design}

\subsubsection{Steady State Thermal Hydraulic Design}

\subsection{Core Design}

The methodology for the zero conversion ratio core thermal hydraulic steady state parameter calculation is the same as for the unity conversion ratio core. In contrast to the $\mathrm{CR}=1$ core, higher radial power peaking is associated with the $\mathrm{CR}=0$ core. The maximum radial power peaking for the zero conversion ratio core occurs at the beginning of the fuel cycle according to the reactor physics analysis in Section 3.3.1. Thus, the BOC peaking factors were used for the thermal hydraulic analysis of the core. Similarly to the unity core, the $\mathrm{CR}=0$ core consists of 349 fuel assemblies. However, every assembly contains control rods, and therefore the effect of "cold" channels is greater for the $\mathrm{CR}=0$ core. The peak cladding temperature and maximum velocity constraints are the same as for the unity conversion ratio core. To assure the same performance of heat exchangers for both $\mathrm{CR}=1$ and $\mathrm{CR}=0$ cores, the inlet and outlet core average temperatures are kept constant for both cores.

Similarly to the $\mathrm{CR}=1$ case, three-zone orificing was sufficient to flatten the core temperature distribution significantly. The highest assembly-average peak cladding temperature was reduced from $645.4^{\circ} \mathrm{C}$ to $617.4^{\circ} \mathrm{C}$ as shown in Figure 3.4.2-1. The maximum velocity in the core was observed at the hottest assembly. Maximum peak guard vessel temperature during steady state full power operating is the same for both reactors. The maximum peak membrane temperature is $428^{\circ} \mathrm{C}$, which is below the steady state limit of $430^{\circ} \mathrm{C}$.

To assure the same performance of heat exchangers for both the $\mathrm{CR}=1$ and $\mathrm{CR}=0$ cores, the inlet and outlet core average temperatures are the same as for the $\mathrm{CR}=1$ core. Also, the IHX design is identical for both the $\mathrm{CR}=1$ and $\mathrm{CR}=0$ concepts. Thus, the RELAP5-3D modeling and analysis of the reactor systems described in Section 3.2.2 and Appendix 3B.2 are applicable for a zero conversion ratio reactor. A summary of main core geometric parameters is provided in Table 3.4.2-1. 
Project No 06-040: Flexible Conversion Ratio Fast Reactor Systems Evaluation

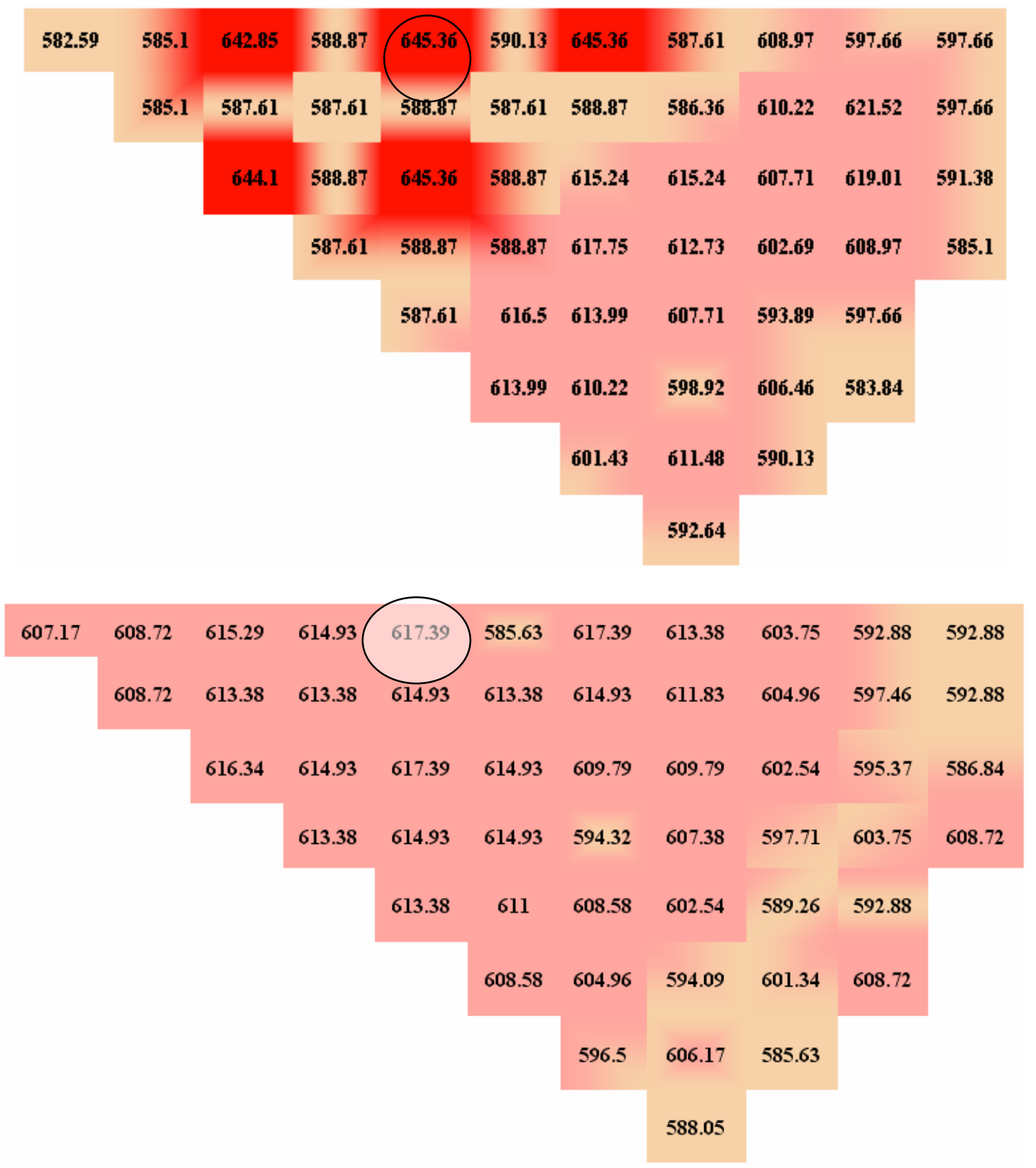

Figure 3.4.2-1 Assembly-average peak cladding temperature $\left({ }^{\circ} \mathrm{C}\right)$ map for unorificed core (top) and for orificed core (bottom). The hottest assemblies are circled. 
Table 3.4.2-1 Summary of Main Parameters of Zero Conversion Ratio Core

\begin{tabular}{|c|c|c|}
\hline \multicolumn{2}{|c|}{ Core thermal power $(\mathrm{MWt})$} & 2400 \\
\hline \multicolumn{2}{|c|}{ Maximum radial power peaking coefficient } & 1.21 \\
\hline \multirow[t]{7}{*}{ Assembly Geometry } & Assembly pitch (m) & $2.175 \mathrm{E}-01$ \\
\hline & Assembly can thickness (m) & $3.940 \mathrm{E}-03$ \\
\hline & Inter assembly gap (hot) (m) & $2.229 \mathrm{E}-03$ \\
\hline & Total number of fuel assemblies & 349 \\
\hline & Number of FA with CRDs & 349 \\
\hline & Number of fuel pins per assembly & 416 \\
\hline & Number of CRD per assembly & 25 \\
\hline \multirow[t]{9}{*}{ Fuel pin geometry } & Pin outer diameter $(\mathrm{m})$ & $7.520 \mathrm{E}-03$ \\
\hline & Cladding thickness (m) & $6.300 \mathrm{E}-04$ \\
\hline & Gap thickness (m) & $4.200 \mathrm{E}-04$ \\
\hline & Fuel heated length (m) & 1.3 \\
\hline & Fuel pin pitch $(\mathrm{cm})$ & 0.9776 \\
\hline & Pitch-to-diameter ratio & 1.3 \\
\hline & Plenum height $(\mathrm{m})$ top/bottom & $1.3 / 1.3$ \\
\hline & Cladding material & T-91 (9Cr-1Mo-V-Nb) \\
\hline & Gap bond & Lead \\
\hline \multirow[t]{3}{*}{ Fuel type } & Zone 1 (U/TRU/Zr), (wt. \%) & $0.00 / 34.00 / 66.00^{1}$ \\
\hline & Zone 2 (U/TRU/Zr), (wt. \%) & Once burnt (middle zone) \\
\hline & Zone 3 (U/TRU/Zr), (wt. \%) & Twice burnt (inner zone) \\
\hline \multirow{3}{*}{ Core average } & Coolant mass flow rate $(\mathrm{kg} / \mathrm{s})$ & 173600 \\
\hline & Inlet temperature $\left({ }^{\circ} \mathrm{C}\right)$ & 479.0 \\
\hline & Outlet temperature $\left({ }^{\circ} \mathrm{C}\right)$ & 573.6 \\
\hline \multirow[t]{6}{*}{ Hot subchannel } & Cladding temperature limit $\left({ }^{\circ} \mathrm{C}\right)$ & 625.0 \\
\hline & Peak Cladding Temperature $\left({ }^{\circ} \mathrm{C}\right)$ & 618 \\
\hline & Temperature margin $\left({ }^{\circ} \mathrm{C}\right)$ & 2.7 \\
\hline & Coolant velocity limit $(\mathrm{m} / \mathrm{s})$ & 3.0 \\
\hline & Velocity $(\mathrm{m} / \mathrm{s})$ & 2.6 \\
\hline & Velocity margin $(\mathrm{m} / \mathrm{s})$ & 0.4 \\
\hline \multirow[t]{3}{*}{ Orificing coefficients } & Zone 1 & 0.40 \\
\hline & Zone 2 & 8.19 \\
\hline & Zone 3 & 29.68 \\
\hline
\end{tabular}

${ }^{1}$ The $\mathrm{CR}=0$ core was designed as a 3 -batch core with TRU-Zr fuel to accommodate the large reactivity swing. Zone 1 is the outer core zone, and numbers correspond to initial (fresh) fuel composition. 
Project No 06-040: Flexible Conversion Ratio Fast Reactor Systems Evaluation

\subsubsection{Transient Analysis}

Transient analysis of the zero conversion ratio core was pursued in a similar manner to the unity CR core. RELAP5-3D was the thermal hydraulic code used for the analysis. Transient analysis was performed for three unprotected accidents: station blackout, unprotected loss of flow, and unprotected overpower. The goals of the analysis and the models are the same as for the unity conversion ratio core. The models used in the transient simulation are described in detail in Appendix 3B.2. The decay heat curve and its effect on the reactor performance were discussed in Section 3.3.2. The reactivity coefficients are also different for the $\mathrm{CR}=0$ core. The PCS, PSACS, and RVACS are kept the same as for the $\mathrm{CR}=1$ core. Table 3.4.2-2 summarizes the initial conditions of the reactor at rated power.

Table 3.4.2-2 Initial conditions for $\mathrm{CR}=0$ core at full power

\section{Primary coolant system}

Core power (MWt)

Mass flow rate $(\mathrm{kg} / \mathrm{s})$

Core inlet temperature $\left({ }^{\circ} \mathrm{C}\right)$

173600

Core outlet temperature $\left({ }^{\circ} \mathrm{C}\right)$

479

Maximum cladding temperature $\left({ }^{\circ} \mathrm{C}\right)(\mathrm{CR}=1 / \mathrm{CR}=0)$

574

Maximum fuel temperature $\left({ }^{\circ} \mathrm{C}\right)$

$610 / 618$

Secondary system

725

Pressure (MPa)

19.96

Mass flow rate $(\mathrm{kg} / \mathrm{s})$

12848

Inlet temperature

397

Outlet temperature $\left({ }^{\circ} \mathrm{C}\right)$

548

\section{RVACS}

Power removed (MW)

Air flow rate $(\mathrm{kg} / \mathrm{s})$

79.1

Air inlet temperature $\left({ }^{\circ} \mathrm{C}\right)$

37.8

Air exit temperature $\left({ }^{\circ} \mathrm{C}\right)$

122.1

Maximum guard vessel temperature $\left({ }^{\circ} \mathrm{C}\right)$

434.0

Under transient conditions, both cores behave very similarly. The differences arise from the peaking factors, which affect the peak cladding temperatures in the early system response, the reactivity coefficients, which affect the time-dependent behavior of the reactor cores, and from different decay heat curves, which affect peak cladding and vessel temperatures in the long term. Since the $C R=1$ case was more limiting, the effect of the decay heat curve on system performance was discussed in Section 3.3.2.

While the increase in the decay heat can be accommodated by changes in the PSACS size, the reactivity coefficients are important for the inherent and safe shutdown of the reactor. The reactivity feedback models used in RELAP5-3D take into account the following reactivity coefficients: coolant temperature coefficient, Doppler, control rod drive expansion, core radial expansion, and fuel thermal expansion. Transient reactor power was calculated using spaceindependent point reactor kinetics. The point kinetics model uses core-average fluid conditions, power squared weighting factors, and feedback coefficients to determine total reactivity, which is 
used for kinetics calculations of total core power [RELAP5, 2005]. Table 3.4.2-3 compares the reactivity coefficients of the $\mathrm{CR}=1$ and $\mathrm{CR}=0$ cores.

It can be observed that the $\mathrm{CR}=0$ core has much smaller (in absolute value) negative coefficients than those of the $\mathrm{CR}=1$ core, but the positive coolant temperature coefficient is near zero. In addition, the decay heat curve corresponding to the zero $\mathrm{CR}$ core is smaller than for the $\mathrm{CR}=1$ core. Thus, the $\mathrm{CR}=1$ core response to the accident is much more severe in terms of peak cladding temperature.

Table 3.4.2-3 Reactivity coefficients

\begin{tabular}{|c|c|c|}
\hline & $\mathrm{CR}=1(\phi / \mathrm{K})$ & $\mathrm{CR}=0(\phi / \mathrm{K})$ \\
\hline$\alpha \mathrm{DC}$ & -111 & -16 \\
\hline$\alpha \mathrm{e}$ & -117 & -198 \\
\hline$\alpha \mathrm{Co}$ & +131 & -6 \\
\hline$\alpha \mathrm{RD}$ & $\sim 0$ & $\sim 0$ \\
\hline$\alpha \mathrm{R}$ & -135 & -161 \\
\hline
\end{tabular}

\subsection{Unprotected Station Blackout}

The unprotected station blackout accident for the zero conversion ratio core is similar to the unity conversion ratio core case. Two fundamental differences between the two cores are decay heat generated after shutdown and the reactivity coefficients. Since the decay heat generated by the $\mathrm{CR}=0$ core is less than that of the $\mathrm{CR}=1$ core, the case is easier to manage during the SBO transient. The difference in reactivity coefficients is reflected in the magnitude of the power oscillations and how quickly the oscillations come to equilibrium.

Figure 3.4.2-2 shows the peak cladding temperature response for the $\mathrm{CR}=0$ core with two out of four PSACS trainsoperating. The first peak in PTC occurs at 1.8 hours and is equal to $694^{\circ} \mathrm{C}$. It occurs earlier than that of the $\mathrm{CR}=1$ core, and the magnitude is smaller in spite of the higher peak cladding temperature during steady state full power operation. This phenomenon can be explained by the difference in reactivity coefficients. Figure 3.4.2-3 compares the reactivity for both cores. The reactivity of the $\mathrm{CR}=0$ core reaches the minimum more quickly, which is reflected in the earlier peak. However, the duration of positive reactivity for the $\mathrm{CR}=0$ core is $\sim 7$ hours while that of the $\mathrm{CR}=1$ core it is $\sim 8.6$ hours. Therefore, the maximum peak cladding temperature for the $\mathrm{CR}=1$ core is higher than that of the $\mathrm{CR}=0$ core.

Figures 3.4.2-4 and 3.4.2-5 show the heat balance for the zero conversion ratio core. The reactor restarts at $\sim 21.4$ hours with the core power peak of $64 \mathrm{MWt}$. The magnitude of power peak for the $\mathrm{CR}=1$ core is $60 \mathrm{MW}$. The magnitude of the restart is largely affected by the reactivity. The power after restart settled at $19 \mathrm{MWt}$, which is comparable to the $\mathrm{CR}=1$ case.

Finally, Figure 3.4.2-6 illustrates the peak membrane vessel temperatures for the $\mathrm{CR}=0$ core. The maximum peak membrane temperature for the reactor vessel is $631^{\circ} \mathrm{C}$ occurring at around 2.3 hours. The temperature is smaller compared to the $\mathrm{CR}=1$ case, which was expected since the overall system temperatures are lower for the $\mathrm{CR}=0$ core during the unprotected $\mathrm{SBO}$ transient. 
Project No 06-040: Flexible Conversion Ratio Fast Reactor Systems Evaluation

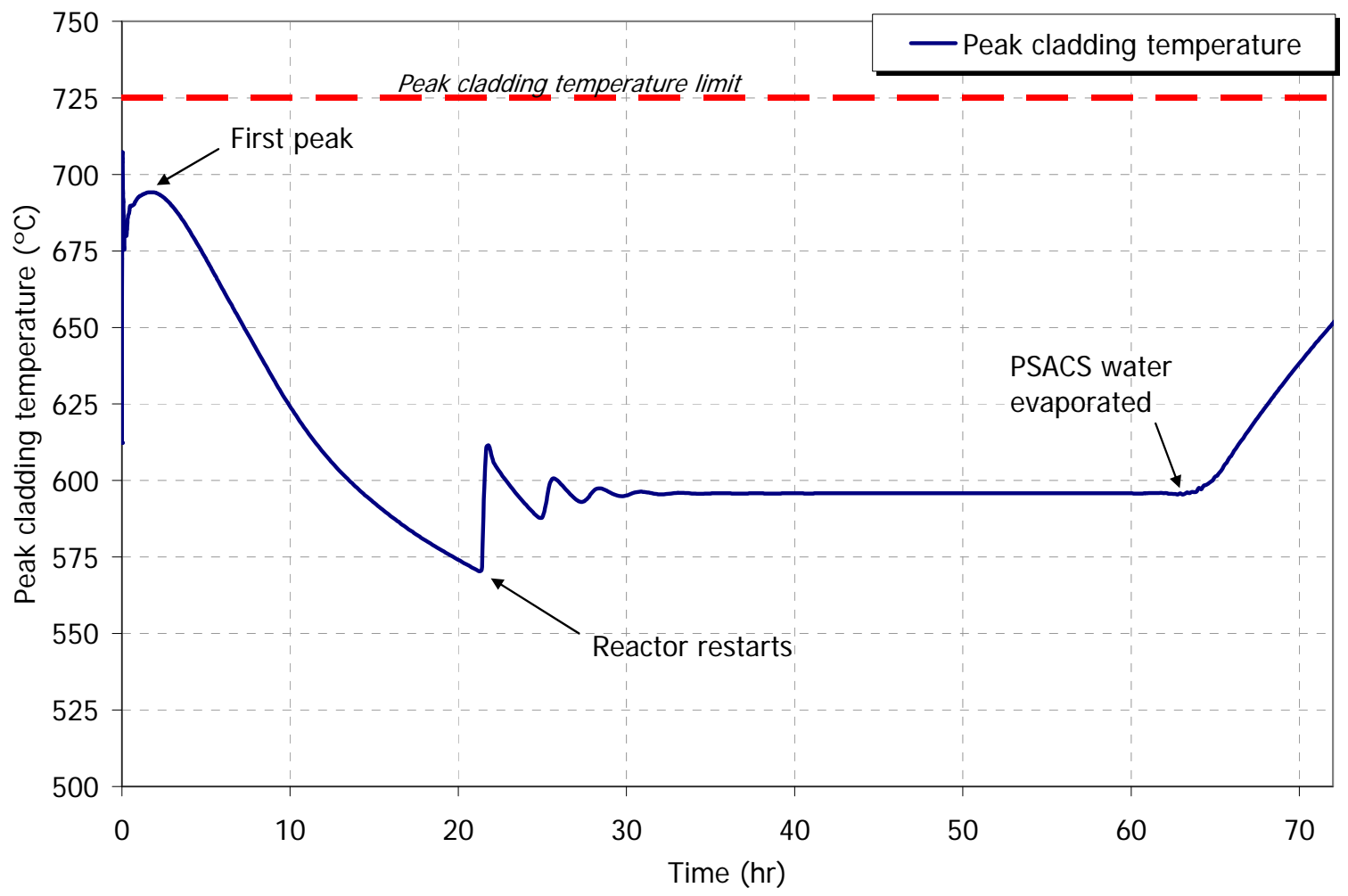

Figure 3.4.2-2 Peak cladding temperature for unprotected PSACS $\times 2$ case for the $\mathrm{CR}=0$ core

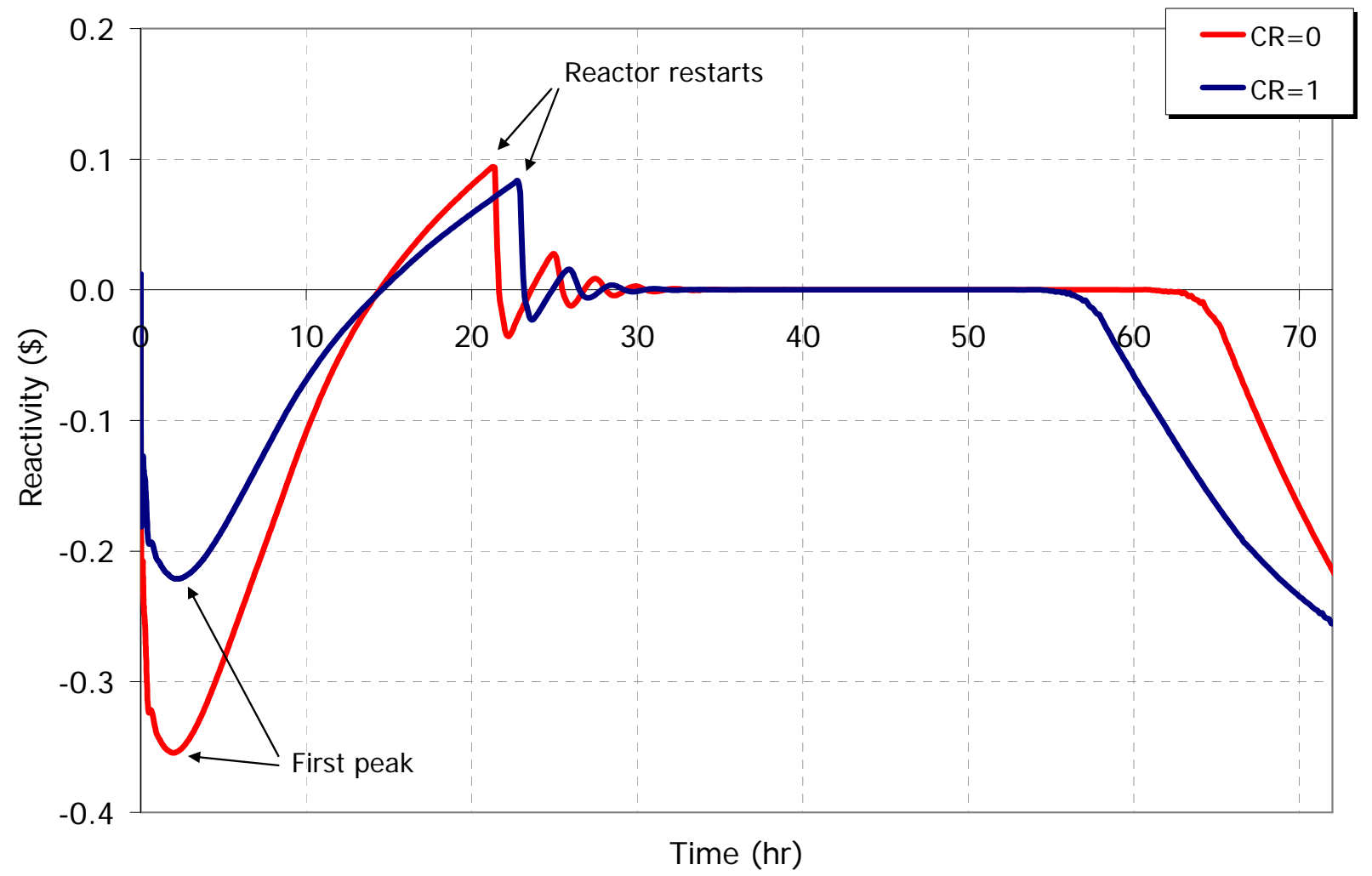

Figure 3.4.2-3 Reactivity during unprotected $\mathrm{SBO}$ for the $\mathrm{CR}=1$ and the $\mathrm{CR}=0$ cores for two PSACS operating trains 
Project No 06-040: Flexible Conversion Ratio Fast Reactor Systems Evaluation

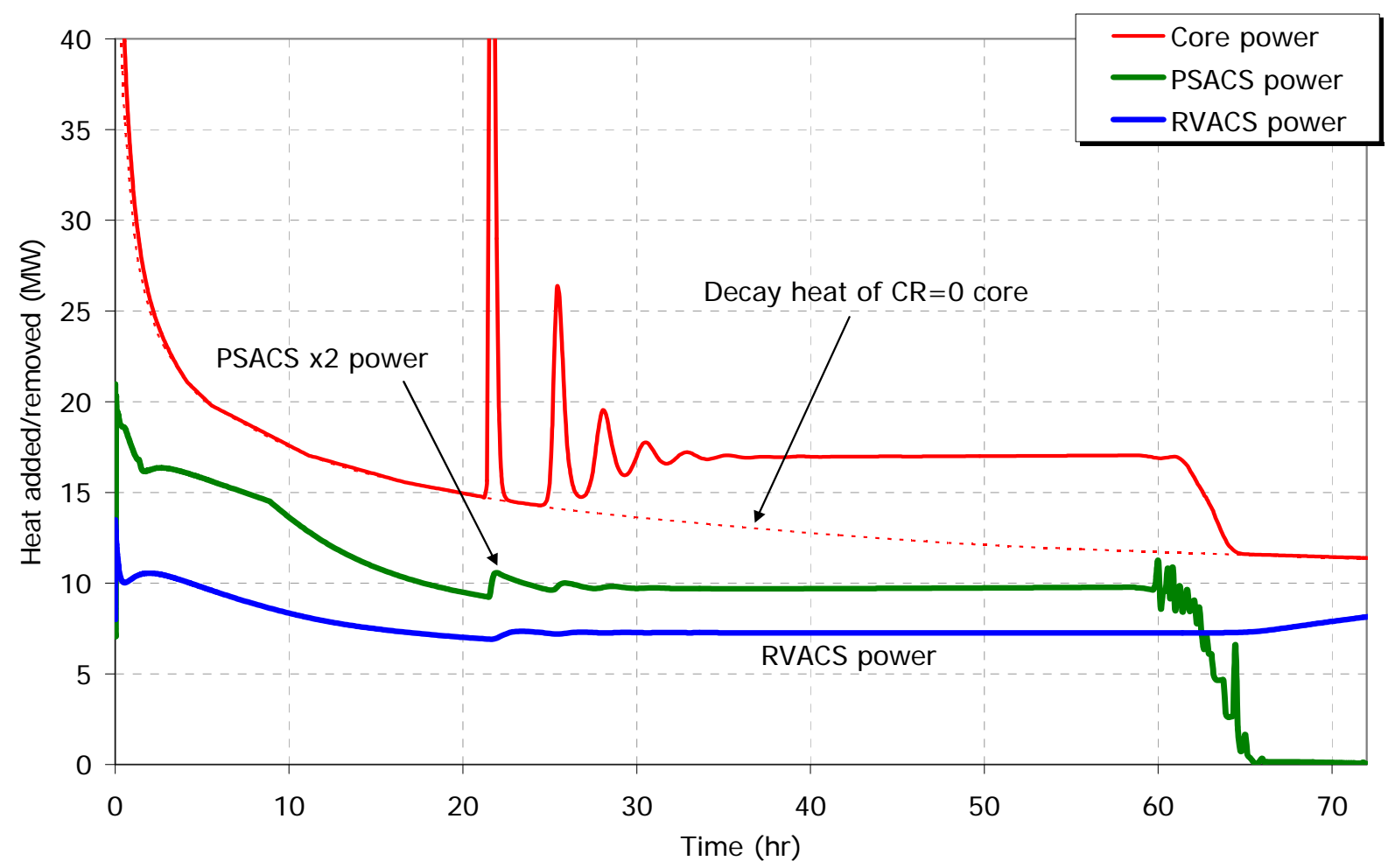

Figure 3.4.2-4 Heat added/removed during SBO with two operating PSACS trains for the CR=0 core

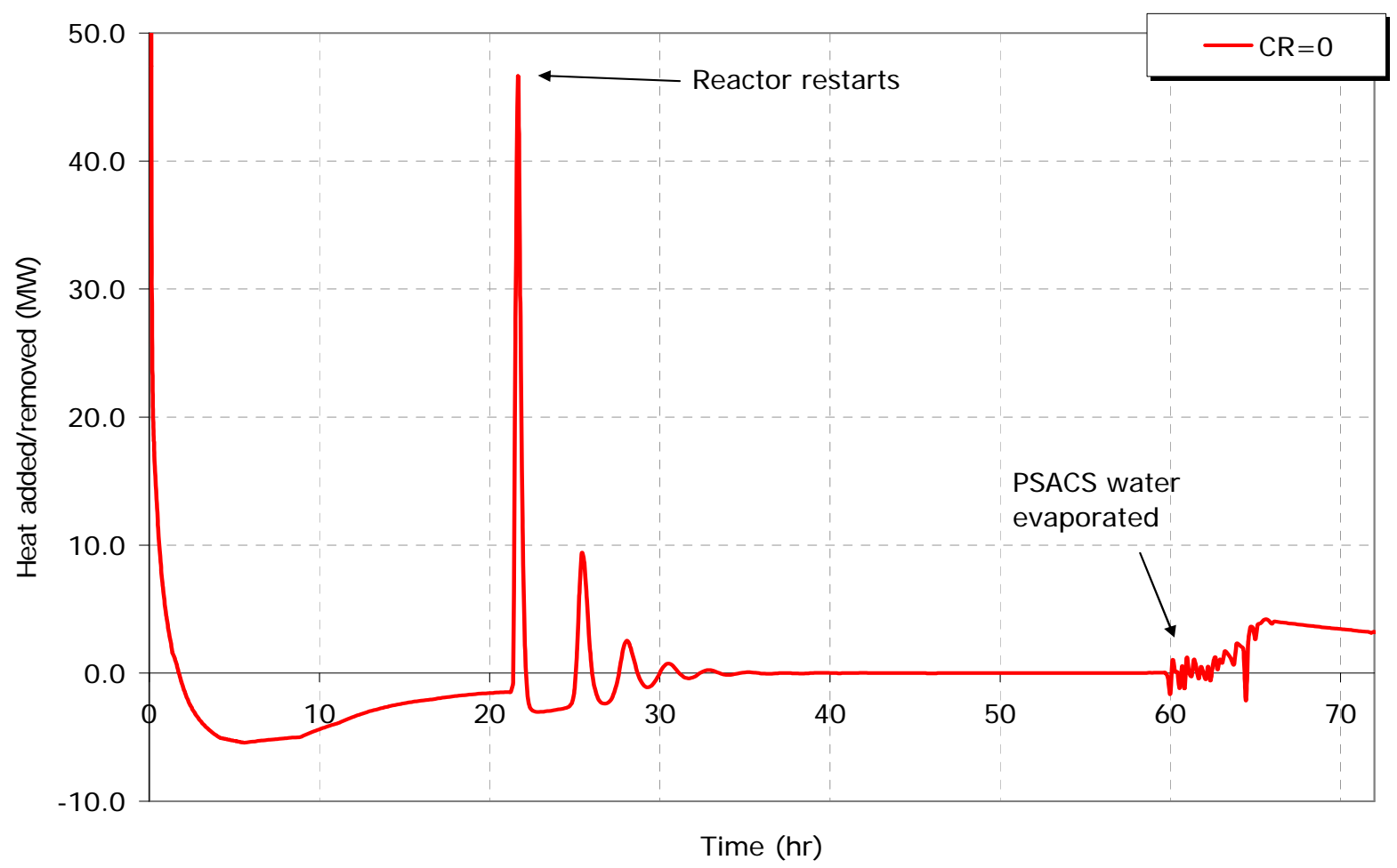

Figure 3.4.2-5 Difference between the core power and heat removed through PSACS and RVACS during unprotected $\mathrm{SBO}$ with two PSACS trains for the $\mathrm{CR}=0$ core 
Project No 06-040: Flexible Conversion Ratio Fast Reactor Systems Evaluation

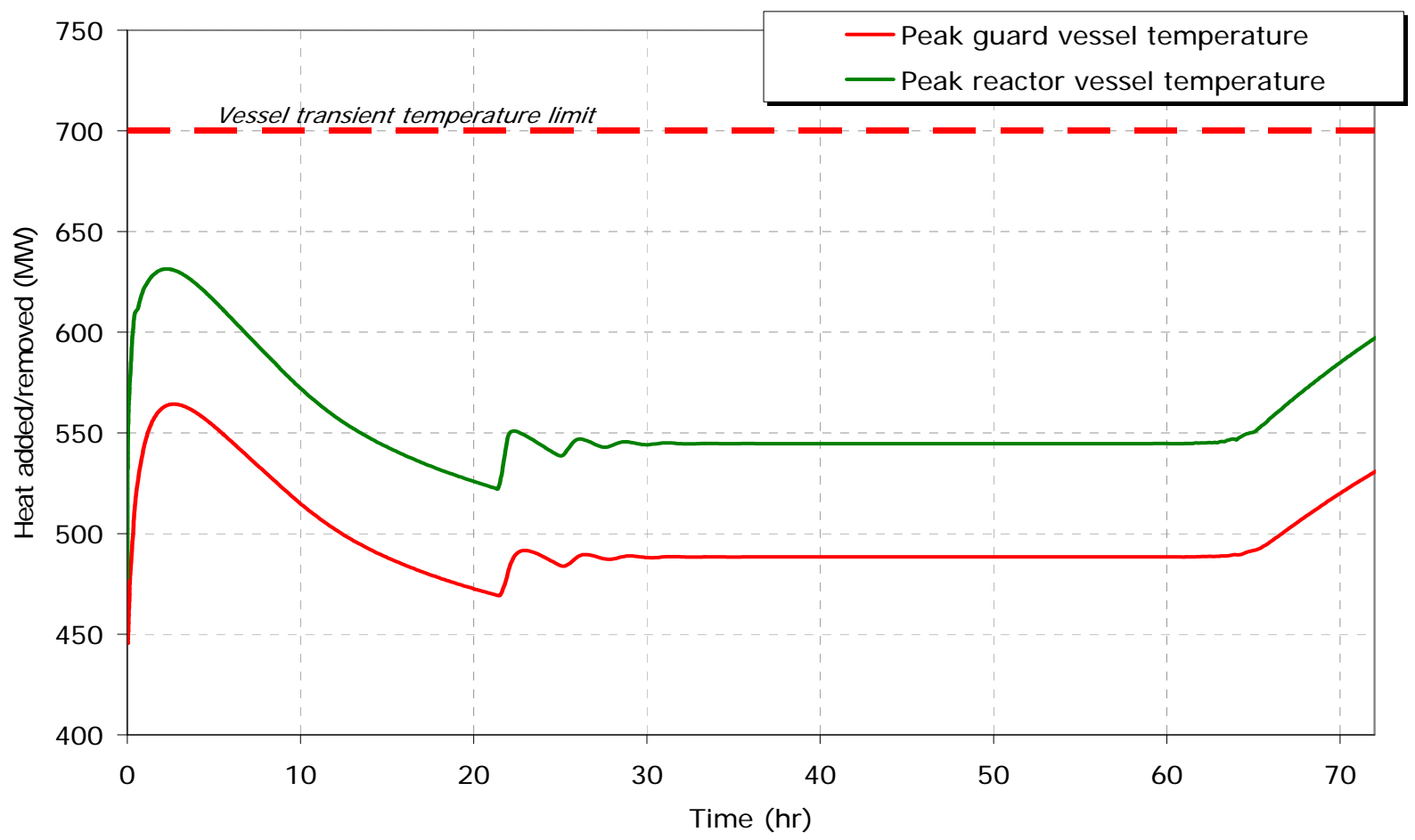

Figure 3.4.2-6 Peak vessel membrane temperature for unprotected SBO with two PSACS trains for the $\mathrm{CR}=0$ core

\subsection{Protected Station Blackout}

The protected station blackout with all trains operating for the zero conversion ratio core is more challenging than the $\mathrm{CR}=1$ case. The challenge arises because the decay heat of the $\mathrm{CR}=0$ is smaller and thus the coolant is more susceptible to overcooling and subsequently freezing. Figure 3.4.2-7 plots peak cladding temperature and the lowest coolant temperature for the $\mathrm{CR}=0$ core. The water in the PSACS tanks has not evaporated during the 72-hour transient. Therefore, the lowest coolant temperature is observed at 72 hours and is equal to $356^{\circ} \mathrm{C}\left(29^{\circ} \mathrm{C}\right.$ margin to freezing.) After 72 hours of transient conditions, it is assumed that the onsite power is restored, and the PSACS can be isolated to avoid later coolant freezing.

Figure 3.4.2-8 compares decay power with the heat rate removed through the RVACS and PSACS, and Figure 3.4.2-9 plots the net heat rate balance between heat generation and removal. It can be observed that the removed heat rate is always larger than the decay heat, confirming the overall decreasing trend of the PCT. Also reactor vessel temperatures remain well below the transient limit, as shown in Figure 3.4.2-10. 
Project No 06-040: Flexible Conversion Ratio Fast Reactor Systems Evaluation

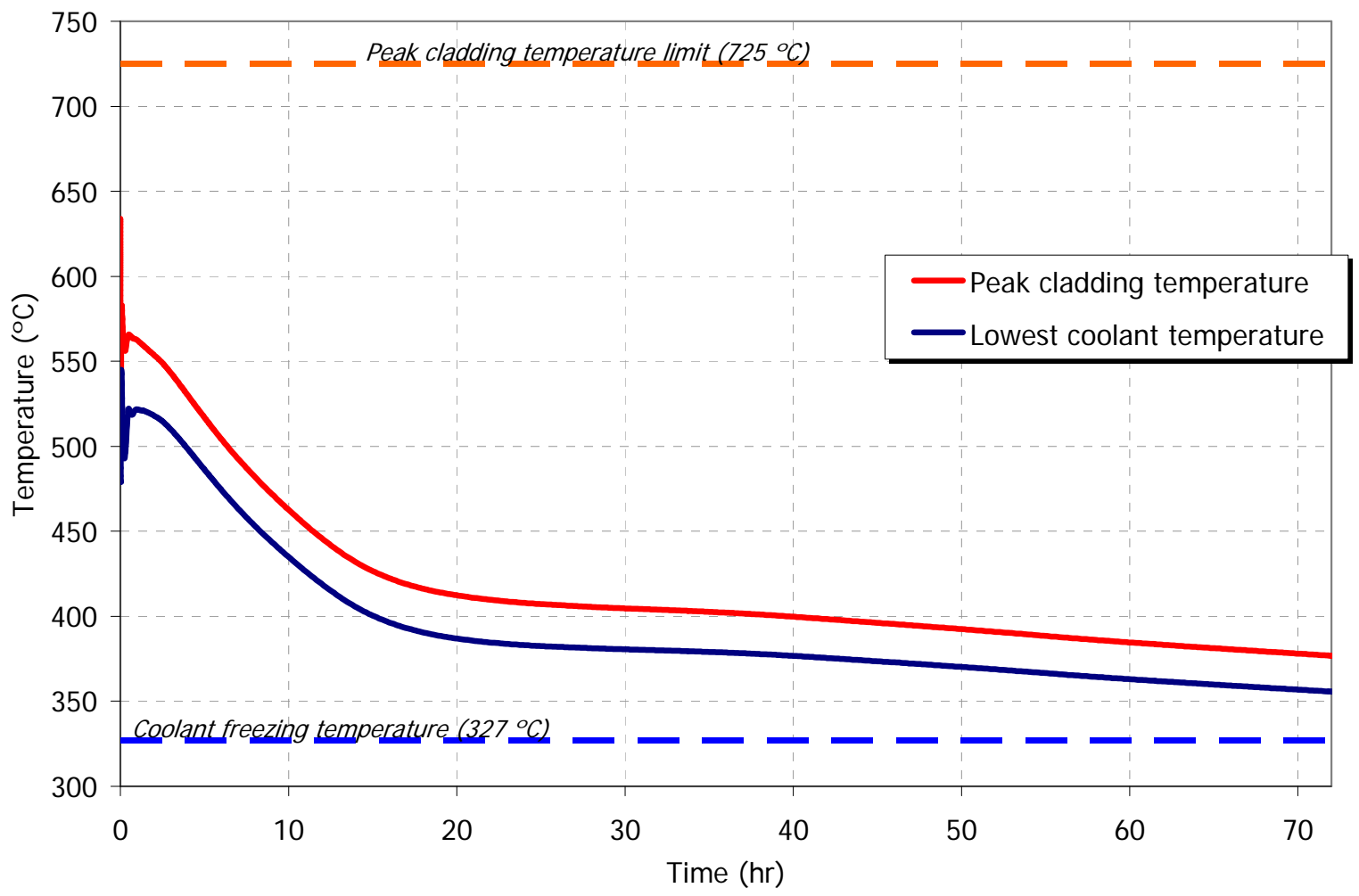

Figure 3.4.2-7 Peak cladding temperature and lowest coolant temperature for protected SBO with four operating trains for the $\mathrm{CR}=0$ core

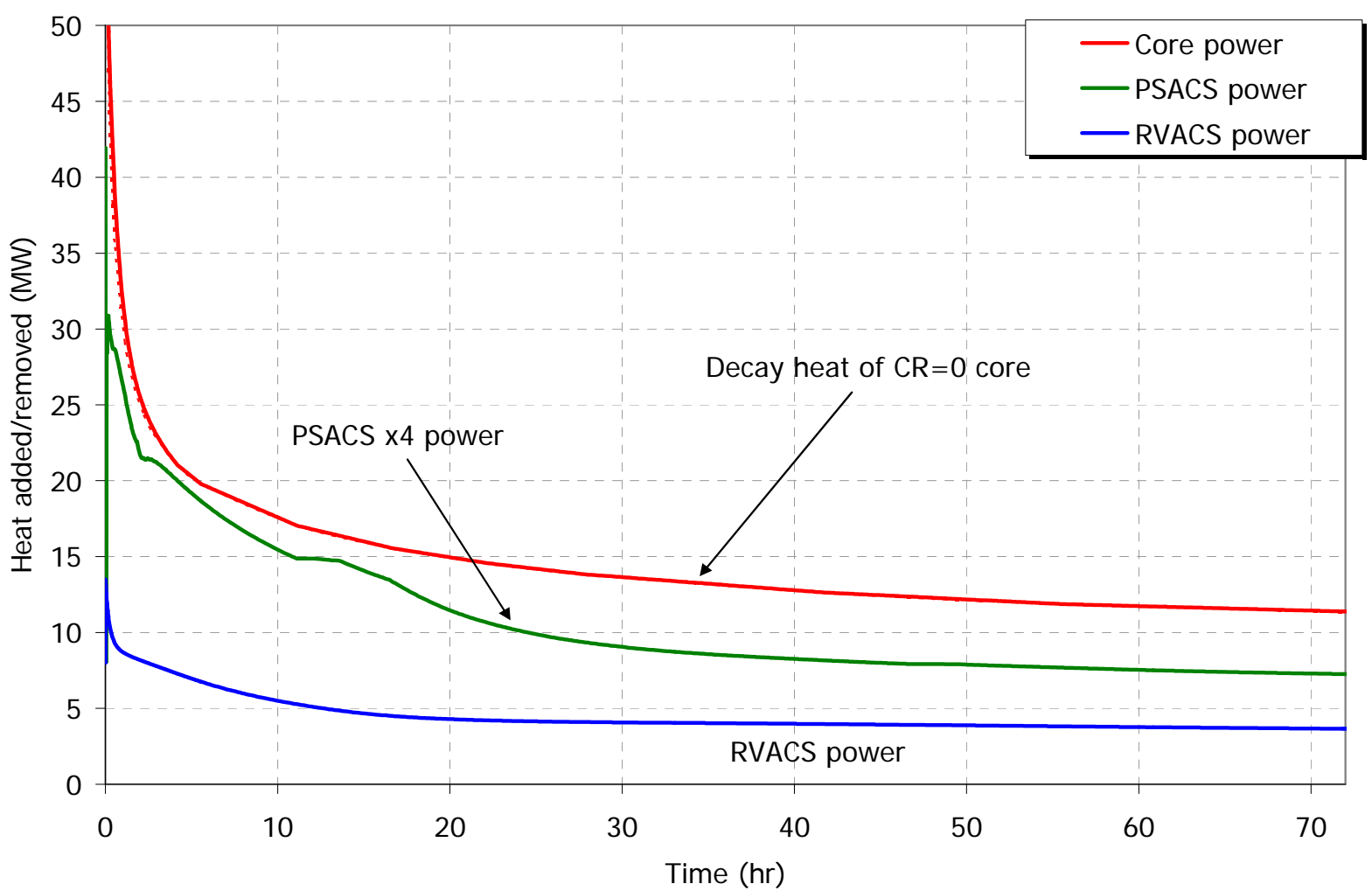

Figure 3.4.2-8 Heat added/removed for protected SBO with four operating PSACS trains $-\mathrm{CR}=0$ 
Project No 06-040: Flexible Conversion Ratio Fast Reactor Systems Evaluation

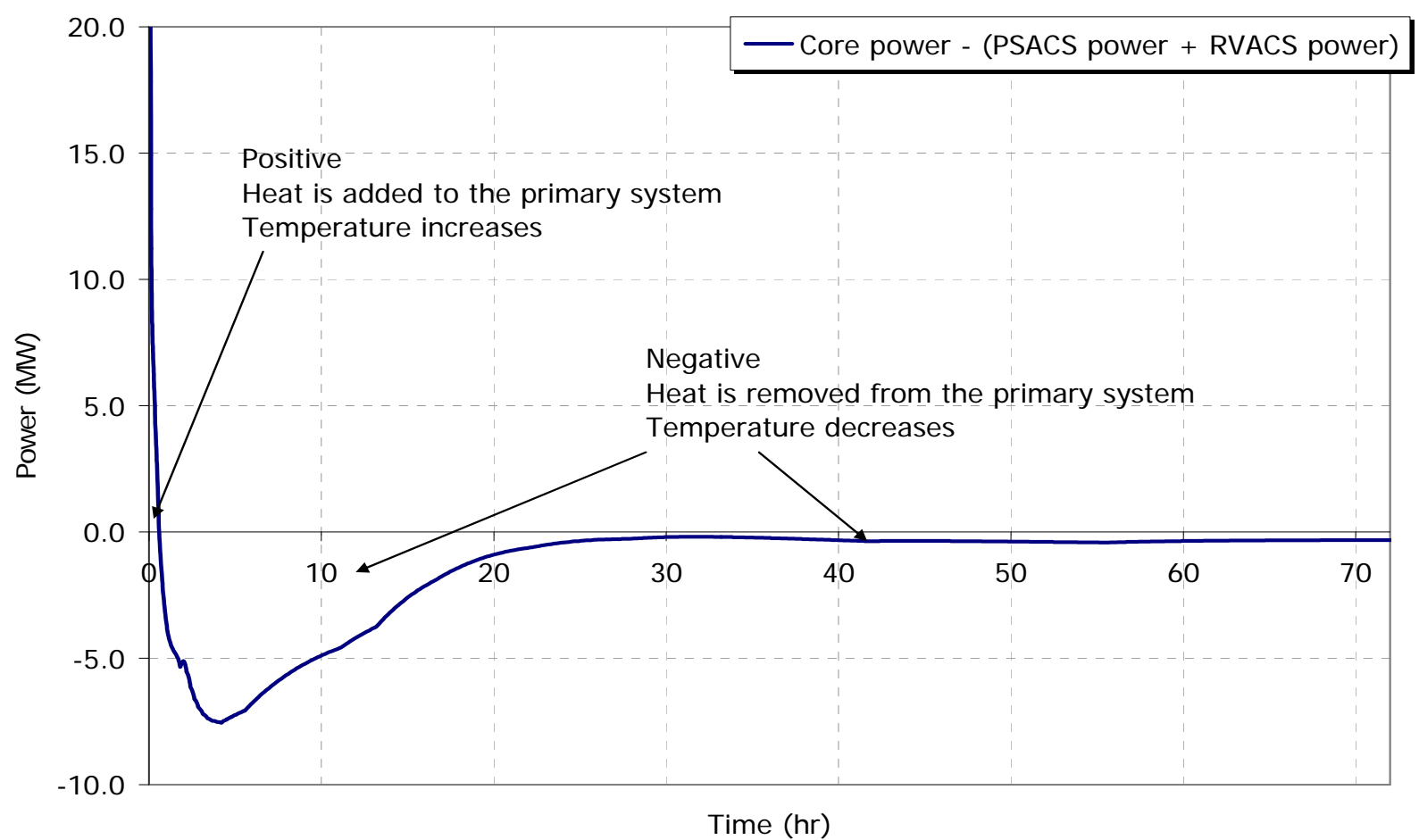

Figure 3.4.2-9 Difference between heat produced by the core and heat removed by the safety systems $(\mathrm{MW})-\mathrm{CR}=0$

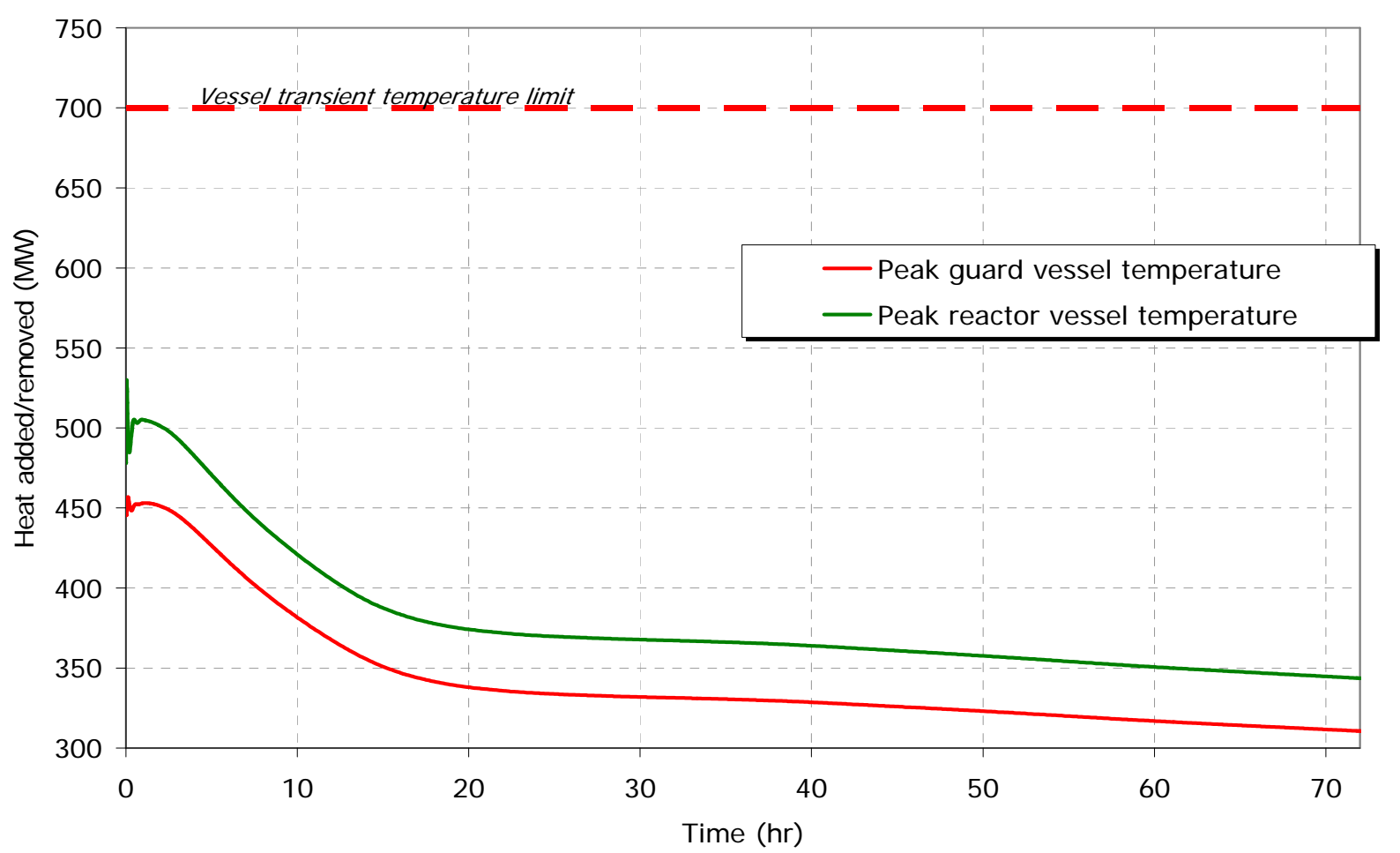

Figure 3.4.2-10 Reactor and guard vessel peak membrane temperature during protected SBO with 4 operating loops $-\mathrm{CR}=0$ 
Project No 06-040: Flexible Conversion Ratio Fast Reactor Systems Evaluation

\subsection{Unprotected Loss of Flow and Overpower Accidents}

The unprotected Loss of Flow and Inadvertent Reactivity Insertion accidents for the $\mathrm{CR}=0$ core are discussed in Section 3.2.2 in parallel with results for the $\mathrm{CR}=1$ core, since it is more instructive to observe differences in the two core responses in the same figures.

\subsection{Conclusions of Lead-cooled Reactor Studies}

Reactor physics analyses of the flexible conversion ratio, $2400 \mathrm{MWt}$, lead-cooled reactor have been completed and the feasibility of both $\mathrm{CR}=0$ and $\mathrm{CR}=1$ cores was established from a neutronics viewpoint.

The analysis performed showed that a sustainable fuel cycle with about 5 tons of makeup natural uranium and no need for additional TRU, while maintaining the desired cycle length, can be achieved without the use of fertile blankets.

The $\mathrm{CR}=1$ lead-cooled core has minimal reactivity control requirements and very flat power distribution with a lifetime maximum radial peaking factor of 1.21 .

The power peaking factors for the $\mathrm{CR}=0$ core are generally larger than those of the $\mathrm{CR}=1$ core. However, they still appear to be manageable with respect to thermal hydraulic performance.

Self-controllability in unprotected accidents of both core options was demonstrated using a quasi-static analysis methodology. Generally, the set of reactivity coefficient ratios for $\mathrm{CR}=0$ and $\mathrm{CR}=1$ cores fall within the ranges that should assure inherent shutdown in unprotected transients. Nevertheless, it is important to note that there are significant uncertainties in the reactivity parameters, both because of MCNP statistical errors and because of uncertainties in cross-section data.

Steady state thermal hydraulic design and analysis of both unity and zero conversion ratio cores confirmed the feasibility of $112 \mathrm{~kW} / 1$ cores to maintain peak cladding temperature within the $650^{\circ} \mathrm{C}$ limit with an appreciable margin. In addition, it was found that it is possible to fit four 600MWt-IHXs in the cavity between the core and the vessel, while keeping an acceptably small temperature difference between the core outlet and turbine inlet temperatures $\left(23^{\circ} \mathrm{C}\right)$ and low $\mathrm{CO}_{2}$ pressure drop $(225 \mathrm{kPa}$ with margin to the target of $500 \mathrm{kPa})$ to maximize plant efficiency. However, it is noted that although the placement of the $2400 \mathrm{MWt}$ core, 4 IHX and 4 pumps within the $10.2 \mathrm{~m}$ diameter vessel appears feasible based on thermal hydraulic considerations, further feasibility study - such as roof mechanics, in-service inspection, seismic analyses, and refueling system design - are necessary to confirm this conclusion.

Transient analysis of both reactor cores was performed for the following three accidents: Unprotected Station Blackout, Unprotected Loss of Flow, and Unprotected Transient Overpower. The protected SBO was also analyzed to confirm existence of a margin to freezing. Both cores showed satisfactory performance during LOFA and UTOP accidents. However, because of the large amount of decay heat generated in the core and reactivity feedback for the shutdown, SBO analysis presented some challenges. An additional safety system for decay heat 
removal, the Passive Safety Auxiliary Cooling System (PSACS), was designed. The PSACS design was optimized with a small PSACS heat exchanger and a very large water tank. Such a design prevented the PCT from crossing the limit while maintaining the coolant temperature above freezing at any combination of accident conditions (protected vs. unprotected) and number of operating trains (two, three, or four.) Figure 3.5-1 summarizes the combinations of limiting conditions for an SBO accident. The simulation of the accident with different conditions showed that surviving the Station Blackout Accident for both cores, for both protected and unprotected conditions for up to 72 hours without exceeding the limits, is possible.

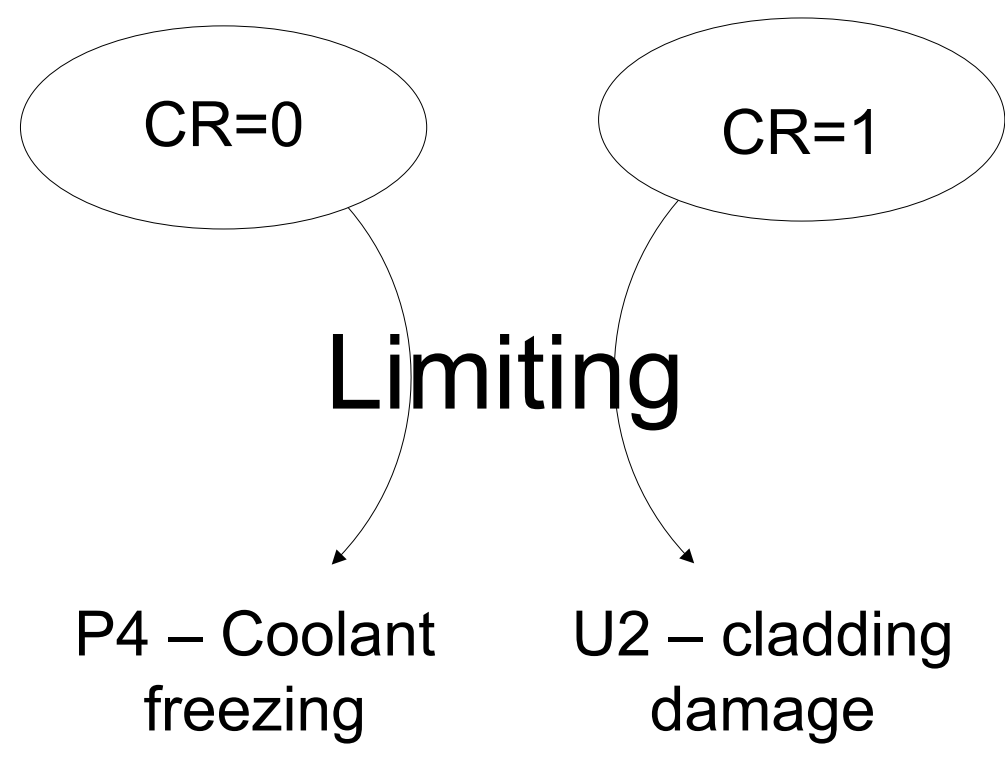

Figure 3.5-1 Limiting conditions for SBO accfident. 


\subsection{References for Chapter 3}

Adamov E., Orlov V., Filin A., Tsikunov V., Sila-Novitski A., Smirnov V., and Leonov V., "Conceptual Design of BREST-300 Lead-Cooled Fast Reactor," Proc. Int. Topl. Mtg. Advances in Reactor Safety (ARS'94), Pittsburgh, Pennsylvania, April 17-21, 1994.

American National Standard "Decay Heat Power in Light Water Reactors," ANSI/ANS-5.12005.

Bergles, A. E., Ravigururajan, T. S., Development and Verification of General Correlations for Pressure Drop and Heat Transfer in Single-Phase Turbulent Flow in Enhanced Tubes, Experimental Thermal and Fluid Science 13, 55-70, 1996

Boardman C., Dubberley A., Carrol D., Hui M., Fanning A., and Kwant W., "A Description of the S-PRISM Plant," Proceedings of ICONE 8, Baltimore, MD, USA, 2000.

Briesmeister J. F. (Ed.), "MCNP ${ }^{\mathrm{TM}}$ - A General Monte Carlo N-Particle Transport Code, Version 4C,” LA-13709M, Los Alamos National Laboratory, April 2000.

Croff, A. G., "ORIGEN2: A Versatile Computer Code for Calculating the Nuclide Compositions and Characteristics of Nuclear Materials," Nucl. Techn. 62, 335-352, 1983.

Duderstadt J., Hamilton L.: Nuclear Reactor Analysis, John Wiley and Sons. Inc. New York, 1976.

Fridman E., Shwageraus E., Galperin A., "Implementation of multi-group cross-section methodology in BGCore MC-depletion code," Proc. of Physor-2008, Interlaken, Switzerland, September 2008 .

Handwerk C. S., Driscoll M. J., Hejzlar P., "Use of Beryllium Oxide to Shape Power and Reduce Void Reactivity in Gas-cooled Fast Reactors," PHYSOR 2006, Vancouver, Canada, September 10-14, 2006.

Hejzlar P., Buongiorno J., MacDonald P. E., Todreas N. E., "Design Strategy and Constraints for Medium-Power Lead-Alloy-Cooled Actinide Burners," Nuclear Technology, 147, 3, pp. 321343, 2004.

Hill R.N., Wade D.C. Liaw J.R. and Fujita E.K., "Physics Studies of Weapons Plutonium Disposition in the Integral Fast Reactor Closed Fuel Cycle," Nucl. Sci. Eng. Vol., 121, pp. 17-31, 1995.

IAEA TECDOC 626, “Safety Related Terms for Advanced Nuclear Plants” September, 1991

MacDonald P. et al., "Design of an Actinide Burning, Lead or Lead-Bismuth Cooled Reactor That produces Low Cost Electricity," INEEL/EXT-02-01249, MIT-ANP-PR-092, Idaho National Engineering and Environmental Laboratory, FY-02 Annual Report, (Oct. 2002). 
Project No 06-040: Flexible Conversion Ratio Fast Reactor Systems Evaluation

RELAP5-3D Code Development Team, "RELAP5-3DC Code Manual Volume 1: Code Structure, System Models and Solution Methods," INEEL-EXT-98-00834-V1 Revision 2.3, Idaho National Engineering and Environmental Laboratory, 2005.

Ravigururajan, T. S., A Comparative Study of Thermal Design Correlations for Turbulent Flow in Helical-Enhanced Tubes, Heat Transfer Engineering 20, 54-70, 1999

Romano A., Hejzlar P., and Todreas N. E., "Fertile-Free Fast Lead-Cooled Incinerators for Efficient Actinide Burning,” Nuclear Technology, 147, 3, pp. 368-387, 2004.

Shwageraus E., Fridman E., Abramski E., Galperin A., BGCore - A Comprehensive Package for Reactor Core and Fuel Storage Analysis, Proc. of 23rd Conference of the Nuclear Societies in Israel, Dead Sea, Israel, February 15-16, (2006).

Wade D.C., Wigeland R.A., Hill D.J., "The safety of the IFR”, Progress in Nuclear Energy, Vol. 31, No. $1 / 2$, pp. 63-82, 1997

Wade, D.C., Chang, Y.I., "The Integral Fast Reactor Concept: Physics of Operation and Safety”, Nuclear Science and Engineering, 100, 507-524, 1988.

Wade D.C. and Fujita E.K., "Trends Versus Reactor Size of Passive Reactivity Shutdown and Control Performance," Nuclear Science and Engineering, Vol. 103, pp. 182-195, 1989.

Xu, Z., Hejzlar, P., Driscoll, M.J., Kazimi, M.S., “An Improved MCNP-ORIGEN Depletion Program (MCODE) and its Verification for High-Burnup Applications," PHYSOR-2002, Seoul, Korea, (2002). 


\section{Liquid Salt-cooled Fast Reactor (LSFR) Designs}

Contrary to the lead-cooled reactor described in Chapter 3, which employs a familiar and well defined coolant, the liquid salt-cooled reactor is a new concept that requires broad investigation to identify the best salt for the fast spectrum high power density core and the optimum geometry to meet the project design goals and constraints. Therefore, this Chapter starts with an overview of various salt candidates and the selection of the most promising salt and determination of its properties. The $\mathrm{CR}=1$ core neutronic design is discussed in Section 4.2. Since it took considerable effort to overcome the challenge of a large positive coolant temperature reactivity coefficient, this section starts with the overview of various core designs considered. Next, the two successful core designs using Lithium thermal Expansion Modules (LEMs) are presented one for a power density of $100 \mathrm{~kW} / 1$ and one for $130 \mathrm{~kW} / 1$. The $130 \mathrm{~kW} / 1$ core was selected as the reference core, for which detailed neutronic and thermal hydraulic analyses were performed as described in Sections 4.2.1 and 4.2.2. Section 4.3 describes the neutronic and thermal hydraulic performance of $130 \mathrm{~kW} / 1$ core with $\mathrm{CR}=0$.

\subsection{Selection of the Most Promising Salt Candidate}

The initial list of potential liquid salt candidates is given in Appendix 4A.1. Fluoride salt selection was performed in two stages (see Appendix 4A.2 for more details). In the first stage, the fluoride salts were reviewed and $\mathrm{KF}-\mathrm{ZrF} 4$ and $\mathrm{NaF}-\mathrm{KF}-\mathrm{ZrF} \mathrm{r}_{4}$ were identified to be the two most promising fluoride candidates. Fluoride salt selection involved first eliminating salts containing rubidium, boron, and lithium. Boron and lithium would require isotopic enrichment for use in a fast reactor, and there is currently no world market for rubidium; therefore, salts containing these elements would be prohibitively expensive at the scale required. This first screening eliminated most of the possible candidates, leaving just one beryllium salt, $\mathrm{NaF}-\mathrm{BeF}_{2}$, and three zirconium salts: NaF-ZrF, $\mathrm{KF}_{4} \mathrm{ZrF}_{4}$, and NaF-KF-ZrF ${ }_{4}$. Neutronic and thermal hydraulics analyses on $\mathrm{NaF}-\mathrm{BeF}_{2}$ revealed that it is far too moderating and viscous for use in fast reactor applications. The melting point of $\mathrm{NaF}_{-} \mathrm{ZrF}_{4}, 500^{\circ} \mathrm{C}$, is too close to the cladding temperature limit of $650^{\circ} \mathrm{C}$ to allow an acceptable power density. This left $\mathrm{KF}_{-} \mathrm{ZrF}$ and $\mathrm{NaF}$ $\mathrm{KF}-\mathrm{ZrF}_{4}$ as the primary fluorides of interest. While both salts have similar properties, the ternary salt was the most promising fluoride candidate because of its lower melting point.

In the second stage, chloride salts were reviewed using a similar salt selection process. Salts containing lithium were eliminated because the high absorption cross section of Li- 6 would necessitate isotopic enrichment, which would be prohibitively expensive at the scale required. This left $\mathrm{NaCl}-\mathrm{MgCl}_{2}, \mathrm{KCl}-\mathrm{MgCl}_{2}$, and $\mathrm{NaCl}-\mathrm{KCl}-\mathrm{MgCl}_{2}$ as the three salt systems of interest. For the $\mathrm{NaCl}-\mathrm{MgCl}_{2}$ system, there is only enough information available about the $58 \% \mathrm{NaCl}-$ $42 \% \mathrm{MgCl}_{2}$ eutectic to permit analysis. These three salt mixtures all have similar thermal hydraulic and neutronic properties. Since thermal hydraulics were limiting for fluorides, the thermal hydraulics analysis described in this report was performed for each salt to determine the most promising candidate. Results for a number of previous core designs were given in past quarterly reports; a summary of the results for the latest and most promising reference design is given in Table 4.1-1. Fixed conditions were used, including a $700 \mathrm{kPa}$ core pressure drop and 
coolant inlet temperature $100^{\circ} \mathrm{C}$ above the melting point. Included for comparison are values for the most promising fluoride candidate, $\mathrm{NaF}-\mathrm{KF}-\mathrm{ZrF}_{4}$.

Fluoride salts were unable to meet the desired power density target of $100 \mathrm{~kW} / 1$ because of thermal hydraulic limitations. The fluoride with the most favorable thermal hydraulic properties, NaF-KF-Z $\mathrm{rF}_{4}(10 \%-48 \%-42 \%)$, could only allow a power density of $70 \mathrm{~kW} / 1$ even for the looserlattice reference design. Higher power densities cause the cladding temperature limit of $650^{\circ} \mathrm{C}$ to be exceeded. In addition, neutronic analysis in the third quarterly report [Todreas et al., 2007] showed that the coolant temperature reactivity coefficient was a greater problem for fluoride salts than for chloride salts, the issue which requires the inclusion of lithium expansion modules (LEMs), as described in the neutronics section.

Table 4.1-1 Achievable reactor characteristics

\begin{tabular}{|l|c|c|c|c|}
\hline Coolant salt & $\begin{array}{c}\mathrm{NaF}-\mathrm{KF}- \\
\mathrm{ZrF}_{4}\end{array}$ & $\begin{array}{c}\mathrm{NaCl}- \\
\mathrm{MgCl}_{2}\end{array}$ & $\begin{array}{c}\mathrm{KCl}- \\
\mathrm{MgCl}_{2}\end{array}$ & $\begin{array}{c}\mathrm{NaCl}- \\
\mathrm{KCl}_{-} \mathrm{MgCl}_{2}\end{array}$ \\
\hline Total power $(\mathrm{MWt})$ & 1302 & 2076 & 2301 & 2516 \\
\hline Power density $(\mathrm{W} / \mathrm{cc})$ & $\mathbf{7 0}$ & $\mathbf{1 1 2}$ & $\mathbf{1 2 4}$ & $\mathbf{1 3 5}$ \\
\hline Average power per pin $(\mathrm{W})$ & $7.50 \times 10^{3}$ & $1.20 \times 10^{4}$ & $1.33 \times 10^{4}$ & $1.45 \times 10^{4}$ \\
\hline Coolant inlet temperature $\left({ }^{\circ} \mathrm{C}\right)$ & 496 & 545 & 526 & 496 \\
\hline Average coolant outlet temperature $\left({ }^{\circ} \mathrm{C}\right)$ & 532 & 598 & 583 & 572 \\
\hline Hot assembly outlet temperature $\left({ }^{\circ} \mathrm{C}\right)$ & 535 & 602 & 588 & 578 \\
\hline Coolant mass flow rate through core $(\mathrm{kg} / \mathrm{s})$ & $3.31 \times 10^{4}$ & $3.63 \times 10^{4}$ & $3.47 \times 104$ & $3.28 \times 10^{4}$ \\
\hline Pumping power $(\mathrm{MW})$ & 8 & 13 & 12 & 12 \\
\hline Hot channel/hot spot characteristics: & & & & \\
\hline Inlet coolant velocity $(\mathrm{m} / \mathrm{s})$ & 2.70 & 4.49 & 4.33 & 4.38 \\
\hline Reynolds number & $3.19 \times 10^{3}$ & $1.95 \times 10^{4}$ & $1.38 \times 104$ & $1.31 \times 10^{4}$ \\
\hline Nusselt number & 39.7 & 114.8 & 102.6 & 92.6 \\
\hline Heat transfer coefficient $\left(\mathrm{W} / \mathrm{m}^{2} \mathrm{~K}\right)$ & $3.86 \times 10^{3}$ & $1.50 \times 10^{4}$ & $1.22 \times 104$ & $1.10 \times 10^{4}$ \\
\hline Maximum film $\Delta \mathrm{T}(\mathrm{K})$ & 103.7 & 42.6 & 58.2 & 70.5 \\
\hline
\end{tabular}

Chloride salt thermal hydraulic performance is greatly superior to that of fluoride salts. The primary reason for this is an approximately five times lower viscosity over the operating temperatures of interest. Low viscosity improves coolant flow rate and heat transfer, as seen by the much higher coolant velocities and much lower film $\Delta$ Ts shown in Table 4.1-1. In addition, chloride salts exhibit significantly smaller coolant temperature reactivity coefficients than fluoride salts, due to their smaller thermal expansion coefficient and smaller moderating power. Each of the selected chloride salts performs similarly well, with the ternary $\mathrm{NaCl}-\mathrm{KCl}-\mathrm{MgCl}_{2}$ yielding the best performance because of its lower melting point. Moreover, $\mathrm{NaCl}-\mathrm{KCl}-\mathrm{MgCl}_{2}$ salt has a significantly smaller coolant temperature reactivity coefficient and a higher reactivity at the same TRU enrichment than that of the best-performing fluoride salt. Because of its superior thermal hydraulic and neutronic performance, the ternary salt $\mathrm{NaCl}-\mathrm{KCl}-\mathrm{MgCl}_{2}$ has been selected as the most promising salt candidate for the liquid salt FCR reactor and is the salt used in the reference design. 


\subsubsection{Properties of the Most Promising Salt Candidate}

The assumed properties for $\mathrm{NaCl}-\mathrm{KCl}-\mathrm{MgCl}_{2}$ are given in Table 4.1-2, with identification of the methods used to obtain them.

Melting point, density, and viscosity are all given in a 1960 BNL report [Raseman et al., BNL$627,1960]$ on fused chloride salts. Because density and viscosity are relatively straightforward to measure, the values given can be used with reasonable certainty.

Heat capacity is estimated using a mole fraction average, using the constituent values recommend in Janz's Molten Salts Handbook [1967]: $22 \mathrm{~W} / \mathrm{mol}-\mathrm{K}$ for $\mathrm{MgCl}_{2}, 16 \mathrm{~W} / \mathrm{mol}-\mathrm{K}$ for $\mathrm{NaCl}$ and $\mathrm{KCl}$. A simple mole fraction average is used because non-ideal behavior may be complex, and there is insufficient data to predict such behavior. The value obtained is slightly less than that given by the Dulong-Petit prediction, which gives a heat capacity of $8 \mathrm{~W} / \mathrm{mol}-\mathrm{K}$ per atom. The thermal expansion coefficient is important for neutronic calculations since it affects the CTC. Measured values from Raseman et al. [1960] were used.

Table 4.1-2 Assumed NaCl-KCl- $\mathrm{MgCl}_{2}$ (30-20-50) physical properties.

\begin{tabular}{|l|c|l|}
\hline \multicolumn{1}{|c|}{ Property } & \multicolumn{1}{|c|}{ Value } & \multicolumn{1}{|c|}{ Method of obtaining } \\
\hline Melting point $\left({ }^{\circ} \mathrm{C}\right)$ & 396 & $\begin{array}{l}\text { Measured value from BNL } \\
\text { report }\end{array}$ \\
\hline Density $\left(\mathrm{kg} / \mathrm{m}^{3}\right)$ & exp $(3040 / \mathrm{T}(\mathrm{K})-2.96)$ & $\begin{array}{l}\text { Measured value from BNL } \\
\text { report }\end{array}$ \\
\hline Dynamic viscosity $(\mathrm{cP})$ & 0.24 & $\begin{array}{l}\text { Mole fraction average } \\
\text { report }\end{array}$ \\
\hline Heat capacity $(\mathrm{cal} / \mathrm{gK})$ & 0.043 & $\begin{array}{l}\text { Measured value from BNL } \\
\text { report }\end{array}$ \\
\hline $\begin{array}{l}\text { Thermal expansion coefficient } \\
(\% \text { vol/K) }\end{array}$ & 0.39 & $\begin{array}{l}\text { Mole fraction average for } \\
\text { KCl- } \mathrm{MgCl}_{2}(50-50)\end{array}$ \\
\hline Thermal conductivity $(\mathrm{W} / \mathrm{m}-\mathrm{K})$ & &
\end{tabular}

Raseman et al. [1960].

Thermal conductivity is the property with the most uncertainty, largely because there is almost no thermal conductivity data on $\mathrm{MgCl}_{2}$ or its mixtures. Only one 1974 paper by Polyakov and Gildebrandt [1974] was found to measure conductivities of $\mathrm{MgCl}_{2}$ salts. However, the thermal conductivities it quotes for $\mathrm{KCl}$, a commonly measured salt, are anomalously high. Several approaches were taken to produce a range of estimates for thermal conductivity. First, one can use the approach taken by Williams and Toth [2006b] to estimate the thermal conductivities of $\mathrm{NaCl}-\mathrm{MgCl}_{2}$ and $\mathrm{KCl}-\mathrm{MgCl}_{2}$. Williams estimated the thermal conductivity of $\mathrm{MgCl}_{2}$ based on its formula weight (he obtained $0.39 \mathrm{~W} / \mathrm{m}-\mathrm{K}$ ), and took a mole fraction average of this with the conductivities of $\mathrm{NaCl}$ and $\mathrm{KCl}$. The value of thermal conductivity obtained in this way for $\mathrm{KCl}-\mathrm{MgCl}_{2}$ (50-50) can be used as a conservative estimate for the thermal conductivity of NaCl$\mathrm{KCl}-\mathrm{MgCl}_{2}$ (30-20-50) because there is a clear trend of increasing thermal conductivity with decreasing formula weight. The value of thermal conductivity obtained using this method is $\mathbf{0 . 3 9}$ $\mathbf{W} / \mathbf{m}-\mathbf{K}$, and is the one adopted by this study, mainly because it is consistent with the thermal conductivity values given for the other chloride salts. 
Other methods to estimate the thermal conductivity of $\mathrm{NaCl}-\mathrm{KCl}-\mathrm{MgCl}_{2}$ incorporate the data given in Polyakov and Gildebrandt [1974]. This is done by multiplying all the Polyakov data by a constant such that its $\mathrm{KCl}$ thermal conductivity values agree with those of reliable modern measurements. Doing this, one obtains a thermal conductivity for $\mathrm{KCl}-\mathrm{MgCl}_{2}$ (50-50) of about $\mathbf{0 . 2 5} \mathbf{W} / \mathbf{m}-\mathbf{K}$, which may again be taken as a conservative value for the ternary. Alternately, one can use the scaled value for $\mathrm{KCl}-\mathrm{MgCl}_{2}(20-80)$ of $0.17 \mathrm{~W} / \mathrm{m}-\mathrm{K}$, and average it with the known conductivities of $\mathrm{NaCl}$ and $\mathrm{KCl}$ to produce a value for the desired ternary composition. Doing this yields a thermal conductivity of around $0.28 \mathrm{~W} / \mathbf{m}-\mathbf{K}$.

Short of performing a measurement, there appears to be no reliable method to obtain thermal conductivities for salts containing $\mathrm{MgCl}_{2}$ at this time. Williams' method relies on an estimate based on formula weight, while methods using the Polyakov data rely on older data and an untested scaling method. Similar concerns can be raised for the other properties: viscosity and density are based on a single 1960 reference, and the mole fraction average used to estimate heat capacity is similar to the Dulong-Petit prediction, which has an uncertainty of around $20 \%$ [Williams 2006a]. Because of the central position of salt properties to the following analyses, present-day measurements to confirm these values would be an economical way to reduce uncertainty.

To quantify the significance of these property uncertainties, sensitivity studies were performed to determine the maximum power density achievable for different values of density, viscosity, thermal conductivity, and heat capacity. Each property was varied from $50 \%$ to $200 \%$ of the value assumed in this report, and the reference core design reanalyzed. Results are given in Figure 4.1-1.

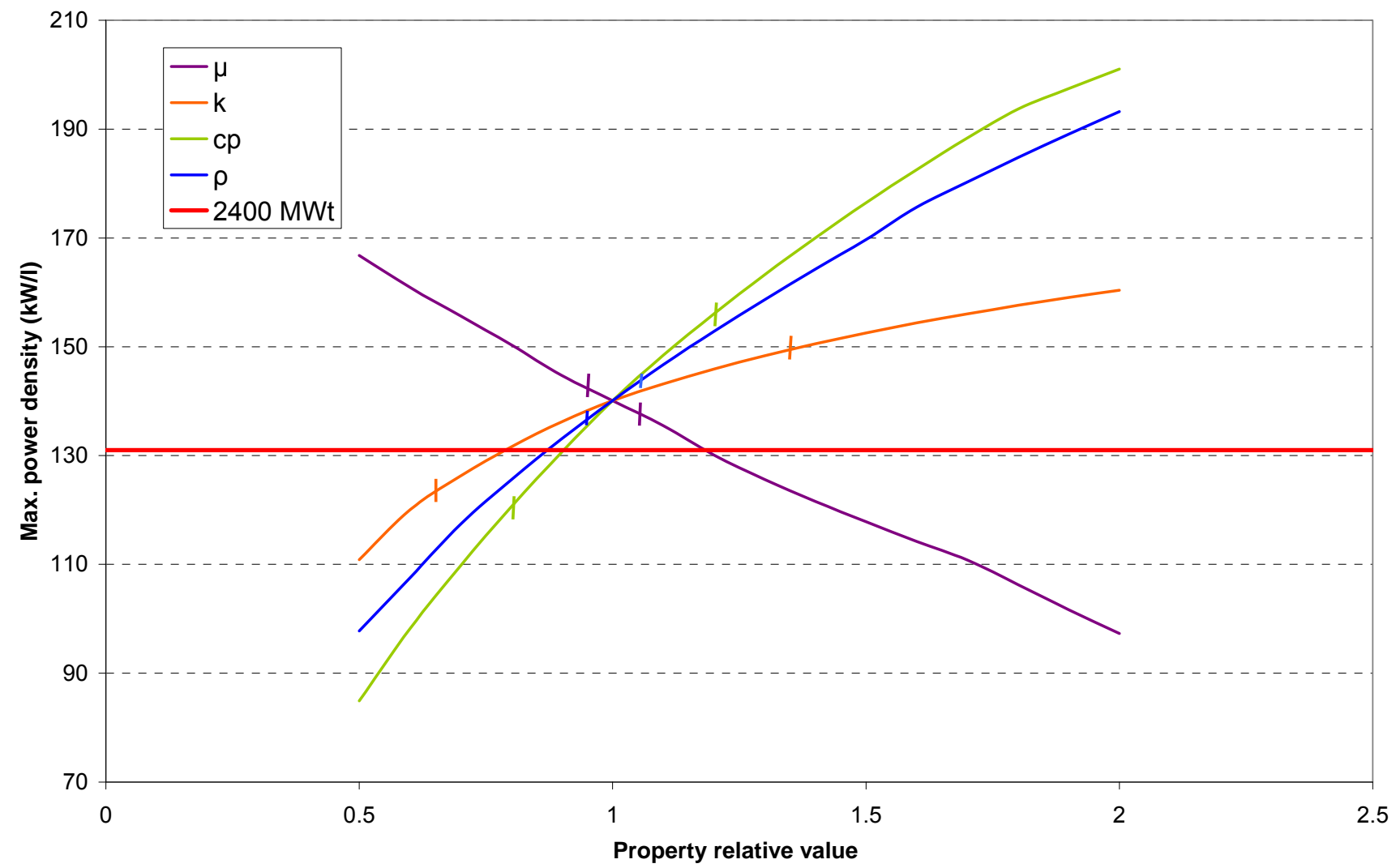

Figure 4.1-1 Power density vs. $\mathrm{NaCl}-\mathrm{KCl}-\mathrm{MgCl}_{2}$ property values. 
The red line denotes the power density that allows the target power rating of $2400 \mathrm{MWt}$ to be achieved for the reference geometry. Using the assumed nominal property values yields a power density above this line because the reference design has a maximum cladding temperature below the $650^{\circ} \mathrm{C}$ limit, allowing some margin for the power to be increased beyond $2400 \mathrm{MWt}$. The small vertical lines correspond to the likely uncertainties for each of the property values. Viscosity measurements from around 1960 give errors of 5\% or lower, suggesting a similar uncertainty in the value used for the ternary chloride adopted. Density measurements from 1960 are similarly reliable, so the density uncertainty also should not be more than $5 \%$. As mentioned, uncertainty in heat capacity may be as large as $20 \%$, the uncertainty of the Dulong-Petit prediction. Finally, the conservative estimate for thermal conductivity $(0.25 \mathrm{~W} / \mathrm{m}-\mathrm{K})$, is about $35 \%$ lower than the assumed value $(0.39 \mathrm{~W} / \mathrm{m}-\mathrm{K})$, so an uncertainty of $35 \%$ is assigned to thermal conductivity.

Figure 4.1-1 shows that low values of thermal conductivity or heat capacity may make the target power level of $2400 \mathrm{MWt}$ unachievable for the current smaller reference core design. The large uncertainties in these two properties are therefore the most in need of addressing. However, it should be noted that, despite property uncertainties, the power density target of $100 \mathrm{~kW} / \mathrm{l}$ can still be achieved even for some adverse changes from nominal values of these two parameters.

As part of modeling the salt reactor design in RELAP, salt properties for $\mathrm{NaCl}-\mathrm{KCl}-\mathrm{MgCl}_{2} \mathrm{were}$ implemented into RELAP. To do so, additional unmeasured properties such as vapor pressure and isothermal compressibility also needed to be included. However, since conditions in the salt reactor do not approach either the saturation line or sonic velocities, the specific value of these properties does not affect RELAP results. Therefore, reasonable estimates for these properties based on those of other liquid salts were used.

Chemical and corrosion characteristics are also important factors in evaluating the viability of a coolant. Chemically, liquid salts act as fluxing agents which prevent oxide film formation. The lack of a chemically passive film makes coolant chemistry control particularly important for liquid salt systems, and while this is easy to accomplish for fluoride salts it is somewhat more difficult for chlorides [Forsberg, 2007]. Corrosion characteristics of the selected ternary chloride are presented in another 1960 BNL report [Susskind et al., BNL-585, 1960], which states that the chloride produces no serious corrosion in most of the steels tested, including a Cr-Mo steel that may be comparable to the T-91 steel used in this design. The general chemical compatibility of liquid salts with structural materials makes it reasonable to expect that no major corrosion issues will be encountered. Nevertheless, experimental tests simulating core conditions for the selected coolant and structural materials will ultimately be needed to fully assess corrosion and chemical behavior.

\subsubsection{Neutron Activation Analysis}

Salts containing chlorine produce the radioisotope $\mathrm{Cl}-36$, which is a $0.709 \mathrm{MeV}$ beta emitter with a 300,000 year half life, through the neutron absorption reaction: 
Project No 06-040: Flexible Conversion Ratio Fast Reactor Systems Evaluation

$$
{ }^{35} \mathrm{Cl}+{ }^{1} \mathrm{n} \rightarrow{ }^{36} \mathrm{Cl}+\gamma \quad(\mathrm{Q}=8580 \mathrm{keV})
$$

Cl-35 has a natural abundance of 75.78\%. Likewise, salts containing potassium also produce $\mathrm{Cl}-$ 36 through the reaction:

$$
{ }^{39} \mathrm{~K}+\mathrm{n} \rightarrow{ }^{36} \mathrm{Cl}+\alpha \quad(\mathrm{Q}=1361 \mathrm{keV})
$$

K-39 has a natural abundance of $93.26 \%$. Activation calculations were performed by first using MCNP to determine the flux-averaged cross sections for the above reactions in the three regions of the core. This value was then multiplied by the average flux and the number of target nuclides in each region to obtain the rate of production of Cl-36. The applicable data is presented in Table 4.1-3.

Each assembly has a coolant volume of $1.32 \times 10^{-2} \mathrm{~m}^{3}$ in the radiation zone. Using the inlet coolant density of $1874 \mathrm{~kg} / \mathrm{m}^{3}$, this corresponds to 351 moles of Cl-35 and 57.6 moles of K-39 per assembly. After 50 EFPY, the expected Cl-36 activity is: $\mathbf{2 . 1 x 1 0}^{3} \mathbf{C i}$ for the entire inventory, assuming no neutron flux outside the active core. This corresponds to $\mathbf{0 . 1 5} \mathbf{~ m C i}$ per kilogram of coolant salt, for a total coolant inventory of about $1.43 \times 10^{6} \mathrm{~kg}$. About $13 \%$ of this Cl-36 activity is due to potassium, with the rest due to chlorine.

Table 4.1-3 Neutron activation data

\begin{tabular}{|l|c|c|c|c|}
\hline Core region & $\begin{array}{c}\text { Cl-35 cross } \\
\text { section (b) }\end{array}$ & $\begin{array}{c}\text { K-39 cross } \\
\text { section (b) }\end{array}$ & $\begin{array}{c}\text { Average Flux } \\
\left(\# / \mathrm{cm}^{2} \mathrm{~s}\right)\end{array}$ & $\begin{array}{c}\text { Number of } \\
\text { assemblies }\end{array}$ \\
\hline Outer - Fresh fuel & $4.04 \times 10^{-3}$ & $3.96 \times 10^{-3}$ & $1.1 \times 10^{15}$ & 234 \\
\hline $\begin{array}{l}\text { Middle - Once } \\
\text { loaded fuel }\end{array}$ & $4.11 \times 10^{-3}$ & $3.61 \times 10^{-3}$ & $1.9 \times 10^{15}$ & 156 \\
\hline $\begin{array}{l}\text { Inner - Twice } \\
\text { loaded fuel }\end{array}$ & $4.14 \times 10^{-3}$ & $3.53 \times 10^{-3}$ & $2.1 \times 10^{15}$ & 61 \\
\hline
\end{tabular}

Cl-36 activation is a significant radwaste issue due to its long half life and chlorine's high mobility in water. While the amount of Cl-36 produced using this salt is not enough to immediately disqualify it, it is also non-negligible and the costs associated with handling Cl-36 need to be considered in the final design. Incidentally, this also holds true for any coolant salt containing potassium, because potassium contributes significantly to Cl-36 activation. Nevertheless, disposal of radioactive $\mathrm{Cl}-36$ is not expected to be a constraining challenge because low-level radioactive coolant salt can likely be cheaply disposed of by injection into a stable geologic salt formation.

In addition to long term activation due to Cl-36 production, use of the selected coolant salt will also result in significant short term activation from Na-24 $\left(\mathrm{T}_{1 / 2}=15 \mathrm{~h}\right)$ and $\mathrm{K}-42\left(\mathrm{~T}_{1 / 2}=12 \mathrm{~h}\right)$. This short-term activation, similar to that in sodium fast reactors, complicates refueling as some time is needed after irradiation to allow activation products to decay. 


\subsection{Unity Conversion Ratio Core}

The main objectives and design constraints of the unity conversion ratio liquid salt-cooled reactor are similar to those of the lead-cooled reactor and summarized in Section 3.3.1.

An extensive screening of various salts with respect to their neutronic and thermal-hydraulic characteristics was initially performed. It was concluded that $\mathrm{NaCl}-\mathrm{KCl}-\mathrm{MgCl}_{2}(30 \%-20 \%-50 \%)$ ternary chloride salt is the most promising candidate for the fast reactor due to a number of favorable properties:

- relatively small thermal expansion coefficient, which helps to mitigate the positive reactivity effect associated with the coolant heat up,

- low moderating power, which is essential for neutron economy and achieving high conversion,

- reasonably low viscosity and melting point, which help to achieve high power density while maintaining the desired safety margins.

The salt screening process summarized in Section 4.1 is described in detail in Appendix 4A.

The major neutronic design challenge of liquid salt-cooled reactor cores is the large positive Coolant Temperature Coefficient (CTC). This large magnitude of CTC leads to considerable difficulty to ensure that the core self controllability criteria are met. A wide range of design strategies, described in Appendix 4B, was explored to reduce the CTC, resulting in only marginal improvements. Among the investigated design strategies, four basic choices were found to be the most effective:

- increasing the core neutron leakage by means of streaming channels and various core geometry modifications,

- introduction of neutron moderators into the core,

- introduction of neutron poisons into the core and axial reflectors, and

- "parfait-type" core geometry with alternating NU and fissile TRU containing fuel layers in the core axial direction.

The results of this study (presented in Appendix 4B) have shown that to ensure the selfcontrollability of the core, the liquid salt-cooled core CTC should be reduced to at least $0.20 \phi / \mathrm{K}$, which is typical for sodium-cooled reactors. A number of strategies to reduce CTC to this value have identified the following liquid salt core configuration as the best performing with respect to this target (see Figure 4.2-1 for layout).

- The core is of parfait shape and does not have an axial top core reflector. With no top reflector, the core would lose reactivity through increased leakage in case of salt temperature increase because of the lower salt density above the core.

- The active core has bottom and top axial natural uranium blankets $20 \mathrm{~cm}$ thick, while preserving the total fuel length of $130 \mathrm{~cm}$ (including blankets). The TRU fuel component is concentrated in the middle axial zone of the core, preserving the total TRU loading per fuel pin. Separation of neutron producing and neutron absorbing materials into axial (parfait) layers would reduce CTC. This is because coolant temperature increase and 
associated spectrum hardening would increase the leakage of neutrons from producing to absorbing regions, reducing the reactivity.

- The fuel pins in the axial blanket zone have annular geometry. $\mathrm{ZrH}_{1.6}$ moderator is located in the center of the annulus and has a volume fraction of $30 \%$. Metallic natural uranium (with $10 \mathrm{wt} . \% \mathrm{Zr}$ ) fuel is located in the outer annular cylinder. The presence of hydrogen in the blankets would lead to reflection of lower worth neutrons back to the fissile core region, increase conversion in the blankets and reduce proliferation attractiveness of $\mathrm{Pu}$ bred in the blankets.

Thermal hydraulic and reactor physics results were iterated to obtain a consistent core design that incorporates axial and radial power peaking and assembly orificing. Although the inclusion of axial blankets challenges core thermal hydraulics by increasing axial peaking, the reference core developed is able to meet the $2400 \mathrm{MWt}$ target power with a core pressure drop of $1.074 \mathrm{MPa}$, a small increase over the $1.0 \mathrm{MPa}$ design constraint.

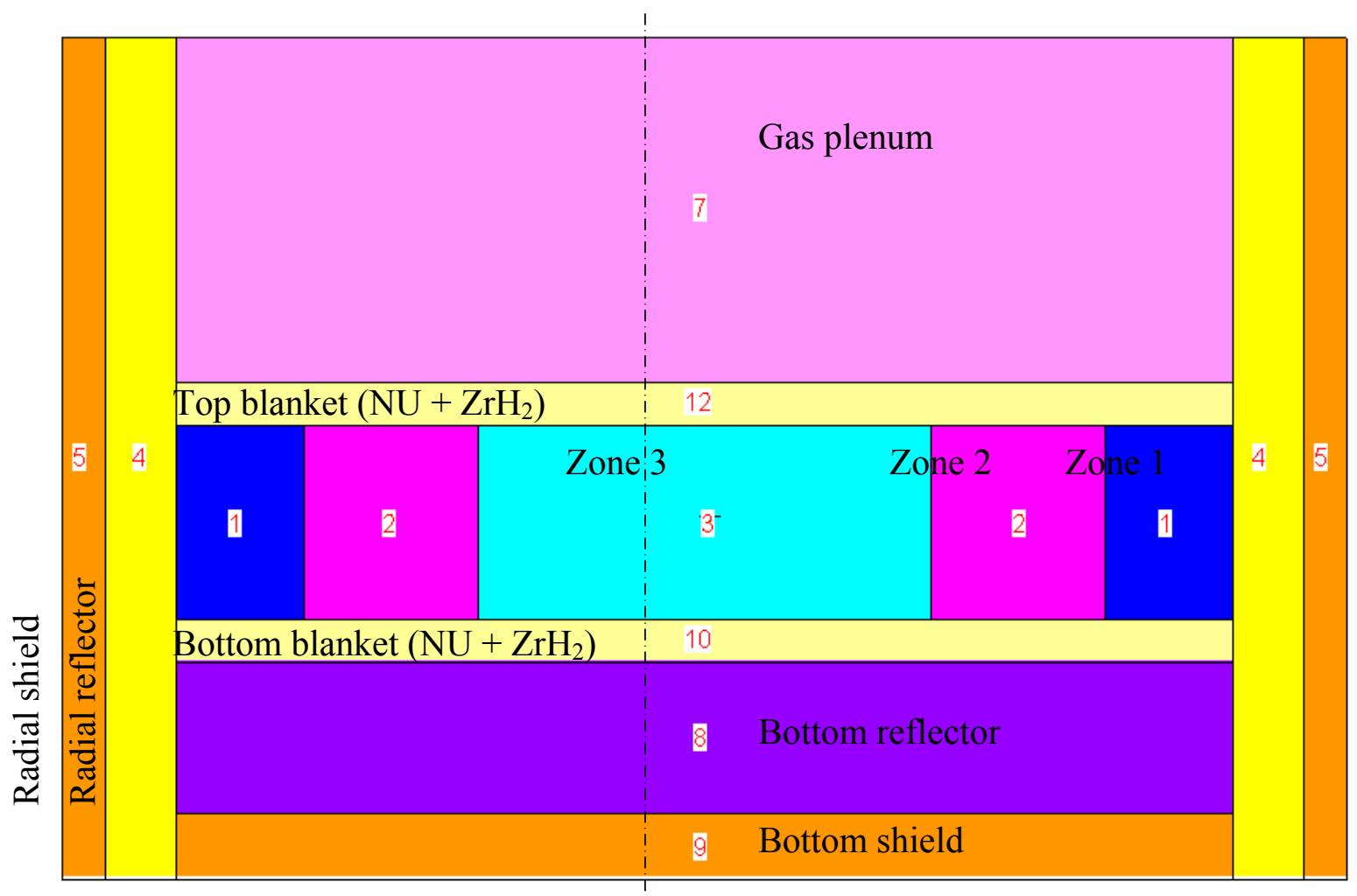

Figure 4.2-1. Liquid salt $\mathrm{CR}=1$ "Parfait-type" core layout (axial cross-section). 
Project No 06-040: Flexible Conversion Ratio Fast Reactor Systems Evaluation

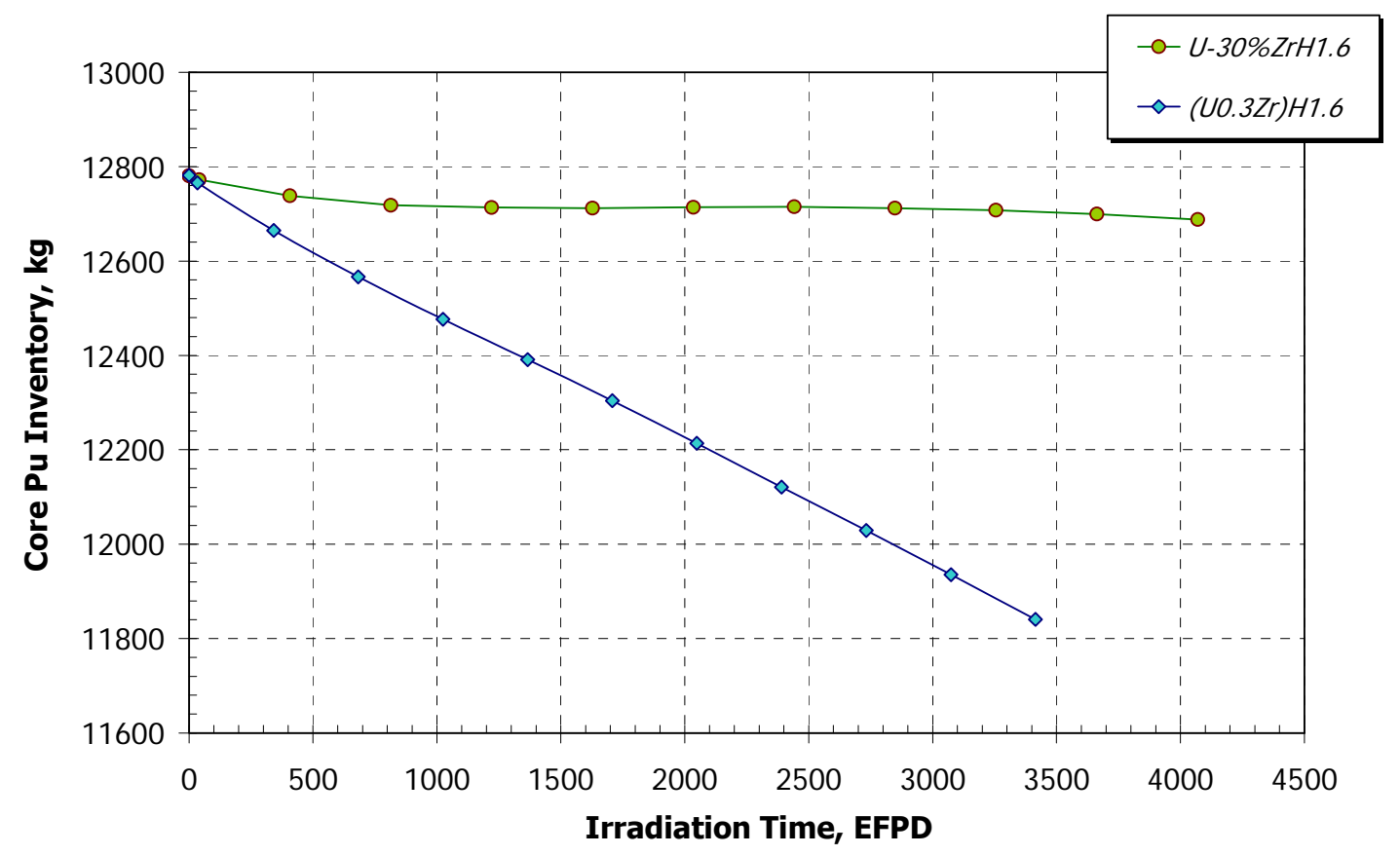

Figure 4.2-2. Core Pu inventory vs. irradiation time for different blanket fuel options.

A series of burnup calculations were performed to investigate the possibility of achieving $\mathrm{CR}=1$, the extent of CTC degradation with burnup, and the effect of hydrogen presence in the axial blankets on $\mathrm{Pu}$ isotopic vector.

The results indicate that a conversion ratio of about unity can be achieved with $15 \mathrm{wt} . \%$ of TRU in the total core heavy metal. The CR is very sensitive to the amount of hydrogen in the axial blankets. Doubling the hydrogen concentration, as compared with the reference case, results in a decrease in $\mathrm{CR}$ to about 0.94. Figure 4.2-2 compares the evolution of $\mathrm{Pu}$ core inventory with time in $\mathrm{CR}=1$ salt-cooled core designs with annular shaped axial blankets $\left(30 \mathrm{vol} \% \mathrm{ZrH}_{1.6}\right)$ and the blankets that use hydride fuel $\left(\mathrm{U}_{0.3} \mathrm{Zr}\right) \mathrm{H}_{1.6}$ similar to that of TRIGA type reactors. The hydrogen density for the latter case is about a factor of two higher than in the annular blanket pin geometry.

The presence of hydrogen in the axial blankets significantly degrades the $\mathrm{Pu}$ isotopic vector, making it unattractive for weapons proliferation. The relative amount of Pu239 in the blanket fuel region at discharge is less than $80 \%$, while the total amount of "even" Pu isotopes with their high spontaneous fission neutron source is more than 15\% (Table 4.2-1). Such $\mathrm{Pu}$ isotopic composition is fairly close to LWR grade $\mathrm{Pu}$.

Additional effort was made to reduce the radial power peaking and optimize the number and locations of the control rods. The power peaking is mitigated through spatial variation of the $\mathrm{Zr}$ fuel matrix diluent in the fuel, while keeping the TRU to NU ratio constant. This strategy allows maintaining the radial power peaking factor below 1.3 throughout the core lifetime with only three radial fuel zones. 
Table 4.2-1. Pu isotopic composition (percent of total $\mathrm{Pu}$ ) at discharge.

\begin{tabular}{|c|c|c|c|c|}
\hline & \multicolumn{2}{|c|}{70 vol.\% NU- 30 vol. $\% \mathrm{ZrH}_{1.6}$} & \multicolumn{2}{|c|}{$\left(\mathrm{U}_{0.3} \mathrm{Zr}\right) \mathrm{H}_{1.6}$} \\
\hline & Blankets & Core & Blankets & Core \\
\hline $\mathrm{Pu} 238$ & 0.6 & 5.2 & 1.2 & 5.2 \\
\hline $\mathrm{Pu} 239$ & 77.0 & 55.8 & 62.8 & 55.7 \\
\hline $\mathrm{Pu} 240$ & 15.8 & 28.9 & 13.9 & 28.7 \\
\hline $\mathrm{Pu} 241$ & 6.0 & 3.9 & 16.9 & 4.3 \\
\hline $\mathrm{Pu} 242$ & 0.7 & 6.2 & 5.6 & 6.2 \\
\hline
\end{tabular}

In contrast to the lead-cooled $\mathrm{CR}=1$ core, the reference salt-cooled core design has a relatively large reactivity swing of about $30 \$$. Therefore, a somewhat larger number of control rods is required to offset the excess reactivity at BOL. It was found that a little over one half of the fuel assemblies (373 out of 691) should contain control rods.

In the course of this study, a large number of Monte Carlo core criticality calculations described in Appendix 4B were performed with statistical accuracy significantly higher than that previously used for identifying the most promising strategies for the reduction of CTC. In some of the calculated cases, considerable differences were observed between the earlier screening study results and the current high accuracy reactivity coefficient calculations.

A thorough investigation of the reasons for these discrepancies, with Monte Carlo calculations using as many as $10^{8}$ particle histories, revealed that, for the large, spatially de-coupled critical systems with relatively uniform power distribution, it is extremely difficult to obtain the source shape close to the system's fundamental mode, and thus, the correct multiplication factor value.

Evaluation of reactivity coefficients for the core design from Figure 4.2-1 and described above showed that such core designs cannot meet the self-controllability criteria both at the beginning and at the end of life. Accumulation of $\mathrm{Pu}$ in the axial blankets results in an appreciable degradation of CTC by nearly $50 \%$, bringing into question the worthiness of design modifications aimed at the reduction of CTC.

As a result of the above findings, some of the CTC reduction strategies were re-evaluated using higher statistical accuracy and the major conclusion of this effort can be summarized as follows:

- The presence of hydrogen in the axial blankets, which was thought to be beneficial for CTC reduction, has, in fact, practically no effect on CTC.

- The presence of neutron streaming channels, on the other hand, was found to reduce CTC quite substantially. The favorable effect of high leakage core configurations on CTC, although expected, was not observed in the screening study because of the statistically insufficient accuracy of the results.

Consequently, the original reference core design, shown in Figure 4.2-1, was modified in the following manner:

- $\mathrm{ZrH}_{1.6}$ was removed from the axial blanket zone of the fuel pins, so that the blankets contain natural uranium only.

- About $15 \%$ of the fuel assemblies were replaced with streaming channels primarily in the central core region with high neutron importance (Figure 4.2-3). 
In addition, the possibility of core reactivity control by moderation was explored through the use of $\mathrm{ZrH}_{1.6}$ control rods (Figure 4.2-4). The main motivation for such design strategy is several fold:

- At the beginning of life, the presence of hydrogen in the core promotes captures in fertile nuclides instead of absorption in the control rods, increasing the conversion ratio.

- At the end of life, the control rods are withdrawn, hardening the spectrum, reducing the conversion ratio, and by that, extending the cycle length.

- Hydrogen containing control rods reside the longest in the vicinity of axial blankets, so that $\mathrm{Pu}$ bred in the blankets has proliferation resistant isotopic composition.

As a result of these modifications in the design, the core self-controllability criteria can be marginally met at BOL, while at EOL the reactivity coefficient ratios are much closer to the required limits than in the previous reference design case. The main reason for such substantial improvement at BOL is a large Doppler Coefficient as a result of hydrogen presence in the core and therefore higher resonance absorption rate in U238.

The modified core, however, has significant performance penalties.

Although the neutron capture rate in fertile nuclides at BOL is increased, the spectrum softening causes a reduction in the number of neutrons released per absorption and thus available for breeding. Overall, no substantial improvement in the core breeding potential or fuel cycle length increase was observed.

The fuel cycle length is reduced by a factor of over 3. Correspondingly, the core average discharge fuel burnup is reduced by nearly as much. This is a result of displacement of fuel with streaming channels and a larger number of control rods. The fuel cycle length penalty can be somewhat mitigated if two or three staggered batch fuel management is adopted. This would reduce the required number of control rods, increase the fuel cycle length, and reduce the difference between the BOL and EOL reactivity coefficient values.

More importantly, the displacement of fuel with streaming channels and a larger number of control rods results in a significant increase in the fuel pin linear power. In order to maintain the target power density of $100 \mathrm{~W} / \mathrm{cm}^{3}$ with the same thermal margin, the core pressure drop must be raised by over a factor of two. Conversely, maintaining the original $1 \mathrm{MPa}$ pressure drop constraint would result in about a $30 \%$ reduction in power density, reducing the economic attractiveness of the concept. 
Project No 06-040: Flexible Conversion Ratio Fast Reactor Systems Evaluation

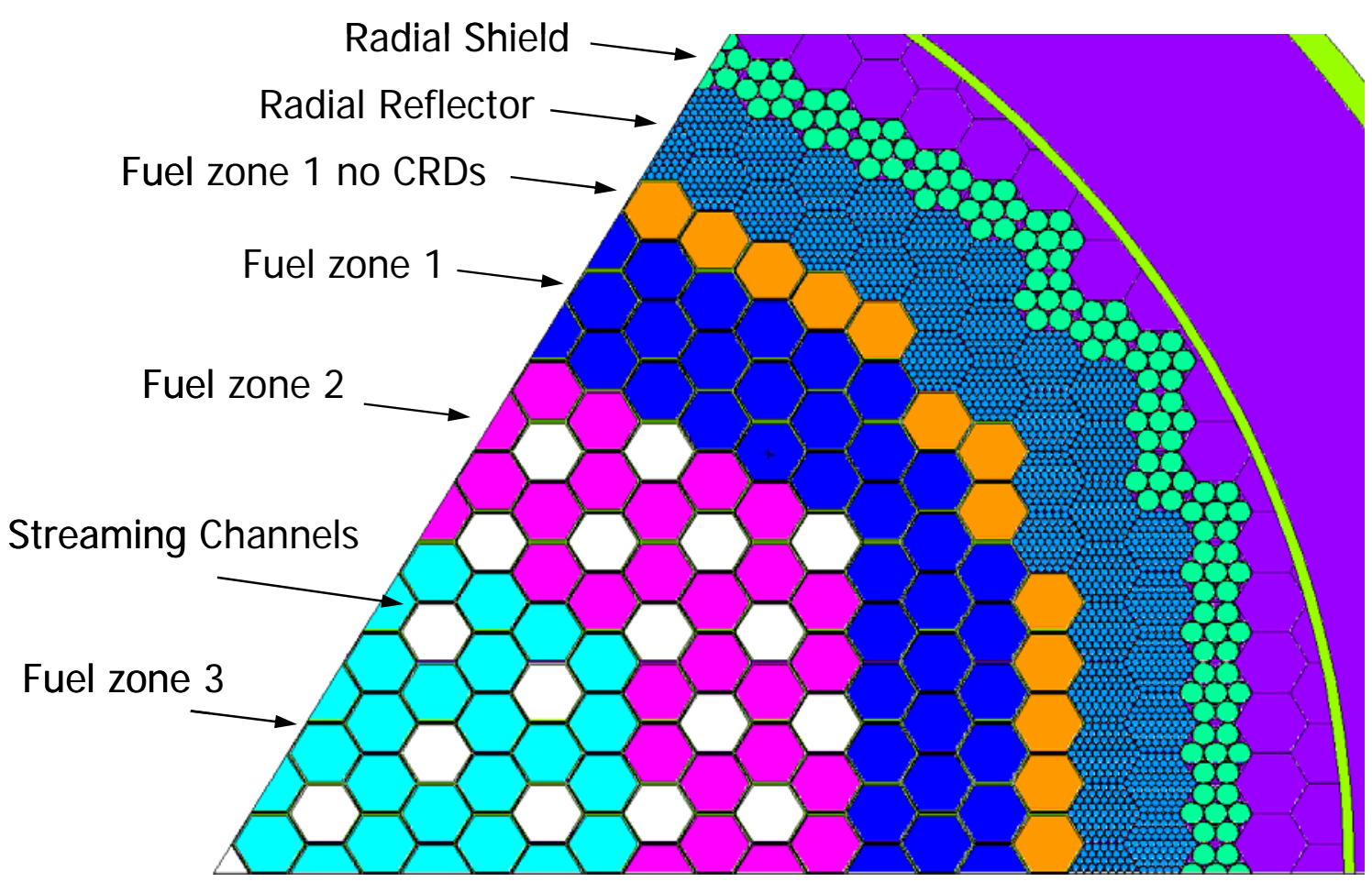

Figure 4.2-3. Modified $\mathrm{CR}=1$ core layout.

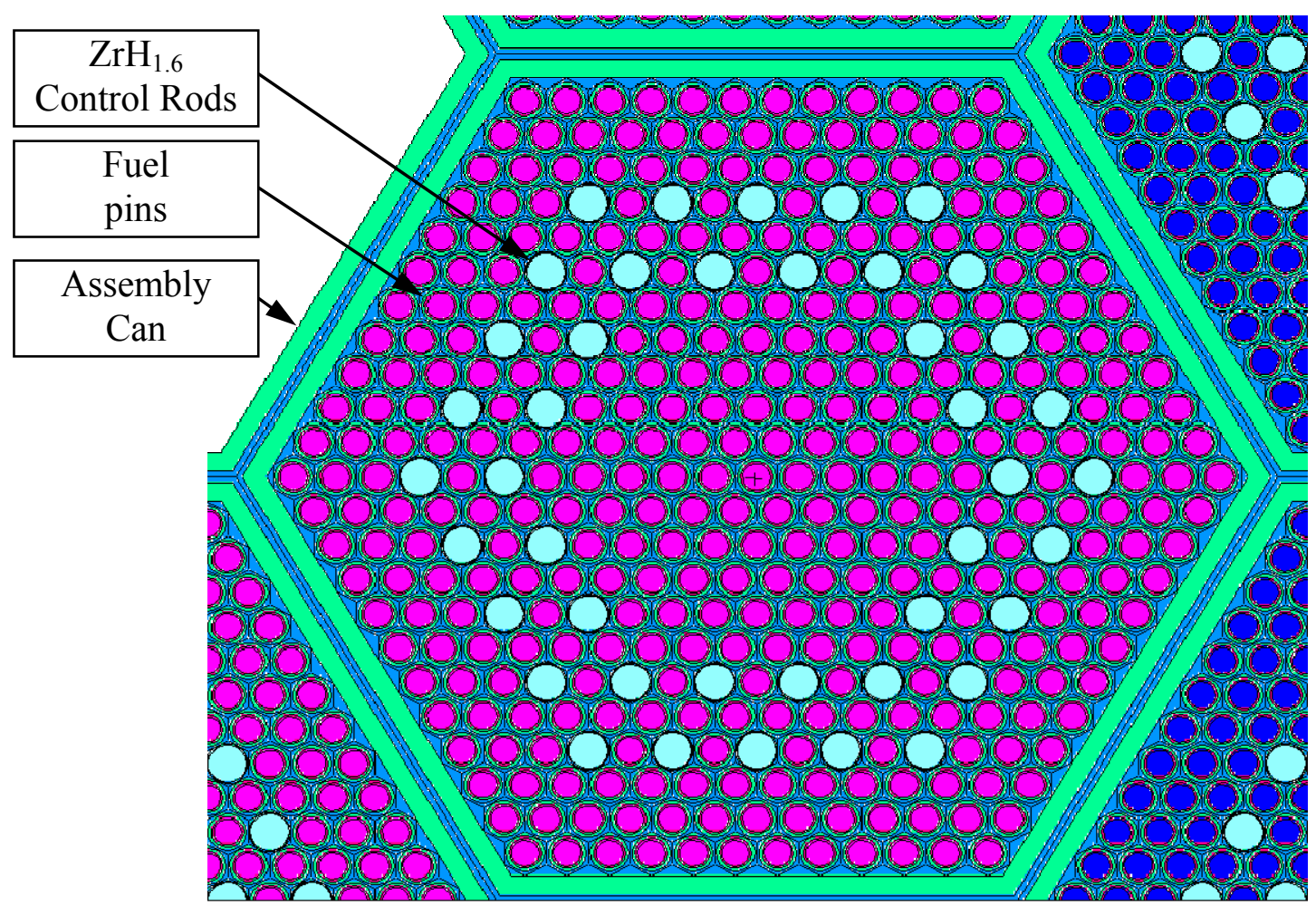

Figure 4.2-4. Fuel Assembly with $\mathrm{ZrH}_{1.6}$ Control Rods. 
The main conclusion from the preliminary design studies, described above, was that although the combination of CTC reduction strategies reduced the CTC substantially, the reduction was not sufficient enough to bring the CTC into the range of values necessary to meet the selfcontrollability criteria. In addition, the design enhancements explored added greatly to the complexity of the core. Furthermore, introduction of axial NU blankets and streaming channels into the core resulted in higher axial power peaking and larger linear power per fuel pin, which, in turn, significantly reduced the achievable power density.

Therefore, the use of a reactivity control device known as the Lithium thermal Expansion Module (LEM) [Kambe et al., 1998] was explored to meet the core self-controllability criteria. The LEM consists of a capillary tube inserted into the core and a lithium (Li) reservoir located above the core (see Appendix 3A.4 for more detailed description) in the gas plenum region. Under nominal operating conditions, no $\mathrm{Li}$ is present in the core region and the capillary tube is filled with inert gas. The liquid lithium enriched to $90 \%$ in the neutron absorbing Li-6 isotope is fully contained within the reservoir by the balance of buoyancy, surface tension, and seismic acceleration forces. As the coolant temperature rises above its nominal value, the reservoir heats up and Li thermal expansion pushes the gas-liquid interface down into the core region, inserting negative reactivity. A schematic view of the LEM is presented in Figure 4.2-5.

Introduction of LEMs allowed the improvement of the salt-cooled core design in several aspects.

- Near zero or even slightly negative CTC can easily be achieved through variation in the number of LEMs or the LEM geometry. Such values of the CTC assure the selfcontrollability of the core, with a significant safety margin.

- The core design can be significantly simplified because the use of axial blankets and streaming assemblies are no longer required to reduce CTC. Consequently, average pin linear power can be increased leading to a much higher achievable core power density.

- In the previously considered design attempts, the requirement to reduce CTC constrained the coolant volume fraction in the core. Utilization of LEMs, however, relaxes this constraint and allows an increase of power density as much as 30\% through an increase in the fuel pin pitch to diameter ratio in conjunction with the use of LEMs.

- The possibility of increasing the coolant volume fraction, and thus the core cooling capabilities, can be directed to an increase of the system thermal margin or reduction in the core pressure losses instead of (or in combination with) achieving higher power density.

Two alternative LEM configuration options are summarized in Figure 4.2-6. As evident from Figure 4.2-6, the Option 1 fuel assembly design has fewer LEMs per assembly but larger LEM diameter, while in the Option 2 design, a larger number of LEMs with the same dimensions as fuel pins were used. The basic design tradeoff here is that a larger LEM diameter would minimize the number of LEMs per assembly, reducing the fuel displacement and increasing the thermal margin. On the other hand, choosing LEM diameter equal to that of the fuel pins would significantly simplify the assembly mechanical design. The results of the performed analysis indicate that both design choices have generally equivalent neutronic performance because the total amount of Li inserted into the core in response to the coolant temperature increase is about the same for both design options. Option 2 design was selected as a reference and used in the analyses. 
Project No 06-040: Flexible Conversion Ratio Fast Reactor Systems Evaluation

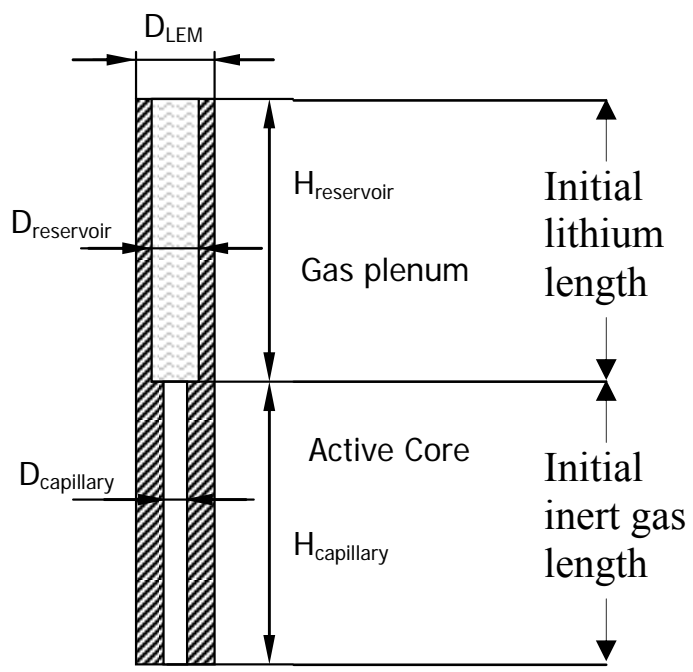

Figure 4.2-5. Schematic view of Lithium Thermal Expansion Module

\begin{tabular}{|l|r|r|}
\hline & Option 1 & Option 2 \\
\hline Li-6 enrichment, wt \% & 90 & 90 \\
\hline Number of LEMs per assembly & 7 & 12 \\
\hline Outer module diameter $\left(\mathrm{D}_{\text {LEM }}\right), \mathrm{cm}$ & 0.892 & 0.752 \\
\hline Capillary diameter $\left(\mathrm{D}_{\text {capillary }}\right), \mathrm{cm}$ & 0.12 & 0.10 \\
\hline Reservoir wall thickness, cm & 0.05 & 0.05 \\
\hline Reservoir height $\left(\mathrm{H}_{\text {reservoir }}\right), \mathrm{cm}$ & 130.0 & 130.0 \\
\hline Capillary height $\left(\mathrm{H}_{\text {capillary }}\right), \mathrm{cm}$ & 130.0 & 130.0 \\
\hline
\end{tabular}

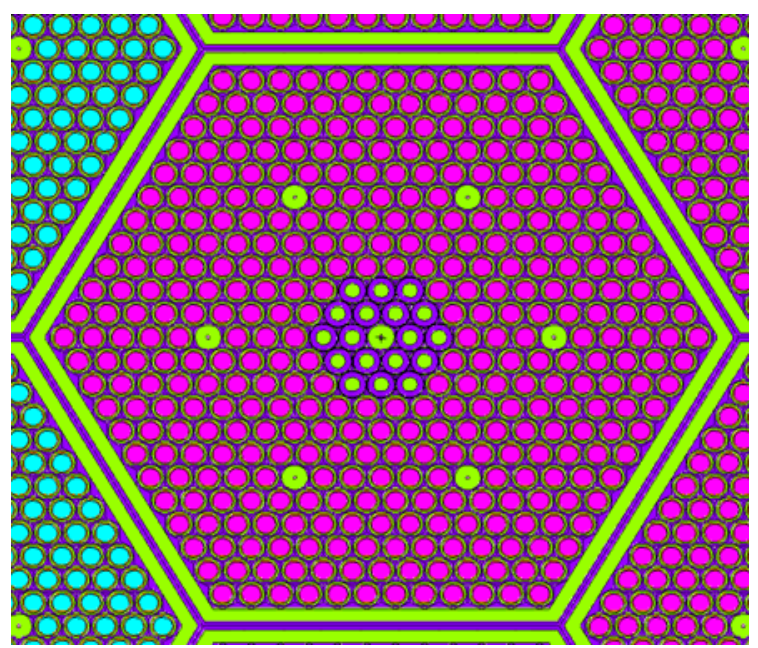

Option 1: 7 LEMs, large diameter

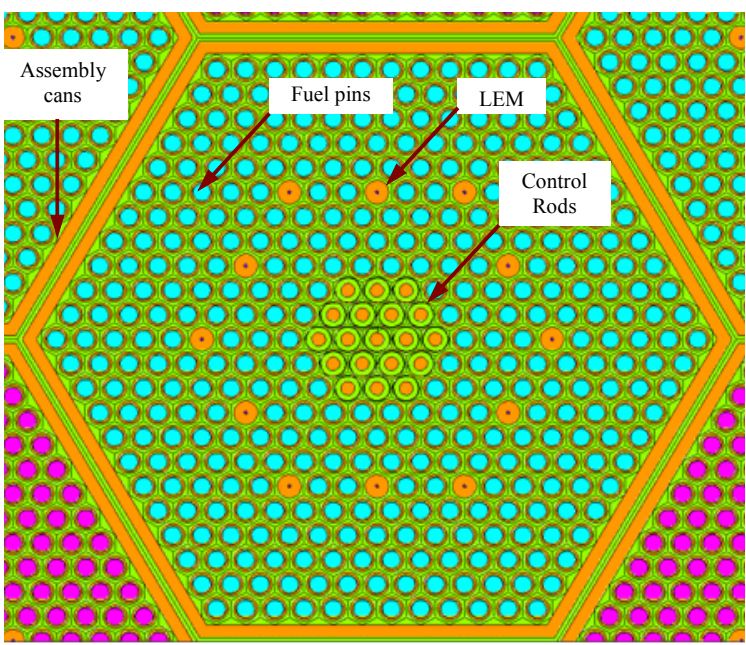

Option 2: 12 LEMs, standard diameter

Figure 4.2-6. Alternative LEM and CRD arrangements within Fuel Assembly 
In the thermal hydraulic arena, major design challenges for a liquid salt reactor are the following: first, the high melting point of liquid salt compared to both sodium and lead means there is less margin between coolant freezing and material temperature limits, which limits power densities and makes coolant freezing a greater concern during transients. Second, the high viscosities of liquid salt compared to other coolants result in higher pressure losses and reduced heat transfer effectiveness. The lower Reynolds numbers of high-viscosity liquid salts also lead to flowregime changes to transition and laminar flow during loss of flow situations, degrading heat transfer. The low thermal conductivity of salt compared to liquid metals also reduces heat transfer effectiveness, resulting in a significantly higher film temperature rise. Because of these factors, the overall thermal hydraulic performance of liquid salt is poorer than that of liquid metals: for a given core geometry, pressure drop, and power density, the difference between the peak cladding temperature and the coolant inlet temperature will generally be greater for liquid salt.

The inferior thermal hydraulic performance of liquid salt drives core design towards a looser lattice and a higher coolant fraction, which for a given mass flux lowers the coolant temperature rise and raises coolant Reynolds numbers. However, as discussed above, a high coolant fraction is problematic for liquid salt because of salt's high coolant temperature reactivity coefficient (CTC). Ultimately, no choice of coolant fraction or CTC reducing strategy could reconcile thermal hydraulic and reactor physics design goals, so LEMs were introduced to ease the CTC constraint and allow a more open core lattice. This allowed a core power density of $130 \mathrm{~kW} / 1$ to be achieved, which is greater than the power density of the reference lead design. Nevertheless, the increased power density of the salt core does not reduce overall vessel size, because contrary to lead-cooled cores, a salt-cooled reactor requires reflector and shielding assemblies and the poorer thermal hydraulic characteristics of salt also necessitate larger intermediate heat exchangers in the vessel's annular region.

LEM design is closely tied to the reactor's thermal hydraulic response during a transient, because LEMs must be designed to be effective over the entire temperature range encountered during the transient. If the LEMs were to become either fully withdrawn or fully inserted during a transient, then they would no longer contribute additional reactivity feedback and the high CTC would control reactor behavior, potentially leading to positive feedback.

\subsubsection{Neutronic Analysis Results}

Because use of LEMs was identified as the most promising approach to achieve selfcontrollability in high-power density liquid salt-cooled cores, LEM assemblies were selected for the development of the reference salt-cooled designs. This section describes two alternative $\mathrm{CR}=1$ core designs, both taking advantage of LEMs to reduce CTC to the value required for core self-controllability.

The first core can be regarded as an evolutionary design extension of the previous attempts aiming at the reduction of CTC. However, in contrast to the earlier designs, the fuel composition was uniform in the axial direction (no axial NU blankets or streaming channels were used) and seven LEMs were introduced into each fuel assembly as presented in Figure 4.2-5 (Option 1). The same fuel pin dimensions and the lattice pitch were used. As in the previous designs, the target $100 \mathrm{~kW} / 1$ core average power density and a single batch refueling were assumed. The core 
had three radial fuel zones with varying $\mathrm{Zr}$ content but the same TRU to total HM ratio in order to flatten the radial power profile and maintain it throughout the fuel cycle. About one quarter of the fuel assemblies included double-entry control rods in addition to LEMs. The rest of the fuel assemblies contained LEMs only. The core loading map is presented in Figure 4.2.1-1.

The core depletion analysis suggested that the cycle length which is limited by cladding fast fluence is much shorter than the reactivity limited one. This is illustrated in Figures 4.2.1-2 and 4.2.1-3, which present the core criticality and peak cladding fast fluence as a function of burnup respectively.

Reduction of TRU enrichment was found to be a somewhat inefficient strategy to match the reactivity and fluence-limited burnup of the core. Setting the coolant volume fraction to the minimum possible value results in a harder neutron spectrum, which leads to very efficient breeding of new TRUs (Figure 4.2.1-4). As a result, the core reactivity increases with time, resulting in very long fuel cycle lengths, even if the initial TRU enrichment is dropped to a value such that the fresh core with all CRDs out is barely critical. In addition, one of the design objectives of this project is to maintain about constant TRU inventory $(C R=1)$ rather than maximizing the breeding potential of the core.

Increasing $\mathrm{Zr}$ content in the fuel in order to reduce the fuel cycle length is also inefficient because the presence of neutral material in the core takes up valuable space.

As mentioned earlier, maintaining minimum possible coolant volume fraction was a direct consequence of the requirement to reduce CTC. Introduction of LEMs, however, allows an increase of the coolant volume fraction while still maintaining the CTC within the desired range.

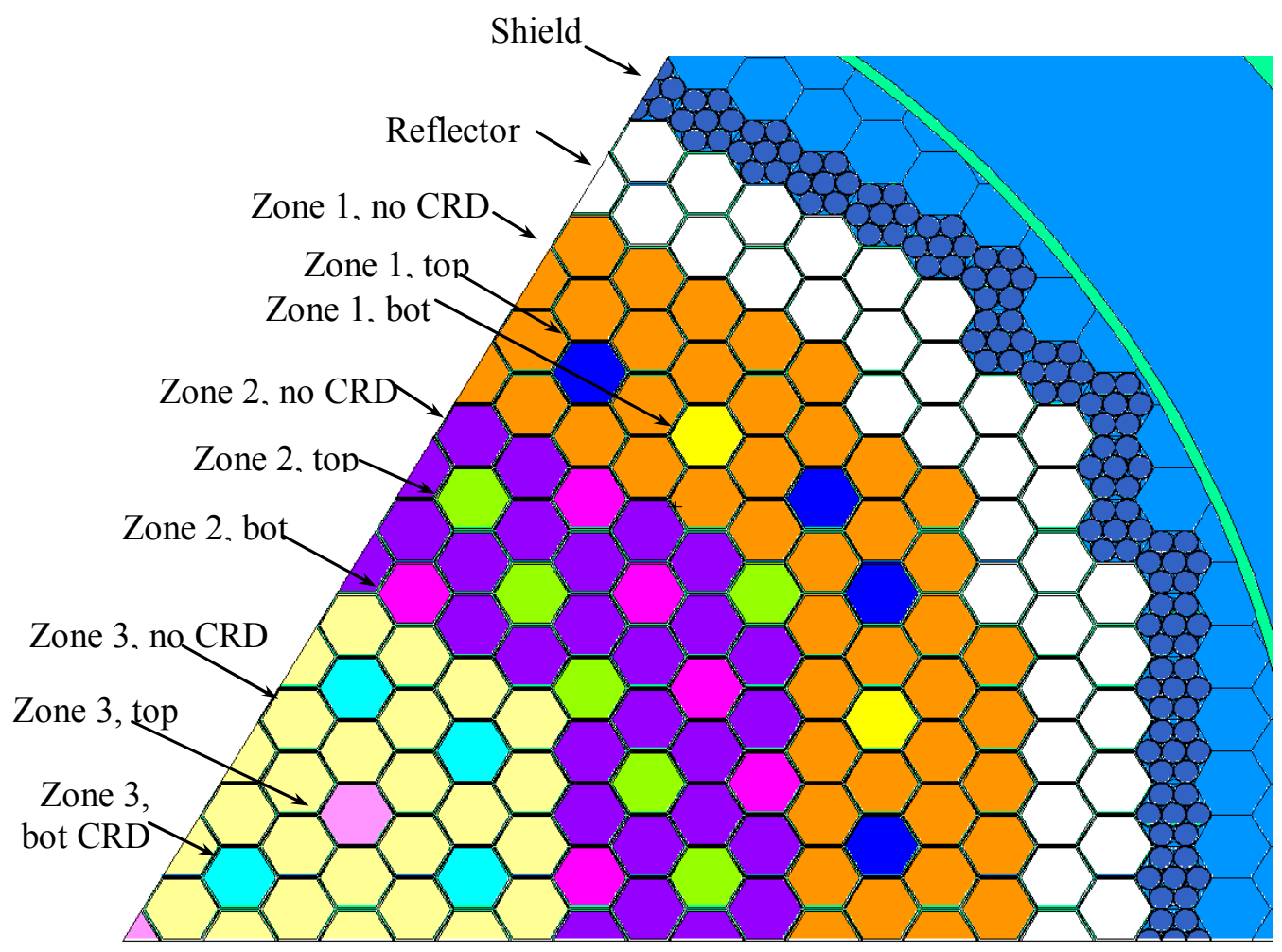

Figure 4.2.1-1. $\mathrm{CR}=1$ Core loading map $(100 \mathrm{~kW} / 1)$. 
Project No 06-040: Flexible Conversion Ratio Fast Reactor Systems Evaluation

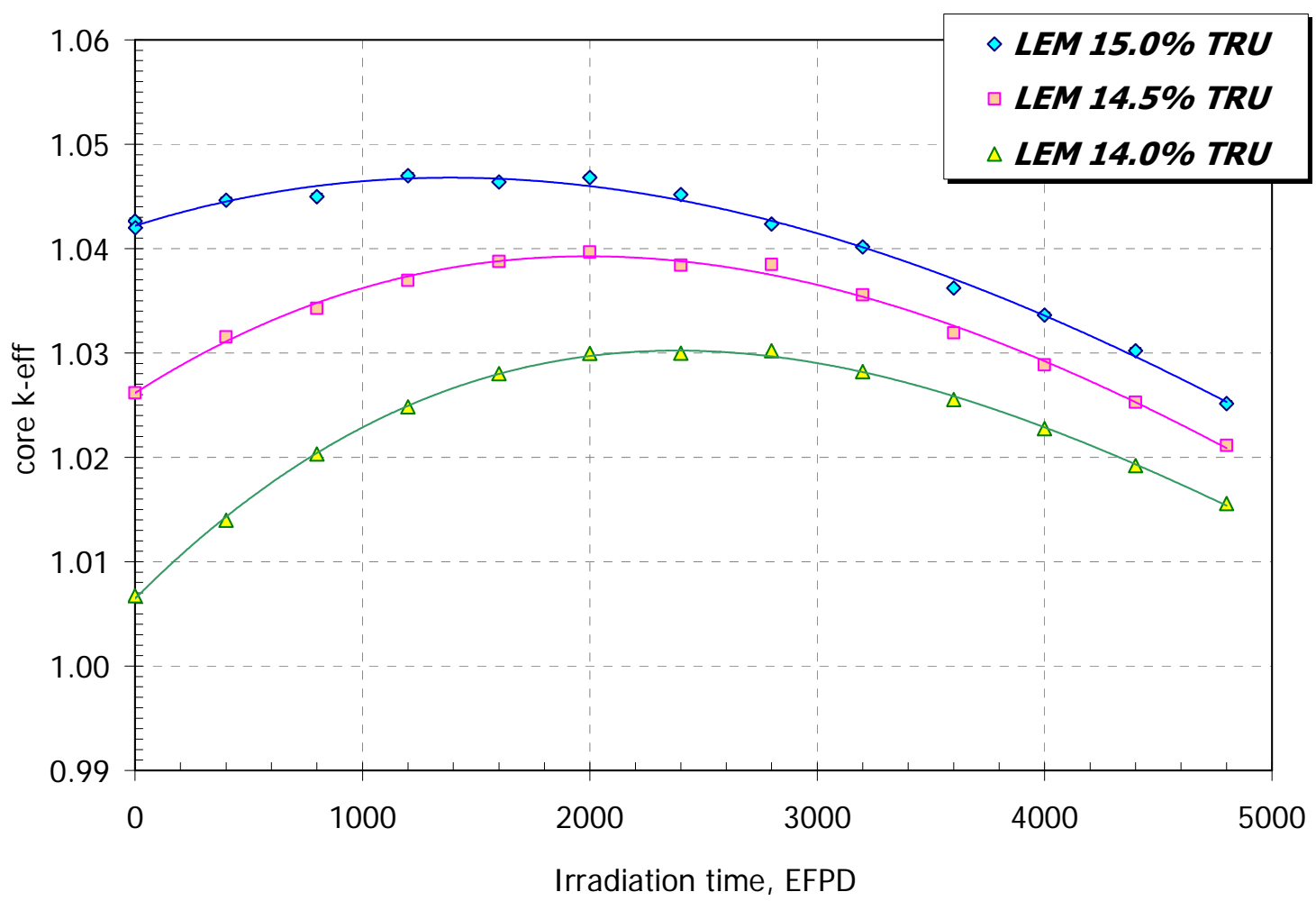

Figure 4.2.1-2. $\mathrm{CR}=1$ Core k-eff for different TRU enrichments (q", $=100 \mathrm{~kW} / \mathrm{l})$

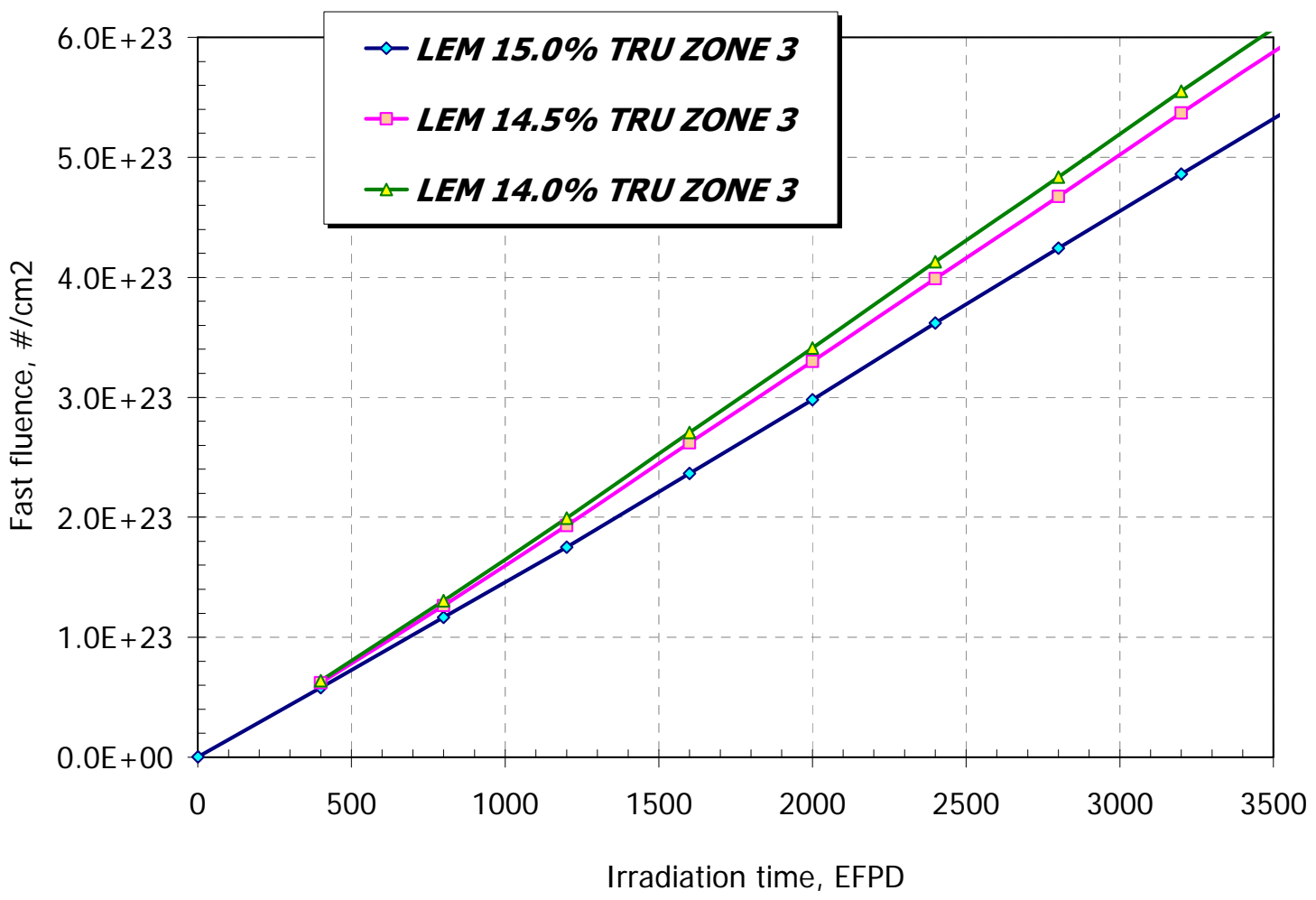

Figure 4.2.1-3. $\mathrm{CR}=1$ Peak fast fluence to $\operatorname{clad}(\mathrm{q}$, ', $=100 \mathrm{~kW} / \mathrm{l})$ 
Project No 06-040: Flexible Conversion Ratio Fast Reactor Systems Evaluation

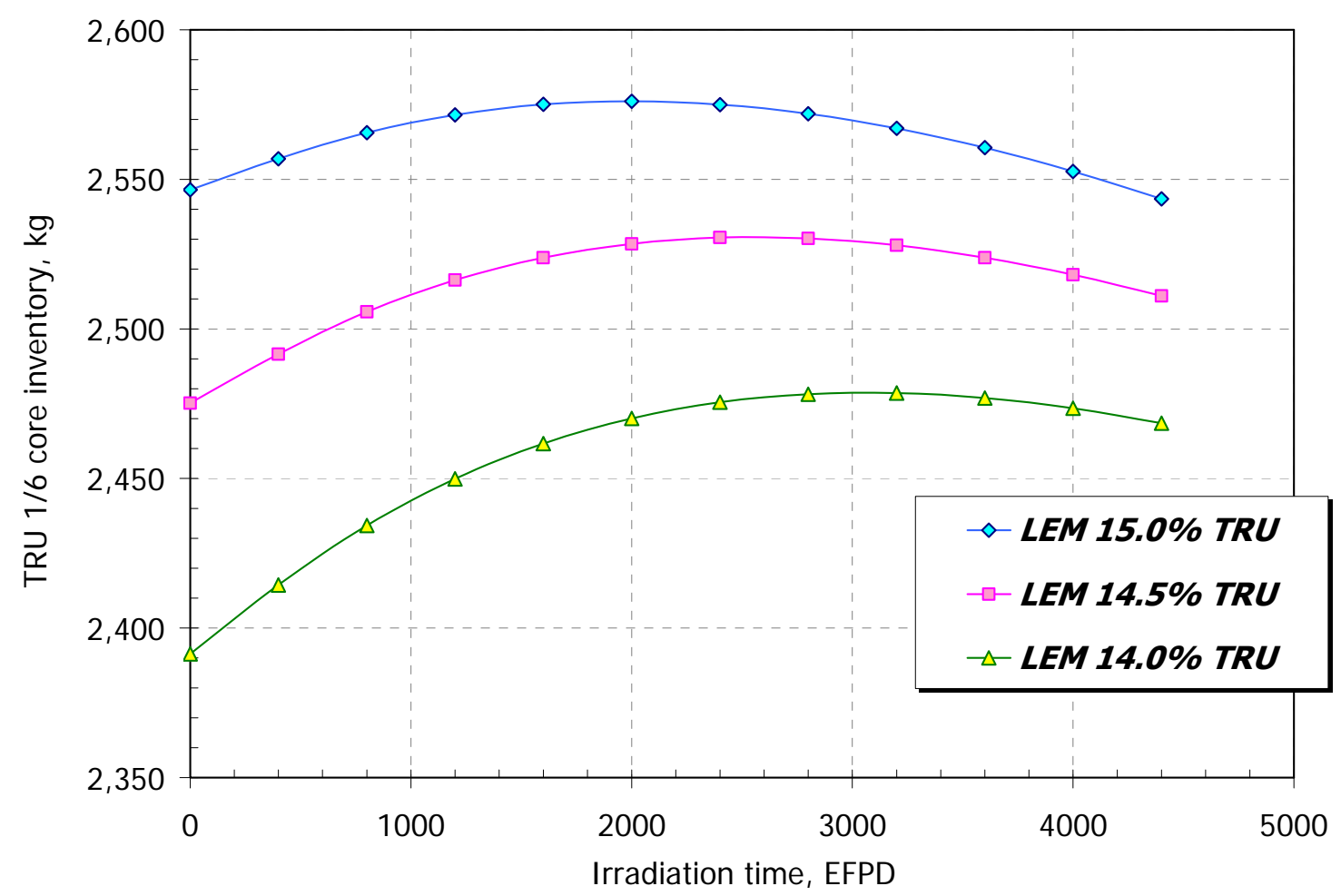

Figure 4.2.1-4. $\mathrm{CR}=1$ Core TRU inventory $(\mathrm{q} ",=100 \mathrm{~kW} / \mathrm{l})$

The second core design explores benefits of the larger $\mathrm{P} / \mathrm{D}$ ratio, which is now possible with LEMs. Preliminary thermal-hydraulic analysis (see Section 4.2.2) showed that increasing the fuel pin pitch to diameter ratio (P/D) from 1.08 (used in the previous designs) to 1.19 would achieve $130 \mathrm{~kW} / 1$ power density for the same core pressure drop and thermal margin. Additionally, a smaller core volume and larger coolant volume fraction would require a higher TRU to HM ratio and lead to less efficient breeding, forcing the Conversion Ratio to a near unity value.

The high power density core with $\mathrm{P} / \mathrm{D}=1.19$ was designed by increasing the fuel lattice pitch but maintaining the same pin dimensions and number of pins per assembly. The main design parameters of the two cores are summarized in Table 4.2.1-1. The high power density core has lower HM loading and correspondingly higher specific power (by about 50\%), which ultimately determines the fuel cycle cost. Specific power of the new core is about $35 \mathrm{~W} / \mathrm{gHM}$, which is comparable to current LWRs. The core fuel cycle parameters are reported in more detail in Table 4.2.1-2.

The new core loading pattern, TRU enrichment, and $\mathrm{Zr}$ content in different fuel zones were optimized to achieve reasonable power distribution during irradiation. The fuel loading map of the $130 \mathrm{~kW} / 1$ core is presented in Figure 4.2.1-5. Figures 4.2.1-6 and 4.2.1-7 show the radial power peaking factors at BOC and EOC respectively. As can be observed, the maximum radial power peaking factors are always below 1.3, proving the $\mathrm{Zr}$ content tailoring strategy for maintaining the power shape throughout the cycle to be very efficient. 
Project No 06-040: Flexible Conversion Ratio Fast Reactor Systems Evaluation

Table 4.2.1-1. $\mathrm{CR}=1$ core designs comparison

\begin{tabular}{|l|l|r|r|}
\hline & & Core 1 & \multicolumn{1}{|c|}{ Core 2 } \\
\hline Core power & MW & 2,400 & 2,400 \\
\hline Core average power density & W/cm & 100.5 & 130.0 \\
\hline Number of assemblies & & 691 & 451 \\
\hline No. of assemblies (Zone 1 - outer) & & 294 & 234 \\
\hline No. of assemblies (Zone 2 - middle) & & 228 & 156 \\
\hline No. of assemblies (Zone 3 - inner) & & 169 & 61 \\
\hline Zr content in the fuel (Zone 1/2/3) & wt. \% & $10 / 16 / 17$ & $10 / 15 / 17$ \\
\hline TRU Enrichment, (wt.\% in HM) & wt. \% & 14.7 & 15.7 \\
\hline Fuel mass (per core) & $\mathrm{kg}$ & 102,939 & 68,847 \\
\hline Specific power & $\mathrm{W} / \mathrm{g}$ & 23.31 & 34.86 \\
\hline Pin diameter & $\mathrm{cm}$ & 0.752 & 0.752 \\
\hline Pin pitch & $\mathrm{cm}$ & 0.817 & 0.894 \\
\hline Pin pitch to diameter ratio (P/D) & & 1.0865 & 1.188 \\
\hline Pins per assembly without CRDs & pins & 390 & 390 \\
\hline Pins per assembly with CRDs & pins & 372 & 372 \\
\hline LEMs per assembly & & & 7 \\
\hline Assembly can thickness & $\mathrm{cm}$ & 0.394 & 0.394 \\
\hline Assembly gap thickness & $\mathrm{cm}$ & 0.222 & 0.222 \\
\hline Assembly size Flat-to-Flat & $\mathrm{cm}$ & 17.298 & 18.846 \\
\hline Active core height & $\mathrm{cm}$ & 130.0 & 130.0 \\
\hline Core equivalent radius & $\mathrm{cm}$ & 241.8 & 212.6 \\
\hline
\end{tabular}


Project No 06-040: Flexible Conversion Ratio Fast Reactor Systems Evaluation

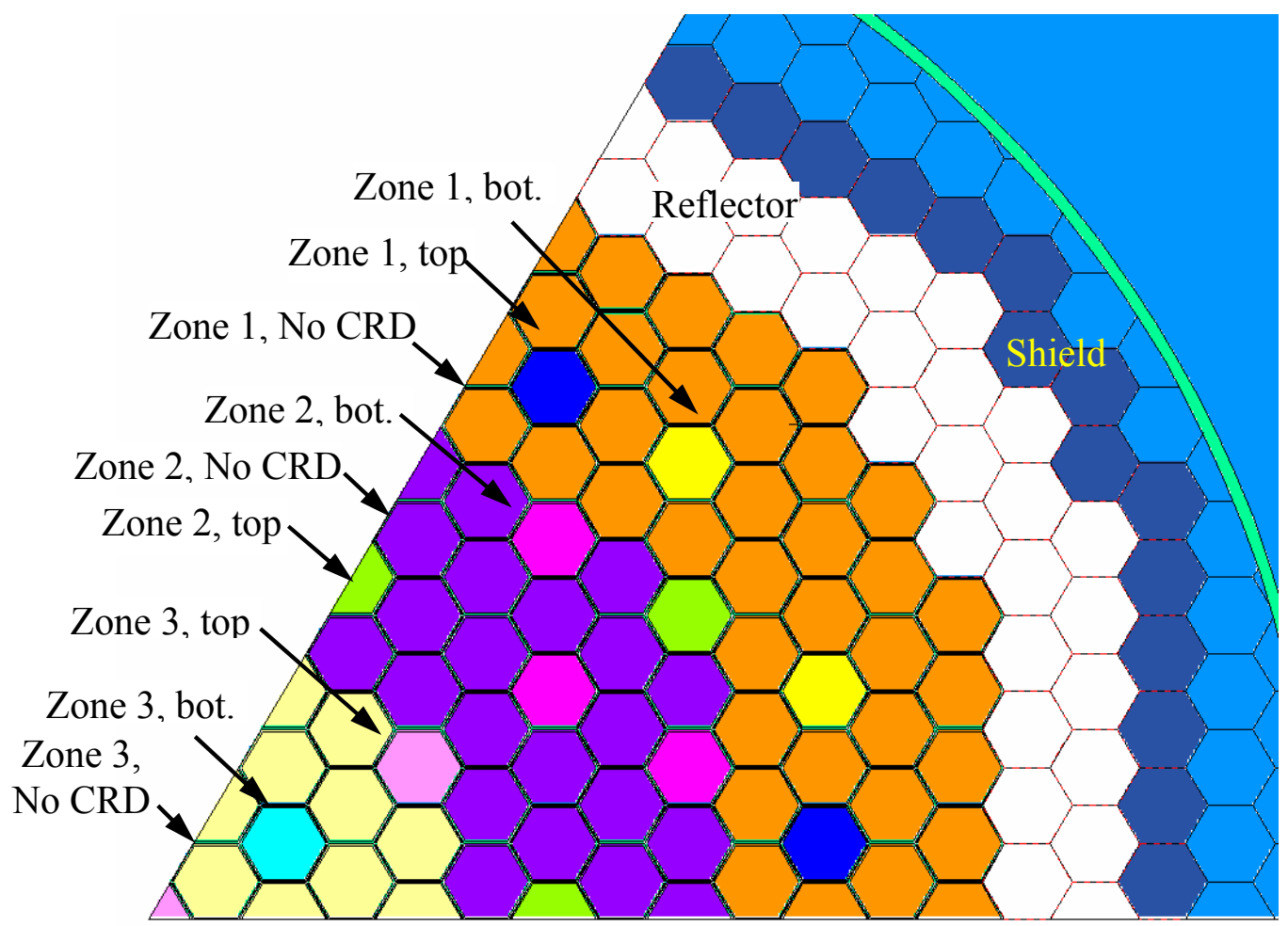

Figure 4.2.1-5. $\mathrm{CR}=1$ Core loading map $(130 \mathrm{~kW} / \mathrm{l})$

\begin{tabular}{|c|c|c|c|c|c|c|c|c|c|c|c|c|}
\hline & & & & & & & & & & & & $\odot .57$ \\
\hline & & & & & & & & & & 1.05 & 0.82 & 0.56 \\
\hline & & & & & & & & 1.17 & 1.21 & $\odot .98$ & $\odot .80$ & 0.53 \\
\hline & & & & & & 1.20 & 1.23 & 1.16 & 1.18 & $\odot .99$ & 0.75 & 0.48 \\
\hline & & & & 1.25 & 1.30 & 1.27 & 1.21 & 1.07 & 1.13 & 0.88 & 0.67 & 0.41 \\
\hline & & 1.25 & 1.25 & 1.25 & 1.29 & 1.25 & 1.18 & 1.08 & 1.06 & 0.84 & 0.57 & \\
\hline 1.18 & 1.25 & 1.19 & 1.25 & 1.17 & 1.28 & 1.16 & 1.14 & 0.96 & 0.97 & 0.72 & 0.45 & \\
\hline & 1.25 & 1.25 & 1.25 & 1.29 & 1.26 & 1.19 & 1.08 & 1.06 & 0.84 & 0.57 & & \\
\hline & & 1.25 & 1.30 & 1.27 & 1.22 & 1.07 & 1.14 & 0.88 & $\odot .68$ & 0.42 & & \\
\hline & & & 1.20 & 1.23 & 1.16 & 1.19 & 1.00 & 0.75 & $\odot .49$ & & & \\
\hline & & & & 1.17 & 1.22 & 0.99 & 0.80 & 0.53 & & & & \\
\hline & & & & & 1.05 & 0.82 & 0.56 & & & & & \\
\hline & & & & & & 0.57 & & & & & & \\
\hline
\end{tabular}

Figure 4.2.1-6. $\mathrm{CR}=1,130 \mathrm{~kW} / 1$ core, radial power profile at $\mathrm{BOC}$ 
Project No 06-040: Flexible Conversion Ratio Fast Reactor Systems Evaluation

\begin{tabular}{|c|c|c|c|c|c|c|c|c|c|c|c|c|}
\hline & & & & & & & & & & & & 0.59 \\
\hline & & & & & & & & & & 1.08 & 0.85 & 0.58 \\
\hline & & & & & & & & 1.16 & 1.24 & 1.02 & 0.83 & 0.55 \\
\hline & & & & & & 1.17 & 1.21 & 1.15 & 1.22 & 1.03 & 0.78 & $\odot .5 \odot$ \\
\hline & & & & 1.21 & 1.26 & 1.24 & 1.20 & 1.07 & 1.16 & 0.91 & 0.70 & 0.43 \\
\hline & & 1.20 & 1.21 & 1.20 & 1.25 & 1.22 & 1.17 & 1.07 & 1.09 & 0.87 & 0.59 & \\
\hline 1.13 & 1.20 & 1.15 & 1.20 & 1.13 & 1.24 & 1.14 & 1.12 & 0.96 & 1.00 & 0.75 & 0.47 & \\
\hline & 1.21 & 1.21 & 1.20 & 1.25 & 1.23 & 1.17 & 1.07 & 1.09 & 0.87 & 0.59 & & \\
\hline & & 1.21 & 1.26 & 1.24 & 1.19 & 1.07 & 1.17 & 0.91 & 0.70 & 0.43 & & \\
\hline & & & 1.17 & 1.21 & 1.15 & 1.22 & 1.03 & 0.78 & 0.50 & & & \\
\hline & & & & 1.16 & 1.25 & 1.02 & 0.83 & 0.55 & & & & \\
\hline & & & & & 1.09 & 0.86 & 0.58 & & & & & \\
\hline & & & & & & 0.59 & & & & & & \\
\hline
\end{tabular}

Figure 4.2.1-7. $\mathrm{CR}=1,130 \mathrm{~kW} / 1$ core, radial power profile at EOC

Figure 4.2.1-8 presents the axial power profile in different radial fuel zones. The axial power peaking is much lower than in the previous core design cases with blankets, which is part of the reason for achieving much higher power density. The axial power profile does not change significantly with burnup.

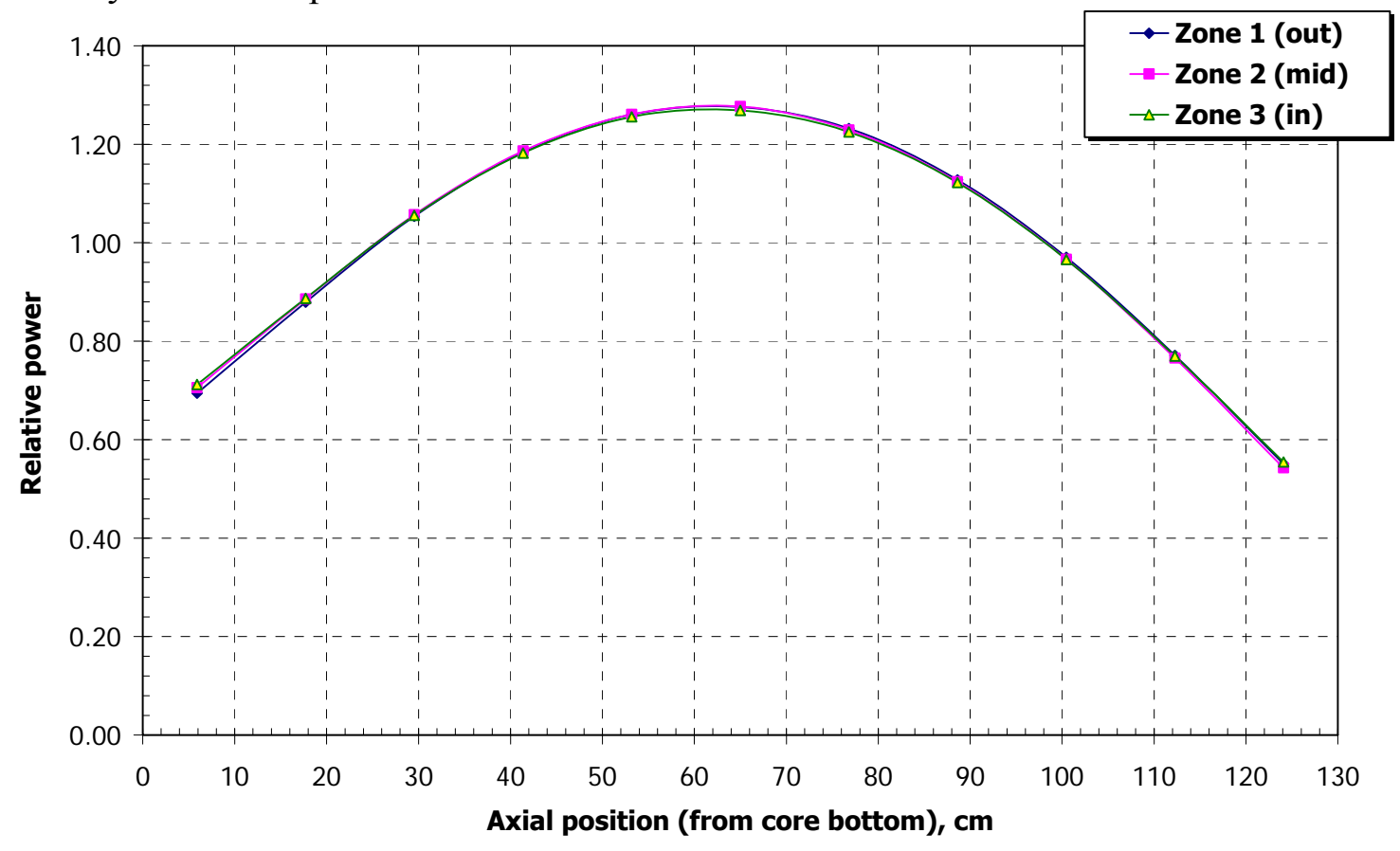

Figure 4.2.1-8. CR1 $130 \mathrm{~kW} / 1$ power density core, BOC axial power distribution 
Project No 06-040: Flexible Conversion Ratio Fast Reactor Systems Evaluation

Table 4.2.1-2. Summary of $\mathrm{CR}=1$ fuel cycle parameters $(130 \mathrm{~kW} / 1$ core $)$

\begin{tabular}{|l|r|r|r|r|}
\hline \multicolumn{1}{|c|}{ Parameters } & \multicolumn{1}{c|}{ Zone 1 } & \multicolumn{1}{c|}{ Zone 2 } & \multicolumn{1}{c|}{ Zone 3 } & \multicolumn{1}{c|}{ Core } \\
\hline Zr content, wt. \% & 10.0 & 15.0 & 17.0 & - \\
\hline Fuel density (g/cc) & 15.40 & 14.29 & 13.89 & - \\
\hline Smear density (g/cc) & 11.54 & 10.71 & 10.42 & - \\
\hline TRU content, wt. \% & 14.13 & 13.35 & 13.03 & - \\
\hline Natural Uranium content, wt. \% & 75.87 & 71.65 & 69.97 & - \\
\hline Number of FA with CRDs & 24 & 30 & 13 & 67 \\
\hline Number of FA without CRDs & 210 & 126 & 48 & 384 \\
\hline Initial HM loading, kg & 37,739 & 21,963 & 8,144 & 67,847 \\
\hline Pu & 5,118 & 2,979 & 1,105 & 9,202 \\
\hline NU (Natural Uranium) & 31,831 & 18,525 & 6,869 & 57,224 \\
\hline MA & 790 & 460 & 171 & 1,421 \\
\hline Discharge burnup, MWd/kg & 51 & 85 & 93 & 67 \\
\hline Cycle length, EFPD & - & - & - & 1,900 \\
\hline
\end{tabular}

Similarly to the lead-cooled core analysis, two additional $\mathrm{CR}=1$ high power density cores were simulated with TRUs recycled for the second and third time in order to evaluate the effect of changing TRU isotopic composition on fuel cycle length and conversion ratio. The TRU discharged from the first core, after a decay period of 7 years, was assumed to be mixed with natural uranium and reloaded to a subsequent core.

Using the same clad fluence limit $\left(4 \times 10^{23} \mathrm{n} / \mathrm{cm}^{2}\right)$ to determine the fuel cycle length of the 130 $\mathrm{kW} / 1$ power density core, the fuel cycle length shortens to about 1900 EFPD instead of 2500 EFPD in the low power density case. In the TRU recycling scenario however, which is likely to be realized sometime in the future, it is reasonable to assume availability of advanced cladding materials capable of withstanding higher fluence limits. Therefore, a $5.5 \times 10^{23} \mathrm{n} / \mathrm{cm}^{2}$ fluence limit was adopted (see Figure 4.2.1-9) for this analysis, which allows achieving the same cycle length (2500 EFPD) as the core with $100 \mathrm{~W} / \mathrm{cm}^{3}$ power density.

The results of these TRU recycling calculations are presented in Figures 4.2.1-10 and 4.2.1-14. Figures 4.2.1-10 and 4.2.1-11 present the evolution of core criticality as a function of irradiation time and core average burnup, respectively. Figures 4.2.1-12, 4.2.1-13, and 4.2.1-14 present the core $\mathrm{Pu}$, Minor Actinide, and total TRU content as a function of burnup. Tables 4.2.1-3 and 4.2.1-4 present the balance of materials in the three modeled consecutive cycles and evolution of TRU isotopic vector, respectively.

As can be observed, the reactivity limited burnup gradually increases with the number of TRU recycles despite the decreasing total TRU inventory. This is because the $\mathrm{Pu}$ content slightly increases with the recycling of TRU, while the MA inventory is decreasing. The core reactivity changes very slightly (less than $2 \% \Delta \rho$ ) over the lifetime of the core. The $\mathrm{Pu}$ isotopic vector remains practically constant, with slight reduction in the amount of the $\mathrm{Pu} 241$ isotope. All MA isotopes exhibit net mass reduction in their amounts except for the two $\mathrm{Cm}$ isotopes $\mathrm{Cm} 245$ and 
Project No 06-040: Flexible Conversion Ratio Fast Reactor Systems Evaluation

Cm246 (see Table 4.2.1-5). All of the observed trends are very similar to those of the leadcooled $\mathrm{CR}=1$ core.

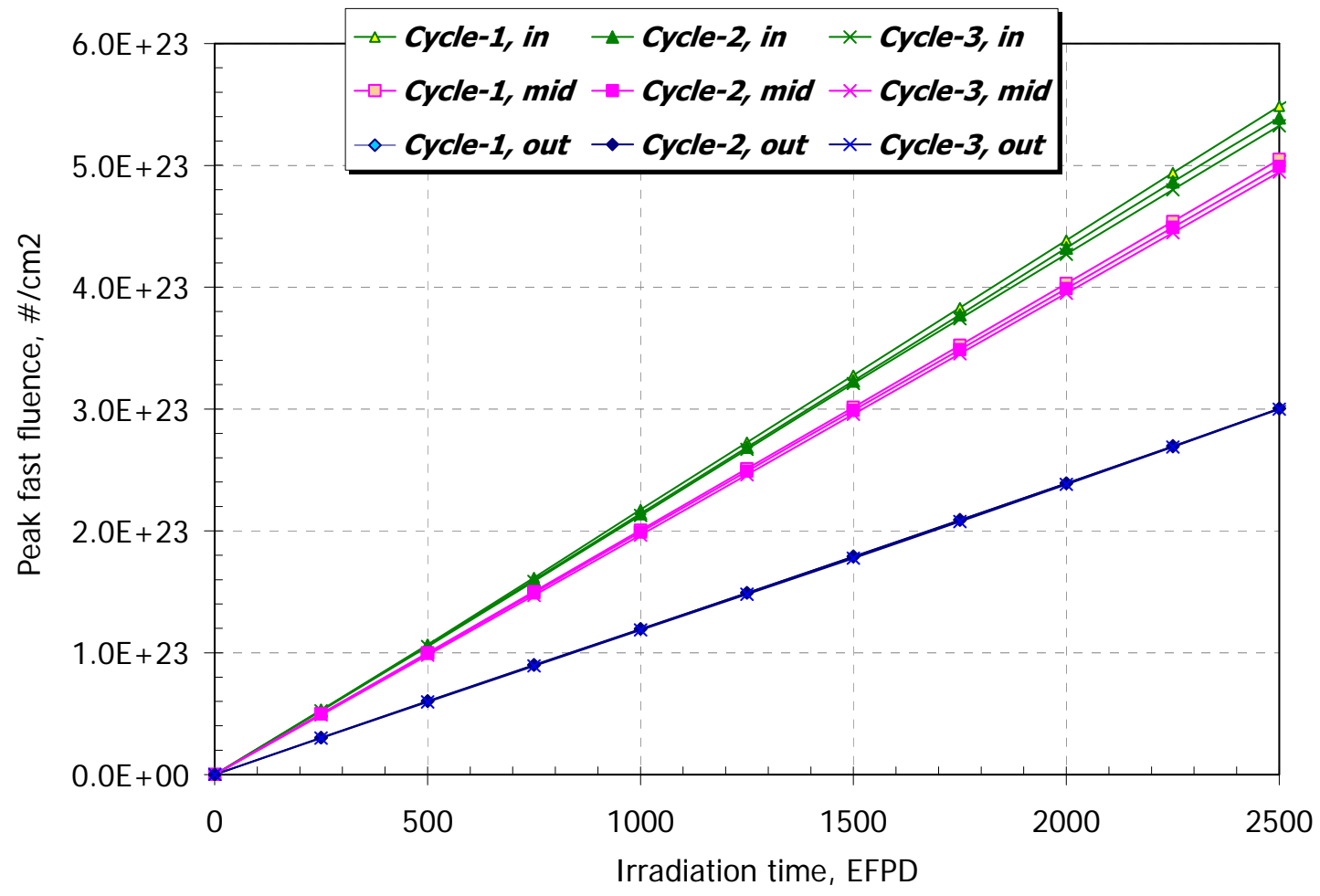

Figure 4.2.1-9. Peak fast fluence to cladding, $C R=1$, q' ' $=130 \mathrm{~W} / \mathrm{cc}$

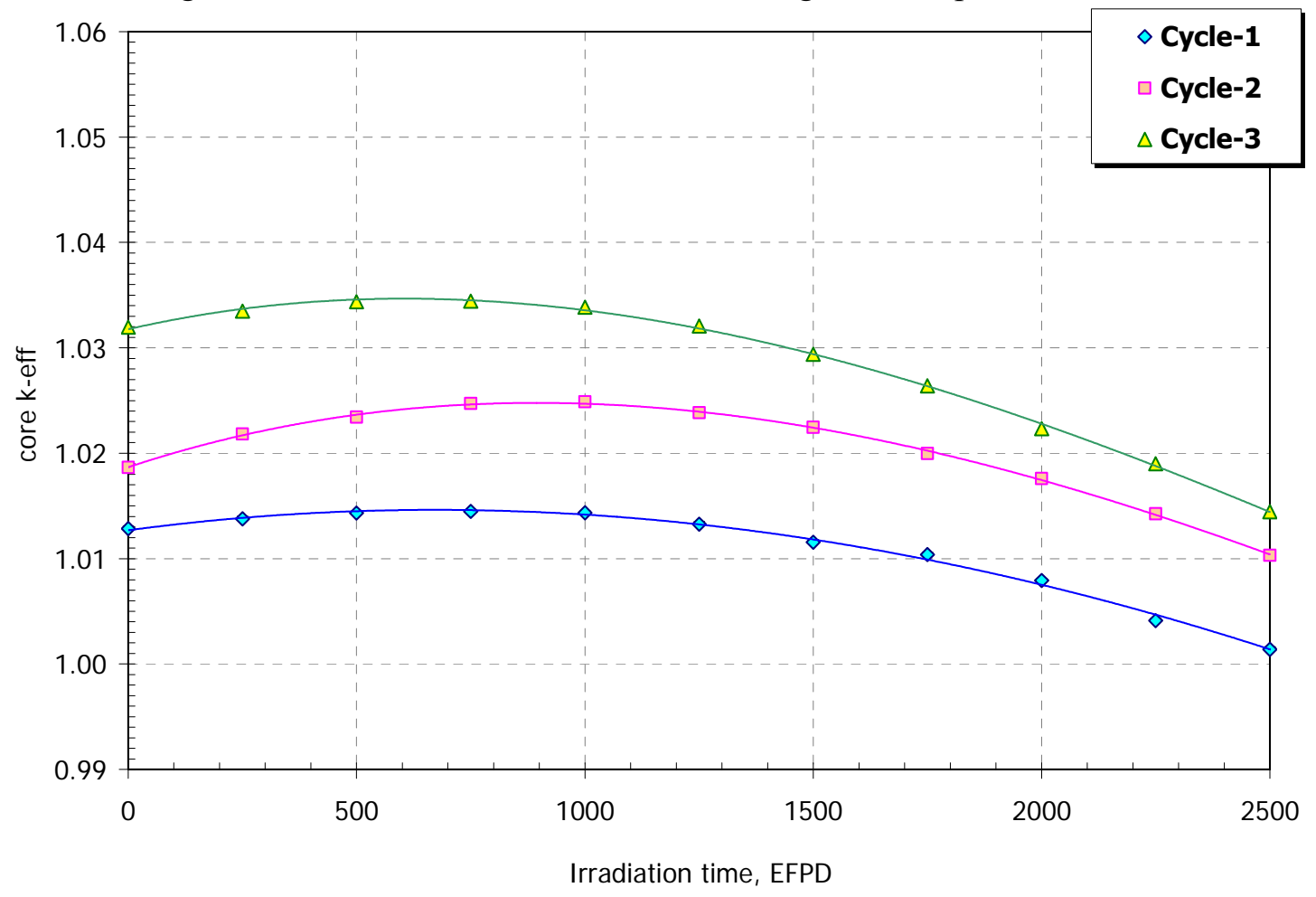

Figure 4.2.1-10. Core k-eff as a function of time, $\mathrm{CR}=1$, q", $=130 \mathrm{~W} / \mathrm{cc}$ 
Project No 06-040: Flexible Conversion Ratio Fast Reactor Systems Evaluation

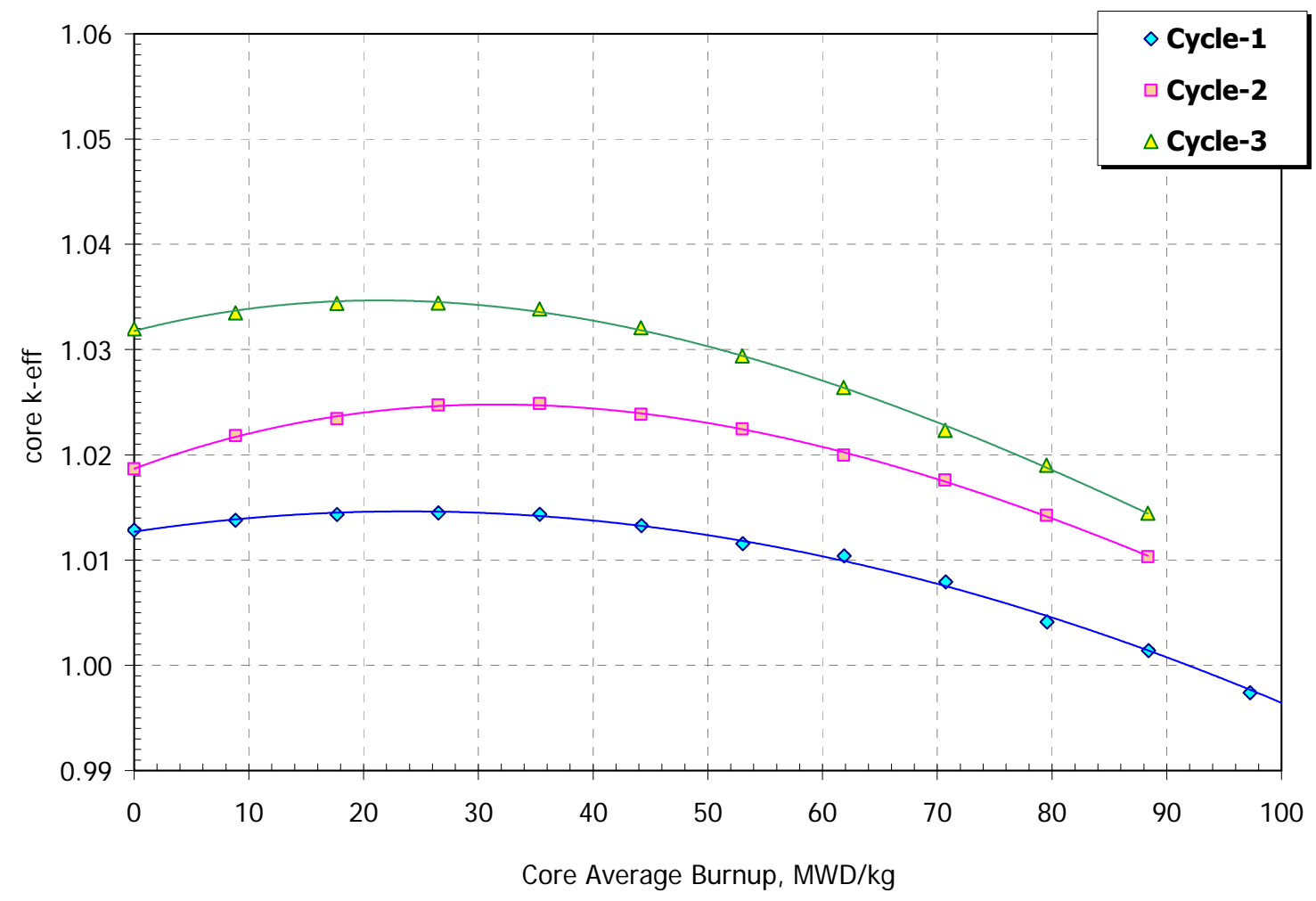

Figure 4.2.1-11. Core k-eff as a function of core average burnup, $C R=1, \mathrm{q} "{ }^{\prime \prime}=130 \mathrm{~W} / \mathrm{cc}$

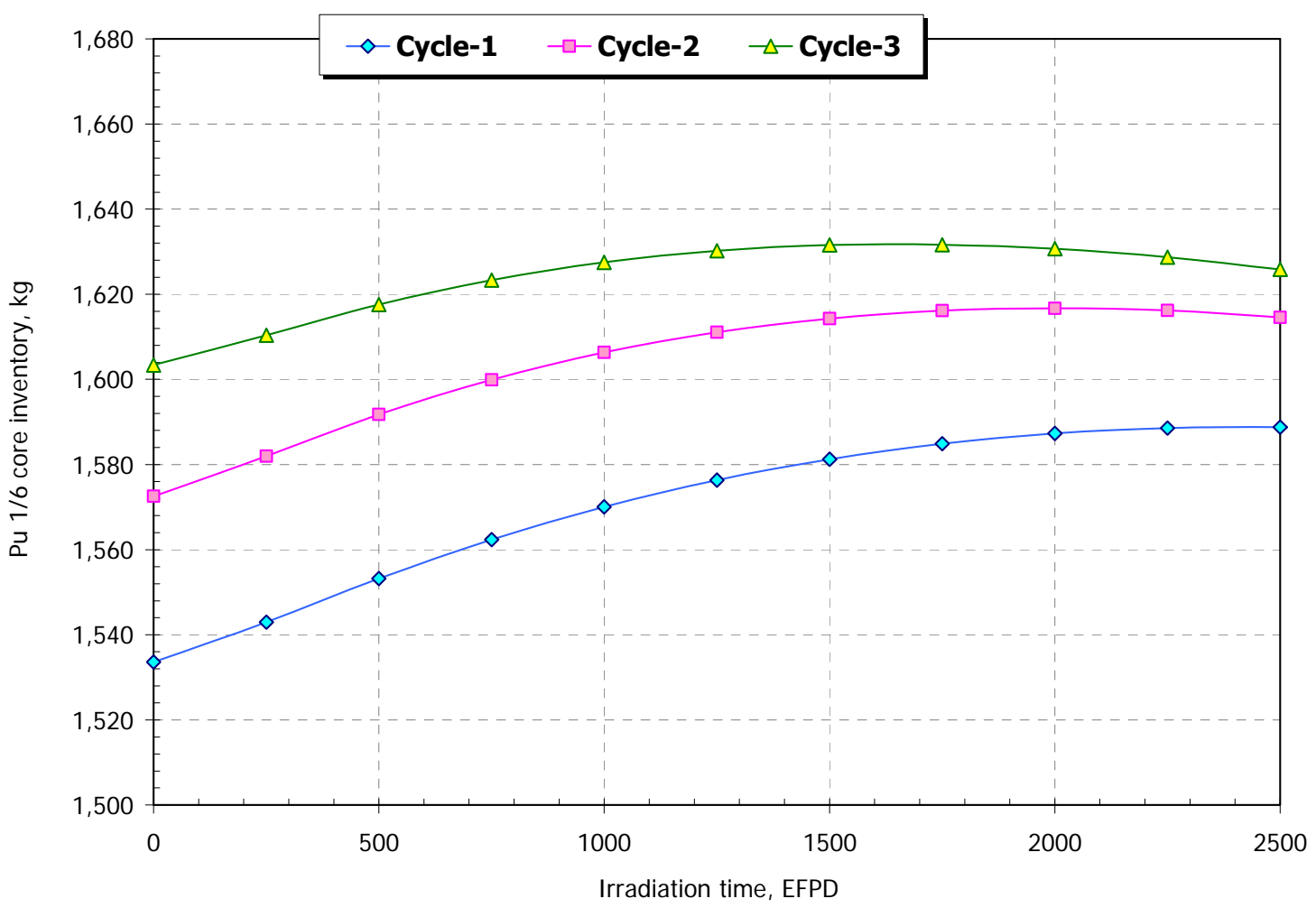

Figure 4.2.1-12. Pu inventory per $1 / 6$ of a core, $\mathrm{CR}=1$, q"' $=130 \mathrm{~W} / \mathrm{cc}$ 
Project No 06-040: Flexible Conversion Ratio Fast Reactor Systems Evaluation

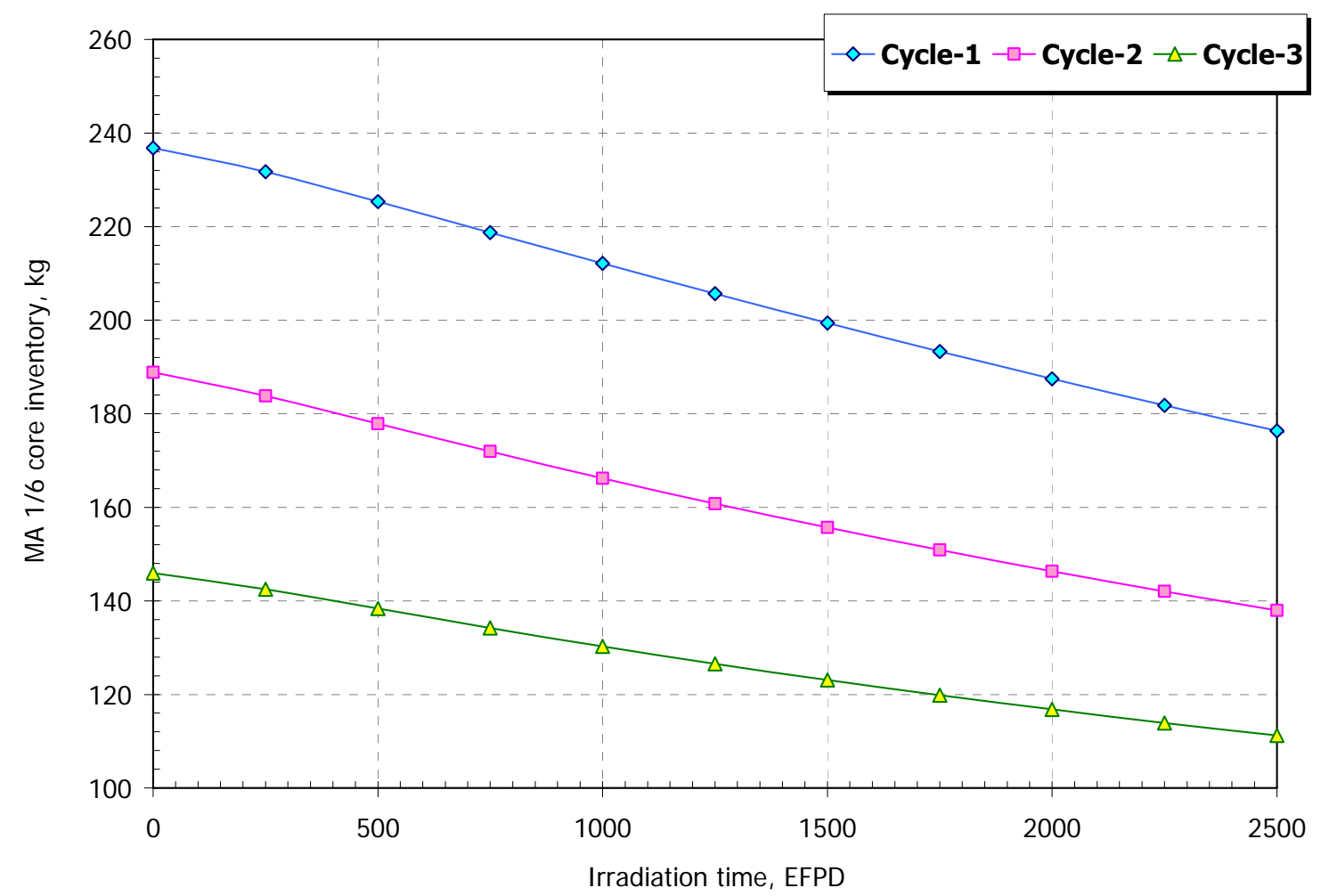

Figure 4.2.1-13. MA inventory per $1 / 6$ of a core, $\mathrm{CR}=1$, q", $=130 \mathrm{~W} / \mathrm{cc}$

Table 4.2.1-3. CR=1 Core materials balance

\begin{tabular}{|c|r|r|r|r|r|r|r|r|r|}
\hline & \multicolumn{3}{|c|}{ Cycle-1 TRU } & \multicolumn{3}{c|}{ Cycle-2 TRU } & \multicolumn{2}{c|}{ Cycle-3 TRU } & \\
\hline & Load, kg & Disch., kg & $\begin{array}{c}\text { After 7y, } \\
\text { kg }\end{array}$ & Load, kg & Disch, kg & $\begin{array}{c}\text { After 7y, } \\
\mathrm{kg}\end{array}$ & Load, kg & Disch, kg & $\begin{array}{c}\text { After 7y, } \\
\mathrm{kg}\end{array}$ \\
\hline Total HM & 67,847 & 61,719 & - & 67,893 & 61,765 & - & 67,903 & 61,778 & - \\
\hline $\mathrm{Pu}$ & 9,202 & 9,533 & 9,435 & 9,435 & 9,688 & 9,620 & 9,620 & 9,755 & 9,692 \\
\hline $\mathrm{U}$ & 57,224 & 51,128 & - & 57,323 & 51,245 & - & 57,402 & 51,349 & - \\
\hline MA & 1,421 & 1,058 & 1,135 & 1,135 & 832 & 880 & 880 & 674 & 721 \\
\hline Pu+MA & 10,622 & 10,591 & 10,570 & 10,570 & 10,520 & 10,501 & 10,501 & 10,429 & 10,413 \\
\hline
\end{tabular}


Project No 06-040: Flexible Conversion Ratio Fast Reactor Systems Evaluation

Table 4.2.1-4. $\mathrm{CR}=1$ Core TRU isotopic vector, wt $\%$

\begin{tabular}{|r|r|r|r|r|r|r|r|}
\hline & \multicolumn{3}{|c|}{ Cycle-1 } & \multicolumn{2}{c|}{ Cycle-2 } & \multicolumn{2}{c|}{ Cycle-3 } \\
\hline $\begin{array}{r}\text { Isotope ID } \\
\text { (ZZ AAA) }\end{array}$ & (initial) & \multicolumn{1}{|c|}{ (disch.) } & (after 7y) & (disch.) & (after 7y) & (disch.) & (after 7y) \\
\hline 93237 & 6.66 & 3.83 & 3.88 & 2.32 & 2.36 & 1.50 & 1.53 \\
\hline 94238 & 2.76 & 4.07 & 3.98 & 3.88 & 3.79 & 3.25 & 3.17 \\
\hline 94239 & 48.81 & 53.82 & 53.98 & 56.49 & 56.64 & 58.01 & 58.15 \\
\hline 94240 & 23.06 & 23.59 & 23.80 & 24.65 & 24.87 & 25.74 & 25.94 \\
\hline 94241 & 6.95 & 3.66 & 2.62 & 2.66 & 1.90 & 2.57 & 1.84 \\
\hline 94242 & 5.05 & 4.87 & 4.88 & 4.41 & 4.42 & 3.97 & 3.97 \\
\hline 95241 & 4.67 & 4.23 & 4.44 & 2.82 & 3.56 & 2.33 & 3.04 \\
\hline $95242 m$ & 0.0191 & 0.2570 & 0.2488 & 0.2850 & 0.2758 & 0.2519 & 0.2438 \\
\hline 95243 & 1.4769 & 1.4062 & 1.4080 & 1.3391 & 1.3407 & 1.2503 & 1.2514 \\
\hline 96242 & 0.0000 & 0.1274 & 0.0007 & 0.1057 & 0.0007 & 0.0869 & 0.0006 \\
\hline 96243 & 0.0050 & 0.0118 & 0.0100 & 0.0116 & 0.0099 & 0.0098 & 0.0084 \\
\hline 96244 & 0.4976 & 0.7870 & 0.6022 & 0.8149 & 0.6235 & 0.7948 & 0.6080 \\
\hline 96245 & 0.0381 & 0.1282 & 0.1284 & 0.1660 & 0.1662 & 0.1774 & 0.1775 \\
\hline 96246 & 0.0060 & 0.0191 & 0.0191 & 0.0382 & 0.0382 & 0.0562 & 0.0562 \\
\hline 96247 & 0.0000 & 0.0013 & 0.0013 & 0.0031 & 0.0031 & 0.0061 & 0.0061 \\
\hline 96248 & 0.0000 & 0.0001 & 0.0001 & 0.0003 & 0.0003 & 0.0010 & 0.0010 \\
\hline
\end{tabular}

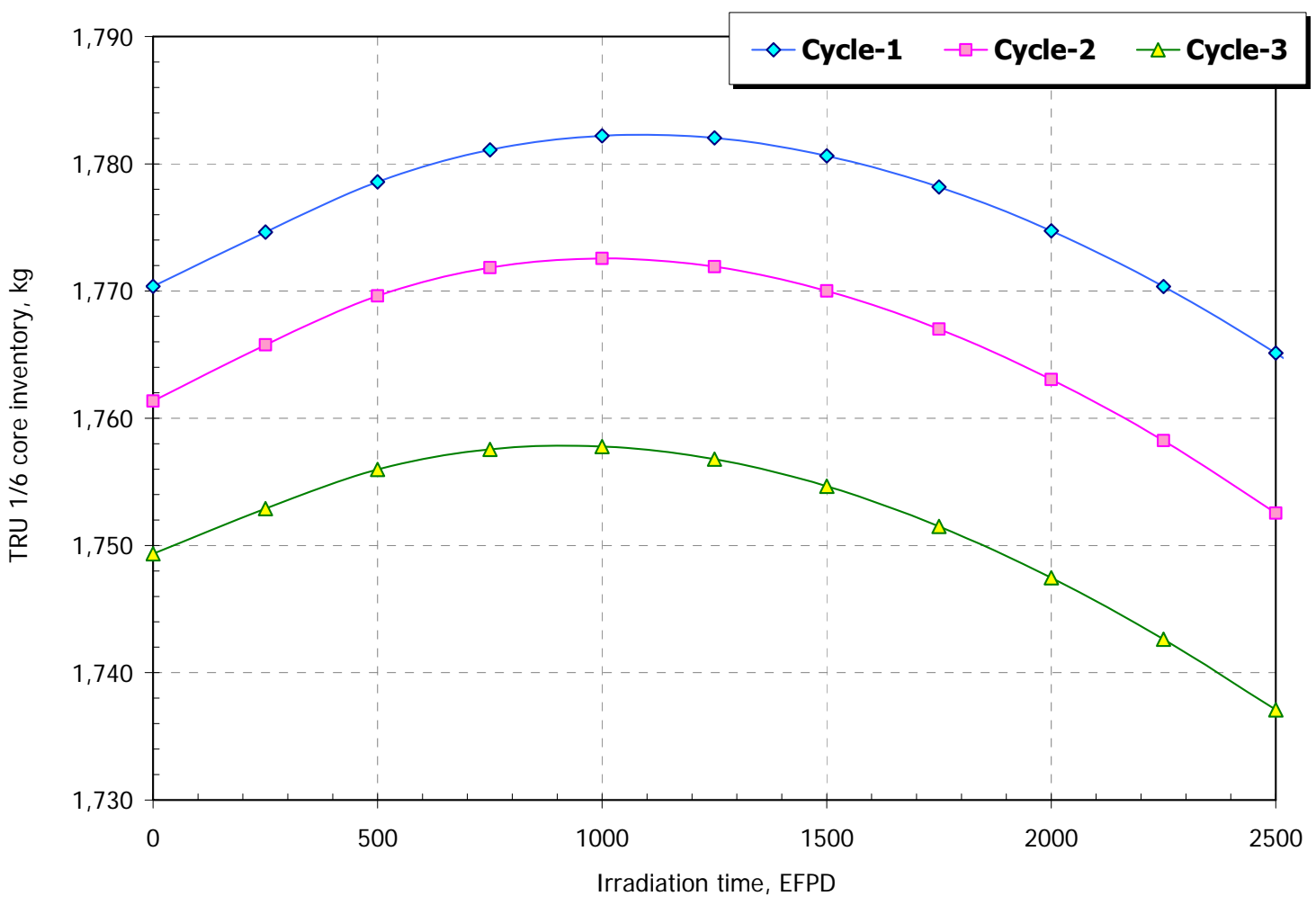

Figure 4.2.1-14. Total TRU inventory per $1 / 6$ of a core, $C R=1, \mathrm{q}$ "' $=130 \mathrm{~W} / \mathrm{cc}$ 
Table 4.2.1-5. Cm isotope inventory $(\mathrm{kg})$ for the full core, 7 years after discharge

\begin{tabular}{|l|r|r|r|}
\hline Isotope ID & \multicolumn{1}{|c|}{ Cycle-1 } & \multicolumn{1}{c|}{ Cycle-2 } & \multicolumn{1}{c|}{ Cycle-3 } \\
\hline 96242 & 0.069 & 0.076 & 0.067 \\
\hline 96243 & 1.061 & 1.038 & 0.873 \\
\hline 96244 & 63.652 & 65.470 & 63.310 \\
\hline 96245 & 13.569 & 17.453 & 18.486 \\
\hline 96246 & 2.022 & 4.015 & 5.855 \\
\hline 96247 & 0.140 & 0.325 & 0.634 \\
\hline 96248 & 0.011 & 0.029 & 0.103 \\
\hline Total Cm & 80.525 & 88.407 & 89.327 \\
\hline
\end{tabular}

\section{Reactivity Coefficients and Self-Controllability Criteria}

Reactivity coefficients required to assess the self controllability of the core based on the quasistatic analysis methodology [Wade and Chang, 1988] were calculated at BOL and EOL for both the $100 \mathrm{~W} / \mathrm{cm}^{3}$ and $130 \mathrm{~W} / \mathrm{cm}^{3}$ power density cores. The calculation methodology was identical to that used for the lead-cooled core analysis and described in details in Section 3A.4 of the Appendix 3A.

The core operating conditions and safety margins used to calculate the self-controllability limits are summarized in Table 4.2.1-6.

Table 4.2.1-6. Core Operating Parameter Limits

\begin{tabular}{|l|c|}
\hline Parameter & Value \\
\hline Coolant Inlet Temperature, ${ }^{\circ} \mathrm{C}$ & 496 \\
\hline Coolant Outlet temperature, ${ }^{\circ} \mathrm{C}$ & 580 \\
\hline Core Coolant Temperature Rise, $\Delta \mathrm{T}_{\mathrm{c}},{ }^{\circ} \mathrm{C}$ & 84 \\
\hline Coolant Freezing Point, ${ }^{\circ} \mathrm{C}$ & 396 \\
\hline Margin to Freezing, ${ }^{\circ} \mathrm{C}$ & 100 \\
\hline Cladding Failure Limit, ${ }^{\circ} \mathrm{C}$ & 725 \\
\hline Margin to Cladding Failure, ${ }^{\circ} \mathrm{C}$ & 145 \\
\hline
\end{tabular}

The Doppler coefficient was evaluated by performing a set of core criticality calculations at 4 different fuel temperatures and fitting a second order polynomial function to the results of these calculations. The $100 \mathrm{~W} / \mathrm{cm}^{3}$ and $130 \mathrm{~W} / \mathrm{cm}^{3}$ core reactivity at BOL and EOL as a function of fuel temperature is reported in Figures 4.2.1-15 through 4.2.1-18 respectively. These data was subsequently used for the core transients modeling with RELAP5 code.

The Coolant Temperature Coefficient was calculated by perturbing the core average coolant temperature by $50 \mathrm{~K}$. The core temperature increase was assumed to be a result of the core power increase, i.e. the core inlet temperatures in the nominal and perturbed cases were assumed to be the same, while the coolant temperature rise across the core was increased by $100 \mathrm{~K}$. The LEMs were designed such that $100 \mathrm{~K}$ outlet coolant temperature increase would result in Li insertion $3 / 4$ 
Project No 06-040: Flexible Conversion Ratio Fast Reactor Systems Evaluation

of the active core height. As mentioned earlier and demonstrated in Figure 4.2.1-19, an additional quarter length of the core insertion of $\mathrm{Li}$ is not effective because it provides practically no additional negative reactivity insertion.

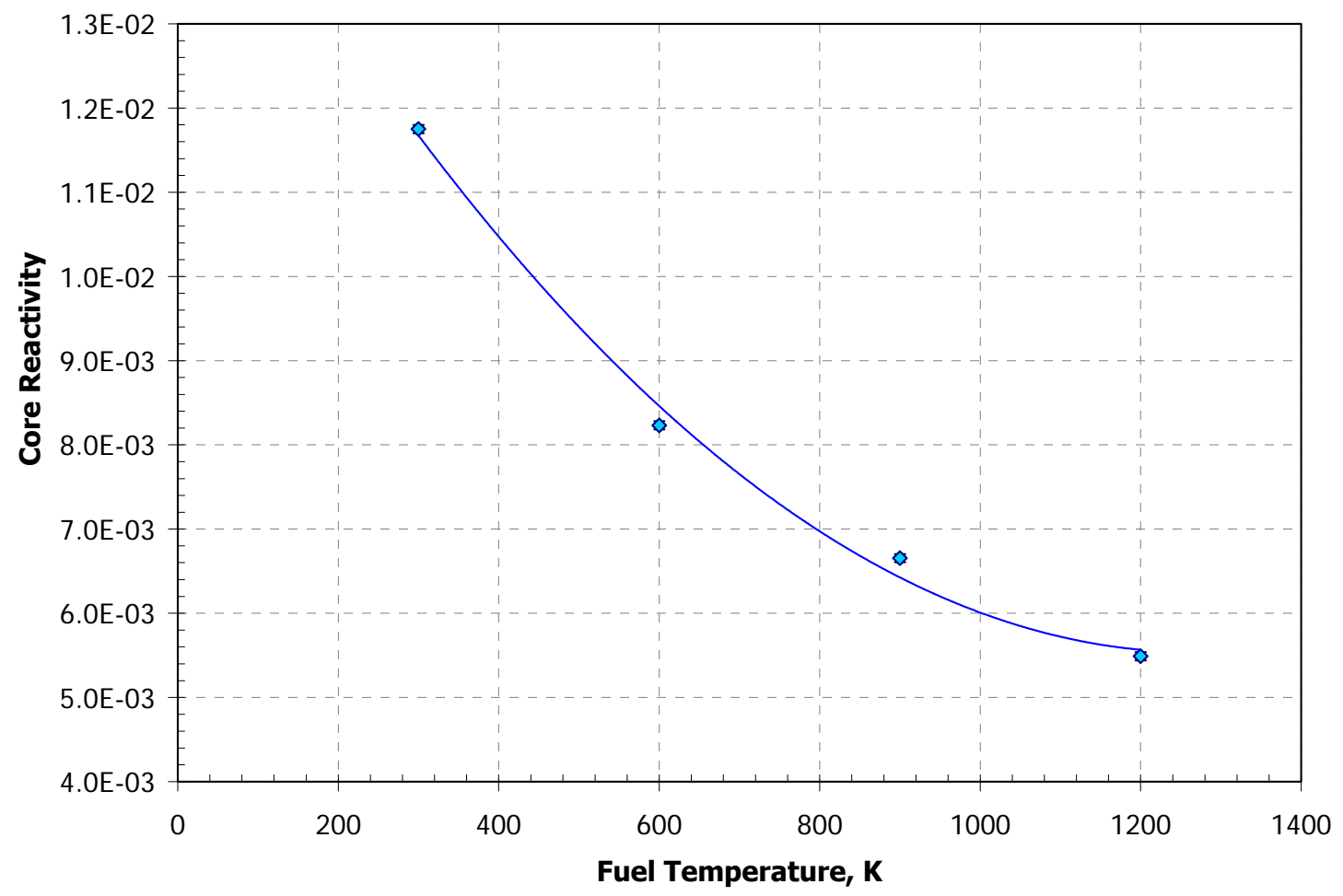

Figure 4.2.1-15. Core reactivity vs. fuel temperature (BOL), $C R=1, P=100 \mathrm{~W} / \mathrm{cc}$

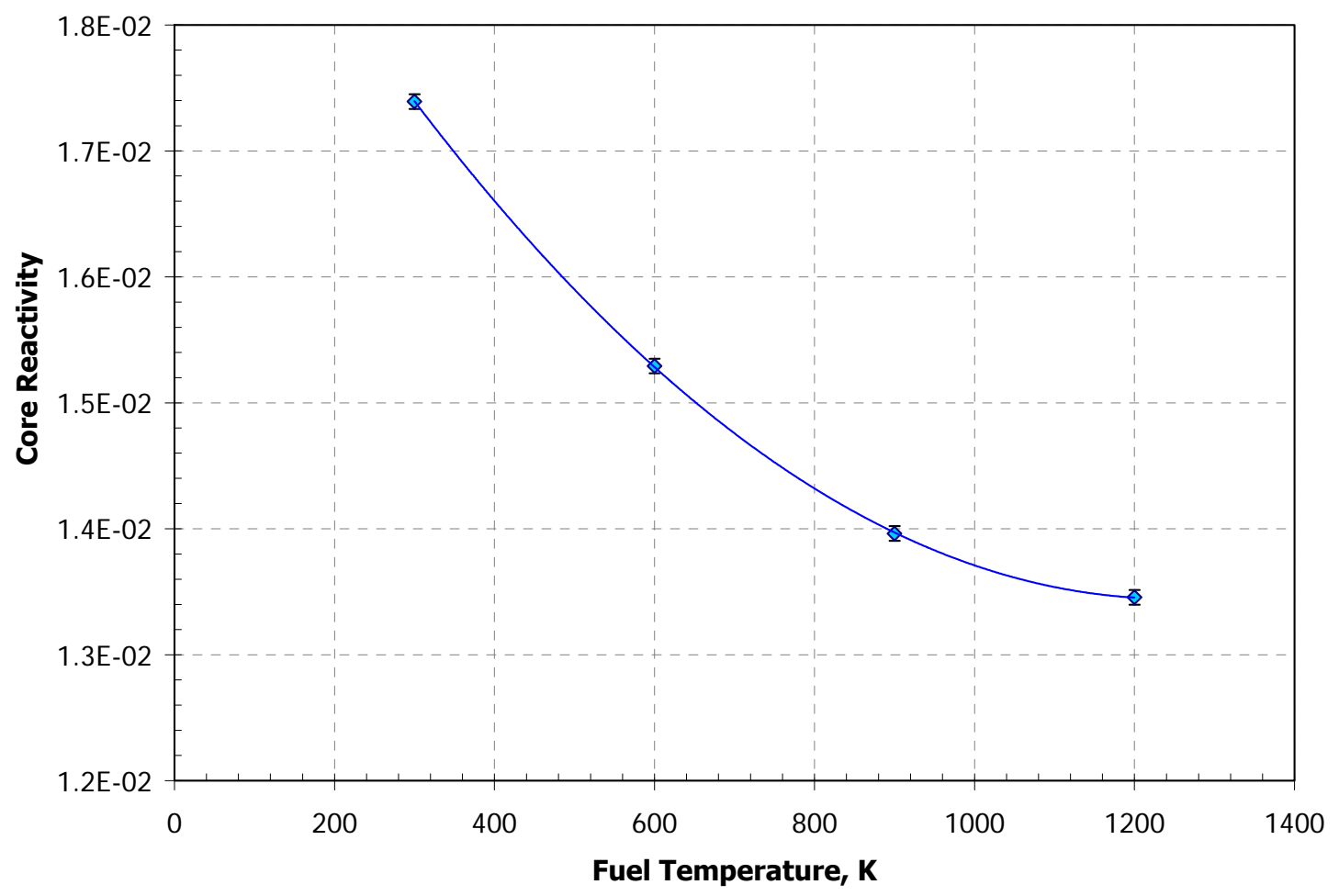

Figure 4.2.1-16. Core reactivity vs. fuel temperature (EOL), $\mathrm{CR}=1, \mathrm{P}=100 \mathrm{~W} / \mathrm{cc}$ 
Project No 06-040: Flexible Conversion Ratio Fast Reactor Systems Evaluation

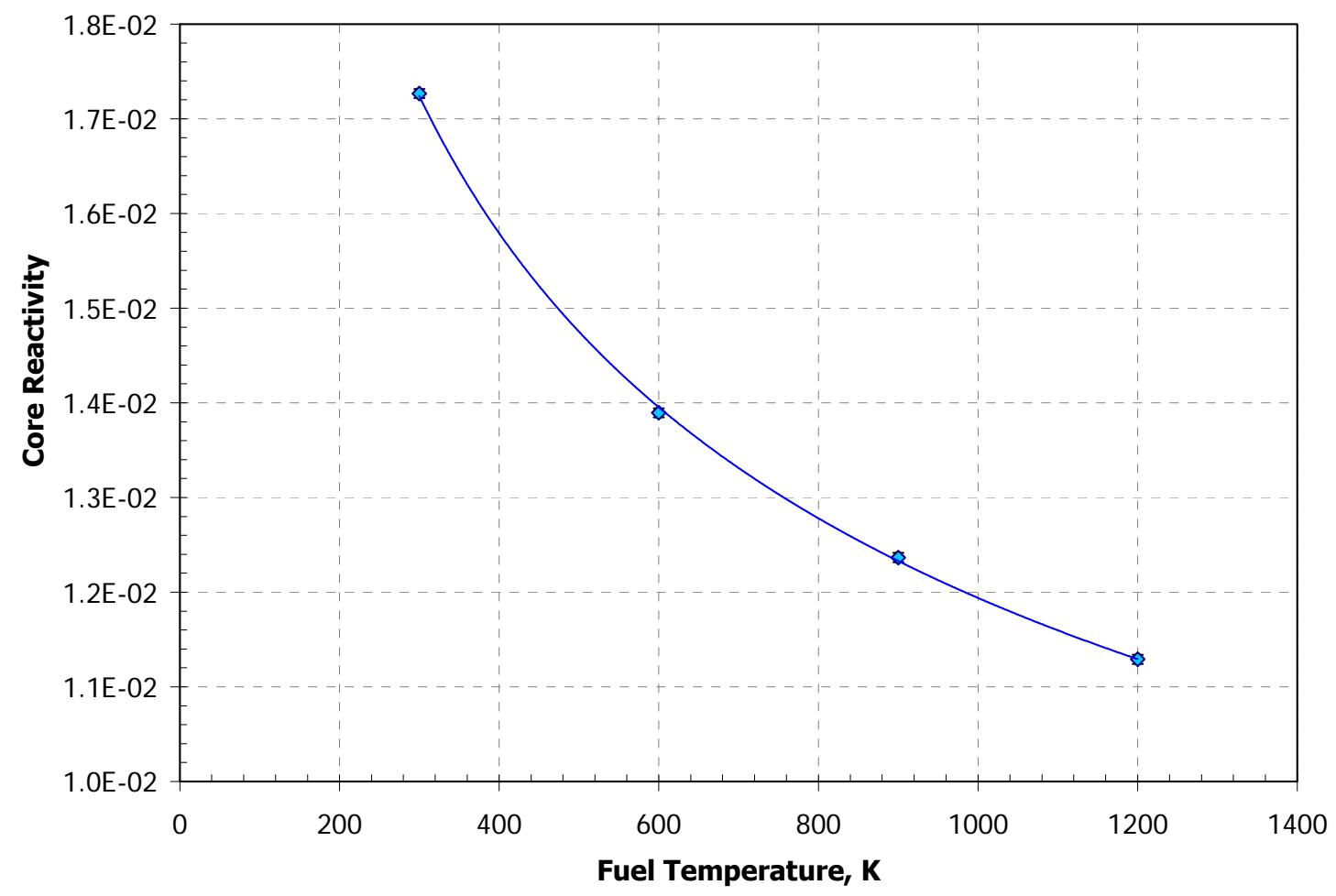

Figure 4.2.1-17. Core reactivity vs. fuel temperature (BOL), $C R=1, P=130 \mathrm{~W} / \mathrm{cc}$

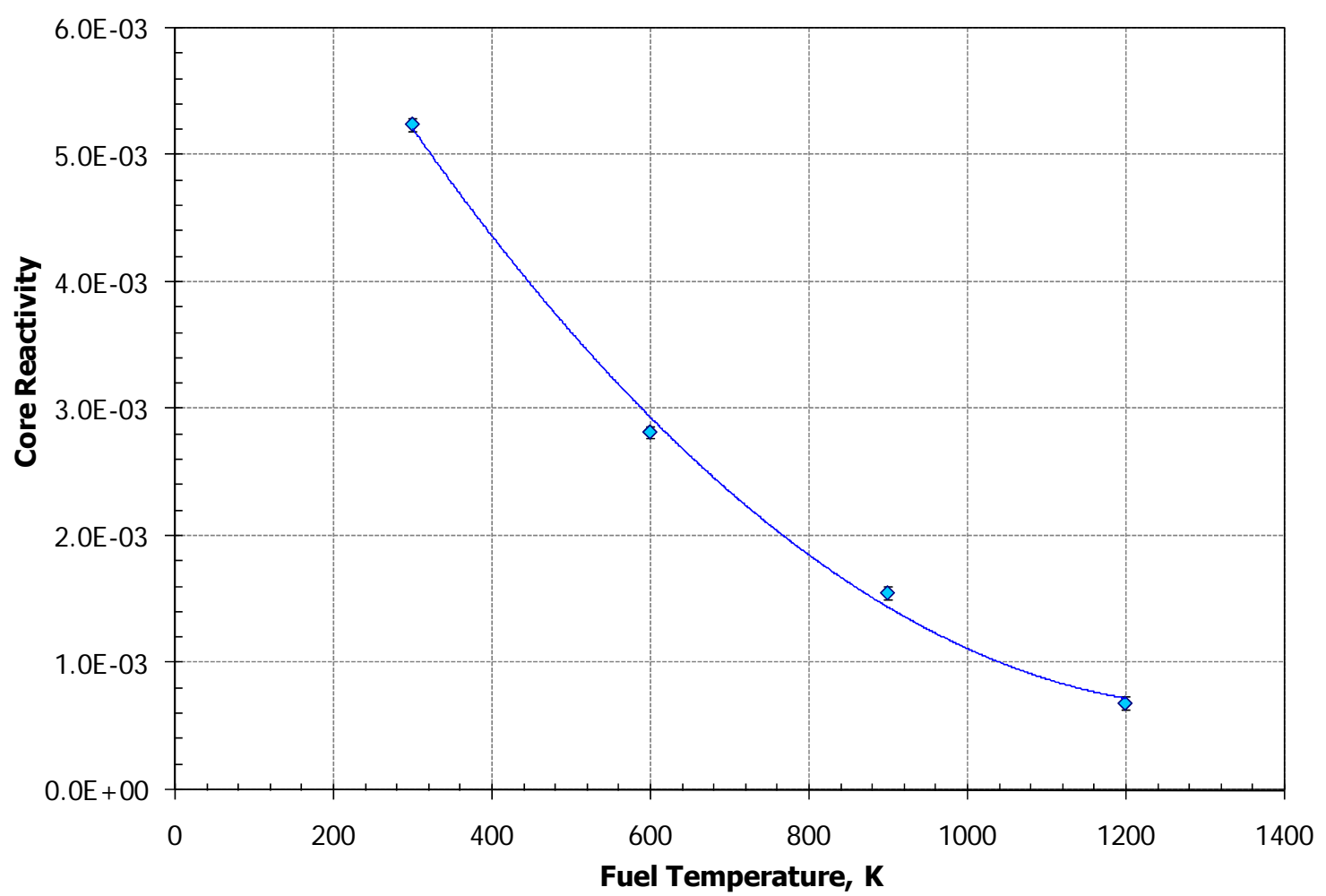

Figure 4.2.1-18. Core reactivity vs. fuel temperature (EOL), $C R=1, P=130 \mathrm{~W} / \mathrm{cc}$ 
Project No 06-040: Flexible Conversion Ratio Fast Reactor Systems Evaluation

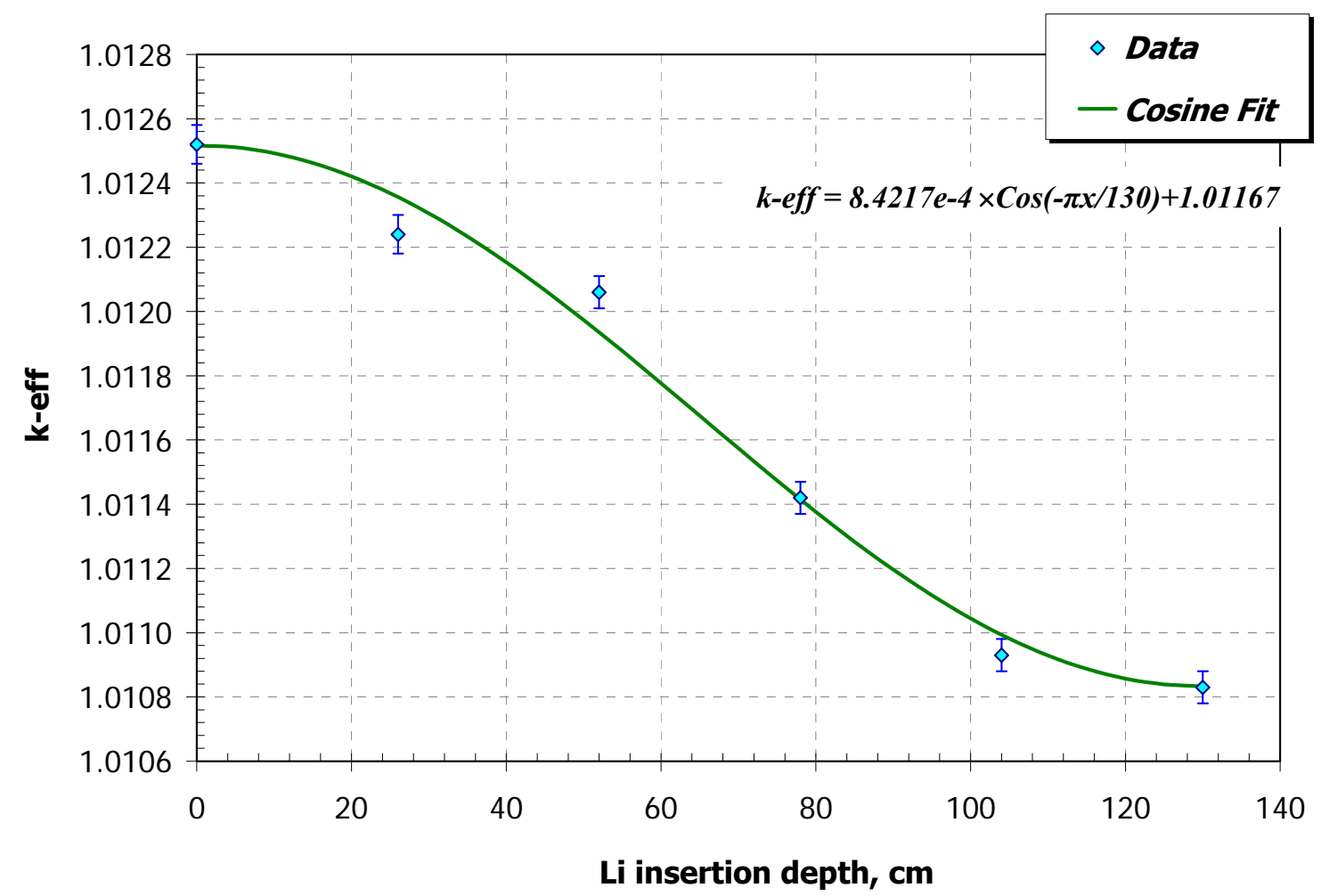

Figure 4.2.1-19. $\mathrm{CR}=1,130 \mathrm{~kW} / 1$, Core k-eff vs. Li insertion depth (all nominal conditions)

Table 4.2.1-7. Reactivity feedback parameters summary, $C R=1$, q", $=100 \mathrm{~kW} / 1$

\begin{tabular}{|c|c|c|c|c|c|}
\hline & Units & $\begin{array}{l}\text { BOL } \\
\text { value }\end{array}$ & $\begin{array}{c}\text { Uncertainty } \\
\pm \sigma\end{array}$ & $\begin{array}{l}\text { EOL } \\
\text { value }\end{array}$ & $\begin{array}{c}\text { Uncertainty } \\
\pm \sigma\end{array}$ \\
\hline$\beta$ & & 0.0040 & 0.0001 & 0.0032 & 0.0001 \\
\hline$\alpha_{\mathrm{DC}}$ & $\phi / K$ & -0.122 & 0.030 & -0.095 & 0.030 \\
\hline$\alpha_{\mathrm{e}}$ & $\phi / \mathrm{K}$ & -0.042 & 0.017 & -0.106 & 0.024 \\
\hline$\alpha_{\mathrm{Co}}$ & $\phi / \mathrm{K}$ & -0.084 & 0.035 & 0.031 & 0.043 \\
\hline$\alpha_{\mathrm{RD}}$ & $\phi / \mathrm{K}$ & $\sim 0$ & $\mathrm{~N} / \mathrm{A}$ & $\sim 0$ & $\mathrm{~N} / \mathrm{A}$ \\
\hline$\alpha_{R}$ & $\phi / \mathrm{K}$ & -0.143 & 0.024 & -0.221 & 0.086 \\
\hline A & $\phi$ & -14.59 & 3.09 & -17.89 & 3.40 \\
\hline $\mathrm{B}$ & $\phi$ & -22.37 & 2.19 & -25.71 & 2.61 \\
\hline $\mathrm{C}$ & $\phi / \mathrm{K}$ & -0.39 & 0.05 & -0.39 & 0.06 \\
\hline $\mathrm{A} / \mathrm{B}$ & & 0.65 & 0.15 & 0.70 & 0.15 \\
\hline $\mathrm{C} \Delta \mathrm{Tc} / \mathrm{B}$ & & 1.46 & 0.24 & 1.28 & 0.23 \\
\hline$\Delta \rho_{\mathrm{TOP}} / \mathrm{B}$ & & 0.42 & 0.04 & 0.45 & 0.05 \\
\hline A/B limits & & \multicolumn{2}{|c|}{$\mathrm{x}<1.15(1.73)$} & \multicolumn{2}{|c|}{$\mathrm{x}<1.15(1.73)$} \\
\hline $\mathrm{C} \Delta \mathrm{T}_{\mathrm{c}} / \mathrm{B}$ limits & & \multicolumn{2}{|c|}{$1<\mathrm{x}<2.36(2.94)$} & \multicolumn{2}{|c|}{$1<x<2.36(2.94)$} \\
\hline$\Delta \rho_{\mathrm{TOP}} / \mathrm{B}$ limits & & \multicolumn{2}{|c|}{$\mathrm{x}<1.15(1.73)$} & \multicolumn{2}{|c|}{$\mathrm{x}<1.15(1.73)$} \\
\hline
\end{tabular}


Table 4.2.1-8. Reactivity feedback parameters summary, $C R=1$, q"'=130 kW/1

\begin{tabular}{|c|c|c|c|c|c|}
\hline & Units & $\begin{array}{l}\text { BOL } \\
\text { value }\end{array}$ & $\begin{array}{c}\text { Uncertainty } \\
\pm \sigma\end{array}$ & $\begin{array}{c}\text { EOL } \\
\text { value }\end{array}$ & $\begin{array}{c}\text { Uncertainty } \\
\pm \sigma\end{array}$ \\
\hline$\beta$ & & 0.0039 & 0.0001 & 0.0035 & 0.0001 \\
\hline$\alpha_{\mathrm{DC}}$ & $\notin / \mathrm{K}$ & -0.092 & 0.030 & -0.089 & 0.030 \\
\hline$\alpha_{\mathrm{e}}$ & $\notin / K$ & -0.050 & 0.018 & -0.068 & 0.020 \\
\hline$\alpha_{\mathrm{Co}}$ & $\phi / K$ & -0.040 & 0.035 & -0.006 & 0.040 \\
\hline$\alpha_{\mathrm{RD}}$ & $\phi / K$ & $\sim 0$ & $\mathrm{~N} / \mathrm{A}$ & $\sim 0$ & $\mathrm{~N} / \mathrm{A}$ \\
\hline$\alpha_{\mathrm{R}}$ & $\phi / \mathrm{K}$ & -0.159 & 0.043 & -0.161 & 0.015 \\
\hline $\mathrm{A}$ & $\not$ & -15.66 & 3.10 & -13.78 & 3.21 \\
\hline $\mathrm{B}$ & $\phi$ & -22.43 & 2.22 & -20.23 & 2.41 \\
\hline $\mathrm{C}$ & $\notin / \mathrm{K}$ & -0.38 & 0.05 & -0.32 & 0.06 \\
\hline $\mathrm{A} / \mathrm{B}$ & & 0.70 & 0.15 & 0.68 & 0.18 \\
\hline $\mathrm{C} \Delta \mathrm{Tc} / \mathrm{B}$ & & 1.40 & 0.24 & 1.33 & 0.28 \\
\hline$\Delta \rho_{\mathrm{TOP}} / \mathrm{B}$ & & 0.24 & 0.02 & 0.29 & 0.04 \\
\hline A/B limits & & \multicolumn{2}{|c|}{$x<1.15(1.73)$} & \multicolumn{2}{|c|}{$x<1.15(1.73)$} \\
\hline $\mathrm{C} \Delta \mathrm{T}_{\mathrm{c}} / \mathrm{B}$ limits & & \multicolumn{2}{|c|}{$1<\mathrm{x}<2.36(2.94)$} & \multicolumn{2}{|c|}{$1<\mathrm{x}<2.36(2.94)$} \\
\hline$\Delta \rho_{\mathrm{TOP}} / \mathrm{B}$ limits & & \multicolumn{2}{|c|}{$\mathrm{x}<1.15(1.73)$} & \multicolumn{2}{|c|}{$\mathrm{x}<1.15(1.73)$} \\
\hline
\end{tabular}

Calculated reactivity coefficients for both cores studied are summarized in Tables 4.2.1-7 and 4.2.1-8. The reactivity coefficient ratios are practically the same for both cores and do not change significantly with burnup. Because of the small or slightly negative CTC, all of the selfcontrollability criteria are easily satisfied.

The Coolant Temperature Coefficient values presented in Tables 4.2.1-7 and 4.2.1-8 were calculated using the core reactivity difference between the nominal and perturbed (by $50 \mathrm{~K}$ ) core average coolant temperatures. The perturbed core conditions assumed $\mathrm{Li}$ insertion depth to $3 / 4$ of the core height. This assumption implies that negative reactivity insertion due to the Li thermal expansion occurs at the same rate as reactivity insertion due to the coolant heatup. It is also implied that the time constant of the transient is much larger than that of the Li reservoir heatup. In practice, however, neither of these assumptions conforms exactly to reality.

\section{LEM Design Considering Thermal Hydraulic Core Response in Transients}

Neutronic studies of LEM performance show that LEMs can be tailored to produce a wide range of different reactivity responses. Important LEM parameters are its operating temperature range and its total reactivity worth. The operating temperature range is the range of temperatures between when the LEM capillary is completely empty and completely full, and depends on the LEM's reservoir and capillary geometry as well as the amount of lithium present in the LEM. The total reactivity worth of a LEM is the difference in reactivity between when the capillary is full and when it is empty, and depends on the volume of the capillary. The reactivity response of LEMs is approximately linear with the number of LEMs; doubling the amount of LEMs (or their size) doubles the reactivity response. Increasing the size of a LEM reservoir reduces the temperature range of the LEM, since a smaller temperature change is needed to produce the same 
increase in lithium volume. Increasing the size of a LEM capillary increases the LEM's temperature range and total reactivity worth proportionally.

In order to ensure the core shutdown by passive means, in case of the most restricting accidents, the LEMs were modeled explicitly in the RELAP5 code in the process of transient analyses. The results of this work revealed that calculation of the integral reactivity effect due to the coolant temperature increase and Li thermal expansion described above is indeed over-simplistic.

The importance of more detailed coolant heat up reactivity effect modeling is illustrated in Figure 4.2.1-20. Within a LEM's operating temperature range, the reactivity response is approximately cosine shaped if the LEM capillary doesn't change size with axial position. Shrinking or bottlenecking parts of the LEM capillary can reduce the reactivity worth and temperature range of specific portions of the response curve, allowing its shape to be carefully tailored. As can be observed from Figure 4.2.1-20, the Li expansion reactivity effect is not linear with the core average coolant temperature because of the axially varying neutron importance. Outside of the LEM's operating temperature range, the LEM is saturated, since an additional increase or decrease in temperature has a minimal effect on reactivity. LEM saturation is undesirable because without the reactivity contribution from LEMs, the high coolant temperature coefficient of liquid salt can lead to positive feedback. For example, at the early stages of a transient, Li reactivity worth is practically zero because its insertion begins from the core upper edge. Therefore, the combined Coolant Temperature Coefficient of reactivity is positive and nearly equal in magnitude to a core with no LEMs. Such a large positive reactivity effect at the early stages of a transient could lead the peak cladding temperature to exceed the limit.

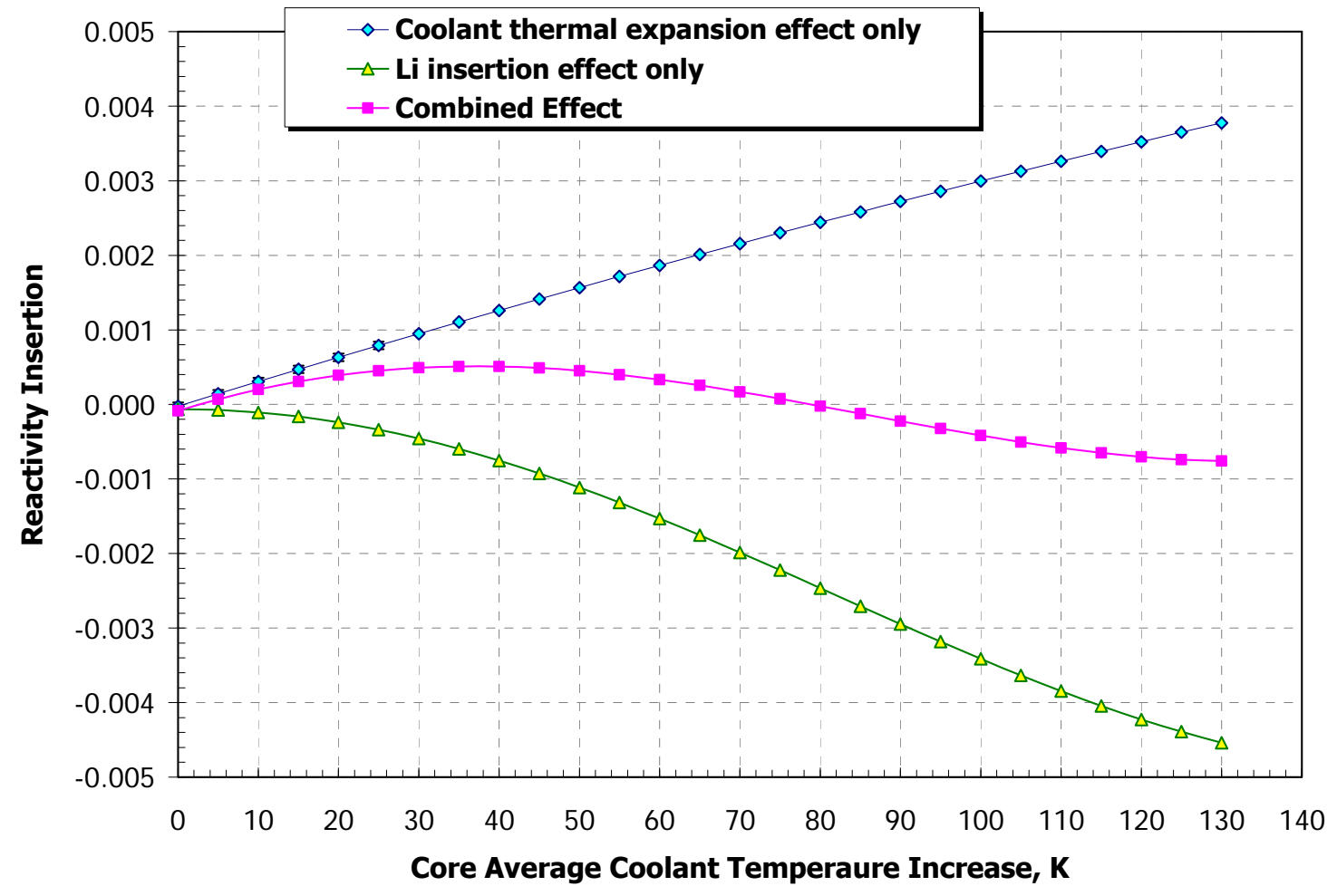

Figure 4.2.1-20. Breakdown of reactivity insertion effects (25 LEMs/assembly) 
A possible solution for this problem could be an alternative LEM design, in which Li insertion begins closer to the core center where Li worth is sufficiently high to compensate fully for the positive reactivity insertion due to coolant thermal expansion. Such a configuration would imply that some of the Li would have to be partially inserted into the core at nominal operating conditions with associated reactivity penalty. This penalty, however, can be minimized if the Li capillary duct has a bottle-like shape as schematically shown in Figure 4.2.1-21. Illustration of such LEM design performance will be presented later in the discussion of $\mathrm{CR}=0$ salt-cooled core design.

In addition, the presence of $\mathrm{Li}$ in a relatively high neutron flux would result in partial depletion of Li-6 (on the order of a few atomic percent over the fuel cycle of 2500 EFPD). This depletion is not expected to cause a significant degradation in the LEMs neutronic performance. However, the accumulation of gaseous products originating in the Li-6 neutron reactions (specifically Tritium and $\mathrm{He}$ ) may result in the creation of gas bubbles and chemical interaction with Li and LEM casing. The significance and implications of these effects will have to be assessed in future studies if such LEM designs would be adopted for reactivity control.

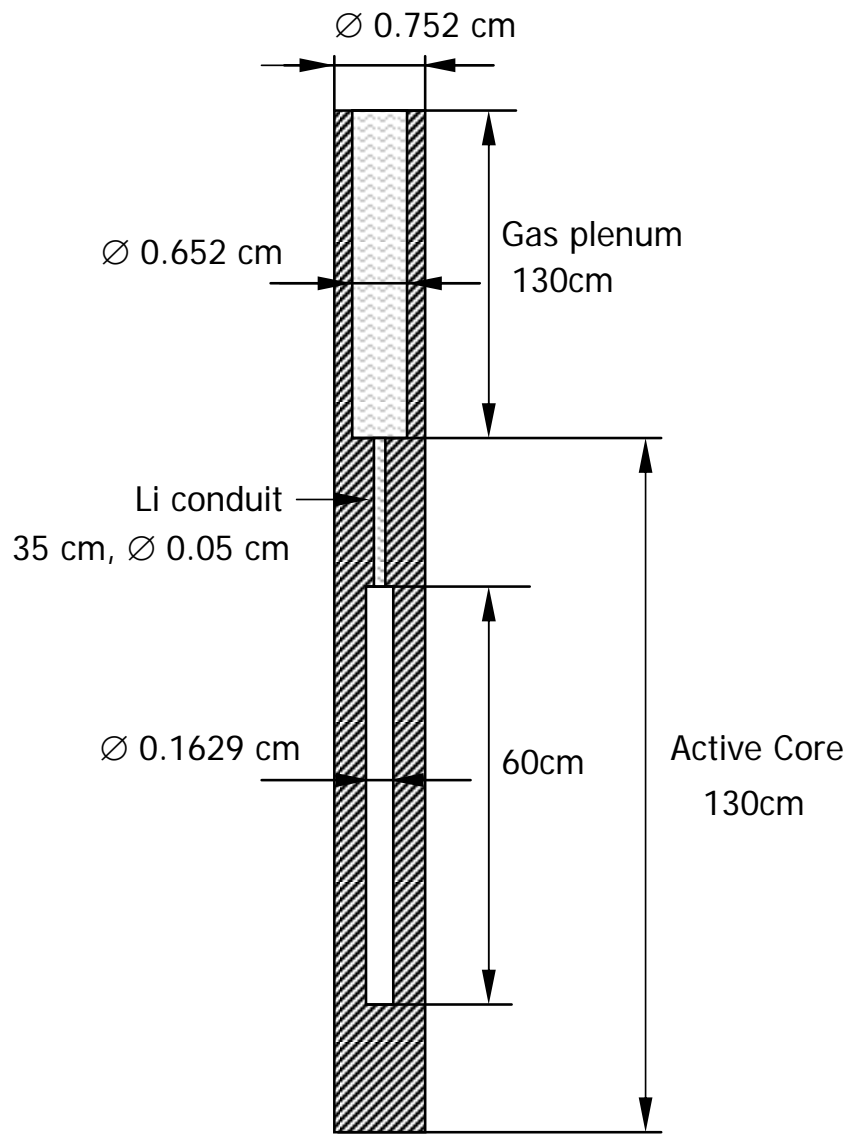

Figure 4.2.1-21. Example of LEM design with bottle-shape capillary

An important assumption was used during LEM design: the LEMs were treated as a lumped entity, with their response based on the coolant conditions at the outlet of the "average" channel 
in the core. In an actual core, different areas of the core will have somewhat different outlet temperatures, meaning not all LEMs will respond identically. This assumption was also used to simplify LEM modeling in both RELAP and MCNP. In principle, a fully 3-D analysis could be performed that tracks the coolant outlet temperature in each assembly and the resulting LEM reactivity insertion. Furthermore, different LEMs could be specifically designed for each radial position in the core to provide a desired power shape.

To ensure passive safety, the reactivity response of the LEMs in the salt core was designed, based on the MCNP calculations above and RELAP5-3D analyses in Section 4.2.2, so the total coolant temperature coefficient would be zero or negative over the range of possible LEM temperatures. This LEM response for the $\mathrm{CR}=1$ core is shown in Figure 4.2.1-22, along with the coolant temperature response. The two reactivity responses do not add directly in practice because the LEM response depends on the coolant outlet temperature while the coolant temperature response depends on the power-squared weighted coolant average temperature. However, it is conservative to assume that a change in coolant outlet temperature is equal to the change in average temperature because the former is usually larger during the early stages of a transient, which would increase the reactivity effect of the LEMs. This assumption is only used for design, not modeling, since LEMs are modeled explicitly in RELAP5-3D. One can see that the "total" reactivity response in Figure 4.2.1-22 has a negative slope between the steady state temperature and $140 \mathrm{~K}$ over the steady state temperature. This temperature range was selected based on thermal hydraulic analyses that showed the core outlet temperature could rise by as much as $120 \mathrm{~K}$ during a transient; the $140 \mathrm{~K}$ value was used to provide a margin past this value. Having the slope of the total reactivity curve equal zero at steady state requires that the LEMs be partially inserted at steady state, resulting in a reactivity penalty of about 25 cents. However, this penalty can be reduced by bottlenecking the top of the LEM capillary, as shown in Figure 4.2.1-21, so less lithium is present in the core at steady state.

The LEM reactivity curves designed for the reference salt reactor are shown in Appendix 3B.2-6. Reactor physics calculations showed that these desired LEM curves could be implemented using 25 LEMs per assembly for the $\mathrm{CR}=1$ reactor and $12 \mathrm{LEMs}$ per assembly for the $\mathrm{CR}=0$ reactor. More LEMs (or larger LEMs) could be added if a stronger reactivity response is desired, although doing so would displace additional fuel rods and lower power density somewhat.

Overall, the LEMs were found to be a very flexible and useful tool for managing the core reactivity response to a coolant temperature increase. Practically any desired shape of the core reactivity response curve can be constructed through careful choice of the LEMs geometry and the number of LEMs in the core. The 25 LEMs with reactivity curve per Figure 4.2.1.22 were used for the $\mathrm{CR}=1$ core thermal hydraulic analysis in Section 4.2.2. 
Project No 06-040: Flexible Conversion Ratio Fast Reactor Systems Evaluation

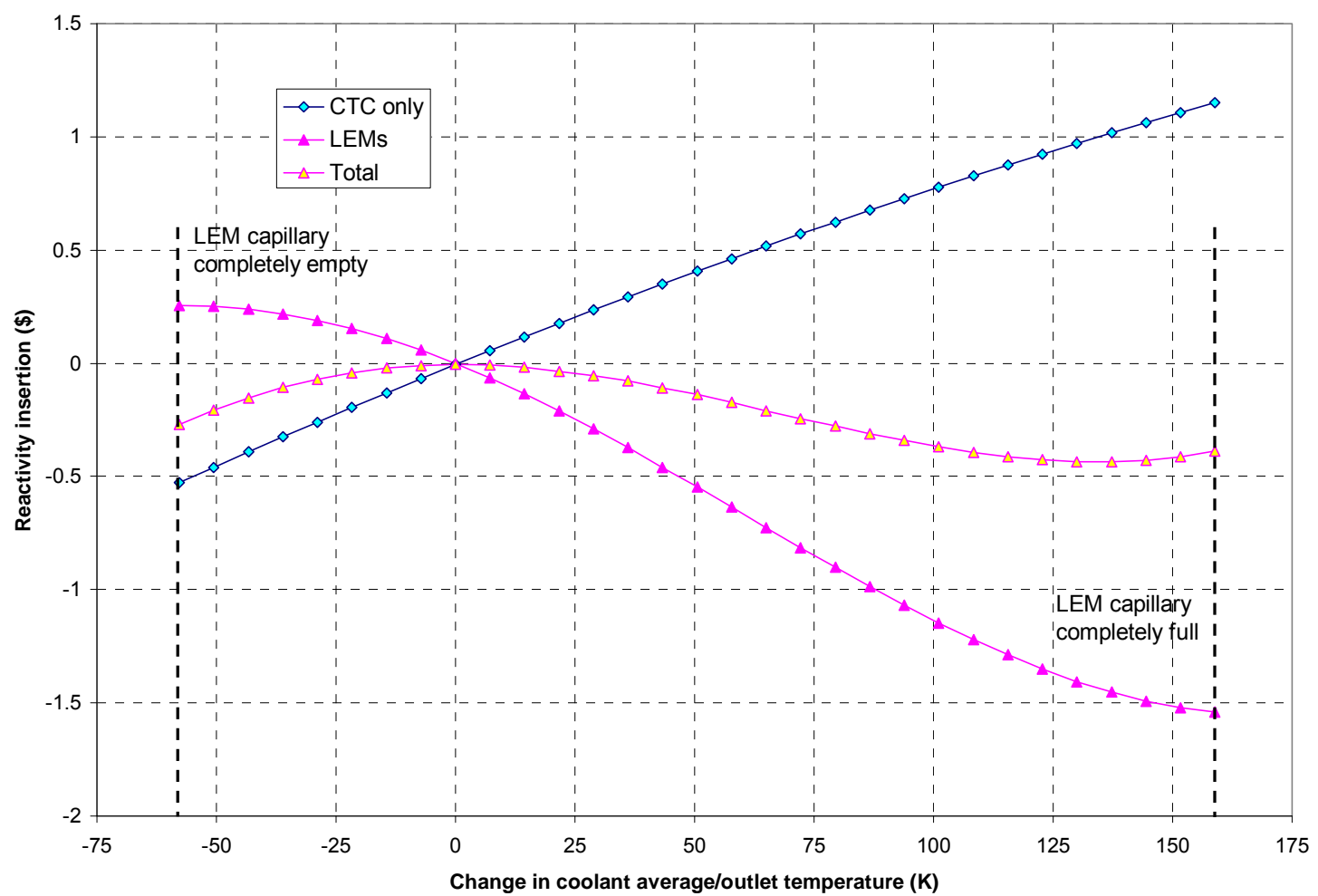

Figure 4.2.1-22 $\mathrm{CR}=1 \mathrm{LEM}$ and CTC reactivity responses (24 LEMs/assembly)

\section{Reactor Vessel Fluence}

As in the lead-cooled core designs, accumulated fast fluence in the reactor vessel and core support plate were calculated for the salt-cooled $\mathrm{CR}=1$ core with high power density. The results are summarized in Table 4.2.1-9 and compared with the lead-cooled $\mathrm{CR}=1$ design. Similarly to the lead-cooled core, the fast fluence to the critical structural components in the current salt core design is well below the limit of $5 \times 10^{19}$ (neutrons above $1 \mathrm{MeV}$ ) $/ \mathrm{cm}^{2}$ adopted for the vessel structural material (stainless steel 316). Fluence to the reactor vessel at the core midplane elevation is much lower for the salt-cooled core due to the use of $\mathrm{B}_{4} \mathrm{C}$ radial shielding assemblies, that were not used in the lead-cooled core design. This result suggests that the radial reflectors and liquid salt filled downcomer may provide sufficient reactor vessel shielding without the need for radial shielding assemblies. Table 4.2.1-9 reports the fluence above 0.1 $\mathrm{MeV}$ (rather than above $1 \mathrm{MeV}$ ) values calculated using the MCNP code because of the poor statistical accuracy of the results at higher energy bins. Even for the more conservative $0.1 \mathrm{MeV}$ threshold, the result for the vessel fluence of the salt-cooled core presented in Table 4.2.1-9 is questionable because it has $\sim 70 \%$ uncertainty. The same tally for total fluence however, does have a statistically reliable value of $(3.8 \pm 0.3) \times 10^{18} \# / \mathrm{cm}^{2}$ which is still lower than the limit. 
Table 4.2.1-9. Fast fluence accumulated over 40 years lifetime in $\mathrm{CR}=1$ core components

\begin{tabular}{|l|c|c|}
\hline Parameter & Salt CR=1 & \multicolumn{1}{c|}{ Lead CR=1 } \\
\hline Vessel above $0.1 \mathrm{MeV}, \# / \mathrm{cm}^{2}$ & $(1.0 \pm 0.7) \times 10^{16}$ & $(6.4 \pm 0.4) \times 10^{16}$ \\
\hline Core support plate above $0.1 \mathrm{MeV}, \# / \mathrm{cm}^{2}$ & $(1.1 \pm 0.1) \times 10^{16}$ & $(3.4 \pm 0.2) \times 10^{6}$ \\
\hline
\end{tabular}

\section{Decay Heat Curves}

Decay heat data required for the transient analysis of the core with the RELAP5 code were calculated by performing detailed core depletion calculations with the BGCore code, tracking explicitly over 1700 nuclide densities throughout fuel burnup and decay following reactor shutdown. The results of these calculations are presented in Figures 4.2.1-23 and 4.2.1-24. The figures compare the decay heat of the salt-cooled $\mathrm{CR}=1$ core with a typical PWR curve. As in the lead-cooled design, the salt-cooled core decay heat becomes considerably higher than that of the PWR after about 100 seconds following shutdown. Lead and salt-cooled $C R=1$ core designs have very similar decay heat because initial fuel composition, burnup, and neutron spectrum are comparable for both cores.

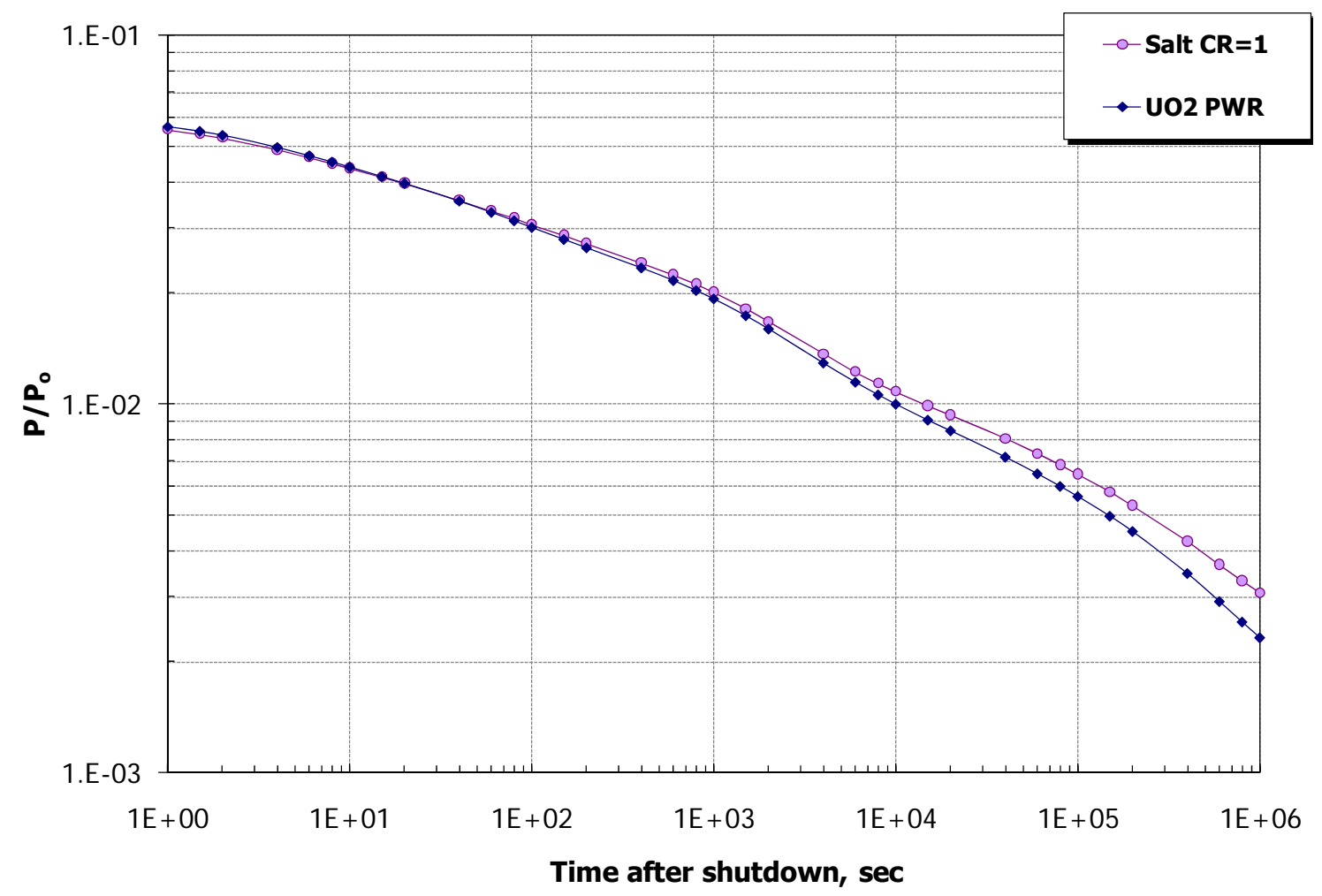

Figure 4.2.1-23 Comparison of $\mathrm{CR}=1$ core decay heat with typical PWR 
Project No 06-040: Flexible Conversion Ratio Fast Reactor Systems Evaluation

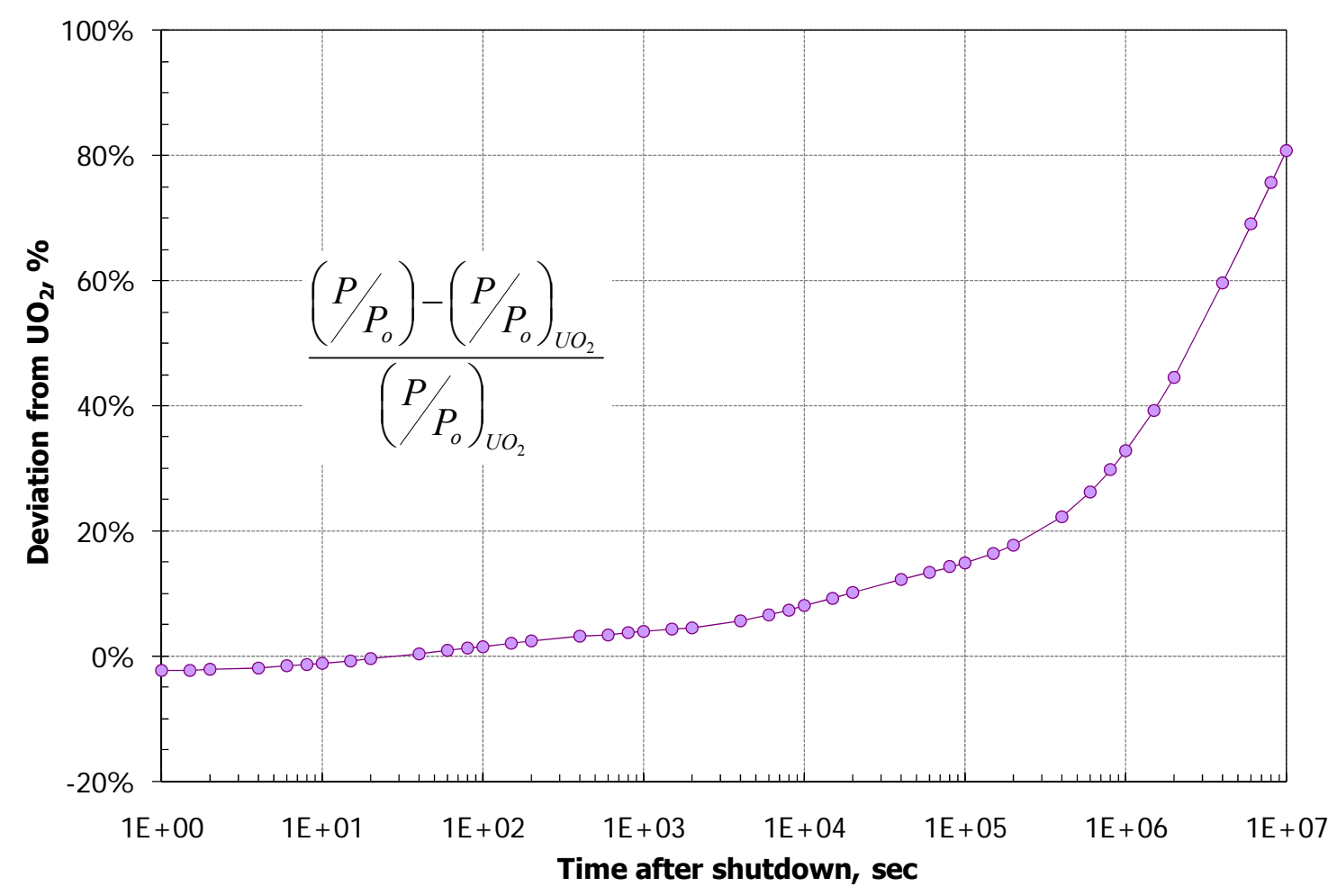

Figure 4.2.1-24 Relative deviation of $\mathrm{CR}=1$ core decay heat from typical PWR 


\subsubsection{Thermal Hydraulic Analysis Results}

The purpose of this project is to develop a competitive design for a 2400 MWt reactor using liquid salt as coolant. Liquid salts are potentially attractive because of their optical transparency (and thus easy inspection), high volumetric heat capacities, and general chemical compatibility. As described in the salt selection section, the ternary chloride eutectic $\mathrm{NaCl}-\mathrm{KCl}-\mathrm{MgCl}_{2}(30 \%$ $20 \%-50 \%$ ) was selected as the liquid salt most suitable for high power density fast reactor applications. The design considered is a dual-free-level pool-type reactor based on the lead reactor design.

A successful design would be able to generate the rated power without violating any materials or pumping constraints, have a power cycle efficiency comparable to that of the lead system, and fit within the same sized reactor vessel. Furthermore, it must be able to survive each limiting transient - unprotected station blackout, unprotected loss of flow, and transient overpower without fuel element damage, relying only on the design's passive systems. The passive safety systems employed to address these transients are the same as those used in the lead system: a reactor vessel auxiliary cooling system (RVACS), and a passive secondary auxiliary cooling system (PSACS).

Steady state design for the core was performed using a subchannel spreadsheet model using the same constituent equations as the SUBCHAN code described in Appendix 3B.1. The intermediate heat exchanger model used is described in Appendix 3C. Results from these two models were incorporated into a RELAP5-3D model of the entire plant system in order to perform transient analyses. The salt reactor RELAP model required the implementation of virtual free levels due to a current limitation in the RELAP code; the model and the virtual-freelevel approximation are described in Appendix 3B.2.

\subsubsection{Steady State Design}

\subsection{Core Design}

The core design selected uses wire-wrapped fuel pins $(\mathrm{OD}=0.752 \mathrm{~cm})$ in a triangular lattice $(\mathrm{P} / \mathrm{D}=1.188)$ arranged into hexagonal assemblies. This geometry was chosen because it is more suitable for providing the low coolant volume fraction needed to meet reactor physics requirements, and the specific value of $\mathrm{P} / \mathrm{D}$ was chosen to correspond to a power density of 130 $\mathrm{kW} / \mathrm{l}$ for the number of assemblies and pins in the core. As for the lead reactor system, the fuel pin active length is $1.3 \mathrm{~m}$, with a $1.3 \mathrm{~m}$ gas plenum region above the core, and $30 \mathrm{~cm}$ of reflector pins followed by $1.0 \mathrm{~m}$ of shield slug below the core. Unlike the lead reactor system, two rings of reflector assemblies and one ring of shield assemblies are added to the periphery of the core to improve neutron economy and protect long-life vessel structural materials. A summary of core geometry parameters is summarized in Table 4.2.2-1. 
Table 4.2.2-1 Reference $\mathrm{CR}=1$ salt core geometry

\begin{tabular}{|l|c|}
\hline Total fuel pin length (m) & 3.9 \\
\hline Fuel pin heated length (m) & 1.3 \\
\hline Pin outer diameter (mm) & 7.52 \\
\hline Pin cladding thickness (mm) & 0.63 \\
\hline Pin pitch P(mm) & 8.94 \\
\hline Pin P/D & 1.188 \\
\hline Wire diameter (mm) & 1.42 \\
\hline Wire axial pitch H (m) & 0.184 \\
\hline H/D & 24.5 \\
\hline Number of pins along each edge of the assembly & 12 \\
\hline Number of pins per assembly & 397 \\
\hline Number of LEMs per assembly & 25 \\
\hline Number of fuel pins per assembly & 372 \\
\hline Assembly wall - fuel pin gap thickness (mm) & 1.70 \\
\hline Assembly wall thickness (mm) & 3.94 \\
\hline Assembly - assembly gap thickness (mm) & 2.22 \\
\hline Assembly pitch (m) & 0.191 \\
\hline Number of fuel assemblies in core & 451 \\
\hline
\end{tabular}

The steady state performance of this core, as calculated by the subchannel model, is given in Table 4.2.2-2. This data is based on several conservative assumptions present in the subchannel model, most notably the assumption that there is no intra-assembly mixing between different temperature subchannels, as well as use of an unmodified Gnielinski heat transfer correlation which is conservative for wire-wrap geometry. The coolant flow rate through the core assumes a three-zone orificing scheme: i.e. the core is divided into three zones based on peaking factors and each zone is orificed to have the smallest flow rate that does not cause the cladding temperature limit of $650^{\circ} \mathrm{C}$ to be exceeded. The margin of a couple degrees centigrade in the reference case was introduced when the minimum core pressure drop needed to meet this criteria was rounded up to the reference value of $700 \mathrm{kPa}$.

The data in Table 4.2.2-2 for the reference core also includes two small non-conservative assumptions. First, the maximum assembly peaking factor, as given in Table 4.2.2-1, was taken as 1.26 rather than the BOL maximum of 1.30 , based on earlier data for the $\mathrm{CR}=1$ core. Second, the presence of control rods in some assemblies, which would displace some fuel rods and therefore raise the average power per pin, was neglected. Since these are both assembly-level effects, they can be addressed using orificing; an adjusted orificing scheme can distribute more coolant flow to the higher-peaked assemblies with a small increase in total pressure drop. Alternatively, the total coolant flow rate through the core can be increased a small amount $(<5 \%)$ to counter the higher peaking. A study examining core flow rate (see the station blackout transient section) showed that even a $20 \%$ increase in coolant flow rate can be designed for without any performance penalties except a higher pressure drop. Since pressure drops are a soft constraint and can be adjusted upward by using larger pumps, these non-conservative assumptions do not change the fundamental conclusions of this report. 
Table 4.2.2-2 CR=1 NaCl-KCl- $\mathrm{MgCl}_{2}$ salt reference core operating characteristics.

\begin{tabular}{|l|c|}
\hline Total Power $(\mathrm{MWt})$ & 2400 \\
\hline Power density $(\mathrm{W} / \mathrm{cc})$ & 130 \\
\hline Average power per pin $(\mathrm{W})$ & $1.43 \times 10^{4}$ \\
\hline Maximum assembly peaking factor & 1.26 \\
\hline Maximum axial peaking factor & 1.276 \\
\hline Coolant inlet temperature $\left({ }^{\circ} \mathrm{C}\right)$ & 496 \\
\hline Average coolant outlet temperature $\left({ }^{\circ} \mathrm{C}\right)$ & 569 \\
\hline Pressure drop across core $(\mathrm{Pa})$ & $7.00 \times 10^{5}$ \\
\hline Coolant mass flow rate through core $(\mathrm{kg} / \mathrm{s})$ & $3.28 \times 10^{4}$ \\
\hline Pumping power through core $(\mathrm{MWt})$ & 12.3 \\
\hline Maximum guard vessel temperature $\left({ }^{\circ} \mathrm{C}\right)$ & $>442$ \\
\hline Hot channel characteristics: & 4.4 \\
\hline Inlet coolant velocity $(\mathrm{m} / \mathrm{s})$ & $1.30 \times 10^{4}$ \\
\hline Reynolds number & 92 \\
\hline Nusselt number & $1.1 \times 10^{4}$ \\
\hline Heat transfer coefficient $\left(\mathrm{W} / \mathrm{m}^{2} \mathrm{~K}\right)$ & 71 \\
\hline Maximum film $\Delta \mathrm{T}(\mathrm{K})$ & 648 \\
\hline Maximum cladding temperature $\left({ }^{\circ} \mathrm{C}\right)$ & $<932$ \\
\hline Maximum fuel temperature $\left({ }^{\circ} \mathrm{C}\right)$ & \\
\hline
\end{tabular}

One of the original design constraints could not be satisfied by the reference design: the steady state vessel temperature constraint of $430^{\circ} \mathrm{C}$, given by the ASME code for the vessel material SS-316. The maximum guard vessel temperature modeled by RELAP for the salt reactor is $442^{\circ} \mathrm{C}$, and this is along the side of the vessel where RVACS flow is highest. Directly underneath the vessel there would be less RVACS airflow, so vessel temperatures would be closer to the coolant inlet temperature of $496^{\circ} \mathrm{C}$. However, this could be addressed though the use of a low-power blower that could provide some cooling flow at the vessel bottom during normal operation. Given the high melting point of liquid salt, lowering the coolant inlet temperature is not an option, so there is no easy way to reconcile the gap between the coolant inlet temperature and the vessel temperature limit for the designs that use RVACS for decay heat removal. One of the main challenges of liquid salt reactor design is therefore the development of advanced vessel materials that can withstand the higher temperatures of a liquid salt system. Another option would be to use a larger vessel with insulation and remove decay heat through DRACS heat exchangers placed in the vessel.

\section{Core spacer options}

The core pitch-to-diameter ratio of $\sim 1.19$ introduces the possibility of using honeycomb-shaped grid spacers instead of wire wrap spacers. A rough comparison study was performed evaluating the pressure drop and heat transfer characteristics of grid spacers; it was determined that wirewrap and grid spacers are about equivalent for this application when taking into account uncertainties. The reference design uses wire wrap, despite uncertainties regarding wire-wrap heat transfer, because there is more experience and literature for wire wrap at a P/D of 1.19. Nevertheless, there may be cause to use grid spacers depending on the configuration of LEMs chosen. Using LEMs with a reservoir diameter equal to fuel pin diameter allows wire wrap to be used along the entire pin length. Larger LEM reservoirs would reduce the number of LEMs 
needed (from 25 per assembly in the reference case) but would be incompatible with wire-wrap because wires would not fit between the reservoirs and the pins adjacent to them. Using larger LEM reservoirs would require either use of grid spacers or a combination of wire-wrap in the fuel region and grids in the reservoir/plenum region.

\section{Radiative heat transfer}

Because liquid salts are transparent to infrared and optical radiation, it is important to consider if radiation contributes significantly to heat transfer in liquid salt systems. For the reference design, the average heat flux in the reference core is $4.7 * 10^{5} \mathrm{~W} / \mathrm{m}^{2}$. In comparison, the radiative heat flux of clad at $650^{\circ} \mathrm{C}$ is given by the Stefan-Boltzmann law:

$$
j=\varepsilon \sigma T^{4}=0.15 * 5.67 * 10^{-8} \mathrm{Wm}^{-2} K^{-4} *(923 K)^{4}=\mathbf{6 . 2} * \mathbf{1 0}^{3} \mathbf{W} / \mathbf{m}^{2}
$$

Here $\sigma$ is the Stefan-Boltzmann constant, and $\varepsilon$ is the emissivity. (approximated as 0.15 for machined steel) This value is less than $2 \%$ of the average heat flux in the core. Considering that $650^{\circ} \mathrm{C}$ is higher than any temperature reached on the cladding outer surface, as well as the small view factor of a pin in a pin bundle, the actual heat transfer due to radiation would be smaller than this value. Therefore, it is reasonable to neglect radiative heat transfer for the liquid salt core at steady state, as long as significantly higher cladding temperatures are not achieved.

The possibility of taking advantage of radiative heat transfer during transient scenarios has also been considered. During a transient, coolant outlet temperatures can reach over $900 \mathrm{~K}$, and the gas plenums and structures above the core would reach the same temperature. The top of the core is composed of many small openings (coolant channels) and would effectively have a high emissivity, since radiation escaping through these openings will mostly be absorbed. Alternatively, the top of the core can be specifically engineered to have a high emissivity, such as through the use of high emissivity coatings. Generously assuming an emissivity of unity can be achieved, the top of the core can be used to reject up to $37.2 \mathrm{~kW} / \mathrm{m}^{2}$, corresponding to 0.53 MW for the $14.3 \mathrm{~m}^{2}$ area core. This amount of heat is a small fraction of the amount that can be removed via the RVACS and PSACS passive cooling systems, so there is no strong incentive to develop systems that can reject heat emitted via radiation to an ultimate heat sink. Furthermore, the view factor between the top of the core and the top of the vessel is on the order of only $4 \%$, due to the tall chimney separating them, making radiative heat transfer even less appealing as an avenue for decay heat removal.

\subsection{IHX Design}

Shell-and-tube intermediate heat exchangers with salt on the shell side and $\mathrm{CO}_{2}$ on the tube side, similar to those used in the lead-cooled reactor, were designed for the liquid-salt-cooled reactor. Again ribbed tubes were employed to enhance heat transfer on the $\mathrm{CO}_{2}$ side, and grid spacers were used to maintain bundle geometry. One alternative to shell-and-tube exchangers was first considered: printed circuit heat exchangers, or PCHEs.

The use of liquid salt as coolant may enable the use of PCHEs as IHXs, since liquid salt doesn't carry the same oxide formation issues as lead coolant. PCHEs use a very large number of tiny channels, which are vulnerable to corrosion and oxide formation but allow for very high power 
densities and smaller pressure losses. Initial estimates of PCHE geometry and performance showed they could fit in the vessel while allowing smaller pressure losses than shell-and-tube heat exchangers on both the primary and secondary sides. However, these reduced pressure drops did not result in a substantive enough performance increase to justify the greater uncertainties associated with designing PCHEs. Pool-type reactor designs may also not be ideally suited for PCHEs because it is awkward to fit rectangular horizontal PCHEs into the annular vertical space of the downcomer. Because the higher power density salt core allows sufficient space in the vessel for reasonably designed shell-and-tube IHXs, shell-and-tube IHXs were chosen for use in the reference design.

Intermediate heat exchangers were designed for the liquid-salt-cooled reactor using the same spreadsheet analysis tools as for the lead-cooled reactor, using the Gnelinski heat transfer correlation on the salt side and substituting the appropriate salt properties and flow conditions. Primary side inlet conditions and coolant flow rates follow from the core design, while secondary side inlet conditions were kept the same as those for the lead reactor so the same power conversion system could be used for the salt reactor. With both hot-side and cold-side conditions specified, designing the IHXs involved determining what heat exchanger geometry would transfer the correct amount of power while fitting in the downcomer annulus and minimizing pressure drops.

As with the lead reactor, four kidney shaped IHXs were used to maximize use of space in the downcomer. The thickness of the heat exchanger tubes and plena were chosen so that material stresses would not exceed the limits set by the updated ASME code for T91 steel at the operating temperatures (the maximum salt temperature $\left(\sim 569^{\circ} \mathrm{C}\right)$ for the tubes and the cold salt temperature $\left(\sim 496^{\circ} \mathrm{C}\right)$ for the plenums) and lifetime (30 years) assumed.

Since both of the free levels are at the same atmospheric pressure, any pressure loss due to flow between the free levels (primarily due to the IHX) will result in a separation in the free levels, $H$, such that pressure rise due to gravity $(\rho g H)$ is equal to this pressure loss. Because of this, there is a maximum allowed pressure loss through the IHX that is determined by the maximum allowed separation distance between the two free levels in the vessel, i.e., the maximum value of $H$. This separation distance is conservatively taken as the length of the IHX itself. To better illustrate this, a to-scale diagram of the vessel is given in Figure 4.2.2-1. The lower "cold" free level should not be below the bottom of the IHX, since this can result in below-atmospheric pressures beneath the IHX and lead to voiding. The upper "hot" free level must be above the top of the IHX. If it is conservatively assumed that vessel height is minimized, i.e. there is only a small clearance between the top of the vessel and the top of the IHXs, then the hot free level can be assumed to be near the top of the IHX. In this case, the maximum level separation distance $H$ is the height of the IHX, since the cold free level cannot be below the bottom of the IHX.

This maximum level-separation distance becomes an important constraint for the salt reactor because the lower density of salt compared to lead permits a much smaller IHX pressure drop. In order to keep the primary-side pressure drop below this constraint, while maintaining a reasonable heat exchanger length and secondary-side pressure loss, it was necessary to make more room in the downcomer by using a bottlenecked chimney above the core. The bottlenecked chimney is also illustrated in Figure 4.2.2-1. The bottlenecked chimney is large enough to fit the entire core at its bottom but gets smaller above the core to only fit the fuel assembly control rods; this is possible because the reflector and shield assemblies surrounding 
the fuel do not have control rods extending upward from them. Bottlenecking the core results in $21 \%$ more space in the surrounding annulus, which allows a dramatic $70 \%$ increase in the number of heat exchanger tubes. This increase in "usable space" is constrained however by the fact that there is a $10 \mathrm{~cm}$ clearance between the IHXs and the vessel walls and a nearly $15 \mathrm{~cm}$ thick IHX gas plenum which cannot be occupied by tubes. More design work needs to be carried out in he future on the removability of the reflector assemblies.

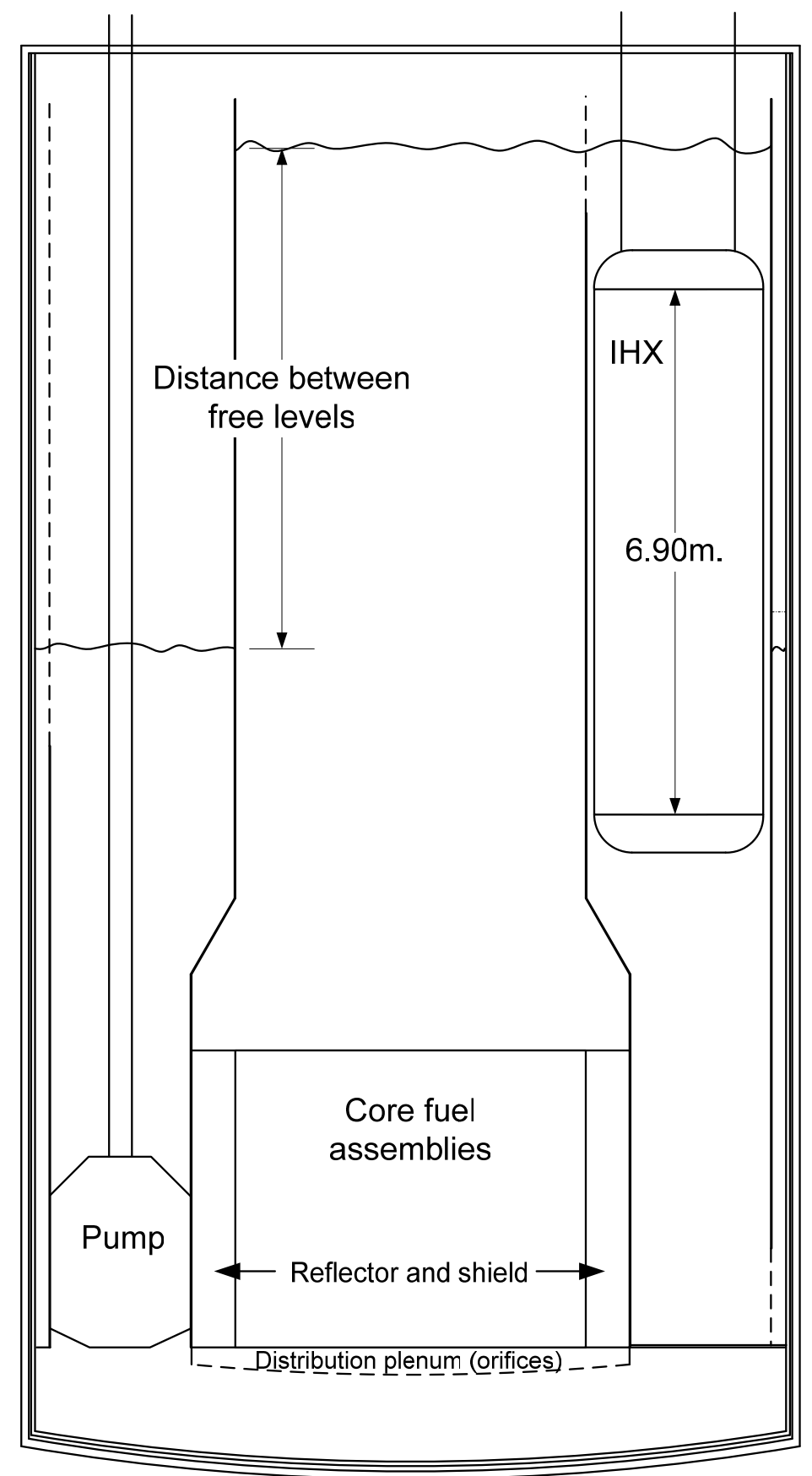

Figure 4.2.2-1 To-scale illustration of vessel layout 
Project No 06-040: Flexible Conversion Ratio Fast Reactor Systems Evaluation

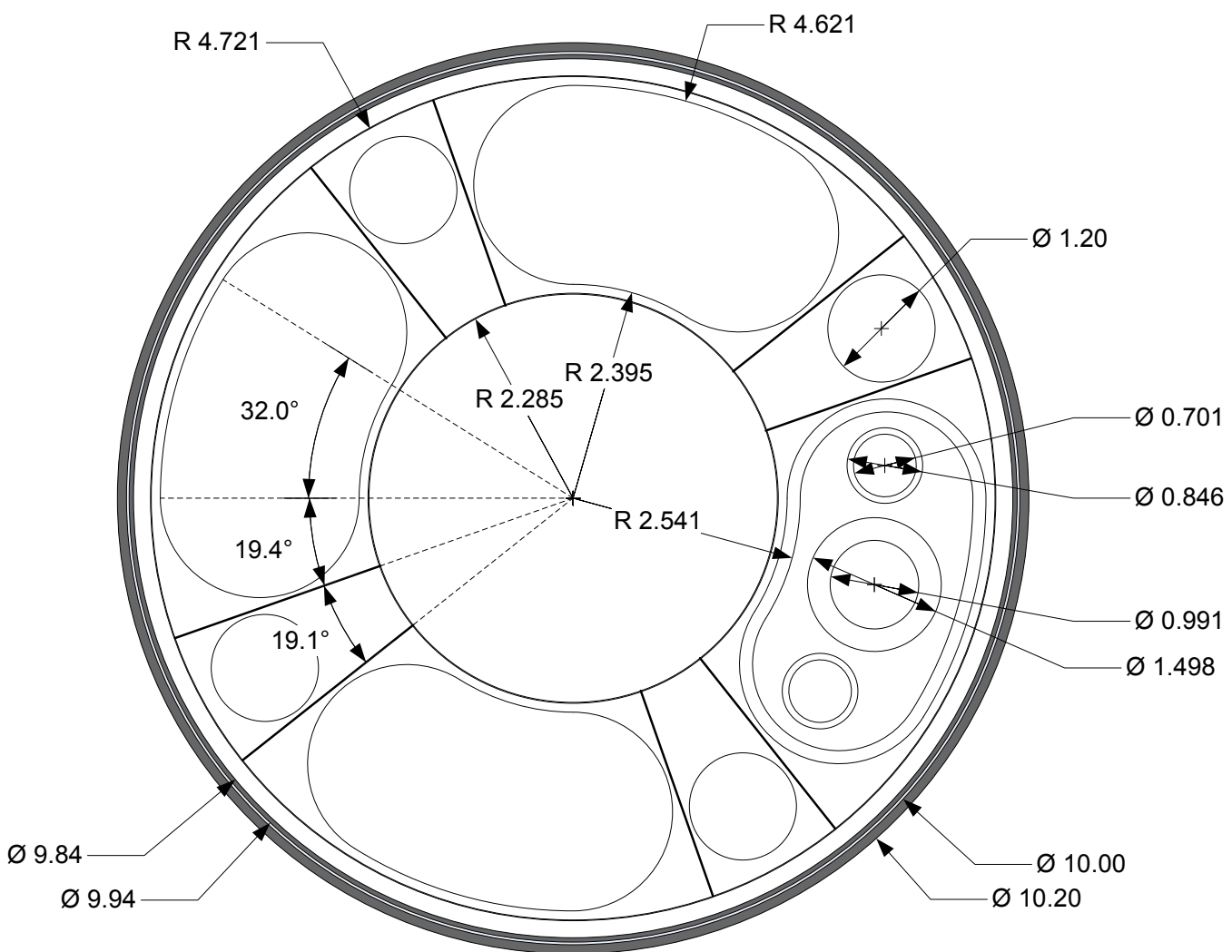

Figure 4.2.2-2 To-scale illustration of IHX layout

Table 4.2.2-3 Salt reactor IHX geometry and performance (for 1 out of 4 IHXs)

\begin{tabular}{|l|c|}
\hline Tube outer diameter $(\mathrm{mm})$ & 13.0 \\
\hline Number of tubes & 21989 \\
\hline P/D & 1.23 \\
\hline Tube thickness $(\mathrm{mm})$ & 2.02 \\
\hline Tube length $(\mathrm{m})$ & 6.8 \\
\hline IHX cross-sectional area $\left(\mathrm{m}^{2}\right)$ & 6.6 \\
\hline Power transferred $(\mathrm{MW})$ & 600. \\
\hline Salt flow rate $(\mathrm{kg} / \mathrm{s})$ & 8200. \\
\hline Salt inlet temperature $\left({ }^{\circ} \mathrm{C}\right)$ & 568.9 \\
\hline Salt outlet temperature $\left({ }^{\circ} \mathrm{C}\right)$ & 496.0 \\
\hline $\mathrm{CO}_{2}$ flow rate $(\mathrm{kg} / \mathrm{s})$ & 3212. \\
\hline $\mathrm{CO}_{2}$ inlet temperature $\left({ }^{\circ} \mathrm{C}\right)$ & 396.4 \\
\hline $\mathrm{CO}_{2}$ outlet temperature $\left({ }^{\circ} \mathrm{C}\right)$ & 548.4 \\
\hline $\mathrm{Salt}^{\circ}$ flow area $\left(\mathrm{m}^{2}\right)$ & 1.95 \\
\hline $\mathrm{Salt}^{2}$ side pressure loss $(\mathrm{kPa})$ & 116. \\
\hline $\mathrm{CO}_{2}$ flow area $\left(\mathrm{m}^{2}\right)$ & 1.38 \\
\hline $\mathrm{CO}_{2}$ side pressure loss $(\mathrm{kPa})$ & 292. \\
\hline
\end{tabular}

For each value of IHX tube diameter, a minimum tube $\mathrm{P} / \mathrm{D}$ exists below which the salt pressure drop exceeds the constraint outlined above. Minimizing tube $\mathrm{P} / \mathrm{D}$ is desirable because it maximizes the heat exchanger power density and $\mathrm{CO}_{2}$ flow area. Selecting the diameter of the IHX tubes involves a tradeoff: smaller tubes increase power density and reduce heat exchanger 
length, while larger tubes reduce the secondary side pressure drop. Larger tubes were chosen because the secondary side pressure drop is important to power conversion system performance, and because fewer large tubes would be easier to produce and maintain than many small tubes. A tube diameter of $13 \mathrm{~mm}$ was chosen, corresponding to a P/D of 1.23 and an IHX tube length of $6.78 \mathrm{~m}$, which fills most of the space available for IHXs while allowing room for the $\mathrm{CO}_{2}$ plenums. IHX geometry and performance characteristics calculated using the spreadsheet model are given in Table 4.2.2-3. Tube ribbing and grid spacer design are the same as for the lead reactor IHXs. A to-scale illustration of the IHX geometry in the salt reactor is given in Figure 4.2.2-2.

Figure 4.2.2-2 and Table 4.2.2-3 shows the salt IHXs are somewhat larger $\left(6.6 \mathrm{~m}^{2}\right.$ vs. $6.0 \mathrm{~m}^{2}$ cross sectional area) and taller (6.8m vs. $5.7 \mathrm{~m}$ tube length) than those for the lead reactor, which is not unexpected given the poorer heat transfer characteristics of liquid salt. Nevertheless, the pressure losses for the primary and secondary sides are both acceptable. The salt pressure losses do not exceed the maximum gravitational head required for free level separation, and the $\mathrm{CO}_{2}$ side pressure losses are not different enough from those of the lead reactor to require significant reworking of the secondary system.

\section{Implementation in RELAP5-3D}

To allow for transient analyses, the core and intermediate heat exchanger designs described above were incorporated into a RELAP5-3D model which also includes the balance of plant and passive decay heat removal systems. Details of this model and the assumptions used are given in Appendix 3B.2. The steady state performance of the RELAP model was found to agree very closely with the values calculated above, with primary side temperatures and pressures agreeing to within $2^{\circ} \mathrm{C}$ and several $\mathrm{kPa}$ respectively.

\subsubsection{Transient Analysis}

\subsection{Unprotected Station Blackout}

The unprotected station blackout (SBO) accident analyzed for the salt case is identical to the one considered for the lead reactor. It assumes that at time zero, the reactor coolant pumps and precooler pumps lose power, the generators become isolated due to loss of load, and the core fails to scram. Loss of precooler pump power means that heat cannot be removed via the secondary system to the ultimate heat sink. Also, loss of generator load puts the turbines at risk of damage due to overspeed, so the protection against overspeed control as described in Section 2.2.3.4 needs to be invoked. Failure to scram means that the reactor must either shut down or reach a safe steady state through inherent reactivity feedbacks. Finally, core decay heat needs to be removed to avoid damage to the fuel cladding or other core structural materials. Decay heat removal is accomplished through two passive systems: the reactor vessel auxiliary cooling system (RVACS), and the passive secondary auxiliary cooling system (PSACS), the same systems used for the lead reactor. The RVACS functions via natural circulation of air past the exterior of the reactor vessel. The PSACS functions by passing secondary side $\mathrm{CO}_{2}$ flow through a heat exchanger immersed in a tank of water; heat is removed via heating and boiling of the water. Description of these DHR systems was given in Chapter 2. 
The SBO accident is initiated in the RELAP model by tripping the reactor cooling pumps at time zero, closing the power conversion system isolation valves (valve 302 and 326 in the model), and opening the PSACS valves (323 and 324). Valve actuation occurs within the first half second of the accident sequence. These valves are ordinarily held open/shut in the actual system via powered solenoids or instrument air, so loss of power would cause them to automatically fail into the correct position. To be conservative, only two PSACS trains are opened to allow for one train in maintenance and another failing. Therefore, all results for unprotected accidents assume that the PSACS system is operating at half of maximum capacity. Because the secondary system is not involved in the accident sequence once it has initiated, it is taken out of the RELAP model and replaced with time-dependant volumes as boundary conditions in order to reduce computational time; this simplification should have no effect on transient behavior.

Reactor decay power for the salt $\mathrm{CR}=1$ core was calculated using the code BGCore (see Section 4.2.1) and implemented into RELAP, while reactor fission power is calculated using the point kinetics model built into RELAP. The reactivity feedbacks implemented are: coolant temperature, fuel temperature, core radial expansion, and LEM feedback. The first two are calculated based on power-squared weighting of the coolant and fuel temperatures, the third is based on the average coolant temperature in the core, while LEM feedback is based on the temperatures calculated for explicitly modeled LEM reservoirs above the core. The values used for these reactivity feedbacks are detailed in Sections 4.1 and 4.2.1. Implementation of the LEM model in RELAP5 is described in Appendix 3B.2.7.

\section{Short term SBO response}

The core peak cladding, core inlet, and core outlet temperature response to a station blackout for the first 1000 seconds is shown in Figure 4.2.2-3, for the reference $\mathrm{CR}=1$ salt reactor. Figure 4.2.2-3 shows that the salt reactor's peak cladding temperature exceeds its limit of $725^{\circ} \mathrm{C}$ less than three minutes after an SBO begins, reaching a maximum close to $750^{\circ} \mathrm{C}$. The PCT data also show unusual double peaked behavior between 50 and 200 seconds. The reason for this unusual behavior is a transition from turbulent to laminar flow. The presence of this transition can be seen by plotting the coolant heat transfer coefficient in the core during the transient; this is done in Figure 4.2.2-4. 
Project No 06-040: Flexible Conversion Ratio Fast Reactor Systems Evaluation

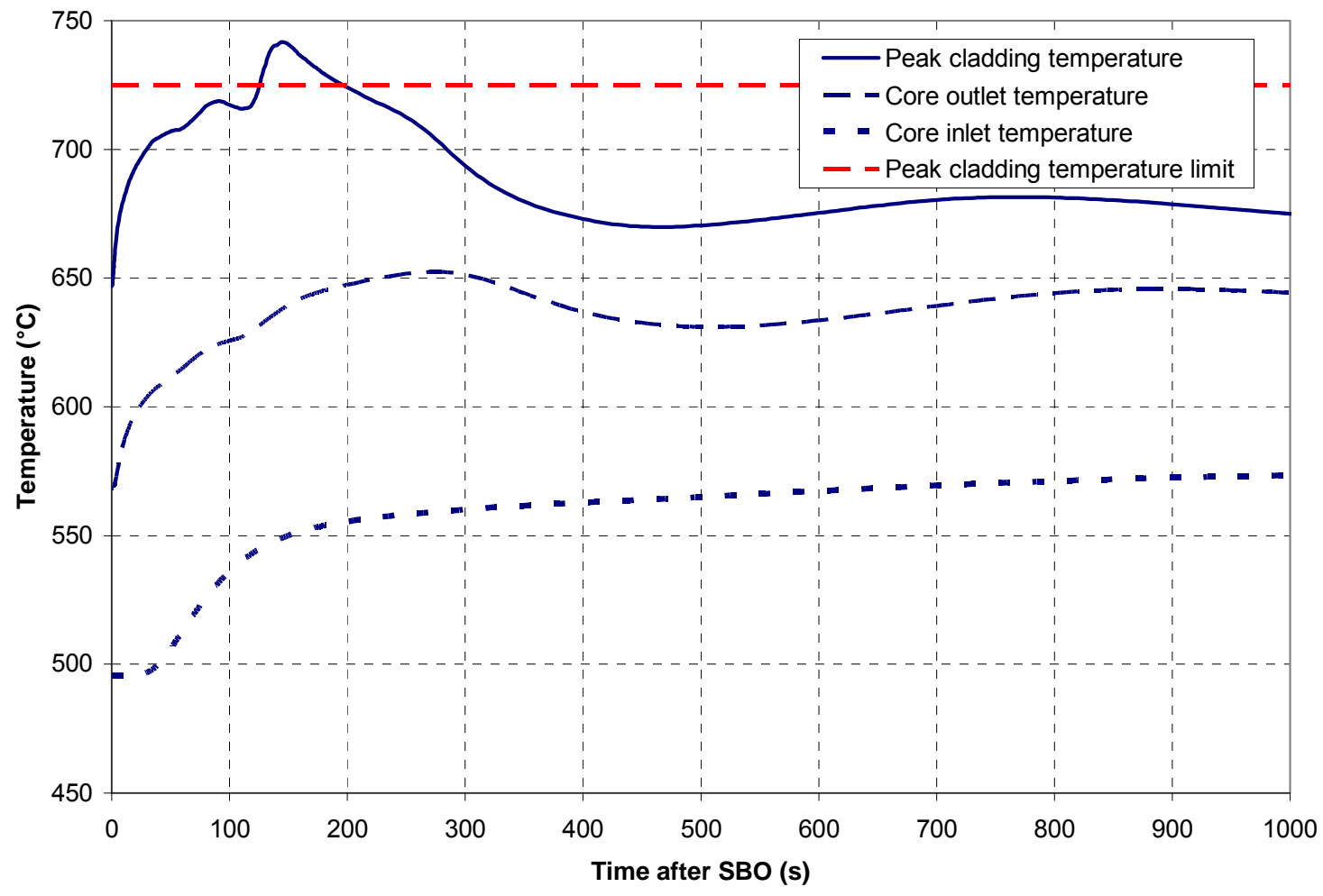

Figure 4.2.2-3 Short-term $\mathrm{CR}=1$ salt reactor response to an $\mathrm{SBO}$

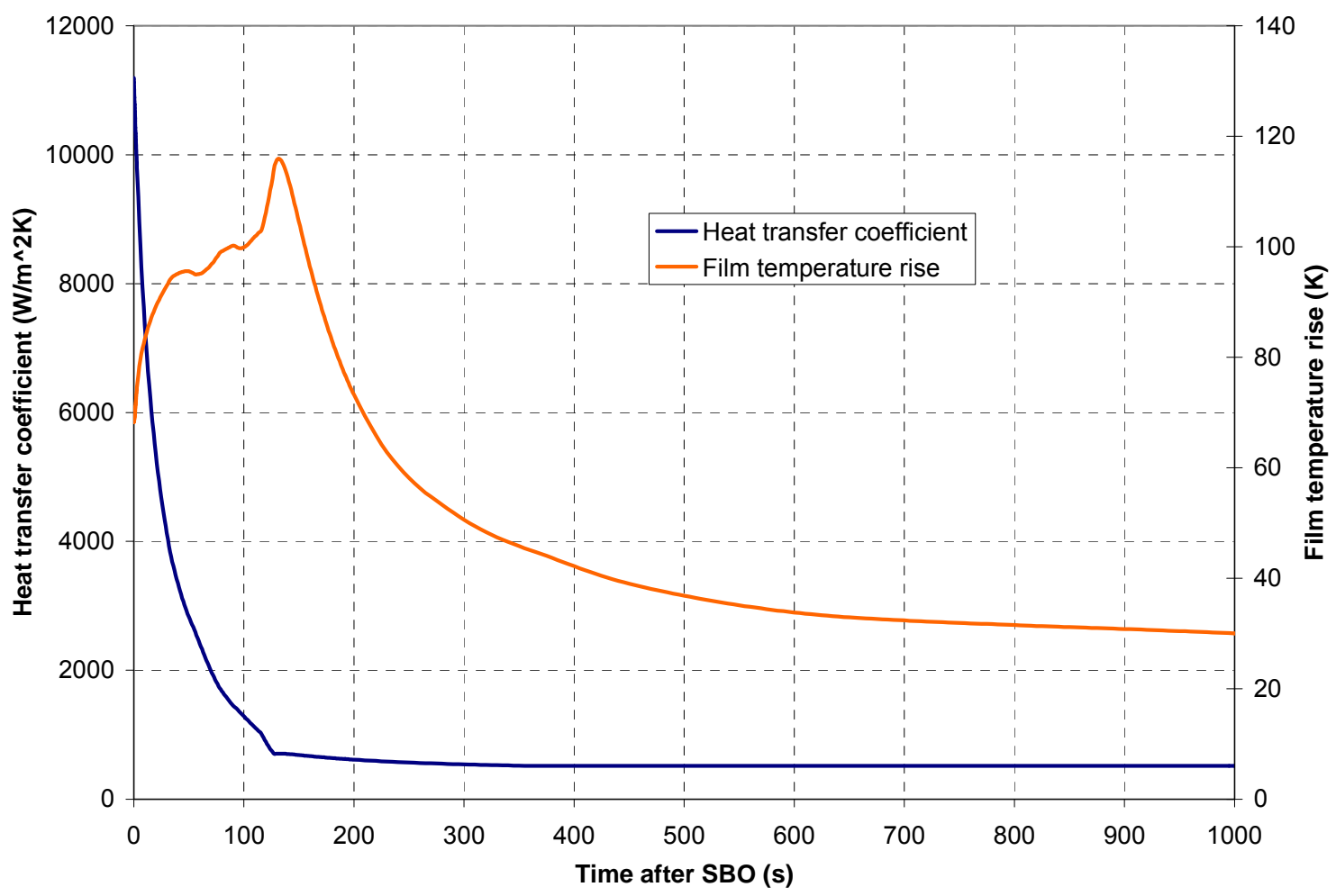

Figure 4.2.2-4 Core midplane heat transfer coefficient and film temperature rise 
Figure 4.2.2-4 shows how RELAP models the heat transfer coefficient as coolant flow transitions from turbulent to laminar (the Gnielinski correlation is used for turbulent flow with $\operatorname{Re}>3000$ ). The heat transfer coefficient does not decrease smoothly; there is a slight knee at about 110 seconds, and a sharp discontinuity in slope at approximately 130 seconds. Meanwhile, heat flux decreases smoothly, so the film temperature rise, which is the ratio of heat flux to heat transfer coefficient, exhibits the strange peaked behavior shown. This behavior is in turn responsible for the shape of the peak cladding temperature curve.

The fact that the shape of the peak cladding temperature curve during an SBO is an artifact of the correlations adopted highlights one of the challenges of salt reactor transient modeling. The high viscosity and low density of salt cause it to operate at much lower Reynolds numbers; during loss of flow transients these Reynolds numbers become sufficiently low to result in transition and laminar flow. Accurately characterizing a salt reactor therefore requires a better understanding of wire-wrap heat transfer not only for turbulent flow, but for transition and laminar flow as well. For RELAP specifically, the pressure drop across the core is also inaccurately modeled during loss of flow, since RELAP uses the Colebrook-White correlation for tubes modified (via the surface roughness factor) to match the more accurate Cheng-Todreas wire-wrap correlation at steady state. The modeling artifacts due to the correlations used also occur at the IHXs and the reactor vessel wall, where there is also heat transfer from the salt; the effect of this on RVACS heat transfer is shown in Figure 4.2.2-5. Again around 100 seconds there is non-smooth behavior attributable to modeling flow regime transitions.

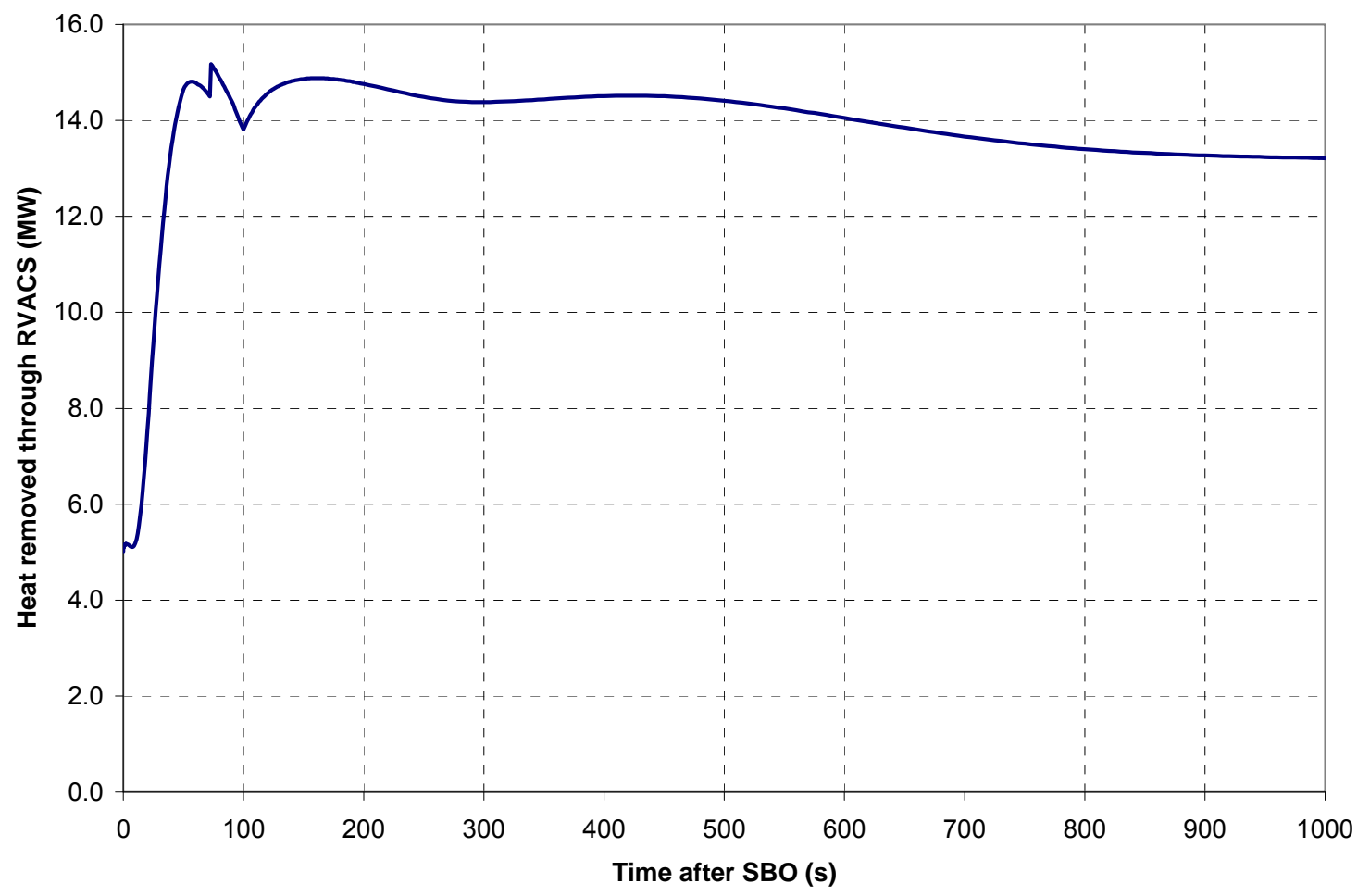

Figure 4.2.2-5 Heat removal through the RVACS after SBO

Despite the modeling challenges present with flow regime transitions, the results obtained can nevertheless be considered conservative estimates of actual transient behavior. With this being the case, it is apparent from Figure 4.2.2-3 that the unmodified salt reactor design exceeds the transient peak cladding temperature limit during an SBO. The primary reason is the poor heat 
transfer characteristics of salt leading to a high film temperature rise; while coolant temperatures are actually lower than those for the lead reactor, the difference between the peak cladding temperature and the coolant temperatures are much higher for the salt core. This situation is exacerbated during a loss of flow situation; the rapid drop off in the heat transfer coefficient leads to a $\sim 70 \%$ increase in the film temperature rise (Figure 4.2.2-4).

Several strategies were tested to reduce the peak cladding temperature during an SBO transient. First, the amount of heat removed by the PSACS was adjusted; results are shown in Figure 4.2.26. The percentages shown in the legend roughly correspond to the amount of the heat each PSACS would remove for a given steady state in the primary system, as compared to the reference design. In reality the heat removal capacity of the PSACS is determined by the design of the passive auxiliary heat exchanger (PAHX) in the PSACS water tank. In RELAP the different PSACS capacities are modeled by changing the PAHX heat structures as well as by varying the number of trains from two to one; this latter approach is necessary because of computational slowdowns for low values of heat removal in a single train. The $200 \%$ PSACS design corresponds to the one used in the reference lead design; i.e. the reference salt system uses a half-power PSACS compared to the lead system. Figure 4.2.2-6 shows that changing the PSACS design does not have a large effect on short term performance, and essentially no effect on the initial peak that exceeds the peak cladding temperature limit. This is not surprising because the primary issue during the early stages of the transient is film temperature rise from reduced flow rather than primary coolant temperature.

An alternative means of addressing reactor transient performance is to modify core steady-state operating characteristics to provide a larger margin to cladding failure. This can be implemented in several ways: the coolant inlet temperature can be decreased, core power density can be decreased, or the coolant flow rate can be increased. Decreasing the coolant inlet temperature by $20^{\circ} \mathrm{C}$ would also reduce the transient peak cladding temperature by about $20^{\circ} \mathrm{C}$, below the $725^{\circ} \mathrm{C}$ limit. However, this option would also reduce the margin to coolant freezing, and lower system temperatures would also reduce the efficiency of the power conversion system $\left(\mathrm{a} 20^{\circ} \mathrm{C}\right.$ decrease corresponds to $\mathrm{a} \sim 1 \%$ reduction in plant efficiency). Lowering the core power density below 130 $\mathrm{kW} / 1$ would reduce the film temperature rise and the transient peak cladding temperature, but would require either a lower power level or a larger reactor vessel. Even though a $100 \mathrm{~kW} / 1$ lead-cooled core is able to fit in a $10.2 \mathrm{~m}$ diameter vessel, a $100 \mathrm{~kW} / 1$ salt-cooled core would not because it requires larger IHXs. 
Project No 06-040: Flexible Conversion Ratio Fast Reactor Systems Evaluation

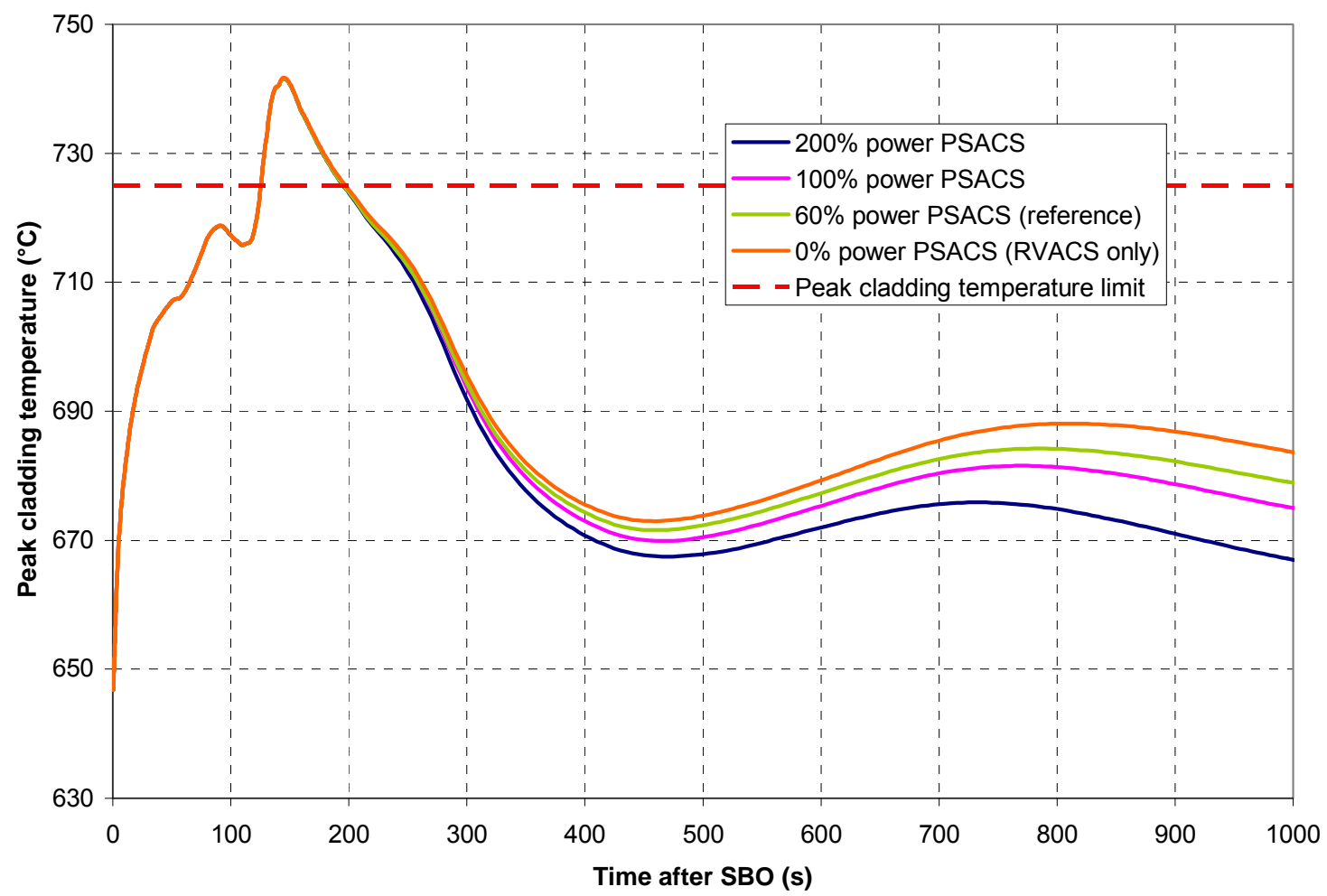

Figure 4.2.2-6 Effect of changing SBO decay heat removal

Increasing the steady-state coolant flow rate is a way to increase the cladding temperature margin without sacrificing system performance. An alternative primary system was designed that could accommodate a coolant flow rate of $40,000 \mathrm{~kg} / \mathrm{s}$, versus $32,800 \mathrm{~kg} / \mathrm{s}$ for the reference design. The high-flow-rate core has coolant inlet and outlet temperatures of $505^{\circ} \mathrm{C}$ and $565^{\circ} \mathrm{C}$ respectively, versus $496^{\circ} \mathrm{C}$ and $569^{\circ} \mathrm{C}$ for the reference core, and the IHXs were redesigned to maintain the same secondary side temperatures and pressures. Increasing the coolant flow rate therefore doesn't impact overall system performance outside of raising system pressure losses, which can be overcome through the use of larger pumps. Most importantly, the high-flow-rate core has a steady-state peak cladding temperature of $633^{\circ} \mathrm{C}, 15^{\circ} \mathrm{C}$ lower than that of the reference core. However, this increased margin does not translate to the same larger margin during a transient; rerunning the SBO transient yields the results shown in Figure 4.2.2-7. While there is a slight reduction in peak cladding temperature during the transient, about $5^{\circ} \mathrm{C}$, the higher flow rate core similarly experiences a rapid decrease in core flow rate and quickly loses its extra coolant velocity. In summary, adjusting the liquid-salt core's steady-state parameters to reduce peak cladding temperature during an SBO requires a sacrifice in reactor performance, since the only method which doesn't sacrifice performance, increasing the core flow rate, does not have a large effect on transient peak cladding temperature. 
Project No 06-040: Flexible Conversion Ratio Fast Reactor Systems Evaluation

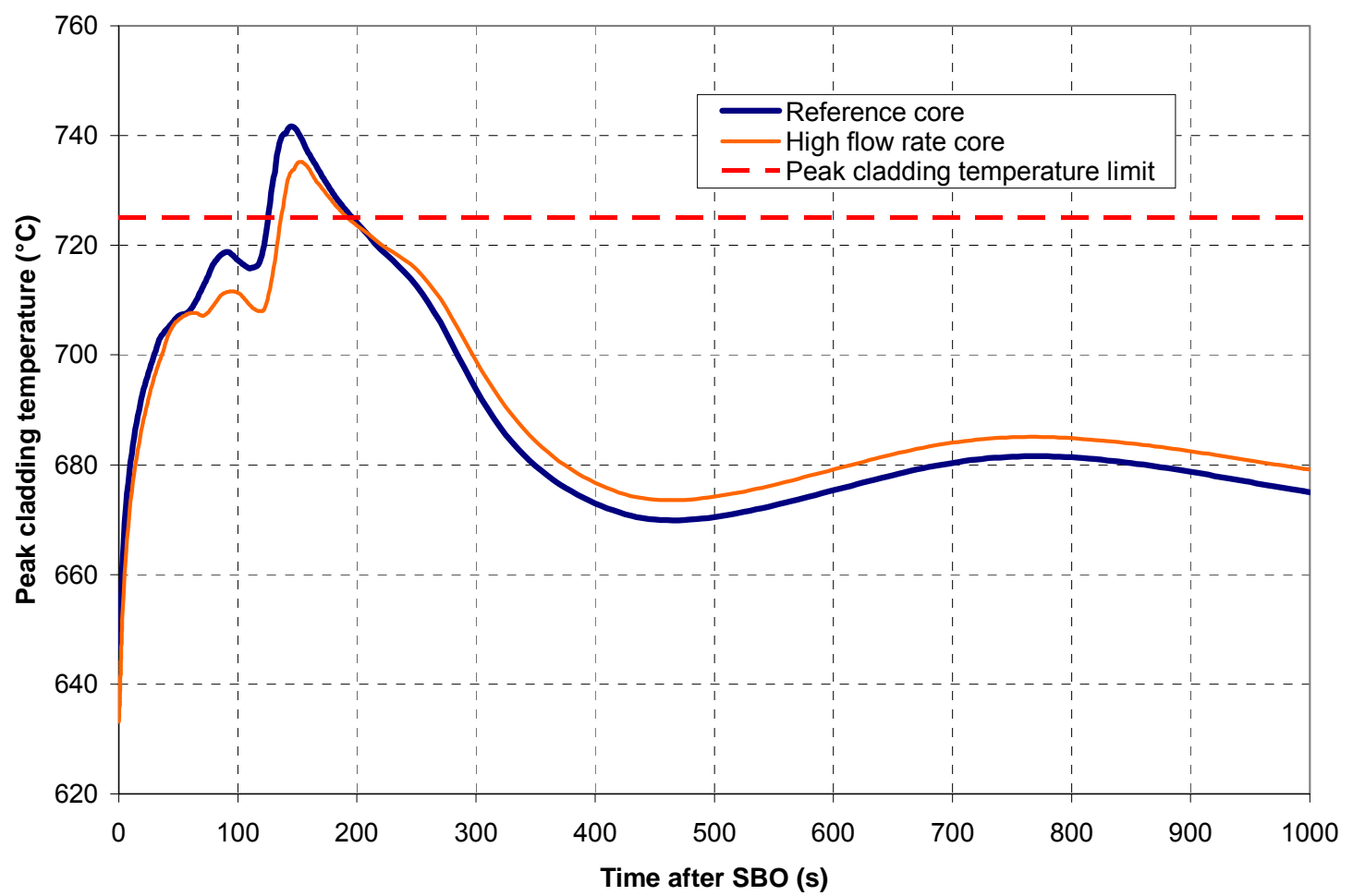

Figure 4.2.2-7 Peak cladding temperatures for a high flow rate core

The initial peak in the maximum cladding temperature occurs primarily because the heat transfer coefficient decreases more quickly than reactor power, so it can be lowered either by making reactor power decrease faster or the coolant flow rate decrease more slowly. For example, in the bounding case of a reactor scram, reactor power decreases very quickly and the peak cladding temperature actually falls instead of rising immediately after an SBO. Reactor power can also be made to decrease more quickly through stronger reactivity feedbacks, which can be instituted by adding LEMs, however this approach would displace fuel rods and therefore increase peaking. Another option is to add flywheels or another form of energy storage to the reactor coolant pumps, so the coolant flow rate and heat transfer coefficient do not decrease as rapidly. Peak cladding temperatures for the flywheel case and the reactor scram case are illustrated in Figure 4.2.2-8. The same double peaked behavior can be observed in the flywheel case, although the second peak now occurs later because the coolant flow rate decreases more gradually.

Increasing pump inertia is an attractive solution because it does not require sacrificing core steady-state performance. However, implementing this solution could be challenging: the case plotted in Figure 4.2.2-8 assumes that the pumps' moment of inertia increases from $28,700 \mathrm{~kg}-$ $\mathrm{m}^{2}$ to $50,000 \mathrm{~kg}-\mathrm{m}^{2}$, or $5,325 \mathrm{~kg}-\mathrm{m}^{2}$ per pump. This inertia increase is equivalent to the addition of a depleted uranium ring $20 \mathrm{~cm}$ thick $(50 \mathrm{~cm}$ inner radius, $70 \mathrm{~cm}$ outer radius), $1 \mathrm{~m}$ tall, and weighing 14.4 metric tons to each reactor coolant pump. At steady state, each cylinder would store approximately $380 \mathrm{MJ}$ in rotational energy. Different energy storage mechanisms (such as batteries) may be an option if the mechanical engineering of such large flywheels is problematic. 
Project No 06-040: Flexible Conversion Ratio Fast Reactor Systems Evaluation

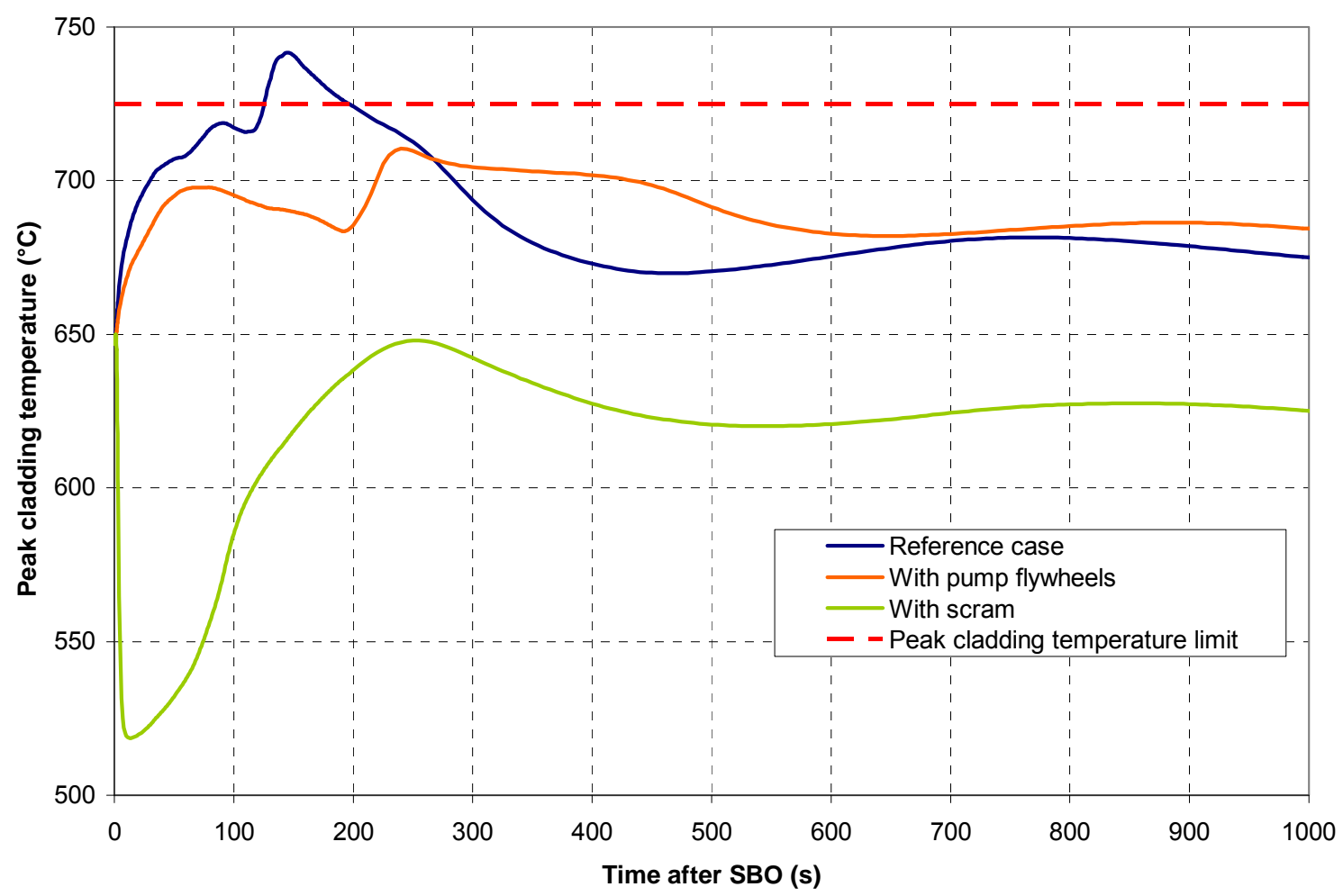

Figure 4.2.2-8 Effect of pump flywheels and a reactor scram on SBO response

Finally, it may be possible that a peak cladding temperature exceeding $725^{\circ} \mathrm{C}$ for a brief period of time may be acceptable. The $725^{\circ} \mathrm{C}$ limit was established because it corresponds to the temperature at which fuel-cladding eutectic formation begins. However, not much interaction occurs at this onset temperature, and even at $100^{\circ} \mathrm{C}$ above the eutectic temperature, the eutectic penetration into cladding is minimal in one hour [Chang, 2007]. Therefore, it is unlikely that the short-duration temperature excursion above $725^{\circ} \mathrm{C}$ encountered during an SBO would lead to cladding failure. Furthermore, since the cladding would already not be reusable for structural reasons after a high-temperature transient, the presence of some fuel-cladding interaction would not change the implications of an SBO. Another possibility would be to use a multilayer rolled metal foil that is laser tackwelded to form a tube, which can be inserted between the fuel and the cladding to form a barrier and prevent eutectic formation [Taylor and Wadekamper, 1994].

In summary, the SBO transient is more challenging for the salt reactor than for the lead reactor in the short term because of tighter thermal hydraulic margins and the poorer heat transfer characteristics of liquid salt. The salt heat transfer coefficient decreases more rapidly than core power, causing the film temperature rise to increase about $70 \%$ during a transient, although there is some uncertainty in the exact behavior because the calculated behavior depends on the correlations adopted. This in turn causes the peak cladding temperature to briefly $(50-80$ seconds) exceed the $725^{\circ} \mathrm{C}$ limit. Several measures can be adopted to reduce the peak cladding temperature. First, the core can be redesigned to provide a larger peak cladding temperature margin, but doing so would require sacrificing steady-state performance. Another set of solutions would be to strengthen reactivity feedbacks by adding LEMs or to store energy in the primary coolant pumps so the coolant flow rate does not decrease as rapidly. However, it is unlikely that exceeding $725^{\circ} \mathrm{C}$ for up to a few minutes during an SBO would lead to fuel failure, 
which suggests that the transient behavior of the unmodified reference core could also be found acceptable.

\section{Long term SBO response}

The long term response of a reactor system to an SBO transient is primarily governed by the design of its passive heat removal systems, since no heat is removed through the power conversion system. With the RVACS design being more or less fixed to remove as much heat as possible through the vessel walls, the major design options available involve the design of the PSACS system. The PSACS has two major parameters that can be adjusted: the rate of heat removal, based mainly on the design of the PAHXs, and how much total energy it can absorb, based on the sizing of the PSACS water tanks. By varying these parameters, several long term response behaviors are possible, as discussed below.

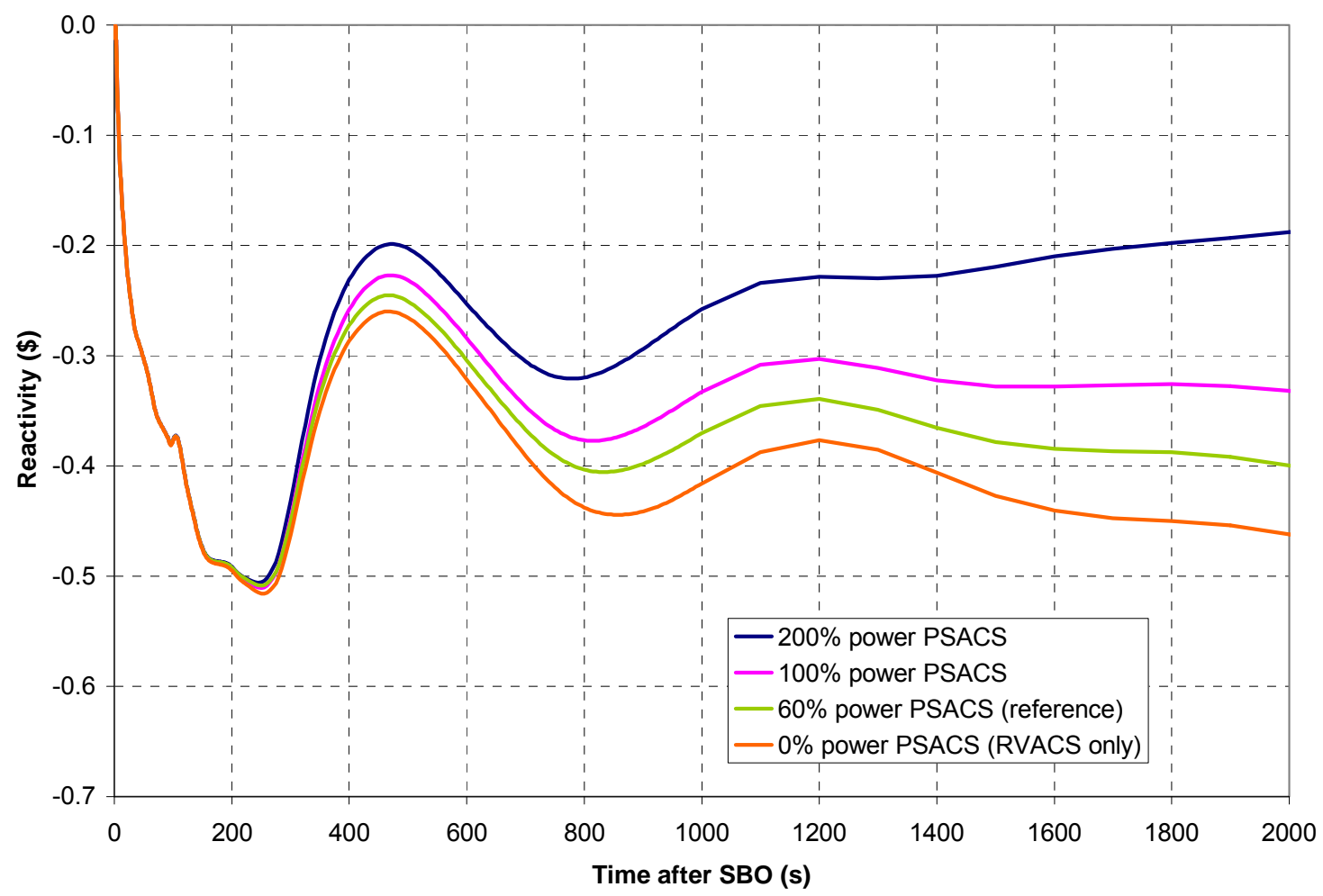

Figure 4.2.2-9 $\mathrm{CR}=1$ reactivity following an SBO

Figures 4.2.2-9 and 4.2.2-10 show the reactivity and fission power of the salt core following an SBO transient for a variety of PSACS power capacities. These figures show that irrespective of PSACS design, the high temperatures of the short term SBO response introduce significant negative reactivity that shut down the reactor within the first 2000 seconds. 
Project No 06-040: Flexible Conversion Ratio Fast Reactor Systems Evaluation

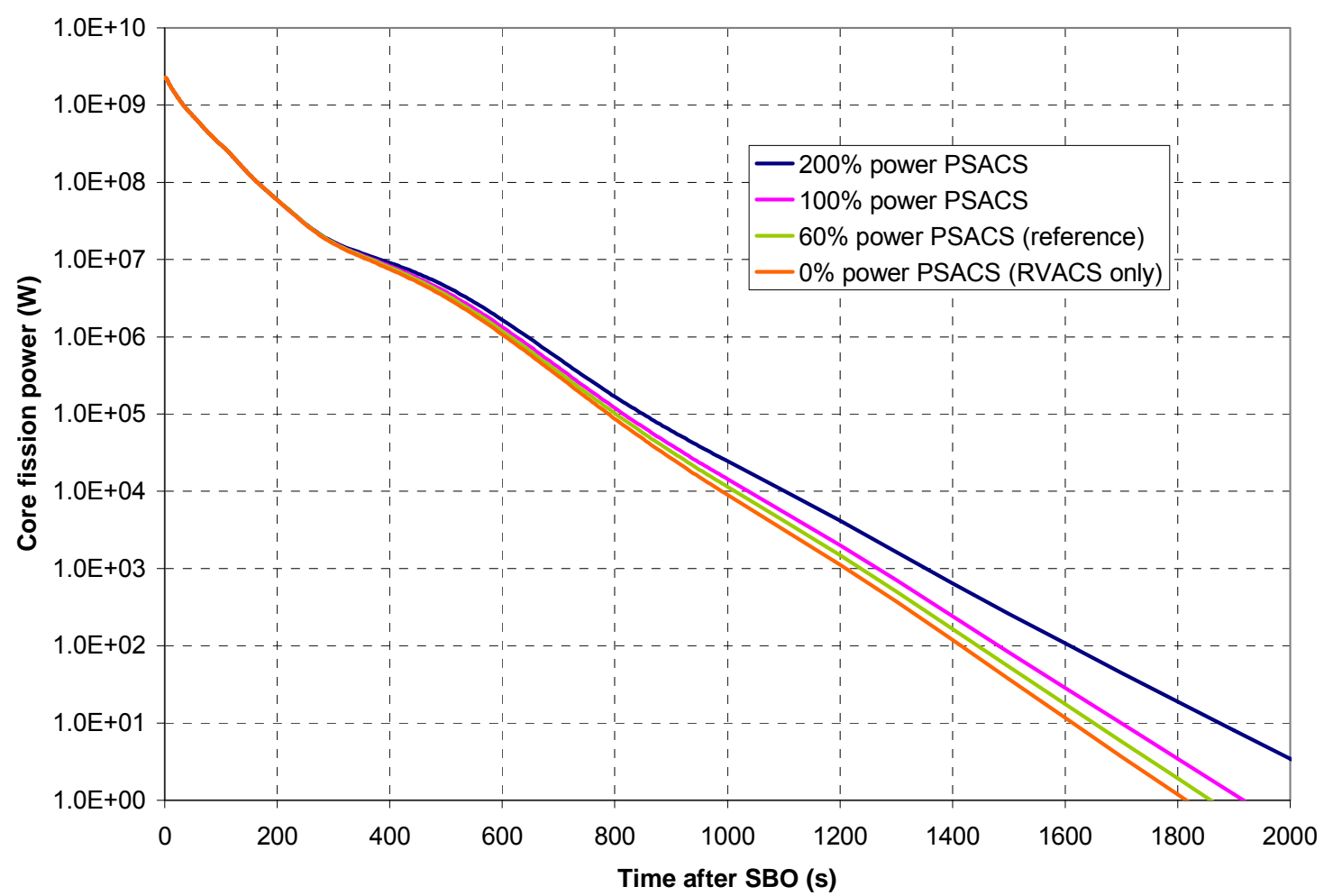

Figure 4.2.2-10 CR=1 Fission power following an SBO

Past this initial shutdown, several possibilities exist depending on the design of the PSACS system. The first design considered was the reference design for the lead reactor PSACS: 700 four-meter-long heat exchanger tubes per PAHX, with a $6 \mathrm{~m}$ diameter, $12 \mathrm{~m}$ tall PSACS water tank. This corresponds to the $200 \%$ PSACS power case shown in the short term response results. Long term peak cladding temperature, reactivity, and power results for this design are shown in Figures 4.2.2-11 through 4.2.2-13. Several important features are evident: first, at around 1.6 hours into the transient, reactivity becomes positive. This occurs because the amount of the heat removed by the RVACS and PSACS exceeds the decay heat, causing coolant and fuel temperatures to decrease and reactivity to increase. About one hour after reactivity becomes positive, the reactor restarts and quickly settles on a steady state power of about $30 \mathrm{MWt}$, corresponding to a peak cladding temperature of $632^{\circ} \mathrm{C}$. In reality, there would not be such a long delay between reactivity becoming positive and a reactor restart. The lengthy delay is an artifact of RELAP model not taking into account the minimum background fission power; RELAP calculates the fission power as falling for all 1.6 hours that the reactivity is negative, reaching a minimum of $3 \times 10^{-8} \mathrm{~W}$. As a result, it takes a long time for fission power to grow from this tiny value to the $30 \mathrm{MW}$ steady state power. An actual reactor would drop to a minimum fission power on the order of $100 \mathrm{~W}$ due to spontaneous fissions, which would more quickly grow to several MW once reactivity becomes positive. Overall, this inaccuracy does not qualitatively affect the results obtained; if minimum fission power had been taken into account one would simply expect smaller oscillations as the system approached steady state. 
Project No 06-040: Flexible Conversion Ratio Fast Reactor Systems Evaluation

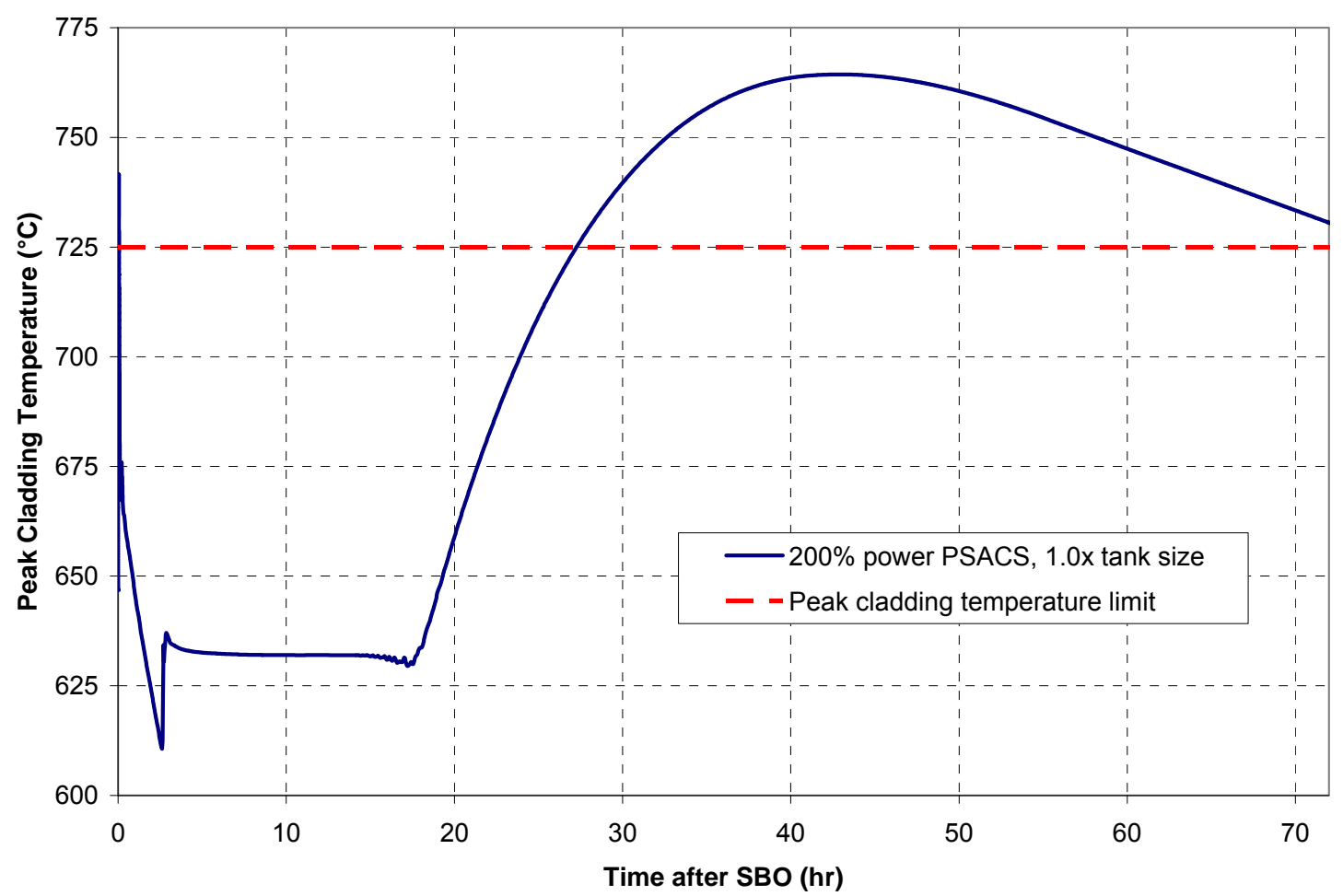

Figure 4.2.2-11 $\mathrm{CR}=1$ long term peak cladding temperature response to an SBO

At approximately 18 hours, the system leaves steady state and begins to heat up, and the reactor shuts down once again. This is due to evaporation in the PSACS water tanks; the power removed via the PSACS rapidly falls to zero as the water level falls below the heat exchanger tubes. RELAP has difficulty modeling the PSACS system after this occurs (possibly because of nearly stagnant $\mathrm{CO}_{2}$ flow conditions or heat transfer to air by the PAHXs), so the PSACS system is disconnected at 68,000 seconds (18.9 hours) by closing the PSACS valves (323 and 324). Doing this has little effect on results because the PSACS is already removing very little heat at this point. With the PSACS operating at nearly zero power, heat removal past 18 hours occurs exclusively through the RVACS. Between 18 and 43 hours into the SBO transient, decay heat from the core is greater than the heat removal capacity of the RVACS, so coolant and peak cladding temperatures rise, with the peak cladding temperature exceeding the $725^{\circ} \mathrm{C}$ limit at about 27 hours. Unlike during the short term SBO response, the temperature limit is exceeded for a long time, upwards of 45 hours, which could allow significant fuel-cladding eutectic formation and lead to fuel failure. Therefore a different PSACS design is needed to ensure passive long-term safety for the liquid salt reactor. 
Project No 06-040: Flexible Conversion Ratio Fast Reactor Systems Evaluation

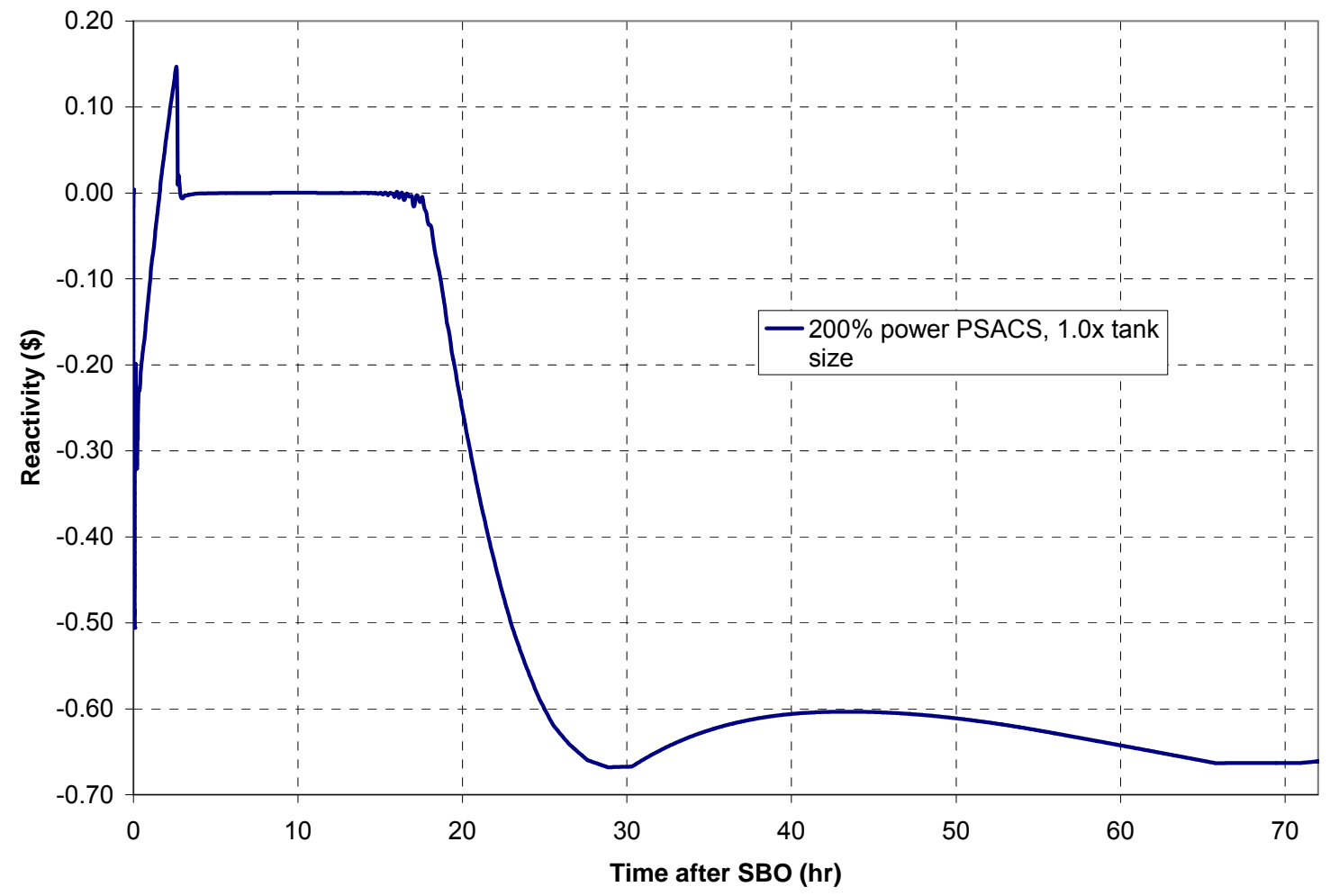

Figure 4.2.2-12 $\mathrm{CR}=1$ long term reactivity response to an SBO

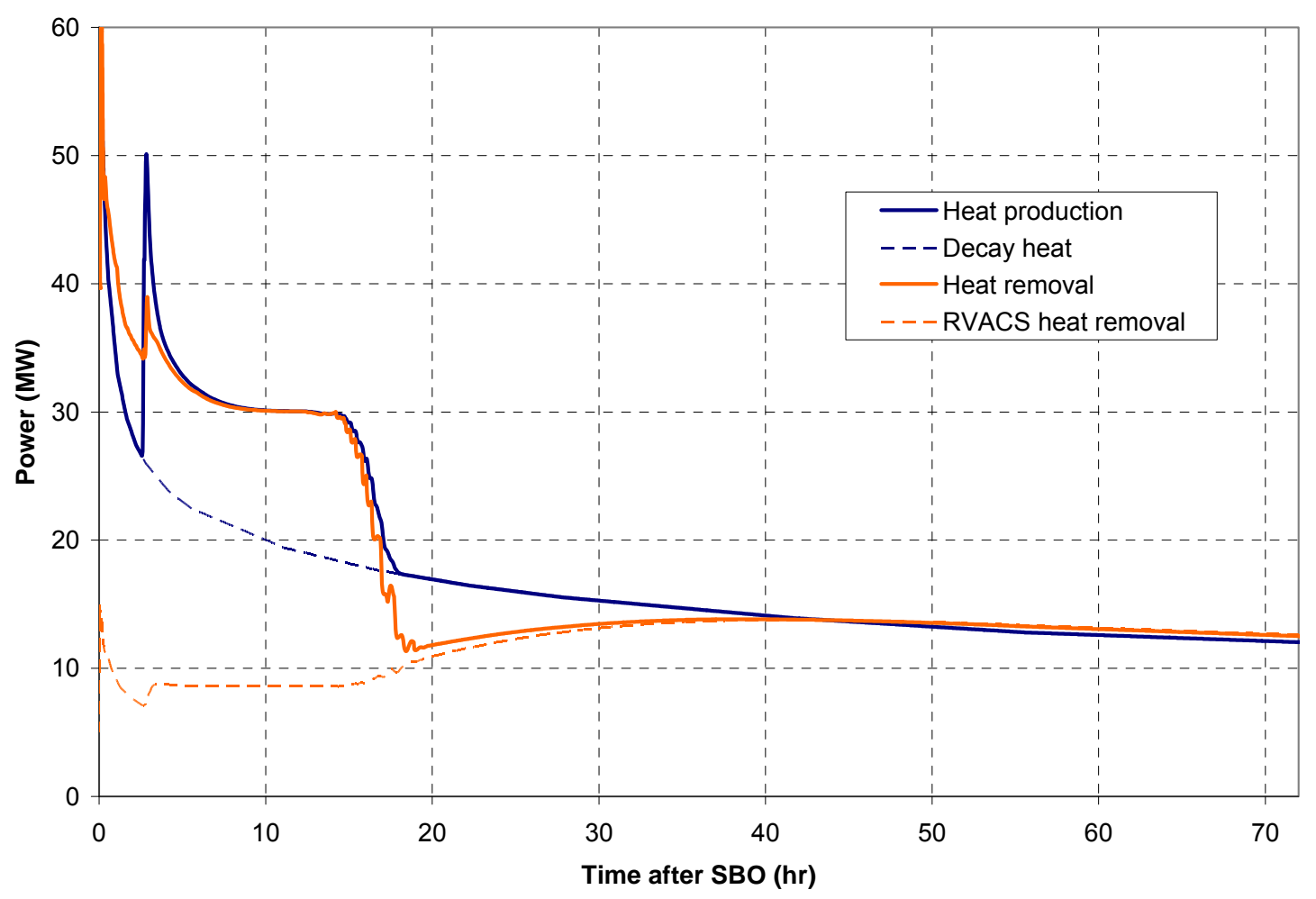

Figure 4.2.2-13 $\mathrm{CR}=1$ long term power response to an SBO; $200 \%$ power PSACS, 1.0x tank size case 
One option to avoid fuel-clad eutectic formation is to increase the size of the PSACS water tanks. This would allow the low-power steady-state period to last longer and give more time for reactor decay heat to subside. This was implemented in RELAP by making the PSACS water tanks much larger (34 $\mathrm{m}$ high) and setting the PSACS disconnect time to correspond to a desired amount of energy removed. For example, to simulate PSACS tanks that are approximately twice as large, a PSACS disconnect time of 130,000 seconds ( $\sim 36$ hours) is chosen, since 36 hours is roughly twice the 18 hour duration the initial tank design can remove heat for. This approach is used so that tank size can be simulated by varying only one parameter (disconnect time), rather than having to manually adjust the tank size and then determining the appropriate disconnect time needed for computational stability. Since the power removed through the PSACS drops rapidly as the PAHX heat exchanger tubes become exposed to air, switching PSACS power quickly to zero by disconnecting the PSACS is a reasonable approximation. Later the total amount of energy removed via the PSACS can be computed to determine the equivalent amount of water needed in the PSACS tank.

Peak cladding temperature results for the large-tank case are shown in Figure 4.2.2-14. The total amount of energy removed through the PSACS in this case is 2.1 times that removed in the initial case, corresponding to a PSACS tank containing 2.1 times as much water. Larger PSACS tanks give decay heat more time to diminish, allowing the RVACS to keep the reactor below the peak cladding temperature limit once the PSACS is depleted. However, doubling the size of PSACS tanks would raise capital costs, since the starting design has tanks that are already a large $6 \mathrm{~m}$ in diameter and $12 \mathrm{~m}$ high. Additionally, the $200 \%$ power PSACS design encounters the same difficulty as the $100 \%$ power design discussed later: during protected transients the high heat removal rate through the PSACS can lead to coolant freezing.

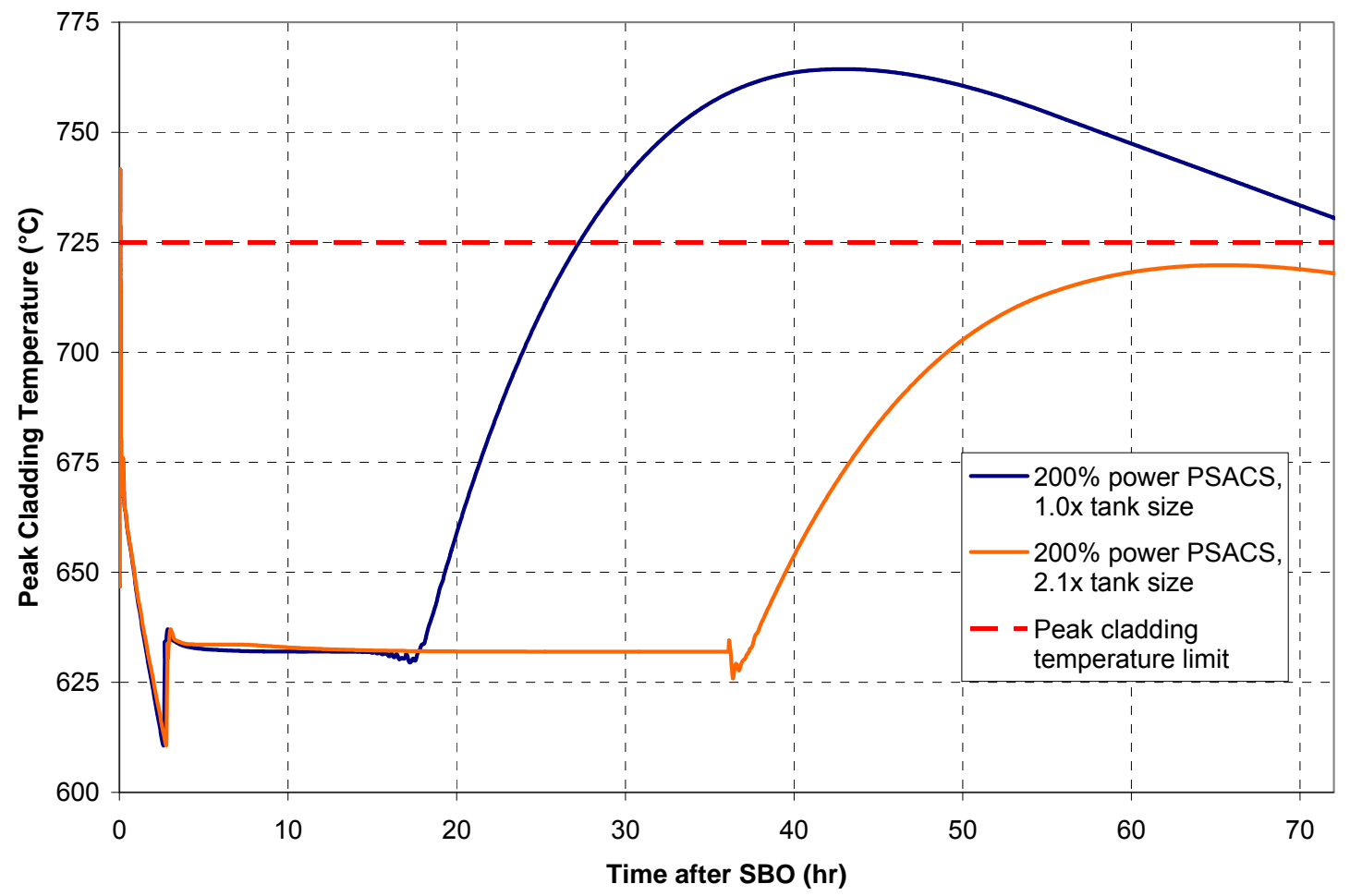

Figure 4.2.2-14 CR=1 long term peak cladding temperature response to an SBO 
Another approach that would yield the same benefit as larger tanks without raising capital costs would be to decrease the heat removal capacity of the PSACS. This can be accomplished in practice by reducing the number (from 700 to 500) and length (from $4 \mathrm{~m}$ to $3 \mathrm{~m}$ ) of heat exchanger tubes in the PAHXs. Doing so would reduce the rate at which PSACS water is boiled off and therefore extend the duration over which the PSACS is effective. A half-power PSACS system was implemented in RELAP by disabling one of the two active PSACS trains. This approach was needed instead of downsizing the PAHXs because RELAP encounters computational difficulties modeling low-power PSACS trains. Again a PSACS disconnect time of 130,000 seconds was used to simulate the PSACS running out of water. Peak cladding temperature results for this case are shown in Figure 4.2.2-15. While the smaller PSACS causes temperatures to rise somewhat initially, it is able to sustain low-power steady state operation long enough to prevent overheating, while only requiring a PSACS tank 1.1 times larger $(13.2 \mathrm{~m}$ height) than the initial design.

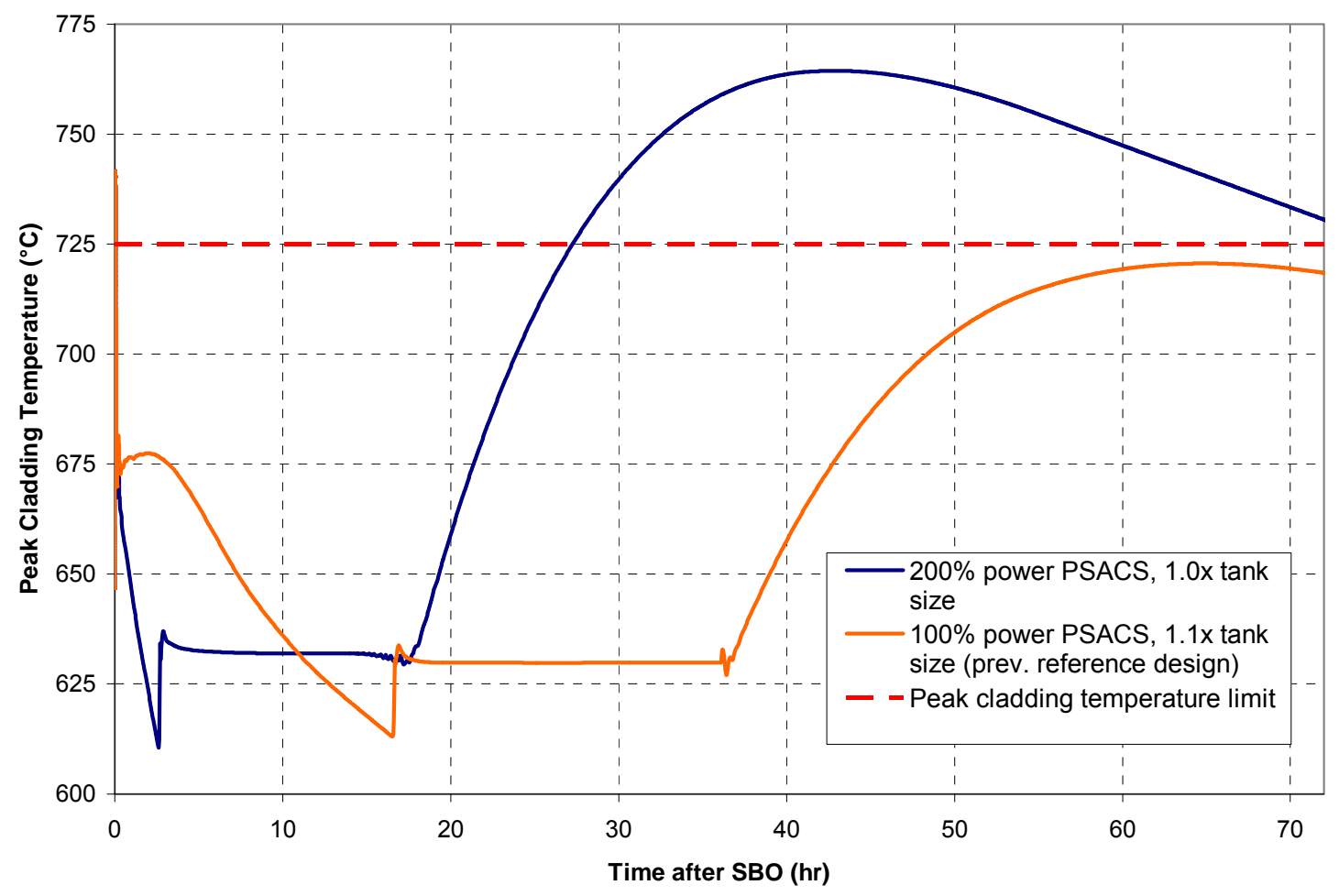

Figure 4.2.2-15 $\mathrm{CR}=1$ long term peak cladding temperature response to an SBO

This low-power PSACS design was originally selected as the reference design because of its ability to successfully mitigate an unprotected SBO without increasing capital cost requirements. It is also a robust design in that its performance is largely independent of the number of PSACS trains operating while accommodating reactor restart to lower power. As long as more than two trains are running the reactor will not exceed $725^{\circ} \mathrm{C}$ after the initial shutdown. After the subsequent restart, the reactor will assume steady state operation at a power level equal to that removed by all the PSACS trains and the RVACS: about $20 \mathrm{MW}$ when two PSACS trains are operating (11MW through PSACS and $9 \mathrm{MW}$ through RVACS) and about $30 \mathrm{MW}$ when all four trains are operating (21MW through PSACS and $9 \mathrm{MW}$ through RVACS). Due to the favorable reactivity coefficients made possible by LEMs, the coolant and fuel temperatures are very similar regardless of the restart power level. Since each PSACS train has its own water tank, this steady state will last until approximately 36 hours into the transient regardless of how many PSACS 
trains are operating. An unprotected SBO with all PSACS trains running would result in a response similar to the large tank case shown in 4.2.2-14.

While accommodation of reactor restart in the original reference design makes for a robust system, it means that transient behavior during a protected transient would be different, since a scram would prevent a restart from occurring. Investigations of a protected transient showed that with all four $100 \%$ power PSACS trains operating, decay heat removal through the PSACS was sufficient to cause coolant freezing within the first 20 hours of an SBO transient. The details of this analysis are given in the protected transient subsection.

To resolve the issue of coolant freezing during protected transients, the power level of the PSACS system was further reduced. Through trial and error it was found that PSACS with a heat removal capacity $60 \%$ that of the reference case is just sufficient to prevent the peak cladding temperature from exceeding $725^{\circ} \mathrm{C}$ with only two trains operating. Peak cladding temperature, reactivity, and power results for this case are shown in Figure 4.2.2-16 through 4.2.2-18. By sizing the PSACS tanks such that each tank runs out of water 36 hours or later into the transient (about 75\% the size of the initially designed tanks -see Table 2.2.3-2 for PSACS final dimensions) allows the peak cladding temperature limit to be satisfied for times past 36 hours. Note that in this reduced-power PSACS design, reactor temperatures never become low enough to cause a restart with just two trains running. With three or four trains running, a reactor restart would occur as it did with the $100 \%$ power PSACS case, and the transient would similarly be safely mitigated. Because of the similar robustness of the $60 \%$ power PSACS design and its additional ability to mitigate protected transients, it was selected as the reference PSACS design for the salt-cooled FCR reactor.

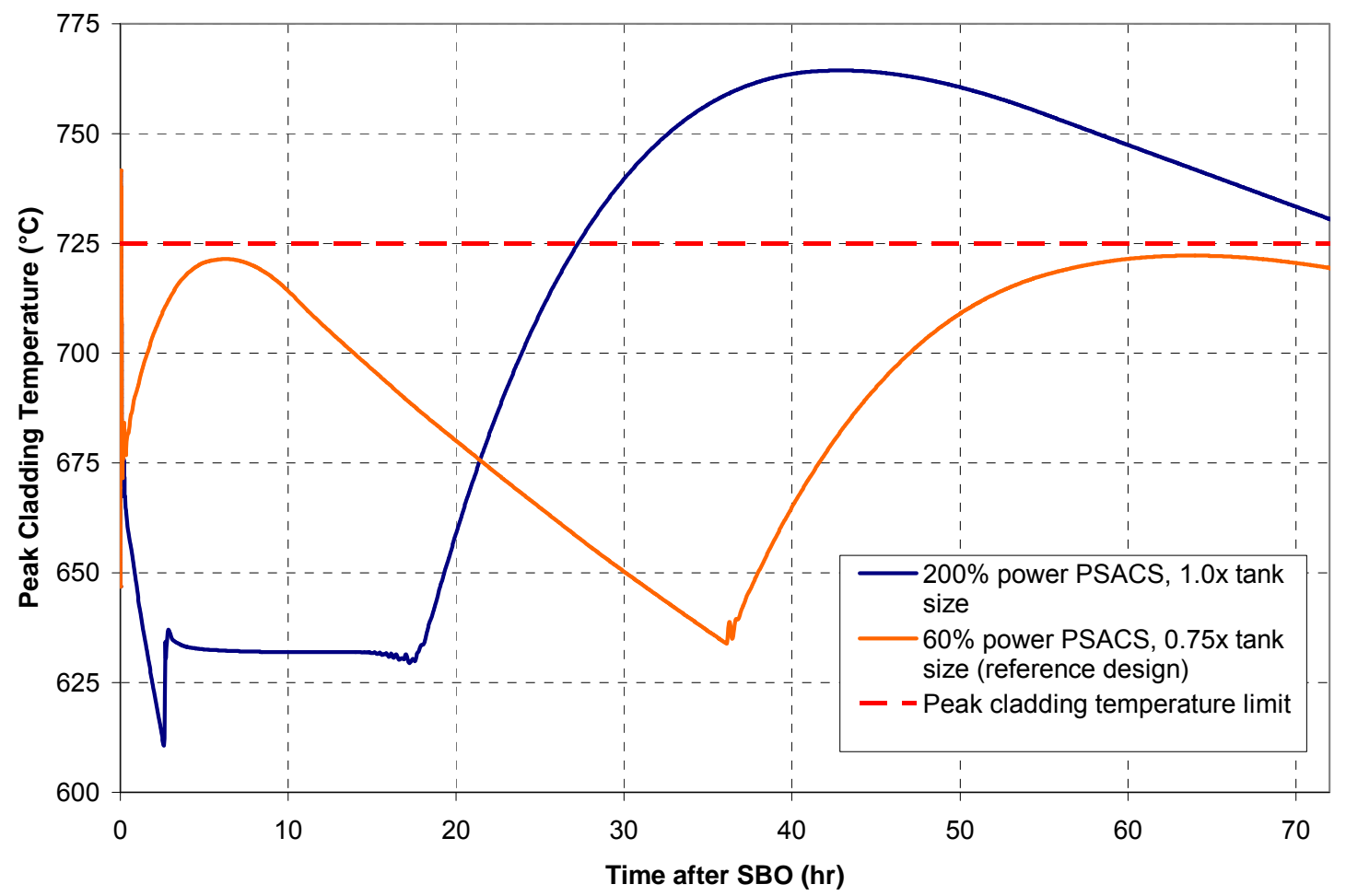

Figure 4.2.2-16 CR=1 long term peak cladding temperature response to an SBO 
Project No 06-040: Flexible Conversion Ratio Fast Reactor Systems Evaluation

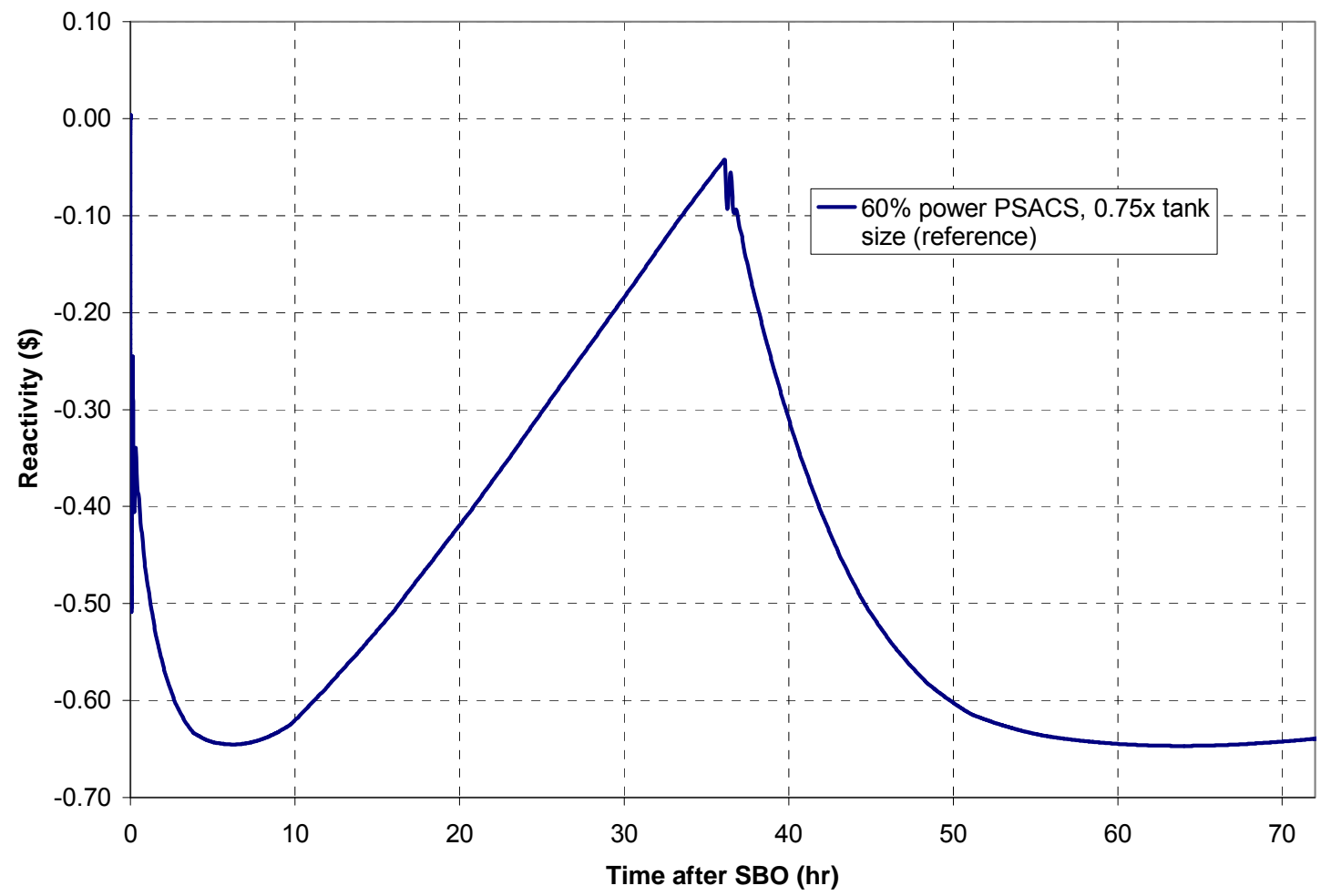

Figure 4.2.2-17 $\mathrm{CR}=1$ long term reactivity response to an $\mathrm{SBO}$

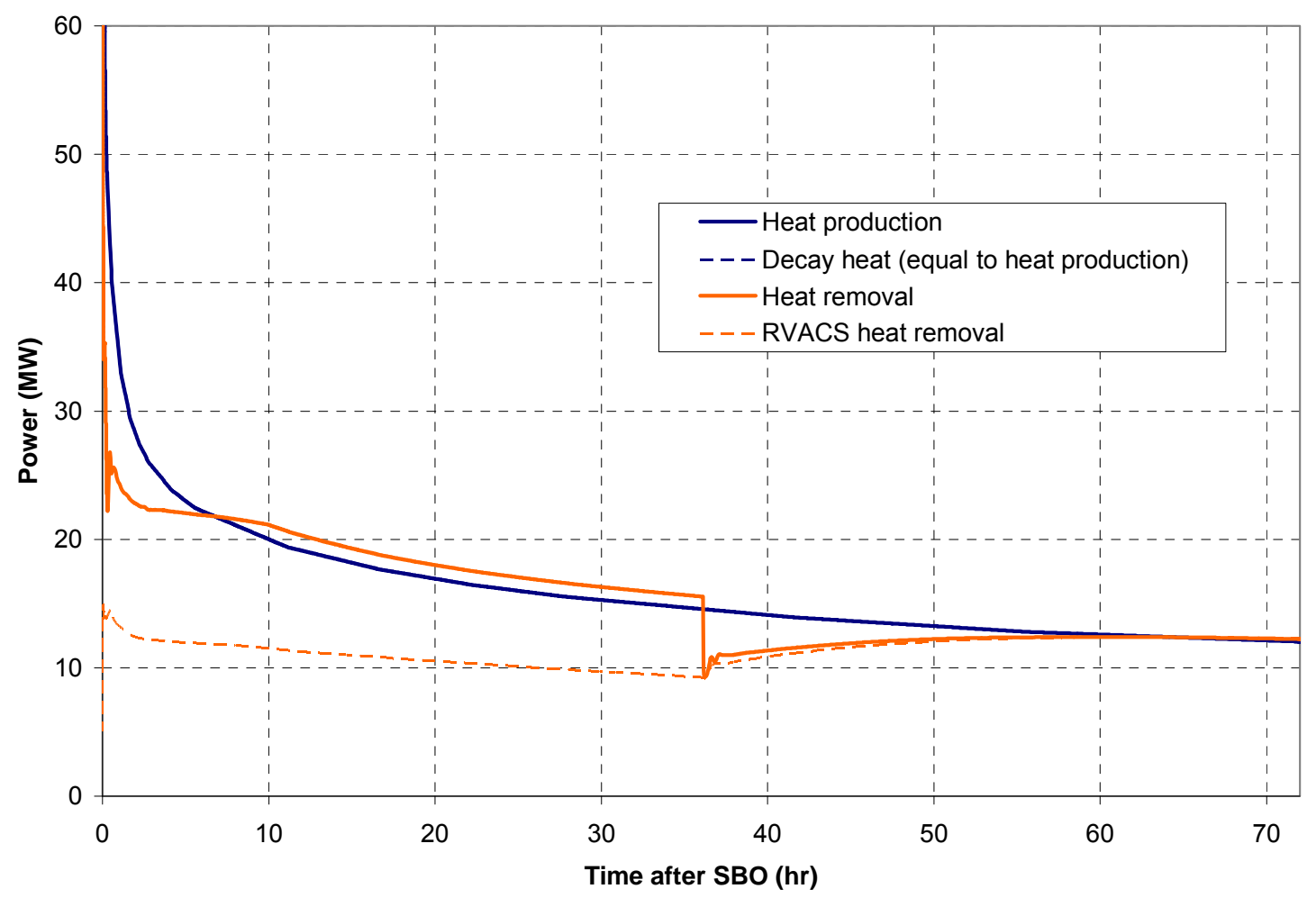

Figure 4.2.2-18 CR=1 long term power response to an SBO; 60\% power PSACS, 0.75x tank size case 
Overall, a liquid salt reactor can be designed to passively mitigate an unprotected station blackout transient. Short and long term responses for the reference design are shown in Figures 4.2.2-6 and 4.2.2-16. The poor heat transfer characteristics of liquid salt cause it to briefly exceed the cladding temperature limit of $725^{\circ} \mathrm{C}$ immediately after the transient begins, but this is unlikely to cause fuel failure and can be avoided through the use of higher inertia pumps. Reactivity feedbacks, including that due to LEMs, cause the reactor to shut down within the first 1000 seconds. Past this initial shutdown, cooling by the PSACS and RVACS causes reactivity to rise again, resulting in a reactor restart into a low-power steady state if three or four PSACS trains are operating. Regardless of the number of PSACS trains operating (2, 3, or 4), PSACS operation is sustained until about 36 hours after the transient begins, after which the PSACS tanks are depleted and all cooling occurs through the RVACS. At 36 hours, decay heat is low enough that the RVACS is sufficient to keep the core peak cladding temperature below its $725^{\circ} \mathrm{C}$ limit.

Because the reference design is able to successfully mitigate an unprotected SBO without operator action, it is unnecessary to develop an incremental mitigation strategy that factors in the ability to scram the reactor immediately or after several hours. However, because the mitigation strategy can involve a reactor restart to a low power state, an SBO accompanied by a scram would yield different behavior. With a scram, the restart would not occur, and core temperatures would continue to decrease until the PSACS tanks are empty. This is potentially problematic for a liquid salt system because of the relatively small margin to coolant freezing; and necessitated a redesign from $100 \%$ power PSACS to $60 \%$ power PSACS. Further analysis of this issue is presented in the section on protected transients.

\subsection{Unprotected Loss of Flow Accident}

An unprotected loss of flow accident (LOFA) is similar to an unprotected SBO in that power to the reactor coolant pumps is lost, generators are decoupled due to loss of load, and there is a failure to scram. Therefore, a LOFA transient can be mitigated in exactly the same manner as an SBO: by diverting secondary side flow from the power conversion system to the PSACS. However, unlike during an SBO, precooler pumps are assumed to be operational and controllable during a LOFA, which allows the power conversion system to be used for decay heat removal, thus removing the need to operate the PSACS.

As for during an SBO, loss of load at the generators can cause turbine overspeed unless part or all of the secondary flow through the turbines can be diverted. This is accomplished by opening fast acting turbine bypass valves, as discussed in Chapter 2. During a LOFA, some flow through the power conversion system is desired to drive the turbine and thus the compressors and to remove heat through the precoolers. Therefore, after turbine speed drops below its nominal value, the turbine bypass valves (306) are used to allow a fraction of the secondary flow to bypass the turbines completely. Flow in the secondary system is maintained by the spinning turbines, which remain connected to the secondary-side compressors. The amount of heat removed via the power conversion system depends on the flow rate in the PCS, which in turn depends on turbine speed. Turbine speed can be controlled by adjusting the position of the turbine bypass valves. By controlling the bypass valves with proportional-integral controllers, turbine speed can be brought to a desired setpoint following a LOFA. 
The proportional-integral controller is implemented in RELAP by setting the valve stem position of the turbine bypass valve to a proportional-integral control variable. The functional form of this control variable is:

$$
\mathrm{Y}=\mathrm{S}\left[\mathrm{A}_{1}\left(\mathrm{~V}-\mathrm{V}_{\mathrm{i}}\right)+\mathrm{A}_{2} \int_{0}^{\mathrm{t}} \mathrm{V}-\mathrm{V}_{\text {set }} \mathrm{dt}\right]
$$

Here $Y$ is valve stem position, which has a value between 0 and 1 and is related to the normalized valve area by the function shown in Figure 4.2.2-19. A larger valve stem position corresponds to a more opened bypass valve and less flow through the turbine. $S$ is a scaling factor which has the value 0.02 . $V$ is the turbine angular velocity, with $V_{i}$ being the initial velocity $(376.99 \mathrm{rad} / \mathrm{s})$ and $V_{\text {set }}$ the turbine setpoint velocity. $A_{1}$ and $A_{2}$ are the proportional and integral weights; adjusting these weights and the setpoint velocity fully determines the behavior of the valves.

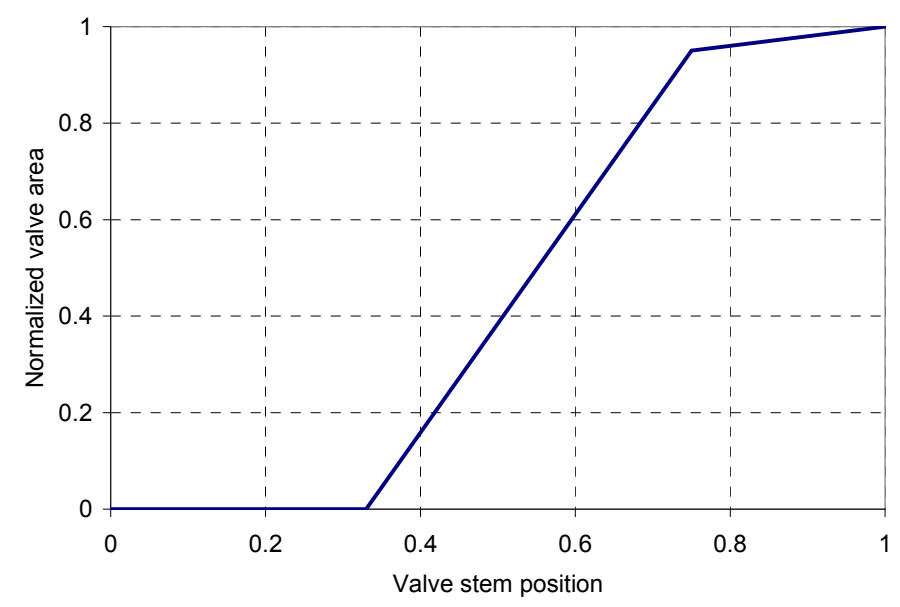

Figure 4.2.2-19 Normalized valve area as a function of valve stem position

Depending on the design of the proportional integral valve controller, two LOFA mitigation strategies are possible. The first strategy, adopted for the reference case, uses a turbine speed setpoint of $25 \mathrm{rad} / \mathrm{s}$, and proportional and integral weights of 2.9 and 0.02 respectively. The LOFA transient was implemented in RELAP by tripping the reactor coolant pumps and generators at time zero, and opening the turbine bypass valve according to the proportional integral controlled parameters. Also, the water flow rate through the precooler is reduced to 5\% its steady state value to reflect the falling reactor power level. Peak cladding temperature, coolant inlet and outlet temperature, reactivity, and power results for this case are given in Figures 4.2.2-20 through 4.2.2-22. 
Project No 06-040: Flexible Conversion Ratio Fast Reactor Systems Evaluation

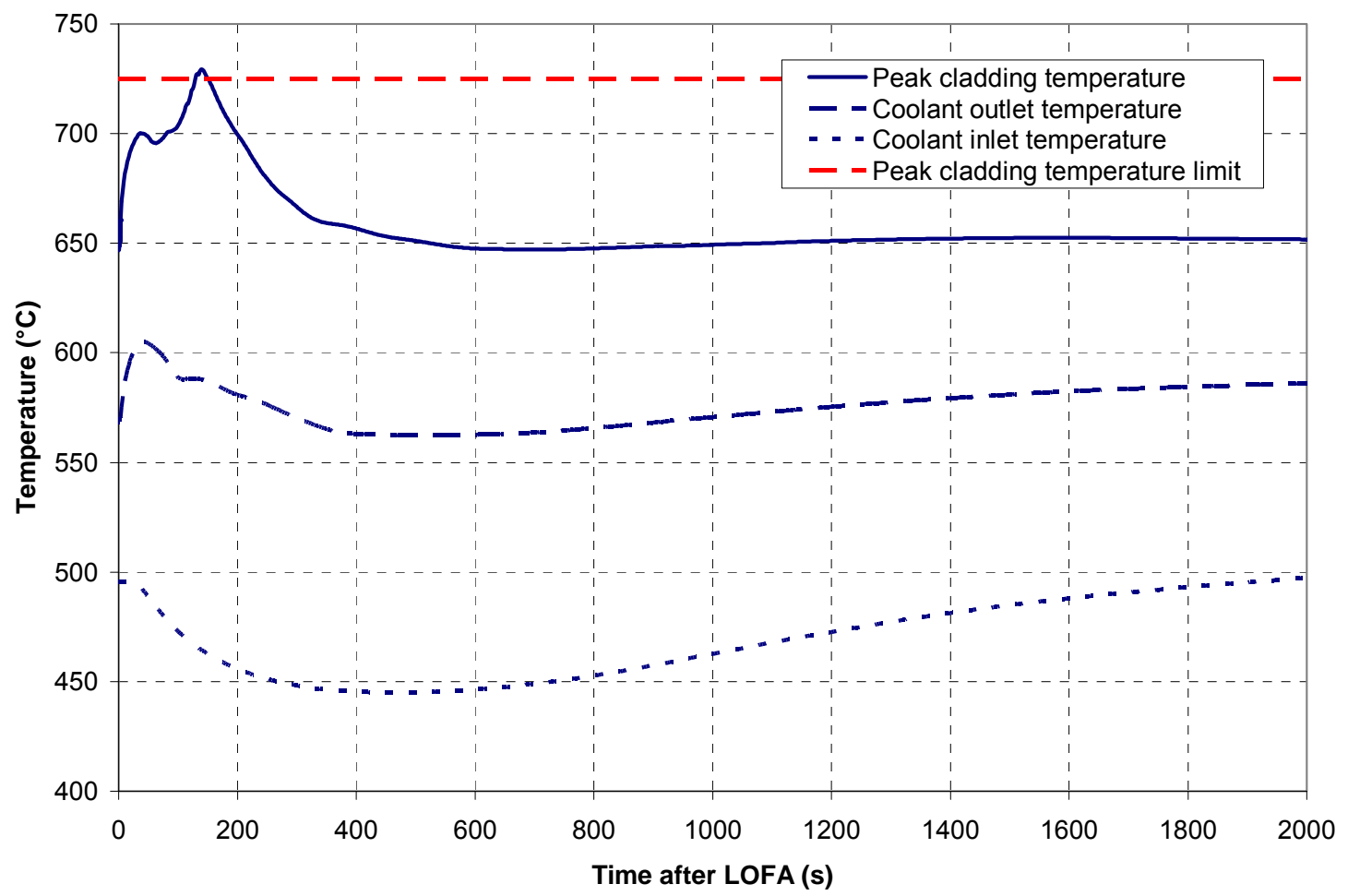

Figure 4.2.2-20 $\mathrm{CR}=1$ salt reactor temperature response to a LOFA

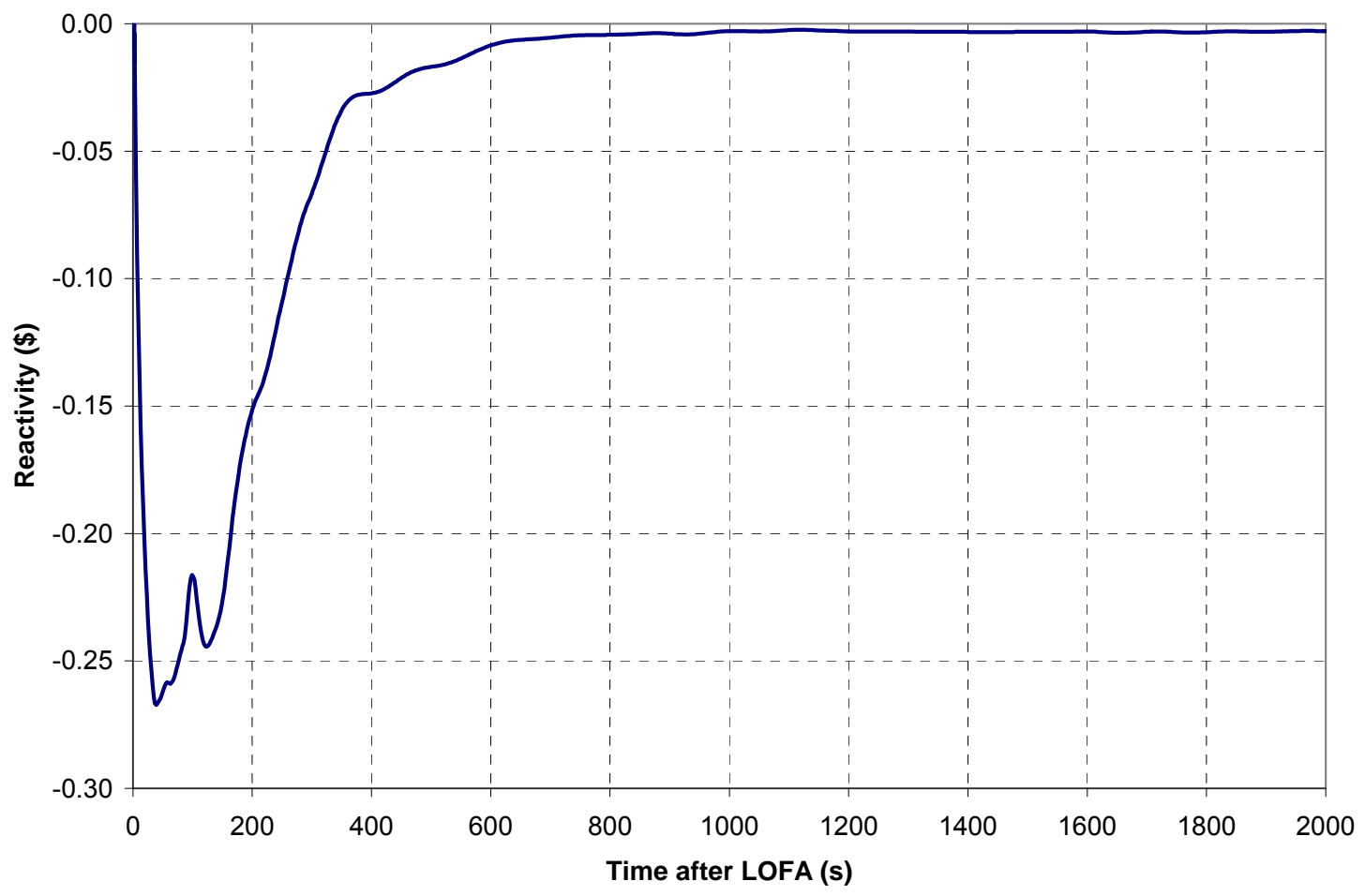

Figure 4.2.2-21 $\mathrm{CR}=1$ salt reactor reactivity response to a LOFA 
Project No 06-040: Flexible Conversion Ratio Fast Reactor Systems Evaluation

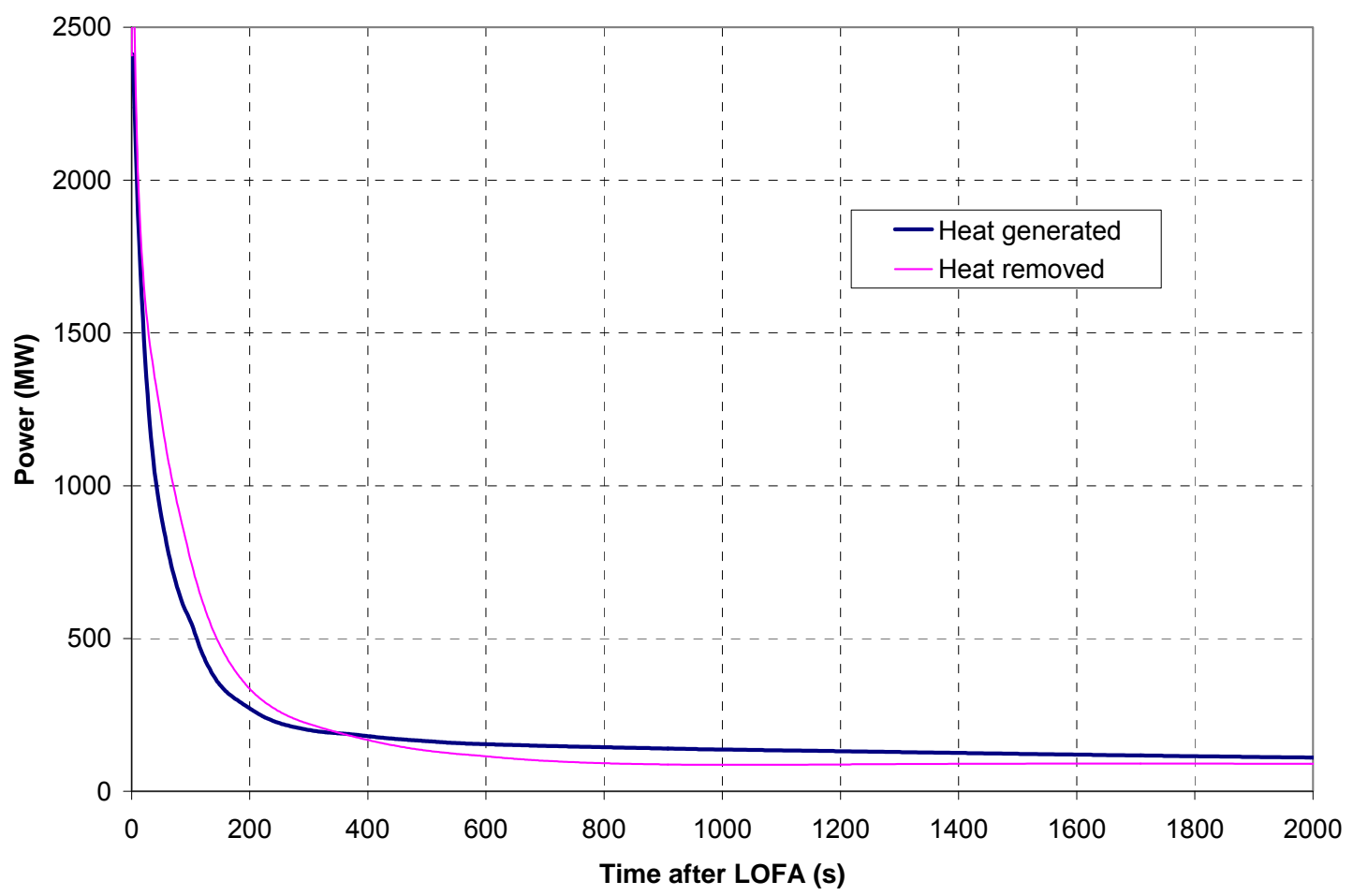

Figure 4.2.2-22 $\mathrm{CR}=1$ salt reactor power response to a LOFA

Like an SBO, loss of power to the reactor coolant pumps causes the primary flow rate to fall, which increases the film temperature rise in the core and creates a peak in the maximum cladding temperature. Increases in fuel and coolant outlet temperatures (thus LEM temperatures) introduce negative reactivity, which drops the reactor power level. Unlike an SBO, the high amount of heat removal with the power conversion system actually exceeds reactor power for the first 350 seconds of the transient, so coolant inlet temperatures fall instead of rise. As a result, the initial peak cladding temperature rise is not as severe as for an SBO, and the cladding temperature limit of $725^{\circ} \mathrm{C}$ is exceeded for only 20 seconds, with a maximum of $730^{\circ} \mathrm{C}$. As in the case of an SBO, this initial peak is unlikely to cause fuel failure and can be avoided using high inertia pumps.

The high rate of heat removal through the power conversion system keeps coolant temperatures low, which means that there is a smaller negative reactivity insertion during a LOFA than during an SBO. As a result the core never experiences a shutdown. Instead it settles smoothly into a new steady state at a reactor power of approximately $87 \mathrm{MW}$, matching the heat removed by the RVACS and power conversion system. This desirable behavior is possible because of the use of a proportional-integral controller, which is able to decrease the heat removal capacity of the power conversion system in a similar fashion to the decrease in reactor power. The turbine speed setpoint of $25 \mathrm{rad} / \mathrm{s}$ corresponds to PCS power that matches the natural circulation capability of the lead coolant reactor when in combination with RVACS power removal. Peak cladding temperature remains below its limit, and core inlet temperature remains near its nominal value, and well above the freezing point. As a result, the system stays close to steady state and doesn't experience the large reactivity swings seen in the SBO case. The PSACS, which is a simpler system that removes an approximately constant power, does not similarly match the drop in reactor power during an SBO, leading to a reactor shutdown and subsequent restart. 
Finally, it is to be noted that the turbine speed setpoint for LOFA mitigation strategy needs to be selected carefully to avoid overcooling and freezing of primary salt. By using the power conversion system to aggressively remove heat from the primary system, it is possible to cool the system enough to cause the LEMs to be fully withdrawn from the core. As described in the LEM design section, this occurs at a coolant outlet temperature approximately $58{ }^{\circ} \mathrm{C}$ below its steady state value. Even before this temperature is reached, the reactivity worth of the LEMs decreases, resulting in a more positive overall coolant temperature coefficient. At these decreased temperatures, it is possible for the power reactivity coefficient to reverse sign and become positive, with lower power decreasing reactivity instead of increasing it. This positive feedback quickly shuts down the reactor without the need for a scram. This was shown by running LOFA scenario with turbine speed setpoint of $50 \mathrm{rad} / \mathrm{s}$, which resulted in salt freezing at 1300 seconds into the transient as the consequence of reactor shutdown and larger PCS heat removal than the decay power.

\subsection{Unprotected Overpower Accident}

A UTOP (unprotected transient overpower) assumes that the highest worth control rod cluster in the core is withdrawn at the drive speed of the control rod mechanism, without an accompanying scram to shut down the core. The primary coolant pumps and secondary system continue operating as normal, with the generators remaining attached to the grid.

The UTOP is simpler to model than the other transients considered because it does not involve any special response from the secondary system. To calculate the reactivity worth of the highest worth control rod assembly, the maximum reactivity of the core was first determined. For the salt fast reactor, reactivity is highest when the core average coolant temperature is high, the fuel temperature is low, and when the LEMs are fully withdrawn (corresponding to a low coolant outlet temperature); in other words during hot zero power conditions. MCNP calculations determined the maximum k-effective during hot full power (HFP) conditions with LEMs fully withdrawn ( 1.0144 for the $\mathrm{CR}=1$ core), corresponding to a reactivity of 3.65 dollars. To obtain the hot zero power (HZP) reactivity, the difference in reactivity between the fuel at the fuel average temperature $(922 \mathrm{~K}$, assuming unirradiated values for thermal conductivity) and the fuel at the coolant average temperature $(808 \mathrm{~K})$ was added to the hot full power reactivity. The total reactivity was divided by the number of control rod clusters to obtain the average worth per cluster. Finally, the maximum control cluster worth was determined by multiplying the average worth by the highest assembly peaking factor squared. A summary of these calculations is given in Table 4.2.2-4. The rate of withdrawal is taken from IFR safety studies [Wade et al., 1997].

Modeling a UTOP in RELAP simply involves inserting the calculated amount of reactivity (9.82 cents) at the assumed rate ( 0.5 cents/second) at time zero. Results for peak cladding and fuel temperatures, reactivity, and relative power are shown in Figures 4.2.2-23 through 4.2.2-25. The initial reactivity insertion quickly raises the power level in the core, which heats up the fuel and coolant, as well as LEMs, and drives reactivity back down. Reactivity peaks at about 3.7 cents and returns to zero at 82 seconds, at which point reactor power reaches a maximum of about $113 \%$ of its steady state value. Shortly thereafter the peak cladding temperature reaches a maximum of about $668^{\circ} \mathrm{C}$, much lower than the $725^{\circ} \mathrm{C}$ transient limit. Due to the high thermal conductivity of metal fuel, the peak fuel temperature is only $781^{\circ} \mathrm{C}$, well below the $1000^{\circ} \mathrm{C}$ limit. 
Within the first 1000 seconds the reactor settles at a new steady state at $101 \%$ reactor power and a peak cladding temperature of $666^{\circ} \mathrm{C}$.

Table 4.2.2-4 CR=1 maximum control rod worth

\begin{tabular}{|l|c|}
\hline k-effective (max) & 1.0144 \\
\hline Excess reactivity (\$) & 3.649 \\
\hline HFP to HZP (\$) & 0.207 \\
\hline Maximum reactivity (\$) & 3.856 \\
\hline \# of CR clusters & 67 \\
\hline \$/cluster (x25 rods) & 0.058 \\
\hline Maximum peaking factor & 1.26 \\
\hline Maximum rod worth (\$) & 0.091 \\
\hline Rate of withdrawal (\$/s) & 0.005 \\
\hline
\end{tabular}

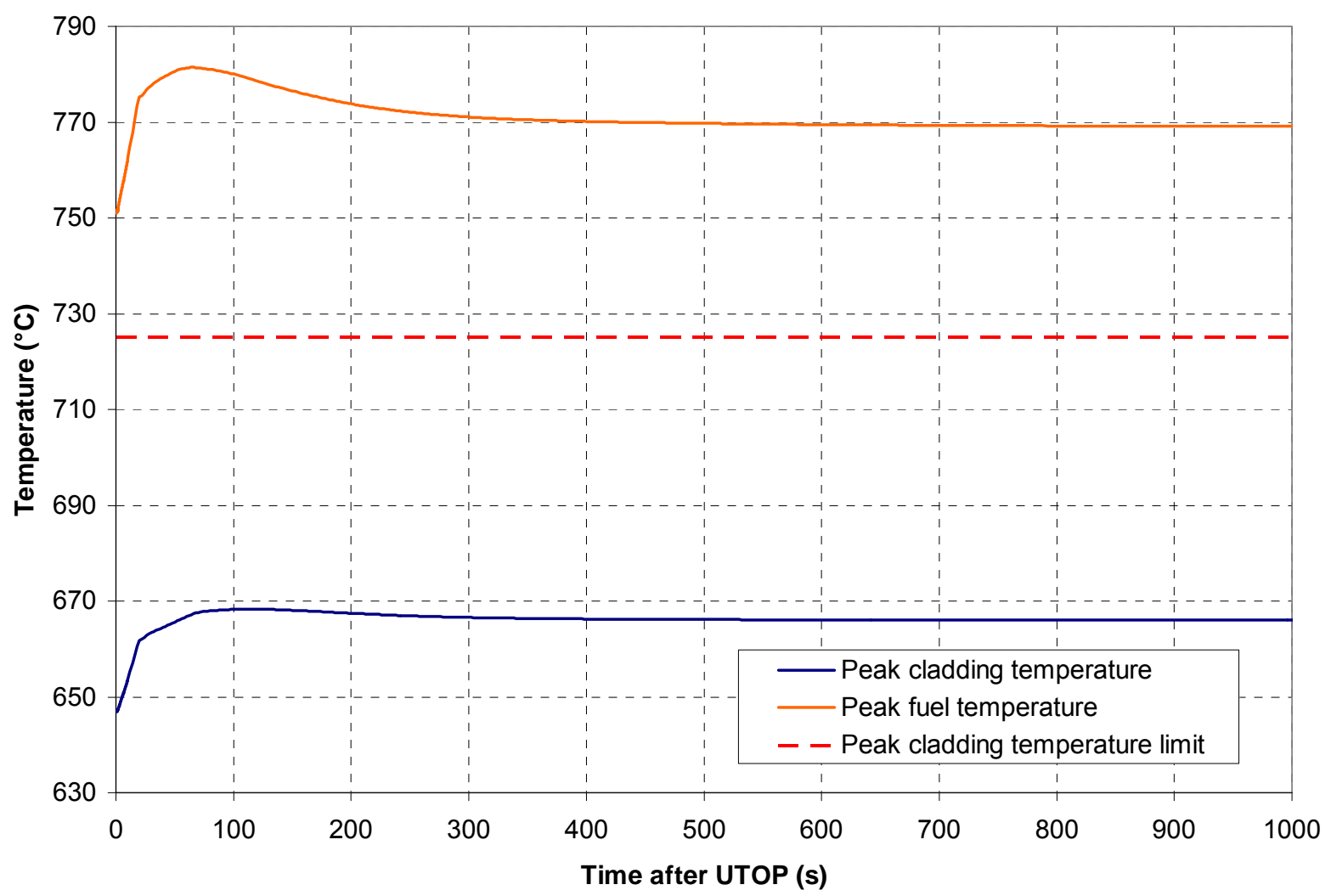

Figure 4.2.2-23 $\mathrm{CR}=1$ salt reactor peak cladding temperature response to a UTOP

The reference salt reactor design displays a very good response to an unprotected overpower transient. This is partly due to small control rod worth of the $\mathrm{CR}=1$ design and partly due to the strong reactivity feedback possible through the use of LEMs, which are able to operate rapidly enough to limit positive reactivity and keep reactor power to an acceptable level. 
Project No 06-040: Flexible Conversion Ratio Fast Reactor Systems Evaluation

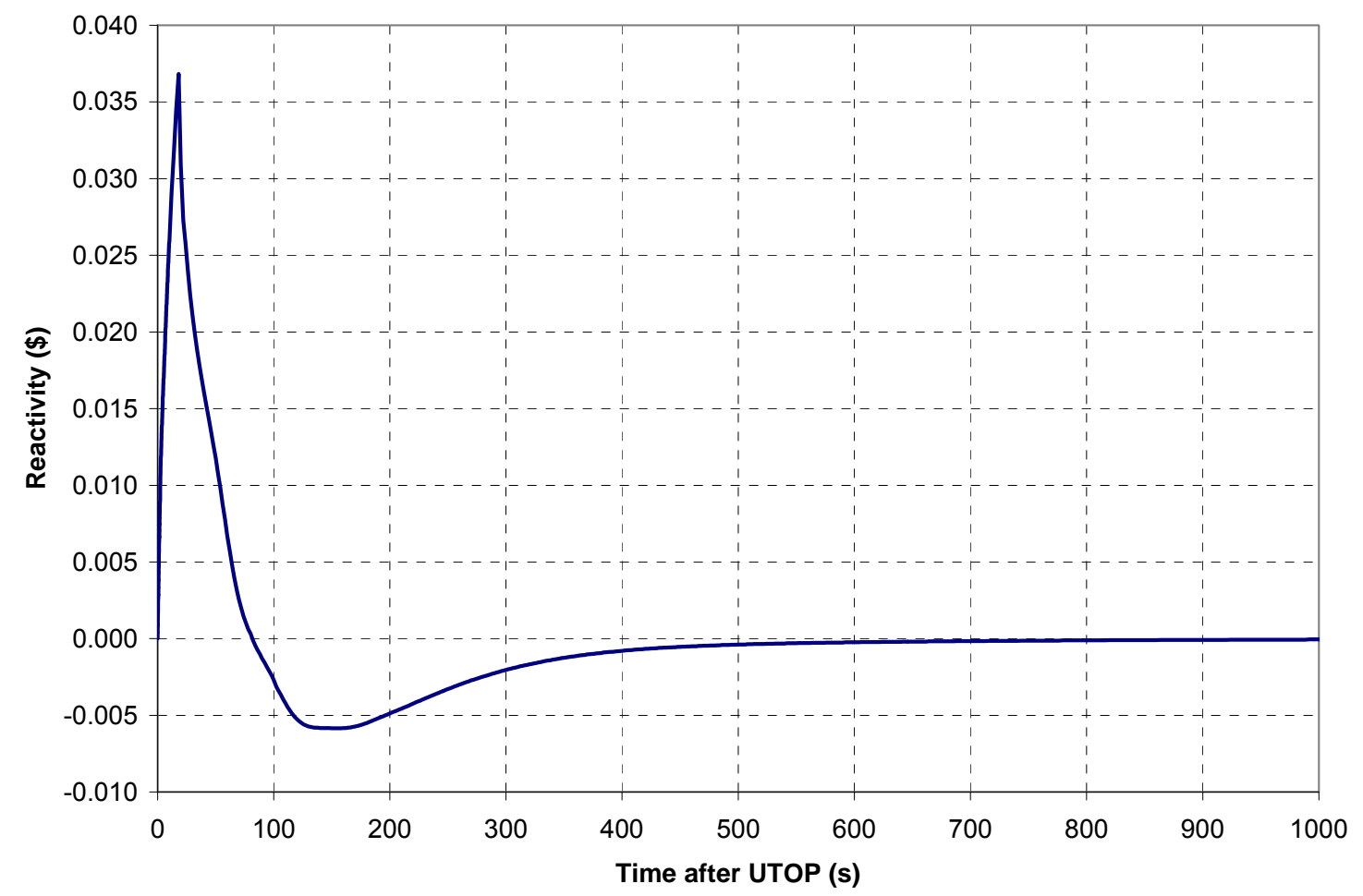

Figure 4.2.2-24 $\mathrm{CR}=1$ salt reactor reactivity response to a UTOP

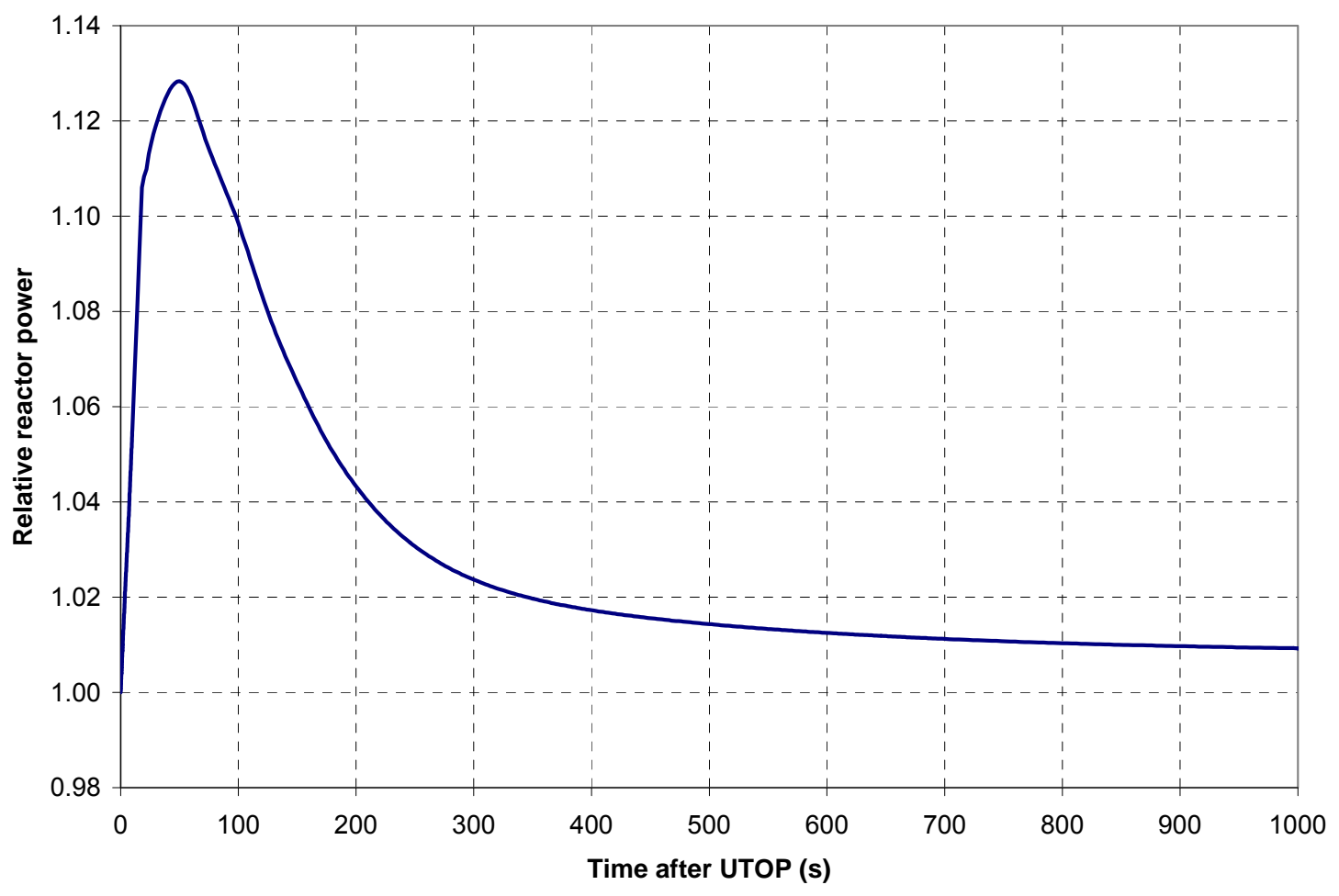

Figure 4.2.2-25 $\mathrm{CR}=1$ salt reactor power response to a UTOP 
Project No 06-040: Flexible Conversion Ratio Fast Reactor Systems Evaluation

\subsection{Protected Transients}

The three transient cases above are all assumed to be unprotected; i.e. the reactor is not scrammed in response to the transient. Furthermore, all three of the reference mitigation strategies employed (with the exception of the two-PSACS-train CR=1 SBO) involve operating the reactor at a safe steady state, i.e. at zero reactivity and some level of fission power. Therefore, the response to a protected transient in which the reactor is scrammed must be different from but still consistent with the reference mitigation strategies given above. Such a mitigation strategy must be able to remove enough decay heat to prevent fuel element damage (cladding temperature over $725^{\circ} \mathrm{C}$ ) but not so much that the coolant freezes. Due to redundant scram systems, protected transients are much more likely than unprotected ones, so the mitigation of protected transients is an important consideration in reactor design.

Because of the high $2400 \mathrm{MWt}$ power level of the reference reactor, the RVACS by itself is insufficient for removing core decay heat after a shutdown. The power conversion system is better suited for removing large amounts of power (as in the unprotected LOFA) but would be overly expensive to qualify as safety grade equipment. Therefore, the PSACS was developed to provide an additional avenue of heat removal during transients. However, if too much energy is removed through the PSACS during a protected transient, coolant freezing can result. Freezing is very undesirable because it can result in complete flow blockage or damage reactor components. Coolant freezing was observed when simulating a protected transient with four $100 \%$ power PSACS trains operating. A protected transient was simulated in RELAP as an SBO (reactor coolant pump trip, isolation of power conversion system), except with a large negative reactivity insertion (the scram) that immediately shuts down the reactor and prevents a restart. Arbitrarily large PSACS tanks were implemented in the model to determine the maximum amount of time the PSACS could operate before coolant freezing occurred. For the protected transient, all four PSACS trains were activated (instead of two for the SBO) to create a worst case scenario for coolant freezing. Results of these simulations are shown for the $100 \%$ power PSACS and $60 \%$ power PSACS for the $\mathrm{CR}=1$ reactor in Figure 4.2.2-26.

With all four trains of the $100 \%$ power PSACS operating, freezing occurs at the IHX outlet approximately 19.6 hours into a protected transient for the $\mathrm{CR}=1$ core. Sizing the PSACS tanks to run out of water before this point would yield unacceptable behavior during unprotected transients, since the PSACS needs to operate for approximately 36 hours before reactor decay heat is low enough to be removed solely by the RVACS. Therefore, the earlier reference design had to be changed to avoid this behavior; this was done by redesigning the PSACS to remove heat at a lower rate $(60 \%$ vs. $100 \%)$. With all four $60 \%$ power PSACS operating, coolant freezing does not occur during the first 72 hours after a protected transient for the $\mathrm{CR}=1$ reactor. Since this happens past 72 hours in the $C R=1$ case, there is no maximum PSACS tank size for the $\mathrm{CR}=1$ reactor since the 72 hour criteria is satisfied even with infinitely large tanks. Therefore, the reference PSACS design can successfully mitigate a protected transient, since it removes enough heat to prevent the cladding temperature limit from being exceeded but cannot lead to coolant freezing within the first 72 hours. It was calculated that the reference PSACS water tanks would actually be depleted 57 hours after a protected transient, after which system temperatures would rise. However, at this point, decay heat is low enough that the RVACS alone is sufficient for decay heat removal. Because of the versatility of the $60 \%$ power PSACS system to passively mitigate both unprotected transients and protected transients with 2, 3, or 4 trains operating, they were selected as part of the salt FCR reactor reference design. 
Project No 06-040: Flexible Conversion Ratio Fast Reactor Systems Evaluation

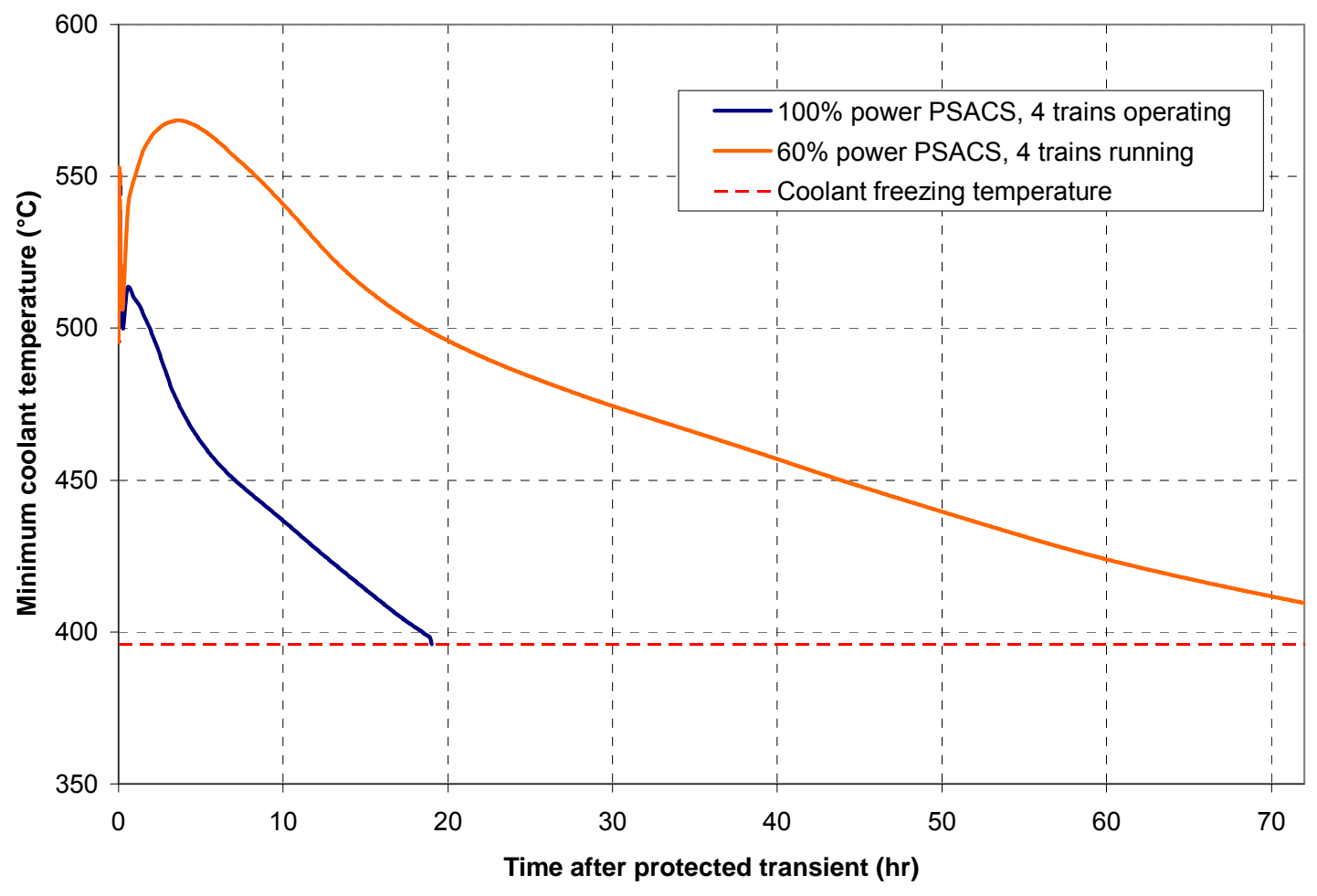

Figure 4.2.2-26 $\mathrm{CR}=1$ response to a protected transient 


\subsection{Zero Conversion Ratio Core}

\subsubsection{Neutronic Analysis Results}

The design of a zero conversion ratio salt-cooled core is based on the high power density open lattice core described in Table 4.2.1-1. As in the lead-cooled case, three-batch fuel management is adopted for the salt-cooled core. Each fuel assembly includes 12 LEMs and 19 Control Rod locations (Figure 4.3.1-1). The requirement of having the control rods in each fuel assembly stems from the fact that the $\mathrm{CR}=0$ core has relatively large excess reactivity. Control rods are of the same double-entry type as described in the lead-cooled reactor section.

The initial TRU loading that provides the cycle length limited by the clad fluence $\left(4 \times 10^{23} \mathrm{n} / \mathrm{cm}^{2}\right)$ was determined to be $30 \mathrm{wt} . \%$. This is somewhat lower than the $34 \mathrm{wt} . \%$ in the $\mathrm{CR}=0$ leadcooled core case. The resulting fuel cycle length is about 540 EFPD. The core k-eff and peak cladding fluence as a function of time are compared in Figures 4.3.1-1 and 4.3.1-2 for the salt and lead-cooled cases respectively.

The fuel loading pattern was developed to provide reasonable radial power peaking factors (Figure 4.3.1-4). As can be observed from Figures 4.3.1-5 and 4.3.1-6, the maximum radial power peaking factors are below 1.35, which is comparable to the lead-cooled core and appear to be manageable from the thermal design perspective. Burnup distribution, simulating an equilibrium core, was determined by an iterative process outlined in the lead-cooled $\mathrm{CR}=0$ core discussion. The results are briefly summarized in Table 4.3.1-1. The achievable discharge fuel burnup is $340 \mathrm{MWd} / \mathrm{kg}$, which corresponds to about $36 \%$ TRU burnup fraction.

Table 4.3.1-1. $\mathrm{CR}=0$ Core fuel cycle parameters summary

\begin{tabular}{|l|r|r|r|}
\hline & \multicolumn{1}{|c|}{ Fresh } & \multicolumn{1}{c|}{ Once } & \multicolumn{1}{c|}{ Twice } \\
\hline Initial HM, kg & 3,867 & 3,476 & 2,989 \\
\hline Final HM, kg & 3,443 & 2,954 & 2,573 \\
\hline Number of assemblies & 75 & 76 & 75 \\
\hline BOC Burnup, MWd/kg & 0 & 107 & 232 \\
\hline EOC Burnup, MWd/kg & 108 & 235 & 341 \\
\hline Cycle Burnup, MWd/kg & 108 & 128 & 109 \\
\hline
\end{tabular}

Table 4.3.1-2 presents the isotopic composition of the loaded and discharged fuel from the saltcooled $\mathrm{CR}=0$ core. The fuel isotopic vector at discharge is very similar to that obtained from the Lead-cooled $\mathrm{CR}=0$ core design. 
Project No 06-040: Flexible Conversion Ratio Fast Reactor Systems Evaluation

Table 4.3.1-2 " $\mathrm{CR}=0$ " Initial and discharge fuel composition summary.

\begin{tabular}{|c|c|c|c|}
\hline \multicolumn{2}{|c|}{ TRU Isotope ID } & Initial, wt \% & Discharge, wt \% \\
\hline 93 & 237 & 5.60 & 5.11 \\
\hline 94 & 238 & 2.50 & 6.38 \\
\hline 94 & 239 & 46.50 & 32.65 \\
\hline 94 & 240 & 23.00 & 33.05 \\
\hline 94 & 241 & 8.20 & 6.18 \\
\hline 94 & 242 & 6.70 & 7.39 \\
\hline 95 & 241 & 5.40 & 4.43 \\
\hline 95 & 243 & 1.60 & 2.17 \\
\hline 95 & $242 m$ & 0.0001 & 0.4837 \\
\hline 96 & 242 & 0.0038 & 0.3451 \\
\hline 96 & 243 & 0.4293 & 0.0328 \\
\hline 96 & 244 & 0.0430 & 1.3475 \\
\hline 96 & 245 & 0.0055 & 0.2204 \\
\hline 96 & 246 & 0.0001 & 0.0138 \\
\hline
\end{tabular}

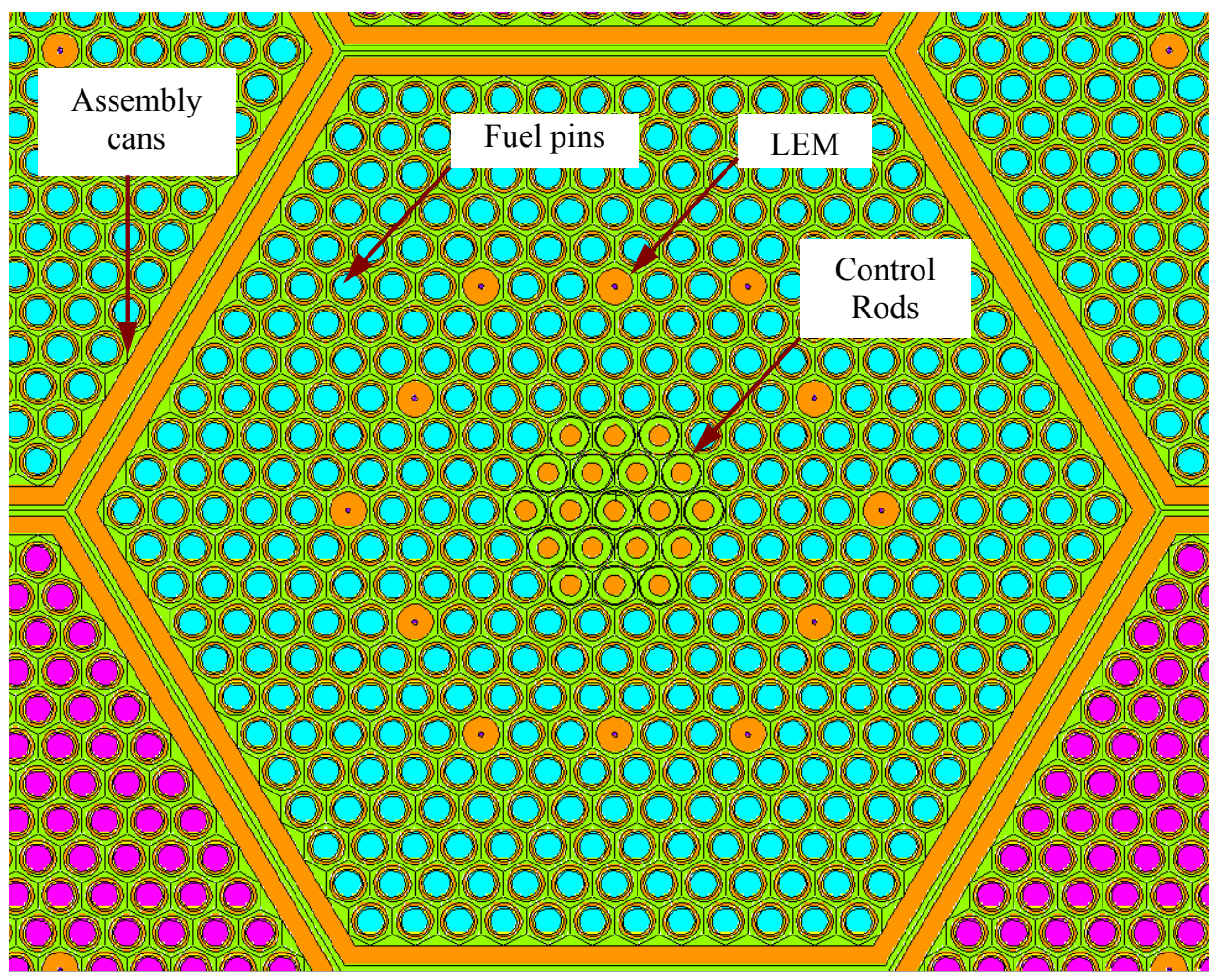

Figure 4.3.1-1. In scale $\mathrm{CR}=0$ fuel assembly cross-sectional view 
Project No 06-040: Flexible Conversion Ratio Fast Reactor Systems Evaluation

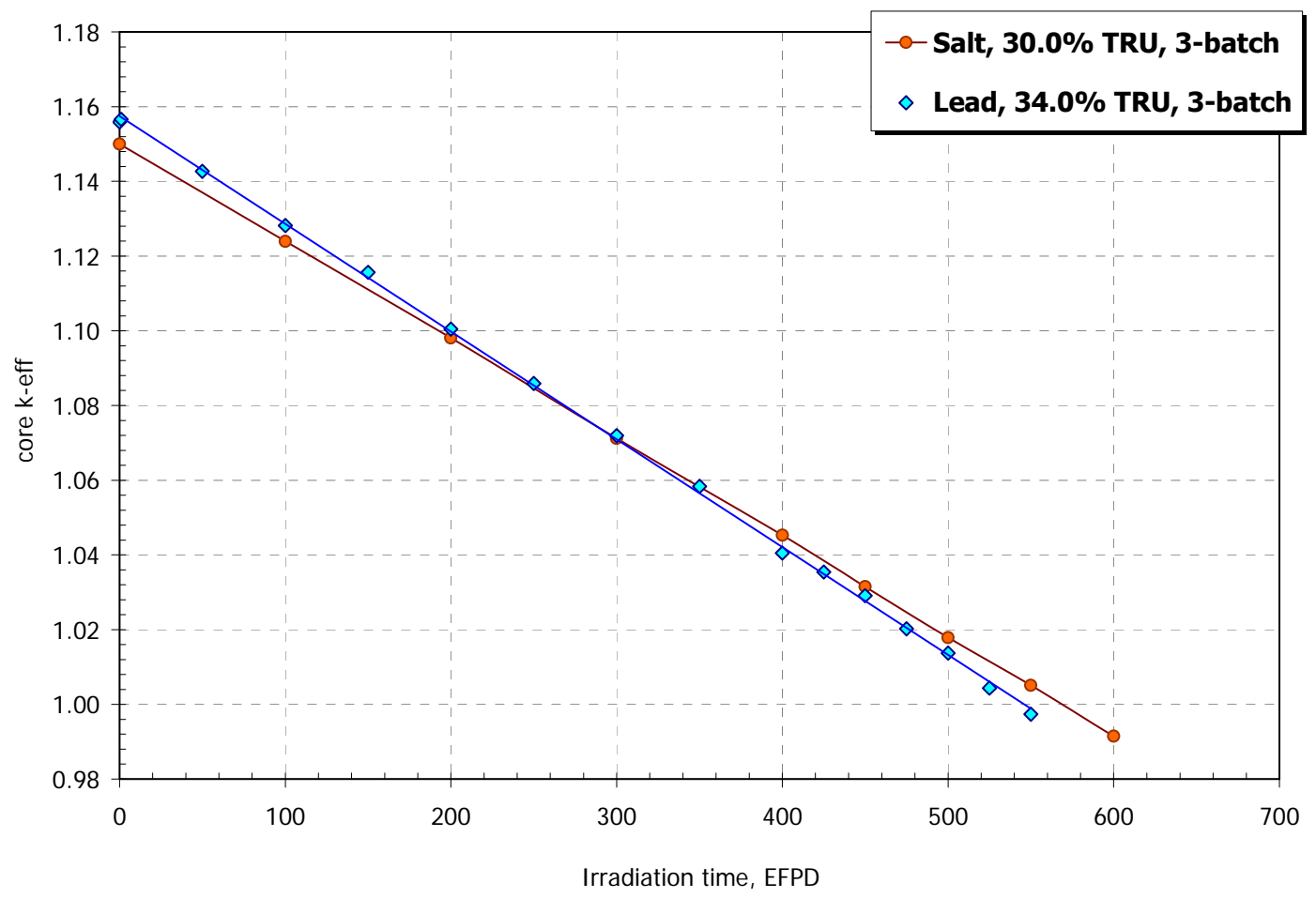

Figure 4.3.1-2. Lead and Salt-cooled $\mathrm{CR}=0$ core $\mathrm{k}$-eff versus irradiation time

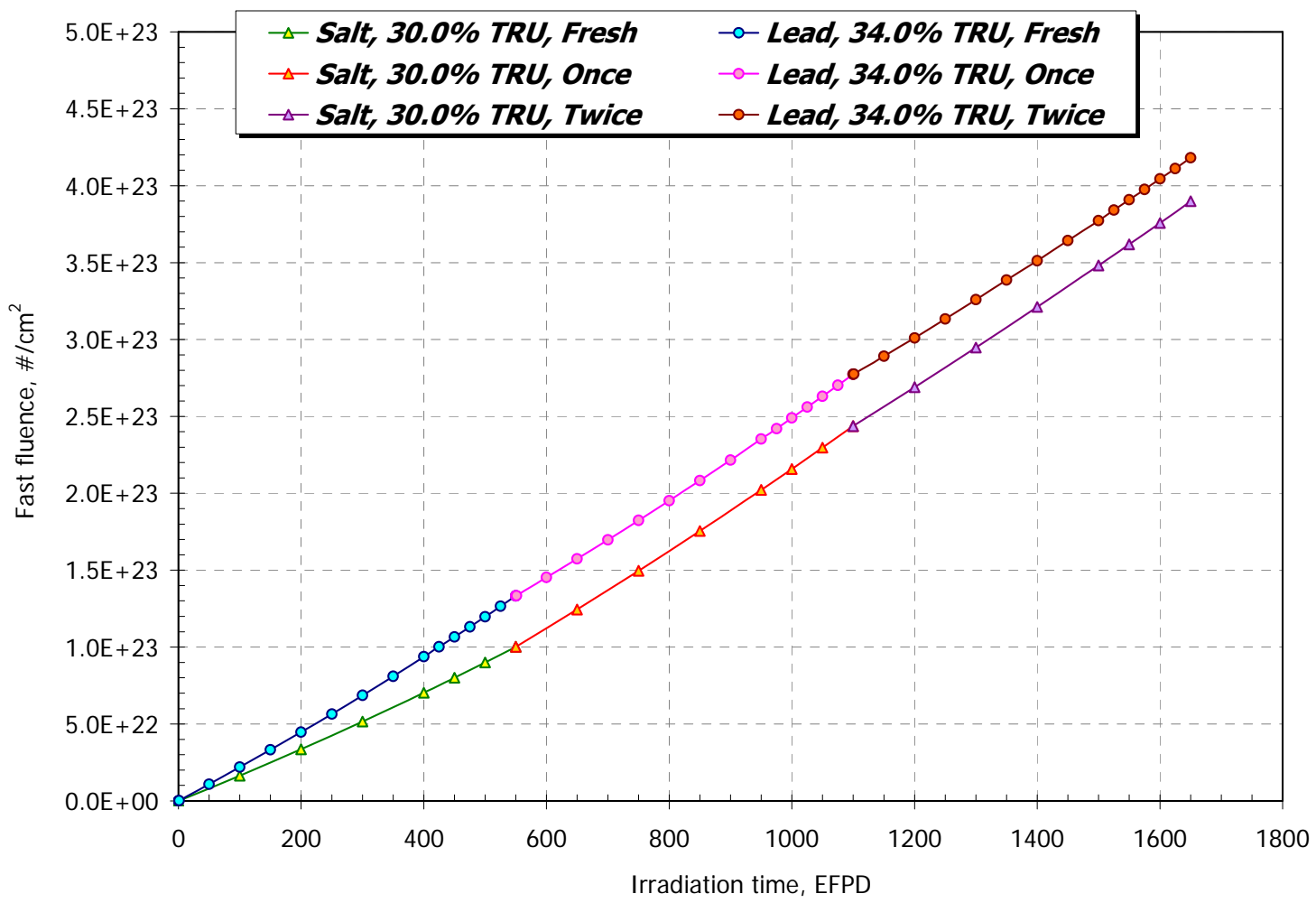

Figure 4.3.1-3. Peak fast fluence comparison, Lead vs Salt-cooled CR=0 core 
Project No 06-040: Flexible Conversion Ratio Fast Reactor Systems Evaluation

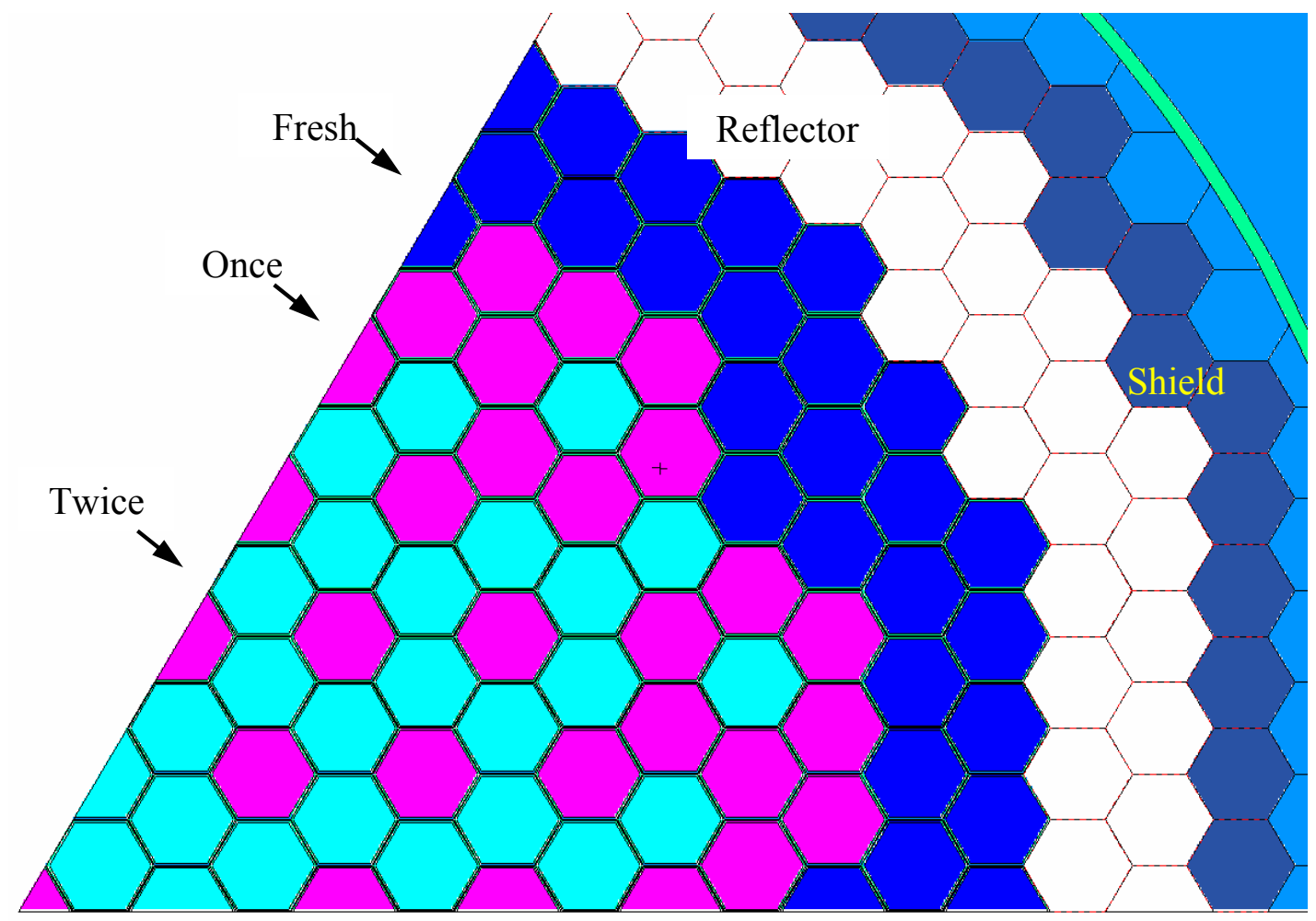

Figure 4.3.1-4. $\mathrm{CR}=0$ core fuel assembly loading map

\begin{tabular}{|c|c|c|c|c|c|c|c|c|c|c|c|c|}
\hline & & & & & & & & & \multirow{3}{*}{$\frac{1.26}{1.05}$} & \multirow{3}{*}{$\begin{array}{l}1.07 \\
1.04\end{array}$} & \multirow{3}{*}{$\begin{array}{c}0.81 \\
0.80 \\
0.77\end{array}$} \\
\hline & & & & & & & \multirow[b]{3}{*}{0.98} & \multirow{3}{*}{$\begin{array}{l}1.19 \\
0.96\end{array}$} & \multirow{3}{*}{$\begin{array}{l}1.15 \\
1.13\end{array}$} & & & \\
\hline & & & & & & \multirow[b]{2}{*}{1.22} & & & & & & \\
\hline & & & & & & & & & & 1.02 & 0.99 & 0.72 \\
\hline & & & & \multirow{2}{*}{$\begin{array}{l}1.20 \\
0.97\end{array}$} & \multirow{2}{*}{$\begin{array}{l}0.98 \\
1.21\end{array}$} & 0.98 & 1.20 & 1.17 & 0.89 & 0.98 & 0.92 & 0.64 \\
\hline & & 0.94 & 0.96 & & & 0.98 & 0.97 & 1.15 & 1.07 & 1.09 & 0.83 & \\
\hline 1.16 & 0.94 & 0.95 & 1.19 & 0.98 & 0.98 & 1.20 & 0.95 & 0.91 & 1.21 & 0.98 & 0.69 & \\
\hline & 0.94 & 0.96 & 0.97 & 1.21 & 0.98 & 0.97 & 1.15 & 1.07 & 1.09 & 0.83 & & \\
\hline & & 1.20 & 0.98 & 0.98 & 1.20 & 1.17 & 0.89 & 0.98 & 0.93 & 0.64 & & \\
\hline & & & 1.21 & 0.98 & 0.96 & 1.13 & 1.02 & 0.99 & 0.72 & & & \\
\hline & & & & 1.19 & 1.15 & 1.05 & 1.04 & 0.77 & & & & \\
\hline & & & & & 1.26 & 1.06 & 0.80 & & & & & \\
\hline & & & & & & 0.81 & & & & & & \\
\hline
\end{tabular}

Figure 4.3.1-5. $\mathrm{CR}=0$ core, radial power peaking map at $\mathrm{BOC}$ 


\begin{tabular}{|c|c|c|c|c|c|c|c|c|c|c|c|c|}
\hline & & & & & & & & & & & & 0.90 \\
\hline & & & & & & & & & & 1.35 & 1.17 & 0.89 \\
\hline & & & & & & & & 1.15 & 1.13 & 1.06 & 1.14 & 0.86 \\
\hline & & & & & & 1.12 & 0.93 & 0.93 & 1.11 & 1.03 & 1.09 & 0.80 \\
\hline & & & & 1.09 & 0.90 & 0.92 & 1.14 & 1.13 & 0.89 & 1.00 & 1.03 & 0.72 \\
\hline & & 0.85 & 0.87 & 0.89 & 1.11 & 0.92 & 0.93 & 1.12 & 1.07 & 1.20 & 0.93 & \\
\hline 1.02 & 0.84 & 0.85 & 1.07 & 0.90 & 0.91 & 1.13 & 0.92 & 0.90 & 1.31 & 1.09 & 0.78 & \\
\hline & 0.85 & 0.87 & 0.89 & 1.11 & 0.92 & 0.93 & 1.12 & 1.08 & 1.20 & 0.93 & & \\
\hline & & 1.09 & 0.90 & 0.92 & 1.14 & 1.14 & ๑.89 & 1.00 & 1.03 & 0.72 & & \\
\hline & & & 1.13 & 0.93 & 0.93 & 1.12 & 1.03 & 1.09 & 0.80 & & & \\
\hline & & & & 1.15 & 1.13 & 1.06 & 1.14 & 0.86 & & & & \\
\hline & & & & & 1.35 & 1.17 & 0.89 & & & & & \\
\hline & & & & & & 0.90 & & & & & & \\
\hline
\end{tabular}

Figure 4.3.1-6. $\mathrm{CR}=0$ core, radial power peaking map at $\mathrm{EOC}$

\section{Reactivity Coefficients and Self Controllability Criteria}

Self-controllability of the $\mathrm{CR}=0$ salt-cooled core design was evaluated by performing a set of reactivity coefficient calculations based on the quasi-static analysis methodology [Wade and Chang, 1988]. The calculations were performed at both Beginning and End of the fuel cycle. The approach to calculation of reactivity coefficients is briefly outlined in Section 2.1.2 of this report and described in detail in Section 3A.4 of Appendix 3A. The $\mathrm{CR}=0$ core operating conditions used in the self-controllability assessment are presented in Table 4.3.1-3.

The results of the calculations are summarized in Table 4.3.1-4. Figures 4.3.1-7 and 4.3.1-8 show the core reactivity as a function of fuel temperature at BOL and EOL respectively. The fuel temperature coefficient due to the Doppler Effect was calculated by fitting a quadratic polynomial function to the calculated core reactivity data. These data was subsequently used in the core transient analysis with RELAP5 code.

Self controllability criteria at both BOC and EOC are satisfied due to the use of Lithium thermal Expansion Modules - LEMs [Kambe and Uotani, 1998] with a design described in Section 4.2. In the $\mathrm{CR}=0$ core, $12 \mathrm{LEMs,}$ with outer diameter equal to that of the fuel pins, were used in each fuel assembly, similar to the number of LEMs used in the $\mathrm{CR}=1$ salt-cooled core.

The Coolant Temperature Coefficient (CTC) is negative and appears to be larger in magnitude than necessary to meet the core self-controllability requirements. This is a result of somewhat smaller $\mathrm{CTC}$ of the LEM-free $\mathrm{CR}=0$ core as compared with the $\mathrm{CR}=1$ core in general. $\mathrm{The} \mathrm{CR}=0$ core is more transparent to neutrons and therefore has higher leakage which mitigates the positive CTC. A similar effect was also observed in the lead-cooled flexible conversion ratio core designs (See Chapter 3).

Thus, the number of LEMs per assembly could potentially be reduced. This, in turn, would reduce the fuel loading required to achieve cycle length limited by cladding fluence and improve 
thermal margin (or, alternatively, increase the power density) because of the smaller pin linear power.

The $\Delta \rho_{\text {TOP }} / \mathrm{B}$ coefficient also seems to be very conservative (Table 4.3.1-4). It means that the number or reactivity worth of the control rods can also be reduced. Reducing the number of CRDs per assembly would provide the same benefits of improved thermal margin or higher power density. Reducing the CRD worth can be achieved through a reduction of boron enrichment. Currently, the active material in the control rods is assumed to be boron enriched to $50 \%$ in ${ }^{10} \mathrm{~B}$ isotope.

Since reduction in the number of LEMs per assembly appeared to be beneficial, as argued above, the reactivity coefficient calculations were repeated for the $\mathrm{CR}=0$ core in which only 6 LEMs per assembly were used instead of 12 (Figure 4.3.1-9). It has to be noted that the neutronic design conclusions based on the 12 LEMs per assembly assumption and presented in the previous section of this report should still be valid. This is because the effect of substituting only 6 LEMs with fuel pins out of a total of 397 pin positions per assembly is expected to be small. Moreover, $\mathrm{CR}=1$ and $\mathrm{CR}=0$ cores can have different numbers of LEMs, since these are part of fuel assemblies which are replaced with the core change.

The self-controllability assessment results of the $\mathrm{CR}=0$ core with 6 LEMs per assembly are summarized in Table 4.3.1-5. Figures 4.3.1-10 and 4.3.1-11 present the core reactivity versus fuel temperature data used for the calculation of Doppler Coefficients at BOC and EOC respectively.

Reducing the number of LEMs from 12 to 6 in the Salt-cooled CR=0 core is still sufficient to assure self-controllability. The CTC is about zero at BOC and becomes slightly negative at EOC. The rest of the reactivity coefficients are practically unaffected by the change in the number of LEMs per assembly. The obtained results support the conclusion that a smaller number of LEMs per fuel assembly could be used in the $\mathrm{CR}=0$ core than in the $\mathrm{CR}=1$ core without compromising the core self-controllability.

Table 4.3.1-3. $\mathrm{CR}=0$ core operating conditions used in self-controllability assessment

\begin{tabular}{|l|c|}
\hline Parameter & Value \\
\hline Coolant Inlet Temperature, ${ }^{\circ} \mathrm{C}$ & 496 \\
\hline Coolant Outlet temperature, ${ }^{\circ} \mathrm{C}$ & 580 \\
\hline Core Coolant Temperature Rise, $\Delta \mathrm{T}_{\mathrm{c}},{ }^{\circ} \mathrm{C}$ & 84 \\
\hline Coolant Freezing Point, ${ }^{\circ} \mathrm{C}$ & 396 \\
\hline Margin to Freezing, ${ }^{\circ} \mathrm{C}$ & 100 \\
\hline Cladding Failure Limit, ${ }^{\circ} \mathrm{C}$ & 725 \\
\hline Margin to Cladding Failure, ${ }^{\circ} \mathrm{C}$ & 145 \\
\hline
\end{tabular}

The results of the self-controllability assessment presented in this section were verified through detailed modeling of the most restricting accidents with the RELAP5 code. As mentioned in the self-controllability discussion of the $\mathrm{CR}=1$ salt-cooled core design, the approach for calculating the CTC in a core with LEMs adopted in this part of the study was over-simplistic. This is 
primarily because the approach does not account for the fact that the reactivity worth of lithium is a non-linear function of the lithium insertion depth and, thus, coolant temperature, while the coolant thermal expansion reactivity varies almost linearly with temperature.

Table 4.3.1-4. Reactivity feedback parameters summary,

$\mathrm{CR}=0$ core, $\mathrm{q}$ " ' $=130 \mathrm{~W} / \mathrm{cc}, 12 \mathrm{LEMs} /$ assembly

\begin{tabular}{|c|c|c|c|c|c|}
\hline & Units & BOC value & $\begin{array}{c}\text { Uncertainty } \\
\pm \sigma\end{array}$ & EOC value & $\begin{array}{c}\text { Uncertainty } \\
\pm \sigma\end{array}$ \\
\hline$\beta_{\text {eff }}$ & & 0.0029 & 0.0001 & 0.0028 & 0.0001 \\
\hline$\alpha_{\mathrm{DC}}$ & $\notin / K$ & -0.036 & 0.030 & -0.057 & 0.030 \\
\hline$\alpha_{\mathrm{e}}$ & $\notin / \mathrm{K}$ & -0.097 & 0.022 & -0.089 & 0.030 \\
\hline$\alpha_{\mathrm{Co}}$ & $\notin / K$ & -0.811 & 0.044 & -1.071 & 0.061 \\
\hline$\alpha_{\mathrm{RD}}$ & $\notin / \mathrm{K}$ & $\sim 0$ & N/A & $\sim 0$ & $\mathrm{~N} / \mathrm{A}$ \\
\hline$\alpha_{R}$ & $\notin / \mathrm{K}$ & -0.229 & 0.022 & -0.286 & 0.024 \\
\hline $\mathrm{A}$ & $\not$ & -11.76 & 3.32 & -12.98 & 3.81 \\
\hline $\mathrm{B}$ & $\phi$ & -58.87 & 2.61 & -75.12 & 3.38 \\
\hline $\mathrm{C}$ & $\notin / \mathrm{K}$ & -1.17 & 0.06 & -1.50 & 0.08 \\
\hline $\mathrm{A} / \mathrm{B}$ & & 0.20 & 0.06 & 0.17 & 0.05 \\
\hline $\mathrm{C} \Delta \mathrm{Tc} / \mathrm{B}$ & & 1.67 & 0.11 & 1.68 & 0.12 \\
\hline$\Delta \rho_{\mathrm{TOP}} / \mathrm{B}$ & & 0.27 & 0.01 & 0.21 & 0.01 \\
\hline A/B limits & & \multicolumn{2}{|c|}{$x<1.15(1.73)$} & \multicolumn{2}{|c|}{$x<1.15(1.73)$} \\
\hline $\mathrm{C} \Delta \mathrm{T}_{\mathrm{c}} / \mathrm{B}$ limits & & \multicolumn{2}{|c|}{$1<x<2.36(2.94)$} & \multicolumn{2}{|c|}{$1<x<2.36(2.94)$} \\
\hline$\Delta \rho_{\mathrm{TOP}} / \mathrm{B}$ limits & & \multicolumn{2}{|c|}{$x<1.15(1.73)$} & \multicolumn{2}{|c|}{$x<1.15(1.73)$} \\
\hline
\end{tabular}

Table 4.3.1-5. Reactivity feedback parameters summary, $\mathrm{CR}=0$ core, $\mathrm{q}$ "' $=130 \mathrm{~W} / \mathrm{cc}, 6 \mathrm{LEMs} /$ assembly

\begin{tabular}{|c|c|c|c|c|c|}
\hline & Units & BOC value & $\begin{array}{c}\text { Uncertainty } \\
\pm \sigma\end{array}$ & EOC value & $\begin{array}{c}\text { Uncertainty } \\
\pm \sigma\end{array}$ \\
\hline$\beta_{\text {eff }}$ & & 0.00298 & 0.00006 & 0.00252 & 0.00008 \\
\hline$\alpha_{\mathrm{DC}}$ & $\phi / K$ & -0.035 & 0.030 & -0.063 & 0.030 \\
\hline$\alpha_{\mathrm{e}}$ & $\phi / \mathrm{K}$ & -0.071 & 0.021 & -0.127 & 0.033 \\
\hline$\alpha_{\mathrm{Co}}$ & $\phi / K$ & 0.035 & 0.043 & -0.071 & 0.066 \\
\hline$\alpha_{\mathrm{RD}}$ & $\phi / K$ & $\sim 0$ & N/A & $\sim 0$ & $\mathrm{~N} / \mathrm{A}$ \\
\hline$\alpha_{R}$ & $\phi / K$ & -0.229 & 0.021 & -0.335 & 0.033 \\
\hline $\mathrm{A}$ & $\not$ & -9.41 & 3.28 & -16.89 & 3.98 \\
\hline $\mathrm{B}$ & $\phi$ & -22.21 & 2.54 & -39.14 & 3.63 \\
\hline $\mathrm{C}$ & $\phi / \mathrm{K}$ & -0.30 & 0.06 & -0.60 & 0.08 \\
\hline $\mathrm{A} / \mathrm{B}$ & & 0.42 & 0.16 & 0.43 & 0.11 \\
\hline $\mathrm{C} \Delta \mathrm{Tc} / \mathrm{B}$ & & 1.13 & 0.26 & 1.28 & 0.21 \\
\hline$\Delta \rho_{\mathrm{TOP}} / \mathrm{B}$ & & 0.75 & 0.09 & 0.43 & 0.04 \\
\hline A/B limits & & \multicolumn{2}{|c|}{$x<1.15(1.73)$} & \multicolumn{2}{|c|}{$x<1.15(1.73)$} \\
\hline $\mathrm{C} \Delta \mathrm{T}_{\mathrm{c}} / \mathrm{B}$ limits & & \multicolumn{2}{|c|}{$1<x<2.36(2.94)$} & \multicolumn{2}{|c|}{$1<x<2.36(2.94)$} \\
\hline$\Delta \rho_{\mathrm{TOP}} / \mathrm{B}$ limits & & \multicolumn{2}{|c|}{$x<1.15(1.73)$} & \multicolumn{2}{|c|}{$x<1.15(1.73)$} \\
\hline
\end{tabular}


Project No 06-040: Flexible Conversion Ratio Fast Reactor Systems Evaluation

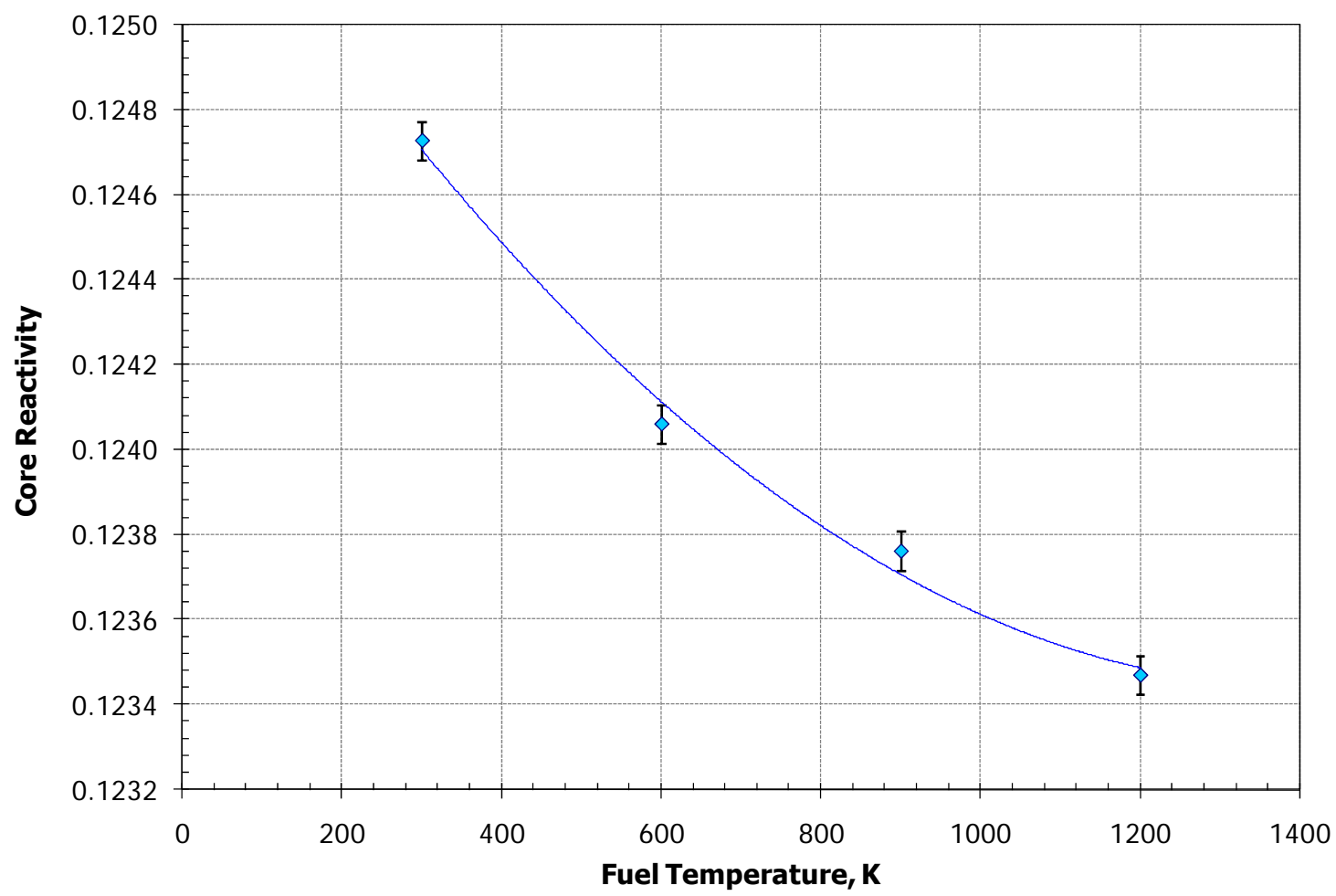

Figure 4.3.1-7. $\mathrm{CR}=0,12 \mathrm{LEMs} /$ assembly, core reactivity vs. fuel temperature at $\mathrm{BOC}$

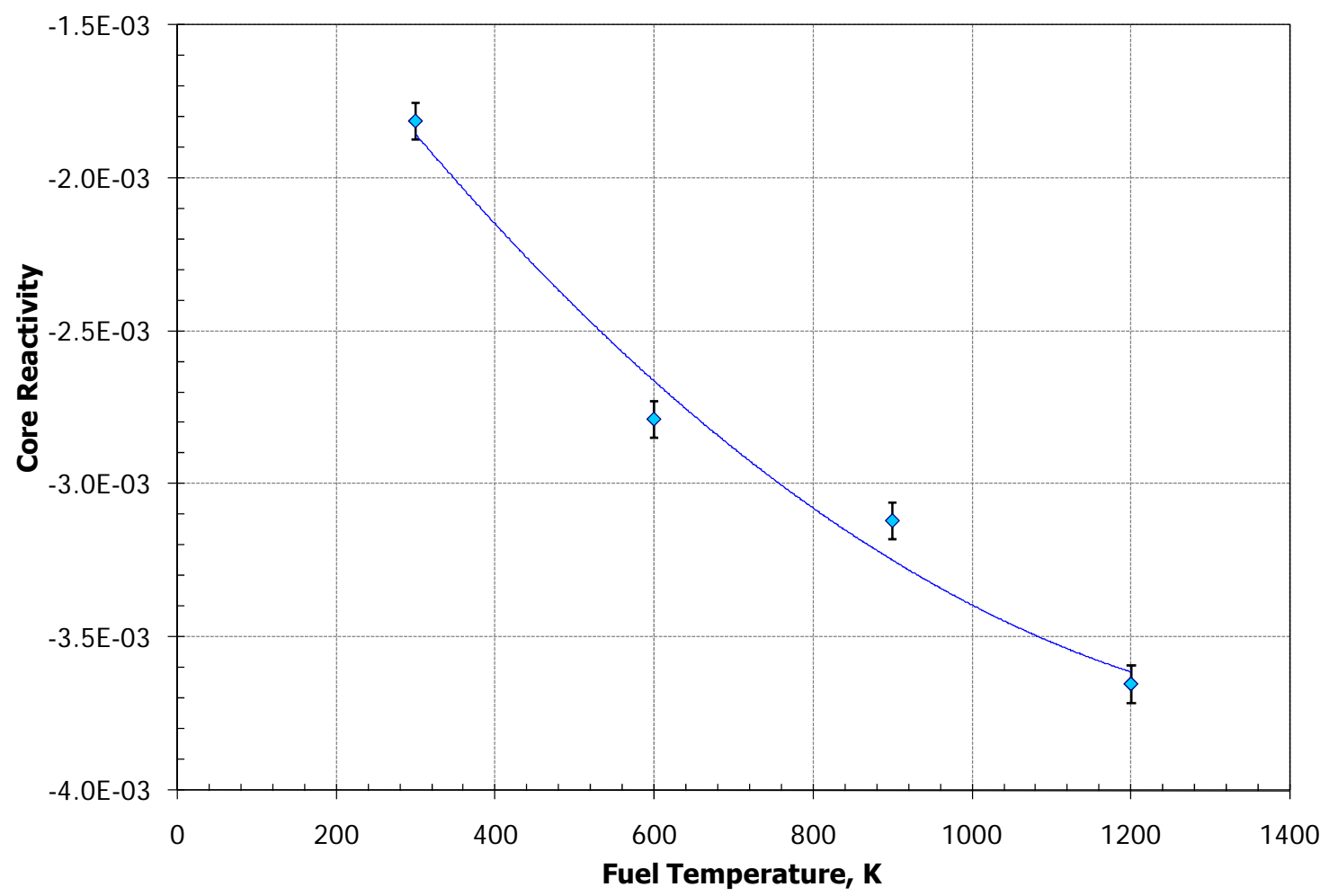

Figure 4.3.1-8. $\mathrm{CR}=0,12 \mathrm{LEMs} /$ assembly, core reactivity vs. fuel temperature at $\mathrm{EOC}$ 
Project No 06-040: Flexible Conversion Ratio Fast Reactor Systems Evaluation

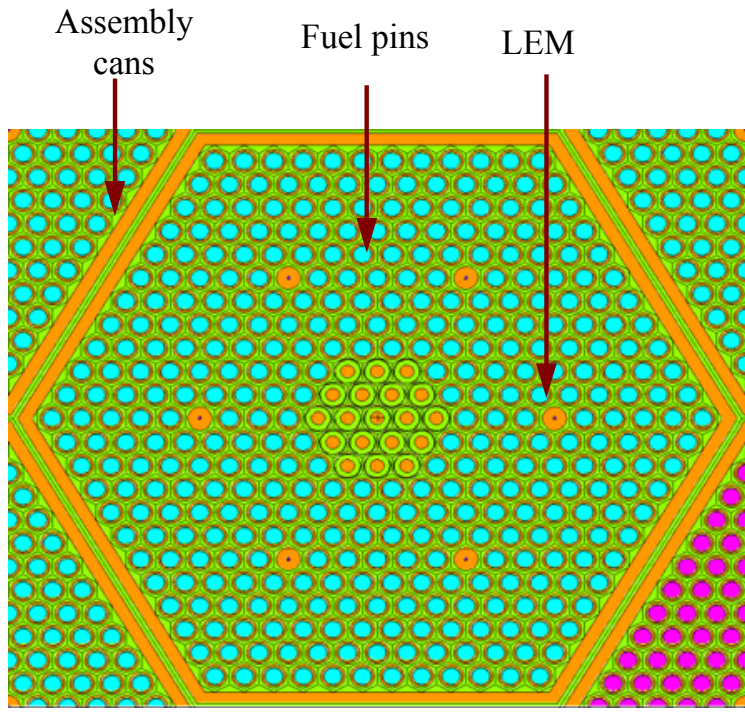

6 LEMS
Control Rods

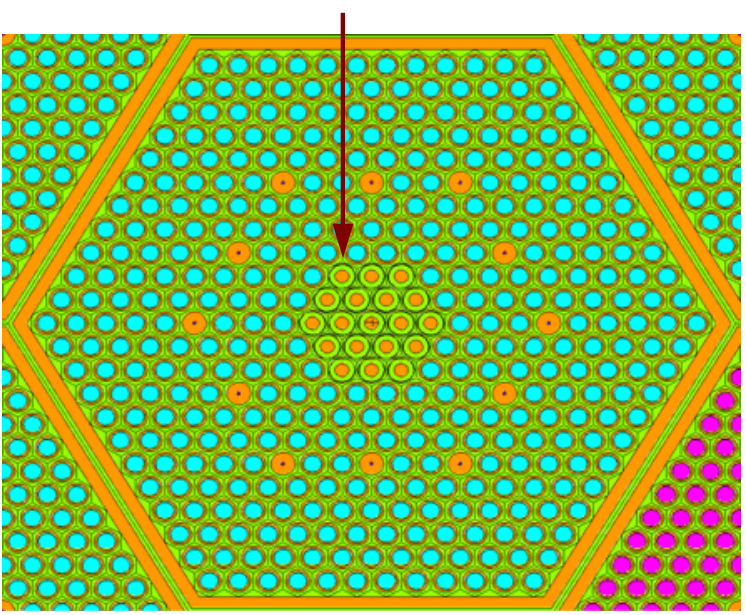

12 LEMS

Figure 4.3.1-9. Alternative LEM arrangements in $\mathrm{CR}=0$ core fuel assembly

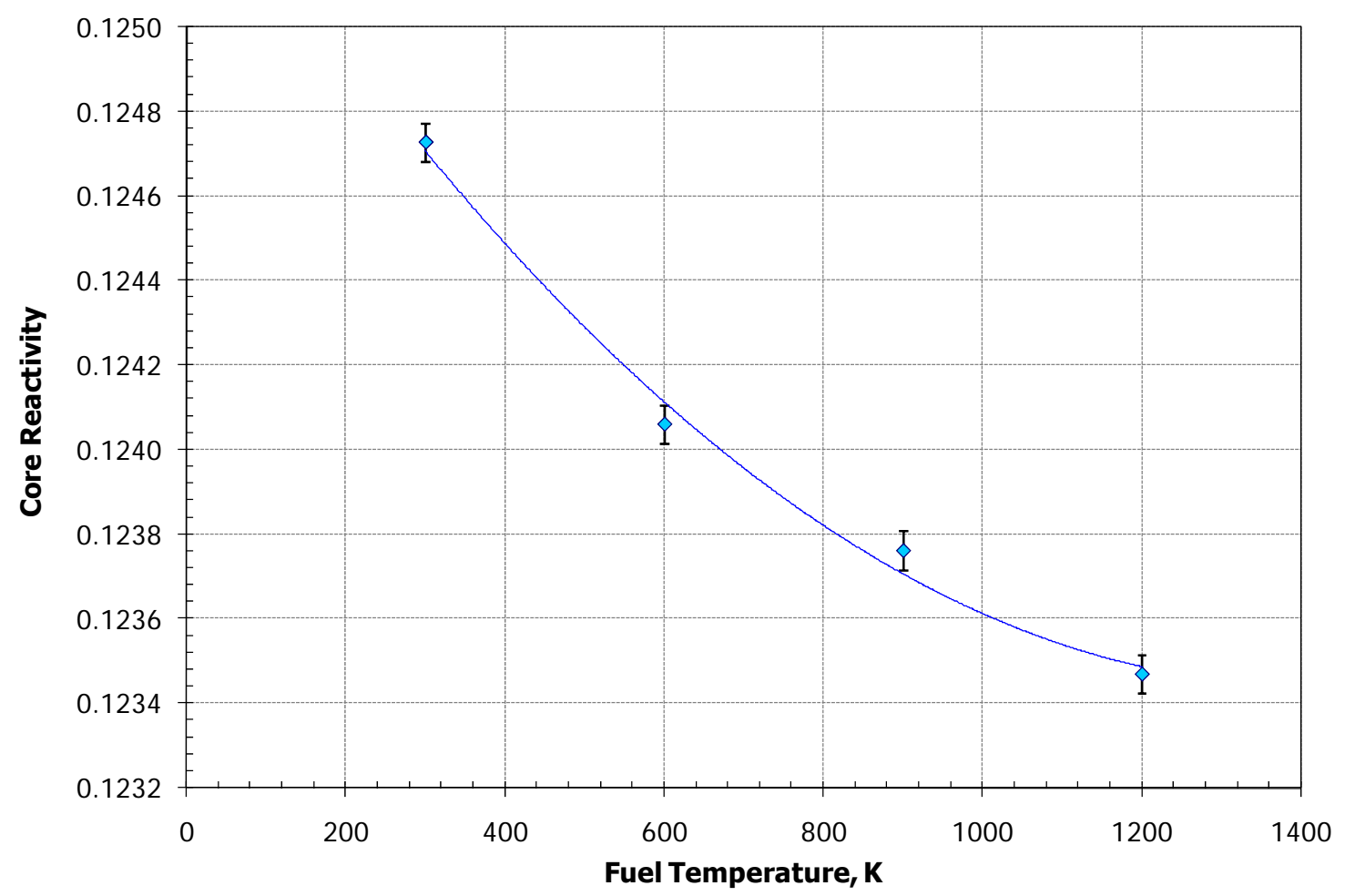

Figure 4.3.1-10. $\mathrm{CR}=0,6 \mathrm{LEMs} / \mathrm{assembly}$, core reactivity vs. fuel temperature at $\mathrm{BOC}$ 
Project No 06-040: Flexible Conversion Ratio Fast Reactor Systems Evaluation

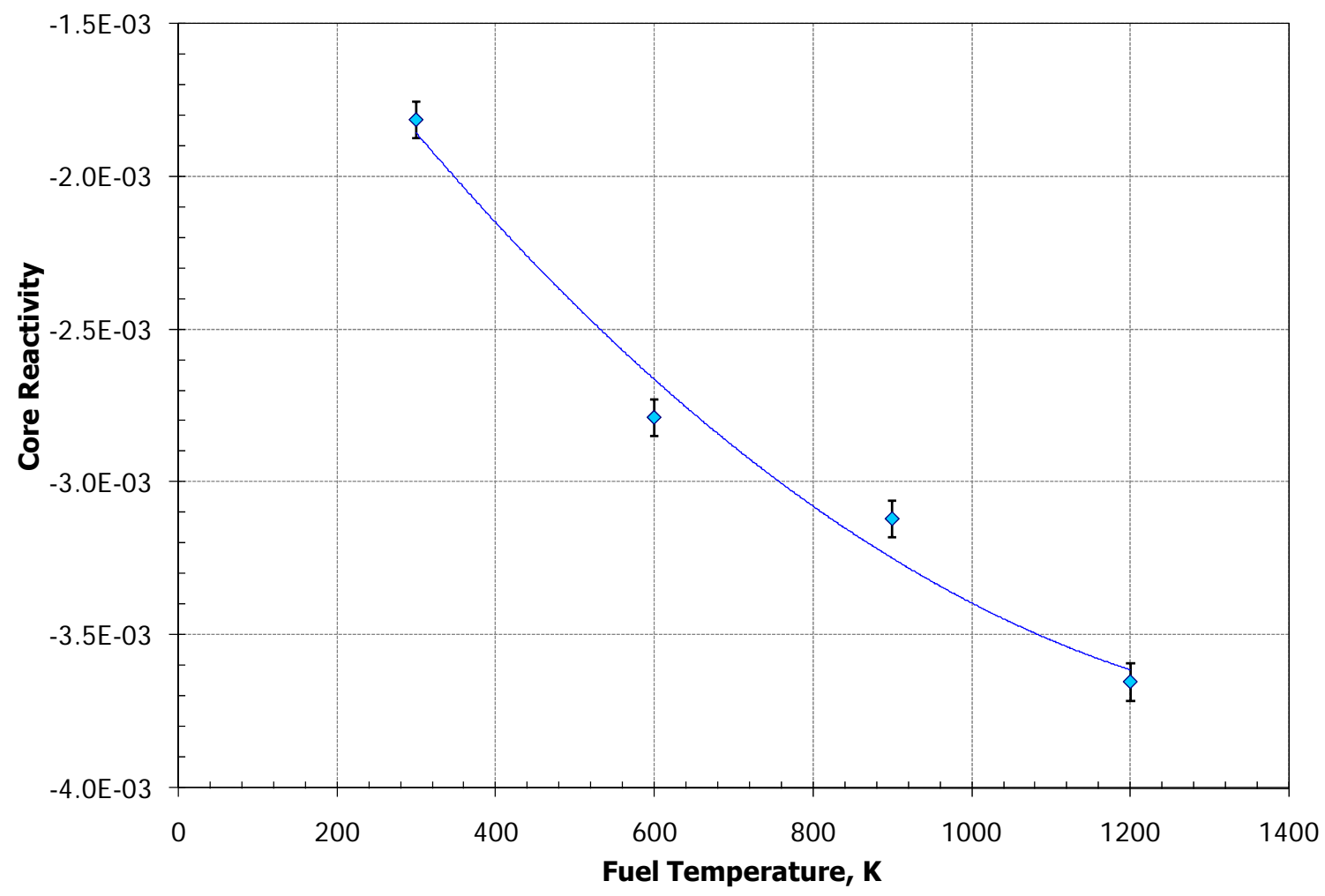

Figure 4.3.1-11. CR=0, $6 \mathrm{LEMs/assembly,} \mathrm{core} \mathrm{reactivity} \mathrm{vs.} \mathrm{fuel} \mathrm{temperature} \mathrm{at} \mathrm{EOC}$

As a result, more detailed modeling of the coolant temperature reactivity feedback was performed and iterated with RELAP5 transient analyses. The results of this iterative process showed that

- 12, rather than 6, LEMs per assembly are required to ensure that peak cladding temperature limit is not violated.

- $\quad$ Li insertion must be initiated at about $35 \mathrm{~cm}$ depth from the core upper boundary in order to compensate for the positive coolant thermal expansion reactivity effect at the early stage of a transient.

In order to satisfy the latter requirement, the bottle-shaped LEM capillary design presented in Figure 4.2.1-21 was used. The LEM dimensions were chosen such that the expansion of Li would be entirely within the high reactivity worth region starting from $35 \mathrm{~cm}$ insertion at nominal coolant temperature and expanding to $95 \mathrm{~cm}$ insertion upon coolant heat-up of $150 \mathrm{~K}$. Figures 4.3.1-12 and 4.3.1-13 show the Li insertion reactivity effect and combined coolant temperature increase effect respectively for the $\mathrm{CR}=0$ core with 12 LEMs per assembly. As can be observed from the figures, the LEMs can be designed such that the CTC will be about zero throughout all stages of a transient. 
Project No 06-040: Flexible Conversion Ratio Fast Reactor Systems Evaluation

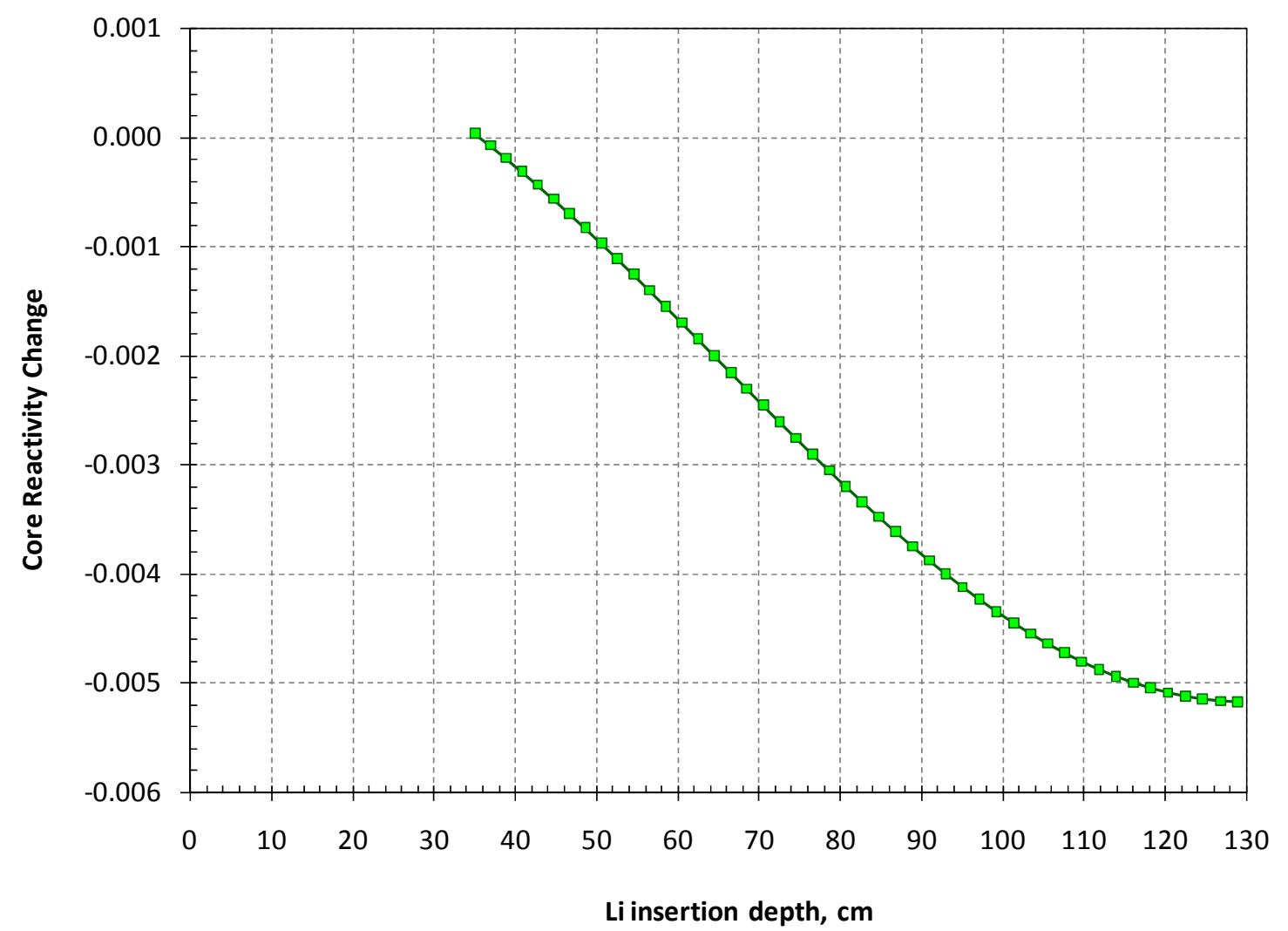

Figure 4.3.1-12. Core reactivity vs lithium insertion depth

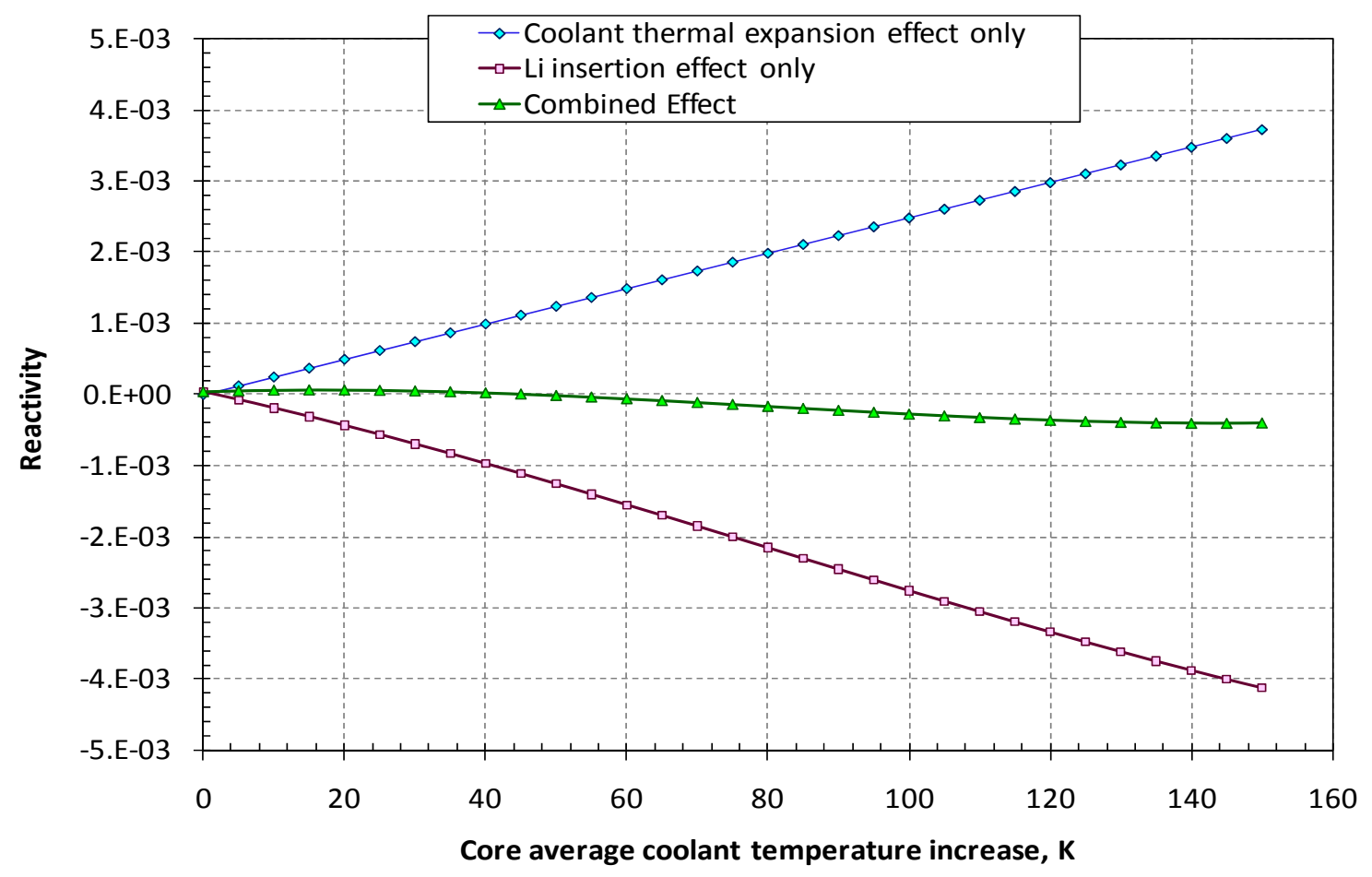

Figure 4.3.1-13 Core reactivity change in response to coolant temperature increase

Fast fluence to the reactor vessel and core support plate was calculated with the MCNP code for the $\mathrm{CR}=0$ salt-cooled core. The results are presented in Table 4.3.1-6 for both $\mathrm{CR}=1$ and $\mathrm{CR}=0$ 
cores. Slightly higher fluence was obtained in the $\mathrm{CR}=0$ core case because the core is more transparent to neutrons and, thus, has higher leakage than the $\mathrm{CR}=1$ core. The same trend was observed for the lead-cooled designs. The fluence values for both $\mathrm{CR}=1$ and $\mathrm{CR}=0$ salt-cooled core designs are slightly lower than the values for corresponding lead-cooled designs. These differences are, most likely, due to the somewhat softer neutron spectrum and the presence of radial $\mathrm{B}_{4} \mathrm{C}$ shielding assemblies in the salt-cooled designs. Overall, the values of fluence accumulated by the reactor vessel and core support plate in both core designs are well below the adopted limit for stainless steel 316.

Table 4.3.1-6. Fast fluence accumulated of 40 years lifetime in $\mathrm{CR}=0$ core components

\begin{tabular}{|l|c|c|}
\hline \multirow{2}{*}{ Parameter } & \multicolumn{2}{|c|}{ Salt } \\
\cline { 2 - 3 } & $\mathbf{C R}=\mathbf{1}$ & $\mathbf{C R}=\mathbf{0}$ \\
\hline Vessel above $0.1 \mathrm{MeV}, \# / \mathrm{cm}^{2}$ & $(1.0 \pm 0.7) \mathrm{j} \times 10^{16}$ & $(3.7 \pm 2.0) \times 10^{16}$ \\
\hline Core support plate above $0.1 \mathrm{MeV}, \# / \mathrm{cm}^{2}$ & $(1.1 \pm 0.1) \times 10^{19}$ & $(1.2 \pm 0.1) \times 10^{19}$ \\
\hline
\end{tabular}

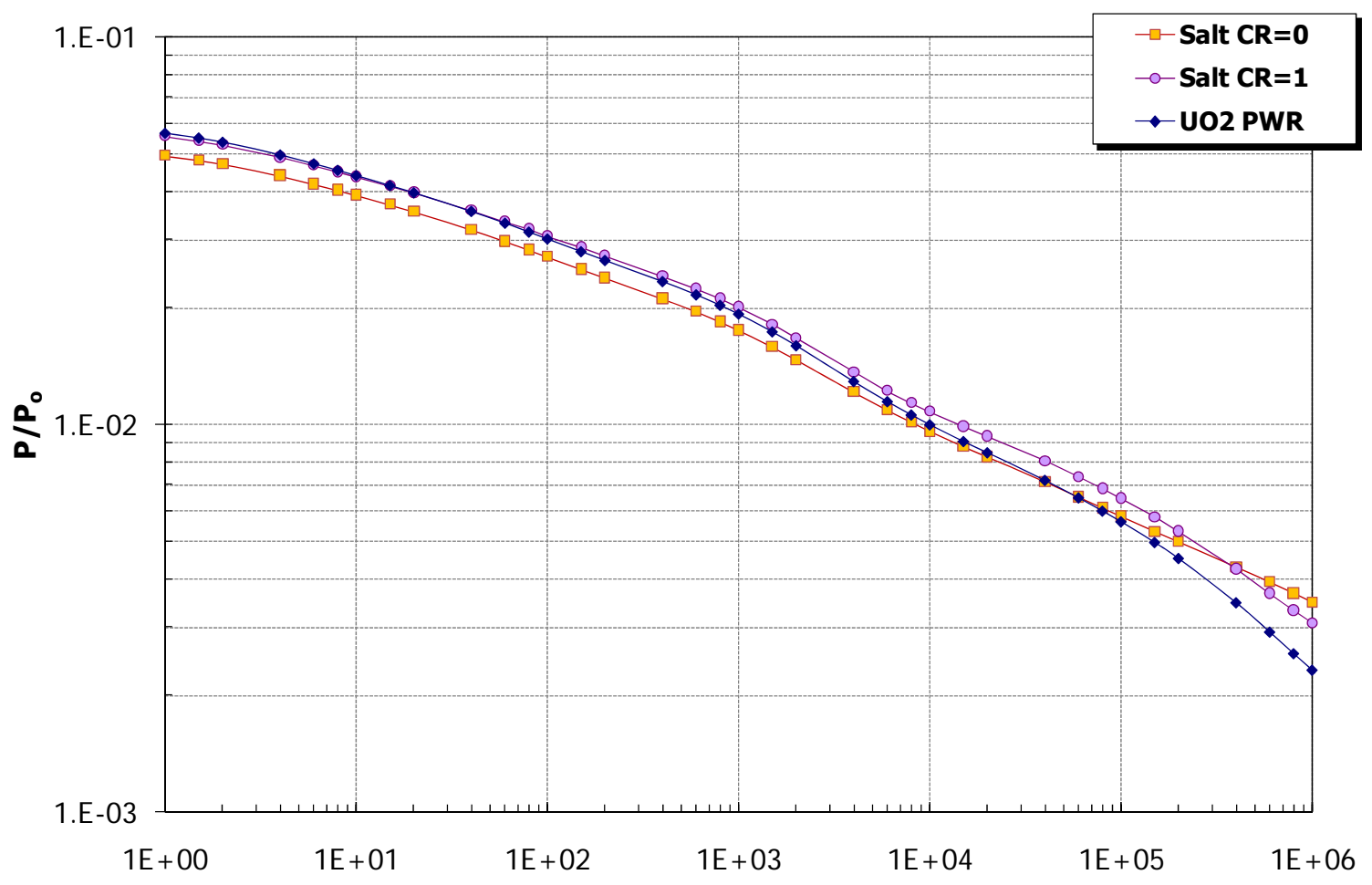

Time after shutdown, sec

Figure 4.3.1-14. Decay heat power for $\mathrm{UO}_{2} \mathrm{LWR}$ and salt-cooled cores (Log-Log scale)

Finally, the results of decay heat calculations for both $\mathrm{CR}=1$ and $\mathrm{CR}=0$ salt-cooled cores are compared with a standard $\mathrm{UO}_{2}$ fueled PWR in Figures 4.3.1-14 and 4.3.1-15. The data was obtained from detailed depletion and decay calculations of the studied systems using the BGCore code. The results were subsequently used in the transients modeling with RELAP5. Decay heat of the $\mathrm{CR}=0$ salt-cooled core is lower than that of the $\mathrm{CR}=1$ core by about $10 \%$. The decay heat values of the two studied designs become roughly equal after $4 \times 10^{5}$ seconds after shutdown. A similar trend was observed for the lead-cooled designs. As compared with the $\mathrm{UO}_{2} \mathrm{PWR}$ case, the $\mathrm{CR}=0$ salt-cooled core has lower decay heat by a few percent up to about $10^{5}$ seconds. After 
Project No 06-040: Flexible Conversion Ratio Fast Reactor Systems Evaluation

that, the $\mathrm{CR}=0$ core decay heat becomes larger and the difference reaches a factor of 2 at about $6 \times 10^{6}$ seconds.

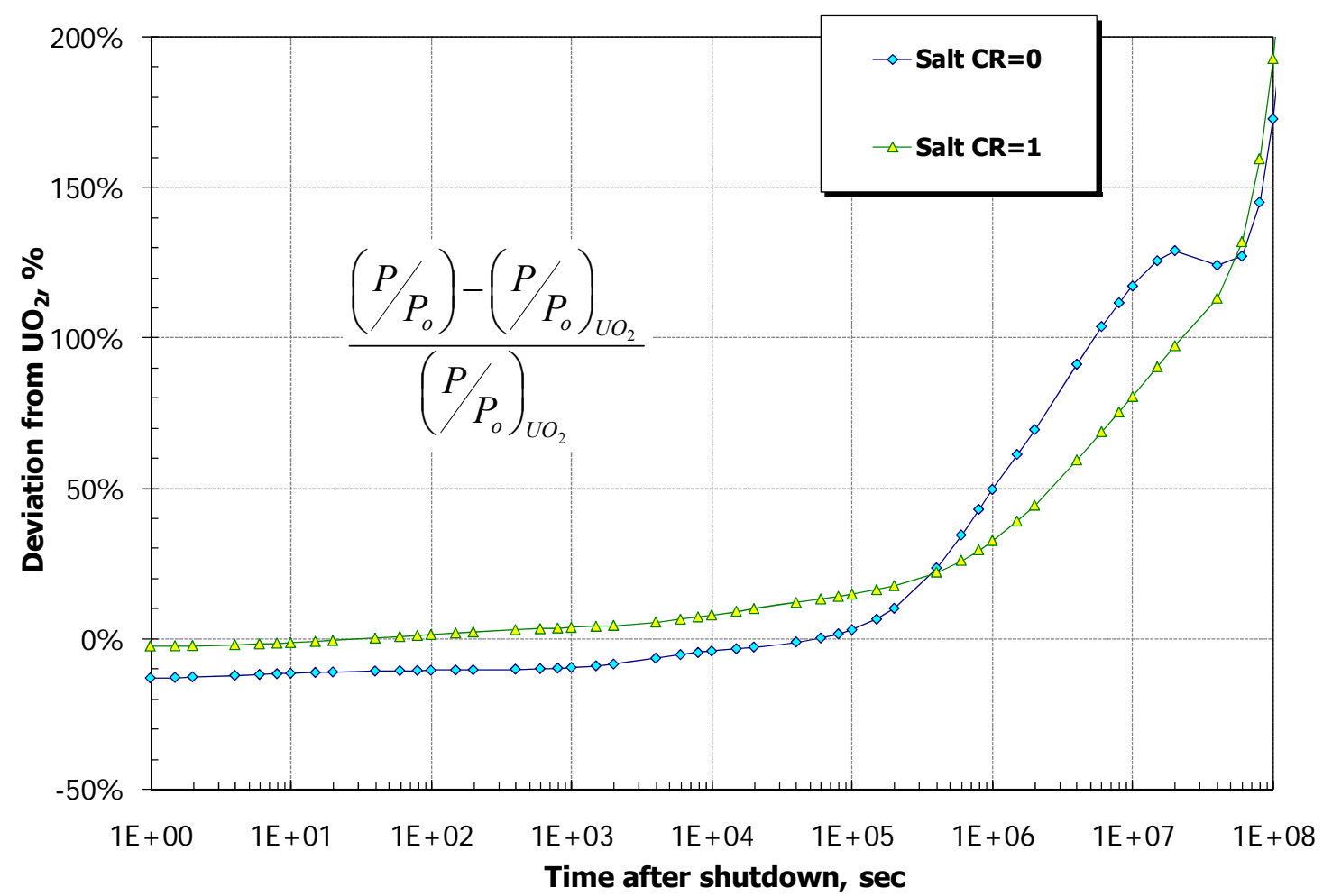

Figure 4.3.1-15. Difference between $\mathrm{P} / \mathrm{P}_{\mathrm{o}}$ values for $\mathrm{UO}_{2} \mathrm{LWR}$ and salt-cooled cores 


\subsubsection{Thermal Hydraulic Analysis Results}

\subsubsection{Steady state design}

The steady state thermal hydraulic model for the $\mathrm{CR}=0$ reactor is nearly identical to that of the $\mathrm{CR}=1$ reactor. The primary difference is with assembly peaking factors calculated by MCNP; the $\mathrm{CR}=1$ core had a maximum peaking factor of 1.26 while the $\mathrm{CR}=0$ core's is 1.35 . In reality, control rods can be adjusted to create a flatter radial power profile, but conservative un-rodded values are adopted to be consistent with prior analyses. The $\mathrm{CR}=0$ core also has a slightly different axial power shape than the $\mathrm{CR}=1$ core. Finally, the $\mathrm{CR}=0$ core has 19 control rods and 12 LEMs in every assembly, compared to 25 LEMs per assembly in the $\mathrm{CR}=1$ core and control rods in only some assemblies, which displaces additional fuel pins and therefore raises the effective peaking somewhat. The $\mathrm{CR}=0$ core is able to use fewer LEMs because the CTC of the $\mathrm{CR}=0$ is smaller due to higher leakage.

The higher radial peaking in the $\mathrm{CR}=0$ core means that the hot channel coolant velocity needs to be increased to keep the peak cladding temperature below the $650^{\circ} \mathrm{C}$ steady state limit. Calculations using the subchannel spreadsheet model showed that a $10 \%$ coolant velocity increase is needed, corresponding to a core pressure drop increase from $700 \mathrm{kPa}$ to $825 \mathrm{kPa}$. It was determined that a three-zone orificing scheme could be used to maintain the same coolant flow rate between the $\mathrm{CR}=0$ and $\mathrm{CR}=1$ cores despite the difference in pressure drop. The higher core pressure drop translates into a larger pumping power, which raises coolant temperatures very slightly $\left(<1^{\circ} \mathrm{C}\right)$. A summary of the $\mathrm{CR}=0$ core operating characteristics is given in Table 4.3.2-1.

Table 4.3.2-1 CR $=0 \mathrm{NaCl}-\mathrm{KCl}-\mathrm{MgCl}_{2}$ salt reference core operating characteristics.

\begin{tabular}{|l|c|}
\hline Total Power $(\mathrm{MWt})$ & 2400 \\
\hline Power density $(\mathrm{W} / \mathrm{cc})$ & 130 \\
\hline Average power per pin $(\mathrm{W})$ & $1.45 \times 10^{4}$ \\
\hline Maximum assembly peaking factor & 1.35 \\
\hline Maximum axial peaking factor & 1.277 \\
\hline Coolant inlet temperature $\left({ }^{\circ} \mathrm{C}\right)$ & 496 \\
\hline Average coolant outlet temperature $\left({ }^{\circ} \mathrm{C}\right)$ & 569 \\
\hline Pressure drop across core $(\mathrm{Pa})$ & $8.25 \times 10^{5}$ \\
\hline Coolant mass flow rate through core $(\mathrm{kg} / \mathrm{s})$ & $3.28 \times 10^{4}$ \\
\hline Pumping power through core $(\mathrm{MWt})$ & 14.4 \\
\hline Hot channel characteristics: & 4.8 \\
\hline Inlet coolant velocity $(\mathrm{m} / \mathrm{s})$ & $1.42 \times 10^{4}$ \\
\hline Reynolds number & 100. \\
\hline Nusselt number & $1.2 \times 10^{4}$ \\
\hline Heat transfer coefficient $\left(\mathrm{W} / \mathrm{m}^{2} \mathrm{~K}\right)$ & 70 \\
\hline Maximum film $\Delta \mathrm{T}(\mathrm{K})$ & 648 \\
\hline Maximum cladding temperature $\left({ }^{\circ} \mathrm{C}\right)$ & $<958$ \\
\hline Maximum fuel temperature $\left({ }^{\circ} \mathrm{C}\right)$ & \\
\hline
\end{tabular}


Because the primary coolant flow rate and temperatures are the same for the $C R=1$ and $C R=0$ cores, the same IHX design and power conversion system can be used for both reactors. This not only satisfies one of the primary goals of the flexible conversion ratio reactor project, but also significantly simplifies modeling for the $\mathrm{CR}=0$ core.

\section{Steady State Fuel performance analysis}

Fuel temperatures were calculated to determine if there is a likelihood for fuel failure in the liquid salt-cooled core. This is of particular concern because of the higher linear heat rates in the new reference core. An important parameter in determining fuel temperatures is fuel thermal conductivity. Fuel thermal conductivity is a function of many factors, including temperature, composition, burnup, migration of fuel constituents and infiltration of bonding material. The fuels with large content of $\mathrm{Zr}$ for the $\mathrm{CR}=0$ core are of special concern because of the lack of data. A conservative value for fuel thermal conductivity was obtained by taking the recently measured value for unirradiated fuel $\mathrm{U}-29 \mathrm{Pu}-4 \mathrm{Am}-2 \mathrm{~Np}-30 \mathrm{Zr}$ at $500^{\circ} \mathrm{C}(12 \mathrm{~W} / \mathrm{m}-\mathrm{K})$ [Meyer, 2007 ] and reducing it by $50 \%$ to take into account deterioration from irradiation. The value at $500^{\circ} \mathrm{C}$ is used because this temperature is close to the coolant inlet temperature; since fuel thermal conductivity increases with temperature, the value obtained sets a lower limit on thermal conductivity for un-irradiated fuel. Lee et. al [2004] states that a maximum degradation of fuel thermal conductivity of about $50 \%$ occurs during irradiation. Degradation past this value does not occur because of bonding material ingress into the fuel at higher burnups. The fuel thermal conductivity is therefore assumed to be $50 \%$ of $12 \mathrm{~W} / \mathrm{m}-\mathrm{K}$, or $6.0 \mathrm{~W} / \mathbf{m}-\mathbf{K}$. For this calculation, pre-irradiation dimensions are used: the fuel pellet diameter is $5.42 \mathrm{~mm}$, and the gap thickness is $0.42 \mathrm{~mm}$. The liquid metal bonding material is assumed to have a thermal conductivity of 8.0 $\mathrm{W} / \mathrm{m}-\mathrm{K}$. Assuming uniform power in the pin, the thermal resistance between the fuel centerline and the cladding inner wall is therefore:

$R_{T}=\frac{\Delta T}{q^{\prime}}=\frac{1}{4 \pi k_{f}}+\frac{\ln \left(\frac{R_{o}}{R_{I}}\right)}{2 \pi k_{g}}=\frac{1}{4 \pi * 6.0 \mathrm{~W} / \mathrm{mK}}+\frac{\ln \left(\frac{3.13 \mathrm{~mm}}{2.71 \mathrm{~mm}}\right)}{2 \pi * 8.0 \mathrm{~W} / \mathrm{mK}}=\mathbf{0 . 0 1 6 K / \mathbf { W m }} \mathbf{m}^{-\mathbf{1}}$

Here $k_{f}$ is the fuel thermal conductivity, $k_{g}$ is the gap bonding material thermal conductivity, $R_{o}$ and $R_{i}$ the inner and outer radii of the gap. The maximum linear heat rate $q$ ' in the new $\mathrm{CR}=1$ reference design is $18 \mathrm{~kW} / \mathrm{m}$; multiplying by the thermal resistance yields a $\Delta T$ between the fuel centerline and cladding inner wall of $288{ }^{\circ} \mathbf{C}$. Since the maximum cladding temperature of $648^{\circ} \mathrm{C}$ allows a $352^{\circ} \mathrm{C} \Delta T$ to fuel failure at $1200^{\circ} \mathrm{C}$, there is a large margin to fuel failure even under conservative assumptions.

The $6.0 \mathrm{~W} / \mathrm{mK}$ value for thermal conductivity is conservative for determining steady state fuel performance, but is not conservative for reactor transient behavior. A low value for fuel thermal conductivity magnifies fuel temperature reactivity feedbacks, which are generally negative. Therefore, for transient studies, unirradiated values for metal fuel thermal conductivity were used, since they are larger and therefore yield conservative reactor physics parameters. This approach is appropriate because for most transients, cladding temperature is more limiting than fuel temperature. 
Project No 06-040: Flexible Conversion Ratio Fast Reactor Systems Evaluation

\subsubsection{Transient performance}

\subsection{Unprotected Station Blackout}

A detailed description of the unprotected station blackout transient is given in the $\mathrm{CR}=1$ reactor transient performance section. The $\mathrm{CR}=0$ system was modeled using the same reference PSACS design as in the $\mathrm{CR}=1$ reference case (the $60 \%$ PSACS power, $0.75 \mathrm{x}$ tank size case). Short-term temperature and reactivity results are given in Figures 4.3.2-1 and 4.3.2-2. The reactivity curves are extremely similar, owing to the ability to use LEMs to obtain a desired reactivity response. As a result, the temperature response of the $\mathrm{CR}=0$ core is nearly identical to that of the $\mathrm{CR}=1$ core, with only a slightly higher maximum short-term peak clad temperature $\left(748^{\circ} \mathrm{C}\right.$ vs. $\left.742^{\circ} \mathrm{C}\right)$. Long term peak cladding temperature, reactivity, and power results are shown in Figures 4.3.2-3 through 4.3.2-5. Again, results are very similar to the $\mathrm{CR}=1$ case, although there is a brief lowpower restart in $\mathrm{CR}=0$ long term response because decay heat from the $\mathrm{CR}=0$ core is significantly less, so temperatures become low enough to cause reactivity to become positive. Overall, the same conclusions can be drawn for the $\mathrm{CR}=0$ core as for the $\mathrm{CR}=1$ core. Following an initial temperature spike the core quickly shuts itself down. Subsequent cooling by the PSACS introduces sufficient reactivity to restart the reactor. A low-power steady state is maintained until the PSACS tanks run out of water, about 36 hours after the SBO begins, after which cooling occurs through only the RVACS.

\subsection{Unprotected Loss of Flow Accident}

A description of the loss of flow accident sequence is given in the $\mathrm{CR}=1$ transient performance section. The same mitigation strategy was tested for the $\mathrm{CR}=0$ system, using a turbine bypass valve governed by a proportional integral controller with a setpoint of $25 \mathrm{rad} / \mathrm{s}$, a proportional weight of 2.9 and an integral weight of 0.02. Results are shown in Figures 4.3.2-6 through 4.3.28. As with the $\mathrm{SBO}$ transient, results are very similar for the $\mathrm{CR}=0$ and $\mathrm{CR}=1$ cores, with the maximum $\mathrm{CR}=0$ temperatures being a few degrees higher. Again the same conclusions can be drawn for the $\mathrm{CR}=0$ core as for the $\mathrm{CR}=1$ core; use of the turbine bypass valve controller allows the heat removed to fairly closely match the heat generated, bringing the reactor smoothly to an 86 MW steady state. 
Project No 06-040: Flexible Conversion Ratio Fast Reactor Systems Evaluation

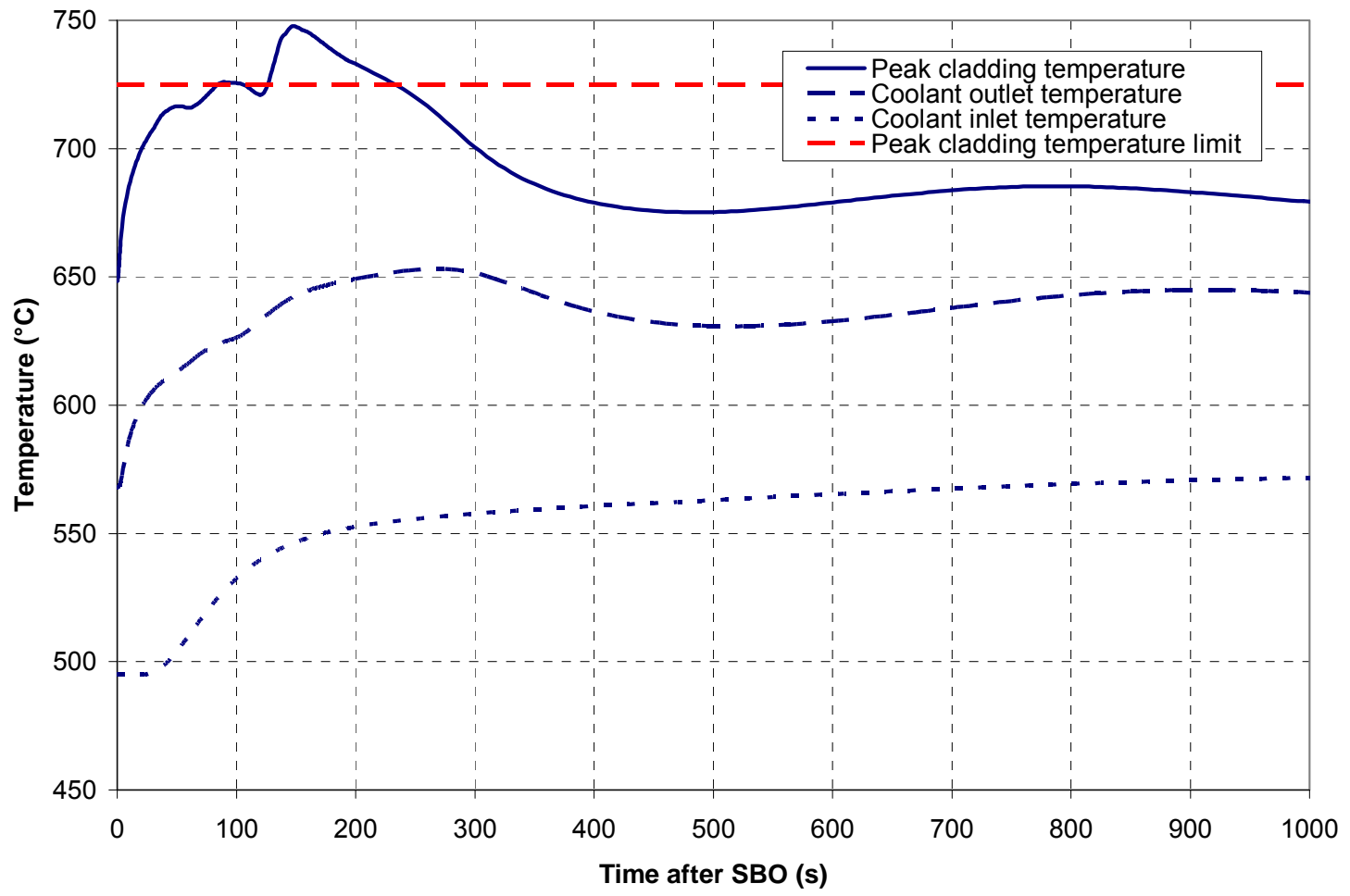

Figure 4.3.2-1 Short-term $\mathrm{CR}=0$ temperature response to an SBO

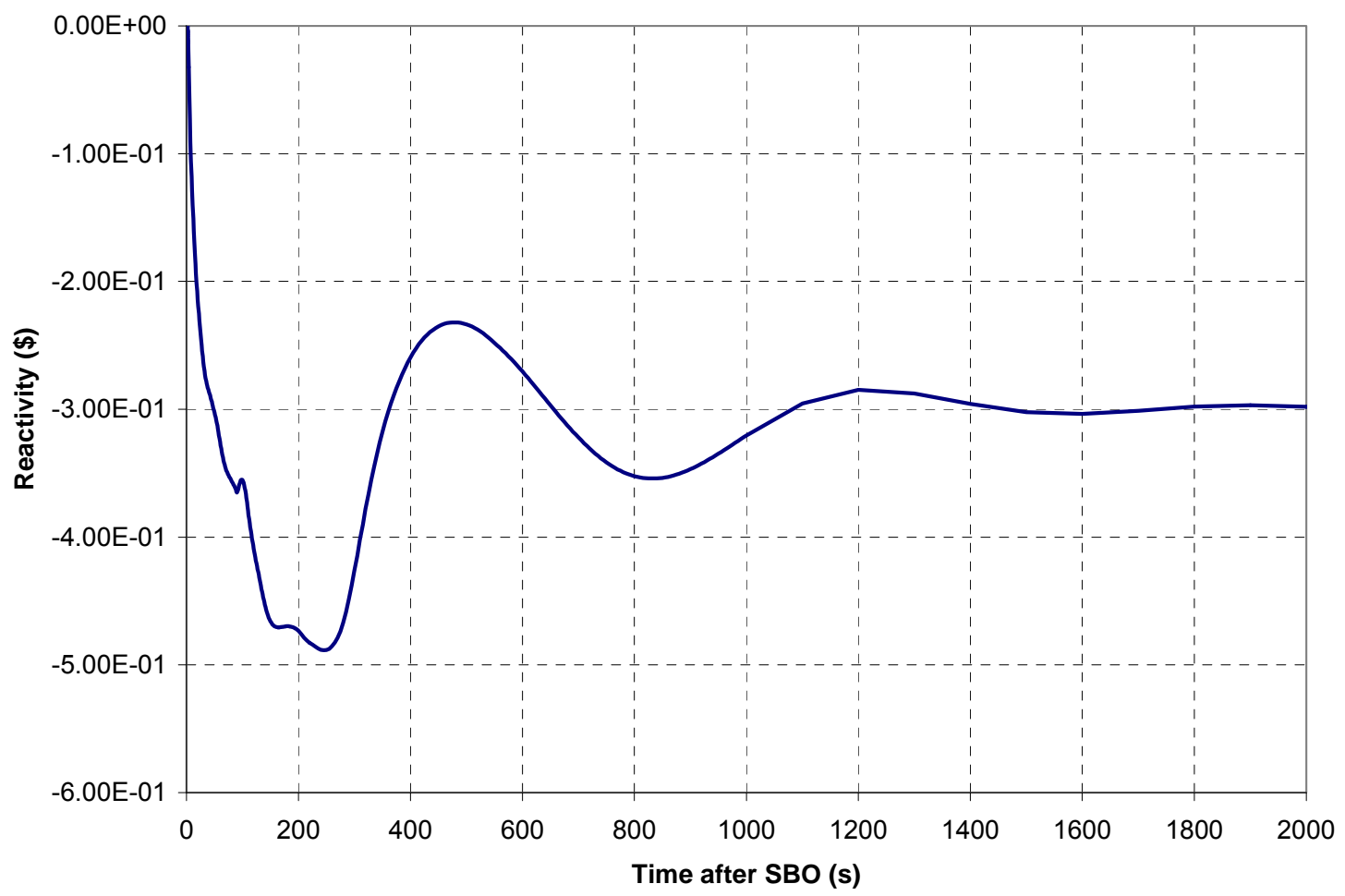

Figure 4.3.2-2 Short-term $\mathrm{CR}=0$ reactivity response to an $\mathrm{SBO}$ 
Project No 06-040: Flexible Conversion Ratio Fast Reactor Systems Evaluation

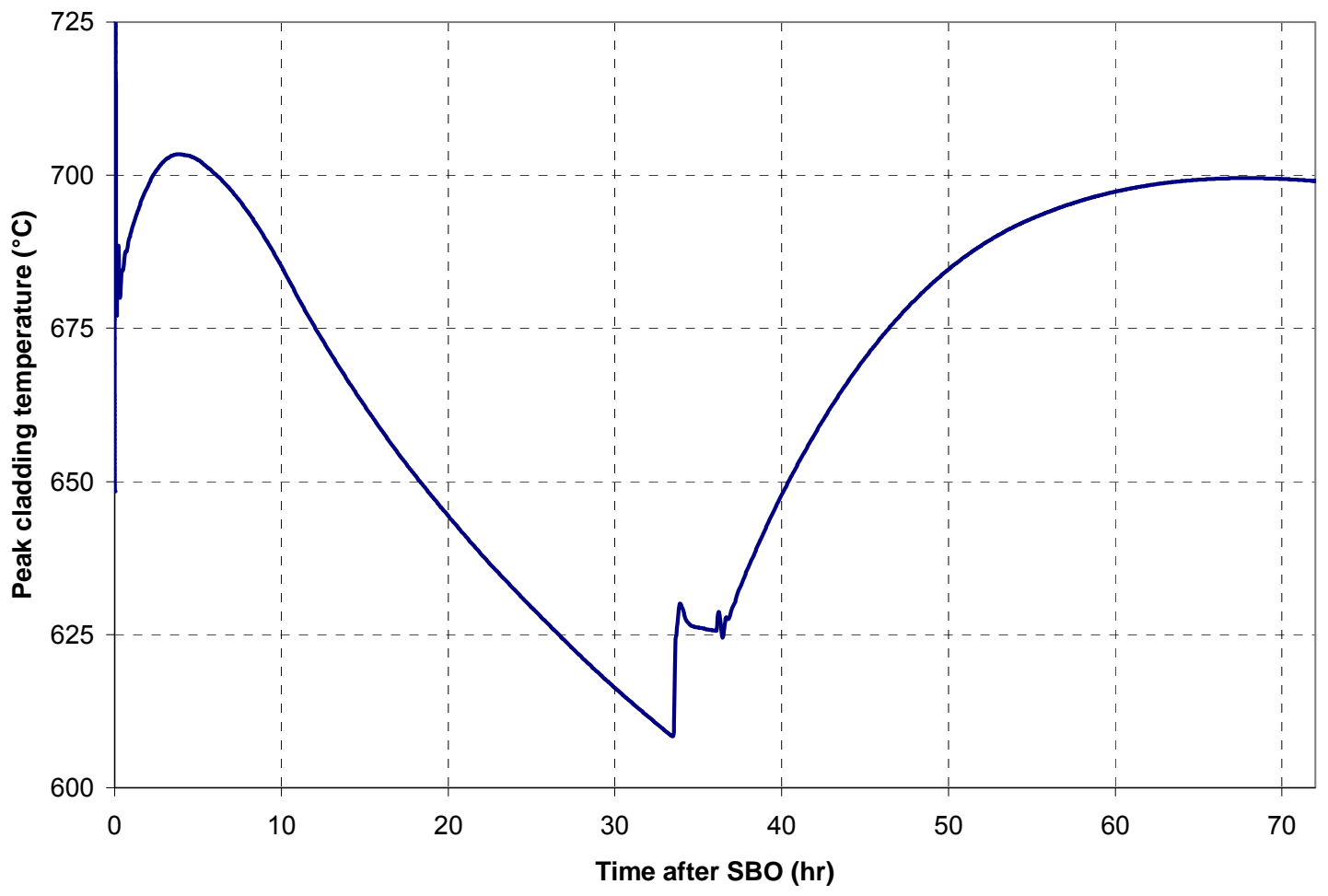

Figure 4.3.2-3 Long-term $\mathrm{CR}=0$ temperature response to an $\mathrm{SBO}$

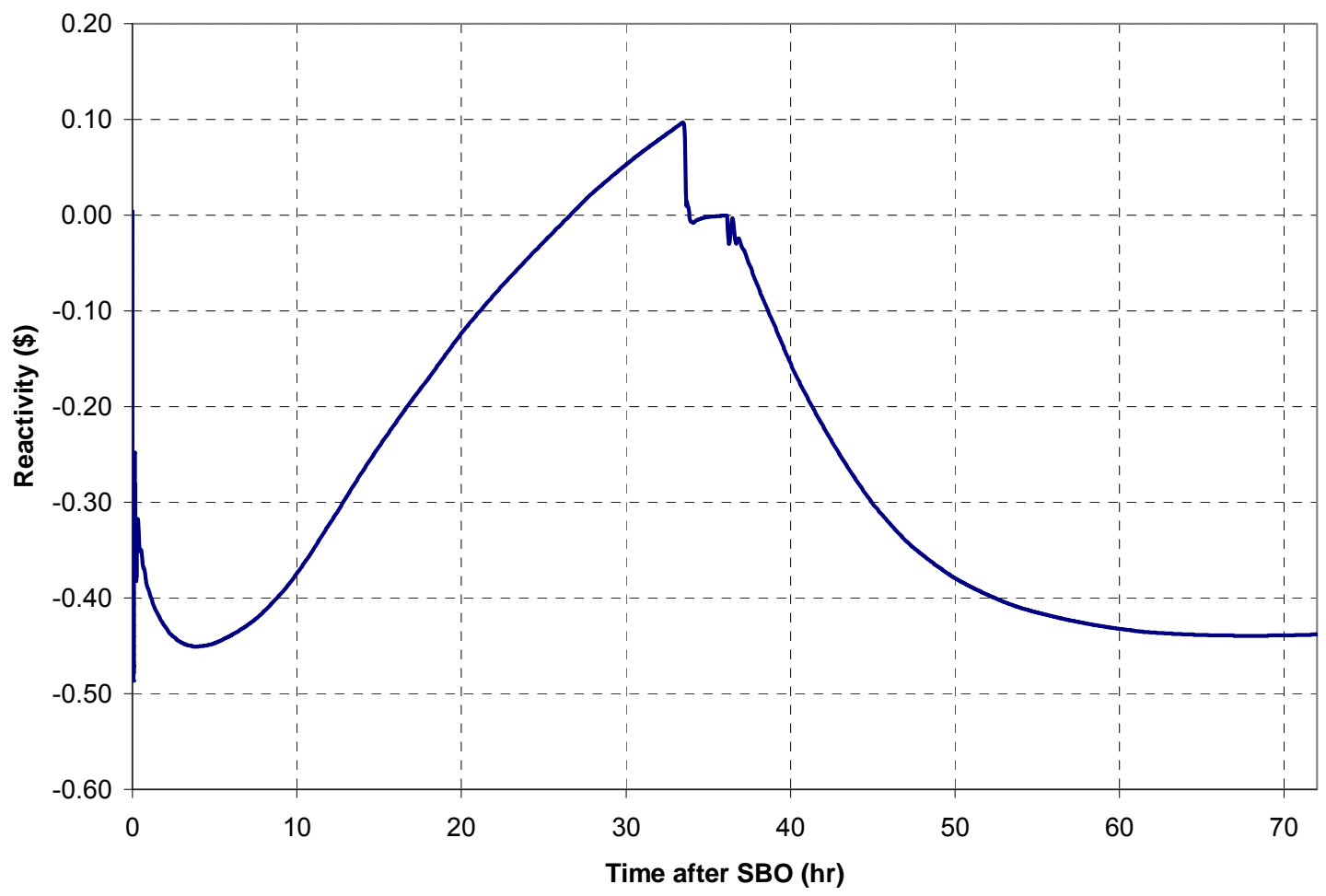

Figure 4.3.2-4 Long-term $\mathrm{CR}=0$ reactivity response to an $\mathrm{SBO}$ 
Project No 06-040: Flexible Conversion Ratio Fast Reactor Systems Evaluation

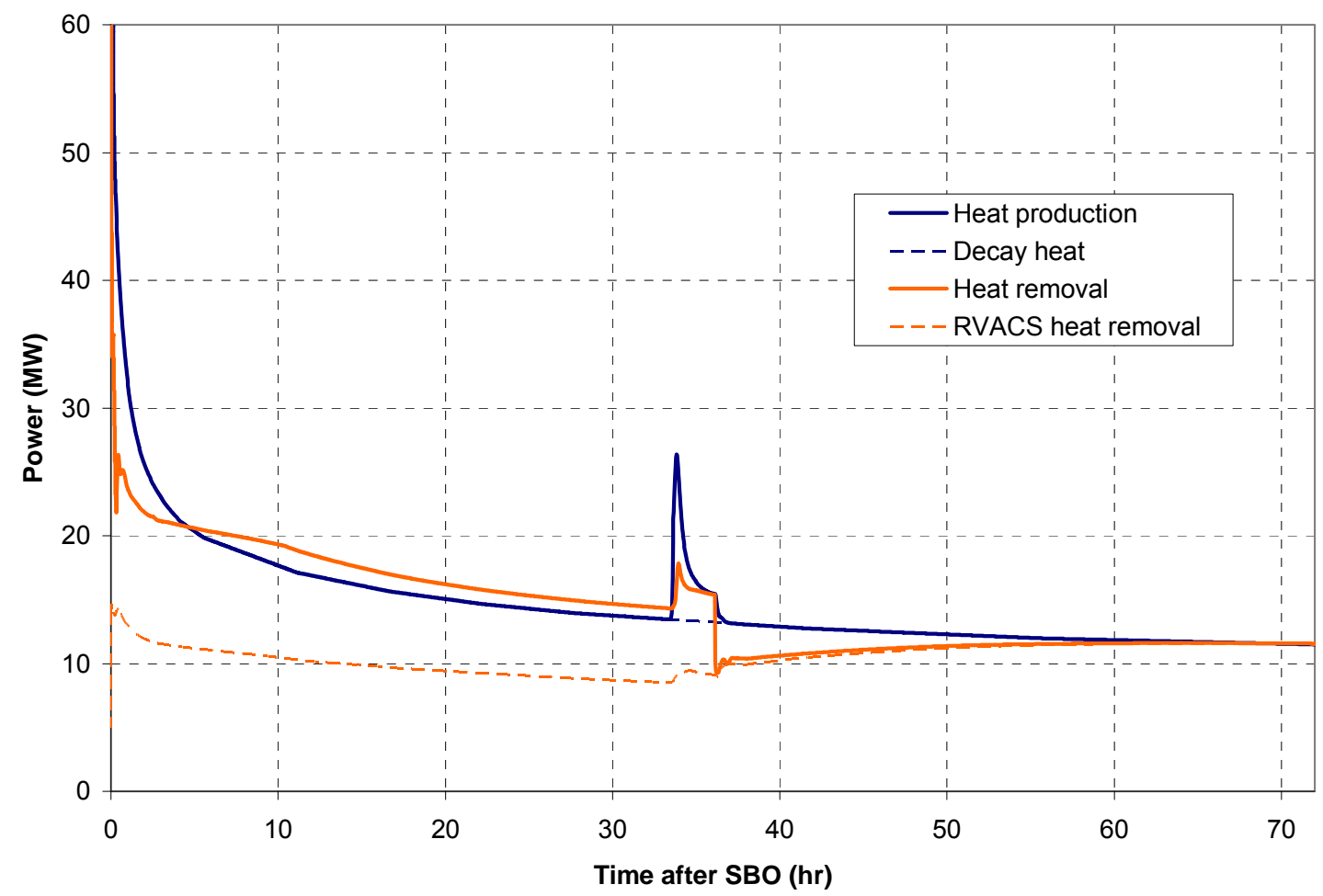

Figure 4.3.2-5 Long-term $\mathrm{CR}=0$ power response to an $\mathrm{SBO}$

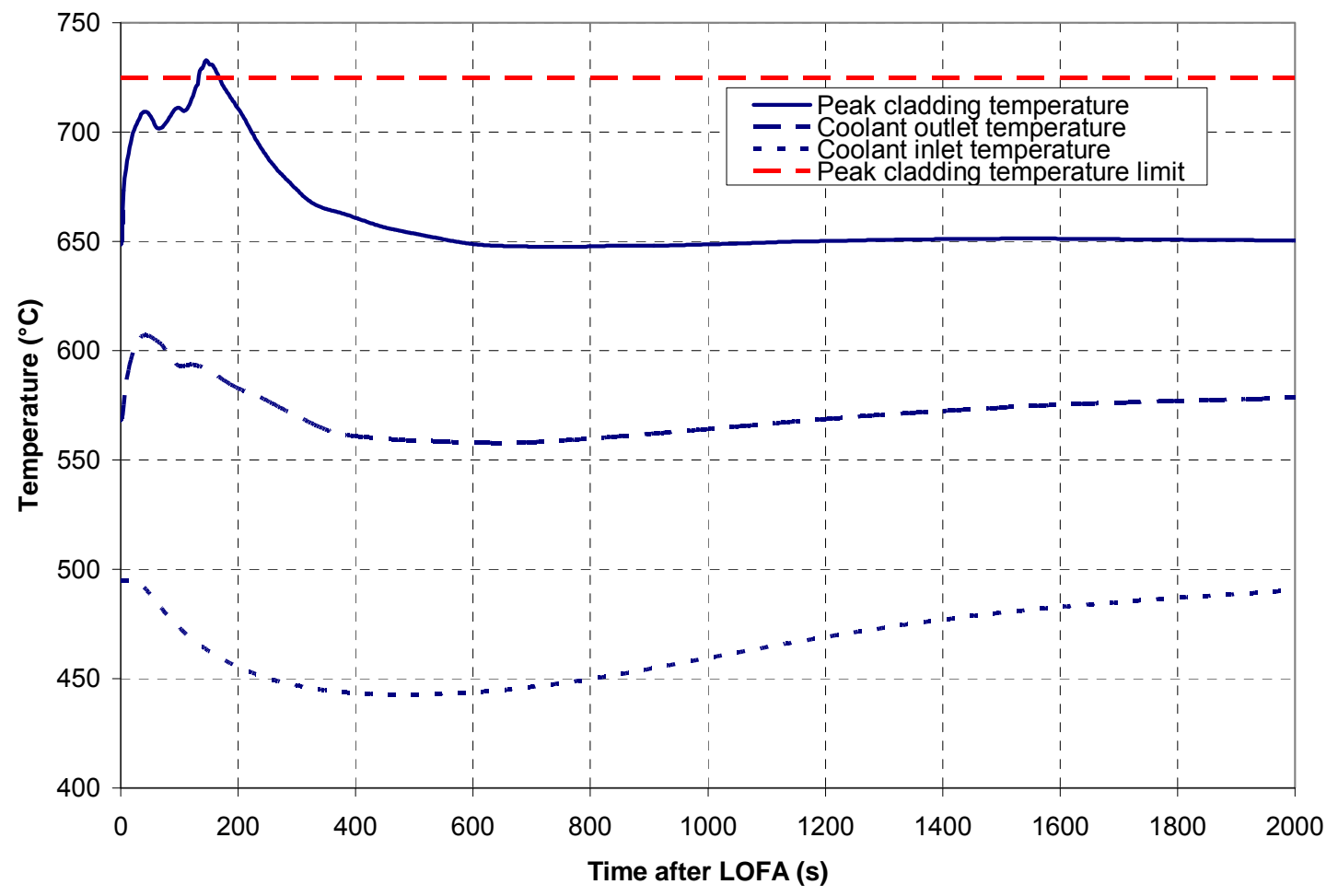

Figure 4.3.2-6 CR=0 temperature response to a LOFA 
Project No 06-040: Flexible Conversion Ratio Fast Reactor Systems Evaluation

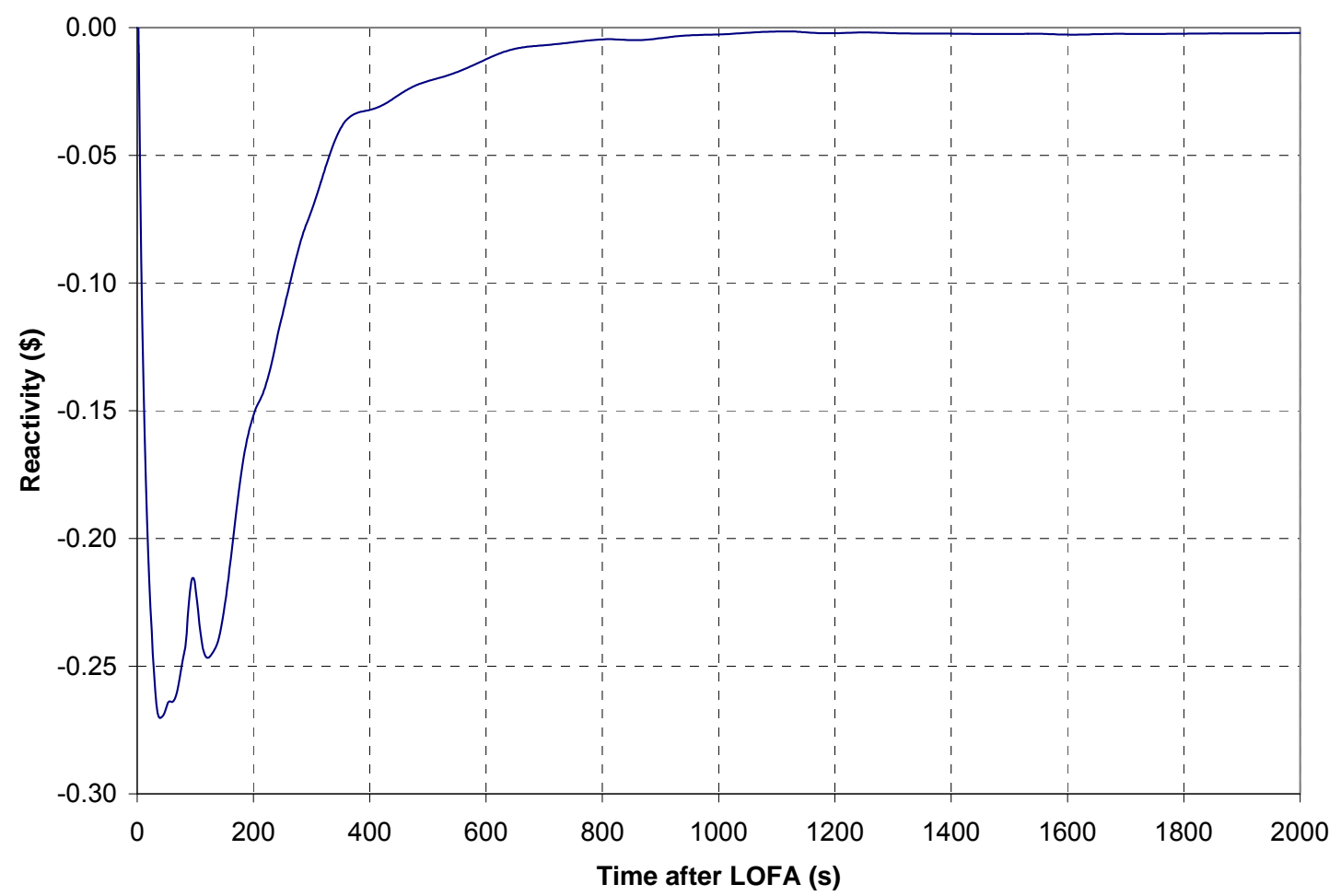

Figure 4.3.2-7 CR=0 reactivity response to a $L O F A$

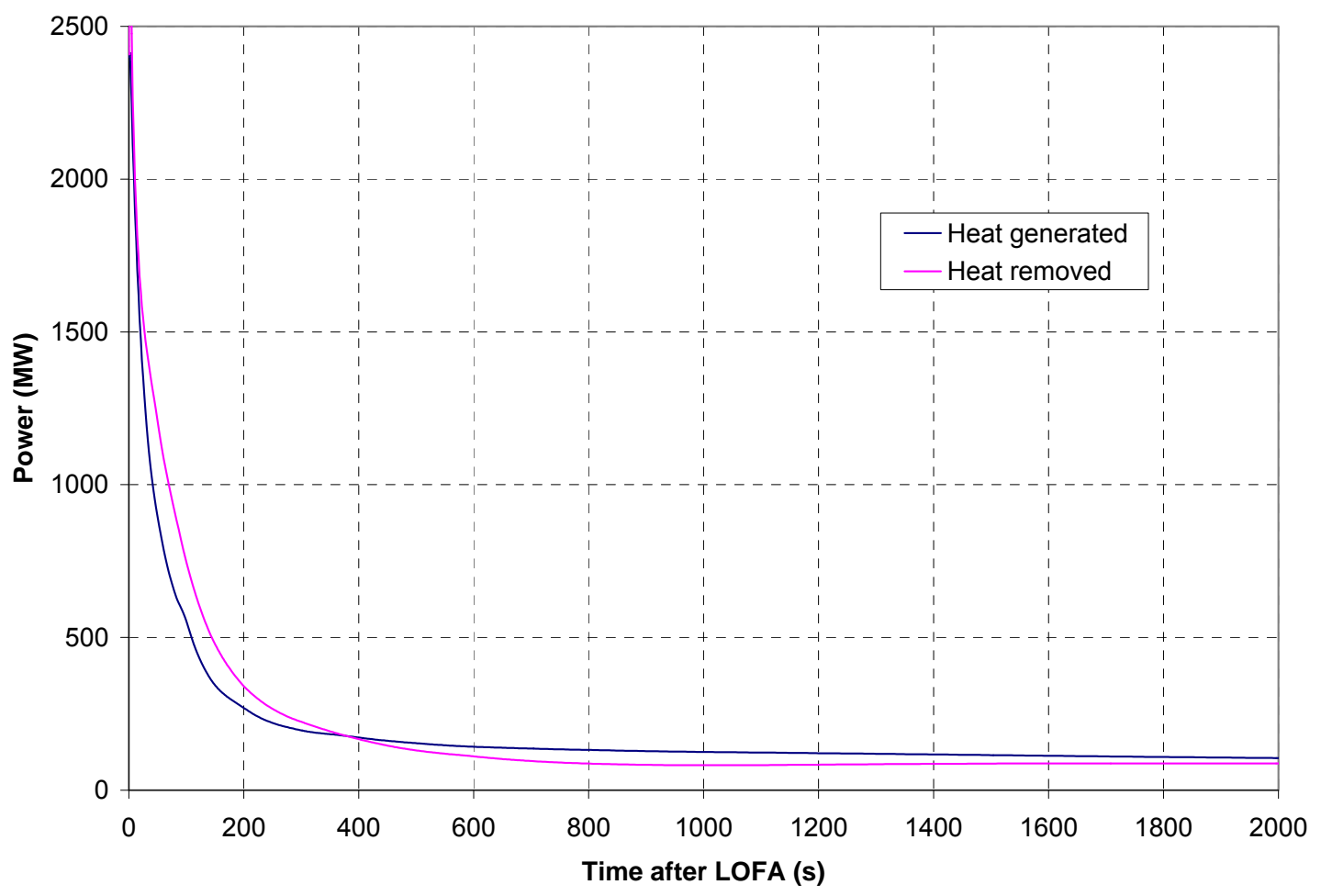

Figure 4.3.2-8 $\mathrm{CR}=0$ power response to a $\mathrm{LOFA}$ 


\subsection{Unprotected Transient Overpower}

Unlike for the SBO and LOFA transients, the $\mathrm{CR}=0$ reactor Unprotected Transient Overpower (UTOP) response is different from that for the $\mathrm{CR}=1$ core because the maximum control rod worth is higher for the $\mathrm{CR}=0$ design. Again, maximum rod worth is obtained by dividing the hot zero power excess reactivity by the number of control rod clusters, then multiplying by the assembly peaking factor squared. The specific values used are given in Table 4.3.2-2. The rate of reactivity withdrawal assumed is twice that of the $\mathrm{CR}=1$ core, corresponding to roughly the same linear speed. Results for the $\mathrm{CR}=0$ UTOP are given in Figures 4.3.2-9 through 4.3.2-11.

Table 4.3.2-2 $\mathrm{CR}=0$ maximum control rod worth

\begin{tabular}{|l|c|}
\hline k-effective (max) & 1.15 \\
\hline Excess reactivity (\$) & 43.770 \\
\hline HFP to HZP (\$) & 0.116 \\
\hline Maximum reactivity (\$) & 43.886 \\
\hline \# of CR clusters & 451 \\
\hline \$/cluster (x25 rods) & 0.097 \\
\hline Maximum peaking factor & 1.35 \\
\hline Maximum rod worth (\$) & 0.177 \\
\hline Rate of withdrawal (\$/s) & 0.01 \\
\hline
\end{tabular}

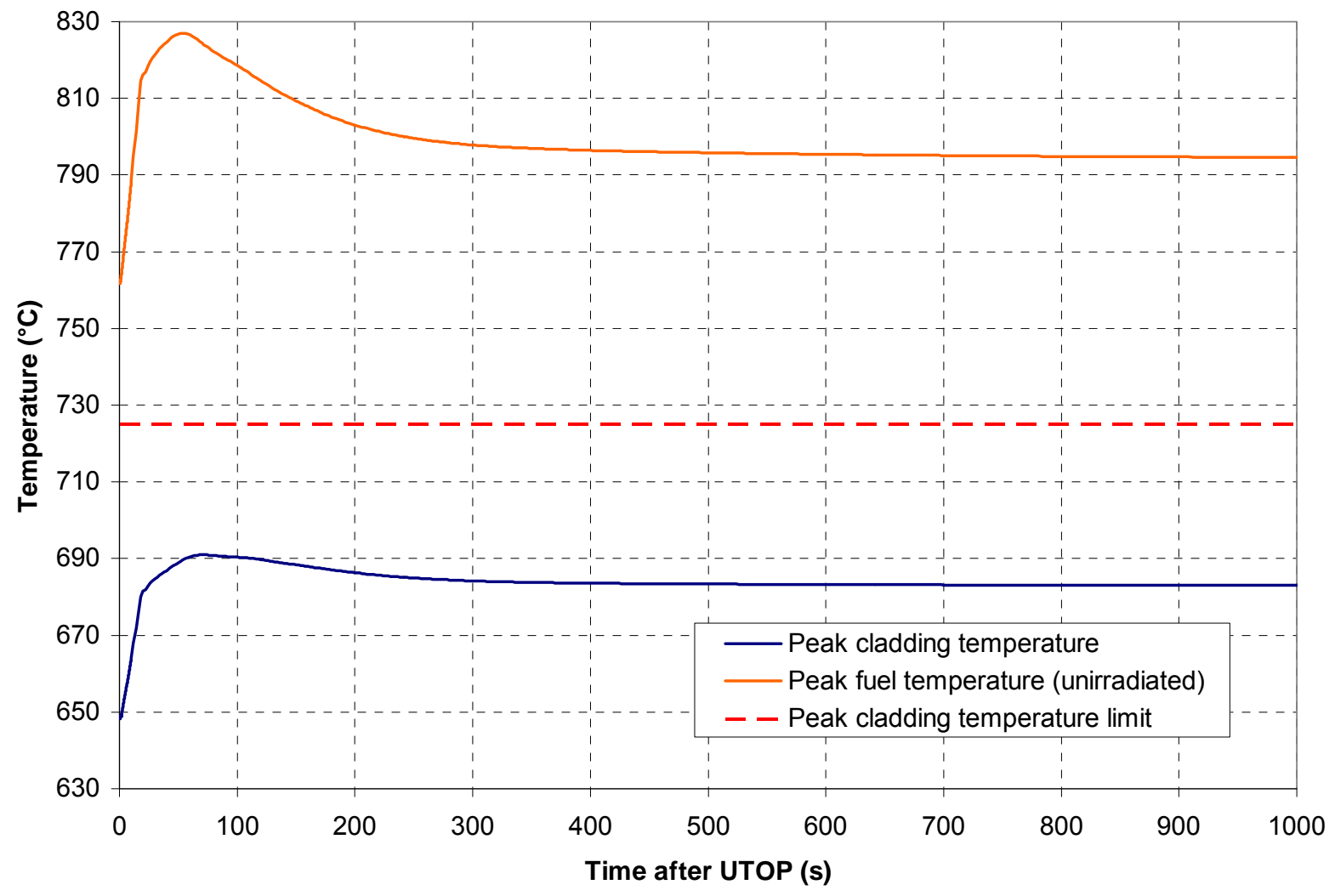

Figure 4.3.2-9 $\mathrm{CR}=0$ temperature response to a UTOP 
Project No 06-040: Flexible Conversion Ratio Fast Reactor Systems Evaluation

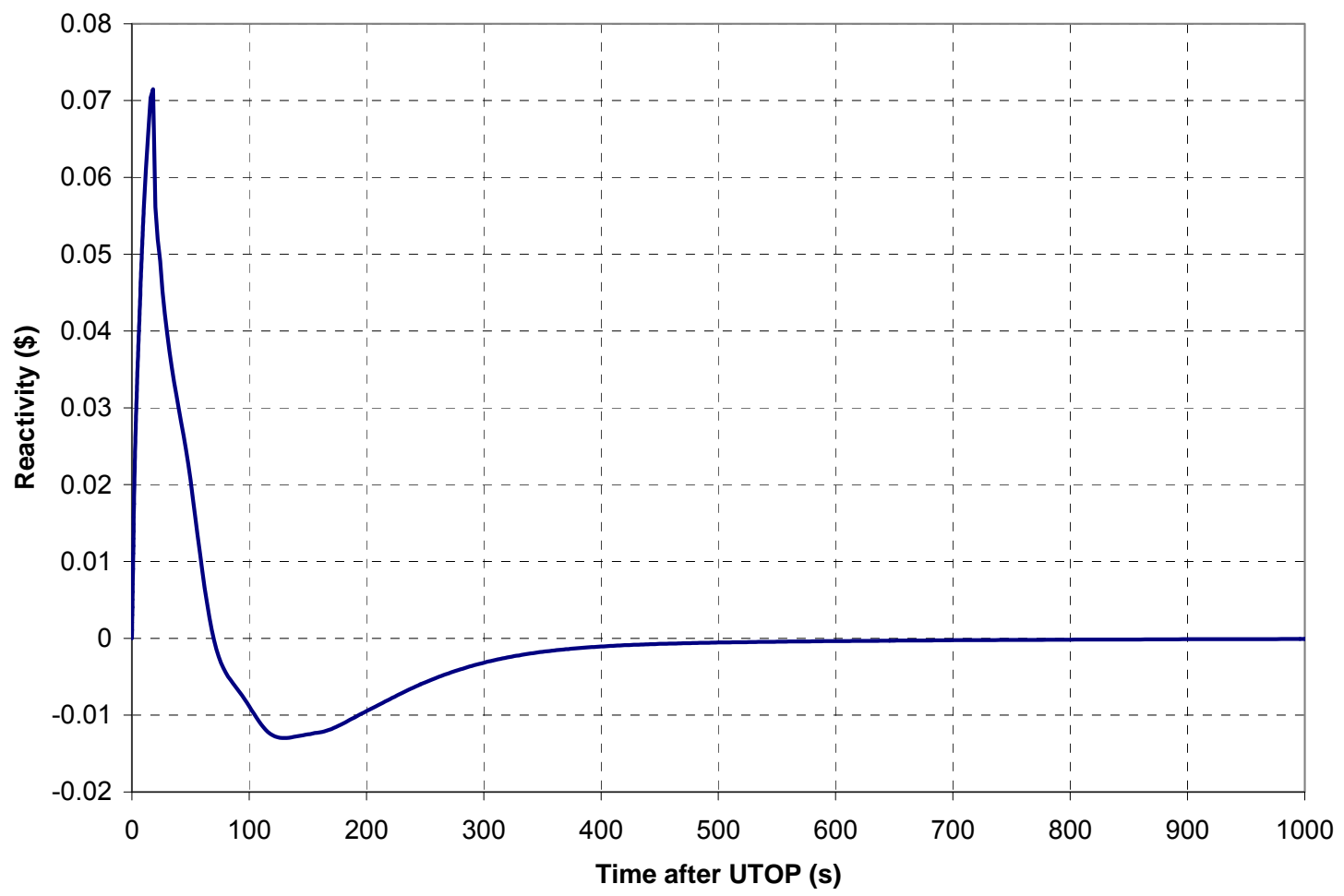

Figure 4.3.2-10 $\mathrm{CR}=0$ reactivity response to a UTOP

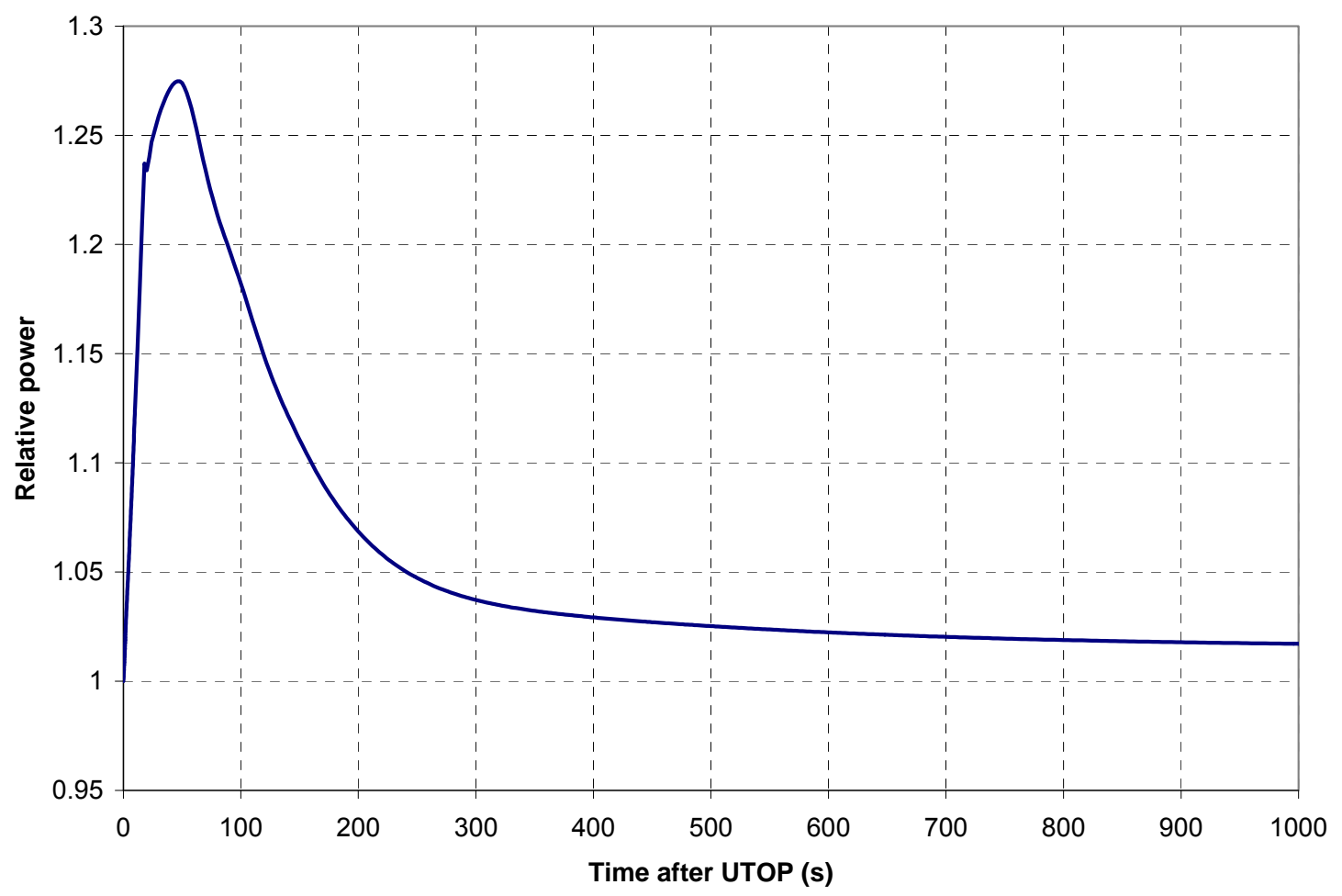

Figure 4.3.2-11 $\mathrm{CR}=0$ power response to a UTOP 
The $\mathrm{CR}=0$ response to a UTOP exhibits higher a maximum reactivity, power, and peak cladding temperature than the $\mathrm{CR}=1$ case. This is a result of the greater reactivity insertion for the $\mathrm{CR}=0$ UTOP. The maximum cladding temperature of $691{ }^{\circ} \mathrm{C}$ is below the $725^{\circ} \mathrm{C}$ transient limit, and the peak fuel temperature of $827^{\circ} \mathrm{C}$ is well below the fertile-free fuel temperature limit of $1200^{\circ} \mathrm{C}$. However, this result assumes a thermal conductivity value for unirradiated fuel; the degradation of thermal conductivity with irradiation introduces the possibility of fuel failure. However, repeating the same fuel performance calculation in Section 4.3.2-1 following Equation 4.3.2-1 with a $28 \%$ higher linear heat rate (from Figure 4.3.2-11) shows the maximum temperature rise between the cladding and the fuel is $1.28 * 320^{\circ} \mathrm{C}=410^{\circ} \mathrm{C}$. Adding this to the maximum cladding temperature of $691^{\circ} \mathrm{C}$ shows the maximum fuel temperature cannot exceed $1101^{\circ} \mathrm{C}$, which is below the $1200^{\circ} \mathrm{C}$ fuel failure limit. Therefore, there is no risk of cladding or fuel failure during an unprotected overpower.

\subsection{Protected Transients}

Figure 4.3.2-12 shows the $\mathrm{CR}=0$ reactor response to a protected transient with all four PSACS trains operating. Like the $\mathrm{CR}=1$ reactor, coolant freezing occurs very early (at $\sim 13.4$ hours) for the $100 \%$ PSACS power design. Freezing occurs more quickly for the $\mathrm{CR}=0$ core because it has lower decay heat than the $\mathrm{CR}=1$ core. Switching to the $60 \%$ power PSACS extends the coolant freezing time to over 69 hours. Since this value is less than 72 hours, the 72 hour transient mitigation criterion would not be satisfied if the PSACS tanks are too large; therefore there is a maximum limit on tank size that needs to be met to avoid coolant freezing. Based on the energy removed by the PSACS during these 69 hours, this maximum tank size was calculated to be $106 \%$ the size of the reference PSACS tanks. Since the reference PSACS tanks are below the minimum size that causes coolant freezing, the coolant freezing behavior seen at 69 hours in the $\mathrm{CR}=0$ case would never be encountered. With the actual reference PSACS system in place, it was calculated that the PSACS water tanks would be depleted at 64 hours, about five hours before coolant freezing would occur. This shows that there is some margin for sizing PSACS tanks so they can remove enough energy during an unprotected transient but not too much during a protected transient. The PSACS tanks of the reference design, 6 meters in diameter and 9 meters high (designated as $0.75 \mathrm{x}$ tank size in Table 2.2.3-2), are sufficient to meet both these criteria. 
Project No 06-040: Flexible Conversion Ratio Fast Reactor Systems Evaluation

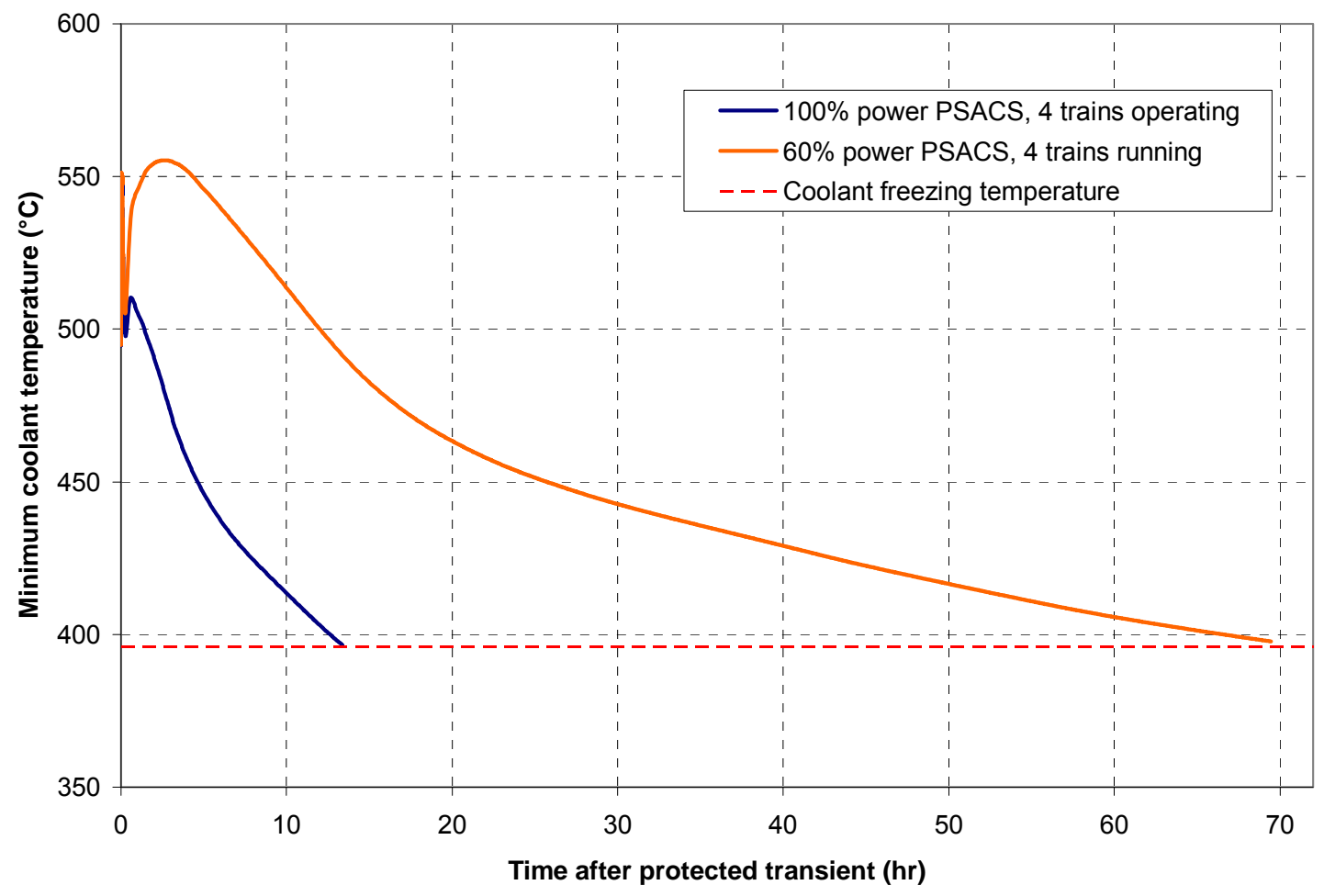

Figure 4.2.2-12 $\mathrm{CR}=0$ response to a protected transient

\subsection{Conclusions of Liquid Salt Reactor Studies}

Feasibility of the flexible conversion ratio molten salt-cooled reactor neutronic design was demonstrated based on the analysis of the two most challenging core options - zero and unity conversion ratios.

An extensive screening study aiming at the selection of the most promising molten salt coolant was performed taking into account both neutronic and thermal hydraulic properties. Ternary $\mathrm{NaCl}-\mathrm{KCl}-\mathrm{MgCl}_{2}$ (30-20-50mol.\%) salt was identified as the best candidate because of its relatively low melting point, low viscosity, low thermal expansion coefficient and low neutron moderating power.

The most challenging design objective to achieve for both $\mathrm{CR}=1$ and $\mathrm{CR}=0$ cores was assuring the cores self-controllability in the most restricting accident scenarios due to the fairly large positive Coolant Temperature Coefficient (CTC) of reactivity. A thorough investigation of different strategies to reduce the CTC to a desired range was performed. It was shown that a combination of some of these strategies can reduce the magnitude of CTC by over a factor of two. However, such reduction was still insufficient to satisfy the core self-controllability criteria.

As a result, the use of Lithium-6 thermal Expansion Modules (LEMs) for reduction of CTC was explored and proved to be very effective and flexible design feature. The desired reactivity 
feedback necessary to assure the core self-controllability was provided by adjusting the number and geometry of LEMs in the core.

The use of LEMs also allowed relaxing the restriction on coolant volume fraction in the core, which originally had to be minimized in order to reduce CTC. Opening the fuel lattice allowed, in turn, for significant increase in the core power density from the target value of 100 to 130 $\mathrm{W} / \mathrm{cm}^{3}$, while maintaining the same thermal margin.

Both $\mathrm{CR}=1$ and $\mathrm{CR}=0$ cores can be designed with fairly flat radial power distribution. In the $\mathrm{CR}=1$ core, this is achieved by variation of zirconium diluent fraction in different radial zones while maintaining constant TRU to HM ratio throughout the core. The $\mathrm{CR}=1$ core is designed as single-batch battery type system with very small excess reactivity. The fuel lifetime is limited by the peak cladding fast fluence and equals about 1800 EFPD with a corresponding core average discharge burnup of $80 \mathrm{MWd} / \mathrm{kg}$. The fuel cycle length and discharge burnup are very similar to those of the lead-cooled $\mathrm{CR}=1$ core design.

Simulation of 3 successive TRU re-cycles showed that a conversion ratio slightly higher than unity can be maintained with respect to total amount of TRU. The relative fraction of Pu in TRU was slightly growing and the fraction of MA decreasing with the number of re-cycles. The amount of recycled TRU was sufficient to maintain the original fuel cycle length in a sustainable manner with natural uranium feed only.

In the $\mathrm{CR}=0$ design, the power distribution is managed by using a multi-batch refueling strategy, which also helps to reduce the reactivity control requirements and achieve higher burnup. About $36 \%$ of TRU can be burned per pass in the totally fertile-free $\mathrm{CR}=0$ core operating in a 3-batch fuel management scheme and 550 EFPD fuel cycle.

Detailed calculation of decay heat following reactor shutdown for all studied cases showed significant differences between $\mathrm{CR}=0$ and $\mathrm{CR}=1$ core designs as well as relative to the standard LWR decay heat curve. As a result, the decay heat data calculated specifically for each design was used in the transient analysis with the RELAP code rather than the standard ANS decay heat curve.

In general, neutronic performance of salt-cooled $\mathrm{CR}=1$ and $\mathrm{CR}=0$ core designs is very similar to corresponding lead-cooled core designs.

Regarding thermal hydraulics, salt thermal hydraulic properties are inferior to those of liquid metals, owing to a very high viscosity and low thermal conductivities. A minimum coolant fraction is needed for a core to have a power density greater than $100 \mathrm{~kW} / \mathrm{l}$. However, this coolant fraction was incompatible with achieving acceptable reactivity coefficients. To reconcile this incompatibility, lithium expansion modules were introduced to improve reactivity coefficients and allow a higher coolant fraction. The higher coolant fraction allowed a $130 \mathrm{~kW} / 1$ power density design to be developed. Although this value is higher than that of the reference lead reactor, it does not translate to a smaller core or vessel because the salt reactor required peripheral reflector and shield assemblies as well as larger intermediate heat exchangers. A bottlenecked chimney was introduced to accommodate both these features without increasing the overall vessel size. The non-corrosiveness of liquid salt makes the use of compact printed circuit 
heat exchangers a possibility for reducing vessel size, but they were judged difficult to implement in the pool type design.

The poor heat transfer characteristics of liquid salt mean that for similar coolant temperatures, the cladding temperatures for a liquid salt system would be significantly higher than cladding temperatures for a liquid metal system. As a result, the liquid salt reactor displays a smaller margin to the cladding temperature limit at steady state as well as higher peak cladding temperatures during transient scenarios. However, due to the use of LEMs, the reactivity response of the salt reactor to transients is very good, and overall transient performance is acceptable. The short term response to SBO and LOFA transients is worse than that for the lead reactor but still unlikely to result in fuel failure. Meanwhile, the long term responses to these transients are similar to those for the lead reactor, but require different PSACS sizing. Because of a smaller CTC due to the use of LEMs in the LSFR and because of a smaller margin to freezing, the LSFR PSACS requires significantly smaller tanks and heat exchangers than the LFR. It has been shown that the proposed design can accommodate both the unprotected and protected SBO with margin. Figure 4.4-1 summarizes the combinations of limiting conditions for the SBO accident (P4 stand for protected SBO with 4 PSACS trains and U2 stand for unprotected SBO with 2 PSACS trains). Performance following a UTOP is also very good due to the strong reactivity feedbacks.

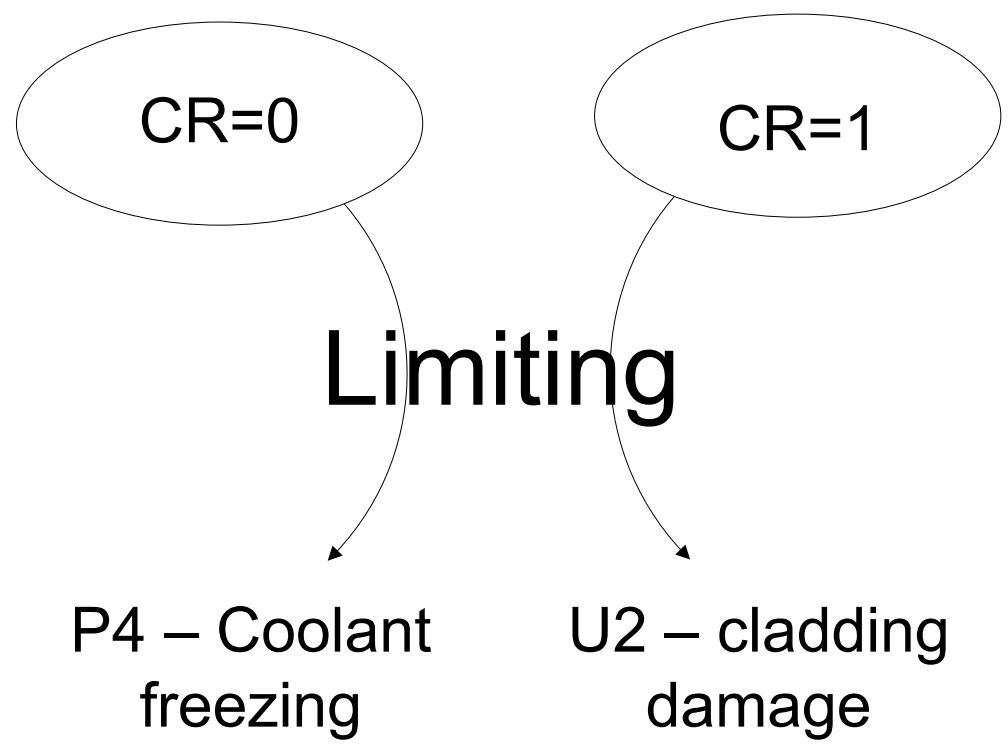

Figure 4.4-1 Limiting conditions for SBO accfident.

Continued development of liquid salt-cooled reactor concepts will require addressing some of the uncertainties associated with liquid salt thermal hydraulics. Salt properties for many candidate coolant salts are not available. Heat transfer for high Prandtl number fluids in a wire-wrap geometry has also not been studied, which has important implications for a liquid salt reactor because film temperature rises are very significant. Also, heat transfer for transition and laminar flow needs to be better understood to properly characterize salt reactor performance during loss of flow conditions. 
Project No 06-040: Flexible Conversion Ratio Fast Reactor Systems Evaluation

\subsection{References for Chapter 4}

ASME, "Boiler \& Pressure Vessel Code. An International Code. Section III, Division 1, Subsection NH (Class 1 Components in Elevated Temperature Service)." ASME, 2001.

Chang Y.I., "Technical Rationale for Metal Fuel in Fast Reactors", Nuclear Engineering and Technology, Vol. 39, pp. 161-170, June 2007.

Cheng S. K. and Todreas N. E., "Hydrodynamic Models and Correlations for Bare and Wirewrapped Hexagonal Rod Bundles - Bundle Friction Factors, Subchannel Friction Factors and Mixing Parameters," Nuclear Engineering and Design, v 92, n 2, Apr, 1986, p 227-251.

Forsberg C. W., Private communication, April, 2007.

Lee B. O., Park W.S., Kim Y., Song T.Y., "The Preliminary Performance of the Transmutation Fuel for HYPER," $8^{\text {th }}$ Information Exchange Meeting on Actinide and Fission Product partitioning and Transmutation, Las Vegas, NV, 9-11 November, 2004.

Meyer M.K., Idaho National laboratory, Private communication, March 27, 2007

Janz G. J., Molten Salts Handbook, Academic Press, NY, 1967

Kambe, M. and Uotani, M. "Design and development of fast breeder reactor passive reactivity control systems: LEM and LIM,” Nucl. Technol., 122, 179, May 1998.

Polyakov P. V. and Gildebrandt E. M., "Investigation of Thermal-Conductivity of Melts of System KCl-MgCl2," High Temperature 12(4), 780-781 (1974)

Raseman C. J., Susskind H., Farber G., McNulty W. E., and Salzano F. J., Engineering Experience at Brookhaven National Laboratory in Handling Fused Chloride Salts, BNL-627, T192, Brookhaven National Laboratory, Brookhaven, NY (1960).

Susskind et al., "Corrosion Studies for a Fused Salt-Liquid Metal Extraction Process for the Liquid Metal Fuel Reactor”, BNL-585, 1960.

Taylor I.N. and Wadekamper D.C., "Tolerant Metal Fuel/Cladding Barrier and Related Method of Installation", U.S. Patent \#5,301,218, April 5 , 1994.

Todreas N.E., Hejzlar P., Shwageraus E., Petroski R., Nikiforova A., and Whitman J., "Flexible Conversion Ratio Fast Reactor Systems Evaluations", $3{ }^{\text {rd }}$ Quarterly report, Center for Advanced Nuclear Energy Systems, MIT, MIT-NFC-PR-090, January 2007.

Wade D.C., Wigeland R.A., Hill D.J., "The Safety of the IFR”, Progress in Nuclear Energy, Vol. 31, No. 1/2, pp. 63-82, 1997 
Project No 06-040: Flexible Conversion Ratio Fast Reactor Systems Evaluation

Wade, D.C. and Chang, Y.I., "The Integral Fast Reactor Concept: Physics of Operation and Safety", Nuclear Science and Engineering, 100, 507-524, 1988.

Williams D.F., Toth L.M. and Clarno K.T., "Assessment of Candidate Molten Salt Coolants for the Advanced High-Temperature Reactor (AHTR)," ORNL/TM-2006/12, March 2006a.

Williams D.F. and Toth L.M., "Assessment of Candidate Molten Salt Coolants for the NGNP/NHI Heat Transfer Loop,” ORNL/TM-2006/69, June 2006b. 


\section{Cross Comparison of Various Designs}

This chapter compares the lead-cooled and liquid salt-cooled reactor concepts studied in this project with two other fast reactor concepts proposed in the GEN-IV program roadmap: those cooled by sodium (SFR) and those cooled by gas (GFR).

\subsection{Design Descriptions}

\subsubsection{Selection of Representative Designs for Comparison}

Specific reactor designs selected for the comparison are all power reactors of the same rating 2400MWt. The designs to be compared are:

1. A gas-cooled fast reactor (GFR) with unity conversion ratio developed at MIT under a NERI project [Handwerk et al., 2006, 2007],

2. An uprated version of a sodium-cooled Actinide Burning Reactor (ABR), designated SFR in this chapter, based on an ANL 1000MWt design [Hoffman et al., 2006],

3. A lead-cooled fast reactor with flexible conversion ratio (LFR), developed in this project under Task 1, and

4. A liquid salt-cooled reactor with flexible conversion ratio (LSFR), developed under Task 2 of this project.

Although two GFR designs are under development, the Commissariat à l'Energie Atomique (CEA) helium cooled GFR concept and the MIT supercritical $\mathrm{CO}_{2}$ cooled concept reactor, only the latter will be used for comparison, since its data are more readily available and the same neutronic analysis methods and libraries were used for its design as for the two concepts in this study. For the SFR concept, a metallic fueled core was selected for consistency with the lead and salt-cooled fuel. The metallic fueled SFR concepts available are rated at $1000 \mathrm{MWt}$ (S-PRISM, ABR1000). For consistency, the 1000 MWt ABR concept developed at ANL [Hoffman et al., 2006] was taken as a starting point and the number of core assemblies was increased to achieve $2400 \mathrm{MWt}$ power rating. Further, the number of batches was changed from 3 to 1 and $\mathrm{Zr}$ weight fraction grading rather than enrichment grading was used, as for the LFR and LSFR cores. Full neutronic analysis of the $2400 \mathrm{MWt}$ SFR core was performed to obtain reactivity coefficients, power distribution and heavy metal mass balances. Core thermal hydraulics will be similar to the original ABR core because core temperature rise is preserved, core peaking is smaller than in the original design, and flow rate per fuel assembly is also preserved. Transient analysis including plant and decay heat removal (DHR) system design were beyond the scope of this project, but it is assumed that adequate DHR systems, using either enhanced RVACS and PSACS or DRACS, can be developed for the SFR. Because the GFR is designed only for $\mathrm{CR}=1$, the comparison will focus on the unity conversion ratio cases.

A general comparison of the reactor characteristics is provided in Table 5-1. Since the sodiumcooled SFR and GFR are not part of this project versus the LFR and LSFR, which were described in detail in Chapters 1 through 4, Sections 5.1.2 and 5.1.3 will provide brief descriptions of the GFR and the SFR, respectively. 
Table 5-1 Main characteristics of fast reactor concepts to be compared

\begin{tabular}{|c|c|c|c|c|}
\hline & GFR & SFR & LFR & LSFR \\
\hline Power rating (MWt) & 2400 & 2400 & 2400 & 2400 \\
\hline Fuel & (U-TRU-Be) $\mathrm{O}_{2}$ & U-TRU-Zr & U-TRU-Zr & U-TRU-Zr \\
\hline TRU enrichment (wt $\%$ ) & $16.6 \%$ & $15.2 \%$ & $16.7 \%$ & $15.7 \%$ \\
\hline Power density $(\mathrm{kW} / \mathrm{l})$ & 85.4 & 290 & 112 & 130 \\
\hline Specific power $(\mathrm{kW} / \mathrm{kg})$ & 20.7 & 64.8 & 44.7 & 35.0 \\
\hline Cycle length (Years) & 18 & 3.5 & 5.4 & 5.8 \\
\hline Discharge burnup (MWd/kg) & 140 & 72 & 77 & 67 \\
\hline Batch management & 1-batch & 1 batch & 1batch & 1batch \\
\hline Radial power peaking & 1.3 & 1.22 & 1.21 & 1.3 \\
\hline Fuel geometry & $\mathrm{TID}^{*} / \mathrm{HEX}$ & Pin/HEX & Pin/Square & Pin/HEX \\
\hline Fuel lattice P/D & $\mathrm{n} / \mathrm{a}$ & 1.08 & 1.3 & 1.19 \\
\hline Core active height $(\mathrm{m})$ & 1.54 & 1.02 & 1.3 & 1.3 \\
\hline Equivalent core diameter $(\mathrm{m})$ & 4.8 & 3.2 & 4.6 & 4.25 \\
\hline Active core volume $\left(\mathrm{m}^{3}\right)$ & 27.9 & 8.7 & 21.5 & 18.5 \\
\hline Vessel outer diameter $(\mathrm{m})$ & $11.5^{* *}$ & 10.2 & 10.2 & 10.2 \\
\hline Number of assemblies & 397 & 360 & 349 & 451 \\
\hline Number of pins per assembly & $265^{*}$ & 271 & $441 / 416$ & $390 / 372$ \\
\hline Primary system pressure (MPa) & 20 & 0.1 & 0.1 & 0.1 \\
\hline Coolant & $\mathrm{S}-\mathrm{CO}_{2}$ & Sodium & Lead & $\begin{array}{l}\mathrm{NaCl}-\mathrm{KCl}- \\
\mathrm{MgCl}_{2} \text { salt }\end{array}$ \\
\hline Core inlet temperature $\left({ }^{\circ} \mathrm{C}\right)$ & 485.5 & 371 & 479 & 496 \\
\hline Core outlet temperature $\left({ }^{\circ} \mathrm{C}\right)$ & 650 & 510 & 573 & 581 \\
\hline Core flow rate $(\mathrm{kg} / \mathrm{s})$ & 11,708 & 13,580 & 173,600 & 29,000 \\
\hline Cladding & ODS steel & HT-9 & T-91 & T-91 \\
\hline Peak cladding temperature $\left({ }^{\circ} \mathrm{C}\right)$ & 810 & $550^{*}$ & 614 & 650 \\
\hline Decay heat removal & Active/passive ${ }^{\dagger}$ & Passive RVACS & $\begin{array}{l}\text { Passive } \\
+ \text { ACS }^{\dagger \dagger}\end{array}$ & $\begin{array}{l}\text { Passive RVACS } \\
+\mathrm{ACS}^{\dagger \dagger}\end{array}$ \\
\hline Power conversion system & Direct S-CO & Rankine & Indirect S-CO & Indirect S-CO \\
\hline Reactor vessel & PCIV $^{*}$ & Pool type & Pool type & Pool type \\
\hline
\end{tabular}

* Tube-In-Duct design with coolant inside the tubes and fuel outside, therefore number of coolant holes is reported instead of number of pins for TID.

${ }^{* * *}$ Pre-stressed Cast Iron Vessel (PCIV)

${ }^{\dagger}$ Active with blowers backed up by natural circulation of $\mathrm{CO}_{2}$ at elevated containment pressure

${ }^{\dagger}$ Enhanced RVACS using dimples and perforated plate plus passive secondary auxiliary cooling system via natural circulation of $\mathrm{CO}_{2}$ through IHX to $\mathrm{HX}$ in the in-containment water storage tank

\subsubsection{Gas-Cooled Fast Reactor Brief Description}

The overall layout of the GFR plant is shown in Figure 5.1.2-1. The reactor core is cooled by supercritical $\mathrm{CO}_{2}$ at a pressure of $20 \mathrm{MPa}$ directly coupled to a $\mathrm{S}-\mathrm{CO}_{2}$ power cycle. The choice of direct cycle is based on economics; the thermodynamic efficiency gained by using a direct cycle versus a gas-to-gas indirect cycle is about $2 \%$, and the capital cost is also reduced by eliminating the need for heat exchange to secondary loops. Heat is removed by two Power Conversion System (PCS) loops rated at 600 MWe each. The PCS loop shown in Figure 5.1.2-1 is of earlier integral design. The newer design is of horizontal layout and has the same arrangement as shown in Figure 2.2.2-1 in Chapter 2. Having two PCS loops versus one allows individual loops to be isolated for maintenance, leak isolation, and part-load operations at high thermal efficiency. Each PCS module utilizes the Brayton recompression cycle with minimum and maximum temperatures of $32^{\circ} \mathrm{C}$ and $650^{\circ} \mathrm{C}$, respectively. Peak and minimum pressures in 
the system are 20 MPa and 7.69 MPa, respectively. Table 5.1.2-1 gives selected plant parameters for the direct $\mathrm{S}-\mathrm{CO}_{2}$ cooled GFR.

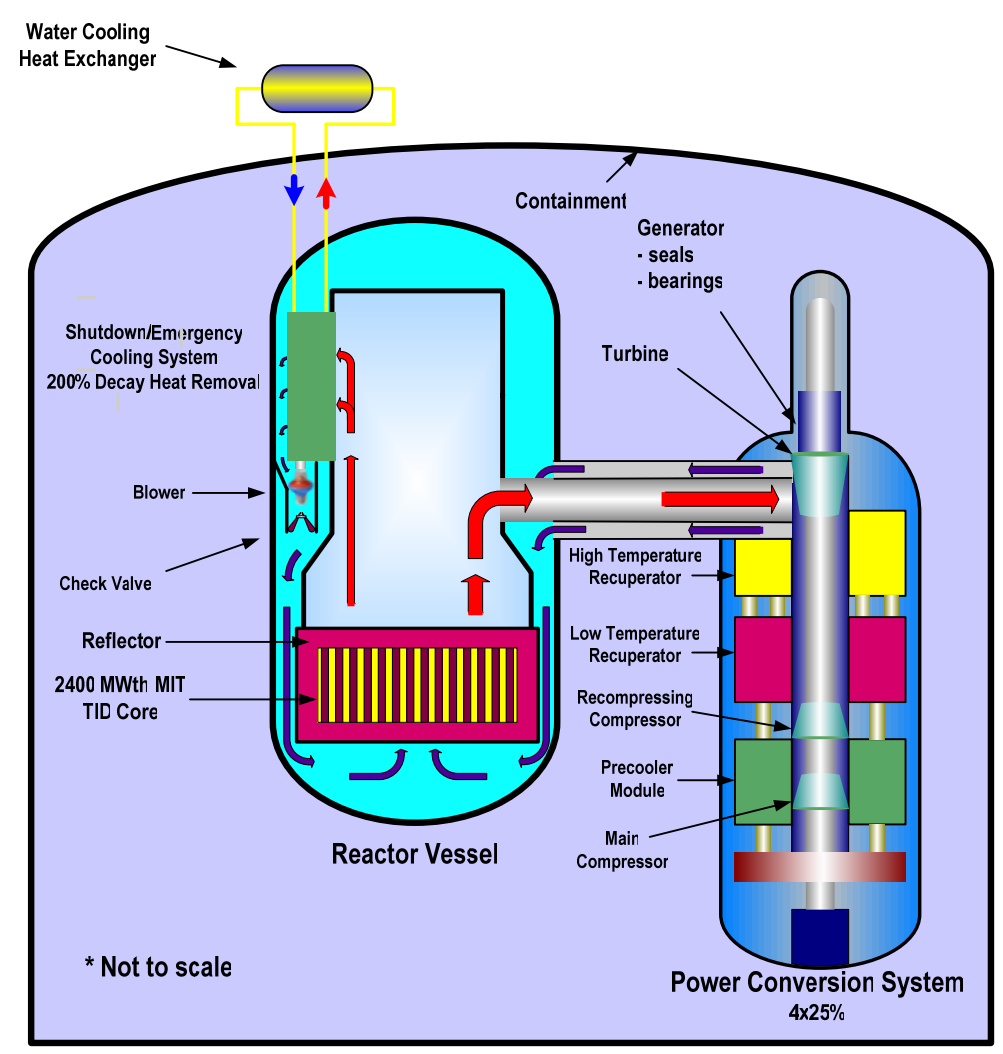

Figure 5.1.2-1. Layout of GFR plant with active SCS/ECS.

The GFR has a conversion ratio of unity and does not use any blankets for enhanced proliferation resistance. In the absence of blankets, a high fuel volume fraction (hence low coolant volume fraction) is necessary to boost the reactivity-limited burnup. The requirement for low coolant void reactivity also requires small coolant fraction. Furthermore, the requirement of fuel chemical stability with the $\mathrm{CO}_{2}$ coolant requires the use of oxide fuel, which has a relatively low heavy metal density and thus favors a high fuel volume fraction in the core. To satisfy these requirements, a low coolant volume fraction of $25 \%$ was selected.

If fuel were arranged in a hexagonal array of pins packed tightly enough to have $25 \%$ coolant by volume, the resulting wetted perimeter would cause an unacceptably high core pressure drop. A fuel pin arrangement was thus discarded in favor of "inverted" fuel geometry such as the prismatic block-type fuel found in a VHTR. In order to achieve high fuel volume fraction with inverted-geometry fuel elements which would not be corroded excessively by high-temperature $\mathrm{CO}_{2}$ and maintain structural integrity with burnup, a Tube-In-Duct (TID) fuel assembly was conceptualized. A TID fuel assembly consists of a hexagonal duct with coolant tubes inside. Fuel is placed around coolant tubes and inside the hexagonal duct. To keep stresses on the duct wall acceptable and to minimize duct thickness, the TID fuel assembly is vented. Figure 5.1.2-2 shows a horizontal cross-sectional view of a TID fuel assembly. Further detail on the conceptual design of the TID assemblies is given in Handwerk et al. [2006] and Pope et al. [2003]. 
$\mathrm{BeO}$ is specified for use as a diluent in the fuel for a number of reasons. If (U,TRU) $\mathrm{O}_{2}$ fuel were to be used without this diluent, the reactor would exhibit a large high positive coolant void reactivity (in excess of \$1). The radial power shape without diluent would change dramatically during a cycle and the reactivity swing would be very large, requiring a large number of highworth control rods. It has been shown that addition of $\mathrm{BeO}$ to the fuel matrix reduces coolant void reactivity and provides the means to flatten the radial power over a very long cycle. BeO also increases the critical enrichment which can lower the conversion ratio to just above unity, giving a relatively flat reactivity during the core life and also reducing the reactivity hold-down burden on the control rods. [Handwerk, et al., 2006] With an unusually high thermal conductivity for an oxide, $\mathrm{BeO}$ also has been shown to augment significantly the thermal conductivity of $\mathrm{UO}_{2}$ pellets. The $\mathrm{S}-\mathrm{CO}_{2}$ GFR employs 3 rows of $\mathrm{S}-\mathrm{CO}_{2}$ reflector, which upon loss of pressure increases leakage to yield, together with the $\mathrm{BeO}$ diluent effect on neutron spectrum, negative coolant void reactivity.

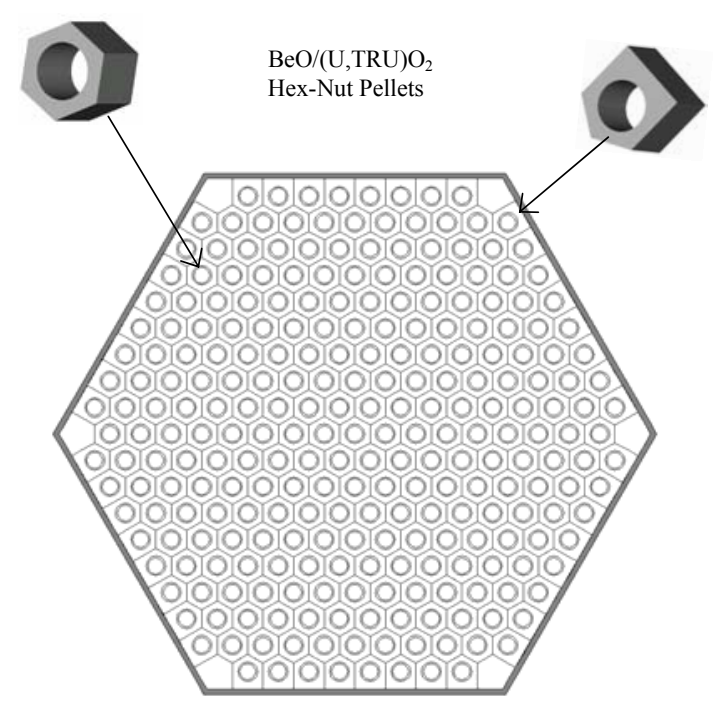

Figure 5.1-2-2. Horizontal cross-section view of TID fuel assembly.

Parametric studies were performed to determine the dimensions of the fuel assemblies and coolant channels which would meet goals of pressure drop, peak fuel temperature, and peak cladding temperature. Table 5.1.2-1 shows selected parameters of the core and TID fuel assemblies.

In Fig. 5.1.2-1, the basic arrangement of the shutdown/emergency cooling system (SCS/ECS) is depicted. This system consists of four sets of $\mathrm{CO}_{2}$-to-water heat exchangers attached to the upper portion of the reactor barrel. There are four separate loops, each capable of removing 50\% of the decay heat. This $4 \times 50 \%$ arrangement forms a 2-out-of-4 system where one SCS/ECS module (or loop) can be out of service for maintenance and a second loop can fail and sufficient decay heat removal is still provided by the two operational loops. This provides highly reliable decay heat removal in shutdown and postulated accident conditions.

In normal operation, the check valves are held shut by the core pressure drop, and $\mathrm{CO}_{2}$ in the SCS/ECS modules is nearly stagnant. During shutdown or emergency cooling, the check valves open, allowing $\mathrm{CO}_{2}$ to leave the upper part of the chimney and enter the printed circuit heat 
exchanger (PCHE) hot side, where it is cooled by a water loop. After leaving the heat exchanger, the $\mathrm{CO}_{2}$ would be circulated by blowers through the open check valves and would then return to the vessel downcomer. The water loop transfers heat from the $\mathrm{CO}_{2}$-to-water heat exchangers to a water/water heat exchanger which serves as the ultimate heat sink, a spray pond located outside of the containment.

Table 5.1.2-1. Selected parameters of TID assemblies and entire core (hot dimensions given in parentheses).

\begin{tabular}{|c|c|}
\hline Parameter (units) & Value \\
\hline \multicolumn{2}{|l|}{ Coolant Channels } \\
\hline Inner diameter (mm) & $7.0 \quad(6.93)$ \\
\hline Cladding thickness (mm) & 0.7 \\
\hline Outer diameter $(\mathrm{mm})$ & $8.4(8.32)$ \\
\hline Channel pitch (mm) & $13.3(13.21)$ \\
\hline Channel roughness (m) & $1 \times 10^{-5}$ \\
\hline Lower inactive length $(\mathrm{m})$ & $1.1 \quad(1.094)$ \\
\hline Active length (m) & $1.54(1.530)$ \\
\hline Upper inactive length $(\mathrm{m})$ & $1.0 \quad(0.992)$ \\
\hline \multicolumn{2}{|l|}{ Fuel Assembly Geometry } \\
\hline Fueled locations per assembly & 265 \\
\hline Unfueled locations per assembly (corners) & 6 \\
\hline Duct wall flat-to-flat inner dimension $(\mathrm{cm})$ & $22.3(22.1)$ \\
\hline Duct wall thickness (mm) & 2 \\
\hline Duct wall flat-to-flat outer dimension $(\mathrm{cm})$ & $22.7(22.5)$ \\
\hline \multicolumn{2}{|l|}{ Core Geometry } \\
\hline Inter-assembly spacing (mm) & $2.8 \quad(5.0)$ \\
\hline Fuel assemblies & 378 \\
\hline Control assemblies & 19 \\
\hline Reflector assembly locations & 234 \\
\hline Shielding assemblies & 288 \\
\hline Active core volume including control assemblies $\left(\mathrm{m}^{3}\right)$ & 28.0 \\
\hline Active core effective diameter (m) & 4.81 \\
\hline Active core H/D & 0.32 \\
\hline Active core area including control assemblies $\left(\mathrm{m}^{2}\right)$ & 18.2 \\
\hline Active core area excluding control assemblies $\left(\mathrm{m}^{2}\right)$ & 17.3 \\
\hline \multicolumn{2}{|l|}{ Area Fractions (neglecting control assemblies) } \\
\hline Coolant flow area $(\%)$ & 24.7 \\
\hline Coolant in channels $(\%)$ & 22.3 \\
\hline Coolant in inter-assembly gaps (\%) & 2.4 \\
\hline Steel $(\%)$ & 13.2 \\
\hline Steel in coolant channel cladding (\%) & 9.8 \\
\hline Steel in duct walls $(\%)$ & 3.4 \\
\hline Fuel $(\%)$ & 59.6 \\
\hline Corner locations for vent tubes or lifting lugs $(\%)$ & 2.5 \\
\hline
\end{tabular}

Although it is possible to design a S-CO $\mathrm{CO}_{2}$ cooled GFR that can survive LOCA by cooling the core through naturally circulating loops between the core and elevated emergency cooling heat 
exchangers, it is not an attractive approach because of various bypass paths that can, depending on break location, degrade core cooling. Moreover, natural circulation gas loops can operate in deteriorated heat transfer regimes with a substantial reduction of the heat transfer coefficient as low as $30 \%$ of forced convection values - and data and correlations in these regimes carry large uncertainties [Lee et al., 2008]. Therefore, reliable battery powered blowers for post-LOCA decay heat removal (DHR) were selected which provide flow in well defined regimes with low uncertainty and can be easily over-designed to accommodate bypass flows. The results confirmed that a GFR with such a DHR system and negative coolant void worth can withstand LOCA with and without scram as well as loss of electrical load without exceeding core temperature and turbomachinery overspeed limits.

\subsubsection{Sodium-Cooled Fast Reactor Brief Description}

The design of the sodium-cooled $2400 \mathrm{MWt}$ reactor concept is beyond the scope of this project. Hence, the $2400 \mathrm{MWt}$ sodium-cooled plant sizing and layout was not carried out except for the conceptual core design. The core configuration is based on an ANL $1000 \mathrm{MWt}$ metallic fueled core design [Hoffman et al., 2006]. It employs 360 hexagonal assemblies, each having 271 fuel pins with the total number of fuel pins in the core significantly smaller than the salt or leadcooled designs. The pressure drop through the active core is relatively small, on the order of 0.2 $\mathrm{MPa}$. The operating temperatures were calculated for a typical design of a sodium core, but with the development of advanced materials for cladding and structural components there is the potential to raise the operating temperatures and achieve higher plant efficiency. A detailed description of core neutronic design and thermal hydraulic subchannel analysis is provided in Appendix 5A.

The ANL design is based on the S-PRISM $1000 \mathrm{MWt}$ design, which is described in Boardman et al. [2000]. Figure 5.1.3-1 shows the schematic of the S-PRISM with main power train and heat removal systems. It employs a safety grade auxiliary cooling system (ACS) via natural circulation of air past the shell of steam generator and safety-grade RVACS as decay heat removal systems. One main difference between the salt/lead and sodium reactors is the chemical reaction of sodium with water, air, and $\mathrm{CO}_{2}$ gas. Therefore, S-PRISM, as well as most sodium reactors, uses an intermediate cooling loop in order to avoid the consequences of such reactions in the primary system as well as steam ingress into the core.

There are two key questions that remain unanswered:

1. Can a sodium plant be designed in a more compact configuration coupled to the $\mathrm{S}-\mathrm{CO}_{2}$ power cycle similar to that for lead/salt-cooled designs in this project? Since $\mathrm{CO}_{2}$ also reacts with sodium, although at a slower rate than water, and does not produce hydrogen, the sodium $/ \mathrm{CO}_{2} \mathrm{IHX}$ would have to be designed with double walls with helium detection for leaks in between the walls. Double wall steam generators were developed in Japan [Kubo et al., 1997], and Westinghouse and Toshiba proposed such steam generators for their actinide recycling reactor for the GNEP program. Therefore, it is not out of the question to consider the placement of IHXs in the annular space between the core barrel and the vessel liner in a similar manner as for lead and salt designs. The double free level reactor vessel design as proposed in this project would also eliminate the potential of high pressure gas ingress into the core. The feasibility of fitting four $600 \mathrm{MWt}$ double-wall IHXs into a sodium vessel of $10.2 \mathrm{~m}$ would have to be confirmed. However, because the 
helium gap is $7 \mu \mathrm{m}$, having an effective thermal conductivity of the gap plus outer wall of $24 \mathrm{~W} / \mathrm{mK}$ per the experimental measurements of Kubo et al. [1997], the double-wall design does not require a large increase of IHX volume. This increase can be compensated by the much higher sodium conductivity than lead or salt and more space available due to the smaller sodium-cooled core. Hence, it is expected that placement of sodium/ $\mathrm{CO}_{2}$ IHXs in the $2400 \mathrm{MWt}$ vessel will be feasible.

2. Can a $2400 \mathrm{MWt}$ core be cooled by passive decay heat removal means? Use of an enhanced RVACS as in the lead and salt-cooled reactors could be also be adopted for the sodium-cooled reactor. The PSACS design coupling the primary coolant to PSACS water tanks via a double-wall IHX can also be used. Overall, if the double-wall IHX can be proven reliable, it is expected that the proposed RVACS/PSACS approach could also be used for passive decay heat removal for the 2400MWt sodium-cooled reactor.

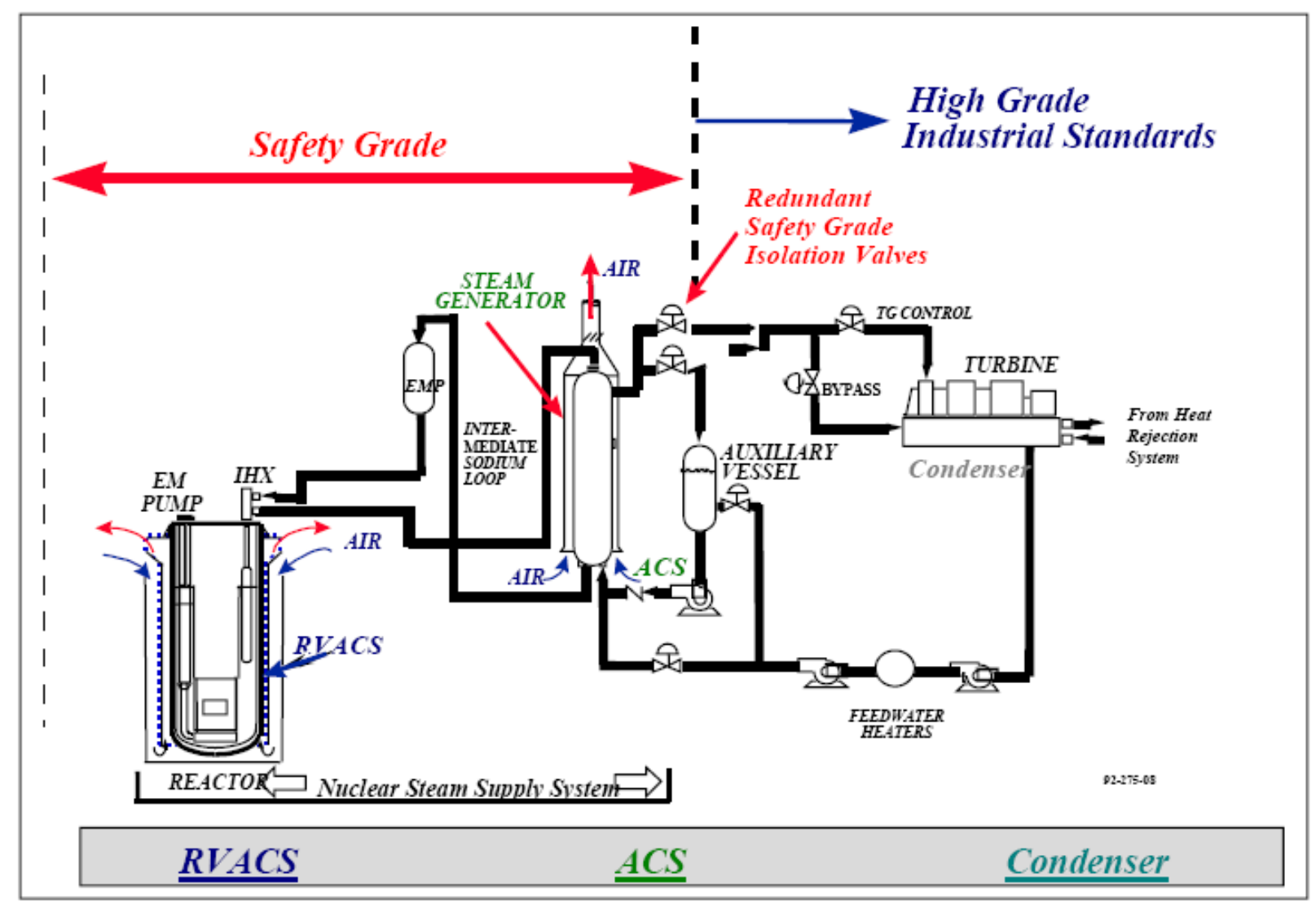

Figure 5.1.3-1 Schematic of main power train and heat removal for S-PRISM (from Boardman et al., 2000)

\subsection{Comparison Goals and Overall Results}

The Generation IV Roadmap established design goals that future reactor designs should strive to achieve [GIF, 2002]. These goals involve:

- $\quad$ Sustainability - "Generation IV nuclear energy systems will provide sustainable energy generation that meets clean air objectives and promotes long-term availability of systems and effective fuel utilization for worldwide energy production. Generation IV 
nuclear energy systems will also minimize and manage their nuclear waste and notably reduce the long-term stewardship burden, thereby improving protection for the public health and the environment."

- $\quad$ Safety and Reliability - "Generation IV nuclear energy systems operations will excel in safety and reliability and will have a very low likelihood and degree of reactor core damage during any possible accident."

- $\quad$ Economics - "Generation IV nuclear energy systems will have a clear life-cycle cost advantage over other energy sources and will have a level of financial risk comparable to other energy projects."

- $\quad$ Proliferation Resistance and Physical Security - "Generation IV nuclear energy systems will increase the assurance that they are a very unattractive and the least desirable route for diversion or theft of weapons-usable materials, and provide increased physical protection against acts of terrorism."

Within this broad set of goals, our comparison will focus primarily on economics and safety. This is because all the four systems to be compared within this project are fast reactors, all of which rank high for the sustainability goal since their $\mathrm{CR}=1$ cores have high uranium resource utilization and can not only manage their own nuclear waste but also reduce the long-term stewardship burden by depleting legacy TRU from spent LWR fuel. Nevertheless we would like to point out some important points with respect to sustainability. But because all reactor concepts have a similar performance in this respect, we will focus our comparison on the $\mathrm{CR}=1$ and $\mathrm{CR}=0$ core performance.

First, it may be surprising that both the $\mathrm{CR}=0$ and $\mathrm{CR}=1$ cores can reduce the stockpile of spent LWR fuel at about the same time, although a smaller number of $\mathrm{CR}=0$ reactors would be needed. This can be observed from "Interim Storage" curves in Figure 5.2-1, which plot distribution of TRU inventories in the U.S. over the next hundred years and under the assumption of nuclear energy growing at a $2.4 \%$ annual rate, assuming that reprocessing and fast reactors become available by 2040 . The results were obtained using the system simulation code developed at MIT, CAFCA II [Acquien et al., 2006]. In Figure 5.2-1, cooling storage curves depict TRU undergoing cooling in spent fuel pools of both LWRs and FRs, interim storage signifies TRU that is cooled enough and available for reprocessing, and LWR cores and FR cores show the amount of TRU in the LWRs cores and FR cores, respectively. In spite of the fact that the net TRU destruction in the $C R=1$ core is zero while $C R=0$ is a pure TRU burner, both the $C R=0$ and $\mathrm{CR}=1$ strategies deplete the legacy TRU at about 2070. This is because electricity growth demand is assumed to be preferentially satisfied by the fast reactor buildup if TRU is available, and new fast reactors require significant TRU loading for their first cores. As a result the TRU legacy is depleted and the construction rate of new fast reactors is limited after 2070 to available TRUs. The main difference between the $\mathrm{CR}=0$ and $\mathrm{CR}=1$ core designs is in the number of fast reactors that need to be built to produce TRU distribution curves in Figure 5.2-1 - 150 $1000 \mathrm{MWe} C R=1$ reactors versus $231000 \mathrm{MWe} C R=0$ reactors would be operating by 2070 .

Secondly, the $C R=1$ cores use uranium resources much more effectively than the $C R=0$ cores. Since $C R=1$ cores manage the uranium resources more effectively than $C R=0$ cores and can still manage legacy TRU, they rank higher than the $\mathrm{CR}=0$ cores in the sustainability goal. However, because a large number of either $\mathrm{CR}=1$ or $\mathrm{CR}=0$ reactors is needed to accomplish TRU management, it is critical that their cost become competitive with that of LWRs in order to be 
preferred by utilities. Hence, attractive fast reactor economics needs to be a major effort in the design of future systems.

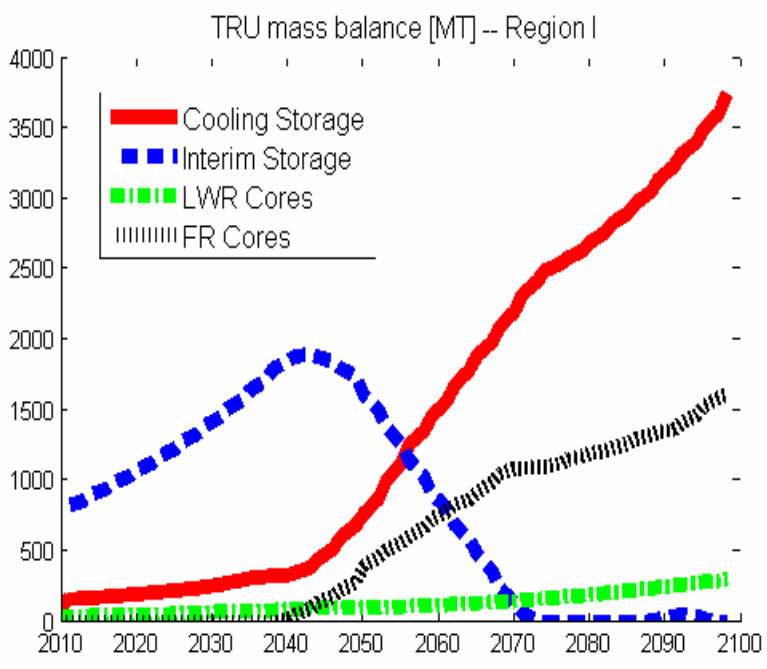

$\mathrm{CR}=0$ Reactor

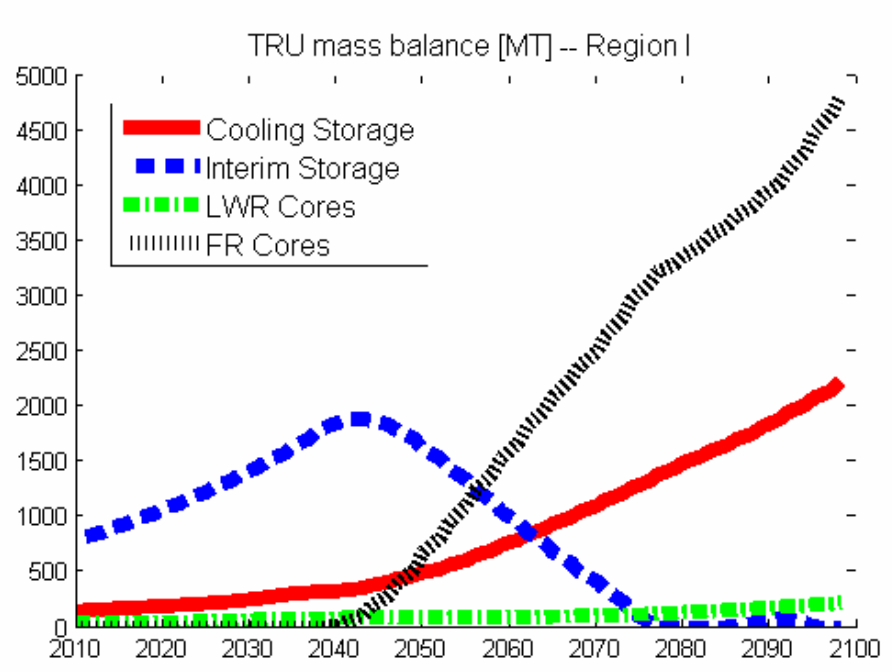

$\mathrm{CR}=1$ Reactor

Figure 5.2-1 Comparison of U.S. TRU inventories for recycling in $\mathrm{CR}=0$ and $\mathrm{CR}=1$ reactors (from Acquien et al., 2006)

Regarding the proliferation goal, all fast reactors considered in this comparison do not use separated plutonium and do not employ blankets to avoid high-grade plutonium generation in the fuel. In fact, the conceptual design of these reactors has been carried out with these goals embedded in the process. As discussed in section 5.3.1, neutron spectra among the different cores are also similar. Hence the plutonium isotopic vectors in the spent FR fuel will also be similar. Therefore, all designs of the same conversion ratio will have similar intrinsic proliferation resistance characteristics: the differences will stem from protective measures implemented throughout the entire fuel cycle, which is beyond the scope of this project.

The major comparison discussion will thus focus on economics and safety goals, which will be discussed in the following subsections. Detailed comparisons of neutronics parameters, coolant comparison, and thermal hydraulic aspects will be given in Sections 5.3.1 through 5.3.3.

\subsubsection{Economics}

If fast reactors are to make a significant impact on energy generation, resource utilization, and TRU management to reduce long-lived waste sent to a repository, large-scale deployment of fast reactors will be needed in the future, as was also revealed by the system-wide CAFCA II simulation above. This will be possible only if these reactors are economically attractive in comparison with LWRs and other power generation alternatives. Thus, in addition to excellent safety and sustainability, substantial cost reduction becomes a major goal of future nuclear system development. 
Today's capital investment to build a nuclear power plant is typically $60 \%$ of electricity generation cost, with fuel cost at $20 \%$ and operation and maintenance (O\&M) cost incurring the remaining 20\%. Since the capital investment cost constitutes the largest share of generation cost, its reduction is of prime interest for the Generation IV plants. The need to reduce capital cost of nuclear power plants has been recognized, and there has been continuous effort for the last two decades. Measures include reliance on passive safety for emergency cooling, which allows reduction or elimination of complex and redundant safety grade equipment, design simplification, modularization, standardization, reduced construction schedule, multiple unit construction, new construction techniques (e.g., open top access, modularization, slip-forming, prefabrication, parallel construction, improved cabling and instrumentation), and taking advantage of economy of scale. More details on various approaches to reduce the capital cost of nuclear plants are given in OECD [2000].

\section{Economy of Scale}

Cost reduction is even more important for fast reactors, which are known to be more expensive than LWRs. One approach that has proven to reduce cost is economy of scale. Development of the Japanese Sodium-cooled Fast Reactor (JFSR) design, with thorough economic studies, has shown that an increase from $660 \mathrm{MWe}$ to $1500 \mathrm{MWe}$ resulted in the largest reduction of cost per installed kWe among other approaches, which involved introduction of various innovative technologies and simplifications [Okada, 2008]. Therefore, a large power rating of $2400 \mathrm{MWt}$ was pursued for all fast reactor concepts in this project rather than small modular reactors. In this respect, all four reactor designs should benefit from economy of scale in the same manner.

\section{Plant Thermal Efficiency}

The second key factor affecting capital cost per installed kWe is plant thermal efficiency. Thus far, the major focus in the initiative for better economy of advanced nuclear power plants has been on the nuclear island, and a classical Rankine power cycle has been used as the balance of plant (BOP). However, the design improvements and simplifications of the nuclear island have only limited potential with respect to the reduction of capital cost, and thus generation cost. Figure 5.2-2 [Hejzlar et al., 2006] shows the capital investment decomposition of a typical advanced LWR per data (since reliable commercial fast reactor data are not available) in OECD [2000]. The direct costs include reactor plant equipment (designated "Reactor" in Figure 5.2-2) and turbine plant equipment (designated "Turbine"), electrical plant equipment ("Electrical") and the rest direct costs (land and land rights, main construction heat rejection system, and miscellaneous plant equipment and construction services). Indirect costs consist of design and engineering and project management. Finally, other costs involve owner's cost, spare parts, initial fuel costs, and contingencies.

In the leftmost column of Figure 5.2-2, the reactor plant equipment clearly constitutes only a small fraction of the total specific overnight cost. Therefore, even large savings on the nuclear island through innovative designs cannot provide substantial reduction of specific cost, as shown on the middle column of Figure 5.2-2, where one can observe that a 50\% smaller cost of reactor plant equipment will lead to only $9 \%$ overnight cost reduction. 


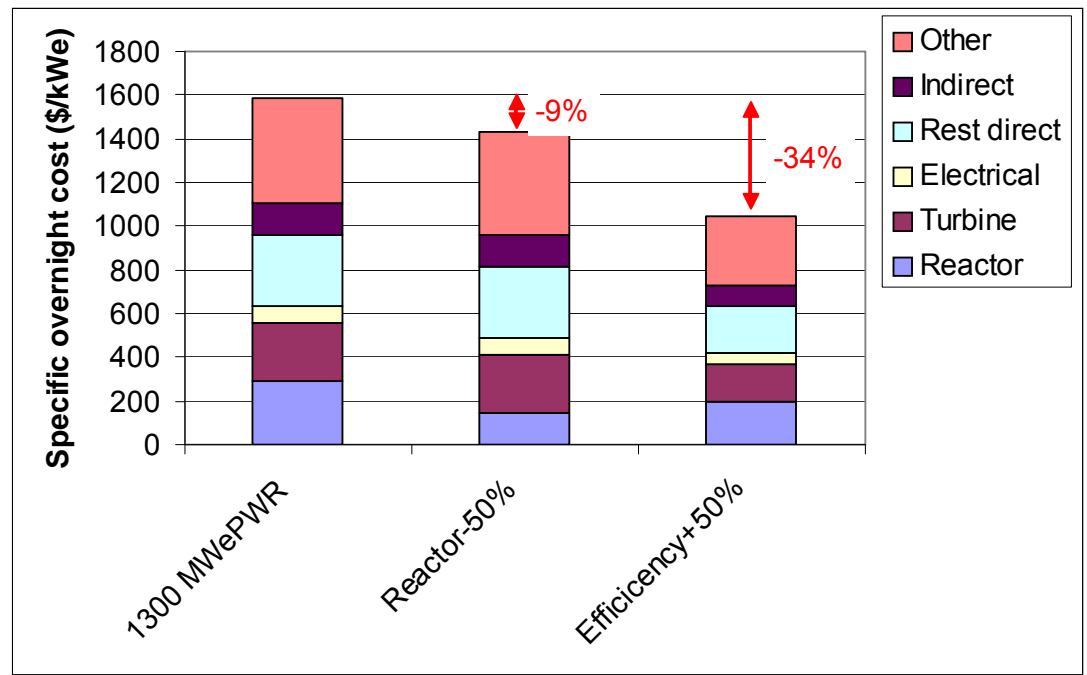

Figure 5.2-2 Capital cost investment decomposition for typical evolutionary ALWR (data from OECD, 2000)

The cost of turbine plant equipment is also a relatively small fraction of the overall capital cost: thus the potential of generation cost reduction through lower BOP capital cost is limited as well. However, advances in the power conversion system can lead to a higher plant thermal efficiency and thus affect all components of the overall specific overnight cost. This is shown in the right column, where plant efficiency was increased by $50 \%$, i.e., from the current $34 \%$ to $50 \%$. Figure $5.2-2$ shows that a $50 \%$ efficiency increase can reduce specific overnight cost by $34 \%$, which is nearly four times more than the $9 \%$ achieved by lowering the cost of reactor plant equipment by $50 \%$. This is primarily because increased power cycle efficiency increases net electrical power and thus leads to a reduction of capital costs of all plant components, including indirect costs, on a per MWe basis. Therefore, if future fast reactors are to be highly competitive with LWRs and other electricity generating stations, the development of fast reactors must pursue higher plant thermal efficiency.

To increase plant efficiency, a number of design strategies can be used. The key strategies involve:

- Use of advanced materials having high allowable stresses and low creep at high temperatures, as well as good corrosion resistance,

- Maximization of core-average outlet temperatures through low radial peaking design and use of orificing,

- Minimization of temperature difference between the core outlet and turbine inlet by use of effective heat exchangers and minimization of heat transfer loops, and

- Use of highly efficient advanced power conversion systems.

All of these approaches were used in the FCR design in this project. The higher the turbine inlet temperature, the higher is the efficiency. However, the achievable core outlet and turbine inlet temperatures are constrained by material limits. Figure 5.2-3 illustrates the logic for selection of the operating temperatures and the key limits on the heat removal path from the reactor to power conversion cycle. 
Note that the core outlet temperature can be increased either by increasing the cladding steady state limit or by the reduction of film $\Delta \mathrm{T}$ and making core outlet temperature more uniform. First the cladding limit will be discussed followed by approaches to reduce film $\Delta \mathrm{T}$ and nonuniformities in core outlet temperature.

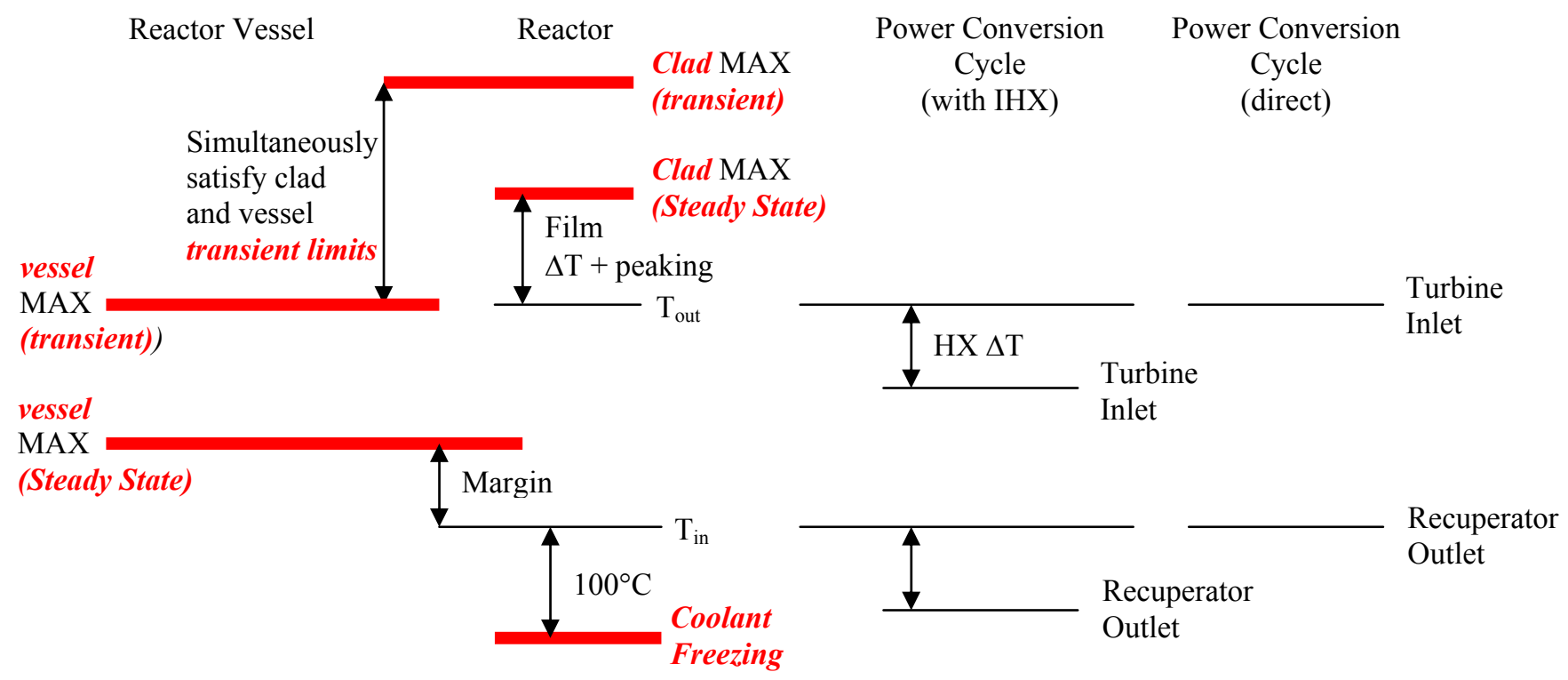

Figure 5.2-3. Thermal design logic (operating temperatures constrained by material limits for steady state and transient conditions).

As discussed in Chapter 2, T-91 with a steady state limit of $650^{\circ} \mathrm{C}$ was selected as cladding material for the LFR and LSFR metal-fueled cores. Because lead corrosion at these temperatures is excessive, a corrosion resistant alloy cladding surface under development at MIT is required for the LFR to be able to operate with this temperature limit. The SFR uses traditional HT-9 steel for cladding, for which we assume the same limit. It is noted that low CR metallic fuel cores may require a lower limit because of the larger content of plutonium in the fuel, for which there are very limited data on $\mathrm{Pu}-\mathrm{Fe}$ eutectic formation. However, should the irradiation data in the future show that eutectic formation is a problem, the potential cladding thinning from the eutectic can be overcome by the introduction of special foil liner between the cladding and the fuel that prevents $\mathrm{Pu}-\mathrm{Fe}$ interaction. Additional $\mathrm{R} \& \mathrm{D}$ on this issue is more than worthwhile since the economic benefit from increased efficiency will more than compensate the expense.

Comparing the metal fueled reactors with respect to the cladding temperature limit, the SFR, FLR and LSFR are assigned the same limit of $650^{\circ} \mathrm{C}$ with assumed modest advances in cladding material development and confirmatory testing. It is interesting to note that, although lead and salt have very high boiling points, which would allow them to operate at much higher temperatures than sodium (which boils at $883^{\circ} \mathrm{C}$ ), they cannot capitalize on this benefit due to the cladding limit, unless breakthrough advances in cladding materials are achieved. But even if such materials are available, the relatively low melting point of metallic fuel would become limiting. The GFR uses tube-in-duct oxide fuel with ODS cladding, which has a much higher temperature limit $\left(800^{\circ} \mathrm{C}\right)$. This is because (1) a much higher clad limit than $650^{\circ} \mathrm{C}$ was necessary due to the large film $\Delta \mathrm{T}$ of gas, and (2) vented fuel is used, which reduces cladding stresses. On the other hand, the manufacturing of long ODS pins and their welding is a very 
difficult task that will require significant $R \& D$ and demonstration. Therefore, ODS was classified in the "Stretch" category in Chapter 2 as opposed to the "Achievable" category for T91. The use of ODS for metallic cores would not allow an increase of the cladding limit because of the eutectic $\mathrm{Pu}-\mathrm{Fe}$ issue. If metallic fuel is replaced with oxide, it would be difficult to achieve the self-controllability goal due to relatively large Doppler feedback, and to design the CR=1 core without blankets because of the low density of $\mathrm{UO}_{2}$. Overall, the highest cladding steady state limit among the four evaluated reactors was the GFR, assuming that significant development and testing is successful, while all metal fueled reactors are constrained by $\sim 650^{\circ} \mathrm{C}$ with no substantial potential for increase. A similar situation occurs with the transient cladding limit, which is significantly smaller for metal-fueled reactor concepts than for the oxide-fueled and ODS clad GFR.

The second strategy to maximize core outlet temperature is by pushing the core average outlet temperature as high as possible while satisfying the peak cladding limit. This can be done by minimizing film $\Delta \mathrm{T}$, minimizing radial peaking, and achieving an assembly flow distribution that well matches assembly power throughout irradiation. Film $\Delta \mathrm{T}$ is proportional to heat flux and inversely proportional to heat transfer coefficient, which depends on coolant properties, flow and lattice geometry. Because the freedom to significantly vary the heat transfer surface in the core is limited, in particular for the $\mathrm{CR}=1$ core where high fuel volume fraction is required, it can be roughly stated that for fixed power density the larger the heat transfer coefficient, the smaller the film $\Delta \mathrm{T}$. Table 5.3.3-1b in Section 5.3 shows that the heat transfer coefficient of the SFR is 6.4 times larger than that of the LFR. The LFR's heat transfer coefficient is 5 times larger than that of the LSFR, and the LSFR is comparable to the GFR. The SFR is by far the clear winner in terms of a small film $\Delta \mathrm{T}$. The small heat transfer coefficient of the LSFR, even slightly smaller than that of the $\mathrm{S}-\mathrm{CO}_{2}$ cooled GFR, is a surprising result. It is a consequence of the very high viscosity of salt coolants, which leads to small Re numbers.

The non-uniform neutron flux in a reactor core results in core-wide power peaking. It is desirable to minimize this peaking and to achieve, as much as possible, a uniform core outlet temperature distribution. The typical strategy to minimize this peaking is though enrichment grading so that the zones with higher neutron flux have a lower content of fissile material than the zones with a lower neutron flux. In addition, fast reactors have canned fuel assemblies and use orificing to reduce flow in assemblies with lower power and force more flow into high-power assemblies. However, in fast reactors with a high conversion ratio, the bred-in plutonium in high flux regions moves the power profile back toward the fundamental mode during irradiation, making it difficult to keep a balanced power-to-flow ratio throughout the cycle using orificing. The innovative approach used here in all four fast reactor concepts differs in that it tailors a diluent content (zirconium in metal fueled reactors and $\mathrm{BeO}$ in the GFR) in the radial fuel zones while keeping the TRU-to-uranium ratio constant. This yields low power peaking, which remains relatively constant throughout the cycle making it easier to orifice the assemblies and make coreoutlet temperature more uniform. Because all four reactors use this approach, they can all benefit from an increased core-average temperature.

It is interesting to note that even though the heat transfer coefficient of the SFR is the largest; its core outlet temperature in Table $5-1$ is the lowest $\left(510^{\circ} \mathrm{C}\right)$. However, this is most likely because core inlet and outlet temperatures were adopted from an earlier S-PRISM design, which used materials available in the 1990s and used internal and radial blankets and enrichment grading in the driver core. Hence peaking was larger than in the blanket-free designs with diluent grading. 
Moreover, S-PRISM went through a much more detailed design, incorporating engineering and hot factors, while the conceptual designs in our scoping study were not examined at this level of detail. Also, it is important to note that the sodium core has a three times greater power density than the other three cores. This requires larger margins to accommodate transients. It is expected that the sodium metallic core outlet temperature can be increased to about $550^{\circ} \mathrm{C}$, as suggested by Westinghouse/Shaw/Toshiba in a recent report on GNEP Deployment Studies for DOE [Energy Solutions, 2008]. This would be much closer to the core outlet temperatures of lead and salt-cooled reactors of $573^{\circ} \mathrm{C}$ and $581^{\circ} \mathrm{C}$, respectively.

Minimization of the temperature difference between the core outlet and turbine inlet is accomplished in the LFR and LSFR by eliminating an intermediate loop, typically used for sodium-cooled reactors (not shown in Figure 5.2-3) to transfer heat directly from the primary coolant to the power conversion system fluid via the IHX. This results in a turbine inlet temperature increase of $20-25^{\circ} \mathrm{C}$, achieving a turbine inlet temperature of $546^{\circ} \mathrm{C}$ for both designs. This is possible because $\mathrm{CO}_{2}$ does not react with lead or salt in case of an IHX leak or tube failure. The $\mathrm{S}-\mathrm{CO}_{2}$ direct cycle GFR is unique among the four contenders because the working fluid of the power cycle can also be used for core cooling in a direct cycle arrangement, eliminating the IHX altogether and achieving a turbine inlet temperature of $650^{\circ} \mathrm{C}$, by far the highest, translating to $47 \%$ plant efficiency compared to $44 \%$ for the LFR and LSFR. For the SFR, elimination of the intermediate loop is challenging because of the energetic reaction of sodium with water and hydrogen generation. However, as discussed in section 5.1.3, this may be possible with the $\mathrm{S}-\mathrm{CO}_{2}$ power cycle since the reaction with $\mathrm{CO}_{2}$ is slower and leaks may be preventible if a double-wall IHX with helium between the walls for leak detection is used. However, significant R\&D is required to confirm the feasibility of this option. Overall, the potential to achieve the highest efficiency among the four reactor concepts can be ranked from highest to lowest as follows: 1. GFR, 2. LFR and LSFR, 3. SFR.

Finally, the selection of power conversion system has key implications for plant efficiency. Four major power conversion system candidates that could be used in conjunction with most Generation IV concepts and achieve higher efficiency than LWRs with a classical Rankine cycle have been explored by Dostal et al. [2004]. Their cycle efficiency as a function of turbine inlet temperature is plotted in Figure 5.2-4. Note that both the superheated and supercritical steam cycles yield higher efficiencies than Brayton cycles at lower turbine inlet temperatures. However, their efficiency gain with temperature is small and at temperatures above $450^{\circ} \mathrm{C}$ (superheated steam) and $550^{\circ} \mathrm{C}$ (supercritical steam) they are outperformed by a supercritical $\mathrm{CO}_{2}$ cycle. The helium Brayton cycle can achieve high efficiencies but requires high temperatures $\left(800^{\circ} \mathrm{C}\right.$ and above). The $\mathrm{S}-\mathrm{CO}_{2}$ cycle was selected as the PCS for all four reactors because it achieves higher efficiencies than a superheated steam cycle for turbine inlet temperatures above $450^{\circ} \mathrm{C}$, which are achievable for all the reactors compared, and because its efficiency gain at the higher temperature range is larger than that of the Rankine cycle. Also, this makes the plant comparison consistent, since each plant has the same power cycle. The supercritical steam cycle is also a strong contender that would deliver higher efficiency for the SFR, but it cannot be used for a direct cycle GFR. Also, supercritical water is very corrosive, and it may be difficult to design a reliable double-wall heat exchanger that would guarantee no leak into sodium. 


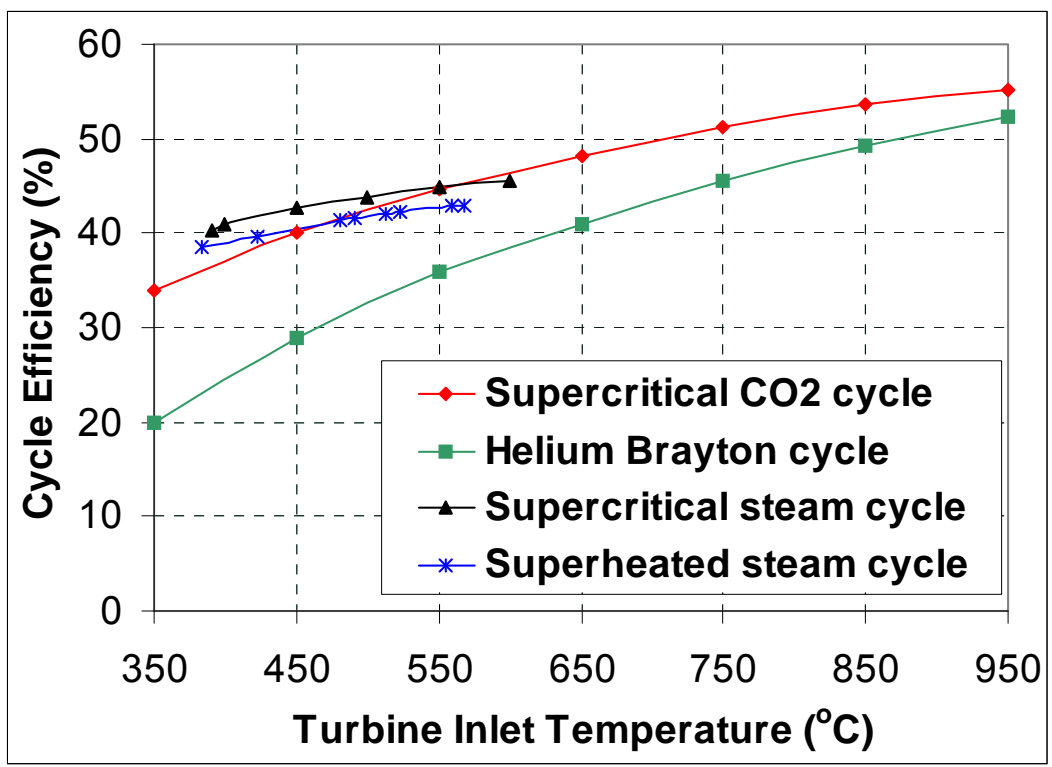

Figure 5.2.4 Achievable efficiencies of various power cycles (from Dostal et al. 2004)

Overall, all four reactors can use the $\mathrm{S}-\mathrm{CO}_{2}$ power cycle, but the reactor with the highest turbine inlet temperature (GFR) will benefit most in terms of efficiency. On the other hand, the SFR will benefit the least, and the efficiency gain compared to a Rankine cycle will be the smallest, depending on the possibility of eliminating the intermediate loop. However, if future $R \& D$ confirms that the $\mathrm{CO}_{2}$ /sodium reaction is slow and not a serious challenge, making it possible to use a sodium $/ \mathrm{CO}_{2}$ double wall IHX without the intermediate loop, the efficiency gain versus the Rankine cycle with intermediate loop will be significant.

\section{Plant compactness}

The capital cost to a large extent is proportional to the amount of steel and concrete consumed to build a new power plant. These two commodities form more than $95 \%$ of construction inputs [Peterson, 2005] and have become increasingly more expensive because of the rapidly growing consumption of these materials in China and India. Furthermore, both these materials require a large amount of energy to produce and have appreciable carbon footprints such that any potential future carbon taxes will exacerbate their cost increase in a carbon-constrained economy. Therefore, plant designs with small volume and a small amount of concrete and steel used per installed MWe are expected to have a lower cost. Figure 5.2-5 compares the volumes of buildings, concrete, and steel needed to build various thermal reactors. It can be observed that modular, low power density systems, such as the PBMR, require much larger volumes than PWRs. On the other hand, the thermal liquid salt intermediate temperature reactor AHTR, which has a large power rating and relies on inherent reactor shutdown and passive decay heat removal, has the lowest consumption of these materials. Although this is partly due to its significantly higher plant efficiency discussed earlier, it shows that highly efficient, simple, and compact designs with large power rating have the potential to substantially reduce cost. 


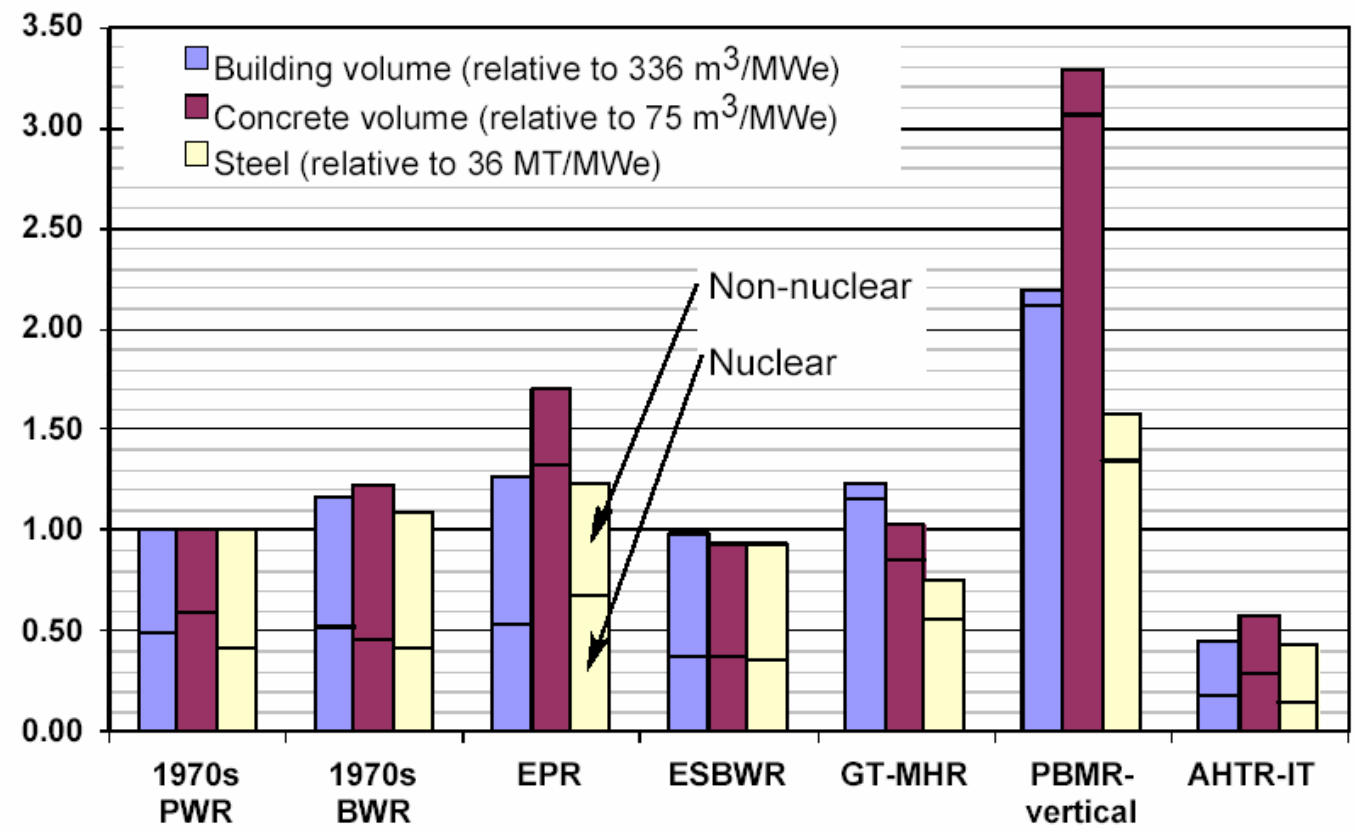

Figure 5.2-5 Comparison of building, concrete and steel volumes for various reactors (from Peterson, 2005)

The lead and salt-cooled fast reactors developed in this project have 10 times higher power density than the AHTR and about the same reactor vessel size but a much smaller guard vessel (10.2m OD versus $16 \mathrm{~m}$ OD for the AHTR). Although the approach of decay heat removal for the AHTR is different, the nuclear island for lead-cooled and salt-cooled designs seems to be more compact than that of the AHTR. In addition, the $\mathrm{S}-\mathrm{CO}_{2} \mathrm{PCS}$ is more compact and simpler than the multi-reheat helium Brayton cycle used in the AHTR. Generally, Brayton cycles are more compact than Rankine power cycles because the lowest cycle pressure of Brayton cycles is significantly higher than the near-vacuum pressure of steam turbines. This is especially the case for the $\mathrm{S}-\mathrm{CO}_{2}$ cycle, where turbine outlet pressure is at $7.7 \mathrm{MPa}$, which is very near the critical point. Above this pressure, density is very high, resulting in very compact turbomachinery and precooler. Figure 5.2-6 compares volumes of key components of Rankine and $\mathrm{S}-\mathrm{CO}_{2}$ power cycles for $300 \mathrm{MWe}$ PWR plants. Very substantially smaller volume of the $\mathrm{S}-\mathrm{CO}_{2} \mathrm{PCS}$ is clearly evident from this figure, and the compactness of this cycle was a major reason (in addition to its superior efficiency) for the selection of the S- $\mathrm{CO}_{2}$ PCS for the fast reactor concepts in this study.

For these reasons, compact designs of lead and salt-cooled FCRs are expected to have steel and concrete volume savings at least comparable to those of the AHTR, which is expected to project to appreciable cost savings. The sodium core has the largest power density among all concepts (3 times more than the lead FCR) and thus the smallest core size. However, for the passive DHR configuration, relying on heat transfer through the vessel, large vessel size is preferred to maximize the decay heat removal rate. Thus, savings from a smaller vessel size cannot be realized. The benefit of a smaller core is more space to place pumps and other primary system components than in the LCR or LSFR. If the feasibility of a sodium reactor coupled to the S- $\mathrm{CO}_{2}$ power cycle without an intermediate loop can be confirmed, it should benefit from similar compactness-related capital cost savings. The GFR has the largest vessel (of prestressed cast iron type) among all four fast reactor concepts and employs $4 \times 50 \%$ large emergency cooling systems plus robust containment that needs to be designed for higher pressures than other contenders. On 
the other hand, it does not require IHXs, which are heavy and costly components. Nevertheless, it is expected the IHX savings will not overcome the increased cost of containment and large DHR loop components. Hence, the GFR will most likely have the largest cost due to concrete and steel consumption among the four concepts investigated.

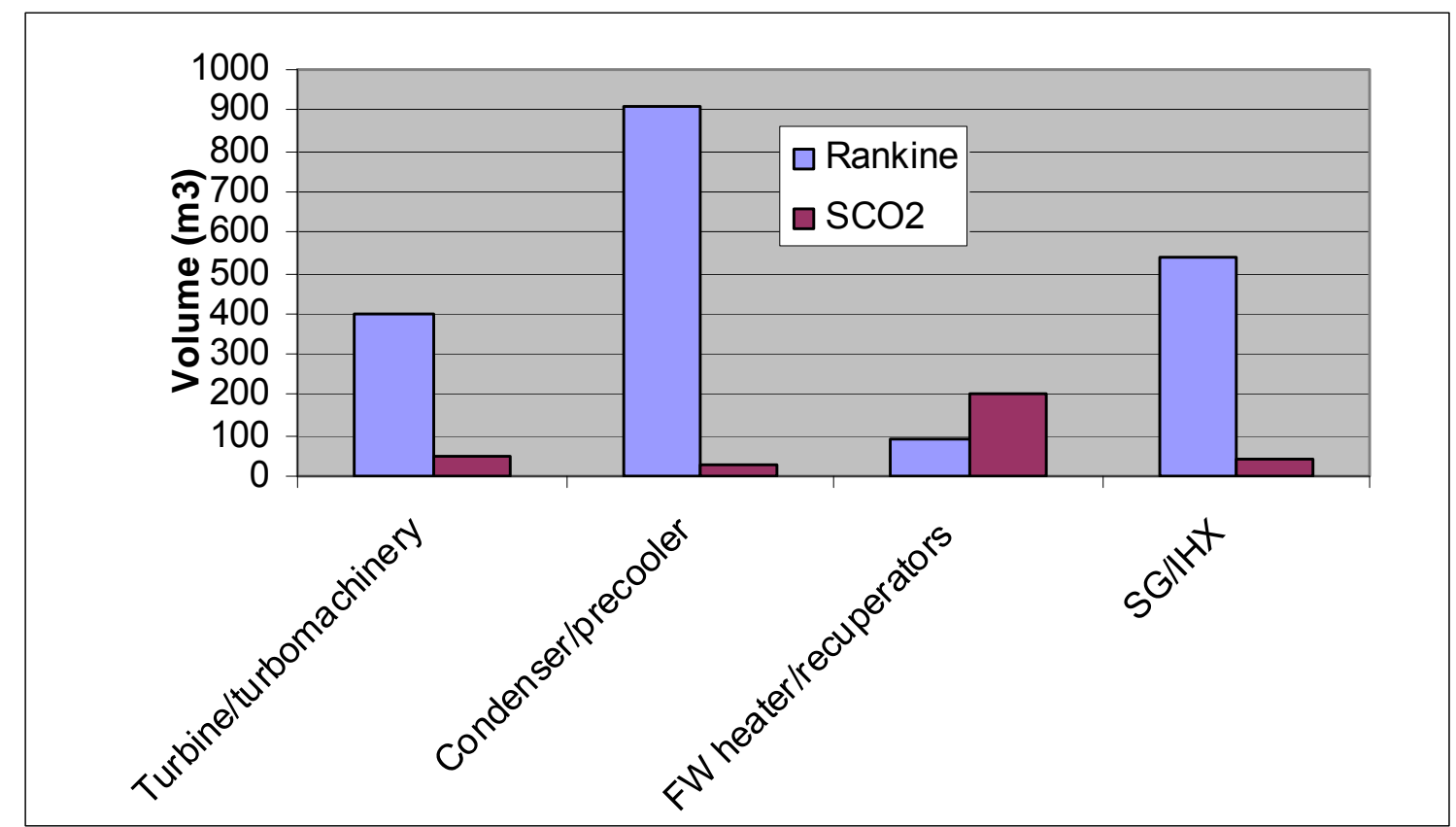

Figure 5.2-6 Comparison of volumes of PCS components for $300 \mathrm{MWe} \mathrm{S-CO} 2$ and Rankine Cycle

\section{Specific Power}

Specific power affects fuel cycle cost. While related to power density, specific power remains an independent variable whose value the designer desires to maximize to achieve acceptable fuel cycle cost. Hejzlar et al. [2002] showed that the minimum specific power of $20 \mathrm{~kW} / \mathrm{kgHM}$ should be achieved to keep fuel cycle cost within reasonable bounds. This was set as a minimum target for the development of FCR reactors in this project. All $\mathrm{CR}=1$ reactors achieved this target, albeit the GFR barely with its $21 \mathrm{~kW} / \mathrm{kgHM}$ value. As expected, the SFR has the largest specific power of $65 \mathrm{~kW} / \mathrm{kgHM}$, followed by the LFR with $45 \mathrm{~kW} / \mathrm{kgHM}$ and the LSFR with 35 $\mathrm{kW} / \mathrm{kgHM}$. Cores with low specific power have a longer cycle length. Therefore, the GFR has a cycle length of 18 years and the SFR only 3.1 years. As discussed in section 5.3, cycle length is limited by peak cladding fluence, which also determines achievable core-average discharge burnups. These are in the range of 70 to $80 \mathrm{MWd} / \mathrm{kgHM}$ for metallic fueled cores - relatively low values for fast reactors, signifying the importance of development of advanced cladding materials.

\subsubsection{Safety}

As for the thermal reactors, fast reactors have to be designed to have excellent safety to protect the health of the public and the workers. As mentioned in the introduction to this section, the Generation IV program set the even more ambitious goal for nuclear energy systems to have a 
very low likelihood and degree of reactor core damage during any possible accident. To quantify the value of this likelihood requires a full PRA (Probabilistic Risk Assessment), which is not possible at this point because the designs are only on a conceptual level. Therefore, the comparison of safety features of the four reactors is focused on the results of deterministic analyses of key transients that were analyzed within this study and identification of key issues or benefits that distinguish individual concepts. The discussion will focus specifically on unprotected station blackout (SBO) ${ }^{*}$, unprotected loss of flow (ULOF), and unprotected overpower (UTOP) accidents since these events form an envelope of the initiators that lead to core heatup and can cause damage (except for the GFR where LOCA is the key bounding accident). The protected SBO will also be addressed since it can potentially lead to coolant freezing for some coolants. The whole spectrum of accidents, including hypothetical core disruptive accidents and seismic related events, will not be addressed.

In the spirit of ambitious Generation IV goals, one of the objectives established before the start of this project was to achieve a level of safety that would exceed the already acceptable levels attained in currently operating reactors. There are many possible approaches to achieve this goal. Our selected approach was the achievement of the inherent, designed-in response of a reactor that would prevent release of radioactivity, as in the IFR. This requires a design that has: (1) a combination of reactivity feedbacks that inherently shut down the reactor without exceeding temperature limits on reactor structures in accidents without scram, and (2) a decay heat removal system based on natural phenomena that do not need external power. Such a combination of inherent and passive means is considered to be highly reliable and potentially more economic than complex redundant active systems with reliable power supplies. It is also noted that including such unprotected accidents with extremely low probability goes far beyond the design basis and is not even considered in licensing the current generation of reactors.

\section{Unprotected Accidents}

The plant response to unprotected accidents depends on two key features: the capability of inherent shutdown and the capability to remove decay heat passively. The discussion of the four concepts will compare these two features in sequence.

The IFR designers have proven by analysis that the sodium-cooled reactor with metal fuel can be designed to achieve the desirable self-controllability characteristics and transit to new asymptotic power levels under loss of heat sink (ULOHS), ULOF, and UTOP accidents without exceeding core material limits [Wade et al, 1997]. Although the IFR and its successors, ALMR and PRISM, had relatively low power rating (up to $1000 \mathrm{MWt}$ ) due to limitations of RVACS passive decay heat removal, reactor physics analyses were applied to larger cores up to $3500 \mathrm{MWt}$. It was shown that it is possible to design the large core with reactivity feedbacks that achieve selfcontrollability, although smaller cores will achieve larger margins [Wade and Hill, 1997]. The SFR design in Table 5-1 is based on the 1000 MWt S-PRISM core, but the number of assemblies is increased to achieve a power of $2400 \mathrm{MWt}$ for consistency with the other concepts. SFR reactor physics analyses in Appendix 5A have shown that the $\mathrm{A} / \mathrm{B}$ reactivity coefficient ratio limit was slightly above the self-controllability limit, indicating that the large core $\mathrm{CR}=1$ design may have difficulty achieving self-controllability. This is primarily due to larger positive CTC

\footnotetext{
${ }^{*}$ IFR analyses are performed typically for unprotected loss of flow and unprotected loss of heat sink. Because SBO is more challenging and because for direct cycle GFR loss of flow is not independent of a a loss of heat sink, unprotected SBO was selected for the analyses.
} 
than for the small core. Since the large-core IFR design contains inner blankets, the CTC is reduced due to increased leakage of neutrons from the driver assemblies to the blanket assemblies upon coolant heatup. The $\mathrm{CR}=1$ core has no blankets and a low leakage core with flat power distribution, resulting in larger CTC. However, because the design of the SFR core was beyond the scope of this project, no effort has been made in SFR core calculations to reduce the CTC, as was the case for the lead and salt-cooled reactors. Since the reduction of this reactivity coefficient needed to achieve self-controllability is small, it should be feasible to design a large SFR core with self-controllability features.

Reactor physics analysis in Chapters 3 and 4 have shown that both the lead and salt-cooled FCRs having $\mathrm{CR}=1$ can be designed for self-controllability. However, there is a significant difference between these two coolants. Lead coolant, due to its small thermal expansion coefficient, low absorption cross section, low slowing down power and high scattering cross-section, exhibits only a small positive CTC (smaller than for SFR - see Section 5.3.1), which makes it possible to design a self-controllable $\mathrm{CR}=1$ core without the need for special features to mitigate the CTC. On the other hand, salt coolants, with their larger absorption cross section and some moderating power, but most importantly their large coefficients of thermal expansion, exhibit significant positive CTC that is difficult to overcome without introducing drastic measures into the core design or without introducing special, albeit passive devices. Ultimately, a salt core design with LEMs was devised, which achieves zero or negative CTC and good self-controllability. The difference among the SFR, LFR and LSFR is that the SFR and LFR can be designed to be selfcontrollable without such devices, while the LSFR requires them.

Gas coolants are neutron transparent and the CTC, or rather coolant void worth, is typically considered not to be an issue. However, there is a significant difference between liquid metal or salt-cooled reactors and GFRs. GFRs operate at high pressure and can lose coolant rapidly, while the loss of coolant accident is not even analyzed for pool type liquid metal cooled reactors having a guard vessel because of the extremely low probability of failure of both reactor and guard vessels. Rapid coolant depressurization of the the GFR core results in spectrum hardening and insertion of positive reactivity, which is very difficult to overcome through increased leakage - the main effect used to mitigate positive CTC in liquid metal reactors. It was also shown [Handwerk, 2006] that to make GFR self-controllable, coolant void worth needs to be negative a significant difference from liquid metal cooled cores, where other negative reactivity feedbacks can compensate for slightly positive CTC. This is because in a GFR coolant depressurization in a large break LOCA can be very rapid and other reactivity coefficients may not have time to respond fast enough to achieve shutdown before material temperature limits are exceeded. A significant design effort has been made at MIT to achieve negative coolant void worth. This is accomplished in the $\mathrm{S}-\mathrm{CO}_{2}$ GFR by minimizing the coolant volume fraction through the use of TID assemblies, adding $\mathrm{BeO}$ diluent to $\mathrm{UO}_{2}$ fuel and using $\mathrm{S}-\mathrm{CO}_{2}$ radial reflectors [Handwerk et al., 2006]. Handwerk et al. [2006] also showed that the GFR can be designed as self-controllable at BOL but not at EOL due to less negative coolant void worth. This has been confirmed by RELAP5 analyses, as can be seen in Figure 5.2-7, which plots peak cladding temperatures for unprotected LOCA [Pope et al., 2008]. 
Project No 06-040: Flexible Conversion Ratio Fast Reactor Systems Evaluation

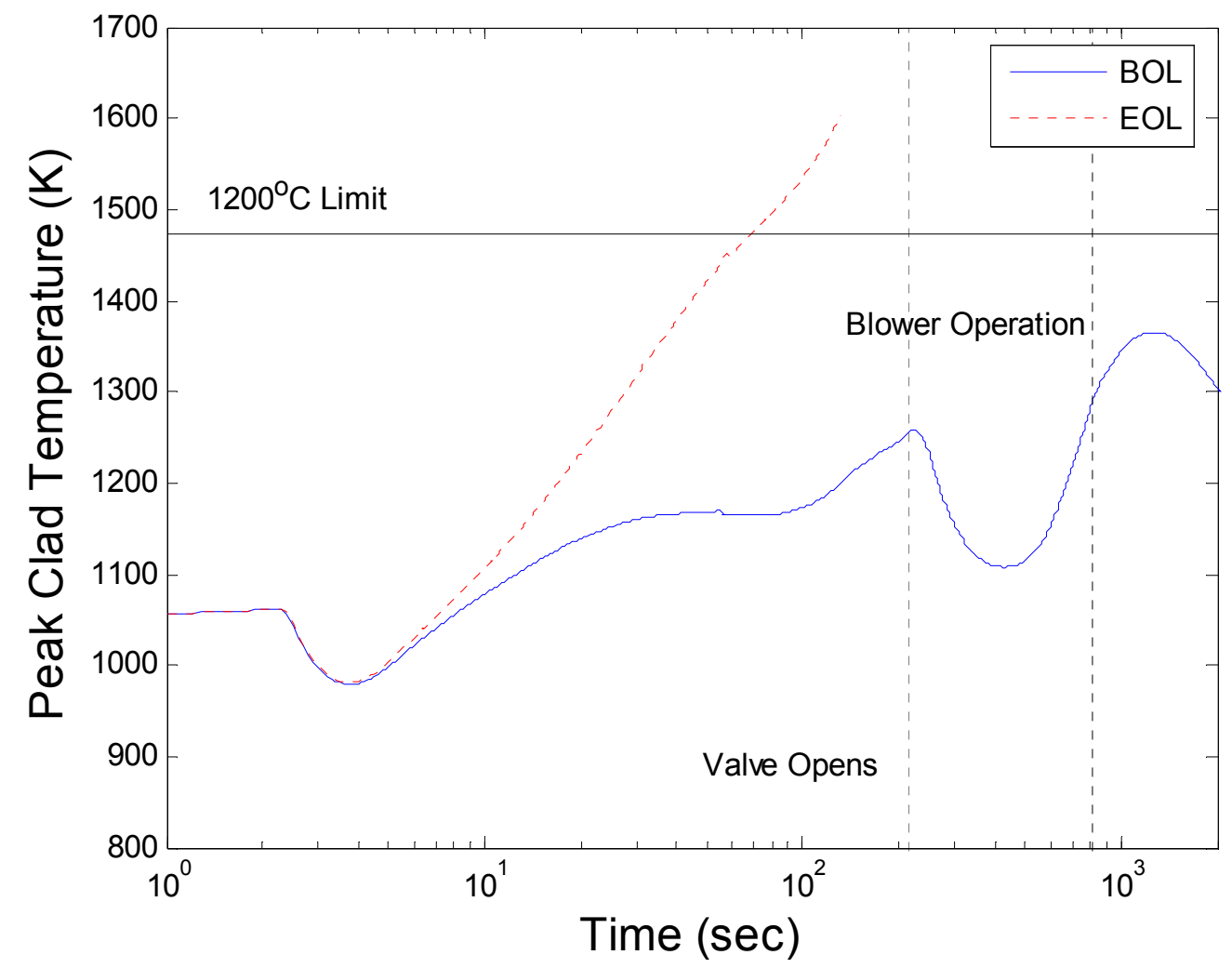

Figure 5.2-7. S-CO2 GFR reactor peak cladding temperature during $100 \mathrm{in}^{2}$ break LOCA without SCRAM at BOL \& EOL (from Pope et al., 2008).

The second feature of self-controllable design is the capability to remove sufficient heat during shutdown passively as well as decay heat during the long term. This is especially challenging for reactors with a large power rating since the driving forces for natural phenomena are small and typically require large decay heat removal systems, negatively affecting capital cost.

It has been shown that the $2400 \mathrm{MWt}$ lead and salt-cooled FCR reactors with passive DHR systems, described in Chapter 2, can be designed to accommodate unprotected accidents, without the need for excessively large DHR systems. The enhanced RVACS alone was found to have insufficient performance and had to be supplemented with PSACS. However, there were differences in performance between the lead and salt-cooled concepts. While the LSFR can accommodate unprotected SBO without exceeding the peak cladding temperature limit for any number of operating PSACS trains with relatively small PSACS tanks, the lead-cooled reactor would require much larger tanks to keep peak cladding temperatures below the limit. This difference stems from different CTCs of each reactor that lead to differences in primary system temperatures and reactor power in the long term restart. During PSACS train operation (before PSACS tanks evaporate) the RVACS plus PSACS remove more heat than the decay heat generated in the core, which causes gradual reactor cooldown until primary temperatures reach a level when reactivity becomes zero and the reactor restarts to low power level (less than 10\%). After reactor restart, its power and temperature stabilize at a low level that matches the heat removal capacity of RVACS plus PSACS. During this period, core temperatures remains constant until the water in the PSACS trains is evaporated. At this point, the primary system temperature rises leading to reactor shutdown, and decay heat at this time is small enough to be removed by RVACS. The LSFR with LEMs has net negative CTC, hence its power increase 
after restarts is smaller than that of the lead-cooled reactor, which has positive CTC. Therefore, the PSACS tanks for the lead-cooled reactor need to be significantly larger to maintain peak cladding temperature below the limit in the long term. Because larger tanks may not be economically attractive, one could also employ smaller tanks and scram the reactor manually or restore power. The operator has 24 hours to initiate scram, which is ample time for such action. The LSFR does not need to scram and can maintain peak cladding temperature within limits for 72 hours with smaller PSACS tanks, independent of the number of operating PSACS trains, as long as 2 out of 4 trains are in operation.

The 1000 MWt SFR concept can rely fully on RVACS, and its self-controllability has been confirmed by S-PRISM analyses. The $2400 \mathrm{MWt}$ SFR requires significant redesign of DHR systems. Section 5.1.3 discussed that it may be possible to use the same approach as for the LFR if a double-wall IHX is used to couple the SFR to the S-CO $\mathrm{CO}_{2}$ PCS. Although not studied, it is expected that such a system would perform similarly as the LFR, after SFR core design is optimized to reduce CTC.

The GFR DHR principle is very different from that of liquid metal cooled reactors. The most promising concept is the use of DHR cooling loops that connect the low $\Delta \mathrm{p}$ core with elevated gas/water heat exchangers, all enclosed in a guard containment designed for pressure of about $0.8 \mathrm{MPa}$. In case of LOCA, the primary system and PCS depressurize into the containment, increasing containment pressure to an equilibrium of about $0.7 \mathrm{MPa}$. This pressure is sufficient to remove about $3 \%$ decay heat by natural circulation of $\mathrm{CO}_{2}$ between the core and DHR HXs. However, detailed studies [Pope et al, 2006] have shown that there are many potential bypasses (e.g., through double-ended break of coaxial pipe or through a PCS loop) that can lead to a significant reduction of core flow. Moreover, the startup of flow through a DHR loop in the correct direction is not reliable, because leaky check valves can cause the reversal of temperature profiles in the DHR loop. Also, PRA studies of a helium cooled GFR with a passive DHR system using uncertainty propagation have shown relatively high conditional damage frequency [Mackay et al., 2008; Patalano et al., 2008]. For these reasons, it has been decided to abandon a fully passive DHR in the MIT GFR design. Battery or fuel cell powered blowers are used and passive natural circulation is used as a backup. This is possible because blower power consumption is very low.

Overall, comparing the four concepts, it can be stated that all can be designed to accommodate the unprotected limiting accidents, but it does not seem to be a preferable option in the GFR where the active or semi-passive approach will likely result in a more economic and more reliable plant. The benefit of using the $\mathrm{S}-\mathrm{CO}_{2} \mathrm{PCS}$ is that it provides an additional heat removal option, since the decay heat can drive the turbine which in turn drives the compressors to circulate $\mathrm{CO}_{2}$ through the IHXs in a self-sustaining operational mode. This has been shown to be feasible and effective for the LFR and LSFR and could also be used in the SFR and GFR.

\section{Protected Accidents}

As mentioned earlier, the probability of unprotected accidents is extremely low, thus these events are not even considered in the licensing process. Typically, one would expect that if the temperature constraints are met in a more challenging unprotected accident, they would also be met in the protected accident. However, this is not the case for liquid metal coolants, especially those with high melting points, since excessive heat removal can lead to primary system 
overcooling and coolant freezing. All three liquid metal-cooled concepts are susceptible to this scenario, the SFR being less likely due to the large margin to melting point of sodium $\left(254^{\circ} \mathrm{C}\right)$, followed by the LFR (margin of $152^{\circ} \mathrm{C}$ ) and the LSFR (margin of $100^{\circ} \mathrm{C}$ ).

Analyses of unprotected SBO for the LFR and LSFR confirmed that this is a significant issue, particularly for salt cores. When sizing the PSACS for the LFR, it was found that larger PSACS tanks are needed to accomodate the unprotected SBO. Because of the much higher probability of protected SBO than an unprotected one, the plant needs to be designed to accommodate protected accidents. To avoid lead freezing in the protected SBO if all four PSACS trains are operating, the small PSACS HX and large PSACS tank designs were chosen. This combination was found to perform satisfactorily in both protected and unprotected accidents independently of the number of operating PSACS trains.

Design of the LSFR against freezing turned out to be particularly difficult, not only because of the smallest margin to freezing, but also because of the largest CTC coefficient. LEMs can be designed to compensate salt CTC in a limited temperature range, primarily to compensate for reactivity increase upon coolant heating. During core cooling below the nominal temperature, LEMs are out of the core and the large positive CTC yields strong power reduction during cooldown, speeding up reactor shutdown and thus increasing the core cooling rate. SBO analyses have shown that for the $\mathrm{CR}=1$ core and originally sized PSACS (tank diameter/height $=6 \mathrm{~m} / 12 \mathrm{~m}$ and 350-tube, $4 \mathrm{~m}$-long heat exchanger) the salt can freeze in about 20 hours if the reactor is scrammed and 4 PSACS trains are operating, and in $\sim 10$ hours for $\mathrm{CR}=0$, which has lower decay heat. The best solution to this problem turned out to be the use of smaller PSACS tanks and heat exchangers. It was shown that sizing the PSACS heat exchangers to transfer $40 \%$ less power (250-tubes, 2.4-long heat exchanger) than the original design and using $25 \%$ smaller PSACS tanks $(\mathrm{D} / \mathrm{H}=6 \mathrm{~m} / 9 \mathrm{~m})$ can accommodate both the unprotected SBO with peak cladding temperatures below the $725^{\circ} \mathrm{C}$ limit and the protected SBO without salt freezing. An alternative solution for future investigation is the use of PSACS-air heat exchangers, which require larger film $\Delta \mathrm{T}$.

Overall, protected accidents need to be given special attention in the LSFR and LFR due to their small margin to freezing, and to a lesser extent in the SFR. The GFR does not pose this challenge. The GFR's response to its most challenging event, the LOCA, will be more benign than in the case of LOCA without scram. 


\subsection{Detailed Comparison}

\subsubsection{Neutronic Performance Comparison}

This section compares neutronic characteristics of the studied reactor concepts. The main design parameters of unity conversion ratio cores are described earlier in Table 5-1. The comparison of different designs with respect to neutronic performance was focused on the following aspects:

- Potential of different designs to achieve high burnup and high power density as two major indicators of economic viability of the concepts;

- Potential of achieving near unity conversion ratio in a sustainable manner;

- Capability of self-control through passive design features in the most limiting accident scenarios; and

- Impact of different coolants and reactor designs on decay heat power following reactor shutdown.

As mentioned earlier, the reactor designs discussed in this section have a significant number of common features, which allows consistent comparison between the concepts.

All four designs have the same thermal power rating of $2400 \mathrm{MW}$ and common design objectives of achieving a self-sustainable fuel cycle with respect to fissile feed requirements, while avoiding the use of fertile blankets, as well as maximizing power density and fuel burnup. Passive safety was also a common objective of all the designs.

Neutronic analyses of the four designs were performed using the same methodology, assumptions and simulation tools: MCODE, BGCore, MCNP described in Appendix 3A. In addition, the calculations were performed using the same JEFF-3.1 cross-section data libraries, unless stated differently.

Metallic U-TRU-Zr fuel was used in all reactors except for the GFR, where oxide fuel form was prescribed. The initial TRU composition was also identical in all the reactor concepts and corresponded to that of a typical spent LWR fuel with $50 \mathrm{MWd} / \mathrm{kg}$ burnup after 10 years of cooling. Single batch fuel management strategy was used in all the compared designs.

The approach to power distribution management by tailoring a diluent content in the radial fuel zones while keeping the TRU to uranium ratio constant was proven to be very effective. The maximum radial power peaking factors do not exceed 1.3 in all core designs, without significant change with the fuel burnup.

In all of the considered cases, the fuel burnup was constrained by the peak cladding fluence. Therefore, all the reactor cores have approximately the same discharge burnup (Table 5-1). The limit of $4 \times 10^{23}$ (neutrons above $0.1 \mathrm{MeV}$ ) $/ \mathrm{cm}^{2}$ roughly translates for liquid metal and salt-cooled reactors into 70 to $80 \mathrm{MWd} / \mathrm{kg}$ of burnup. The small differences in discharge burnup can be attributed to slightly different neutron spectra and calculation uncertainty. GFR fuel has a notably higher burnup of $140 \mathrm{MWd} / \mathrm{kg}$. This is partially due to a softer spectrum (only $49 \%$ of GFR neutrons are above $0.1 \mathrm{MeV}$ versus $69 \%$ for the lead-cooled reactor), but most importantly due to significantly lower core-average neutron flux. The much smaller neutron flux of the GFR 
core is the consequence of significantly higher heavy metal, and in particular TRU loading, and thus higher number density of fissile isotopes. The neutron flux comparison among the concepts is given in Table 5.3.1-1. In addition, the GFR uses ODS steel as cladding, which is expected to have a higher fluence limit than HT-9 steel. GFR cladding has an accumulated peak fluence of $4.7 \times 10^{23} \mathrm{n} / \mathrm{cm}^{2}(\mathrm{E}>0.1 \mathrm{MeV})$. This is within the limit of $5 \times 10^{23} \mathrm{n} / \mathrm{cm}^{2}(\mathrm{E}>0.1 \mathrm{MeV})$ used by Japanese designers for JSFR with ODS cladding [Mizuno et al., 2005]. In addition, the unique TID fuel assembly design allows controlled venting of the fission gases and, thus, more flexibility in managing the mechanical stresses within the assembly.

With respect to achievable power density, the concepts differ quite substantially. To a large extent, the power density is related to a combination of heat transfer properties of the respective coolants, as discussed in Sections 5.3.2 and 5.3.3. Temperature limits of the core components and pressure drop constraints largely determine the coolant volume fraction in the core, and consequently power density, if the core power is fixed. For these reasons, sodium coolant with exceptionally good heat transfer properties has a clear advantage, which results in two to three times higher power density than those of the other concepts. Also, large power density results in smaller heavy metal loading and thus larger neutron flux, as shown by comparing Tables 5.3.1-1 and 5.3.1-2. The SFR flux is about twice as large as that of the lead-cooled reactor.

Table 5.3.1-1 Comparison of core average neutron flux

\begin{tabular}{|l|r|r|r|r|}
\hline & GFR & Lead & Salt & Na \\
\hline Flux, average over the cycle $\left(\mathrm{n} / \mathrm{cm}^{2}\right)$ & $1.05 \times 10^{15}$ & $2.82 \times 10^{15}$ & $2.73 \times 10^{15}$ & $4.89 \times 10^{15}$ \\
\hline Fraction of fast neutrons $>0.1 \mathrm{MeV}$ & 0.49 & 0.69 & 0.69 & 0.70 \\
\hline Cycle length, days & 6000 & 1800 & 1800 & 1150 \\
\hline
\end{tabular}

In the lead and salt-cooled reactors, additional considerations play an important role in setting the coolant volume fraction. For the lead coolant, there is a limit on coolant velocity, required to prevent corrosion of the core structural components. As a result, a relatively open fuel lattice has to be used, which limits the power density to values comparable to conventional LWRs.

For the salt, large positive CTC necessitates a small coolant volume fraction in order to minimize the reactivity insertion upon coolant heatup. However, high viscosity for most of the molten salts limits the achievable power density for a given pumping power constraint. Using some innovative design strategies to reduce the CTC (as discussed in Chapter 4 and Appendix 4) or reliance on redundant active shutdown mechanisms, allows one to somewhat relax the constraint on the coolant volume fraction and achieve a power density of $130 \mathrm{~W} / \mathrm{cm}^{3}$. This is notably higher than in the lead-cooled core but still far from the Na-cooled core power density by over a factor of two.

Variation in achievable power density for the fixed total power leads to large differences in volume of the studied cores (Table 5-1). Generally, all the designs have a relatively small core height and height-to-diameter ratio to minimize the core pressure losses, and take advantage of large neutron leakage in order to mitigate the positive CTC common in all fast reactors. While power density has a significant impact on economic viability of each reactor design, specific power is an important indicator of the fuel cycle cost competiveness. In this respect, the leadcooled core has certain advantages over the salt because of the looser fuel lattice of the former. 
Despite the very tight lattice of the sodium-cooled core, very high power density also leads to the highest specific power among all the designs (Table 5-1).

Reactivity of the studied cores as a function of time and core average burnup are plotted in Figures 5.3.1-1 and 5.3.1-2, respectively. The GFR core has the longest fuel cycle of about 18 years and highest discharge burnup because of the combination of the following factors: high HM loading, large dimensions, and relatively low specific power. The sodium-cooled reactor, on the other hand, reaches its fluence limited burnup relatively fast due to the high specific power. The cycle length of the lead and salt-cooled reactors is on the order of 5 years, which is roughly comparable to a typical LWR fuel residence time in a three batch core.

Table 5.3.1-2 summarizes the balances of materials in the compared designs. The last line of the table gives a Fissile Inventory Ratio (FIR) defined as the discharged mass of TRU divided by the TRU initially loaded. All the designs can achieve FIR about unity. In all cases, the relative fraction of $\mathrm{Pu}$ increases, while the fraction of MA decreases. It was shown that the recycled first generation TRU is sufficient to sustain the next fuel cycle of at least the same length with natural uranium makeup only.

Table 5.3.1-2 HM inventory comparison of $\mathrm{CR}=1$ core designs

\begin{tabular}{|c|r|r|r|r|}
\hline & Lead & \multicolumn{1}{c|}{ Salt } & \multicolumn{1}{c|}{$\mathrm{S}-\mathrm{CO}_{2}$} & \multicolumn{1}{c|}{$\mathrm{Na}$} \\
\hline Core initial HM loading, $\mathrm{kg}$ & 56,472 & 67,847 & 115,711 & 35,444 \\
\hline $\mathrm{Pu}$ & 8,131 & 9,202 & 17,203 & 4,662 \\
\hline $\mathrm{MA}$ & 1,255 & 1,421 & 1,905 & 720 \\
\hline $\mathrm{NU}$ & 47,086 & 57,224 & 96,604 & 30,062 \\
\hline Core HM inventory at discharge, $\mathrm{kg}$ & 51,878 & 61,719 & 99,261 & 32,616 \\
\hline $\mathrm{Pu}$ & 8,268 & 9,533 & 18,774 & 4,856 \\
\hline $\mathrm{MA}$ & 953 & 1,058 & 1,278 & 536 \\
\hline $\mathrm{NU}$ & 42,657 & 51,128 & 79,209 & 27,224 \\
\hline Fissile Inventory Ratio, discharged/loaded & 0.98 & 1.00 & 1.05 & 1.00 \\
\hline
\end{tabular}

Reactivity versus time of zero conversion ratio lead and salt-cooled cores are compared in Figure 5.3.1-3. This figure illustrates the importance of detailed geometry modeling as well as uncertainty associated with the use of different cross-section libraries. The difference in the keffective for the same core modeled using ENDF-VI and JEFF-3.1 cross-section data may reach $2 \%$, while homogeneous rather than explicit geometry representation results in an additional $1 \%$ underestimation of the core criticality. The lead-cooled $\mathrm{CR}=0$ core was initially modeled with ENDF libraries and homogeneous representation. As a result, the equilibrium core TRU content was determined to be $34 \%$ as compared with $30 \%$ for the salt-cooled core which was modeled in detail with JEFF-3.1 cross-sections. The trends shown in Figure 5.3.1-3 suggest that the difference between equilibrium lead and salt-cooled core TRU enrichments should be much smaller, leading to the conclusion that both cores have roughly equivalent neutronic performance. 
Project No 06-040: Flexible Conversion Ratio Fast Reactor Systems Evaluation

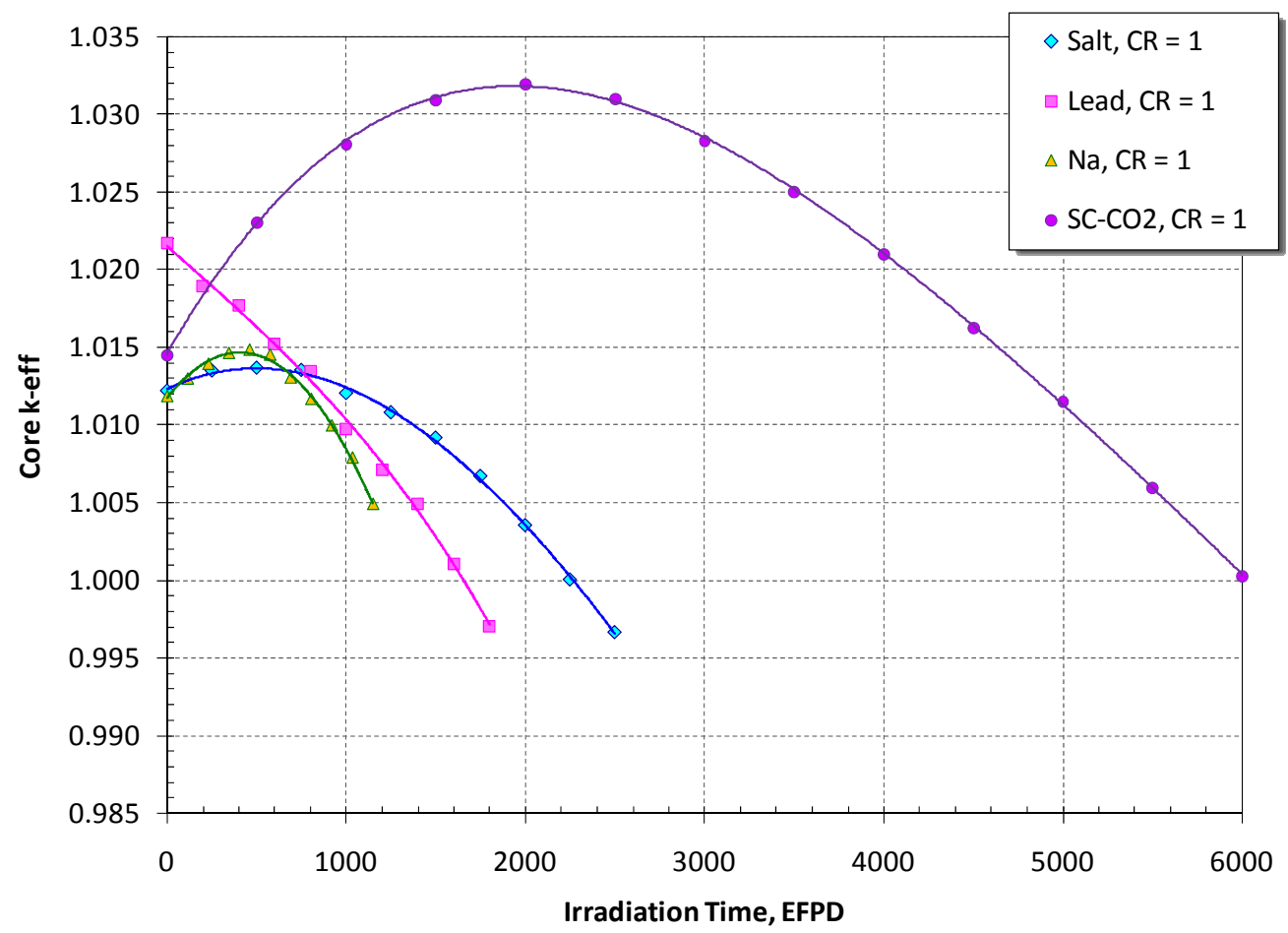

Figure 5.3.1-1 $\mathrm{CR}=1$ cores multiplication factors versus irradiation time

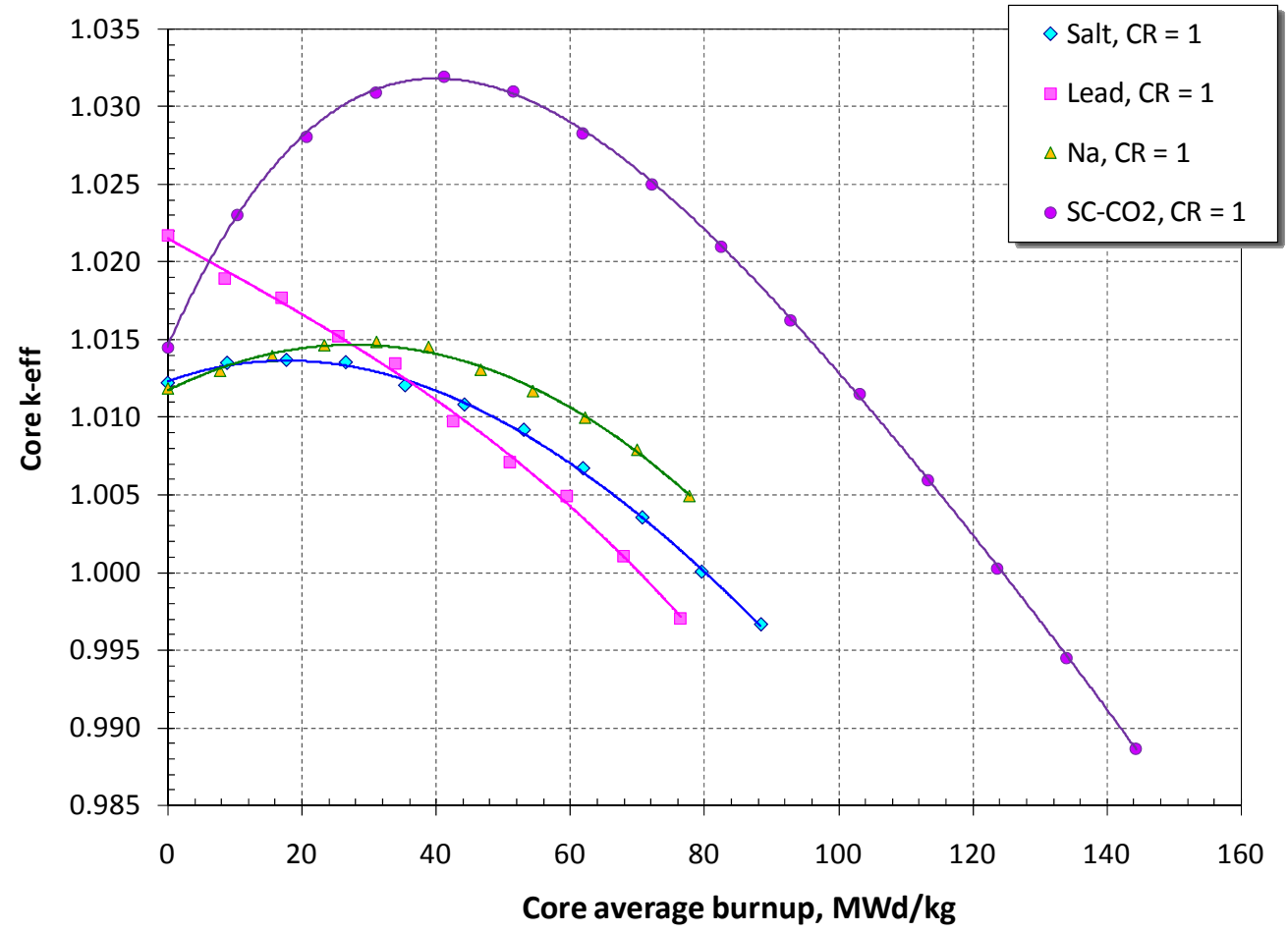

Figure 5.3.1-2 $\mathrm{CR}=1$ cores multiplication factors versus core average burnup 
Project No 06-040: Flexible Conversion Ratio Fast Reactor Systems Evaluation

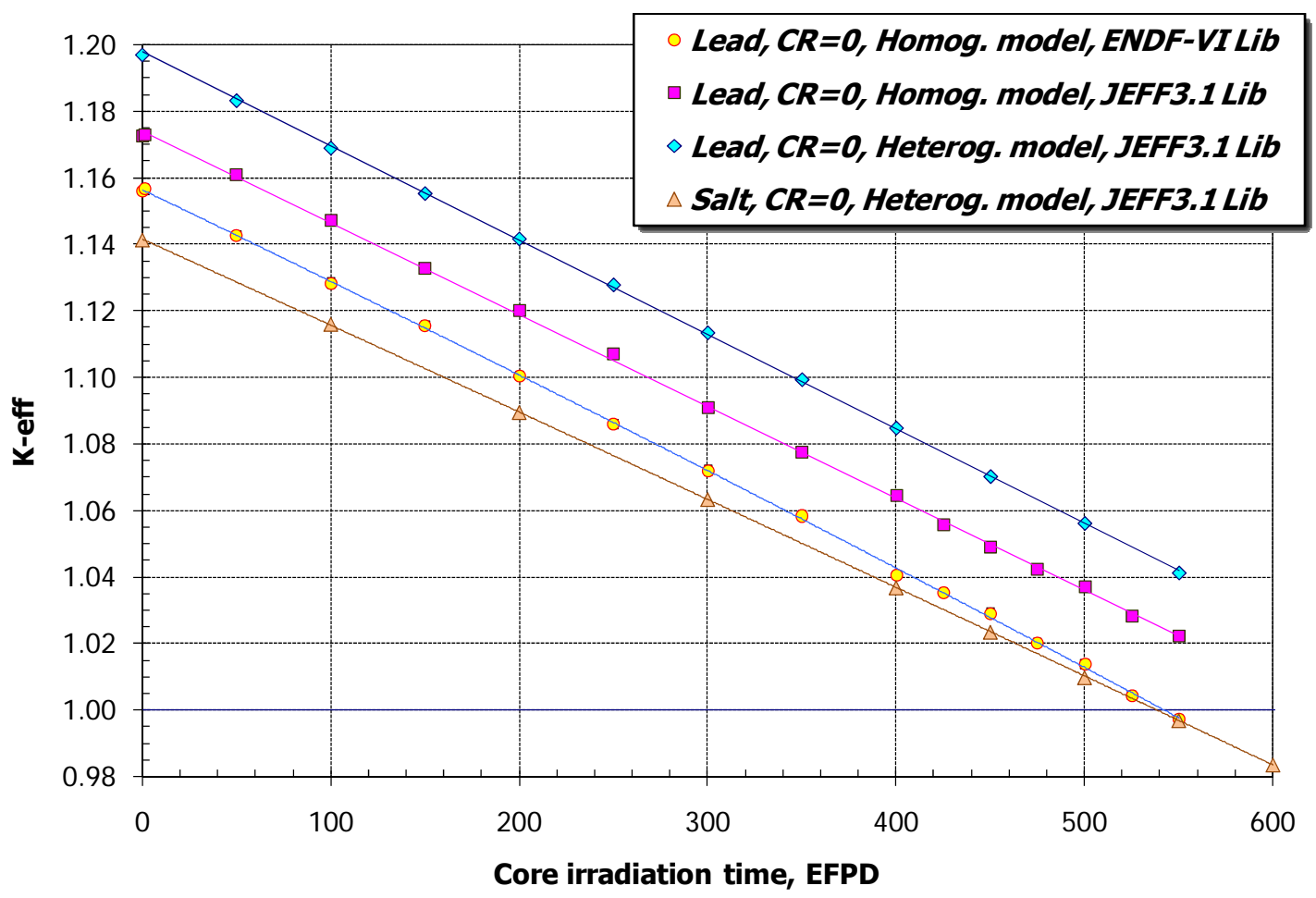

Figure 5.3.1-3 $\mathrm{CR}=0$ cores multiplication factors versus irradiation time

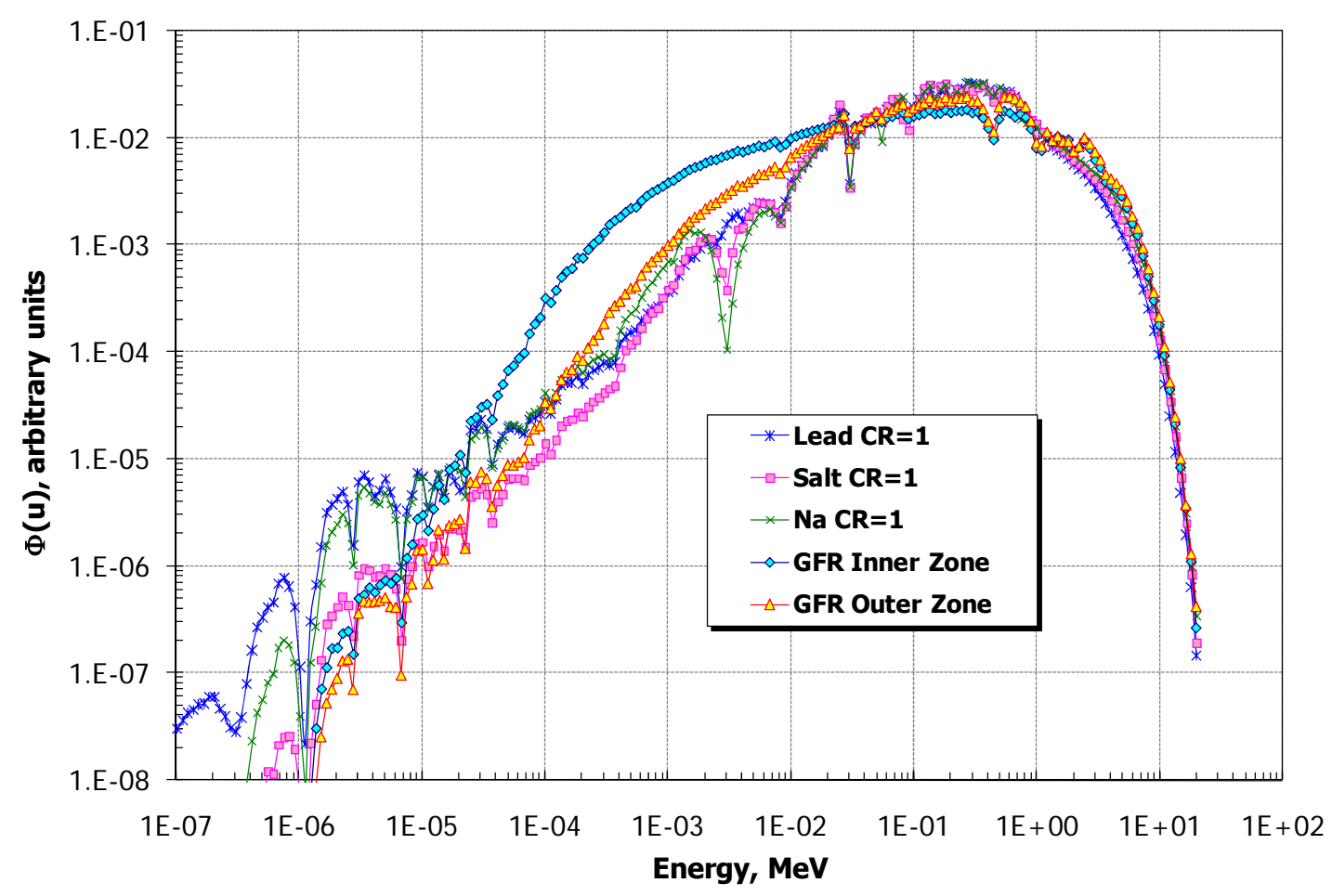

Figure 5.3.1-4 Comparison of neutron spectra in $\mathrm{CR}=1$ cores 
Project No 06-040: Flexible Conversion Ratio Fast Reactor Systems Evaluation

Table 5.3.1-3 One-group cross-section comparison for different reactor types

\begin{tabular}{|c|c|c|c|c|}
\hline \multirow{2}{*}{$\begin{array}{c}\text { Nuclide } \\
\text { (ZZAAA) }\end{array}$} & \multicolumn{4}{|c|}{ GFR } \\
\cline { 2 - 5 } & \multicolumn{2}{|c|}{$\sigma(\mathrm{n}, \gamma)$} & \multicolumn{2}{c|}{$\sigma(\mathrm{n}, \mathrm{f})$} \\
\cline { 2 - 5 } & Outer & Inner & Outer & Inner \\
\hline 92235 & 0.51 & 0.89 & 1.83 & 2.59 \\
\hline 92238 & 0.25 & 0.38 & 0.05 & 0.05 \\
\hline 94238 & 0.50 & 0.96 & 1.26 & 1.49 \\
\hline 94239 & 0.45 & 0.93 & 1.75 & 2.19 \\
\hline 94240 & 0.45 & 0.81 & 0.42 & 0.38 \\
\hline 94241 & 0.45 & 0.75 & 2.44 & 3.40 \\
\hline 94242 & 0.45 & 0.77 & 0.30 & 0.27 \\
\hline
\end{tabular}

\begin{tabular}{|c|c|c|c|}
\hline \multicolumn{4}{|c|}{$\mathrm{Na}$} \\
\hline \multicolumn{2}{|c|}{$\sigma(\mathrm{n}, \gamma)$} & \multicolumn{2}{c|}{$\sigma(\mathrm{n}, \mathrm{f})$} \\
\hline Outer & Inner & Outer & Inner \\
\hline 0.43 & 0.47 & 1.65 & 1.73 \\
\hline 0.22 & 0.24 & 0.04 & 0.03 \\
\hline 0.41 & 0.46 & 1.16 & 1.15 \\
\hline 0.34 & 0.39 & 1.68 & 1.70 \\
\hline 0.38 & 0.41 & 0.38 & 0.35 \\
\hline 0.38 & 0.42 & 2.21 & 2.31 \\
\hline 0.36 & 0.40 & 0.27 & 0.24 \\
\hline
\end{tabular}

\begin{tabular}{|c|c|c|c|c|}
\hline \multirow{2}{*}{$\begin{array}{c}\text { Nuclide } \\
(\text { ZZAAA })\end{array}$} & \multicolumn{4}{|c|}{$\mathrm{Pb}(\mathrm{CR} 1)$} \\
\cline { 2 - 5 } & \multicolumn{2}{|c|}{$\sigma(\mathrm{n}, \gamma)$} & \multicolumn{2}{c|}{$\sigma(\mathrm{n}, \mathrm{f})$} \\
\cline { 2 - 5 } & Outer & Inner & Outer & Inner \\
\hline 92235 & 0.42 & 0.43 & 1.64 & 1.65 \\
\hline 92238 & 0.22 & 0.23 & 0.03 & 0.02 \\
\hline 94238 & 0.41 & 0.41 & 1.15 & 1.13 \\
\hline 94239 & 0.34 & 0.35 & 1.66 & 1.65 \\
\hline 94240 & 0.38 & 0.38 & 0.36 & 0.34 \\
\hline 94241 & 0.38 & 0.39 & 2.20 & 2.21 \\
\hline 94242 & 0.36 & 0.37 & 0.25 & 0.23 \\
\hline
\end{tabular}

\begin{tabular}{|c|c|c|c|}
\hline \multicolumn{4}{|c|}{$\mathrm{Pb}(\mathrm{CR} 0)$} \\
\hline \multicolumn{2}{|c|}{$\sigma(\mathrm{n}, \gamma)$} & \multicolumn{2}{c|}{$\sigma(\mathrm{n}, \mathrm{f})$} \\
\hline Fresh & Twice & Fresh & Twice \\
\hline 0.50 & 0.50 & 1.80 & 1.79 \\
\hline 0.32 & 0.29 & 0.03 & 0.02 \\
\hline 0.49 & 0.48 & 1.22 & 1.18 \\
\hline 0.44 & 0.44 & 1.75 & 1.71 \\
\hline 0.44 & 0.43 & 0.38 & 0.34 \\
\hline 0.45 & 0.44 & 2.41 & 2.38 \\
\hline 0.44 & 0.43 & 0.27 & 0.24 \\
\hline
\end{tabular}

\begin{tabular}{|c|c|c|c|c|}
\hline \multirow{2}{*}{$\begin{array}{c}\text { Nuclide } \\
\text { (ZZAAA) }\end{array}$} & \multicolumn{4}{|c|}{ Salt(CR1) } \\
\cline { 2 - 5 } & \multicolumn{2}{|c|}{$\sigma(\mathrm{n}, \gamma)$} & \multicolumn{2}{c|}{$\sigma(\mathrm{n}, \mathrm{f})$} \\
\cline { 2 - 5 } & Outer & Inner & Outer & Inner \\
\hline 92235 & 0.41 & 0.43 & 1.62 & 1.66 \\
\hline 92238 & 0.22 & 0.23 & 0.03 & 0.03 \\
\hline 94238 & 0.39 & 0.42 & 1.15 & 1.14 \\
\hline 94239 & 0.33 & 0.36 & 1.65 & 1.65 \\
\hline 94240 & 0.36 & 0.38 & 0.37 & 0.35 \\
\hline 94241 & 0.37 & 0.39 & 2.17 & 2.23 \\
\hline 94242 & 0.35 & 0.37 & 0.26 & 0.25 \\
\hline
\end{tabular}

\begin{tabular}{|c|c|c|c|}
\hline \multicolumn{4}{|c|}{ Salt(CR0) } \\
\hline \multicolumn{2}{|c|}{$\sigma(\mathrm{n}, \gamma)$} & \multicolumn{2}{c|}{$\sigma(\mathrm{n}, \mathrm{f})$} \\
\hline Fresh & Twice & Fresh & Twice \\
\hline 0.51 & 0.54 & 1.81 & 1.87 \\
\hline 0.31 & 0.32 & 0.04 & 0.03 \\
\hline 0.49 & 0.52 & 1.25 & 1.22 \\
\hline 0.45 & 0.49 & 1.75 & 1.76 \\
\hline 0.44 & 0.47 & 0.40 & 0.36 \\
\hline 0.45 & 0.47 & 2.42 & 2.49 \\
\hline 0.44 & 0.47 & 0.29 & 0.25 \\
\hline
\end{tabular}

Similarities in the neutronic performance of the compared cores can be attributed to the fact that all cores have generally similar neutron spectra despite the differences in the coolants and lattice geometries. Neutron spectra for all the reactor concepts are presented in Figure 5.3.1-4. Significant differences can be observed only in GFR core regions with large $\mathrm{BeO}$ content. Otherwise, the neutron spectra are very similar. This statement is supported by the comparison of 
one-group cross-sections calculated for the most important actinides and all the reactor types (Table 5.3.1-3). Table 5.3.1-4 summarizes the capture to fission cross-section ratios for the same cases. Only minor variations in the cross-sections and in the cross-section ratios can be observed with no clear advantage of one coolant type over the other. As a result of such minor differences, the goal of achieving near unity conversion ratio with about the same initial enrichment can be achieved by all the considered reactors.

Table 5.3.1-4. One-group capture to fission cross-section ratio comparison

\begin{tabular}{|c|c|c|c|c|}
\hline \multirow{2}{*}{$\begin{array}{c}\text { Nuclide } \\
\text { (ZZAAA) }\end{array}$} & \multicolumn{2}{|c|}{ GFR(CR1) } & \multicolumn{2}{c|}{$\mathrm{Na}(\mathrm{CR} 1)$} \\
\cline { 2 - 5 } & Outer & Inner & Outer & Inner \\
\hline 92235 & 0.28 & 0.34 & 0.26 & 0.27 \\
\hline 92238 & 4.87 & 7.93 & 5.76 & 7.36 \\
\hline 94238 & 0.40 & 0.65 & 0.36 & 0.40 \\
\hline 94239 & 0.26 & 0.43 & 0.20 & 0.23 \\
\hline 94240 & 1.06 & 2.13 & 0.99 & 1.19 \\
\hline 94241 & 0.18 & 0.22 & 0.17 & 0.18 \\
\hline 94242 & 1.46 & 2.83 & 1.34 & 1.66 \\
\hline
\end{tabular}

\begin{tabular}{|c|c|c|c|c|}
\hline \multirow{2}{*}{$\begin{array}{c}\text { Nuclide } \\
\text { (ZZAAA) }\end{array}$} & \multicolumn{2}{|c|}{$\mathrm{Pb}(\mathrm{CR} 1)$} & \multicolumn{2}{c|}{$\mathrm{Pb}(\mathrm{CR} 0)$} \\
\cline { 2 - 5 } & Outer & Inner & Fresh & Twice \\
\hline 92235 & 0.26 & 0.26 & 0.28 & 0.28 \\
\hline 92238 & 7.77 & 9.32 & 10.26 & 11.79 \\
\hline 94238 & 0.35 & 0.37 & 0.40 & 0.41 \\
\hline 94239 & 0.21 & 0.21 & 0.25 & 0.26 \\
\hline 94240 & 1.04 & 1.12 & 1.17 & 1.27 \\
\hline 94241 & 0.17 & 0.18 & 0.18 & 0.18 \\
\hline 94242 & 1.45 & 1.59 & 1.61 & 1.83 \\
\hline
\end{tabular}

\begin{tabular}{|c|c|c|c|c|}
\hline \multirow{2}{*}{$\begin{array}{c}\text { Nuclide } \\
\text { (ZZAAA) }\end{array}$} & \multicolumn{2}{|c|}{ Salt(CR1) } & \multicolumn{2}{c|}{ Salt(CR0) } \\
\cline { 2 - 5 } & Outer & Inner & Fresh & Twice \\
\hline 92235 & 0.25 & 0.26 & 0.28 & 0.29 \\
\hline 92238 & 6.60 & 7.80 & 8.54 & 10.80 \\
\hline 94238 & 0.34 & 0.37 & 0.40 & 0.43 \\
\hline 94239 & 0.20 & 0.21 & 0.25 & 0.28 \\
\hline 94240 & 0.97 & 1.09 & 1.11 & 1.31 \\
\hline 94241 & 0.17 & 0.18 & 0.19 & 0.19 \\
\hline 94242 & 1.34 & 1.53 & 1.50 & 1.85 \\
\hline
\end{tabular}

An additional parameter for comparison of different core designs is their potential for selfcontrollability in the most restricting accident scenarios by passive means. The quasi-static safety 
analysis approach was adopted in order to assess this potential. The analysis methodology is described in detail in Appendix 3A. Table 5.3.1-5 summarizes the operating parameters required for the analysis for all the reactor designs.

The results of the reactivity coefficients and self-controllability criteria calculations are summarized in Table 5.3.1-6. The reactivity coefficient due to the Doppler effect is practically the same for all the designs because it is primarily determined by the fuel composition, which is similar in all cases.

The fuel and core radial thermal expansion coefficients depend on a combination of fuel lattice and core geometry but still appear to be very similar for all the designs.

The CTC generally follows the coolant thermal expansion coefficient. Therefore, it is smallest in magnitude for the lead core and should be the largest for the salt core. Negative CTC in the salt core was achieved due to the use of Lithium thermal Expansion Modules (LEMs) described in Chapter 4 of this report. Without the LEMs, the salt-cooled core would have positive CTC of about $0.80 \notin / \mathrm{K}$ which is larger than the CTC of the lead or sodium-cooled cores by over a factor of five. A core with such a large positive CTC cannot satisfy self-controllability criteria.

The lead-cooled design can satisfy all the self-controllability criteria, although the A/B limit is satisfied only for a core with near uniform power distribution. The limit on the A/B ratio for the sodium-cooled core is not satisfied even without a conservative power peaking margin. The saltcooled core satisfies all the criteria exclusively due to the use of LEMs.

The GFR design was not considered in this part of the comparison because the quasi-static approach to reactor safety is somewhat different for gas-cooled reactors with a direct power conversion cycle [Handwerk et al., 2007]. Application of the modified approach had shown that passive core shutdown is possible in all enveloping accident scenarios except for the unprotected LOCA at the end of the cycle. A unique feature of the considered GFR design is negative coolant void worth which can be achieved using a $\mathrm{S}-\mathrm{CO}_{2}$ radial reflector [Handwerk et al., 2007].

Tables 5.3.1-7 and 5.3.1-8 summarize calculations of fast fluence to the critical structural components of the $\mathrm{CR}=1$ and $\mathrm{CR}=0$ cores respectively. The adopted limit of $5 \times 10^{19}$ (neutrons $>1$ $\mathrm{MeV}) / \mathrm{cm}^{2}$ is satisfied for all the designs and conversion ratios with a significant margin. The use of axial and radial $\mathrm{B}_{4} \mathrm{C}$ shields was found to be very effective; thus the radiation damage to the reactor vessel and core support plate does not represent a major concern for the assumed core configurations. In the lead-cooled core, the fluence limits are conservatively satisfied without the use of radial shielding assemblies due to the favorable lead properties as a neutron reflector. Zero conversion ratio cores have slightly higher fluence values than $\mathrm{CR}=1$ cores with corresponding coolants because of the higher neutron leakage from the former core designs. 
Project No 06-040: Flexible Conversion Ratio Fast Reactor Systems Evaluation

Table 5.3.1-5. Core Operating Parameter Limits

\begin{tabular}{|l|r|r|r|}
\hline Parameter & Lead & Salt & $\mathrm{Na}$ \\
\hline Coolant Inlet Temperature, ${ }^{\circ} \mathrm{C}$ & 479 & 496 & 352 \\
\hline Coolant Outlet temperature, ${ }^{\circ} \mathrm{C}$ & 574 & 580 & 502 \\
\hline Core Coolant Temperature Rise, $\Delta \mathrm{T}_{\mathrm{c}},{ }^{\circ} \mathrm{C}$ & 95 & 84 & 150 \\
\hline Coolant Freezing Point, ${ }^{\circ} \mathrm{C}$ & 327 & 396 & 98 \\
\hline Margin to Freezing, ${ }^{\circ} \mathrm{C}$ & 152 & 100 & 254 \\
\hline${\text { Cladding Failure Limit, }{ }^{\circ} \mathrm{C}}^{\text {Margin to Cladding Failure, }}{ }^{\circ} \mathrm{C}$ & 725 & 725 & 725 \\
\hline
\end{tabular}

Table 5.3.1-6. Summary of reactivity feedback parameters

\begin{tabular}{|c|c|c|c|c|c|c|c|}
\hline & Units & Lead & $\pm \sigma$ & Salt & $\pm \sigma$ & $\mathrm{Na}$ & $\pm \sigma$ \\
\hline$\beta$ & & 0.0036 & 0.0001 & 0.0039 & 0.0001 & 0.0038 & 0.0001 \\
\hline$\alpha_{\mathrm{DC}}$ & $\phi / \mathrm{K}$ & -0.111 & 0.030 & -0.092 & 0.030 & -0.130 & 0.030 \\
\hline$\alpha_{e}$ & $\phi / K$ & -0.117 & 0.026 & -0.050 & 0.022 & -0.091 & 0.018 \\
\hline$\alpha_{\mathrm{Co}}$ & $\phi / \mathrm{K}$ & +0.131 & 0.052 & -0.040 & 0.044 & +0.156 & 0.041 \\
\hline$\alpha_{\mathrm{RD}}$ & $\phi / \mathrm{K}$ & $\sim 0$ & $\mathrm{~N} / \mathrm{A}$ & $\sim 0$ & N/A & $\sim 0$ & N/A \\
\hline$\alpha_{R}$ & $\phi / K$ & -0.135 & 0.013 & -0.159 & 0.022 & -0.145 & 0.018 \\
\hline $\mathrm{A}$ & $\phi$ & -22.92 & 3.99 & -15.66 & 3.32 & -44.19 & 7.03 \\
\hline $\mathrm{B}$ & $\phi$ & -17.43 & 2.43 & -22.43 & 2.61 & -26.67 & 4.25 \\
\hline $\mathrm{C}$ & $\notin / \mathrm{K}$ & -0.23 & 0.05 & -0.38 & 0.06 & -0.21 & 0.06 \\
\hline $\mathrm{A} / \mathrm{B}$ & & 1.31 & 0.29 & 0.70 & 0.06 & 1.66 & 0.37 \\
\hline $\mathrm{C} \triangleq \mathrm{Tc} / \mathrm{B}$ & & 1.27 & 0.31 & 1.40 & 0.11 & 1.18 & 0.36 \\
\hline$\Delta \rho_{\mathrm{TOP}} / \mathrm{B}$ & & 0.33 & 0.05 & 0.24 & 0.01 & 1.05 & 0.17 \\
\hline A/B limits & & \multicolumn{2}{|c|}{$\mathrm{x}<1.06\left(1.59^{* *}\right)$} & \multicolumn{2}{|c|}{$x<1.15(1.73)$} & \multicolumn{2}{|c|}{$x<0.99(1.49)$} \\
\hline $\mathrm{C} \Delta \mathrm{T}_{\mathrm{c}} / \mathrm{B}$ limits & & \multicolumn{2}{|c|}{$1<\mathrm{x}<1.99(2.39)$} & \multicolumn{2}{|c|}{$1<x<2.36(2.94)$} & \multicolumn{2}{|c|}{$1<x<1.90(2.25)$} \\
\hline$\Delta \rho_{\mathrm{TOP}} / \mathrm{B}$ limits & & \multicolumn{2}{|c|}{$\mathrm{x}<1.06(1.59)$} & \multicolumn{2}{|c|}{$x<1.15(1.73)$} & \multicolumn{2}{|c|}{$x<0.99(1.49)$} \\
\hline
\end{tabular}

${ }^{* *}$ Values in parentheses pertain to margin factor $\gamma=1$ (Eq. 1 in Section 4 of Appendix 3A).

Table 5.3.1-7 Fast fluence accumulated in critical structural components of $\mathrm{CR}=1$ designs

\begin{tabular}{|l|c|c|c|}
\hline & Lead & Salt & Na \\
\hline Parameter & CR=1 & CR=1 & CR=1 \\
\hline Vessel $(>0.1 \mathrm{MeV})$ & $(6.4 \pm 0.4) \times 10^{18}$ & $(1.0 \pm 0.7) \times 10^{16}$ & $(3.3 \pm 2.0) \times 10^{16}$ \\
\hline Core support plate $(>0.1 \mathrm{MeV})$ & $(3.4 \pm 0.2) \times 10^{19}$ & $(1.1 \pm 0.1) \times 10^{19}$ & $(8.9 \pm 0.1) \times 10^{20}$ \\
\hline
\end{tabular}


Project No 06-040: Flexible Conversion Ratio Fast Reactor Systems Evaluation

Table 5.3.1-8 Fast fluence accumulated in critical structural components of $\mathrm{CR}=0$ designs

\begin{tabular}{|l|c|c|}
\hline & Lead & Salt \\
\hline Parameter & CR=0 & CR=0 \\
\hline Vessel $(>0.1 \mathrm{MeV})$ & $(9.3 \pm 0.5) \times 10^{18}$ & $(3.7 \pm 2.0) \times 10^{16}$ \\
\hline Core support plate $(>0.1 \mathrm{MeV})$ & $(4.3 \pm 0.2) \times 10^{19}$ & $(1.2 \pm 0.1) \times 10^{19}$ \\
\hline
\end{tabular}

Finally, the studied reactor designs were compared with respect to their decay heat generation after shutdown. It was found that fast spectrum reactors with actinide bearing fuel have decay heat powers which differ substantially from the standard decay heat curve used for the safety analysis of LWRs. The differences between the decay heat of the concepts studied and that of a typical PWR core are plotted versus time elapsed after shutdown in Figures 5.3.1-4 and 5.3.1-5 for $C R=1$ and $C R=0$ cores, respectively. All $C R=1$ core designs have very similar decay power up to about $10^{4}$ seconds after shutdown. In this period, the decay heat is also comparable to that of a PWR. In the following period, the decay heat of all $\mathrm{CR}=1$ cores becomes significantly larger than the PWR. The difference reaches $50 \%$ for the sodium core and over $70 \%$ for the lead and salt-cooled cores. Generally, the decay heat of salt and lead-cooled cores with both conversion ratios is practically identical up to $10^{7}$ seconds. All the reactor designs have decay heat that eventually becomes much higher than that of a PWR.

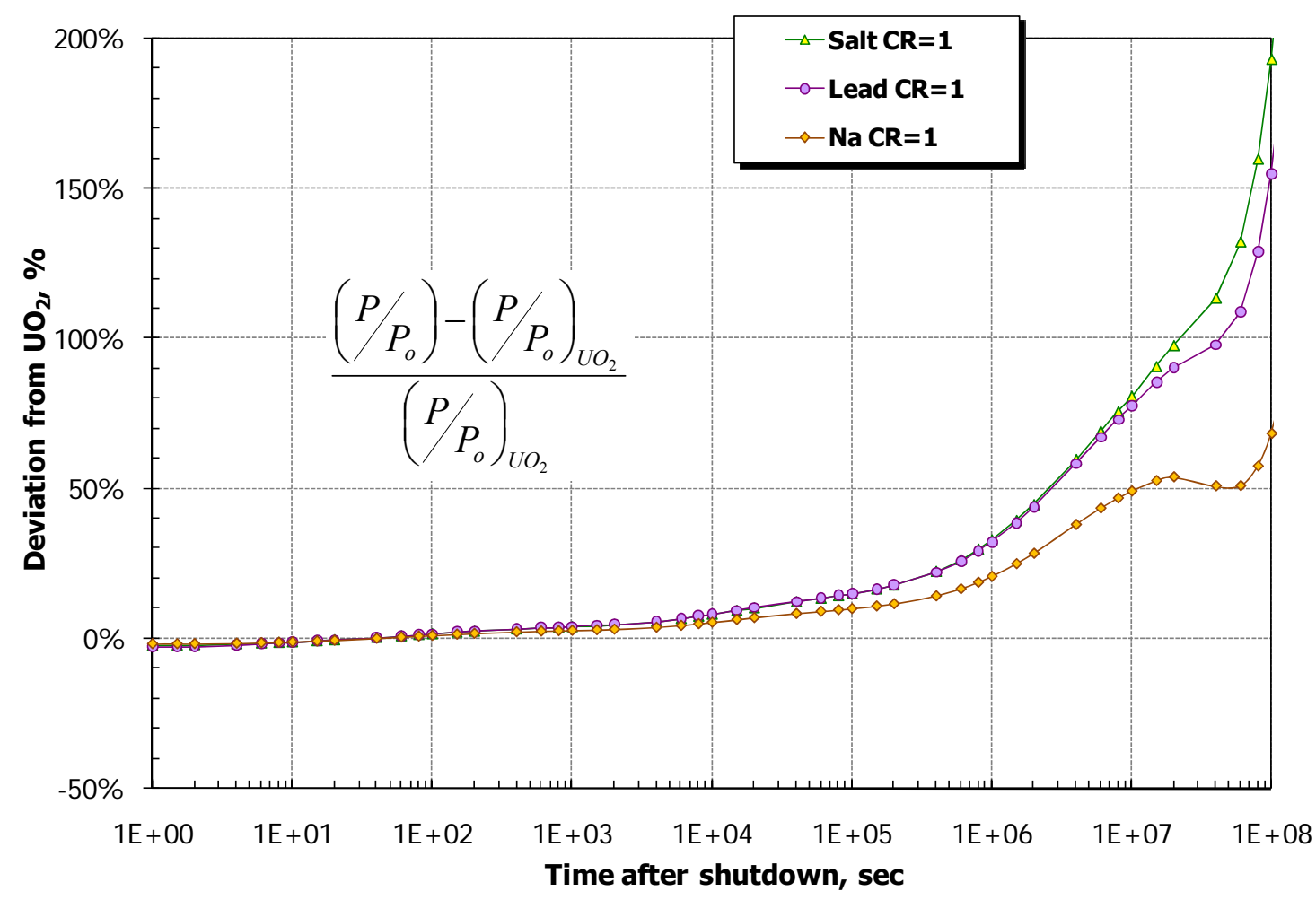

Figure 5.3.1-4. Deviation of $\mathrm{CR}=1$ core decay heat from typical PWR decay heat 
Project No 06-040: Flexible Conversion Ratio Fast Reactor Systems Evaluation

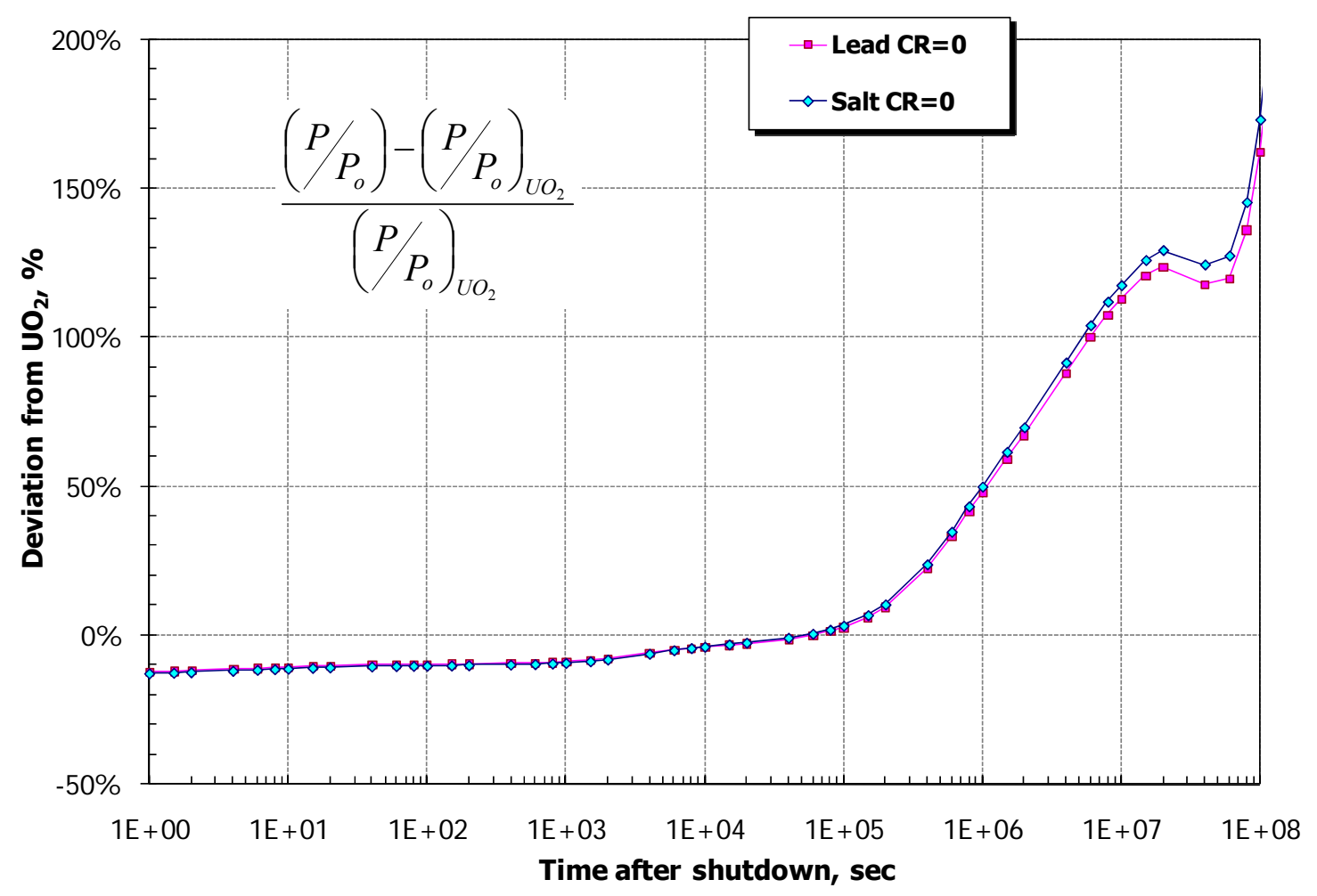

Figure 5.3.1-5. Deviation of $\mathrm{CR}=1$ core decay heat from typical PWR decay heat

\subsubsection{Coolant Comparison}

The coolant is an important contributor to safety characteristics of the reactor and affects its economics. Since the early development of fast reactors, various coolant types have been considered based on the comparison of multiple design aspects: reactor physics, thermal hydraulics, achievable parameters of the reactor operation, safety, corrosion, etc. In addition, the selection of coolant is a function of economic considerations and technological maturity. Three fast reactor systems included in the Gen IV Roadmap [Roadmap, 2002] are sodium, lead, and gas-cooled reactors. In addition, a FCR liquid salt-cooled fast reactor system has been developed in this project at MIT. This chapter compares the coolant types based on their physical and chemical properties and discusses some implications for thermal hydraulic and safety performance.

\subsubsection{Thermophysical Properties}

Table 5.3.2-1 compares thermophysical properties of five coolants: lead, lead-bismuth, sodium, liquid salt, and supercritical carbon dioxide. The properties are presented for two temperatures: $450^{\circ} \mathrm{C}$, which is a typical core inlet or average temperature during steady state, and $700^{\circ} \mathrm{C}$, which represents an expected temperature during transients. Liquid metals are an attractive choice of coolant because of their high heat transfer capabilities and no need for pressurization. Gases and salt coolants are non-corrosive, transparent and do not react with secondary fluids or air. 
Table 5.3.2-1. Thermophysical properties

\begin{tabular}{|c|c|c|c|c|c|}
\hline & Lead* & $\begin{array}{c}\text { Lead- } \\
\text { Bismuth* } \\
(0.445 \mathrm{~Pb}- \\
0.555 \mathrm{Bi})\end{array}$ & Sodium* & $\begin{array}{c}\text { Salt } \\
\mathrm{NaCl-KCl-MgCl} \\
(30-20-50)\end{array}$ & $\begin{array}{l}\mathrm{S}-\mathrm{CO}_{2} * * \\
\text { at } 20 \mathrm{MPa}\end{array}$ \\
\hline Atomic Number & 82 & - & 11 & - & - \\
\hline Atomic Weight & 207.21 & - & 22.997 & - & 44.01 \\
\hline Boiling Point, ${ }^{\circ} \mathrm{C}$ & 1737 & 1670 & 892 & 2500 & -78 \\
\hline Melting Point, ${ }^{\circ} \mathrm{C}$ & 327.4 & 123.5 & 97.8 & 396 & -58 \\
\hline $\begin{array}{l}\text { Density, } \rho, \mathrm{kg} / \mathrm{m}^{3} \\
\text { At } 450^{\circ} \mathrm{C} \\
\text { At } 700^{\circ} \mathrm{C} \\
\end{array}$ & $\begin{array}{l}10536 \\
10242 \\
\end{array}$ & $\begin{array}{c}10180 \\
9876 \\
\end{array}$ & $\begin{array}{l}842 \\
780 \\
\end{array}$ & $\begin{array}{l}1910 \\
1715 \\
\end{array}$ & $\begin{array}{l}143.75 \\
104.16 \\
\end{array}$ \\
\hline $\begin{array}{l}\text { Thermal Expansion Coefficient, } \\
\alpha, \% \mathrm{Vol} / \mathrm{K} \\
\text { At } 450^{\circ} \mathrm{C} \\
\text { At } 700^{\circ} \mathrm{C} \\
\end{array}$ & $\begin{array}{l}0.011 \\
0.012 \\
\end{array}$ & $\begin{array}{l}0.0130 \\
0.0135 \\
\end{array}$ & $\begin{array}{l}0.029 \\
0.031 \\
\end{array}$ & $\begin{array}{l}0.041 \\
0.045 \\
\end{array}$ & $\begin{array}{l}0.152 \\
0.104 \\
\end{array}$ \\
\hline $\begin{array}{l}\text { Dynamic Viscosity, } \mu, \mathrm{kg} / \mathrm{m}-\mathrm{s} \\
\text { At } 450^{\circ} \mathrm{C} \\
\text { At } 700^{\circ} \mathrm{C}\end{array}$ & $\begin{array}{l}2.01 \times 10- \\
3 \\
1.40 \times 10^{-3} \\
\end{array}$ & $\begin{array}{l}1.49 \times 10^{-3} \\
1.13 \times 10^{-3}\end{array}$ & $\begin{array}{l}2.59 \times 10^{-4} \\
1.81 \times 10^{-4}\end{array}$ & $\begin{array}{l}3.47 \times 10^{-3} \\
1.18 \times 10^{-3}\end{array}$ & $\begin{array}{l}3.46 \times 10^{-5} \\
4.17 \times 10^{-5}\end{array}$ \\
\hline $\begin{array}{l}\text { Thermal Conductivity, } \mathrm{k}, \mathrm{W} / \mathrm{m}- \\
\mathrm{K} \\
\text { At } 450^{\circ} \mathrm{C} \\
\text { At } 700^{\circ} \mathrm{C}\end{array}$ & $\begin{array}{l}15.4 \\
17.7 \\
\end{array}$ & $\begin{array}{l}14.9 \\
16.7 \\
\end{array}$ & $\begin{array}{l}66.1 \\
59.1 \\
\end{array}$ & $\begin{array}{l}\sim 0.39 \\
\sim 0.39 \\
\end{array}$ & $\begin{array}{l}0.056 \\
0.072 \\
\end{array}$ \\
\hline $\begin{array}{l}\text { Specific Heat, } \mathrm{c}_{\mathrm{p}}, \mathrm{J} / \mathrm{kgK} \\
\text { At } 450^{\circ} \mathrm{C} \\
\text { At } 700^{\circ} \mathrm{C}\end{array}$ & $\begin{array}{l}147 \\
147\end{array}$ & $\begin{array}{l}146 \\
146 \\
\end{array}$ & $\begin{array}{l}1272 \\
1276 \\
\end{array}$ & $\begin{array}{l}\sim 1004 . \\
\sim 1004 .\end{array}$ & $\begin{array}{l}1227.0 \\
1267.9 \\
\end{array}$ \\
\hline $\begin{array}{l}\text { Density Specific Heat Product, } \rho \\
\mathrm{c}_{\mathrm{p},} \mathrm{J} / \mathrm{cm}^{3} \mathrm{~K} \\
\text { At } 450^{\circ} \mathrm{C} \\
\text { At } 700^{\circ} \mathrm{C}\end{array}$ & $\begin{array}{l}1.55 \\
1.51\end{array}$ & $\begin{array}{l}1.49 \\
1.45\end{array}$ & $\begin{array}{l}1.07 \\
1.00\end{array}$ & $\begin{array}{l}1.92 \\
1.72\end{array}$ & $\begin{array}{l}0.18 \\
0.13\end{array}$ \\
\hline $\begin{array}{r}\text { Pr number } \\
\text { At } 450^{\circ} \mathrm{C} \\
\text { At } 700^{\circ} \mathrm{C} \\
\end{array}$ & $\begin{array}{l}0.0192 \\
0.0116 \\
\end{array}$ & $\begin{array}{l}0.0146 \\
0.0099 \\
\end{array}$ & $\begin{array}{l}0.0050 \\
0.0039 \\
\end{array}$ & $\begin{array}{l}8.9330 \\
3.0377 \\
\end{array}$ & $\begin{array}{l}0.7581 \\
0.7343 \\
\end{array}$ \\
\hline Transparency & Opaque & Opaque & Opaque & Transparent & Transparent \\
\hline
\end{tabular}

* Kutateladze et al., "Liquid Metal Coolants", Atomisdat, Moscow, 1976

${ }^{* *}$ NIST Website: www.nist.org

To a large extent, melting and boiling temperatures of coolants define the operating temperature window of the reactor systems. The boiling temperatures for all liquid coolants are well beyond the cladding failure limits. In addition, due to the high boiling temperatures of salt and leadalloy coolants, certain problems such as coolant voiding due to boiling in the core and associated reactivity insertion during accidents are eliminated. Sodium has the lowest boiling temperature among all coolants, which raises safety concerns during accidents involving substantial coolant heatup. On the other hand, the melting temperatures of salt and lead are relatively high, which creates additional operational constraints on reactor temperature during transients and refueling to avoid freezing. These boiling or freezing concerns are eliminated for gas-cooled reactors. However, gas reactors must be kept at high pressure to achieve an acceptably high heat transfer rate and, in the case of the direct $\mathrm{S}-\mathrm{CO}_{2}$ cycle, to take advantage of reduced pumping power near 
the critical point. This raises challenges for the design of post-LOCA decay heat removal systems, as heat removal capacities of gases at low pressure are mediocre.

Sodium coolant allows for a tight core packing. A small coolant fraction is acceptable because of the high thermal conductivity of sodium, resulting in a small film temperature drop. In addition, the relatively low viscosity of sodium means acceptable pressure drops and pumping power. As can be seen in Table 5.3.2-1, thermal conductivity of lead-alloy coolants is nearly four times smaller than sodium, resulting in higher values for film temperatures.

The coolant velocity in lead reactors is limited to $3 \mathrm{~m} / \mathrm{s}$ because of corrosion issues. A typical velocity for sodium is around $8-10 \mathrm{~m} / \mathrm{s}$ [Tucek, 2006]. Low coolant velocity in a lead-cooled core affects the heat removal capabilities and consequently the cladding temperatures and reactor operating temperatures. To keep the coolant velocity within the $3 \mathrm{~m} / \mathrm{s}$ constraint, the lead-cooled cores must have a higher coolant volume fraction. This is possible due to the small absorption cross-section and low moderating power of lead alloys. Because of the lower heat transfer coefficient and higher density, lead and lead-bismuth cooled reactors require higher core pumping power than sodium cores. Increasing core coolant volume fraction by opening the core lattice can compensate for those effects but reduces the core power density as a consequence. Because of the superior thermal properties of sodium and smaller pumping power requirements, the power density of sodium cores can be up to three times higher than in lead-cooled reactors. Correspondingly, the core size of sodium-cooled reactors is much smaller. On the other hand, due to the high density of lead and lead-bismuth, radial reflectors and shields to attenuate gamma-rays and energetic neutrons are not required for heavy-metal cooled reactors, which somewhat compensates for the core size difference.

In the case of salt-cooled reactors, coolant density is comparable to sodium, but the required pumping power is much larger due to higher viscosity and tight core lattice. Contrary to leadalloy coolants, liquid salt coolants cannot employ a more open lattice because of the appreciable moderating power and large thermal expansion coefficient of liquid salts, which would result in unacceptably high coolant temperature coefficients. Therefore, liquid salt-cooled cores require a tight core lattice. The thermal conductivity of salts is very small, resulting in a large film temperature drop. On the other hand, because of their high heat capacity relative to sodium, salt coolants can store large amounts of decay heat during transients, making them attractive from a safety point of view. $\mathrm{S}-\mathrm{CO}_{2}$ gas is a poor heat transfer fluid compared to the other coolants because of its low density. To overcome the negative effects of low density, the gas must be pressurized. The very small thermal conductivity of $\mathrm{CO}_{2}$ results in a small heat transfer coefficient. In order to decrease cladding and fuel temperatures, a variety of techniques is generally used, including cladding surface roughening or implementation of repeated ribs.

\subsubsection{Chemical Properties}

Coolant chemical properties are summarized in Table 5.3.2-2. Compatibility of primary coolant with structural materials and secondary fluid is essential for safe plant operation. Lead is inert in contact with other coolants, but poses significant corrosion and degradation of structural materials concerns. Conversely, while sodium has favorable thermophysical properties, it reacts with water or air and is one of the most electropositive metals [IAEA TECDOC-1289, 2002]. The reaction of sodium with air or water can lead to fire, and therefore an intermediate heat transport loop or double wall heat exchanger is required. 
Project No 06-040: Flexible Conversion Ratio Fast Reactor Systems Evaluation

Table 5.3.2-2. Chemical Properties

\begin{tabular}{|c|c|c|c|c|}
\hline & Lead & Sodium & Salt & $\mathrm{S}-\mathrm{CO} 2$ \\
\hline $\begin{array}{l}\text { Interaction } \\
\text { with } \mathrm{H}_{2} \mathrm{O} \\
200-300^{\circ} \mathrm{C} \\
>420^{\circ} \mathrm{C}\end{array}$ & $\begin{array}{l}\text { Hydroxide is } \\
\text { produced } \mathrm{Pb}(\mathrm{OH}) 2 \\
\text { Depending on } \\
\text { pressure and } \\
\text { temperature of } \\
\text { injected water, at } 1 \\
\text { atm pressure } \\
\text { (operating pressure } \\
\text { of lead reactors), a } \\
\text { steam explosion is } \\
\text { possible over an } \\
\text { interface } \\
\text { temperature range } \\
\text { from about } 300^{\circ} \mathrm{C} \\
\text { to the water critical } \\
\text { temperature. } \\
\text { [Kurata, } 2004]\end{array}$ & $\begin{array}{l}2 \mathrm{Na}+2 \mathrm{H}_{2} \mathrm{O}= \\
2 \mathrm{NaOH}+\mathrm{H}_{2}+ \\
142 \mathrm{~kJ} / \text { mole. } \\
\\
2 \mathrm{Na}+\mathrm{H}_{2} \mathrm{O}= \\
\mathrm{Na}_{2} \mathrm{O}+\mathrm{H}_{2}+ \\
420 \mathrm{~kJ} / \text { mole } \\
\text { Burning reaction, } \\
\text { zone of small } \\
\text { flames at the } \\
\text { sodium-air } \\
\text { interface. } \\
\text { [TECHDOC } \\
\text { 1289] }\end{array}$ & $\begin{array}{l}\text { No chemical } \\
\text { reaction; salt } \\
\text { dissolves in } \\
\text { water }\end{array}$ & $\begin{array}{l}\text { Compatible with } \\
\text { water. No } \\
\text { reaction. }\end{array}$ \\
\hline $\begin{array}{l}\text { Interaction } \\
\text { with } \mathrm{S}-\mathrm{CO}_{2}\end{array}$ & $\begin{array}{l}\text { None reported } \\
\text { (Interaction with } \\
\text { air results in } \mathrm{Pb}_{2} \mathrm{O} \\
\text { and then } \mathrm{PbO} \text {. At } \\
\text { the temperature of } \\
450^{\circ} \mathrm{C} \text { the latter is } \\
\text { transformed to } \\
\mathrm{Pb}_{2} \mathrm{O}_{3} \text { and then at } \\
450^{\circ}-470^{\circ} \mathrm{C} \text { to } \\
\mathrm{Pb}_{3} \mathrm{O}_{4} \text {. Being } \\
\text { unstable, all these } \\
\text { compositions } \\
\text { dissociate into } \mathrm{PbO} \\
\text { and } \mathrm{O} 2 \text {.) }\end{array}$ & $\begin{array}{l}\text { When sodium } \\
\text { interacts with the } \\
\text { small amount of } \\
\text { oxygen, } \mathrm{Na}_{2} \mathrm{O} \\
\text { oxide is produced. } \\
\text { When it burns in } \\
\text { air, } \mathrm{Na}_{2} \mathrm{O}_{2} \text { is } \\
\text { formed. In the } \\
\text { molten sodium, } \\
\text { only } \mathrm{Na}_{2} \mathrm{O} \text { oxide } \\
\text { is stable. } \\
\text { [TECHDOC } \\
\text { 1289] }\end{array}$ & None reported & No reaction. \\
\hline $\begin{array}{l}\text { Compatibility } \\
\text { with } \\
\text { structural } \\
\text { materials }\end{array}$ & $\begin{array}{l}\text { Aggressive } \\
\text { corrosion by: } \\
-\quad \text { Direct } \\
\text { dissolution by } \\
\text { a surface } \\
\text { reaction } \\
\text { - Intergranular } \\
\text { attack. } \\
\text { Oxide film } \\
\text { formation tends in } \\
\text { inhibit the } \\
\text { corrosion rates. }\end{array}$ & $\begin{array}{l}\text { Corrosion is lower } \\
\text { than for lead or } \\
\text { water. Sodium is } \\
\text { practically non- } \\
\text { corrosive with } \\
\text { respect to } \\
\text { stainless steel. }\end{array}$ & $\begin{array}{l}\text { No serious } \\
\text { corrosion of } \\
\text { most stainless } \\
\text { steels }\end{array}$ & $\begin{array}{l}\text { Corrosion process } \\
\text { through radiolysis } \\
\text { follows the } \\
\text { pattern: } \\
-\quad \text { Formation of } \\
\text { protective } \\
\text { oxide layer } \\
-\quad \text { Breakaway } \\
\text { oxidation after } \\
\text { saturation } \\
\text { level is } \\
\text { reached. }\end{array}$ \\
\hline
\end{tabular}


For example, during a sodium based steam generator tube leak/rupture, the chemical reaction that takes place depends on the temperature of the fluid and the presence of impurities [IAEA TECDOC-1289, 2002]. At lower temperatures, hydroxide is produced, but at temperatures above $420^{\circ} \mathrm{C}$ the reaction is more energetic and is characterized by hydrogen release. The reaction results in small flames and a relatively low heat release. When sodium leaks into air, the ignition happens at temperatures above $180^{\circ} \mathrm{C}$ [Bagdassarov, 1998]. While interaction of liquid lead with air or water does not result in ignition and heat release, oxidation and compound formation are possible. Salt and gas coolants are inert in contact with air, water, or $\mathrm{CO}_{2}$. Therefore, from the prospective of the primary coolant interacting with the secondary fluid or leaking in the air, sodium is the least desired candidate.

Salt chemical properties were described in the section on salt properties and are repeated below. Chemically, liquid salts act as fluxing agents which prevent oxide film formation. The lack of a chemically passive film makes coolant chemistry control particularly important for liquid salt systems, and while this is easy to accomplish for fluoride salts it is somewhat more difficult for chlorides [Forsberg, 2007]. Corrosion characteristics of the selected ternary chloride are presented in a 1960 BNL report [Susskind et al., 1960], which states that the chloride produces no serious corrosion in most of the steels tested, including a Cr-Mo steel that may be comparable to the T-91 steel used in this design. The general chemical compatibility of liquid salts with structural materials makes it reasonable to expect that no major corrosion issues will be encountered. Nevertheless, experimental tests simulating core conditions for the selected coolant and structural materials will ultimately be needed to fully assess corrosion and chemical behavior.

With lead and lead-bismuth coolants, the key design challenge is not interaction with the secondary coolant, but corrosion of the primary systems, structures, and components (SSCs). Corrosion influenced by liquid metal interaction with primary SSCs can occur by direct dissolution or by intergranular attack. Since most materials have finite solubility in lead, the component surfaces must be protected. Solubility of various elements in sodium and lead are shown in Tables 5.3.2-3a and 5.3.2-3b, respectively. Table 5.3.2-4 lists the main elements of which T-91 (generally used as cladding material) and $316 \mathrm{~L}$ (vessel) are composed. The solubility is determined using Equation 5.3.2-1, which assumes that saturation concentration of the element in solution follows the Arrhenius equation [IAEA TECDOC-1289, 2002]. In the equation, $\mathrm{A}$ and $\mathrm{B}$ are experimentally determined constants, where A corresponds to entropy of solution $(\mathrm{kJ} / \mathrm{mole})$, and $\mathrm{B}$ is heat of evaporation $(\mathrm{kJ} / \mathrm{mole})$.

$\log C_{S}=A-B / T$

$5.3 .2-1$

The driving force for corrosion is the chemical activity of structural metals and lead. [LBE Handbook, 2007] Figure 5.3.2-1, derived from Tables 5.3.2-3a and 5.3.2-3b, shows the solubility of select elements in sodium and lead. The corrosion rate is also a function of temperature. As the temperature increases, the solubility increases as well. The solubility in lead is generally higher than in sodium except for Mo. In fact, the corrosion rates in sodium are generally so low that they are not considered. Another concern for lead and sodium reactors is the presence of oxygen in the coolant. For extended operations of a sodium reactor between 400 and $600^{\circ} \mathrm{C}$, the oxide $\left(\mathrm{Na}_{2} \mathrm{O}\right)$ content should not exceed 0.005 w/o because of potential mass 
transport and plugging [Handbook, 1957]. In lead-cooled reactors, careful oxygen control as a function of temperature is required. If the concentration of oxygen in lead is below a minimum value of activity, steel corrosion via dissolution takes place. On the other hand, oxygen activity above a certain limit leads to coolant contamination by lead oxide formation [LBE Handbook, 2007].

Table 5.3.2-3a. Solubility of different elements in liquid sodium [IAEA TECDOC 1289]

\begin{tabular}{|c|c|c|c|}
\hline Elements & \multicolumn{2}{|c|}{ Constants of Eq. 5.3.2-1 } & \multirow{2}{*}{$\begin{array}{c}\text { Temperature } \\
\text { range, } \mathrm{K}\end{array}$} \\
\hline $\mathrm{C}$ & A & B & $873-1223$ \\
\hline $\mathrm{Cu}$ & 5.2 & 5465 & $573-973$ \\
\hline $\mathrm{Fe}$ & 5.16 & 3055 & $573-1173$ \\
\hline $\mathrm{H}_{2}$ & 6.067 & 4310 & $273-673$ \\
\hline $\mathrm{Mo}$ & 3.27 & 2880 & $1073-1278$ \\
\hline $\mathrm{Na}_{2} \mathrm{O}$ & 1.2 & 3962 & $373-873$ \\
\hline $\mathrm{Ni}$ & 2.07 & 1777 & $573-1173$ \\
\hline $\mathrm{O}_{2}$ & - & 1570 & $383-823$ \\
\hline
\end{tabular}

Table 5.3.2-3b. Solubility of different elements in liquid lead [IAEA TECDOC 1289]

\begin{tabular}{|c|c|c|c|}
\hline Elements & \multicolumn{2}{|c|}{ Constants of Eq. 5.3.2-1 } & \multirow{2}{*}{$\begin{array}{l}\text { Temperature } \\
\text { range, } \mathrm{K}\end{array}$} \\
\hline & A & $\mathrm{B}$ & \\
\hline $\mathrm{C}$ & 1.026 & 3850 & $350-1000$ \\
\hline Co & 2.60 & 4400 & $350-1650$ \\
\hline $\mathrm{Cr}$ & 3.74 & 6750 & $908-1210$ \\
\hline $\mathrm{Cu}$ & 2.72 & 2360 & $327-1000$ \\
\hline $\mathrm{Fe}$ & 0.34 & 3450 & $330-910$ \\
\hline $\mathrm{H}_{2}$ & -1.946 & 2360 & $500-900$ \\
\hline $\mathrm{Mn}$ & 2.02 & 1825 & $327-1200$ \\
\hline Mo & \multicolumn{3}{|c|}{ solubility $<10-3 \mathrm{wt} . \%$ at $1000^{\circ} \mathrm{C}$} \\
\hline $\mathrm{N}_{2}$ & \multicolumn{3}{|c|}{ no solubility } \\
\hline $\mathrm{Nb}$ & \multicolumn{3}{|c|}{ solubility $<10-5$ wt. $\%$ at $1000^{\circ} \mathrm{C}$} \\
\hline $\mathrm{Ni}$ & 2.78 & 1000 & $330-1300$ \\
\hline \multirow[t]{2}{*}{$\mathrm{O}_{2}$} & - & 2176 & $350-850$ \\
\hline & 0.106 & & \\
\hline $\mathrm{Si}$ & 3.886 & 7180 & $1050-1250$ \\
\hline $\mathrm{Ti}$ & \multicolumn{3}{|c|}{ solubility $\sim 5.6 \cdot 10-4$ wt. $\%$ at $500^{\circ} \mathrm{C}$} \\
\hline $\mathrm{U}$ & 3.921 & 5121 & $400-800$ \\
\hline $\mathrm{Zr}$ & \multicolumn{3}{|c|}{ solubility $\sim 1.2 \cdot 10-9$ wt. $\%$ at $500^{\circ} \mathrm{C}$} \\
\hline
\end{tabular}


Table 5.3.2-4. Composition of T-91 and 316L steels.

\begin{tabular}{|l|l|l|l|l|l|l|l|l|l|l|}
\hline & $\mathrm{C}$ & $\mathrm{Cr}$ & $\mathrm{Ni}$ & $\mathrm{Mo}$ & $\mathrm{Mn}$ & $\mathrm{Si}$ & $\mathrm{Cu}$ & $\mathrm{Nb}$ & $\mathrm{Co}$ & $\mathrm{V}$ \\
\hline $\mathrm{T}-91$ & $0.1-0.11$ & $8.26-8.63$ & $0.13-0.23$ & $0.91-0.95$ & $0.43-0.78$ & $0.31-0.43$ & $0.19-0.05$ & $0.07-0.09$ & 0.02 & $0.20-0.23$ \\
\hline 316L & $0.012-0.02$ & $16-18$ & $10-17.392$ & $2-2.75$ & $0.2-2$ & $0.1-1$ & & & $0.06-0.14$ & \\
\hline
\end{tabular}

Reactor systems experience a temperature gradient along the coolant path. Therefore, without a protective layer between a material and lead coolant, removal of materials from hot regions and their deposition in cooler regions can occur [Ballinger, et al., 2004]. This phenomenon creates a buildup of corrosion products which can potentially plug heat exchanger tubes. Furthermore, blockage of core coolant channels reduces heat transfer and can lead to fuel pin overheating. Besides temperature, other contributing (or in some cases limiting) factors of material degradation are exposure time, flow rate, and coolant and material composition, including oxygen content in coolant. The following measures can be taken to reduce corrosive effects on the system:

- Reduction of operating temperatures

- Use of coating (corrosion resistant but structurally unsatisfactory material to face lead environment)

- Environment with self-protective film formation, provided through careful oxygen control in the system

- Use of materials with low solubility in lead

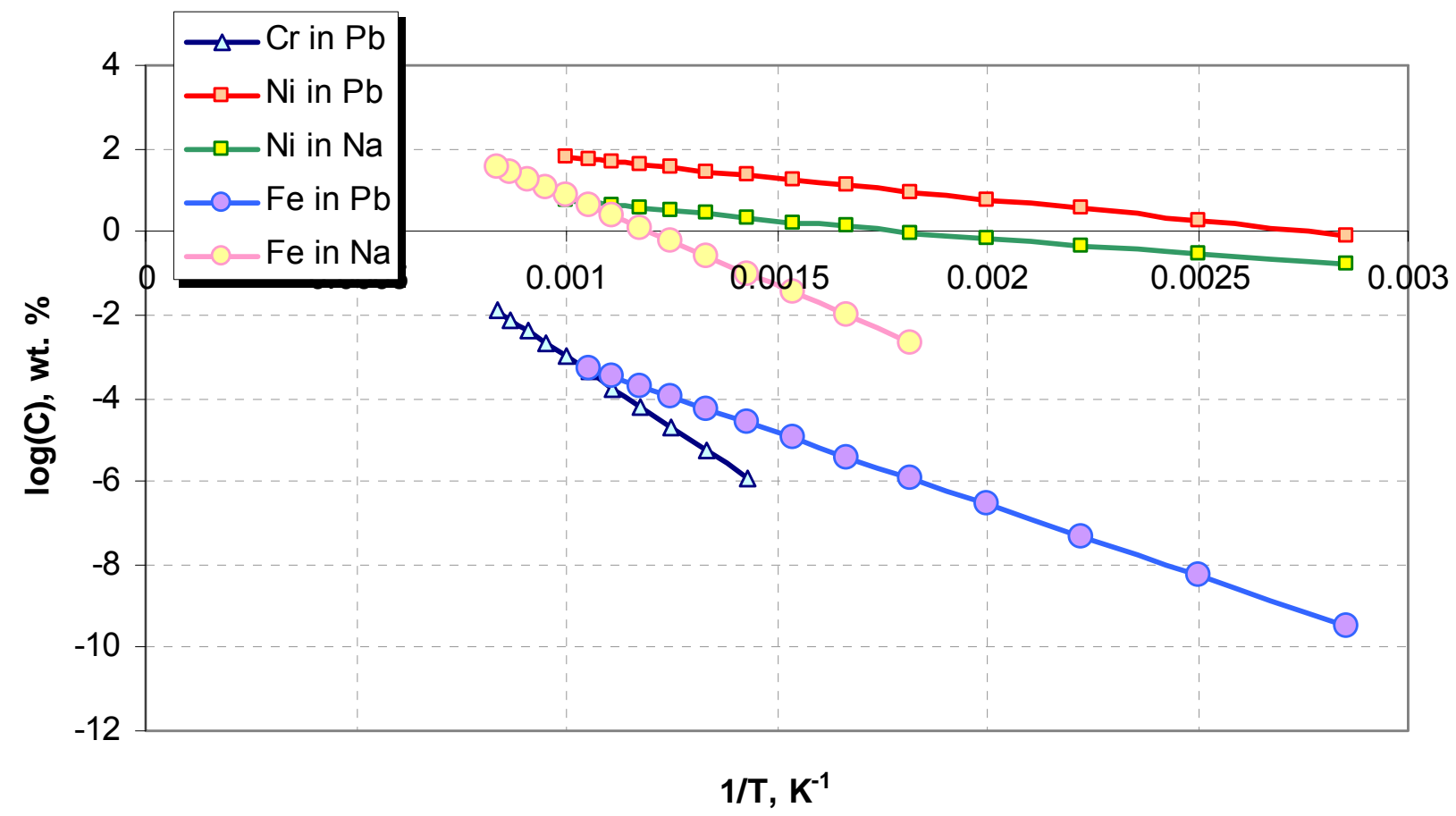

Figure 5.3.2-1. Solubility data of $\mathrm{Fe}, \mathrm{Cr}$, and $\mathrm{Ni}$ in liquid $\mathrm{Pb}$ and $\mathrm{Na}$

Self-protective films, of the same kind as oxide layers, have been considered as another defense mechanism against corrosion. A protective oxide layer can serve as a diffusion barrier, slowing the overall corrosion rate and preventing more severe materials degradation. However, both 
Project No 06-040: Flexible Conversion Ratio Fast Reactor Systems Evaluation

material dissolution in case of low oxygen concentration and surface oxidation in case of high oxygen concentration can occur. Therefore, an oxide layer can form given sufficient oxygen dissolved in the coolant, and active oxygen control is available. Thus, a lead-cooled system can only operate in a narrow range of oxygen concentration and temperatures.

The main mechanism of corrosion in $\mathrm{S}-\mathrm{CO}_{2}$ cooled reactors is radiolysis. The corrosion process begins with the formation of protective oxidation. The extent of the protective oxidation period depends on the operating temperatures, impurities in gas, and steel composition. [Thon, 2002] The growth of the oxide layer is characterized by the outward diffusion of chromium and simultaneous inward diffusion of $\mathrm{CO}_{2}$. The protective oxidation period can be sustained provided that the structural steel is able to accept the carbon produced by the oxidation reaction [Thon, 2002]. The second stage of the $\mathrm{CO}_{2}$ corrosion process, known as breakaway oxidation, is characterized by saturation of carbon in steel and the formation of a second layer of oxide on the oxide-metal interface [Thon, 2002].

\subsubsection{Coolant Activation}

\section{Operational Radioactivity}

Coolant activation during reactor operation can present challenges during refueling, repair work, and coolant disposal. In addition, activation products can affect the coolant purity requirements and accelerate the corrosion process. Lead coolant has four stable isotopes. The composition of unirradiated lead and neutron fission spectrum average radiative capture cross sections for each isotope are shown in Table 5.3.2-5. Lead-bismuth eutectic coolant has a lower melting point than pure lead, which reduces the possibility of coolant freezing during maintenance and refueling shutdowns. However, potential hazards from accumulated radioactivity because of Po210 outweigh the benefits of lower melting temperature. Po-210 emits energetic (5.3 MeV) alpha-particles with a 138-day half-life to form stable $\mathrm{Pb}-206$. The scheme of Po-210 generation is shown below. In lead-cooled reactors, Po-210 is generated through neutron capture by stable $\mathrm{Pb}-208$. $\mathrm{Pb}-209$ then quickly decays into $\mathrm{Bi}-209$ which in turn can undergo a neutron capture to produce Bi-210. Beta decay of Bi-210 leads to hazardous Po-210. However, if Bi-209 is present, as in the case for $\mathrm{Pb}$-Bi coolants, the generation rates are higher because of direct production of Po-210 from Bi-209. The other products of neutron capture in lead systems involve hydrogen, tritium, and helium [LBE Handbook, 2007].

$$
P b^{208} \stackrel{+n}{\longrightarrow} P b^{209} \stackrel{\beta^{-}(3.253 h r)}{\longrightarrow} B i^{209} \stackrel{+n(2.7 m b)}{\longrightarrow} B i^{210} \stackrel{\beta^{-}(5.013 d)}{\longrightarrow} P o^{210} \stackrel{\alpha(138.4 d)}{\longrightarrow} P b^{206}
$$

Sodium has only one stable isotope. Radiative neutron capture in sodium results in the formation of Na-24. Na-24 can undergo beta decay with the energy of $1.4 \mathrm{MeV}$ or gamma decay with a half-life of 15 hours with energies of 1.4 and $2.8 \mathrm{MeV}$. Na-24 is the isotope that requires protection against gamma radiation. The sodium activity during normal operation can be about $10 \mathrm{Ci}$ per kilogram of coolant [IAEA TECDOC-1289, 2002]. Therefore, when a fuel assembly or a structural component is removed from the reactor, the residuals of sodium must be cleaned off to ensure no reaction with the air and that no radioactive isotopes remain on surfaces. The advantage of Na-24 is its much shorter half-life in comparison with that of Po-210. 
Project No 06-040: Flexible Conversion Ratio Fast Reactor Systems Evaluation

$N a^{23} \stackrel{+n}{\longrightarrow} N a^{24} \stackrel{\beta(15 h r)}{\longrightarrow} M g^{24}$

The characteristic reaction that carbon dioxide experiences in the gas reactor core is the capture of a neutron by O-16 and subsequent conversion into N-16 via proton emission [Wang, 2005]:

$O^{16}(n, p) N^{16}$

Table 5.3.2-5. Neutron fission spectrum average radiative capture cross sections of unirradiated coolant isotopes

\begin{tabular}{|c|c|c|}
\hline & $\begin{array}{c}\text { Content, } \\
\% \text { mass }[\text { KAERI] }\end{array}$ & $\begin{array}{c}\text { Neutron capture cross } \\
\text { section }(\mathrm{mb})^{*} \\
{[\mathrm{KAERI}]}\end{array}$ \\
\hline \multicolumn{3}{|l|}{ Lead } \\
\hline 204 & 1.40 & 19.19 \\
\hline 206 & 24.1 & 4.118 \\
\hline 207 & 22.1 & 3.297 \\
\hline 208 & 52.4 & 1.437 \\
\hline \multicolumn{3}{|c|}{ Sodium } \\
\hline 23 & 100 & 0.226 \\
\hline \multicolumn{3}{|c|}{ Salt NaCl-KCl-MgCl2 (30-20-50)** } \\
\hline $\mathrm{Na}-23$ & 100 & 0.226 \\
\hline $\mathrm{Cl}-35$ & 75.77 & 56.45 \\
\hline $\mathrm{Cl}-37$ & 24.23 & 0.550 \\
\hline K-39 & 93.26 & 2.679 \\
\hline $\mathrm{K}-40$ & 0.0117 & 27.41 \\
\hline $\mathrm{K}-41$ & 6.73 & 5.858 \\
\hline $\mathrm{Mg}-24$ & 79.0 & 0.376 \\
\hline $\mathrm{Mg}-25$ & 10.0 & 0.346 \\
\hline $\mathrm{Mg}-26$ & 11.0 & 0.319 \\
\hline \multicolumn{3}{|l|}{$\mathrm{CO}_{2} * *$} \\
\hline $\mathrm{C}-12$ & 98.9 & 0.0223 \\
\hline C-13 & 1.10 & \\
\hline $0-16$ & 99.8 & $\begin{array}{l}0.0950(\mathrm{n}, \gamma) \\
0.0203(\mathrm{n}, \mathrm{p})\end{array}$ \\
\hline O-17 & 0.038 & \\
\hline O-18 & 0.2 & \\
\hline
\end{tabular}

* The data is for radiative neutron capture unless noted otherwise.

** The composition is given in isotope percent mass in a given element.

The N-16 isotope quickly decays with a half-life of 7.13 seconds via beta emission with the energy of 4.3 and $10.4 \mathrm{MeV}$. Decay associated with gamma emission is with half-life of 7.25 seconds with energy of 6.1 and $7.1 \mathrm{MeV}$ [Chart of Nuclides]. Because of highly energetic gammas, shielding is required. Similarly to N-16, the N-17 isotope is formed by a neutron interacting with O-17. N-17 has a half-life of 4.173 seconds and decays to O-16 by neutron emission with energy of $4.54 \mathrm{MeV}$ [KAERI]. Because of low production rates of O-17, the neutron radiation produced by $\mathrm{N}-17$ is negligible compared to N-16 gammas. Another concern is related to the production of $\mathrm{C}-14$ which is a beta emitter. However, because the amount of C-13 
in $\mathrm{CO}_{2}$ is also very small, and the half-life of $\mathrm{C}-14$ is 5715 years, the activity is of greater concern during coolant disposal.

Since the chloride salt used in the salt-cooled reactor under study in this project is a new coolant that was not used in reactors before, its activation is described in the section on the selection of the salt coolant candidate in Subsection 4.1.3 and will not be repeated here.

\section{$\underline{\text { Residual Radioactivity }}$}

After the plant is decommissioned, one of the concerns is the residual radioactivity of the coolant. Because of coolant activation during operation, the coolant must be either stored on site until the radioactivity level allows for its disposal or its purification. Table 5.3.2-6 summarizes the comparison of coolants based on their disposal and recycle options. From the perspective of coolant disposal, $\mathrm{CO}_{2}$ is the most desired candidate because of the lack of significant activation products. On the other hand, sodium coolant can be recycled multiple times without a significant increase in activation.

Table 5.3.2-6 Comparison of coolants based on their recycle and disposal options

\begin{tabular}{|c|c|c|c|c|}
\hline & Lead & Sodium & Salt & $\mathrm{S}-\mathrm{CO} 2$ \\
\hline $\begin{array}{l}\text { Important } \\
\text { contributors } \\
\text { to long-lived } \\
\text { residual } \\
\text { radioactivity }\end{array}$ & $\begin{array}{l}\mathrm{Pb}-205 \\
\mathrm{~T}_{1 / 2}=1.5 \mathrm{E} 7 \mathrm{yr} \\
\varepsilon, 0.05 \mathrm{MeV} \\
\mathrm{Bi}-210 \mathrm{~m} \\
\mathrm{~T}_{1 / 2}=3.0 \mathrm{E} 6 \mathrm{yr} \\
\alpha, 5.3 \mathrm{MeV}\end{array}$ & $\begin{array}{l}\mathrm{Na}-22 \\
\mathrm{~T}_{1 / 2}=2.6 \mathrm{yr} \\
\text { Electron capture, } 2.8 \mathrm{MeV}\end{array}$ & $\begin{array}{l}\mathrm{Na}-22 \\
\mathrm{~T}_{1 / 2}=2.6 \mathrm{yr} \\
\mathrm{e}^{-} \text {capture, } \\
2.8 \mathrm{MeV} \\
\mathrm{Cl}-36 \\
\mathrm{~T}_{1 / 2}=300,000 \mathrm{yr} \\
0.709 \mathrm{MeV} \\
\text { beta }\end{array}$ & $\begin{array}{l}\mathrm{N}-16 \text { and } \mathrm{N}-17 \\
\text { quickly decay } \\
\text { into stable } \\
\text { oxygen. } \\
\mathrm{C}-14 \\
\mathrm{~T}_{1 / 2}=5715 \mathrm{yr} \\
\mathrm{B}, 0.157 \mathrm{MeV}\end{array}$ \\
\hline Recycle & $\begin{array}{l}\text { Every recycle } \\
\text { increases the } \\
\text { activation }\end{array}$ & $\begin{array}{l}\text { Activation reaches its } \\
\text { equilibrium } \sim 10 \text { years } \\
\text { after the start of the } \\
\text { reactor and does not } \\
\text { change with subsequent } \\
\text { cycles. }\end{array}$ & $\begin{array}{l}\text { Activation } \\
\text { increases with } \\
\text { each cycle }\end{array}$ & $\begin{array}{l}\text { Every recycle } \\
\text { increases the } \\
\text { amount of C-14 } \\
\text { present. } \\
\text { However, the } \\
\text { total activation } \\
\text { is very small. In } \\
\text { addition, C-14 is } \\
\text { beta emitter. }\end{array}$ \\
\hline $\begin{array}{l}\text { Final } \\
\text { disposal }\end{array}$ & $\begin{array}{l}\text { Final } \\
\text { purification can } \\
\text { be too } \\
\text { expensive }\end{array}$ & $\begin{array}{l}\text { Can be purified and reused } \\
\text { or stored for decay and } \\
\text { disposal: } \\
\text { Coolant from } 1 \mathrm{GWe} \\
\text { LMFR after } 50 \text { yrs of } \\
\text { operation and } 50 \text { yrs of } \\
\text { storage on site may be } \\
\text { exempted for free use in } \\
\text { industry [TECHDOC } \\
\text { 1289] }\end{array}$ & $\begin{array}{l}\text { Can be injected } \\
\text { into stable salt } \\
\text { deposits }\end{array}$ & $\begin{array}{l}\text { Used coolant } \\
\text { can be vented } \\
\text { into the } \\
\text { atmosphere } \\
\text { because of lack } \\
\text { of significant } \\
\text { activation } \\
\text { products. }\end{array}$ \\
\hline
\end{tabular}




\subsubsection{Thermal Hydraulics Aspects}

Table 5-1 summarized the operating parameters of the reactors under comparison. All reactors have the same power rating, but the operating temperatures are different. Sodium temperatures are lower than those of the other cores. All reactor designs correspond to unity conversion ratio to have consistent comparison. Except for the GFR, all cores use metallic fuel.

The comparison is conducted based on important operating characteristics of the reactor cores. Sodium is one of the most promising coolants for fast reactors. Thus, the compared parameters are normalized to sodium conditions. The summary of the normalized compared quantities is provided in Tables 5.3.3-1a and 5.3.3-1b. Table 5.3.3-1a summarizes the complimentary metrics while Table 5.3.3-1b lists the key Figures of Merit.

Metric 1:

Core power density is a figure of merit for core and vessel size. Core size is directly related to the capital cost of the reactor. Therefore, if the core size is reduced for the same power generated, fewer fuel assemblies are used, reducing the cost of the core. It also allows reduction of the vessel size, although this may not be the case for passive decay heat removal systems, which use the vessel as a heat transfer surface and thus favor a large vessel size. Even for the reactors having passive DHR, high power density cores provide more space for the placement of heat exchangers and pumps and for refueling storage space, simplifying the system, and thus reducing the cost. Therefore, it can be stated that high power density leads to lower capital cost. Because of the superior thermal hydraulic characteristics of sodium coolant, its power density is about three times the power densities of the other reactors evaluated in this project. As expected, the $\mathrm{S}-\mathrm{CO}_{2}$ cooled reactor exhibits the lowest power density.

\section{Metric 2:}

The amount of heat that can be stored in the primary coolant is important during transient conditions. Coolants with a greater capacity to absorb decay heat offer a greater temperature margin with respect to peak clad temperature limits. All liquid metal-cooled reactors exhibit a large capacity to store decay heat; thus long times (on the order of hours) to reach peak cladding temperature are characteristic for them during accidents with loss of heat sink. This is different for the GFR. Although it has a very large coolant volume because of the direct coupling to the PCS, the gas fluid is kept at a very high pressure and temperature, and the coolant escapes rather rapidly during large LOCA events. In this metric, salt coolant shows the best performance mainly because of its large specific heat.

$$
\frac{Q_{1}}{Q_{2}}=\frac{\left(\text { Volume } \cdot\left(t_{f}-t_{i}\right) \cdot \rho \cdot c_{p}\right)_{1}}{\left(\text { Volume } \cdot\left(t_{f}-t_{i}\right) \cdot \rho \cdot c_{p}\right)_{2}}
$$


Table 5.3.3-1a. Complimentary metrics*

\begin{tabular}{|c|cccc|}
\hline & GFR & SFR & LFR & LSFR \\
\hline Mass flow rate through the core, $\mathrm{kg} / \mathrm{s}$ & 11,708 & 13,580 & 173,600 & 29,000 \\
\hline Mass flow rate, norm to $\mathrm{Na}$ & 0.862 & 1.000 & 12.784 & 2.135 \\
\hline norm to $\mathrm{Pb}$ & 0.067 & 0.078 & 1.000 & 0.167 \\
\hline Coolant velocity, average, $\mathrm{m} / \mathrm{s}$ & 21.112 & 8.533 & 2.034 & 3.315 \\
\hline Velocity ratio, norm to $\mathrm{Na}$ & 2.474 & 1.000 & 0.238 & 0.388 \\
\hline norm to $\mathrm{Pb}$ & 10.379 & 4.195 & 1.000 & 1.630 \\
\hline Pressure drop through active core, $\mathrm{Pa}$ & 421,500 & 236,584 & 450,000 & 227,000 \\
\hline Pressure drop ratio, norm to $\mathrm{Na}$ & 1.782 & 1.000 & 1.902 & 0.959 \\
\hline norm to $\mathrm{Pb}$ & 0.937 & 0.526 & 1.000 & 0.504 \\
\hline Reynolds number & $613,979.2$ & $74,916.4$ & $83,608.3$ & $6,003.4$ \\
\hline norm to $\mathrm{Na}$ & 8.196 & 1.000 & 1.116 & 0.080 \\
\hline norm to $\mathrm{Pb}$ & 7.344 & 0.896 & 1.000 & 0.072 \\
\hline Friction factor & 0.0126 & 0.0195 & 0.0191 & 0.0323 \\
\hline norm to $\mathrm{Na}$ & 0.648 & 1.000 & 0.978 & 1.657 \\
\hline norm to $\mathrm{Pb}$ & 0.663 & 1.022 & 1.000 & 1.693 \\
\hline Nusselt number & 816.224 & 7.379 & 14.328 & 49.003 \\
\hline norm to $\mathrm{Na}$ & 110.621 & 1.000 & 1.942 & 6.641 \\
\hline norm to $\mathrm{Pb}$ & 56.968 & 0.515 & 1.000 & 3.420 \\
\hline
\end{tabular}

Table 5.3.3-1b. Key Figures of Merit ${ }^{*}$

\begin{tabular}{|c|c|c|c|c|c|}
\hline & Metric \# & GFR & SFR & LFR & LSFR \\
\hline Core power density, $\mathrm{kW} / \mathrm{L}$ & 1 & 85.4 & 290 & 112 & 104 \\
\hline Power density ratio, norm to $\mathrm{Na}$ & & 0.294 & 1.000 & 0.386 & 0.359 \\
\hline norm to $\mathrm{Pb}$ & & 0.763 & 2.589 & 1.000 & 0.929 \\
\hline Core specific power, $\mathrm{kW} / \mathrm{kg}$ & - & 20.7 & 64.8 & 44.7 & 22.2 \\
\hline Specific power ratio, norm to $\mathrm{Na}$ & & 0.319 & 1.000 & 0.690 & 0.343 \\
\hline norm to $\mathrm{Pb}$ & & 0.463 & 1.450 & 1.000 & 0.497 \\
\hline$\rho c_{p}, J / \mathrm{cm}^{3} K$ & 2 & 0.18 & 1.07 & 1.55 & 1.92 \\
\hline Stored heat ratio, norm to $\mathrm{Na}$ & & 0.168 & 1.000 & 1.449 & 1.794 \\
\hline norm to $\mathrm{Pb}$ & & 0.116 & 0.690 & 1.000 & 1.239 \\
\hline Pumping power, $\mathrm{W}$ & 5 & $3.43 \mathrm{E}+07$ & $3.82 \mathrm{E}+06$ & $7.41 \mathrm{E}+06$ & $3.45 \mathrm{E}+06$ \\
\hline Pumping power ratio, norm to $\mathrm{Na}$ & & 8.997 & 1.000 & 1.943 & 0.903 \\
\hline norm to $\mathrm{Pb}$ & & 4.630 & 0.515 & 1.000 & 0.465 \\
\hline Prandtl number & 6 & 0.7581 & 0.0050 & 0.0192 & 8.9330 \\
\hline norm to $\mathrm{Na}$ & & 151.620 & 1.000 & 3.840 & 1786.600 \\
\hline norm to $\mathrm{Pb}$ & & 39.484 & 0.260 & 1.000 & 465.260 \\
\hline Heat transfer coefficient & 6 & $6,529.791$ & $180,607.467$ & $28,139.388$ & $5,808.923$ \\
\hline norm to $\mathrm{Na}$ & & 0.036 & 1.000 & 0.156 & 0.032 \\
\hline norm to $\mathrm{Pb}$ & & 0.232 & 6.418 & 1.000 & 0.206 \\
\hline $\mathrm{FOM}^{* *}$-Forced convection, turbulent & 7 & 766.111 & 30.195 & 122.252 & 19.125 \\
\hline norm to $\mathrm{Na}$ & & 25.372 & 1.000 & 4.049 & 0.633 \\
\hline norm to $\mathrm{Pb}$ & & 6.267 & 0.247 & 1.000 & 0.156 \\
\hline $\mathrm{FOM}^{* *}$-Natural convection, turbulent & 7 & 70.078 & 40.425 & 43.571 & 27.892 \\
\hline norm to $\mathrm{Na}$ & & 1.734 & 1.000 & 1.078 & 0.690 \\
\hline norm to $\mathrm{Pb}$ & & 1.608 & 0.928 & 1.000 & 0.640 \\
\hline $\mathrm{FOM}^{* *}$-Natural convection, laminar* & 7 & 61.289 & 64.371 & 68.448 & 98.326 \\
\hline norm to $\mathrm{Na}$ & & 0.952 & 1.000 & 1.063 & 1.527 \\
\hline norm to $\mathrm{Pb}$ & & 0.895 & 0.940 & 1.000 & 1.436 \\
\hline
\end{tabular}

${ }^{*}$ All properties are for $450^{\circ} \mathrm{C}$; properties of $\mathrm{CO}_{2}$ are for $20 \mathrm{MPa}$ pressure; laminar flow is only for LSFR transients

${ }^{* *}$ Figure of Merit $(\mathrm{FOM})$ - for these factors a smaller value is preferable. 
Metric 3:

Mass flow rates for fixed core power depend on core temperature rise and the specific heat capacity of the coolant. Since all reactor concepts in this project employ the $\mathrm{S}-\mathrm{CO}_{2} \mathrm{PCS}$, which optimizes at a temperature rise across a heat source close to $150^{\circ} \mathrm{C}$, all reactor concepts have a similar core temperature rise. Therefore, the mass flow ratios are roughly inversely proportional to the specific heats. Because lead has almost 10 times lower specific heat than sodium, its mass flow rate is about 10 times higher. Coolant velocity ratio is also shown for relative comparison: it depends on coolant density and coolant volume fraction in the core. In spite of having the largest mass flow rate, the lead-cooled core has the smallest velocity. The mass flow rate is high because of the large density of lead and an open core lattice, but the velocity is kept low because of the limit imposed by the corrosion constraint. The relatively low velocity of the coolant limits the heat removal capacity of the lead reactor. An open lattice is thus necessary to keep the cladding temperatures within the limits. On the other side of the spectrum is the $\mathrm{S}-\mathrm{CO}_{2}$ cooled GFR. The small density and coolant volume fraction of $\mathrm{CO}_{2}$ require a large coolant velocity to attain $\mathrm{CR}=1$ with the lower heavy metal density $\mathrm{UO}_{2}$ fuel.

$$
\begin{aligned}
& \frac{\dot{m}_{1}}{\dot{m}_{2}}=\frac{\left(\dot{Q} /\left(T_{\text {out }}-T_{\text {in }}\right) \cdot c_{p}\right)_{1}}{\left(\dot{Q} /\left(T_{\text {out }}-T_{\text {in }}\right) \cdot c_{p}\right)_{2}}=\frac{\left(\left(T_{\text {out }}-T_{\text {in }}\right) \cdot c_{p}\right)_{2}}{\left(\left(T_{\text {out }}-T_{\text {in }}\right) \cdot c_{p}\right)_{1}} \\
& \frac{v_{1}}{v_{2}}=\frac{\left(A\left(T_{\text {out }}-T_{\text {in }}\right) \cdot \rho \cdot c_{p}\right)_{2}}{\left(A\left(T_{\text {out }}-T_{\text {in }}\right) \cdot \rho \cdot c_{p}\right)_{1}}
\end{aligned}
$$

\section{Metric 4:}

The pressure drop ratio across the reactor core is an important parameter affecting pumping power and liftoff forces acting on fuel assemblies. Moreover, low pressure drop is important for systems relying on passive decay heat removal. A small pressure drop results in increased driving forces for natural circulation of the coolant. Generally, the Na-cooled reactor core pressure drop is very small (factor of 3-5 smaller) compared to that of lead or salt. However, because of the small hydraulic diameter (tight core) and high coolant velocity, the pressure drop through the active sodium core is comparable to that of the lead-cooled core ( $\sim$ only factor of 2 smaller than lead). The larger pressure drop of the lead-cooled core comes from the much higher density of lead versus sodium and the use of grid spacers versus wire wraps. These two aspects more than counterbalance the effect of lower lead velocity. It may be surprising that the pressure drop of the liquid salt reactor is comparable to that of sodium and smaller than of the LFR in spite of the high viscosity of liquid salt. This is due to the much smaller velocity of the saltcoolant versus sodium and its low density as compared to lead.

\section{Metric 5:}

The pumping power ratio through the core is an important figure of merit because it affects power consumption and thus net plant efficiency. The goal is to minimize the pumping power to increase the "useful" power production.

$$
\frac{\text { Pump power }_{1}}{\text { Pump power }_{2}}=\frac{\Delta P_{1}}{\Delta P_{2}} \cdot \frac{\dot{m}_{1} \rho_{2}}{\dot{m}_{2} \rho_{1}}
$$

The lead-cooled reactor exhibits about two times larger pumping power. This is proportional to the larger pressure drop of the lead-cooled core since the flow rate over density ratios are about 
the same for both coolants. As expected, the GFR has the largest core pumping power because of a small coolant density. However, since the GFR is a direct cycle plant and compressor pumping power is part of PCS efficiency calculations, it does not lead to additional plant efficiency reduction in a transparent manner. For indirect cycle plants, this pumping power would have a significant negative impact on plant efficiency, since it would have to be included separately through main gas coolant circulators.

Metric 6:

To provide a more detailed picture of heat transfer and hydrodynamics of each core, parameters such as Re, Pr, friction factors, Nusselt number and heat transfer coefficient are also given.

The Reynolds number measures the ratio of inertia force to viscous force:

$$
\mathrm{Re}=\frac{\rho V L}{\mu}
$$

The largest Re number is for the GFR. This is a result of the high velocity and small kinematic viscosity of $\mathrm{CO}_{2}$. On the other side of the spectrum is the LSFR, which has a much smaller Re number than either the sodium-cooled or the lead-cooled reactors. The very low Re number of liquid salts is primarily the consequence of high salt viscosity.

The Prandtl number is the ratio of momentum diffusivity to thermal diffusivity:

$$
\operatorname{Pr}=\frac{\mu c_{P}}{k}
$$

Comparing Prandtl numbers for the coolants, it can be seen that for lead, lead-bismuth and sodium, thermal diffusivity is dominant; hence heat conduction is more effective than convection. The thickness of the velocity boundary layer of salt and gas is bigger than the thermal boundary layer, resulting in effective convection.

The Nusselt number describes the relationship between convective heat transfer and conductive heat transfer:

$$
N u=\frac{h D_{h}}{k}
$$

The Nusselt number is typically proportional to Re and $\operatorname{Pr}$ numbers. For gases and liquid salt [Gnielinski, 1976]:

$$
N u=0.0214\left(\operatorname{Re}^{0.8}-100\right) \cdot \operatorname{Pr}^{0.4}
$$

For lead and sodium, the correlation developed by Westinghouse [Todreas, 1993] for metallic fluids flowing through rod bundles can be used:

$$
N u=4.0+0.33(P / D)^{3.8}(P e / 100)^{0.86}+0.16(P / D)^{5.0}
$$


A high $\mathrm{Nu}$ number indicates very active convection. Lead and sodium coolants have very high thermal conductivity, which is reflected in their smaller Nu number. On the other hand, $\mathrm{CO}_{2}$ has the largest $\mathrm{Nu}$ number due to its small conductivity and large Reynolds number.

Heat transfer coefficient:

More important than the $\mathrm{Nu}$ number is the heat transfer coefficient, which determines film temperature. It is directly proportional to the $\mathrm{Nu}$ number and fluid conductivity and indirectly proportional to the hydraulic diameter, as can be obtained from the above $\mathrm{Nu}$ number definition:

$$
h=\frac{k N u}{D_{h}} .
$$

Because the heat transfer coefficient depends on thermal conductivity, metallic coolants (especially sodium) have very large $h$ as compared to the other fluids. Even though the thermal conductivity of sodium is only four times that of lead, the heat transfer coefficient is over six times larger. Such difference arises from the low film temperature drop and favorable neutronic properties of sodium, which result in a tight lattice and small hydraulic diameter. Gas and salt are on the opposite spectrum of the metals with very low heat transfer coefficients as a result of their low conductivity in spite of their large $\mathrm{Nu}$ numbers.

\section{Metric 7:}

Other generalized heat transfer metrics used were originally developed by Bonilla [Bonilla, 1957] and later employed in simplified form by Williams [Williams, 2006]. The figures of merit are based on minimal pumping power for a given coolant temperature rise as the objective function for forced convection. Salt is the best for the given temperature, and gas shows the highest requirements for the pumping power.

$$
F O M(\text { forced convection, turbulent })=\frac{\mu^{0.2}}{\rho^{2} c_{p}^{2.8}}
$$

The forced convection Figure of Merit (FOM) agrees well with the pumping power metric described earlier, i.e., the smallest values for salt followed by sodium, lead and $\mathrm{CO}_{2}$ coolants.

For passive cooling Williams used the following FOMs originally derived by Bonilla:

$$
\begin{aligned}
& \text { FOM (natural convection, turbulent })=\left[\frac{\mu^{0.2}}{\beta \rho^{2} c_{p}^{1.8}}\right]^{0.357} \\
& \text { FOM (natural convection, laminar })=\left[\frac{\mu}{\beta \rho^{2} c_{p}}\right]^{0.5}
\end{aligned}
$$

The above two FOMs measure the efficiency of a coolant to dissipate heat with low coolant temperature rise and are applicable to any coolant. The response of the reactor during accident 
conditions is difficult to estimate without detailed simulation. It is important to note that the above FOMs are figures of merit of potential performance of coolants without incorporating the impact of system geometry. However, the presented metrics can provide the first insight into the potential of various coolants to effectively dissipate heat. The smaller number corresponds to the better performer.

Turbulent natural convection results rate the coolants similarly as for forced convection, with salt being the best performer (primarily due to its large $\rho c_{p}$ ) followed by sodium, lead, and gas as the worst performing coolants. However, the low Reynolds number of salt coolant suggests that the turbulent conditions under accidents involving loss of pumping power (natural circulation) are unlikely. Moreover, laminar conditions are unlikely for sodium, lead, and gas coolants because of their thermal hydraulic characteristics discussed earlier. Therefore, the natural circulation conditions must be compared for the laminar regime, for the salt reactor, and for the transient regime for the other reactors. Based on those conditions, sodium becomes the best coolant for the natural circulation condition, with lead coolant following it very closely.

\subsubsection{Summary and Conclusions}

The overview of the coolant options shows a direct relation between the coolant type and the reactor safety and economics. All reactors demonstrate a capability for waste management and self-sustained fuel cycles. Table 5.3.4-1 shows the summary comparison among different coolants. The main limitations of sodium are chemical interaction with a secondary coolant or air. Except for the volatile behavior of sodium, it shows superior thermophysical characteristics as compared to the other reactors. The main limitation of the lead-cooled system is its extreme corrosivity with respect to the structural components and cladding. The weight of lead can also lead to significant complications with vessel design. The $\mathrm{S}-\mathrm{CO}_{2}$ cooled reactor has no significant corrosion or chemical issues, but it must be pressurized to $20 \mathrm{MPa}$ to take advantage of the supercritical fluid characteristics and achieve high power density. Salt coolant is relatively light, potentially not very corrosive at temperatures up to $650^{\circ} \mathrm{C}$, and non-reactive with air, $\mathrm{CO}_{2}$ or water. A significant advantage of salts in comparison with liquid metal coolants is their transparency, making inspection much easier. However, certain thermo-physical and neutronic properties (primarily a large thermal expansion coefficient and a high viscosity) make the design of a high power density fast reactor very challenging. Also, their relatively high melting point poses difficulties in vessel material selection. 
Project No 06-040: Flexible Conversion Ratio Fast Reactor Systems Evaluation

Table 5.3.4-1. Summary comparison of various metrics.

\begin{tabular}{|c|c|c|c|c|c|}
\hline Property & Metric & Sodium & Lead & Salt & $\mathrm{CO}_{2}$ \\
\hline \multirow[t]{6}{*}{ Thermophysical } & Low melting temperature & + & - & - & + \\
\hline & High boiling temperature & 0 & + & + & + \\
\hline & Vessel pressure & + & - & + & - \\
\hline & Thermal conductivity & + & + & - & - \\
\hline & $\rho c_{p}$ & 0 & + & + & - \\
\hline & Low viscosity & + & 0 & - & + \\
\hline \multirow[t]{3}{*}{ Chemical } & Interaction with $\mathrm{H}_{2} \mathrm{O}$ & - & 0 & + & + \\
\hline & Interaction with $\mathrm{CO}_{2}$ & - & + & + & + \\
\hline & Interaction with SSCs & 0 & - & + & + \\
\hline \multirow[t]{4}{*}{ Coolant activation } & $\gamma$ activation & - & + & - & - \\
\hline & $\alpha$ activation & + & - & + & + \\
\hline & Residual activity & 0 & - & - & + \\
\hline & Difficult disposal & 0 & - & 0 & + \\
\hline \multirow[t]{3}{*}{ Thermal hydraulics } & Core power density & + & 0 & 0 & - \\
\hline & Pumping power & + & 0 & + & - \\
\hline & Specific power & + & 0 & - & - \\
\hline \multirow[t]{2}{*}{ Safety } & Ability to store heat & 0 & + & + & - \\
\hline & Effective natural circulation & + & + & 0 & 0 \\
\hline
\end{tabular}

Legend:

+ excellent

0 intermediate/unclear

- inferior 


\subsection{References for Chapter 5}

Aquien A., Kazimi M. S., and Hejzlar P., "Transuranics Recycling in Various Reactor/Fuel Cycle Systems", Transactions of the American Nuclear Society, Vol. 95, Albuquerque NM, USA, November 12-16, 2006.

Bagdassarov Y.E., Report presented at the Int. Conf. on "Heavy Metal Coolants in Nuclear Technology", Obninsk, Russia, October 5-9, 1998.

Ballinger R.G., Lim J., "An Overview of Corrosion Issues for the Design and Operation of High-Temperature Lead- and Lead-Bismuth-Cooled Reactor Systems", Nuclear Technology, September 2004.

Boardman C.E. et al., "A Description of the S-PRISM Plant", ICONE-8168, Proc. of ICONE-8, Baltimore, MD, USA, April 2-6, 2000.

Bonilla C.F., "Comparison of Coolants," in Nuclear Engineering Handbook, H. Etherington editor, Sect. 9-3, Chap. 6.5, pp. 9-90, 1958.

Chart of Nuclides, "Chart of the Nuclides and Isotopes", Lockheed Martin Corporation, 2003.

Derstine K.L., "DIF3D: A code to Solve One-, Two-, and Three-Dimensional FiniteDifference Diffusion Theory Problems", Applied Physics Division, ANL82-64, Argonne National Laboratory, April 1984.

Dostal V., Hejzlar P., and Todreas N.E., "Medium Power Lead Alloy Fast Reactor Balance of Plant Options“, Nuclear Technology, Vol. 147, pp. 388-405, September 2004.

Dubberley A. E., Boardman C. E., Yoshida K., and Wu T., "SuperPRISM Oxide and Metal Fuel Core Designs", ICONE-8002, Proc. of ICONE-8, $8^{\text {th }}$ Int. Conf. on Nucl. Eng., Baltimore, MD, Apr. 2-6, 2000.

Energy Solutions, "GNEP Deployment Studies: Overall Summary Report", Revision 1, No. DOE/NE/24503.1-1, May 19, 2008.

Fridman E., E. Shwageraus, A. Galperin, "Efficient Generation of One-group CrossSections for Coupled Monte Carlo Depletion Calculations," Accepted for publication in Nuclear Science and Engineering (2007)

Forsberg C. W., Private communication, April, 2007.

Gnielinski, V., "New Equations for Heat and Mass Transfer in Turbulent Pipe and Channel Flow", International Chemical Engineering, v 16, n 2, Apr, 1976, p 359-368. 
Project No 06-040: Flexible Conversion Ratio Fast Reactor Systems Evaluation

GIF, “A Technology Roadmap for Generation IV Nuclear Energy Systems", GIF-002-00, Dec. 2002.

Handwerk C. S., Driscoll M. J., Hejzlar P., "Use of Beryllium Oxide to Shape Power and Reduce Void Reactivity in Gas-cooled Fast Reactors," PHYSOR 2006, Vancouver, Canada, September 10-14, 2006.

Handwerk C.S., Hejzlar P., and Driscoll M.J., "Core Design and Performance Assessment for a Supercritical $\mathrm{CO}_{2}$-Cooled Fast Reactor", MIT-ANP-TR-113, PhD Thesis, Department of Nuclear Engineering and Sciences, Massachusetts Institute of Technology, 2007.

Hejzlar P., Dostal V. and Driscoll M.J., "A Supercritical $\mathrm{CO}_{2}$ Cycle - a Promising Power Conversion System for Generation IV Reactors", Proc. International Congress on Advances in Nuclear Power Plants ICAPP '06, Paper 6307, Reno, Nevada,USA, June 4$8,2006$.

Henryson II H., Toppel B.J., and Stenberg C. G., "MC'-2: A Code to Calculate Fast Neutron Spectra and Multigroup Cross Sections", Applied Physics Division, ANL81-44, Argonne National Laboratory, June 1976.

Hoffman E.A, Yang W.S., and Hill R.N., "Preliminary Core Design Studies for the Advanced Burner Reactor over a Wide Range of Conversion Ratios", ANL-AFCI-177, Advanced Fuel Cycle Initiative, Argonne National Laboratory, 2006.

Lawrence R.D., "DIF3D Nodal Neutronics Option for Two- and Three-Dimensional Diffusion Theory Calculations in Hexagonal Geometry", Applied Physics Division, ANL83-1, Argonne National Laboratory, March 1983.

KAERI, “Table of Nuclides”, http://atom.kaeri.re.kr/

Klueh, R., "Elevated-Temperature Ferritic and Martenistic Steels and Their Application to Future Nuclear Reactors," ORNL/TM-2004/176, November 2004.

Kubo A. et al., "Feasability Study on the Reliable Steam Generator with Helically Coiled Double Wall Tubes on FBR", ICONE5-2327, May 26-30, 1997.

Kutateladze, "Liquid Metal Coolants," Atomizdat, Moscow, 1976

LBE Handbook, "Handbook on Lead-bismuth Eutectic Alloy and Lead Properties, Materials Compatibility, Thermal-hydraulics and Technologies", ANE NEA, 2007.

Lee J. I., P. Hejzlar, P. Saha, P. Stahle, M. S. Kazimi and D. M. McEligot, "Deteriorated Turbulent Heat Transfer of Gas Up-flow in a Circular Tube: Experimental Data," International Journal of Heat and Mass Transfer, Vol. 51, pp. 3259-3266, 2008. 
Mackay F.J., Apostolakis G. and Hejzlar P., ,Incorporating Reliability Analysis into the Design of Passive Cooling Systems with an Application to a Gas-Cooled Reactor", Nucl. Eng. Des., Vol. 238, pp. 217-228, 2008.

Mizuno T., Ogawa T., Sugino K., and Naganuma M., “Advanced Core Design Studies with Oxide and Metal Fuels for Next Generation Sodium-cooled Fast Reactors", Proc. International Congress on Advances in Nuclear Power Plants ICAPP '05, Paper 5195, Seoul, Korea, May 15-19, 2005.

OECD, "Reduction of Capital Cost of Nuclear Power Plants", OECD Nuclear Energy Agency Report, 2000.

Okada K. "Approach to FBR Commercialization in Japan”, Proc. International Congress on Advances in Nuclear Power Plants ICAPP '08, Paper 8397, Anaheim, CA,USA, June 8-12, 2008.

Patalano G., Apostolakis G.E., and Hejzlar P., "Risk-Informed Design Changes in Passive Decay Heat Removal System", Nuclear Technology, Vol. 163, pp. 191-208, 2008.

Peterson P.F., "Roles and Needs for Simulation for the Development of New Reactors", Presentation at Nuclear Fuel Cycle Workshop, Lawrence Livermoore National Laboratory, December 14-15, 2005.

Pope M.A., Hejzlar P., and Driscoll M.J.,"Thermal Hydraulics of a $2400 \mathrm{MWt}$ Supercritical $\mathrm{CO}_{2}$-Direct Cycle GFR", MIT-ANP-TR-107, Center for Advanced Nuclear Energy Systems, Massachusetts Institute of Technology, 2006.

Pope M.A., Lee J.I., Hejzlar P., and Driscoll M.J.,"Thermal Hydraulic Challenges of Gas-cooled Fast Reactors with Passive Safety Features", accepted for publication in Nuclear Engineering and Design, 2008.

Shwageraus E., E. Fridman, E. Abramski, A. Galperin, BGCore - A Comprehensive Package for Reactor Core and Fuel Storage Analysis, Proc. of 23rd Conference of the Nuclear Societies in Israel, Dead Sea, Israel, February 15-16, (2006).

Susskind et al., "Corrosion Studies for a Fused Salt-Liquid Metal Extraction Process for the Liquid Metal Fuel Reactor", BNL-585, 1960.

TECDOC-1289, "Comparative Assessment of Thermophysical and Thermohydraulic Characteristics of Lead, lead-bismuth and Sodium Coolants for Fast Reactors", IAEA, Vienna, 2002.

Thon S., "Selection of Materials for a Supercritical $\mathrm{CO}_{2}$ Cooled GCFR", MIT-GCFR001, Department of Nuclear Science and Engineering, Massachusetts Institute of Technology, August 2002. 
Todreas N.E, and Kazimi M.S, Nuclear Systems I: Thermal Hydraulic Fundamentals, Hemisphere Publishing Corp. 1993.

Todreas N.E., Hejzlar P., Shwageraus E., Petroski R., Nikiforova A., and Whitman J., "Flexible Conversion Ratio Fast Reactor Systems Evaluations", 2 ${ }^{\text {nd }}$ Quarterly report, Center for Advanced Nuclear Energy Systems, MIT, MIT-NFC-PR-087, October 2006.

Todreas N.E., Hejzlar P., Shwageraus E., Petroski R., Nikiforova A., and Whitman J., "Flexible Conversion Ratio Fast Reactor Systems Evaluations", $1{ }^{\text {st }}$ Yearly report, Center for Advanced Nuclear Energy Systems, MIT, MIT-NFC-PR-092, June 2007.

Toppel B.J., “A User's Guide for the Rebus-3 Fuel Cycle Analysis Capability”, Applied Physics Division, ANL83-2, Argonne National Laboratory, March 1983.

Wade D. C. and Hill R. N., "The Design Rationale of the IFR," Prog.in Nucl Energy, Vol. 31 (1), pp.13-42, January 1997.

Wade D.C., Wigeland R.A., Hill D.J., "The safety of the IFR", Progress in Nuclear Energy, Vol. 31, No. 1/2, pp. 63-82, 1997

Williams D.F., Toth L.M., Clarno K.T., "Assessment of Candidate Molten Salt Coolants for the Advanced High-Temperature Reactor (AHTR)", ORNL/TM-2006/12, March 2006. 


\section{Project Publications}

Shwageraus E., Hejzlar P. and Driscoll M.J., "Nuclear Design Feasibility of a Leadcooled Fast Reactor with Flexible Conversion Ratio", 2007 ANS/ENS international Meeting, Washington D.C. November 11-15, 2007.

Nikiforova A., Hejzlar P. and Todreas N.E., "Thermal Hydraulics of Liquid Lead-cooled Flexible Conversion Ratio (FCR) Reactor", 2007 ANS/ENS international Meeting, Washington D.C. November 11-15, 2007.

Todreas Neil E., Thermal Hydraulic Challenges in Fast Reactor Design. The $12^{\text {th }}$ International Topical Meeting on Nuclear Reactor Thermal Hydraulics (NURETH-12), Pittsburgh, PA, Sept. 30 - Oct. 4, 2007.

Todreas, Neil E., Thermal Hydraulic Challenges in Fast Reactor Design, Accepted for publication in Nuclear Technology (2008).

Nikiforova A., P. Hejzlar, N. Todreas, J. Whitman, C. J. Fong, M. J. Driscoll, R. Petroski, "A 2400 MWt Liquid Lead-Cooled Flexible Conversion Ratio (FCR) Reactor", submitted to $8^{\text {th }}$ International Congress on Advanced Nuclear Power Plants (ICAPP08), Anaheim, June 2008.

Shwageraus E and Hejzlar P., „Flexible Conversion Ratio Lead-Cooled Reactor Design, submitted to International Conference on Reactor Physics, Interlaken, Switzerland, September 14-19, 2008.

Fong, C. J., G. E. Apostolakis, P. Hejzlar, N. E. Todreas, and M. J. Driscoll, Reliability Analysis of a Passive Cooling System Using a Response Surface with an Application to the Flexible Conversion Ratio Reactor, Submitted for publication in Nuclear Engineering and Technology (2008). 


\section{Appendix 2A The S- $\mathrm{CO}_{2}$ Power Conversion Unit for a 2400MWt Fast Reactor}

This appendix provides information about the design and operational characteristics of the $\mathrm{S}-\mathrm{CO}_{2}$ Power Conversion unit for the 2400MWt Lead-Cooled Flexible Conversion Ratio Fast Reactor. The methodology and results can be extended with modifications to the 2400MWt Liquid SaltCooled Flexible Conversion Ratio Fast Reactor.

\section{A.1 Power Conversion Unit}

The balance of plant for the lead and salt-cooled FCRs is formed by $4 \times 600 \mathrm{MWt} \mathrm{S}-\mathrm{CO}_{2}$ power conversion systems (PCS) in the distributed horizontal arrangement, as developed by Gibbs et al. [2006] under direct Generation IV funding via Sandia National Laboratory. This is the third generation of the $\mathrm{S}-\mathrm{CO}_{2}$ PCS developed at MIT, which minimizes pressure losses in piping and maximizes modularity and ease of maintenance. Figure 2A-1 shows the layout of one out of four $600 \mathrm{MWt}$ power conversion system units. A possible arrangement of 4 units is shown in Figures $2 \mathrm{~A}-2 \mathrm{a}$ and $2 \mathrm{~A}-2 \mathrm{~b}$, where the base of $30 \mathrm{~m}$-diameter containment is also drawn. Figure $2 \mathrm{~A}-3$ shows the flow schematic of the cycle with the flow paths.

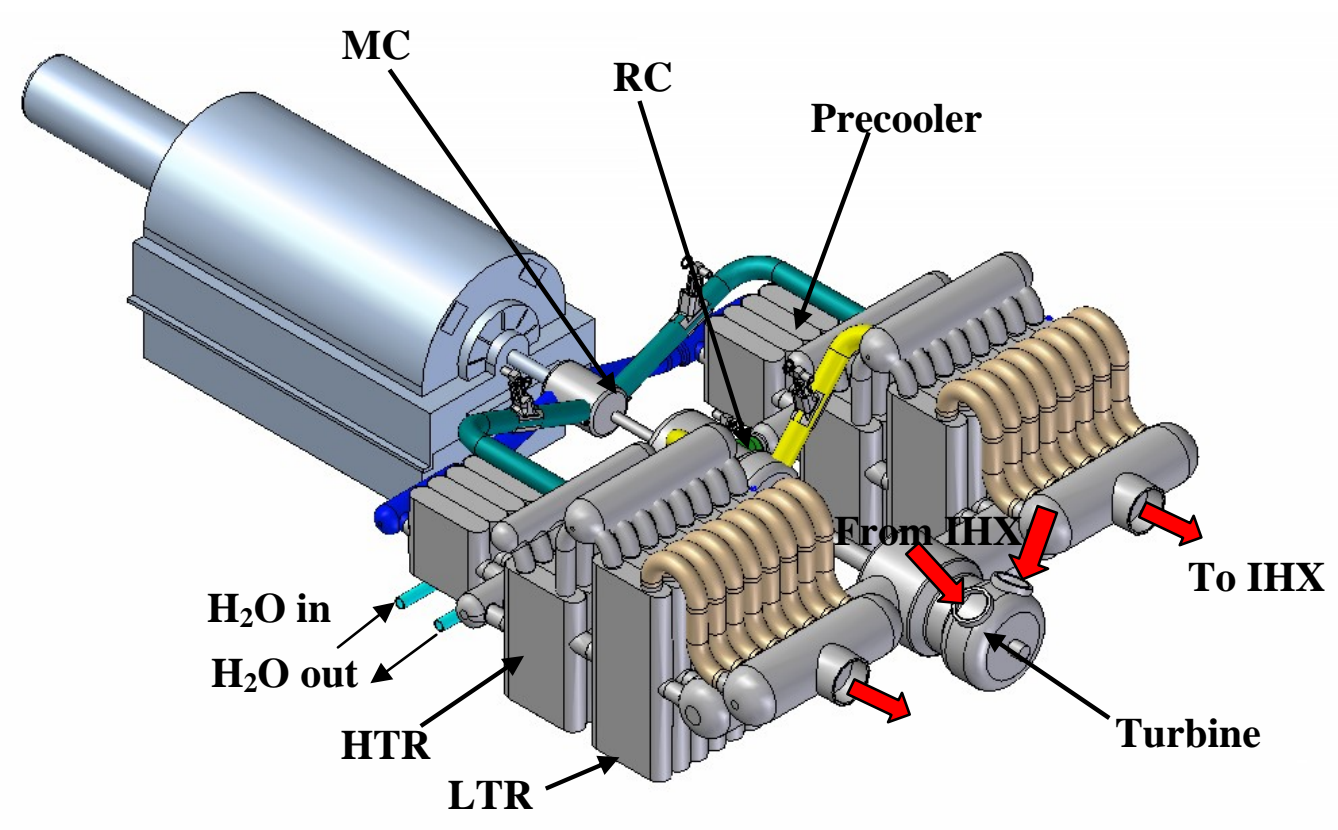

Figure 2A-1 Isometric view of 600 MWt PCS layout (from Gibbs et al., 2006)

In the main compressor, $\mathrm{MC}$, (points $1-2$ in Figure 2A-3) a fraction of the fluid flow is compressed to high pressure. It is preheated in the low temperature recuperator (LTR) (points 23 ) and proceeds to the recompressing compressor (RC) outlet where it is merged with the rest of the fluid flow from the recompressing compressor. The total fluid flow is now preheated in the 
high temperature recuperator to the IHX inlet temperature (points $4-5$ ). The heat addition into the cycle takes place in the IHX (points 5-6) and enters the turbine at the highest temperature, where it undergoes expansion (points $6-7$ ). After leaving the turbine the high temperature fluid exchanges heat in the high (points $7-8$ ) and low (points $8-9$ ) temperature recuperators. Before entering the precooler (PRE) the fluid flow is split (stream 10 and 11). One fraction of the fluid is recompressed to high pressure (points $11-12$ ), the other is cooled in the precooler (points 10 -1) to the main compressor inlet temperature.

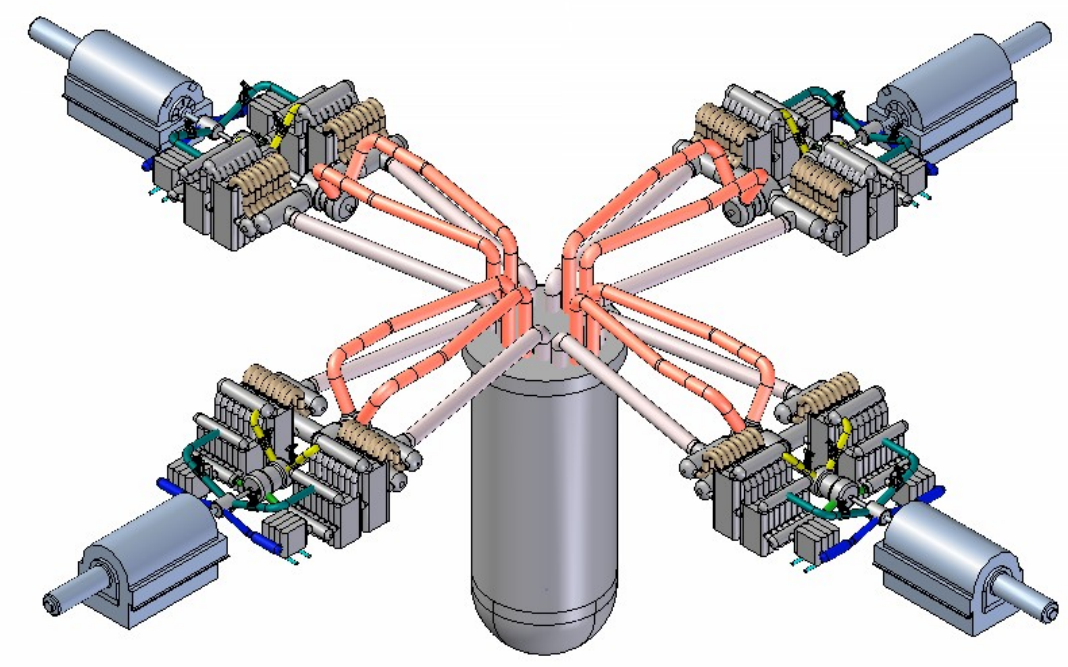

Figure 2A-2a Possible arrangement of 600MWt PCS units around reactor vessel (Isometric view)

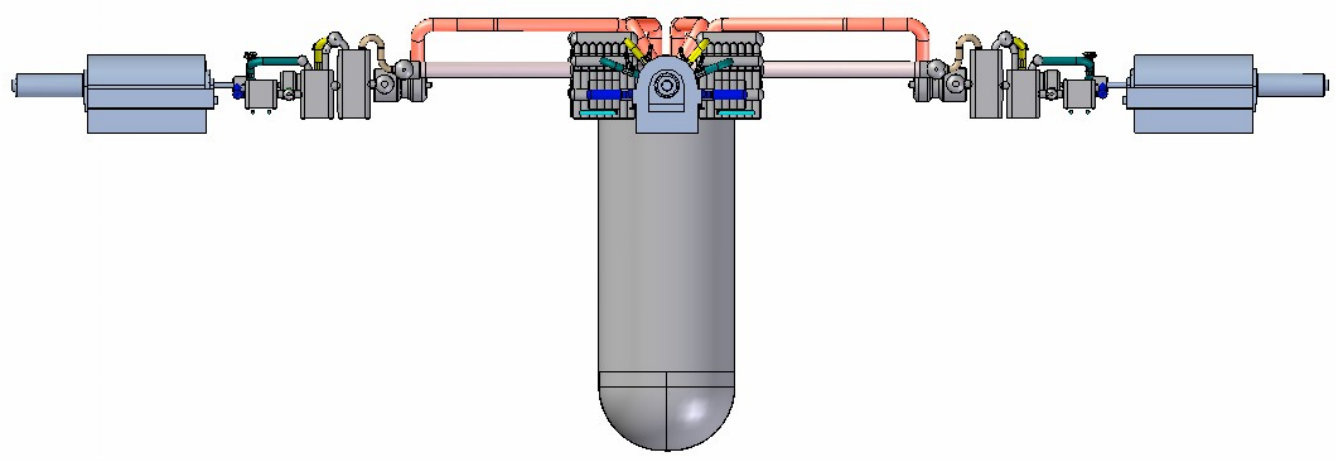

Figure 2A-2b Possible arrangement of 600MWt PCS units around reactor vessel (Front view) 
The implementation of the $\mathrm{S}-\mathrm{CO}_{2}$ power cycle scheme into the actual layout needs to overcome the challenge of minimization of pressure drops in the interconnecting pipes and distribution plena. This has been resolved in the third generation layout in Figure 2A-1 through an employment of parallel modules and pipes and by using two 300MWt trains in parallel. After the $\mathrm{CO}_{2}$ is expanded in the turbine it enters two large diffusers which double as distribution manifolds, to deliver the fluid to the low pressure side of the high temperature recuperators. Because the precooler modules are much smaller than the two recuperators it is not effective to try to evenly pair the precooler modules with the LTR modules. Also, an effective flow split mechanism is required between the LTR and precooler. Therefore, the LTR cannot directly discharge the $\mathrm{CO}_{2}$ to the precooler the way that the HTR delivers the fluid to the LTR. The flow from the LTR to the precooler is handled by using a large collection manifold between the two heat exchangers. The LTR discharges to the collection manifold and the precooler receives the fluid from the opposite side, thus allowing a variation in the number of modules. The precooler is arranged in four modules per train to receive the fluid from the collection manifold and discharge directly to a smaller collection manifold which directs the fluid to the main compressor.

Further, to reduce fractional pressure drops, the arrangement of flow streams in HEATRIC printed circuit heat exchangers (LTR,HTR) is such that the high pressure stream is directed through distributors inside the plates of port-design type, while the low pressure stream goes straight through the heat exchangers as shown in Figure 2A-4.

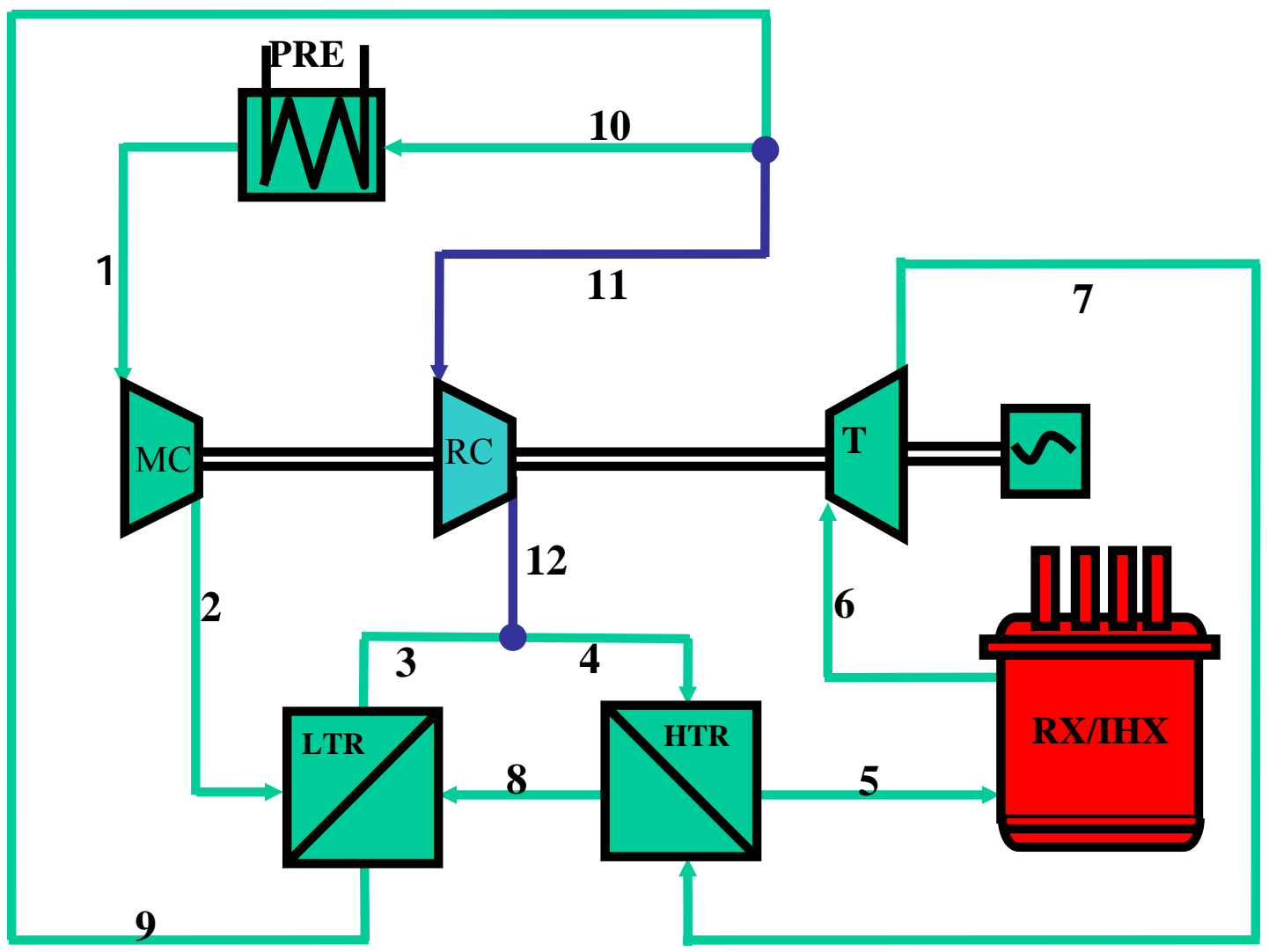

Figure 2A-3 Schematic of recompression $\mathrm{CO}_{2}$ cycle with flow paths 
Because the pressure drop in the IHX is higher and IHX $\mathrm{CO}_{2}$ outlet temperature is different than those assumed in earlier MIT analyses, the cycle has to be reoptimized to match lead-cooled reactor conditions. This was performed using the in-house code CYCLES [Dostal et al., 2004, Hejzlar et.al., 2006]. The input data used for the optimization are given in Table 2A-1.

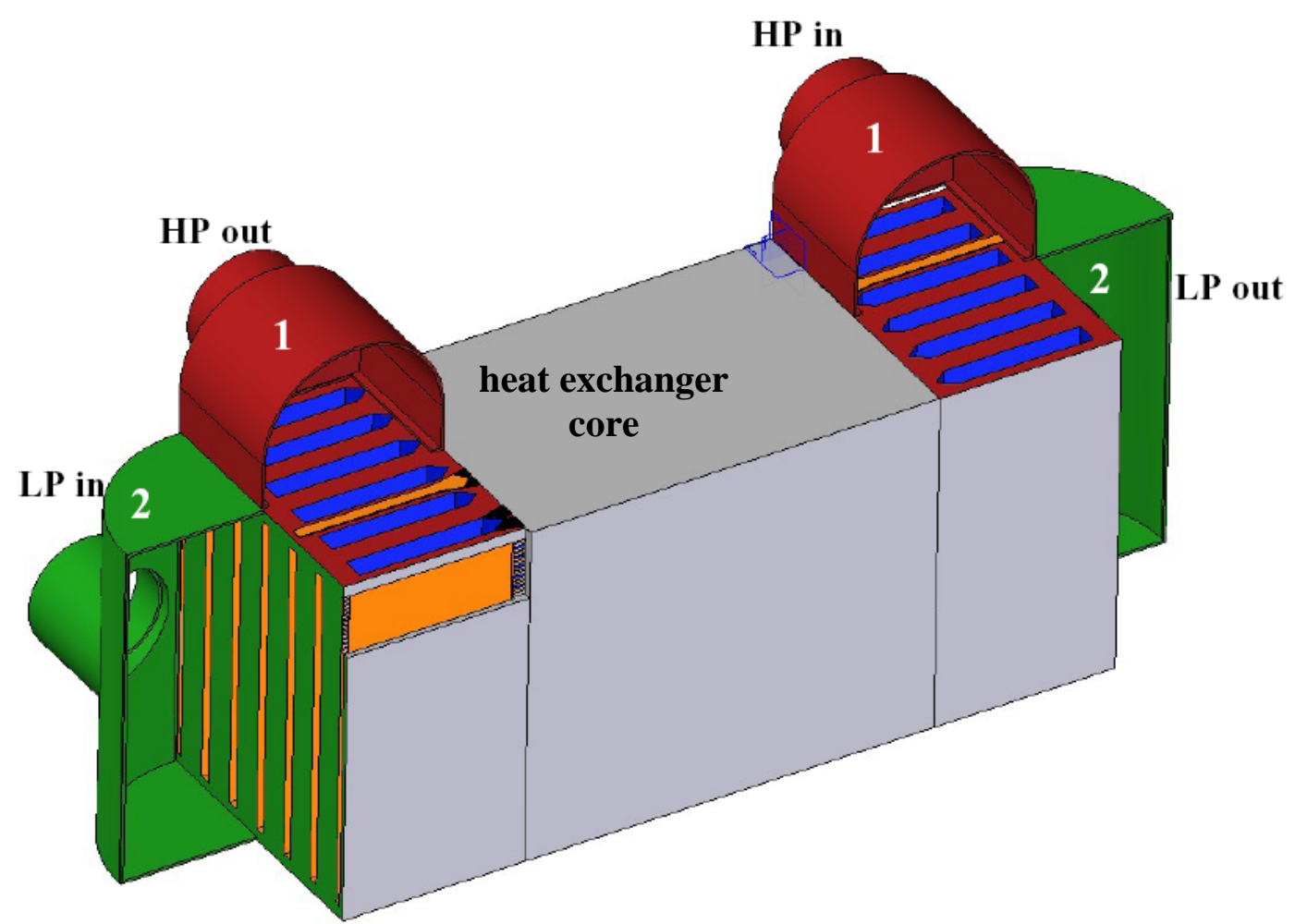

Figure 2A-4 Cutout view of printed circuit heat exchanger (from Gibbs et al., 2006)

Table 2A-1- Pertinent data for cycle performance calculations

$\begin{array}{ll}\text { Thermal Power }\left(\mathrm{MWt}_{\text {ermal }}\right) & 600.0 \\ \text { Maximum operating pressure (MPa) } & 20.0 \\ \text { Turbine Inlet Temp }\left({ }^{\circ} \mathrm{C}\right) & 547.5 \\ \text { Pressure Ratio } & 2.60 \\ \text { Reactor/lHX pressure drop (kPa) } & 590.0 \\ \text { Turbine Efficiency (\%) } & 94.0 \\ \text { Main Compressor Efficiency (\%) } & 91.0 \\ \text { Recompressing Compressor Efficiency (\%) } & 90.0 \\ \text { Mechanical Efficiency (couplings) (\%) } & 99.0 \\ \text { Generator Efficiency }(\%) & 98.0 \\ \text { Main Comp Inlet Temp }\left({ }^{\circ} \mathrm{C}\right) & 32.0 \\ \text { Cooling water temp }\left({ }^{\circ} \mathrm{C}\right) & 20.0\end{array}$

The schematic diagram of one 600MWt PCS with its design state points is shown in Figure 2A5. Recuperator data are summarized in Table 2A-2 and precooler data in Table 2A-3. Table 2A4 summarizes the piping and distributor data used in the PCS calculations. 
Project No 06-040: Flexible Conversion Ratio Fast Reactor Systems Evaluation

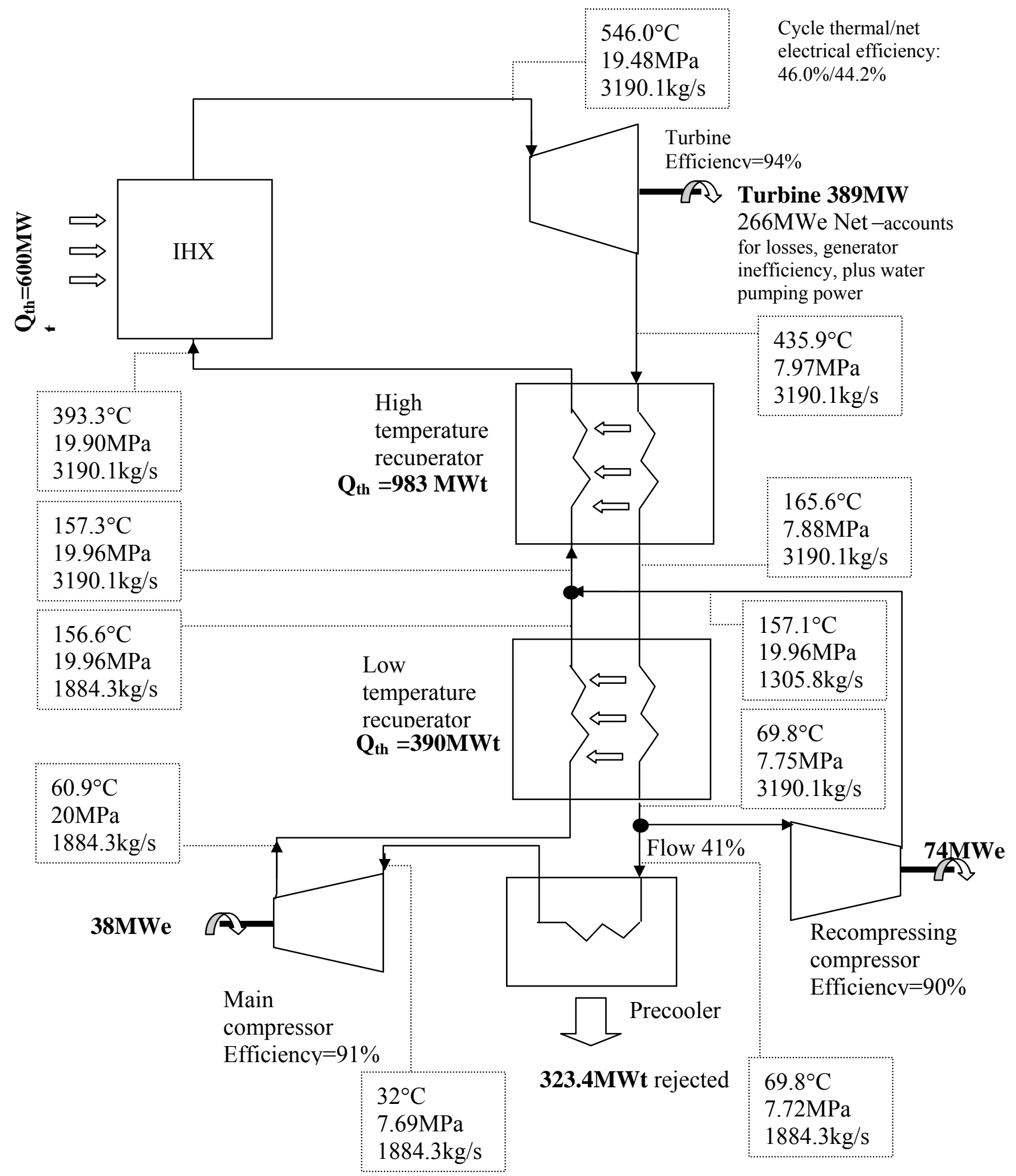

Figure 2A-5 Thermodynamic S-CO2 Cycle State Points for S- $\mathrm{CO}_{2}$ PCS design-600MWt(Nominal) 
Project No 06-040: Flexible Conversion Ratio Fast Reactor Systems Evaluation

Table 2A-2 Recuperator design summary

\begin{tabular}{|l|c|c|}
\hline Recuperator & High temperature & Low temperature \\
\hline Total volume $\left(\mathrm{m}^{3}\right)$ & 55.8 & 53.2 \\
\hline Width $(\mathrm{m})$ & 0.6 & 0.6 \\
\hline Active length $(\mathrm{m})$ & 1.85 & 2.05 \\
\hline Total height $(\mathrm{m})$ & 50.3 & 43.3 \\
\hline Height per module $(\mathrm{m})$ & 3.14 & 2.70 \\
\hline Number of modules per HX & 16 & 16 \\
\hline Channel type & straight & straight \\
\hline Semicircular channel diameter $(\mathrm{mm})$ & 2.00 & 2.00 \\
\hline Plate thickness $(\mathrm{mm})$ & 1.50 & 1.50 \\
\hline Effective conduction thickness $(\mathrm{mm})$ & 1.69 & 1.69 \\
\hline Total number of cold/hot plates & $16766 / 16766$ & $14433 / 14433$ \\
\hline Channel pitch $(\mathrm{mm})$ & 2.30 & 2.30 \\
\hline Total number of hot channels & $4,359,160$ & $3,752,580$ \\
\hline Total number of cold channels & $4,359,160$ & $3,752,580$ \\
\hline Hot side pressure drop $(\mathrm{kPa})$ & 91 & 83 \\
\hline Cold side pressure drop $(\mathrm{kPa})$ & 32 & 8 \\
\hline Total power $(\mathrm{MWt})$ & 983 & 7.4 \\
\hline Power density $\left(\mathrm{MWt} / \mathrm{m}^{3}\right)$ & 17.9 & \\
\hline
\end{tabular}

Table 2A-3 Precooler design

\begin{tabular}{|l|c|}
\hline Total volume $\left(\mathrm{m}^{3}\right)^{*}$ & 11.00 \\
\hline Width $(\mathrm{m})$ & 0.60 \\
\hline Active Length $(\mathrm{m})$ & 1.0 \\
\hline Total height $(\mathrm{m})$ & 19.3 \\
\hline Height per module $(\mathrm{m})$ & 2.41 \\
\hline Number of modules per HX & 8 \\
\hline Channel type & straight \\
\hline Semicircular channel diameter $(\mathrm{mm})$ & 2.00 \\
\hline Plate thickness $(\mathrm{mm})$ & 1.50 \\
\hline Effective conduction thickness $(\mathrm{mm})$ & 1.61 \\
\hline Channel pitch $(\mathrm{mm})$ & 2.40 \\
\hline Total number of cold/hot plates & $6433 / 6433$. \\
\hline Total number of hot channels & $1,588,951$ \\
\hline Total number of cold channels & $1,588,951$ \\
\hline Water inlet temperature $\left({ }^{\circ} \mathrm{C}\right)$ & 20 \\
\hline Water flow rate $(\mathrm{kg} / \mathrm{s})$ & 5515 \\
\hline Gas side pressure drop $(\mathrm{kPa})$ & 29 \\
\hline Water side pumping power $(\mathrm{MW})$ & 0.55 \\
\hline Total power $(\mathrm{MWt})$ & 323 \\
\hline Power density $\left(\mathrm{MWt} / \mathrm{m}^{3}\right)$ & 30 \\
\hline
\end{tabular}


Table 2A-4 summarizes pipe dimensions and loss coefficients and Table A-5 gives the detailed pressure loss distribution. .

Table 2A-4 Piping and distributor data

\begin{tabular}{|c|c|c|c|c|c|c|c|c|}
\hline Path & $\#^{*}$ & Npipe & $\mathrm{D}_{\mathrm{h}}(\mathrm{m})$ & $A\left(m^{2}\right)$ & $L(m)$ & $\mathrm{K}$ & $\zeta(m)$ & Description \\
\hline \multicolumn{9}{|c|}{ From precooler to main compressor } \\
\hline 1 & 4 & 48 & 0.0354 & $\odot .018000$ & 0.2800 & $\odot .04$ & 1. $\odot E-\odot 4$ & precooler outlet plenum LP \\
\hline 1 & & 63162 & 0.0030 & 0.000090 & 0.0050 & 1.20 & 1. $0 \mathrm{E}-04$ & precooler outlets LP \\
\hline 1 & & 8 & 0.3500 & 0.140000 & 0.6000 & 0.40 & 1. $\odot E-\odot 4$ & precooler side plenum LP \\
\hline 1 & & 2 & 0.5080 & 0.202683 & 4.0000 & 1.12 & 1. $0 \mathrm{E}-04$ & pipe to main compressor \\
\hline \multicolumn{9}{|c|}{ From main compressor to LTR } \\
\hline 2 & 3 & 2 & $\odot .6350$ & ๑. 316692 & 7.5000 & 2.92 & 1. $\odot E-\odot 4$ & pipe to LTR \\
\hline 2 & & 16 & 0.3048 & 0.072966 & 0.3000 & 0.40 & 1. $0 \mathrm{E}-04$ & LTR inlet side plenum HP \\
\hline 2 & & 96 & 0.0822 & 0.010410 & 1.7800 & 0.70 & 1. $\odot E-\odot 4$ & LTR inlet distribution plena HP \\
\hline \multicolumn{9}{|c|}{ LTR to merge $T$ junction } \\
\hline 3 & 3 & 96 & 0.0822 & $\odot .010410$ & $2.0 \odot \odot \odot$ & 0.70 & 1. $\odot E-\odot 4$ & LTR outlet distribution plena HP \\
\hline 3 & & 16 & 0.3556 & 0.099315 & 0.3000 & 0.40 & 1. $0 \mathrm{E}-04$ & LTR outlet side plenum HP \\
\hline 3 & & 16 & 0.3997 & 0.125475 & 1.7874 & 2.44 & 1. $\odot E-\odot 4$ & Pipe from LTR to merge $\mathrm{T}$ junction \\
\hline \multicolumn{9}{|r|}{-1 - } \\
\hline 4 & 3 & 16 & $\odot .3997$ & 0.125475 & $\odot .5500$ & 1.12 & 1. $\odot E-\odot 4$ & Pipe from merge $\mathrm{T}$ junction to HTR \\
\hline 4 & & 16 & 0.5080 & 0.202683 & 0.3000 & 0.40 & 1. $\odot E-\odot 4$ & HTR inlet side plenum HP \\
\hline 4 & & 96 & 0.0822 & 0.010410 & 2.6500 & 0.70 & 1. $\odot E-\odot 4$ & HTR inlet distribution plena HP \\
\hline \multicolumn{9}{|c|}{ From HTR to IHX (reactor) } \\
\hline 5 & 3 & 96 & 0.0822 & 0.010410 & 2.6500 & 0.70 & 1. $0 \mathrm{E}-04$ & HTR outlet distribution plena HP \\
\hline 5 & & 16 & 0.3556 & $\odot .099315$ & 0.3000 & 0.40 & 1. $\odot E-\odot 4$ & HTR outlet side plenum HP \\
\hline 5 & & 2 & 1.0000 & 0.785398 & 13.500 & 2.00 & 1. $. \mathrm{E}-\odot 4$ & Pipe from HTR to IHX (reactor) \\
\hline \multicolumn{9}{|r|}{ 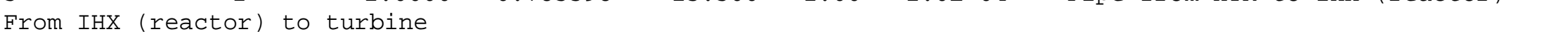 } \\
\hline 6 & 1 & 2 & 1.0000 & 0.785398 & 16.500 & 2.00 & 1. $0 \mathrm{E}-\odot 4$ & Pipe From IHX (reactor) to turbine \\
\hline \multicolumn{9}{|c|}{ bine to HTR } \\
\hline 7 & 4 & 16 & 0.3997 & 0.125475 & 0.2500 & 1.12 & 1. $0 \mathrm{E}-04$ & Pipe From turbine to HTR \\
\hline 7 & & 16 & $\odot .3500$ & 0.140000 & 2.6500 & 0.40 & 1. $\odot E-\odot 4$ & HTR inlet side plenum LP \\
\hline 7 & & 62880 & 0.0030 & 0.000090 & 0.0050 & 1.20 & 1. $0 \mathrm{E}-04$ & HTR inlets LP \\
\hline 7 & & 96 & 0.0359 & $0.09000 \odot$ & 0.2800 & 0.40 & 1. $\odot E-\odot 4$ & HTR inlet plenum LP \\
\hline \multicolumn{9}{|c|}{ From HTR to LTR } \\
\hline 8 & 7 & 96 & 0.0359 & $\odot .090000$ & $\odot .2800$ & 0.40 & 1. $\odot E-\odot 4$ & HTR outlet plenum LP \\
\hline 8 & & 62880 & 0.0030 & $\odot .00009 \odot$ & 0.0050 & 1.20 & 1. $\odot E-\odot 4$ & HTR outlets LP \\
\hline 8 & & 16 & 0.3500 & 0.140000 & 2.6500 & 0.40 & 1. $\odot E-\odot 4$ & HTR outlet side plenum LP \\
\hline 8 & 2 & 16 & 0.5080 & 0.202683 & 0.5000 & 1.12 & 1. $. \mathrm{E}-\odot 4$ & Pipe From HTR to LTR \\
\hline \multicolumn{9}{|c|}{246} \\
\hline & & & & & & & & \\
\hline
\end{tabular}


Project No 06-040: Flexible Conversion Ratio Fast Reactor Systems Evaluation

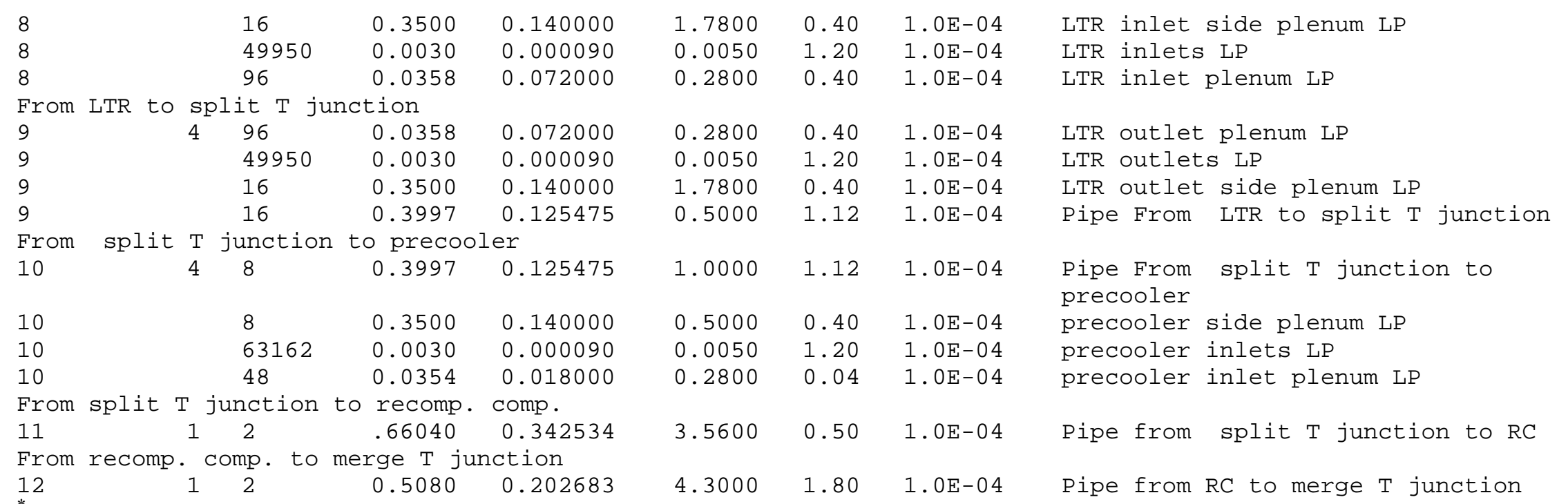

*Path numbers coincide with numbering in Figure A-3, Ns = number of sections per path with different pipe characteristics , Npipe $=$ number of parallel pipes/flow passages per section, $\mathrm{D}_{\mathrm{h}}=$ hydraulic diameter, $\mathrm{A}=$ flow area, $\mathrm{K}$ is form loss coefficient of a section , $\zeta=$ roughness of a section. 
Project No 06-040: Flexible Conversion Ratio Fast Reactor Systems Evaluation

Table 2A-5 Detailed pressure loss distribution through the system

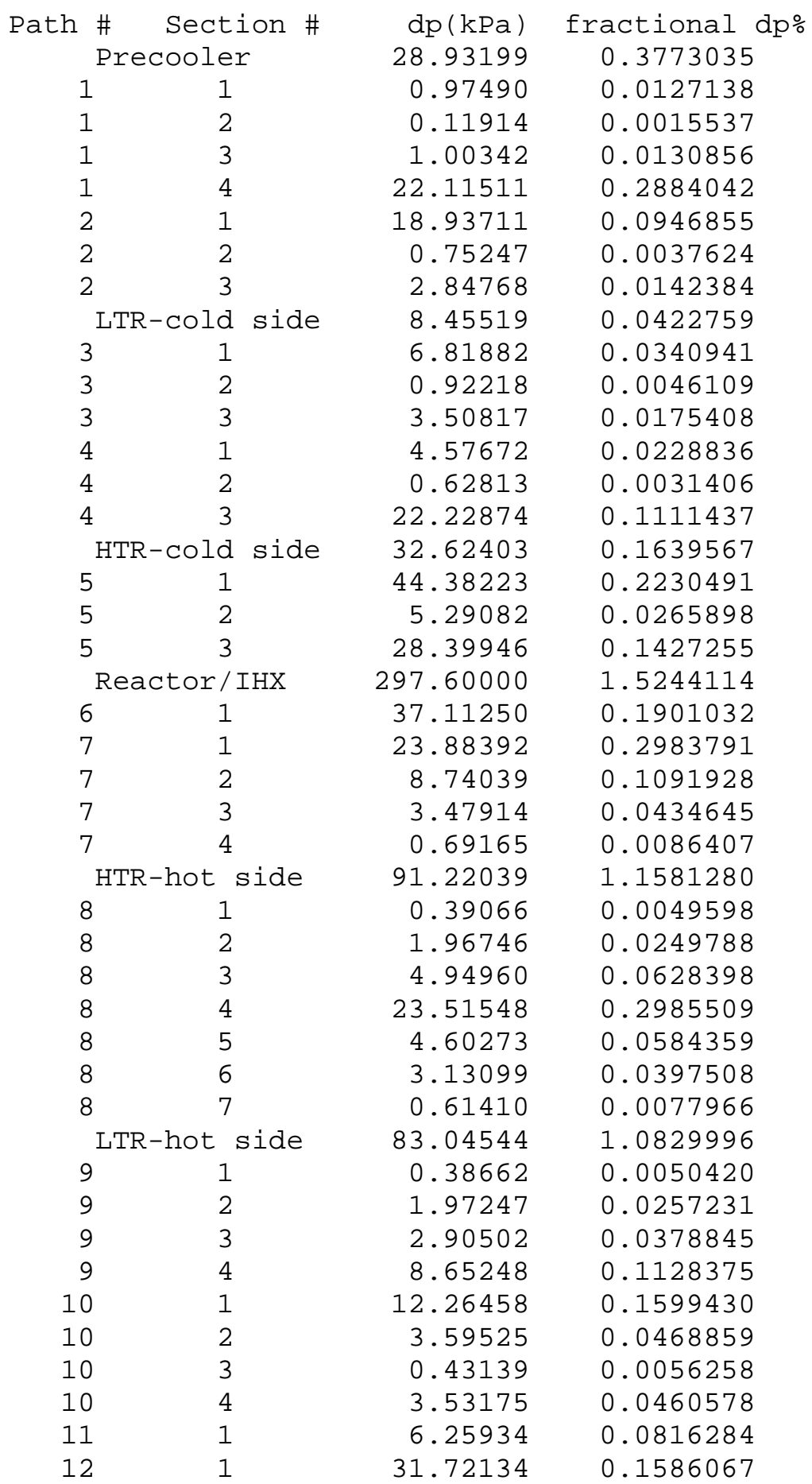


Project No 06-040: Flexible Conversion Ratio Fast Reactor Systems Evaluation

\section{References for Appendix 2A}

Dostal V., Driscoll M.J., Hejzlar P., "A Supercritical Carbon Dioxide Cycle for Next Generation Nuclear Reactors”, MIT CANES Report MIT-ANP-TR-100, March 2004.

Gibbs J.P., Hejzlar P.. and Driscoll M.J., "Applicability of Supercritical $\mathrm{CO}_{2}$ Power Conversion Systems to Gen IV Reactors", MIT-GFR-037, Center of Advanced Nuclear Energy Systems, September, 2006.

Hejzlar P., Driscoll M.J., Gibbs J., Gong Y., Kao S., "Supercritical $\mathrm{CO}_{2}$ Brayton Cycle for Medium Power Applications”, MIT CANES Report MIT-ANP-PR-117, April 2006. 


\section{Appendix 2B \\ RVACS Decay Heat Removal Options and Analysis Model}

In order to quickly prototype various RVACS decay heat removal options, computer models were developed to quantify the effect of the various heat transfer enhancements. These models were used to produce best fit lines of heat removal versus primary coolant temperature at steady state. The steady state heat removal rates were then used for time dependent analysis, making use of the primary coolant average temperature, which was used to predict the instantaneous heat removal rate. This appendix describes the RVACS design options evaluated and simplified models used to evaluate performance of basic RVACS and the enhancements.

\section{B.1 Option of Finned Guard Vessel - Problem Formulation}

In order to maximize decay heat removal from an RVACS-like system, the first idea proposed was to add axial fins to the exterior of the guard vessel to enhance heat transfer from the guard vessel to the air. The design for this model is shown in Figures $2 \mathrm{~B}-1$ and 2B-2. 
Project No 06-040: Flexible Conversion Ratio Fast Reactor Systems Evaluation

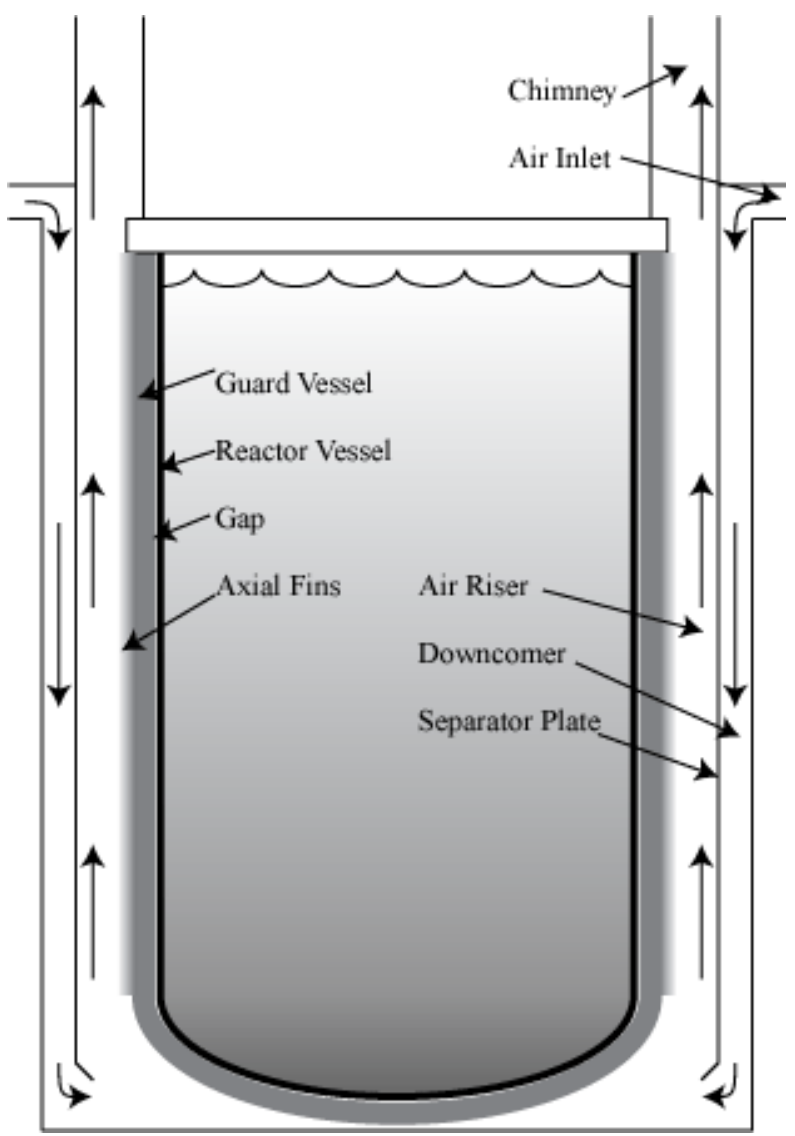

Figure 2B-1 Side view of RVACS system, showing air-side flow path

Two vessels, an interior reactor vessel, and an exterior guard vessel, are separated by a gap filled with a liquid metal bond. The heat is removed by air flow down the downcomer, up through the riser, and out the chimney, which is driven by buoyancy forces caused by density changes within the air. Heat is convected from three surfaces: the guard vessel outer wall, the fins, and the separator plate. Heat is transferred to the separator plate through thermal radiation from both the fins and the guard wall. Heat is conducted through the reactor and guard vessels, and is modeled as a conduction process through the liquid metal gap as well. 


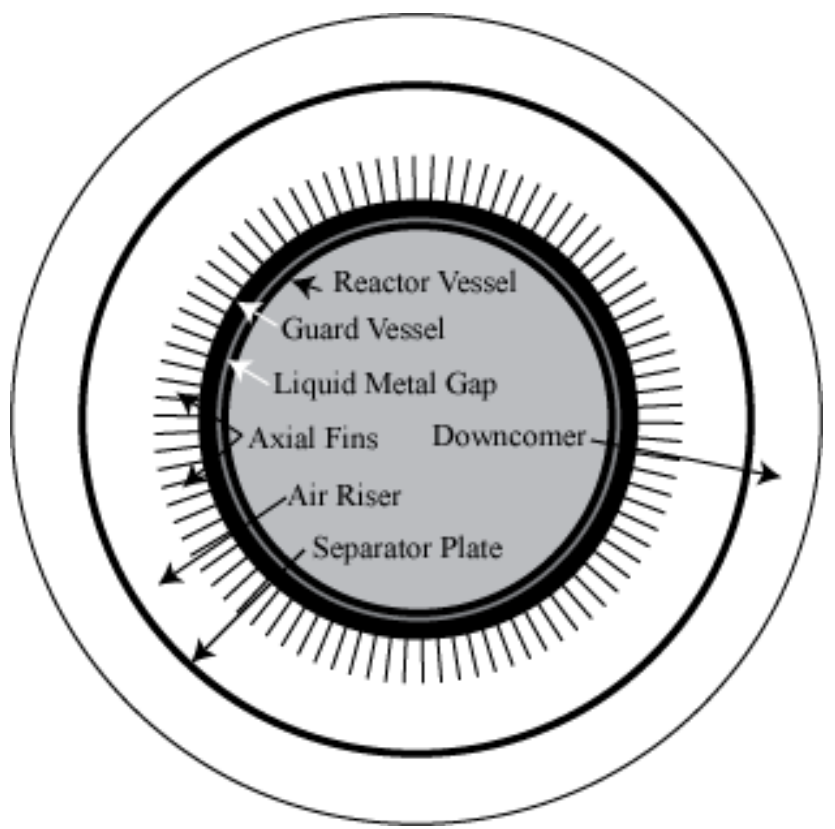

Figure 2B-2 Overhead view of RVACS geometry, with added fins.

To assess heat removal potential from the finned guard vessel, simplified model has been developed and used as the reference model. This model will be described in the following sections of this appendix. This reference model was then modified to analyze other RVACS options, as described in sections 2B.8 through 2B.10.

\section{B.2 Model Assumptions}

The assumptions used by this model are:

- steady state;

- temperature of walls and vessels are considered constant in the azimuthal direction;

- the surfaces involved in radiation are grey;

- the air does not participate with respect to radiation;

- the separator plate is perfectly insulating;

- radiation between adjacent fins is neglected;

- boundary layer buildup between fins is insignificant;

- convection heat transfer coefficient is constant throughout the riser azimuthally;

- all inlet and outlet ducting is perfectly insulating;

- the convective and conduction heat transfer between the lead and the inner wall is constant throughout;

- the inner lead temperature varies linearly in the axial direction;

- the fins are securely attached to the guard vessel so that no thermal contact resistance is present;

- heat transfer through the liquid metal gap can be modeled as conduction;

- axial radiation is neglected;

- axial conduction is neglected. 


\section{B.3 Energy Balances}

The code calculates the surface temperatures of both the outside of the guard vessel and the separator plate wall by iteration. For both cases, the program solves for the temperature at which the heat transferred to the surface is equal to the heat transferred away from the surface.

For the heat balance within the separator plate, the heat transfer area is divided into $\mathrm{N}_{1}$ nodes of equal height $\Delta x$, as shown in Figure 2B-3. Define the nodal surface area of the separator plate, the outer wall of the guard vessel, and the fin tips as

$$
\begin{aligned}
& A_{\text {separator }}=2 \pi R_{6} \Delta x, \\
& A_{\text {guard }}=\left(2 \pi R_{4}-N_{f i n} W_{f i n}\right) \Delta x, \text { and } \\
& A_{\text {fintip }}=N_{\text {fin }} W_{\text {fin }} \Delta x,
\end{aligned}
$$

where $R_{4}$ and $R_{6}$ are the radii of the outer wall of the guard vessel and of the separator plate as shown in Figure $2 \mathrm{~B}-3$, and $\mathrm{N}_{\text {fin }}$ and $\mathrm{W}_{\text {fin }}$ are the number and thickness of the axial fins as shown in Figure 2B-4.

The only method of heat transfer to the separator plate is through radiation from the fins and the guard vessel. Since the number of fins results in a very low view factor from the sides of the fin, the fin tips and the guard wall are the only surfaces that are modeled as participating in the radiation heat transfer. The net transfer of heat to the separator plate in the $\mathrm{j}^{\text {th }}$ node can be calculated from:

$$
\dot{Q}_{\text {in }, \text { separator }, j}=C_{\text {guard }} A_{\text {guard }}\left(T_{\text {guard }, j}^{4}-T_{\text {separator }, j}^{4}\right)+C_{\text {fintip }} A_{\text {fintip }}\left(T_{\text {fintip }, j}^{4}-T_{\text {separator }, j}^{4}\right),
$$

where $T_{\text {guard,j }}, T_{\text {fintip, }}$, and $T_{\text {separator, } j}$ are the temperatures at node $\mathrm{j}$ of the guard wall, fin tips, and separator, and $\mathrm{C}_{\text {guard }}$ and $\mathrm{C}_{\text {fintip }}$ are defined as:

$$
C_{\text {guard }}=F \sigma\left[\frac{1}{\varepsilon_{\text {guard }}}+\frac{A_{\text {guard }}}{A_{\text {separator }}}\left(\frac{1}{\varepsilon_{\text {separator }}}-1\right)\right]^{-1} \text {, and }
$$


Project No 06-040: Flexible Conversion Ratio Fast Reactor Systems Evaluation

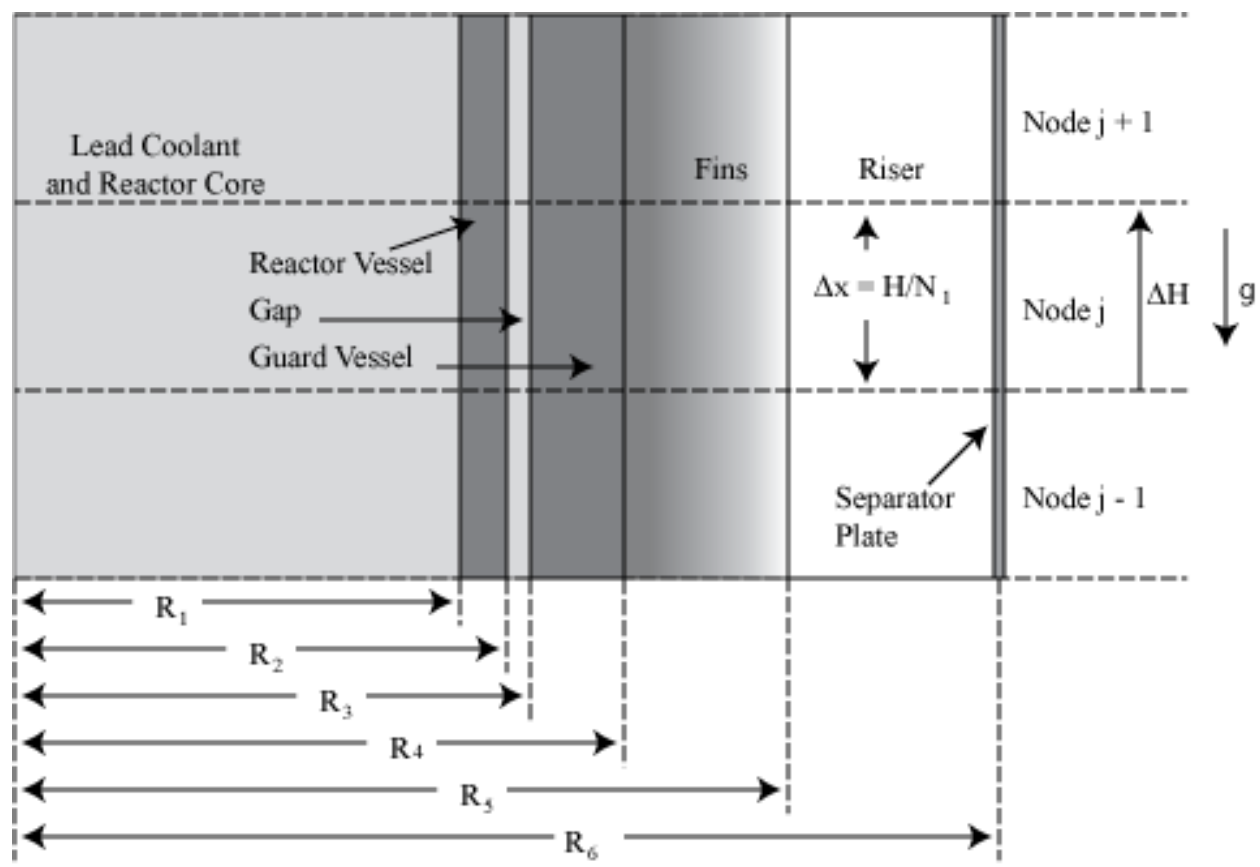

Figure 2B-3. Close up of RVACS geometry, and depiction of naming conventions.

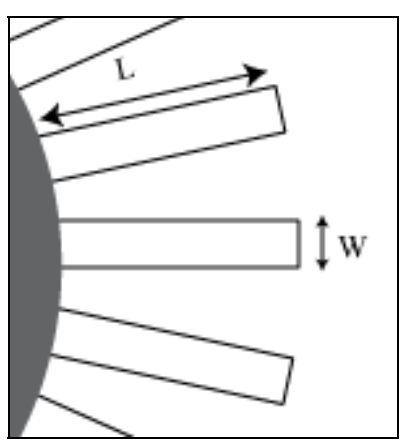

Figure 2B-4. Close up of fin geometry, with naming conventions.

$$
C_{\text {fintip }}=\sigma\left[\frac{1}{\varepsilon_{\text {fintip }}}+\frac{A_{\text {fintip }}}{A_{\text {separator }}}\left(\frac{1}{\varepsilon_{\text {separator }}}-1\right)\right]^{-1} \text {, }
$$

where $\mathrm{F}$ is the user-set radiation view factor between the guard vessel wall and the separator plate, $\sigma$ is Boltzmann's constant, and $\varepsilon_{\text {guard }}, \varepsilon_{\text {fintip, and }} \varepsilon_{\text {separator }}$ are the emissivities of the guard vessel, fin tips, and separator plate. Since the view factor is not calculated explicitly, this addition to the model is used primarily for bracketing purposes.

The heat transfer from the plate to the air is modeled as pure convection, with a heat transfer coefficient derived from the correlation described in Eq. 2B-8. The heat transfer rate from the separator plate is thus:

$$
\dot{Q}_{\text {out }, \text { separator }, j}=h_{j} A_{\text {separator }}\left(T_{\text {separator }, j}-T_{\text {bulkair }, j}\right),
$$


where $T_{\text {bulkair,j }}$ is the bulk air temperature entering the node, and $h_{j}$ is the convective heat transfer coefficient calculated from a correlation developed experimentally by ANL for heat transfer in an RVACS as [Heineman et al., 1988], [Hejzlar, 1994]:

$$
h_{j}=0.0229 \operatorname{Re}_{j}^{0.8} \operatorname{Pr}_{j}^{0.4} \frac{k_{\text {air }, j}}{D_{h}}\left(\frac{T_{\text {guard }, j}}{T_{\text {air }, j}}\right)^{-0.4}\left[1+\left(\frac{z_{j}}{D_{h}}\right)^{-0.36}\right] \text {, }
$$

where $\mathrm{Re}$ is the Reynolds number, $\operatorname{Pr}$ is the Prandtl number, $\mathrm{k}_{\mathrm{air}}$ is the thermal conductivity of the air, $\mathrm{D}_{\mathrm{h}}$ is the hydraulic diameter of the ducting, and $\mathrm{z}_{\mathrm{j}}$ is the distance above the riser inlet.

Finally, to find the steady state solution equations $2 \mathrm{~B}-4$ and $2 \mathrm{~B}-7$ are set equal, and the separator temperature is solved for.

The guard vessel outer wall temperature is found using the same heat-balance methodology. Heat is transferred away from the vessel by four parallel pathways: convection from the guard vessel, convection from the fins, and radiation from the guard vessel surface and the fin tips. Since convection from the separator plate must be equal to radiation from the guard vessel and fins, the convection heat rate described by Eq. $2 \mathrm{~B}-$ 7 is used to represent the latter two pathways. The remaining heat removal rates are shown to be:

$$
\dot{Q}_{\text {out }, \text { guard }, j}=h_{j} A_{\text {guard }}\left(T_{\text {guard }, j}-T_{\text {bulkair }, j}\right)
$$

and [Incropera and DeWitt, 2002]

$$
\dot{Q}_{\text {out }, \text { fin }, j}=N_{f i n}\left[M \frac{\sinh (m L)+\left(h_{j} / m k\right) \cosh (m L)}{\cosh m L+\left(h_{j} / m k\right) \sinh (m L)}\right],
$$

where $\mathrm{L}$ is the length of the fins, $\mathrm{k}$ is the conductivity of the fins, and $\mathrm{M}$ and $\mathrm{m}$ are defined as:

$$
M=\left(T_{\text {guard }, j}-T_{\text {bulkair }, j}\right) \sqrt{h_{j} P k A_{c}}=\left(T_{\text {guard }, j}-T_{\text {bulkair }, j}\right) \Delta x \sqrt{2 h_{j} k W_{\text {fin }}},
$$

and

$$
m=\sqrt{\frac{h_{j} P}{k A_{c}}}=\sqrt{\frac{2 h_{j}}{k W_{\text {fin }}}} .
$$


Heat transfer to the guard vessel outer surface from the hot lead coolant is modeled as a series of resistances between the lead temperature and the guard vessel outer wall. The resistance between the hot lead and the reactor vessel is:

$$
R_{\text {lead }}=\left(h_{\text {lead }} 2 \pi R_{1} \Delta x\right)^{-1}
$$

where $\mathrm{h}_{\text {lead }}$ is a user defined input. The remaining resistances can be represented as:

$$
R_{\text {cylinder }}=\frac{\ln \left(R_{\text {out }} / R_{\text {in }}\right)}{2 \pi k \Delta x}
$$

where $R_{\text {out }}$ and $R_{\text {in }}$ are the outer and inner radius of the cylindrical barrier, and $k$ is the thermal conductivity of the vessel or gap material. For the case of $\mathrm{R}_{\text {gap }}$, the primary mode of heat transfer across the liquid metal gap was assumed to be conduction. The total resistance is thus:

$$
R_{\text {total }}=R_{\text {lead }}+R_{\text {reactor vessel }}+R_{\text {gap }}+R_{\text {guard vessel }},
$$

with the last three resistances on the right hand side calculated from Eq. 2B-14, and the total heat transfer into the guard vessel is:

$$
\dot{Q}_{\text {in }, \text { guard }, j}=R_{\text {total }}^{-1}\left(T_{\text {lead }, j}-T_{\text {guard }, j}\right) .
$$

Using the same technique as is used to find the separator plate temperature, Eq. $2 \mathrm{~B}-16$ is set equal to the sum of Eqs. 2B-7, 2B-9, and 2B-10, and the guard vessel outer wall temperature is solved for.

\section{B.4 Mass Flow Rate Determination}

The air mass flow rate is determined from a balance between buoyancy forces and pressure losses using

$$
\dot{m}=\sqrt{\frac{\Delta p_{b}}{c}},
$$

where c represents the pressure drop due to form and friction losses, defined as:

$$
c=\sum_{j=1}^{N}\left(K_{j}+f_{j} \frac{L_{j}}{D_{h, j}}\right)\left(2 \rho_{j} A_{j}^{2}\right)^{-1}
$$

where $\mathrm{N}$ is the total number of nodes (heated and unheated), $\mathrm{K}$ is the form loss coefficient, $\mathrm{f}$ is the friction loss coefficient defined below in Eq. $2 \mathrm{~B}-24$, $\mathrm{L}$ is the length of 
the node, $D_{h}$ is the hydraulic diameter, $\rho$ is the average density of air within the node, and $\mathrm{A}$ is the total cross sectional area of the ducting.

The thermal buoyancy coefficient, $\Delta \mathrm{p}_{\mathrm{b}}$ is defined as:

$$
\Delta p_{b}=\sum_{j=1}^{N} \rho_{j}\left(\Delta \vec{H}_{j} \bullet \vec{g}\right),
$$

where $\mathrm{g}$ is the gravitational acceleration, $\rho$ is the average air density, and $\Delta \mathrm{H}$ is the elevation change. Sign conventions followed are shown in Figure 2B-3.

\section{B.5 Air properties calculation}

In order to most accurately model the RVACS system, air density, specific heat, viscosity, and thermal conductivity must be modeled as functions of air temperature and/or pressure.

For density calculations, air is treated as an ideal gas. Thus a simple rearrangement of the ideal gas law yields:

$$
\rho=\frac{m}{V}=\frac{P}{R T}
$$

where $\mathrm{P}$ is the pressure is Pascals, $\mathrm{T}$ is temperature in Kelvin, and $\mathrm{R}$ is the gas constant for air, $287 \mathrm{j} / \mathrm{kg}-\mathrm{K}$.

The remaining properties were calculated from formulae in Irvin [1984]. They are as follows:

$$
\begin{aligned}
C_{p}=1034.09-(0.284887) T+\left(7.816818 \times 10^{-4}\right) T^{2}-\left(4.970789 \times 10^{-7}\right) T^{3} \\
+\left(1.077024 \times 10^{-10}\right) T^{4}, \\
k=-2.2276501 \times 10^{-3}+\left(1.2598485 \times 10^{-4}\right) T-\left(1.4815235 \times 10^{-7}\right) T^{2} \\
\quad+\left(1.4815235 \times 10^{-10}\right) T^{3}-\left(1.066657 \times 10^{-13}\right) T^{4}+\left(2.47663035 \times 10^{-17}\right) T^{5}, \\
\mu=\left(-0.98601+\left(9.080125 \times 10^{-2}\right) T-\left(1.17635575 \times 10^{-4}\right) T^{2}\right. \\
\left.\quad+\left(1.2349703 \times 10^{-7}\right) T^{3}-\left(5.7971299 \times 10^{-11}\right) T^{4}\right) \times 10^{-6},
\end{aligned}
$$

where $\mathrm{T}$ is in units of Kelvin, $\mathrm{C}_{\mathrm{p}}$ is the specific heat in units $\mathrm{J} / \mathrm{kg}-\mathrm{K}$, $\mathrm{k}$ is thermal conductivity in $\mathrm{W} / \mathrm{m}-\mathrm{K}$, and $\mu$ is kinematic viscosity in $\mathrm{kg} / \mathrm{m}-\mathrm{s}$. 


\section{B.6 Pressure drop and change in temperature calculations}

To facilitate the calculation of a solution the heat exchanger is divided into a user-defined number of nodes of equal height, while the inlet and outlet ducting is divided into user specified nodes of independent lengths. The inlet air temperature and pressure for each node is provided by the node prior. All air properties are calculated at the inlet of the node, and assumed constant throughout.

Pressure drop is calculated identically for all nodes, heated and unheated. The friction factor is found from Idelchik [1986]:

$$
f_{j}=0.11\left(\frac{\zeta}{D_{h}}+\frac{68}{\operatorname{Re}}\right)^{0.25},
$$

where $f_{j}$ is the fanning friction factor, where $D_{h}$ is the hydraulic diameter in the $j^{\text {th }}$ section of ducting, $\zeta$ is the sand-grain roughness of the $\mathrm{j}^{\text {th }}$ node, and $\mathrm{Re}$ is the Reynolds number, calculated at the inlet of the node. This leads to the pressure drop through:

$$
P_{i n, j+1}=P_{i n, j}-\rho\left(f_{j} \frac{L}{D_{h}} \frac{v^{2}}{2}+K \frac{v^{2}}{2}\right),
$$

where $P_{i n, j}$ and $P_{i n, j+1}$ are the pressures at the inlet and outlet of node $j, \rho$ is the inlet density of the air, $\mathrm{L}$ is the length of the ducting in the node, $\mathrm{v}$ is the velocity at the inlet of the node, and $\mathrm{K}$ is the form loss coefficient.

Temperature change is calculated only for the heated section of the RVACS system. The heat transfer to the air in the node was calculated using the sum of Eqs. 2B-7, 2B-9, and 2B-10, once the guard vessel outer wall and separator plate temperatures were determined. The temperature increase of the air is then calculated from:

$$
T_{o u t, j}=T_{i n, j}+\frac{Q_{t o t a l, j}}{\dot{m} C_{p}},
$$

where $T_{i n, j}$ and $T_{\text {out,j }}$ are the inlet and outlet temperatures of node $j, Q_{\text {total, }}$ is the total heat transfer to the air within the node, $m$ is the mass flow rate, and $C_{p}$ is the specific heat at constant pressure of the air, calculated at the inlet of the node.

\section{B.7 Solution approach}

Once initiated, the code generates a number of "node" objects in a queue, one for each heated and unheated node. Following this, an initial guess of the mass flow rate is made, 
and the buoyancy forces and pressure loss are calculated for this flow rate, as depicted in Figure 2B-5. Dependent on the flow rate being incorrect, this process is iterated until the flow rate balances the buoyancy and pressure loss forces.

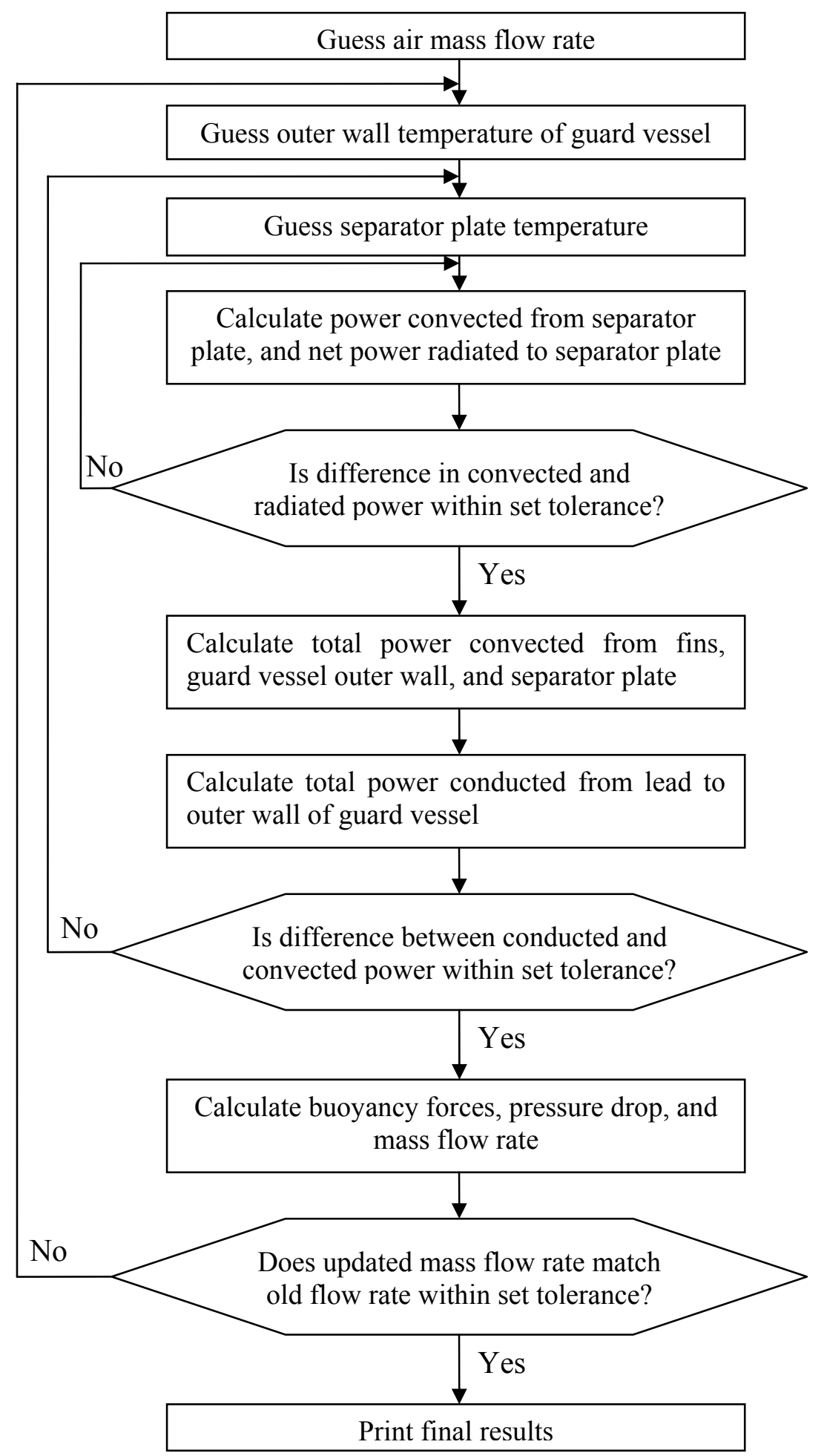

Figure 2B-5. Simplified flow chart of program structure. 
In order to calculate the buoyancy forces, the heat transfer rate is needed to calculate the temperature increase in the air, and the resulting change in density. At each heated node, the air properties are calculated from the outlet temperature and pressure of the previous node. The guard vessel outer wall temperature is then bracketed between the guard vessel temperature at the node prior, and the air temperature. A bisection method using energy balances then solves for the guard vessel temperature at the node, in doing so calling a bisection method on the separator plate temperature, which is bracketed between the guard vessel temperature, and the air temperature. Following completion of the bisection methods the total heat transfer to the air and the output air temperature for the node are calculated. To incorporate pressure losses due to friction forces, Eqs. 2B-24 and 2B-25 are used to calculate the outlet air pressure.

Following pressure and heat transfer calculations, the next node is called, and the process repeats. After tallying up total buoyancy and pressure forces, an adjustment to the mass flow rate is made, and the process iterates. After a suitable solution is found, the program prints the result to file. The computer program is coded in Java.

\section{B.8 Modification for Perforated Plate Heat Transfer Calculation:}

The second heat transfer enhancement on the air side explored was GE's S-PRISM design with a perforated plate added to the air riser to provide an additional surface for the guard vessel to radiate energy to, and two additional surfaces from which the heat can be convectively removed, as shown in Figure 2B-6.

In order to calculate the radiant heat transfer to the perforated plate, a different set of energy balances was used, similar to but expanding upon those used for the finned vessel case. The different pathways for heat from the guard vessel to the air are depicted in Figure 2B-7.

Three heat balances must be used to calculate temperatures and heat transfer rates from the three surfaces in the riser. They are:

$$
\begin{aligned}
& \dot{Q}_{g, s}+\dot{Q}_{p, s}=\dot{Q}_{s, a}, \\
& \dot{Q}_{g, p}=\dot{Q}_{p, s}+\dot{Q}_{p, a}, \\
& \dot{Q}_{i n}=\dot{Q}_{g, p}+\dot{Q}_{g, s}+\dot{Q}_{g, a},
\end{aligned}
$$

for the separator plate, perforated plate, and guard vessel, respectively, and where $\mathrm{Q}_{\text {in }}$ is the energy conducted through the guard vessel to the outer surface, calculated as in Equation 2B-16. 


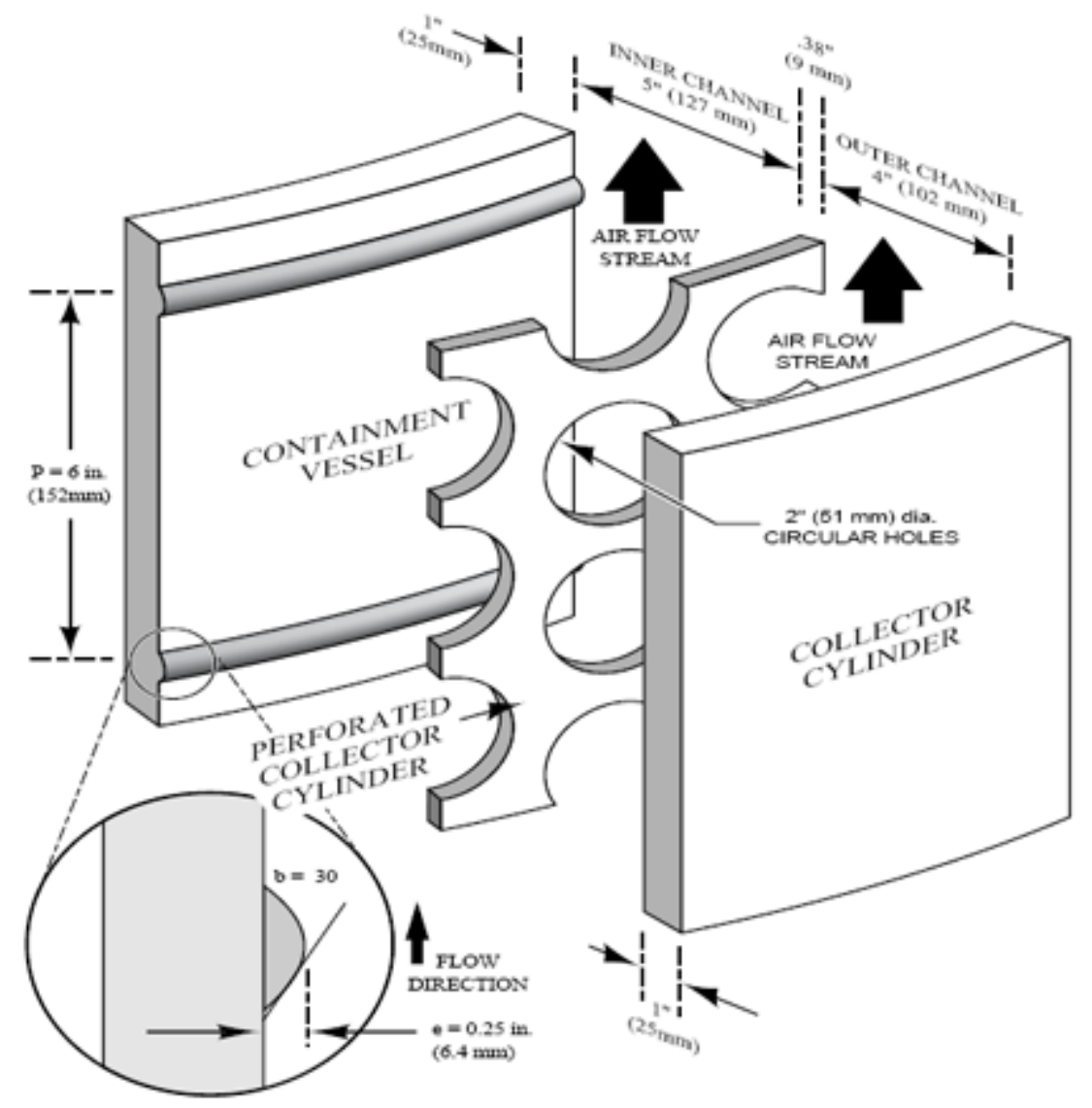

ENHANCED RVACS HOT AIR RISER WITH BOUNDARY LAYER TRIPS AND PERFORATED COLIECTOR CYLNDER

Figure 2B-6. RVACS hot air riser with boundary layer trips and perforated plate. (from Boardman et al, 2000)

The radiative heat transfers, $\mathrm{Q}_{\mathrm{g}, \mathrm{s}}, \mathrm{Q}_{\mathrm{g}, \mathrm{p}}$, and $\mathrm{Q}_{\mathrm{p}, \mathrm{s}}$, all can be represented by:

$\left.\dot{Q}_{\text {radiation }, j}=C_{i} A_{\text {hot }}\left(T_{\text {hot }, j}^{4}-T_{\text {cold }, j}^{4}\right)\right)$,

where $A_{\text {hot }}$ is the area of the hot surface, $T_{\text {hot }}$ and $T_{\text {cold }}$ are the temperatures, in Kelvin, of the hot and cold surfaces, and $\mathrm{C}_{\mathrm{i}}$ is:

$C_{i}=\sigma\left[\frac{1}{\varepsilon_{\text {hot }}}+\frac{A_{\text {hot }}}{A_{\text {cold }}}\left(\frac{1}{\varepsilon_{\text {cold }}}-1\right)\right]^{-1}$,

where $\sigma$ is the Stefan-Boltzmann constant, $\varepsilon_{\text {hot }}$ and $\varepsilon_{\text {cold }}$ are the emissivities of the hot and cold surfaces, and $A_{\text {hot }}$ and $A_{\text {cold }}$ are the areas of the hot and cold surfaces. In order to 
accommodate the shielding effect of the perforated plate during radiation transfer between the guard vessel and the separator plate, the $\mathrm{A}_{\text {cold }}$ used is the area taken up by the perforations in the perforated plate. In order to approximate view factors for the perforated and separator plates, the areas participating in the radiative heat transfer are calculated as:

$\mathrm{A}_{\text {guard }}=\left(\pi \mathrm{D}_{\text {guard }}\right) \Delta \mathrm{z}$

$\mathrm{A}_{\text {perforated }}=\mathrm{F}_{\text {area }}\left(\pi \mathrm{D}_{\text {perf }}\right) \Delta \mathrm{z}$,

$\mathrm{A}_{\text {separator,guard }}=\left(1-\mathrm{F}_{\text {area }}\right)\left(\pi \mathrm{D}_{\text {perf }}\right) \Delta \mathrm{z}$, and

$\mathrm{A}_{\text {separator,perforated }}=\left(\pi \mathrm{D}_{\text {separator }}\right) \Delta \mathrm{z}$,

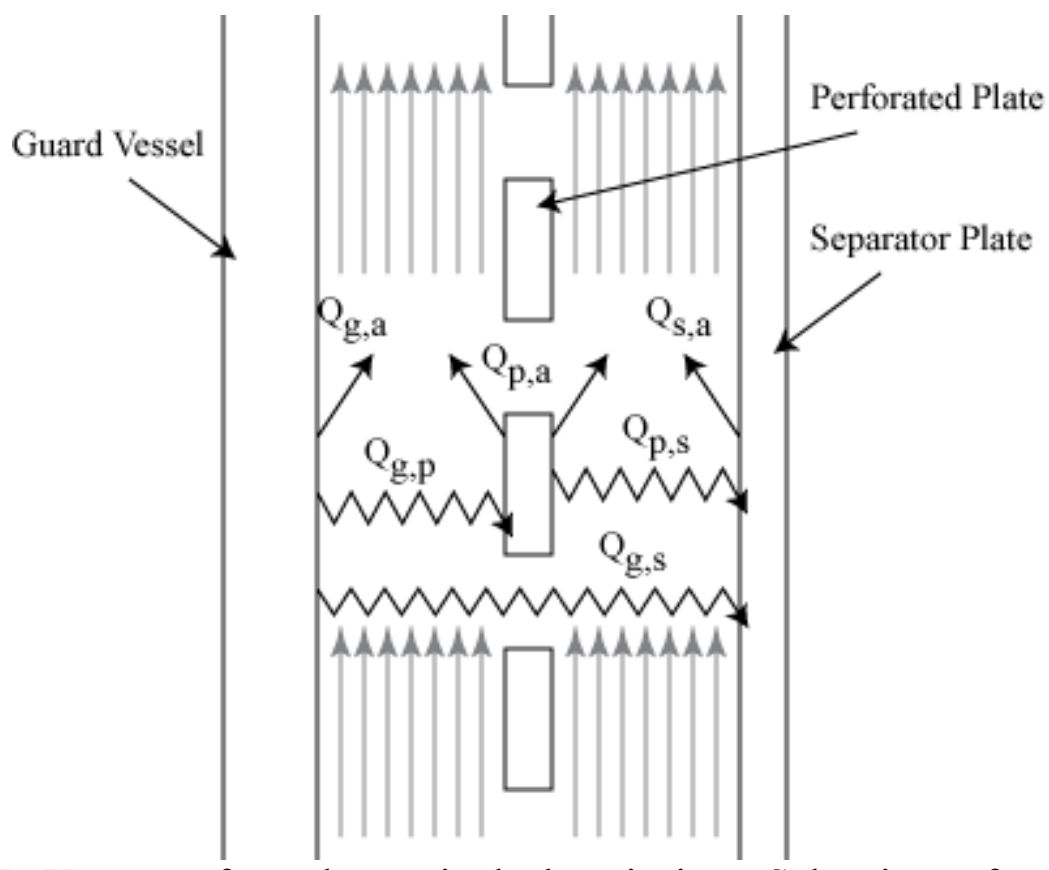

Figure 2B-7. Heat transfer pathways in the hot air riser. Subscripts refer to guard (g), perforated plate $(\mathrm{p})$, and separator plate $(\mathrm{s})$.

where $A_{\text {separator,guard }}$ is used for the calculation of radiation from the guard vessel to the separator plate, $\mathrm{As}_{\text {eparator,perforated }}$ is used for calculation of radiation from the perforated plate to the separator plate, $D_{\text {guard }}, D_{\text {perf }}$, and $D_{\text {separator }}$ are the diameters of the three surfaces, $\mathrm{F}_{\text {area }}$ is the percentage of the perforated plate that is solid, and $\Delta \mathrm{z}$ is the nodal length.

$\mathrm{Q}_{\mathrm{p}, \mathrm{a}}, \mathrm{Q}_{\mathrm{g}, \mathrm{a}}$, and $\mathrm{Q}_{\mathrm{s}, \mathrm{a}}$ are all calculated from:

$\dot{Q}_{\text {out }, \text { convection }, j}=h_{j} A_{j}\left(T_{h o t, j}-T_{\text {bulkair }, j}\right)$, 
where $h_{j}$ is calculated from Eq. $2 B-8, A$ is the heat transfer area, and $T_{\text {hot,j }}$ and $T_{\text {bulkair,j }}$ are the wall or plate temperature and the bulk air temperature at node $\mathrm{j}$, respectively.

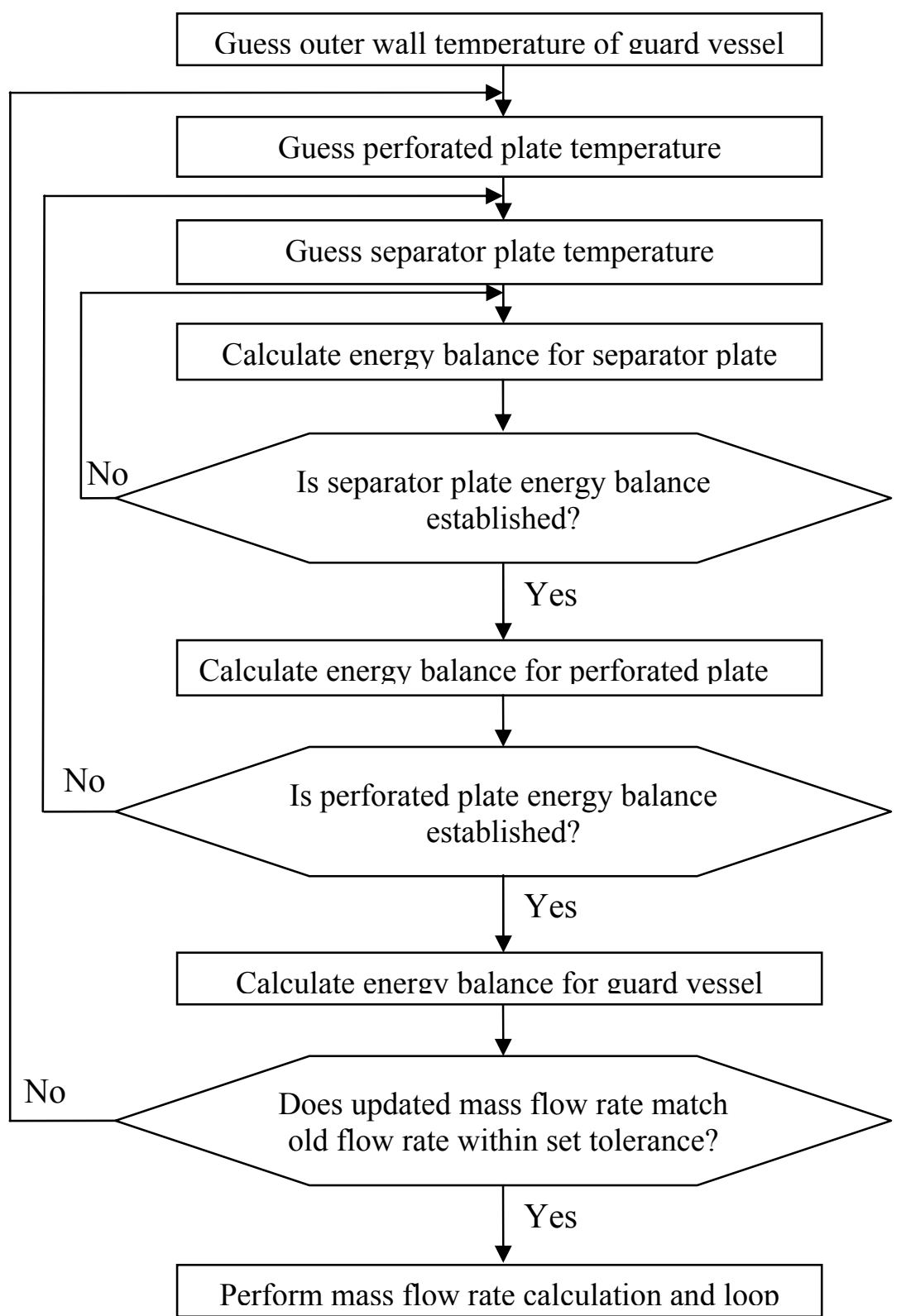

Figure 2B-8. Simplified flow chart of heat-balance calculations for perforated plate model.

\section{Solution Approach}

The solution approach is similar to that used in the finned vessel case, differing only in how the heat balances are calculated. In order to determine the temperatures of the guard vessel outer wall, perforated plate, and separator plate, the program creates equation objects that represent the above heat balances (Eqs. 2B-27 through 2B-29). The program 
then iterates in order to determine the correct heat transfer within the node. The process is the same as that in the finned vessel model, except for the addition of a loop to determine separator plate temperature. The nodal energy balance section of the code is described by Figure 2B- 8 .

\section{B.9 Modification for Dimpled Wall Heat Transfer Approximation}

A third air-side enhancement that was examined was the addition of dimples to the exterior of the guard vessel and/or the separator plate. Dimpling has been studied in recent years, with very promising results showing large heat transfer enhancement with relatively small friction factor increase. The heat transfer enhancement is due to a combination of increased surface area and boundary layer separation. Most studies that have been performed on dimples have been on much smaller systems, however, so only very rough calculations can be done, with simple multipliers added to the correlations for Nusselt numbers and friction factors.

Modification of the code in order to approximate the effect of dimpled channel walls on heat removal is a relatively trivial process. The number of fins was set to 1 , and the fin length was made negligibly small $(0.001 \mathrm{~cm})$. This avoids errors when dividing by the number of fins, as occurs often in the program, but eliminates any fin effects from the calculations.

The only other modification needed was to the convection heat transfer coefficient subroutine, and the friction factor subroutine. These factors are calculated as normal, but then multiplied by a constant coefficient, depending on what Nusselt number and friction factor augmentations are desired. The augmentation factors used are based on experimental results from the literature, as discussed next.

\section{B.9.1 Dimpled Wall Performance Estimates Based on Experimental Results}

Research on dimpled heat exchangers has been mostly confined to the turbine industry, where flows are generally in much smaller passages, and therefore at lower Reynolds numbers than those being considered for the RVACS system. Unfortunately, this means that only rough estimates and a general bracketing of values can be used for calculating the enhancement effects of dimples on the wall of the guard vessel and separator plate. Of the experiments studied, Moon and Lau's in Figure 2B-9 had the least promising results; that is, the lowest Nusselt number augmentation with the highest friction factor increase. These tests, while calculated at lower Reynolds numbers than experienced in the RVACS hot air riser, provide a rough estimate of the lower bounds expected. 
Using the most conservative dimpling multipliers in a bare-walled RVACS and the pseudo-steady state analysis described in Section 2B.11, the fuel clad temperature limit is not exceeded, as shown in Figure 2B-10.

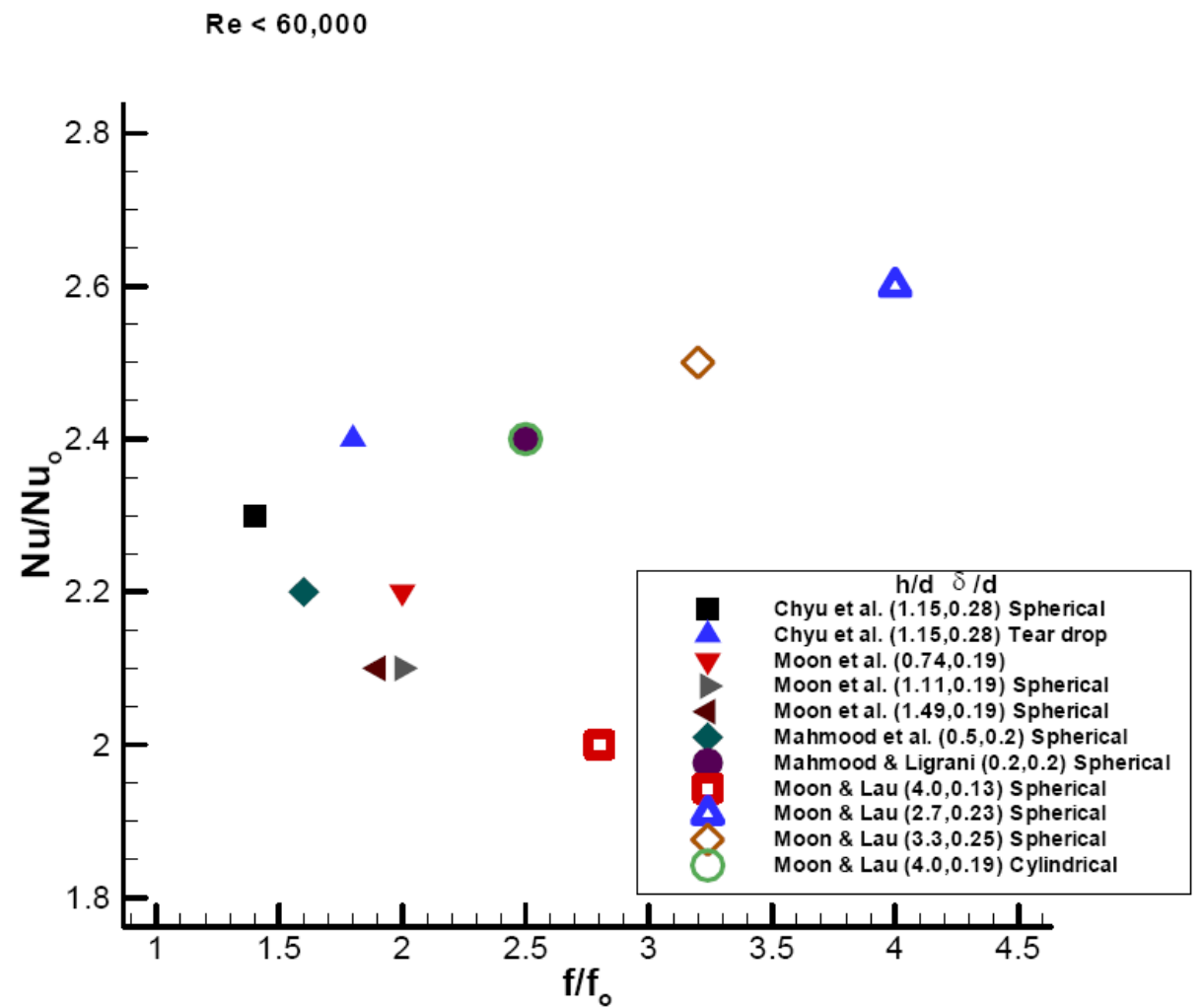

Figure 2B-9. Past results of calculations on dimples by various researchers [Patrick, 2005]. In the ratios $h / d$ and $\delta / d, h$ refers to the height of the channel, $d$ is the diameter of the dimple, and $\delta$ is the dimple depth. 
Project No 06-040: Flexible Conversion Ratio Fast Reactor Systems Evaluation

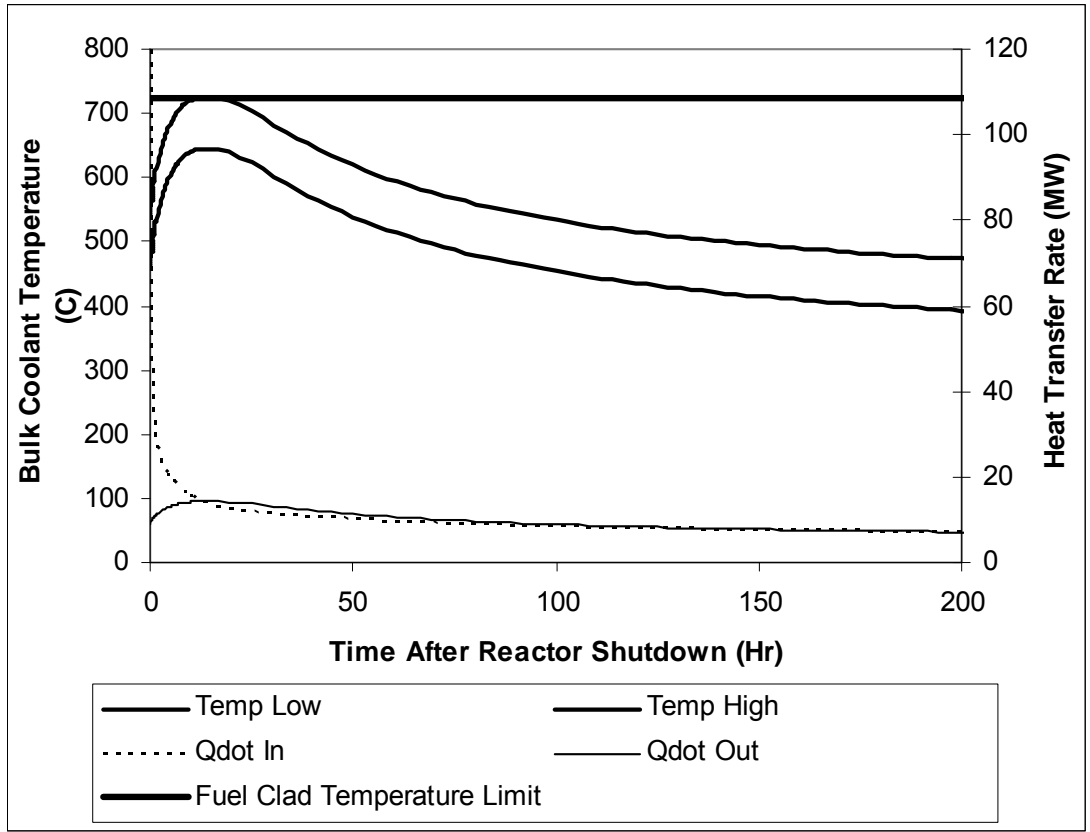

Figure 2B-10. Temperature and Heat Transfer rate time response for single-stage RVACS with dimpled guard vessel, with $\mathrm{Nu} / \mathrm{Nu}_{0}=2$ and $\mathrm{f} / \mathrm{f}_{0}=2.8$

\section{B.9.2 Dimpled Wall Numerical Evaluations}

Since the above model used to represent the heat transfer and pressure drop effects of the dimples had large uncertainties, numerical simulations were also performed using a Computational Fluid Dynamics (CFD) code called Fluent. First, a benchmark test using experimental data was run to confirm that Fluent can capture all of the intricacies of the dimples' effect on the fluid flow. The laboratory experiment performed by Burgess et al. [2003], who experimentally measured pressure drop and localized and global Nusselt numbers for a specific dimple geometry, was used for the benchmark. The setup used included a $1.22 \mathrm{~m}$ long, smooth-walled inlet duct of the same cross section as the dimpled section, to ensure that entrance effects were not affecting the flow. This was followed by a $1.233 \mathrm{~m}$ long, $0.411 \mathrm{~m}$ wide, and $5.08 \mathrm{~cm}$ tall duct with 29 rows of dimples on the bottom surface, as shown in Figure 2B-11a. This surface was heated to generate a heat flux of $625 \mathrm{~W} / \mathrm{m}^{2}$, and air was blown through the channel at Reynolds numbers between 10,000 and 25,000. The dimples were machined to be $1.524 \mathrm{~cm}$ deep and $5.08 \mathrm{~cm}$ across, as shown in Figure 2B-11b. 


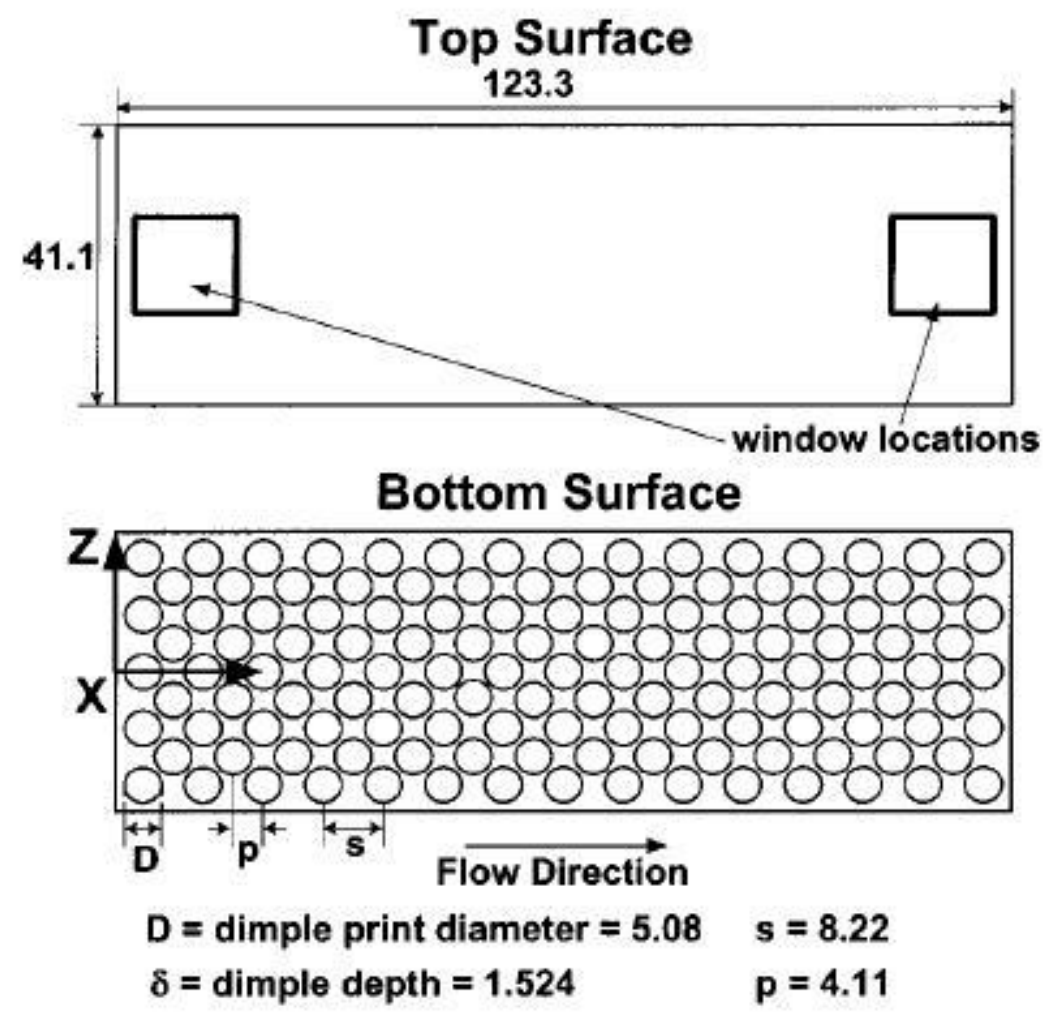

Figure 2B-11a Diagram of dimple geometry. All measurements in $\mathrm{cm}$. From Burgess et al. [2003].

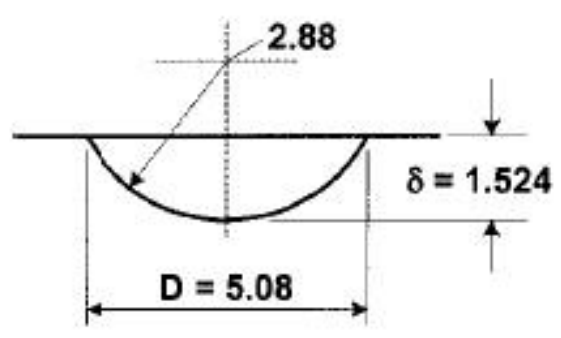

Present study

Figure 2B-11b Diagram of individual dimple. All units are $\mathrm{cm}$. (from Burgess et al. [2003]).

As the computational resources necessary to run a large geometry with a small mesh were prohibitive, Fluent's built-in periodic flow conditions were used to simulate the performance of those dimples located beyond any entrance-effect regions. This boundary condition forces the inlet flow to conform to the outlet flow, simulating the fullydeveloped region. This allowed the use of very fine mesh points with further refinement using the "adapt mesh" feature in Fluent, where the code automatically divides cells that have large gradients in any of a number of properties. One full dimple was modeled in addition to four one-quarter dimples, as shown in Figure 2B-12. 

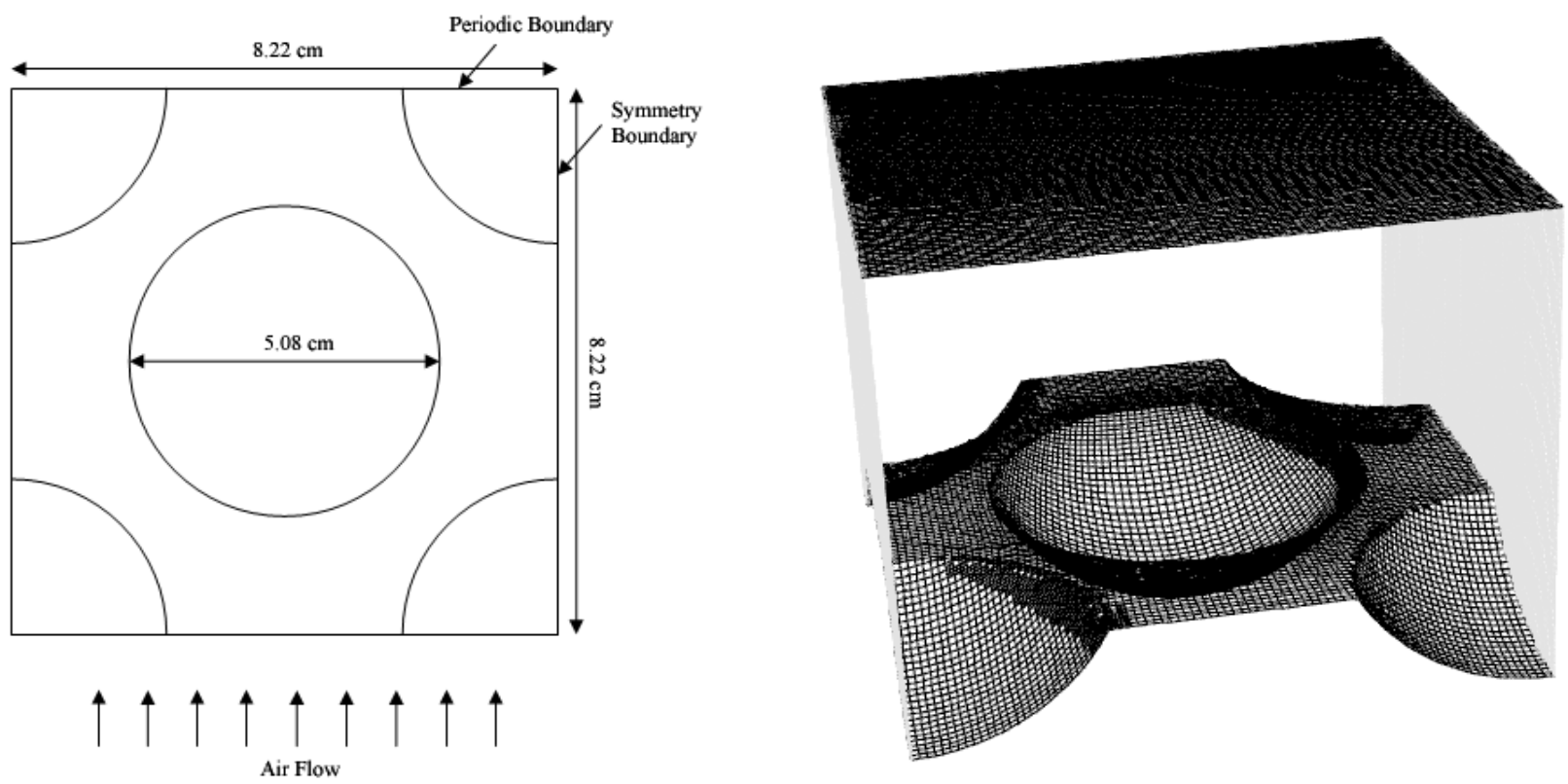

Figure 2B-12 Unit cell model on dimple geometry with boundary condition designations.

The Reynolds Stress Model, or RSM, which solves 7 equations in addition to the Navier Stokes equations, was used. This method is superior for situations with large turbulence effects, as well as those with boundary layer separation. The model was used without wall functions, fully resolving the boundary layer. Results from Fluent using periodic geometry on the small dimple geometry are shown in Figures 2B-13 -2b-14. For all cases, only the result along the dimples' wall is displayed, and flow is down the page.

This result produced a globally average Nusselt number ratio, $\mathrm{Nu} / \mathrm{Nu}_{0}$, of 1.5 when the Dittus Boelter correlation was used as $\mathrm{Nu}_{0}$; considerably less than the expected value of 2.5 from the laboratory experiment, as shown in Table 2B-1. Furthermore, a comparison of friction factor ratios, $\mathrm{f} / \mathrm{f}_{0}$, showed even worse agreement, as the CFD code predicted $\mathrm{f} / \mathrm{f}_{0}$ of 5.4 , whereas the laboratory result showed a value of 1.8 . Literature review showed that Won and Ligrani, [2004] encountered a similar problem and were unable to predict the Nusselt number enhancement effect of dimples using CFD. They vastly underpredicted experimental local $\mathrm{Nu} / \mathrm{Nu}_{0}$ ratios (between 0.8 and 1.3 versus 2.5 and 2.7).

To check for consistency of modeling approaches, FLUENT run was also performed on a rectangular prism with smooth surface having the same dimensions $(8.22 \mathrm{~cm} \mathrm{x} 8.22 \mathrm{~cm} \mathrm{x}$ $5.08 \mathrm{~cm}$ ) and the same boundary conditions as the periodic dimple mesh. The results showed excellent agreement to within 5\% for both the friction factor and the heat transfer coefficient using the Gnielinski correlation [1976]. Although the RSM model with periodic boundary conditions could well predict heat transfer and pressure drop over the flat plate, it was not able to reproduce experimental data on the dimpled geometry. This is most likely due to RSM turbulence parameters, which are tuned to traditional smooth surfaces and their adaptation to achieve better results for dimpled surfaces would require 
significant effort beyond the scope of this project. Moreover, RELAP5 analysis of the unprotected station blackout showed that enhanced RVACS alone would not be sufficient to remove the required decay heat. Therefore, it was decided to no longer pursue a reduction of uncertainties of heat transfer from dimpled surfaces using FLUENT, in favor of researching additional DHR options.

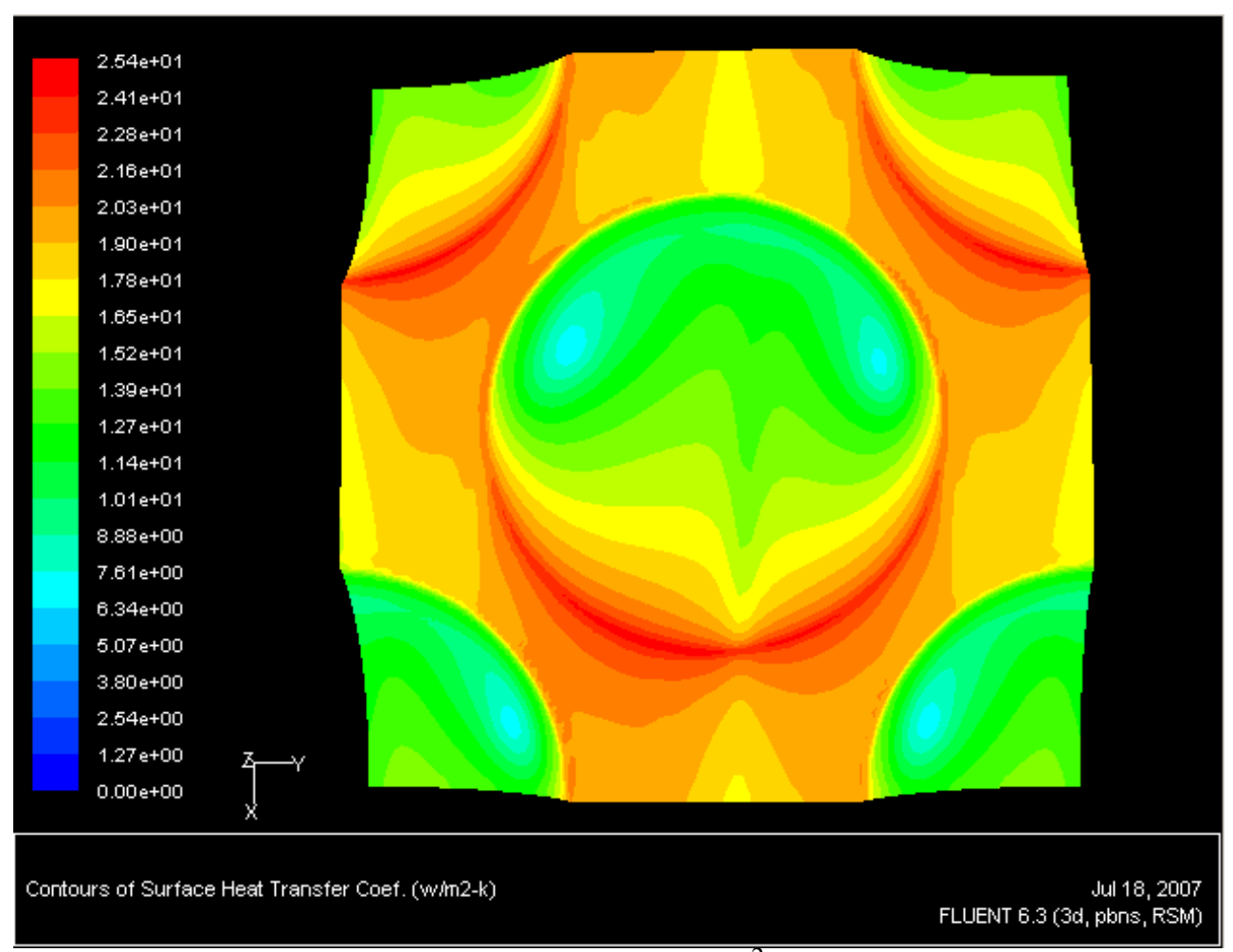

Figure .2B-13. Heat transfer coefficient $\left(\mathrm{w} / \mathrm{m}^{2} \mathrm{~K}\right)$ contour plot from Fluent. 


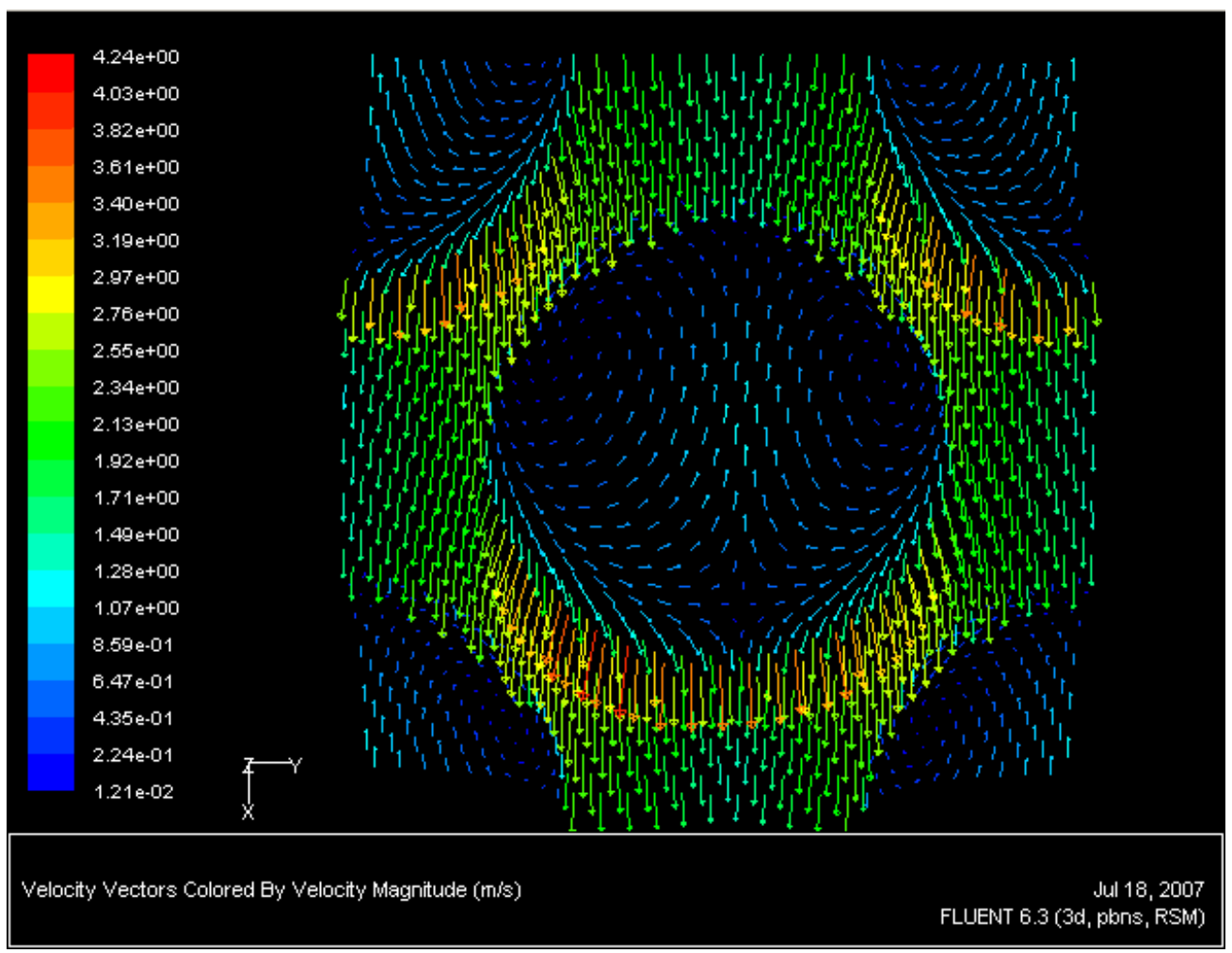

Figure 2B-14. Plot of velocity magnitude (m/s) vectors, from Fluent.

\section{B.10 Option of Multiple-Stage RVACS}

The final air-side enhancement was the idea of a multiple-stage RVACS, where air would be introduced at two or three points vertically along the guard vessel, as shown in Figure 2B-15. This would benefit the heat transfer by increasing the temperature difference between the hot guard vessel and the bulk air temperature. This is because heat transfer rate is directly proportional to temperature difference between the heat source and the heat sink and adding the secondary air cooling loop with inlet at the vessel midplane reduces bulk air temperature in the upper half of the vessel, where the wall-to-bulktemperature is the smallest in the one-path RVACS.

Model modification involved splitting the vessel height into two vertical sections and adding a second air path with cold inlets at the vessel midplane level. However, the increase in heat transfer rate achieved through this 2-stage RVACS arrangement was less than originally anticipated - about $10 \%$. This is because lower bulk air temperature reduces buoyancy driving force and consequently air flow rate and heat transfer coefficient. Because the modest gain of heat transfer rate of the 2-stage RVACS over the 1 -stage configuration is not worthwhile in view of its increased complexity, this approach was dropped from further consideration. 


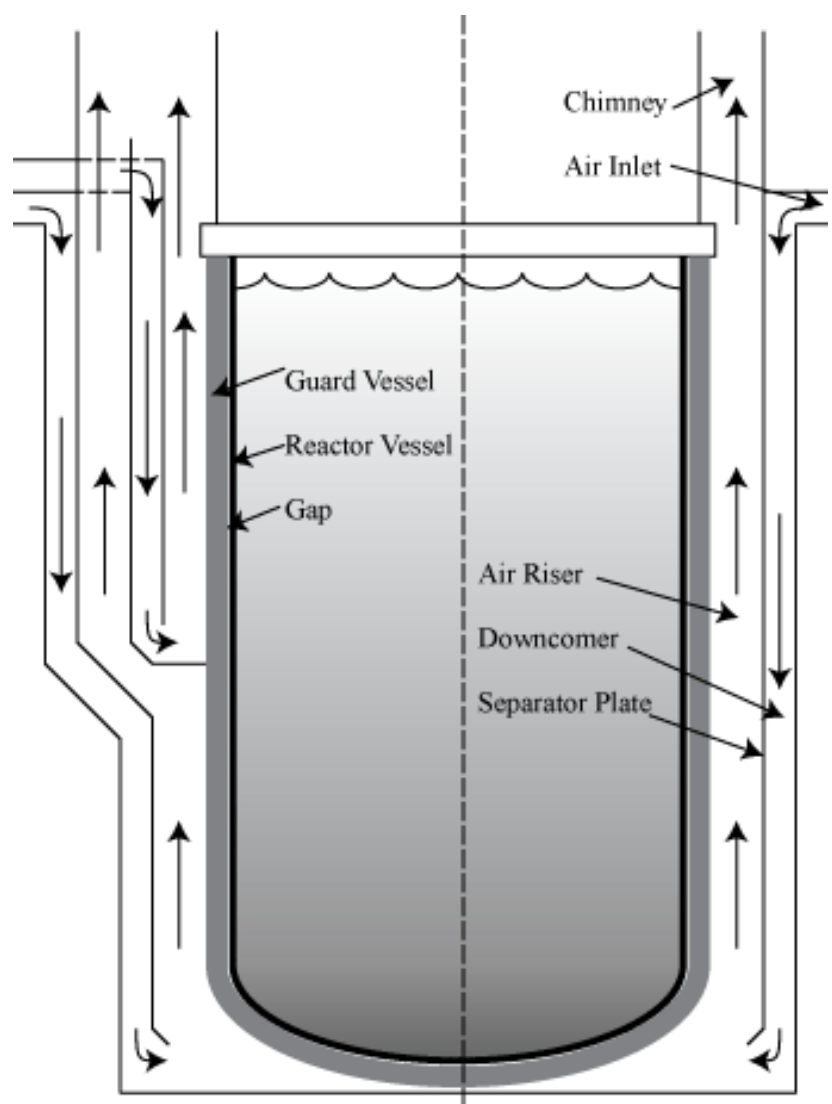

Figure 2B-15 Representation of air flow in normal RVACS (right), and split-level RVACS (left.)

\section{B.11 Pseudo-Steady State Transient Analysis}

In order to provide an estimate of the maximum primary coolant temperature inside the reactor vessel, a time-dependent analysis was done using steady state heat removal data. This calculation allows for a fast comparison of different RVACS designs, and gives an idea of the viability of the designs. It does not, however, perform any calculations on internal flow, and is therefore only an approximation that will need to be followed by a more rigorous analysis in RELAP5-3D.

After a design is chosen, the Java code described in Sections 2B.1 through 2B.8 is used to generate a set of steady state heat removal rates for varying lead temperatures. These points are then plotted, and an equation for heat removal rate vs. coolant temperature is created from a linear best fit line, of the form:

$\dot{Q}(T)=m T+\dot{Q}_{0}$,

where $\mathrm{T}$ is bulk coolant temperature measured in ${ }^{\circ} \mathrm{C}$, and $\mathrm{Q}$ is heat removal rate, measured in watts. $\mathrm{Q}_{0}$ is the theoretical heat removal rate at a lead temperature of $0^{\circ} \mathrm{C}$, 
and $\mathrm{m}$ is the increase in heat transfer rate per degree Celsius increase in coolant temperature.

The transient assumes that the reactor is shutdown and generates time-dependent decay heat. Simultaneously, decay power and integrated decay power with respect to time since shutdown are generated from an 11-exponential approximation as reported in McFaden [1984] using the DECAY program, written in FORTRAN77.

Using Excel, a discrete-time step analysis is conducted on the bulk coolant temperature. For a time step, $\Delta \mathrm{t}$, the increase in coolant temperature is calculated from:

$T_{j}=T_{j-1}+\frac{\left(\dot{Q}_{i n, j-1}-\dot{Q}_{o u t, j-1}\right) \Delta t}{m c_{p}}$,

where $T_{j}$ is the temperature at time $t, T_{j-1}$ is the temperature at time $t-\Delta t, Q_{i n, j-1}$ is the decay heat rate at time $\mathrm{t}-\Delta \mathrm{t}$ from the DECAY code, $\mathrm{Q}_{\text {out, } \mathrm{j}-1}$ is the decay heat removal rate at time $\mathrm{t}-\Delta \mathrm{t}$, calculated from Eq. $2 \mathrm{~B}-37$ at temperature $\mathrm{T}_{\mathrm{j}-1}, \mathrm{~m}$ is the total mass of lead coolant in the vessel, and $\mathrm{c}_{\mathrm{p}}$ is the specific heat capacity of lead at constant pressure.

Time steps were chosen that were suitably small as to limit the rounding errors, and enough were chosen to model the behavior of the system throughout the transient, until temperatures were approximately constant. The starting temperature was chosen to be the core inlet temperature for two reasons. First, this provides a conservative estimate of the operating temperature of the decay heat removal system, as this is the lowest coolant temperature in the reactor at the moment of shutdown, and secondly, the multi-coolant level design of the primary coolant flow path is such that the coolant that comes in contact with the vessel during normal operation is at or almost at the core inlet temperature.

In order to predict the core outlet temperature during the transient, it was assumed that the maximum temperature difference in the primary coolant would not exceed that measured during normal operation, $92^{\circ} \mathrm{C}$. Thus, the lowest temperature was used to model the operation, but the highest temperature is used to measure adherence to temperature limits.

\section{B.12 Enhancement of Gap Heat Transfer and Guard Vessel Stress Intensity Evaluation}

The S-PRISM design used argon to fill the gap, and therefore radiation was the primary mode of heat transfer to the inner wall of the guard vessel. To increase heat removal rate across this gap, the gap between these two vessels was filled with liquid metal bond, namely lead bismuth eutectic. Lead-bismuth was originally considered for the Actinide burner Reactor [Hejzlar et al., 2004]. While this increases heat transfer to the guard vessel, the guard vessel bears the full load of the reactor vessel and of the liquid metal in 
the gap. Thus, its thickness must be increased to withstand seismic events, which increases to some extent heat transfer resistance across the guard vessel wall.

To assess guard vessel thickness for the lead-cooled reactor, seismic analysis was carried out using a non-dimensionalization method described by Buongiorno and Hawkes [2003]. The results in Table 2B-1 are for a non-seismically isolated reactor vessel in a $0.5 \mathrm{~g}$ peak ground acceleration earthquake. The maximum allowable stress for SS316 from ASME code (Level D Service Loadings) is $263.1 \mathrm{MPa}$. This limit is not reached until the vessel with a lead-bismuth gap reaches $22 \mathrm{~cm}$ in thickness.

Table 2B-1 Response of lead-filled guard vessel in $0.5 \mathrm{~g}$ magnitude earthquake

\begin{tabular}{|lllll|}
\hline Gap Fill & $\begin{array}{l}\text { Vessel } \\
\text { Thickness } \\
{[\mathrm{cm}]}\end{array}$ & $\begin{array}{l}1^{\text {st }} \text { Mode } \\
\text { Frequency } \\
{[\mathrm{Hz}]}\end{array}$ & $\begin{array}{l}\text { Peak } \\
\text { Acceleration } \\
{\left[\mathrm{m} / \mathrm{s}^{2}\right]}\end{array}$ & $\begin{array}{l}\text { Peak Stress } \\
\text { Intensity } \\
{[\mathrm{MPa}]}\end{array}$ \\
\hline Lead/ & 10 & 3.3 & 18.8 & 603 \\
Bismuth & 15 & 4.1 & 18.4 & 393 \\
& 20 & 4.7 & 18.1 & 288 \\
& 22 & 5.0 & 18.0 & 260 \\
\hline
\end{tabular}

This analysis indicates that the minimum allowable vessel thickness would be $22 \mathrm{~cm}$ for a lead filled gap. However, heat removal requirements necessitate a guard vessel not to be thicker than about $10 \mathrm{~cm}$; therefore, it is necessary to consider seismic isolation schemes.

Buongiorno and Hawkes found that the $1^{\text {st }}$ mode of oscillation during an earthquake was a simple lateral bending, and that this mode is the major contributor to the total peak stress intensity. Therefore, it might be possible to significantly reduce the stress by protecting the vessel from lateral motions near the base. Additionally, GE's S-PRISM design utilizes seismic isolators, which GE claims reduce the lateral load by a factor greater than 3. Therefore, seismic isolation, such as GE S-PRISM was adopted to make possible the use of a $10 \mathrm{~cm}$ thick guard vessel with a LBE filled gap without compromising the guard vessel integrity in the event of an earthquake.

Further, it is important to ensure that temperature constraints on the reactor and guard vessels are met during transients, since the allowable stresses will decrease at higher temperatures. Thus, the two selected configurations of the optimistic and conservative dimples cases were examined at their estimated peak coolant temperature during a simulated unprotected transient (assumes heat generation per a 11-exponential approximation of decay heat curve as reported in McFaden [1984]) from Table 2B-2 to determine the theoretical maximum vessel temperatures. The results are shown in Table 2B-3. It should be noted that the three cases that satisfy the temperature constraint placed on the coolant also satisfy the ASME vessel temperature constraints discussed in Chapter 2 .

The reactor vessel maximum temperature, however, is highly dependent on the heat transfer coefficient between the lead coolant and the wall, which is only roughly 
estimated in this analysis. As the reactor vessel is not a weight bearing structure, it is considerably less likely to rupture due to elevated temperatures.

Table 2B-2 Decay Heat Removal Results for Selected Dimple Cases

\begin{tabular}{|l|l|l|l|l|l|l|}
\hline $\begin{array}{l}\text { RVACS } \\
\text { Type }\end{array}$ & $\begin{array}{l}\text { Optimal } \\
\text { Riser } \\
\text { Width }\end{array}$ & $\begin{array}{l}\text { Mass } \\
\text { Flow } \\
\text { Rate at } \\
460^{\circ} \mathrm{C}^{1}\end{array}$ & $\begin{array}{l}\text { Heat Removal } \\
\text { Rate at } \\
460{ }^{\circ} \mathrm{C}\end{array}$ & $\begin{array}{l}\text { Mass Flow } \\
\text { Rate at } \\
600{ }^{\circ} \mathrm{C}\end{array}$ & $\begin{array}{l}\text { Heat Removal } \\
\text { Rate at } \\
600{ }^{\circ} \mathrm{C}\end{array}$ & $\begin{array}{l}\text { Maximum Coolant } \\
\text { Temperature } \\
\text { During Passive } \\
\text { Shutdown }\end{array}$ \\
\hline $\begin{array}{l}\text { Conservative } \\
\text { Dimples 1- } \\
\text { Stage }\end{array}$ & $0.41 \mathrm{~m}$ & $140 \mathrm{~kg} / \mathrm{s}$ & $9.7 \mathrm{MW}$ & $153 \mathrm{~kg} / \mathrm{s}$ & $13.8 \mathrm{MW}$ & $730^{\circ} \mathrm{C}$ \\
\hline $\begin{array}{l}\text { Optimistic } \\
\text { Dimples 1- } \\
\text { Stage }\end{array}$ & $0.35 \mathrm{~m}$ & $158 \mathrm{~kg} / \mathrm{s}$ & $11.5 \mathrm{MW}$ & $172 \mathrm{~kg} / \mathrm{s}$ & $16.0 \mathrm{MW}$ & $\mathbf{7 0 0}^{\circ} \mathbf{C}$ \\
\hline
\end{tabular}

The four cases shown in Table 2B-3 above were analyzed for compliance with ASME Level $\mathrm{C}$ service limits. In order to perform this analysis the primary membrane stress intensity was calculated to be 105.3 MPa using the formulae from Buongiorno [2001]. Finally, the time needed for the passive RVACS system to reduce the primary coolant temperature to normal operation levels was found to be approximately 70 hours. Using the values for temperature, stress, and duration of shutdown, it was shown that even for the 1-stage conservative dimples case the vessel will satisfy the service limits set forth by ASME for a SS316 vessel, proving that the vessel primary membrane stress intensity is not the limiting factor during a passive decay heat removal scenario.

Table 2B-3 Maximum Vessel Temperatures During Passive Decay Heat Removal

\begin{tabular}{|l|l|l|l|}
\hline RVACS Type & $\begin{array}{l}\text { Maximum Coolant } \\
\text { Temperature During } \\
\text { Passive Shutdown }\end{array}$ & $\begin{array}{l}\text { Reactor Vessel Max } \\
\text { Temperature }\end{array}$ & $\begin{array}{l}\text { Guard Vessel Max } \\
\text { Temperature }\end{array}$ \\
\hline Conservative Dimples 1-Stage & $730^{\circ} \mathrm{C}$ & $715^{\circ} \mathrm{C}$ & $610^{\circ} \mathrm{C}$ \\
Conservative Dimples 2-Stage & $717^{\circ} \mathrm{C}$ & $702^{\circ} \mathrm{C}$ & $593{ }^{\circ} \mathrm{C}$ \\
Optimistic Dimples 1-Stage & $700{ }^{\circ} \mathrm{C}$ & $684^{\circ} \mathrm{C}$ & $568^{\circ} \mathrm{C}$ \\
Optimistic Dimples 2-Stage & $688^{\circ} \mathrm{C}$ & $672^{\circ} \mathrm{C}$ & $554^{\circ} \mathrm{C}$ \\
\hline
\end{tabular}

\section{B.13 Cases Evaluated and Numerical Results}

Overall, ten cases of RVACS heat transfer enhancement to air were evaluated. The cases, shown in Table 2B-4, were chosen to illustrate the effects of different configurations for the hot air riser. All cases studied employ a liquid lead-bismuth gap fill. Additionally, all cases share the parameters depicted in Table 2B-5. Paired cases have the same properties with the exception of the number of stages. Those with 2 stages have the multi-level design described in Section 2B.10, while those marked 1 have the standard RVACS riser layout.

Cases 1A and 1B are provided as a baseline comparison for RVACS with no air-side enhancements. These cases also illustrate the effect of the multi-level RVACS. Cases $2 \mathrm{~A}$ 
and 2B have 200 axial fins on the guard vessel which are $15 \mathrm{~cm}$ long and $2 \mathrm{~cm}$ wide. Radiation is taken into account from the guard vessel wall to the separator plate, and from the fin tips to the separator plate using bracketing methods rather than direct calculation of view factors. Cases $5 \mathrm{~A}$ and $5 \mathrm{~B}$ incorporate a perforated plate in the hot air riser, similar to GE's S-PRISM design. The model for these cases contains many simplifications in order to increase the calculation efficiency, described in Section 2B.8. Ultimately, this leads to unexpected results, and this model will need to be refined. The current model assumes a thermal emissivity of 0.8 for all surfaces. The plate is perforated so that $40 \%$ of its surface is removed to allow some of the heat to be transferred through the perforated plate to the separator plate directly by thermal radiation. Finally, Cases 3A, 3B, 4A, and 4B use estimates for the effect of dimples on the Nusselt number and pressure drop by looking at experimental data in Figure $2 \mathrm{~B}-9$ to find the most conservative and most optimistic case. The lowest value (the hollow square, Moon \& Lau(4.0,0.13) Spherical) was used as a conservative estimate of Nusselt number and friction factor augmentation possible at higher Reynolds numbers, and the highest performance case (the solid square, Chyu et al. $(1.15,0.28)$ Spherical) was used as the optimistic case.

Table 2B-4 Description and Naming of Cases

\begin{tabular}{|c|c|c|}
\hline Case No. & Stages $^{1}$ & $\begin{array}{l}\text { Air-side } \\
\text { Enhancement }\end{array}$ \\
\hline $1 \mathrm{~A}$ & 1 & \multirow[t]{2}{*}{ None } \\
\hline $1 \mathrm{~B}$ & 2 & \\
\hline $2 \mathrm{~A}$ & 1 & \multirow[t]{2}{*}{ Fins $^{2}$} \\
\hline $2 B$ & 2 & \\
\hline $3 \mathrm{~A}$ & 1 & \multirow{2}{*}{$\begin{array}{l}\text { Conservative } \\
\text { Dimples }^{3}\end{array}$} \\
\hline $3 B$ & 2 & \\
\hline $4 \mathrm{~A}$ & 1 & \multirow{2}{*}{$\begin{array}{l}\text { Optimistic } \\
\text { Dimples }\end{array}$} \\
\hline $4 B$ & 2 & \\
\hline $5 \mathrm{~A}$ & 1 & \multirow{2}{*}{$\begin{array}{l}\text { Perforated } \\
\text { Plate }\end{array}$} \\
\hline $5 B$ & 2 & \\
\hline \multicolumn{3}{|c|}{$\begin{array}{l}\text { 1. A value of " } 1 \text { " refers to a normal RVACS, } \\
\text { whereas " } 2 \text { " refers to the split level design } \\
\text { shown in Section } 3.3 \\
\text { 2. Case has } 200 \text { axial fins with thickness } 2 \mathrm{~cm} \text { and } \\
\text { length } 15 \mathrm{~cm} \text {. } \\
\text { 3. Assumes a bare-walled RVACS with } \mathrm{Nu} / \mathrm{Nu}_{0} \text { of } \\
2.0 \text { and } \mathrm{f} / \mathrm{f}_{0} \text { of } 2.8 \\
\text { 4. Assumes bare-walled RVACS with } \mathrm{Nu} / \mathrm{Nu}_{0} \text { of } \\
2.2 \text { and } \mathrm{f} / \mathrm{f}_{0} \text { of } 1.4\end{array}$} \\
\hline
\end{tabular}

Because of competing effects of increased buoyancy driven flow rate at higher bulk air temperature (and thus larger heat transfer coefficient) and larger temperature difference between the guard vessel wall and the air flow, there exists an optimum air riser width for each case. For each case a series of code runs were completed using a constant vessel bulk reactor coolant temperature of $600^{\circ} \mathrm{C}$, with a range of riser widths. From these 
results, the optimum riser size that maximized heat transfer was chosen. The results are shown in Table 2B-6.

Following the optimization of the riser width, the air-side mass flow rate for the RVACS was calculated using optimum riser width and the same parameters. Table $2 \mathrm{~B}-6$ summarizes air flow rates for a bulk lead temperature of $460^{\circ} \mathrm{C}$, which is indicative of what could be expected during normal operation of the plant, and at $600^{\circ} \mathrm{C}$, i.e. the temperature reached during passive shutdown of the reactor.

Table 2B-5 Description of Initial Design

\begin{tabular}{|l|l|}
\hline Geometry: & \\
\hline Vessel: & $9.24 \mathrm{~m}$ \\
\hline Reactor Vessel Inner Diameter & $5 \mathrm{~cm}$ \\
\hline Reactor Vessel Thickness & $3 \mathrm{~cm}$ \\
\hline Reactor/Guard Vessel Gap & $10 \mathrm{~cm}$ \\
\hline Guard Vessel Thickness & $9.6 \mathrm{~m}$ \\
\hline Guard Vessel Outer Diameter & $1 \mathrm{~cm}$ \\
\hline Collector Cylinder Thickness & $80 \mathrm{~cm}$ \\
\hline Downcomer Gap & $19.5 \mathrm{~m}$ \\
\hline Vessel Active Heated Length & \\
\hline Air chimney: & $20 \mathrm{~m}$ \\
\hline Height & $6.0 \mathrm{~m}$ \\
\hline Diameter & $4^{1}$ \\
\hline Number & \\
\hline Air intakes: & $3.0 \mathrm{~m}$ \\
\hline Length & $6.0 \mathrm{~m}$ \\
\hline Diameter & 4 \\
\hline Number & \\
\hline Operating Parameters: & $35^{\circ} \mathrm{C}$ \\
\hline Air Inlet Temperature & Uniform \\
\hline Lead Temperature Profile & $2000 \mathrm{~W} / \mathrm{m}^{2} \mathrm{~K}$ \\
\hline Lead Convection Coefficient & \\
\hline $\begin{array}{l}\text { 1. In the split-level design, } 2 \text { intakes and } 2 \mathrm{chimneys} \text { are } \\
\text { used for each level }\end{array}$ & \\
\hline & \\
\hline
\end{tabular}

Table 2B.6 Optimized Riser Widths at $600{ }^{\circ} \mathrm{C}$ bulk reactor coolant temperature

\begin{tabular}{|l|l|}
\hline Case No. & $\begin{array}{l}\text { Optimized } \\
\text { Riser Width }\end{array}$ \\
\hline 1A & $0.29 \mathrm{~m}$ \\
\hline 1B & $0.19 \mathrm{~m}$ \\
\hline 2A & $0.40 \mathrm{~m}$ \\
\hline 2B & $0.28 \mathrm{~m}$ \\
\hline 3A & $0.41 \mathrm{~m}$ \\
\hline 3B & $0.27 \mathrm{~m}$ \\
\hline
\end{tabular}


Project No 06-040: Flexible Conversion Ratio Fast Reactor Systems Evaluation

\begin{tabular}{|l|l|}
\hline $4 \mathrm{~A}$ & $0.35 \mathrm{~m}$ \\
\hline $4 \mathrm{~B}$ & $0.23 \mathrm{~m}$ \\
\hline $5 \mathrm{~A}$ & $0.39 \mathrm{~m}^{1}$ \\
\hline $5 \mathrm{~B}$ & $0.26 \mathrm{~m}^{1}$ \\
\hline $\begin{array}{l}\text { 1. Perforated plate is placed in } \\
\text { the center of the riser; value } \\
\text { displayed is total riser width }\end{array}$ \\
\hline
\end{tabular}

The decay heat removal rate results are shown in Figure 2B-16 and maximum bulk primary coolant temperature achieved during the passive decay heat removal shutdown event is plotted in Figure 2B-17.

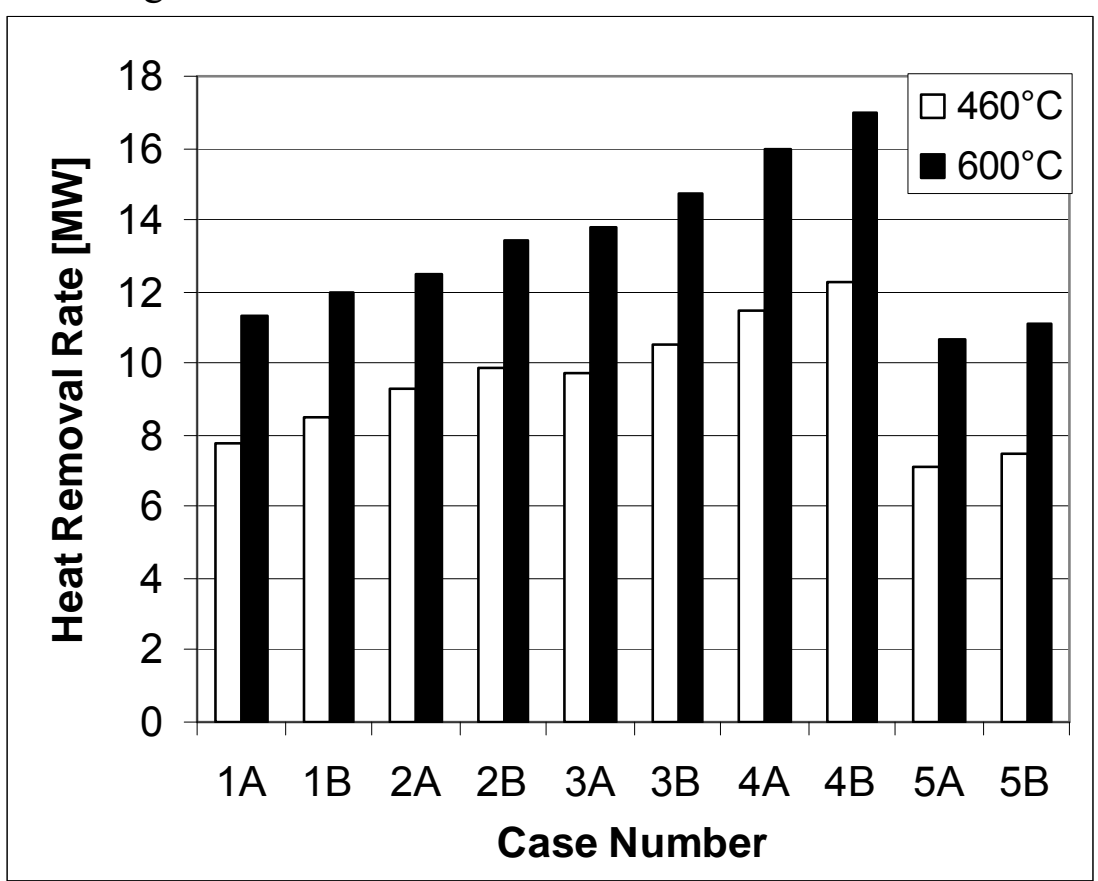

Figure 2B.16 Decay Heat Removal Rates at $460^{\circ} \mathrm{C}$ and $600^{\circ} \mathrm{C}$ bulk lead temperature 


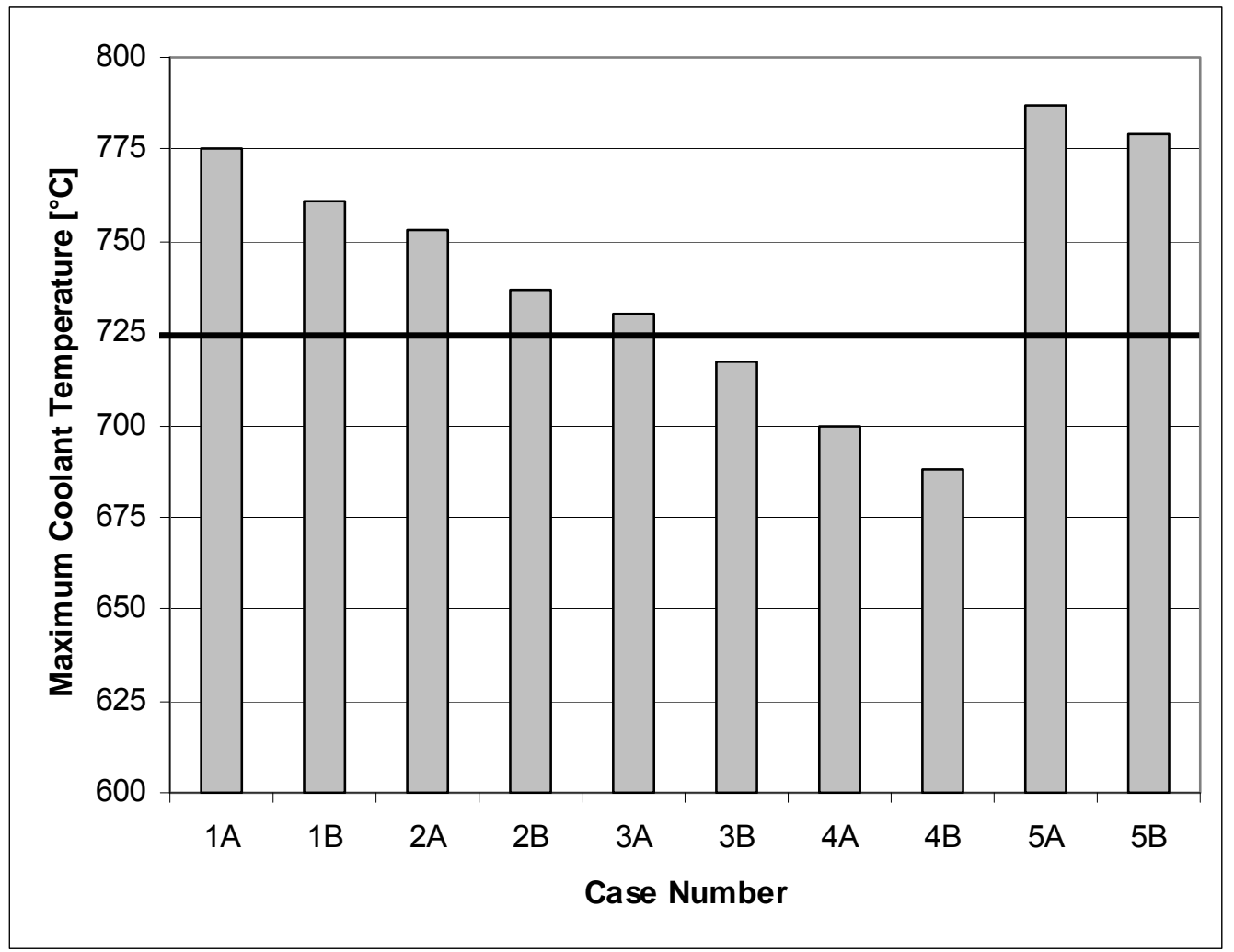

Figure 5.2 Maximum bulk primary coolant temperature achieved during passive decay heat removal shutdown event. The darkened line indicates the maximum clad temperature limit.

By comparing the multi-level cases to the associated single-stage RVACS cases it is found that the average increase due to the additional riser is $7 \pm 2 \%$ - a small gain not worthy of increased complexity. Ultimately, three cases were found to meet the reactor vessel temperature limit. These cases represent the spectrum of dimpled wall performance that can be expected for different geometries. One notable anomaly in the results is the lack of performance by the perforated plate. The model seems to indicate that the pressure drop increase outweighs any heat transfer benefits of adding the plate; however, a number of important simplifications were made to the model to enable the program to run quickly. This result is considered dubious as it contradicts GE results, thus the effect of the perforated plate used in RELAP5 simulations throughout the study was estimated from scaling the S-PRISM and ALMR data.

\section{References for Appendix 2B}

ASME, "Boiler \& Pressure Vessel Code. An International Code. Section III, Division 1, Subsection NH (Class 1 Components in Elevated Temperature Service).” ASME, 2001

Buongiorno J., "Temperature Limits for Heavy-Liquid-Metal Reactor Vessels." Trans. Am. Nucl. Soc., Vol. 85, pp. 45-46, 2001. 
Buongiorno J. and Hawkes B.D., "Seismic Analysis of Heavy-Liquid-Metal-Cooled Reactor Vessels," Nuclear Engineering and Design, 228, pp. 305-317, 2004.

Burgess N.K., Oliveira M.M., and Ligrani P.M., "Nusselt Number Behavior on deep Dimpled Surfaces within a Channel”, J. Heat Transfer, Vol., 125, pp. 11-18, 2003.

Heineman, J., M. Kraimer, P. Lottes, D. Pedersen, R. Stewart and J. Tessier, "Experimental and Analytical Studies of a Passive Shutdown Heat Removal System for Advanced LMRs," Proceedings of International Topical Meeting on Safety of Next Generation Power Reactors, Seattle, May, 1991

Hejzlar P., "Conceptual Design of a Large, Passive, Pressure-Tube Light Water Reactor," Doctoral Thesis, MIT, 1994.

Hejzlar P., Buongiorno J., MacDonald P., and Todreas N., "Design Strategy and Constraints for Medium-Power Lead-Alloy-Cooled Actinide Burners," Nuclear Technology, 147, pp.321-343, 2004.

Idel'chik, I. E., Handbook of Hydraulic Resistance, Hemisphere Pub., 2nd ed., 1986.

Incropera F., and DeWitt D., Fundamentals of Heat and Mass Transfer, Fifth Edition, John Wiley and Sons, 2002.

Irvin, T. F., Steam and Gas Tables with Computer Equations, Academic Press, New York, 1984.

McFaden, J. H. et al., "RETRAN-02-A Program for Transient Thermal-Hydraulic Analysis of Complex Fluid Flow Systems," EPRI NP-1850-CCMA, Vol.1, Revision 2, 1984.

Patrick W. "Computations of Flow Structures and Heat Transfer in a Dimpled Channel at Low to Moderate Reynolds Number," Master's Thesis, Virginia Tech, 2005.

White F., "Fluid Mechanics," Fifth Edition, McGraw Hill, Boston, MA, 2003. 


\section{Appendix 2C Supplementary Decay Heat Removal Options}

Because enhanced RVACS alone was not sufficient to remove decay power without exceeding the peak cladding temperature limit, it was necessary to provide a supplementary decay heat removal system. Various DHR systems were considered. This appendix describes DHR systems that were assessed and the selection process applied to identify the most promising decay heat removal system that would aid RVACS in decay heat removal, so that the peak cladding temperature remains below the limit of $650^{\circ} \mathrm{C}$ during reactor passive shutdown. Initial brainstorming resulted in the selection of three different systems to be explained below. These three systems were then examined and compared using engineering, cost, and safety criteria in order to arrive at a final design. Ultimately, eleven qualitative metrics were determined for the comparison of the designs, and two of the three were selected for more detailed evaluation. The final selection was then made using an Analytic Deliberative Process (ADP).

\section{C.1 DHR Design Options Evaluated}

The three different design options examined were the Direct Reactor Auxiliary Cooling System (DRACS), and the Passive Secondary Auxiliary Cooling System (PSACS) with two different ultimate heat sinks, air and water. These options are discussed below. The models used to evaluate feasibility of each decay heat removal option are described in Appendix 2D.

\section{C.1.1 DRACS Option}

The DRACS system uses a Lead-Bismuth Eutectic cooling loop to remove decay heat from the reactor vessel, and is depicted in Figure $2 \mathrm{C}-1$. The loop consists of two heat exchangers, the In-Vessel Heat Exchanger, or IVHX, located within the reactor vessel and the Passive Auxiliary Heat Exchanger (PAHX), located in the region of the selected heat sink. The vessel is already quite full, so the location of the IVHX was one of the engineering decisions that needed to be made. Figure 2C-2 shows an overhead layout of the vessel, and the different options that were considered. There are three areas within the vessel that might potentially have enough space for a small heat exchanger: the core chimney, the vessel liner, and the pump downcomer. The chimney option was discarded due to interference with refueling operations and control rod function, as well as instability of the natural circulation loop, with cooling taking place above the heated portion of the primary loop. The liner option was discarded as it was deemed difficult to ensure that lead flow would cross the heat exchanger without substantial increase of the pressure drop on the primary side. The pump downcomer location has one major disadvantage, which is that enough room must be left so that the pump can be extracted vertically for servicing and maintenance. This can be overcome by placing the heat 
exchanger in the "corners" of the pump downcomer, as the flow channel is assumed to be pseudo-trapezoidal, but the pump will be primarily circular.

Two options are also available as to the location of the PAHX. One option is to place the PAHX within a separate chimney, in order to maximize the temperature difference between the hot lead-bismuth and the cold air. The other option is to place the PAHX within the RVACS chimney. This location has several advantages, as it experiences increased flow rate due to the driving forces of the RVACS heating, and it in turn amplifies the performance of the RVACS by reducing the air density within the chimney. An additional benefit is that the RVACS exhaust air is preheated to near the melting point of the LBE. This will help eliminate the possibility of overcooling and freezing the LBE in the heat exchanger tubes.

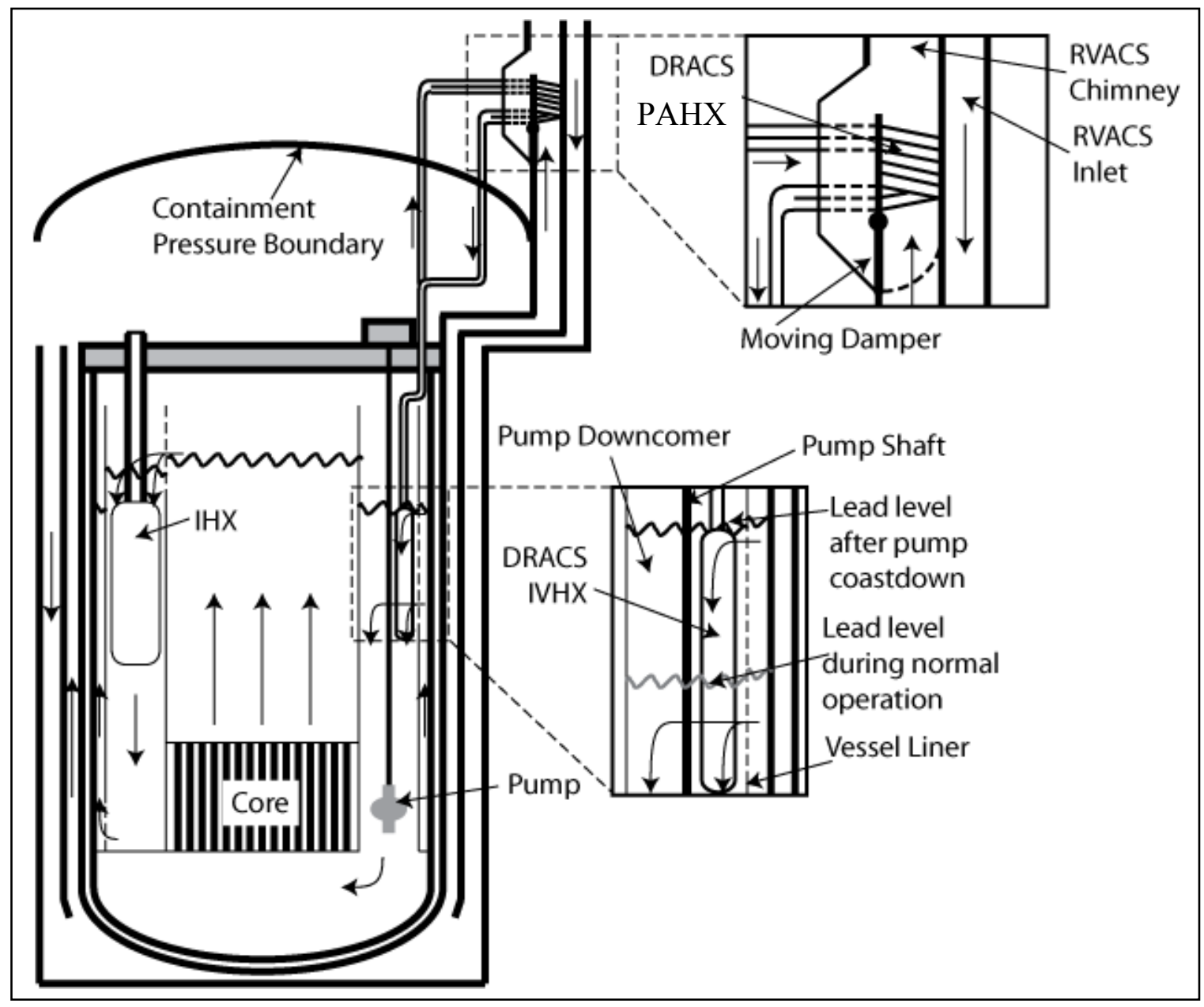

Figure 2C-1. Schematic of DRACS system adapted to the FCR vessel.

Since the DRACS LBE loop must constantly circulate, it also must constantly remove some heat. This reduces the reactors' economy, since heat lost through the DRACS during normal operation means that less energy is available for the power conversion system. In order to minimize this effect while maximizing the heat removal in a SBO 
scenario, two strategies were adopted. First, a movable damper was added to the RVACS chimney to reduce or eliminate flow over the PAHX during normal operation, as shown in Figure 2C-3. Heat would still be lost through natural convection and radiation heat transfer. If this proved insufficient to maintain the circulation of the LBE, perforations could be made in the damper to allow limited flow through the PAHX. When the station experiences a LOOP, the damper would fail open. The bypass loop shown is present to allow the RVACS to operate as normal even in the event that the damper fails to open.

The second improvement made to reduce heat loss during normal operation is the placement of the IVHX at the very top of the pump downcomer, partially exposed during normal operation. When the pump fails, the lead level in the downcomer rises about 1 meter and fully covers the IVHX, increasing the heat transfer area and thus the heat removal capacity of the system.

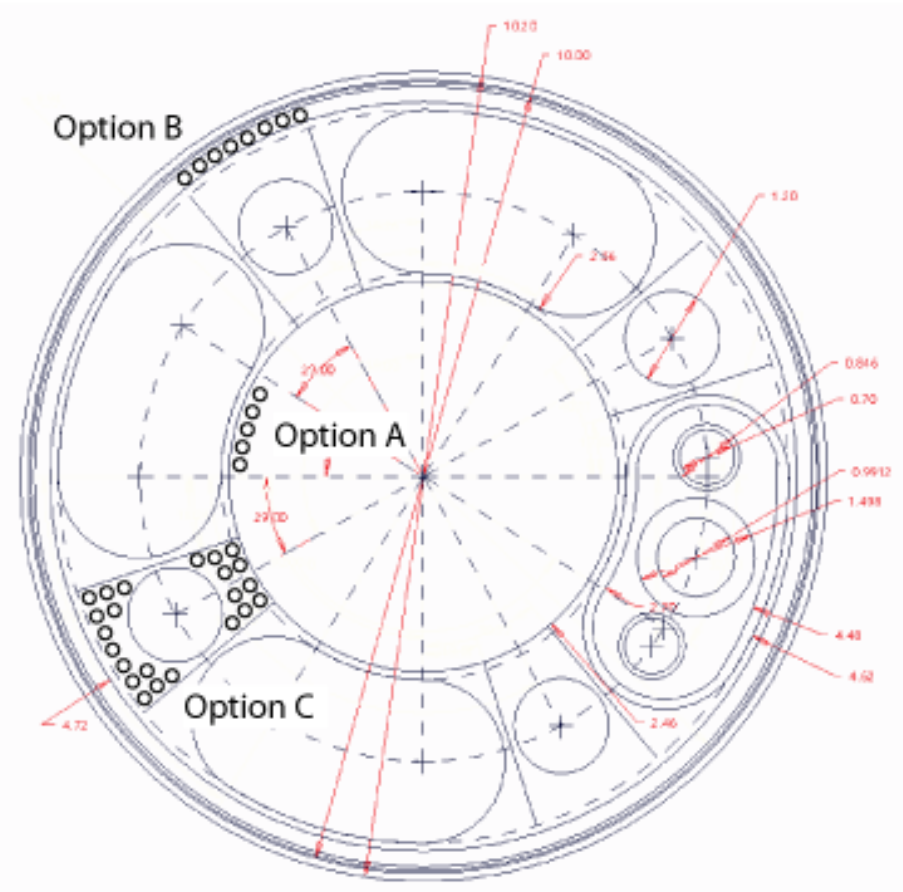

Figure 2C-2. Overhead view of reactor vessel, with locations for IVHX placement options. Option A is located within the core chimney, Option B is located within the vessel liner, and Option $\mathrm{C}$ is located in the "corners" of the pump downcomer.

\section{C.1.1 PSACS Options}

Rather than use a separate fluid and IVHX for the decay heat removal, both PSACS options use the PCS working fluid along with the IHX to remove decay heat. They both use a standby loop filled with $\mathrm{S}-\mathrm{CO}_{2}$, which is connected to the PCS IHXs. This loop is isolated from the PCS during normal operation using valves. The location of these valves relative to the reactor containment is still undecided, and will be elaborated on later. The primary difference between the air and water options for this system is therefore the location of the PAHX. The Air option PAHX is located either in the RVACS chimney, 
like the DRACS, or in its own chimney. The same benefits and disadvantages apply to the PAHX location for the PSACS-Air and the DRACS, except that the former will not freeze. The Water option's PAHX is located in a large water tank either adjacent to the containment, or next to the turbine building. These DHR systems are shown in Figures $2 \mathrm{C}-4$ and $2 \mathrm{C}-5$.
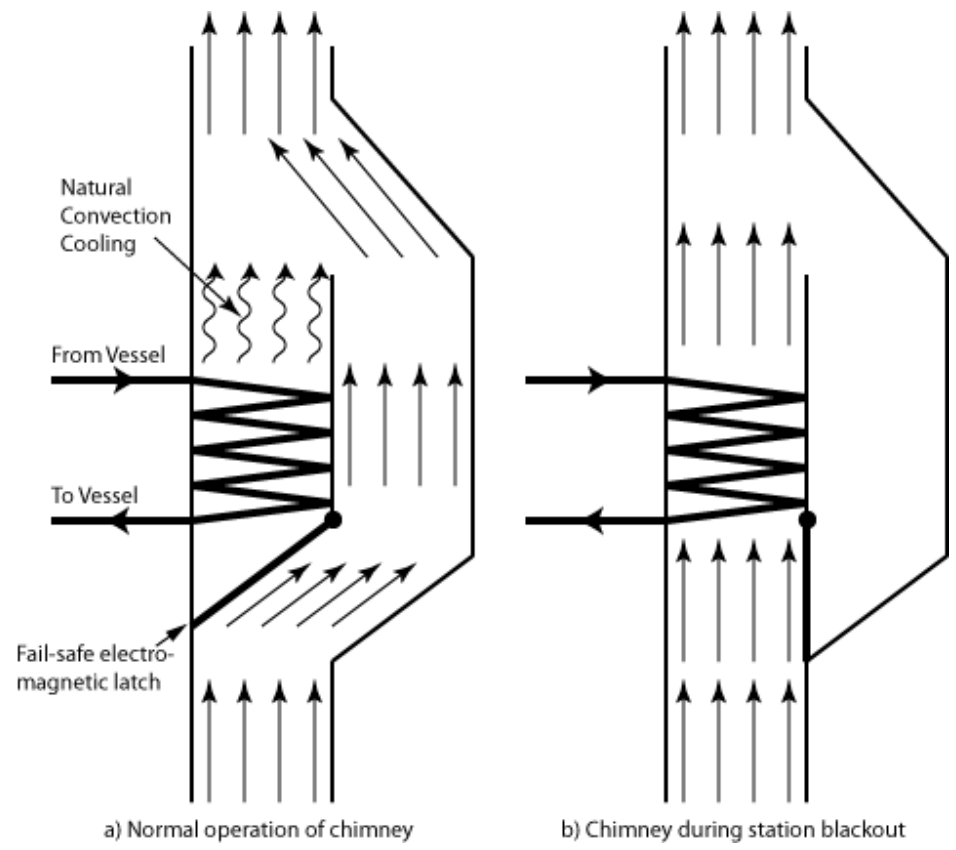

Figure 2C-3. Chimney baffle used in DRACS design to reduce heat loss during normal reactor operation

In order to narrow the number of designs being considered, and reduce the amount of modeling needed in RELAP5, the designs were compared against 11 qualitative metrics to arrive at a final decision. A summary of these metrics is shown in Table $2 \mathrm{C}-1$. Since the dimensions of the PAHXs, IVHX, and the cross tubing were primarily unconstrained, this meant that the different options could be engineered to remove whatever heat load was deemed necessary in future transient modeling. First order steady-state models were constructed in Excel to confirm that the designs were feasible, with optimization of the designs tabled until the completion of the full selection process. After comparing the three designs against these eleven metrics, the decision was made to discard the DRACS option and focus on the PSACS-Air and PSACS-Water options. One of the driving reasons for making this selection was concern over the ability to fit the DRACS IVHX into the vessel. Since the pumps have yet to be fully designed and described, it may become apparent at a later date that the pump down-comer will need to be entirely free of other components so that the pump and housing can be removed for inspection and maintenance. 
Project No 06-040: Flexible Conversion Ratio Fast Reactor Systems Evaluation

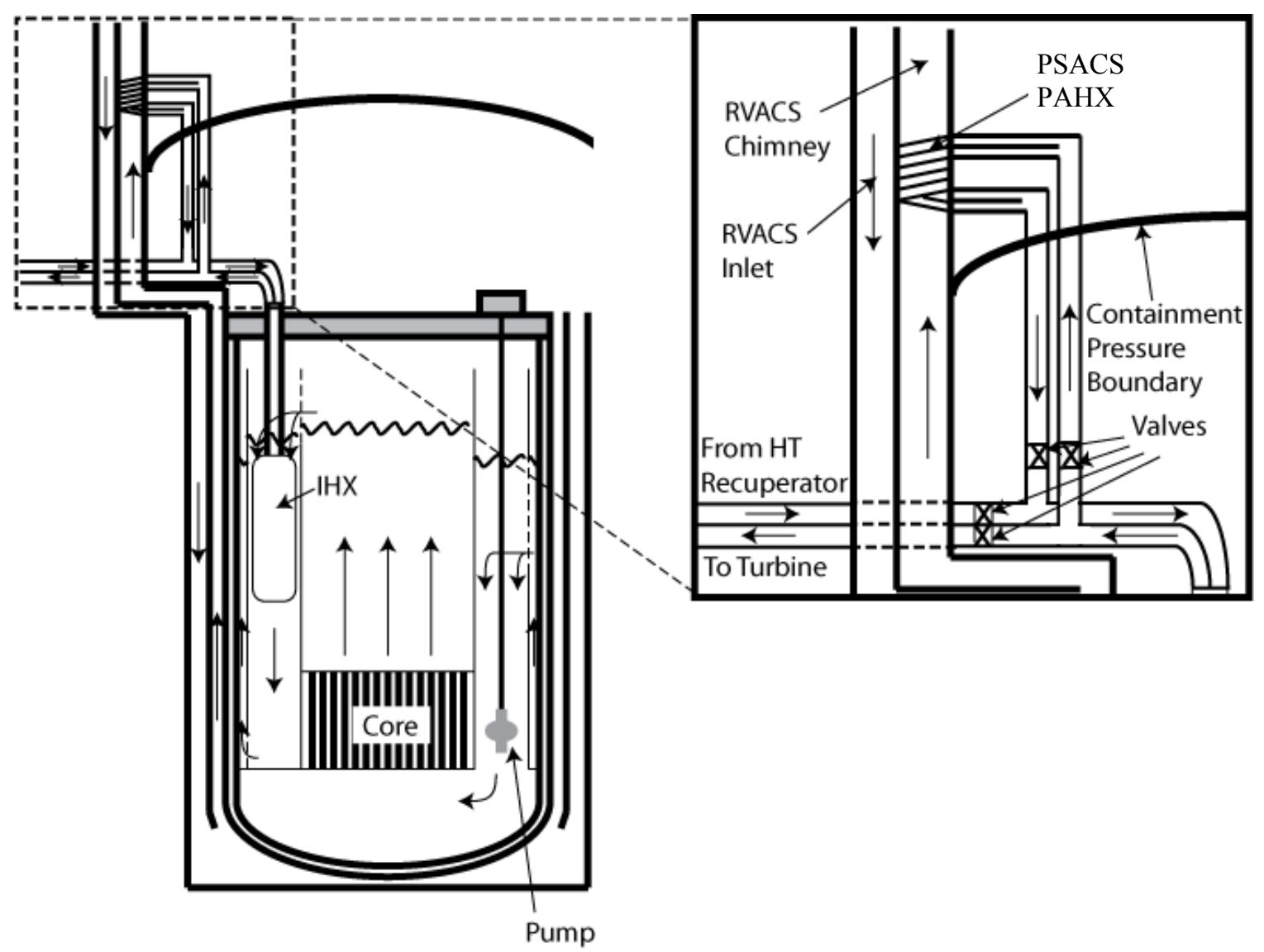

Figure 2C-4. Schematic of PSACS-Air DHR system.

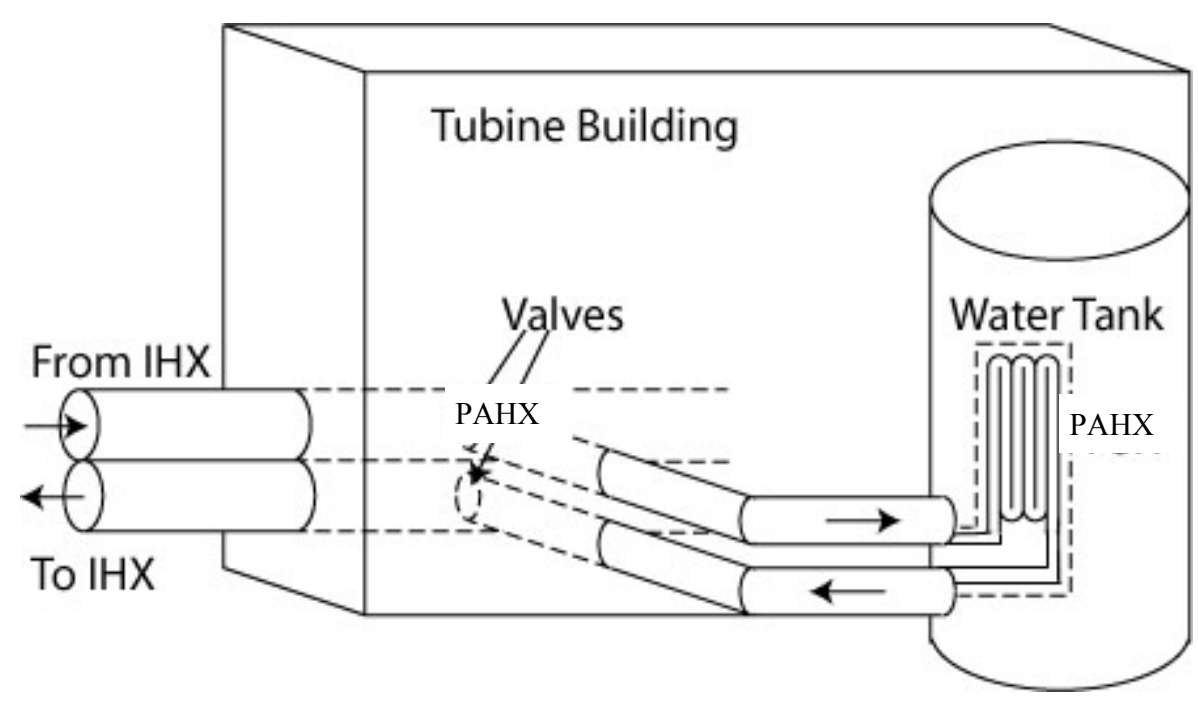

Figure 2C-5. Schematic of PSACS-Water system 


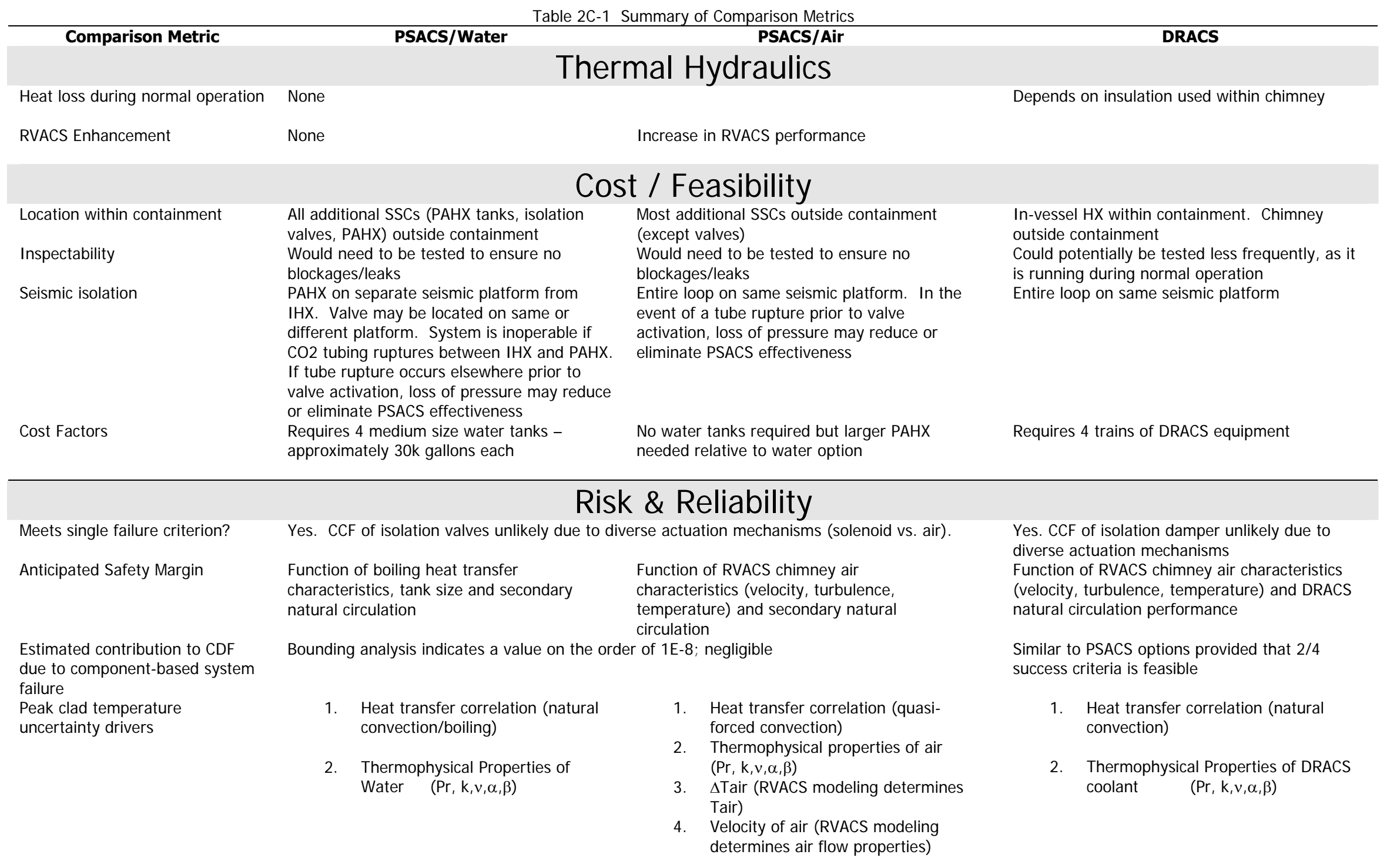




\section{C.2 Selection of PSACS Design for Further Studies}

Since both PSACS-Air and PSACS-Water were determined to have merit, a formal decision making process known as the Analytic Deliberative Process (ADP) was employed to select the system which best met the project's objectives. The ADP provides an objective and transparent framework for decision-making which integrates input from multiple stakeholders / decision makers. Furthermore, the ADP is able to integrate information from a variety of sources such as risk insights and traditional engineering judgment. The process is shown graphically in Figure $2 \mathrm{C}-6$.

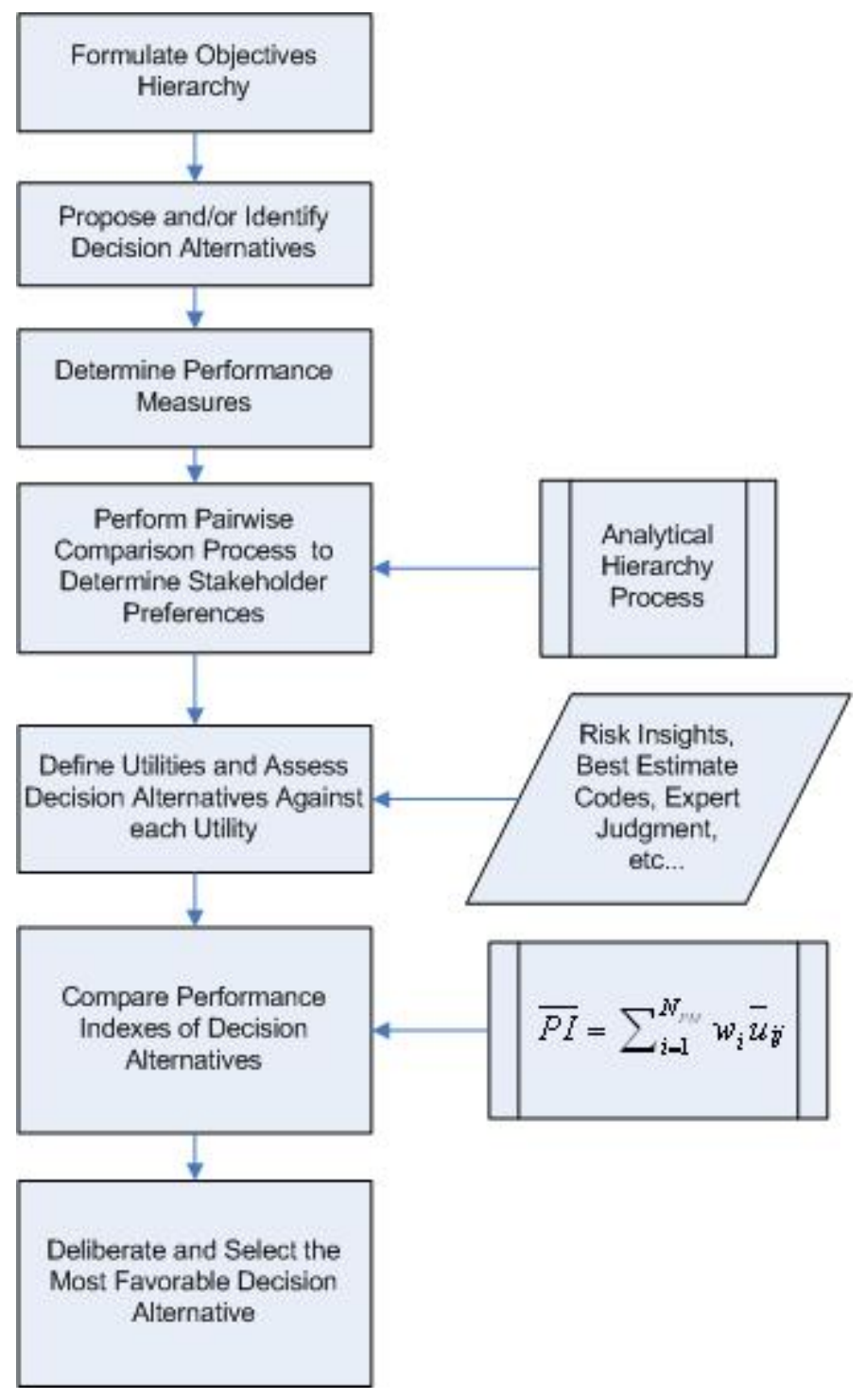

Figure 2C-6 The Analytic Deliberative Process [from Apostolakis et al, 2007]

The first step of the ADP was to capture the objectives of each stakeholder (group member) by constructing an objectives hierarchy. Group discussion and deliberation indicated that the main 
or top-level objective of the proposed system would be, "PSACS maintains safety during SBO and does not compromise normal operations." Next, the group members determined that this toplevel goal relies on achieving two sub-level objectives, "PSACS net impact on reactor safety" and "PSACS inherent design characteristics." In other words, the selected design option should meet the top level objective by having a positive impact on reactor safety and exhibiting favorable inherent design characteristics.

The second step of the ADP (identify decision alternatives) had already been completed by the FCR team, so the next step was identification of bottom-level objectives or performance measures (PMs). The PMs are used to compare the design options quantitatively in a specific area of performance that supports the overall system mission. Through analysis, engineering judgment, and group deliberation, the following PMs were identified:

- Safety \& Reliability Under Normal Operating Conditions

- Safety \& Reliability During SBO

- Accessibility (for Maintenance \& Inspection)

- Degree of Simplicity

- Robustness

- Designability

- Cost / Economics

The PMs and higher-level objectives were then integrated to create an Objectives Hierarchy, shown in Figure 2C-7.

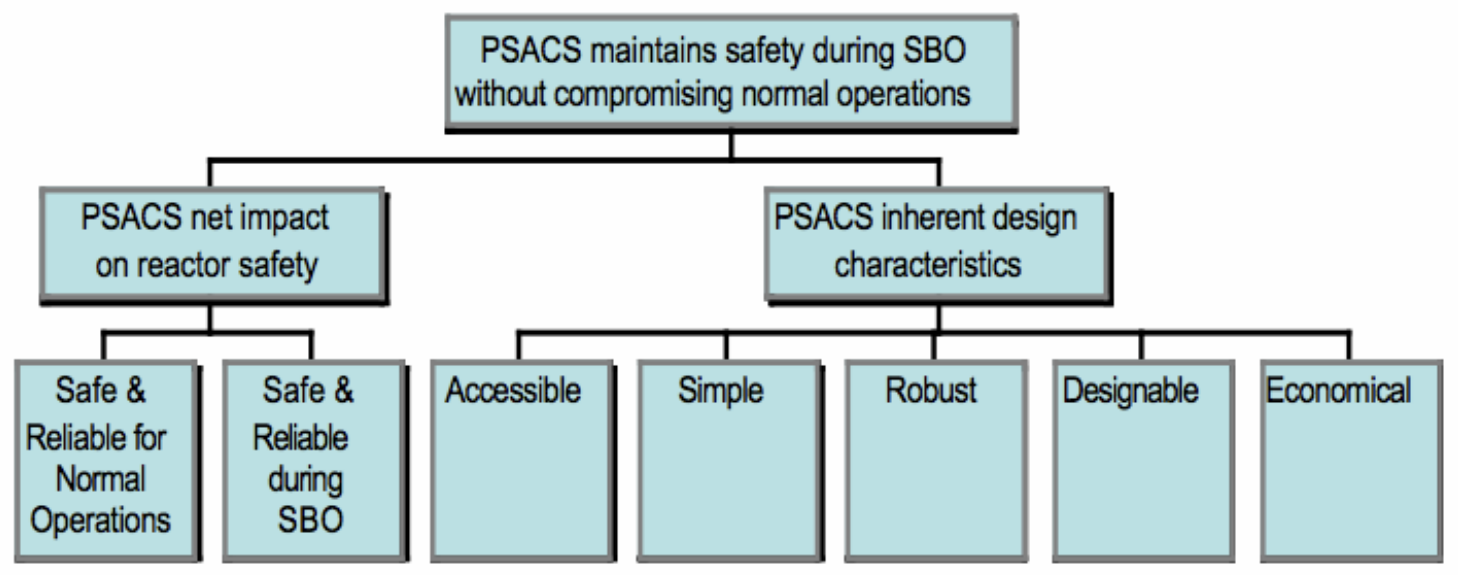

Figure 2C-7 FCR DHR System Objectives Hierarchy

Following the identification of the PMs, the group used the Analytic Hierarchy Process (AHP) to capture each stakeholder's preferences [Zio, et al, 2003]. This is an important step because the PMs are not necessarily of equal importance. In order to determine their relative importance, each group member was asked to make a series of pair-wise comparisons between PMs, deciding which of the pair is more important and by how much. This data was then integrated to develop a series of stakeholder specific weights for the PMs. Additionally, the group members were 
asked to document their rationales for each pairwise comparison; this information was later used to support group deliberations.

Finally, both the PSACS-Air and PSACS-Water systems were compared quantitatively against the PMs using Multi-Attribute Utility Theory (MAUT). MAUT is a method of comparing variables with different units (e.g. cost and safety) by constructing a common scale. In this case, the scale was defined from zero (worst case) to unity (best case) and the PSACS-Air and PSACS-Water options assessed against each PM using a combination of analysis and expert judgment.

Finally, with this information collected from the stakeholders, a Performance Index (PI) was determined for both design alternatives. The PI for a design option $\mathrm{j}$ is defined as the sum of the expected utilities, $\mathrm{u}_{\mathrm{ij}}$, associated with the $\mathrm{i}^{\text {th }}$ objective performance measure weighted by the AHP determined stakeholder preference for that objective, $\mathrm{w}_{\mathrm{i}}$.

$$
\overline{P I_{j}}=\sum_{i=1}^{N_{P M}} w_{i} \bar{u}_{i j}
$$

While the determination of the utility scores was a collaborative effort, each group member had different PI scores for the design options due to their PM weights. This was expected since the ADP is designed to capture input from stakeholders from varying backgrounds, design preferences, and areas of expertise. The results of the ADP are displayed in Table 2C-3.

Table 2C-2 Results of ADP

\begin{tabular}{|c|c|c|}
\hline Group Member & $\mathrm{PI}_{\text {air }}$ & $\mathrm{PI}_{\text {water }}$ \\
\hline A & 0.44 & 0.70 \\
\hline $\mathrm{B}$ & 0.47 & 0.63 \\
\hline $\mathrm{C}$ & 0.52 & 0.69 \\
\hline $\mathrm{D}$ & 0.50 & 0.59 \\
\hline $\mathrm{E}$ & 0.48 & 0.61 \\
\hline Average & 0.48 & 0.65 \\
\hline
\end{tabular}

These results, combined with further deliberation supported the decision to select the PSACSWater option as the supplemental DHR system of choice.

\section{C.3 References for Appendix 2C}

Apostolakis, G., Hoffman, J., Kadak, A., Stawicki, M., "Methods for Risk Informed Decision Making for Multiple-attribute Design Decisions", unpublished, (2007)

Zio, E., Cantarella, A., Cammi, A., "The Analytic Hierarchy Process as a Systematic Approach to the Identification of Important Parameters for the Reliability Assessment of Passive Systems", Nuclear Engineering and Design 226 (2003) 311-336. 


\section{Appendix 2D Analysis of Supplementary Decay Heat Removal Options}

\section{D.1 Problem Formulation}

In order to ensure that each of the decay heat removal (DHR) designs was feasible, workbooks were created in Microsoft Excel to analyze the three systems. The goal of the analysis was not to create a best-estimate code, but rather to use a conservative estimate to determine if the proposed DHR system is feasible and if dimensions needed to successfully remove the decay heat were reasonable. Because of this, conservative assumptions were made in several cases. Bestestimate analysis of the most promising DHR system then followed using RELAP5-3D.

\section{D.2 DRACS Analysis}

\section{D.2.1 Assumptions}

- The DHR systems are operating at steady state

- The lead temperature on the primary side is at the normal core inlet temperature (the lowest expected temperature in the primary side)

- All cross tubing (including the IVHX downcomer and plenums) are perfectly insulated

- The RVACS chimney outlet (IHX inlet) temperature and flow rate are unchanged from their values calculated without IHX (for DRACS, PSACS-Air systems)

- Air-side heat transfer in the chimney is due to forced convection

- Heat transfer coefficient is constant over entire surface exposed to air flow

\section{D.2.2 Energy Transfer}

There are two locations in each system where heat transfer occurs: the Passive Auxiliary Heat eXchanger (PAHX) and the In-Vessel Heat eXchanger (IVHX). The energy transfers are handled by a combination of nodalization and the lumped parameter/ $\varepsilon$-NTU method.

The IVHX is modeled as a concentric tube counter flow heat exchanger with $\mathrm{N}$ tubes of length $\mathrm{L}$ and height $\mathrm{H}$. The IVHX is then divided into 100 nodes of equal length and each node is treated as an individual heat exchanger. At each node, inlet temperature and pressure of the LBE and lead were used to determine the properties of the fluids, as described in a later section. To use the $\varepsilon$-NTU method, the parameter NTU was calculated, as:

$$
N T U=\frac{U A}{C_{\min }}
$$


where $\mathrm{C}_{\min }$ is the lowest capacity rate between the two streams, and UA is found from:

$U A=\left(R_{\text {conv }, P b}+R_{\text {cond }}+R_{\text {conv }, L B E}\right)^{-1}$

where the resistances are defined as:

$R_{\text {conv }, P b}=(h A)^{-1}$, and

$R_{\text {cond }}=\frac{\ln \left(r_{\text {in }} / r_{\text {out }}\right)}{2 \pi k L}$,

where $\mathrm{h}$ is the convection coefficient, calculated below in Eqs. (2D-5) and (2D-7), $\mathrm{A}$ is the heat transfer area of the node, $r_{i n}$ and $r_{\text {out }}$ are the inner and outer radii of the tubing, $k$ is the thermal conductivity of the heat exchanger tubing, and $\mathrm{L}$ is the node length. The convection coefficient for the tube interior, h, was calculated as [Todreas and Kazimi, 1990]:

$$
N u=\frac{h D_{i n}}{k}=5+0.025 P e^{0.8},
$$

where $D_{\text {in }}$ is the inner diameter of the tube, $k$ is the thermal conductivity of LBE, and Pe is the Peclet number, defined as

$$
P e=\operatorname{Re} \cdot \operatorname{Pr}=\frac{\rho v D}{\mu} \cdot \frac{\mu c_{p}}{k},
$$

where $\rho$ is the LBE density, $\mathrm{v}$ is the average velocity through the tube, $\mathrm{D}$ is the tube inner diameter, $\mu$ is the dynamic viscosity of the fluid, $c_{p}$ is the specific heat and $\mathrm{k}$ is the thermal conductivity of the LBE. The convection coefficient for the tube exterior was calculated from [Todreas and Kazimi, 1990]:

$$
N u=\frac{h D_{i n}}{k}=4.496\left[-16.15+24.96 \frac{P}{D}-8.55\left(\frac{P}{D}\right)^{2}\right]
$$

where $\mathrm{P}$ is the tube pitch, and $\mathrm{D}$ is the outer diameter of the tube. Once NTU is calculated, $\varepsilon$ can be found from [Cravalho et al., 2005]:

$$
\varepsilon=\frac{1-\exp \left(-N T U\left(1-C^{*}\right)\right)}{1-C^{*} \cdot \exp \left(-N T U\left(1-C^{*}\right)\right)},
$$

where $\mathrm{C}^{*}$ is the ratio:

$$
C^{*}=\frac{C_{\min }}{C_{\max }},
$$


and $\mathrm{C}_{\min }$ and $\mathrm{C}_{\max }$ are the minimum and maximum capacity rate of the two streams, respectively. Once $\varepsilon$ was found, the total heat transfer between the streams within the node was found using the relation [Cravalho et al., 2005]:

$$
\varepsilon=\frac{Q}{Q_{\max }}=\frac{Q}{C_{\min }\left(T_{h, i}-T_{c, i}\right)},
$$

where $T_{h, i}$ and $T_{c, i}$ are the inlet and temperatures of the hot and cold stream, respectively.

Once the heat transfer through the node was calculated, the outlet temperature was calculated from the inlet temperature for each flow path using

$$
Q=\dot{m} \cdot c_{p}\left(T_{\text {out }}-T_{\text {in }}\right)
$$

where $c_{p}$ is the specific heat of the fluid, $m$ is the mass flow rate, and $T_{\text {in }}$ and $T_{\text {out }}$ are the inlet and outlet temperatures of the node, respectively.

The process is then repeated with the following node, using the outlet temperature of node $\mathrm{N}$ as the inlet temperature for node $\mathrm{N}+1$.

The PAHX was analyzed using a similar approach, but was treated as a cross-flow heat exchanger. The heat transfer coefficient, h, was calculated from [Cravalho et al., 2005]:

$$
N u=\frac{h D_{\text {in }}}{k}=0.3+\frac{0.62 \operatorname{Re}_{D}^{0.5} \operatorname{Pr}^{1 / 3}}{\left[1+(0.4 / \operatorname{Pr})^{2 / 3}\right]^{1 / 4}}\left[1+\left(\frac{\operatorname{Re}_{D}}{282,000}\right)^{1 / 2}\right],
$$

Additionally, the air-side of the heat exchanger was enhanced with annular fins, using an estimated fin efficiency. Using the equation [Cravalho et al., 2005]:

$$
\varepsilon=\left[\frac{1}{1-\exp (-N T U)}+\frac{C^{*}}{1-\exp \left(-C^{*} \cdot N T U\right)}-\frac{1}{N T U}\right]^{-1},
$$

the heat transfer rate was solved for, and the same procedure was followed to find the node outlet temperatures as was used for the IVHX.

\section{D.2.3 Pressure drop calculations}

Pressure drop in the LBE loop is calculated identically for all nodes, heated and unheated. The friction factor is found from [Hejzlar, 1994]:

$$
f_{j}=(0.79 \ln (\mathrm{Re})-1.64)^{-2} \text {, }
$$


where $f_{j}$ is the fanning friction factor, $D_{h}$ is the hydraulic diameter in the $j^{\text {th }}$ section of the heat exchanger, $\zeta$ is the sand-grain roughness of the $\mathrm{j}^{\text {th }}$ node, and $\mathrm{Re}$ is the Reynolds number, calculated at the inlet of the node. This leads to the pressure drop through:

$$
P_{i n, j+1}=P_{i n, j}-\rho\left(f_{j} \frac{L}{D_{h}} \frac{v^{2}}{2}\right),
$$

where $P_{i n, j}$ and $P_{i n, j+1}$ are the pressures at the inlet and outlet of node $j, \rho$ is the inlet density of the air, $\mathrm{L}$ is the length of the node, and $\mathrm{v}$ is the velocity at the inlet of the node.

\section{D.2.4 LBE Properties}

In order to most accurately model the DRACS system LBE density, specific heat, viscosity, and thermal conductivity must be modeled as functions of temperature. These properties were found in Sobolev [2007] to be:

$$
\begin{aligned}
& \rho_{L B E}\left(\mathrm{~kg} / \mathrm{m}^{3}\right)=11096-1.3236 \times T, \\
& c_{p, L B E}(\mathrm{~J} / \mathrm{kgK})=159-2.72 \times 10^{-2} \cdot T+7.12 \times 10^{-6} \cdot T^{2}, \\
& \mu_{L B E}(\mathrm{~Pa} \cdot \mathrm{s})=4.9 \times 10^{-4} \cdot e^{760.1 / T}, \text { and } \\
& k_{L B E}(\mathrm{~W} / \mathrm{mK})=6.8543-0.010179 \times T
\end{aligned}
$$

where $\rho$ is the density, $c_{p}$ is the specific heat, $\mu$ is the dynamic viscosity, $\mathrm{k}$ is the thermal conductivity, and $\mathrm{T}$ is temperature in Kelvin.

\section{D.2.5 Air properties calculation}

In order to most accurately model the PAHX system, air density, specific heat, viscosity, and thermal conductivity must be modeled as functions of air temperature and/or pressure.

For density calculations, air is treated as an ideal gas. Thus a simple rearrangement of the ideal gas law yields:

$$
\rho=\frac{m}{V}=\frac{P}{R T}
$$

where $\mathrm{P}$ is the pressure is Pascals, $\mathrm{T}$ is temperature in Kelvin, and $\mathrm{R}$ is the gas constant for air, $287 \mathrm{~J} / \mathrm{kg}-\mathrm{K}$.

The remaining properties were calculated from formulae in Irvin [1984]. They are as follows: 
Project No 06-040: Flexible Conversion Ratio Fast Reactor Systems Evaluation

$$
\begin{aligned}
& C_{p}=1034.09-(0.284887) T+\left(7.816818 \times 10^{-4}\right) T^{2}-\left(4.970789 \times 10^{-7}\right) T^{3} \\
&+\left(1.077024 \times 10^{-10}\right) T^{4} \\
& k=-2.2276501 \times 10^{-3}+\left(1.2598485 \times 10^{-4}\right) T-\left(1.4815235 \times 10^{-7}\right) T^{2} \\
& \quad+\left(1.4815235 \times 10^{-10}\right) T^{3}-\left(1.066657 \times 10^{-13}\right) T^{4}+\left(2.47663035 \times 10^{-17}\right) T^{5} \\
& \mu=\left(-0.98601+\left(9.080125 \times 10^{-2}\right) T-\left(1.17635575 \times 10^{-4}\right) T^{2}\right. \\
&\left.\quad+\left(1.2349703 \times 10^{-7}\right) T^{3}-\left(5.7971299 \times 10^{-11}\right) T^{4}\right) \times 10^{-6}
\end{aligned}
$$

where $\mathrm{T}$ is in units of Kelvin, $\mathrm{C}_{\mathrm{p}}$ is the specific heat in units $\mathrm{J} / \mathrm{kg}-\mathrm{K}$, $\mathrm{k}$ is thermal conductivity in $\mathrm{W} / \mathrm{m}-\mathrm{K}$, and $\mu$ is kinematic viscosity in $\mathrm{kg} / \mathrm{m}-\mathrm{s}$.

\section{D.2.6 Mass Flow Rate Determination:}

The LBE mass flow rate is determined from a balance between buoyancy forces and pressure losses using

$$
\dot{m}=\sqrt{\frac{\Delta p_{b}}{c}},
$$

where c represents the pressure drop due to form and friction losses as defined as:

$$
c=\sum_{j=1}^{N}\left(K_{j}+f_{j} \frac{L_{j}}{D_{h, j}}\right)\left(2 \rho_{j} A_{j}^{2}\right)^{-1},
$$

where $\mathrm{N}$ is the total number of nodes (heated and unheated), $\mathrm{K}$ is the form loss coefficient, $\mathrm{f}$ is the friction loss coefficient defined below in Eq. (2D-14), $\mathrm{L}$ is the length of the node, $\mathrm{D}_{\mathrm{h}}$ is the hydraulic diameter, $\rho$ is the average density of air within the node, and A is the total cross sectional area of the ducting.

The thermal buoyancy coefficient, $\Delta \mathrm{p}_{\mathrm{b}}$ is defined as:

$$
\Delta p_{b}=\sum_{j=1}^{N} \rho_{j}\left(\Delta \vec{H}_{j} \bullet \vec{g}\right)
$$

where $g$ is the gravitational acceleration, $\rho$ is the average air density, and $\Delta H$ is the elevation change. 


\section{D.2.7 Solution procedure}

All heat exchanger geometry, as well as that for the cross-tubing, is soft-coded so that changes can be made to the entire system easily. In order to test a geometry, the values of these system parameters was first chosen:

First, the inlet temperatures of the three fluids (Lead, LBE, and Air) are set, along with the Lead and Air mass flow rates. The lead temperature is taken to be the core inlet temperature during normal operation and the air temperature and mass flow rates are taken from the RELAP model that only incorporates the RVACS. These are all conservative assumptions, as both mass flow rates will increase with additional DHR, the air temperature should decrease, and the lead temperature is the lowest temperature in the primary before the heat-up from the decay power.

The temperatures and pressures are calculated in a linear fashion through the LBE loop, starting at the inlet to the PAHX, and terminating at the same location. The mass flow rate and inlet temperature for the LBE loop is first estimated, and then the new mass flow rate calculated in Eq. (2D-24) is used to iterate until the flow rates match. Next, the inlet temperature for the system is iterated until it matches the outlet temperature. Then the process repeats alternating between iteration of the mass flow rate and temperature until the values converge on a solution. This is done by hand, and for reasonable geometries these values converge quickly.

\section{D.3 PSACS-Air Analysis}

The PSACS-Air system was analyzed using very similar methods to the DRACS analysis. The primary differences are in the working fluid of the loop, S- $\mathrm{CO}_{2}$, and the IHX. Since $\mathrm{S}-\mathrm{CO}_{2}$ properties do not behave as nicely as those for lead bismuth, the REFPROP8.0 package from NIST was used. REFPROP8.0 is bundled with Excel sheets that can utilize the property data, which are used in the analysis code to determine the properties of the working fluid.

Heat transfer on the $\mathrm{S}-\mathrm{CO}_{2}$ side of the IHX is enhanced using helical ribs to both turbulize the flow and increase heat transfer surface. These tubes were also used for the PAHX to similarly reduce the length of tubing needed. The new Nusselt number and friction factors were calculated from [Bergles, et al., 1996] to be:

$$
N u=\frac{h D}{k}=N u_{s m}\left[1+\left(2.64 \operatorname{Re}^{0.036}\left(\frac{e}{d}\right)^{0.212}\left(\frac{p}{d}\right)^{-0.21}\left(\frac{a}{90}\right)^{0.29} \operatorname{Pr}^{-0.024}\right)^{7}\right]^{\frac{1}{7}}
$$

where:

$$
N u_{s m}=\frac{h D}{k}=\frac{f \cdot \operatorname{Re} \cdot \operatorname{Pr}}{2\left(1+12.7\left(\frac{f}{2}\right)^{0.5}\left(\operatorname{Pr}^{2 / 3}-1\right)\right)} \text {, and }
$$




$$
\begin{aligned}
& \frac{f_{a}}{f_{s m}}=\left\{1+\left[29.1 \mathrm{Re}^{(0.67-0.06 p / d-0.49 \alpha / 90)} \times\left(\frac{e}{d}\right)^{(1.37-0.157 p / d)} \times\left(\frac{p}{d}\right)^{(-1.66 E-6 \mathrm{Re}-0.33 \alpha / 90)}\right.\right. \\
& \left.\times\left(\frac{\alpha}{90}\right)^{(4.59+4.11 E-6 \mathrm{Re}-0.15 p / d)} \times(1+2.94 / n \sin (\beta)]^{15 / 16}\right\}^{16 / 15}
\end{aligned}
$$

where:

$f_{s m}=(1.58 \ln (\mathrm{Re})-3.28)^{-2}$, and

$e$ is rib height, $d$ is maximum inside diameter, $p$ is pitch of ribs $\alpha$ is helix angle of rib (deg), $\beta$ is contact angle of profile (deg), and $n$ is the number of sharp corners facing the flow that characterizes the rib profile.

The only other difference in the analysis of the PSACS-Air versus the DRACS is that the geometry of the IHX is constrained. The pressure in the loop is thus far unknown, so calculations were performed at the lowest system pressure seen on the secondary side (the compressor inlet pressure). $\mathrm{S}-\mathrm{CO}_{2}$ at this pressure has the least favorable heat transfer characteristics, making this a conservative assumption.

\section{D.4 PSACS-Water Analysis}

The PSACS-Water system analysis differs from that of the PSACS-Air in the way that the PAHX was modeled. In order to model the PAHX, the following assumptions were made:

- The PSACS-Water cooling tank water is at boiling temperature.

- Pool boiling effects dominate

- The system remains in the nucleate boiling regime

These assumptions affect the heat transfer coefficient, $h$, on the water side of the PAHX, and also change the $\varepsilon-\mathrm{NTU}$ correlation.

The pool boiling coefficient was determined from [Incropera and Dewitt, 2002]:

$$
N u=\frac{h D}{k}=0.62\left(\frac{g \cdot h_{f g}\left(\rho_{f}-\rho_{g}\right) D^{3}}{\mu_{g} \cdot k_{g}\left(T_{o}-T_{b}\right)}\right)^{0.25},
$$

where $g$ is gravitational acceleration, $h_{f g}$ is the enthalpy of vaporization, $\rho_{\mathrm{f}}$ and $\rho_{\mathrm{g}}$ are the densities of water vapor and liquid, respectively. $\mathrm{D}$ is the outer diameter of the heat exchanger tubing, $\mu_{\mathrm{g}}$ is the viscosity of the vapor, $\mathrm{k}_{\mathrm{g}}$ is the thermal conductivity of the vapor, and $\mathrm{T}_{\mathrm{o}}$ and $\mathrm{T}_{\mathrm{b}}$ are the temperature of the outside of the heat exchanger tubing, and the bulk temperature of the water.

The static pressure of $10 \mathrm{~m}$ deep water was used to determine the boiling temperature. 
The $\varepsilon$-NTU correlation chosen was that for a single stream heat exchanger, where $\mathrm{C}^{*}=0$, and [Cravalho et al., 2005]

$\varepsilon=1-\exp (-N T U)$

This makes use of the assumption that the system remains in the nucleate boiling regime, and that the water is initially at the boiling temperature.

\section{D.5 Preliminary Results}

Solutions were found using the conservative estimate codes above for various geometries of the DRACS, PSACS-Air, and PSACS-Water systems. The three different designs are described in Tables 2D-1 through 2D-3. The conclusion is that all the DHR concepts can remove the target decay power of about 5MWt, PSACS-Air having the largest heat transfer area.

Table 2D-1 Preliminary DRACS Design

\begin{tabular}{|l|l|}
\hline Geometry: & \\
\hline PAHX: & 10 \\
Number of Tubes in parallel & $5 \mathrm{~cm}$ \\
Inner Diameter of tubes & $2.8 \mathrm{~cm}$ \\
Tube thickness & $12 \mathrm{~m}$ \\
Tube Length & $4 \mathrm{~m}$ \\
Heat Exchanger Height & 300 \\
Number of fins per meter & $1 \mathrm{~mm}$ \\
Fin thickness & $2.6 \mathrm{~cm}$ \\
Fin length & \\
& \\
IVHX: & 64 \\
Number of Tubes in parallel & $3.5 \mathrm{~cm}$ \\
Inner Diameter of tubes & $2.8 \mathrm{~mm}$ \\
Tube thickness & 4 \\
Tube Length & $11.4 \mathrm{~cm}$ \\
Downcomer Inner Diameter & $3 \mathrm{~mm}$ \\
Downcomer thickness & \\
Cross-Piping: & \\
Hot-leg length & $20 \mathrm{~m}$ \\
Hot-leg height & $15 \mathrm{~m}$ \\
Hot-leg inner diameter & $1 \mathrm{~m}$ \\
Cold-leg length & $16 \mathrm{~m}$ \\
Cold-leg height & $11 \mathrm{~m}$ \\
Cold-leg inner diameter & $1 \mathrm{~m}$ \\
& \\
\hline Operating Parameters: & $5.3 \mathrm{MW}$ \\
\hline Decay Heat Removed & \\
\hline
\end{tabular}


Project No 06-040: Flexible Conversion Ratio Fast Reactor Systems Evaluation

Table 2D-2 Preliminary PSACS-Air Design

\begin{tabular}{|l|l|}
\hline Geometry: & \\
\hline PAHX: & 50 \\
Number of Tubes in parallel & $8.4 \mathrm{~cm}$ \\
Inner Diameter of tubes & $8 \mathrm{~mm}$ \\
Tube thickness & $6 \mathrm{~m}$ \\
Tube Length & $5 \mathrm{~m}$ \\
Heat Exchanger Height & 300 \\
Number of fins per meter & $1 \mathrm{~mm}$ \\
Fin thickness & $2.6 \mathrm{~cm}$ \\
Fin length & \\
& \\
Cross-Piping: & $20 \mathrm{~m}$ \\
Hot-leg length & $13 \mathrm{~m}$ \\
Hot-leg height & $1 \mathrm{~m}$ \\
Hot-leg inner diameter & \\
Cold-leg length & $16 \mathrm{~m}$ \\
Cold-leg height & $8 \mathrm{~m}$ \\
Cold-leg inner diameter & $1 \mathrm{~m}$ \\
\hline \multicolumn{2}{|l}{ Operating Parameters: } \\
\hline Decay Heat Removed & $5.2 \mathrm{MW}$ \\
\hline
\end{tabular}

Table 2D-3 Preliminary PSACS-Water Design

\begin{tabular}{|c|c|}
\hline \multicolumn{2}{|l|}{ Geometry: } \\
\hline PAHX: & \\
\hline Number of Tubes in parallel & 100 \\
\hline Inner Diameter of tubes & $8.4 \mathrm{~mm}$ \\
\hline Tube thickness & $2.8 \mathrm{~mm}$ \\
\hline Tube Length & $4 \mathrm{~m}$ \\
\hline Heat Exchanger Height & $0 \mathrm{~m}$ \\
\hline \multicolumn{2}{|l|}{ Cross-Piping: } \\
\hline Hot-leg length & $20 \mathrm{~m}$ \\
\hline Hot-leg height & $5 \mathrm{~m}$ \\
\hline Hot-leg inner diameter & $1 \mathrm{~m}$ \\
\hline Cold-leg length & $16 \mathrm{~m}$ \\
\hline Cold-leg height & $5 \mathrm{~m}$ \\
\hline Cold-leg inner diameter & $1 \mathrm{~m}$ \\
\hline \multicolumn{2}{|l|}{ Operating Parameters: } \\
\hline Decay Heat Removed & $4.5 \mathrm{MW}$ \\
\hline
\end{tabular}




\section{D.6 References for Appendix 2D}

BERGLES, A. E., Ravigururajan, T. S., Development and Verification of General Correlations for Pressure Drop and Heat Transfer in Single-Phase Turbulent Flow in Enhanced Tubes, Experimental Thermal and Fluid Science 13, 55-70, 1996

Cravalho E.G., Smith J. L. Jr., Brisson J. B., McKinley G., Thermal-Fluid Property Data, Supplement to course notes for MIT course 2.006. 2005.

Incropera F., and DeWitt D., Fundamentals of Heat and Mass Transfer, Fifth Edition, John Wiley and Sons, 2002.

Sobolev, V. Thermophysical Properties of Lead and Lead-Bismuth Eutectic. Journal of Nuclear Materials, V. 362, 2007. pp 235-247.

Todreas N.E, and Kazimi M.S, Nuclear Systems I: Thermal Hydraulic Fundamentals, Hemisphere Publishing Corp. 1993. 
Project No 06-040: Flexible Conversion Ratio Fast Reactor Systems Evaluation

\section{Appendix 3A Reactor Physics Analysis Tools and Methods}

This Appendix describes the computer codes and methods used for the neutronic analysis of Flexible Conversion Ratio designs presented in this report. Major assumptions, limitations and other issues associated with the use of the codes are outlined.

\section{A.1 Computer Codes}

\section{A.1.2 MCNP}

MCNP-4C [Briesmeister J.F., 2000] is a general purpose Monte Carlo particle transport code developed at Los Alamos National Laboratory. It can be used in neutron, photon or electron transport mode as well as in a mode which is any combination of the above three. In the Monte Carlo approach, unlike in deterministic methods, the particle transport problem is solved by following the histories of individual particles. The average particle characteristics in the physical system are determined by average behavior of simulated particles. The major advantage of the Monte Carlo method is its capabilities of solving a particle transport problem in complex generalized 3-D geometries which cannot be practically handled by deterministic methods. In principle, Monte Carlo simulation can yield the exact transport equation solution provided that physical models, nuclear data, and number of particle histories are sufficient. The major drawback of the Monte Carlo method is considerably higher computation power requirements to achieve high accuracy of the results. MNCP provides great flexibility in definition of particle source distributions, system geometries and tallied parameters.

In this project, the code was used for criticality and power distribution calculations in the studied reactor designs. The power distribution was obtained using the fission energy deposition tally option. Spatial and energy segmentation of the neutron flux tallies were used to determine peak fluence values in the critical structural components such as fuel cladding and reactor vessel.

MCNP-4C was also used in a coupled Monte-Carlo - burnup calculations as an integral part of the MCODE and BGCore computer codes, described below, and used for the burnup and fuel cycle analysis of the studied reactor concepts.

In addition, the MCNP-4C code was used for calculation of reactivity feedback coefficients required for assessing self-controllability potential of the studied reactor designs. The calculated reactivity effects were also subsequently used as part of the input in transients modeling with the RELAP5 code.

In order to accurately evaluate a reactivity feedback in response to a certain change in the core operating parameter, the perturbation in this parameter should be small. As a result, the difference in the core eigenvalue between the nominal and perturbed conditions is on the order of the k-effective statistical uncertainty typically obtained in the fuel cycle analyses. Therefore, calculation of reactivity effects requires much higher accuracy of the core k-effective eigenvalue, and thus, a larger number of particle histories. 
At the early stages of this project, about $1 \mathrm{M}$ particle histories were used per time step in a typical burnup run, while $10 \mathrm{M}$ histories were used for evaluation of reactivity feedbacks. One of the key factors in obtaining reliable $\mathrm{k}$ eigenvalue estimation with the Monte Carlo method is to assure that the spatial fission source distribution has converged to its fundamental shape. Monitoring the behavior of k-effective standard deviation as the only indicator of the convergence is sometimes insufficient and misleading because the criticality eigenvalue converges faster than the source shape. In some cases, the source iterations may lock up on higher than fundamental flux shape modes, which results in extremely slow convergence of the core multiplication factor towards its real value.

The problem is especially notable in large, spatially decoupled cores with relatively flat flux distribution. The latest version of the MCNP code (MCNP5) includes advanced statistical diagnostic tools that allow monitoring of the fission source convergence. In this study, once the problematic nature of high accuracy k-eff calculations with the Monte Carlo technique was discovered, the calculations of reactivity effects were performed with significantly larger number histories: from $40 \mathrm{M}$ up to $100 \mathrm{M}$ histories were used with $100 \mathrm{~K}$ to $200 \mathrm{~K}$ of histories per source iteration cycle. In addition, the radial flux profile was tallied in all calculations with intentionally symmetric core configurations in order to assure the symmetry of the flux distribution as indication of the source convergence.

The following example illustrates the importance of careful k-eff convergence diagnostics in cases for which high accuracy is required.

As discussed in Section 4.3 of this report, the major challenge of the liquid salt-cooled Flexible Conversion Ratio core design is the large positive Coolant Temperature Coefficient (CTC). Therefore, extensive study was carried out to identify the best strategies for reducing the CTC to acceptable values that would ensure self-controllability of the core design. These strategies are summarized in Appendix 4B. It was found that the use of natural uranium, $\mathrm{Zr}$ hydride containing axial blankets reduce the core CTC very effectively.

Once the most effective strategies were integrated into preliminary core design, reactivity feedback coefficients calculations were performed with statistical accuracy significantly higher than previously used for identifying the most promising strategies for the reduction of CTC.

In some of the calculated cases, considerable differences were observed between the previous screening study results and the current high accuracy reactivity coefficient calculations. For example, optimization of the amount of $\mathrm{ZrH}_{1.6}$ in the axial blankets showed a clear minimum in the vicinity of 20 volume \% of $\mathrm{ZrH}_{1.6}$. However, the same cases recalculated with substantially higher statistical accuracy suggested that the CTC is practically insensitive to the amount of hydrogen in the blankets (Figure 3A.1.2-1).

Figure 3A.1.2-2 shows the core multiplication factor evolution with the number of source iteration cycles for the case of $20 \% \mathrm{Zr}$ hydride in the axial blankets. The two sets of curves in Figure 3A.1.2-2 correspond to the same case but calculated with different total number of histories and different number of histories per source iteration cycle. As can be observed from the Figure, the core criticality values exhibit changing trends even with very large number of 
histories per cycle. Therefore, on the basis of several sets of calculations performed with various numbers of total particle histories and histories per cycle, it was concluded that at least 150,000 particles per cycle and 60 million total histories should be used to obtain reasonably reliable reactivity coefficient results for the studied core configuration.

As a result of the above findings, some of the CTC reduction strategies required re-evaluation using higher statistical accuracy.

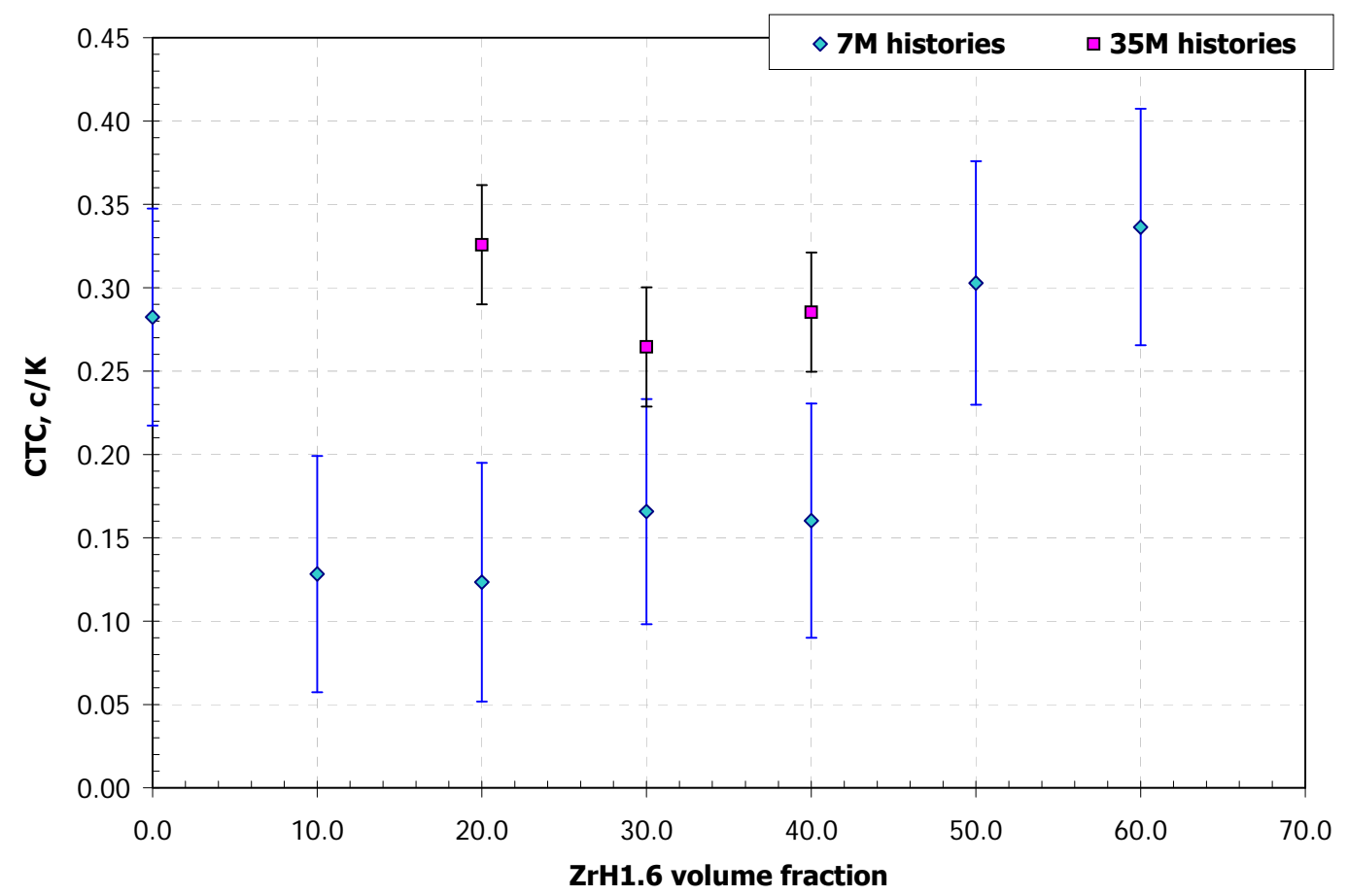

Figure 3A.1.2-1. CTC vs blanket Zr hydride volume fraction: \# of neutron histories effect. 
Project No 06-040: Flexible Conversion Ratio Fast Reactor Systems Evaluation

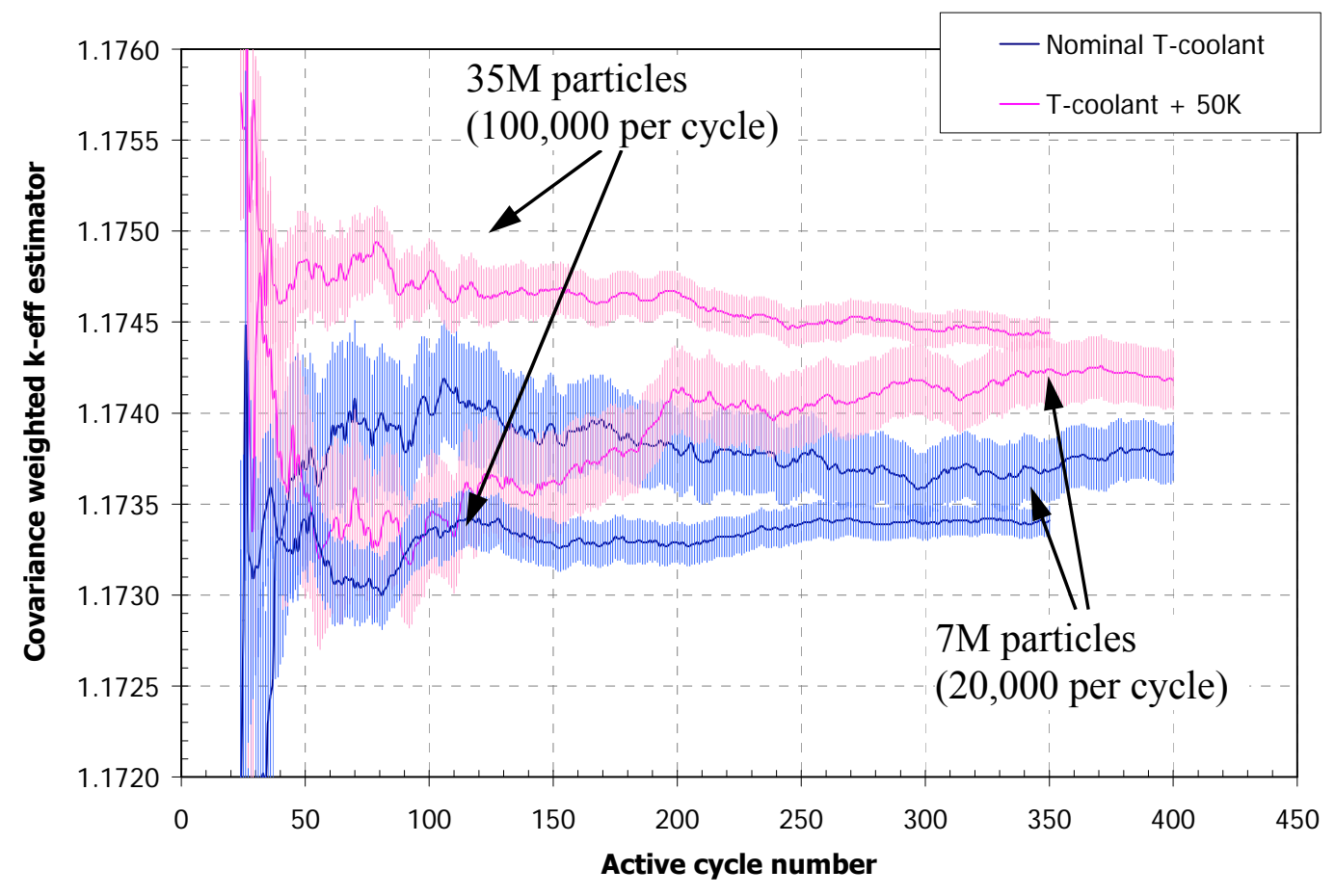

Figure 3A.1.2-2. Combined, covariance weighted k-eff vs. source iteration cycle (20v/o $\mathrm{ZrH}_{1.6}$ case from Fig. 3A.1.2-1)

\section{A.1.3 MCODE}

MCODE (MCNP-ORIGEN DEpletion) is a utility program developed at MIT to perform burnup calculations [Xu et al., 2002]. The program combines the continuous-energy Monte Carlo code, MCNP-4C [Briesmeister, 2000], and the one-group depletion code, ORIGEN2.1 [Croff, 1983]. MCNP provides the neutron flux and effective one-group cross sections for different MCNPdefined regions. ORIGEN, in turn, carries out multi-nuclide depletion calculations for each region and provides material compositions to update beginning-of time step MCNP input. This console program is written in ANSI $\mathrm{C}$ and is fully portable under Windows and UNIX environments. Two significant features of MCODE are important to emphasize:

1) Convenient and user friendly interface including simplified and centralized user input data, automatic generation of tally materials and tallies, automatic execution of MCNP and ORIGEN, and

2) Enhanced functionality including flexible normalization options (either constant flux or constant power), internal burnup corrector (in ORIGEN depletions), and implementation of a burnup predictor-corrector algorithm.

MCODE performance accuracy has been confirmed by numerous benchmark calculations against the results of various state of the art computer codes [Xu et al., 2002]. 
In this project, the code was used for burnup calculations and fuel cycle analysis of the studied reactor designs.

\section{A.1.4 BGCore}

BGCore code [Fridman et al. 2008] was developed for the neutronic analysis of reactor systems. The main part of the BGCore is the continuous energy Monte Carlo particle transport code MCNP-4C [Briesmaister, 2000] coupled with the decay and burnup module SARAF.

The SARAF module was independently developed at Ben-Gurion University. The module can be used in a stand-alone mode similarly to the well known ORIGEN2 code [Croff, 1983]. In the BGCore system, the SARAF module receives the relevant data from MCNP, executes the depletion time step, and passes back the updated fuel composition for the next MCNP time step.

The SARAF data library, required for its execution, is based on JEFF3.1 evaluated data files [Koning, 2006]. The library includes fast and thermal fission product yields for over 30 fissionable nuclides, decay constants, atomic masses, decay reactions' branching ratios and recoverable energy per decay for decay heat calculations.

Currently, about 1700 isotopes are tracked in the SARAF code. The following guidelines were used in choosing these nuclides:

- All the nuclides that have evaluated cross-sections in JEFF-3.1 file with their respective decay chains.

- All nuclides with available fission yield data including their decay chains

The BGCore system is written entirely in the MATLAB programming environment. This greatly simplifies the source code, making it more transparent, efficient, and less error prone. In addition, the MATLAB data can be stored in a standard, fast and easy access, platform independent binary format which is also easy to visualize.

Similar to the ORIGEN2 code, SARAF uses the matrix exponential method to solve a set of first order differential equations representing the evolution of each nuclide concentration with time. However, no asymptotic approximations are used, that is the main calculation matrix always includes all of the 1700 isotopes. The execution time for the depletion step is notably larger than that of the ORIGEN code for similar input. However, it is still negligible compared to the Monte Carlo step.

The depletion calculations are executed for each burnable region with the calculated real neutron flux values in two stages known as the Predictor-Corrector (P-C) algorithm. The P-C procedure is required to reduce the error introduced by the fact that the depletion calculation is performed using the beginning of time step values of the flux and cross sections, which in reality, may change significantly during the time step. 
The conventional approach to calculation of one-group cross-sections, required for the depletion calculation, assumes that reaction rates for each nuclide and reaction type are tallied directly by MCNP. Therefore, MCNP execution time increases dramatically as the number of important nuclides increases during fuel depletion.

Alternatively, the BGCore approach for generation of one group cross-sections takes advantage of the fact that dividing the neutron flux tally into multiple energy bins has practically no effect on the MCNP execution time. The following calculation procedure is therefore adopted. A fine group spectrum (currently 50000 lethargy points) is tallied at each burnable region by MCNP and passed on to the SARAF module. The one-group cross-sections are not tallied, but calculated in a separate subroutine using a pre-generated multi-group cross-section set and the fine group neutron spectrum obtained from MCNP. Such an approach allows for significant speedup of the depletion calculations by a factor of 2 to 10 depending on the complexity of the problem.

An additional advantage of the method is the fact that the one group cross-sections are calculated for all available isotopes and, in principle, for all available reaction types without any increase in computation time. In contrast, in the conventional coupling method, the calculated cross-section data is limited only to the most neutronically important nuclides and reactions, while the rest of the data is taken from a standard reactor-type dependent ORIGEN library.

Considerable effort was made to ensure that the multi-group approach gives one group crosssection values identical to those obtained with the conventional direct reaction rate tally approach. It was found that for the nuclides with complex resonance structure, which are present in the fuel at high concentrations, increasing the number of energy groups does not reduce the error in one group cross section below $\sim 1 \%$ especially at low fuel temperatures. The error originates almost exclusively from the unresolved resonances energy region. This is due to the probabilistic treatment of unresolved resonances in MCNP, which correctly predicts the average value of the reaction rates but in principle cannot provide the fine structure of the neutron flux. As a result, the self-shielding effect in the unresolved resonances energy region is not accounted for correctly. The error introduced is not statistical in nature but systematic since the shielded cross-section is always smaller than the infinite dilution one.

In order to overcome that inaccuracy, the multi-group approach was extended by introducing the background cross-section $\left(\sigma_{0}\right)$ tabulation into the calculation scheme. An approximated formulation for estimate of the background $\sigma_{0}$ for a given lattice is proposed in Segev [1992] and presented by Eq. below:

$\sigma_{0, i}=\frac{\sum_{j=1}^{M} N_{j} \sigma_{p, j}+\frac{1 / \bar{R}}{1 / a+1 / \gamma-1}}{N_{i}}$

where:

$i$ or $j=$ isotope number,

$M \quad=$ number of isotopes in the fuel,

$\sigma_{o, j} \quad=$ background cross-section of isotope $\mathrm{i}$,

$N_{j} \quad=$ atom density of isotope $\mathrm{j}$,

$\sigma_{p, j} \quad=$ potential scattering cross-section of isotope $\mathrm{j}$, 
$\bar{R} \quad=$ mean chord length of a fuel element,

$a \quad=$ Bell factor,

$\gamma \quad=$ Dancoff factor.

The adopted simplified model is based on the assumption: $\alpha=\gamma=1$. This assumption neglects the probability that neutron born in a given fuel lump will suffer next collision in another fuel lump (Dancoff factor) and empirical correction to the Wigner rational approximation for the fuel escape probability (Bell factor).

A series of multi-group cross-section sets is generated for selected isotopes with significant resonance cross-sections for several values of $\sigma_{0}$. The approximate value of the $\sigma_{0}$ is then used to extract the appropriate set of the multi-group cross-section sets for a specific resonance isotope (by linear interpolation), which is further used to obtain the "shielding corrected" one group cross-section value. Introduction of this extension reduces the difference between directly tallied and collapsed from multi-group cross-sections to well below 1\% while still taking advantage of the fast MCNP execution.

In this project, BGCore was used for the fuel cycle and burnup analysis of the studied concepts and to verify similar calculations performed with MCODE. In addition, the code was used for the calculation of decay heat power of the studied designs that was subsequently used in transient analysis with the RELAP5 code.

\section{A.1.5 ANL Suite of Diffusion Codes}

The ANL suite of codes for reactor physics and fuel cycle analysis was used for complete assessment of the $2400 \mathrm{MWt}$ lead-cooled reactor with flexible conversion ratio performance as well as for the sodium-cooled reactor design and analysis. This section contains a brief description of the codes. The reactor physics calculations were performed using the DIF3D8 diffusion theory code. DIF3D8 was further coupled with the REBUS-3 code to perform burnup and fuel cycle calculations. A 33-group neutron cross section set for the DIF3D8 code was generated using the $\mathrm{MC}^{2}-2$ code. The basic neutron data was obtained from the ENDF/B-V data files. The steps in the analysis are shown in Figure 3A.1.5-1. The results obtained from the above codes were further compared to MCNP and MCODE analysis. 


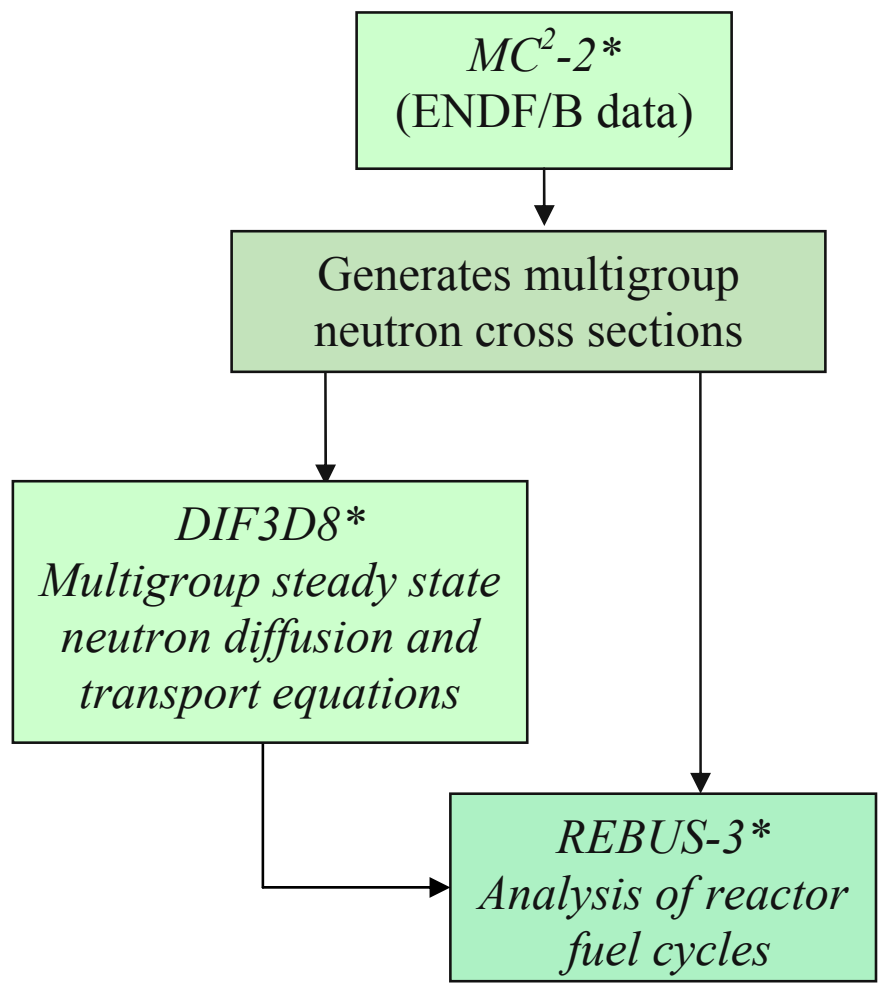

* Developed at Argonne National Laboratory

Figure 3A.1.5-1 The ANL suite of reactor physics and fuel cycle codes.

\section{MC2-2}

The $\mathrm{MC}^{2}-2$ (Multigroup Constant Codes) was used to solve the neutron slowing-down equations. The improved Goertzel-Grueling approximation was used for continuous slowing down calculations, and the spatial dependence was handled using the consistent B1 approximation.

A series of group averages from homogeneous ultra-fine groups to a 33-group structure was completed for every isotope in each distinct region of the reactor model. The fixed source was determined for each non-fueled region using a utility program $\mathrm{DB}^{2}$. Rather than using an explicit reactor geometry to obtain broad group cross sections, modern computing technology allows more simplistic approaches. In this respect, a standard critical breeding model was used for each of the fuel core regions while a fixed source calculation was used for non-fueled regions. This process has been found sufficient for design studies as long as a sufficient number of groups are used in the global calculation. For this type reactor, 33 groups are generally found to be sufficient.

The generated multigroup neutron cross section output was exported in ISOTXS format. Then, data for each region was merged into a single ISOTXS file to be used by the DIF3D8 and 
Project No 06-040: Flexible Conversion Ratio Fast Reactor Systems Evaluation

REBUS- 3 codes. The $\mathrm{MC}^{2}-2$ runs in this report used ENDF-V homogenous ultra-fine group libraries delivered with the code.

\section{REBUS-3}

REBUS-3 was developed by Argonne National Laboratory primarily for fast reactor applications and validated against EBR-II irradiation data. REBUS-3 has an ability to solve various problem types including an infinite-time (equilibrium) fixed fuel cycle management scheme or an explicit cycle-by-cycle (non-equilibrium) scheme with a specified periodic or non-periodic fuel management program.

\section{A.2 REBUS-3 Analysis for Lead-cooled Core and Comparison with MCODE Results}

Neutronic analysis of both lead and salt-cooled cores in this report was performed with MCNP and MCODE using JEF3.1 libraries. However, because most analyses of sodium-cooled actinide recycling reactors performed elsewhere is done using diffusion codes, such as the ANL suite of codes described above in Section 3A.1.5 and because some neutronic calculations performed under this project for the sodium-cooled 2400MWt reactor core used ANL codes, it is of interest to compare the results between MCNP-based codes and ANL codes. This section performs this comparison for lead-cooled $\mathrm{CR}=1$ and $\mathrm{CR}=0$ cores.

\section{A.2.1 Computational Model of Lead-Cooled Core for DIF3D8 and REBUS-3}

One fourth of the reactor core symmetry was used due to limitations of DIF3D8 when the Cartesian coordinate system is applied. The core is a three-zone core with metallic fuel. Each assembly was modeled individually, but the assembly components were homogenized. Since MCNP calculations in Chapter 3 showed that the power profile within an assembly is very flat with the power peaking not exceeding 1.02 , only assembly power peaking will be calculated. The axial neutron shield with $\mathrm{B}_{4} \mathrm{C}$ is a strong neutron absorber, hence caution should be taken when modeling those shields since diffusion theory cannot cope with strong neutron absorbers as accurately as MCNP. The model also assumed that no fuel shuffling is performed, and there is no external TRU feed. In the current model, the All Rods Out condition was assumed.

The dimensions and materials of the lead-cooled reactor core are explicitly described in Chapter 3. The geometric and thermal hydraulic parameters were taken from the steady state thermalhydraulic section; reactor physics parameters were directly provided by an MCNP input file to ensure that the initial heavy metal loading is the same. The initial isotopic loading of TRU corresponds to typical LWR spent fuel and is summarized in Table 3A.2.1-1. The fuel, coolant and structure temperatures for the cross section calculations were taken directly from thermal hydraulic analysis (average values). 
Table 3A.2.1-1 TRU Isotopic Composition

\begin{tabular}{|c|c|c|}
\hline \multicolumn{2}{|c|}{ TRU Isotope ID } & wt \% \\
\hline 93 & 237 & 0.056 \\
\hline 94 & 238 & 0.025 \\
\hline 94 & 239 & 0.465 \\
\hline 94 & 240 & 0.230 \\
\hline 94 & 241 & 0.082 \\
\hline 94 & 242 & 0.067 \\
\hline 95 & 241 & 0.054 \\
\hline 95 & 243 & 0.016 \\
\hline 95 & $242 \mathrm{~m}$ & 0.000001 \\
\hline 96 & 242 & 0.000038 \\
\hline 96 & 243 & 0.004293 \\
\hline 96 & 244 & 0.000430 \\
\hline 96 & 245 & 0.000055 \\
\hline 96 & 246 & 0.000001 \\
\hline 96 & 248 & 0.000090 \\
\hline
\end{tabular}

\section{A.2.2 CR=1 Core}

\section{Initial Conditions}

Table 3A.2.2-1 compares the initial isotopic loading for MCNP and REBUS-3 for the inner core zone (ICORE), middle core zone (MCORE), and outer core zone (OCORE). Both cases are in good agreement, but the slight difference is due to variations in Avogadro's number and atomic masses. In MCNP, every fuel pin is modeled explicitly; DIF3D/REBUS-3 uses a homogeneous assembly approach. Thus, due to the different nature of the codes, it is important to compare the initial loading of the fuel. Comparison confirms very good agreement between both codes for all core regions.

\section{Core Performance}

The comparison of multiplication factor throughout the core irradiation time is summarized in Table 3A.2.2-2 and Figure 3A.2.2-1. K-effective calculated by DIF3D/REBUS-3 is slightly higher than the one computed by MCNP. Consistent overprediction of the criticality over the core life time by DIF3D/REBUS-3 is similar as for the sodium core discussed in Appendix 5A. Studies in Appendix 5A showed that this discrepancy cannot be attributed solely to the differences of cross section libraries used by $\mathrm{MC}^{2}-2$ and MCNP (ENDF-V and JEFF-3.1, respectively) and more investigations would be needed to identify the reason for this difference. The final isotopic loading outlined in Table 3A.2.2-3 shows that the TRU destruction and uranium burnup are somewhat slower when computed by DIF3D/REBUS-3, which might also result in higher reactivity. 
Table 3A.2.2-1 Initial isotopic loading (all in $\mathrm{kg}$.) for $\mathrm{CR}=1$ core.

\begin{tabular}{|l|r|r|r|r|r|r|}
\hline & \multicolumn{3}{|c|}{ REBUS-3 } & \multicolumn{3}{c|}{ MCNP } \\
U-234 & ICORE & \multicolumn{1}{c|}{ MCORE } & \multicolumn{1}{c|}{ OCORE } & \multicolumn{1}{c|}{ ICORE } & \multicolumn{1}{c|}{ MCORE } & OCORE \\
\cline { 2 - 7 } U-235 & 0.00 & 0.00 & 0.00 & 0.00 & 0.00 & 0.00 \\
U-236 & 81.61 & 115.58 & 137.65 & 81.61 & 115.58 & 137.65 \\
U238 & 0.00 & 0.00 & 0.00 & 0.00 & 0.00 & 0.00 \\
NP237 & 11396.60 & 16141.48 & 19222.60 & 11396.60 & 16141.49 & 19222.56 \\
PU236 & 152.45 & 215.92 & 257.14 & 152.45 & 215.92 & 257.14 \\
PU238 & 0.00 & 0.00 & 0.00 & 0.00 & 0.00 & 0.00 \\
PU239 & 63.11 & 89.38 & 106.44 & 63.11 & 89.38 & 106.44 \\
PU240 & 1116.88 & 1581.88 & 1883.84 & 1116.88 & 1581.89 & 1883.84 \\
PU241 & 527.54 & 747.18 & 889.81 & 527.54 & 747.18 & 889.80 \\
PU242 & 159.00 & 225.20 & 268.18 & 159.00 & 225.20 & 268.18 \\
AM241 & 115.54 & 163.65 & 194.89 & 115.54 & 163.65 & 194.89 \\
AM242 & 106.84 & 151.32 & 180.21 & 106.84 & 151.32 & 180.21 \\
AM243 & 0.44 & 0.62 & 0.74 & 0.44 & 0.62 & 0.74 \\
CM242 & 33.79 & 47.86 & 57.00 & 33.79 & 47.86 & 57.00 \\
CM243 & 0.00 & 0.00 & 0.00 & 0.00 & 0.00 & 0.00 \\
CM244 & 0.11 & 0.16 & 0.19 & 0.11 & 0.16 & 0.19 \\
CM245 & 11.39 & 16.13 & 19.21 & 11.39 & 16.13 & 19.21 \\
CM246 & 0.87 & 1.24 & 1.47 & 0.87 & 1.24 & 1.47 \\
\hline SUM & 0.14 & 0.20 & 0.23 & 0.14 & 0.20 & 0.23 \\
\hline
\end{tabular}

Table 3A.2.2-2 Comparison of k-effective at BOL and EOL

\begin{tabular}{|l|c|c|}
\hline & MCNP & REBUS-3 \\
\hline BOL & 1.020 & 1.032 \\
\hline EOL (1800d) & 1.000 & 1.025 \\
\hline $\mathrm{dk} / \mathrm{k}, \%$ & $2.0 \%$ & $0.7 \%$ \\
\hline
\end{tabular}

The maps of differences in radial power peaking factors at the Beginning (BOC), Middle (MOC), and at the End of fuel cycle (EOC) are compared for REBUS/DIF3D and MCODE in Figures 3A.2.2-2, 3A.2.2-3, and 3A.2.2-4, respectively. The results show very good agreement between the two codes, except for the peripheral assemblies at EOL where the difference is up to $10 \%$. Given the differences in the libraries used, the fact that these assemblies have small power and face a lead coolant reflector, where diffusion theory has some limitations, these differences are acceptable. 
Project No 06-040: Flexible Conversion Ratio Fast Reactor Systems Evaluation

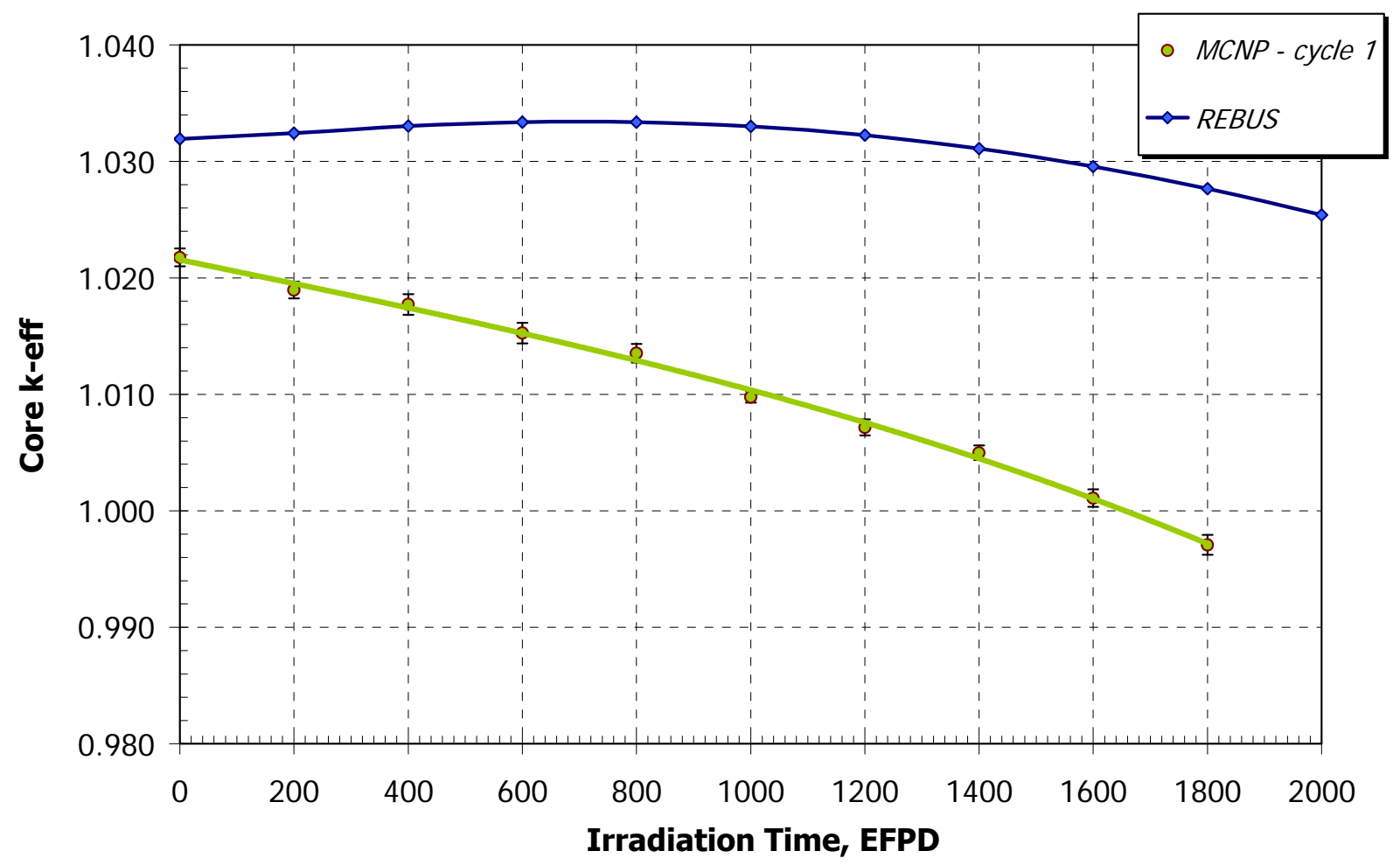

Figure 3A.2.2-1 Comparison of k-effective

\begin{tabular}{|c|c|c|c|c|c|c|c|c|c|c|}
\hline 1 & 2 & 3 & 4 & 5 & 6 & 7 & 8 & 9 & 10 & 11 \\
\hline $0.9 \%$ & $1.5 \%$ & $1.3 \%$ & $1.3 \%$ & $1.0 \%$ & $1.5 \%$ & $-0.9 \%$ & $-1.3 \%$ & $-0.2 \%$ & $-0.3 \%$ & $4.9 \%$ \\
\hline 2 & $0.8 \%$ & $1.2 \%$ & $1.5 \%$ & $0.6 \%$ & $1.4 \%$ & $-0.4 \%$ & $-1.0 \%$ & $-0.3 \%$ & $0.0 \%$ & $4.8 \%$ \\
\hline 3 & & $2.2 \%$ & $0.8 \%$ & $0.1 \%$ & $0.5 \%$ & $0.2 \%$ & $-1.2 \%$ & $0.2 \%$ & $0.1 \%$ & $4.5 \%$ \\
\hline 4 & & & $1.5 \%$ & $-0.1 \%$ & $-1.0 \%$ & $-1.3 \%$ & $-2.2 \%$ & $-2.4 \%$ & $-1.0 \%$ & $7.2 \%$ \\
\hline 5 & & & & $-0.8 \%$ & $-0.9 \%$ & $-1.4 \%$ & $-1.9 \%$ & $-1.9 \%$ & $2.1 \%$ & \\
\hline 6 & & & & & $-1.3 \%$ & $-1.7 \%$ & $-2.3 \%$ & $-0.2 \%$ & $5.7 \%$ & \\
\hline 7 & & & & & & $-0.8 \%$ & $-0.8 \%$ & $4.8 \%$ & & \\
\hline 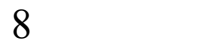 & & & & & & & $4.0 \%$ & & & \\
\hline
\end{tabular}


Figure 3A.2.2-2 CR=1 Core, Radial Power Distribution Map at BOL (0 days) (percentage difference, (REBUS-MCNP)/ REBUS)

\begin{tabular}{|c|c|c|c|c|c|c|c|c|c|c|}
\hline 1 & 2 & 3 & 4 & 5 & 6 & 7 & 8 & 9 & 10 & 11 \\
\hline $0.0 \%$ & $0.6 \%$ & $0.8 \%$ & $0.0 \%$ & $-0.2 \%$ & $0.5 \%$ & $-0.4 \%$ & $-0.1 \%$ & $0.7 \%$ & $0.9 \%$ & $4.3 \%$ \\
\hline 2 & $0.4 \%$ & $0.0 \%$ & $-0.2 \%$ & $0.2 \%$ & $-0.3 \%$ & $-1.0 \%$ & $-0.5 \%$ & $0.4 \%$ & $1.3 \%$ & $4.3 \%$ \\
\hline 3 & & $-0.5 \%$ & $-1.6 \%$ & $-0.8 \%$ & $-0.3 \%$ & $-0.8 \%$ & $0.4 \%$ & $0.4 \%$ & $1.1 \%$ & $4.9 \%$ \\
\hline 4 & & & $-1.0 \%$ & $-0.5 \%$ & $-0.5 \%$ & $-0.4 \%$ & $-0.1 \%$ & $1.1 \%$ & $1.7 \%$ & $7.5 \%$ \\
\hline 5 & & & & $-1.2 \%$ & $-0.5 \%$ & $-0.3 \%$ & $-0.5 \%$ & $1.2 \%$ & $3.7 \%$ & \\
\hline 6 & & & & & $-0.2 \%$ & $-0.6 \%$ & $0.2 \%$ & $1.0 \%$ & $6.3 \%$ & \\
\hline 7 & & & & & & $0.4 \%$ & $0.6 \%$ & $4.3 \%$ & & \\
\hline & & & & & & & $3.3 \%$ & & & \\
\hline
\end{tabular}

Figure 3A.2.2-3 CR=1 Core, Radial Power Distribution Map at MOL (800 days) (percentage difference, (REBUS-MCNP)/ REBUS)

\begin{tabular}{|c|c|c|c|c|c|c|c|c|c|c|}
\hline 1 & 2 & 3 & 4 & 5 & 6 & 7 & 8 & 9 & 10 & 11 \\
\hline$-3.4 \%$ & $-3.8 \%$ & $-3.6 \%$ & $-4.3 \%$ & $-3.5 \%$ & $-2.4 \%$ & $-1.0 \%$ & $0.6 \%$ & $1.2 \%$ & $3.3 \%$ & $10.6 \%$ \\
\hline 2 & $-4.0 \%$ & $-4.6 \%$ & $-4.6 \%$ & $-3.0 \%$ & $-2.6 \%$ & $-2.7 \%$ & $-0.7 \%$ & $0.6 \%$ & $3.5 \%$ & $10.7 \%$ \\
\hline 3 & & $-5.9 \%$ & $-5.5 \%$ & $-2.7 \%$ & $-1.8 \%$ & $-1.6 \%$ & $-0.6 \%$ & $0.7 \%$ & $3.6 \%$ & $10.3 \%$ \\
\hline 4 & & & $-4.6 \%$ & $-2.6 \%$ & $-1.3 \%$ & $-0.8 \%$ & $-0.5 \%$ & $3.6 \%$ & $4.4 \%$ & $10.2 \%$ \\
\hline 5 & & & & $-1.0 \%$ & $0.1 \%$ & $1.4 \%$ & $2.1 \%$ & $3.8 \%$ & $6.0 \%$ & \\
\hline 6 & & & & & $1.0 \%$ & $2.8 \%$ & $5.6 \%$ & $5.2 \%$ & $9.3 \%$ & \\
\hline 7 & & & & & & $5.5 \%$ & $5.8 \%$ & $8.6 \%$ & & \\
\hline & & & & & & & $7.6 \%$ & & & \\
\hline
\end{tabular}

Figure 3A.2.2-4 CR=1 Core, Radial Power Distribution Map at EOL (1800 days) (percentage difference, (REBUS-MCNP)/ REBUS

The fuel cycle length for $\mathrm{CR}=1$ is restricted by the peak cladding fluence limit of $4.0 \times 10^{23}$ $(\mathrm{E}>0.1 \mathrm{MeV}) / \mathrm{cm}^{2}$, as discussed in Chapter 2. Average discharge burnup corresponding to the EOL $(1800 \mathrm{~d}$ ) was calculated by REBUS-3 to be $74 \mathrm{MWd} / \mathrm{kg}$, which is slightly less than the value calculated by MCODE. Figure 3A.2.2-5 shows the accumulated burnup with irradiation time for the core average and each core zone individually. Figure 3A.2.2-6 compares the MCODE, REBUS, and BGCore [Fridman et al., 2008] performance. All three codes are in good agreement. Numbers 10, 12, and 14 in the Figure 3A.2.2-6 legend refer to the ID numbers of burnable materials in the inner, middle, and outer core regions respectively. 
Project No 06-040: Flexible Conversion Ratio Fast Reactor Systems Evaluation

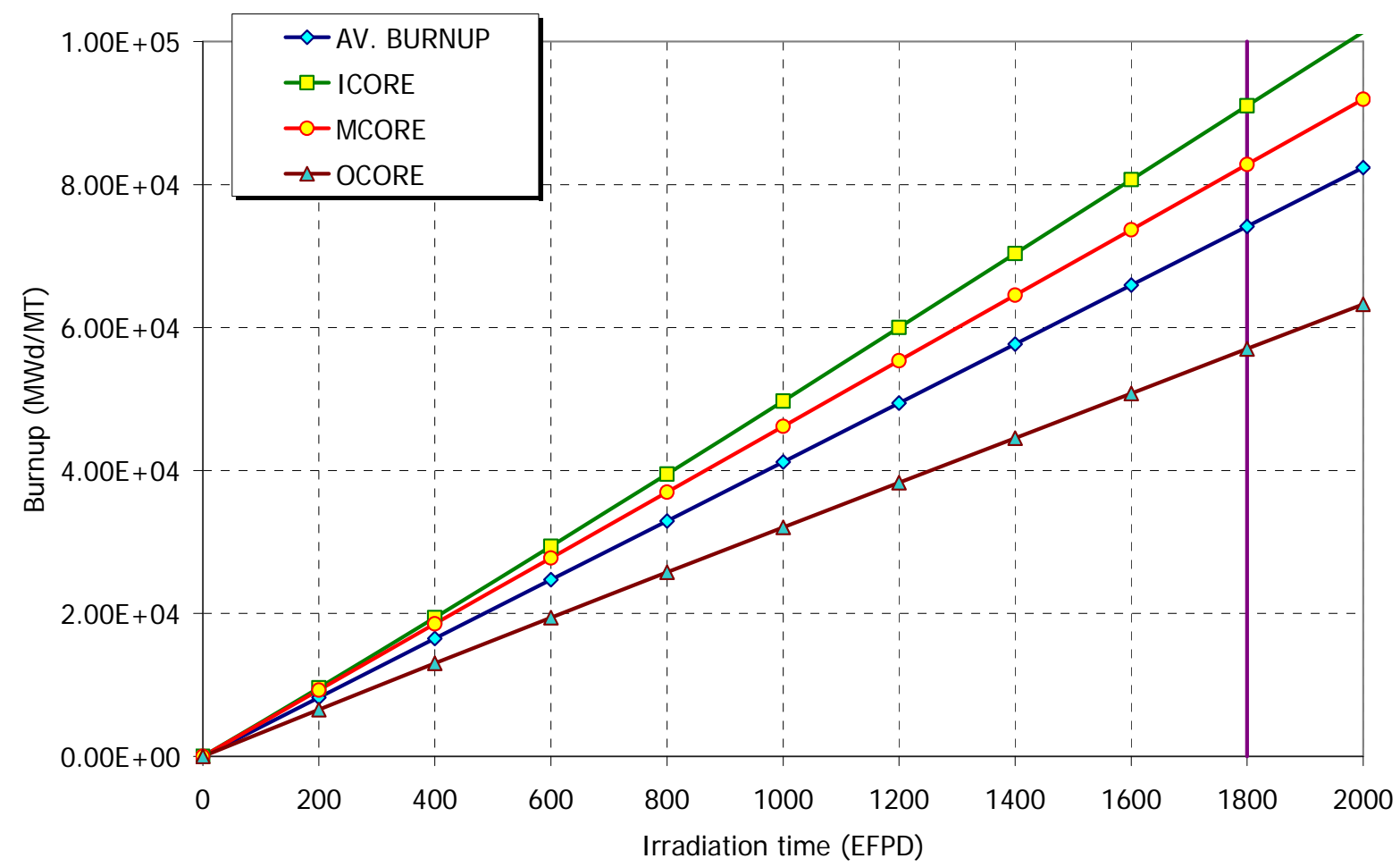

Figure 3A.2.2-5 Core burnup (MWd/MTHM) vs. irradiation time (EFPD)

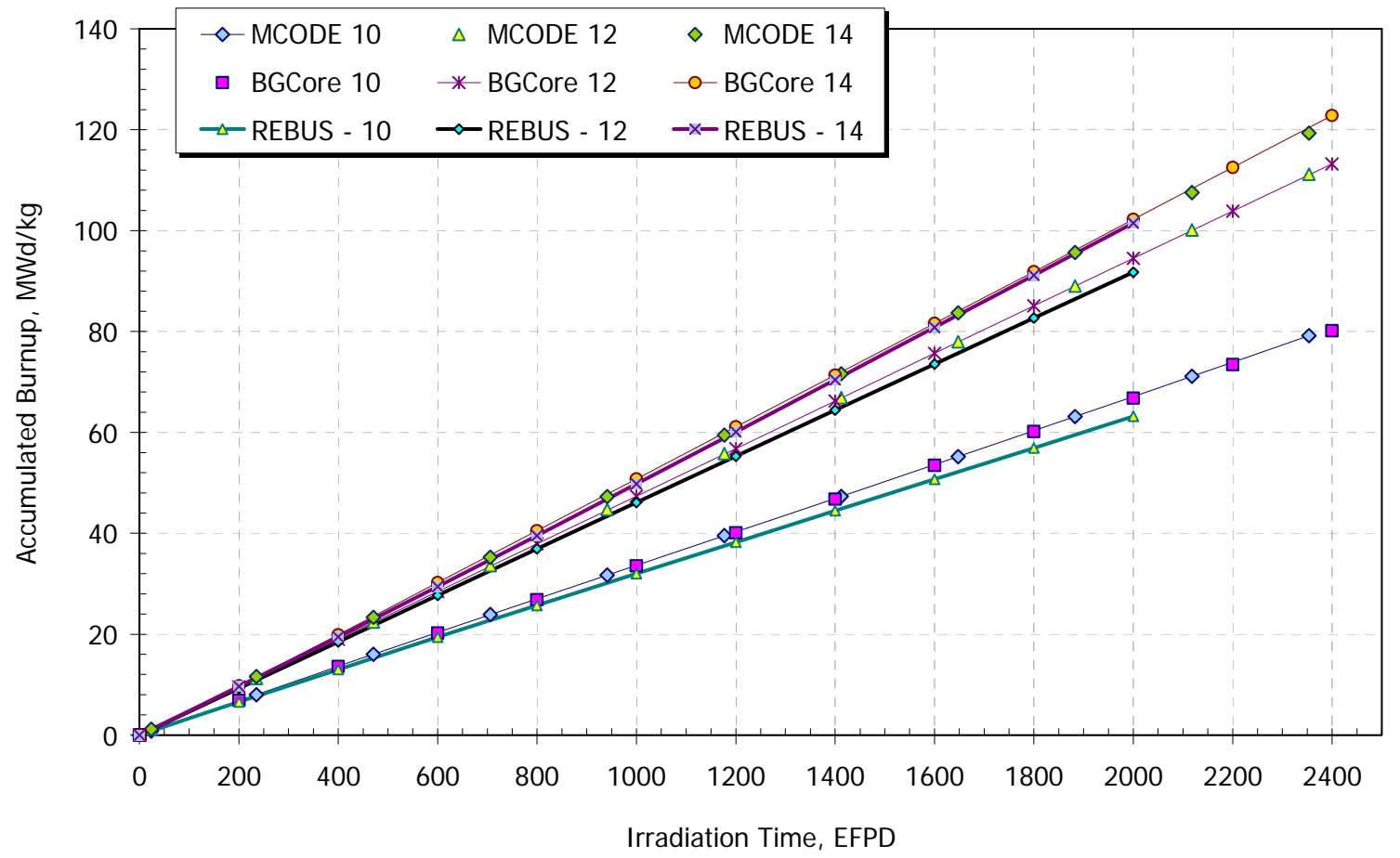

Figure 3A.2.2-6 Core burnup (MWd/MTHM) vs. irradiation time (EFPD). Comparison between MCODE, REBUS and BGCore. $(10=$ outer zone, $12=$ middle zone, $14=$ inner zone $)$ 
Table 3A.2.2-3 compares the plutonium, minor actinide and uranium masses at BOL and EOL. Note that 1800 days, i.e. EOL for REBUS-3 run was taken as EOL for both codes here to compare at the same time point. Figure 3A.2.2-7 plots plutonium inventory changes during the first cycle for both MCODE and REBUS-3. The Pu inventory increases with burnup, and REBUS and MCODE results agree closely. Mass of minor actinides is reduced, mainly due to Np237 and Am421 burning. REBUS-3 shows about 2\% smaller mass of minor actinides than MCODE. The EOL difference in uranium $(151 \mathrm{~kg}$, or by $0.3 \%$, more $U$ for the REBUS-3 run) is larger than the difference in EOL TRU mass $(18 \mathrm{~kg})$. This suggests that more uranium is fissioned in MCODE run than in the REBUS-3 run as a result of differences in cross sections between JEF3.1 and REBUS-3.

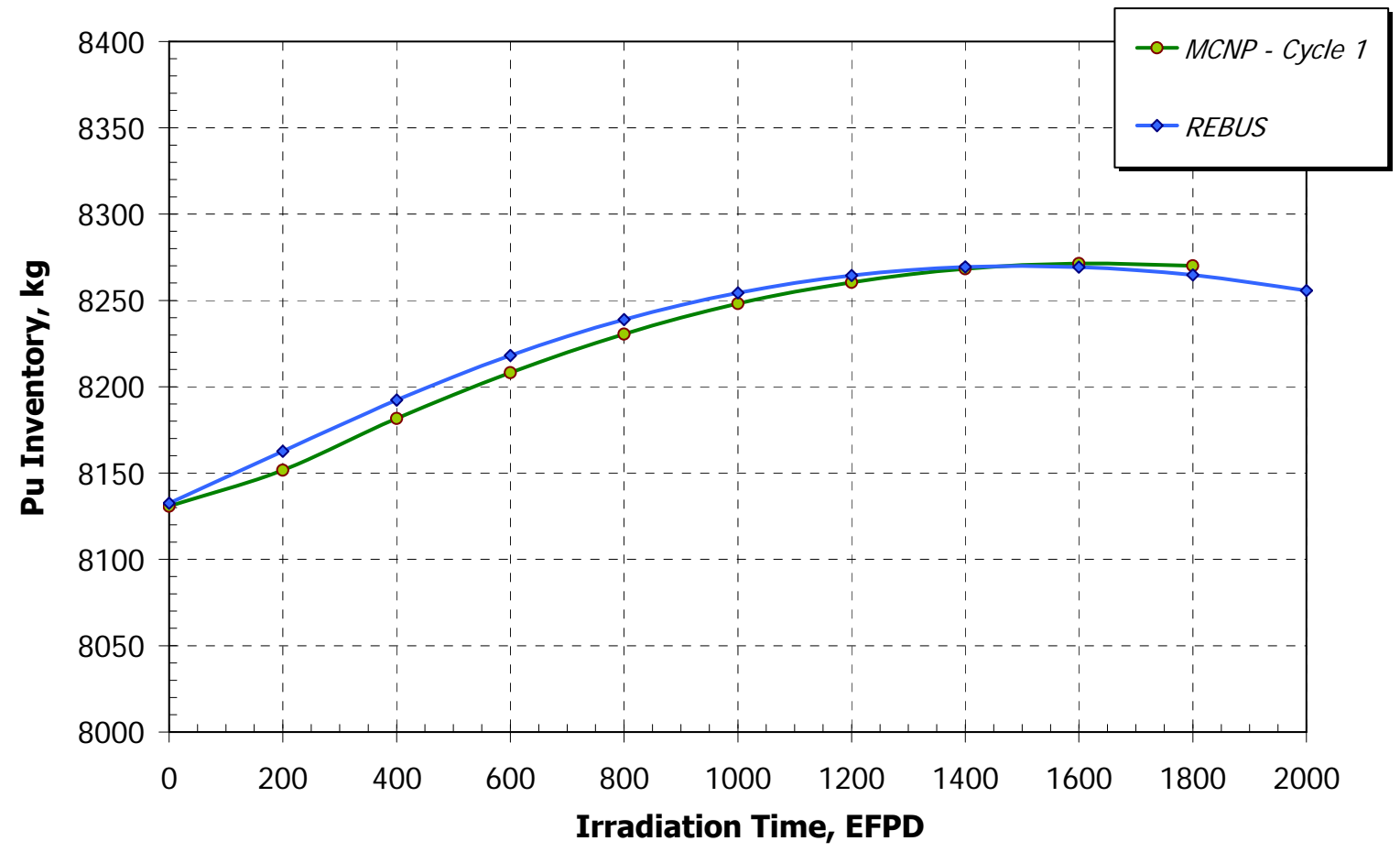

Figure 3A.2.2-7 $\mathrm{CR}=1$ Core Pu inventory (kg) vs. core irradiation time (EFPD)

Table 3A.2.2-3 Initial and final isotopic loading (all in $\mathrm{kg}$.) for $\mathrm{CR}=1$ core

\begin{tabular}{|l|r|r|}
\hline & MCNP & REBUS-3 \\
\hline BOL (0 days) & \multicolumn{2}{|l|}{} \\
\hline TOTAL PU (kg) & 8132.52 & 8132.53 \\
\hline TOTAL MA (kg) & 1255.67 & 1255.67 \\
\hline TOTAL U (kg) & 47095.49 & 47095.52 \\
\hline TRU (kg) & 9388.20 & 9388.21 \\
\hline HM (kg) & 56483.69 & 56483.73 \\
\hline EOL (1800 days) & 8268 & 8264.66 \\
\hline TOTAL PU (kg) & 953 & 975.31 \\
\hline TOTAL MA (kg) & 42657 & 42808.23 \\
\hline TOTAL U (kg) & 9221 & 9239.96 \\
\hline TRU (kg) & 51878 & 52048.19 \\
\hline HM (kg) &
\end{tabular}




\section{A.2.3 CR=0 Core}

\section{Initial Conditions}

Table 3A.2.3-1 compares the initial heavy metal loadings for two benchmark cases. As in the $\mathrm{CR}=1$ case, the slight difference between MCNP and REBUS loadings is due to variation in Avogadro's number and isotopic masses used for the two cases.

Table 3A.2.3-1 Initial isotopic loading (all in $\mathrm{kg}$.) for $\mathrm{CR}=0$ core.

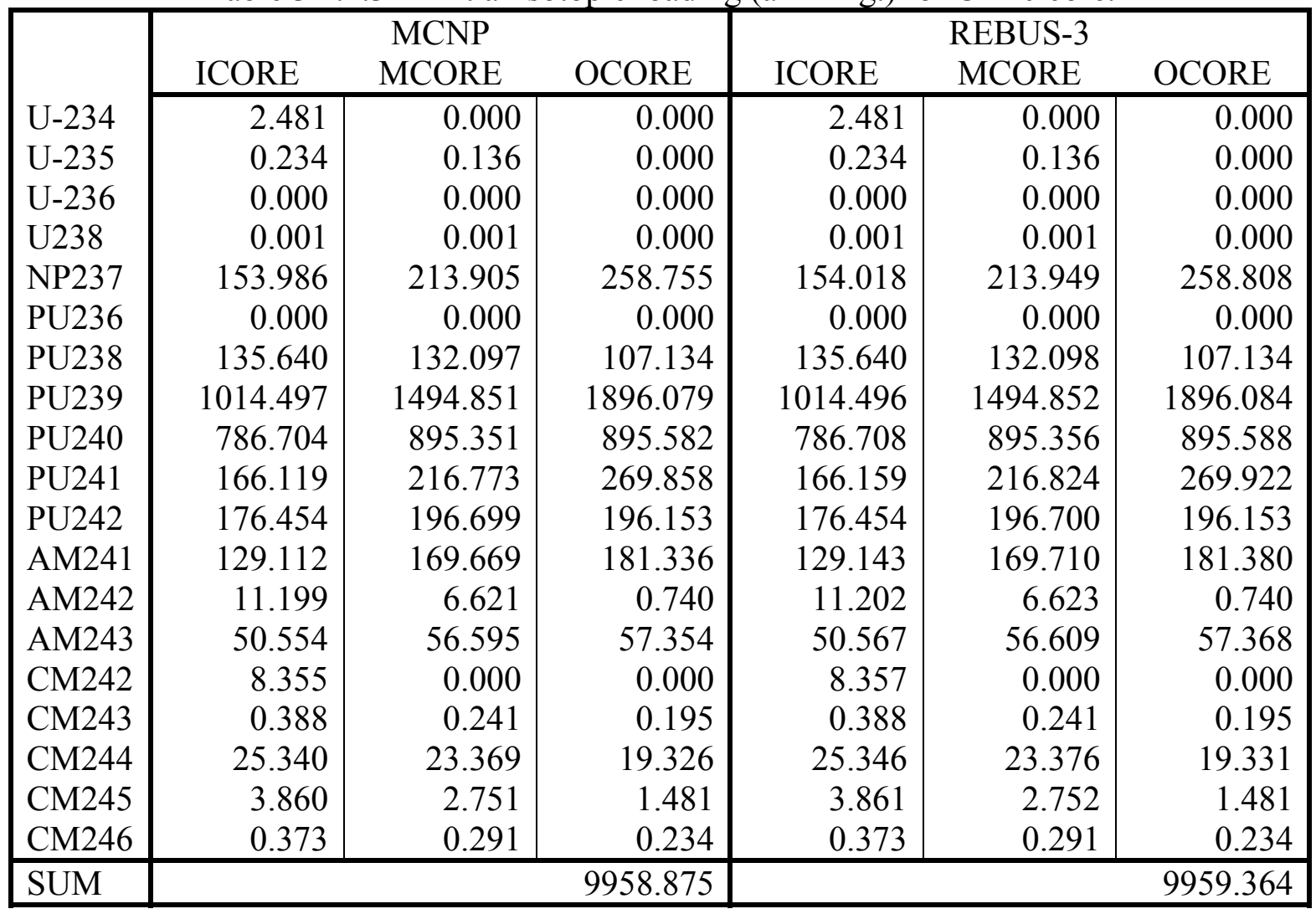

\section{Core Performance}

The problem was run for 550 EFPD. As can be seen from Figure 3A.2.3-1, MCODE and REBUS/DIF3D are in excellent agreement. The two codes have better agreement for $\mathrm{CR}=0$, partially due to a lower conversion ratio (lower ratio of TRU loading in the core relative to total fuel loading.) The figure also illustrates the impact of the cross-section libraries used for the analysis. The reactivity calculated with REBUS and MCODE with ENDF-VI cross-section data (circles and triangles curves) agree fairly well, while the MCODE results for the core reactivity obtained using the JEFF-3.1 library (squares curve) are higher by about $2 \% \Delta \rho$. 
Project No 06-040: Flexible Conversion Ratio Fast Reactor Systems Evaluation

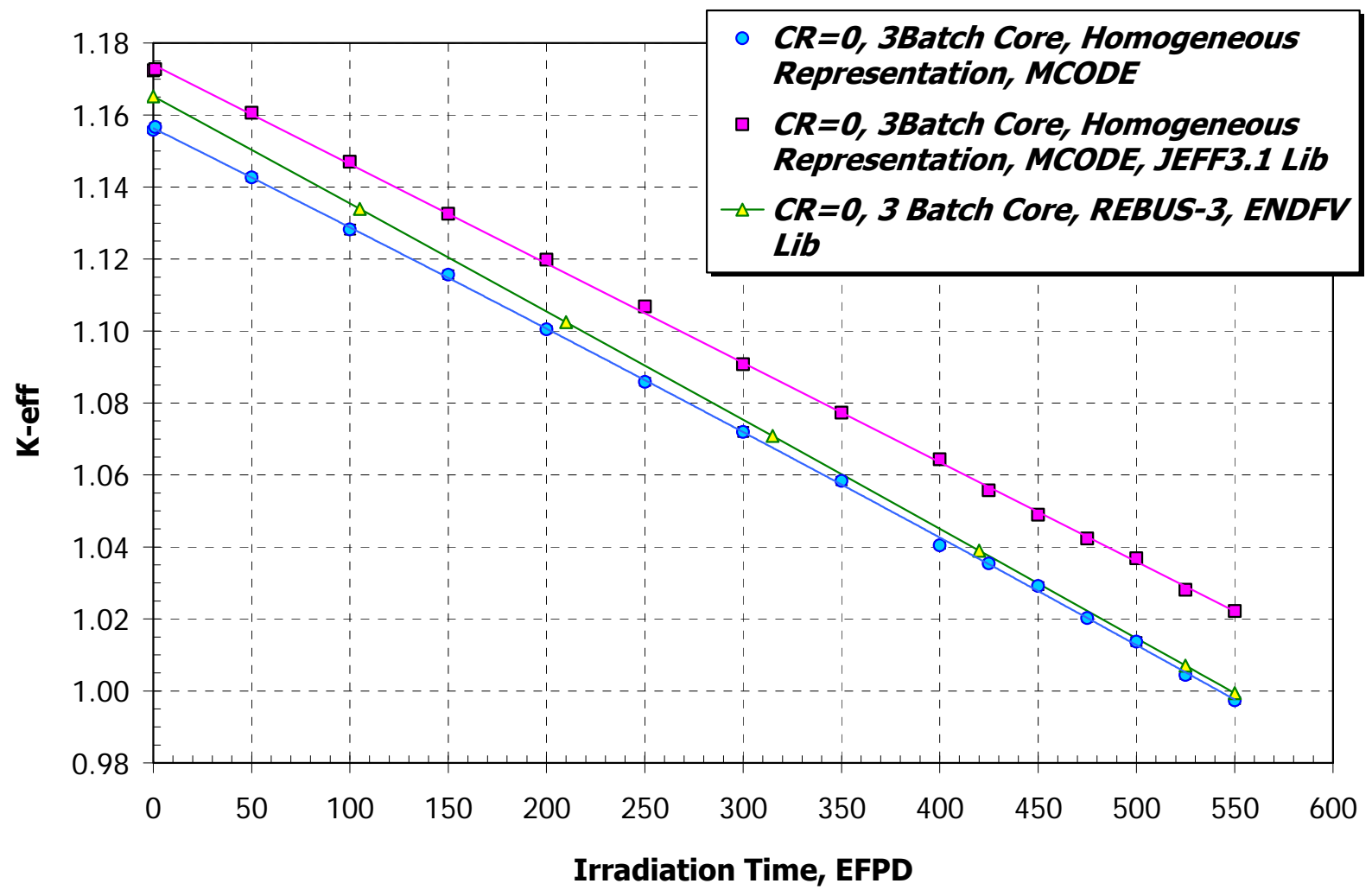

Figure 3A.2.3-1 Comparison of the k-effective evolution with time (EFPD)

The radial power peaking results (see Figures 3A.2.3-2 and 3A.2.3-3) obtained using REBUS/DIF3D are comparable to the results produced by MCNP/MCODE. The largest difference is $8.1 \%$ in the central assembly of the core. The power peaking becomes flatter with the burnup time.

\begin{tabular}{|c|c|c|c|c|c|c|c|c|c|c|c|}
\hline & 1 & 2 & 3 & 4 & 5 & 6 & 7 & 8 & 9 & 10 & 11 \\
\hline 1 & $4.8 \%$ & $4.7 \%$ & $3.0 \%$ & $4.5 \%$ & $1.5 \%$ & $3.3 \%$ & $0.7 \%$ & $1.1 \%$ & $-1.0 \%$ & $-3.1 \%$ & $1.0 \%$ \\
\hline 2 & & $5.8 \%$ & $3.4 \%$ & $4.5 \%$ & $2.2 \%$ & $3.4 \%$ & $1.1 \%$ & $1.1 \%$ & $-1.9 \%$ & $-4.3 \%$ & $0.0 \%$ \\
\hline 3 & & & $1.5 \%$ & $3.4 \%$ & $0.7 \%$ & $1.1 \%$ & $0.0 \%$ & $-0.9 \%$ & $-1.9 \%$ & $-4.4 \%$ & $1.1 \%$ \\
\hline 4 & & & & $4.5 \%$ & $2.2 \%$ & $2.2 \%$ & $0.0 \%$ & $-0.9 \%$ & $-3.0 \%$ & $-3.8 \%$ & $2.3 \%$ \\
\hline 5 & & & & & $1.1 \%$ & $-0.9 \%$ & $-1.8 \%$ & $-2.9 \%$ & $-2.2 \%$ & $-1.0 \%$ & \\
\hline 6 & & & & & & $-1.8 \%$ & $-2.8 \%$ & $-2.1 \%$ & $-1.9 \%$ & $4.7 \%$ & \\
\hline 7 & & & & & & & $-2.0 \%$ & $-1.9 \%$ & $3.3 \%$ & & \\
\hline 8 & & & & & & & & $3.3 \%$ & & & \\
\hline
\end{tabular}

Figure 3A.2.3-2 CR=0 Core, Radial Power Distribution Map at BOL (0 days) (percentage difference) 
Project No 06-040: Flexible Conversion Ratio Fast Reactor Systems Evaluation

\begin{tabular}{|c|c|c|c|c|c|c|c|c|c|c|c|}
\hline & 1 & 2 & 3 & 4 & 5 & 6 & 7 & 8 & 9 & 10 & 11 \\
\hline 1 & $-8.1 \%$ & $-6.6 \%$ & $-5.2 \%$ & $-3.7 \%$ & $-1.7 \%$ & $0.0 \%$ & $0.8 \%$ & $0.0 \%$ & $0.9 \%$ & $-2.0 \%$ & $0.0 \%$ \\
\hline 2 & & $-5.2 \%$ & $-5.1 \%$ & $-2.5 \%$ & $-1.2 \%$ & $0.0 \%$ & $0.0 \%$ & $1.1 \%$ & $0.0 \%$ & $2.4 \%$ & $-1.0 \%$ \\
\hline 3 & & & $-4.2 \%$ & $-1.2 \%$ & $0.8 \%$ & $1.2 \%$ & $1.9 \%$ & $1.8 \%$ & $0.9 \%$ & $0.8 \%$ & $-1.0 \%$ \\
\hline 4 & & & & $0.0 \%$ & $1.2 \%$ & $3.4 \%$ & $3.6 \%$ & $2.8 \%$ & $-1.0 \%$ & $0.0 \%$ & $-3.3 \%$ \\
\hline 5 & & & & & $2.3 \%$ & $3.6 \%$ & $2.7 \%$ & $0.9 \%$ & $-3.1 \%$ & $-2.9 \%$ & \\
\hline 6 & & & & & & $3.6 \%$ & $1.9 \%$ & $-1.0 \%$ & $-0.9 \%$ & $0.0 \%$ & \\
\hline 7 & & & & & & & $-1.0 \%$ & $0.0 \%$ & $1.0 \%$ & & \\
\hline 0 & & & & & & & & $2.0 \%$ & & & \\
\hline
\end{tabular}

Figure 4.2.3-3 CR=0 Core, Radial Power Distribution Map at EOL (525 days) (percentage difference)

\section{A.2.4 Conclusion}

The results obtained showed relatively good agreement between MCODE and REBUS-3. The two codes have better overall agreement for $C R=0$. This is not surprising since the $C R=0$ core is a pure burner with no conversion of more TRUs from uranium, hence for fixed core power, the amount of TRUs destroyed is proportional to number of fissions and residence time. In the unity conversion ratio case, k-effective calculated by DIF3D is slightly higher than the one computed by MCNP, which can be attributed partially to different cross section libraries used by $\mathrm{MC}^{2}-2$ and MCNP, but as discussed in section 3A.2.2, more investigation would be required to resolve this discrepancy. Overall, the results including burnup, power peaking over irradiation time, and criticality independently confirm the calculations done by MCODE.

\section{A.3 Decay Heat Calculation Methodology}

One of the key factors in assessing the performance of reactor systems during accidents is the amount of heat generated by the core after shutdown, as a result of fission product decay. In the safety analysis of LWRs, the decay heat power as a function of time elapsed after shutdown is calculated using the ANS Standard [ANS, 2005] procedure developed specifically for this purpose. However, the use of the ANS Standard procedure for the safety analysis of advanced reactors, in general, and those studied in this project in particular, may introduce significant uncertainty into the system performance during accidents for a number of reasons.

The ANS Standard considers only 4 fissionable nuclides (U235, U238, Pu239, and Pu241). Except for U238, the fissions are assumed to be induced by thermal neutrons. In the advanced reactors, however, actinides (other than the above four) may contribute a significant fraction to the total power and, thus, generate a non-negligible fraction of fission products. Each actinide has a unique distribution of fission product yields and the value of energy released per fission.

Moreover, the fission yield distribution for any actinide depends on the energy of the fissioninducing neutrons. Therefore, the concentration and variety of fission products can be different 
for the reactor systems operated at the same nominal power but with different fuel composition and neutron energy spectrum.

In order to estimate the extent of this difference, we performed a series of detailed burnup calculations, which included accurate tracking of densities for 1743 isotopes originating from fissions of 30 fissionable actinides, for all the reactor concepts studied in this project. The calculations were performed with the BGCore reactor analysis system [Fridman et al., 2008], which couples the MCNP code with fuel depletion and decay routines. The cross-sections, decay constants, decay energies, and fission yield data for all 1743 isotopes included in the analysis were based on the most recent JEFF3.1 data library.

In the first stage of the analysis, the decay heat power following reactor shutdown was calculated for a standard PWR unit cell with conventional $\mathrm{UO}_{2}$ fuel enriched to $4.5 \%$ using the BGCore system. BGCore was used for both fuel burnup and subsequent decay calculations, so that the decay heat power was obtained directly from the code. In addition, the relative contribution of different fissionable nuclides to total power during fuel burnup was also calculated with BGCore in the same burnup calculation (Table 3A.3-1). However, this data was used as an input for the Standard ANS decay heat calculation procedure. Then, the decay heat calculated directly with BGCore was compared with that calculated with the ANS standard procedure.

Table 3A.3-1. Initial data for decay power calculation with ANS Standard methodology

\begin{tabular}{|c|c|c|c|c|}
\hline & \multicolumn{4}{|c|}{ Fractional Fissions } \\
\hline Irradiation time, days & U235 & U238 & Pu239 & Pu241 \\
\hline 0 & 0.94 & 0.06 & 0.00 & 0.00 \\
\hline 100 & 0.89 & 0.06 & 0.05 & 0.00 \\
\hline 200 & 0.81 & 0.06 & 0.12 & 0.00 \\
\hline 300 & 0.75 & 0.07 & 0.18 & 0.01 \\
\hline 400 & 0.69 & 0.07 & 0.22 & 0.02 \\
\hline 500 & 0.64 & 0.07 & 0.26 & 0.03 \\
\hline 600 & 0.59 & 0.08 & 0.30 & 0.04 \\
\hline 700 & 0.55 & 0.08 & 0.33 & 0.05 \\
\hline 800 & 0.51 & 0.08 & 0.36 & 0.06 \\
\hline 900 & 0.47 & 0.08 & 0.38 & 0.07 \\
\hline 1000 & 0.43 & 0.08 & 0.40 & 0.08 \\
\hline 1100 & 0.40 & 0.09 & 0.42 & 0.10 \\
\hline 1200 & 0.36 & 0.09 & 0.44 & 0.11 \\
\hline 1300 & 0.33 & 0.09 & 0.46 & 0.12 \\
\hline & & & & \\
\hline Q value, MeV/fission & 202.2 & 205.5 & 211.2 & 213.7 \\
\hline
\end{tabular}


The results obtained with BGCore agreed with ANS Standard predictions within $5 \%$ up to $10^{8}$ seconds after shutdown (Figure 3A.3-1), which is well within the uncertainty band of the ANS Standard.

Figure 3A.3-2 shows integrated decay heat power calculated for a $3400 \mathrm{MWt}$ PWR reactor core with BGCore and using ANS Standard data. Here, again, the obtained agreement between the results of the two codes is excellent proving that BGCore can be reliably used for decay heat calculations.

Once the capability of BGCore code to predict the decay heat after reactor shutdown was verified, the code was used to calculate the decay heat power of all the reactor designs studied in this project.

The performed calculations clearly demonstrate the importance of using decay heat data derived from an appropriate reactor model, which takes into account fuel composition and neutron spectrum. The use of the ANS Standard LWR decay heat data for the safety analysis of advanced reactors may result in poor design choices, either compromising the reactor safety or unnecessary overdesign of decay heat removal systems, and associated cost increase.

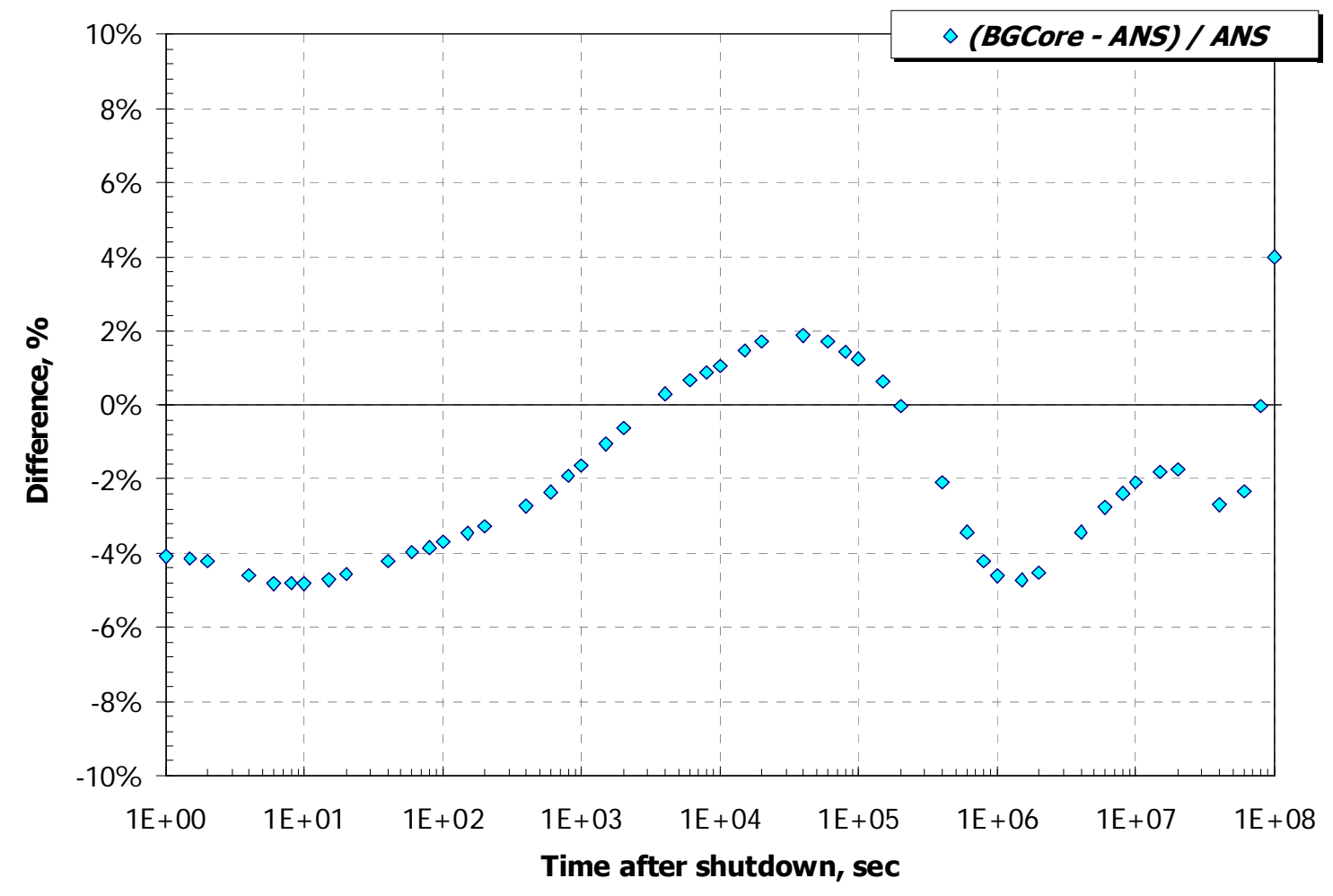

Figure 3A.3-1. Percent difference between BGCore and ANS Standard decay heat calculation, PWR unit cell case 
Project No 06-040: Flexible Conversion Ratio Fast Reactor Systems Evaluation

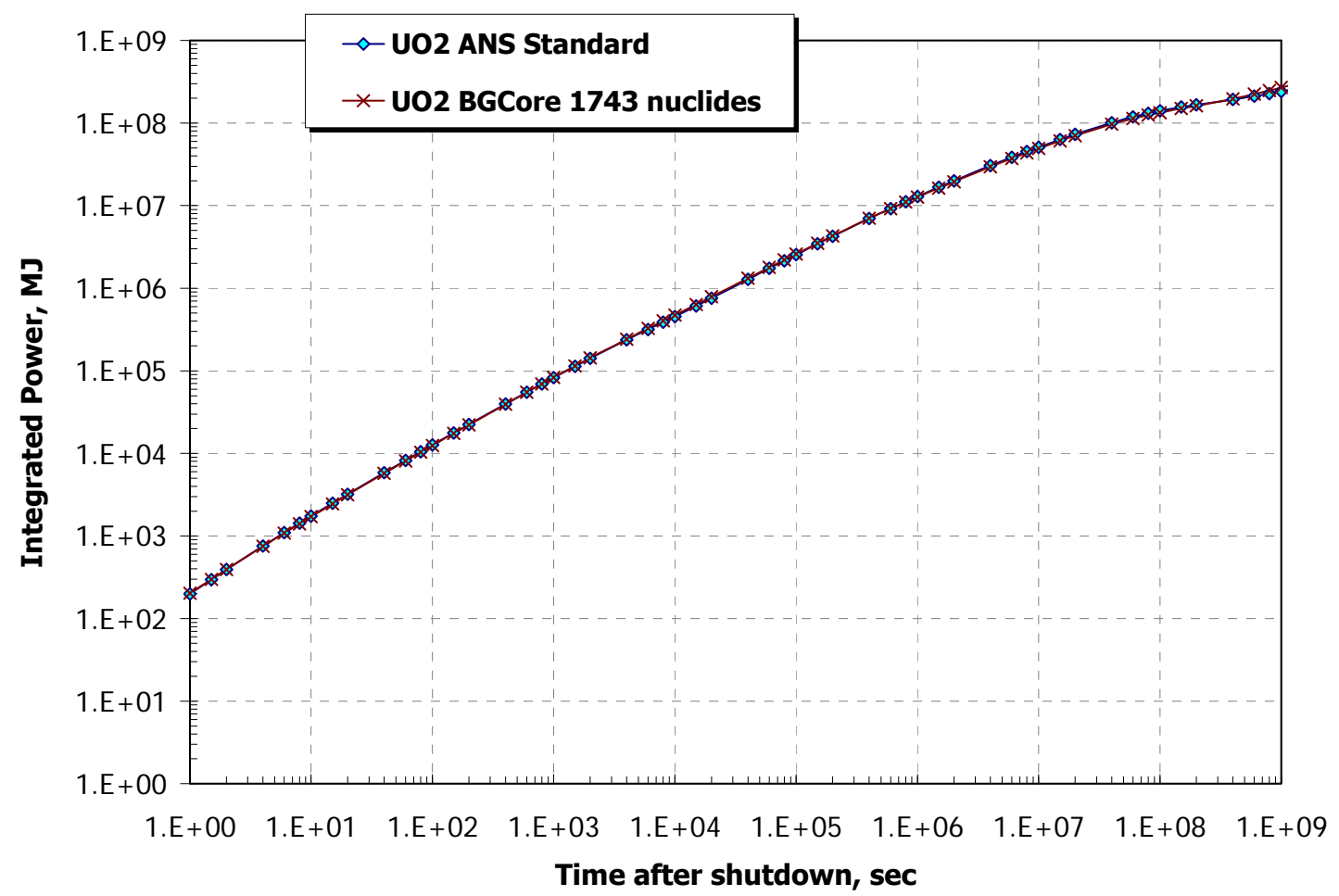

Figure 3A.3-2. Integrated decay power for 3400MWt PWR core

\section{A.4 Quasi-Static Analysis of Reactivity Coefficients}

The quasi static approach to reactor safety was originally developed at Argonne National Laboratory in the framework of Integral Fast Reactor development [Wade and Chang, 1988]. The method suggests that the reactor can be considered passively safe if, as a result of any external reactivity insertion due to an accident, this reactivity will be compensated by a combination of the inherent reactivity feedbacks without crossing the safety limits on any of the core operating parameters.

Such a reactivity balance equation can be expressed via lumped reactivity feedback coefficients $\mathrm{A}, \mathrm{B}$, and $\mathrm{C}$ :

$$
0=\Delta \rho_{\text {ext }}+\delta T_{i n} C+\left(\frac{P}{F}-1\right) B+(P-1) A
$$

Where $\Delta \rho_{\text {ext }}$ is the external reactivity insertion, $\mathrm{P}$ is the power normalized to its nominal value, $\mathrm{F}$ is the coolant flow rate normalized to its nominal value, and $\delta T_{\text {in }}$ is the change from nominal coolant inlet temperature.

As can be observed from the above reactivity balance, the reactivity coefficients $\mathrm{A}, \mathrm{B}$, and $\mathrm{C}$ have the following physical interpretation:

A $[\phi]$ is the net core power feedback coefficient;

$\mathrm{B}[\phi]$ is the power to flow ratio reactivity coefficient;

$\mathrm{C}[\phi / \mathrm{K}]$ is the core inlet temperature reactivity coefficient. 
The coefficients are calculated as follows:

$$
\begin{aligned}
& A=\left(\alpha_{D}+\alpha_{e}\right) \Delta T_{f} \\
& B=\left(\alpha_{D}+\alpha_{e}+\alpha_{C o}+2 \alpha_{R D}+2 \alpha_{R}\right) \frac{\Delta T_{c}}{2} \\
& C=\alpha_{D}+\alpha_{e}+\alpha_{C o}+\alpha_{R}
\end{aligned}
$$

Where $\Delta T_{f}$ is the temperature difference between the fuel and coolant $[\mathrm{K}]$,

$\Delta T_{c}$ is the temperature rise across the core at steady state conditions $[\mathrm{K}]$,

$\alpha_{D}$ is the reactivity coefficient due to the Doppler effect $[\phi / \mathrm{K}]$,

$\alpha_{e} \quad$ is the fuel thermal expansion reactivity coefficient $[\varnothing / \mathrm{K}]$,

$\alpha_{C o}$ is the coolant temperature coefficient $[\phi / \mathrm{K}]$,

$\alpha_{R D}$ is the control rod drive line thermal expansion coefficient $[\phi / \mathrm{K}]$,

$\alpha_{R} \quad$ is the radial core thermal expansion coefficient $[\phi / \mathrm{K}]$.

For liquid metal cooled reactors, three accident scenarios define the design envelope. These are the Unprotected Loss of Flow, Unprotected Loss of Ultimate Heat Sink, and Unprotected Control Rod Withdrawal accidents. The limiting conditions are coolant freezing at the core inlet and cladding failure limit at the core outlet.

It was shown [Wade and Chang, 1988] that in the above three accident scenarios, the asymptotic coolant inlet and outlet temperatures can be expressed through a combination of the above lumped reactivity coefficients using the reactivity balance equation. As a result, for the leadcooled design developed in this project, the following three inequalities have to be satisfied for the system to stay within the safety envelope* .

$$
\begin{aligned}
& \frac{A}{B} \leq 1.06(1.59) \\
& 1 \leq \frac{C \Delta T_{c}}{B} \leq 1.99(2.39) \\
& \frac{\Delta \rho_{T O P}}{|B|} \leq 1.06(1.59)
\end{aligned}
$$

The first limit numbers were obtained for a margin factor of $\gamma=2 / 3$ applied to the maximum asymptotic coolant outlet temperature for conservatism and to accommodate local effects from peaking. The limits in parentheses were calculated for the margin factor $\gamma=1$ and would be characteristic for uniform core radial power peaking. Therefore, striving for a small radial peaking is important, as it increases the acceptability range of the reactivity coefficient ratios. $\Delta \rho_{T O P}$ is the reactivity introduced in a control rod inadvertent withdrawal accident. The limits on

\footnotetext{
* The limits depend on nominal core temperature rise and the cladding limits and coolant melting point. The derivation for lead-cooled reactors was performed by Romano et al. [2004]. The inequalities below are slightly different than in Romano et al. because of slight differences in core temperature rise.
} 
the reactivity coefficient ratios for all the designs analyzed in this project are summarized in Table 3A.4-1 together with the relevant core operating parameters used for the derivation of this limits. The coolant boiling limit is less restrictive than the cladding failure limit and therefore is not considered.

Table 3A.4-1. Core Operating Parameter Limits

\begin{tabular}{|l|c|c|c|}
\hline Parameter & $\mathrm{Pb}$ & Salt & $\mathrm{Na}$ \\
\hline Coolant Inlet Temperature, ${ }^{\circ} \mathrm{C}$ & 479 & 496 & 352 \\
\hline Coolant Outlet temperature, ${ }^{\circ} \mathrm{C}$ & 574 & 580 & 502 \\
\hline Core Coolant Temperature Rise, $\Delta \mathrm{T}_{\mathrm{c}},{ }^{\circ} \mathrm{C}$ & 95 & 84 & 150 \\
\hline Coolant Freezing Point, ${ }^{\circ} \mathrm{C}$ & 327 & 396 & 98 \\
\hline Margin to Freezing, ${ }^{\circ} \mathrm{C}$ & 152 & 100 & 254 \\
\hline Cladding Failure Limit, ${ }^{\circ} \mathrm{C}$ & 725 & 725 & 725 \\
\hline Margin to Cladding Failure, ${ }^{\circ} \mathrm{C}$ & 151 & 145 & 223 \\
\hline A/B limits & $\mathrm{x}<1.06(1.59)$ & $\mathrm{x}<1.15(1.73)$ & $\mathrm{x}<0.99(1.49)$ \\
\hline $\mathrm{C} \Delta \mathrm{T}_{\mathrm{c}} / \mathrm{B}$ limits & $1<\mathrm{x}<1.99(2.39)$ & $1<\mathrm{x}<2.36(2.94)$ & $1<\mathrm{x}<1.90(2.25)$ \\
\hline$\Delta \rho \mathrm{TOP} / \mathrm{B}$ limits & $\mathrm{x}<1.06(1.59)$ & $\mathrm{x}<1.15(1.73)$ & $\mathrm{x}<0.99(1.49)$ \\
\hline
\end{tabular}

All the coefficients were calculated using a MCNP4C model of the core where each pin was modeled in full detail.

Doppler coefficient was evaluated by performing a set of core criticality calculations at 4 different fuel temperatures and fitting a polynomial function to the results of these calculations. An example of the core reactivity versus fuel temperature data used for the calculation of Doppler Coefficient is presented in Figure 3A.4-1.

Over 60 million neutron histories were typically run in the MCNP calculations in order to obtain reactivity coefficients with sufficient accuracy.

To calculate the thermal expansion effect, all dimensions and concentrations throughout the core were kept fixed, except for the fuel, which was assumed to elongate its height into the upper gas plenum and increase its diameter. Fuel density change leads to changes of number densities. To eliminate the effects of fuel temperature variation on other reactivity-related aspects, such as the Doppler coefficient and fuel scattering properties, the fuel temperature was held constant in all calculations. Thus, the analysis yields only the effect of thermal expansion of the fuel. Fuel was expanded between fuel temperatures of $300 \mathrm{~K}$ and $900 \mathrm{~K}$. 
Project No 06-040: Flexible Conversion Ratio Fast Reactor Systems Evaluation

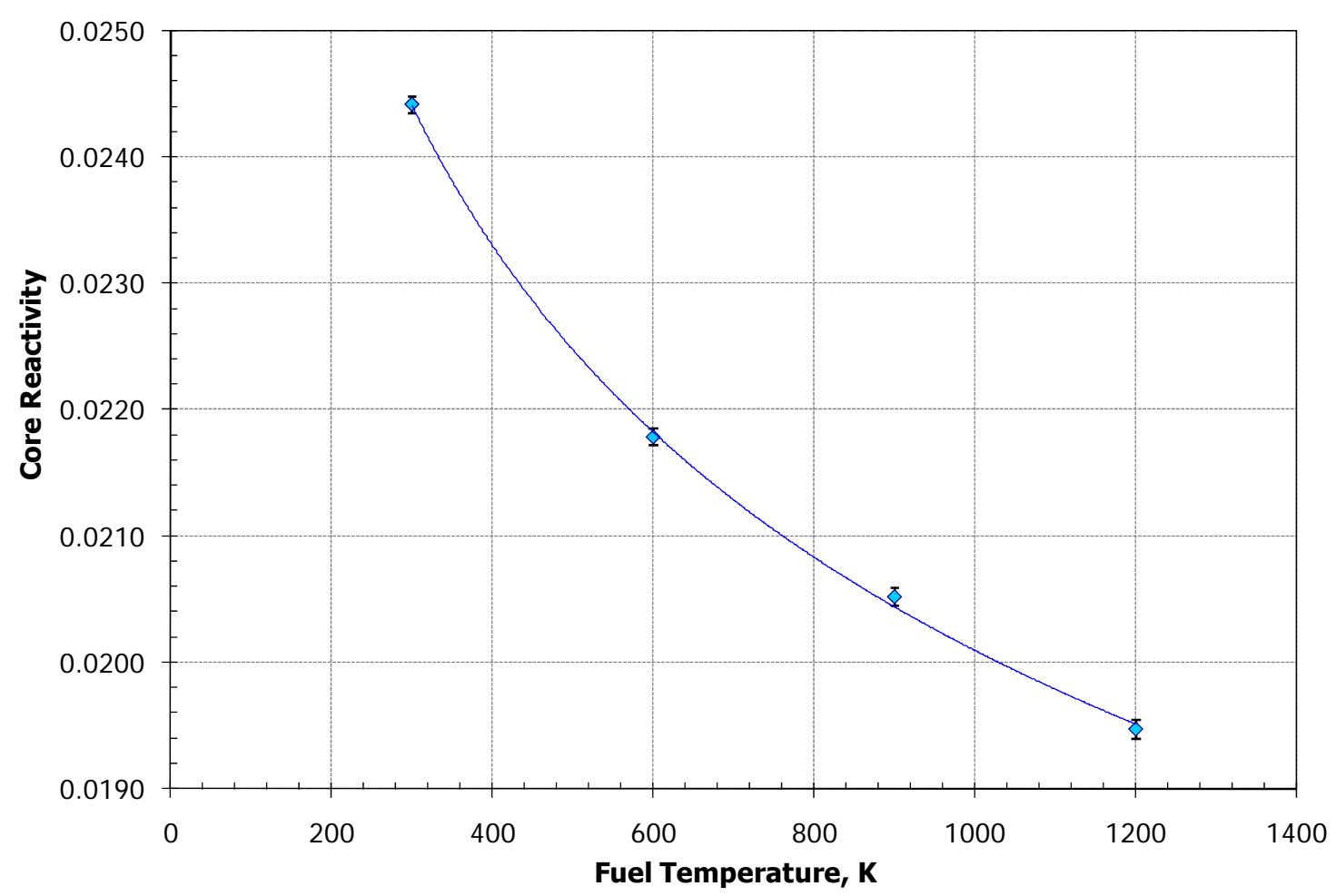

Figure 3A.4-1. $\mathrm{CR}=1$ Lead-cooled core reactivity versus fuel temperature

The above approach is applicable to fresh and low burnup fuel because the calculations assume an open gap between the fuel and the cladding, allowing free movement of the fuel in both the radial and upward axial directions. The $\mathrm{Pb}-\mathrm{Bi}-\mathrm{Sn}$ bond is assumed to be squeezed up into the gas plenum upon fuel expansion. For metallic fuel, after 1 or $2 \%$ burnup the metal becomes bound to clad and axial expansion is controlled by coolant temperature, not fuel temperature, thus the thermal expansion coefficient cannot be counted as part of fuel temperature feedback and is taken as zero. It will also be responsible for a reactivity decrease from core heat up, but on a different time scale.

The control rod drive thermal expansion reactivity coefficient was calculated from the reactivity difference between the reference core and the core after expansion of CRD drives. The calculations assumed that $\mathrm{CRD}$ drives are heated by core outlet temperature along the entire length submerged in the lead pool. The temperature difference used to calculate the two reactivity values was $255^{\circ} \mathrm{C}$. The calculated value of the control rod drive thermal expansion reactivity coefficient is practically zero because of the unique double-entry control rod design, where half of the control rods are inserted into the core and half are being pushed out of the core upon CRD driveline expansion, thus canceling this effect.

Core radial expansion coefficients depend strongly on the core design and are typically negative, but can also be positive if the design is not carried out properly. To achieve negative feedback, a limited-free-bow core restraint is used. It provides constraints to limit the motion of the active core zones of fuel assemblies to outward displacement as the core heats up from increased power. The constraints necessitate minimum radial gap clearance between assemblies, but the 
gap must also provide sufficient space to accommodate creep, both thermal and irradiation induced, swelling effects and adequate tolerance for easy refueling during shutdown. This is achieved through the employment of above-core load pads (ACLP) - a continuous network of contacting load pads - above the core, which allows radial movement of fuel assemblies in the above-core plane up to the ACLP restraint ring. Similarly, the top load pads (TLP) in the plane above the gas plenum of the outer fuel assemblies are restrained from further radial expansion by the TLP restraint ring.

Because the exact calculation of core radial expansion coefficient is very complex, a simplified approach using the MCNP4C code was used. The calculations assumed that the core design employs a limited-free-bow core restraint to allow well-defined core expansion resulting in reactivity reduction from power/flow increase. The core radial expansion coefficient is calculated by comparing the reactivity of the radially expanded core with that of the reference core at nominal operating conditions. The radially expanded core and the core radial expansion coefficient were modeled as follows:

1. Uniform expansion of the whole core is assumed, i.e., the core support plate, the ACLP and TLP are assumed to be subjected to the same temperature change, resulting in an increase of rod pitch, which is identical at each core level. Hence, all pins remain parallel, but their pitch is opened.

2. A thermal expansion coefficient of $2 \times 10^{-5}{ }^{\circ} \mathrm{C}^{-1}$, typical of HT-9 steel at temperatures representative of the ABR core outlet, is used for all structural materials (assumed constant). The expanded dimensions are calculated for a sufficiently large temperature difference of $210^{\circ} \mathrm{C}$. Note that except for changes in radial dimensions, all other parameters in the MCNP input had their nominal values and remain identical.

3. The total value of the uniform core radial expansion coefficient is obtained by subtracting the reactivity of the reference core from that of the expanded core and dividing by the temperature difference of $210^{\circ} \mathrm{C}$ to obtain the linearized value per ${ }^{\circ} \mathrm{C}$.

4. The value obtained from step 4 is divided by 2 to obtain the radial expansion coefficient controlling reactivity changes in the early phases of the transient, i.e., only the upper part of the core is assumed to expand early in the transient.

This approach was benchmarked by Hejzlar against the reported value of core radial expansion coefficient of the sodium-cooled burner ALMR core design [Oda, 1993] and showed very good agreement [MacDonald et al.,. 2002].

The effective delayed neutron fraction was also calculated using the MCNP4C model of the full core using the expression

$$
\beta_{\text {eff }}=\frac{k-k_{p}}{k}
$$

where $\mathrm{k}$ is the eigenvalue obtained with all neutrons, i.e., both prompt and delayed, and the $k_{p}$ is the eigenvalue computed using prompt neutrons only. Note that MCNP4C accounts for the different spectra of delayed and prompt neutrons. For consistency, identical libraries accounting for unresolved resonances were used and the effect of delayed neutrons in prompt criticality 
calculations was turned off through the TOTNU card. These calculations did not incorporate the effect of photoneutrons produced outside the fuel. Some of these photoneutrons are produced by delayed gamma rays, contributing to the delayed neutron population. Also, some delayed neutrons will be multiplied by $(n, 2 n)$ and $(n, 3 n)$ reactions in the large mass of coolant. However, it is expected that the contribution from photoproduction and $(n, x n)$ reactions to the total effective yield will be small.

\section{A.4 Analysis of Lithium Expansion Modules}

The Lithium thermal Expansion Module (LEM) is a device developed for passive reactivity control of fast spectrum reactor cores [Kambe et al., 1998]. In this study, the use of LEMs was considered to compensate for the relatively large positive Coolant Temperature feedback Coefficient in salt-cooled Flexible Conversion ratio core designs.

LEM consists of a capillary tube inserted into the core and a Li reservoir located above the core (Figure 3A.4-1) in the gas plenum region. Under nominal operating conditions, no Li is present in the core region and the capillary tube is filled with inert gas. The liquid lithium enriched to $90 \%$ in the neutron absorbing Li-6 isotope is fully contained within the reservoir by the balance of buoyancy, surface tension, and seismic acceleration forces. As the coolant temperature rises above its nominal value, the reservoir heats up and Li thermal expansion pushes the gas-liquid interface down into the core region, inserting negative reactivity.

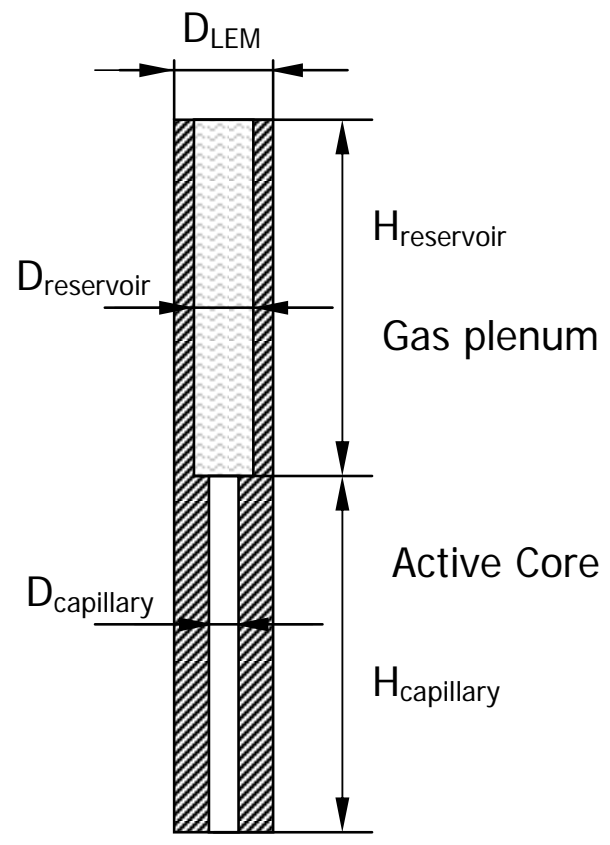

Figure 3A.4-1. Schematic view of Lithium Thermal Expansion Module

The choice of the number of LEMs per fuel assembly and LEM dimensions was guided by the following logic. 
- The capillary diameter must be smaller than the critical value determined by the balance of buoyancy, surface tension, and seismic acceleration forces [Kambe et al., 1998].

$$
\frac{1}{12} \pi D^{3} \rho g n=\pi D \sigma
$$

where $D$ is the critical capillary diameter, $\sigma$ is Li surface tension coefficient $(\mathrm{N} / \mathrm{m}), \rho-\mathrm{Li}$ density, $g$ is acceleration of gravity, and $n$ - anticipated acceleration due to a seismic event in units of $g$. The critical capillary diameter can be then expressed as:

$$
D_{c r i t}=\sqrt{\frac{12 \sigma}{\rho g n}}
$$

For the applicable $\mathrm{Li}$ temperature range and $\mathrm{n}=1.3$ [Kambe et al., 1998], the critical capillary diameter is on the order of $20 \mathrm{~mm}$.

- Average negative reactivity insertion by Li thermal expansion per degree increase in the core average coolant temperature should be sufficient to satisfy the core self controllability criteria.

- A change of $100^{\circ} \mathrm{C}$ in coolant core outlet temperature should provide Li insertion depth $3 / 4$ of the "full stroke". Such a change in coolant exit temperature leaves about $50^{\circ} \mathrm{C}$ margin to the cladding failure limit. A Li level drop on the order of three quarters of the core height accounts for nearly all of the negative reactivity insertion because of the low differential Li reactivity worth near the core boundaries.

- The reservoir height should not extend beyond the gas plenum height of the neighboring fuel pins into the coolant chimney to reduce the coolant to Li heat transfer time constant and simplify the assembly mechanical design.

- The LEM outer diameter should preferably be identical to that of the fuel pins, again, to simplify the fuel assembly design. However, larger reservoir diameter (up to the value of unit cell pitch) allows increasing the capillary diameter and reducing the number of LEMs in the core. Although technologically feasible in principle, larger diameter would likely necessitate the use of grid spacers rather than wire wraps and somewhat complicate the assembly design. In addition, concentration of $\mathrm{Li}$ in fewer LEMs would reduce the heat transfer area and increase the response time to coolant temperature increases.

For a LEM with the reservoir diameter equal to that of a fuel pin, preserving the Li mass within the module, the $\mathrm{Li}$ insertion depth into the core, $h$, can be expressed as:

$h=\frac{\rho_{o}-\rho}{\rho} \times \frac{H_{\text {reservoir }} \times R_{\text {reservoir }}^{2}}{R_{\text {capillary }}^{2}}$

where, $\rho_{o}$ and $\rho$ are Li densities at the nominal and transient coolant temperatures respectively. 


\section{References for Appendix 3A}

ANS, 2005. Decay Heat Power in Light Water Reactors. ANSI/ANS-5.1-2005.

Briesmeister, J. F., "MCNP - A General Monte Carlo N-Particle Transport Code, Version 4C", LA-13709M, Los Alamos National Laboratory, 2000.

Croff, A. G., "ORIGEN2: A Versatile Computer Code for Calculating the Nuclide Compositions and Characteristics of Nuclear Materials," Nucl. Techn. 62, 335-352, 1983.

Fridman, E., Shwageraus, E., Galperin, A., "Efficient generation of 1-g cross-sections for coupled Monte Carlo depletion calculations," Nucl. Sci. Eng. 159, 37-47, 2007.

Haeck W., Verboomen B., “An Optimum Approach to Monte Carlo Burnup," Nucl. Sci. Eng., 156, 180-196, (2007).

Koning, A., Forrest, R., Kellett, M., Mills, R., Henrikson, H., Rugama, Y., "The JEFF-3.1 Nuclear Data Library. JEFF Report 21," OECD/NEA, Paris, France, 2006.

Segev, M., “Applied Resonance Equivalence,” Nucl. Sci. Eng., 111, 271, 1992.

Shwageraus, E., Hejzlar, P., Driscoll, M.J., "Nuclear Design Feasibility of a Lead-cooled Fast Reactor with Flexible Conversion Ratio," ANS/ENS international Meeting, Washington D.C., 2007.

Xu, Z., Hejzlar, P., Driscoll, M.J., Kazimi, M.S., “An Improved MCNP-ORIGEN Depletion Program (MCODE) and its Verification for High-Burnup Applications," PHYSOR-2002, Seoul, Korea, (2002).

Romano A., Hejzlar P., and Todreas N. E., "Fertile-Free Fast Lead-Cooled Incinerators for Efficient Actinide Burning,” Nuclear Technology, 147, 3, pp. 368-387, 2004.

Kambe, M. and Uotani, M. "Design and development of fast breeder reactor passive reactivity control systems: LEM and LIM,” Nucl. Technol., 122, 179, May 1998.

Wade, D.C., Chang, Y.I., "The Integral Fast Reactor Concept: Physics of Operation and Safety", Nuclear Science and Engineering, 100, 507-524, 1988.

Fridman E., Shwageraus E., Galperin A., Implementation of multi-group cross-section methodology in BGCore MC-depletion code," Physor-2008, Interlaken, Switzerland, September 2008.

Toppel B.J., "A User's Guide for the REBUS-3 Fuel Cycle Analysis Capability", Applied Physics Division, ANL83-2, Argonne National Laboratory, March 1983.

Derstine K.L., "DIF3D: A code to Solve One-, Two-, and Three-Dimensional Finite-Difference Diffusion Theory Problems", Applied Physics Division, ANL82-64, Argonne National Laboratory, April 1984. 
Henryson II H., Toppel B.J., and Stenberg C. G., "MC2-2: A Code to Calculate Fast Neutron Spectra and Multigroup Cross Sections", Applied Physics Division, ANL81-44, Argonne National Laboratory, June 1976.

Oda, R. T., Editor, "ALMR Summary Plant Design Description," GE Nuclear Energy, GEFR00909, March 1993.

MacDonald P. et al., "Design of an Actinide Burning, Lead or Lead-Bismuth Cooled Reactor That produces Low Cost Electricity," INEEL/EXT-02-01249, MIT-ANP-PR-092, Idaho National Engineering and Environmental Laboratory, FY-02 Annual Report, (Oct. 2002). 


\section{Appendix 3B Thermal Hydraulics Analysis Tools and Methods}

\section{B.1 SUBCHAN - A Simplified Model for Thermal Hydraulic Analysis of Lead-cooled Reactor Core}

To evaluate thermal-hydraulic performance of lead-cooled cores, a simple model has been developed. The goal of the model is to determine key thermal hydraulic parameters of interest to identify if sufficient margins to the limits are maintained. The parameters of interest include core pressure drop, flow rate distribution among assemblies and subchannels, cladding and fuel temperature distribution, and lead velocities. The limits to be satisfied are

- Peak cladding temperature,

- Peak fuel temperature, and

- Maximum lead velocity to prevent erosion of protective oxide layer.

Because the detailed transient and steady state analyses will be performed using the more robust code RELAP5-3D, the purpose of this model is to provide, rapidly, preliminary steady state evaluation of the feasibility of the design, rather than best estimate calculations, as for example in the ANL SASS computer code for sodium-cooled reactors [ANL, 1996]. Therefore, the model adopts a number of simplifying assumptions. These assumptions are summarized as follows:

- Steady state

- The lead flow is considered one dimensional, fully developed

- Each channel is divided into a number of axial nodes with uniform heat generation within the node

- Lead properties are temperature dependent and are evaluated at operating pressure (local pressure variation due to pressure losses is not accounted for in the property equations)

- The channels can be individual or lumped involving more subchannels and fuel rods and can be of arbitrary shape

- Direct gamma and neutron heating of coolant is neglected and all heat is conservatively assumed to be deposited in the fuel

- Turbulent mixing and lateral conduction between adjacent subchannels is neglected.

Because the last assumption is an atypical one for subchannels of pin-type cores, it deserves discussion and justification. Typically, all subchannel codes for PWR and BWR cores model turbulent mixing because it significantly affects CHF margins. This is because critical heat flux is strongly dependent on quality, which is significantly affected by local enthalpy which in turn is affected by turbulent mixing. Lateral conduction is neglected in LWR thermal hydraulic analysis because the conductivity of water coolant is small and conduction impact on the overall results is negligible. On the other hand, thermal analyses of sodium-cooled reactors typically 
incorporate the effect of lateral conduction [ANL, 1996], since sodium has very high thermal conductivity and the conduction effect is not negligible.

The lead-cooled core is in between the LWR and sodium-cooled cores. First, the high boiling point $\left(\sim 1700^{\circ} \mathrm{C}\right)$ practically excludes existence of two-phase flow in the core and mixing in one phase flow is small. Secondly, critical heat flux is practically not an issue in liquid metal heated flows, hence the effect of mixing on cladding temperature is small, since bulk temperature changes from mixing are small and will not affect cladding temperature significantly. Further, the heat transfer coefficient is almost independent of coolant temperature changes (only very weak dependence from lead property variations). Thirdly, the thermal conductivity of lead is significantly smaller than that of sodium $(14 \mathrm{~W} / \mathrm{m}-\mathrm{K}$ versus $62 \mathrm{~W} / \mathrm{m}-\mathrm{K})$, reducing the conduction contribution. Fourthly, intra-assembly peaking is small and assemblies are ducted, hence bulk temperature differences between subchannels will be small. As a result, the effect of turbulent mixing and lateral conduction is expected to be very small and can be neglected in scoping study analyses. Moreover, analyses without inclusion of mixing and lateral conduction will be conservative because they will yield larger peak cladding and fuel temperatures.

To justify this assumption, the contribution of turbulence mixing and lateral conduction to heat balance along the $1 \mathrm{~m}$-long section of a sub-channel can be derived using typical lead-cooled core parameters as follows:

1. Turbulent thermal conductivity, $\mathrm{k}_{\mathrm{t}}$, can be calculated as $k_{t}=\beta G c_{p} L$, where $\beta$ is mixing coefficient, $\mathrm{G}$ is mass flux in axial direction, $\mathrm{C}_{\mathrm{p}}$ is specific heat capacity of lead (146 $\mathrm{J} / \mathrm{kg}-\mathrm{K}$ for core-average temperature) and $\mathrm{L}$ is the effective conduction length between two adjacent subchannels (taken as pitch, $\mathrm{L}=9.776 \mathrm{E}-3 \mathrm{~m}$ ). Core average mass flux for the $2 \mathrm{~m} / \mathrm{s}$ velocity limit is $\mathrm{G}=2070 \mathrm{~kg} / \mathrm{m}^{2}$-s. Taking $\beta$ as the value of 0.02 suggested by Cheng and Hwang based on their CFD calculations [Cheng and Hwang, 2005], one can calculate turbulent thermal conductivity to yield the value of $59 \mathrm{~W} / \mathrm{m}-\mathrm{K}$. This agrees with the results of Cheng and Hwang [2005], who report the value to vary along the channel between 5 and 60 with average value of about 40 .

2. Thermal conductivity of lead for the pertinent temperature range is about $14 \mathrm{~W} / \mathrm{m}-\mathrm{K}$, which is more than 3 times less than the turbulent conductivity. Thus, conduction importance is significantly smaller than that of turbulent mixing.

3. Using the flow area of four gaps per meter channel length,

$$
\mathrm{A}_{\text {gaps }}=4 *(\mathrm{P}-\mathrm{D})=4(9.776-7.52) * 1 \mathrm{E}-3=9.024 \mathrm{E}-3 \mathrm{~m}^{2} / \mathrm{m}
$$

and a conservatively large temperature difference between adjacent sub-channels of $10^{\circ} \mathrm{C}$, one can calculate total (conduction plus turbulent mixing) lateral linear heat rate from a sub-channel at higher temperature to 4 adjacent sub-channels (all assumed at $10^{\circ} \mathrm{C}$ lower temperature) to be

$$
\mathrm{q}_{\text {lat }}{ }^{\prime}=(59+14) / 9.776 \mathrm{e}-3 * 9.024 \mathrm{e}-3 * 10=673 \mathrm{~W} / \mathrm{m} \text {. }
$$

4. Core-average linear heat rate generated in a pin and which is carried away by axial flow is $11,000 \mathrm{~W} / \mathrm{m}$. Therefore, the turbulent mixing and conduction heat transport is only $6 \%$. Such a small value can be safely neglected for the purposes of this study and will not have any significant impact on cladding or fuel peak temperatures. 
Because turbulent mixing and lateral conduction are not effective enough to appreciably affect directly enthalpy distribution, core analysis can be simplified by treating the sub-channels (or whole assemblies) as parallel non-communicating channels.

\section{B.1.1 Flow Distribution among Parallel Non-communicating Channels}

Because various core geometries may need to be explored, it is desirable to make the model general enough to handle various geometries and number of channels. Therefore, it is assumed that the core consists of $\mathrm{N}$ types of channels, where each channel type can represent differences in geometry and/or heat flux profiles and can contain an arbitrary number of channels of the same geometry.

The pressure drop is calculated by applying coupled mass and momentum conservation equations to every channel, and the equality condition for total pressure drop of every parallel channel. Mass conservation gives the condition

$$
\dot{m}=\sum_{i=1}^{N} \dot{m}_{i}
$$

where $\dot{m}$ is the total mass flow rate per system ${ }^{*}$ and $\mathrm{N}$ is the number of coolant channel types. Note that $\dot{\mathrm{m}}_{\mathrm{i}}$ is the total flow rate through all coolant channels of the same type, $i$. Since the fluid properties along the channels vary, all channels must be axially divided into NZ nodes. Separating the friction and form pressure losses, the total pressure drop for the i-th type channel can be written as

$$
\Delta p_{i}=\Delta p_{f, i}+\Delta p_{f o r m, i}+\Delta p_{a c c, i}+\Delta p_{g r a v, i}
$$

with the friction pressure losses

$$
\Delta p_{f, i}=\dot{m}_{i}^{2} \sum_{j=1}^{N Z} f_{i}\left(\dot{m}_{i}\right) \frac{\Delta z_{j}}{D_{e, i}} \frac{1_{j}}{2 \rho_{i, j} N P_{i}^{2} A_{i}^{2}}
$$

the form losses

$$
\Delta p_{f o r m, i}=\dot{m}_{i}^{2} \sum_{j=1}^{N Z} K_{j} \frac{1_{j}}{2 \rho_{i, j} N P_{i}^{2} A_{i}^{2}},
$$

the acceleration losses

\footnotetext{
* The system can encompass the entire core, or one fuel assembly or group of fuel assemblies, depending on the modeled region.
} 


$$
\Delta p_{\text {form }, i}=\dot{m}_{i}^{2} \sum_{j=1}^{N Z} \frac{1_{j}}{2 \rho_{i, j} N P_{i}^{2} A_{i}^{2}}\left(\frac{1}{\rho_{i, j}}-\frac{1}{\rho_{i, j-1}}\right) .
$$

and gravity pressure drop is

$$
\Delta p_{\text {grav }, i}=\sum_{j=1}^{N Z} \rho_{j} g \Delta z_{j}
$$

$\mathrm{NP}_{\mathrm{i}}$ is the number of channels of the same type, $i, \mathrm{NZ}$ is the total number of axial nodes, $\mathrm{A}_{\mathrm{i}}$ and $\mathrm{D}_{\mathrm{e}, \mathrm{i}}$ are the flow area and hydraulic diameter of one channel of type $i$, respectively and $\mathrm{K}_{\mathrm{i}, \mathrm{j}}$ is the form loss coefficient of the $j$-th node of $i$-th channel type.

Coolant density, $\rho_{i, j}$, at each node is calculated from the node bulk temperature, $T_{i, j}$

$$
\rho_{i, j}=f\left(T_{i, j}\right) \text {. }
$$

The Moody friction factor in the axial node $\mathrm{j}$ of channel $\mathrm{i}, \mathrm{f}_{\mathrm{i}, \mathrm{j}}$, is calculated as a function of Reynolds number and surface roughness, $\zeta$, after Idelchik, [Idelchik, 1986]

$$
\mathrm{f}_{\mathrm{i}, \mathrm{j}}=0.11\left[\frac{\zeta}{\mathrm{D}_{\mathrm{h}, \mathrm{i}}}+\frac{68}{\mathrm{Re}_{\mathrm{i}, \mathrm{j}}}\right]^{0.25}
$$

where

$$
\begin{aligned}
& \operatorname{Re}_{\mathrm{i}, \mathrm{j}}=\frac{\dot{m}_{\mathrm{i}} \mathrm{D}_{e, \mathrm{i}}}{\mu_{\mathrm{i}, \mathrm{j}} \mathrm{NP}_{\mathrm{i}} \mathrm{A}_{\mathrm{i}}}, \\
& \mu_{\mathrm{i}, \mathrm{j}}=\mathrm{f}\left(\mathrm{T}_{\mathrm{i}, \mathrm{j}}\right) .
\end{aligned}
$$

The condition of equal total pressure drop for all types of channels can be written in the form

$$
\Delta \mathrm{p}_{\mathrm{i}}=\Delta \mathrm{p}_{\mathrm{i}+1} ; \mathrm{i}=1, \ldots \mathrm{N}-1 \text {. }
$$

Substituting for friction, form, and acceleration terms from Eqs. (3B.1-3) through (3B.1-5) into Eq. (3B.1-10) yields

$$
\dot{\mathrm{m}}_{\mathrm{i}+1}=\dot{\mathrm{m}}_{\mathrm{i}} \sqrt{\frac{\mathrm{F}_{\mathrm{i}}\left(\dot{\mathrm{m}}_{\mathrm{i}}\right)}{\mathrm{F}_{\mathrm{i}}\left(\dot{\mathrm{m}}_{\mathrm{i}+1}\right)}} ; \mathrm{i}=1, \ldots \mathrm{N}-1
$$

where

$$
F_{i}\left(\dot{m}_{i}\right)=\sum_{j=1}^{N Z} f_{i, j}\left(\dot{m}_{i}\right) \frac{\Delta z_{j}}{D_{e, i}} \frac{1_{j}}{2 \rho_{i, j} N P_{i}^{2} A_{i}^{2}}+K_{j} \frac{1_{j}}{2 \rho_{i, j} N P_{i}^{2} A_{i}^{2}}+\frac{1_{j}}{2 \rho_{i, j} N P_{i}^{2} A_{i}^{2}}\left(\frac{1}{\rho_{i, j}}-\frac{1}{\rho_{i, j-1}}\right)
$$

Mass conservation, Eq. (3B.1-1), together with (N-1) equations (3B.1-11), form a complete set of $\mathrm{N}$ equations with $\mathrm{N}$ unknown mass flow rates. The system of equations (3B.1-11) cannot be 
solved analytically since functions $\mathrm{F}_{i}$ depend on mass flow rates through the Reynolds number, as well as through the coolant properties, which in turn depend on mass flow rates. Hence an iterative process is applied. First, a guess of mass flow rates is made, then the fluid properties are obtained from an energy balance, and the friction factor is calculated. Using Eq. (3B.1-11), mass flow rates are updated and compared to old values. The procedure is repeated until the change in mass flow rate is less than the prescribed tolerance. Note that Eq. (3B.1-11) ensures equality of pressure drops. To ensure mass conservation, Eq. (3B.1-1), another iteration loop must be performed. This is accomplished by alternating the mass flow rate of the reference channel (channel \#1 is the reference channel by virtue of Eq. (3B.1-11)) using the relation

$$
\dot{m}_{1}^{k+1}=\dot{m}_{1}^{k} \frac{\dot{m}}{\sum_{i=1}^{N} N P_{i} \dot{m}_{i}^{k}}
$$

where the superscript $\mathrm{k}$ denotes iteration index.

\section{Energy Balance and Cladding and Fuel Temperature Profiles}

To solve the energy balance in the coolant, the heat flux to each axial node in each type of coolant channel must be known. The axial heat flux distribution in the $\mathrm{i}$-th channel type is obtained as

$$
q_{i, j}^{\prime \prime}=\xi_{i, j} \overline{q_{i}^{\prime \prime}} \quad \mathrm{i}=1,2 \ldots \mathrm{N}, \mathrm{j}=1, \ldots, \mathrm{NZ} .
$$

where $\zeta_{\mathrm{i}, \mathrm{j}}$ is the heat flux distribution parameter relating heat flux in node $\mathrm{j}$ of channel type $\mathrm{i}$ to the average heat flux in the $\mathrm{i}$-th channel.

The fluid enthalpy at the exit of node $\mathrm{j}$ can be calculated by integrating the energy balance over the node,

$$
h_{i, j}=h_{i, j-1}+\frac{q^{\prime \prime}, j\left(N P_{i} P_{h, i}\right) \Delta z_{j}}{\dot{m}_{i}} .
$$

Fluid bulk temperature is computed as a function of node enthalpy, i.e.,

$$
T_{b, i, j}=f\left(h_{i, j}\right)
$$

The heat transfer coefficient is calculated using the Westinghouse correlation [Kazimi and Carelli, 1976] for liquid metal cooled bundles

$$
h_{i, j}=\left[4+0.33\left(\frac{P}{D_{c o}}\right)^{3.8}\left(\frac{P e}{100}\right)^{0.86}+0.16\left(\frac{P}{D_{c o}}\right)^{5}\right] \frac{k_{i, j}}{D_{e, i, j}}
$$


where $\mathrm{Pe}$ is Peclet number, $\mathrm{P}$ is rod pitch and $\mathrm{D}_{\text {co }}$ is cladding outer diameter. Cladding temperature for the $\mathrm{j}$-th node of the $\mathrm{i}$-th channel is then determined from Newton's law as

$$
T_{c o, i, j}=T_{b, i, j}+\frac{q_{i, j}^{\prime \prime}}{h_{i, j}}
$$

Finally, fuel temperature distribution is calculated from the 1-D conduction equation in cylindrical geometry as

$$
T_{f, i, j}=T_{c o, i, j}+q_{i, j}^{\prime}\left[\begin{array}{c}
\ln \frac{D_{c o}+2 t_{o x}}{D_{c o}} \frac{1}{2 \pi k_{o x}}+\ln \frac{D_{c o}}{D_{c i}-2 t_{o x}} \frac{1}{2 \pi k_{c l}}+\ln \frac{D_{c i}-2 t_{o x}}{D_{c i}} \frac{1}{2 \pi k_{o x}}+ \\
\ln \frac{D_{c i}-2 t_{o x}}{D_{f o}} \frac{1}{2 \pi k_{g a p}}+\frac{1}{4 \pi \bar{k}_{f}}
\end{array}\right]
$$

In Eqn (3B.1-19), the oxide films are assumed to exist on both inside and outside of the clad surface and $D_{c i}$ and $D_{c o}$ are the clad inner and outer diameter before oxidation takes place. $D_{\text {fo }}$ is fuel outer diameter, $\mathrm{k}_{\mathrm{cl}}, \mathrm{k}_{\mathrm{ox}} \mathrm{k}_{\mathrm{gap}}$ and $\mathrm{k}_{\mathrm{f}}$ are thermal conductivities of cladding, oxide gap and fuel and $t_{o x}$ is oxide thickness. Since conductivity of metallic fuel is only a weak function of temperature and since temperature rise in the fuel rod is small, constant average conductivity of the fuel is used. The gap between the fuel and cladding is filled with lead bond. Experiments at MIT showed [Carpenter and Kohse, 2005] that lead-bismuth gaps have appreciably smaller effective conductivities than those of liquid metal. This is because lead alloys do not wet surfaces well and there is contact resistance both at the clad/bond and fuel/bond interfaces. Because these experiments have shown about $50 \%$ reduction in conductivity, $50 \%$ lower conductivity than that of pure lead was used in all calculations.

\section{B.1.2 Lead Properties}

Two sources were used for lead properties. Transport properties and density were taken from Kutateladze et al. [1958] -see Table 3B.1-1

In Table 3B.1-1, $\gamma$ is density in $\mathrm{kg} / \mathrm{m}^{3}, \lambda$ is thermal conductivity in $\mathrm{kcal} / \mathrm{m}-\mathrm{hr}-{ }^{\circ} \mathrm{C}, \mathrm{c}_{\mathrm{p}}$ is specific heat capacity in $\mathrm{kcal} / \mathrm{m}-\mathrm{hr}-{ }^{\circ} \mathrm{C}$, a is thermal diffusivity in $100 \mathrm{~m}^{2} / \mathrm{hr}$, and $v$ is kinematic viscosity in $10^{8} \mathrm{~m}^{2} / \mathrm{s}$. Properties needed for the model are dynamic viscosity, thermal conductivity and density. Using the least square method, data from Table 3B.1-1 were converted to polynomials, shown in Figure 3B.1-1 and 3B.1-2. Polynomials are valid in the temperature range between the melting point of $327^{\circ} \mathrm{C}^{1}$ and $800^{\circ} \mathrm{C}$ and temperature is expressed in ${ }^{\circ} \mathrm{C}$.

Lead density is expressed as $\rho=11.054505-(0.0011464762+1.9047619 \mathrm{E}-8 * \mathrm{t}) * \mathrm{t}$ where temperature $\mathrm{t}$ is in ${ }^{\circ} \mathrm{C}$.

\footnotetext{
${ }^{1}$ Data in Table 1 are from $400^{\circ} \mathrm{C}$. They were extrapolated to $327^{\circ} \mathrm{C}$.
} 
Project No 06-040: Flexible Conversion Ratio Fast Reactor Systems Evaluation

Table 3B.1-1 Lead properties (from Kutateladze et al., 1958) (See text for symbols and units in English)

\begin{tabular}{|c|c|c|c|c|c|c|}
\hline${ }^{t} \mathrm{C}$ & $\kappa e / \mathrm{s}^{3}$ & $\begin{array}{c}\lambda \\
\kappa \kappa a . n / \Delta t \cdot u a c \cdot{ }^{\circ} \mathrm{C}\end{array}$ & $\frac{c_{p}}{\text { kra.t/ke. }}$ & $\begin{array}{l}a \cdot 10^{2} \\
a^{2} / u a c\end{array}$ & $\begin{array}{l}\because 10^{8} \\
\varkappa^{2} / \mathrm{cen}\end{array}$ & $\operatorname{Pr} \cdot 10^{2}$ \\
\hline 400 & 10592 & 13,0 & 0,0352 & 3,49 & 21,0 & 2,17 \\
\hline 450 & 10536 & 13,2 & 0,0352 & 3,56 & 19,1 & 1,93 \\
\hline 500 & 10476 & 13,3 & 0,0352 & 3,61 & 17,5 & 1,75 \\
\hline 550 & 10419 & $\$ 3,4$ & 0,0352 & 3,65 & 16,3 & 1,61 \\
\hline 600 & 10360 & 13,7 & 0,0352 & 3,76 & 15,3 & 1,47 \\
\hline 650 & 10300 & 14,4 & 0,0352 & 3,97 & 14,5 & 1,32 \\
\hline 700 & 10242 & 15,2 & 0,0352 & 4,22 & 13,7 & 1,17 \\
\hline 750 & 10185 & 16,2 & 0,0352 & 4,52 & 13,1 & 1,04 \\
\hline 800 & 10125 & 17,0 & 0,0352 & 4,77 & 12,5 & 0,94 \\
\hline
\end{tabular}

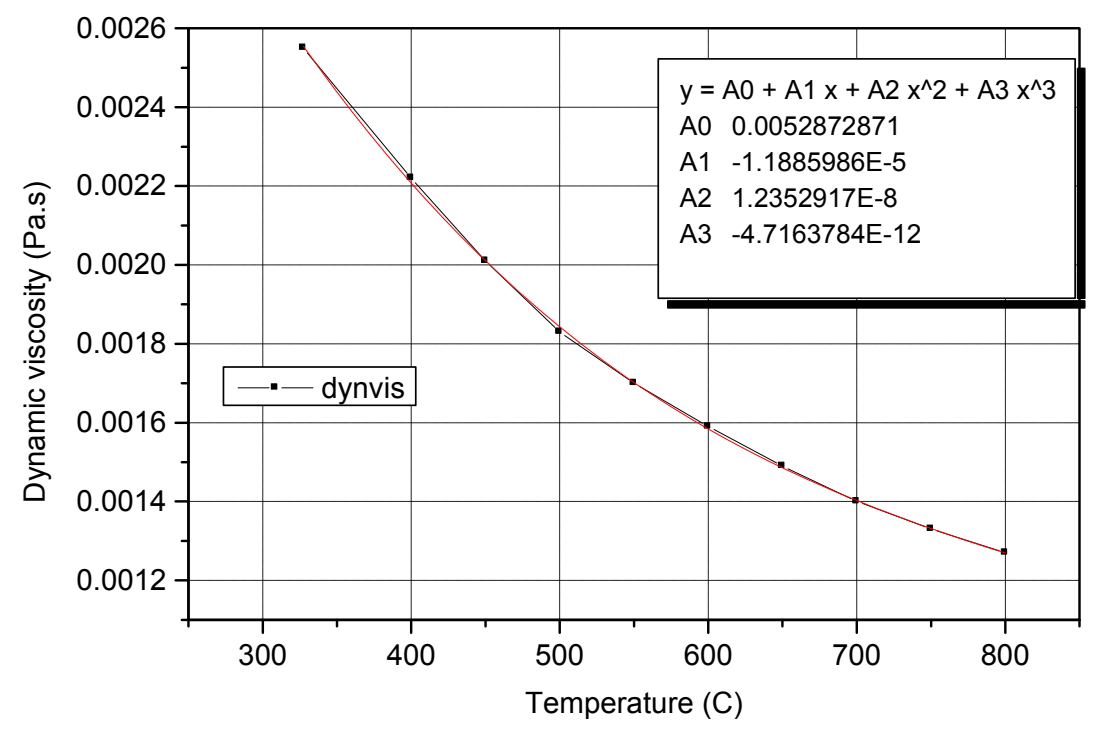

Figure 3B.1-1 Dynamic viscosity of lead 


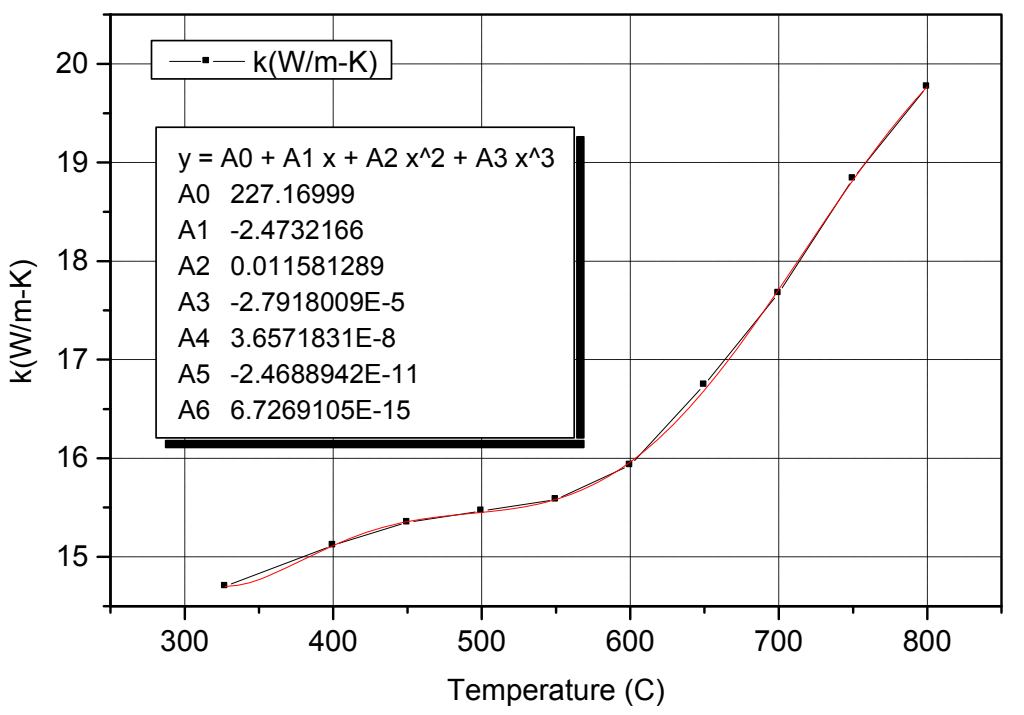

Figure 3B.1-2 Thermal conductivity of lead

Enthalpy and specific heat capacity were taken from the INSC Matprop database, which recommends the relation of Gurvich et al., [1991], where liquid phase enthalpy is given as

$$
\begin{aligned}
H(l, T)-H(s, 298.15)= & -7389.27+36.287 T-5.140 \times 10^{-3} T^{2}+3.158 \times 10^{5} T^{-1}+1.371 \times 10^{-6} T^{3} \\
& -1.0875 \times 10^{-10} T^{4}
\end{aligned}
$$

The above equation is valid for the temperature range $298 \leq \mathrm{T} \leq 3600 \mathrm{~K}$ and $\mathrm{T}$ is in $\mathrm{K}$.

The relation for specific heat capacity, valid in the same temperature range is

$$
C_{p}=+36.287-10.280 \times 10^{-3} T-3.158 \times 10^{5} T^{-2}+4.113 \times 10^{-6} T^{2}-4.35 \times 10^{-10} T^{3}
$$

where temperature $\mathrm{T}$ is again in $\mathrm{K}$.

\section{B.1.3 Model Verification}

Data of the ABRT core from the earlier INEEL/MIT project were used to verify the code. The data of the ABRT core are summarized in Table 3B.1-2. Input data are given in Table 3B.1-3, where EPS is iteration tolerance, ELT is total length of the pin (including fission gas plenum), $\mathrm{N} 1$ is number of parallel channel sets, NZ is number of axial nodes, NP(I) is number of parallel channels in set I, NGRID is number of grids, TIN and PIN are inlet temperature and pressure, respectively, and EMT is total core flow rate. Note that all units are SI (m, m², Pa, $\mathrm{kg}, \mathrm{s}, \mathrm{K}$, $\mathrm{W} / \mathrm{m}^{2}$ ). To compare the results with the Excel spreadsheet model developed by Dostal for analysis of ABRT lead-bismuth cores, some input data were modified to match Dostal's input data. These involve core inlet temperature of $430^{\circ} \mathrm{C}$ (lower than the ABRT value) and hot 
channel hydraulic diameter, which had to be reduced to match prescribed inlet velocity to the hot channel, since the Excel spreadsheet did not have the capability to calculate flow split.

The core is modeled as two channels - an average channel having 156 fuel assemblies, each containing 312 fuel rods, and a hot channel having 1 fuel assembly with 312 fuel rods. Intraassembly peaking is neglected and radial assembly peaking factor (hot assembly over average assembly) is taken to be 1.5 per Dostal's analysis. This is reflected in the QPPM(I) variable showing the axially-averaged heat fluxes in the hot assembly and average assemblies. Gamma heating in materials and reflectors is neglected, hence heat flux below and above the active heated length is zero. 8 grids are assumed as shown by NGRID, ZGRID and XSIGR data.

Table 3B.1-2 Design parameters for ABRT core (from Hejzlar et al. 2004)

\begin{tabular}{lll}
\hline & & ABRT \\
\hline & Fuel outer diameter $(\mathrm{mm})$ & 5.48 \\
& Cladding inner diameter $(\mathrm{mm})$ & 6.32 \\
& Cladding outer diameter $(\mathrm{mm})$ & 7.52 \\
& Cladding thickness $(\mathrm{mm})$ & 0.6 \\
& Fuel heated length $(\mathrm{m})$ & 1.3 \\
& Fission-gas plenum height $(\mathrm{m})$ & 2.47 \\
& Cladding material & HT-9 \\
& Gap bond & liquid Pb \\
& Pin linear power (W/cm) & 110 \\
\hline \multirow{5}{*}{ Core } & Number of fuel assemblies (FA) & 157 \\
geometry & Number of positions per FA & $21 \times 21$ \\
& Number of fuel rods per FA & 312 \\
& Number of CRD fingers per FA & 24 \\
& Number of void positions in center & $7 \mathrm{x} 7$ \\
& P/D (square pitch) & 1.3 \\
& Number of CRDs & 49
\end{tabular}

Core power (MWt) 700

The main output data regarding the flow split and pressure distribution are summarized in Table 3B.1-4. It is interesting to note that hydrostatic pressure drop is the largest. Friction and form loss pressure drops are significantly smaller than the hydrostatic pressure drop. This is not surprising given the high density of lead and small velocity to avoid erosion and oxide layer disturbances. Also, relatively large P/D and square lattice contribute to small pressure drops. Finally, it is noted that use of a hexagonal lattice with small P/D would pose a challenge to meet the $2 \mathrm{~m} / \mathrm{s}$ velocity limit.

The distribution of parameters of interest along the hot and average channel is shown in Table 3B.1-5. The bold typeface values indicate active core. The core mixed outlet temperature of $518.2^{\circ} \mathrm{C}$ differs from Dostal's calculation $\left(517.5^{\circ} \mathrm{C}\right)$ by $\left.0.7^{\circ} \mathrm{C}\right)$. This is due to different properties since Dostal used lead-bismuth properties. Similarly, there is a small difference on hot channel outlet temperature $\left(570.7^{\circ} \mathrm{C}\right.$ versus Dostal's $\left.572^{\circ} \mathrm{C}\right)$ as a result of different properties and use of 
constant $\mathrm{c}_{\mathrm{p}}$ by Dostal versus temperature dependent $\mathrm{c}_{\mathrm{p}}$ used in the new code. Peak cladding outer temperature $\mathrm{T}_{\mathrm{co}}$ is $580.3^{\circ} \mathrm{C}$, in comparison with $593.8^{\circ} \mathrm{C}$ by Dostal. The difference is due to the different heat transfer correlation used by Dostal. Peak fuel centerline temperature of $702.6^{\circ} \mathrm{C}$ is slightly smaller than Dostal's $706.3^{\circ} \mathrm{C}$. However, if the effect of a different heat transfer correlation is accounted for, peak fuel temperature would be higher than Dostal's predictions. This is because contact resistance of the lead bonding, which is accounted for in our calculations, reduces effective thermal conductivity of the gap between fuel and cladding and leads to higher fuel temperature. Overall, it can be stated that good agreement with the earlier results of Dostal's Excel spreadsheet is achieved and minor differences can be easily explained by different properties or modeling approaches. There is a need to review available heat transfer correlations for lead-cooled pin bundles to reduce uncertainty on cladding temperature calculations.

Table 3B.1-3 Input data for hot and average channel of ABRT core

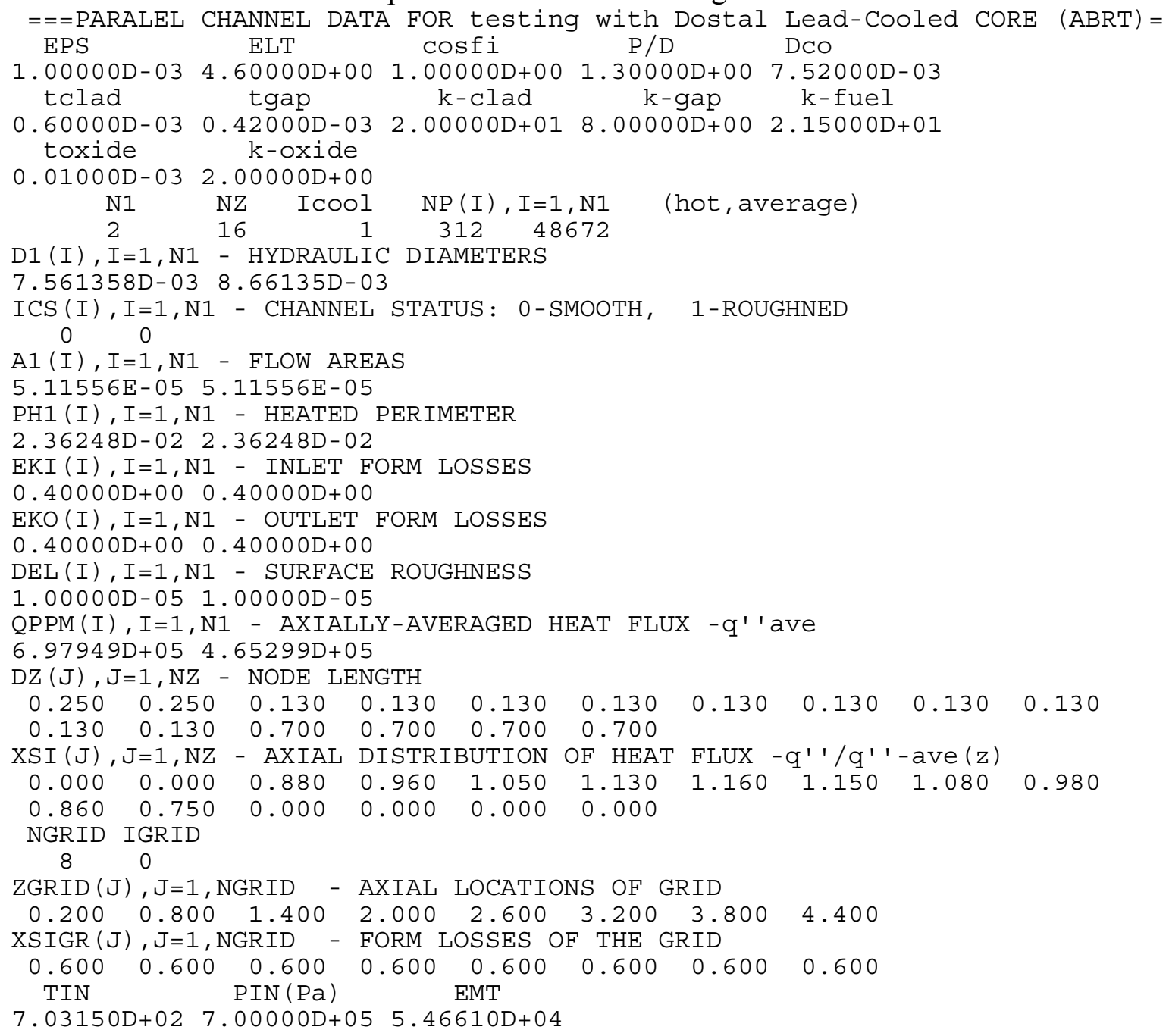

Table 3B.1-4 Main data for ABRT Core

$\begin{array}{llll} & \text { Hot chan. } & \text { Average chan. } \\ \text { FLOW RATE (KG/S) } & 3.2764 \mathrm{E}+02 & 5.4332 \mathrm{E}+04 \\ \text { PRES.DROP-TOTAL (Pa) } & 8.6083 \mathrm{E}+05 & 8.6087 \mathrm{E}+05\end{array}$


Project No 06-040: Flexible Conversion Ratio Fast Reactor Systems Evaluation

$\begin{array}{lll}\text { FRICTION DP (Pa) } & 2.8889 \mathrm{E}+05 & 2.7424 \mathrm{E}+05 \\ \text { Form losses (Pa) } & 1.0086 \mathrm{E}+05 & 1.1351 \mathrm{E}+05 \\ \text { Acceleration DP (Pa) } & 3.1480 \mathrm{E}+02 & 2.2093 \mathrm{E}+02 \\ \text { Gravity DP (Pa) } & 4.7077 \mathrm{E}+05 & 4.7289 \mathrm{E}+05 \\ \text { HEAT TRANSFER COEF. } & 2.7766 \mathrm{E}+04 & 2.7117 \mathrm{E}+04 \\ \text { REYNOLDS NUMBER } & 9.4034 \mathrm{E}+04 & 1.0562 \mathrm{E}+05 \\ \text { INLET VELOCITY (M/S) } & 1.9443 \mathrm{E}+00 & 2.0669 \mathrm{E}+00 \\ \text { MASS FLUX KG/m2-S } & 2.0528 \mathrm{E}+04 & 2.1822 \mathrm{E}+04\end{array}$

Table 3B.1-5 Distribution of parameters along the channels

\begin{tabular}{|c|c|c|c|c|c|c|c|c|}
\hline $\begin{array}{l}\# \\
-\end{array}$ & & $\begin{array}{l}\text { Tbulk } \\
\left({ }^{\circ} \mathrm{C}\right)\end{array}$ & $\begin{array}{l}\text { Tco } \\
\left({ }^{\circ} \mathrm{C}\right)\end{array}$ & $\begin{array}{l}\text { Tci } \\
\left({ }^{\circ} \mathrm{C}\right)\end{array}$ & $\begin{array}{l}\text { Tfmax } \\
\left({ }^{\circ} \mathrm{C}\right)\end{array}$ & $\begin{array}{l}\mathrm{h} \\
(\mathrm{kW} / \mathrm{m} 2 \mathrm{~K})\end{array}$ & $\begin{array}{l}v \\
\text { '(m/s) }\end{array}$ & $\begin{array}{l}\text { q" } \\
\left(\mathrm{MW} / \mathrm{m}^{2}\right)\end{array}$ \\
\hline \multicolumn{9}{|c|}{ Channel \#1 - Hot } \\
\hline 1 & 0.25 & 430 & 430 & 430 & 430 & 27.69 & 1.94 & 0 \\
\hline 2 & 0.5 & 430 & 441.09 & 454.3 & 501.74 & 27.69 & 1.94 & 0 \\
\hline 3 & 0.63 & 442.29 & 465.47 & 493.09 & 592.28 & 27.7 & 1.95 & 0.61 \\
\hline 4 & 0.76 & 455.72 & 481.03 & 511.21 & 619.56 & 27.71 & 1.95 & 0.67 \\
\hline 5 & 0.89 & 470.43 & 497.88 & 530.61 & 648.12 & 27.71 & 1.95 & 0.73 \\
\hline 6 & 1.02 & 486.28 & 515.13 & 549.51 & 672.96 & 27.7 & 1.96 & 0.79 \\
\hline 7 & 1.15 & 502.59 & 531.7 & 566.38 & 690.9 & 27.69 & 1.96 & 0.81 \\
\hline 8 & 1.28 & 518.78 & 546.89 & 580.37 & 700.58 & 27.69 & 1.96 & 0.8 \\
\hline 9 & 1.41 & 534.02 & 559.98 & 590.91 & 701.96 & 27.69 & 1.97 & 0.75 \\
\hline 10 & 1.54 & 547.87 & 571.04 & 598.67 & 697.85 & 27.71 & 1.97 & 0.68 \\
\hline 11 & 1.67 & 560.04 & 580.29 & 604.47 & 691.26 & 27.73 & 1.97 & 0.6 \\
\hline 12 & 1.8 & 570.66 & 580.09 & 591.35 & 631.78 & 27.77 & 1.98 & 0.52 \\
\hline 13 & 2.5 & 570.66 & 570.66 & 570.66 & 570.66 & 27.77 & 1.98 & 0 \\
\hline 14 & 3.2 & 570.66 & 570.66 & 570.66 & 570.66 & 27.77 & 1.98 & 0 \\
\hline 16 & 4.6 & 570.66 & 570.66 & 570.66 & 570.66 & 27.77 & 1.98 & 0 \\
\hline \multicolumn{9}{|c|}{ Channel \#2 - Average } \\
\hline 1 & 0.25 & 430 & 430 & 430 & 430 & 27.14 & 2.07 & 0 \\
\hline 2 & 0.5 & 430 & 437.54 & 446.35 & 477.98 & 27.14 & 2.07 & 0 \\
\hline 3 & 0.63 & 437.71 & 453.48 & 471.89 & 538.02 & 27.15 & 2.07 & 0.41 \\
\hline 4 & 0.76 & 446.12 & 463.34 & 483.46 & 555.7 & 27.15 & 2.07 & 0.45 \\
\hline 5 & 0.89 & 455.33 & 474.01 & 495.83 & 574.17 & 27.15 & 2.07 & 0.49 \\
\hline 6 & 1.02 & 465.26 & 484.88 & 507.8 & 590.1 & 27.15 & 2.07 & 0.53 \\
\hline 7 & 1.15 & 475.46 & 495.25 & 518.37 & 601.39 & 27.15 & 2.08 & 0.54 \\
\hline 8 & 1.28 & 485.58 & 504.69 & 527.02 & 607.16 & 27.14 & 2.08 & 0.54 \\
\hline 9 & 1.41 & 495.1 & 512.76 & 533.38 & 607.41 & 27.13 & 2.08 & 0.5 \\
\hline 10 & 1.54 & 503.74 & 519.52 & 537.94 & 604.06 & 27.13 & 2.08 & 0.46 \\
\hline 11 & 1.67 & 511.33 & 525.14 & 541.26 & 599.12 & 27.12 & 2.09 & 0.4 \\
\hline 12 & 1.8 & 517.96 & 524.39 & 531.9 & 558.85 & 27.12 & 2.09 & 0.35 \\
\hline 13 & 2.5 & 517.96 & 517.96 & 517.96 & 517.96 & 27.12 & 2.09 & 0 \\
\hline 14 & 3.2 & 517.96 & 517.96 & 517.96 & 517.96 & 27.12 & 2.09 & 0 \\
\hline 16 & 4.6 & 517.96 & 517.96 & 517.96 & 517.96 & 27.12 & 2.09 & 0 \\
\hline
\end{tabular}




\section{B.2 RELAP5 Models}

The RELAP5-3D code has been developed at Idaho National Laboratory for simulation of steady state and transient behavior of reactor systems [RELAP, 2005]. In the current version of the code, liquid lead coolant properties are not available; thus, lead-bismuth, which has almost the same properties as lead, was used in our studies.

The overall RELAP5-3D model was built in five stages:

1. An overall model of the primary system was built with the core represented as two channels: hot channel representing a group of hot fuel assemblies and average channel modeling the rest of the core.

2. A detailed intermediate heat exchanger model was created separately, optimized, and then connected to the primary loop within the reactor vessel.

3. The RVACS with guard vessel, the lead-bismuth gap between the reactor and guard vessels, dimples on the outer guard vessel wall and perforated plate for heat transfer enhancement were added, and analysis of the RVACS decay heat removal capability was conducted.

4. A complete power conversion system (PCS) with the turbine, compressors, recuperators and the precooler was connected to the primary system through the IHX to simulate overall system response to accident conditions.

5. A preliminary design of a Passive Secondary Auxiliary Safety System (PSACS) to aid RVACS decay heat removal was conducted. The passive system was built in RELAP53D and connected to the PCS.

After each model testing and steady state analysis was complete, the accident conditions were simulated.

\section{B.2.1 Overall RELAP5-3D Model Nodalization}

The overall reactor RELAP5-3D model nodalization is illustrated in Figure 3B.2-1. The RELAP5-3D model is applicable to both unity conversion ratio and zero conversion ratio cores with a modification in the core modeling due to different radial peaking factors and orificing arrangements.

Both the primary coolant system (components 500 through 595) and RVACS (components 800 through 830) are depicted. The nodalization starts with the lower plenum, 500. The flow is subsequently split into two parallel channels: hot channel (component 516) and average channel (component 510). The hot channel represents four assemblies with the highest peaking factor of 1.21 for $\mathrm{CR}=1$, or 16 assemblies with the highest peaking factor of 1.34 for $\mathrm{CR}=0$, lumped together. The average channel represents remaining assemblies. The active core components were further nodalized into 5 axial volumes. The flow is recombined in the chimney, 520 . Component 540 corresponds to the upper plenum. 
Project No 06-040: Flexible Conversion Ratio Fast Reactor Systems Evaluation

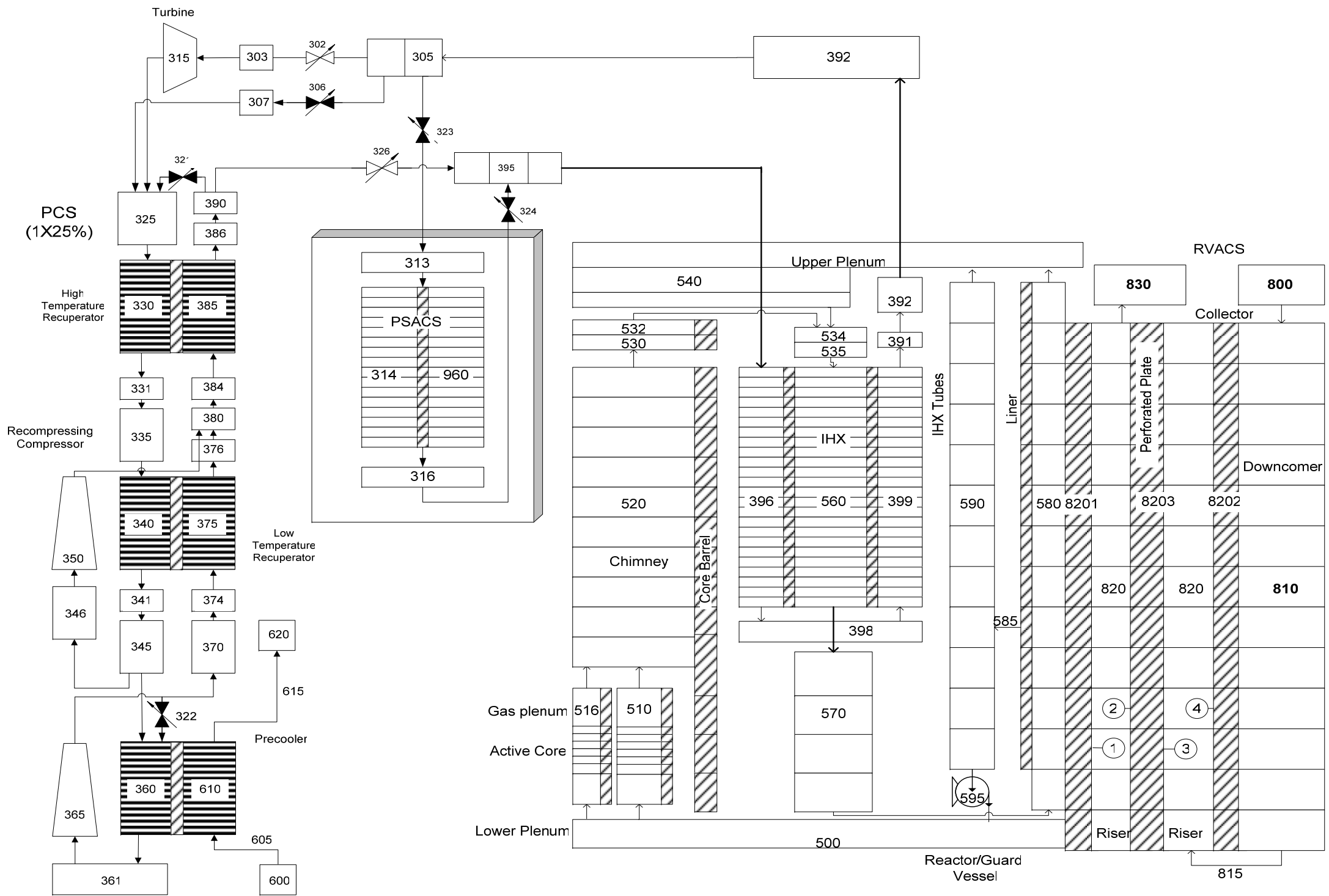

Figure 3B.2-1 Integrated layout of the primary and secondary (PCS and PSACS) reactor coolant systems and RVACS. 
Four heat exchangers are represented by components 560 and 561. Component 560 depicted in Figure 3B.2-1 corresponds to one heat exchanger's lead coolant channels. The other three are lumped together in component 561 (not shown.) Detailed illustration of a heat exchanger with both lead and $\mathrm{CO}_{2}$ sides is shown in Figure 3B.2-2. Heat exchanger downcomer, vessel riser (liner), and the pump downcomer are represented by components 570, 580 and 590, respectively. The above volumes are connected by perforation holes to allow the coolant to follow its path. The perforation holes are modeled as a single junction with flow area corresponding to the total connection area, but the hydraulic diameter corresponding to a single perforation hole. Such simplification is necessary because of the 1-D nature of the model. The geometry of perforations is calculated based on the velocity limit of the coolant. Four centrifugal pumps are lumped together as component 595.

Hatched components correspond to the heat structures. Heat structures are connected thermally to the attached hydrodynamic volumes. The primary system includes five main structures: average fuel pins, hot fuel pins, core barrel, heat exchanger tubes, and the reactor vessel liner. The RVACS heat structures contain the reactor and guard vessels with lead-bismuth as the conducting fluid modeled as one component, perforated plates and the collector cylinder.

The reactor power is calculated using a point reactor kinetics model.

Two time-dependent volumes, 800 and 830, set the air supply and exhaust conditions and are at atmospheric pressure. The downcomer is represented by component 810 . Volume 820 is the riser with the perforated plate installed in the middle. Radiation heat transfer from the guard vessel through the perforated plate to the collector was represented as a radiation enclosure model; thus, there are four radiation enclosure heat slabs.

\section{B.2.2 Details of RELAP5-3D Core Model}

In the core model, the flow through the core is represented as two parallel channels: hot channel and average channel. The hot channel contains four assemblies with the highest peaking factor of 1.21 for $\mathrm{CR}=1$ or 16 assemblies with the highest peaking factor of 1.34 for $\mathrm{CR}=0$ lumped together. The average channel represents remaining assemblies.

Detailed subchannel calculation were performed using SUBCHAN to flatten the core coolant temperature distribution and to minimize the peak cladding temperature through three-zone orificing. The calculations resulted in the desired flow split between the average and hot channels. In the RELAP5-3D model this flow split was represented through form losses (forward and reverse loss coefficients) associated with the orifices. Table 3B.2-1 shows the orificing and the calculated flow split for both cores.

Fuel pins are modeled in detail including fuel pellets, lead-alloy bond, cladding and the oxide layer on the outside of cladding. The active core components were further nodalized into 5 axial volumes $0.26 \mathrm{~m}$ in length and 8 radial meshes. The axial power distribution was then applied to heat structures connected to both hot and average channels. The power distribution simulates the heat generated in the fuel pins. An internal source multiplier used in the RELAP5-3D core model allows for distinguishing between average and hot channels by applying higher peaking 
factor to the hot channel. Another purpose of the internal source multiplier is to account for the number of channels included either in the average or hot channel. Table 3B.2-2 summarizes the multipliers. The unity conversion ratio core has significantly lower hot channel multipliers due to fewer hot channels and lower peaking factor.

Table 3B.2-1 Orificing and the flow split in the core

\begin{tabular}{|c|c|c|c|}
\hline & $\mathrm{CR}=1$ & $\mathrm{CR}=0$ \\
\hline \multicolumn{2}{|c|}{ Highest peaking factor } & 1.21 & 1.35 \\
\hline \multicolumn{2}{|c|}{ Number of assemblies } & 4 & 16 \\
\hline \multicolumn{2}{|c|}{$\begin{array}{l}\text { Orificing coefficients } \\
\text { (zone1/zone2/zone } 3 \text { ) }\end{array}$} & $0.4 / 4.96 / 13.24$ & $0.4 / 8.19 / 29.68$ \\
\hline \multirow{2}{*}{$\begin{array}{l}\text { Flow split } \\
(\mathrm{kg} / \mathrm{s})\end{array}$} & Hot & 2196.5 & 9511.8 \\
\hline & Average & 171403.5 & 164088.2 \\
\hline
\end{tabular}

Table 3B.2-2 Internal power multipliers.

\begin{tabular}{|l|c|c|c|c|}
\hline \multirow{2}{*}{$\begin{array}{l}\text { Relative axial flux } \\
\text { multiplier }\end{array}$} & \multicolumn{2}{|c|}{$\mathrm{CR}=0$} & \multicolumn{2}{c|}{ CR = 1 } \\
\cline { 2 - 5 } & Average & Hot & Average & Hot \\
\hline 0.813 & 0.16443 & 0.01086 & 0.17286 & $\mathbf{0 . 0 0 2 4 3}$ \\
1.06 & 0.21439 & 0.01416 & 0.22537 & $\mathbf{0 . 0 0 3 1 7}$ \\
1.23 & 0.24877 & 0.01643 & 0.26152 & $\mathbf{0 . 0 0 3 6 8}$ \\
0.95 & 0.19214 & 0.01269 & 0.20199 & $\mathbf{0 . 0 0 2 8 4}$ \\
$\mathbf{0 . 5 8 5}$ & $\mathbf{0 . 1 1 8 3 2}$ & $\mathbf{0 . 0 0 7 8 1}$ & $\mathbf{0 . 1 2 4 3 8}$ & $\mathbf{0 . 0 0 1 7 5}$ \\
\hline
\end{tabular}

Another significant difference between the unity and zero conversion ratio cores is the fuel composition. The zero conversion ration core has a larger transuranic content, which lowers the fuel conductivity. The comparison of estimated fuel conductivities is provided in Table 3B.2-3. Thus, the maximum fuel temperature of the $\mathrm{CR}=0$ is expected to be higher than for the $\mathrm{CR}=1$ core.

Table 3B.2-3 Fuel conductivities (W/mK)

\begin{tabular}{|l|c|c|}
\hline Temperature $(\mathrm{K})$ & $\mathrm{CR}=0$ & $\mathbf{C R}=\mathbf{1}$ \\
\hline 293 & 3.75 & $\mathbf{8 . 2 2}$ \\
373 & 4.60 & $\mathbf{9 . 0 0}$ \\
873 & 10.95 & $\mathbf{1 5 . 2 6}$ \\
1173 & 13.70 & $\mathbf{2 0 . 1 4}$ \\
$\mathbf{1 8 7 3}$ & $\mathbf{2 2 . 8 0}$ & $\mathbf{3 4 . 8 1}$ \\
\hline
\end{tabular}

\section{B.2.3 Details of RELAP5-3D Model of Intermediate Heat Exchanger}

The IHX design is an important part of the RELAP5-3D model. To avoid multiple design iterations of the heat exchanger design and to save computational time, the IHX was first modeled separately from the rest of the reactor system. The following constraints were taken into account:

1. Inlet and outlet temperatures on both sides are fixed by the core thermal hydraulic design and the $\mathrm{S}-\mathrm{CO}_{2}$ power cycle. 
2. Mass flow rates on both sides are fixed by the core thermal hydraulic design and the $\mathrm{CO}_{2}$ cycle.

3. Heat exchanger size is constrained by the annulus size between the core barrel and the liner, including space needed for the pumps.

4. Pressure drop on the $\mathrm{CO}_{2}$ side must be minimized to ensure good efficiency of the $\mathrm{CO}_{2}$ cycle. It is directly related to the size of the heat exchanger.

5. Pressure drop on the lead side must be minimized to ensure reasonable pumping power.

6. Component wall thicknesses are calculated based on material properties as function of design pressure and temperatures.

\section{$\underline{\text { Design Methodology }}$}

The initial design of the intermediate heat exchanger was performed using MS Excel worksheet. The details of the design and optimization of the intermediate heat exchanger in Excel are provided in Appendix 3C. Enhanced heat transfer applied to the inner surface of the heat exchanger tubes allows for the reduction in heat exchanger size without a significant increase in the pressure drop on the $\mathrm{CO}_{2}$ side. The increase in heat transfer coefficient between the ribbed and smooth tubes was calculated using Excel worksheet. The ratio of enhanced heat transfer coefficient and smooth heat transfer coefficient was calculated and then further applied to the RELAP5-3D model. To simulate the enhanced heat transfer in RELAP5-3D, the obtained ratio was factored into the gas heat transfer coefficient. In addition the small increase in the pressure drop through the gas-side of the IHX tubes due to the helical ribs was included in the model. The heat exchanger length was reduced from $6.8 \mathrm{~m}$ to $5.7 \mathrm{~m}$ which resulted in a lead-side pressure drop cutback from $380 \mathrm{kPa}$ to $325 \mathrm{kPa}$.

In the RELAP5-3D model, coolant mass flow rates, inlet and outlet temperatures, and inlet pressures were used as boundary conditions. The values are shown in Table 3B.2-4. Optimized geometric parameters were taken from the Excel model. For quick optimization purposes, the secondary side was modeled through time-dependent volumes and junctions to avoid remodeling the entire power conversion system in RELAP5. The output values of pressures and temperatures were then compared to the Excel model.

Table 3B.2-4 Design boundary conditions for the heat exchangers

\begin{tabular}{|l|c|c|}
\hline & $\mathrm{CO}_{2}$ side & Lead side \\
\hline Mass flow rate $(\mathrm{kg} / \mathrm{s})$ & 3189.2 & 43400.0 \\
\hline Inlet temperature $\left({ }^{\circ} \mathrm{C}\right)$ & $393.1^{\circ} \mathrm{C}$ & $573.3^{\circ} \mathrm{C}$ \\
\hline Outlet temperature $\left({ }^{\circ} \mathrm{C}\right)$ & $546.0^{\circ} \mathrm{C}$ & $477.0^{\circ} \mathrm{C}$ \\
\hline Inlet pressure $(\mathrm{MPa})$ & $19.5 \mathrm{MPa}$ & N/A \\
\hline
\end{tabular}

Figure 3B.2-2 depicts the schematic representation of the RELAP5-3D heat exchanger model. "Gas-side source" is a time-dependent volume that sets the boundary conditions for $\mathrm{CO}_{2}$ temperature and pressure simulating the turbine outlet. Junction 370 is a time-dependent junction that sets the gas mass flow rate. Similarly, on the lead side, time-dependent volume 535 and junction 536 specify the boundary conditions for the primary side. Thus, $\mathrm{CO}_{2}$ gas enters through volume 360 , goes through the main inlet tube (modeled as pipe-volume 380), mixes in the bottom plenum 384, heats up while going through the small tubes represented by volume 
385 , enters the top mixing plenum (volume 386), and exits through two outlet tubes (390) into the sink (398). For the lead side, the path is much simpler: lead-coolant enters through the "source" volume, transfers heat to the gas-coolant through channels modeled as volume 560, and exits through sink 565 .

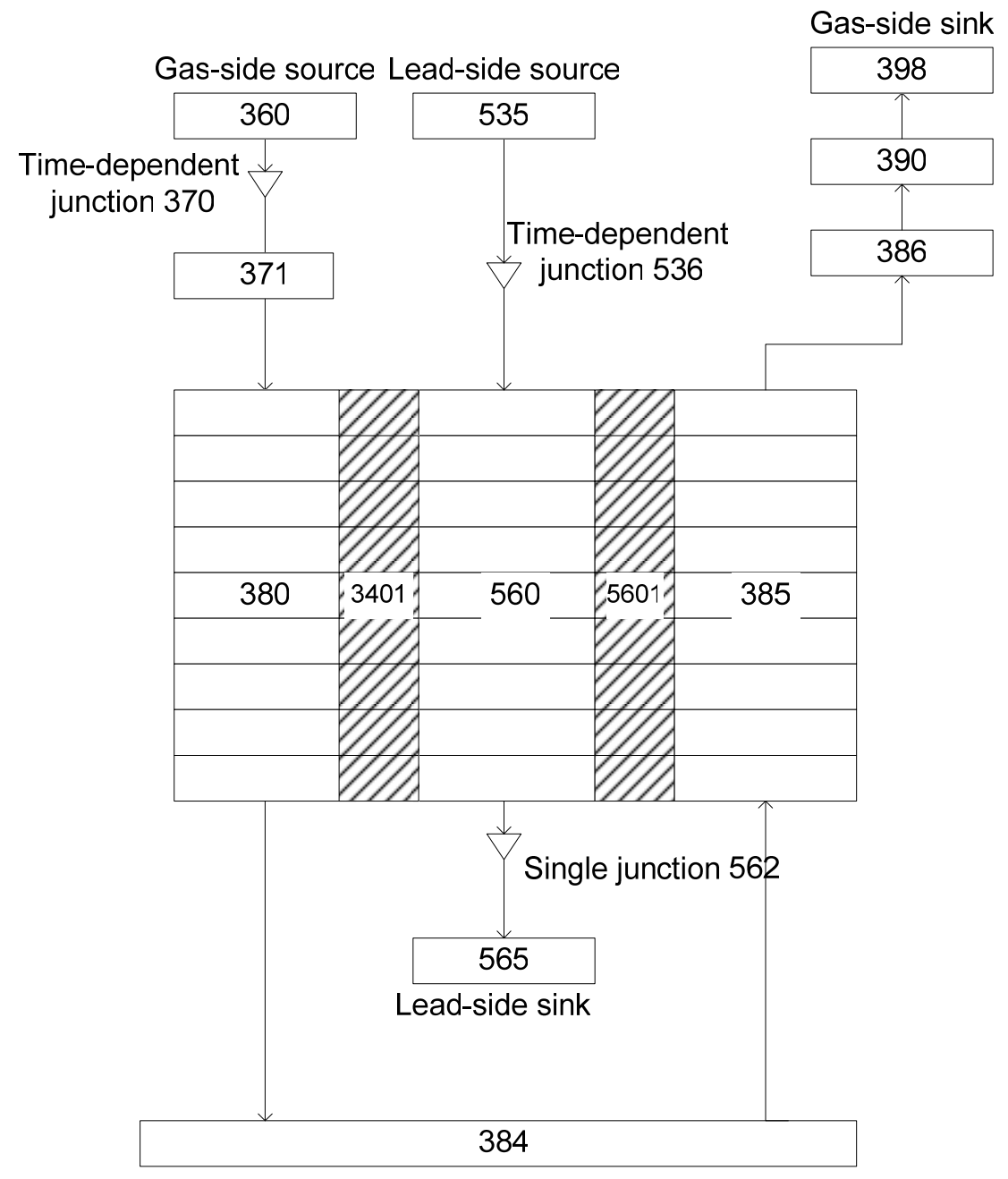

Figure 3B.2-2 RELAP5-3D schematic of the heat exchanger

Similarly to the core model, hatched areas correspond to the heat structures: 3401 is the $\mathrm{CO}_{2}$ inlet tube wall, and 5601 represents all of the small tubes. Small tubes were nodalized radially into five meshes including the oxide layer on the lead side.

After the model was built, the output was compared to the Excel model. Originally, a large difference between the two models was observed. In the initial setup of the model, coarse axial meshing for the tubes in RELAP5-3D was used because of single-phase fluids in the system. Coarse vs. fine meshing allows a significant savings in computational time. However, large discrepancies in the power removed from the lead coolant between that calculated using RELAP5-3D and that estimated by Excel using the Log Mean Temperature Difference approximation were observed. This led to investigation of the effects of mesh size on the model 
performance. The RELAP5-3D model of the IHX shows a strong dependence of the results on meshing as can be seen from Figure 3B.2-3. Even though the fluids are both single-phase, large difference in heat transfer coefficients and other thermal properties can lead to poor numerical results. As the mesh becomes finer, the transmitted power calculated using RELAP5-3D saturates around the target value of $600 \mathrm{MW}$. Thus, it was concluded that 50 meshes per heat exchanger length is sufficient to acquire adequate results.

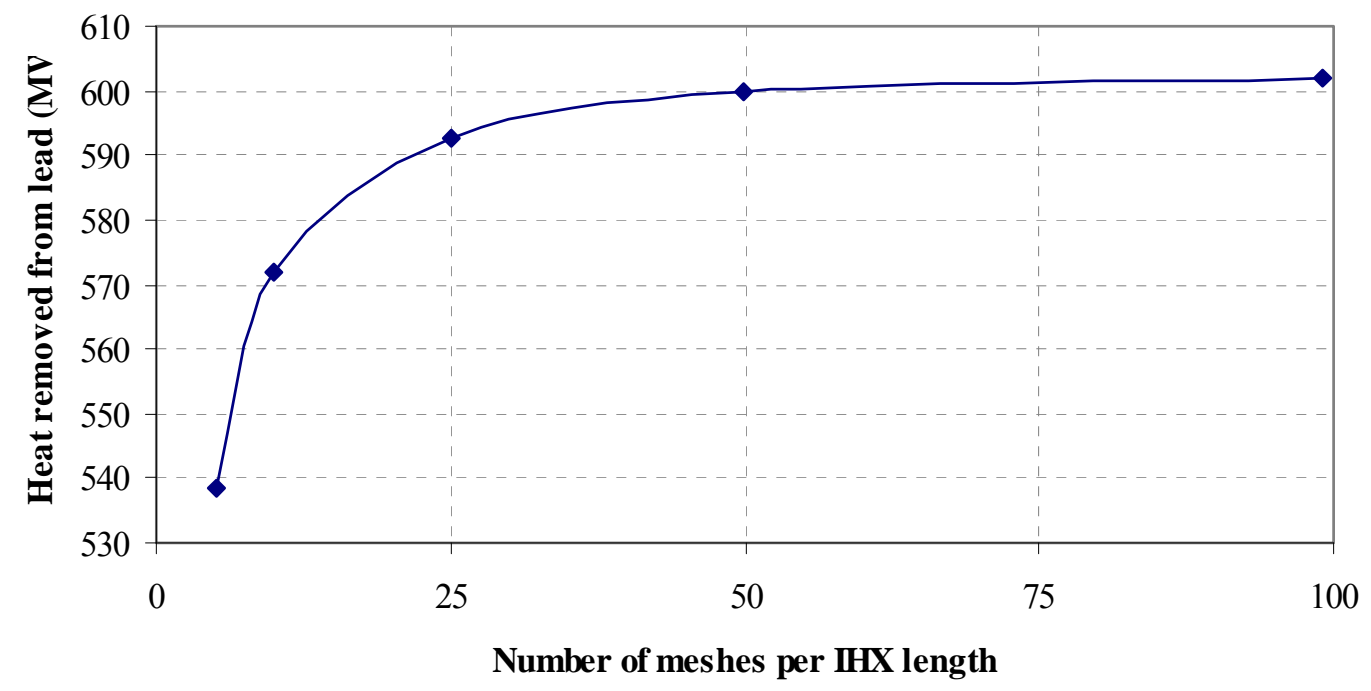

Figure 3B.2-3 Effect of axial mesh size (RELAP5) on the model performance.

The major heat exchanger design parameters obtained from an Excel worksheet and RELAP53D simulation are summarized in Table 3B.2-6. Note that the RELAP5-3D simulation was run with lead-bismuth alloy coolant since pure lead is not yet available as a fluid in RELAP5. Nonetheless, lead and lead-bismuth have very close thermal properties. Table 3B.2-5 provides a comparison of a few thermal hydraulic parameters of lead and lead-bismuth eutectic (Martynov, 1998). Average values for heat transfer coefficients of lead and $\mathrm{CO}_{2}$ are in good agreement when estimated using the Excel worksheet and RELAP5-3D model.

Table 3B.2-5 Comparison of lead and lead-bismuth eutectic selected physical parameters

\begin{tabular}{ccccccccc}
\hline \multirow{2}{*}{$\begin{array}{c}\text { Temperature } \\
\left({ }^{\circ} \mathrm{C}\right)\end{array}$} & \multicolumn{2}{c}{ Density $\left(\mathrm{kg} / \mathrm{m}^{3}\right)$} & \multicolumn{2}{c}{$\begin{array}{c}\text { Thermal conductivity } \\
(\mathrm{W} / \mathrm{mK})\end{array}$} & \multicolumn{2}{c}{$\begin{array}{c}\text { Specific heat } \\
(\mathrm{kJ} / \mathrm{kgK})\end{array}$} & \multicolumn{2}{c}{ Pr number } \\
\cline { 2 - 9 } & Lead & $\mathrm{Pb}-\mathrm{Bi}$ & Lead & $\mathrm{Pb}-\mathrm{Bi}$ & Lead & $\mathrm{Pb}-\mathrm{Bi}$ & Lead & $\mathrm{Pb}-\mathrm{Bi}$ \\
\hline 300 & 10709 & 10364 & 14.88 & 12.67 & 147 & 146 & 0.0268 & 0.0224 \\
\hline 400 & 10593 & 10242 & 15.11 & 13.72 & 146 & 146 & 0.0213 & 0.0172 \\
\hline 500 & 10477 & 10120 & 15.45 & 14.65 & 144 & 146 & 0.0171 & 0.0137 \\
\hline 600 & 10360 & 10000 & 15.96 & 15.81 & 142 & 146 & 0.0141 & 0.0115 \\
\hline
\end{tabular}


Table 3B.2-6 Comparison of heat exchanger performance between Excel calculations and RELAP5-3D simulation

\begin{tabular}{|c|c|c|}
\hline INPUT & Excel calculations & $\begin{array}{l}\text { RELAP5-3D } \\
\text { simulation }\end{array}$ \\
\hline Core power $(\mathrm{MWt})$ & \multicolumn{2}{|c|}{2400} \\
\hline Lead mass flow rate $(\mathrm{kg} / \mathrm{s})$ & \multicolumn{2}{|c|}{173600} \\
\hline $\mathrm{S}-\mathrm{CO}_{2}$ mass flow rate $(\mathrm{kg} / \mathrm{s})$ & \multicolumn{2}{|c|}{12848} \\
\hline Number of heat exchangers & \multicolumn{2}{|c|}{4} \\
\hline $\begin{array}{l}\text { Target power transmitted in the IHX (per IHX) } \\
(\mathrm{MWt})\end{array}$ & \multicolumn{2}{|c|}{600} \\
\hline Lead inlet temperature $\left({ }^{\circ} \mathrm{C}\right)$ & \multicolumn{2}{|c|}{573.3} \\
\hline Lead outlet temperature $\left({ }^{\circ} \mathrm{C}\right)$ & \multicolumn{2}{|c|}{477.0} \\
\hline $\mathrm{S}-\mathrm{CO}_{2}$ inlet temperature $\left({ }^{\circ} \mathrm{C}\right)$ & \multicolumn{2}{|c|}{398.0} \\
\hline $\mathrm{S}-\mathrm{CO}_{2}$ target outlet temperature $\left({ }^{\circ} \mathrm{C}\right)$ & \multicolumn{2}{|c|}{549.6} \\
\hline $\mathrm{S}-\mathrm{CO}_{2}$ pressure $(\mathrm{MPa})$ & \multicolumn{2}{|c|}{19.7} \\
\hline \multicolumn{3}{|l|}{ GEOMETRY } \\
\hline Lattice & \multicolumn{2}{|c|}{ Triangular } \\
\hline Number of tubes (per IHX) & \multicolumn{2}{|c|}{16356} \\
\hline Outer tube diameter (mm) & \multicolumn{2}{|c|}{14} \\
\hline Tube wall thickness (mm) & \multicolumn{2}{|c|}{2.8} \\
\hline Pitch to diameter ratio & \multicolumn{2}{|c|}{1.23} \\
\hline Inner IHX radius $\left(\mathrm{r}_{\mathrm{i}}\right)(\mathrm{m})$ & \multicolumn{2}{|c|}{2.711} \\
\hline Outer IHX radius $\left(\mathrm{r}_{\mathrm{o}}\right)(\mathrm{m})$ & \multicolumn{2}{|c|}{4.471} \\
\hline \multicolumn{3}{|l|}{ OUTPUT } \\
\hline Calculated power $(\mathrm{MWt})$ & 598.7 & 598.2 \\
\hline Tube length (m) & 5.7 & 5.7 \\
\hline Logarithmic temperature difference $\left({ }^{\circ} \mathrm{C}\right)$ & 46.7 & $\mathrm{~N} / \mathrm{A}$ \\
\hline S- $\mathrm{CO}_{2}$ velocity (average) $(\mathrm{m} / \mathrm{s})$ & 16.8 & 17.0 \\
\hline Lead velocity (average) $(\mathrm{m} / \mathrm{s})$ & 2.17 & 2.18 \\
\hline $\begin{array}{l}\mathrm{S}-\mathrm{CO}_{2} \text {-side pressure drop (through small tubes) } \\
(\mathrm{kPa})\end{array}$ & 226 & 230 \\
\hline
\end{tabular}

\section{B.2.4 Details of RELAP5-3D Model of RVACS}

A brief description of the nodalization was given in the overview. In this model, RVACS chimneys were lumped together. The model consists of three hydrodynamic volumes, a downcomer and two risers separated by the perforated plate, and three structures, collector wall, perforated plate and the vessel. Reactor vessel, guard vessel, and the liquid metal gap between them are lumped into one structure with material properties preserved.

The view factors for each surface are given in Table 3B.2-7. The numbers for each view surface are identified in Figure 3B.2-1. The emissivity of the surfaces was taken to be 0.75 [Hejzlar, 2004]. In the perforated plate, $40 \%$ of the total area was voided to account for the presence of 
holes. The description of the effects of heat transfer enhancement through placement of dimples on the outer surface of the guard vessel is provided in Appendix 2B.9. Description of the RVACS design is given in Section 2.2.3.1.

Table 3B.2-7 View Factors

\begin{tabular}{ccc}
\hline Surface Emitting & View Factor & Surface Receiving \\
\hline 1 & 0 & 1 \\
\hline 1 & 0.6 & 2 \\
\hline 1 & 0 & 3 \\
\hline 1 & 0.4 & 4 \\
\hline 2 & 0.980592 & 1 \\
\hline 2 & 0.019408 & 2 \\
\hline 2 & 0 & 3 \\
\hline 2 & 0 & 4 \\
\hline \multicolumn{3}{c}{0} \\
\hline 3 & 0 & 1 \\
\hline 3 & 0 & 2 \\
\hline 3 & 1 & 3 \\
\hline 3 & 0.384384 & 1 \\
\hline & 0 & 2 \\
\hline 4 & 0.588589 & 3 \\
\hline 4 & 0.027027 & 4 \\
\hline 4 & & \\
\hline 4 & 0 & \\
\hline
\end{tabular}

\section{B.2.4 Details of RELAP5-3D Model of PSACS}

The PSACS model consists of a large tank of water with the tube-and-shell auxiliary heat exchanger placed inside. To enhance natural circulation, the PSACS is located 2.0 meters above the in-vessel IHXs. In case of an accident, the $\mathrm{CO}_{2}$ gas from the power cycle is directed into the PSACS by opening the PSACS isolation valve (shown as 323 in Figure 3B.2-3.) $\mathrm{CO}_{2}$ is then distributed into the auxiliary heat exchanger tubes in the upper plenum 313. The coolant then travels downward through the gas-to-water heat exchanger tubes 314, while cooling, providing additional driving head for the natural circulation. The gas is collected in the bottom plenum and directed back to the IHX. The size of the water tank and the size of the PAHX can be adjusted depending on the requirements of the incremental strategy for beyond DBA accidents. The inner diameters of the pipes connecting the PSACS and PCS are the same as used throughout the PCS $(0.7 \mathrm{~m})$; however, such large diameter might be unnecessary because of low gas mass flow rate through the PSACS. Table 3B.2-8 provides the summary of the PSACS parameters. The final PSACS design consists of four trains $(4 \times 50 \%)$, i.e., for each IHX, but the operation of only two trains out of four is sufficient for satisfactory performance during an SBO. 
Project No 06-040: Flexible Conversion Ratio Fast Reactor Systems Evaluation

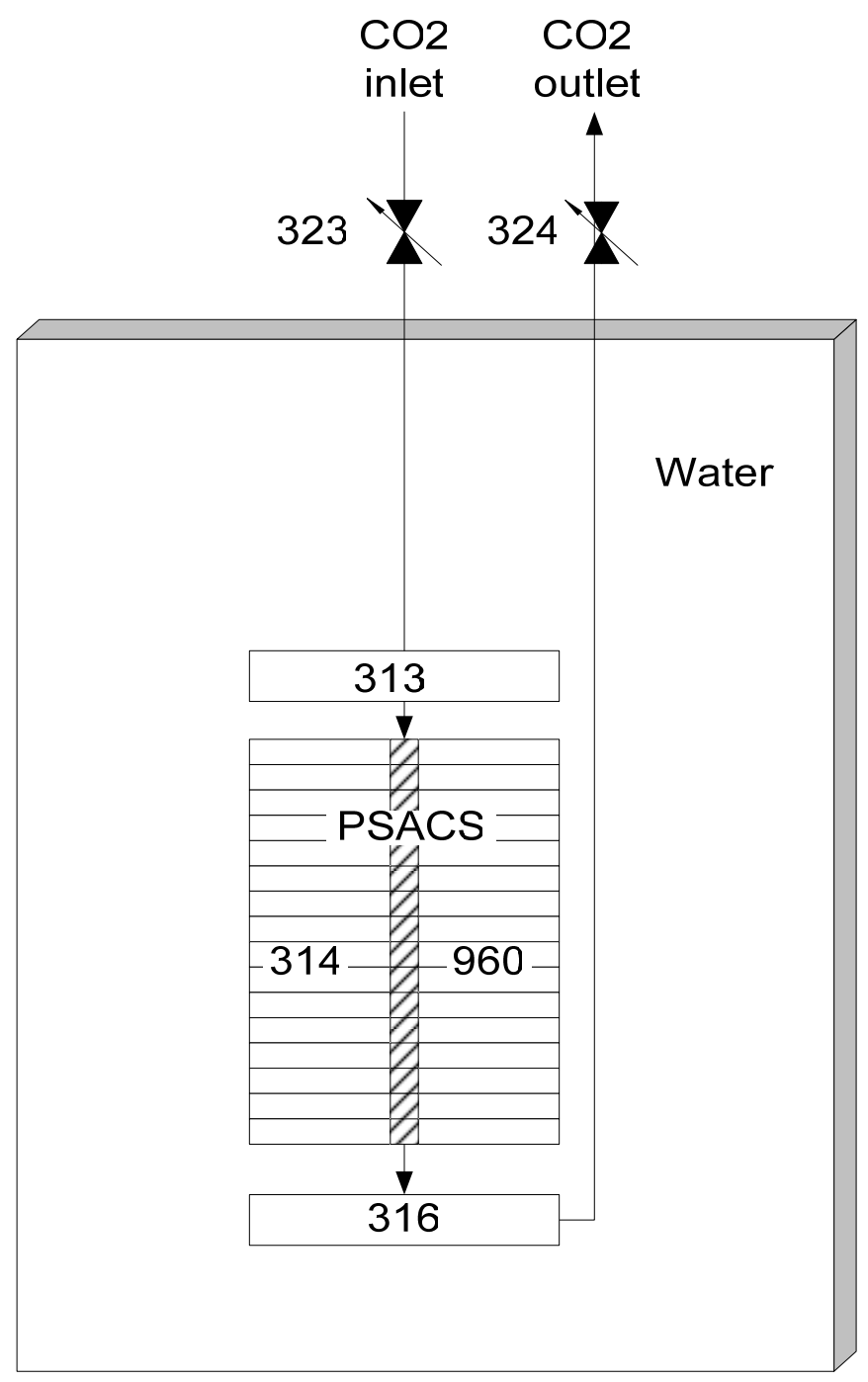

Figure 3B.2-3 RELAP5-3D schematic of PSACS.

Table 3B.2-8. Design parameters of the PSACS.

\begin{tabular}{|l|c|l|}
\hline Parameter & Initial Value & Comments/Remarks \\
\hline Water Tank $-\mathrm{H}_{2} \mathrm{O}$ initial conditions & \multicolumn{2}{|l|}{} \\
\hline $\mathrm{H}_{2} \mathrm{O}$ temperature $\left({ }^{\circ} \mathrm{C}\right)$ & 6.0 & $\begin{array}{l}\text { Room pressure and temperature } \\
\text { based on water properties and possible } \\
\text { duration of the accident. }\end{array}$ \\
\hline Tank diameter $(\mathrm{m})$ & 12.0 & \\
\hline Tank height $(\mathrm{m})$ & 700 & \\
\hline Passive Auxiliary Heat Exchanger & PAHX) & \\
\hline Number of tubes & 4.0 & \\
\hline Tube length $(\mathrm{m})$ & $10.5 \mathrm{E}-03$ & \\
\hline Inner diameter $-\mathrm{CO}_{2}$ side $(\mathrm{m})$ & $1.40 \mathrm{E}-02$ & \\
\hline Outer diameter $-\mathrm{water}$ side $(\mathrm{m})$ & 3.0 & \\
\hline P/D ratio & &
\end{tabular}


In the station blackout accident, the valves that would normally isolate the PSACS from the rest of the gas cycle start opening. Simultaneously, power conversion cycle valves close in order to isolate the turbomachinery from the rest of the loop. The purpose of the turbomachinery isolation is twofold: the gas must be directed through the PSACS equipment to remove as much heat as possible and to prevent the turbine rotational overspeed that would result in turbine blade damage. The turbine overspeed and the potential ways to overcome the problem are discussed in the Power Conversion System Model section. During the SBO accident, the valves 302, 306 and 326 shown in Figure 3B.2-1 will shut closed, isolating the PCS while the valves 323 and 324 will be open letting $\mathrm{CO}_{2}$ enter the PSACS.

The timeline of the station blackout accident with PSACS used to aid RVACS with the decay heat removal is presented in Table 3B.2-9. Time nodes $t_{1}$ and $t_{2}$ are to be determined by transient analysis and depend on the strategy chosen to mitigate the accident.

Table 3B.2-9. Timeline of the station blackout accident with PSACS

\begin{tabular}{|l|l|}
\hline Time & Event \\
\hline 0 seconds -0.5 seconds & $\begin{array}{l}\text { Both independent sources of offsite power } \\
\text { are simultaneously lost }\end{array}$ \\
& Failure to energize onsite emergency buses \\
Failure to SCRAM reactor \\
PCS isolation valves close due to loss of \\
AC \\
PSACS-Water isolation valve actuators de- \\
energized;
\end{tabular}




\section{B.2.5 Details of RELAP5-3D Model of PCS}

The SBO is the limiting transient case, and therefore requires PSACS for the decay heat removal. Moreover, the PSACS is required to be a part of the reactor system's decay heat removal because the PCS is classified as non-safety-grade. However, in case of the less severe transients, Loss of Flow and Transient Overpower, the PCS can be used to mitigate the accident while the PSACS is still available as the ultimate safety-grade equipment in case the PCS fails to perform its function. Note that the case when LOFA is accommodated with PSACS becomes identical to SBO since in order for PSACS to operate, the PCS isolation valves must fail closed.

The PCS is a recompression $\mathrm{S}-\mathrm{CO}_{2}$ cycle developed at MIT under other NERI and direct Generation IV funding via Sandia National Laboratory. Each loop of the $\mathrm{S}_{-} \mathrm{CO}_{2}$ PCS is $265 \mathrm{MWe}(600 \mathrm{MWt})$ power corresponding to one intermediate heat exchanger. The description of the PCS is provided in Section 2.2.2 and the detailed data are given in Appendix 2A. Figure 3B.2-4 shows the nodalization diagram of the PCS in RELAP5. Volumes 300 and 398 are the pressure and temperature boundary conditions of the cycle, since the cycle model was first generated and tested separately from the rest of the reactor systems.

The main components of the cycle shown in Figure 3B.2-4 include turbine, compressors, high and low temperature recuperators, precooler, and shaft and generator. The PCS is split into four loops. However, for computational efficiency, the loops are lumped into two loops $(2 \times 2$.) Thus, loop 300 is identical to loop 400 . The turbine represented by volume 315 is modeled with shaft speed of $3600 \mathrm{rpm}$ and efficiency of $94 \%$. The turbine is connected to the hot side of the high temperature recuperator (HTR) shown as volume 330. The flow is then directed into the hot side of the low temperature recuperator (LTR) represented by volume 340. Both HTR and LTR are modeled as heat exchangers with vertical semicircular channels. The diameter of the channels is $2 \mathrm{~mm}$. In volume 345 , the flow is split into two streams. $40 \%$ of the original flow is directed into the recompressing compressor 350 . The other $60 \%$ is cooled in the precooler 360 to $32^{\circ} \mathrm{C}$, after which it is pumped through main compressor 365. The precooler is a heat exchanger in which the gas is the primary fluid on the tube side, and water is on the secondary shell side. The water flow is simulated by time-dependent volumes 600 and 620 . The mass flow rate of water through the precooler is kept constant at $4625 \mathrm{~kg} / \mathrm{s}$, and the inlet temperature is assumed to be $20^{\circ} \mathrm{C}$. Both compressors are modeled as homologous pumps. The RELAP5/ATHENA code has the capability of modeling compressors with detailed performance curves. However, the band of operating conditions for the axial compressors is generally rather constricted, which can result in flow surge or choke during transient simulation [Pope, et al., 2006]. A transient resulting in choke or surge would immediately be stopped. This is the main reason for the approximation of compressors as homologous pumps. The model can be advanced with radial compressors which allow for wider operating range, but this is left for future work.

Once disconnected from the grid, the turbine provides energy to drive compressors mounted on the same shaft and circulate $\mathrm{CO}_{2}$ flow through the IHXs, making it possible to remove significant power from the reactor vessel without electrical power supply. A proportional-integral (PI) controller shown in Figure 3B.2-4 can be used to periodically adjust valve position to maintain an acceptable turbine speed. 
Project No 06-040: Flexible Conversion Ratio Fast Reactor Systems Evaluation

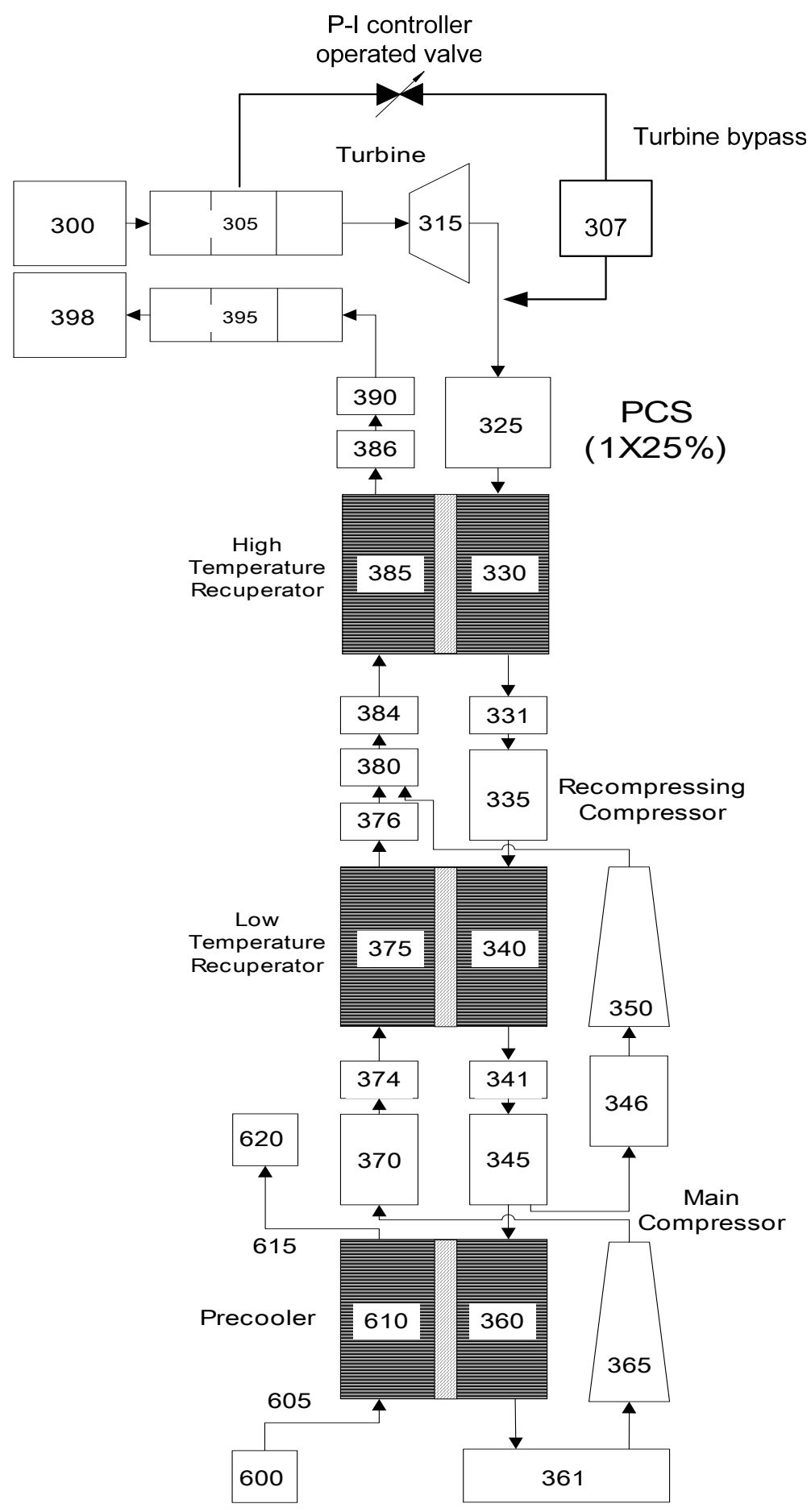

Figure 3B.2-4 RELAP5 Nodalization Diagram 


\section{B.2.6 Modifications for salt reactor design}

The following components were changed from the lead reactor model to model the salt reactor: reactor core, chimney and downcomer geometries, IHXs, primary coolant pumps, and secondary side precoolers (ultimate heat sinks). Additionally, the salt RELAP model introduces the use of virtual free levels to model the two free levels in the reactor vessel.

The reactor core model was completely rewritten for the salt core, to account for its different geometry, radial and axial power shapes, reactor physics characteristics, and the presence of LEMs. Details for these modifications are given below. The chimney and downcomer geometries were changed to account for the different core/IHX sizes and the bottlenecked chimney, as were the heat structures associated with them; this has very little effect on system performance. The IHX model was rewritten to reflect the IHX design described in section 4.2.2.1.2. The IHX length was increased by $12 \mathrm{~cm}$ in the RELAP model to $6.9 \mathrm{~m}$ to better match the power transferred, and again surface roughness values were varied to match computed friction factors. Reactor coolant pump parameters were changed to reflect the different pumping power and mass flow rate required for the salt reactor. Finally, because changing the IHXs did slightly modify the performance of the power conversion system, the size of the precoolers was adjusted a small amount so the correct amount of power was rejected to the ultimate heat sink.

\section{Core model}

As with the lead core model, the salt core was divided into a hot channel and an average channel. Each channel was axially divided into 23 regions, one each for the blanket and reflector, 11 for the heated region of the core, and 10 for the gas plenum/LEM region above the core. Since the interior subchannels of the hot assemblies have the highest cladding temperatures, the hot channel in the RELAP model is composed exclusively of interior subchannels, rather than of entire assemblies. This hot channel is equivalent to the heated interior subchannels of 12 assemblies, all using a hot subchannel peaking factor $2 \%$ greater than the highest assembly peaking factor, the same peaking factor used in the subchannel model.

A summary of the core RELAP implementation is given in Tables 3B.2-10 and 3B.2-11. The hot channel area is different for the two conversion ratios because the $\mathrm{CR}=1$ core has more fuel rods and thus more heated channels per assembly. Because of the higher peaking in the $\mathrm{CR}=0$ core, the average channel is more strongly orificed, directing more flow through the hot channel. For the power multipliers, values are listed starting from the bottom of the core. Fuel conductivities for the salt reactor cores are assigned the same values as those for the lead reactor, given in Table 3B.2-3.

A simplification was made for modeling wire-wrap pressure drop in the salt core by adapting RELAP's Colebrook \& White correlation to match the results given by the Cheng-Todreas correlation. This was done by varying the value of the surface roughness parameter in the Colebrook \& White correlation so that the total pressure drop across the hot channel matched that in the subchannel model. Compared to the Cheng-Todreas correlation, this adapted Colebrook \& White correlation has a weaker dependence on Reynold's number; it tends to underpredict the friction factor for lower Reynolds numbers and overpredict it for higher 
Reynolds numbers. Over the range of Reynolds numbers for the reference core at steady state, the relative error is less than $5 \%$, which is less than the uncertainty of each correlation. This simplification may affect the accuracy of modeling transient behavior, which involves low Reynolds numbers, but is necessary because RELAP does not include an implementation of the Cheng-Todreas correlation.

Table 3B.2-11 Orificing and the flow split in the core

\begin{tabular}{|l|c|c|}
\hline & $\mathrm{CR}=1$ & $\mathrm{CR}=0$ \\
\hline Highest assembly peaking factor & 1.26 & 1.35 \\
\hline Number of assemblies & 12 & 12 \\
\hline Channel area $\left(\mathrm{m}^{2}\right)$ (hot/average) & $0.09391 / 4.48985$ & $0.09224 / 4.49152$ \\
\hline Orificing coefficients (hot/average) & $0.0 / 13.610$ & $0.0 / 23.116$ \\
\hline Mass flow rate $(\mathrm{kg} / \mathrm{s})$ (hot/average) & $771 . / 32034$. & $833 . / 31972$. \\
\hline
\end{tabular}

Table 3B.2-12 Internal power multipliers.

\begin{tabular}{|c|c|c|c|c|c|}
\hline \multicolumn{3}{|c|}{ CR=1 } & \multicolumn{3}{c|}{ CR=0 } \\
\hline $\begin{array}{c}\text { Axial power } \\
\text { shape }\end{array}$ & Average & Hot & $\begin{array}{c}\text { Axial power } \\
\text { shape }\end{array}$ & Average & Hot \\
\hline 0.706 & 0.06218 & 0.00199 & 0.601 & 0.05282 & $\mathbf{0 . 0 0 1 8 2}$ \\
0.886 & 0.07804 & 0.00250 & 0.823 & 0.07233 & $\mathbf{0 . 0 0 2 4 9}$ \\
1.057 & 0.09310 & 0.00299 & 1.014 & 0.08912 & $\mathbf{0 . 0 0 3 0 6}$ \\
1.187 & 0.10455 & 0.00335 & 1.158 & 0.10177 & $\mathbf{0 . 0 0 3 5 0}$ \\
1.261 & 0.11106 & 0.00356 & 1.247 & 0.10960 & $\mathbf{0 . 0 0 3 7 7}$ \\
1.276 & 0.11239 & 0.00360 & 1.277 & 0.11223 & $\mathbf{0 . 0 0 3 8 6}$ \\
1.229 & 0.10825 & 0.00347 & 1.246 & 0.10951 & $\mathbf{0 . 0 0 3 7 6}$ \\
1.124 & 0.09900 & 0.00317 & 1.157 & 0.10169 & $\mathbf{0 . 0 0 3 5 0}$ \\
0.966 & 0.08508 & 0.00273 & 1.016 & 0.08929 & $\mathbf{0 . 0 0 3 0 7}$ \\
0.766 & 0.06747 & 0.00216 & 0.832 & 0.07312 & $\mathbf{0 . 0 0 2 5 1}$ \\
$\mathbf{0 . 5 4 3}$ & $\mathbf{0 . 0 4 7 8 3}$ & $\mathbf{0 . 0 0 1 5 3}$ & $\mathbf{0 . 6 2 9}$ & $\mathbf{0 . 0 5 5 2 8}$ & $\mathbf{0 . 0 0 1 9 0}$ \\
\hline
\end{tabular}

To benchmark the RELAP core model, it was run at $2400 \mathrm{MWt}$ and a total coolant flow rate of $3.28 \mathrm{E} 4 \mathrm{~kg} / \mathrm{s}$, corresponding to the nominal steady state operating conditions. The pressure drop across the core and coolant and cladding temperatures were compared to the values obtained by the subchannel model. Results are given in Figures 3B.2-5 and 3B.2-6. As these figures show, there is extremely good agreement between the RELAP model and the subchannel model used to develop the core. The total pressure drop across the core matches within $2 \mathrm{kPa}$, the matching coolant temperatures show the correct flow split has been achieved, and the peak cladding temperature matches within $1{ }^{\circ} \mathrm{C}$. 
Project No 06-040: Flexible Conversion Ratio Fast Reactor Systems Evaluation

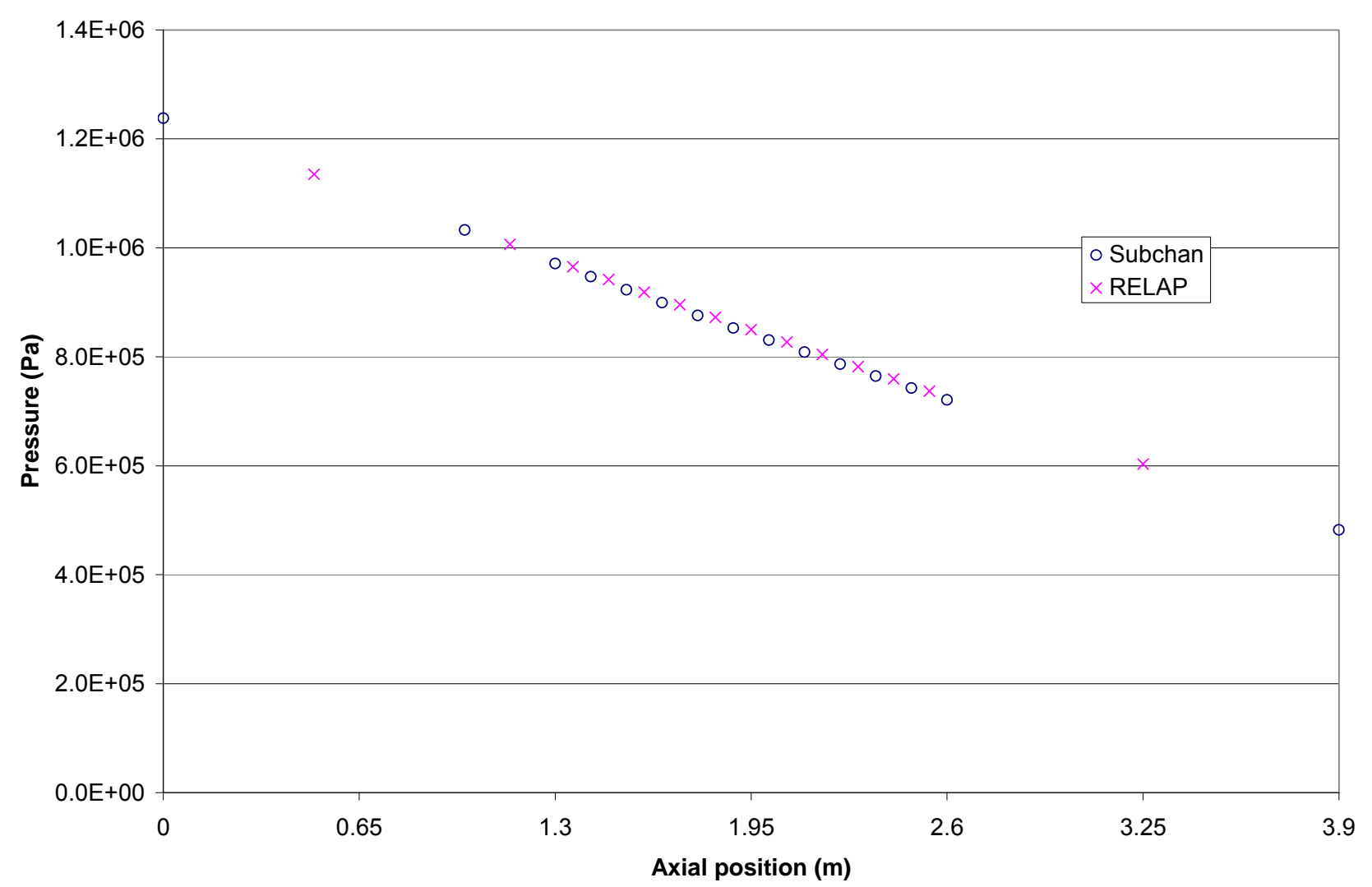

Figure 3B.2-5 RELAP and subchannel model pressure drop comparison

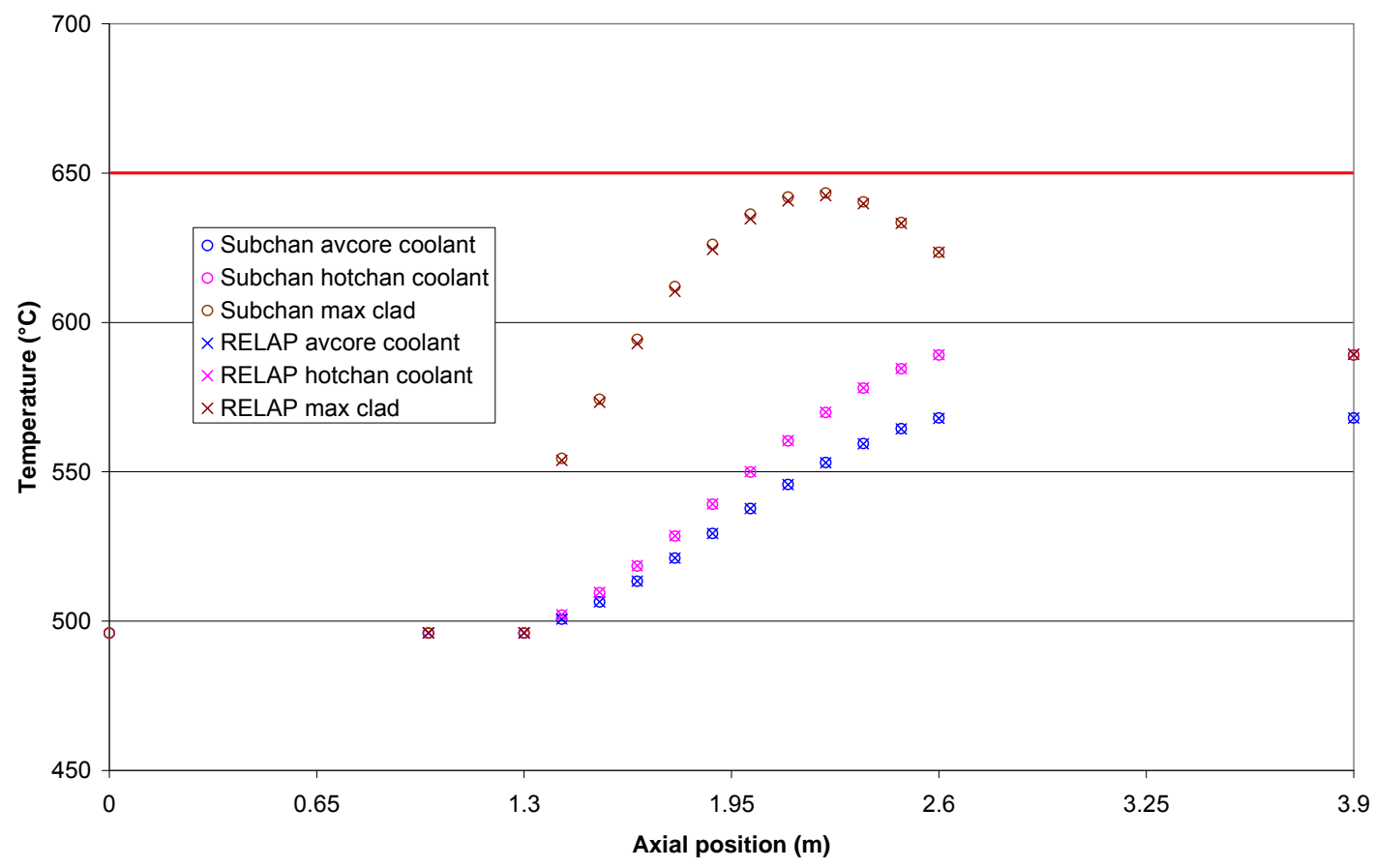

Figure 3B.2-6 RELAP and subchannel temperature comparison 
Project No 06-040: Flexible Conversion Ratio Fast Reactor Systems Evaluation

\section{Lithium expansion module model}

The hydrodynamic volumes and heat structures above the core corresponding to the gas plena were modified to incorporate the presence of LEMs. First, they were divided into 10 axial nodes 0.13 meters long each to obtain a better estimate of time dependent heat transfer to the LEMs. Part of the heat structure above the core average channel corresponding to gas plena was replaced by heat structures modeling the LEM lithium reservoirs. These LEM heat structures consist of three radial nodes bounding two meshes: the first mesh extends from a radius of $0.0 \mathrm{~mm}$ to $3.26 \mathrm{~mm}$ and is composed of liquid lithium, and the second mesh extends from $3.26 \mathrm{~mm}$ to $3.76 \mathrm{~mm}$ and is composed of T-91 cladding material. Heat transfer in the liquid lithium is assumed to be due to conduction only, which is reasonable for stationary liquid metals. Molten lithium properties are taken from Ohse [1985]. Heat transfer from the primary coolant to the LEMs is calculated using the same Gnielinski correlation used for the active core.

The average temperature of the liquid lithium at the centerline node of the LEM heat structure is calculated using RELAP control variables. This LEM reservoir temperature is converted to a reactivity insertion using a RELAP general table function, according to the temperaturereactivity curves specified in the section on LEM design, and is added to the contributions from the other reactivity feedbacks. The reactivity contribution of LEMs is also given in Section 3B.2-7 of this appendix.

\section{Intermediate heat exchanger model}

The salt reactor intermediate heat exchangers were designed using the same spreadsheet model as the lead reactor IHXs, with some small differences specified in Appendix 3C. A comparison of RELAP model results with the spreadsheet results is given in Table 3B.2-13. The two sets of results do not match exactly because RELAP uses a different correlation (Colebrook-White with fitted roughness term) for pressure losses than the spreadsheet model. Also, the RELAP model incorporates the power lost through the RVACS and power gained from the reactor coolant pumps, meaning the RELAP heat exchangers do not reject exactly 600MW each. Nevertheless, results agree very well and validate the performance of the RELAP model.

\section{Virtual free levels}

A limitation in the current RELAP5-3D version means that free levels cannot be modeled for some coolants, including sodium and liquid salt. This limitation relates to partial pressure of coolant vapor in the gas-filled free space, thus the primary system model cannot include any air and must be completely filled with coolant. However, free levels are an integral part of the dualfree-level design, and free level positions must be known to determine if there is any overflow or if any components become exposed to air. Furthermore, the free level position in the outer annulus determines the amount of heat removed by the RVACS, since heat transfer to the guard vessel is much higher below the free level than above it. To account for free level positions without being able to explicitly model them, "virtual free levels" were built into the salt reactor RELAP model. 
Table 3B.2-13 Comparison of salt reactor heat exchanger performance between Excel calculations and RELAP5-3D simulation

\begin{tabular}{|c|c|c|}
\hline INPUT & Excel calculations & $\begin{array}{c}\text { RELAP5-3D } \\
\text { simulation }\end{array}$ \\
\hline Core power (MWt) & \multicolumn{2}{|c|}{2400} \\
\hline Salt mass flow rate $(\mathrm{kg} / \mathrm{s})$ & \multicolumn{2}{|c|}{32800} \\
\hline $\mathrm{S}-\mathrm{CO}_{2}$ mass flow rate $(\mathrm{kg} / \mathrm{s})$ & \multicolumn{2}{|c|}{12848} \\
\hline Number of heat exchangers & \multicolumn{2}{|c|}{4} \\
\hline $\begin{array}{l}\text { Target power transmitted in the IHX (per IHX) } \\
\text { (MWt) }\end{array}$ & \multicolumn{2}{|c|}{600} \\
\hline Salt inlet temperature $\left({ }^{\circ} \mathrm{C}\right)$ & \multicolumn{2}{|c|}{569.} \\
\hline Salt outlet temperature $\left({ }^{\circ} \mathrm{C}\right)$ & \multicolumn{2}{|c|}{496.} \\
\hline S-CO ${ }_{2}$ inlet temperature $\left({ }^{\circ} \mathrm{C}\right)$ & \multicolumn{2}{|c|}{397.} \\
\hline S-CO $\mathrm{CO}_{2}$ target outlet temperature $\left({ }^{\circ} \mathrm{C}\right)$ & \multicolumn{2}{|c|}{548.} \\
\hline $\mathrm{S}-\mathrm{CO}_{2}$ pressure $(\mathrm{MPa})$ & \multicolumn{2}{|c|}{19.7} \\
\hline \multicolumn{3}{|l|}{ GEOMETRY } \\
\hline Lattice & \multicolumn{2}{|c|}{ Triangular } \\
\hline Number of tubes (per IHX) & \multicolumn{2}{|c|}{21989} \\
\hline Outer tube diameter $(\mathrm{mm})$ & \multicolumn{2}{|c|}{13} \\
\hline Tube wall thickness (mm) & \multicolumn{2}{|c|}{2.02} \\
\hline Pitch to diameter ratio & \multicolumn{2}{|c|}{1.23} \\
\hline Inner IHX radius $\left(r_{i}\right)(m)$ & \multicolumn{2}{|c|}{2.551} \\
\hline Outer IHX radius $\left(\mathrm{r}_{\mathrm{o}}\right)(\mathrm{m})$ & \multicolumn{2}{|c|}{4.465} \\
\hline \multicolumn{3}{|l|}{ OUTPUT } \\
\hline Calculated power (MWt) & 600.0 & 601.4 \\
\hline Tube length $(\mathrm{m})$ & 6.78 & 6.90 \\
\hline Logarithmic temperature difference $\left({ }^{\circ} \mathrm{C}\right)$ & 49.9 & N/A \\
\hline S-CO $\mathrm{CO}_{2}$ velocity (average) $(\mathrm{m} / \mathrm{s})$ & 16.8 & 17.2 \\
\hline Salt velocity (average) $(\mathrm{m} / \mathrm{s})$ & 2.29 & 2.30 \\
\hline $\begin{array}{l}\mathrm{S}-\mathrm{CO}_{2} \text {-side pressure drop (through small tubes) } \\
(\mathrm{kPa})\end{array}$ & 291 & 293 \\
\hline Salt-side pressure drop $(\mathrm{kPa})$ & 116 & 116 \\
\hline
\end{tabular}

To construct the virtual free level model, first volumes where air would have been present in the reactor vessel were removed from the model (parts of volumes 540 and 580, as well as all of volume 599). This way, the virtual free level model would contain the same amount of coolant and have the same thermal inertia as the actual reactor system. What results are two "ceilings" close to where the free levels should be, one above the chimney and one along the periphery of the vessel, where the second riser and downcomer are. This is depicted in Figure 3B.2-7, with the dot-dash lines indicating the positions of the ceilings. 


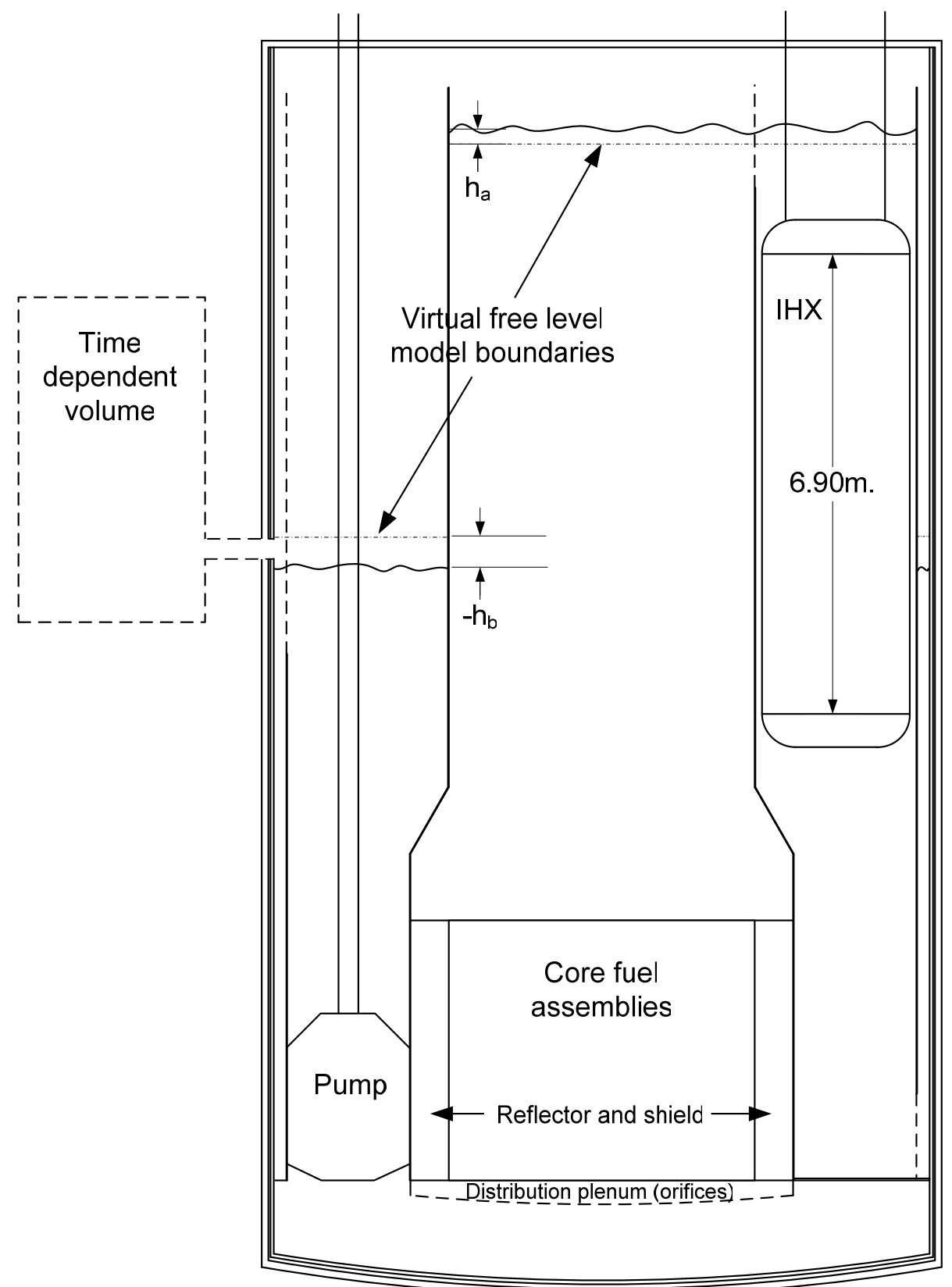

Figure 3B.2-7 Vessel layout showing virtual free levels and time dependent volume

In order to allow for thermal expansion, a time-dependent volume (number 588) was connected to the top of peripheral riser; this functions similarly to a pressurizer by holding the pressure constant while allowing coolant to enter and exit. With this model, it is possible to calculate where the free level positions should be based on the pressures at the ceilings and total mass of coolant in the system. First, imagine that the "correct" free level positions exist at height $h_{a}$ and $h_{b}$ above the ceilings, where the subscript $a$ denotes the hot free level (chimney) and $b$ denotes the cold free level (periphery); these heights can also be negative. Then, the total mass of coolant in the system is simply:

$$
M_{\text {total }}=M_{\text {model }, i}+\rho_{a, i} A_{a} h_{a, i}+\rho_{b, i} A_{b} h_{b, i}=M_{\text {model }}+\rho_{a} A_{a} h_{a}+\rho_{b} A_{b} h_{b}
$$


Here $A$ is the area of the free level, $\rho$ is the coolant density at the free level, and the subscript $i$ represents initial or nominal conditions. $M_{\text {model }}$ is the total mass of coolant modeled by RELAP, the actual total coolant mass $M_{\text {total }}$ is simply this mass plus the mass of the "virtual" coolant not modeled (Recall that vessel volume is initially chosen so that $M_{\text {total }} \approx M_{\text {model, }, i}$ ). This equation takes into account the effect of thermal expansion; if the coolant heats up and expands, some of it will be pushed into the time-dependent volume, reducing the mass of coolant in the model. For the total coolant mass to remain constant, there must be more virtual coolant, i.e. the free levels must rise. To determine the relative position of the free levels, one can use the fact that both free levels are at the same atmospheric pressure:

$$
P_{a}-\rho_{a} g h_{a}=P_{b}-\rho_{b} g h_{b}
$$

Here $P_{a}$ and $P_{b}$ are the coolant pressures measured by RELAP at the "ceilings" of the model; subtracting the hydrostatic pressure due to virtual coolant yields the pressure at the virtual free levels. Together these two equations allow one to solve for the free level positions $h_{a}$ and $h_{b}$, since all other quantities can be derived from RELAP output.

The final step of the virtual free level model is connecting the position of the peripheral free level $h_{b}$ to RVACS performance. This is necessary because heat transfer to the guard vessel from the atmosphere above the coolant free level is much lower than from the coolant below the free level. This is done using a first-order approximation, depicted graphically in Figure 3B.2-8. The blue diamonds show RVACS heat flux as a function of height along the periphery in the lead reactor, which has an explicitly modeled free level. One can see that the heat flux decreases linearly below the free level, then falls dramatically to an approximately constant value above the free level, where heat transfer from the cover gas inside the vessel to the guard vessel constitutes the primary thermal resistance. One can assume similar behavior exists for the salt reactor - a linear decrease below the free level then a small and constant value above it. In the virtual free level salt reactor model, only heat fluxes below the ceiling are computed by RELAP, however these heat flux values for the salt reactor can be extrapolated to the virtual free level position as shown by the dashed line in Figure 3B.2-8. Above the free level the heat flux is assumed to have the same constant value as for the lead reactor, which is reasonable since the cover gas in the salt and lead reactor vessels will be similar. The total heat removed by the RVACS is then the sum over the modeled heat fluxes and the extrapolated amount, which is the L-shaped area under the dashed curve in Figure 3B.2-8. Control variables were used to perform the extrapolation described and calculate the total amount of additional heat that should be removed by the RVACS. To actually remove the heat from the coolant in the virtual free level model, an artificial heat structure was set up at the top of the peripheral riser that would reject this calculated amount of heat based on these control variables. 
Project No 06-040: Flexible Conversion Ratio Fast Reactor Systems Evaluation

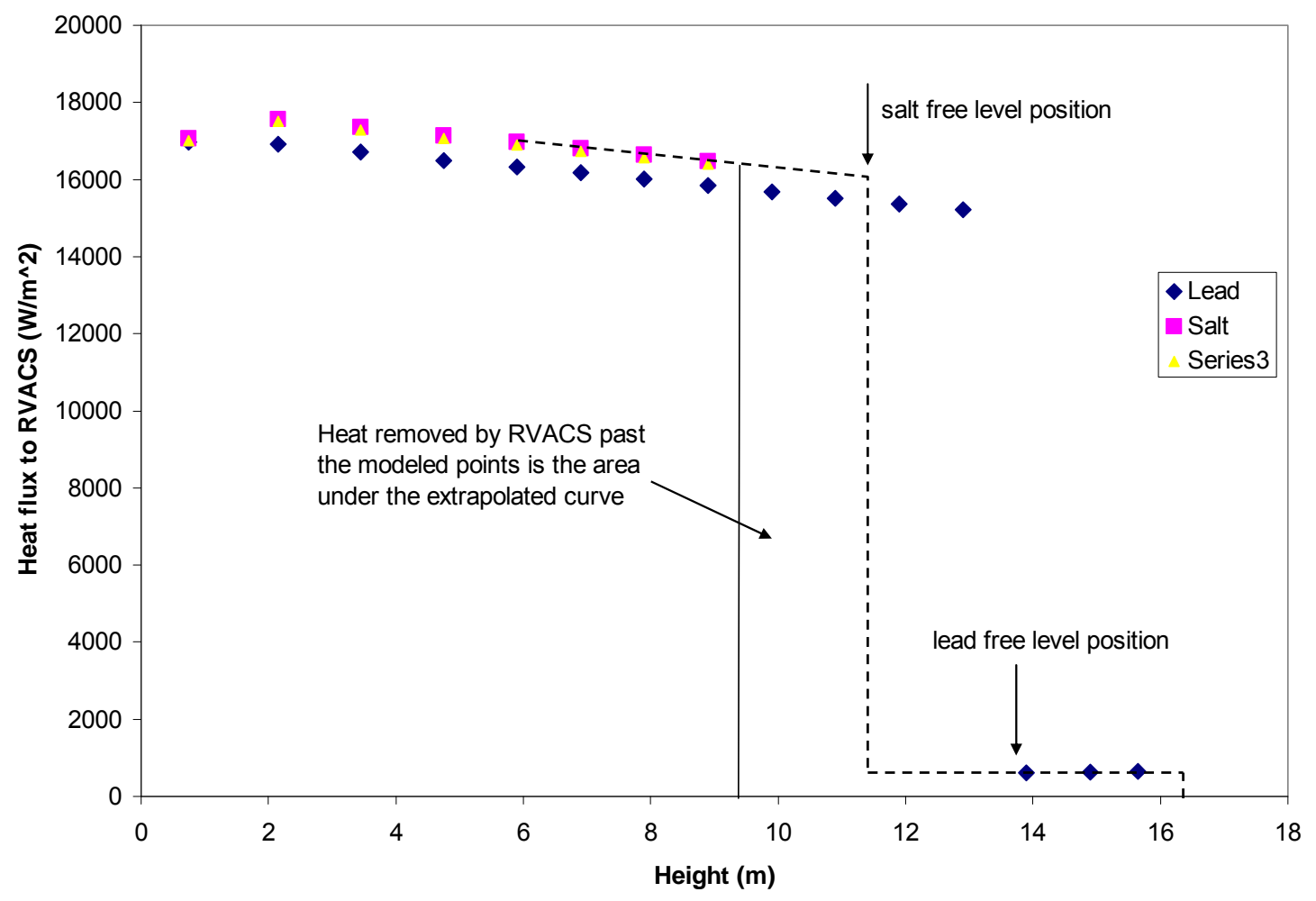

Figure 3B.2-8 RVACS heat flux as a function of position

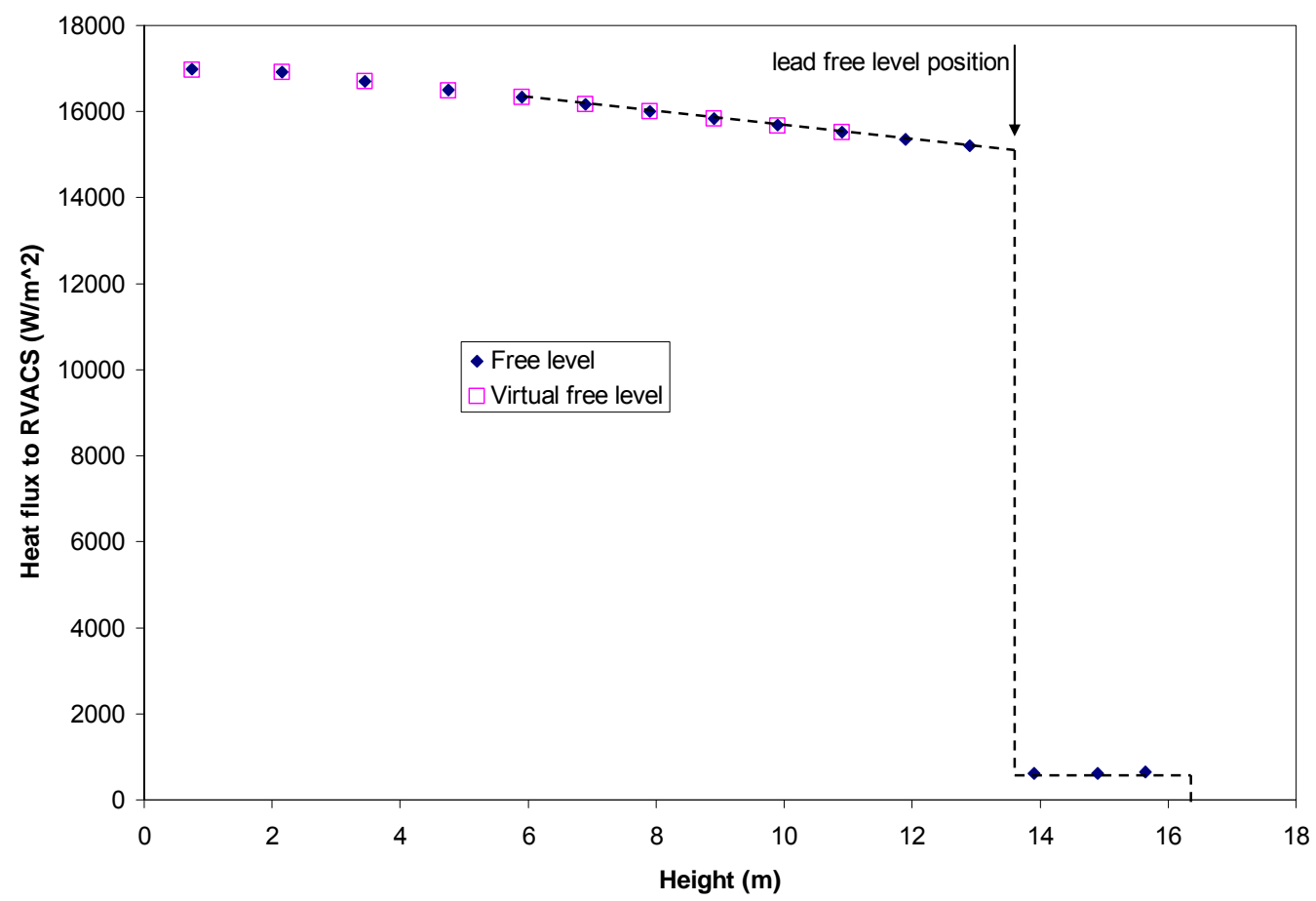

Figure 3B.2-9 RVACS heat flux for explicit- and virtual-free-level models 
To benchmark the virtual free level model, it was implemented and tested as part of the lead reactor model and compared against the run with actual free level (note that lead coolant allows modeling of actual free levels since the issue of partial coolant pressure has been resolved in RELAP5-3D for lead). The testing demonstrated that heat fluxes from the coolant to the RVACS were nearly identical for the virtual free level model and the original (explicit free level) model, (Figure 3B.2-9) showing that the linear extrapolation method employed is accurate. While the virtual free level model possesses the same thermal inertia as the system being modeled, it does not account for the movement of coolant masses. For example, during a loss of flow accident the coolant level will fall in the chimney and rise in the periphery; in the virtual free level model this movement is tracked but no actual coolant migration occurs. Finally, there is a small error introduced by the movement of coolant into and out of the time dependent volume due to thermal expansion; this amount is less than 5\% for a bounding accident and therefore does not significantly impact results.

\section{Incorporation of chloride salt properties into RELAP5-3D}

It was necessary to first implement the properties of the selected coolant salt into the RELAP53D executable before any of the salt systems could be modeled. This was done by Cliff Davis at Idaho National Laboratory and Matthew Memmott at MIT, based on the set of salt properties submitted to them by this project. In addition to the basic thermal hydraulic properties described in the salt properties section of this report (density, viscosity, thermal conductivity, and heat capacity), RELAP also requires values for salt isothermal compressibility, vapor pressure, vapor properties, surface tension, as well as triple point and critical point properties. Data for many of these properties do not exist, so values similar to properties of other liquid salts were used. Since the coolant in the liquid salt-cooled reactor never approaches the saturation line or sonic velocities, the values of these properties have no effect on the results obtained. The salt property values implemented into RELAP are given in Tables 3B.2-14 numbers 1 through 9 below. The symbols used for the properties are the same as those used in the report "Implementation of Molten Salt Properties into RELAP5-3D/ATHENA" (INEEL/EXT-05-02658).

Tables 3B.2-14 NaCl-KCl-MgCl 2 (30\%-20\%-50\%) properties for RELAP

Table 1. Constants for liquid salt

\begin{tabular}{|l|c|}
\hline $\mathrm{T}_{\text {melt }}(\mathrm{K})$ & 669.15 \\
\hline $\mathrm{A}_{\mathrm{D}}\left(\mathrm{kg} / \mathrm{m}^{3}-\mathrm{K}\right)$ & -0.778 \\
\hline $\mathrm{B}_{\mathrm{D}}\left(\mathrm{kg} / \mathrm{m}^{3}\right)$ & 2260 \\
\hline $\mathrm{A}_{\mathrm{K}}(1 / \mathrm{Pa})$ & $1.62 \mathrm{E}-10$ \\
\hline $\mathrm{B}_{\mathrm{K}}(1 / \mathrm{K})$ & 0.0018 \\
\hline $\mathrm{c}_{\mathrm{P}}(\mathrm{J} / \mathrm{kg}-\mathrm{K})$ & 1005. \\
\hline
\end{tabular}

Table 2. Parameters for vapor components

\begin{tabular}{|c|c|c|}
\hline Component & $\mathrm{Mi}(\mathrm{g} / \mathrm{mol})$ & $\widetilde{\mathrm{c}}_{\mathrm{P}_{i}}(\mathrm{~J} / \mathrm{mol}-\mathrm{K})$ \\
\hline $\mathrm{NaCl}$ & 58.443 & 37.921 \\
\hline $\mathrm{KCl}$ & 74.551 & 38.061 \\
\hline $\mathrm{MgCl}_{2}$ & 95.211 & 61.748 \\
\hline
\end{tabular}


Table 3. Constants for salt vapor

\begin{tabular}{|l|c|}
\hline $\mathrm{M}(\mathrm{g} / \mathrm{mole})$ & 80.049 \\
\hline $\mathrm{R}(\mathrm{J} / \mathrm{kg}-\mathrm{K})$ & 103.862 \\
\hline $\mathrm{c}_{\mathrm{P}}(\mathrm{J} / \mathrm{kg}-\mathrm{K})$ & 662.9 \\
\hline
\end{tabular}

Table 4. Saturation line constants

\begin{tabular}{|l|c|}
\hline $\mathrm{A}_{\text {sat }}$ & 8.806 \\
\hline $\mathrm{B}_{\mathrm{sat}}(\mathrm{K})$ & 10375 \\
\hline
\end{tabular}

Table 5. Values for triple and critical points

\begin{tabular}{|l|c|}
\hline $\mathrm{T}_{0}(\mathrm{~K})$ & 669.15 \\
\hline $\mathrm{P}_{0}(\mathrm{~Pa})$ & $2.668 \mathrm{E}-5$ \\
\hline $\mathrm{T}_{\text {crit }}(\mathrm{K})$ & 2615.1 \\
\hline $\mathrm{P}_{\text {crit }}(\mathrm{Pa})$ & $9.196 \mathrm{E} 6$ \\
\hline
\end{tabular}

Table 6. Reference values for specific internal energy and specific entropy.

\begin{tabular}{|l|c|}
\hline $\mathrm{u}_{\mathrm{f} 0}(\mathrm{~J} / \mathrm{kg})$ & 0.0 \\
\hline $\mathrm{S}_{\mathrm{f} 0}(\mathrm{~J} / \mathrm{kg}-\mathrm{K})$ & 0.0 \\
\hline $\mathrm{u}_{\mathrm{g} 0}(\mathrm{~J} / \mathrm{kg})$ & $8.164 \mathrm{E} 5$ \\
\hline $\mathrm{s}_{\mathrm{g} 0}(\mathrm{~J} / \mathrm{kg}-\mathrm{K})$ & 3201 \\
\hline $\mathrm{u}_{\mathrm{crit}}(\mathrm{J} / \mathrm{kg})$ & $1.9042 \mathrm{E} 6$ \\
\hline $\mathrm{S}_{\mathrm{crit}}(\mathrm{J} / \mathrm{kg}-\mathrm{K})$ & 1356 \\
\hline
\end{tabular}

Table 7. Constants for transport properties of liquid.

\begin{tabular}{|l|c|}
\hline $\mathrm{A}_{\mu}(\mathrm{Pa}-\mathrm{s})$ & $5.18 \mathrm{E}-5$ \\
\hline $\mathrm{B}_{\mu}(\mathrm{K})$ & 3040 \\
\hline $\mathrm{K}(\mathrm{W} / \mathrm{m}-\mathrm{K})$ & 0.39 \\
\hline
\end{tabular}

Table 8. Constants for surface tension.

\begin{tabular}{|l|c|}
\hline $\mathrm{A}_{\sigma}(\mathrm{N} / \mathrm{m}-\mathrm{K})$ & $-4.31 \mathrm{E}-5$ \\
\hline $\mathrm{B}_{\sigma}(\mathrm{N} / \mathrm{m})$ & 0.1131 \\
\hline
\end{tabular}

Table 9. Parameters used for calculating the dynamic viscosity of the vapor components.

\begin{tabular}{|c|c|c|c|c|c|c|}
\hline Component & $\begin{array}{c}\mathrm{Mi} \\
(\mathrm{g} / \mathrm{mol})\end{array}$ & $\begin{array}{c}\widetilde{\mathrm{c}}_{\mathrm{P}_{i}} \\
(\mathrm{~J} / \mathrm{mole}-\mathrm{K})\end{array}$ & $\mathrm{T}_{\text {melt }}(\mathrm{K})$ & $\begin{array}{c}\widetilde{\mathrm{V}} \\
\left(\mathrm{cm}^{3} / \mathrm{mole}\right)\end{array}$ & $\left.\frac{\varepsilon}{\mathrm{K}}\right|_{\mathrm{i}}$ & $\begin{array}{c}\sigma_{\mathrm{i}} \\
(\AA)\end{array}$ \\
\hline $\mathrm{NaCl}$ & 58.443 & 37.921 & 1073.8 & 35.68 & 2062 & 4.02 \\
\hline $\mathrm{KCl}$ & 74.551 & 38.061 & 1044.0 & 46.38 & 2004 & 4.39 \\
\hline $\mathrm{MgCl}_{2}$ & 95.211 & 61.748 & 987.0 & 53.84 & 1895 & 4.61 \\
\hline
\end{tabular}




\section{B.2.7 RELAP5-3D Model of Reactivity Coefficients}

\section{Implementation in Lead-cooled Cores}

The reactivity coefficients are key parameters for correct determination of the reactor power generation during transients. The description of the quasi-static methodology used to determine the reactivity coefficients is provided in Section 2.1.2 of this report. In this section, the summary of the reactivity feedback model for RELAP5-3D is provided.

The latest values of recalculated coefficients with higher accuracy than those from initial calculations (see Section 2.1.2 for more discussion) were incorporated into the RELAP5-3D model. Tables 3.3.1-8 and 3.4.1-3 summarize the reactivity feedback coefficients for lead-cooled unity and zero conversion ratio cores, respectively. The beginning-of-life values for the $\mathrm{CR}=0$ and $\mathrm{CR}=1$ cores are used because they constitute the worst case. Coolant density coefficients as well as fuel temperature (Doppler) coefficients are modeled as functions of density and temperature, respectively, and an example of input for the models for the $\mathrm{CR}=1$ core are shown in Tables 3B.2-14 and 3B.2-15 and on Figures 3B.2-10 and 3B.2-11.

Table 3B.2-14 Density reactivity model for RELAP5-3D model for $\mathrm{CR}=1$.

\begin{tabular}{|c|c|c|c|}
\hline $\mathrm{T}\left({ }^{\circ} \mathrm{C}\right)$ & $\begin{array}{c}\text { Pb-Bi density } \\
(\mathrm{kg} / \mathrm{m} 3) \text { from RELAP }\end{array}$ & $\begin{array}{c}\text { Fitted reactivity } \\
(\mathrm{pcm})^{\mathrm{a}}\end{array}$ & $\begin{array}{c}\text { Reactivity }(\$) \\
\text { with } \beta=0.0036\end{array}$ \\
\hline 300 & $10439.46^{*}$ & 1912.74 & 5.313 \\
\hline 350 & $10345.42^{*}$ & 1948.10 & 5.411 \\
\hline 420 & 10222 & 1992.30 & 5.534 \\
\hline 450 & 10188 & 2009.35 & 5.582 \\
\hline 495 & 10137 & 2032.79 & 5.647 \\
\hline 519 & 10110 & 2044.25 & 5.678 \\
\hline 534 & $\mathbf{1 0 0 9 3 . 2 4}$ & $\mathbf{2 0 5 1 . 0 5}$ & 5.697 \\
\hline 547 & 10079 & 2056.71 & 5.713 \\
\hline 568 & 10055 & 2065.40 & 5.737 \\
\hline 581 & 10040 & 2070.50 & 5.751 \\
\hline 600 & 10020 & 2077.57 & 5.771 \\
\hline 650 & $9976.24^{*}$ & 2094.00 & 5.817 \\
\hline 700 & $9932.94^{*}$ & 2107.29 & 5.854 \\
\hline 800 & $9855.39^{*}$ & 2124.39 & 5.901 \\
\hline 1000 & $9727.14^{*}$ & 2120.76 & 5.891 \\
\hline 1500 & $9498.36^{*}$ & 1890.96 & 5.253 \\
\hline
\end{tabular}

* Extrapolated linearly $\rho=14,591 \cdot \mathrm{T}^{-0.0587}$

${ }^{\text {a }} \rho=-6.3064 \mathrm{E}-04 \mathrm{~T}^{2}+1.1170 \mathrm{~T}+1.6344 \mathrm{E}+03$ 
Project No 06-040: Flexible Conversion Ratio Fast Reactor Systems Evaluation

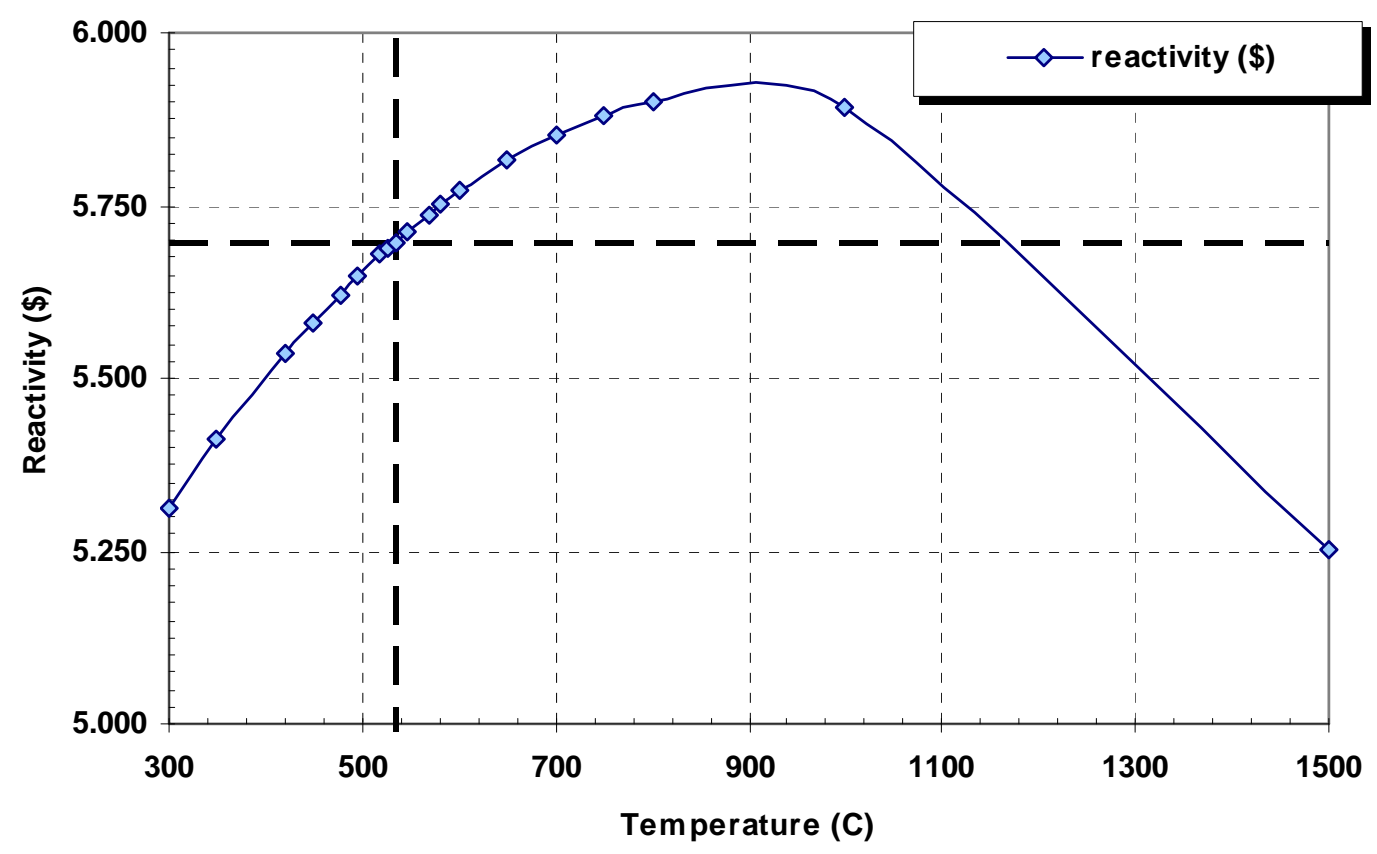

Figure 3B.2-10 Reactivity (\$) vs. coolant temperature. Dashed lines represent steady state active core average coolant temperature $\left(534^{\circ} \mathrm{C}\right)$ and corresponding reactivity.

Table 3B.2-15 Fuel temperature reactivity model for RELAP5-3D model for CR=1.

\begin{tabular}{|c|c|c|}
\hline $\begin{array}{c}\text { T (K) } \\
\text { of fuel }\end{array}$ & Fitted reactivity & $\begin{array}{c}\text { Reactivity }(\$) \\
\text { with } \beta=0.0036\end{array}$ \\
\hline 300 & 0.024361 & 6.767009 \\
\hline 400 & 0.023472 & 6.519953 \\
\hline 500 & 0.022671 & 6.297389 \\
\hline 600 & 0.021958 & 6.099318 \\
\hline 700 & 0.021333 & 5.925739 \\
\hline 800 & 0.020796 & 5.776652 \\
\hline 900 & 0.020347 & 5.652058 \\
\hline 1000 & 0.019987 & 5.551956 \\
\hline 1100 & 0.019715 & 5.476346 \\
\hline 1200 & 0.019531 & 5.425229 \\
\hline 1300 & 0.019435 & 5.398604 \\
\hline 1400 & 0.019427 & 5.396471 \\
\hline 1500 & 0.019508 & 5.418831 \\
\hline 1600 & 0.019676 & 5.465683 \\
\hline 1700 & 0.019933 & 5.537027 \\
\hline 1800 & 0.020278 & 5.632864 \\
\hline
\end{tabular}

The reason the curves are used for coolant density and Doppler reactivity models rather than simple coefficients is the strongly non-linear dependence of the reactivity coefficients on 
temperature. As can be seen in Figure 3B.2-10, the feedback is positive at nominal temperature but with decreasing slope as the temperature of the coolant increases. Hence the effect of the positive reactivity feedback of the coolant diminishes as the coolant heats up. On the other hand, the negative feedback of the fuel temperature is stronger when the temperatures are lower. Both effects result in very strong feedback when the core is cooled down. As is observed in Section 3.3.2.2, during an unprotected station blackout accident, once the core is cooled to a temperature corresponding to peak cladding temperature of about $608 \mathrm{~K}$, the restart of the reactor happens.

The core radial expansion and fuel thermal expansion effects are modeled with constant coefficients. The core radial expansion, Doppler, fuel thermal expansion, and coolant density coefficients are computed using a power squared weighting technique. The internal multipliers discussed in Section 3B.2.1 are used to calculate the average temperature of the coolant and fuel or the averaged density which is further applied to the reactivity model.

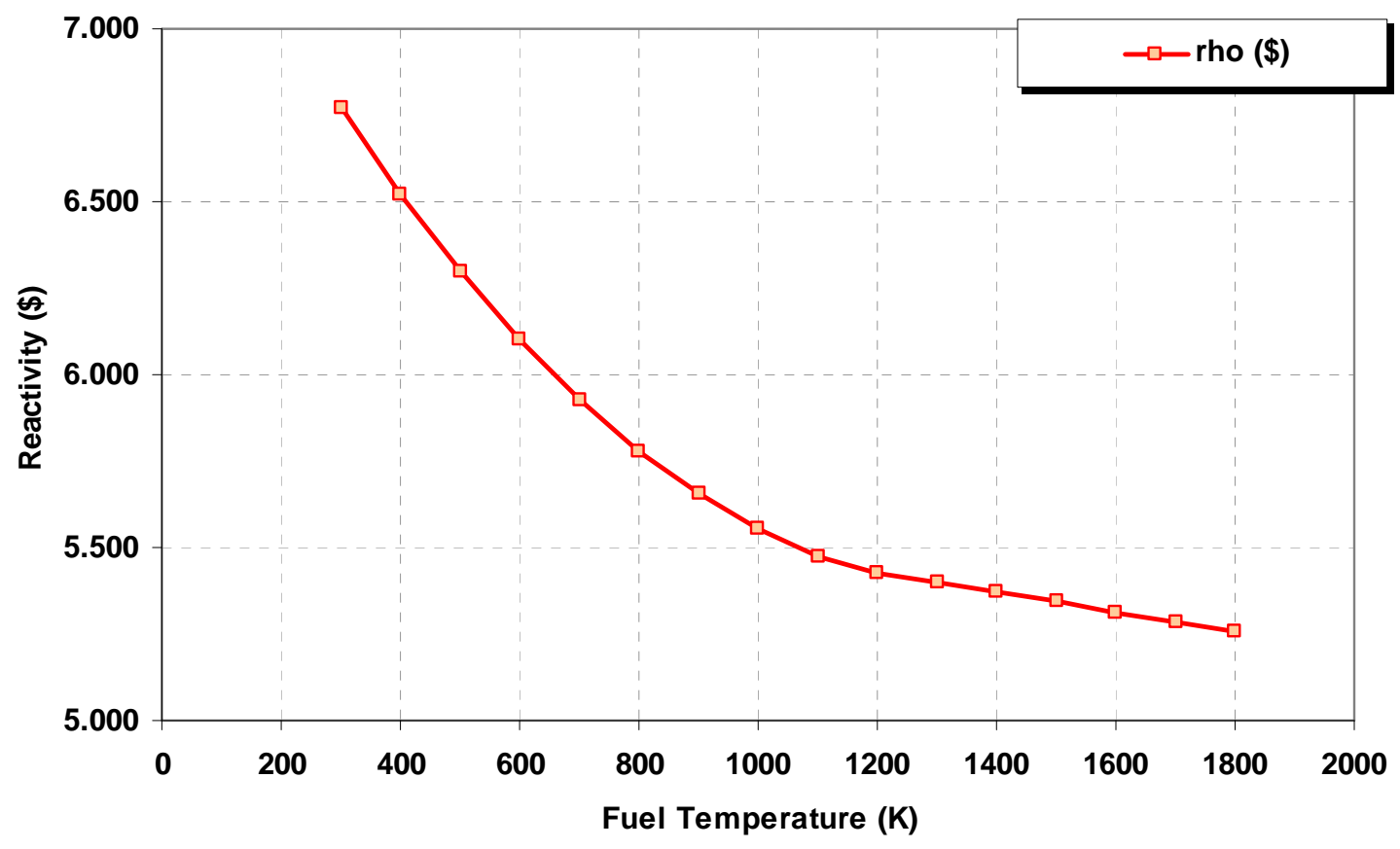

Figure 3B.2-11 Reactivity (\$) vs. fuel temperature.

Neutronic analysis of both cores was done assuming All Rods Out (ARO) conditions. Therefore, the temperature dependence of Doppler and coolant density reactivity coefficients shown on Figures 3B.2-5 and 3B.2-6 is several dollars. Although the reactivity of the core for the steady state conditions is zero, this representation is fine for RELAP5-3D calculations since RELAP5$3 \mathrm{D}$ uses the deviation in reactivity from the nominal conditions as a function of either temperature or density to calculate the reactivity dynamics during transients. The ARO reactivity coefficients were used because they provide conservative results because: (1) coolant temperature coefficient is less positive for CRDs in and (2) power peaking is reduced through appropriate control rod insertion management. 


\section{Salt reactor reactivity feedback implementation}

As with the lead reactor reactivity coefficients, beginning of life (BOL) values are used because they are more challenging in terms of transient response.

\section{Coolant temperature/density change}

The reactivity response to varying coolant temperature in the $\mathrm{CR}=1$ and $\mathrm{CR}=0$ cores is shown in Figures 3B.2-12 and 3B.2-13. Values implemented in RELAP are taken from the fitted equations and are given in Table 3B.2-18. The "average" value of core coolant density used by RELAP to determine the reactivity response is calculated using power-squared weighing, following the power multipliers given in Table 3B.2-12.

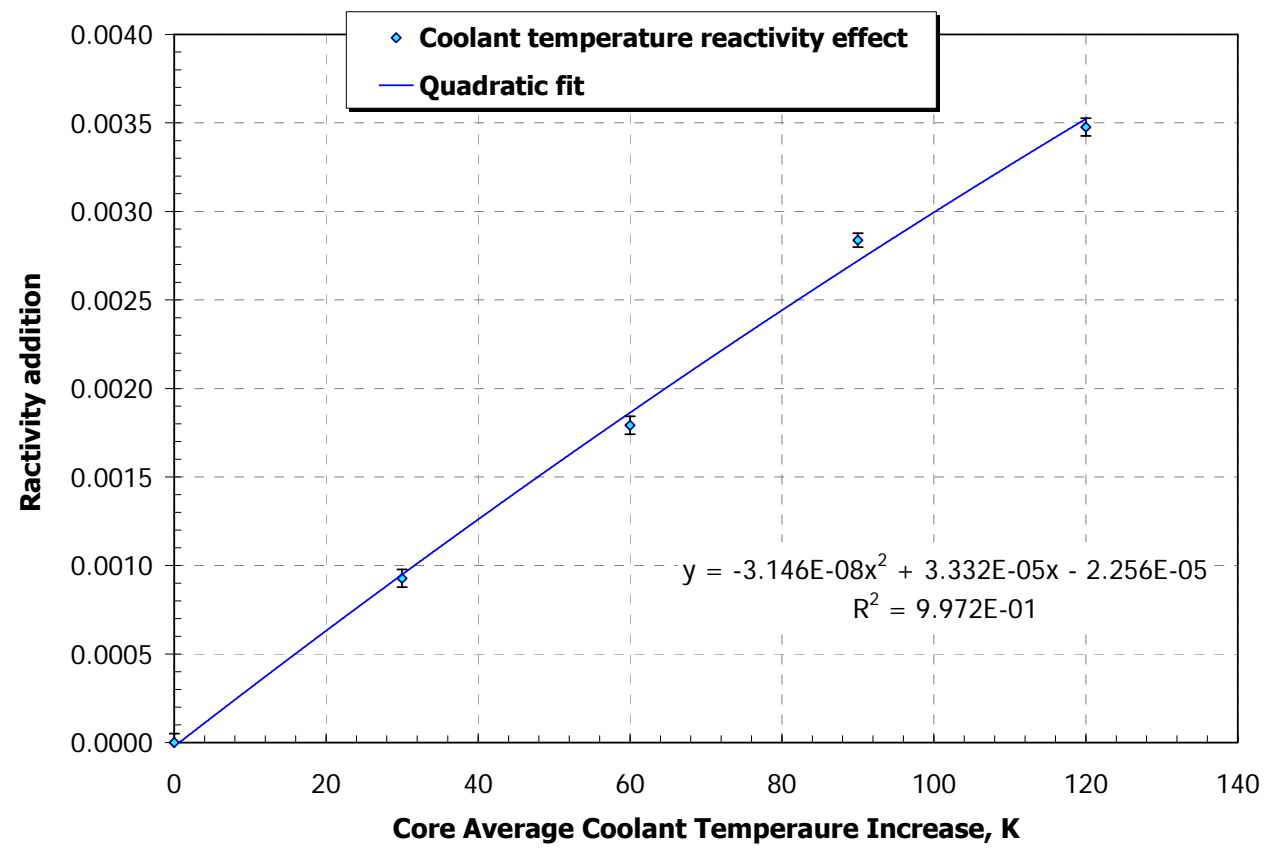

Figure 3B2.12 Reactivity insertion due to coolant thermal expansion, $\mathrm{CR}=1 \mathrm{BOL}$

\section{Fuel temperature (Doppler)}

The reactivity response to varying coolant temperature in the $\mathrm{CR}=1$ and $\mathrm{CR}=0$ cores is shown in Figures 3B.2-14 and 3B.2-15. Values implemented in RELAP are taken from the fitted power equations and are given in Table 3B.2-18. The "average" value of fuel temperature used by RELAP to determine the reactivity response is calculated using power-squared weighing, following the power multipliers given in Table 3B.2-13. 
Project No 06-040: Flexible Conversion Ratio Fast Reactor Systems Evaluation

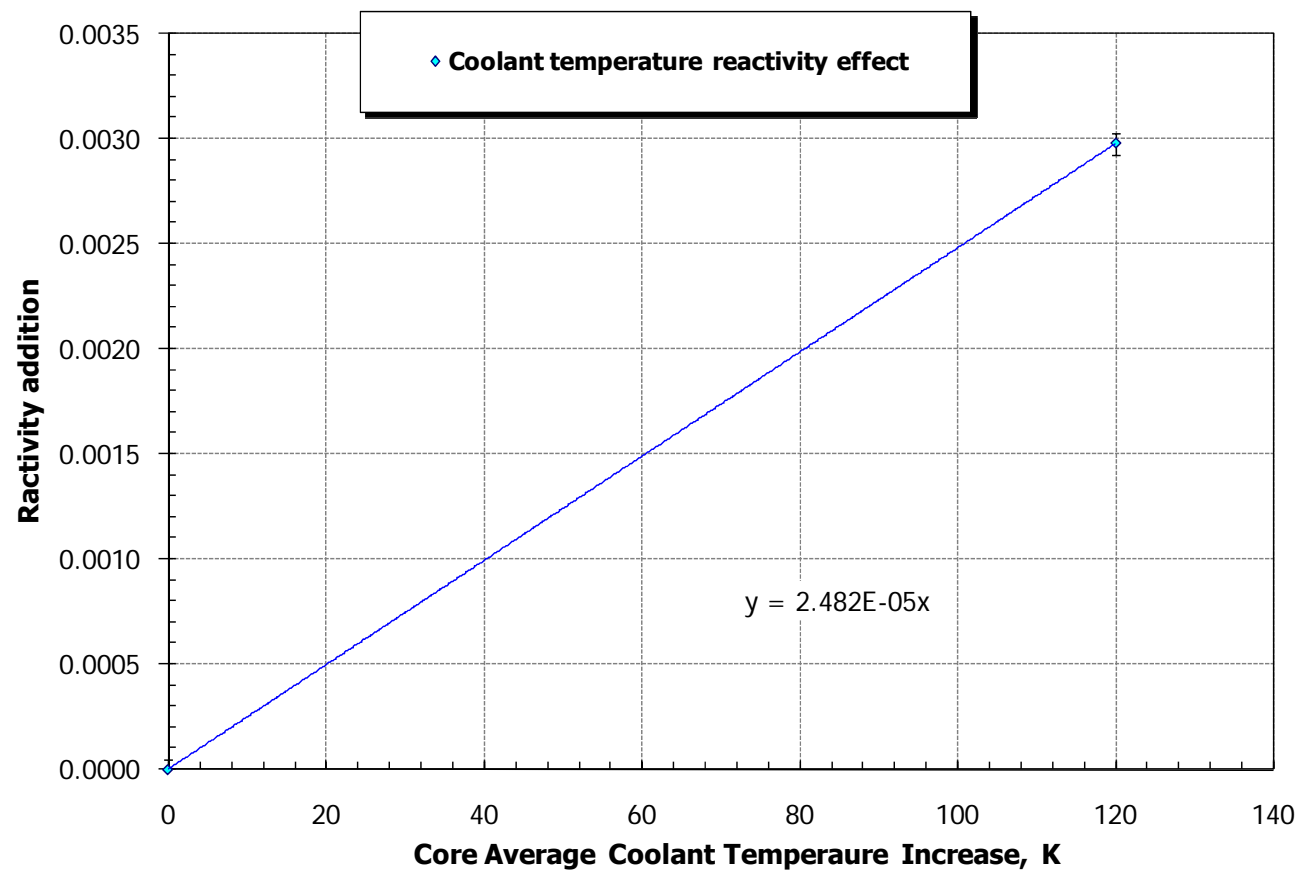

Figure 3B2.13 Reactivity insertion due to coolant thermal expansion, $\mathrm{CR}=0 \mathrm{BOL}$

Table 3B.2-18 Salt reactor coolant density reactivity model for RELAP5-3D

\begin{tabular}{|c|c|c|c|}
\hline $\mathrm{T}\left({ }^{\circ} \mathrm{C}\right)$ & $\begin{array}{c}\text { Salt density } \\
(\mathrm{kg} / \mathrm{m} 3)\end{array}$ & $\begin{array}{c}\mathrm{CR}=1 \text { reactivity }(\$) \\
\beta=0.00389\end{array}$ & $\begin{array}{c}\mathrm{CR}=0 \text { reactivity }(\$) \\
\beta=0.00298\end{array}$ \\
\hline 853 & 1596.4 & $1.907 \mathrm{E}+00$ & $2.665 \mathrm{E}+00$ \\
\hline 833 & 1611.9 & $1.836 \mathrm{E}+00$ & $2.499 \mathrm{E}+00$ \\
\hline 813 & 1627.5 & $1.759 \mathrm{E}+00$ & $2.332 \mathrm{E}+00$ \\
\hline 793 & 1643.0 & $1.675 \mathrm{E}+00$ & $2.166 \mathrm{E}+00$ \\
\hline 773 & 1658.6 & $1.584 \mathrm{E}+00$ & $1.999 \mathrm{E}+00$ \\
\hline 753 & 1674.2 & $1.487 \mathrm{E}+00$ & $1.832 \mathrm{E}+00$ \\
\hline 733 & 1689.7 & $1.384 \mathrm{E}+00$ & $1.666 \mathrm{E}+00$ \\
\hline 713 & 1705.3 & $1.274 \mathrm{E}+00$ & $1.499 \mathrm{E}+00$ \\
\hline 693 & 1720.8 & $1.158 \mathrm{E}+00$ & $1.333 \mathrm{E}+00$ \\
\hline 673 & 1736.4 & $1.035 \mathrm{E}+00$ & $1.166 \mathrm{E}+00$ \\
\hline 653 & 1752.0 & $9.056 \mathrm{E}-01$ & $9.995 \mathrm{E}-01$ \\
\hline 633 & 1767.5 & $7.699 \mathrm{E}-01$ & $8.329 \mathrm{E}-01$ \\
\hline 613 & 1783.1 & $6.277 \mathrm{E}-01$ & $6.663 \mathrm{E}-01$ \\
\hline 593 & 1798.6 & $4.790 \mathrm{E}-01$ & $4.997 \mathrm{E}-01$ \\
\hline 573 & 1814.2 & $3.239 \mathrm{E}-01$ & $3.332 \mathrm{E}-01$ \\
\hline 553 & 1829.8 & $1.623 \mathrm{E}-01$ & $1.666 \mathrm{E}-01$ \\
\hline 533 & 1845.3 & $-5.799 \mathrm{E}-03$ & $0.000 \mathrm{E}+00$ \\
\hline 513 & 1860.9 & $-1.803 \mathrm{E}-01$ & $-1.666 \mathrm{E}-01$ \\
\hline 493 & 1876.4 & $-3.614 \mathrm{E}-01$ & $-3.332 \mathrm{E}-01$ \\
\hline 473 & 1892.0 & $-5.488 \mathrm{E}-01$ & $-4.997 \mathrm{E}-01$ \\
\hline 453 & 1907.6 & $-7.428 \mathrm{E}-01$ & $-6.663 \mathrm{E}-01$ \\
\hline 433 & 1923.1 & $-9.432 \mathrm{E}-01$ & $-8.329 \mathrm{E}-01$ \\
\hline 413 & 1938.7 & $-1.150 \mathrm{E}+00$ & $-9.995 \mathrm{E}-01$ \\
\hline
\end{tabular}


Project No 06-040: Flexible Conversion Ratio Fast Reactor Systems Evaluation

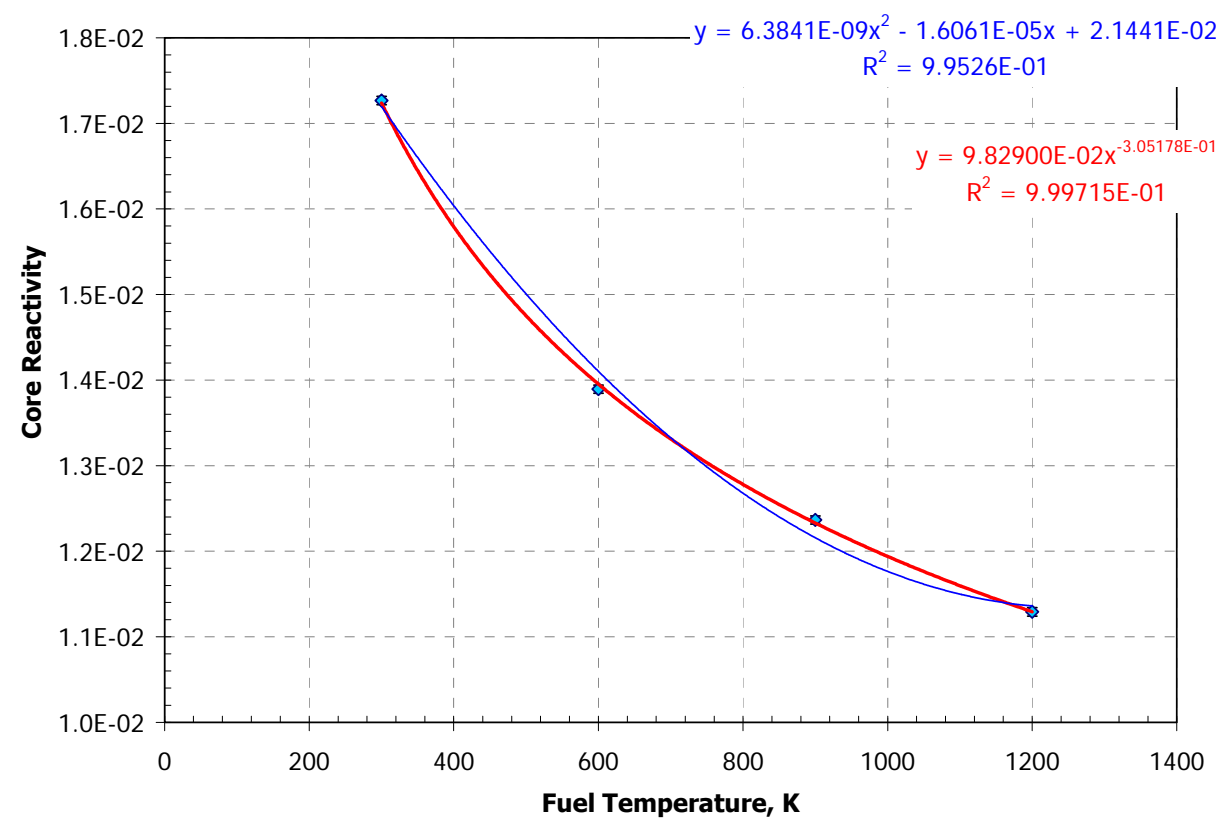

Figure 3B2.14 Reactivity insertion due to fuel temperature increase, $\mathrm{CR}=1 \mathrm{BOL}$

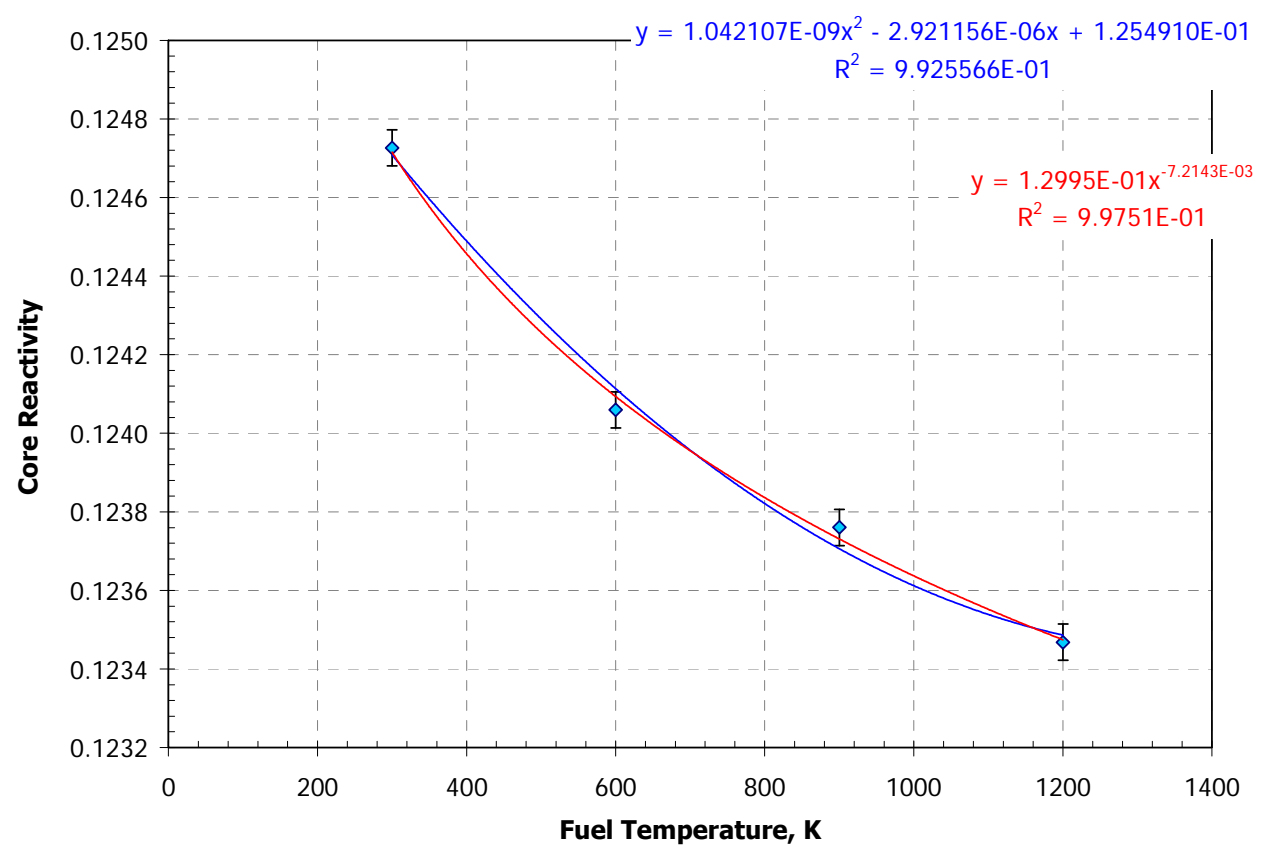

Figure 3B2.15 Reactivity insertion due to fuel temperature increase, $\mathrm{CR}=0 \mathrm{BOL}$

Core radial expansion and control rod drive expansion

As with the lead reactor, constant values are used for the core radial expansion and control rod drive expansion coefficients. For core radial expansion, the $\mathrm{CR}=1$ and $\mathrm{CR}=0$ reactivity coefficients were calculated to be $-0.00159 \$ / \mathrm{K}$ and $-0.00229 \$ / \mathrm{K}$ respectively. These reactivity coefficients are based on the average core coolant temperature, defined as the linear average of 
the coolant temperatures in the 11 axial meshes of the "average" channel in the core. The control rod drive expansion coefficient is conservatively assumed to be zero.

Table 3B.2-18 Salt reactor fuel temperature reactivity model for RELAP5-3D

\begin{tabular}{|c|c|c|}
\hline $\begin{array}{c}\mathrm{T}(\mathrm{K}) \\
\text { of fuel }\end{array}$ & $\begin{array}{c}\mathrm{CR}=1 \text { reactivity }(\$) \\
\beta=0.00389\end{array}$ & $\begin{array}{c}\mathrm{CR}=0 \text { reactivity }(\$) \\
\beta=0.00298\end{array}$ \\
\hline 300.0 & 0.0 & 0.0 \\
\hline 400.0 & -0.4225 & -0.13667 \\
\hline 600.0 & -0.9950 & -0.3709 \\
\hline 900.0 & -1.5625 & -0.6759 \\
\hline 1000.0 & -1.7128 & -0.7707 \\
\hline 1200.0 & -1.9789 & -0.9540 \\
\hline 1500.0 & -2.3200 & -1.2174 \\
\hline 1600.0 & -2.4229 & -1.3030 \\
\hline 1800.0 & -2.6168 & -1.4715 \\
\hline
\end{tabular}

\section{Lithium expansion modules}

Results from the lithium expansion module design were incorporated into RELAP as shown in Figure 3B2.16 and Table 3B2.19. As described in section 4.2.2.2, these curves were obtained by taking the characteristic cosine shape of the LEM reactivity response and expanding it to fit the needed temperature range, as well as to ensure a sufficiently low coolant reactivity coefficient at steady state. These curves do not incorporate the bottlenecked LEM design shown in 4.2.1-21, which would reduce the positive reactivity from lower LEM temperatures. However, since none of the bounding accidents considered result in the LEM reservoir temperature decreasing, this has no effect on the results obtained. As described in section 3B.2-6 of this appendix, the LEM reservoir temperature is calculated through the use of heat structures which explicitly model the LEMs above the core.

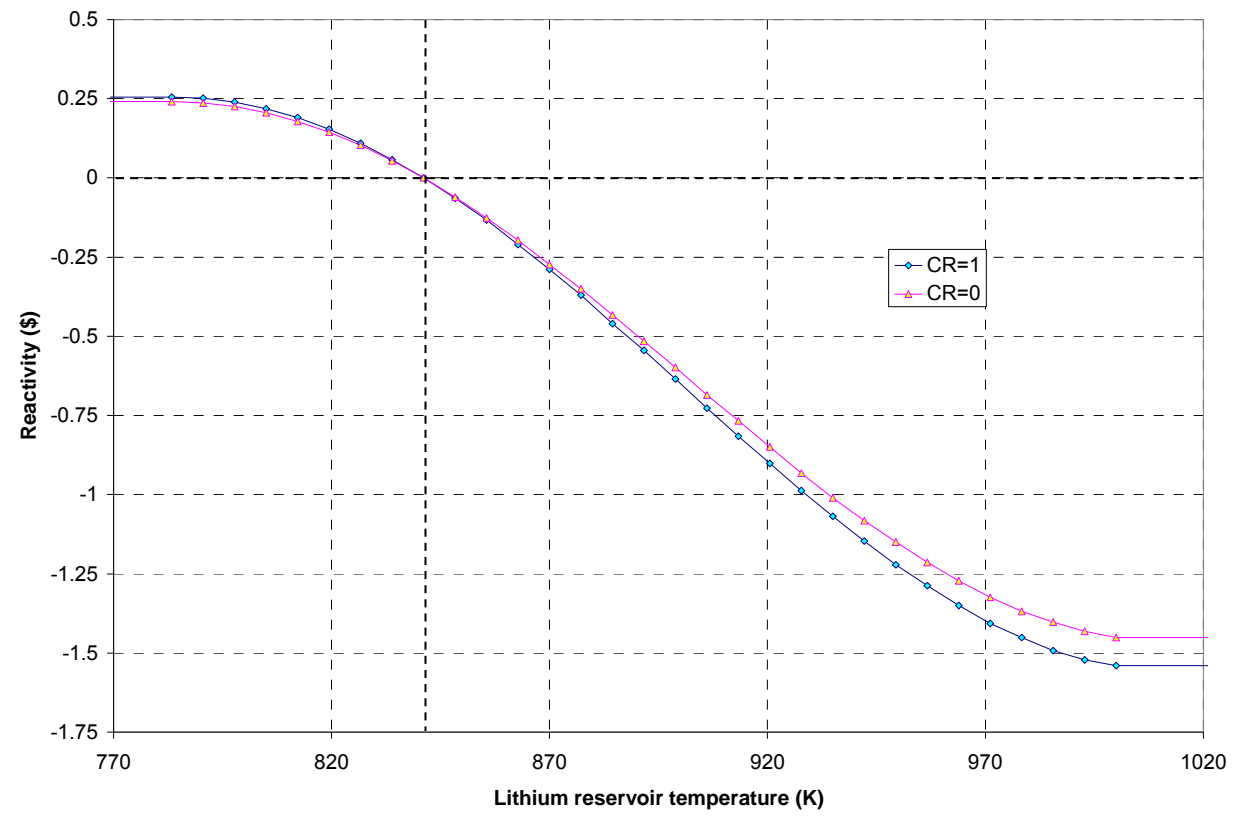

Figure 3B2.16 Reactivity insertion due to lithium expansion modules (dashed lines indicate steady state values) 
Project No 06-040: Flexible Conversion Ratio Fast Reactor Systems Evaluation

Table 3B.2-19 Salt reactor LEM reactivity model for RELAP5-3D

\begin{tabular}{|c|c|c|}
\hline $\begin{array}{l}\text { Temperature }(\mathrm{K}) \\
\text { of LEM reservoir }\end{array}$ & $\begin{array}{c}\mathrm{CR}=1 \text { reactivity }(\$) \\
\beta=0.00389\end{array}$ & $\begin{array}{c}\mathrm{CR}=0 \text { reactivity }(\$) \\
\beta=0.00298\end{array}$ \\
\hline 676 & $2.56 \mathrm{E}-01$ & $2.41 \mathrm{E}-01$ \\
\hline 783 & $2.56 \mathrm{E}-01$ & $2.41 \mathrm{E}-01$ \\
\hline 791 & $2.52 \mathrm{E}-01$ & 2.37E-01 \\
\hline 798 & 2.39E-01 & $2.25 \mathrm{E}-01$ \\
\hline 805 & 2.19E-01 & 2.06E-01 \\
\hline 812 & 1.90E-01 & 1.79E-01 \\
\hline 819 & 1.53E-01 & 1.44E-01 \\
\hline 827 & 1.10E-01 & 1.03E-01 \\
\hline 834 & $5.79 \mathrm{E}-02$ & $5.48 \mathrm{E}-02$ \\
\hline 841 & $0.00 \mathrm{E}+00$ & $0.00 \mathrm{E}+00$ \\
\hline 848 & $-6.42 \mathrm{E}-02$ & $-6.06 E-02$ \\
\hline 856 & $-1.33 E-01$ & $-1.27 E-01$ \\
\hline 863 & $-2.11 \mathrm{E}-01$ & -1.97E-01 \\
\hline 870 & $-2.89 \mathrm{E}-01$ & $-2.73 E-01$ \\
\hline 877 & $-3.71 \mathrm{E}-01$ & $-3.50 \mathrm{E}-01$ \\
\hline 884 & $-4.60 \mathrm{E}-01$ & $-4.33 E-01$ \\
\hline 892 & $-5.45 \mathrm{E}-01$ & $-5.15 E-01$ \\
\hline 899 & $-6.34 \mathrm{E}-01$ & $-5.98 E-01$ \\
\hline 906 & $-7.27 \mathrm{E}-01$ & $-6.85 E-01$ \\
\hline 913 & $-8.16 E-01$ & -7.67E-01 \\
\hline 921 & $-9.02 E-01$ & $-8.50 \mathrm{E}-01$ \\
\hline 928 & $-9.87 E-01$ & $-9.32 E-01$ \\
\hline 935 & $-1.07 E+00$ & $-1.01 \mathrm{E}+00$ \\
\hline 942 & $-1.15 E+00$ & $-1.08 E+00$ \\
\hline 949 & $-1.22 \mathrm{E}+00$ & $-1.15 E+00$ \\
\hline 957 & $-1.29 E+00$ & $-1.21 E+00$ \\
\hline 964 & $-1.35 E+00$ & $-1.27 E+00$ \\
\hline 971 & $-1.41 E+00$ & $-1.32 E+00$ \\
\hline 978 & $-1.45 E+00$ & $-1.37 E+00$ \\
\hline 986 & $-1.49 E+00$ & $-1.40 \mathrm{E}+00$ \\
\hline 993 & $-1.52 E+00$ & $-1.43 E+00$ \\
\hline 1000 & $-1.54 E+00$ & $-1.45 E+00$ \\
\hline 1276 & $-1.54 E+00$ & $-1.45 E+00$ \\
\hline
\end{tabular}




\section{B.3 References for Appendix 3B}

ANL, "The SAS4A/SASSYS-1 LMR Analysis Code System," Report ANL-FRA-1996-3 Vol. 1, reactor Analysis Division, August 1996.

Carpenter D. and Kohse G., "Experimental Determination of the Thermal Conductivity of a Lead Bismuth Eutectic Filled Annulus," Report MIT-NFC-81, Center for Advanced Nuclear Energy Systems, MIT, June 2005.

Cheng S.K. and Hwang D.H., "Sub-channel Analysis of LBE-Cooled Fuel Assemblies of Accelerator Driven Systems,” Proc. Of Global 2005, Tsukuba, Japan, Oct. 9-13, 2005, Paper no. 115.

Gurvich L.V. et al., "Thermodynamic Properties of Individual Substances," Fourth Edition, Vol. 2, Parts 1 and 2, Hemisphere, NY, 1991.

Hejzlar P., Buongiorno J., MacDonald P. E., Todreas N. E., "Design Strategy and Constraints for Medium-Power Lead-Alloy-Cooled Actinide Burners," Nuclear Technology, 147, 3, pp. 321343, 2004.

Idelchik I.E., "Handbook of Hydraulic Resistance," Second Edition, Revised and Augmented. Hemisphere Publishing Corp., Washington, 1986.

Kazimi M.S. and Carelli M.D., "Heat Transfer Correlation for Analysis of CRBRP Assemblies." Westinghouse Report, CRBRP-ARD-0034, 1976.

Kutateladze S.S., Borishanskij V.M., Novikov I.I. and Fedinskij O.S., "Zhidkometalliceskie Teplonositeli” (in Russian), Atomizdat, Moscow, 1958.

Samsonov E. G. V., “The Oxide Handbook," (Originally, Russian, translated by C. N. Turton and T. I. Turton), Plenum Press, London (1973). 


\section{Appendix 3C Intermediate Heat Exchanger Model}

This appendix describes the analytical model of the intermediate heat exchanger between lead coolant and supercritical $\mathrm{CO}_{2}$. The design and analysis of the intermediate heat exchangers (IHXs) have been a challenge due to high operating pressures and temperatures. The high pressure $(20 \mathrm{MPa})$ on the $\mathrm{CO}_{2}$ side required a detailed analysis to determine appropriate tube thickness. Furthermore, the large difference in heat transfer coefficients between the lead coolant and supercritical carbon dioxide stimulated interest in enhanced heat transfer. Finally, the pressure drop constraint on the $\mathrm{S}-\mathrm{CO}_{2}$ side is directly related to the power conversion system efficiency; thus, the minimum achievable pressure drop was pursued. The above challenges are linked to the material properties.

T-91 alloy (with surface treatment on the $\mathrm{CO}_{2}$ side) was investigated for the use in heat exchangers since the $316 \mathrm{SS}$ alloy is not compatible with lead's corrosive environment at temperatures above $550{ }^{\circ} \mathrm{C}$. The 2007 ASME Boiler and Pressure Vessel code included T-91 alloy as an acceptable material for Sec. III, Division 1, Subsection NB/NH for Class 1 components. Note that when the optimization analysis was conducted, the time-dependent properties of T-91 were not available in the ASME Boiler and Pressure Vessel code. Thus, the analysis was conducted for very conservative estimated values of the thermal conductivity and design stress intensity. The conclusions obtained in this analysis were later applied to the updated design of the IHX reported in Section 3.3.2.

The heat exchangers are placed within the annulus between the vessel liner and the core riser; thus, the primary coolant never leaves the vessel. The heat exchangers have a kidney shape to utilize the tight space efficiently. The $\mathrm{CO}_{2}$ coolant enters the IHX through the large main inlet tube and proceeds to the lower plenum where it is distributed through the smaller tubes. The gas flows upward through the tubes, exchanging the heat with lead coolant which is on the shell side. Heated $\mathrm{CO}_{2}$ then mixes in the upper plenum and leaves the heat exchanger through two outlet tubes.

\section{C.1 Thermal analysis}

The S- $\mathrm{CO}_{2}$ cycle sets constraints on the secondary fluid temperatures and flow rate. The lead coolant has also predetermined values for the core inlet and outlet temperatures and the mass flow rate. Therefore, the heat exchanger must be designed to satisfy all requirements. The radial size of the heat exchanger is constrained by the vessel and core geometry. The $\mathrm{CO}_{2}$ - and leadside pressure drops are dependent on the axial length of the IHX tubes. The constraint on the $\mathrm{CO}_{2}$ pressure drop was set by its effect on Brayton cycle efficiency to $0.7 \mathrm{MPa}$.

The outlet temperature of the $\mathrm{CO}_{2}$ can be obtained from the heat transfer balance. The target is around $550^{\circ} \mathrm{C}$ as optimum temperature for cycle efficiency.

$$
\dot{Q}=\bar{k} A \Delta t_{l m}
$$


An important part of the heat exchanger design is the overall heat transfer coefficient. For the tube-and-shell heat exchanger, the following equation is used for the heat transfer:

$$
Q=\frac{T_{i}-T_{o}}{\frac{1}{h_{i} A_{i}}+\frac{R_{f l}}{A_{i}}+\frac{\ln \left(r_{o} / r_{i}\right)}{2 \pi L k_{w}}+\frac{R_{f o}}{A_{o}}+\frac{1}{h_{o} A_{o}}}
$$

where $R_{f o}$ and $R_{f i}$ are fouling resistances on the outside and inside of the tubes respectively. In the inner side of tubes where $\mathrm{CO}_{2}$ is present, the fouling layer is generally of negligible size $\left(\mathrm{R}_{\mathrm{fi}}\right.$ can be ignored). On the other hand, with lead on the outside of the tubes, the fouling layer plus $\mathrm{PbO}$ deposition can reach significant values and must be considered. Such fouling resistance will come mostly from the corrosion of tube materials and can be approximated using oxide layer characteristics. With the oxide layer modeled as a plane, the fouling coefficient of the oxide layer is the ratio of the layer thickness to its thermal conductivity.

$$
R_{f, s}=\frac{t_{\text {oxide }}}{k_{\text {oxide }}}
$$

The average heat transfer coefficient corrected for the oxide layer presence is:

$$
\bar{k}=\frac{1}{\frac{1}{h_{C O 2}}+\frac{r_{i} \ln \left(r_{i} / r_{I L}\right)}{k_{I L}}+\frac{r_{i} \ln \left(r_{o} / r_{i}\right)}{k_{w}}+\frac{r_{i} \ln \left(r_{O L} / r_{o}\right)}{k_{O L}}+\frac{r_{i}}{r_{O L} h_{P b}}}
$$

where:

$\dot{m}_{P b}=$ mass flow rate of lead through the IHX

$\dot{m}_{\mathrm{CO} 2}=$ mass flow rate of $\mathrm{CO}_{2}$ through the IHX

$\mathrm{h}_{\mathrm{co} 2}=\quad \mathrm{CO}_{2}$ heat transfer coefficient

$\mathrm{h}_{\mathrm{Pb}}=$ lead heat transfer coefficient

$\mathrm{k}_{\mathrm{w}}=$ wall material thermal conductivity

$\mathrm{k}_{\mathrm{OL}}=\quad$ oxide layer thermal conductivity

$\mathrm{r}_{\mathrm{i}}=$ inner diameter if the IHX tube

$\mathrm{r}_{\mathrm{o}}=$ outer diameter if the IHX tube

$\mathrm{r}_{\mathrm{OL}}=$ outer diameter if the IHX tube with oxide layer on it

Effective heat transfer surface can be calculated as:

$$
A=n_{\text {tubes }}(A L)_{\text {tube }}=n_{\text {tubes }}(2 \pi r L)_{\text {tube }}
$$

Log-mean temperature difference $\Delta t_{l m}$ is evaluated using equation (3C.1-6):

$$
\Delta t_{l m}=\frac{\left(T_{\text {in }, \mathrm{Pb}}-T_{\text {out }, \mathrm{CO}}\right)-\left(T_{\text {out }, P b}-T_{\text {in }, \mathrm{CO}_{2}}\right)}{\ln \frac{\left(T_{\text {in }, \mathrm{Pb}}-T_{\text {out }, \mathrm{CO} O_{2}}\right)}{\left(T_{\text {out }, \mathrm{Pb}}-T_{\text {in }, \mathrm{CO}_{2}}\right)}}
$$




\section{C.2 Pressure Drop on the Tube Side}

The pressure drop on the $\mathrm{S}-\mathrm{CO}_{2}$ side is one of the design constraints. Pressure head on the $\mathrm{CO}_{2}$ side must be limited to $0.7 \mathrm{MPa}$ to ensure cycle efficiency. The total pressure drop is comprised of friction, acceleration, gravity and form losses.

Friction:

$$
\Delta P_{\text {fric }}=f\left(\frac{L}{D}\right) \frac{\rho V^{2}}{2}
$$

Acceleration:

$$
\Delta P_{a c c}=G^{2}\left(\frac{1}{\rho_{\text {out }}}-\frac{1}{\rho_{\text {in }}}\right)
$$

Gravity:

$$
\Delta P_{\text {grav }}=\left(\rho_{\text {in }}-\rho_{\text {out }}\right) g L
$$

Form losses:

$$
\Delta P_{\text {form }}=\left(k \frac{G^{2}}{2 \rho}\right)_{\text {inlet }}+\left(k \frac{G^{2}}{2 \rho}\right)_{\text {outlet }}
$$

where: $\quad f$ is the friction factor given by the McAdams relation

$\mathrm{G}$ is the mass flux

$\mathrm{k}$ is inlet/outlet form loss coefficient

\section{C.3 Lead heat transfer coefficient and friction factor}

The heat transfer coefficient, $\mathrm{h}$, between the heat exchanger tubes and the $\mathrm{Pb}-\mathrm{Bi}$ coolant was determined from the Lyon-Martinelli correlation [El-Wakil, 1978].

$$
\begin{gathered}
N u_{\infty}=7.0+0.025 P e^{0.8} \\
h_{P b}=\frac{N u_{\infty} k_{P b}}{d}
\end{gathered}
$$

The pressure drop on the shell side is across a bank of tubes. For lead flow, Rehme's method for solving the turbulent flow case in actual geometry was used. The results of this method were fitted by Cheng and Todreas [1986] with the following polynomial: 
Project No 06-040: Flexible Conversion Ratio Fast Reactor Systems Evaluation

$$
C_{f i t}=a+b_{1}(P / D-1)+b_{2}(P / D-1)^{2}
$$

where

$$
f_{i T} \equiv \frac{C_{f i t}}{\left(\operatorname{Re}_{i T}\right)^{n}}
$$

For triangular geometry (assume interior subchannels) with P/D greater 1.1, the following coefficients are applicable:

$$
\begin{aligned}
& a=0.1458 \\
& b_{1}=0.03632 \\
& b_{2}=-0.03333 \\
& n=0.18
\end{aligned}
$$

\section{C.4 Pressure Drop on the Shell Side}

It is important to minimize the shell-side pressure drop in order to reduce size and cost of the primary coolant pumps, maximize natural circulation in LOFA events and minimize free level separation. While calculation of the tube-side pressure drop was rather straightforward, the shell side is more complicated because of the presence of baffles. Also, the effect of different bypass and leakage should be taken into account. For the preliminary heat exchanger design, the effect of spacers on the pressure drop was considered. The pressure drop should further be corrected for different flow streams due to baffle presence. For present analysis, the total pressure drop consists of friction, acceleration and form losses.

Friction:

$$
\Delta P_{\text {fric }}=f_{i T}\left(\frac{L}{D}\right) \frac{\rho V^{2}}{2}
$$

Acceleration and form losses: $\Delta P_{\text {form }}=\left(k \frac{G^{2}}{2 \rho}\right)_{\text {inlet }}+\left(k \frac{G^{2}}{2 \rho}\right)_{\text {outlet }}+C_{v} \frac{\rho V_{v}^{2}}{2}\left(\frac{A_{s}}{A_{v}}\right)^{2}$

where the last term of form loss was suggested by Rehme to account for the spacer pressure losses [Todreas and Kazimi, 1990].

$C_{v} \quad$ is modified drag coefficient

$C_{v}=6.5+3(5-\log \mathrm{Re})$ for honey-comb type spacer

$V_{v} \quad$ is average bundle velocity

$A_{s} \quad$ is projected frontal area of the spacer

$A_{v} \quad$ is unrestricted flow area away from the spacer 


\section{C.5 Tube Thickness}

High pressure on the $\mathrm{S}-\mathrm{CO}_{2}$ side requires special attention to the hoop stresses in the tubes. The required tube thickness can be calculated using ASME code requirements for primary membrane intensity in thick cylinders. The tube is considered thick if the following ratio is satisfied:

$$
t_{\text {tube }} / R_{\text {mean }} \geq 0.1 \text {. }
$$

Primary membrane intensity, $S_{m}$, is determined for the straight pipe under internal pressure as defined in ASME Section NB. Thus, the tube thickness is defined as:

$$
t_{\text {tube }}=\frac{P D_{o}}{2\left(S_{m}+P / 2\right)}=\frac{D_{o}}{1+2 \frac{S_{m}}{P}} .
$$

\section{$3 \mathrm{C} .6 \mathrm{CO}_{2}$ heat transfer coefficient and friction factor}

\section{C.6.1 Smooth tube option}

For gases in circular smooth tubes, the simplified correlation for Nusselt number by Gnielinski [1976] is used:

$$
\begin{gathered}
N u=0.0214\left(\operatorname{Re}^{0.8}-100\right) \operatorname{Pr}^{0.4} \\
h_{C O 2}=\frac{N u_{\infty} k_{C O 2}}{d}
\end{gathered}
$$

The friction factor is given by the McAdams relation:

$$
f=0.184 \mathrm{Re}^{-0.2}
$$

\section{C.6.2 Enhanced Heat Transfer Option}

Because the intermediate heat exchanger is constrained by size, there is a strong interest in enhancement of heat transfer capabilities to reduce IHX dimensions and temperature difference. One of the possible methods to accomplish this goal is improvement of the performance of the heat exchanger through tube roughening on the inside surface. Tube augmentation was considered on the $\mathrm{CO}_{2}$ side due to its lower heat transfer coefficient when compared to lead (about a factor of 3-5). Surface alternation on the $\mathrm{CO}_{2}$ side achieved by introducing repeated ribs promotes an increase in heat transfer through disturbance of the surface sublayer [Ravigururajan, 1999].

Thus, tubes with repeated helical ribs on the inner side were used for the IHX. The following requirements and assumptions were followed in the design: 
Project No 06-040: Flexible Conversion Ratio Fast Reactor Systems Evaluation

Requirements

- Pressure drop on $\mathrm{CO}_{2}$ side is around $500 \mathrm{kPa}$ (does not exceed $700 \mathrm{kPa}$ )

- Pitch is large enough so that no flow stagnation between the ribs occurs

Assumptions:

- Steady state operation

- Homogeneous material

- No contact resistance between the ribs and the tube (extruded ribs)

- Constant heat transfer coefficient of the rib to the gas flow over the entire rib surface

\section{C.6.2.1 Literature review and comparison}

Due to intensive use of augmented tubes in industry, correlations with different ranges of applicability have been developed and a number of papers on tube augmentation and heat transfer have been published. However, depending on the application of the tubes, a specific type of enhancement must be chosen, i.e. ribs, flutes, wire inserts, or grooves, each in helical configuration. Two approaches for developing correlations are usually employed: the analogy method and a statistical/empirical approach [Ravigururajan, 1999]. Correlations based on the latter approach have certain advantages over the analogy-based ones. They are generally simpler to use, and friction factor and heat transfer coefficient correlations are decoupled.

The following comparison was conducted for the enhanced heat transfer and friction factor correlations for single-phase forced convection flow inside circular ducts. Thus, passive tube augmentation through extended surfaces (i.e. ribbed tubes) is considered in the following evaluation. A common trend in these correlations is improved Nusselt number and an accompanying increase in friction factor.

\section{Analogy Approach}

Webb et al. [2000] in his paper provides experimental results as well as correlations developed from experiments for friction and Colburn factors for water in different geometries of augmented tubes. The correlations predict that friction factor and Colburn factor increase with increasing number of starters, rib height to inner diameter ratio, and helical angle, with friction factor being a stronger function of the last two parameters than Colburn [Webb,2000]. When compared to experimental data, the correlations appear to over-predict the friction factor values by $0-15 \%$ while the Colburn j-factor error remains within $10 \%$.

Gee and Webb [1980] performed an experimental investigation of helix angle change impact on single phase flow in circular tubes. The report presented the heat transfer and friction characteristics for air flow with three helix angles $\left(30,49\right.$ and $\left.70^{\circ}\right)$ all having a rib pitch-toheight ratio of 15 . The preferred helix angle is approximately $45^{\circ}$. However, Pr number and pitch variations are not included in the functions. Thus, the applicability range of the correlations is limited. 


\section{Statistical Approach}

Bergles et al. [1996] attempted to construct a general correlation for friction factor and heat transfer coefficient over a wide range of hydraulic and geometric parameters for internally augmented tubes. Starting with a database previously developed by various authors' experimental and statistical correlations for different fluids and geometries, statistical analysis was applied to put together wide-ranging correlations. Further, different types of commercially available tubes were tested with heated water to validate the obtained correlations. The friction factor and $\mathrm{Nu}$ number correlations reduce to smooth-tube correlations as the rib height approaches zero. The friction factor correlation predicts $96 \%$ of the database to within $+50 \%$ and $77 \%$ of the database to within $+20 \%$. Corresponding prediction figures for the heat-transfer correlation are $99 \%$ within $50 \%$ and $69 \%$ within $20 \%$ [Bergles at al., 1996].

\section{C.6.2.2 Selected Correlations}

Table 3C.6-1 provides a summary of various heat transfer and friction factor correlations for augmented tubes. The study carried out by Ravigururajan [1999] tested and compared analogy based correlations and correlations developed using the statistical approach. Further, the correlations were evaluated for application to heat exchanger design. His work reveals the limitations of the analogy method. One of the main conclusions drawn from the study is the effectiveness of the statistical empirical methods over the analogy approach in predicting friction factor and Nusselt number [Ravigururajan, 1999]. Due to the generality of the Ravigururajan and Bergles correlations, they were selected for FCR heat exchanger design.

\section{C.6.2.3 Heat exchanger with ribbed tubes design}

\section{Evaluation of different fin geometries}

The thermal design of the modified heat exchanger was unchanged. As in a straight tube IHX, the constant parameters were temperatures, energy balance, and flow rates. However, the $\mathrm{CO}_{2}$ side correlations were changed to account for enhanced heat transfer.

Correlations suggested by Bergles et al. [1996] were used for the comparison analysis. The friction factor and heat transfer correlations developed by Bergles were intended for a wide range of parameters. Moreover, when applied to smooth tubes (assuming that the rib height approaches zero), such correlations produce results very close to the results obtained from the smooth tube analysis (see Table 3C.6-2). Correlations by Bergles et al. were statistically developed for a wide range of experimental data. They are based on correlations by Petukhov and Popov for Nusselt number and Filonenko for friction factor for smooth tubes. 
Project No 06-040: Flexible Conversion Ratio Fast Reactor Systems Evaluation

Table 3C.6-1 Summary of different correlations for augmented tubes

\begin{tabular}{|c|c|c|c|c|c|c|c|}
\hline Author & Fluid & $\begin{array}{c}\text { Range of } \\
\text { applicability }\end{array}$ & Geometry range & Nusselt number $(\mathrm{Nu})$ correlation & Friction factor $(f)$ correlation & Comments & Nomenclature \\
\hline $\begin{array}{l}\text { Webb, } \\
\text { et al. } \\
(2000)\end{array}$ & $\begin{array}{l}\text { Single } \\
\text { phase } \\
\text { water }\end{array}$ & $\begin{array}{l}\text { Pr: } \\
5.08-6.29 \\
\text { Re: } \\
20,000- \\
80,000\end{array}$ & \begin{tabular}{l}
\multicolumn{2}{c}{$\begin{array}{c}\text { Helically } \\
\text { ribbed tube }\end{array}$} \\
$\mathrm{N}_{\mathrm{s}}: 18-45$ \\
$\alpha\left(^{\circ}\right): 25-45$ \\
$\mathrm{e}(\mathrm{mm}): 0.33-0.55$
\end{tabular} & $\begin{array}{c}j=0.00933 \operatorname{Re}^{-0.181} N_{s}^{0.285}\left(\frac{e}{D_{i}}\right)^{0.323} \\
\times \alpha^{0.505} \\
\text { where } \\
j=\text { Colburn j factor } \\
j=S t \operatorname{Pr}^{2 / 3}\end{array}$ & $f=0.108 \mathrm{Re}^{-0.283} N_{s}^{0.221}\left(\frac{e}{D_{i}}\right)^{0.785} \alpha^{0.78}$ & $\begin{array}{l}\text { Correlations were } \\
\text { developed for a } \\
\text { specific range of } \mathrm{Pr} \\
\text { number. While } \\
\text { providing good } \\
\text { accuracy, they are } \\
\text { not applicable for } \\
\mathrm{CO}_{2} \text { heat transfer } \\
\text { and friction factor } \\
\text { of } \mathrm{PR} \approx 0.7 \text {. }\end{array}$ & $\begin{array}{l}f \text { fanning friction } \\
\text { factor } \\
e \text { rib height, } \mathrm{m} \\
d \text { maximum inside } \\
\text { diameter, } \mathrm{m} \\
\alpha \text { helix angle of rib } \\
\quad(\mathrm{deg}) \\
N s \text { number of } \\
\quad \text { starts }\end{array}$ \\
\hline $\begin{array}{l}\text { Gee and } \\
\text { Webb } \\
(1980)\end{array}$ & Air & $\begin{array}{l}\text { Pr for air } \\
\text { Re: } \\
6,000- \\
65,000\end{array}$ & $\begin{array}{l}\text { Helically } \\
\text { ribbed tube }\end{array}$ & $\begin{array}{l}g=6.03\left(e^{+}\right)^{0.2}(\alpha / 50)^{j} \\
\text { for } e^{+}>8 \\
j=0.37 \text { for } \alpha<50^{\circ} \\
j=-0.16 \text { for } \alpha>50^{\circ}\end{array}$ & $\begin{array}{l}A=6.83\left(e^{+}\right)^{0.07}(\alpha / 50)^{0.16} \\
\text { for } e^{+}>5\end{array}$ & $\begin{array}{l}\text { Re number range is } \\
\text { outside of the } \\
\text { operating range of } \\
\text { FCR IHX }\end{array}$ & $\begin{array}{c}\alpha \begin{array}{l}\text { helix angle of rib } \\
\text { (deg) }\end{array} \\
e^{+} \text {roughness Re } \\
\text { number } \\
g \text { heat transfer } \\
\text { correlator } \\
A \begin{array}{l}\text { friction } \\
\text { correlator }\end{array}\end{array}$ \\
\hline $\begin{array}{l}\text { Bergles } \\
\text { et al. } \\
\text { (1996) } \\
\text { with } \\
\text { subse- } \\
\text { quent } \\
\text { correc- } \\
\text { tions }\end{array}$ & $\begin{array}{l}\text { Air, water, } \\
\text { hydrogen, } \\
\text { n-butyl } \\
\text { alcohol }\end{array}$ & $\begin{array}{l}\operatorname{Pr}: \\
0.66-37.6 \\
\text { Re : } \\
3,000- \\
500,000\end{array}$ & $\begin{array}{l}\text { Helical } \\
\text { e/d : } 0.01-0.2 \\
\mathrm{p} / \mathrm{d}: 0.1-7.0 \\
\alpha / 90: 0.3-1.0\end{array}$ & $\begin{array}{l}\frac{N u_{a}}{N u_{s m}}=\left\{1+\left[2.64 \operatorname{Re}^{0.036}\left(\frac{e}{d}\right)^{0.212}\right.\right. \\
\left.\left.\times\left(\frac{p}{d}\right)^{-0.21}\left(\frac{\alpha}{90}\right)^{0.29} \operatorname{Pr}^{-0.024}\right]^{7}\right\} \\
\text { Where } \mathrm{Nu}_{\text {sm }} \text { number is given by } \\
N u_{s m}=\frac{\frac{f}{2} \operatorname{Re} \operatorname{Pr}}{1+12.7\left(\frac{f}{2}\right)^{0.5}\left(\operatorname{Pr}^{2 / 3}-1\right)}\end{array}$ & $\begin{array}{l}\frac{f_{a}}{f_{s m}}=\left\{1+\left[29.1 \operatorname{Re}^{(0.67-0.06 p / d-0.49 \alpha / 90)}\right.\right. \\
\times\left(\frac{e}{d}\right)^{(1.37-0.157 p / d)}\left(\frac{p}{d}\right)^{(-1.66 E-6 \mathrm{Re}-0.33 \alpha / 90} \\
\times\left(\frac{\alpha}{90}\right)^{(4.59+4.11 E-6 \mathrm{Re}-0.15 p / d)} \\
\left.\times(1+2.94 / n \sin (\beta)]^{15 / 16}\right\}^{16 / 15} \\
\text { Where } \mathrm{f}_{\text {sm }} \text { is given by Filonenko: } \\
f_{s m}=(1.58 \ln \mathrm{Re}-3.28)^{-2}\end{array}$ & $\begin{array}{l}\text { One of the better } \\
\text { correlations found. } \\
\text { Very wide range of } \\
\text { applicability. The } \\
\text { friction factor } \\
\text { correlation predicts } \\
96 \% \text { of the } \\
\text { database to within } \\
+50 \% \text { and } 77 \% \text { of } \\
\text { the database to } \\
\text { within }+20 \% \text {. } \\
\text { Corresponding } \\
\text { prediction figures } \\
\text { for the heat- } \\
\text { transfer correlation } \\
\text { are } 99 \% \text { and } 69 \% \text {. }\end{array}$ & $\begin{array}{l}e \text { rib height, } \mathrm{m} \\
d \text { maximum inside } \\
\text { diameter, } \mathrm{m} \\
p \text { pitch of ribs, } \mathrm{m} \\
\alpha \text { helix angle of rib } \\
\text { (deg) } \\
\beta \text { contact angle of } \\
\text { profile (deg) } \\
n \text { number of sharp } \\
\text { corners facing } \\
\text { the flow that } \\
\text { characterizes the } \\
\text { rib profile } \\
\text { Subscripts: } \\
\begin{array}{l}a \text { augmented tube } \\
s m \text { smooth tube }\end{array} \\
\end{array}$ \\
\hline
\end{tabular}


The comparison of friction factor and heat transfer coefficient for a tube of outer diameter of 16 $\mathrm{mm}$ and pitch-to-diameter ratio of 1.161 was performed using the smooth tube Gnielinski correlation [1976] and the Bergles et al. correlation with zero rib height. Table 1.1.12 compares these results and shows that the Bergles et al. correlation can closely reproduce smooth correlation results in the limit. Moreover, Bergles et al. provides conservative results for both the heat transfer coefficient and pressure drop.

Table 3C.6-2 Comparison of correlations by Bergles, et al. [1996] and correlations used for "smooth" heat exchanger design (same tube geometry)

\begin{tabular}{lcc}
\hline & SMOOTH & BERGLES (-> SMOOTH) \\
\hline$h=N u \cdot k / D$ & 7360 & 7290 \\
\hline$N u$ correlation by & Gnielinski & Petukhov and Popov \\
\hline Pressure drop & $620.96 \mathrm{kPa}$ & $643.25 \mathrm{kPa}$ \\
\hline$f$ correlation by & McAdams & Filonenko \\
\hline Tube length & $7.86 \mathrm{~m}$ & $8.04 \mathrm{~m}$ \\
\hline
\end{tabular}

The purpose of ribs inside the tubes is twofold: first, they will allow for greater heat transfer area, and second, they will result in a constant turbulent sublayer disturbance enhancing the heat transfer. In the second case, the flow interrupted by the rib will cause the layers close to the wall to separate from the wall and reattach downstream of the rib at a distance of 5 to 8 times the rib height. If the pitch of the ribs is less than the distance required to achieve reattachment, the flow will slide over the ribs causing secondary flow patterns between the ribs [Ravigururajan, 1999]. For highly turbulent flows, the layer height is small; thus small roughness height is required. Helix angle also plays a significant role in the flow patterns.

Before the final heat exchanger design was selected, an evaluation of friction factor and Nusselt number variation with geometry of the internal ribs was conducted. Figure 3C.6-1 illustrates fin configuration inside the tube. As can be seen from Figures 3C.6-2 through 3C.6-3, both quantities increase with a rise in the number of ribs and helix angle.

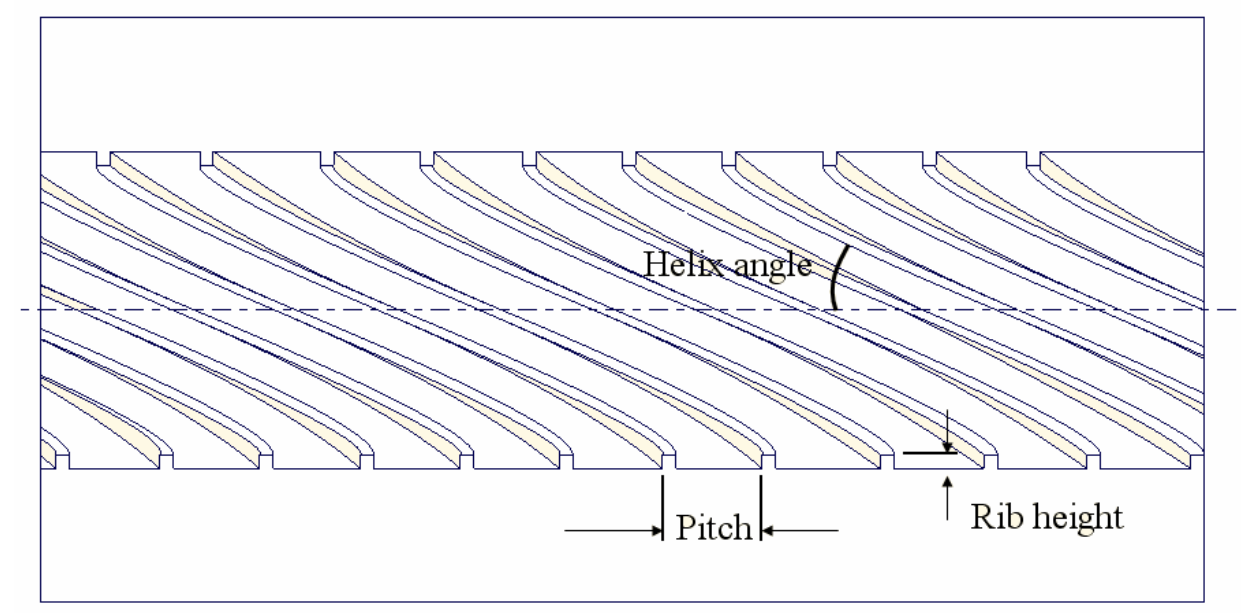

Figure 3C.6-1 Schematics of helical ribs inside the tube [Gee and Webb, 1980] 
Tube OD = 15 mm, P/D=1.17

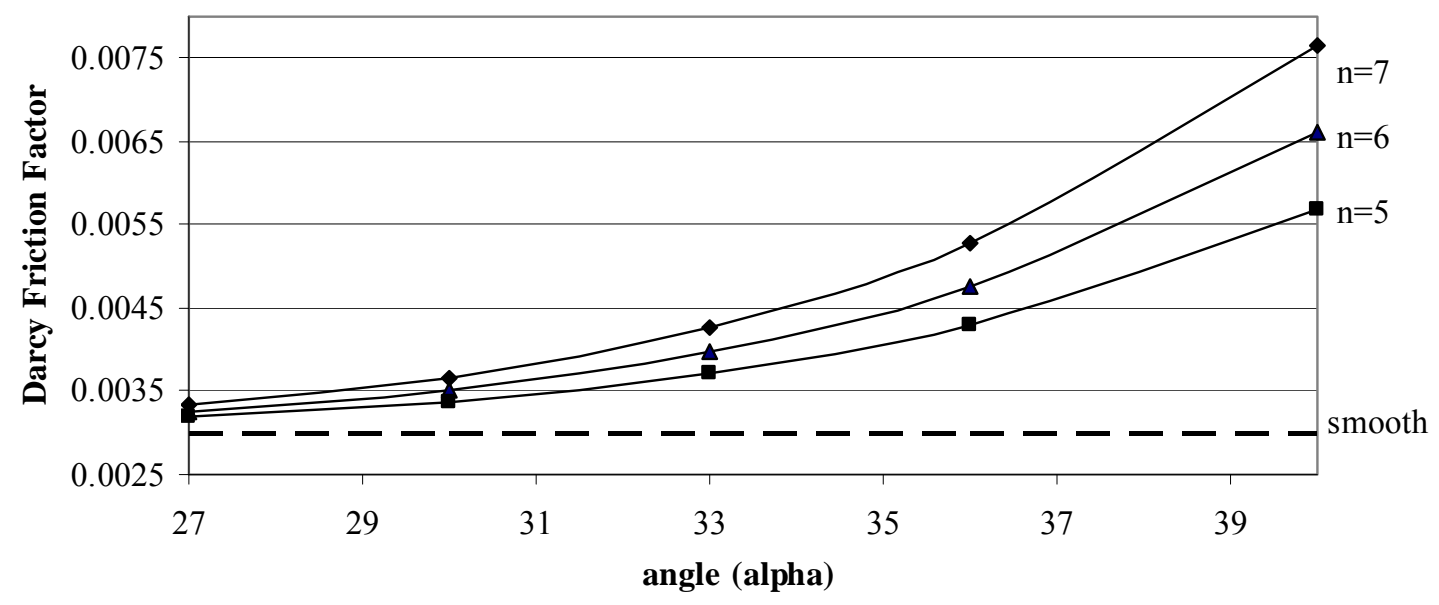

Figure 3C.6-2 Friction factor variation with the helix angle and number of fins

The effect of the number of ribs on the heat transfer is not as pronounced as the angle of the helix. For the comparison, the pitch between the fins was kept less than 5 times the rib height as discussed previously. Thus, the heat transfer enhancement happens mostly due to the turbulent sublayer disturbance, and less due to the increase in area. The friction factor increases exponentially with the rib helix angle while the Nusselt number is linear. Thus, smaller angle values will assure less pressure drop without largely affecting the heat transfer coefficient.

Tube $\mathrm{OD}=15 \mathrm{~mm}, \mathrm{P} / \mathrm{D}=\mathbf{1 . 1 7}$

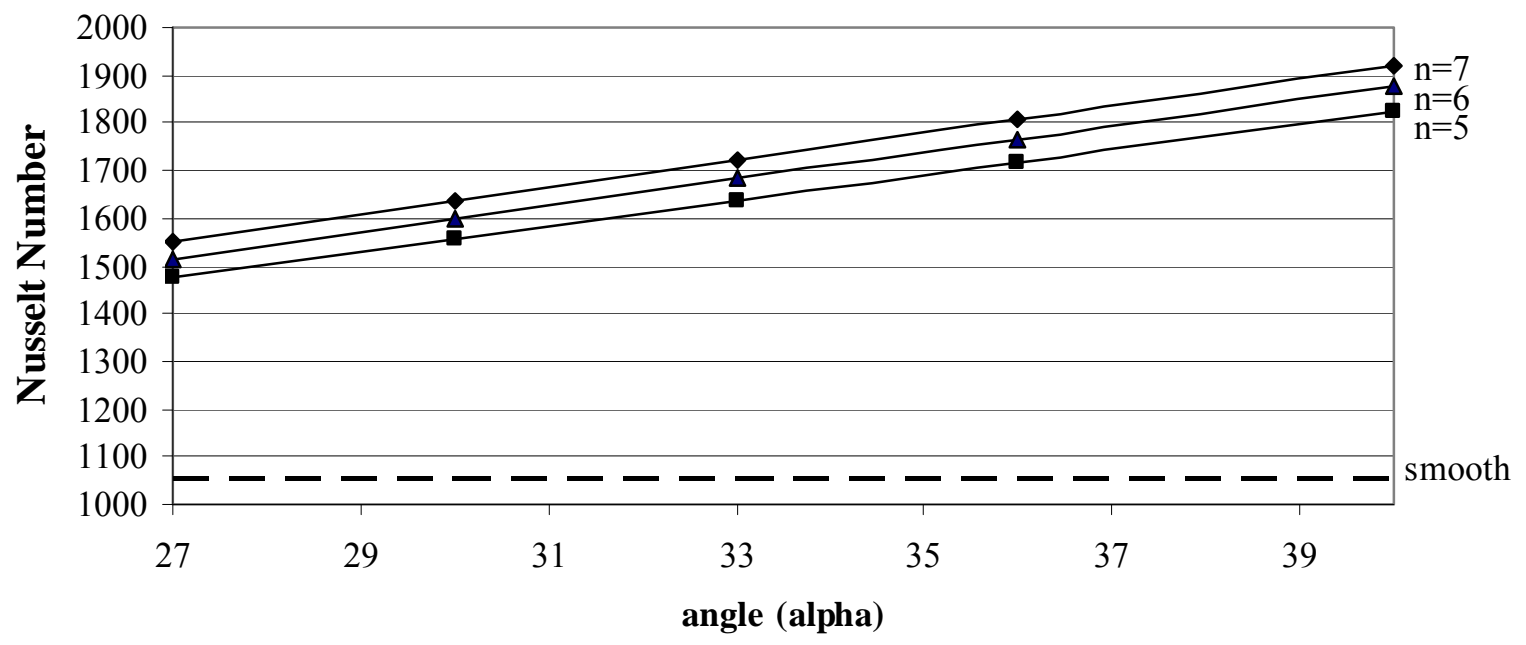

Figure 3C.6-3 Nusselt number variation with the helix angle and number of fins 


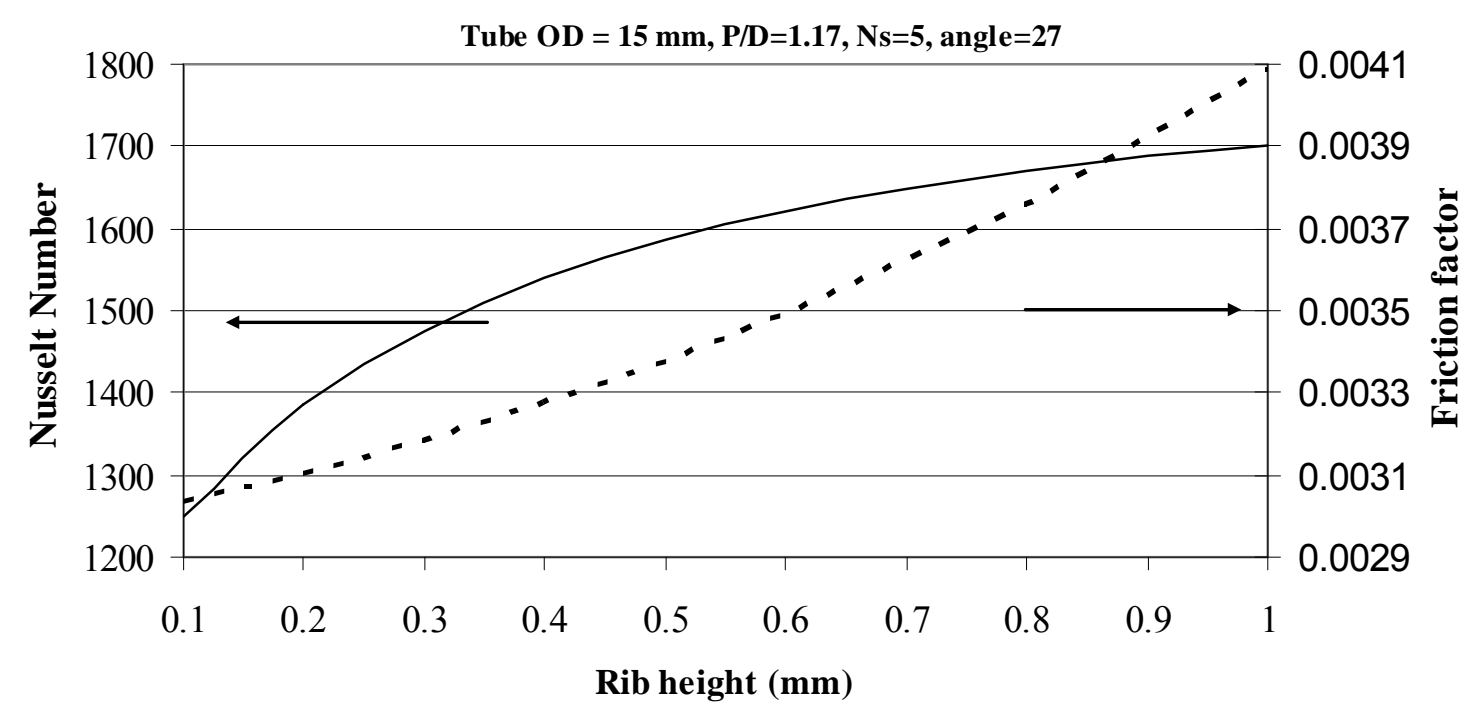

Figure 3C.6-4 Nu number and friction factor dependence on the rib height

Pressure drop and heat transfer of the flow are illustrated in Figure 3C.6-4. At first, Nu number shows a strong increase with increasing rib height. However, for a given geometry, it saturates around 1700. On the other hand, the friction factor demonstrates a non-linear increase with increased rib height. Thus, the optimum value for the rib height is around 0.3-0.5 $\mathrm{mm}$.

\section{Evaluation of different IHX tube geometries}

Taking all of the above recommendations into consideration, an evaluation of different tube geometries was conducted. The same tube geometry as for smooth tubes was used for the calculations. Table 3C.6-3 summarizes the output values for the IHX with enhanced heat transfer tubes.

Figure 3C.6-5 compares the pressure drops for both sides in smooth and augmented tubes. The values are for tubes with an outer diameter of $14 \mathrm{~mm}$. Other geometries exhibit similar behavior. Enhanced heat transfer allowed a reduction in tube length (active heat transfer area) therefore a significant reduction of the pressure drop on the lead side. As a result, the required pumping power values are decreased as well.

In the augmented tubes, the pressure drop of carbon dioxide does not vary significantly with the tube diameter (see Figure 3C.6-6). However, it increases rapidly with increasing P/D ratio (smaller number of tubes increases the $\mathrm{CO}_{2}$ velocity), as can be seen from Figure 3C.6-5. The outer diameter of $15 \mathrm{~mm}$ yields the smallest pressure drop on the secondary side. Ideally, a pitch-to-diameter ratio of 1.15 or smaller should be used; however, this creates an increase in lead velocity to above $3 \mathrm{~m} / \mathrm{s}$. Thus, the optimal P/D that also provides a margin to the lead velocity constraint is 1.17 . 
Project No 06-040: Flexible Conversion Ratio Fast Reactor Systems Evaluation

Table 3C.6-3 Comparison of different tube geometries for IXH with augmented ${ }^{*}$ tubes

\begin{tabular}{ccccccccc}
\hline $\mathrm{P} / \mathrm{D}$ & $\begin{array}{c}\text { Lead } \\
\text { velocity } \\
(\mathrm{m} / \mathrm{s})\end{array}$ & $\begin{array}{c}\mathrm{CO}_{2} \\
\text { velocity } \\
(\mathrm{m} / \mathrm{s})\end{array}$ & $\begin{array}{c}\text { Lead } \\
\text { pressure } \\
\text { drop } \\
(\mathrm{kPa})\end{array}$ & $\begin{array}{c}\mathrm{CO} 2 \\
\text { pressure } \\
\text { drop } \\
(\mathrm{kPa})\end{array}$ & $\begin{array}{c}\text { Tube } \\
\text { Length } \\
(\mathrm{m})\end{array}$ & $\begin{array}{c}\text { Lead side } \\
\text { pumping } \\
\text { power }\end{array}$ & $\begin{array}{c}\text { HT area } \\
\left(\mathrm{m}^{2}\right)\end{array}$ & $\begin{array}{c}\text { Number } \\
\text { of tubes }\end{array}$ \\
\hline $\mathrm{OD}=14 \mathrm{~mm}$ & & & & & & & \\
\hline 1.15 & 2.99 & 26.13 & 823.04 & 604.72 & 5.41 & 1.23 & 2544.7 & 19678 \\
\hline 1.17 & 2.79 & 27.04 & 660.29 & 652.10 & 5.55 & 1.12 & 2520.5 & 19011 \\
\hline 1.2 & 2.54 & 28.45 & 494.93 & 728.59 & 5.75 & 1.01 & 2483.2 & 18073 \\
\hline 1.25 & 2.24 & 30.87 & 333.07 & 871.98 & 6.08 & 0.89 & 2418.9 & 16656 \\
\hline $\mathrm{OD}=15 \mathrm{~mm}$ & & & & & & & \\
\hline 1.15 & 2.99 & 26.11 & 835.69 & 601.70 & 6.04 & 1.24 & 2650.4 & 17142 \\
\hline 1.17 & 2.79 & 27.02 & 670.12 & 649.89 & 6.20 & 1.13 & 2625.5 & 16561 \\
\hline 1.2 & 2.54 & 28.43 & 502.06 & 727.91 & 6.42 & 1.01 & 2586.9 & 15743 \\
\hline 1.25 & 2.24 & 30.84 & 337.59 & 874.37 & 6.79 & 0.90 & 2520.6 & 14509 \\
\hline $\mathrm{OD}=16 \mathrm{~mm}$ & & & & & & & \\
\hline 1.15 & 2.99 & 26.09 & 849.20 & 602.22 & 6.70 & 1.25 & 2754.5 & 15066 \\
\hline 1.17 & 2.79 & 27.01 & 680.72 & 651.38 & 6.87 & 1.14 & 2728.8 & 14555 \\
\hline 1.2 & 2.54 & 28.41 & 509.67 & 730.93 & 7.12 & 1.02 & 2689.2 & 13837 \\
\hline 1.25 & 2.24 & 30.82 & 342.52 & 880.74 & 7.53 & 0.90 & 2620.8 & 12752 \\
\hline $\mathrm{OD}=17 \mathrm{~mm}$ & & & & & & & \\
\hline 1.15 & 2.99 & 26.08 & 863.18 & 605.25 & 7.38 & 1.26 & 2857.2 & 13346 \\
\hline 1.17 & 2.79 & 26.99 & 691.75 & 655.46 & 7.57 & 1.14 & 2830.8 & 12893 \\
\hline 1.2 & 2.54 & 28.39 & 517.71 & 736.72 & 7.85 & 1.02 & 2790.1 & 12257 \\
\hline 1.25 & 2.24 & 30.81 & 347.72 & 889.92 & 8.30 & 0.90 & 2719.8 & 11296 \\
\hline
\end{tabular}

*Helical ribs with rib height of $0.35 \mathrm{~mm}$, rib pitch of $1.4 \mathrm{~mm}$ and helix angle of $27^{\circ}$.

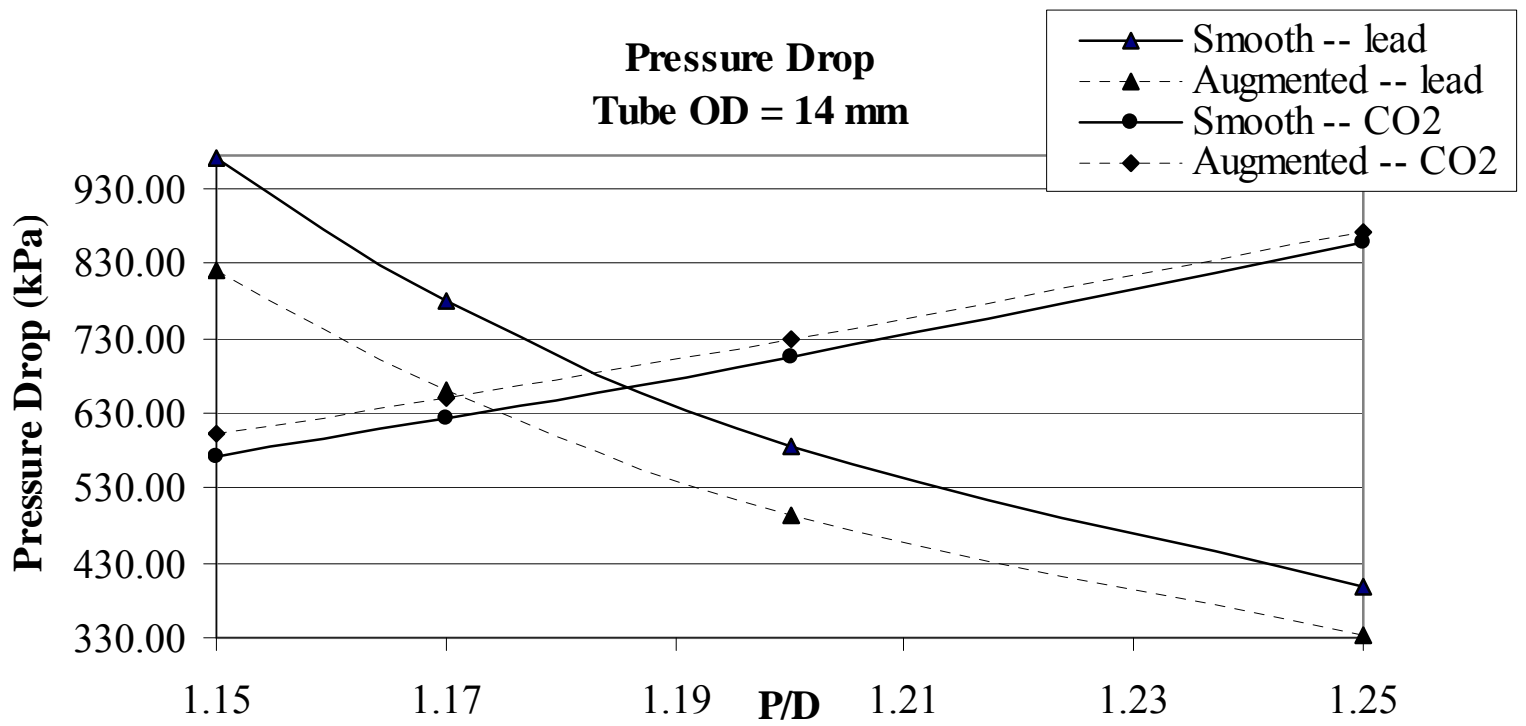

\footnotetext{
${ }^{* *}$ Expressed in percent of the total core thermal power. Includes pressure drop through the core and heat exchanger.
} 
Figure 3C.6-5 Pressure drop dependence on the P/D ratio

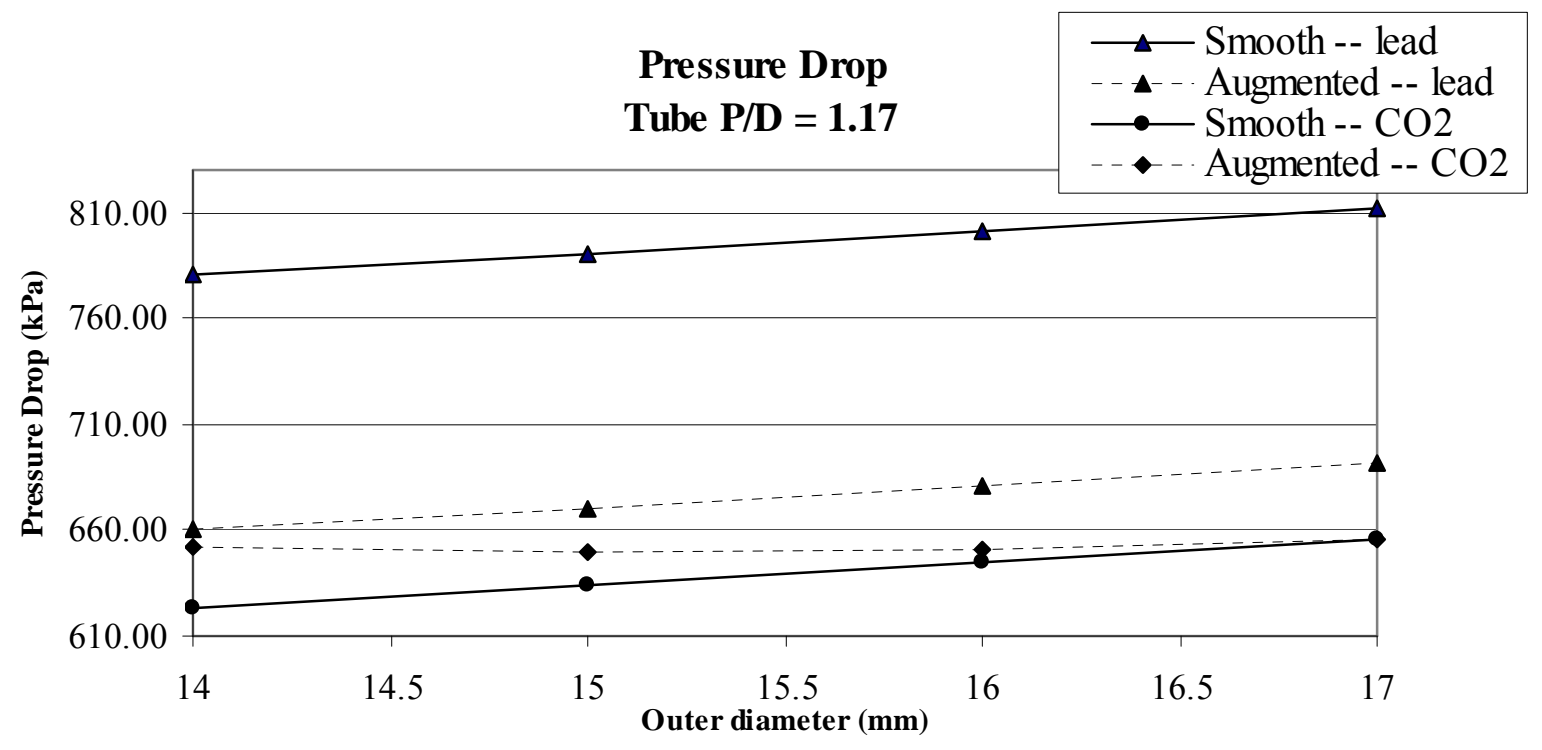

Figure 3C.6-6 Pressure drop dependence on the tube outer diameter

Heat exchanger tube wall thickness varies with the diameter of the tube. As the outer diameter increases, the wall thickness also increases. As can be seen in Figure 3C.6-6, even though the inside diameter of the tube increases, the $\mathrm{CO}_{2}$ pressure drop continues to increase. This occurs due to the decrease in the overall heat transfer coefficient. The overall heat transfer coefficient strongly depends on the steel wall conduction heat transfer, which becomes the dominant heat transfer resistance for thick walls. Thus, longer tubes are needed to accommodate the loss in the overall heat transfer coefficient, causing increased pressure drop.

\section{C.6.2.4 Modifications for salt reactor IHX design}

The same spreadsheet model was used for designing the intermediate heat exchangers for the liquid salt reactor. A few modifications were made to make it suitable for modeling liquid salt. Primary side coolant properties were changed to match those of the selected salt NaCl-KCl$\mathrm{MgCl}_{2}$ (30\%-20\%-50\%). The salt inlet temperature and flow rate were changed to match the results from the steady state core analysis. Finally, the heat transfer correlation was changed from the Lyon-Martinelli correlation, used for liquid metals, to the Gnielinski correlation, which is appropriate for high Prandtl number liquid salts. This has the effect of greatly reducing the primary-side heat transfer coefficient. For the lead reactor, the thermal resistance due to convection between the primary coolant and the heat exchanger tubes constitutes $19 \%$ of the total thermal resistance, while for the salt reactor it constitutes $59 \%$. As a result, to maintain the same secondary side temperatures, the salt reactor IHXs need to be larger than the ones in the lead reactor, necessitating the use of a bottle-necked chimney to maintain the same overall vessel dimensions. The IHX secondary side for the salt reactor uses the same enhanced tubes as in the lead reactor, and is modeled using the same pressure drop and heat transfer correlations. 
The IHX design approach using the spreadsheet model is described in section 4.2.2.1.2 on salt IHX design. The geometry and performance parameters of the reference IHX design are given in Table 4.2.2-3 in that section.

\section{References for Appendix 3C}

Bergles, A. E., Ravigururajan, T. S., Development and Verification of General Correlations for Pressure Drop and Heat Transfer in Single-Phase Turbulent Flow in Enhanced Tubes, Experimental Thermal and Fluid Science 13, 55-70, 1996

Cheng S. K. and Todreas N. E., "Hydrodynamic models and correlations for bare and wirewrapped hexagonal rod bundles - Bundle friction factors, subchannel friction factors and mixing parameters," Nuclear Engineering and Design, v 92, n 2, Apr, 1986, p 227-251.

Derstine K.L., "DIF3D: A code to Solve One-, Two-, and Three-Dimensional Finite-Difference Diffusion Theory Problems", Applied Physics Division, ANL82-64, Argonne National Laboratory, April 1984.

El-Wakil, M. M., Nuclear Heat Transport, American Nuclear Society, La Grange Park, IL, USA. 1978

Fridman E., E. Shwageraus, A. Galperin, “Efficient Generation of One-group Cross-Sections for Coupled Monte Carlo Depletion Calculations," Nuclear Science and Engineering, Vol. 159 No. 1, pp. 37-47, May 2008

Gee, D. L., and Webb, R. L., Forced Convection Heat Transfer in Helically Rib-Roughened Tubes, Int. J. Heat Mass Transfer 23, 1127-1136, 1980

Gnielinski, V., "New Equations for Heat and Mass Transfer in Turbulent Pipe and Channel Flow”, International Chemical Engineering, v 16, n 2, Apr, 1976, p 359-368.

Henryson II H., Toppel B.J., and Stenberg C. G., "MC2-2: A Code to Calculate Fast Neutron Spectra and Multigroup Cross Sections", Applied Physics Division, ANL81-44, Argonne National Laboratory, June 1976.

Lawrence R.D., "DIF3D Nodal Neutronics Option for Two- and Three-Dimensional Diffusion Theory Calculations in Hexagonal Geometry", Applied Physics Division, ANL83-1, Argonne National Laboratory, March 1983.

Ravigururajan, T. S., A Comparative Study of Thermal Design Correlations for Turbulent Flow in Helical-Enhanced Tubes, Heat Transfer Engineering 20, 54-70, 1999 
Shwageraus E., E. Fridman, E. Abramski, A. Galperin, BGCore - A Comprehensive Package for Reactor Core and Fuel Storage Analysis, Proc. of 23rd Conference of the Nuclear Societies in Israel, Dead Sea, Israel, February 15-16, (2006).

Todreas, N.E., and Kazimi, M.S., Nuclear Systems I: Thermal Hydraulic Fundamentals, Taylor and Francis, 1993.

Toppel B.J., “A User's Guide for the Rebus-3 Fuel Cycle Analysis Capability”, Applied Physics Division, ANL83-2, Argonne National Laboratory, March 1983.

Webb, R. L., Narayanamurthy, R., Thors, P., Heat Transfer and Friction Characteristics of Internal Helical-Rib Roughness, Journal of Heat Transfer 122, 134-142, 2000 


\section{Appendix 4A Overview of Potential Salt Candidates}

\section{A.1 Database of Initial Liquid Salt Candidates}

There are a large number of primary coolant salt options available for liquid salt reactors, each with different physical, chemical, and nuclear properties. Possible coolant salts are listed in Williams et al., [2006a], Williams and Toth [2006b] and Forsberg [2004], selected based on chemical stability and a reasonably low $\left(<525^{\circ} \mathrm{C}\right)$ melting point. The list of potential salt candidates for fast reactor use includes both fluoride and chloride salts. The initial salt selection was chosen based on chemical stability and a reasonable $\left(<525^{\circ} \mathrm{C}\right)$ melting point. The list of potential salt candidates for fast reactor use includes both fluoride and chloride salts; these are listed with their thermal-hydraulic properties in Table 4A.1-1.

Table 4A.1-1 Physical properties of candidate coolant salts ${ }^{5}$

\begin{tabular}{|c|c|c|c|c|c|c|c|}
\hline $\begin{array}{l}\text { Salt } \\
\text { (composition) }\end{array}$ & $\begin{array}{l}\text { Tmelt } \\
\left({ }^{\circ} \mathrm{C}\right)\end{array}$ & $\begin{array}{l}\mu \text { at } 550^{\circ} \mathrm{C} \\
(\mathrm{kg} / \mathrm{m}-\mathrm{s}){ }^{1}\end{array}$ & $(\mathrm{~W} / \mathrm{m}-\mathrm{K})^{2}$ & $\begin{array}{l}\text { Th.exp. c. } \\
(\% / K)^{3}\end{array}$ & $\begin{array}{l}\text { Density } \\
\left(\mathrm{kg} / \mathrm{m}^{3}\right)^{3}\end{array}$ & $\begin{array}{l}\mathrm{c}_{\mathrm{p}}(\mathrm{cal} \\
/ \mathrm{gK})^{4}\end{array}$ & $\begin{array}{l}\rho c_{p} \\
(\mathrm{cal} / \mathrm{ccK})\end{array}$ \\
\hline \multicolumn{8}{|l|}{ Alkali fluorides } \\
\hline $\begin{array}{l}{ }^{7} \mathrm{LiF}-\mathrm{NaF}-\mathrm{KF} \\
(46.5-11.5-42)\end{array}$ & 454 & $6.3 \mathrm{E}-3$ & $\begin{array}{l}0.6 \\
{[0.85]}\end{array}$ & $\begin{array}{l}0.034 \\
{[0.029]}\end{array}$ & $\begin{array}{l}2129 \\
{[2070]}\end{array}$ & $\begin{array}{l}0.45 \\
{[0.387]}\end{array}$ & 0.96 \\
\hline $\begin{array}{l}{ }^{7} \mathrm{LiF}-\mathrm{RbF} \\
(44-56)\end{array}$ & 475 & $6.2 \mathrm{E}-3$ & {$[0.53]$} & $\begin{array}{l}0.034 \\
{[0.029]}\end{array}$ & $\begin{array}{l}2772 \\
{[2850]}\end{array}$ & $\begin{array}{l}0.284 \\
{[0.226]}\end{array}$ & 0.79 \\
\hline $\begin{array}{l}{ }^{7} \mathrm{LiF}-\mathrm{NaF}-\mathrm{RbF} \\
(42-6-52)\end{array}$ & 435 & & {$[0.54]$} & [0.029] & [2816] & {$[0.236]$} & 0.66 \\
\hline \multicolumn{8}{|l|}{$\begin{array}{l}\text { Beryllium } \\
\text { fluorides }\end{array}$} \\
\hline $\begin{array}{l}{ }^{7} \mathrm{LiF}_{-\mathrm{BeF}} \\
(67-33)\end{array}$ & 458 & $11.1 \mathrm{E}-3$ & $\begin{array}{l}1.0 \\
{[1.04]}\end{array}$ & $\begin{array}{l}0.024 \\
{[0.021]}\end{array}$ & $\begin{array}{l}2012 \\
{[1980]}\end{array}$ & $\begin{array}{l}0.577 \\
{[0.566]}\end{array}$ & 1.16 \\
\hline $\begin{array}{l}\mathrm{NaF-BeF} 2 \\
(57-43)\end{array}$ & 340 & $18.1 \mathrm{E}-3$ & {$[0.80]$} & $\begin{array}{l}0.018 \\
{[0.022]}\end{array}$ & $\begin{array}{l}2067 \\
{[2123]}\end{array}$ & $\begin{array}{l}0.52 \\
{[0.440]}\end{array}$ & 1.07 \\
\hline $\begin{array}{l}{ }^{7} \mathrm{LiF}-\mathrm{NaF}-\mathrm{BeF}_{2} \\
(31-31-38)\end{array}$ & 315 & & {$[0.89]$} & {$[0.022]$} & [2066] & [0.489] & 1.01 \\
\hline \multicolumn{8}{|l|}{$\begin{array}{l}\text { Zirconium } \\
\text { fluorides }\end{array}$} \\
\hline $\begin{array}{l}{ }^{7} \mathrm{LiF}-\mathrm{ZrF}_{4} \\
(51-49)\end{array}$ & 509 & & {$[0.41]$} & {$[0.029]$} & {$[3230]$} & {$[0.292]$} & 0.94 \\
\hline $\begin{array}{l}\mathrm{NaF}-\mathrm{ZrF}_{4} \\
(59.5-40.5)\end{array}$ & 500 & $11.2 \mathrm{E}-3$ & {$[0.42]$} & $\begin{array}{l}0.028 \\
{[0.029]}\end{array}$ & $\begin{array}{l}3166 \\
{[3095]}\end{array}$ & $\begin{array}{l}0.28 \\
{[0.275]}\end{array}$ & 0.89 \\
\hline $\begin{array}{l}\mathrm{KF}-\mathrm{ZrF}_{4} \\
(58-42)\end{array}$ & 390 & $7.6 \mathrm{E}-3$ & {$[0.38]$} & {$[0.030]$} & [2928] & {$[0.251]$} & 0.73 \\
\hline $\begin{array}{l}\mathrm{RbF}-\mathrm{ZrF}_{4} \\
(58-42)\end{array}$ & 410 & & {$[0.32]$} & {$[0.030]$} & {$[3371]$} & {$[0.200]$} & 0.67 \\
\hline & & & & & & & \\
\hline
\end{tabular}


Project No 06-040: Flexible Conversion Ratio Fast Reactor Systems Evaluation

\begin{tabular}{|c|c|c|c|c|c|c|c|}
\hline $\begin{array}{l}\text { Salt } \\
\text { (composition) }\end{array}$ & $\begin{array}{l}\text { Tmelt } \\
\left({ }^{\circ} \mathrm{C}\right)\end{array}$ & $\begin{array}{l}\mu \text { at } 550^{\circ} \mathrm{C} \\
(\mathrm{kg} / \mathrm{m}-\mathrm{s}){ }^{1}\end{array}$ & $\begin{array}{l}\mathrm{k} \\
(\mathrm{W} / \mathrm{m}-\mathrm{K})^{2}\end{array}$ & $\begin{array}{l}\text { Th.exp. c. } \\
(\% / \mathrm{K})^{3}\end{array}$ & $\begin{array}{l}\text { Density } \\
\left(\mathrm{kg} / \mathrm{m}^{3}\right)^{3}\end{array}$ & $\begin{array}{l}\mathrm{c}_{\mathrm{p}}(\mathrm{cal} \\
/ \mathrm{gK})^{4}\end{array}$ & $\begin{array}{l}\rho \mathrm{c}_{\mathrm{p}} \\
(\mathrm{cal} / \mathrm{ccK})\end{array}$ \\
\hline $\begin{array}{l}{ }^{7} \mathrm{LiF}-\mathrm{NaF}-\mathrm{ZrF}_{4} \\
(26-37-37)\end{array}$ & 436 & $16.6 \mathrm{E}-3$ & {$[0.45]$} & $\begin{array}{l}0.028 \\
{[0.028]}\end{array}$ & $\begin{array}{l}2914 \\
{[3055]}\end{array}$ & \begin{tabular}{|l|}
0.35 \\
{$[0.296]$} \\
\end{tabular} & 1.02 \\
\hline $\begin{array}{l}\text { NaF-KF-ZrF } \\
(10-48-42)\end{array}$ & 385 & & {$[0.38]$} & {$[0.030]$} & [2956] & \begin{tabular}{|l|}
0.26 \\
{$[0.255]$} \\
\end{tabular} & 0.77 \\
\hline $\begin{array}{l}\text { NaF-RbF-ZrF } 4 \\
(8-50-42)\end{array}$ & 400 & & {$[0.33]$} & {$[0.030]$} & [3342] & {$[0.207]$} & 0.69 \\
\hline \multicolumn{8}{|l|}{ Chlorides } \\
\hline $\begin{array}{l}\mathrm{NaCl}-\mathrm{MgCl}_{2} \\
(63-37)\end{array}$ & 475 & & & & & & \\
\hline $\begin{array}{l}\mathrm{NaCl}-\mathrm{MgCl}_{2} \\
(58-42)\end{array}$ & 445 & $1.6 \mathrm{E}-3$ & $(0.43)$ & 0.025 & 2018 & $\begin{array}{l}0.258 \\
{[0.262]} \\
\end{array}$ & 0.52 \\
\hline $\begin{array}{l}\mathrm{KCl}-\mathrm{MgCl}_{2} \\
(68-32)\end{array}$ & 426 & $2.2 \mathrm{E}-3$ & $(0.39)$ & 0.024 & 1994 & $\begin{array}{l}0.276 \\
{[0.229]}\end{array}$ & 0.55 \\
\hline $\begin{array}{l}{ }^{7} \mathrm{LiCl}-\mathrm{KCl}- \\
\mathrm{MgCl}_{2} \\
(9-63-28)\end{array}$ & 402 & & & & & & \\
\hline $\begin{array}{l}\mathrm{NaCl}-\mathrm{KCl}- \\
\mathrm{MgCl}_{2} \\
(30-20-50)\end{array}$ & 396 & $2.1 \mathrm{E}-3$ & $(0.39)$ & 0.043 & 1798 & {$[0.250]$} & 0.45 \\
\hline $\begin{array}{c}{ }^{7} \mathrm{LiCl}-\mathrm{KCl} \\
(59.5-40.5)\end{array}$ & 355 & $1.8 \mathrm{E}-3$ & $\begin{array}{l}0.28-0.69 \\
(0.43) \\
\end{array}$ & 0.062 & 1399 & \begin{tabular}{|l|}
0.287 \\
{$[0.289]$} \\
\end{tabular} & 0.40 \\
\hline $\begin{array}{l}{ }^{7} \mathrm{LiCl-KCl}- \\
\mathrm{MgCl}_{2} \\
(55-40-5)\end{array}$ & 323 & & & & & & \\
\hline $\begin{array}{l}{ }^{7} \mathrm{LiCl}-\mathrm{RbCl} \\
(58-42)\end{array}$ & 313 & & $(0.39)$ & 0.029 & 2363 & $\begin{array}{l}0.213 \\
{[0.212]}\end{array}$ & 0.50 \\
\hline
\end{tabular}

${ }^{1}$ Values are only given for salts with measured and known viscosity temperature dependence; values are evaluated at $550^{\circ} \mathrm{C}$. Multiply by 1000 to obtain centipoises.

${ }^{2}$ Very few measured values available; values in brackets are estimated using the Khoklov correlation [Williams et al., 2006a] at $550^{\circ} \mathrm{C}$, values in parenthesis are estimated using a mole fraction average. There is very little data on salts containing $\mathrm{ZrF}_{4}$ and $\mathrm{MgCl}_{2}$.

${ }^{3}$ Percent change in density per degree, and density, are evaluated at $550^{\circ} \mathrm{C}$. Values in brackets are calculated using the method of additive molar volumes.

${ }^{4}$ Measured values are taken at $700^{\circ} \mathrm{C}$; values in brackets are calculated from the Dulong-Petit prediction [Williams et al., 2006a]. Temperature dependence is small and typically neglected during preliminary calculations.

${ }^{5}$ Fluoroborates are not included because of the need for isotopic enrichment of boron.

The capture and scattering one-group cross-sections of the various liquid salts constituent nuclides were calculated using a liquid salt fast reactor core spectrum ${ }^{*}$ to provide further guidance in salt selection. The results are presented in Table 4A.1-2 together with one-group cross-sections in a fast gas-cooled reactor spectrum for comparison. It can be seen that absorption cross sections of most constituents are higher in the LSFR spectrum than in the GFR

\footnotetext{
${ }^{*}$ Tight-pitch (P/D=1.086) hexagonal lattice, Zr-TRU- Nat.U (10-14-76 wt.\%) fueled core with NaF-KF-ZrF 4 liquid salt coolant.
} 
spectrum. This is due to the softer spectrum of the LSFR, but differences are relatively small except for $\mathrm{Rb}, \mathrm{Cl}$, and $\mathrm{Sn}$. Table 4A.1-2 also includes the scattering cross section for the LSFR spectrum to compare the moderating effect of the various nuclides.

Table 4A.1-2. Cross section comparison for potential salt constituent nuclides.

\begin{tabular}{|l|r|r|r|}
\hline Nuclide & $\begin{array}{c}\sigma_{\mathrm{a}}(\mathrm{mb})-G F R^{*} \\
{[\mathrm{Yu}, 2002]}\end{array}$ & $\sigma_{\mathrm{a}}(\mathrm{mb})$-LSFR & $\sigma_{\mathrm{s}}(\mathrm{mb})$-LSFR \\
\hline Li-nat & 73.9 & $71.54^{\dagger}$ & 460 \\
\hline $\mathrm{Li}-7$ & 0.03 & 0.04 & 74 \\
\hline $\mathrm{C}$ & 0.064 & 0.11 & 3977 \\
\hline $\mathrm{F}-19$ & 3.68 & 2.42 & 4651 \\
\hline $\mathrm{Na}-23$ & 2.0 & 2.09 & 5710 \\
\hline $\mathrm{Mg}$ & 1.0 & 2.36 & 1470 \\
\hline $\mathrm{Al}-27$ & 2.8 & 2.75 & 415 \\
\hline $\mathrm{Si}$ & 3.1 & 3.35 & 2938 \\
\hline $\mathrm{Cl}$ & 8.3 & 23.30 & 1337 \\
\hline $\mathrm{K}$ & 20.1 & 28.31 & 1667 \\
\hline $\mathrm{Ca}$ & 17.8 & 17.67 & 2876 \\
\hline $\mathrm{Rb}$ & 97.8 & 143.83 & 5363 \\
\hline $\mathrm{Sn}$ & 54.0 & 79.47 & 5982 \\
\hline $\mathrm{Sr}$ & 11.9 & 14.79 & 1745 \\
\hline $\mathrm{Zr}$ & 22.8 & 22.85 & 8267 \\
\hline $\mathrm{Ti}$ & 12.9 & 16.46 & 597 \\
\hline
\end{tabular}

*total absorption $(\mathrm{n}, \gamma)+(\mathrm{n}, \mathrm{p})$

${ }^{\dagger}$ statistical error $<1 \%$

\section{A.2 Preliminary Liquid Salt Prescreening}

Prescreening of liquid salts for use in fast spectrum reactors was performed in two stages. In the first stage, only fluoride salts, which are typically considered as the coolant for thermal liquid salt-cooled reactors, such as AHTR, were considered. Chloride salts have not been studied for use as primary coolants for the liquid salt FCR reactor in the first screening phase for three reasons. First, Cl-35 absorbs thermal neutrons to produce radioactive Cl-36, with a 300,000 year half life that may create an undesirable radwaste problem. Second, compared to fluoride salts, chloride salts are difficult to purify and to keep pure during reactor operation. Finally, chloride salts have not been as extensively studied as fluoride salts. The fluoride salts considered and their melting points are given in the first part of Table 4A.1-1.

Even considering only fluoride salts, there are a large number of ways that constituent salts can be combined into binary and ternary mixtures. These can be divided into four groups: salts containing only alkali fluorides, salts containing $\mathrm{BeF}_{2}$, salts containing $\mathrm{ZrF}_{4}$, and fluoroborate salts with $\mathrm{a} \mathrm{BF}_{4}$ anion. 
A selected set of five fluoride liquid salts was initially examined with regards to two neutronic performance characteristics: coolant density reactivity coefficient and neutron spectrum softening. The former parameter is of major importance for reactor safety, while the latter has a direct effect on the core criticality and can serve as an indicator of the core breeding/burning potential.

Liquid salts considered for the analysis and their select properties are presented in Table 4A.2-1. This set of salts in Table 4A.2-1 is narrower than that in Table 4A.1-1 and was selected to encompass a spectrum of possible candidates that contain different elements to assess their impact on neutronic performance and have reasonable melting point. Other most commonly considered coolants are liquid metals, in particular, $\mathrm{Pb}$ and $\mathrm{Na}$. These two coolants were also evaluated for the comparison purposes using the exact same model setup as that used for the liquid salts.

Table 4A.2-1: Selected Physical Properties of Selected Salts and Other Liquid Metal Coolants [Forsberg, 2004]

\begin{tabular}{|c|c|c|c|c|}
\hline $\begin{array}{c}\text { Case } \\
\#\end{array}$ & Salt/Liquid metal coolant & $\begin{array}{l}\text { Mol. } \\
\text { Weight, } \\
\text { g/mol }\end{array}$ & $\begin{array}{l}\text { Melting } \\
\text { Point, } \\
{ }^{\circ} \mathrm{C}\end{array}$ & $\begin{array}{l}\text { Density, } \\
\mathrm{g} / \mathrm{cm}^{3}\left({ }^{\circ} \mathrm{C}\right)\end{array}$ \\
\hline 1 & $\mathrm{NaF}-\mathrm{BeF}_{2}(57 \%-43 \%)$ & 44.1 & 340 & $2.27-3.7 \mathrm{E}-4 \times \mathrm{T}$ \\
\hline 2 & ${ }^{7} \mathrm{LiF}-\mathrm{RbF}(43 \%-57 \%)$ & 70.7 & 475 & $3.30-6.9 \mathrm{E}-4 \times \mathrm{T}$ \\
\hline 3 & $\mathrm{NaF}-\mathrm{Na}^{10} \mathrm{BF}_{4}(8 \%-92 \%)$ & 104.4 & 385 & $2.252-7.11 \mathrm{E}-4 \times \mathrm{T}$ \\
\hline 4 & NaF-KF-ZrF 4 (10\%-48\%-42\%) & 102.3 & 385 & $3.45-8.9 \mathrm{E}-4 \times \mathrm{T}$ \\
\hline 5 & $\mathrm{RbF}-\mathrm{Rb}^{10} \mathrm{BF}_{4}(31 \%-69 \%)$ & 151.3 & 442 & 2.494-8.7E-4×T \\
\hline \multirow[b]{2}{*}{6} & \multirow[b]{2}{*}{$\mathrm{Na}$} & \multirow[b]{2}{*}{23} & \multirow[b]{2}{*}{98} & $219+275.32 \times\left[1-\frac{(\mathrm{T}+273.15)}{2503.7}\right]$ \\
\hline & & & & $\begin{array}{l}\frac{511.58 \times \sqrt{1-\frac{(\mathrm{T}+273.15)}{2503.7}}}{1000} \\
\end{array}$ \\
\hline 7 & $\mathrm{~Pb}$ & 207.4 & 328 & $\begin{array}{r}11.054505-(1.1464762 \mathrm{E}-03+ \\
1.9047619 \mathrm{E}-08 \times \mathrm{T}) \times \mathrm{T}\end{array}$ \\
\hline
\end{tabular}

The analysis was performed for the specific isotopes indicated.

The study was performed on the basis of a one-dimensional fuel unit cell in an infinite medium in the radial direction, and axial leakage. The active core height was assumed to be $1 \mathrm{~m}$. The thickness of stainless steel (HT-9) axial reflectors was taken as $20 \mathrm{~cm}$. The calculations were performed with the MCNP-4C computer code. The cross-section data is based on the ENDFB/VI library. Plutonium isotope cross-sections evaluated at $900 \mathrm{~K}$ temperature were used, while $300 \mathrm{~K}$ data was used for all other isotopes. Main parameters of the computational model are summarized in Table 4A.2-2. 
The composition of the fuel considered in this analysis was Zr-TRU- Nat.U (10-14-76 wt.\%) metallic alloy with $12.5 \mathrm{~g} / \mathrm{cm}^{3}$ density ( $80 \%$ of T.D.). The isotopic composition of TRU corresponds to that of a typical LWR spent fuel with initial enrichment of $4.2 \%$, discharge burnup $50 \mathrm{MWd} / \mathrm{kg}$, and 10 years of decay after discharge. The fuel, cladding and coolant were represented in the model as a homogeneous mixture, which is a reasonable assumption for fast spectrum systems.

Table 4A.2-2. Computational Model Parameters

\begin{tabular}{|l|l|}
\hline Core height, cm & 100.0 \\
\hline Core diameter & Infinite \\
\hline Axial reflector height, cm & 20.0 \\
\hline Reflector material & HT-9 \\
\hline Cladding material & HT-9 \\
\hline Fuel volume fraction & 0.62 \\
\hline Salt volume fraction & 0.28 \\
\hline Cladding volume fraction & 0.10 \\
\hline Fuel P/D ratio & 1.15 \\
\hline
\end{tabular}

The results of the analysis are summarized in Table 4A.2-3. Figures 4A.2-1 through 4A.2-7 show the core reactivity dependence on the coolant temperature for each considered salt. Practically linear dependence was observed in all cases.

Table 4A.2-3: Results Summary

\begin{tabular}{|c|c|c|c|c|}
\hline $\begin{array}{c}\text { Case } \\
\#\end{array}$ & Salt & $\begin{array}{c}\text { Slowing Down } \\
\text { Power } \\
\left(\xi \Sigma_{\mathrm{s}}\right), \mathrm{cm}^{-1}\end{array}$ & $\begin{array}{l}\mathrm{K} \text {-eff }(\mathrm{BOL}) \\
\text { at } \mathrm{T}_{\text {salt }}=600^{\circ} \mathrm{C}\end{array}$ & $\begin{array}{l}\text { Coolant Density } \\
\text { Coeff., }\left(\mathrm{pcm} /{ }^{\circ} \mathrm{C}\right)\end{array}$ \\
\hline 1 & $\mathrm{NaF}-\mathrm{BeF}_{2}(57 \%-43 \%)$ & $5.66 \mathrm{E}-03$ & $1.15401 \pm 0.00026$ & $+1.8( \pm 0.1)$ \\
\hline 2 & ${ }^{7} \mathrm{LiF}-\mathrm{RbF}(43 \%-57 \%)$ & $3.16 \mathrm{E}-03$ & $1.18172 \pm 0.00033$ & $+2.5( \pm 0.1)$ \\
\hline 3 & $\mathrm{NaF}-\mathrm{Na}^{10} \mathrm{BF}_{4}(8 \%-92 \%)$ & $4.43 \mathrm{E}-03$ & $1.17158 \pm 0.00030$ & $+3.7( \pm 0.1)$ \\
\hline 4 & $\mathrm{NaF}-\mathrm{KF}-\mathrm{ZrF}_{4}(10 \%-48 \%-42 \%)$ & $3.08 \mathrm{E}-03$ & $1.17976 \pm 0.00034$ & $+2.9( \pm 0.1)$ \\
\hline 5 & $\mathrm{RbF}-\mathrm{Rb}^{10} \mathrm{BF}_{4}(31 \%-69 \%)$ & $2.27 \mathrm{E}-03$ & $1.21011 \pm 0.00031$ & $+3.5( \pm 0.1)$ \\
\hline 6 & $\mathrm{Na}$ & 7.32E-04 & $1.33203 \pm 0.00022^{\mathrm{a}}$ & $+0.7( \pm 0.1)$ \\
\hline 7 & $\mathrm{~Pb}$ & 4.63E-04 & $1.35147 \pm 0.00022^{\mathrm{b}}$ & $+0.06( \pm 0.10)$ \\
\hline
\end{tabular}

${ }^{\mathrm{a}}$ at $\mathrm{Na}$ temperature of $450^{\circ} \mathrm{C}$

${ }^{\mathrm{b}}$ at $\mathrm{Pb}$ temperature of $500^{\circ} \mathrm{C}$

All cation nuclides composing the salts have approximately the same (potential) scattering crosssection in the fast spectrum (on the order of a few barns). Therefore, the differences in slowing down power between the salts come primarily from the differences in average lethargy gain per 
collision or, in other words, differences in the atomic mass of the nuclides. As a result, high atomic mass salts ( $\mathrm{Zr}$ and $\mathrm{Rb}$ based) have lower moderating power and consequently higher reactivity of the system. The salts with larger molecular weights generally exhibit higher reactivity values and therefore more potential flexibility in the neutronic core design.

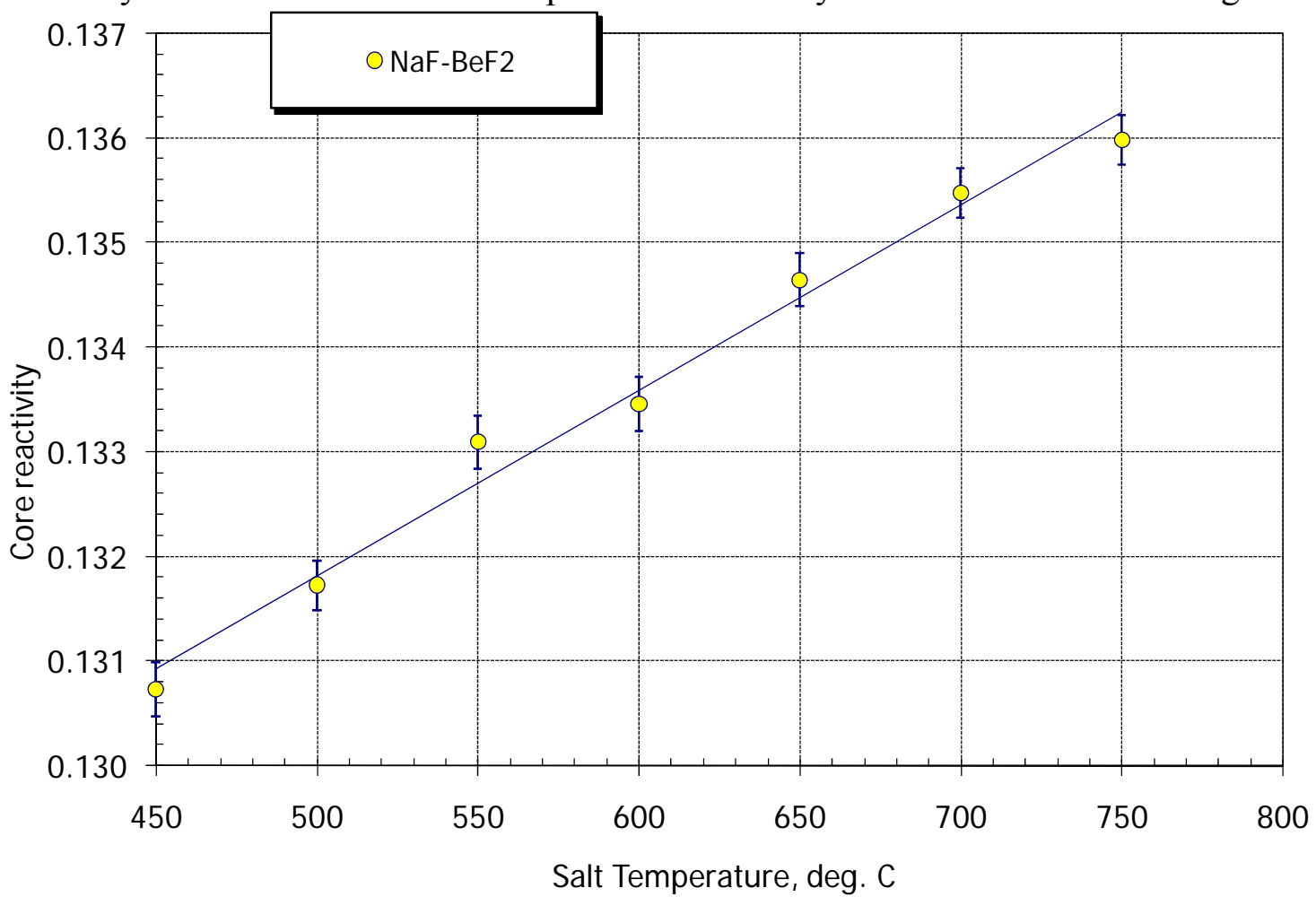

Figure 4A.2-1. Core reactivity as a function of $\mathrm{NaF}_{-}-\mathrm{BeF}_{2}$ salt temperature

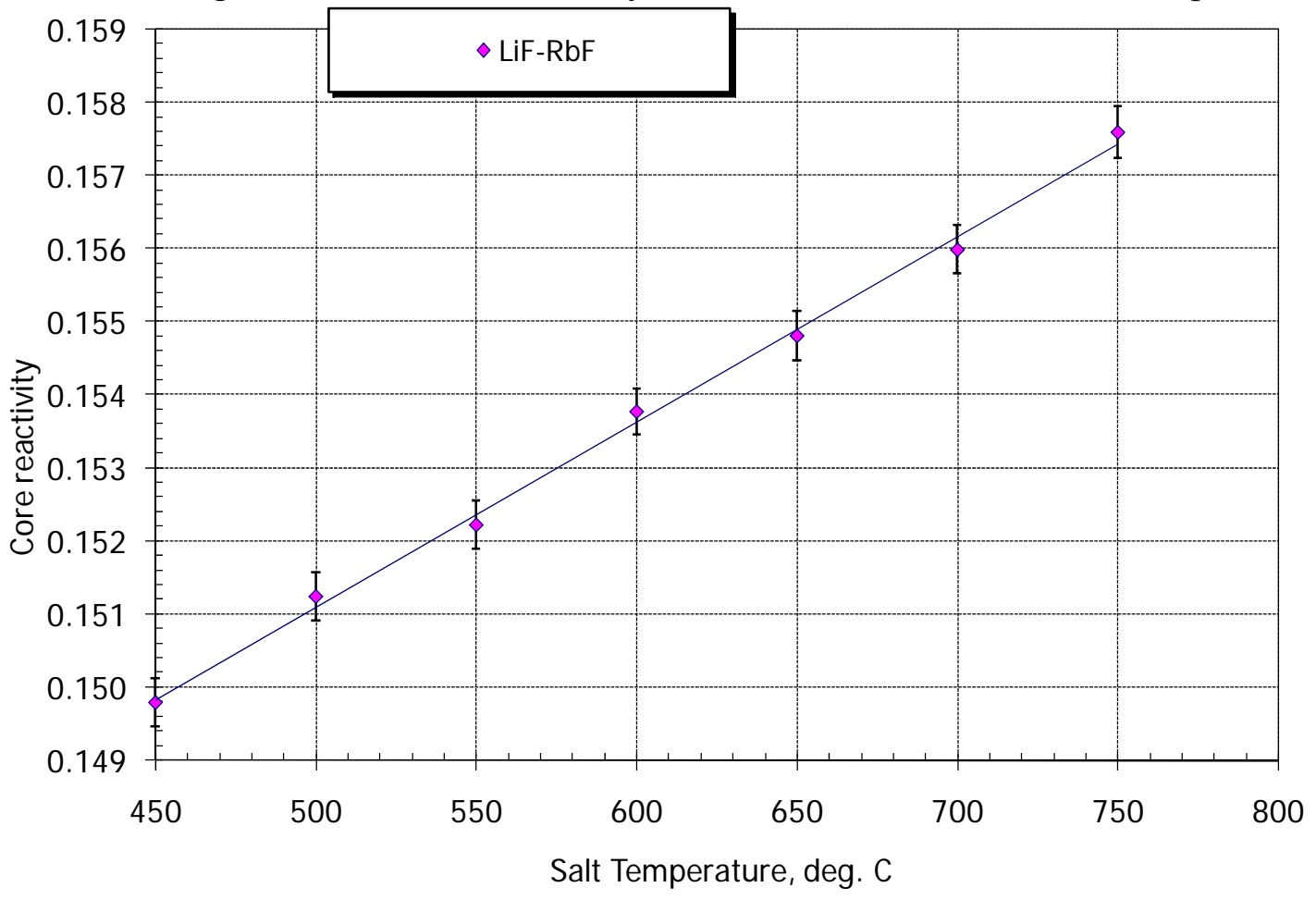


Project No 06-040: Flexible Conversion Ratio Fast Reactor Systems Evaluation

Figure 4A.2-2. Core reactivity as a function of LiF-RbF salt temperature

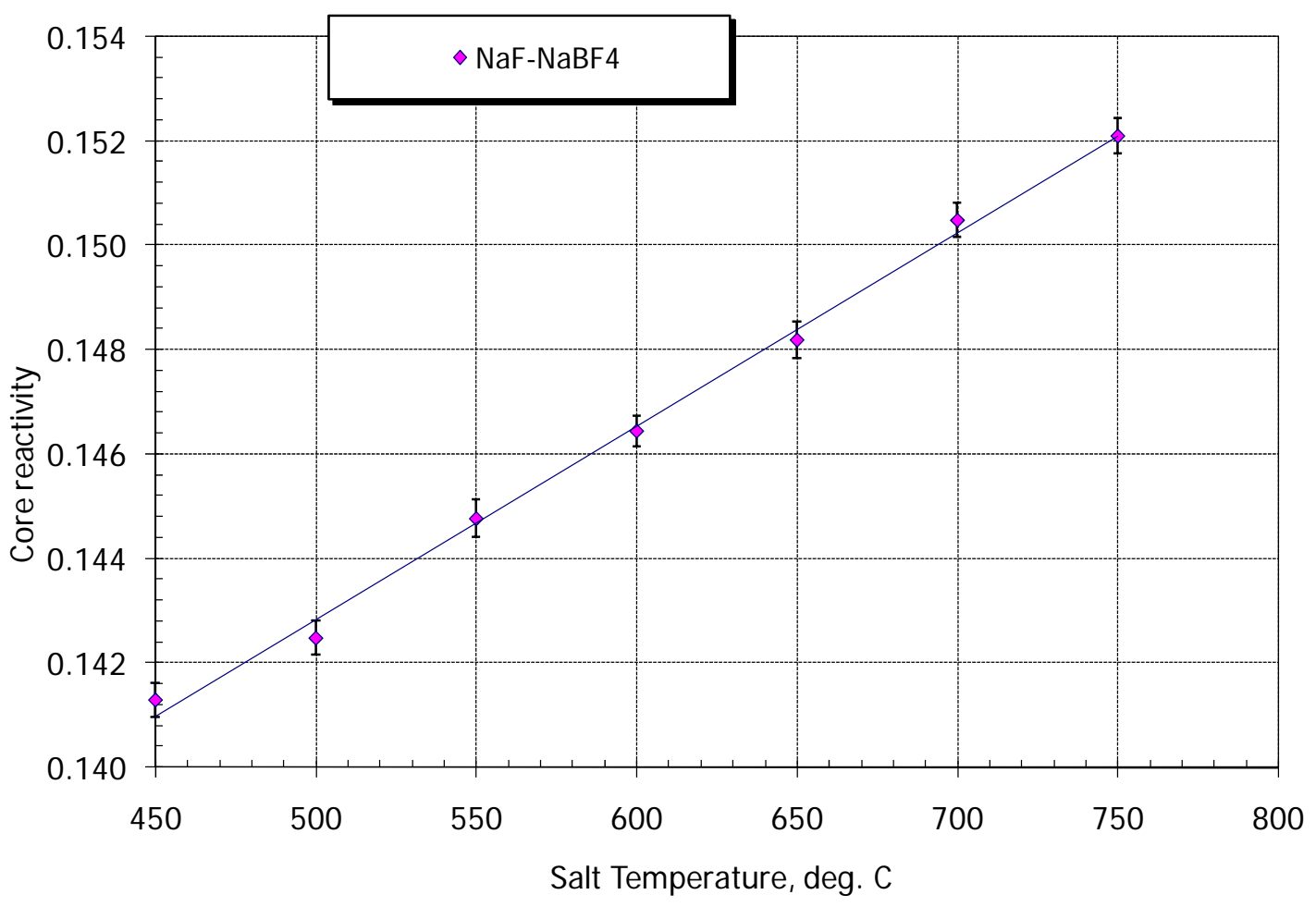

Figure 4A.2-3. Core reactivity as a function of $\mathrm{NaF}_{-} \mathrm{NaBF}_{4}$ salt temperature

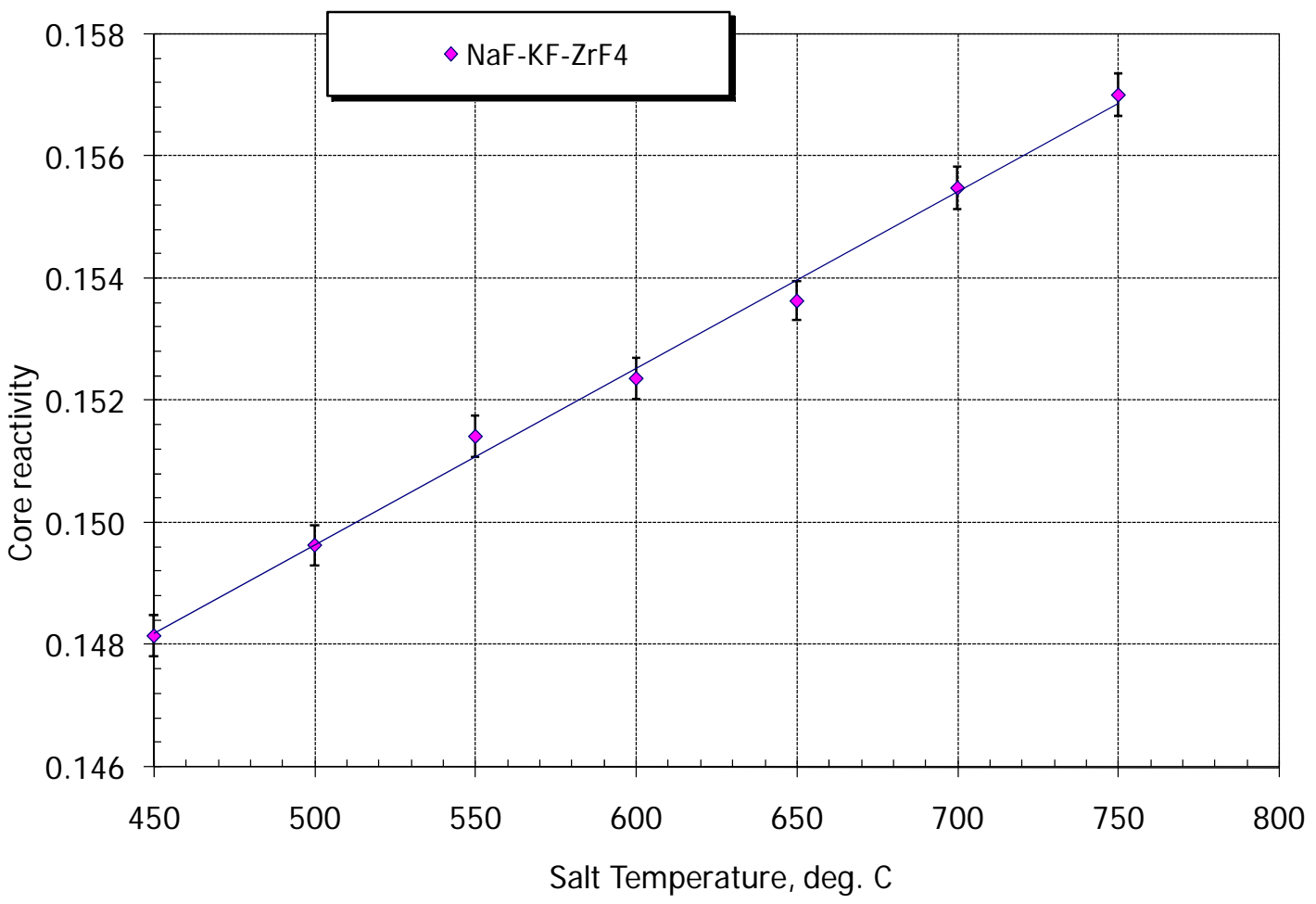

Figure 4A.2-4. Core reactivity as a function of $\mathrm{NaF}-\mathrm{KF}-\mathrm{ZrF}_{4}$ salt temperature 
Project No 06-040: Flexible Conversion Ratio Fast Reactor Systems Evaluation

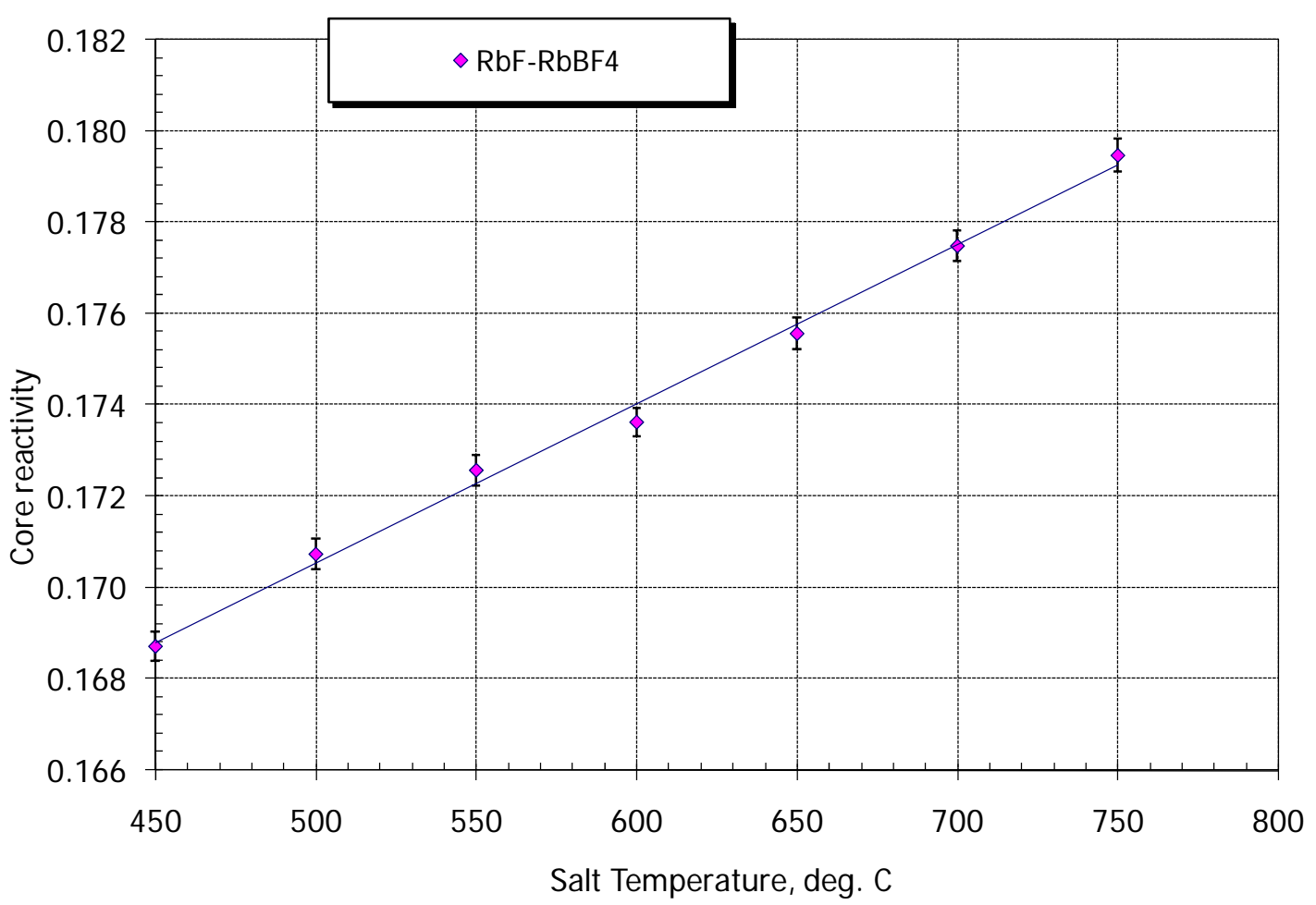

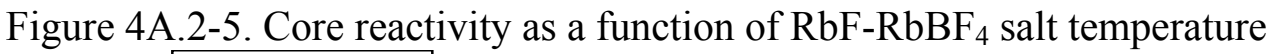

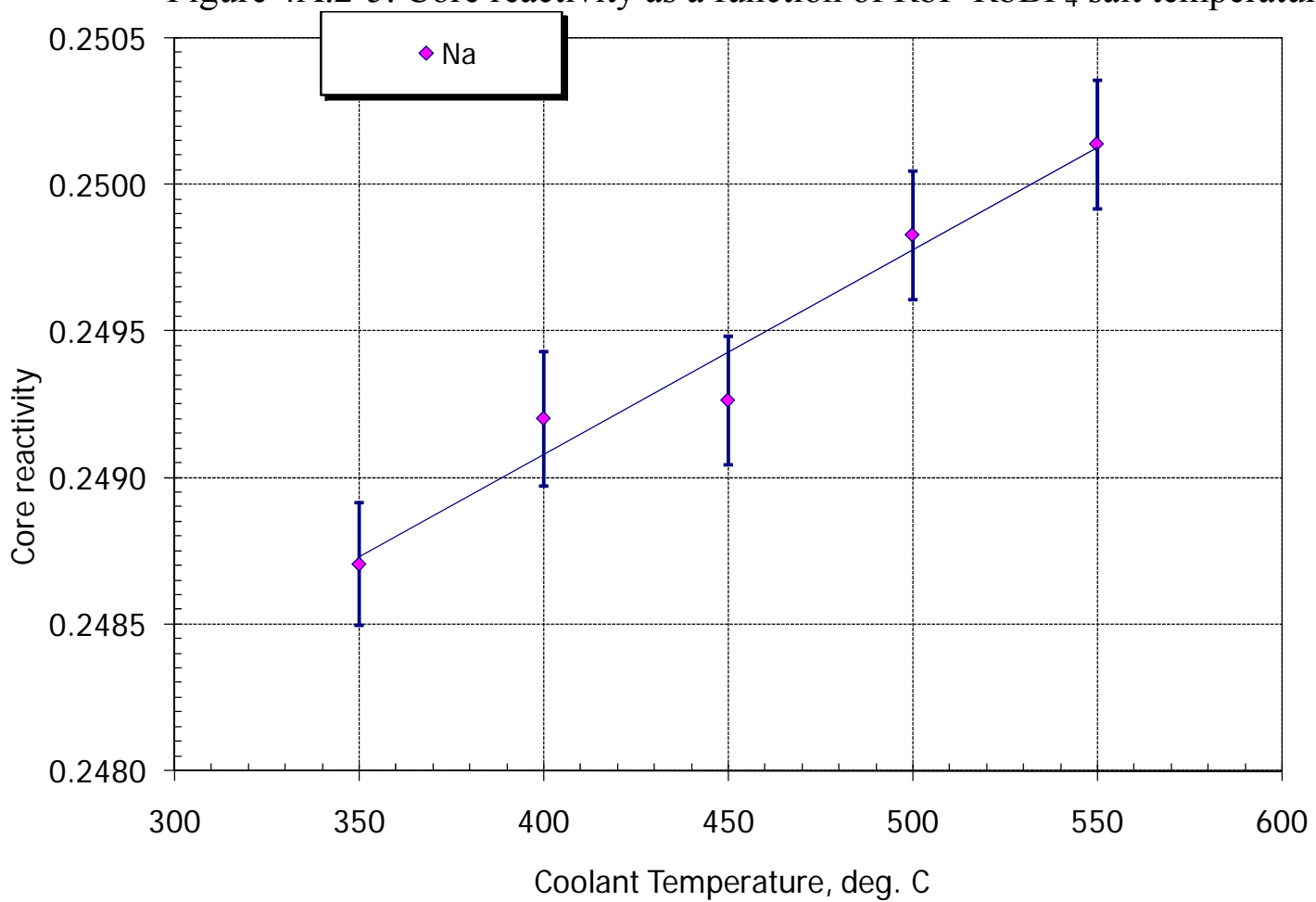

Figure 4A.2-6. Core reactivity as a function of $\mathrm{Na}$ temperature 
Project No 06-040: Flexible Conversion Ratio Fast Reactor Systems Evaluation

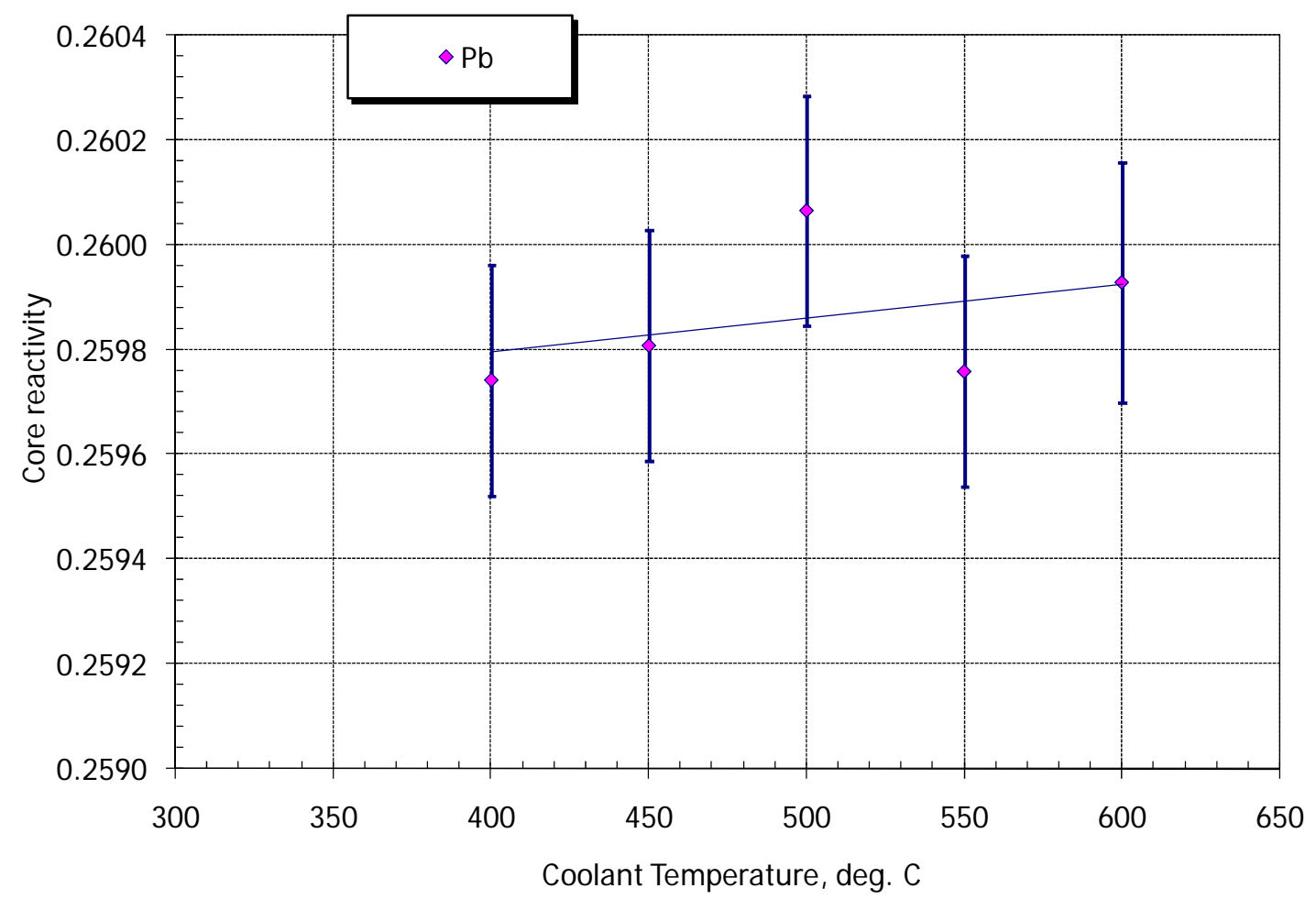

Figure 4A.2-7. Core reactivity as a function of $\mathrm{Pb}$ temperature

As expected, both liquid metal coolants considered are neutronically superior to the liquid salts with regard to the analyzed parameters. Both $\mathrm{Na}$ and $\mathrm{Pb}$ have much lower slowing down power, therefore considerably higher initial $\mathrm{k}_{\mathrm{eff}}$ than the liquid salts. The sodium temperature coefficient is positive but lower in magnitude than that of the best performing salt, $\mathrm{NaF}-\mathrm{BeF}_{2}$. The temperature coefficient of lead is practically zero.

The coolant temperature coefficient follows the slope of the density vs. temperature curve for each salt. Namely, the salts with strongest dependence of density on temperature exhibit the largest positive reactivity coefficient. The absolute values of the calculated salt temperature coefficients should not be treated as estimates for a real system but rather they should serve exclusively for comparison of different salt options. This is due to the fact that only axial leakage was considered in the current model and no specific core design features aiming at the improvement of reactivity coefficients were included.

The lowest value of the reactivity coefficient was obtained for $\mathrm{NaF}-\mathrm{BeF}_{2}$ salt. However, the same salt shows the lowest multiplication factor among all salts considered choices due to significant softening of the spectrum. Moreover, thermal-hydraulic analysis using $\mathrm{NaF}-\mathrm{BeF}_{2}$ as the primary coolant of FCR have shown that extremely high viscosity of this salt results in near-laminar flow in the core, which yields unattractively low power densities. Therefore, the $\mathrm{NaF}_{-} \mathrm{BeF}_{2}$ salt had to be discarded from further considerations. 
It seems that a good compromise between the two desired performance characteristics is the ${ }^{7} \mathrm{LiF}-\mathrm{RbF}$ salt. However, it consists of high cost materials $\left(\mathrm{Rb}^{*}\right.$ and enriched $\left.\mathrm{Li}\right)$ and has the highest melting point among all considered choices $\left(475^{\circ} \mathrm{C}\right)$. Furthermore, the melting point is too high for a medium temperature application where the peak cladding temperature is between 625 and $650^{\circ} \mathrm{C}$ and the core inlet temperature required would have to be above the vessel temperature limit.

Eliminating salts containing lithium, boron, rubidium and $\mathrm{NaF}_{-} \mathrm{BeF}_{2}$ for reasons discussed above, the large list is reduced to several zirconium salts. The zirconium salt $\mathrm{NaF}-\mathrm{ZrF}_{4}$ has a melting temperature of $500^{\circ} \mathrm{C}$, too close to the cladding temperature limit of $650^{\circ} \mathrm{C}$ to allow an appreciable margin to freezing. Therefore, the two fluoride salts found to be most promising for further study were $\mathrm{KF}-\mathrm{ZrF}$, and $\mathrm{NaF}-\mathrm{KF}-\mathrm{ZrF}_{4}$. While both salts have similar properties, the ternary salt was the most promising fluoride candidate because of its lower melting point.

Although the NaF-KF-ZrF 4 salt offers the best balance between neutronic and thermal hydraulic parameters, it was unable to meet the desired power density target of $100 \mathrm{~kW} / \mathrm{l}$ because of its high viscosity, which leads to a high pumping power and low heat transfer coefficient. Even with the looser assembly lattice $(\mathrm{P} / \mathrm{D}=1.19)$ of the reference core, fluoride salts only allow a power density of about $60 \mathrm{~kW} / 1$ for a core pressure drop of $700 \mathrm{kPa}$. Therefore, the salt selection process was extended to include chloride salts, which exhibit about 5 times lower viscosity and have lower moderating power than fluoride salts.

Salts containing lithium were eliminated because the high absorption cross section of Li- 6 would necessitate isotopic enrichment, which would be prohibitively expensive at the scale required. This left $\mathrm{NaCl}-\mathrm{MgCl}_{2}, \mathrm{KCl}-\mathrm{MgCl}_{2}$, and $\mathrm{NaCl}-\mathrm{KCl}-\mathrm{MgCl}_{2}$ as the three salt systems of interest. For the $\mathrm{NaCl}-\mathrm{MgCl}_{2}$ system, there is only enough information available about the $58 \% \mathrm{NaCl}-$ $42 \% \mathrm{MgCl}_{2}$ eutectic to permit analysis. These three salt mixtures all have similar thermal hydraulic and neutronic properties. The thermal hydraulics analysis described in this report was performed for each chloride salt to determine the most promising candidate. A summary of the results is given in Table 4A.2-4 (This table shows results for the pre-LEM salt core design, with $\mathrm{P} / \mathrm{D}=1.086$.). Fixed conditions were used, including a $1.0 \mathrm{MPa}$ core pressure drop and coolant inlet temperature $100^{\circ} \mathrm{C}$ above the melting point. Included for comparison are values for the most promising fluoride candidate, $\mathrm{NaF}-\mathrm{KF}-\mathrm{ZrF}_{4}$.

Chloride salt thermal hydraulics are greatly superior to those of fluoride salts. The primary reason for this is an approximately five times lower viscosity. Low viscosity improves coolant flow rate and heat transfer, as seen by the much higher coolant velocities and much lower film $\Delta$ Ts shown in Table 4A.2-4. In addition, chloride salts exhibit significantly smaller coolant temperature reactivity coefficients than fluoride salts, due to their smaller thermal expansion coefficient, and smaller moderating power. Each of the selected chloride salts performs similarly well, with the ternary $\mathrm{NaCl}-\mathrm{KCl}-\mathrm{MgCl}_{2}$ yielding the best performance because of its lower melting point. Because of its superior thermal hydraulic and neutronic performance, the ternary salt $\mathrm{NaCl}-\mathrm{KCl}-\mathrm{MgCl}_{2}$ is selected as the most promising salt candidate for the liquid salt FCR reactor, and is the salt used in the reference design.

\footnotetext{
* Although $\mathrm{Rb}$ is not traded and no market price is available, small quantities have been offered in 2005 for a price of about $\$ 1000$ per 100g (US Geological Survey, http://www.usgs.gov ).
} 
Table 4A.2-4 T-H analysis results for selected coolant salts

\begin{tabular}{|c|c|c|c|c|}
\hline Coolant salt & $\begin{array}{c}\text { NaF-KF- } \\
\mathrm{ZrF}_{4}\end{array}$ & $\begin{array}{l}\mathrm{NaCl}- \\
\mathrm{MgCl}_{2}\end{array}$ & $\begin{array}{c}\mathrm{KCl}- \\
\mathrm{MgCl}_{2}\end{array}$ & $\begin{array}{c}\mathrm{NaCl}- \\
\mathrm{KCl}-\mathrm{MgCl}_{2}\end{array}$ \\
\hline Total power $(\mathrm{MWt})$ & 844 & 2039 & 2270 & 2472 \\
\hline Power density (W/cc) & 36 & 86 & 96 & 104 \\
\hline Average power per pin $(\mathrm{W})$ & $3.07 E+03$ & $7.43 E+03$ & $8.27 E+03$ & $9.01 \mathrm{E}+03$ \\
\hline Coolant inlet temperature $\left({ }^{\circ} \mathrm{C}\right)$ & 485 & 545 & 526 & 496 \\
\hline Average coolant outlet temperature $\left({ }^{\circ} \mathrm{C}\right)$ & 515 & 603 & 591 & 581 \\
\hline Hot assembly outlet temperature $\left({ }^{\circ} \mathrm{C}\right)$ & 523 & 619 & 609 & 605 \\
\hline Coolant mass flow rate through core $(\mathrm{kg} / \mathrm{s})$ & $2.63 E+04$ & $3.25 E+04$ & $3.04 E+04$ & $2.89 \mathrm{E}+04$ \\
\hline Pumping power (MW) & 9 & 16 & 15 & 15 \\
\hline \multicolumn{5}{|l|}{ Hot channel characteristics: } \\
\hline Inlet coolant velocity $(\mathrm{m} / \mathrm{s})$ & 2.12 & 4.03 & 3.78 & 3.85 \\
\hline Reynolds number & $1.37 E+03$ & $1.07 E+04$ & $7.41 \mathrm{E}+03$ & $7.02 E+03$ \\
\hline Nusselt number & 8.4 & 68.0 & 57.7 & 52.1 \\
\hline Heat transfer coefficient $\left(\mathrm{W} / \mathrm{m}^{2} \mathrm{~K}\right)$ & $1.33 E+03$ & $1.44 \mathrm{E}+04$ & $1.11 \mathrm{E}+04$ & $1.00 \mathrm{E}+04$ \\
\hline Maximum film $\Delta \mathrm{T}(\mathrm{K})$ & 138.7 & 30.9 & 44.7 & 53.9 \\
\hline
\end{tabular}

\section{References for Appendix 4A}

Forsberg C.W., "Reactors with Molten Salts: Options and Missions," Proc. of the Frédéric Joliot \& Otto Hahn Summer School, August 25 - September 3, 2004, Cadarache, France.

Todreas N.E., Hejzlar P., Shwageraus E.., Petroski R. Nikiforova A., and Whitman J., "Flexible Conversion Ratio Fast Reactor Systems Evaluations", $3{ }^{\text {rd }}$ Quarterly report, Center for Advanced Nuclear Energy Systems, MIT, MIT-NFC-PR-090, January 2007.

Williams D.F., Toth L.M. and Clarno K.T., "Assessment of Candidate Molten Salt Coolants for the Advanced High-Temperature Reactor (AHTR)," ORNL/TM-2006/12, March 2006a.

Williams D.F. and Toth L.M., "Assessment of Candidate Molten Salt Coolants for the NGNP/NHI Heat Transfer Loop,” ORNL/TM-2006/69, June 2006b.

Forsberg C. W., Private communication, April, 2007.

Konings R., Private communication February - May 2007

Janz G. J., Molten Salts Handbook, Academic Press, NY, 1967

Polyakov P. V. and Gildebrandt E. M., "Investigation of Thermal-Conductivity of Melts of System KCl-MgCl2," High Temperature 12(4), 780-781 (1974) 
Project No 06-040: Flexible Conversion Ratio Fast Reactor Systems Evaluation

Raseman C. J., Susskind H., Farber G., McNulty W. E., and Salzano F. J., Engineering Experience at Brookhaven National Laboratory in Handling Fused Chloride Salts, BNL-627, T192, Brookhaven National Laboratory, Brookhaven, NY (1960).

Susskind et al., "Corrosion Studies for a Fused Salt-Liquid Metal Extraction Process for the Liquid Metal Fuel Reactor", BNL-585, 1960. 


\section{Appendix 4B Alternative Strategies to Reduce the Coolant Temperature Reactivity Coefficient for LSFR}

In the early stages of this project, a large positive coolant temperature reactivity coefficient, further designated as Coolant Temperature Coefficient (CTC), was identified as a major challenge in the design of liquid salt-cooled cores. Therefore, a significant effort was spent on the neutronic analysis exploring strategies for CTC reduction. The approaches explored will be summarized in this appendix.

The first salt candidate, $\mathrm{NaF}-\mathrm{KF}-\mathrm{ZrF}_{4}$, exhibits a particularly large CTC mostly due to its large thermal expansion coefficient. The value of CTC for the $\mathrm{NaF}-\mathrm{KF}-\mathrm{ZrF}_{4}$ salt was shown to be nearly four to five times larger than the value typical for $\mathrm{Na}$ cooled reactors. A number of strategies were applied to reduce the $\mathrm{CTC}$ of the $\mathrm{NaF}-\mathrm{KF}-\mathrm{ZrF}_{4}$ cooled core. Then, sensitivity studies were carried out in order to identify the range of CTC values that would ensure selfcontrollability of the core based on a quasi-static approach.

In addition, two chloride salts (binary $\mathrm{NaCl}-\mathrm{MgCl}_{2}$ and ternary $\mathrm{NaCl}-\mathrm{KCl}-\mathrm{MgCl}_{2}$ ) were considered as an alternative to $\mathrm{NaF}-\mathrm{KF}-\mathrm{ZrF}_{4}$ salt. These chloride salts have considerably lower thermal expansion coefficient and lower viscosity, which should reduce the CTC of the core and increase the achievable power density. Ternary $\mathrm{NaCl}-\mathrm{KCl}-\mathrm{MgCl}_{2}$ salt was chosen for further analysis due to its lower melting point, although the binary $\mathrm{NaCl}-\mathrm{MgCl}_{2}$ salt showed a more favorable CTC. The results of all cases analyzed in this study are summarized in Table 4B-1 and discussed below.

\section{B.1 Investigation of CTC reduction strategies for NaF-KF- $\mathrm{ZrF}_{4}$ cooled core}

The objective of this part of the study was to investigate several possibilities to reduce the CTC of the core cooled by $\mathrm{NaF}-\mathrm{KF}-\mathrm{ZrF}_{4}$ salt. The preliminary $\mathrm{CR}=1$ salt-cooled core design described in Todreas et al. [2007] was used as a reference (Case 1 in Table 4B-1).

The reference core has $100 \mathrm{~W} / \mathrm{cm}^{3}$ power density, hexagonal fuel assemblies, and 3 radial fuel zones with variable $\mathrm{Zr}$ content to tailor the radial power distribution. In addition to a heterogeneous core model with detailed geometry description, a homogeneous model was also developed to speed up the calculations. Homogenization of the core results in about $500 \mathrm{pcm}$ underestimation of the core reactivity, and reproduces the CTC value of the heterogeneous model within the statistical error of the calculations (see Cases 2 and 3 in Table 4B-1). 
Project No 06-040: Flexible Conversion Ratio Fast Reactor Systems Evaluation

Table 4B-1 Summary of investigated cases for CTC reduction

\begin{tabular}{|c|c|c|c|c|c|c|c|c|c|}
\hline Case & $\begin{array}{l}\text { Geometry / } \\
\text { representation }\end{array}$ & Salt & $\begin{array}{l}\text { Top } \\
\text { reflector }\end{array}$ & $\begin{array}{l}\text { TRU:HM } \\
\text { ratio, w/o }\end{array}$ & $\begin{array}{l}\text { Core diluent, } \\
\text { v/o (z1/z2/z3) }\end{array}$ & $\begin{array}{c}\text { Blanket } \\
\text { Composition }\end{array}$ & $\begin{array}{c}\text { Blanket } \\
\text { dimensions }\end{array}$ & k-eff & $\begin{array}{l}\text { CTC, } \\
\notin / \mathrm{K}\end{array}$ \\
\hline 1 & Heterogeneous & $\mathrm{NaF}-\mathrm{KF}-\mathrm{ZrF} \mathrm{F}_{4}$ & $\mathrm{Zr}$ & 15 & - & - & - & 0.98817 & $0.63 \pm 0.08$ \\
\hline 2 & Heterogeneous & NaF-KF-ZrF 4 & $\mathrm{Ti}$ & 15 & - & - & - & 0.99358 & $0.64 \pm 0.08$ \\
\hline 3 & Homogeneous & $\mathrm{NaF}-\mathrm{KF}-\mathrm{ZrF}_{4}$ & $\mathrm{Ti}$ & 15 & - & - & - & 0.98873 & $0.68 \pm 0.08$ \\
\hline 4 & Heterogeneous & $\mathrm{NaF}-\mathrm{KF}-\mathrm{ZrF} \mathrm{F}_{4}$ & All-salt & 15 & - & - & - & 0.99475 & $0.61 \pm 0.08$ \\
\hline 5 & Parfait/Homog. & NaF-KF-ZrF 4 & $\mathrm{Ti}$ & 15 & - & $\mathrm{NU}$ & $1 \times 30 \mathrm{~cm}$ & 1.01066 & $0.50 \pm 0.09$ \\
\hline 6 & Heterogeneous & $\mathrm{NaCl}-\mathrm{MgCl}_{2}$ & $\mathrm{Ti}$ & 15 & - & - & - & 1.04609 & $0.33 \pm 0.08$ \\
\hline 7 & Homogeneous & $\mathrm{NaCl}-\mathrm{MgCl}_{2}$ & $\mathrm{Ti}$ & 15 & - & - & - & 1.04347 & $0.33 \pm 0.08$ \\
\hline 8 & Annular/Heterog. & $\mathrm{NaCl}-\mathrm{MgCl}_{2}$ & $\mathrm{Ti}$ & 15 & - & - & - & 1.03886 & $0.31 \pm 0.08$ \\
\hline 9 & Heterogeneous & $\mathrm{NaCl}-\mathrm{MgCl}_{2}$ & $\mathrm{Ti}$ & 15 & $\mathrm{BeO}(0 / 0 / 23)$ & - & - & 1.03047 & $0.27 \pm 0.08$ \\
\hline 10 & Homogeneous & $\mathrm{NaCl}-\mathrm{MgCl}_{2}$ & $\mathrm{Ti}$ & 15 & - & NU & $1 \times 30 \mathrm{~cm}$ & 1.04250 & $0.33 \pm 0.08$ \\
\hline 11 & Homogeneous & $\mathrm{NaCl}-\mathrm{MgCl}_{2}$ & $\mathrm{Ti}$ & 15 & - & NU & $3 \times 10 \mathrm{~cm}$ & 1.09928 & $0.22 \pm 0.08$ \\
\hline 12 & Homogeneous & $\mathrm{NaCl}-\mathrm{KCl}-\mathrm{MgCl}_{2}$ & $\mathrm{Ti}$ & 15 & - & - & - & 1.05945 & $0.42 \pm 0.08$ \\
\hline 13 & Homogeneous & $\mathrm{NaCl}-\mathrm{KCl}-\mathrm{MgCl}_{2}$ & $\mathrm{Ti}$ & 15 & - & NU & $3 \times 10 \mathrm{~cm}$ & 1.11170 & $0.50 \pm 0.08$ \\
\hline 14 & Homogeneous & $\mathrm{NaCl}-\mathrm{KCl}-\mathrm{MgCl}_{2}$ & $\mathrm{Ti}$ & 14 & - & NU & $3 \times 10 \mathrm{~cm}$ & 1.07074 & $0.36 \pm 0.08$ \\
\hline 15 & Homogeneous & $\mathrm{NaCl}-\mathrm{KCl}-\mathrm{MgCl}_{2}$ & $\mathrm{Ti}$ & 13 & - & NU & $3 \times 10 \mathrm{~cm}$ & 1.02720 & $0.37 \pm 0.08$ \\
\hline 16 & Homogeneous & $\mathrm{NaCl}-\mathrm{KCl}-\mathrm{MgCl}_{2}$ & $\mathrm{Ti}$ & 13 & - & NU & $2 \times 15 \mathrm{~cm}$ & 1.09371 & $0.40 \pm 0.08$ \\
\hline 17 & Homogeneous & $\mathrm{NaCl}-\mathrm{KCl}-\mathrm{MgCl}_{2}$ & $\mathrm{Ti}$ & 12 & - & NU & $2 \times 15 \mathrm{~cm}$ & 1.04629 & $0.41 \pm 0.08$ \\
\hline 18 & Homogeneous & $\mathrm{NaCl}-\mathrm{KCl}-\mathrm{MgCl}_{2}$ & - & 14 & - & NU & $2 \times 15 \mathrm{~cm}$ & 1.13944 & $0.33 \pm 0.08$ \\
\hline 19 & Homogeneous & $\mathrm{NaCl}-\mathrm{KCl}-\mathrm{MgCl}_{2}$ & - & 14 & - & $\mathrm{NU}$ & $2 \times 20 \mathrm{~cm}$ & 1.18848 & $0.29 \pm 0.08$ \\
\hline 20 & Homogeneous & $\mathrm{NaCl}-\mathrm{KCl}-\mathrm{MgCl}_{2}$ & - & 14 & $\operatorname{Be}(10 / 10 / 10)$ & NU & $2 \times 20 \mathrm{~cm}$ & 1.09705 & $0.27 \pm 0.08$ \\
\hline 21 & Homogeneous & $\mathrm{NaCl}-\mathrm{KCl}-\mathrm{MgCl}_{2}$ & - & 14 & $\operatorname{Be}(15 / 15 / 15)$ & $\mathrm{NU}$ & $2 \times 20 \mathrm{~cm}$ & 1.05633 & $0.28 \pm 0.08$ \\
\hline 22 & Homogeneous & $\mathrm{NaCl}-\mathrm{KCl}-\mathrm{MgCl}_{2}$ & - & 14 & $\operatorname{Be}(15 / 15 / 15)$ & $\mathrm{NU}+\mathrm{Hf}, 20 \%$ & $2 \times 20 \mathrm{~cm}$ & 1.05228 & $0.36 \pm 0.08$ \\
\hline 23 & Homogeneous & $\mathrm{NaCl}-\mathrm{KCl}-\mathrm{MgCl}_{2}$ & - & 14 & $\operatorname{Be}(10 / 10 / 10)$ & $\mathrm{NU}+{ }^{10} \mathrm{~B}, 5 \%$ & $2 \times 20 \mathrm{~cm}$ & 1.08225 & $0.28 \pm 0.08$ \\
\hline 24 & Homogeneous & $\mathrm{NaCl}-\mathrm{KCl}-\mathrm{MgCl}_{2}$ & - & 14 & $\operatorname{Be}(15 / 15 / 15)$ & $\mathrm{NU}+{ }^{10} \mathrm{~B}, 10 \%$ & $2 \times 20 \mathrm{~cm}$ & 1.03522 & $0.37 \pm 0.08$ \\
\hline 25 & Homogeneous & $\mathrm{NaCl}-\mathrm{KCl}-\mathrm{MgCl}_{2}$ & - & 14 & $\operatorname{Be}(15 / 15 / 15)$ & $\mathrm{NU}+{ }^{10} \mathrm{~B}, 5 \%$ & $2 \times 20 \mathrm{~cm}$ & 1.04251 & $0.25 \pm 0.08$ \\
\hline 26 & Homogeneous & $\mathrm{NaCl}-\mathrm{KCl}-\mathrm{MgCl}_{2}$ & - & 14 & - & $\mathrm{NU}+\mathrm{Ca}$ & $2 \times 20 \mathrm{~cm}$ & 1.18867 & $0.37 \pm 0.08$ \\
\hline 27 & Homogeneous & $\mathrm{NaCl}-\mathrm{KCl}-\mathrm{MgCl}_{2}$ & - & 14 & - & $\mathrm{NU}+\mathrm{Ni}$ & $2 \times 20 \mathrm{~cm}$ & 1.18873 & $0.39 \pm 0.08$ \\
\hline 28 & H-shape/Homog. & $\mathrm{NaCl}-\mathrm{KCl}-\mathrm{MgCl}_{2}$ & - & 14 & - & - & - & 1.05419 & $0.39 \pm 0.08$ \\
\hline 29 & H-shape/Homog. & $\mathrm{NaCl}-\mathrm{KCl}-\mathrm{MgCl}_{2}$ & - & 12 & - & NU & $2 \times 20 \mathrm{~cm}$ & 1.00092 & $0.25 \pm 0.08$ \\
\hline
\end{tabular}


Project No 06-040: Flexible Conversion Ratio Fast Reactor Systems Evaluation

Table 4B-1 Summary of investigated cases for CTC reduction

\begin{tabular}{|c|c|c|c|c|c|c|c|c|c|}
\hline Case & $\begin{array}{l}\text { Geometry / } \\
\text { representation }\end{array}$ & Salt & $\begin{array}{c}\text { Top } \\
\text { reflector }\end{array}$ & $\begin{array}{l}\text { TRU:HM } \\
\text { ratio, w/o }\end{array}$ & $\begin{array}{l}\text { Core diluent, } \\
\text { v/o (z1/z2/z3) }\end{array}$ & $\begin{array}{c}\text { Blanket } \\
\text { Composition }\end{array}$ & $\begin{array}{c}\text { Blanket } \\
\text { dimensions }\end{array}$ & k-eff & $\begin{array}{c}\text { CTC } \\
\notin / \mathrm{K}\end{array}$ \\
\hline 30 & H-shape/Homog. & $\mathrm{NaCl}-\mathrm{KCl}-\mathrm{MgCl}_{2}$ & - & 14 & - & $\mathrm{NU}$ & $2 \times 20 \mathrm{~cm}$ & 1.23614 & $0.33 \pm 0.08$ \\
\hline 31 & H-shape/Homog. & $\mathrm{NaCl}-\mathrm{KCl}-\mathrm{MgCl}_{2}$ & - & 14 & $\operatorname{Be}(0 / 0 / 10)$ & $\mathrm{NU}$ & $2 \times 20 \mathrm{~cm}$ & 1.21204 & $0.34 \pm 0.08$ \\
\hline 32 & H-shape/Homog. & $\mathrm{NaCl}-\mathrm{KCl}-\mathrm{MgCl}_{2}$ & - & 14 & $\operatorname{Be}(0 / 8 / 10)$ & NU & $2 \times 20 \mathrm{~cm}$ & 1.16940 & $0.30 \pm 0.08$ \\
\hline 33 & Homogeneous & $\mathrm{NaCl}-\mathrm{KCl}-\mathrm{MgCl}_{2}$ & - & 14 & - & $\mathrm{NU}+\mathrm{CaH}_{2}, 10 \%$ & $2 \times 20 \mathrm{~cm}$ & 1.17701 & $0.32 \pm 0.08$ \\
\hline 34 & Homogeneous & $\mathrm{NaCl}-\mathrm{KCl}-\mathrm{MgCl}_{2}$ & - & 14 & - & $\mathrm{NU}+\mathrm{CaH}_{2}, 20 \%$ & $2 \times 20 \mathrm{~cm}$ & 1.17014 & $0.25 \pm 0.08$ \\
\hline 35 & Homogeneous & $\mathrm{NaCl}-\mathrm{KCl}-\mathrm{MgCl}_{2}$ & - & 14 & - & $\mathrm{NU}+\mathrm{CaH}_{2}, 30 \%$ & $2 \times 20 \mathrm{~cm}$ & 1.16495 & $0.29 \pm 0.08$ \\
\hline 36 & Homogeneous & $\mathrm{NaCl}-\mathrm{KCl}-\mathrm{MgCl}_{2}$ & - & 14 & - & $\mathrm{NU}+\mathrm{ZrH}_{1.6}, 20 \%$ & $2 \times 20 \mathrm{~cm}$ & 1.16673 & $0.23 \pm 0.08$ \\
\hline 37 & Homogeneous & $\mathrm{NaCl}-\mathrm{KCl}-\mathrm{MgCl}_{2}$ & - & 14 & - & $\mathrm{NU}+\mathrm{ZrH}_{1.6}, 30 \%$ & $2 \times 20 \mathrm{~cm}$ & 1.16210 & $0.23 \pm 0.08$ \\
\hline 38 & Homogeneous & $\mathrm{NaCl}-\mathrm{KCl}-\mathrm{MgCl}_{2}$ & - & 12 & - & $\mathrm{NU}+\mathrm{ZrH}_{1.6}, 30 \%$ & $2 \times 20 \mathrm{~cm}$ & 1.06822 & $0.29 \pm 0.08$ \\
\hline 39 & Heterogeneous & $\mathrm{NaCl}-\mathrm{KCl}-\mathrm{MgCl}_{2}$ & - & 14 & - & $\mathrm{NU}+\mathrm{ZrH}_{1.6}, 30 \%$ & $2 \times 20 \mathrm{~cm}$ & 1.16349 & $0.20 \pm 0.08$ \\
\hline 40 & Heterogeneous & $\mathrm{NaCl}-\mathrm{KCl}-\mathrm{MgCl}_{2}$ & - & 14 & - & $\left(\mathrm{U}_{0.31} \mathrm{Zr}\right) \mathrm{H}_{1.6}$ & $2 \times 20 \mathrm{~cm}$ & 1.15934 & $0.22 \pm 0.08$ \\
\hline 41 & Heterogeneous & $\mathrm{NaCl}-\mathrm{KCl}-\mathrm{MgCl}_{2}$ & - & 12 & - & $\left(\mathrm{U}_{0.31} \mathrm{Zr}\right) \mathrm{H}_{1.6}$ & $2 \times 20 \mathrm{~cm}$ & 1.06556 & $0.31 \pm 0.08$ \\
\hline 42 & Homogeneous & $\mathrm{NaCl}-\mathrm{KCl}-\mathrm{MgCl}_{2}$ & - & 14 & $\mathrm{BeO}(5 / 5 / 5)$ & $\mathrm{NU}+\mathrm{ZrH}_{1.6}, 30 \%$ & $2 \times 20 \mathrm{~cm}$ & 1.07564 & $0.32 \pm 0.08$ \\
\hline 43 & Annular/Homog. & $\mathrm{NaCl}-\mathrm{KCl}-\mathrm{MgCl}_{2}$ & - & 14 & - & $\mathrm{NU}+\mathrm{ZrH}_{1.6}, 30 \%$ & $2 \times 20 \mathrm{~cm}$ & 1.15744 & $0.24 \pm 0.08$ \\
\hline 44 & Homogeneous & $\mathrm{NaCl}-\mathrm{KCl}-\mathrm{MgCl}_{2}$ & - & 14 & WA Str. Ch. & $\mathrm{NU}+\mathrm{ZrH}_{1.6}, 30 \%$ & $2 \times 20 \mathrm{~cm}$ & 1.13119 & $0.37 \pm 0.08$ \\
\hline 45 & Homogeneous & $\mathrm{NaCl}-\mathrm{KCl}-\mathrm{MgCl}_{2}$ & - & 14 & $\mathrm{Zr} \times 1.5+\mathrm{Str} . \mathrm{Ch}$. & $\mathrm{NU}+\mathrm{ZrH}_{1.6}, 30 \%$ & $2 \times 20 \mathrm{~cm}$ & 1.08682 & $0.27 \pm 0.08$ \\
\hline 46 & Heterogeneous & $\mathrm{NaCl}-\mathrm{KCl}-\mathrm{MgCl}_{2}$ & - & 14 & Str. Ch. pins & $\mathrm{NU}+\mathrm{ZrH}_{1.6}, 30 \%$ & $2 \times 20 \mathrm{~cm}$ & 1.14249 & $0.36 \pm 0.08$ \\
\hline 47 & Heterogeneous & $\mathrm{NaCl}-\mathrm{KCl}-\mathrm{MgCl}_{2}$ & - & 14 & - & $\mathrm{Th}+\mathrm{ZrH}_{2}, 30 \%$ & $2 \times 20 \mathrm{~cm}$ & 1.15816 & $0.33 \pm 0.08$ \\
\hline
\end{tabular}


Project No 06-040: Flexible Conversion Ratio Fast Reactor Systems Evaluation

The CTC coefficient was calculated by performing two MCNP runs corresponding to nominal, and perturbed by $+100 \mathrm{~K}$ coolant temperatures. The coolant density was reduced accordingly in the core and in the upper plenum. The nominal coolant temperature in the core was assumed to be uniform axially and radially and equal to $500^{\circ} \mathrm{C}$. The nominal coolant temperature in the upper plenum was assumed to be $550^{\circ} \mathrm{C}$.

In the course of preliminary analysis, the relative effects of the coolant salt absorption and moderation, which comprise the total coolant density effect on the core reactivity, were investigated. For this purpose, a hypothetical case was calculated, in which significantly higher absorbing potassium atoms were substituted with less absorbing $\mathrm{Na}$ atoms. The results showed that substitution of $\mathrm{K}$ with $\mathrm{Na}$ atoms reduces the overall reactivity by $\sim 200 \mathrm{pcm}$ and has practically no effect on CTC. Therefore, it was concluded that the contribution of salt absorption to CTC is negligible, and most of the effect is due to reduced moderation by the coolant atoms.

\section{Ti Reflectors}

The first strategy for CTC reduction was the use of Ti reflectors. The reference core design had radial stainless steel (SS) and axial Zr reflectors. The motivation for the use of Ti instead of Zr or $\mathrm{SS}$ is that $\mathrm{Ti}$ has a large scattering resonance at the lower energy end of the spectrum. The Ti elastic scattering cross-section and the neutron spectrum in the central fuel zone of the core with three different coolants are plotted in Figures 4B-1 and 4B-2 respectively. The albedo of the Ti reflector should decrease with the spectrum hardening as a result of the coolant temperature increase. However, as can be observed from Table 4B-1, the replacement of $\mathrm{Zr}$ and SS reflectors with $\mathrm{Ti}$ ones has practically no effect on CTC.

\section{All-Salt Top Reflector}

The basic idea for this strategy is to reduce the fuel pin diameter in the top reflector axial zone. This will increase the coolant volume fraction above the core. Therefore, an increase in the core coolant temperature will also result in coolant density reduction in the top reflector region, reducing its albedo.

In the current analysis, the fuel pin diameter in the top reflector region was reduced to zero, which represents a hypothetical limiting case for this design strategy. As demonstrated in Case 4 (Table 4B-1), the effect of an All-salt top reflector on CTC is only marginal: $\sim 5 \%$ less positive compared to the reference case. Therefore, this strategy clearly cannot be sufficient for a selfcontrollable core design.

\section{Parfait Core Configuration}

Redistribution of fissile (TRU) fuel component into alternating natural uranium only and NU+TRU axial fuel zones is known as a Parfait-type core. It was shown in previous studies [Ducat G.A. 1974] that parfait-type core arrangement offers a number of important advantages, among them, substantial reduction in the CTC. Natural Uranium blankets are mostly neutron absorbing regions. Therefore, the spectrum hardening due to lower coolant density results in higher leakage into neutron absorbing NU blanket regions without causing additional fissions, and increasing reactivity. In this study, the parfait core was modeled as three axial zones, where the middle $30 \mathrm{~cm}$ thick zone contained NU only, surrounded by NU and TRU mixture zones. 
Project No 06-040: Flexible Conversion Ratio Fast Reactor Systems Evaluation

The total TRU loading in the core was preserved and equal to that of the reference core. A schematic axial cross cut of the core is presented in Figure 4B-3.

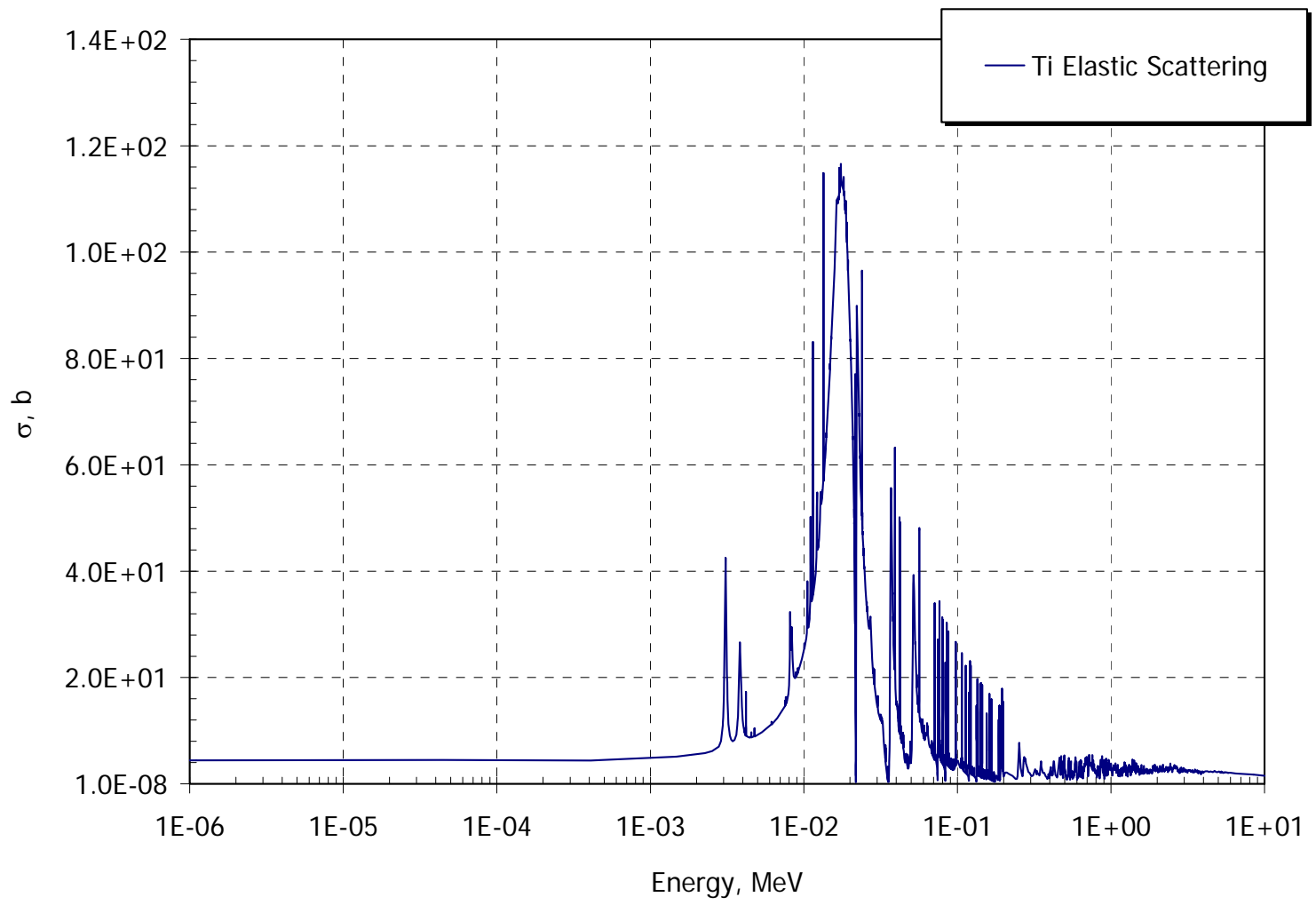

Figure 4B-1. Ti Elastic Scattering cross-section.

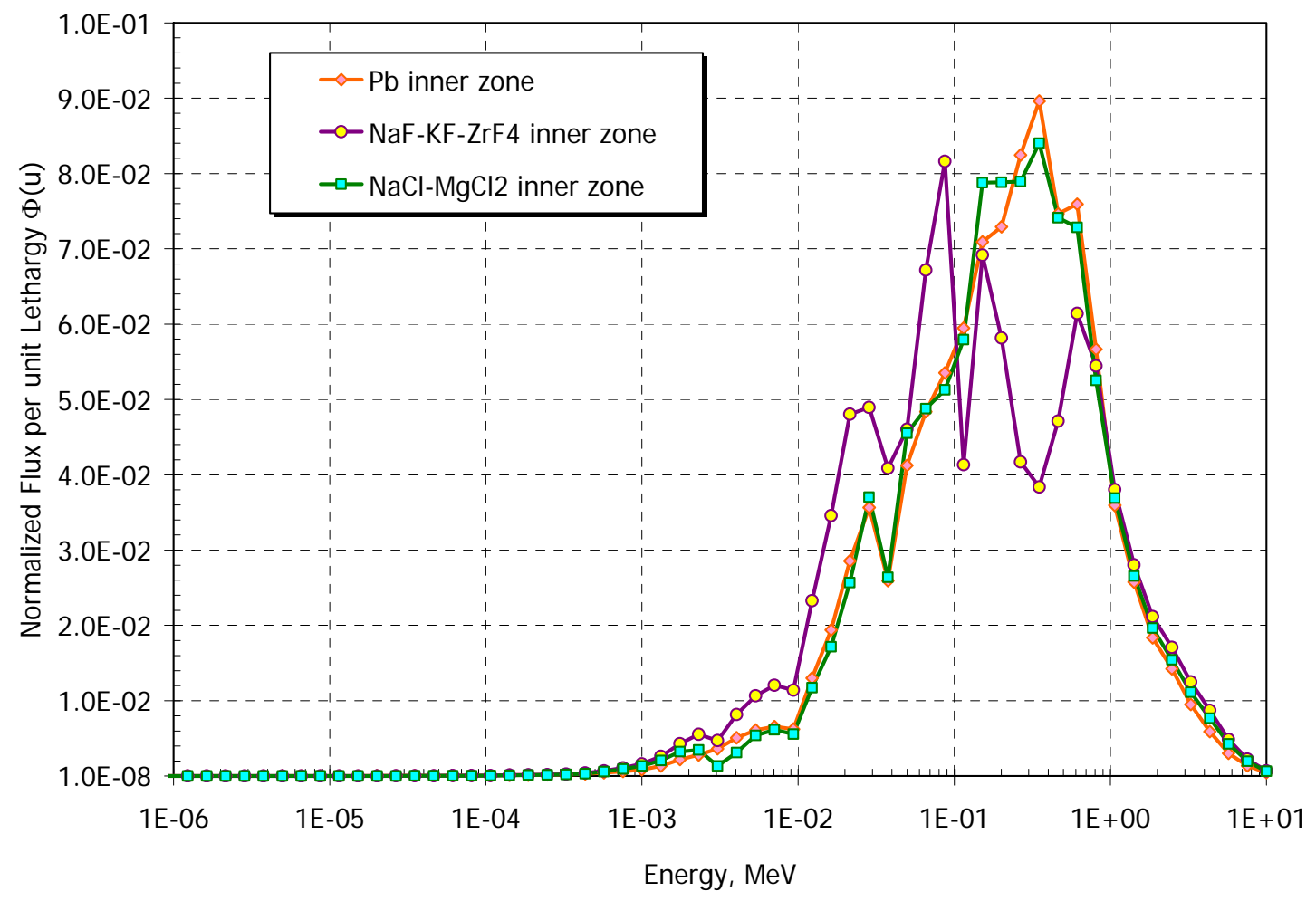

Figure 4B-2 Spectrum comparison 


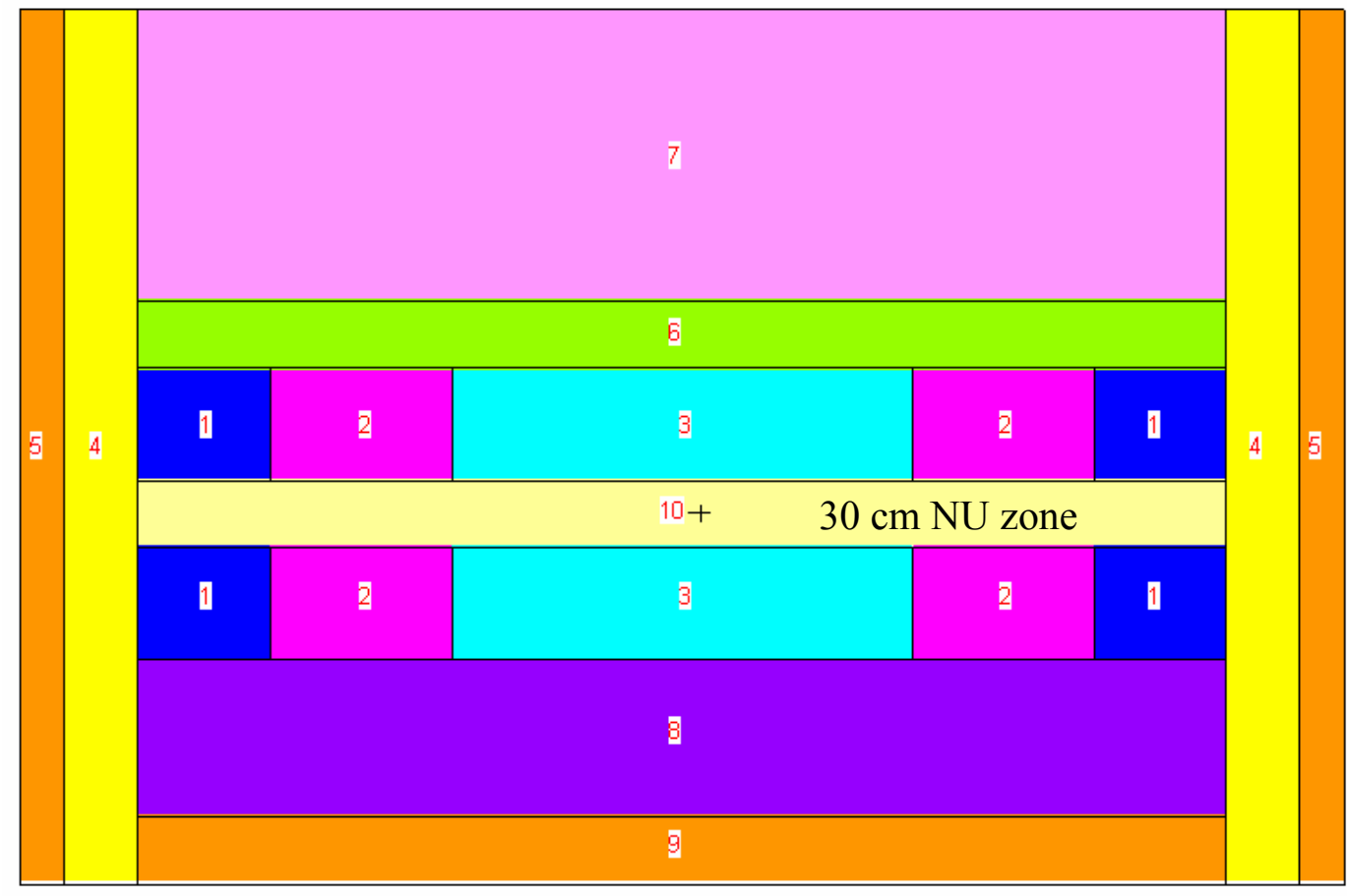

Figure 4B-3 Axial parfait core, single $30 \mathrm{~cm}$ NU zone.

Application of the parfait core design strategy results in substantial reduction of CTC. Case 5 in Table 4B-1 with a $30 \mathrm{~cm}$ NU middle blanket shows a reduction in CTC by nearly $30 \%$. However, clearly, this improvement is also insufficient for achieving self controllability of the core. In addition, $\mathrm{Pu}$ breeding in the blanket is expected to reduce the benefits from the parfait core design towards the end of the fuel cycle.

\section{B.2 Determination of Target CTC Values}

The main objective of this part of the study was to establish the range of CTC values that would ensure a self-controllable core based on the quasi static approach described in details in Appendix 3A.

As mentioned above, the $\mathrm{CTC}$ of the $\mathrm{NaF}-\mathrm{KF}-\mathrm{ZrF}_{4}$ salt is too large to satisfy the selfcontrollability criteria and unlikely to be reduced by any of the considered design strategies to acceptable values. Therefore, chloride $\mathrm{NaCl}-\mathrm{MgCl}_{2}$ and $\mathrm{NaCl}-\mathrm{KCl}-\mathrm{MgCl}_{2}$ salts were considered as potential coolant candidates. The binary and ternary chloride salts' melting points and densities are compared in Table 4B-2.

Table 4B-2 Comparison of Salt Properties.

\begin{tabular}{|l|l|l|}
\hline Salt & Melting point, ${ }^{\circ} \mathrm{C}$ & Density, $\mathrm{g} / \mathrm{cm}^{3}$ \\
\hline $\mathrm{NaF}-\mathrm{KF}-\mathrm{ZrF}_{4}(10-48-42)$ & 385 & $3.450-0.000890 \times \mathrm{T}\left[{ }^{\circ} \mathrm{C}\right]$ \\
\hline $\mathrm{NaCl}-\mathrm{MgCl}_{2}(58-42)$ & 445 & $2.297-0.000507 \times \mathrm{T}\left[{ }^{\circ} \mathrm{C}\right]$ \\
\hline $\mathrm{NaCl}-\mathrm{KCl}-\mathrm{MgCl}_{2}(30-20-50)$ & 396 & $2.226-0.000778 \times \mathrm{T}\left[{ }^{\circ} \mathrm{C}\right]$ \\
\hline
\end{tabular}


Binary chloride salt has a lower thermal expansion coefficient, which primarily determines the CTC, than the ternary salt, but a somewhat higher melting point, which can be considered as marginally acceptable. Chloride salts, in general, should have a harder neutron spectrum than fluoride salts because of their higher atomic weight. The effect of spectrum hardening is notable and illustrated by Case 6 in Table 4B-1, where NaF-KF-ZrF 4 coolant in the reference core is replaced by $\mathrm{NaCl}-\mathrm{MgCl}_{2}$. A substantial increase in core reactivity can be observed due to the harder spectrum, and a nearly factor of two reduction of CTC due to the lower thermal expansion coefficient.

All reactivity coefficients required for the quasi static analysis were calculated for the reference core configuration with $\mathrm{NaCl}-\mathrm{MgCl}_{2}$ coolant. The results are summarized in Table 4B-3, which also includes the criteria to be satisfied in order to ensure self controllability of the core as well as previously obtained values for the lead-cooled $\mathrm{CR}=1$ core case. In general, all reactivity coefficients of the liquid salt-cooled core are comparable to those of the lead-cooled core except for the Doppler and Coolant Temperature Coefficients, which are somewhat larger in magnitude than those of the lead-cooled core. As a result, the A/B coefficient criterion of self controllability is not satisfied.

A number of points regarding the values presented in the Table 4B-3 should be emphasized.

- The Doppler coefficient was calculated by fitting the core reactivity data at four different fuel temperatures to either polynomial or power law models (Figure 4B-4). The calculated $\mathrm{DC}$ of the $\mathrm{NaCl}-\mathrm{MgCl}_{2}$ cooled core ranges from $-0.11 \phi / \mathrm{K}$ to $-0.23 \pm 0.02 \phi / \mathrm{K}$ depending on the applied model. As can be seen, there is a considerable uncertainty in the value of DC.

- There is also uncertainty in the definition of the core temperature rise, $\Delta T_{\text {coolant }}$, since $T_{\text {in }}$ is determined by the margin to coolant freezing while $T_{\text {out }}$ is primarily fixed by the margin to cladding failure. The magnitude of both margins can be varied to some extent to optimize the power conversion cycle performance.

- Finally, the value of CTC itself is uncertain and because it affects most significantly all the reactivity coefficient ratios it is the main parameter for optimization.

In light of the considerations presented above, the sensitivity of reactivity coefficient ratios to the parameters with significant uncertainty $\left(\mathrm{CTC}, \Delta \mathrm{T}_{\text {coolant, }}\right.$ and $\left.\mathrm{DC}\right)$ was calculated.

The results are presented in Figures 4B-5, 4B-6, and 4B-7.

Figure 4B-5 shows the sensitivity of reactivity coefficient ratios to CTC. As can be observed from the Figure, the CTC must be reduced from the current reference $0.33 \phi / \mathrm{K}$ value to below $\sim 0.20 \phi / \mathrm{K}$, which is fixed by the $\mathrm{A} / \mathrm{B}$ ratio criterion. The $\mathrm{A} / \mathrm{B}$ limit is the only self controllability limit which is not met by the reference core design with the chloride salt coolant.

Figure 4B-6 shows the sensitivity of reactivity coefficient ratios to Doppler Coefficient. The data presented in the Figure suggests that an increase in the magnitude of DC is seemingly beneficial because more negative $\mathrm{DC}$ values shift the $\mathrm{A} / \mathrm{B}$ ratio closer to its target value. However, consideration of both DC and CTC sensitivities simultaneously (presented in Figure 4B-7) reveal that higher DC values would actually require even larger reduction of $\mathrm{CTC}$ than $0.20 \phi / \mathrm{K}$ due to the less steep A/B vs CTC curve. 
Project No 06-040: Flexible Conversion Ratio Fast Reactor Systems Evaluation

In the case of the $\mathrm{C} \Delta \mathrm{T}_{\mathrm{c}} / \mathrm{B}$ ratio, the higher magnitude of $\mathrm{DC}$ makes it easier to meet the required self controllability criterion. Although for the CTC below $0.23 \phi / \mathrm{K}$, this criterion is met for all DC values within the DC uncertainty range. These observations indicate that a reduction of DC value is desirable in order to relax the requirements for CTC improvement. For example, a value of $\mathrm{DC}=0.11 \phi / \mathrm{K}$ would require a reduction in $\mathrm{CTC}$ to about $0.21 \phi / \mathrm{K}$ in order to satisfy all the self controllability limits.

Figure 4B-8 shows the sensitivity of reactivity coefficient ratios to the coolant temperature rise across the core. The $\mathrm{C} \Delta \mathrm{Tc} / \mathrm{B}$ coefficient is insensitive to the core temperature rise because the $\Delta \mathrm{T}_{\mathrm{c}}$ term cancels out. Increasing the $\Delta \mathrm{T}_{\mathrm{c}}$ helps to improve $\mathrm{A} / \mathrm{B}$ somewhat. However, the limit itself depends on $\Delta \mathrm{T}_{\mathrm{c}}$, making the core temperature rise adjustment not a worthwhile strategy to satisfy the self controllability limits.

Table 4B-3 Summary of Reactivity Coefficients.

\begin{tabular}{|c|c|c|}
\hline Parameter & $\mathbf{P b}$ & $\mathrm{NaCl}-\mathrm{MgCl}_{2}$ \\
\hline Coolant Inlet Temperature, ${ }^{\circ} \mathrm{C}$ & 461 & 496 \\
\hline Coolant Outlet temperature, ${ }^{\circ} \mathrm{C}$ & 555 & 555 \\
\hline Core Coolant Temperature Rise, $\Delta \mathrm{T}_{\mathrm{c}},{ }^{\circ} \mathrm{C}$ & 94 & 70 \\
\hline Coolant Freezing Point, ${ }^{\circ} \mathrm{C}$ & 327 & $396^{*}$ \\
\hline Margin to Freezing, ${ }^{\circ} \mathrm{C}$ & 134 & 89 \\
\hline Cladding Failure Limit, ${ }^{\circ} \mathrm{C}$ & 725 & 725 \\
\hline Margin to Cladding Failure, ${ }^{\circ} \mathrm{C}$ & 170 & 170 \\
\hline$\beta$ & 0.0038 & 0.0046 \\
\hline$\alpha_{\mathrm{DC}}, \quad 1 \mathrm{e}-3 \phi / \mathrm{K}$ & -123 & -236 \\
\hline$\alpha_{\mathrm{e}}, \quad 1 \mathrm{e}-3 \phi / \mathrm{K}$ & -131 & -137 \\
\hline$\alpha_{\mathrm{Co}}, \quad 1 \mathrm{e}-3 \phi / \mathrm{K}$ & +133 & 330 \\
\hline$\alpha_{\mathrm{RD}}, \quad 1 \mathrm{e}-3 \phi / \mathrm{K}$ & $\sim 0$ & $\sim 0$ \\
\hline$\alpha_{R}, \quad 1 \mathrm{e}-3 \phi / K$ & -154 & -136 \\
\hline$A=\left(\alpha_{D}+\alpha_{e}\right) \Delta T_{f}$ & -29.7 & $-39.9 \pm 3.3$ \\
\hline$B=\left(\alpha_{D}+\alpha_{e}+\alpha_{C o}+2 \alpha_{R D}+2 \alpha_{R}\right) \frac{\Delta T_{c}}{2}, \phi$ & -17.6 & $-11.0 \pm 2.1$ \\
\hline$C=\alpha_{D}+\alpha_{e}+\alpha_{C o}+\alpha_{R}$ & -0.25 & $-0.18 \pm 0.05$ \\
\hline $\mathrm{A} / \mathrm{B}$ & 1.69 & $3.62 \pm 0.74$ \\
\hline $\mathrm{C} \Delta \mathrm{T}_{\mathrm{c}} / \mathrm{B}$ & 1.32 & $1.14 \pm 0.36$ \\
\hline$\Delta \rho_{\mathrm{TOP}} / \mathrm{B}$ & 0.70 & $0.91 \pm 0.17$ \\
\hline $\mathrm{A} / \mathrm{B}$ limits & $\mathrm{x}<1.21\left(1.8^{*}\right)$ & $\mathrm{x}<1.62\left(2.43^{* *}\right)$ \\
\hline $\mathrm{C} \Delta \mathrm{T}_{\mathrm{c}} / \mathrm{B}$ limits & $1<\mathrm{x}<2.21(2.7)$ & $1<x<2.73(3.49)$ \\
\hline$\Delta \rho_{\mathrm{TOP}} / \mathrm{B}$ limits & $\mathrm{x}<1.21(1.8)$ & $\mathrm{x}<1.62(2.43)$ \\
\hline
\end{tabular}

* Ternary salt melting point value is used

** Values in the brackets correspond to safety margin factor $\gamma=1$ 
Project No 06-040: Flexible Conversion Ratio Fast Reactor Systems Evaluation

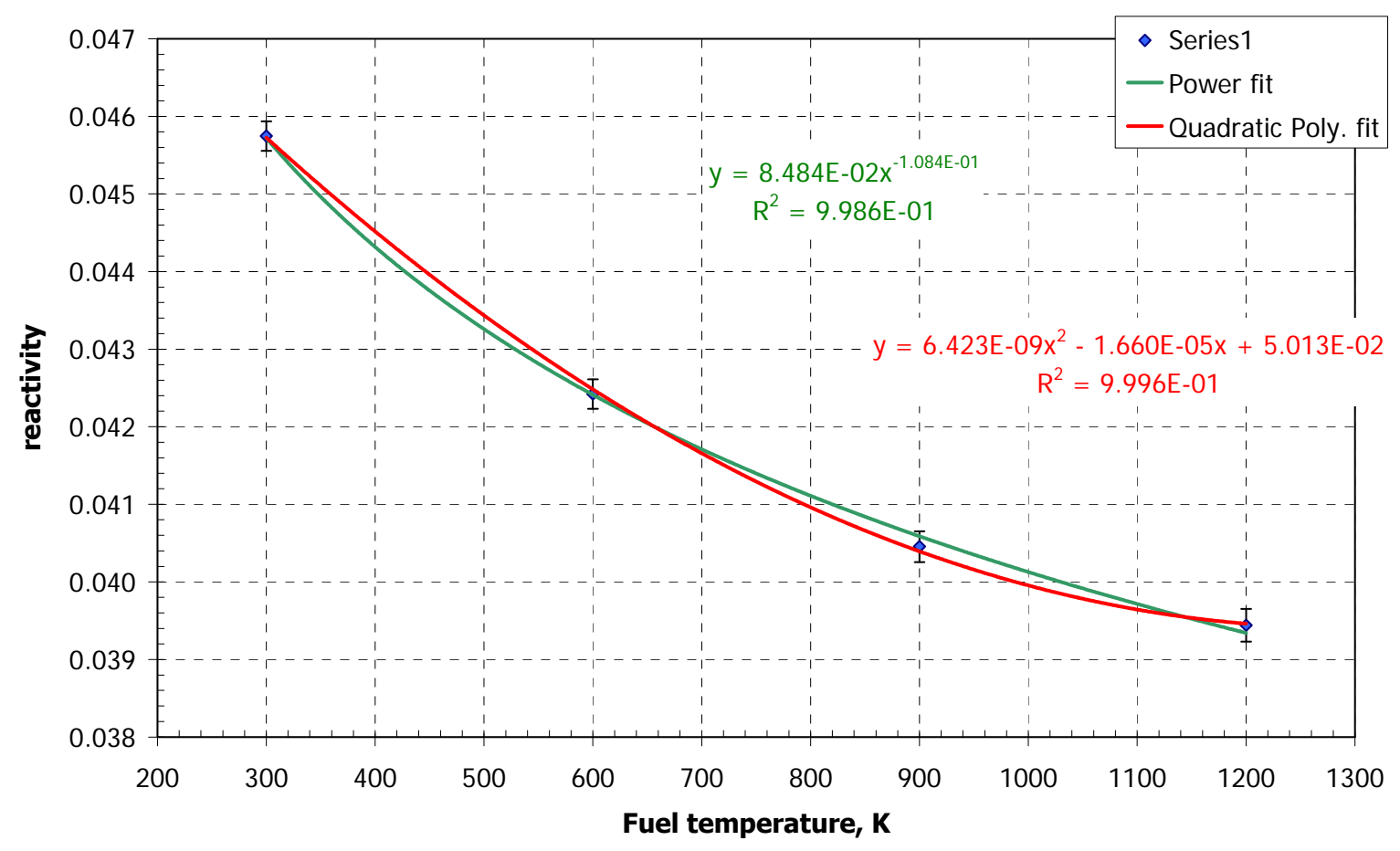

Figure 4B-4 Reactivity vs. fuel temperature least square fit

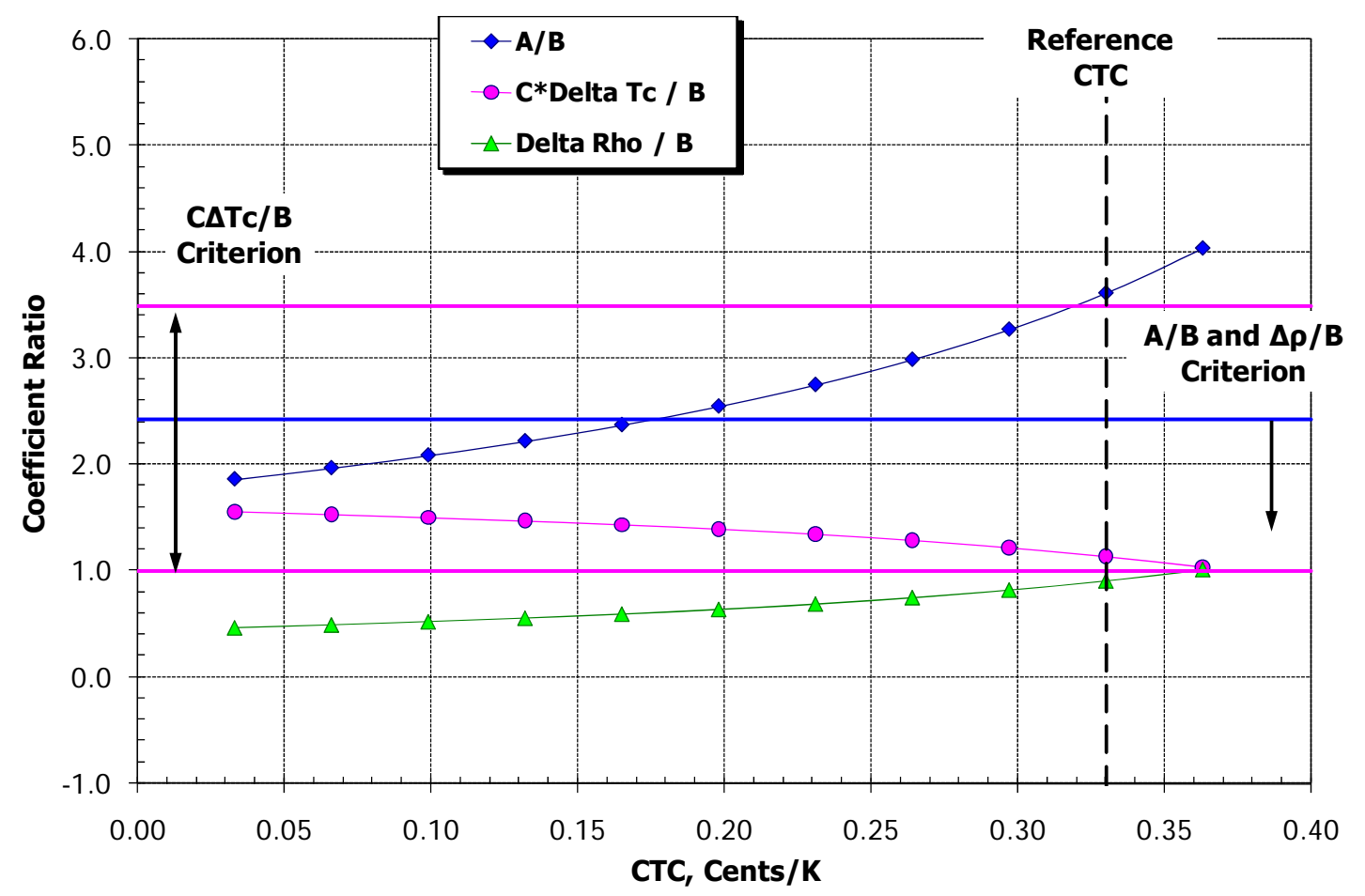

Figure 4B-5 Reactivity coefficient ratios vs. CTC 
Project No 06-040: Flexible Conversion Ratio Fast Reactor Systems Evaluation

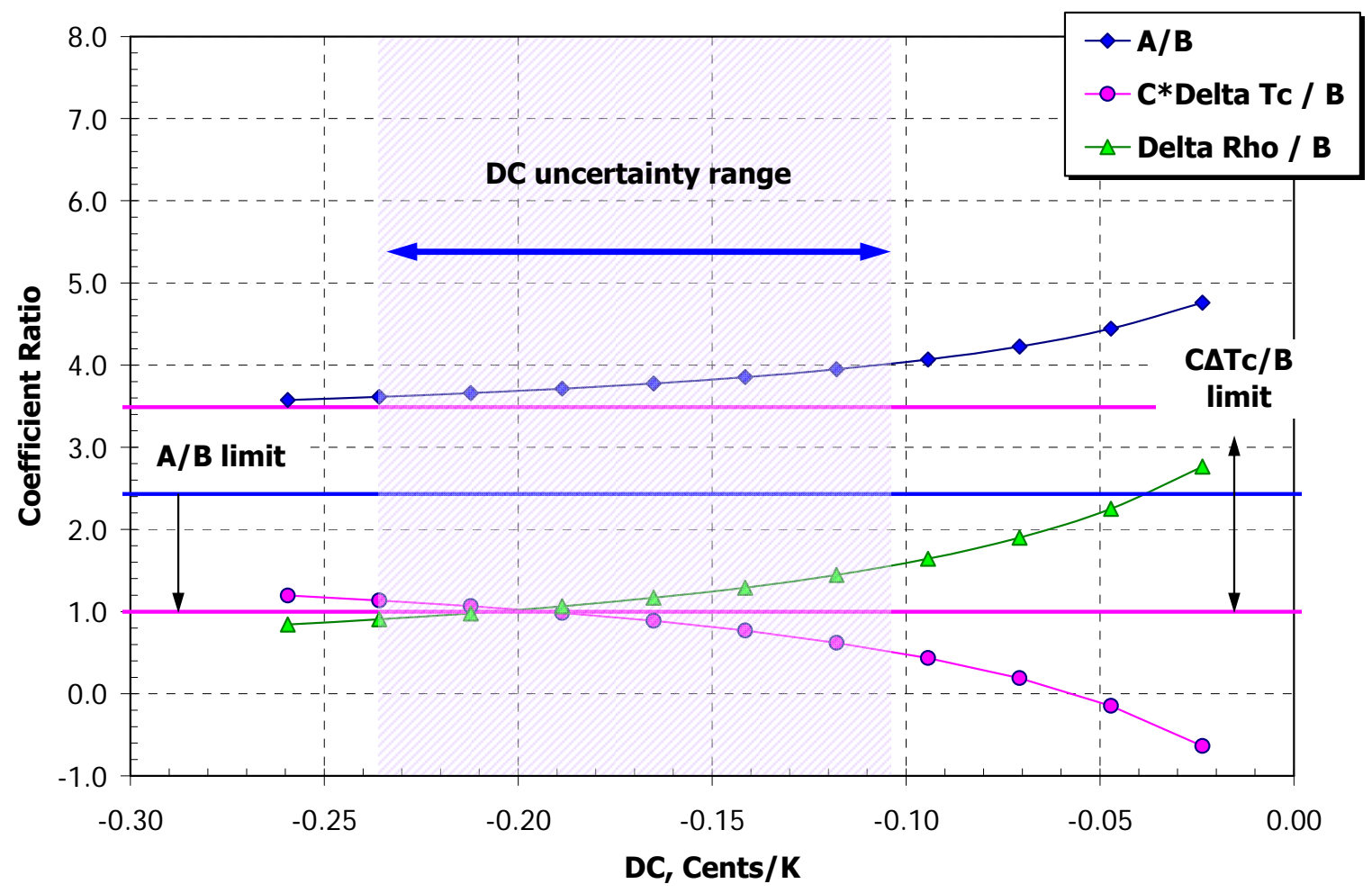

Figure 4B-6 Reactivity coefficient ratios vs. DC

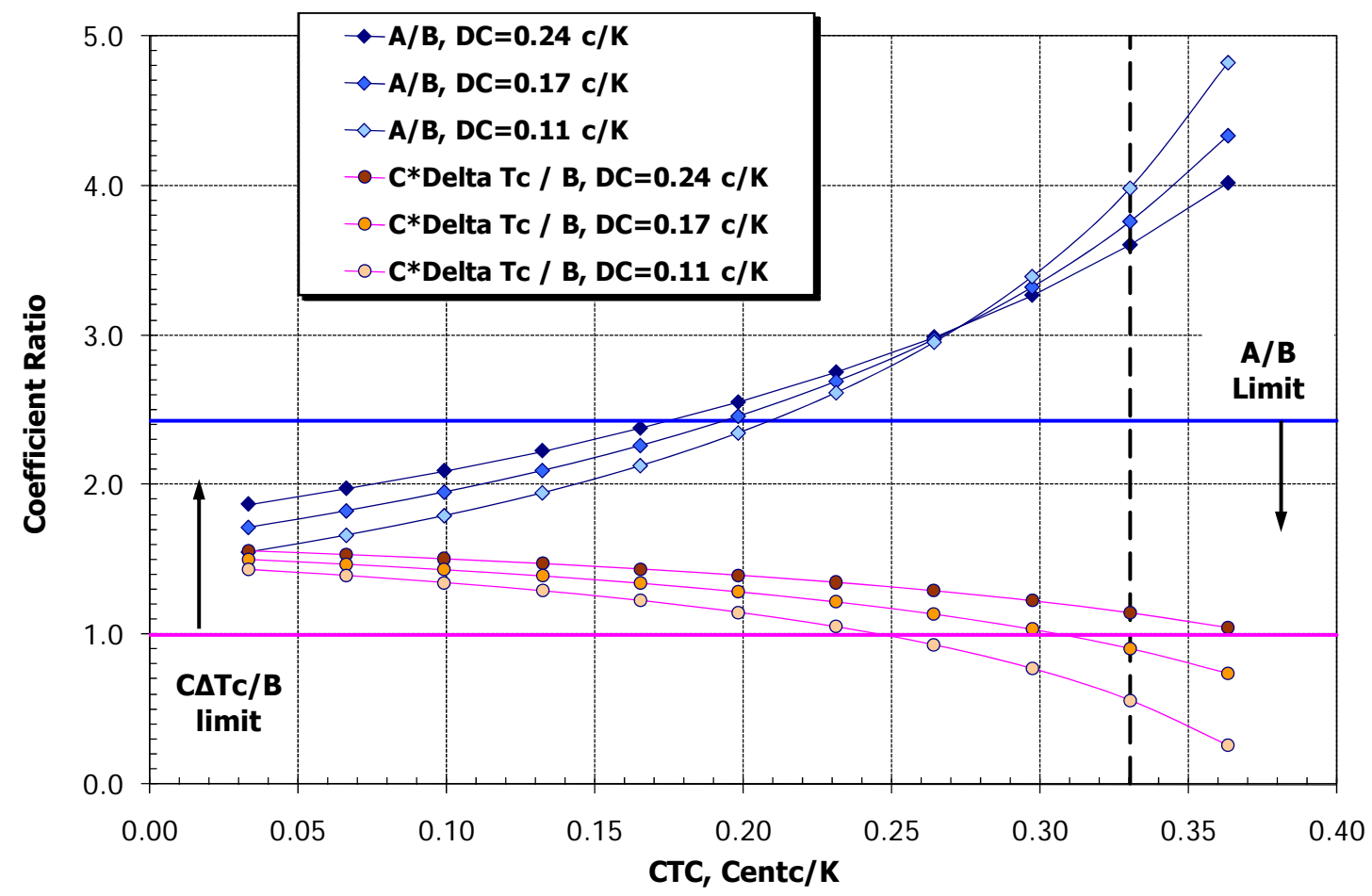

Figure 4B-7 A/B ratio vs. CTC for different DC values. 
Project No 06-040: Flexible Conversion Ratio Fast Reactor Systems Evaluation

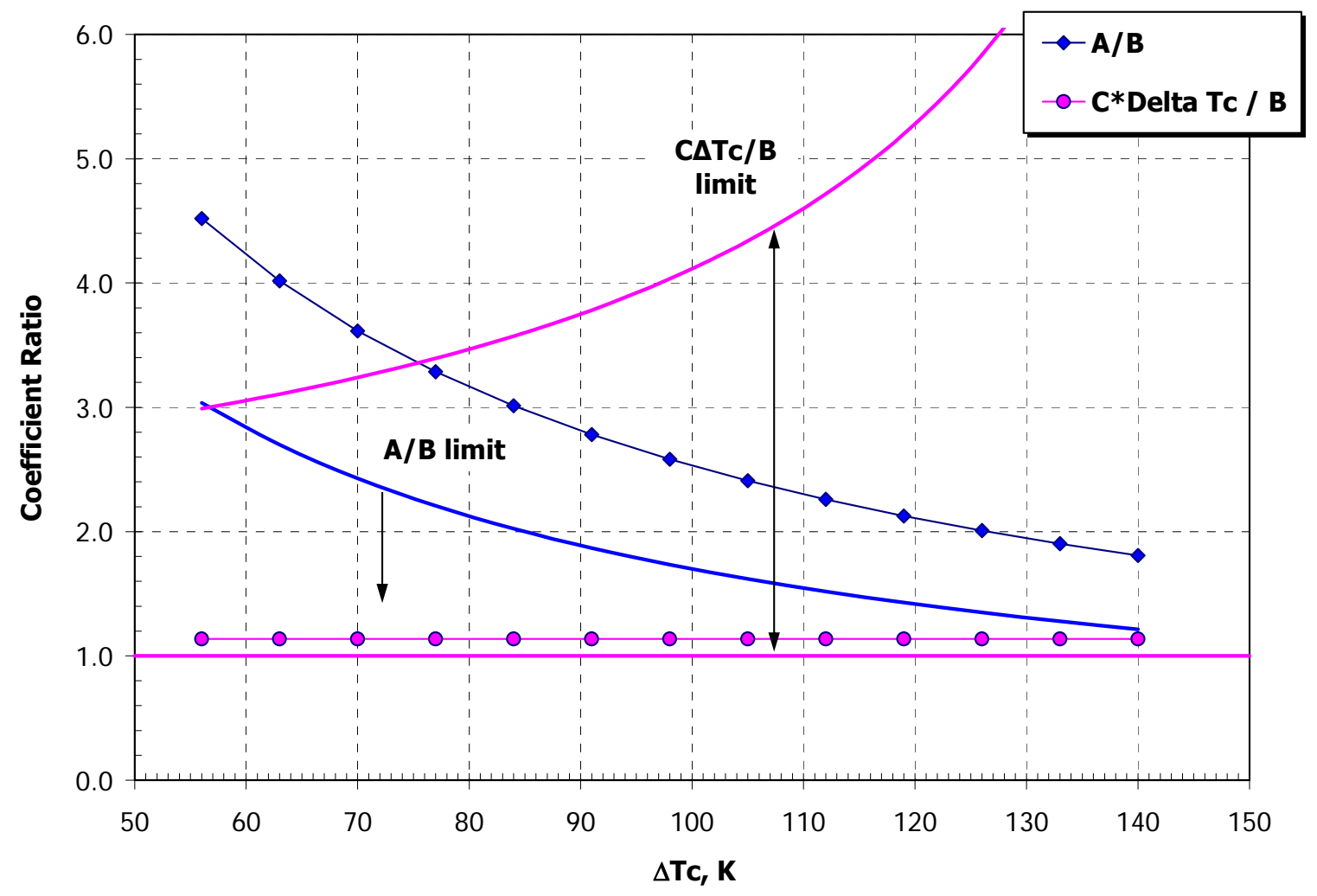

Figure 4B-8 Reactivity coefficient ratios vs. $\Delta \mathrm{T}_{\text {coolant }}$

\section{B.3 Investigation of CTC reduction strategies for chloride salts cooled core}

This section reports the findings of various design strategies applied to reduce the CTC of the $\mathrm{CR}=1$ core cooled by chloride salts. Both the binary $\mathrm{NaCl}-\mathrm{MgCl}_{2}$ and ternary $\mathrm{NaCl}-\mathrm{KCl}-\mathrm{MgCl}_{2}$ salts were considered.

\section{Annular Core with Ti Central Reflector}

In the course of this study, it was found that the local CTC has increasingly larger values towards the center of the core, where neutrons importance is the highest. This effect is illustrated by the results presented in Table 4B-4.

In this strategy, the fuel in the central high neutron importance region of the core is replaced by Ti reflector assemblies. The benefits from such a design strategy are twofold. The core surface area is increased resulting in larger core leakage, which typically reduces the CTC. Additionally, as argued earlier, the Ti reflector should have an albedo highly sensitive to changes in neutron spectrum, and thus should also reduce CTC. 
Project No 06-040: Flexible Conversion Ratio Fast Reactor Systems Evaluation

Table 4B-4 Local CTC Summary for NaCl- $\mathrm{MgCl}_{2}$ cooled core

\begin{tabular}{|l|c|c|c|c|}
\hline $\mathrm{T}_{\text {coolant}}$, Outer zone & $\mathrm{T}_{\text {coolant }}$, Middle zone & $\mathrm{T}_{\text {coolant }}$ Inner zone & $\mathrm{k}$-eff & $\mathrm{CTC}, \boldsymbol{\phi} / \mathrm{K}$ \\
\hline Nominal & Nominal & Nominal & 1.04609 & - \\
\hline Nominal $+100 \mathrm{~K}$ & Nominal $+100 \mathrm{~K}$ & Nominal $+100 \mathrm{~K}$ & 1.04775 & $0.33 \pm 0.08$ \\
\hline Nominal $+100 \mathrm{~K}$ & Nominal & Nominal & 1.04683 & $0.15 \pm 0.08$ \\
\hline Nominal & Nominal $+100 \mathrm{~K}$ & Nominal & 1.04706 & $0.19 \pm 0.08$ \\
\hline Nominal & Nominal & Nominal $+100 \mathrm{~K}$ & 1.04708 & $0.20 \pm 0.08$ \\
\hline
\end{tabular}

The fuel assemblies in the innermost core zone with high $\mathrm{Zr}$ content were replaced with $\mathrm{Ti}$ reflector assemblies identical to those used in the radial reflector. An additional row of fuel assemblies with low $\mathrm{Zr}$ content was added to the outermost zone in order to 1) preserve criticality of the core 2) preserve the $100 \mathrm{~W} / \mathrm{cm}^{3}$ power density of the core (total number of fuel assemblies was kept identical to the reference core).

Homogeneous core representation was used to explore this strategy. As in the $\mathrm{NaF}-\mathrm{KF}_{-} \mathrm{ZrF}$ salt case, the effect of homogeneous representation on the core reactivity and on CTC is small as can be observed from comparing the results of Case 6 with those of Case 7 in Table 4B-1.

The results of the annular core strategy application are summarized in Table 4B-1, Case 8. Only a slight CTC improvement was observed, with the magnitude lower than the statistical error of the calculation.

\section{Moderating $\mathrm{BeO}$ pins in the central core region}

In this strategy, about $20 \%$ of the fuel pins in the central core region with largest contribution to CTC are replaced with moderating pins containing Be oxide. Shifting the neutron spectrum to thermal energies should reduce CTC because the $\eta$-factor versus energy curve becomes less steep at lower neutron energies for most of the important fissile isotopes (Figure 4B-9).

The schematic view of the fuel assembly with moderating $\mathrm{BeO}$ pins is presented in Figure 4B10. Zirconium content in the central region assemblies was reduced to $10 \mathrm{wt} . \%$ to compensate for the reactivity loss due to the fuel displacement and due to the moderation effect.

The results of this strategy application are shown in Table 4B-1, Case 9. The CTC is reduced from 0.33 to $0.27 \phi / \mathrm{K}$, which according to the sensitivity study presented above, is probably insufficient. Moreover, the use of moderating pins with $\mathrm{BeO}$ could be problematic because of the increase in the linear power per fuel pin if the core power density is to be preserved, and potential chemical toxicity problems associated with Be handling. 
Project No 06-040: Flexible Conversion Ratio Fast Reactor Systems Evaluation

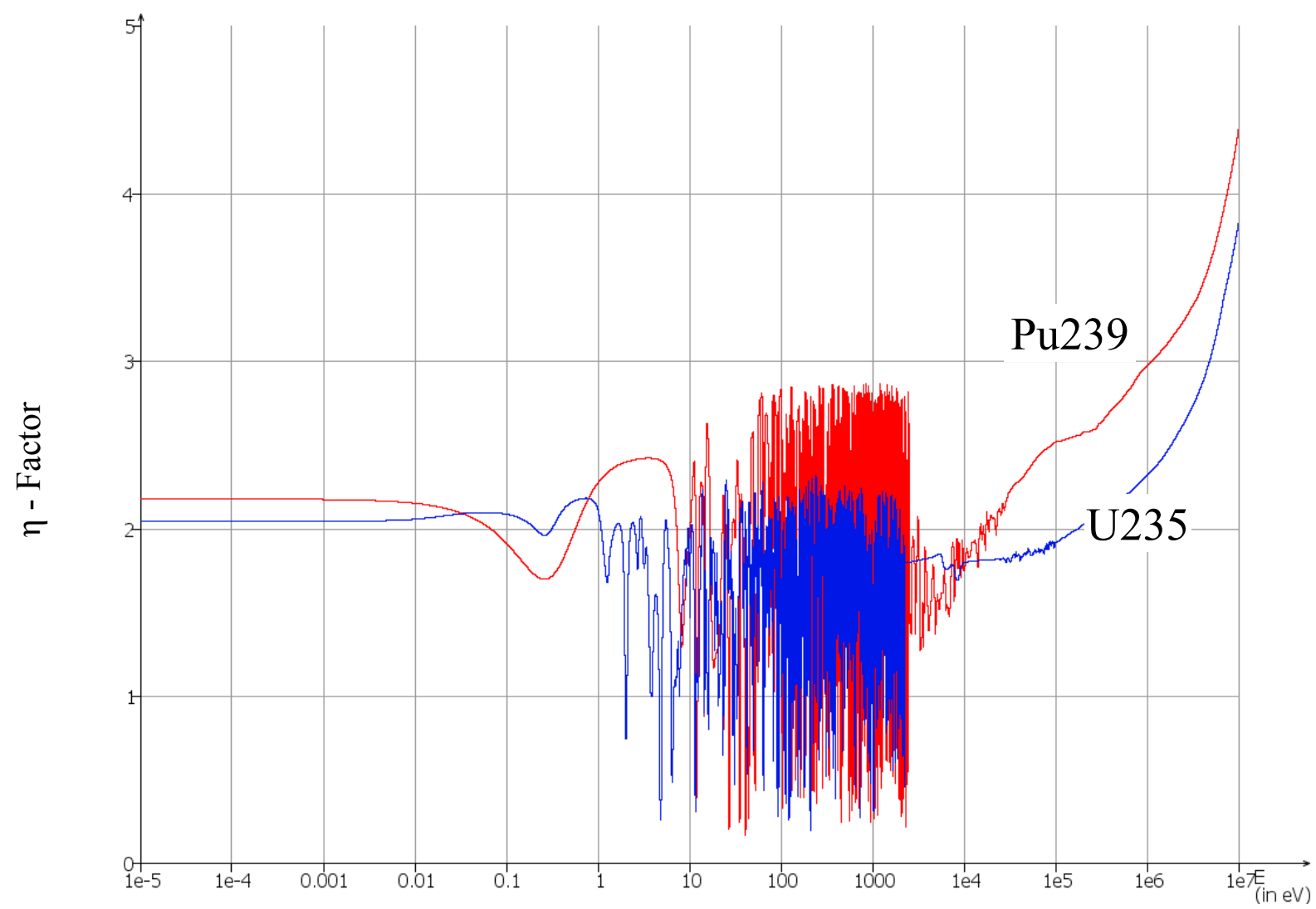

Figure 4B-9 Neutron production per neutron absorbed ( $\eta$-factor) for U235 and Pu239. (from ENDF/B-VII.0)

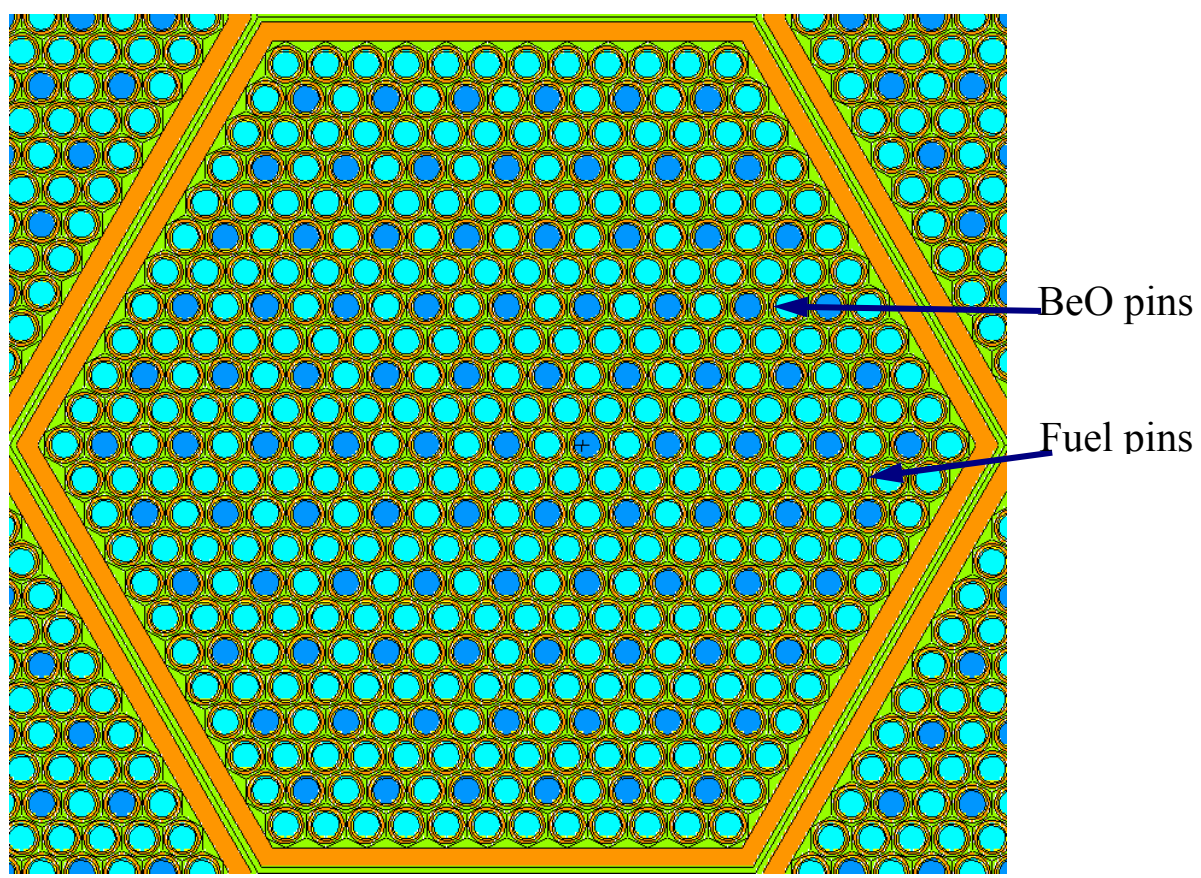

Figure 4B-10 Schematic view of fuel assembly with $\mathrm{BeO}$ pins in the central core region. 


\section{Parfait Core}

The same "parfait" core design approach as described in the $\mathrm{NaF}-\mathrm{KF}-\mathrm{ZrF}_{4}$ cooled core case was applied to the $\mathrm{NaCl}-\mathrm{MgCl}_{2}$ cooled core. A homogeneous geometry representation was used. The validity of the homogenous core model was verified again by comparing the reactivity and CTC of the $\mathrm{NaCl}-\mathrm{MgCl}_{2}$ cooled core modeled in detail and as homogenized regions (Cases 5 and 6 in Table 4B-1). The homogeneously modeled core slightly underestimates the core reactivity by about $250 \mathrm{pcm}$ and accurately reproduces the CTC of the explicitly modeled core.

Two "parfait" core configurations were modeled.

- A single $30 \mathrm{~cm}$ thick NU axial zone at the core center (Figure 4B-3)

- Three axial zones with NU $10 \mathrm{~cm}$ thick each - one in the center and two axial blankets (Figure 4B-11).

Total TRU core loading was conserved.

The results are presented in Table 4B-1, Cases 10 and 11 . In the single $30 \mathrm{~cm}$ central blanket case, no significant effects were observed on either k-eff or CTC. This is in contrast to the NaF$\mathrm{KF}-\mathrm{ZrF}_{4}$ salt case, where higher k-eff and lower CTC were observed for the same arrangement.

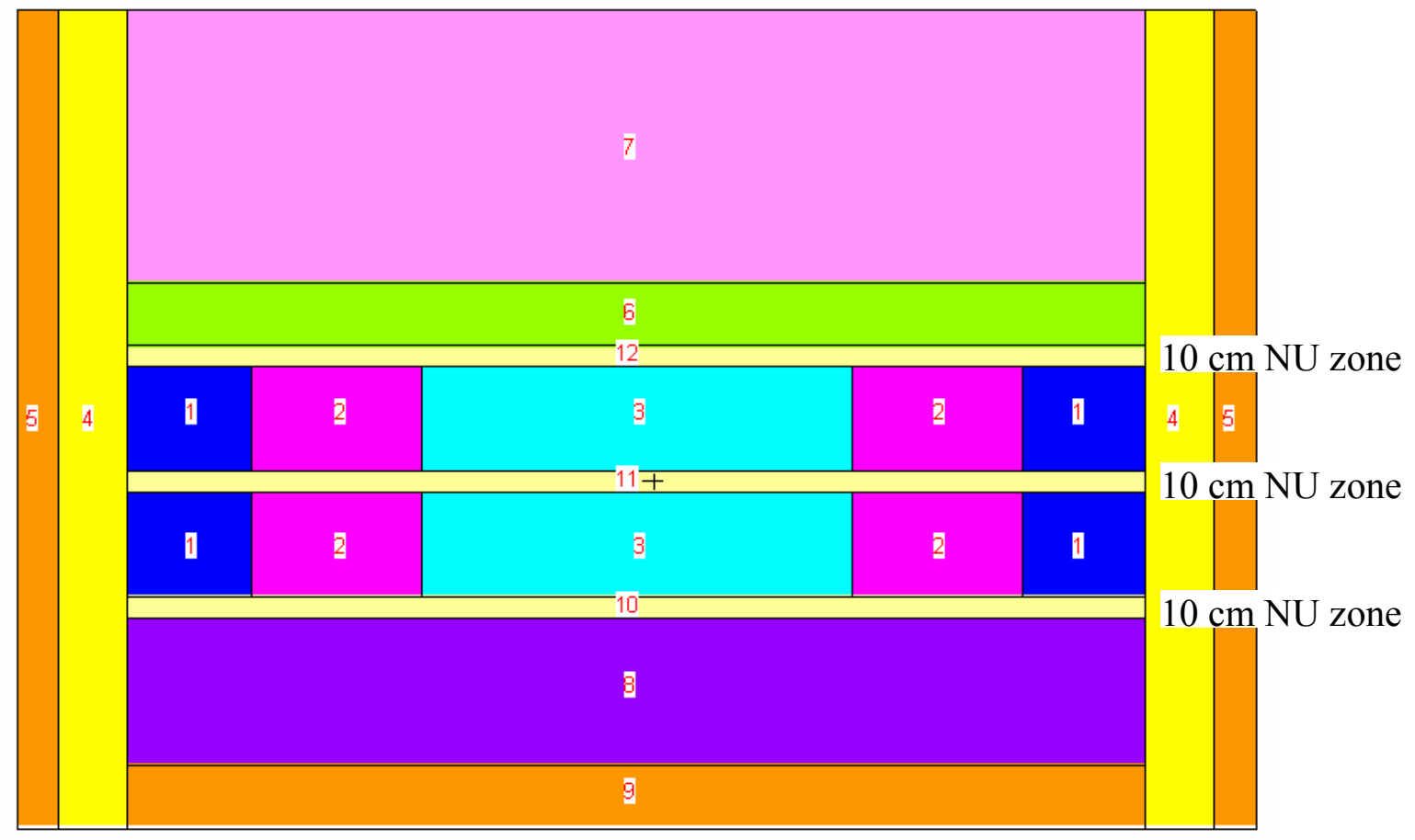

Figure 4B-11 Axial parfait core, three 10cm NU zones.

Adding axial $10 \mathrm{~cm}$ thick NU blankets seems to have a considerable effect. The core reactivity increased by almost $6 \%$, while CTC is reduced by $30 \%$ to the value of $0.22 \phi / \mathrm{K}$, which is already very close to the target range.

In order to optimize the observed trends, deeper understanding of the effects behind reactivity increase and CTC reduction of the "parfait" core configuration is required. Therefore, additional 
effort was made to investigate the underlying physics of these effects. Three potential causes were investigated:

- Leakage effect

- U238 fast fission effect

- $\quad$ Spectrum effect

To estimate the magnitude of the leakage effect, each case was calculated with and without axial leakage contributions. The core with no axial leakage was modeled by defining the top and bottom core surfaces as reflective boundaries. In addition, the following quantities were tallied in each case:

- fission energy deposition (power density) in each cell

- fission reaction rate (total and U238) in each cell

- capture reaction rate (total and U238) in each cell

- $\quad$ fine group spectrum in each cell

The results of the axial leakage effect investigation showed that leakage seems to be the dominating reason for reactivity addition. The leakage reactivity worth of the reference axially uniform core is about $6 \% \Delta \rho$. Introduction of a central $30 \mathrm{~cm}$ thick blanket nearly doubles the

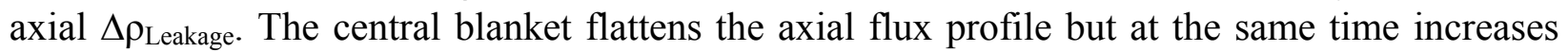
the "local" buckling at the core edges, which leads to a significant axial leakage increase. The set of three axial blanket zones, on the other hand, seems to be a very effective reflector, actually reducing the axial leakage to only $\sim 3 \%$.

Table 4B-5 summarizes the contribution of fast fissions in U238 to total fission rate. The presence of NU blankets only reduces the U238 fission contribution, despite the fact that total U238 content in the core is larger due to the fact that the blanket $\mathrm{Zr}$ content was assumed to be the minimum required 10wt.\% in all radial fuel zones. The U238 is more efficient in 3 thin blankets than in one thick blanket, probably due to self-shielding effects. In general, the obtained results point out that fast fission in U238 is not the major effect.

Spectrum differences in the fuel zones are observable, but also appear to be a second order effect. Figures 4B-11 through 4B-13 show the neutron spectrum in different core zones. The spectrum in the fuel zone is slightly harder in the case with "triple" blankets versus the case with the single blanket. However, this difference does not translate into any noticeable difference in the fission rates in any of the fuel zones.

Table 4B-5 Contribution of Fast Fissions in U238 to total power

\begin{tabular}{|l|c|c|c|}
\hline Case & $\begin{array}{c}\text { U238 } \\
\text { fissions, } \\
\text { \% of total }\end{array}$ & $\begin{array}{c}\text { U238 fissions in the core, } \\
\% \text { of total }\end{array}$ & $\begin{array}{c}\text { U238 fissions in the } \\
\text { blankets, \% of total }\end{array}$ \\
\hline Reference core & 12.91 & 12.91 & 0.00 \\
\hline Parfait core $1 \times 30 \mathrm{~cm}$ blanket & 12.28 & 11.17 & 1.12 \\
\hline Parfait core $3 \times 10 \mathrm{~cm}$ blankets & 12.21 & 10.69 & 2.28 \\
\hline
\end{tabular}


Project No 06-040: Flexible Conversion Ratio Fast Reactor Systems Evaluation

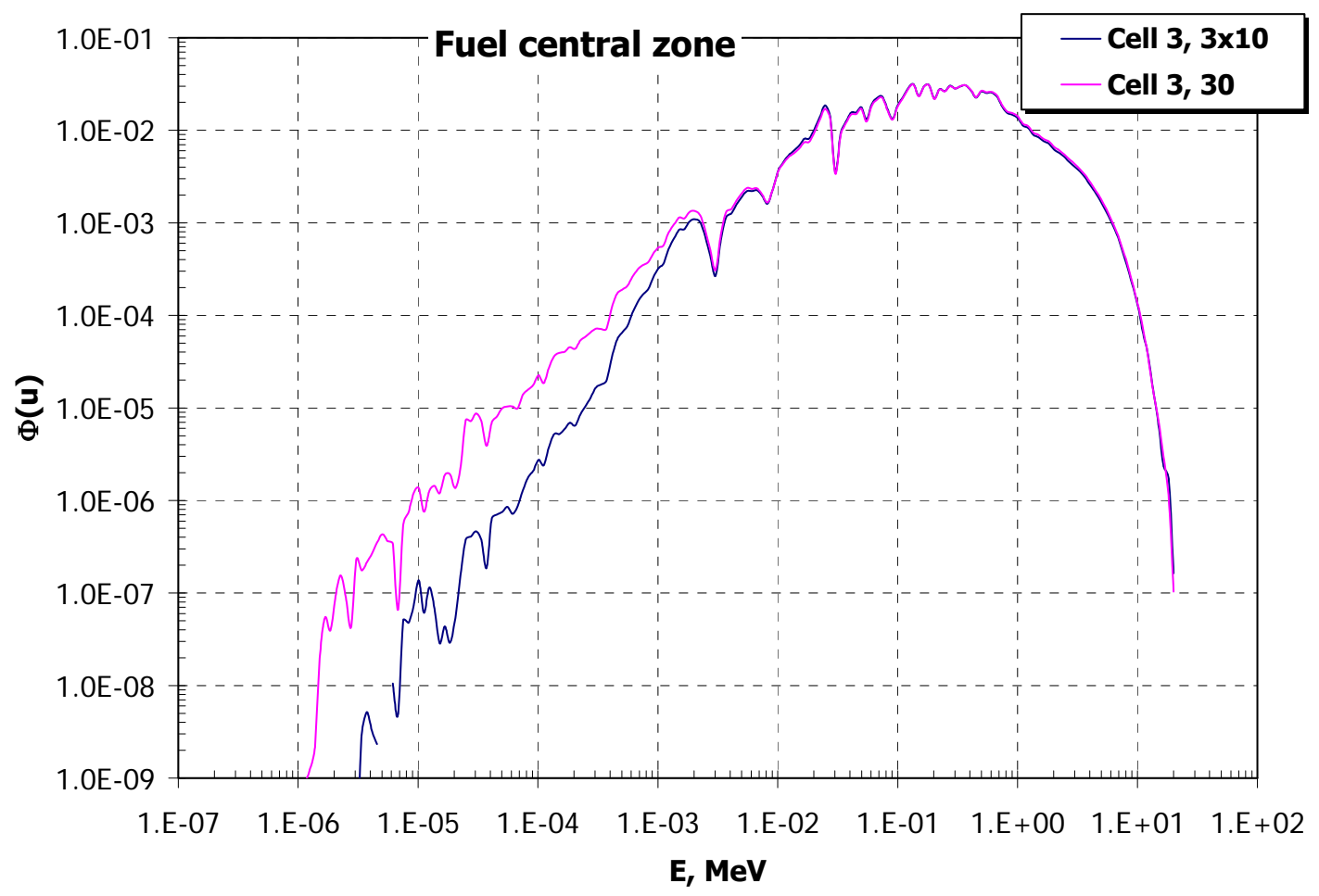

Figure 4B-12 Neutron spectrum in the radial innermost fuel zone.

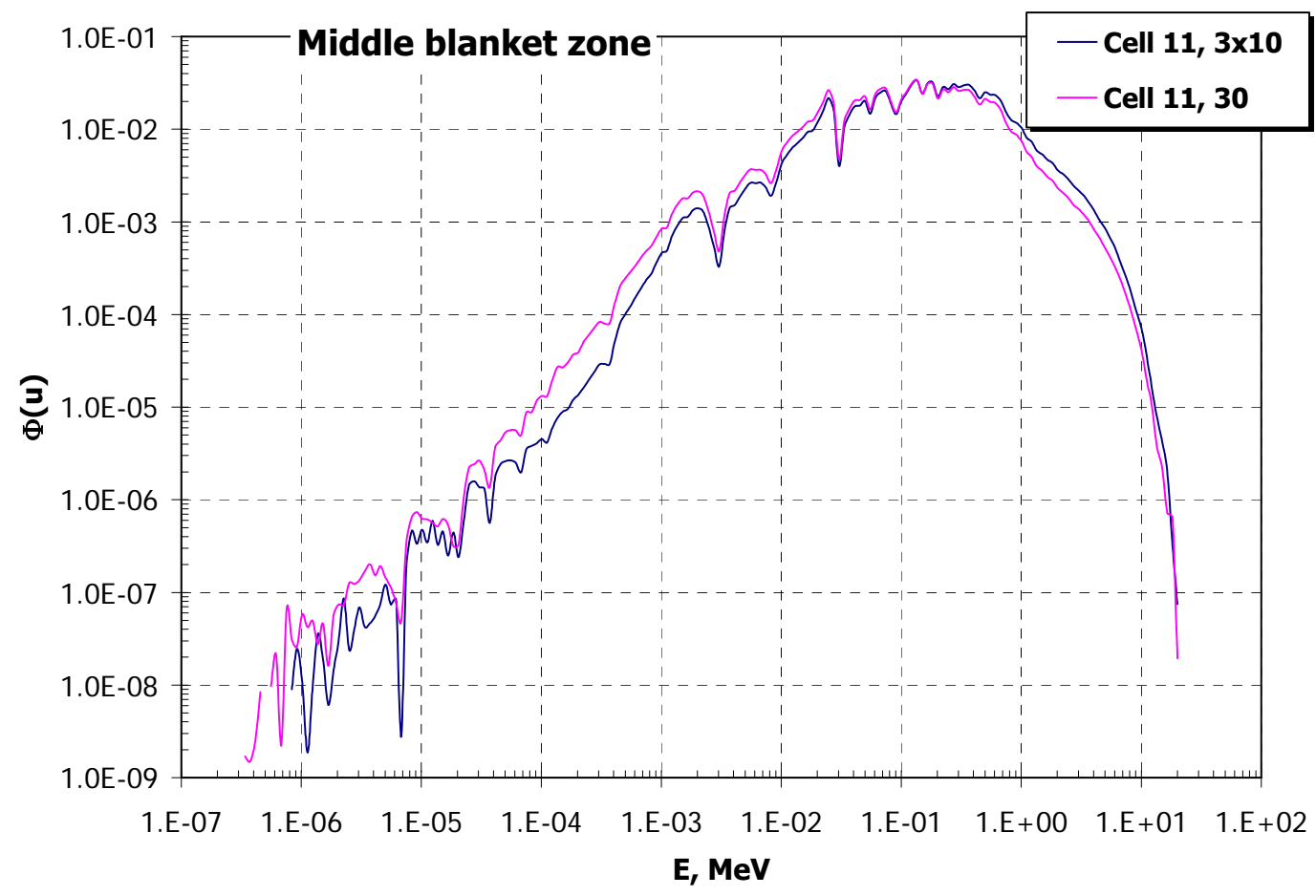

Figure 4B-13 Neutron spectrum in the middle axial blanket zone. 
Project No 06-040: Flexible Conversion Ratio Fast Reactor Systems Evaluation

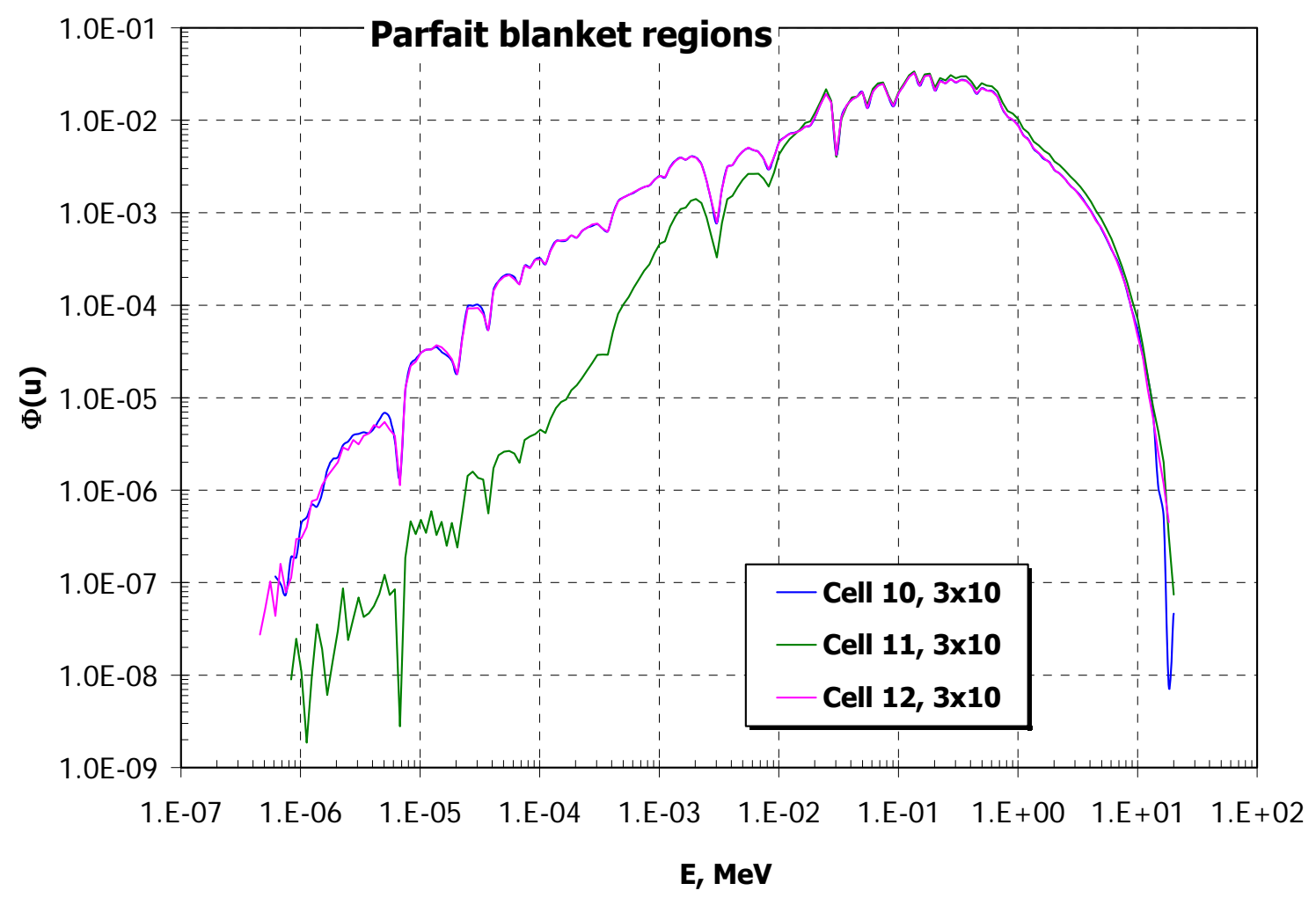

Figure 4B-14 Neutron spectrum in the bottom, middle, and top axial blanket zones.

\section{Consideration of $\mathrm{NaCl}-\mathrm{KCl}-\mathrm{MgCl}_{2}$ Salt Coolant}

The results of the $\mathrm{NaCl}-\mathrm{MgCl}_{2}$ salt coolant analysis presented above showed that the target CTC of about $0.20 \varnothing / \mathrm{K}$ can be achieved by applying the "parfait" core design strategy. However, the $\mathrm{NaCl}-\mathrm{MgCl}_{2}$ salt has a relatively high, and only marginally acceptable, melting point of $445{ }^{\circ} \mathrm{C}$. The more favorable chloride salt candidate in this respect is the ternary $\mathrm{NaCl}-\mathrm{KCl}-\mathrm{MgCl}_{2} \mathrm{salt}_{\text {. }}$

The substitution of $\mathrm{NaCl}-\mathrm{MgCl}_{2}$ salt with the $\mathrm{NaCl}-\mathrm{KCl}-\mathrm{MgCl}_{2}$ salt in the reference core model resulted in a notable reactivity gain of about $1.5 \% \Delta \rho$ due to somewhat lower moderation by the ternary salt (Table 4B-1, Case 12). In addition, the ternary salt-cooled core exhibits considerably larger CTC due to the larger, by about $50 \%$, thermal expansion coefficient than that of the binary salt.

Application of the "parfait" design strategy in a configuration with 3 axial $10 \mathrm{~cm}$ thick blankets (Figure 4B-11) resulted in a further reactivity gain of $4.4 \% \Delta \rho$, but did not improve the CTC (Table 4B-1, Case 13) as in the case of the $\mathrm{NaCl}-\mathrm{MgCl}_{2}$ salt.

\section{Reduction of Core Enrichment}

The less moderating ternary salt in combination with axial "parfait" NU blankets provided a considerable increase in the core reactivity, which allows some reduction in the TRU loading. The CTC should be smaller in the lower enrichment core because of the competition of U238 with the salt for neutron absorption. The higher the U238 share in total absorption, the lower the positive contribution of the salt absorption to CTC. 
The core enrichment was reduced gradually from $15 \mathrm{wt} . \%$ to $12 \mathrm{wt} . \%$, first in the $3 \times 10 \mathrm{~cm}$ "parfait" blanket configuration, then, through elimination of the central blanket and increasing the thickness of the two external blankets to $15 \mathrm{~cm}$.

The results are summarized in Table 4B-1, Cases 13 through 17. Reducing the equivalent enrichment from $15 \%$ to $14 \%$ TRU helps reduce CTC by $\sim 40 \%$, but further reduction of enrichment to $13 \%$ seems to result in no additional improvement.

Removing the middle parfait blanket and increasing the thickness of top and bottom axial blankets to $15 \mathrm{~cm}$ adds another $6 \%$ of reactivity, which allows even further enrichment reduction: to $12 \%$. The CTC, however, remains unaffected by these manipulations and even exhibits some increase due to re-location of NU from the middle to top and bottom blankets.

\section{Elimination of top reflector}

The presence of axial NU blankets reduced considerably the axial leakage component, as reported above. However, the leakage effect plays an important role in mitigation of the CTC. This is because the leakage from the core has significant sensitivity to the coolant density change. Hardening of the spectrum associated with coolant density reduction leads to higher neutron loss through leakage, which somewhat compensates the reactivity increase due to the positive slope of $\eta(E)$.

Elimination of the top reflector would bring the gas plenum in the upper part of the fuel pins closer to the active core. The gas plenum can be considered as a nearly "black" neutron absorber removing the extra neutrons leaking from the core upon reduction of the coolant density. Therefore, it should improve the CTC. Furthermore, the presence of a top reflector in the "parfait" configuration is not essential, since it hardy contributes to the core reactivity.

The results of the core with no top reflector analysis are reported in Table 4B-1, Case 18 . Removing the top reflector has indeed a notable effect on CTC, reducing it from $\sim 0.40$ to 0.30 $\notin / \mathrm{K}$. As a result, this strategy was adopted in all further cases considered in this analysis.

\section{Softening Spectrum with Moderator Mixed with the Fuel}

As a result of the performed analysis, it was concluded that reducing the enrichment beyond $14 \%$ is not useful, since further reduction stops affecting the CTC, while the conversion ratio of the core should already be sufficient. Judging by the $\mathrm{Pb}$ cooled core experience, an enrichment of slightly above $15 \%$ already provided a CR of about unity. Alternatively, the excess reactivity available due to the axial blanket dimension optimization can be "spent" on various CTC reduction strategies, such as spectrum softening by adding some moderating atoms to the fuel. As already mentioned, the main idea is to shift the spectrum to lower energies where the $\eta(E)$ slope is less steep, and therefore the reactivity response to changes in coolant density is less pronounced.

The core reactivity can be increased further through an increase of the axial blanket thickness. However, an increase of the blanket thickness beyond $20 \mathrm{~cm}$ is probably impractical since for fixed core power most of the fuel pin power would be concentrated in the central region containing fissile TRU, significantly increasing cladding and fuel temperature. The axial blanket thickness increase from 15 to $20 \mathrm{~cm}$ adds about $5 \%$ to the core reactivity (Case 19, Table 4B-1). 
Metallic Be admixture to the fuel, either heterogeneously in the center of annular fuel pin or mixed homogeneously in the form of Be-Zr alloy, was considered as an option for softening the neutron spectrum inside the core. The results of such a spectrum softening strategy are presented in Table 4B-1, Cases 20 and 21. Addition of Be to the fuel provided a certain reduction of CTC but, again, insufficient for achieving the target CTC value. Moreover, the softer spectrum is likely to result in an increase in magnitude of the Doppler coefficient, which, as shown in the previous section, would reduce the target value for CTC to below $0.20 ф / \mathrm{K}$ and make it more challenging to achieve.

\section{Addition of Neutron Absorbers to Axial Blankets}

This strategy is once again based on the core leakage sensitivity to changes in coolant density. The extra neutrons leaking to the axial blanket regions as a result of higher leakage would be absorbed, offsetting some of the positive reactivity addition and therefore reducing the CTC. The presence of neutron absorbers in the blankets has another advantage because its effect on CTC is burnup independent whereas the "parfait" configuration effect is expected to diminish as $\mathrm{Pu}$ is being bred in the blankets towards the end of the core campaign.

Four neutron absorber materials were considered: Boron, Hafnium, Nickel, and Calcium. The former two were selected due to their large absorption cross section in a fast spectrum. The latter two are known to be "pseudo" threshold absorbers. That is, their absorption in the fast spectrum increases with spectrum hardening, which is also a favorable feature for CTC reduction. The absorption cross sections for ${ }^{10} \mathrm{~B}(\mathrm{n}, \alpha), \mathrm{Hf}, \mathrm{Ni}$, and $\mathrm{Ca}$ are compared in Figure 4B-15.

This strategy was explored by itself and in combination with Be addition to the fuel. The selected results of various combinations of the absorber materials at different concentrations, with different concentrations of Be in the fuel are presented in Table 4B-1, Cases 22 through 27.

The best, in terms of the CTC, combination was observed for Case 25, corresponding to 15 volume $\%$ of $\mathrm{Be}$ in the fuel distributed evenly throughout the core and a $5 \%$ addition of ${ }^{10} \mathrm{~B}$ to the blankets. The CTC for this case was reduced to $0.25 \phi / \mathrm{K}$, which is fairly close to the target value. It should be noted, however, that this case is somewhat hypothetical since it does not consider the chemical form of Boron in the blankets, or its distribution throughout the pin, and assumes $100 \%$ enrichment in ${ }^{10} \mathrm{~B}$.

\section{H-shape (Stepped Geometry) Core}

In the H-shape core configuration, the fuel pins have variable length in every radial zone of the core [Okawa and Greenspan, 2004]. This core geometry provides higher core surface area and, thus, a larger leakage component, which in turn, reduces the CTC. In addition, the core radial power distribution can be tailored through variation of the fuel pin length.

Two cases for the H-shape core geometry - with and without NU axial blankets were evaluated. The schematic view of these core configurations is presented in Figures 4B-16 and 4B-17. The reference $130 \mathrm{~cm}$ length was maintained for the fuel pins in the middle radial zone. The pin length in the central zone was $90 \mathrm{~cm}$ (reduced by $20 \mathrm{~cm}$ on each end), while in the outer zone the pin length was $170 \mathrm{~cm}$ (increased by $20 \mathrm{~cm}$ on each end). The thickness of axial blankets was $20 \mathrm{~cm}$. 


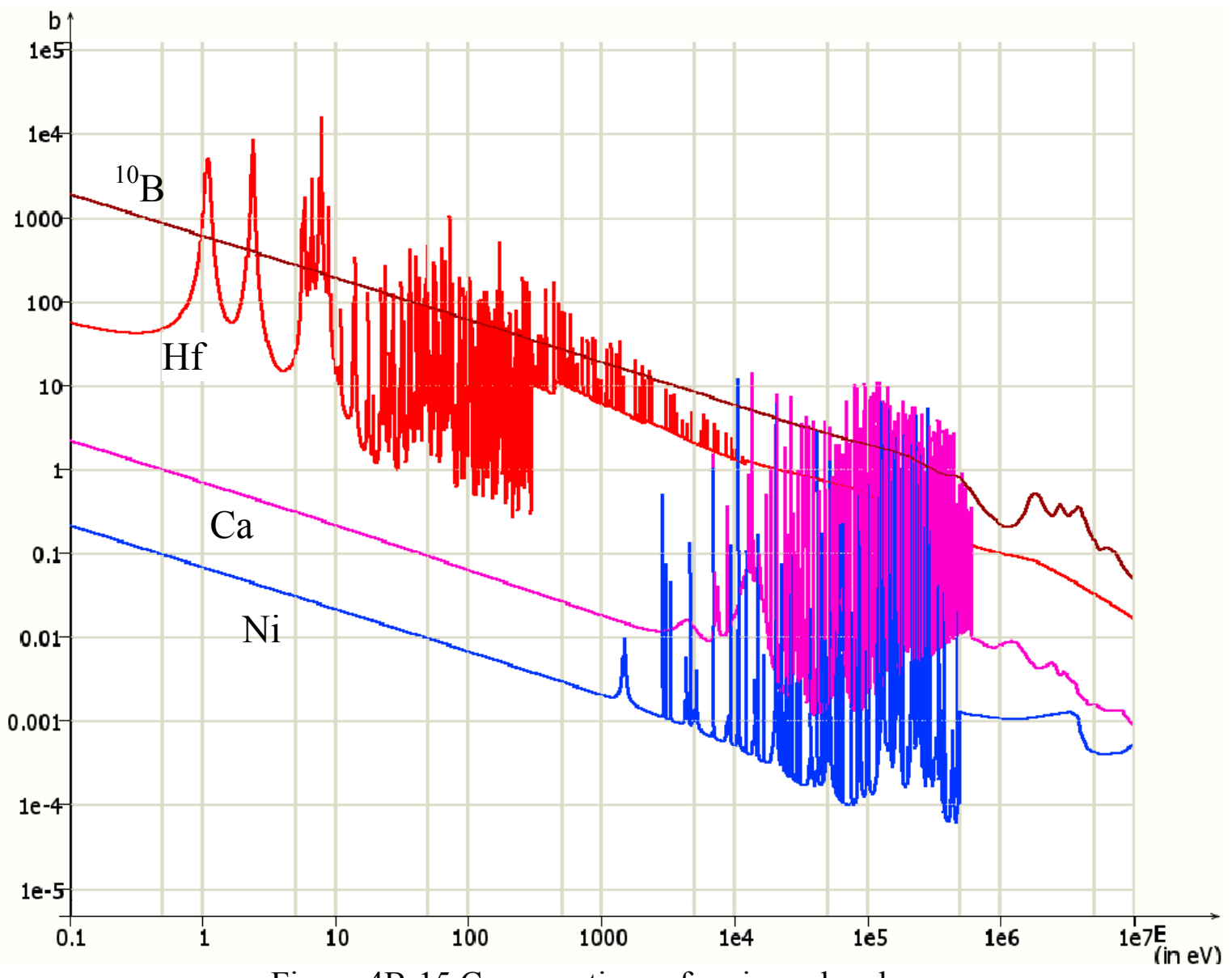

Figure 4B-15 Cross sections of various absorbers

Achieving a reasonable power shape only by adjusting the heights of the core radial zones within reasonable limits is a fairly complicated task. A variation of $\mathrm{Zr}$ content in the fuel is still required.

In addition to axial blankets, TRU enrichment reduction and spectrum softening in the fuel strategies were analyzed in combination with the H-shape core geometry.

The results of the analysis are reported in Table 4B-1, Cases 28 through 32. For the H-shape core with no blankets, the CTC is comparable to that of the conventionally shaped core 0.39 vs 0.42 $\notin / \mathrm{K}$. This is likely due to the fact that the core geometry modification was not drastic enough to affect the leakage significantly. The reduction of TRU enrichment to $12 \%$ in combination with the use of axial blankets provided the most favorable CTC value $(0.25 \phi / \mathrm{K})$ of all considered $\mathrm{H}$ shape core cases. The other combinations were not capable of reducing the CTC to below 0.30 $\phi / \mathrm{K}$. 
Project No 06-040: Flexible Conversion Ratio Fast Reactor Systems Evaluation

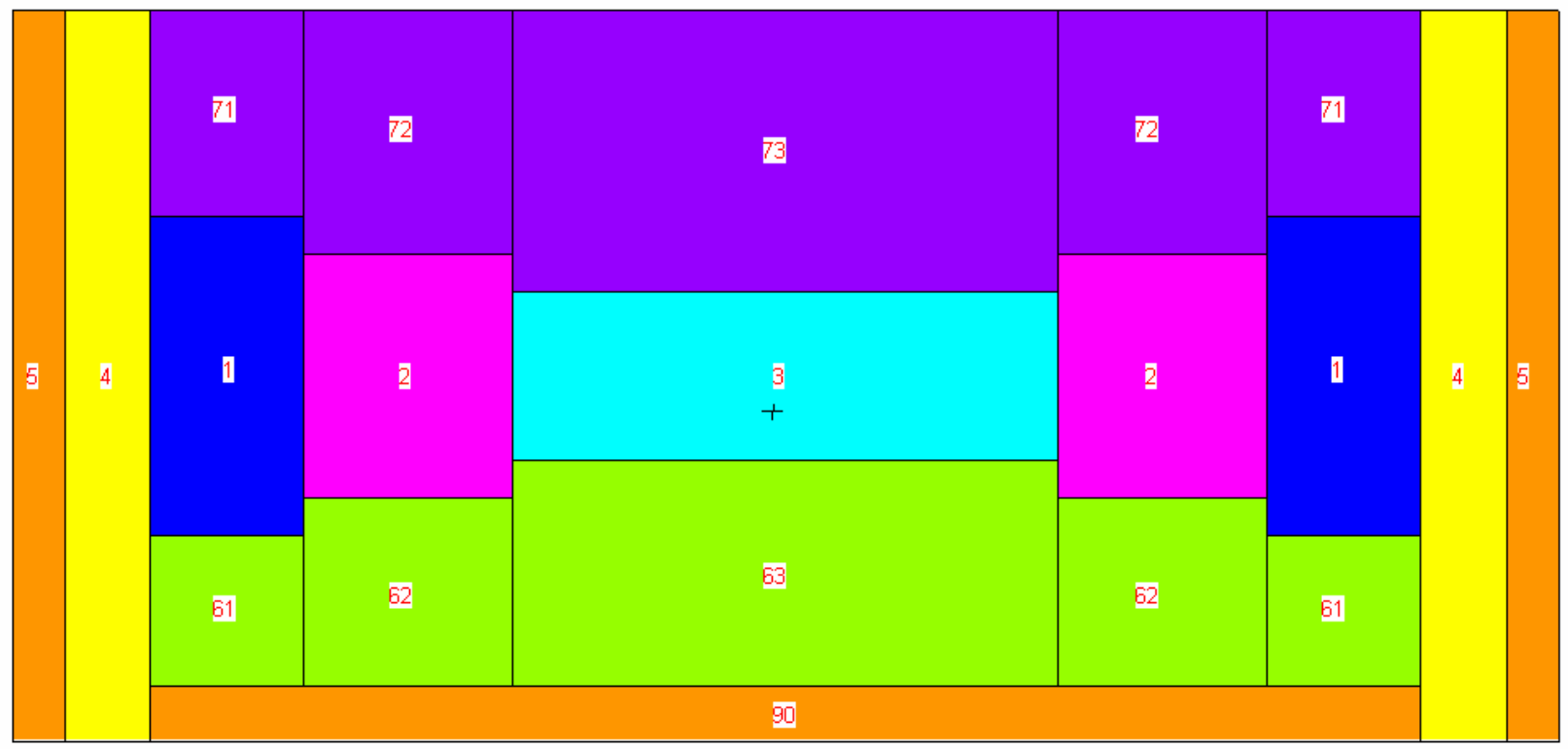

Figure 4B-16 Schematic view of H-shape Core with no axial blankets.

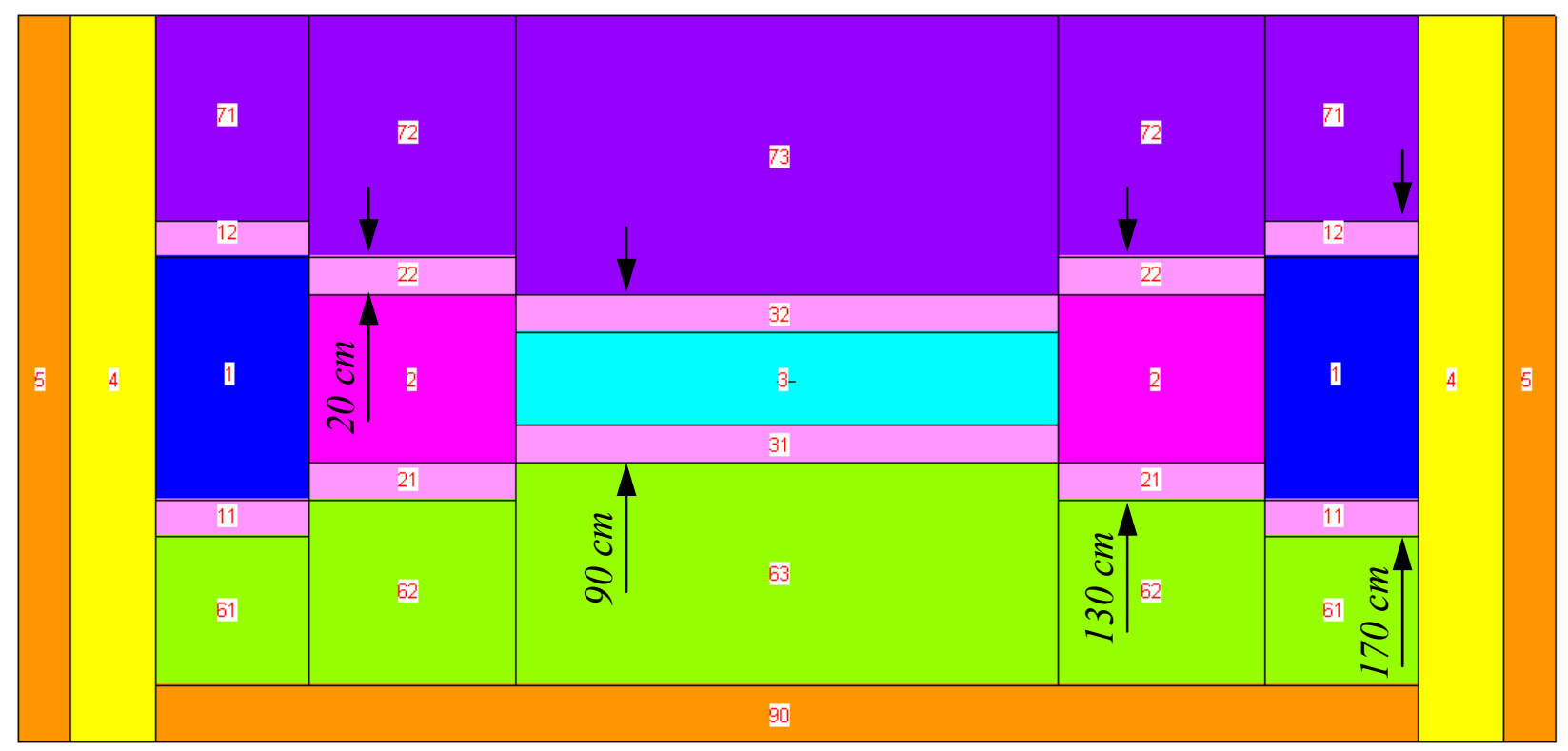

Figure 4B-17 Schematic view of H-shape Core with axial blankets.

\section{Moderator Addition to Axial Blankets}

In this strategy, various moderator materials were added to the axial blankets to provide the effect of reflecting lower energy, and thus, lower reactivity worth, neutrons back to the core upon decrease in the coolant density. In particular, $\mathrm{Ca}$ and $\mathrm{Zr}$ hydrides were considered. $\mathrm{CaH}_{2}$ was considered because of the "threshold absorber" effect mentioned earlier as beneficial for CTC reduction. An additional advantage of adding moderator to the blankets is that the isotopic composition of bred $\mathrm{Pu}$ would be more proliferation resistant in a softer spectrum.

The moderating material was assumed to be located in the center of an annular fuel pin occupying up to 30 volume \%. In the case of $\mathrm{Zr}$ hydride, an alternative two-phase $\left(\mathrm{U}_{0.31} \mathrm{Zr}\right) \mathrm{H}_{1.6}$ fuel was considered. In such a hydride fuel, higher hydrogen atom density can be achieved at the 
expense of the HM loading. This type of U-Zr hydride fuel form is routinely used in TRIGA research reactors and was also suggested for use in high power density LWRs [Diller et al., 2006].

The results of the calculations are reported in Table 4B-1, Cases 33 through 41. A heterogeneous core representation in the calculation model was shown to be important for the cases with high concentrations of hydrogen atoms. The lowest CTC of $0.20 \phi / \mathrm{K}$ was obtained in Case 39 with $30 \mathrm{vol} \%$ of $\mathrm{Zr}$ hydride content in the blanket region. Case 40 with even higher hydrogen concentration shows similar improvement in CTC. However, significantly lower uranium loading may reduce the overall breeding performance of the core.

Attempts at further improving the CTC through combination of already mentioned techniques, such as fuel spectrum softening (Case 42) or lowering the enrichment (Cases 38 and 41), with the moderated blanket strategy were unsuccessful.

\section{Streaming Channels}

Introduction of neutron streaming channels into the core is another way of exploiting the leakage effect on CTC. A number of streaming channel $\backslash$ configurations were considered:

- Annular core with central voided region $70 \mathrm{~cm}$ in diameter

- Whole Assembly (WA) streaming channels, where about $10 \%$ of the fuel assemblies are replaced with voided regions (Figure 4B-18).

- Fuel assembly where about $10 \%$ of the fuel pins are replaced with "empty" fuel pins, which provide streaming paths for neutrons (Figure 4B-19).

All considered cases assumed $20 \mathrm{~cm}$ thick axial blankets with $30 \% \mathrm{Zr}$ hydride content.

The results of the analysis are summarized in Table 4B-1, Cases 43 through 46. The CTC was not improved by the introduction of streaming channels, which is somewhat surprising. The reasons for such a counter-intuitive result required further investigation, which showed that more neutron histories were needed to achieve well converged source distribution. As discussed in Chapter 4, rerunning these cases with a much larger number of histories, showed the beneficial impact of streaming channels, although not sufficiently large to attain the target CTC values.

\section{Thorium Blankets}

The final strategy explored in this study was the substitution of NU in the blankets with Th. Thorium should improve CTC because it has a smaller increase in the fission-to-capture cross section ratio compared to $\mathrm{U} 238$ as a result of the spectrum hardening. Also, the fission cross section of ${ }^{232} \mathrm{Th}$ is considerably smaller than that of U238 and makes the threshold effect from the fast fissions in the fertile fuel component smaller than in the case of U238.

However, substitution of NU by Th in the blankets did not result in substantial CTC reduction, as can be observed from Table 4B-1, Case 47. 
Project No 06-040: Flexible Conversion Ratio Fast Reactor Systems Evaluation

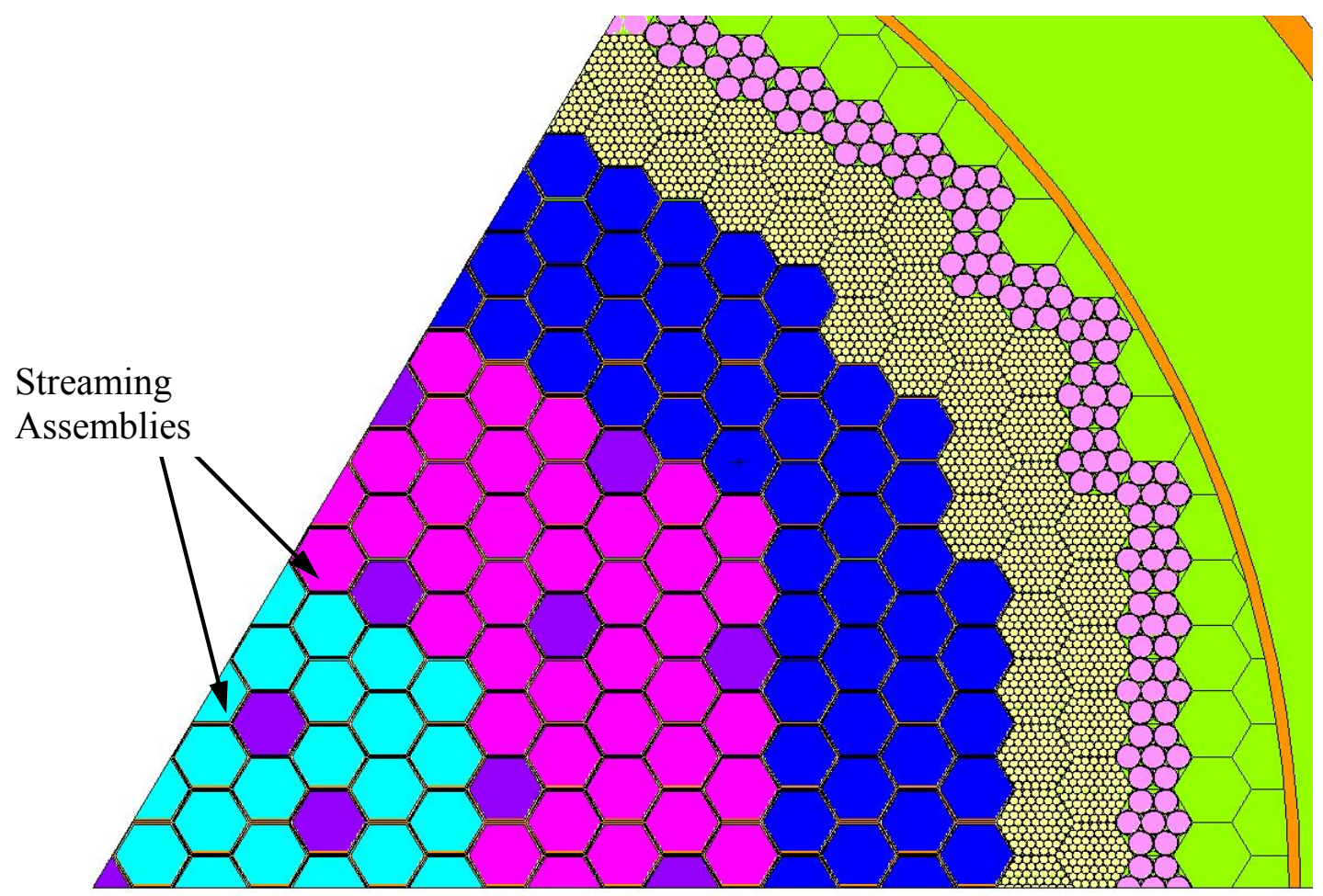

Figure 4B-18. Schematic view of the core with streaming assemblies.

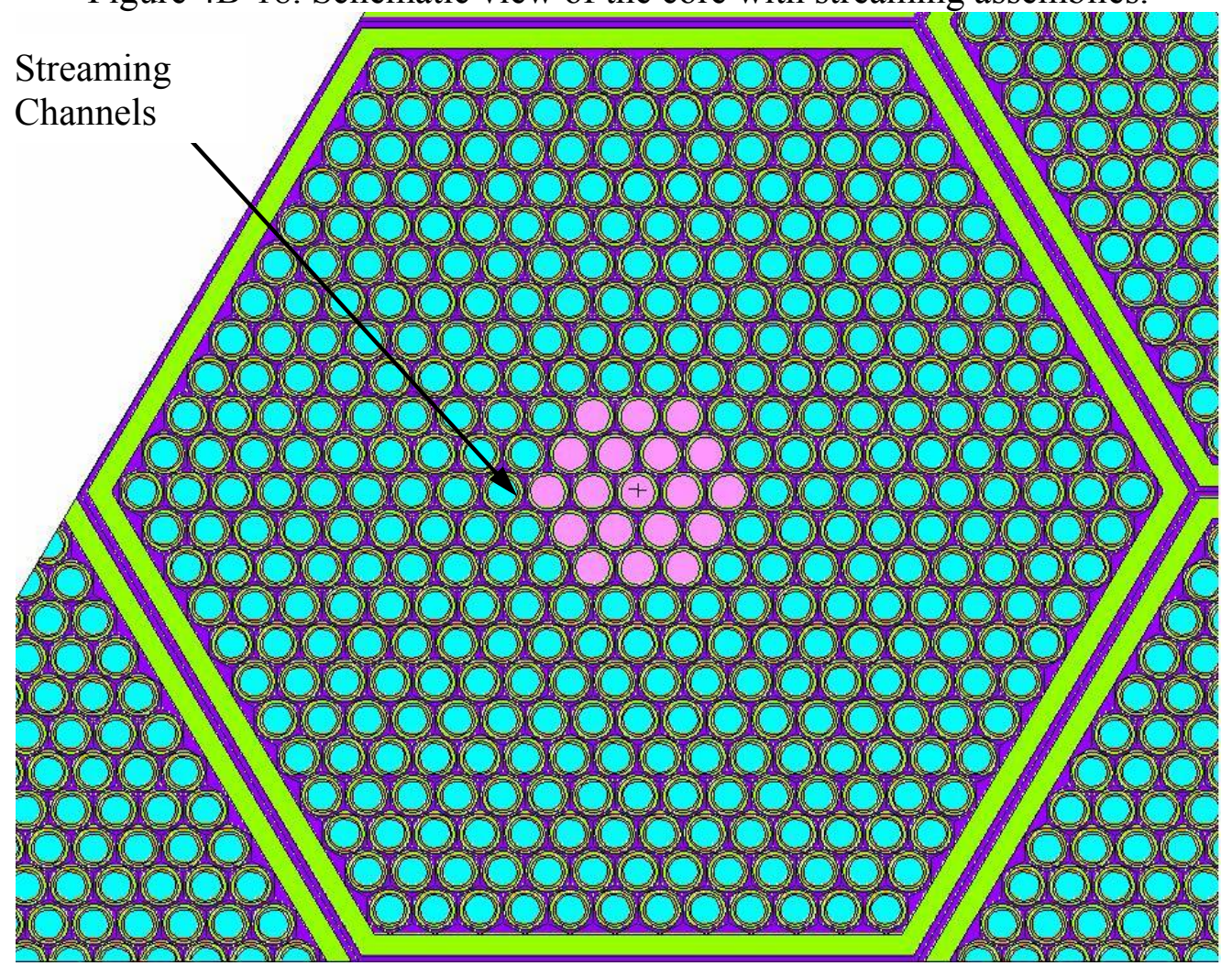

Figure 4B-19. Schematic view of the fuel assembly with streaming channels. 


\section{B.4 Summary of the findings}

The analysis revealed that in contrast to $\mathrm{NaF}-\mathrm{KF}-\mathrm{ZrF}_{4}$ salt, chloride, either $\mathrm{NaCl}-\mathrm{MgCl}_{2}$ or $\mathrm{NaCl}-$ $\mathrm{KCl}-\mathrm{MgCl}_{2}$, salt-cooled core has a potential to satisfy the self controllability criteria based on the quasi-static analysis approach.

Although $\mathrm{NaCl}-\mathrm{MgCl}_{2}$ salt has a lower thermal expansion coefficient, $\mathrm{NaCl}-\mathrm{KCl}-\mathrm{MgCl}_{2}$ salt is a preferred coolant choice because of its lower melting point.

In order to meet the constraints of self controllability, the CTC must be reduced below $0.20 \varnothing / \mathrm{K}$.

This target value of CTC can be achieved in the $\mathrm{NaCl}-\mathrm{KCl}-\mathrm{MgCl}_{2}$ cooled core by applying the following core design modifications as compared with the reference core design.

- The top core reflector is removed.

- Axial NU blankets $20 \mathrm{~cm}$ thick are introduced at the top and bottom of the active core. The total fuel length is preserved $(130 \mathrm{~cm})$. The TRU fuel component is concentrated in the middle axial zone of the core, preserving the total TRU loading per fuel pin.

- The fuel pins in the axial blanket zone have annular geometry. $\mathrm{ZrH}_{1.6}$ moderator is located in the center of the annulus and has a volume fraction of $30 \%$. Metallic natural uranium (with 10wt.\% $\mathrm{Zr}$ ) fuel is located in the outer annular cylinder.

The axial cross section of the core layout is schematically depicted in Figure 4B-20. However, this core is economically unattractive because it cannot achieve the target power density of $100 \mathrm{~kW} / 1$, as a result of large liner heat rates and axial peaking in the active core. Therefore, a lithium expansion module strategy, described in Chapter 4 was used for final LSFR core design.

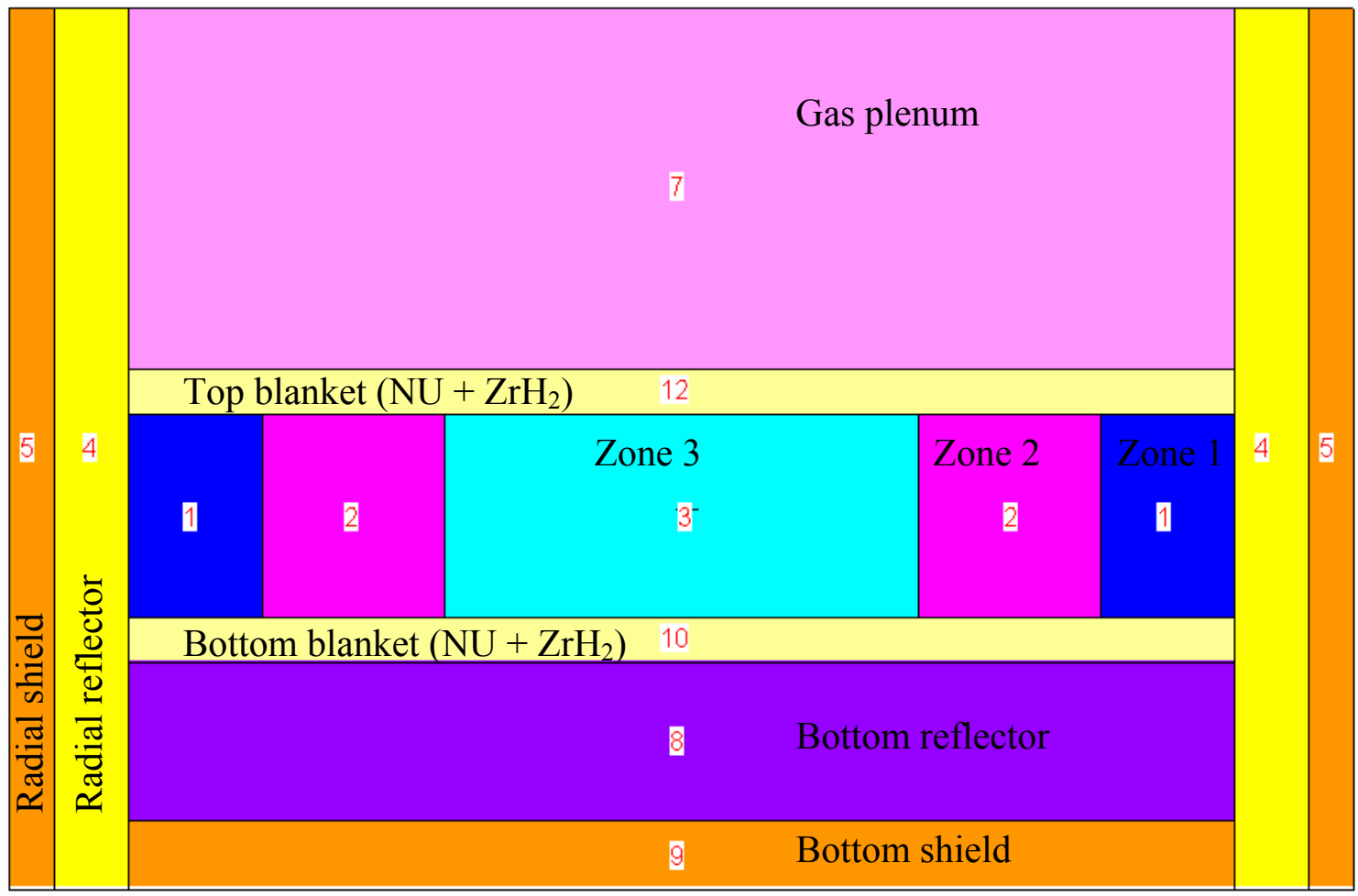

Figure 4B-20 Liquid salt CR=1 "Parfait-type" core layout. 


\section{References for Appendix 4B}

Diller P., Todreas N.E., and Hejzlar P., "Wire Wrapped Hexagonal Pin Arrays for PWR Service", Proc. International Congress on Advances in Nuclear Power Plants ICAPP '06, Paper 6156, Reno, Nevada,USA, June 4-8, 2006.

Ducat G.A., "Evaluation of the Parfait Blanket Concept for Fast Breeder Reactors," PhD Thesis, Department of Nuclear Engineering, Massachusetts Institute of Technology, 1974.

Forsberg C.W., "Reactors with Molten Salts: Options and Missions," Proc. of the Frédéric Joliot \& Otto Hahn Summer School, August 25 - September 3, 2004, Cadarache, France.

Okawa T. and Greenspan E., “Alternative EHNS Design using Stepped Geometry Core”, ANS Trans. Vol. 91, pp. 332-333, 2004.

Todreas N.E., Hejzlar P., Shwageraus E.., Petroski R. Nikiforova A., and Whitman J., "Flexible Conversion Ratio Fast Reactor Systems Evaluations", $3{ }^{\text {rd }}$ Quarterly report, Center for Advanced Nuclear Energy Systems, MIT, MIT-NFC-PR-090, January 2007.

Williams D.F., Toth L.M. and Clarno K.T., "Assessment of Candidate Molten Salt Coolants for the Advanced High-Temperature Reactor (AHTR)," ORNL/TM-2006/12, March 2006a.

Williams D.F. and Toth L.M., "Assessment of Candidate Molten Salt Coolants for the NGNP/NHI Heat Transfer Loop,” ORNL/TM-2006/69, June 2006b. 


\section{Appendix 5A \\ Core Conceptual Design of a 2400MWt Sodium- cooled Reactor}

This appendix describes analysis of a conceptual core design of a $2400 \mathrm{MWt}$ sodium-cooled fast reactor with unity conversion ratio, which was developed in this project to have a sodium-cooled version with the same power rating as the lead-cooled and salt-cooled reactors. The $1000 \mathrm{MWt}$ Advanced Burner Reactor (ABR) having $\mathrm{CR}=1$ developed at Argonne National Laboratory [Hoffman et al., 2006] was taken as a starting point. The reactor is a pool-type modular design and utilizes sodium coolant and metallic fuel. Geometric configuration of the fuel pins and assemblies is taken from the reference design. The ABR employs U-TRU-Zr metallic fuel with the fuel pins and assemblies in hexagonal arrangement. Since the fuel assemblies are kept the same as in ANL ABR design and power increase is achieved through larger number of assemblies and proportional increase of flow rate while maintaining the core temperature rise, only neutronic analysis is performed. Thermal hydraulic performance of the core will be similar to that of the reference core, provided that power peaking is not larger. To keep power peaking low throughout the cycle, the same approach of varying $\mathrm{Zr}$ content, rather than TRU enrichment, as for lead- and salt-cooled designs is used.

\section{A.1 Description of 1000MWt ABR Core}

ANL's reactor with unity conversion ratio and metallic fuel is taken as the initial reference design. Figure 5A-1 shows the schematic of the reference core. The assembly dimensions for the reference core design are provided in Table 5A-1. The ANL ABR reactor is based on the commercialized version of the 1000WMth S-PRISM. The ABR design deviated from S-PRISM by investigating different conversion ratio options and eliminating the blankets.

Table 5A-1 Assembly dimensions for reference design

Assembly pitch, cm

Inter-assembly gap, cm

Duct outside flat to flat distance, $\mathrm{cm}$

Duct thickness, cm
16.142

0.432

15.710

0.394 
Project No 06-040: Flexible Conversion Ratio Fast Reactor Systems Evaluation

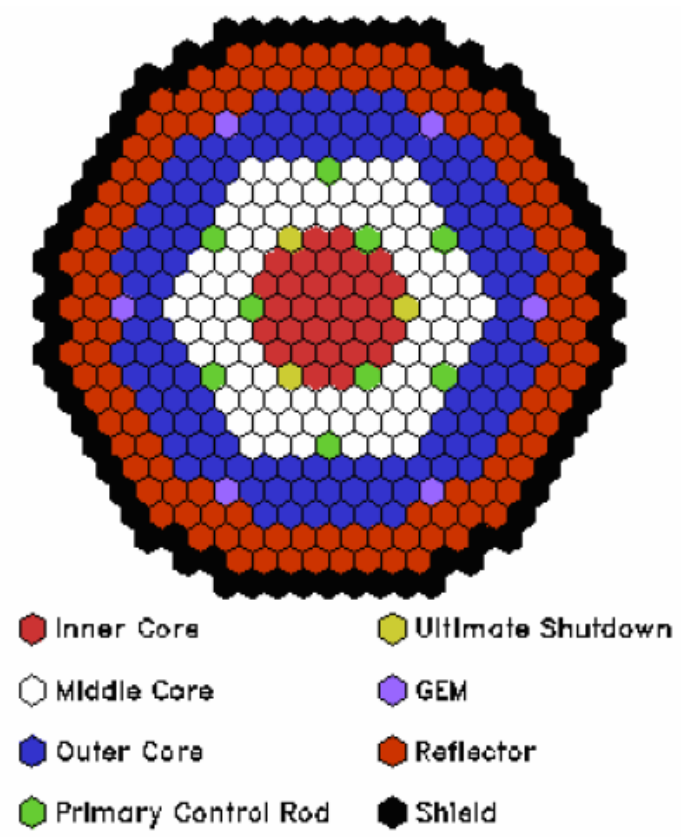

Figure 5A-1 Metal-fueled ABR core layout for CR=1 [Hoffman et al., 2006]

\section{A.2 Core Model}

\section{Material Properties}

Material properties are essential for accurate core modeling. In the reference design, the fuel pins are composed of metallic fuel with sodium bond and HT-9 cladding. HT-9 alloy is also used for the other structural components.

\section{Cladding}

The reference design employs HT-9 (Fe-12Cr-1Mo) alloy as cladding material. While this steel exhibits excellent resistance to radiation-induced swelling, the operating temperatures of the core must be limited. The peak cladding temperature cannot exceed $650^{\circ} \mathrm{C}$ due to potential fuelcladding interaction. The detailed isotopic composition of HT-9 steel used in the analysis is provided in Table 5A-2.

Table 5A-2 Isotopic composition of HT-9 steel [Klueh, 2004]

$\begin{array}{cr} & \text { Weight fract } \\ \mathrm{Fe} & 0.859 \\ \mathrm{Cr} & 0.116 \\ \mathrm{Mo} & 0.014 \\ \mathrm{Mn} & 0.006 \\ \mathrm{Ni} & 0.005 \\ \mathrm{~W} & 0.005 \\ \mathrm{Si} & 0.004 \\ \mathrm{~V} & 0.003 \\ \mathrm{C} & 0.002\end{array}$

The fuel residence time is also limited by the cladding irradiation limit. The peak fast fluence limit is $4.0 \cdot 10^{23} \mathrm{n} / \mathrm{cm}^{2}$. 
Project No 06-040: Flexible Conversion Ratio Fast Reactor Systems Evaluation

\section{Fuel and Fuel Assembly}

The first core loading consists of the TRU, NU and Zr loaded in different proportions depending on the core region. The isotopic TRU vector was the same as for the startup lead-cooled core, given in Table 3.3.1-5 in Chapter 3 of this report. For consistency with the lead- and salt-cooled reactor designs, the following assumptions about spent LWR fuel have been adopted:

- initial enrichment of $4.2 \%$,

- average discharge burnup $50 \mathrm{MWd} / \mathrm{kg}$,

- 10 years of decay after the discharge.

The fuel assembly arrangement was adopted from the reference design, and main assembly dimensions are provided in Table 5A-3. In the current analysis, thermal expansion of the materials was not accounted for, but all of the material properties are for the assembly-averaged temperatures.

Table 5A-3 Assembly parameters Reference $1000 \mathrm{MWt}$

ABR

271

Pin data

Bond material

Pin height $(\mathrm{cm})$

Gas plenum height $(\mathrm{cm})$

Fuel smeared density(\%TD)

Pin diameter $(\mathrm{cm})$

$\mathrm{P} / \mathrm{D}$ ratio

Cladding thickness $(\mathrm{cm})$

Wire wrap diameter $(\mathrm{cm})$

Volume fraction, $\%$

fuel (TRU-U-10Zr)

Structure (HT9)

Coolant

bond
$\mathrm{Na}$

101.6

191.14

75

0.808

1.100

0.0559

0.0805

34.26

25.73

28.59

11.42
$2400 \mathrm{MWt}$ core with

$\mathrm{CR}=1$

271

$\mathrm{Na}$

102.0

191.0

75

0.808

1.100

0.0559

0.0805

34.29

25.73

28.54

11.43

\section{Core Layout}

The first step in the core design was to identify the core layout without blankets that will produce $\mathrm{CR}=1$. The design of a fast reactor includes optimization of core layout to achieve reasonably low power peaking. If use of burnable poisons is not considered (harder spectrum than in LWR), the flatter power distribution is achieved through enrichment zoning. In the ABR reference design, three TRU enrichment core zones to flatten the power profile were utilized. As an alternative, the method employed in the Flexible Conversion Ratio Lead-cooled reactor can be used: changing the concentration of zirconium in the fuel while constraining the uranium to TRU ratio [Handwerk et al. 2006.] Fuel shuffling can also be used for power shaping. 
Core design optimization was performed through an iterative process using both enrichment zoning and zirconium weight fraction variation approaches. In the search for the best performing core, 6 cases were evaluated. For each case, the core, assembly and pin dimensions were held constant as well as isotopic composition of the TRU vector. The final design of the core utilizes zirconium tailoring which was found to be more effective in the core power flattening than variable TRU enrichment. The composition of the final design is presented in Table 5A-4; radial core layout is depicted in Figure 5A-2; and the axial core dimensions are presented in Figure 5A3.

Table 5A-4 Composition of final core configuration

\begin{tabular}{cccccc} 
& & U w/o & TRU w/o & Zrw/o & $\begin{array}{c}\text { Enrichment } \\
\text { Split }\end{array}$ \\
\hline \multirow{2}{*}{ Final } & Inner Core & $67.00 \%$ & $12.00 \%$ & $21.00 \%$ & 1 \\
design & Middle Core & $71.25 \%$ & $12.75 \%$ & $16.00 \%$ & 1 \\
& Outer Core & $76.33 \%$ & $13.67 \%$ & $10.00 \%$ & 1
\end{tabular}

Main core parameters are summarized in Table 5A-5. The region above the active core zone is the gas plenum for the fission gases. Lack of a top reflector allows for more neutrons to leak out of the core, which reduces coolant temperature reactivity coefficient. Additional safety analysis was performed using the MCNP code to determine whether self-controllability of the core is feasible and is reported in Section 5A-4.

Table 5A-5 Main core characteristics

Thermal power (MW)

Number of assemblies

Fuel pins per assembly

Number of control assemblies

Linear power $(\mathrm{kW} / \mathrm{m})$

Power density $(\mathrm{kW} / \mathrm{L})$

Specific power $(\mathrm{kW} / \mathrm{kg})$
2400

360

271

19

24.12

289.65

64.80 


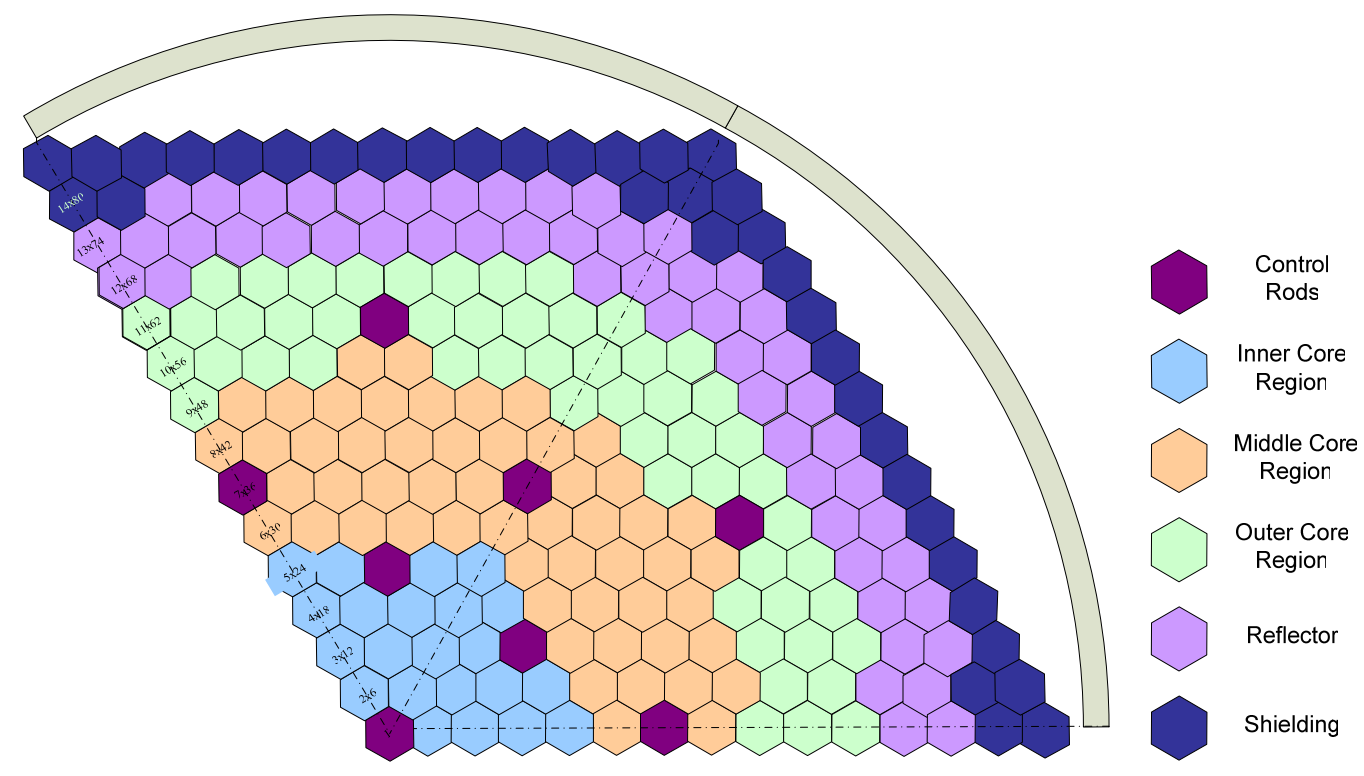

Figure 5A-2 Radial reactor core layout

\section{Thermal Hydraulic Considerations}

A simplified subchannel analysis was performed to estimate the thermal hydraulic performance of the core. Subchannel schematic and main dimensions are depicted in Figure 5A-4. Assembly and pin dimensions were taken from the ABR reference design. Table 5A-6 summarizes the main thermal hydraulic parameters and results for the $\mathrm{CR}=1$ core. The scoping thermal hydraulic analysis shows that the proposed core arrangement is feasible and the peak cladding temperature remains below the limit.

Properties of sodium at the average core temperature were determined using data compiled by Kutateladze [Kutateladze, 1976] and summarized in Table 5A-7. Nusselt number was determined using a Westinghouse correlation for metallic fluid in rod bundles [Todreas and Kazimi, 1993]. For pressure drop across the core calculation, an average friction factor was determined using the McAdams relation [Todreas and Kazimi, 1993]. 
Project No 06-040: Flexible Conversion Ratio Fast Reactor Systems Evaluation

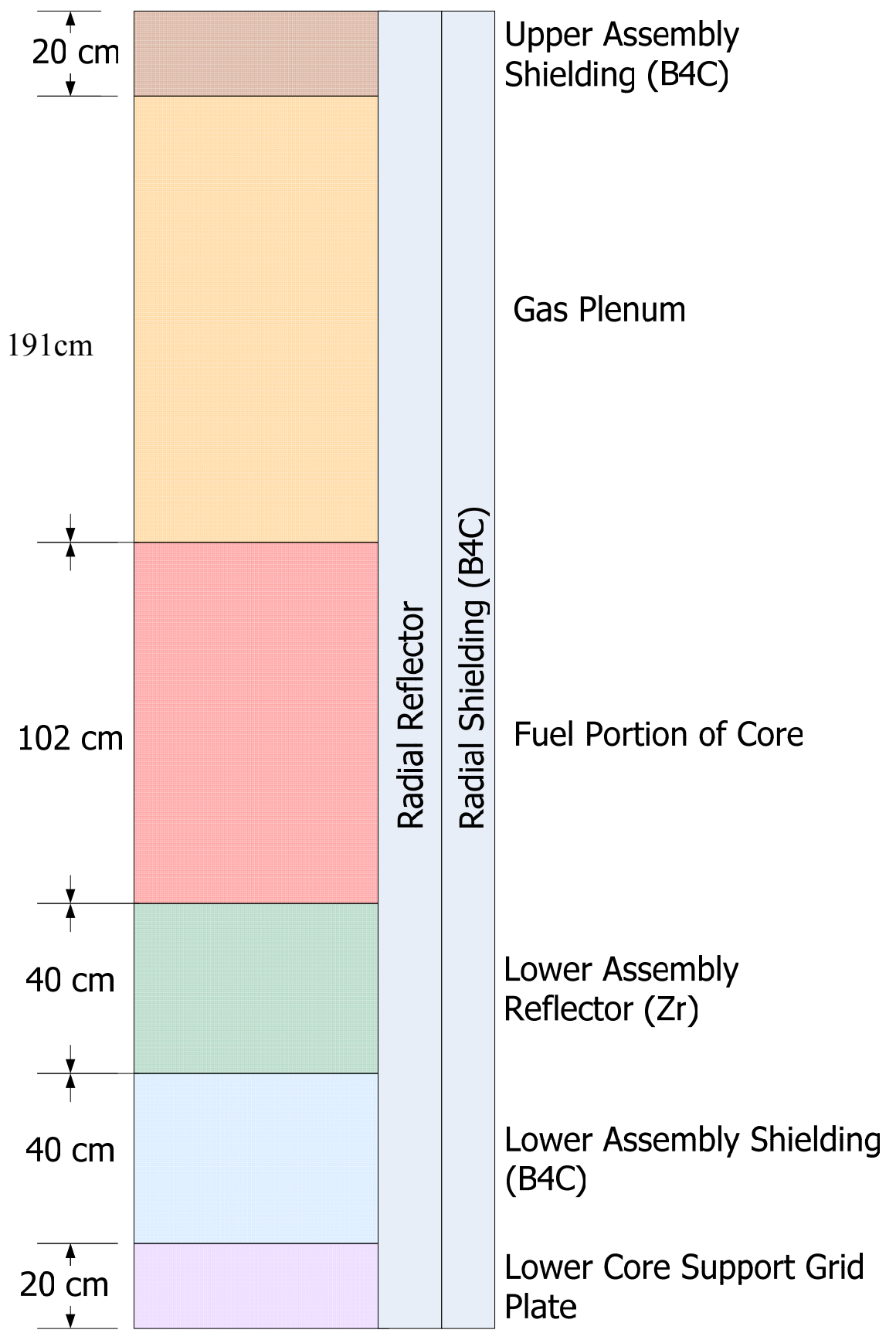

Figure 5A-3 Axial reactor layout. 
Core thermal power (MWt)

Table 5A-6 Summary of main core TH parameters

Maximum radial power peaking coefficient

Assembly pitch, hexagon flat-to-flat $(\mathrm{cm})$

Assembly can thickness (cm)

Inter assembly gap $(\mathrm{cm})$

Total number of fuel assemblies

Number of CRD assemblies

Number of fuel pins per assembly

Fuel pin geometry

Pin outer diameter $(\mathrm{cm})$

Cladding thickness $(\mathrm{cm})$

0.808

Gap thickness $(\mathrm{cm})$

0.0559

Fuel heated length $(\mathrm{cm})$

0.05

Fuel pin pitch $(\mathrm{cm})$

102.0

Pitch-to-diameter ratio

0.89

Plenum height $(\mathrm{cm})$

Cladding material

120.0

Gap bond

HT-9

Coolant mass flow rate $(\mathrm{kg} / \mathrm{s})$

$\mathrm{Na}$

Core average

Inlet temperature $\left({ }^{\circ} \mathrm{C}\right)$

12561

Outlet temperature $\left({ }^{\circ} \mathrm{C}\right)$

352.0

Re number

502.0

67727

Pr number

$5.1 \mathrm{E}-3$

$\mathrm{Nu}$ number (Westinghouse correlation)

Heat transfer coefficient $(\mathrm{kW} / \mathrm{m} 2-\mathrm{K})$

139.2

Core pressure drop ${ }^{*}(\mathrm{MPa})$

0.20

Average subchannel

Coolant average temperature $\left({ }^{\circ} \mathrm{C}\right)$

427.0

Cladding temperature limit $\left({ }^{\circ} \mathrm{C}\right)$

600.0

Cladding inner surface temperature $\left({ }^{\circ} \mathrm{C}\right)$

461.7

Fuel centerline temperature $\left({ }^{\circ} \mathrm{C}\right)$

630.0

Coolant velocity $(\mathrm{m} / \mathrm{s})$

7.86

Hot subchannel

Peak cladding temperature $\left({ }^{\circ} \mathrm{C}\right)$

568.0

Fuel centerline temperature $\left({ }^{\circ} \mathrm{C}\right)$

788.0

Power

Linear power, average $(\mathrm{kW} / \mathrm{m})$

24.12

Power density $(\mathrm{kW} / \mathrm{l})$

289.7

Specific power $(\mathrm{kW} / \mathrm{kgHM})$

64.80

*Active core, does not account for wire wraps or grids 
Table 5A-7 Select properties of materials at average coolant temperature

Parameter

\section{Sodium}

Coolant average temperature, ${ }^{\circ} \mathrm{C}$

Density, g/cc

Thermal conductivity, $\mathrm{W} / \mathrm{m}-\mathrm{K}$

Specific heat, J/kg-K

Viscosity, $\mathrm{kg} / \mathrm{m}-\mathrm{s}$

Steel HT-9

Thermal conductivity, $\mathrm{W} / \mathrm{m}-\mathrm{K}$

Metallic fuel (U-TRU-Zr)

Assumed thermal conductivity, W/m-K
Value

427.0

0.846

66.70

1272.00

2.65E-04

20.35

12.0

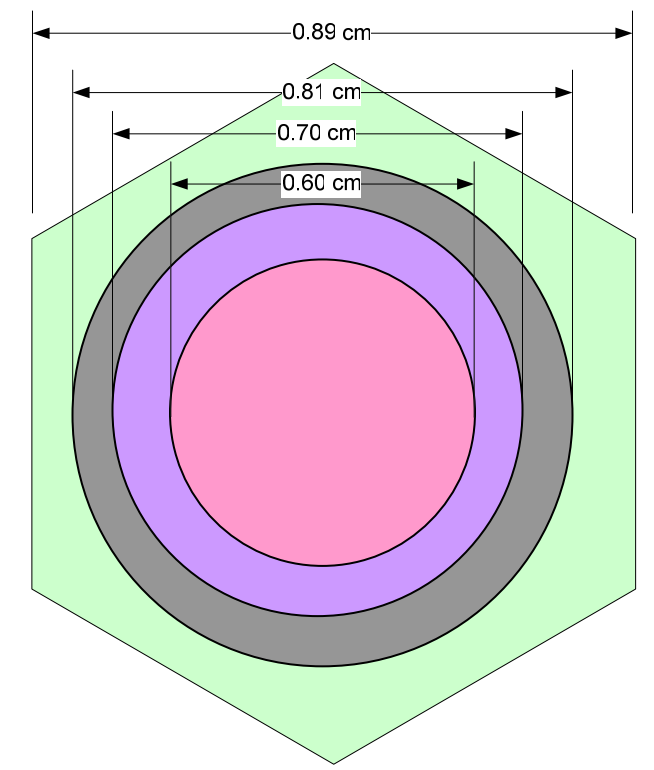

Figure 5A-4 Subchannel schematic and dimensions

\section{A.3 REBUS-3 Results}

Main results obtained using the REBUS-3 suit of codes are discussed in this section. Tables 5A-8 and 5A-9 list the core loading and TRU isotopic evolution throughout the cycle. Net MA destruction is observed with total TRU loading being nearly constant due to Pu breeding.

K-effective and peak cumulative cladding fluence are shown on Figures 5A-5 and 5A-6. As can be observed from the figures, the fuel cycle length is limited by the peak cumulative fluence to cladding in the middle core zone. The effective fuel cycle length for a single batch core is 1160 full power days or nearly 3 years. 
Project No 06-040: Flexible Conversion Ratio Fast Reactor Systems Evaluation

Table 5A-8 Core loading $(\mathrm{kg})$

\begin{tabular}{lccc}
\multicolumn{1}{c}{ BOL $(0 \mathrm{~d})$} & MOL $(600 \mathrm{~d})$ & $\mathrm{EOL}(1200 \mathrm{~d})$ \\
\hline $\mathrm{U}$ & $3.18 \mathrm{E}+04$ & $3.02 \mathrm{E}+04$ & $2.88 \mathrm{E}+04$ \\
$\mathrm{Pu}$ & $4.96 \mathrm{E}+03$ & $5.12 \mathrm{E}+03$ & $5.18 \mathrm{E}+03$ \\
$\mathrm{TRU}$ & $5.72 \mathrm{E}+03$ & $5.78 \mathrm{E}+03$ & $5.76 \mathrm{E}+03$ \\
$\mathrm{MA}$ & $7.64 \mathrm{E}+02$ & $6.65 \mathrm{E}+02$ & $5.79 \mathrm{E}+02$ \\
Core Total & $3.75 \mathrm{E}+04$ & $3.60 \mathrm{E}+04$ & $3.45 \mathrm{E}+04$
\end{tabular}

Table 5A-9 Core TRU isotopic vector evolution, w/o

\begin{tabular}{cccc} 
& BOL $(0 \mathrm{~d})$ & MOL $(600 \mathrm{~d})$ & EOL $(1200 \mathrm{~d})$ \\
\hline NP237 & 6.66 & 5.14 & 4.03 \\
PU236 & 0.00 & 0.00 & 0.00 \\
PU238 & 2.74 & 3.51 & 3.88 \\
PU239 & 48.80 & 52.47 & 54.04 \\
PU240 & 23.06 & 23.01 & 23.12 \\
PU241 & 6.95 & 5.41 & 4.52 \\
\hline PU242 & 5.08 & 5.06 & 4.94 \\
AM241 & 4.68 & 3.89 & 3.25 \\
AM242 & 0.00 & 0.20 & 0.36 \\
AM243 & 1.47 & 1.45 & 1.44 \\
CM242 & 0.00 & 0.23 & 0.21 \\
CM243 & 0.01 & 0.01 & 0.01 \\
\hline CM244 & 0.50 & 0.62 & 0.71 \\
CM245 & 0.04 & 0.08 & 0.11 \\
CM246 & 0.01 & 0.01 & 0.01
\end{tabular}

The conversion ratio is near unity throughout the cycle, as shown in Figure 5A-7. As can be seen in Figure 5A-8, average cumulative burnup is $72 \mathrm{MWd} / \mathrm{kgHM}$, and peak burnup, which occurs in the inner core zone, is $92 \mathrm{MWd} / \mathrm{kgHM}$ at the end of the cycle. Burnup is also limited by fluence cladding limit (see Figure 5A-9 for peak fluence in each core zone). The burnup is comparable to the lead-cooled reactor with same power, fuel type and conversion ratio (See Chapter 3 of the current report). However, the fuel cycle length of the FCR lead-cooled reactor is 1800 EFPD versus 1160 EFPD for the sodium-cooled reactor. The shorter cycle length of the sodium-cooled core is due to the difference in power density between the two cores and differences in heavy metal loading. The FCR lead-cooled reactor's power density is $112 \mathrm{~kW} / \mathrm{L}$ versus $290 \mathrm{~kW} / \mathrm{L}$ for the current design.

One of the major goals of the reactor core with unity conversion ratio is to preserve the net amount of TRU while destroying MA. Figures 5A-10 and 5A-11 show the Pu and TRU mass changes throughout the cycle. TRU mass remains nearly constant, while $\mathrm{Pu}$ mass exhibits a slight increase. Figure 5A-12 depicts relative amounts of TRU, MA, Pu and U. As can be seen, the relative amount of plutonium increases while the mass of minor actinides decreases. This keeps the net amount of TRU nearly constant. Figure 5A-13 compares mass flow for various isotopes of interest. Finally, Figure 5A-14 shows the radial power maps for BOC, MOC and EOC. It can be observed that the power peaking is kept low and constant throughout the whole cycle. Maximum peaking factor occurs in a middle core zone assembly at 600 EFPD. 
Project No 06-040: Flexible Conversion Ratio Fast Reactor Systems Evaluation

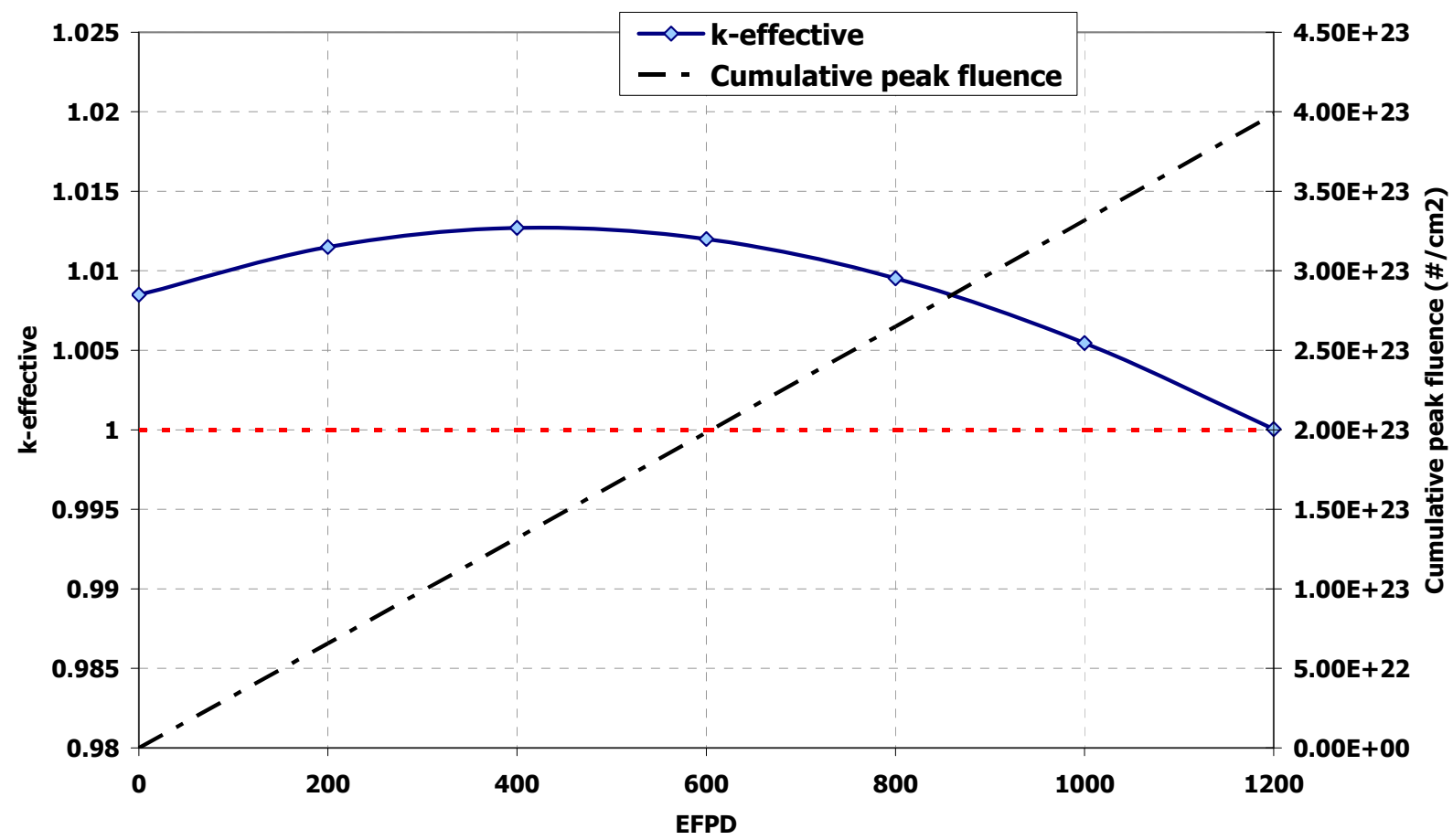

Figure 5A-5 K-effective and cumulative peak fluence evolution vs. EFPD

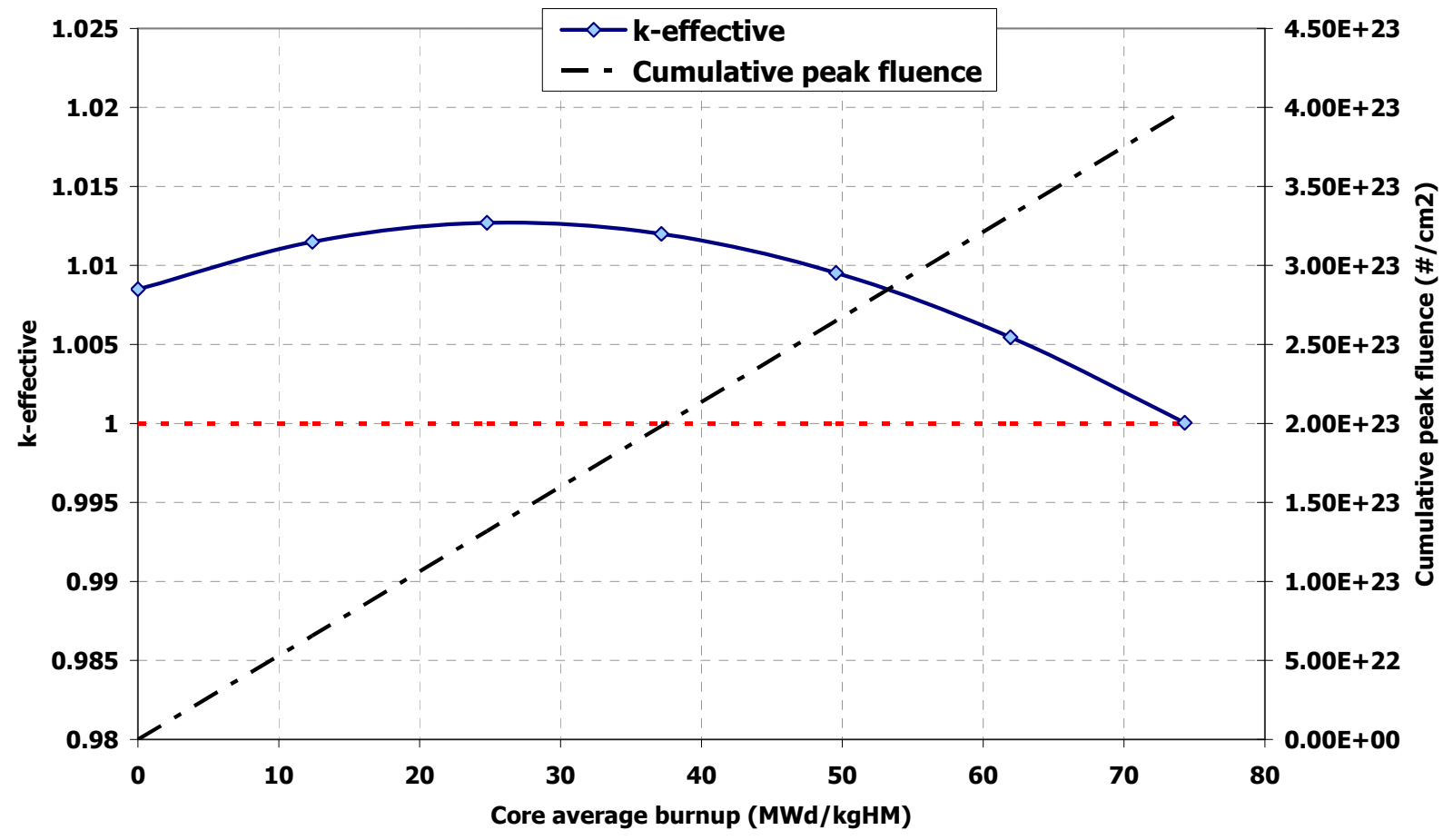

Figure 5A-6 K-effective and cumulative peak fluence evolution vs. core average burnup 
Project No 06-040: Flexible Conversion Ratio Fast Reactor Systems Evaluation

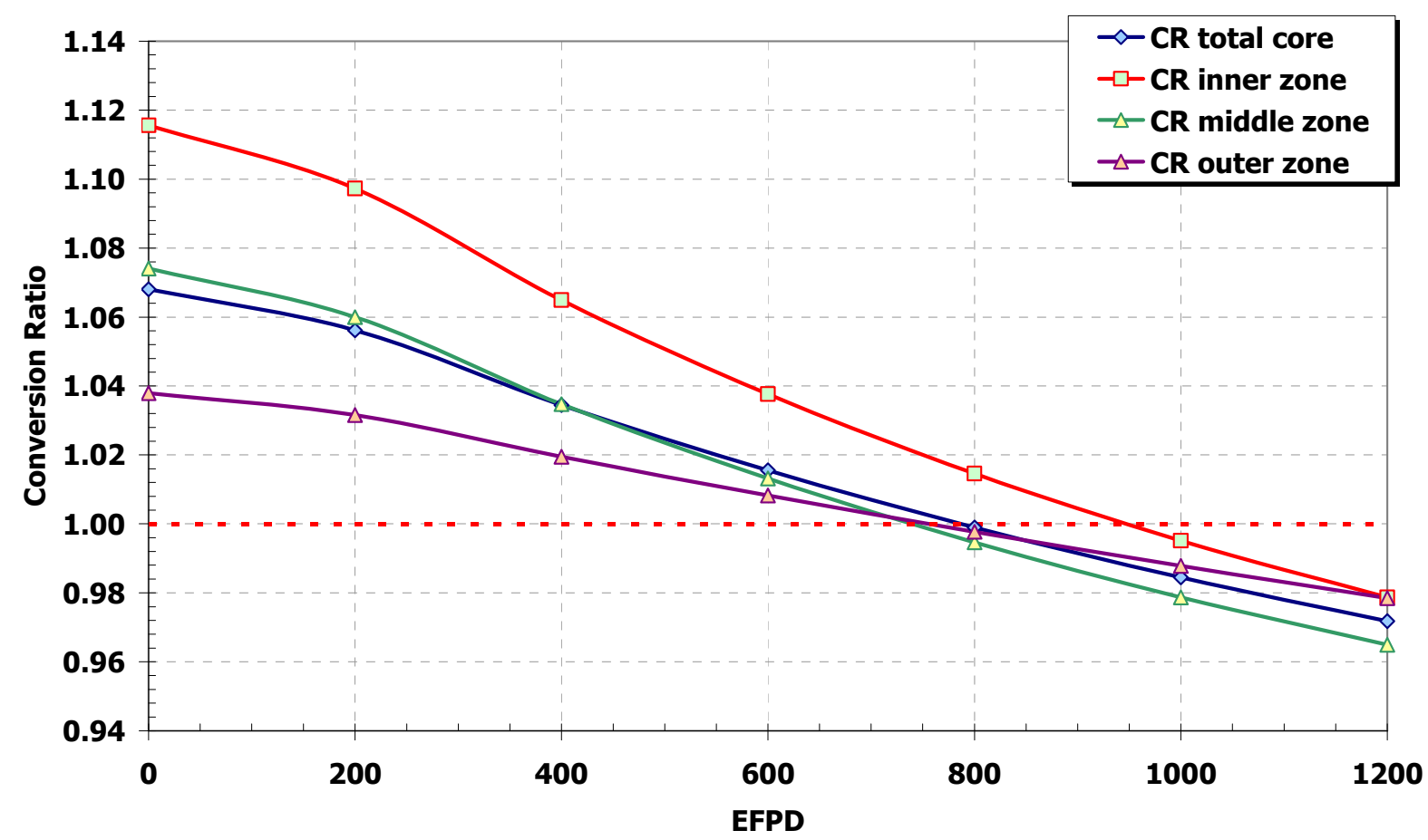

Figure 5A-7 Conversion ratio for different core zones vs. EFPD

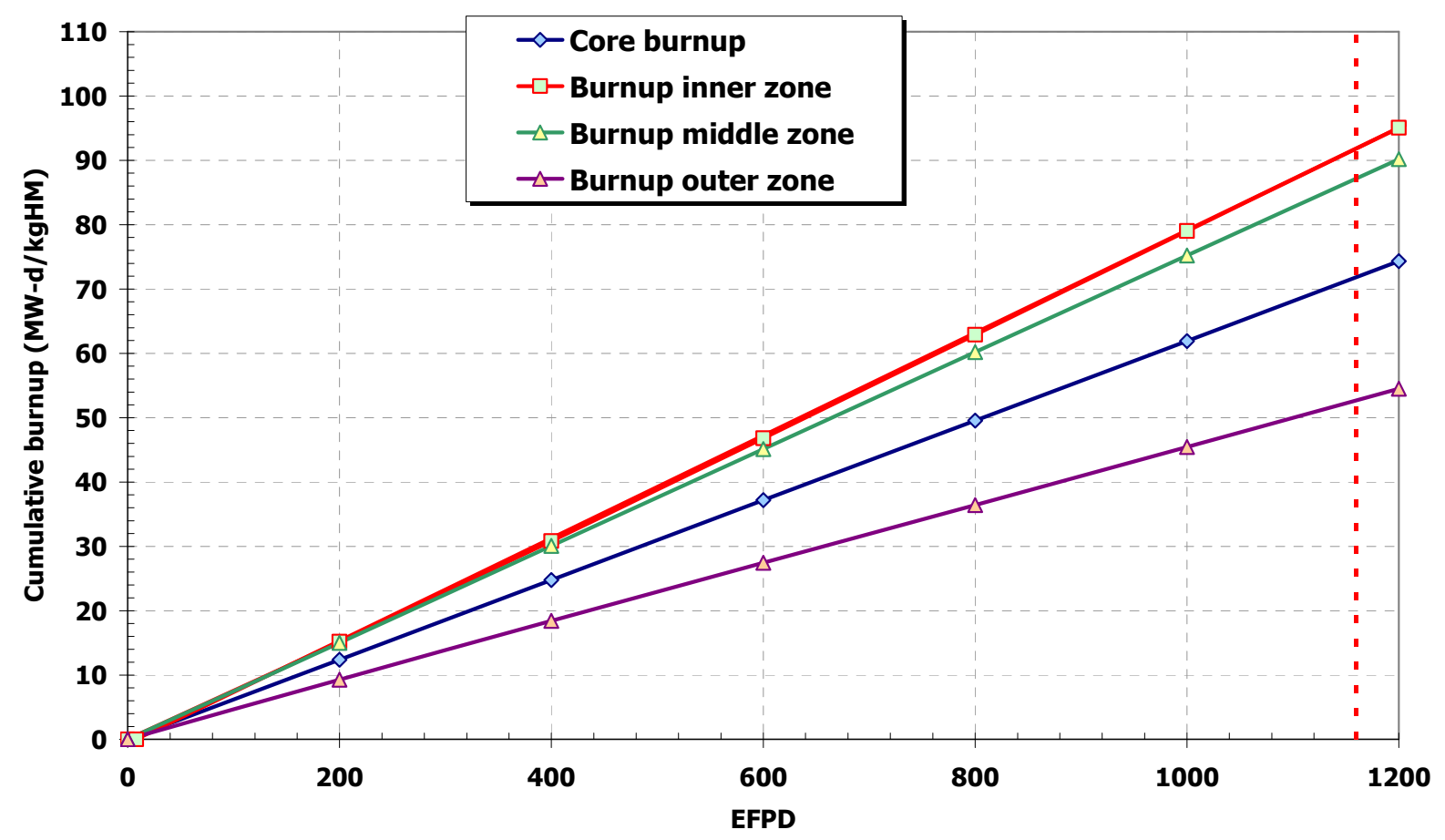

Figure 5A-8 Cumulative burnup 
Project No 06-040: Flexible Conversion Ratio Fast Reactor Systems Evaluation

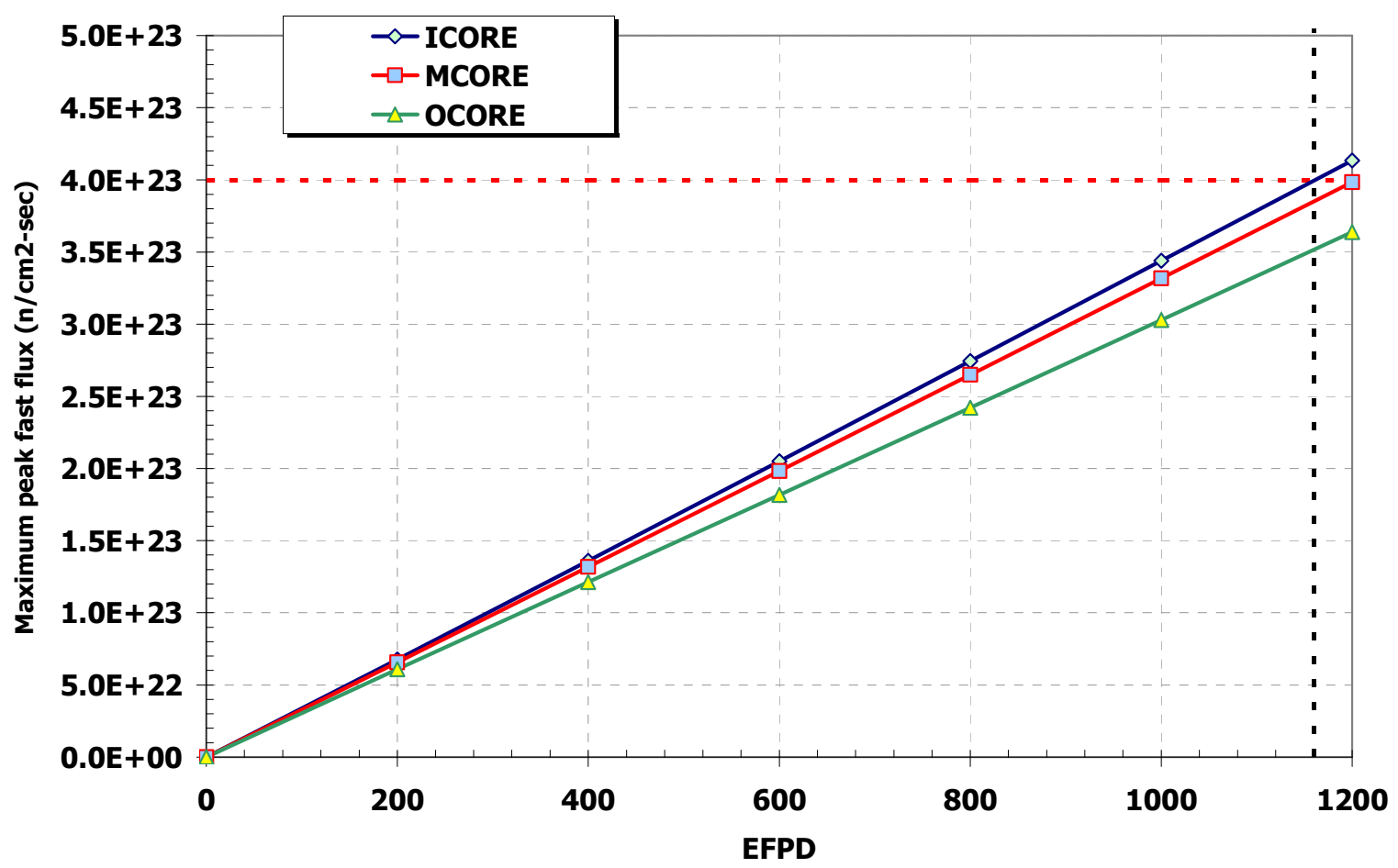

Figure 5A-9 Accumulated peak fast ( $>0.1 \mathrm{MeV}$ neutrons) fluence

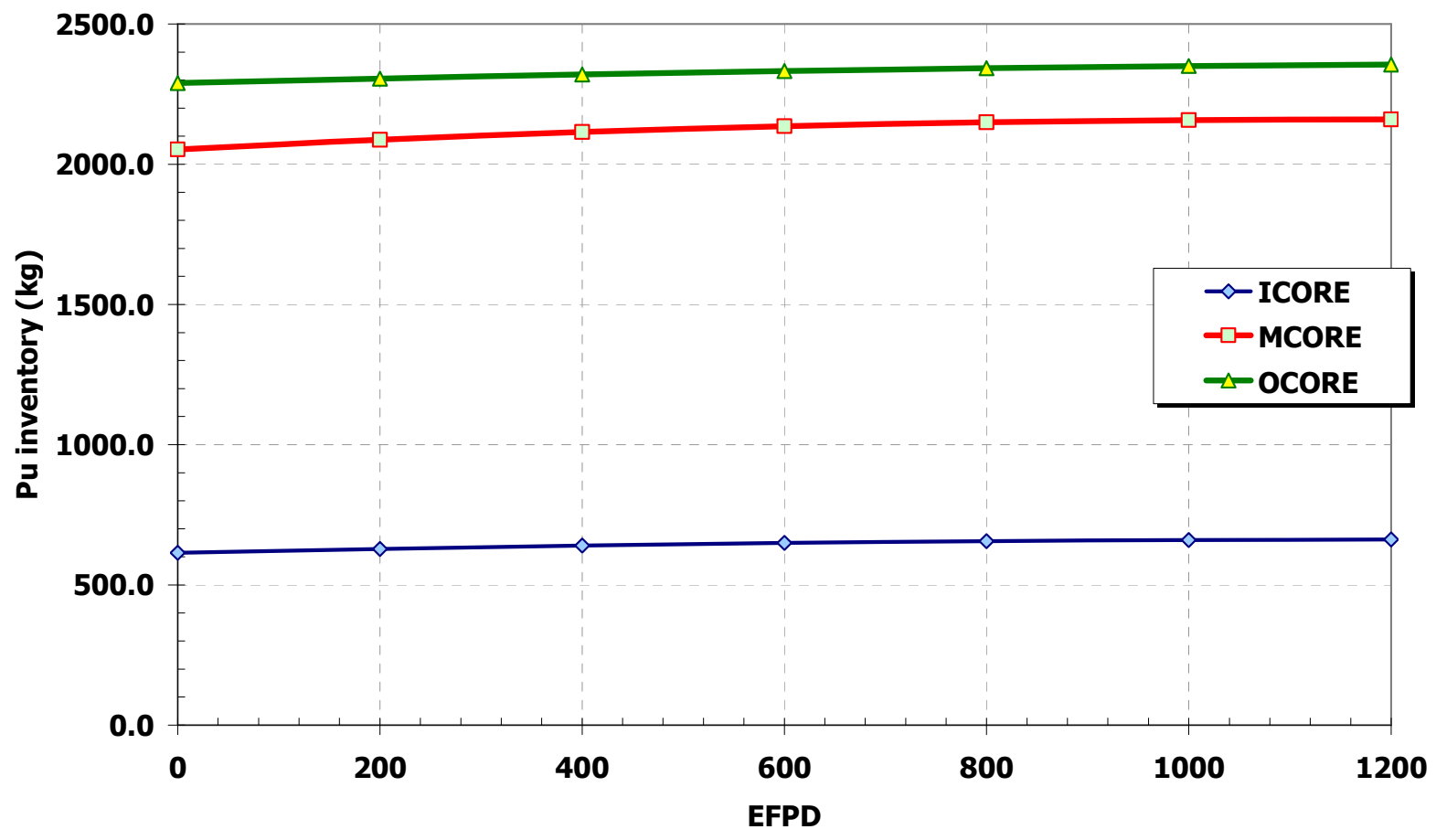

Figure 5A-10 Plutonium inventory 
Project No 06-040: Flexible Conversion Ratio Fast Reactor Systems Evaluation

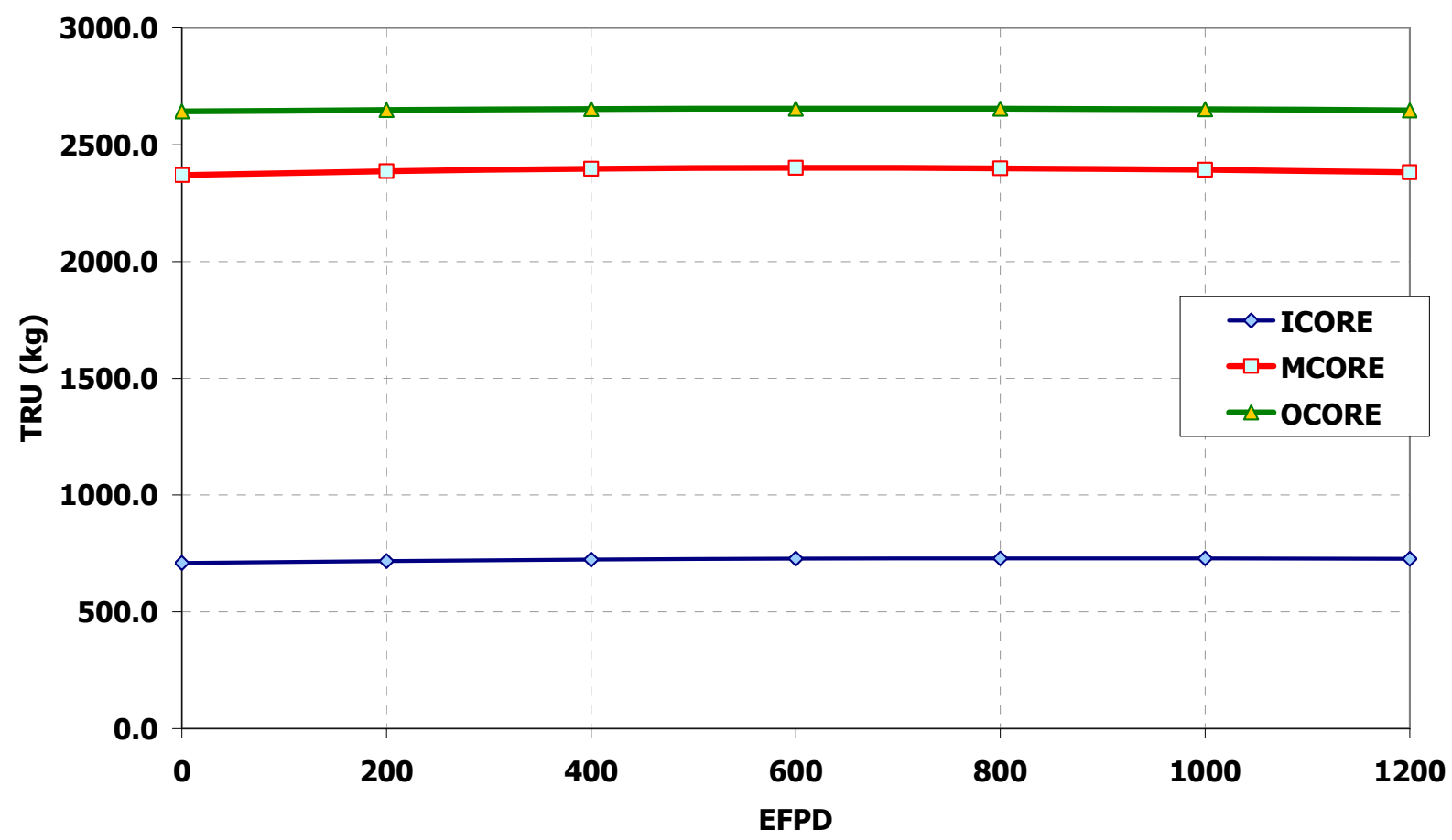

Figure 5A-11 TRU inventory

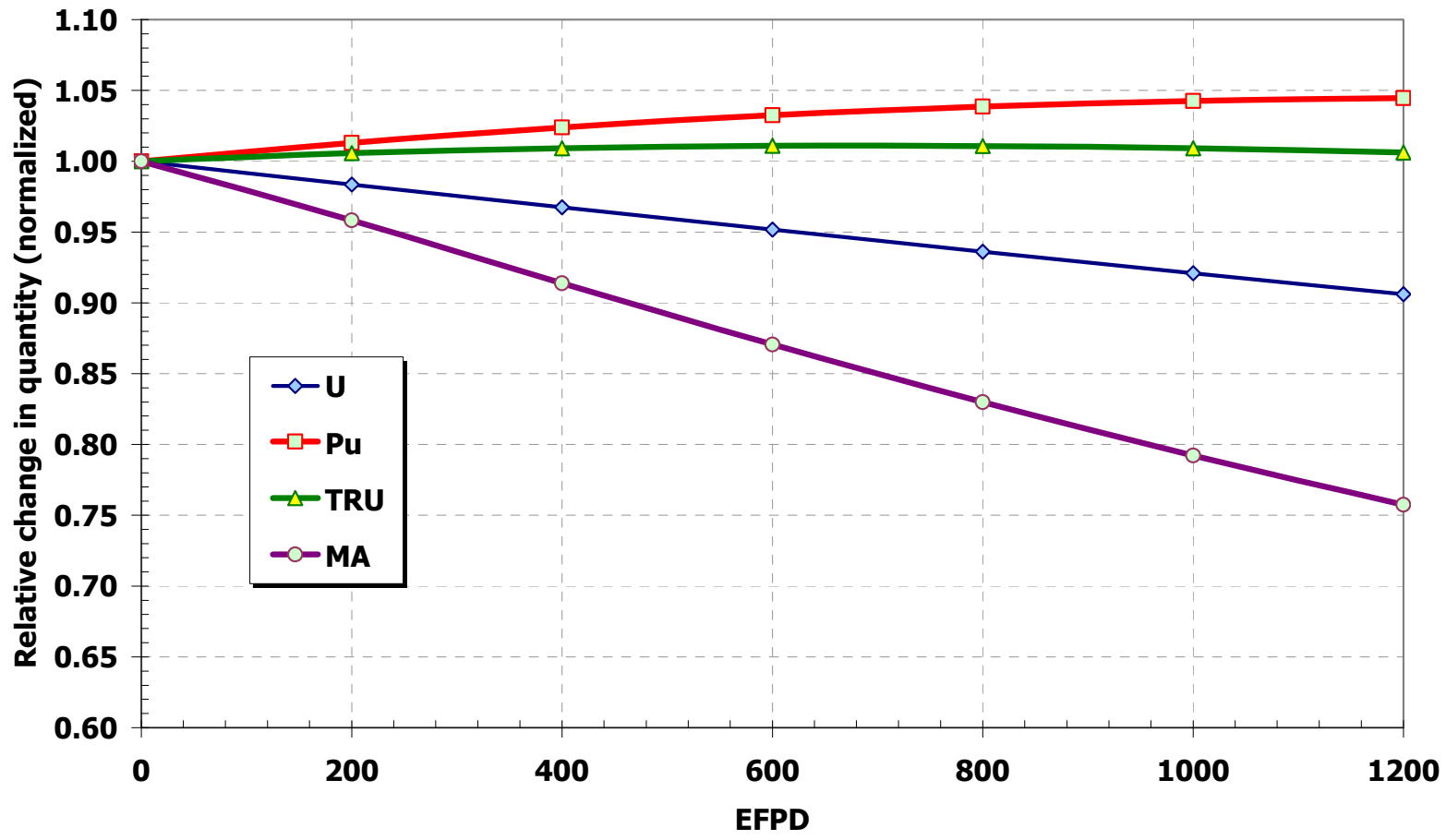

Figure 5A-12 Relative change in quantity (normalized to BOL values) 
Project No 06-040: Flexible Conversion Ratio Fast Reactor Systems Evaluation
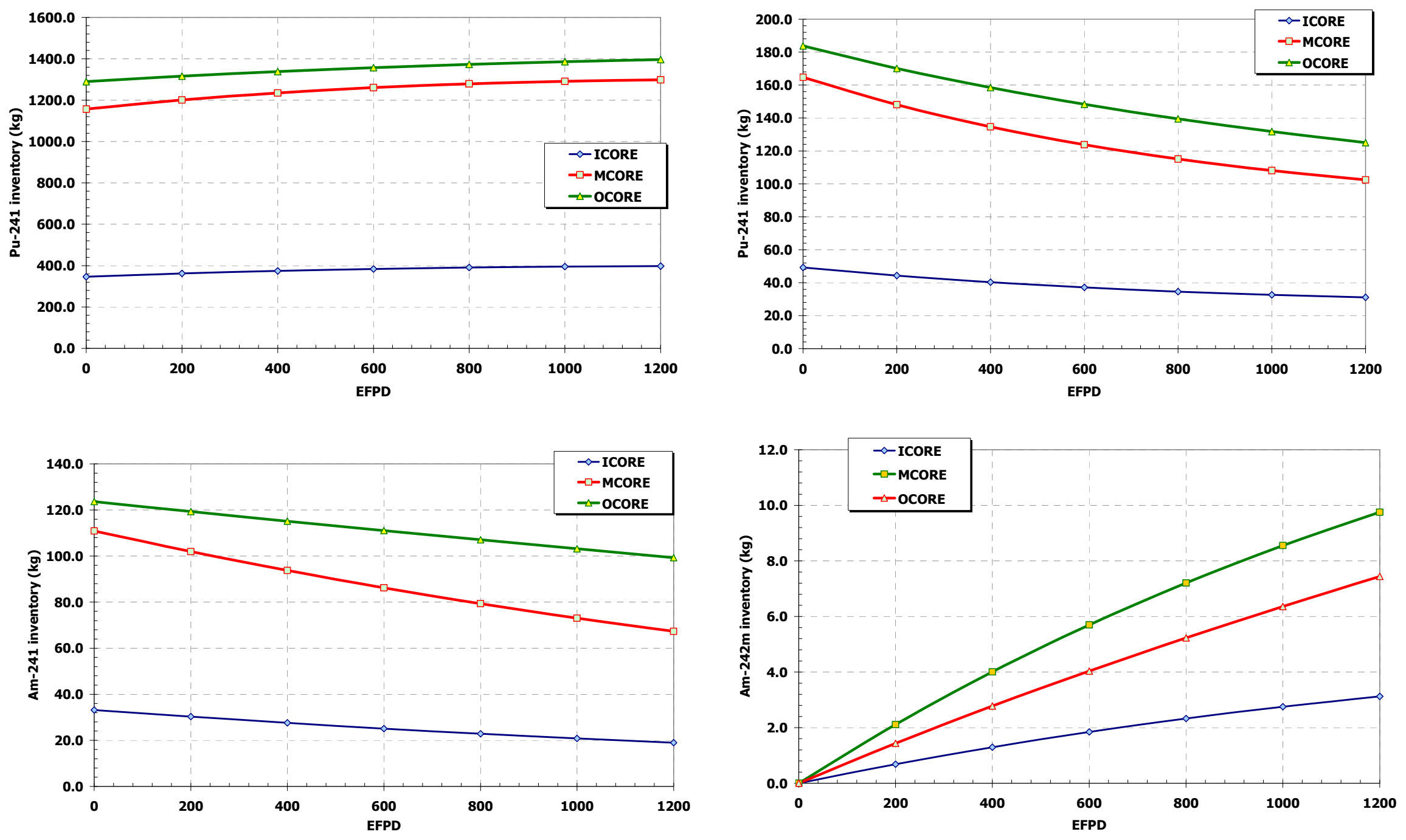

Figure 5A-13 Fissile inventory in the core for select isotopes 
Project No 06-040: Flexible Conversion Ratio Fast Reactor Systems Evaluation

\begin{tabular}{|c|c|c|c|c|c|c|c|c|c|c|c|c|c|c|c|c|c|c|}
\hline 15 & 0.00 & 0.00 & 0.00 & 0.00 & 0.01 & 0.01 & 0.01 & 0.01 & 0.01 & 0.01 & 0.01 & 0.00 & 0.00 & 0.00 & 0.00 \\
\hline 14 & 0.00 & 0.00 & 0.00 & 0.00 & 0.00 & 0.00 & 0.00 & 0.00 & 0.00 & 0.00 & 0.00 & 0.00 & 0.01 & 0.00 & 0.00 \\
\hline 13 & 0.00 & 0.01 & 0.01 & 0.01 & 0.01 & 0.01 & 0.01 & 0.01 & 0.01 & 0.01 & 0.00 & 0.00 & 0.00 & 0.01 & 0.00 \\
\hline 12 & 0.01 & 0.01 & 0.53 & 0.60 & 0.62 & 0.63 & 0.63 & 0.62 & 0.60 & 0.52 & 0.01 & 0.01 & 0.00 & 0.00 & 0.00 \\
\hline 11 & 0.58 & 0.74 & 0.86 & 0.91 & 0.90 & 0.00 & 0.90 & 0.91 & 0.86 & 0.74 & 0.58 & 0.01 & 0.00 & 0.00 & 0.01 \\
\hline 10 & 0.93 & 1.06 & 1.13 & 1.14 & 0.94 & 0.94 & 1.14 & 1.13 & 1.06 & 0.93 & 0.74 & 0.52 & 0.01 & 0.00 & 0.01 \\
\hline 9 & 1.19 & 1.07 & 1.10 & 1.11 & 1.10 & 1.11 & 1.10 & 1.06 & 1.18 & 1.06 & 0.86 & 0.60 & 0.01 & 0.00 & 0.01 \\
\hline 8 & 1.12 & 1.15 & 1.18 & 1.19 & 1.19 & 1.18 & 1.15 & 1.12 & 1.06 & 1.13 & 0.91 & 0.62 & 0.01 & 0.00 & 0.01 \\
\hline 7 & 0.00 & 1.19 & 1.22 & 1.23 & 1.22 & 1.19 & 0.00 & 1.15 & 1.10 & 1.14 & 0.90 & 0.63 & 0.01 & 0.00 & 0.01 \\
\hline 6 & 1.20 & 1.21 & 1.21 & 1.21 & 1.21 & 1.20 & 1.19 & 1.18 & 1.11 & 0.94 & 0.00 & 0.63 & 0.01 & 0.00 & 0.01 \\
\hline 5 & 1.04 & 1.03 & 0.00 & 1.03 & 1.04 & 1.21 & 1.22 & 1.19 & 1.10 & 0.94 & 0.90 & 0.62 & 0.01 & 0.00 & 0.01 \\
\hline 4 & 1.01 & 1.01 & 1.01 & 1.01 & 1.03 & 1.21 & 1.23 & 1.19 & 1.11 & 1.14 & 0.91 & 0.60 & 0.01 & 0.00 & 0.00 \\
\hline 3 & 0.99 & 0.99 & 0.99 & 1.01 & 0.00 & 1.21 & 1.22 & 1.18 & 1.10 & 1.13 & 0.86 & 0.52 & 0.01 & 0.00 & 0.00 \\
\hline 2 & 0.98 & 0.98 & 0.99 & 1.01 & 1.03 & 1.21 & 1.19 & 1.15 & 1.07 & 1.06 & 0.74 & 0.01 & 0.00 & 0.01 & 0.00 \\
\hline 1 & 0.00 & 0.98 & 0.99 & 1.01 & 1.04 & 1.20 & 0.00 & 1.12 & 1.19 & 0.93 & 0.58 & 0.01 & 0.00 & 0.00 & 0.00 \\
\hline & 1 & 2 & 3 & 4 & 5 & 6 & 7 & 8 & 9 & 10 & 11 & 12 & 13 & 14 & 15 \\
\hline
\end{tabular}

Core power map for BOL (0.0 EFPD)

\begin{tabular}{|c|c|c|c|c|c|c|c|c|c|c|c|c|c|c|c|c|}
\hline 15 & 0.00 & 0.00 & 0.00 & 0.00 & 0.01 & 0.01 & 0.01 & 0.01 & 0.01 & 0.01 & 0.01 & 0.00 & 0.00 & 0.00 & 0.00 \\
\hline 14 & 0.00 & 0.00 & 0.00 & 0.00 & 0.00 & 0.00 & 0.00 & 0.00 & 0.00 & 0.00 & 0.00 & 0.00 & 0.01 & 0.00 & 0.00 \\
\hline 13 & 0.00 & 0.00 & 0.00 & 0.00 & 0.01 & 0.01 & 0.01 & 0.01 & 0.01 & 0.00 & 0.00 & 0.00 & 0.00 & 0.01 & 0.00 \\
\hline 12 & 0.01 & 0.01 & 0.50 & 0.57 & 0.61 & 0.62 & 0.62 & 0.60 & 0.57 & 0.50 & 0.01 & 0.01 & 0.00 & 0.00 & 0.00 \\
\hline 11 & 0.54 & 0.69 & 0.81 & 0.88 & 0.88 & 0.00 & 0.88 & 0.87 & 0.81 & 0.69 & 0.54 & 0.01 & 0.00 & 0.00 & 0.01 \\
\hline 10 & 0.87 & 1.00 & 1.08 & 1.11 & 1.10 & 1.10 & 1.11 & 1.08 & 1.00 & 0.87 & 0.69 & 0.50 & 0.00 & 0.00 & 0.01 \\
\hline 9 & 1.13 & 1.03 & 1.08 & 1.10 & 1.10 & 1.10 & 1.08 & 1.03 & 1.13 & 1.00 & 0.81 & 0.57 & 0.01 & 0.00 & 0.01 \\
\hline 8 & 1.10 & 1.14 & 1.18 & 1.20 & 1.20 & 1.18 & 1.14 & 1.10 & 1.03 & 1.08 & 0.87 & 0.60 & 0.01 & 0.00 & 0.01 \\
\hline 7 & 0.00 & 1.20 & 1.23 & 1.24 & 1.23 & 1.20 & 0.00 & 1.14 & 1.08 & 1.11 & 0.88 & 0.62 & 0.01 & 0.00 & 0.01 \\
\hline 6 & 1.22 & 1.23 & 1.24 & 1.24 & 1.23 & 1.22 & 1.20 & 1.18 & 1.10 & 1.10 & 0.00 & 0.62 & 0.01 & 0.00 & 0.01 \\
\hline 5 & 1.08 & 1.07 & 0.00 & 1.07 & 1.08 & 1.23 & 1.23 & 1.20 & 1.10 & 1.10 & 0.88 & 0.61 & 0.01 & 0.00 & 0.01 \\
\hline 4 & 1.07 & 1.06 & 1.06 & 1.07 & 1.07 & 1.24 & 1.24 & 1.20 & 1.10 & 1.11 & 0.87 & 0.57 & 0.00 & 0.00 & 0.00 \\
\hline 3 & 1.05 & 1.04 & 1.05 & 1.06 & 0.00 & 1.24 & 1.23 & 1.18 & 1.08 & 1.08 & 0.81 & 0.50 & 0.00 & 0.00 & 0.00 \\
\hline 2 & 1.04 & 1.04 & 1.04 & 1.06 & 1.07 & 1.23 & 1.20 & 1.14 & 1.03 & 1.00 & 0.69 & 0.01 & 0.00 & 0.01 & 0.00 \\
\hline 1 & 0.00 & 1.04 & 1.05 & 1.07 & 1.08 & 1.22 & 0.00 & 1.10 & 1.13 & 0.87 & 0.54 & 0.01 & 0.00 & 0.00 & 0.00 \\
\hline & 1 & 2 & 3 & 4 & 5 & 6 & 7 & 8 & 9 & 10 & 11 & 12 & 13 & 14 & 15 \\
\hline
\end{tabular}

Core power map for MOL (600.0 EFPD) 


\begin{tabular}{|c|c|c|c|c|c|c|c|c|c|c|c|c|c|c|c|}
\hline 15 & 0.00 & 0.00 & 0.00 & 0.00 & 0.01 & 0.01 & 0.01 & 0.01 & 0.01 & 0.01 & 0.01 & 0.00 & 0.00 & 0.00 & 0.00 \\
\hline 14 & 0.00 & 0.00 & 0.00 & 0.00 & 0.00 & 0.00 & 0.00 & 0.00 & 0.00 & 0.00 & 0.00 & 0.00 & 0.01 & 0.00 & 0.00 \\
\hline 13 & 0.00 & 0.00 & 0.01 & 0.01 & 0.01 & 0.01 & 0.01 & 0.01 & 0.01 & 0.01 & 0.00 & 0.00 & 0.00 & 0.01 & 0.00 \\
\hline 12 & 0.01 & 0.01 & 0.52 & 0.59 & 0.63 & 0.64 & 0.64 & 0.63 & 0.59 & 0.51 & 0.01 & 0.01 & 0.00 & 0.00 & 0.00 \\
\hline 11 & 0.55 & 0.71 & 0.83 & 0.89 & 0.90 & 0.00 & 0.90 & 0.89 & 0.83 & 0.71 & 0.55 & 0.01 & 0.00 & 0.00 & 0.01 \\
\hline 10 & 0.88 & 1.01 & 1.09 & 1.12 & 1.10 & 1.10 & 1.12 & 1.08 & 1.01 & 0.88 & 0.71 & 0.51 & 0.01 & 0.00 & 0.01 \\
\hline 9 & 1.13 & 1.03 & 1.07 & 1.09 & 1.10 & 1.09 & 1.07 & 1.03 & 1.13 & 1.01 & 0.83 & 0.59 & 0.01 & 0.00 & 0.01 \\
\hline 8 & 1.09 & 1.13 & 1.17 & 1.19 & 1.19 & 1.17 & 1.13 & 1.09 & 1.03 & 1.08 & 0.89 & 0.63 & 0.01 & 0.00 & 0.01 \\
\hline 7 & 0.00 & 1.18 & 1.22 & 1.23 & 1.22 & 1.18 & 0.00 & 1.13 & 1.07 & 1.12 & 0.90 & 0.64 & 0.01 & 0.00 & 0.01 \\
\hline 6 & 1.20 & 1.22 & 1.22 & 1.22 & 1.22 & 1.20 & 1.18 & 1.17 & 1.09 & 1.10 & 0.00 & 0.64 & 0.01 & 0.00 & 0.01 \\
\hline 5 & 1.07 & 1.06 & 0.00 & 1.06 & 1.07 & 1.22 & 1.22 & 1.19 & 1.10 & 1.10 & 0.90 & 0.63 & 0.01 & 0.00 & 0.01 \\
\hline 4 & 1.06 & 1.06 & 1.06 & 1.06 & 1.06 & 1.22 & 1.23 & 1.19 & 1.09 & 1.12 & 0.89 & 0.59 & 0.01 & 0.00 & 0.00 \\
\hline 3 & 1.05 & 1.04 & 1.05 & 1.06 & 0.00 & 1.22 & 1.22 & 1.17 & 1.07 & 1.09 & 0.83 & 0.51 & 0.00 & 0.00 & 0.00 \\
\hline 2 & 1.04 & 1.04 & 1.04 & 1.06 & 1.06 & 1.22 & 1.18 & 1.13 & 1.03 & 1.01 & 0.71 & 0.01 & 0.00 & 0.01 & 0.00 \\
\hline 1 & 0.00 & 1.04 & 1.05 & 1.06 & 1.07 & 1.20 & 0.00 & 1.09 & 1.13 & 0.88 & 0.55 & 0.01 & 0.00 & 0.00 & 0.00 \\
\hline & 1 & 2 & 3 & 4 & 5 & 6 & 7 & 8 & 9 & 10 & 11 & 12 & 13 & 14 & 15 \\
\hline
\end{tabular}

Figure 5A-14 Core power maps.

\section{A.4 Sodium-cooled $\mathrm{CR}=1$ core modeling with MCNP}

In order to verify the results obtained with the REBUS/DIF-3D [Derstine, 1984] computer code system, the Na cooled core design described in the previous section was analyzed with MCNP and BGCore (coupled MCNP and fuel depletion routine) [Fridman et al., 2007, 2008] codes. Additionally, reactivity feedback coefficients were calculated using MCNP and compared with a previously studied sodium-cooled reactor design [Wade and Fujita, 1989].

The created MCNP model of the Na cooled $\mathrm{CR}=1$ core was identical to the DIF-3D model with respect to the core dimensions and materials composition except for a number of differences.

An explicit, heterogeneous core and fuel assembly geometry representation was used in MCNP as opposed to the DIF-3D model, where all the materials within individual fuel assemblies are homogenized. Homogenization reduces the spatial self-shielding effect. Therefore, reactivity of the core will be underpredicted as a result of fuel and control rod materials homogenization with the core structures and coolant. In the performed analysis, the control rods were assumed to be fully withdrawn and located in the upper plenum region above the core. Therefore, the effect of homogenization of the control rods should be minor.

On the other hand, homogenization of the gas plenum region in the DIF-3D model should increase the core reactivity because the neutron streaming effect would be underestimated.

In the MCNP model, the coolant density was varied axially to simulate sodium heat up as it flows through the core. The axial coolant density variation could be important for calculation of the Coolant Temperature Coefficient (CTC). In contrast, the DIF-3D model assumed average Na density throughout the core. 
Additionally, "cold" sodium density was used in the downcomer and lower core plenum, while $\mathrm{Na}$ density corresponding to the core outlet temperature was used in the upper core regions. In the DIF-3D model however, the $\mathrm{Na}$ densities in all regions of the model were identical and corresponded to the core average coolant temperature.

Burnup calculations were performed for the $\mathrm{Na}$ cooled $\mathrm{CR}=1$ core with BGCore code up to 1150 EFPD based on the peak cladding fluence calculation results presented above in Section 5A.3.

The cross-section library used for the burnup calculations with BGCore was based on JEFF-3.1 evaluated data, while the REBUS/DIF-3D code used ENDF-V based cross-sections.

The results of the performed calculations are presented in Figures 5A-15 through 5A-18.

Figure 5A-15 shows evolution of the core k-effective as a function of irradiation time predicted by the two codes. The core reactivity calculated by BGCore is lower than that calculated by REBUS/DIF-3D even though the difference due to the homogenization effect was expected to be in the opposite direction. However, the relative difference between the two codes core keffective predictions is fairly small: on the order of $300 \mathrm{pcm}$. The lower core reactivity calculated by BGCore results in the fuel cycle length shortening by about 50 EFPD.

Figures 5A-16, 17 and 18 present the core radial power distribution at BOC calculated by MCNP, DIFF-3D, and relative difference between the two codes respectively. Both codes predicted the same location of the hot channel. The maximum peaking factor value prediction was also similar for the two codes. The difference for most of the power peaking factors is approximately within 5\%. In general, good agreement between the two codes was observed.

In order to investigate the source of the differences in reactivity predictions between DIF-3D and MCNP, the effect of data libraries on the sodium-cooled $\mathrm{CR}=1$ core reactivity was studied. A series of core criticality calculations was performed with fuel temperature at $300 \mathrm{~K}$ and different cross-section libraries using the MCNP code.

The results are summarized in Table 5A-10. The core calculated with the most recent JEFF-3.1 data has higher reactivity by about $0.3 \%$ than the core calculated with ENDF-V (cross-section library used by DIF-3D). This difference is in the opposite direction than the one observed between MCNP and DIF-3D at nominal conditions. Therefore, effects other than the crosssection library are likely to be responsible for this difference. 
Project No 06-040: Flexible Conversion Ratio Fast Reactor Systems Evaluation

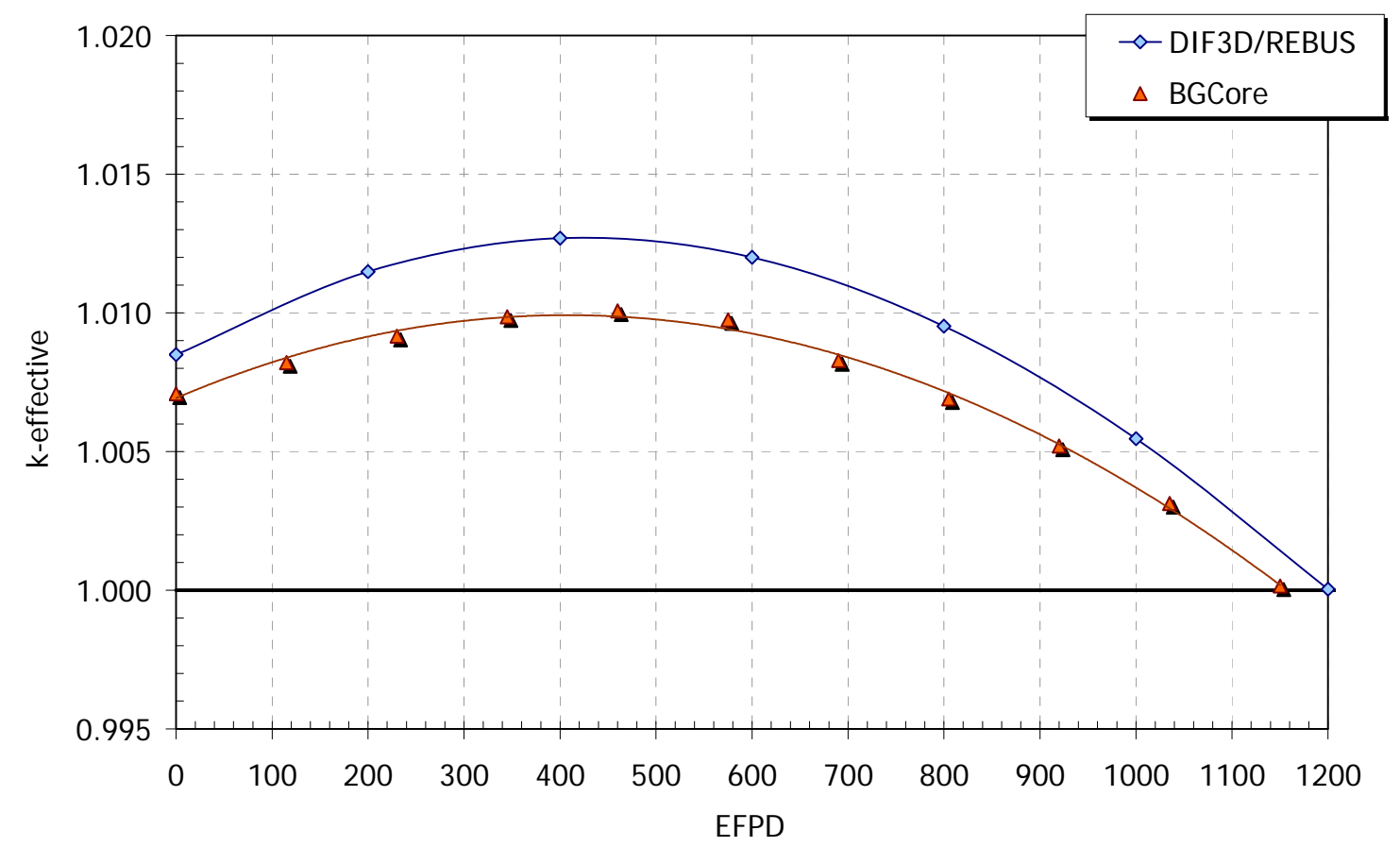

Figure 5A-15. Na cooled $\mathrm{CR}=1$ core $\mathrm{k}-\mathrm{eff}$, DIF3D/REBUS versus BGCore

Table 5A-10. Effect of cross-section library on criticality

\begin{tabular}{|l|c|c|c|c|c|}
\hline & $\mathrm{T}_{\text {fuel }}, \mathrm{K}$ & $\begin{array}{c}\text { Fuel XS } \\
\text { Library }\end{array}$ & $\begin{array}{c}\text { Na XS } \\
\text { Library }\end{array}$ & Core k-eff & $\begin{array}{c}\text { Deviation } \\
\text { from DIF-3D, \% }\end{array}$ \\
\hline DIF-3D & 900 & ENDF-V & ENDF-V & 1.0084935 & N/A \\
\hline MCNP & 900 & JEFF 3.1 & JEFF 3.1 & $1.00708 \pm 0.00005$ & -0.14 \\
\hline MCNP & 300 & JEFF 3.1 & JEFF 3.1 & $1.01353 \pm 0.00005$ & 0.50 \\
\hline MCNP & 300 & ENDF-V & JEFF 3.1 & $1.01238 \pm 0.00005$ & 0.39 \\
\hline MCNP & 300 & ENDF-V & ENDF-V & $1.01026 \pm 0.00005$ & 0.18 \\
\hline
\end{tabular}

\section{Sodium-Cooled Reactor Reactivity Coefficients}

This section compares reactivity coefficients as well as self-controllability potential of the unity conversion ratio sodium-cooled reactor core with those of Integral Fast Reactor (IFR) [Wade and Chang, 1988]. Calculations of the reactivity coefficients were performed with the MCNP code using the methodology described in Appendix 3A of this report. The core operating conditions relevant for the self-controllability assessment are summarized in Table 5A-11. As before, the ability of the core self-regulation was evaluated based on the quasi-static analysis methodology originally developed for sodium-cooled IFR design.

The results of the analysis are presented in Table 5A-12. Figure 5A-19 presents the Na cooled core reactivity versus fuel temperature data used for the calculation. All reactivity coefficient values are close to those of the IFR except for the radial thermal expansion coefficient which is somewhat lower than in IFR because of the larger core dimensions. 


\begin{tabular}{|c|c|c|c|c|c|c|c|c|c|}
\hline & & & & & 0.67 & & & & \\
\hline & & & 1.09 & 0.94 & ๑. 91 & 0.66 & & & \\
\hline & & 1.22 & 1.18 & 1.09 & 1.13 & 0.90 & 0.63 & & \\
\hline & & 1.22 & 1.22 & 1.17 & $1 . \odot 8$ & 1.10 & 0.85 & 0.56 & \\
\hline 1.03 & 1.04 & 1.06 & 1.22 & 1.20 & 1.14 & 1.04 & 1.03 & 0.75 & \\
\hline $1 . \odot 2$ & 1.03 & 1.05 & 1.06 & 1.21 & & 1.10 & 1.15 & ๑. 91 & $\odot .61$ \\
\hline 1.03 & $1 . \odot 4$ & 1.06 & 1.22 & 1.19 & 1.14 & 1.04 & 1.03 & 0.75 & \\
\hline & & 1.22 & 1.22 & 1.16 & 1.07 & 1.10 & 0.85 & 0.56 & \\
\hline & & 1.22 & 1.18 & 1.09 & 1.12 & 0.90 & 0.62 & & \\
\hline & & & 1.08 & 0.94 & 0.91 & 0.65 & & & \\
\hline & & & & & 0.67 & & & & \\
\hline
\end{tabular}

Figure 5A-16. Radial power distribution of Na cooled CR1 core obtained from MCNP model

\begin{tabular}{|c|c|c|c|c|c|c|c|c|c|}
\hline & & & & & & \\
\hline & & & & & 0.63 & & & & \\
\hline & & & 1.10 & 0.94 & 0.90 & 0.62 & & & \\
\hline & & 1.23 & 1.19 & 1.11 & 1.14 & $\odot .91$ & $\odot .60$ & & \\
\hline & & 1.21 & 1.22 & 1.18 & 1.10 & 1.13 & $\odot .86$ & $\odot .52$ & \\
\hline$\odot .99$ & 1.01 & 1.03 & 1.21 & 1.19 & 1.15 & 1.06 & 1.06 & $\odot .74$ & \\
\hline$\odot .98$ & $\odot .99$ & 1.01 & 1.04 & 1.20 & & 1.12 & 1.18 & $\odot .93$ & $\odot .58$ \\
\hline 0.99 & 1.01 & 1.03 & 1.21 & 1.19 & 1.15 & 1.06 & 1.06 & 0.74 & \\
\hline & & 1.21 & 1.22 & 1.18 & 1.10 & 1.13 & $\odot .86$ & $\odot .52$ & \\
\hline & & 1.23 & 1.19 & 1.11 & 1.14 & 0.91 & 0.60 & & \\
\hline & & & 1.10 & 0.94 & 0.90 & 0.62 & & & \\
\hline & & & & & 0.63 & & & & \\
\hline
\end{tabular}

Figure 5A-17. Radial power distribution of Na cooled CR1 core obtained from DIF3D model

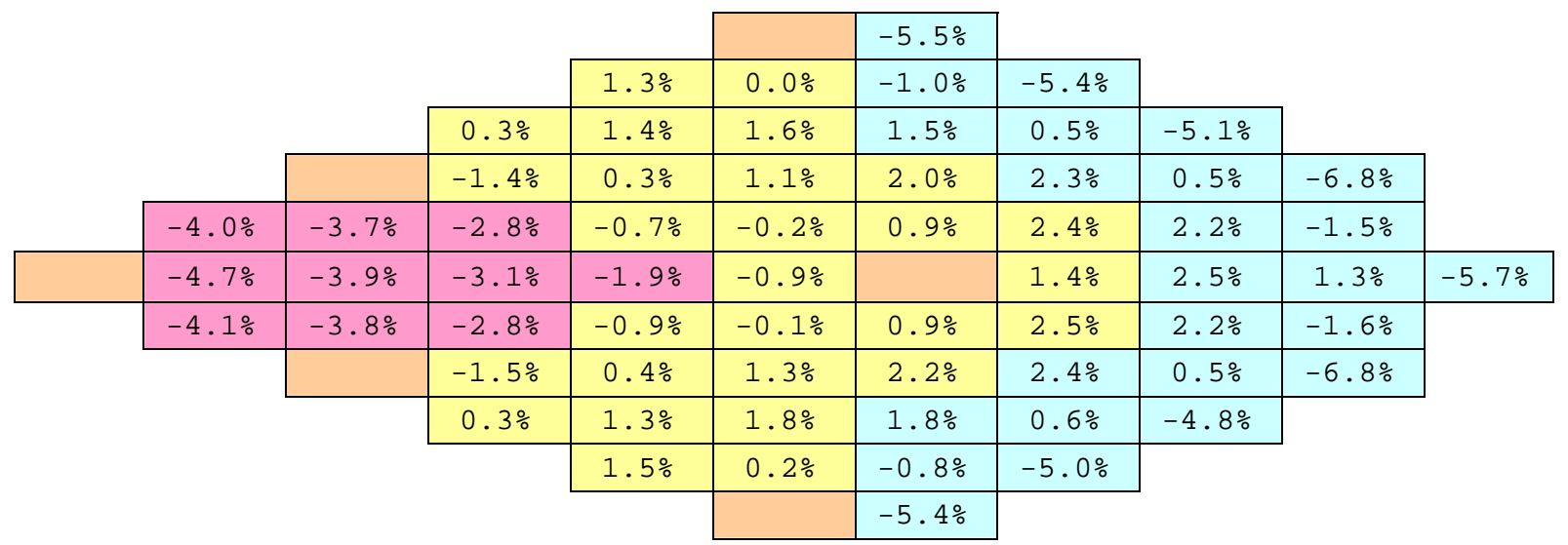

Figure 5A-18. Relative difference in radial power peaking factors (DIF3D-MCNP)/DIF3D

As a result of the difference in radial core expansion coefficient, the $2400 \mathrm{MW}$ Na-cooled core does not satisfy the $\mathrm{A} / \mathrm{B}$ criterion, which indicates that the cladding failure limit is likely to be exceeded in the Loss Of Flow Without Scram (LOFWS) accident. 
Project No 06-040: Flexible Conversion Ratio Fast Reactor Systems Evaluation

Also, the $\Delta \rho_{\text {TOP }} / \mathrm{B}$ limit is marginally met because of the relatively small number of control rods in the core. Control rod drive thermal expansion coefficient was excluded from the analysis at this stage. In principle, double-entry control rods, similar to those suggested for use in the Lead and liquid salt-cooled cores designed in this project, can also be employed in the sodium-cooled reactor. In such case, exclusion of the control rod drive thermal expansion coefficient from the analysis is justified.

Table 5A-11. Sodium-cooled $\mathrm{CR}=1$ core operating conditions

\begin{tabular}{|l|c|}
\hline Parameter & Value \\
\hline Coolant Inlet Temperature, ${ }^{\circ} \mathrm{C}$ & 352 \\
\hline Coolant Outlet temperature, ${ }^{\circ} \mathrm{C}$ & 502 \\
\hline Core Coolant Temperature Rise, $\Delta \mathrm{T}_{\mathrm{c}},{ }^{\circ} \mathrm{C}$ & 150 \\
\hline Coolant Freezing Point, ${ }^{\circ} \mathrm{C}$ & 98 \\
\hline Margin to Freezing, ${ }^{\circ} \mathrm{C}$ & 254 \\
\hline Cladding Failure Limit, ${ }^{\circ} \mathrm{C}$ & 725 \\
\hline Margin to Cladding Failure, ${ }^{\circ} \mathrm{C}$ & 223 \\
\hline
\end{tabular}

Table 5A-12. Comparison of reactivity coefficients and self-controllability criteria for Na cooled $\mathrm{CR}=1$ and IFR cores

\begin{tabular}{|c|c|c|c|c|}
\hline & & \multicolumn{2}{|c|}{$\mathrm{Na}$} & \multirow[t]{2}{*}{ IFR $^{*}$} \\
\hline & Units & Value & $\pm \sigma$ & \\
\hline$\beta_{\text {eff }}$ & & 0.0038 & 0.0001 & 0.0035 \\
\hline$\alpha_{\mathrm{DC}}$ & $\notin / \mathrm{K}$ & -0.130 & 0.030 & -0.120 \\
\hline$\alpha_{\mathrm{e}}$ & $\phi / \mathrm{K}$ & -0.091 & 0.018 & -0.090 \\
\hline$\alpha_{\mathrm{Co}}$ & $\notin / K$ & 0.156 & 0.041 & +0.180 \\
\hline$\alpha_{\mathrm{RD}}$ & $\notin / K$ & $\sim 0$ & $\mathrm{~N} / \mathrm{A}$ & $\sim ?$ \\
\hline$\alpha_{R}$ & $\phi / \mathrm{K}$ & -0.145 & 0.018 & -0.220 \\
\hline A & $\phi$ & -44.19 & 7.03 & -31 \\
\hline $\mathrm{B}$ & $\phi$ & -26.67 & 4.25 & -35 \\
\hline $\mathrm{C}$ & $\phi / \mathrm{K}$ & -0.21 & 0.06 & -0.25 \\
\hline $\mathrm{A} / \mathrm{B}$ & & 1.66 & 0.37 & 0.88 \\
\hline $\mathrm{C} \triangleq \mathrm{T} \mathrm{c} / \mathrm{B}$ & & 1.18 & 0.36 & 1.1 \\
\hline$\Delta \rho_{\mathrm{TOP}} / \mathrm{B}$ & & 1.05 & 0.17 & - \\
\hline A/B limits & & \multicolumn{2}{|c|}{$x<0.99(1.49)$} & $x<1.0$ \\
\hline $\mathrm{C} \Delta \mathrm{T}_{\mathrm{c}} / \mathrm{B}$ limits & & \multicolumn{2}{|c|}{$1<x<1.90(2.25)$} & $1<x<2$ \\
\hline$\Delta \rho_{\mathrm{TOP}} / \mathrm{B}$ limits & & \multicolumn{2}{|c|}{$x<0.99(1.49)$} & $x<1.0$ \\
\hline
\end{tabular}

* Typical IFR values for 1800 MWt core [Wade and Fujita, 1989]. 
Project No 06-040: Flexible Conversion Ratio Fast Reactor Systems Evaluation

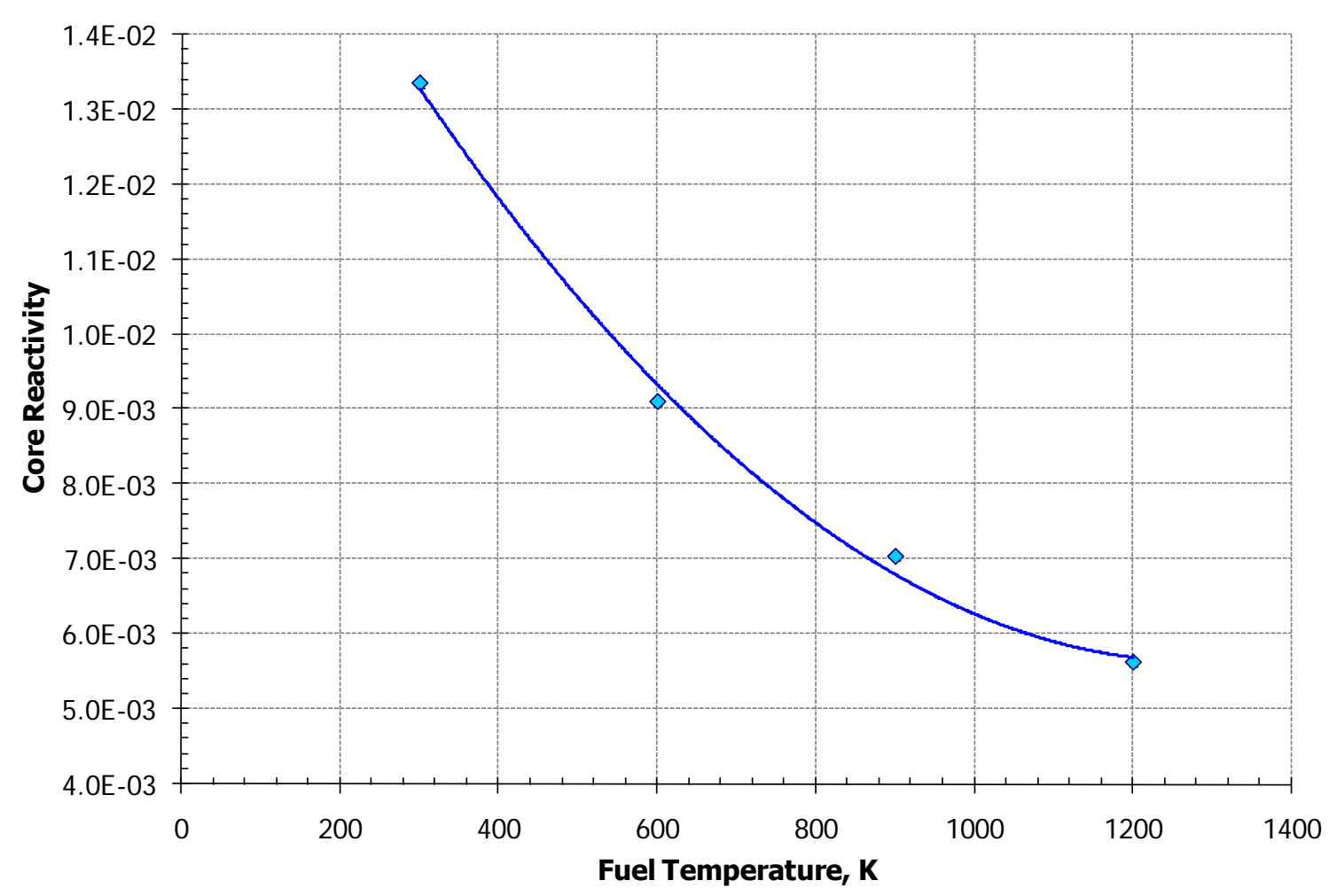

Figure 5A-19. Sodium-cooled $\mathrm{CR}=1$ core reactivity versus fuel temperature

\section{References for Appendix 5A}

Derstine K.L., "DIF3D: A code to Solve One-, Two-, and Three-Dimensional Finite-Difference Diffusion Theory Problems", Applied Physics Division, ANL82-64, Argonne National Laboratory, April 1984.

Fridman E., Shwageraus E., Galperin A., Implementation of multi-group cross-section methodology in BGCore MC-depletion code," Physor-2008, Interlaken, Switzerland, September 2008.

Fridman, E., Shwageraus, E., Galperin, A., "Efficient generation of 1 -g cross-sections for coupled Monte Carlo depletion calculations," Nucl. Sci. Eng. 159, 37-47, 2007.

Handwerk C. S., Driscoll M. J., Hejzlar P., "Use of Beryllium Oxide to Shape Power and Reduce Void Reactivity in Gas-cooled Fast Reactors," PHYSOR 2006, Vancouver, Canada, September 10-14, 2006.

Hoffman E.A, Yang W.S., and Hill R.N., "Preliminary Core Design Studies for the Advanced Burner Reactor over a Wide Range of Conversion Ratios", ANL-AFCI-177, Advanced Fuel Cycle Initiative, Argonne National Laboratory, 2006. 
Project No 06-040: Flexible Conversion Ratio Fast Reactor Systems Evaluation

Klueh, R., "Elevated-Temperature Ferritic and Martenistic Steels and Their Application to Future Nuclear Reactors," ORNL/TM-2004/176, November 2004.

Kutateladze, "Liquid Metal Coolants," Atomizdat, Moscow, 1976.

Todreas N.E, and Kazimi M.S, Nuclear Systems I: Thermal Hydraulic Fundamentals, Hemisphere Publishing Corp. 1993.

Wade, D.C., Chang, Y.I., “The Integral Fast Reactor Concept: Physics of Operation and Safety”, Nuclear Science and Engineering, 100, 507-524, 1988.

Wade D.C., Fujita E.K., “Trends Versus Reactor Size of Passive Reactivity Shutdown and Control Performance," Nuclear Science and Engineering, Vol. 103, pp. 182-195, 1989. 